\title{
Advances in Raw Material Industries for Sustainable Development Goals
}

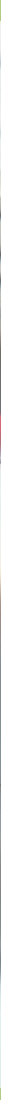

Editor

\section{Vladimir Litvinenko}


ADVANCES IN RAW MATERIAL INDUSTRIES FOR SUSTAINABLE DEVELOPMENT GOALS 


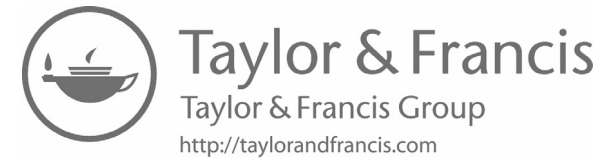




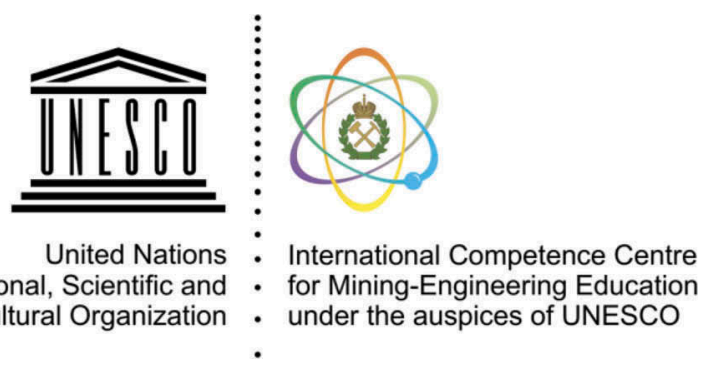

\section{Advances in Raw Material Industries for Sustainable Development Goals}

\section{Editor}

Vladimir Litvinenko

Rector of Saint-Petersburg Mining University, Saint-Petersburg, Russia Co-chairman of Russian-German Raw Materials Forum

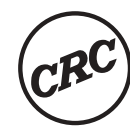


CRC Press/Balkema is an imprint of the Taylor \& Francis Group, an informa business

(C) 2021 Taylor \& Francis Group, London, UK

Typeset by Integra Software Services Pvt. Ltd., Pondicherry, India

All rights reserved. No part of this publication or the information contained herein may be reproduced, stored in a retrieval system, or transmitted in any form or by any means, electronic, mechanical, by photocopying, recording or otherwise, without written prior permission from the publisher.

Although all care is taken to ensure integrity and the quality of this publication and the information herein, no responsibility is assumed by the publishers nor the author for any damage to the property or persons as a result of operation or use of this publication and/or the information contained herein.

\section{Library of Congress Cataloging-in-Publication Data}

Applied for

Published by: CRC Press/Balkema

Schipholweg 107C, 2316XC Leiden, The Netherlands

e-mail: Pub.NL@taylorandfrancis.com

www.routledge.com - www.taylorandfrancis.com

ISBN: 978-0-367-75881-3 (Hbk)

ISBN: 978-1-003-16439-5 (eBook)

DOI: $10.1201 / 9781003164395$

https://doi.org/10.1201/9781003164395 


\section{Table of contents}

Preface $\quad$ ix

Organizers $\quad$ xi

Processing of oil products by hydrocarbon-oxidizing microorganisms $\quad 1$

O.M. Prishchepa, Y.V. Nefedov \& P.A. Morgunov

The secondary dispersion halos of platinum group elements and rare elements in rocks of the 12 Vysotsky ore occurrence, Svetloborsky massif, Middle Urals

V.S. Nikiforova, I.V. Talovina \& G. Heide

Hydrodynamic features of the formation and placement of thermal waters of the Eastern

Ciscaucasia and their protection from surface pollution

M.M. Labazanov, Z.I. Gadaeva, P.U. Musaeva, T.Kh. Ozdieva \& Z.M-E. Damzaev

Productive formations ranking methodology in order to select the optimal developing system A.A. Farukshin, A.M. Zharkov \& M.G. Ayrapetyan

Prospective petroleum accumulation areas in the non-structural traps in the Upper Permian sequences of the southern part of the Vilyuy Syneclise (Eastern Siberia)

G. A. Cherdancev, V.P. Semenov \& I. A. Kushmar

Bituminous sandstones of the Chechen Republic

Sh.Sh. Zaurbekov, M.M. Labazanov, T.Kh. Ozdieva, P.U. Musaeva, Z.I. Gadaeva,

A.A. Batukaev \& Z.M-E. Damzaev

The method of multivariate geological modeling and wells correlation of pashiysky horizon M.G. Ayrapetyan, A.A. Farukshin \& Y.V. Nefedov

Geological and economic assessment of resources of oil field of the West-Siberian oil and gas province

A.Kh. Ibatullin, A.M. Zharkov \& O.E. Kochneva

Mineral formation sequence in the hyperbasites of the Serovsko-Maukski ophiolite belt (the Northern Urals)

R. K. Ilalova, I.V. Talovina \& I.V. Vorontsovac

Granulite from the Bunger Hills, Eastern Antarctica: Mineral parageneses and terms of metamorphism

I.A. Abdrakhmanov \& Yu.L. Gulbin

The principal characterized features of earth's crust within regional strike-slip zones

A. Ageev, A. Egorov \& N. Krikun

Dyke-like and veined bodies' complex of the Elov deposit (the Northern Urals)

E. Nikolaeva, I.V. Talovina \& G. Heide

Longwall panel width optimization

D. Belova, A. Sidorenko \& A. Meshkov 
Design of seismic-resistant linings for rock burst conditions

Results of plasma-impulse technology application at uranium Inkay deposit, Kazakhstan

A.V. Chekulaev, A.S. Egorov \& A.A. Molchanov

Geomechanical issues in the development of the Udachnaya diamondiferous pipe

K.A. Anisimov, D. G. Sokol \& V.P. Zubov

Increasing the degree of nepheline raw materials use based on the conversion of sludge from alumina production

M.A. Gorbachev, V.M. Sizyakov, R.V. Kurtenkov \& I.S. Bormotov

Development of methods for calculating non-stationary heat transfer between multilayer structures

A. Gorshkov, A. Demidov \& A. Makarov

Effect of sintering temperature on the alumina extraction from kaolin

A.B. ElDeeb, V.M. Sizyakov, V.N. Brichkin \& R.V. Kurtenkov

New approaches in mineral raw materials comminution tests modelling

L.S. Chitalov \& V.V. Lvov

Research on the patterns of structure formation processes of a clinker-free alkaline stone

S-A. Yu. Murtazaev, M.Sh. Salamanova, M.Sh. Mintsaev \& D.K-S. Bataev

Energy estimates of relaxation and creep deformation processes of polymeric materials

A. Makarov, A. Demidov, N. Pereborova \& M. Egorova

Increasing the corrosion resistance of tubular furnace elements at temperature range

$400-700^{\circ} \mathrm{C}$ in accelerated testing for real operational conditions

B. Issa, V.Y. Bazhin \& T.A. Aleksandrova

Technogenic byproduct filler-based earthquake-resistant super concrete

M.S. Saidumov, A.Kh. Alashkhanov, S-A. Yu. Murtazaev \& T.S-A. Murtazaeva

Recent technologies in selective removal of arsenic in copper ore processing

A. Kobylyanski, V. Zhukova, V. Grigoreva \& A. Ya. Boduen

Spectral-time analysis of relaxation and creep processes of polymeric materials

N. Pereborova, A. Makarov, A. Demidov \& V. Wagner

Ecotoxicological assessment of underwater welding impact during the construction of marine pipelines

K.Y. Kirichenko, K.S. Pikula, A.M. Zakharenko, A.V. Gridasov, S. G. Parshin, S. A. Medvedev, I.A. Vakhniuk \& K.S. Golokhvast

Assessment of coal dust particles influence on marine mollusk Modiolus modiolus

K.Y. Kirichenko, K.S. Pikula, V.V. Chaika, A.M. Zakharenko, A.S. Kholodov,

V.V. Chernyshev, M.O. Tretyakova, K.S. Golokhvast, A.S. Kholodov \& K.S. Golokhvast

Air sample system optimization for the raw materials industry objects monitoring

M.V. Volkodaeva, Ya.A. Volodina \& V.A. Kuznetsov

Method of MSW landfill reclamation using waste conversion products

N.O. Milyutina, N.A. Averianova, E.S. Velikoselsksya, D. M. Malyuhin \& N.A. Politaeva

Microalgae biotechnology multiple use of Chlorella sorokiniana

N.A. Politaeva, Y.A. Smyatskaya, I.V. Dolbnya \& D.S. Sobgaida

Geochemical traits of urban landscapes

V.A. Alekseenko, N.V. Shvydkaya, A.V. Puzanov \& A.V. Nastavkin 
Soil evolution and reclamation of technogenic landscapes in Siberia

Lightning exposure of oil tanks with changing roof position

A.I. Adekitan \& M. Rock

Simulating the formation of wax deposits in wells using electric submersible pumps

A.N. Aleksandrov, M.A. Kishchenko \& Thang Nguyen Van

Separation of water-oil emulsions in device with enlarged throughflow capacity

O.S. Dmitrieva, I.I. Sharipov \& V.E. Zinurov

Increasing the efficiency of pipeline transport of viscous oil based on rheological features

N.A. Zaripova, A.K. Nikolaev \& Y.G. Matveeva

Development of detergent for drilling muds while directional drilling

R.R. Gizatullin, M.E. Budovskaya \& M.V. Dvoynikov

Stress-stain state of a vertical steel tank affected by bottom sediments in conditions of extreme temperature differences

R.R. Sultanbekov, R.D. Terekhin \& M.N. Nazarova

Modification of sodium lignosulfonate with reagent obtaining for drilling fluids

R.A. Fedina, A.D. Badikova, I.N. Kulyashova, D. A. Dubovtsev \& M.A. Tsadkin

Improving the technical and economic efficiency of the Reservoir Pressure Maintenance system (RPM)

Sh.Sh. Zaurbekov, M.M. Labazanov, P.U. Musaeva, Z.I. Gadaeva, T.Kh Ozdieva,

I.R. Masarov \& Z.M-E. Damzaev

Effective axial load as a function of the ultimate stress state of rocks to be drilled

L.K. Gorshkov \& A.N. Dmitriev

Polymer compositions for well killing operation in fractured reservoirs

S.R. Islamov, A.V. Bondarenko, A.F. Gabibov \& D.V. Mardashov

Paper methodology for pipe steels in hydrogen containing environments. Review

A.B. Arabey, V.A. Egorov, K.B. Konischev \& A. M. Semenov

Investigation of pump-ejector systems characteristics for water alternating gas injection

A.N. Drozdov, S.D. Karabaev, N.P. Olmaskhanov, Y.A. Gorbyleva,

I. M. Narozhnyy \& E.I. Gorelkina

The choice of fluid and thermal grid of the organic Rankine cycle in the conditions of its application at the oil refineries

M.A. Peretyatko, P.V. Yakovlev, V.A. Lebedev \& A.S. Deev

Cluster analysis of electric energy consumption in metallurgy enterprises

R.V. Klyuev, I.I. Bosikov \& O.A. Gavrina

Potential of Modelica for the creation of digital twins

S. Vöth \& M. Vasilyeva

Analysis and research of the coverage area of the LoRaWAN gateway in various conditions

for smart city applications

V.A. Shpenst \& A.V. Terleev

Traffic management at the enterprises of the mineral industry 
Study of structural features of draglines for their possible adaptability to changing mining and geological conditions

A.A. Khoreshok, M.A. Tyulenev \& S.O. Markov

Effect evaluation of the boom length and the bucket capacity of a dragline on its weight

A.A. Khoreshok, M.A. Tyulenev, S. O. Markov, M. Cehlár \& J. Janočko

Analysis of hazardous processes in the natural-industrial system

I.I. Bosikov, R.V. Klyuev \& Yu.V. Dmitrak

The implementation of Indonesian PSC gross split scheme in Russian offshore

M.I. Kiat, S.I. Iliukhin \& A.Kh. Ozdoeva

Risk management: Systematization in the context of oil and gas projects

D.C Trinh, A.E Cherepovitsyn \& A. A Ilinova

Role of renewables in strategies of oil companies from Central and Eastern Europe

A. Ilic \& T.V. Ponomarenko

Strategic forecasting of REE mining projects development in Russian Arctic

V.M. Solovyova, A.A. Ilinova \& A.E. Cherepovitsyn

Organizational and economic mechanism for the development of the oil and gas complex of developing countries

K. Y.B. Cofie \& N.V. Romasheva

Implementation of renewable energy into the mining industry: A hybrid energy system

K. Pollack, J.C. Bongaerts \& C. Drebenstedt

Possible effects of economy digitalization processes on Russian mining industry from economic theory point of view

M. Khaikin, M. Shabalov, D. Ivanova \& N.A. Shapiro

Economic and legal aspects of digital transformation in mining industry

M. Paschke, O. Lebedeva, M. Shabalov \& D. Ivanova

Alexander von Humboldt's letters to Sergey Uvarov in the Russian manuscript collections E. G. Pivovarov \& A. Yu Skrydlov

J. Hermann's studies on salt production in the Urals in late 18th century

L.D. Bondar

Author index 


\section{Preface}

Here are the results of joint scientific research conducted in the context of the RussianGerman Raw Materials Forum. These results reflect the main promising areas of cooperation between Russian Federation and Germany.

Today Russia and Germany are exploring various forms of cooperation in the field of mining, geology, mineralogy, mechanical engineering and energy. The Forum accumulates information on current trends - the development of raw materials markets and the world economy or environmental issues and new technologies in the industry - to respond to modern challenges efficiently. In 2018, we decided to annually publish the collection of research articles to promote relevant information discussed at the Forum, and to highlight socially significant problems of the raw materials sector, and this has now become a strong tradition.

For more than 12 years of its existence, the Russian-German Raw Materials Forum has proven its effectiveness and social and political significance, becoming an important platform for discussing the most pressing relations issues between Russia and Germany, not only in the mineral and raw materials sector, but also in international economic and geopolitical aspects.

Economic and technological cooperation have always played an important and sometimes decisive role in Russian-German relations. At the same time, Russian oil and gas exports remain the most important economic link between Russia and Germany. But in addition, the access to German technologies traditionally stimulating the economy development continues to be essential for the Russian side.

We focus on the main fields of cooperation, development areas and business opportunities for technological cooperation in the mineral sector.

At the same time, we have significantly expanded the scope of the Russian-German cooperation: not only traditional oil and gas issues are raised now, but also the topics of energy of the future, digitalization of the raw materials industry, raw materials processing, circular economy and joint scientific projects on Earth exploration.

Taking into account the traditionally high interest of young people in the Forum, as well as thanks to the support of the International Competence Centre for Mining Engineering Education under the auspices of UNESCO, the programme for young scientists has also been significantly expanded recently.

We are very glad that, at present, despite the world political challenges, the interest in the Russian-German Raw Materials Forum is constantly growing, and the joint projects with various Russian regions and cooperation of scientists make the Raw Materials Forum the main dialogue platform for both countries here and now.

We are confident that exactly such deep and dynamic Russian-German scientific and academic dialogue will continue contributing to strong, wide-ranging, mutually beneficial and equal relations between the countries. And we will do everything in our power to maintain and develop such relationships. 


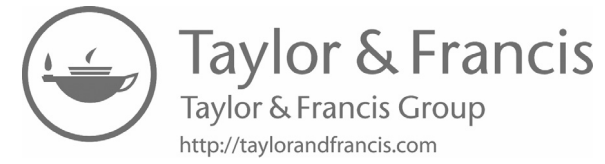




\section{Organizers}

International Competence Centre for Mining Engineering Education under the auspices of UNESCO

Russian-German Raw Materials Forum

Saint Petersburg Mining University

SIBUR

PhosAgro

Freiberg University of Mining and Technology

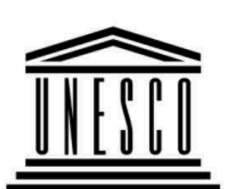

United Nations : Educational, Scientific and Cultural Organization

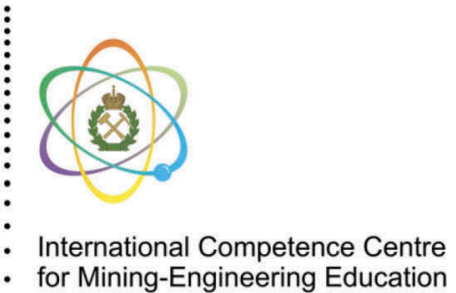

under the auspices of UNESCO

\section{Rohstoff-Forum}

Российско-Германский сырьевой форум

\section{SAINT-PETERSBURG MINING UNIVERSITY}
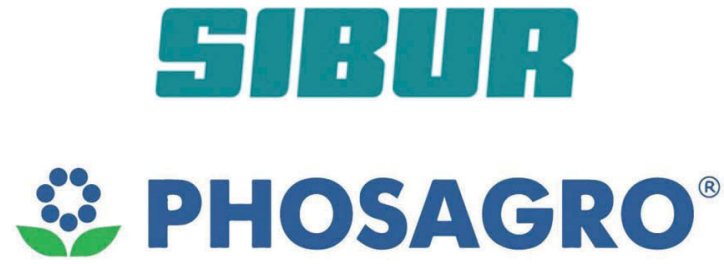

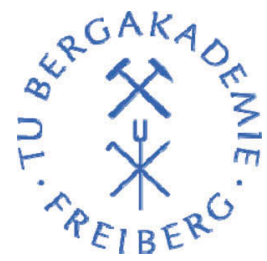

$V N G$ 


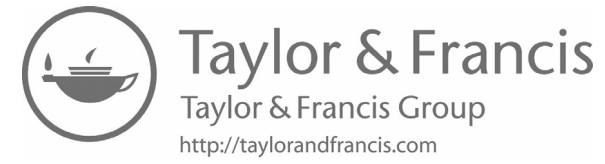




\title{
Processing of oil products by hydrocarbon-oxidizing microorganisms
}

\author{
O.M. Prishchepa \\ Doctor of geological and mineralogical Sciences, Head of department, Saint-Petersburg Mining University, \\ Saint-Petersburg, Russia \\ Y.V. Nefedov \\ PhD in Geology and Mineralogy, Associate Professor, Deputy Head of Oil and Gas Geology Department, \\ Saint-Petersburg Mining University, Saint-Petersburg, Russia
}

\section{P.A. Morgunov}

PhD in Chemisty, All-Russia Petroleum Research Exploration Institute» JSC ("VNIGRI” JSC)

\begin{abstract}
This paper presents the results of laboratory studies concerning biodegradation of oil and diesel fuel put into actions by strains of hydrocarbon-oxidizing microorganisms. The degree of biodegradation of oil and oil products in the laboratory is estimated by balance calculations, according to which the destruction could reach up to 56.6-71.6\%, while the destruction of individual fractions of the oil pollutant could exceeds $80-90 \%$. A theoretical explanation of the activity of hydrocarbon-oxidizing microorganism strains is presented.
\end{abstract}

Keywords: Hydrocarbon-oxidizing bacteria, strains of microorganisms, biodegradation of oil and oil products

\section{INTRODUCTION}

The purpose of experimental and scientific activity is to determine in the laboratory the capacity and efficiency of transformation of oil and oil products by selected strains of hydrocarbon-oxidizing microorganisms. Long-term researches of VNIGRI allowed to create a collection of microorganisms possessing high oil-oxidizing and bio emulsifying properties.

Studies of biodegradation properties of individual strains related to oil degradation are aimed for compiling a data base of microorganisms "destructors" clearing of oil (including the conditions of high concentration of oil products, in a wide temperature and $\mathrm{pH}$ range) suitable for soil and water ecosystems.

\section{PROBLEM STATEMENT}

Samples of diesel fuel and oil were selected as research objects on the hydrocarbon ecology problem. Samples of polluting oil were analyzed according to the scheme of detailed complex genuine chemical and bituminological analysis, developed and used in the laboratory practice of VNIGRI, in order to be able to compare the results in pre- and post-experimental stages.

Identification of the most active strains of hydrocarbon-oxidizing microorganisms based on the capacity to dispose of polluting oils is aimed to creating the basis of the new biological products. 
The results obtained and subsequent balance calculations based on them will allow to determine not only the activity of strains for the utilization of oil pollution in general, but also its specific fractions.

\section{OIL AND OIL PRODUCTS BIODEGRADATION BY HYDROCARBON-OXIDIZING STRAINS OF MICROORGANISMS}

In the special literature the studies about the utilization of various classes of oil hydrocarbons by pure cultures of hydrocarbon-oxidizing microorganisms devoted a significant amount of work.

Since oil and oil products are among the most common pollutants of the biosphere, the problem of cleaning the environment from oil pollution is becoming increasingly acute due to both limited possibilities (and sometimes environmental harm) of using mechanical and physic and chemical cleaning methods for these purposes. Oil is a toxin, which, covering the surface of the soil, destroys vegetation, creates conditions of oxygen starvation in the soil, has a toxic effect on humans and all living organisms, etc. Accordingly, oil, getting into the soil, changes its physical characteristics. It has brightly expressed hydrophobic properties, which are transmitted to soil particles. There are significant violations of water and air regimes of soils, leading to the development of anaerobic processes, which adversely affects soil fertility. Oil pollution causes an increase in the carbon content in the soil, leading to a high ratio of carbon to nitrogen; in addition, there is a decrease in the concentration of mobile phosphorus (Rueter et al., 1994).

Oil components, interacting with soil particles in different ways, are distributed along the vertical profile of the soil. For the vertical movement of oil down the soil section in the humus level is going high-molecular oil components, the beneath layers penetrate mostly low molecular compounds: the simplest structure of the paraffinic, naphthenic and aromatic oil hydrocarbons. On the surface of the soil oil undergoes chemical oxidation, partially photo-oxidation. However, it should be noted that abiotic oxidation is rather slow, therefore, to a greater extent the destruction of oil hydrocarbons is associated with the process of their biological oxidation, which occurs only with the participation of oil-oxidizing microorganisms.

In this regard, in recent years, more and more attention of environmentalists attracts biological method of purification from oil pollution. The method is based on the use of microorganisms capable of using oil hydrocarbons as the only source of carbon. This makes it possible to reduce the oil content to background values (the values of background concentrations vary widely depending on the area) at low operating costs and facility of decision.

\section{MECHANISMS OF HYDROCARBON OXIDATION BY MICROORGANISMS}

The processes of biogenic oxidation of hydrocarbons are so complex that currently there is not clear enough to define this mechanism. This question is complicated because the direction of the biogenic oxidation process is influenced by many factors: hydrogen potential $(\mathrm{Ph})$, oxidative-reductive potential ( $\mathrm{Rh} 2)$, temperature, lighting, osmotic pressure, etc. In addition to these factors, the physiological characteristics of the microorganisms themselves, which are obvious related to the oxidation of individual hydrocarbons and their mixtures, are also very important.

Microorganisms have the property of selective attitude to different hydrocarbons, and this capacity is determined not only by the difference in the structure of the substance, but even by the number of carbon atoms contained in the structure. For example, selected and described by V. Petrov and I. Tauch Bacterium aliphaticum and Bacterium aliphaticum liquefaciens oxidized n-hexane, n-octane, decan, hexadecan, triacontane and tetra trioctane. Bacterium paraffinicum described by the same authors, oxidized only the higher homologues of this series, starting with hexadecane. 
Oxidation of hydrocarbons by the majority of well-known microorganisms is carried out by adaptive enzymes (ferments). This fact is established by numerous experiments about the oxidation of hydrocarbons by the cells of microorganisms grown on nonhydrocarbon substrates. It has been shown, for example, that cells of heptane-oxidant bacteria grown on glucose are unable to oxidize hydrocarbons in the presence of chloramphenicol. This compound inhibits protein synthesis and thus prevents the emergence of adaptive enzymes.

Ways of microbiological oxidation of hydrocarbons are established by various methods:

- The simultaneous adaptation method proposed by R.Y. Stanier (1947) is based on the high specificity of adaptive enzymes induced by hydrocarbons to intermediate oxidation products. The basic principles of this method are: cells adapted to the oxidation of hydrocarbon are simultaneously adapted to the oxidation of subsequent intermediate products. Hence, if cells grown on hydrocarbon are simultaneously adapted to oxidation of any compound, this compound can be a member of a series of hydrocarbon metabolites.

- A method of checking the growth of microorganisms on the expected intermediate product.

The methods give the indirect evidence of metabolic pathways. Direct evidence of metabolism is obtained by the following two methods:

- Separation and determination of intermediate products of oxidation of hydrocarbons. In recent years, more advanced methods of separation and identification of products of microorganisms - gas and liquid chromatography, infrared spectrophotometry, ultraviolet rays and mass spectrometry have been used. The most accurate and reliable evidence is provided by the method of application marked by isotope substrates and mark detection in oxidation products.

- Making of enzymatic preparations out of microbial cells that catalyze specific reactions in the metabolic chain.

\section{DISPERSION OF HYDROCARBON-OXIDIZING MICROORGANISMS IN NATURE}

Microorganisms degrading hydrocarbons are widely spread in the nature. There are 22 species of bacteria, 31 species of microscopic fungi, including 19 species of yeast selected from soil ecosystems capable of biodegradation of various oil hydrocarbons. There are 25 species of hydrocarbon-degrading bacteria and 27 species of hydrocarbon-using microscopic fungi that were isolated from the marine environment.

Among them:

- bacteria (Achromobacter, Acinetobacter, Alcaligenes, Arthrobacter, Bacillus, Brevibacterium, Citrobacter, Clostridium, Corynebacterium, Desulfovibrio, Eneribacer, Escherichia, Flavobacterium, Methanobacterium, Micrococcus, Micromonospora, Mycobacterium, Nocardia, Rhodococcus, Pseudomonas, Sarcina, Serratia, Spirillum, Streptomyces, Thiobacillus, Vibrio),

- mycelial fungi (Aspergillus, Cephalosporium, Penicillium, Mucor, Fusarium, Trichoderma),

- yeast (Candida, Debaryomyces, Endomyces, Endomycopsis, Hansenula, Rhodotorula, Saccharomyces, Torulopsis, Trichosporon),

- cyanobacteriums (Agmenellum, Aphanocapsa, Lyngbya, Microcoleus, Oscillatoria, Phormidium, Plectonema).

Most hydrocarbon-oxidizing microorganisms are found both in soil and water habitats (Petrikov et. al., 2008). 


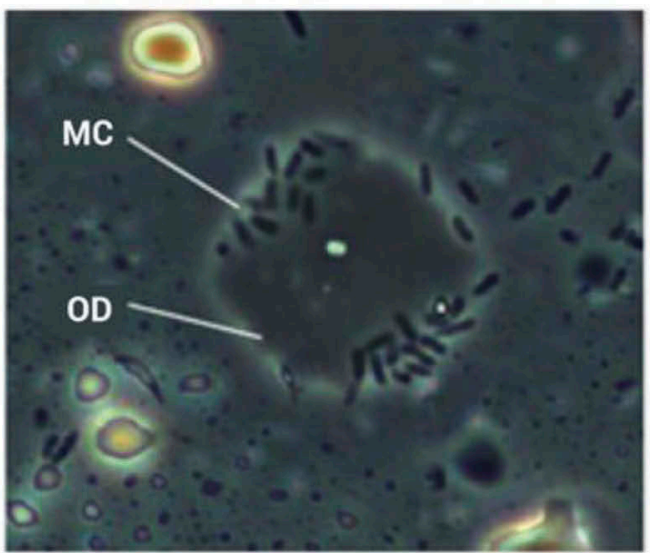

A

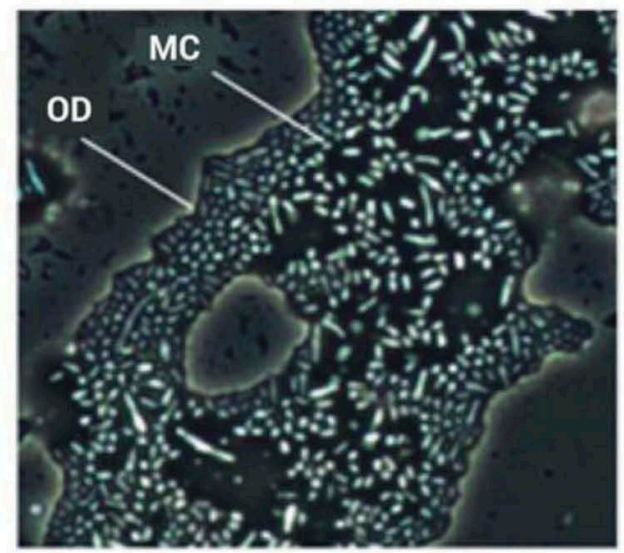

B

Figure 1. Pure cultures of microorganisms in the process of oil destruction (optical microscopy).

A - Pseudomonas putida BS3701 (pBS1141, pBS1142), B - Rhodococcus sp. S67: MC - microbe cells, OD - oil drop.

\section{OIL EFFECT ON SOIL MICROORGANISMS}

The effect of long-term impact of oil on the soil can be emerged in the change of its microbiological properties. All soils contain a large number of microorganisms capable of oxidizing various hydrocarbons. The breeding effect of oil on the soil microbiota is primarily expressed in the fact that in contaminated soils there are microorganisms using n-alkanes and aromatic hydrocarbons much more than in soils without oil. There is an increase in the number of highly specialized forms of microorganisms oxidizing gaseous hydrocarbons, solid paraffin's, aromatic hydrocarbons. The effect of oil on living organisms of the soil is largely determined by its composition and concentration. It is well known that at low concentrations oil has a stimulating effect on soil biota, as it is an energy substrate for a large group of microorganisms and contains substances that stimulate the growth of plants. On the other hand, the massive oil pollution caused by accidental spills is accompanied by an acute toxic effect of oil on living organisms (Petrikov et al., 2008).

With the help of optical microscope, the behavior of strains belonging to different species and having a different structure of the cell wall with growth in a medium with crude oil was studied. As it can be seen from Figure 1, the nature of interaction with oil gram-negative cells Pseudomonas putida BS3701 and gram-positive cells Rhodococcus sp. S67 differ significantly.

Optical studies of these cultures after three days of cultivation in medium with crude oil showed that Pseudomonas are localized on the oil drops surface, and the cells Rhodococcus are inside of oil drops (Nikulin et al., 2017).

\section{HYDROCARBONS ENTRYWAYS INTO BACTERIAL CELLS}

Today there are no reliable experimental data on the oxidation of hydrocarbons by extracellular enzymes of microorganisms. Special studies have shown that in the growth of yeast in the medium with hexadecane p. Candida enzymes responsible for the oxidation of hydrocarbons, as well as products of primary oxidation of the substrate - cetyl alcohol and palmitic aldehyde - they were contained only in cells and were not found in the culture medium. The available various data on the hydrocarbons diffusing into the cells of microorganisms, localization of hydrocarbon-oxidizing enzymes and the resulting products leave no doubt that 
hydrocarbons are oxidized intracellularly. Hence the need arises to explain the entry of waterinsoluble substrate into the cell (Gottslak, 2008).

There are the following known types of transport of hydrocarbons into the cells of microorganisms:

Passive transfer:

a) simple diffusion - a non-specific flow of substances into the cell, where various compounds penetrate the cell without interacting with any carrier;

b) facilitated diffusion - a specific process in which the transferred substance reversibly binds to the carrier located in the membrane and enters the cell in the form of a substrate-protein complex;

In this case, the rate of entry of substances is equal to the rate of its release from the cell.

Both of these processes and their speed depends on the concentration of the substrate in the medium.

Active transfer: the substance enters the cell against the concentration gradient in the medium; the process requires energy and occurs with the help of specific protein-carriers (permeases).

Further restrictions are related to the solubility of the substrate in water. The substrate can enter the microbial cell either from the state of the true solution or by its direct contact with the cell.

The absorption process is defined as active transport according to the following parameters:

- specificity with respect to the substrate; on the outer surface of the membrane formed a complex carrier-substrate;

- the need for metabolic energy; the carrier has a high affinity for the substrate, if it is facing the outer surface of the membrane, and low affinity to it, if it is facing its inner surface. These changes in the carrier consume metabolic energy;

- transport of the corresponding substrate against the concentration gradient; this is due to a change in the affinity of the carrier to the substrate during the transition from outside to inside;

- release of unmodified substrate into cytoplasm (as opposite to group transfer) (Skryabin, G. K., 2008).

Only low molecular weight liquid hydrocarbons from $\mathrm{C} 5$ to $\mathrm{C} 11$, as well as some aromatic hydrocarbons, can slightly dissolve in water, higher molecular weight homologues are practically insoluble (Gottslak, 2008).

\section{MICROBIOLOGICAL OXIDATION OF OIL HYDROCARBONS AND OIL PRODUCTS}

Microbiological transformations of hydrocarbons are a special area because of some features of these processes. Their specificity is due to the peculiarity of hydrocarbons as chemical compounds with the maximum recovery associated with these hydrophobic properties. It turned out that the hydrophobicity of the hydrocarbon molecule is of great importance for the chemistry of microbiological oxidation of these compounds, their transport to the microbial cell, the dynamics of culture growth, their physiology, and many aspects of the processes technology associated with the use of hydrocarbon substrates.

All reactions of microbiological transformation of hydrocarbons are oxidation reaction. The limiting recovery of these substances makes it necessary for their oxidation the presence of oxygen. The hydrophobic nature of the molecule is the reason that the oxidation processes are carried out by oxygenases, in contrast to the oxidation of more hydrophilic substances that occur under the action of dehydrogenases. The hydrophobicity of hydrocarbon substrates and their poor solubility in water determine the methods of transport of substances into the cell, that was discussed above (Petrikov et. al., 2008). 
A characteristic feature of the process of assimilation of hydrocarbons as a carbon source is the frequent accumulation of intermediate products in the culture medium of microorganisms growing due to such substrates (Nikulin, A., Epifancev, K. 2017).

Let us consider these processes by the example of normal paraffins oxidation. The ways of oxidation of normal paraffins by microorganisms using these compounds as sources of carbon and energy were studied in sufficient detail.

In the vast majority of cases, as a result of the primary enzymatic attack of the n-paraffin molecule, the oxidation of the terminal carbon atom occurs.

The first stable products of oxidation of hydrocarbons are primary alcohols. The next stage is the usual biological transformation of alcohol into aldehyde and aldehyde into acid. The general scheme of reaction is as follows.

\section{$\mathrm{R}-\mathrm{CH} 2-\mathrm{CH} 3+[\mathrm{O}] \quad \mathrm{R}-\mathrm{CH} 2-\mathrm{CH} 2 \mathrm{OH}-2 \mathrm{H} \quad \mathrm{R}-\mathrm{CH} 2-\mathrm{CHO}-2 \mathrm{H}+\mathrm{HOH} \quad \mathrm{R}-\mathrm{CH} 2-\mathrm{COOH}$}

The further mechanism of fatty acids assimilation, arising during hydrocarbons oxidation, proceeds by $\beta$-oxidation, which consists in successive spliting of two-carbon fragments in the form of active acetate entering the tricarboxylic acid cycle.

Further reduction of fatty acid formed as a result of microbiological oxidation of n-alkanes along with classical $\beta$-oxidation may include a number of minor products:

1) $\omega$-hydroxylation, leading to the formation of $\omega$-oxycarboxylic acids, and then dicarboxylic acids with further partitioning. This oxidation way has been experimentally proven in many microorganisms;

2) $\alpha$-oxidation, decarboxylation, which is proven in cases where the carbon subterminal atom carries a ketogroup or hydroxyl; 3) dehydrogenation of fatty acid followed by oxidative cleavage of the double bond. The existence of this mechanism is suggested by a group of researchers (W.R. Finnerty, R.E. Kallio, 1964).

The terminal oxidation mechanism described above is not the only way to degrade n-alkanes. In some microorganisms, the oxidation of subterminal or internal carbon atoms is described, which leads to the formation of secondary alcohols and ketones. This way sometimes goes as a minor along with terminal oxidation.

H.B. Lukins and J.W. Foster (1963) found that some mycobacteria metabolize n-alkanes through methylketone with the intermediate formation of peroxide and secondary alcohol. Further oxidation of ketones has not been sufficiently studied. In the experiments of J.R. Vestal and J.J. Perry (1969) Brevibacterium sp. was oxidized propane through acetone with subsequent attack on the terminal methyl and decarboxylation:

$\mathrm{CH} 3 \mathrm{CH} 2 \mathrm{CH} 3 \rightarrow \mathrm{CH} 3 \mathrm{CHOHCH} 3 \rightarrow \mathrm{CH} 3 \mathrm{COCH} 3 \rightarrow \mathrm{CH} 3 \mathrm{COCH} 2 \mathrm{OH} \rightarrow \mathrm{CH} 3 \mathrm{COOH}$

Based on the works of F.W. Forney and A.J. Markovetz (1970) the degradation of tridecane by culture of Pseudomonas aeruginosa appears to be as follows:

$\mathrm{CH} 3(\mathrm{CH} 2) 11 \mathrm{CH} 3 \rightarrow \mathrm{CH} 3(\mathrm{CH} 2) 10 \mathrm{CHOHCH} 3 \rightarrow \mathrm{CH} 3(\mathrm{CH} 2) 10 \mathrm{COCH} 3 \rightarrow$ $\mathrm{CH} 3(\mathrm{CH} 2) 9 \mathrm{CH} 2 \mathrm{OCOCH} 3 \rightarrow$

$\mathrm{CH} 3(\mathrm{CH} 2) 9 \mathrm{CH} 2 \mathrm{OH}+\mathrm{CH} 3 \mathrm{COOH}$

$\downarrow$

$\mathrm{CH} 3(\mathrm{CH} 2) 9 \mathrm{COOH}$

\section{BIOGENIC OXIDATION OF OILS OF DIFFERENT CHEMICAL COMPOSITION}

In the process of oil oxidation, the mutual influence of hydrocarbon and non-hydrocarbon components included in its composition plays an important role (Khotimskii et. al., 1970).

With anaerobic and aerobic microbial destruction, regardless of the type of oil, their density increases, the content of resinous-asphaltene compounds, sulfur increases and the concentration of paraffin hydrocarbons in the system decreases. The residual accumulation of naphthenic hydrocarbons was noticed (Bruheim et al., 1998).

Reduction of paraffin potential of oils in biochemical oxidation is due to the removal of model systems of $\mathrm{n}$-alkanes as substances mainly consumed by microorganisms. Among n-alkanes, bacteria are better able to absorb low molecular weight compounds, which has 
Table 1. The classification of the components of the oils according to their capacity to biodegradation.

\begin{tabular}{|c|c|c|c|}
\hline Group & $\begin{array}{l}\text { Attitude to the } \\
\text { microorganism } \\
\text { effects }\end{array}$ & $\begin{array}{l}\text { Degree of biodegradation, } \\
\% \text { to the original content }\end{array}$ & Oil components \\
\hline I & Highly sensitive & $80-100$ & $\mathrm{n}$-alkanes; isoalkane \\
\hline II & Sensitive & $60-80$ & $\begin{array}{l}\text { cycloalkanes with } 6,1,5 \text { and } 2 \text { rings; } \\
\text { s-aromatics; monoaromatic }\end{array}$ \\
\hline III & $\begin{array}{l}\text { Moderately } \\
\text { sensitive }\end{array}$ & $45-60$ & $\begin{array}{l}\text { cycloalkanes with } 3 \text { and } 4 \text { rings; three } \\
\text { aromatic hydrocarbons }\end{array}$ \\
\hline IV & Resistant & $30-45$ & $\begin{array}{l}\text { tetra-aromatic hydrocarbons; sterane; } \\
\text { triterpene; naphtene aromatic } \\
\text { hydrocarbons }\end{array}$ \\
\hline V & Highly resistant & $0-30$ & $\begin{array}{l}\text { pentha-aromatic hydrocarbons; asphal- } \\
\text { tenes; resins }\end{array}$ \\
\hline
\end{tabular}

been proven on the range of $\mathrm{C} 14$ to $\mathrm{C} 20$ hydrocarbons. In addition, no selectivity has been found in the biooxidation of hydrocarbons with an even or uneven number of $\mathrm{C}$ atoms in the molecule (Bruheim et al., 1998).

From the physiological characteristics of each kind of microorganisms depends on the direction of the process of destruction of individual hydrocarbons and their mixtures with different degrees of resistance to oxidation (Table 1).

The above-mentioned, undoubtedly complicates obtaining unambiguous results of research of predictability of transformation of various classes of oils. However, oil microbiology has research works, in the results of which can be traced geochemical changes in the composition of oils during biodegradation.

In 1960-1970-ies in "VNIGRI" JSC under the guidance of doctor of biological sciences T. L. Simakova were conducted long-term comprehensive studies of the change pecularities of different chemical composition of oils, some of their fractions and individual hydrocarbons in

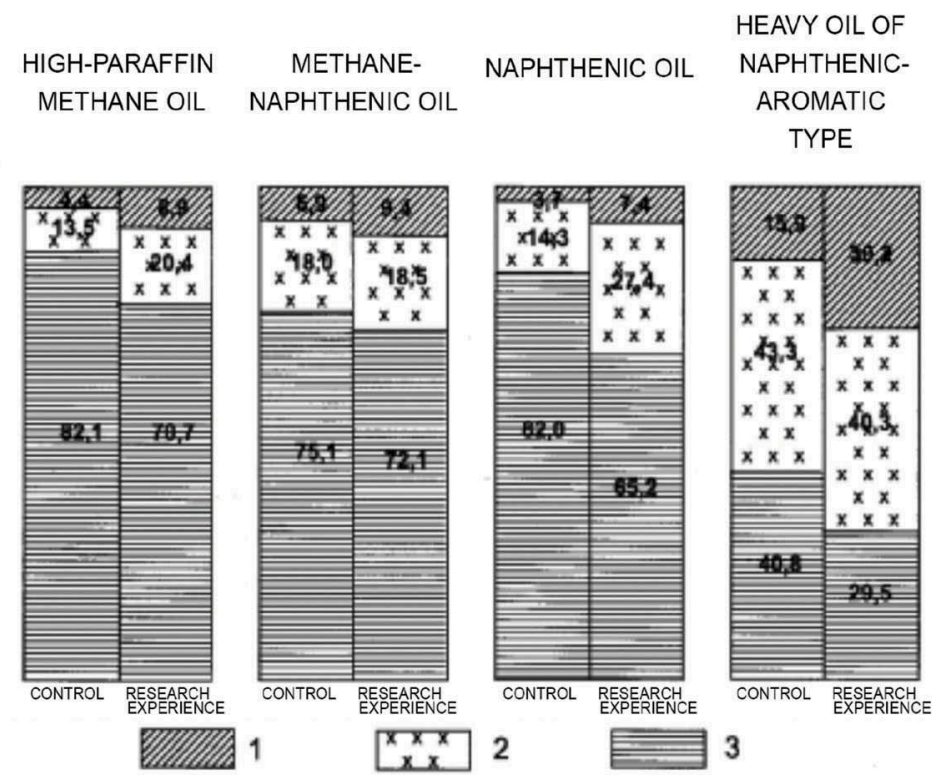

Figure 2. Changes of the chemical group composition of oils under the influence of biogenic factor. 1 - asphalt-resinous components; 2 - aromatic hydrocarbons; 3 - methane and naphthenic hydrocarbons. 
biodegradation. Biocenoses of microorganisms were isolated from formation waters of the same wells, from which oil was selected for experiments.

As a result of these studies on a large factual material, it was shown that as a result of biogenic oxidation in aerobic conditions, there are significant changes in the group hydrocarbon composition of oils, leading to the transition of one geochemical type of oil to another (Skryabin, G. K., 2008)., (Figure 2).

The authors came to the following main conclusions (Khotimskii et. al., 1970):

- High-paraffin methane oil under the influence of microorganisms becomes heavier, its viscosity and the content of asphalt-resinous substances increase, the content of solid paraffins decreases. In the group hydrocarbon composition, it is redistributed in the content of separate groups of hydrocarbons with a decrease in the amount of methane (normal and isostructure), as well as aromatic hydrocarbons that are part of the kerosene fractions. The total content of naphthenic and aromatic hydrocarbons in oil as a whole increase. Thus, methane oils under the influence of the biogenic factor change with the approach to the methane-naphthenic type.

- Methane-naphthenic oil type under the influence of the biogenic factor changes in the same direction, as a result of which it is weighted, it also increases the content of asphalt-resinous substances, the number of saponification due to the ethereal number and the number of solid paraffins decreases. Its hydrocarbon composition changes, as in methane oil, with a decrease in the amount of methane hydrocarbons and aromatic hydrocarbons, but the last one is only in kerosene fractions. In general, methane-naphthenic oils change with increasing content of naphthenic and aromatic hydrocarbons in their composition.

- Naphthenic oil type with a high content of naphthenic hydrocarbons under conditions of biogenic oxidation changes with increasing specific gravity, viscosity, content of asphaltresinous components and acid number in oils. Its hydrocarbon composition reduces the content of methane and naphthenic hydrocarbons. In contrast to the above types of oils, the amount of aromatic hydrocarbons included in the composition of kerosene fractions increases. Thus, as a result of the vital activity of microorganisms, the oxidation of naphthenic oil is accompanied by an increase in its aromatic fraction and a decrease in methane and naphthenic hydrocarbons.

- Oxidation of heavy oil of naphthenic-aromatic type is accompanied by its tarring with a significant increase in specific gravity and viscosity. Unlike other types of oils studied by the authors, as a result of biogenic oxidation in oils of naphthenic-aromatic oil, both acid and ethereal number increases. The hydrocarbon composition of this oil reduces the content of all groups of hydrocarbons: methane, naphthenic and aromatic - by increasing the asphalt-resinous components.

According to the above, during biodegradation of the studied types of oils in their group composition, there are serious changes: the relative content of the asphalt-resinous components increase in 1.4-2 times, aromatic hydrocarbons increases in 1.02-1.9 times (the exception is naphthene-aromatic oil). The relative content of methane and methane-naphthenic hydrocarbons, compared with the control, is reduced in 0.12-1.4 times.

Changes in the group composition of oils should be taken into account in the development of technology for cleaning soils from oil pollution.

The practical help of oil microbiology in solving this problem is the allocation of pure cultures of hydrocarbon-oxidizing microorganisms, the establishing of their origin and the degree of activity in the oxidation of oils and oil products.

The most active strains of hydrocarbon-oxidizing microorganisms, oxidizing to a large extent resistant to biodegradation components of oil, are the most promising for the creation on their basis of biological products for soil purification from oil pollutant.

The study of the ability of microorganisms to oxidize specific classes of hydrocarbons in the composition of oils, as shown above, allows to create biological products for the purpose in the future. 


\section{LABORATORY RESEARCH ABOUT OIL BIODEGRADATION BY STRAINS OF HYDROCARBON-OXIDIZING MICROORGANISMS}

In the study of oil utilization activity, as noted above, 9 strains of HOM were involved in laboratory experiments. Series of experiments with oil was carried out at a temperature of $280 \mathrm{C}$ on the laboratory shaker for 12 days. This regime was conditioned by the time frame for research. Extraction conditions of post-experimental samples differed from the conditions for pre- experimental samples. Chloroform, as in post-experimental samples with diesel fuel, extracted residual oil and culture medium (containing microbial mass and intermediate products of bio-oxidation of oil). Then the chloroform extracts were combined and on full complex chemical bitumen analysis the total extract was coming, chloroform bitumoid (CHB), which is actually not recycled oil and the residual products of its oxidation. This allowed without preliminary calculations to immediately assess the loss of oil as a whole and its individual fractions, which, in fact, is provided by the objectives of the planned research (Nikulin et al., 2017).

Consideration of the results of the analysis of CHBDF and CHBCM of bio-oxidized diesel fuel showed that these data are of interest from the point of view of the physiology study of hydrocarbon-oxidizing microorganisms, the study of this direction is out of this research topic (Saitgaleev et al., 2019).

The selected mode of laboratory experiments and analytical data on oil utilization allow us to compare the tested strains of HOM on the ability to oil dispose under specified conditions and select the most active.

The main parameters of experiments on oil utilization by the studied strains: a charge of oil is $1.45-2.02 \mathrm{~g} / 100 \mathrm{ml}$, or $14500-202000 \mathrm{mg} / \mathrm{l}$. This is a fairly high oil contamination. HOM is in the range of (0.80-5.30) 108 cells $/ \mathrm{ml}$. After 12 days in post-experimental samples the $\mathrm{pH}$ of the culture medium remained at pre-experimental level or increased to 7.5 - 8.0. Decrease of pH was not recorded (Sukplanga et al., 1999).

Table 2 shows the change in qualitative composition of crude oil in post-experimental samples of studying the activity of utilization of the tested strains of HOM. As it follows from the table, there were some changes in the qualitative composition of oils within 12 days. In the initial experiments samples the content of oils was $69.98 \%$. In the post-experimental samples the oil content varies from 63.76 to $70.67 \%$, that is, in the qualitative composition of the postexperimental samples there is a decrease in the oil content ( 7 strains of HOM), and its increase (2 strains $-1-\mathrm{R}$ and $99-\mathrm{T})$.

Table 2. Changes in oil composition (\% rel.) in experiments on the study of the biodegradation activity of hydrocarbon-oxidizing microorganisms (the duration of experiments is 12 days).

\begin{tabular}{|c|c|c|c|c|c|c|c|c|c|c|}
\hline \multirow{3}{*}{$\begin{array}{l}\text { Strain } \\
\text { HOM in } \\
\text { experiments }\end{array}$} & \multicolumn{4}{|c|}{ Group composition of bitumoid, $\%$} & \multicolumn{4}{|c|}{ Hydrocarbons oils composition, $\%$} & \multirow{3}{*}{$\begin{array}{l}\frac{\text { Sat. }}{\mathrm{HC}} \\
\frac{\mathrm{Ar}}{\mathrm{HC}}\end{array}$} & \multirow[b]{3}{*}{ HOM type } \\
\hline & \multirow[b]{2}{*}{ oils } & \multirow[b]{2}{*}{$\begin{array}{l}\text { benz. } \\
\text { resins }\end{array}$} & \multirow{2}{*}{$\begin{array}{l}\text { sp./ } \\
\text { benz. } \\
\text { resins }\end{array}$} & \multirow[b]{2}{*}{ asphaltene } & \multirow[b]{2}{*}{$\begin{array}{l}\text { saturated } \\
\text { hydrocarbons }\end{array}$} & \multicolumn{3}{|c|}{$\begin{array}{l}\text { Aromatic } \\
\text { hydrocarbons }\end{array}$} & & \\
\hline & & & & & & Ar I & Ar II & $\begin{array}{l}\text { poly- } \\
\text { Ar }\end{array}$ & & \\
\hline Initial oil & 69,98 & 14,08 & 11,80 & 4,14 & 50,76 & 17,52 & 21,15 & 10,57 & 1,03 & - \\
\hline $4-\mathrm{D}$ & 67,59 & 13,92 & 13,12 & 5,37 & 51,51 & 20,61 & 18,79 & 9,09 & 1,06 & Pseudomonas \\
\hline $12-\mathrm{R}$ & 63,76 & 14,34 & 16,86 & 5,04 & 50,46 & 20,31 & 24,00 & 5,23 & 1,02 & Pseudomonas \\
\hline $1-K P$ & 68,66 & 13,57 & 12,38 & 5,39 & 54,71 & 12,76 & 28,27 & 4,26 & 1,21 & Rhodococcus \\
\hline $1-\mathrm{R}$ & 70,65 & 11,96 & 13,04 & 4,35 & 47,63 & 23,66 & 14,20 & 14,51 & 0,91 & Pseudomonas \\
\hline $2-\mathrm{V}$ & 69,40 & 13,80 & 11,40 & 5,40 & 51,34 & 19,76 & 16,22 & 12,68 & 1,05 & Pseudomonas \\
\hline $99-\mathrm{T}$ & 70,67 & 11,81 & 13,19 & 4,33 & 47,73 & 22,16 & 17,04 & 13,07 & 0,91 & Pseudomonas \\
\hline $4-G$ & 66,14 & 13,94 & 13,35 & 6,57 & 48,15 & 25,00 & 16,36 & 10,49 & 0,93 & Mycobacterium \\
\hline 1-SH & 67,00 & 14,80 & 13,60 & 4,60 & 55,38 & 16,31 & 15,69 & 12,62 & 1,24 & Mycobacterium \\
\hline $48-\mathrm{U}$ & 65,88 & 15,58 & 14,40 & 4,14 & 50,90 & 22,75 & 19,16 & 7,19 & 1,04 & Pseudomonas \\
\hline
\end{tabular}


Similar changes occurred in the content of other fractions of post-experimental bitumoids, comparing with the original oil. It is almost impossible to make a certain predictability in the change of oils during biodegradation based on the results of the study of the qualitative composition (Nikulin et al., 2017).

Somewhat greater certainty in the characteristic of this process makes the ratio of saturated hydrocarbons to aromatic hydrocarbons. According to the deviation of the value of this ratio, comparing with that in the original oil, the tested strains can be divided into two groups. In case of oil biodegradation by one group of strains, the value of this ratio, in comparison with the original oil, it decreases, and in case of destruction by another group of strains - it increases (Dashko et al., 2016).

It is possible to evaluate and compare the activity of the tested strains of HOM only after carrying out the balance calculations of the processes of utilization in the conditions of laboratory experiments with oil and its specific fractions. Remaining oil in every experience and qualitative composition of post-experimental samples allowed to make balance calculations of the process of oil utilization by tested strains and to find loss of oil in whole and in its separate fractions in the weight \% relatively to the content of their source in the sample (Table 3).

According to the table, oil losses in these experiments are $1.4-73.4 \%$ of its original components. The loss of specific fractions in the composition of the oil is the following: oil 5.0 to $75.8 \%$, benzene resin 2.4-72.9\%, alcohol benzene resin 9.0-62.0\%, asphaltenes $17.0-67.6 \%$. There were losses in the fractional composition of oils: the content of saturated hydrocarbons decreased by $2.8-75.9 \%$, Ar I $-12.8-71.9 \%$, Ar II $-14.1-72.5 \%$, poly Ar $-1.0-88.0 \%$ relative to their initial content (Dashko et al., 2016).

The following fact is noteworthy. During oil biodegradation in the specified conditions of the experiments, a significant formation of intermediate products was recorded, which, according to their chemical characteristics, were analytically established in the fractions of oils (strain 1-R), resins and asphaltenes of the group composition of CHB and in the fractions of saturated hydrocarbons (strains 1-KP and 1-SH) and aromatic hydrocarbons in the oils. In the post-experimental samples of strains $48-\mathrm{U}$ and $1-\mathrm{R}$ the amount of remaining oil exceeds the initial sample weight.

Additionally, the calculations of oil losses in whole and oils fractions (strain 99-T) excluding new formations were carried out. In this case, as shown by calculations, the losses during the experiments of oil in whole and oil fractions increased. Based on the results of the study of the

Table 3. Loss of oil in experiments on the biodegration activity of hydrocarbon-oxidizing microorganisms (the duration of experiments is 12 days).

Loss, weight $\%$ relative to the specific initial oil fraction

\begin{tabular}{|c|c|c|c|c|c|c|c|c|c|c|}
\hline \multirow[b]{2}{*}{ Strain HOM } & \multirow[b]{2}{*}{ Oil in whole } & \multirow[b]{2}{*}{ Oils } & \multirow[b]{2}{*}{ benz. $\mathrm{cm}$. } & \multirow{2}{*}{$\begin{array}{l}\mathrm{sp} / \\
\text { benz. } \\
\mathrm{cm} .\end{array}$} & \multirow[b]{2}{*}{ Asph. } & \multicolumn{4}{|c|}{ In oils } & \multirow[b]{2}{*}{$\begin{array}{l}\text { HOM } \\
\text { type }\end{array}$} \\
\hline & & & & & & $\mathrm{HC}$ & Ar I & Ar II & $\begin{array}{l}\text { poly } \\
\text { Ar }\end{array}$ & \\
\hline $12-\mathrm{R}$ & 73,4 & 75,8 & 72,9 & 62,0 & 67,6 & 75,9 & 71,9 & 72,5 & 88,0 & Pseud. \\
\hline 99-T & 20,7 & $19,9 / 20,2$ & 33,5 & 11,4 & 17,0 & 24,7 & $+1,3$ & 35,5 & 1,0 & Pseud. \\
\hline 4-D & $5,6 / 7,1$ & $\overline{8,9 / 1} 0,1$ & 6,7 & $+5,0$ & $+22,5$ & 7,5 & $+7,2$ & 19,0 & 21,6 & Pseud. \\
\hline $2-\mathrm{V}$ & $5,8 / 6,8$ & $6,6 / 8,8$ & 7,7 & 9,0 & $+22,9$ & 5.6 & $+5,2$ & 28,4 & $+11,9$ & Pseud. \\
\hline 1-SH & $\overline{2,1} / 4,4$ & $\overline{6,3} / 8,7$ & +2.9 & $+12,8$ & $+8,7$ & +2.2 & 12,8 & 30,5 & $+11,9$ & Myc. \\
\hline $1-K P$ & $3,1 / 4,4$ & 5,0 & 6,7 & $+1,6$ & $+26,2$ & $+2,4$ & 30,8 & $+27,0$ & 61,7 & Rhod. \\
\hline 4-G & $\overline{1,4} / 5,1$ & 6,8 & 2,4 & $+11,5$ & $+56,5$ & 11,6 & $+32,9$ & 28,0 & 7,6 & Myc. \\
\hline $48-\mathrm{U}$ & $\overline{ \pm 0}, 7 / 3,7$ & 5,2 & $+11,4$ & $+22,9$ &,+ 07 & 5,0 & $+23,1$ & 14,1 & 25,5 & Pseud. \\
\hline $1-\mathrm{R}$ & $\pm \overline{2,3} / 4,4$ & $\pm \underline{3,6 / 11,4}$ & 12,9 & $+13,3$ & $+7,8$ & 2,8 & $+39,8$ & 30,5 & $+42,2$ & Pseud. \\
\hline
\end{tabular}


activity of oil utilization in laboratory experiments, the most active strain is $12-\mathrm{R}$, the strain 99-T is noticeably worse in activity (Kotiukov et al., 2019).

Other tested strains did not show their activity in these experiment conditions. Disposal of oil in whole it amounted to 3.7-7.1\%, oils 5.0 to 10.1 per cent (excluding new formations). But these strains showed quite high activity in the utilization of aromatic hydrocarbons in oils (up to $61.7 \%$ - strain $1-\mathrm{KP}$ ).

\section{CONCLUSIONS}

The degree of biodegradation of oil is evaluated by balance calculations under laboratory experiments. According to calculations, in general utilization makes 56.6 and $71.6 \%$. Utilization of separate fractions of oil pollutant exceeds $80-90 \%$. The theoretical substantiation of activity of hydrocarbon-oxidizing strains of microorganisms on utilization of oil and oil products is given.

\section{REFERENCES}

Bruheim P., Eimhjellen K. Chemically emulsified crude oil as substrate for bacterial oxidation: differences in species response // Canadian Journal of Microbiology. - 1998. -Vol. 44(2). - p. 195-204.

Dashko, R., Karpova, Y. Engineering geology and geotechnics of fractured clays as building base and surrounding medium (by the example as clayey bedrocks in Saint-Petersburg) (2016) International Multidisciplinary Scientific GeoConference Surveying Geology and Mining Ecology Management, SGEM, 3, pp. 85-92.

Dashko, R. E., Kotiukov, P.V. Fractured clay rocks as a surrounding medium of underground structures: The features of geotechnical and hydrogeological assessment (2018) Geomechanics and Geodynamics of Rock Masses, 1, pp. 241-248.

Nikulin, A., Nikulina, A.Y. 2017. Assessment of occupational health and safety effectiveness at a mining company. Ecology, Environment and Conservation, 23(1), pp. 351-355.

P. V. Kotiukov, I. Yu. Lange, Engineering Geological Analysis of the Landslide Causes During the Construction of Industrial Building, International Journal of Civil Engineering and Technology 10(4), 2019, pp. 316-323. http://www.iaeme.com/IJCIET/issues.asp?JType=IJCIET\&VType=10\&IType $=4$

Rueter P., Rabus R., Wilkest H., Aeckersberg F., Rainey Fred A., Holger W. Anaerobic oxidation of hydrocarbons in crude oil by new types of sulphate-reducing bacteria//Nature. - 1994. -Vol. 372. - p. 455-458.

Saitgaleev, M., Senchina, N., Sokolova, J. 2019. Application of the method of ion-selective electrodes in exploration work on the sea shelf. Marine Technologies 2019, Gelendzhik. DOI: 10.3997/22144609.201901811

Sukplanga P., Thongmeea A., Velaa G. Roland. Degradation of Linseed Oil Vapors by Soil Bacteria in Trickling Biofilters / / Bioremediation Journal. - 1999. -Vol. 3. - p. 189-200.

The study of the survival of microorganisms-oil destructors of Pseudomonas and Rhodococcus with different storage methods

K. V. Petrikov, T. V. Yakshina, E. P. Vlasova, etc. // Materials of worldwide conference "Current state and prospects of Microbiology and biotechnology". Minsk, June 2-6, 2008. 223-225 pp. 


\title{
The secondary dispersion halos of platinum group elements and rare elements in rocks of the Vysotsky ore occurrence, Svetloborsky massif, Middle Urals
}

\author{
V.S. Nikiforova \\ Engineer, Department of geology of oil and gas, Saint Petersburg, Mining University, Saint Petersburg, \\ Russia \\ I.V. Talovina \\ Professor, Head of the Hystorical and dynamic geology department, Mining University, Saint-Petersburg, \\ Russia \\ G. Heide \\ Professor, Institutsdirektor, Technische Universität Bergakademie Freiberg, Freiberg, Germany
}

\begin{abstract}
Geological searches for secondary dispersion halos have important practical search value in areas with lack of exposure. In weakly exposed areas with a loose cover thickness of 0.2-10 m, testing is carried out using secondary dispersion halos - i.e. on the surface of eluvium, deluvium or the bottoms of a loose incision. The Svetloborsky duniteclinopyroxenite zonal massif, like other massifs of the Ural Platinum belt, is characterized by a rather closed inaccessible territory, partially covered by a cover of quaternary sediments with a thickness of up to $10 \mathrm{~m}$, in some areas - up to $25 \mathrm{~m}$. Also, almost complete absence of chromite schlieres is characteristic of the Svetloborsky massif, which are usually a clear visual sign of the presence of platinum-metal mineralization. Therefore, when conducting search operations within the massif, in addition to direct ore testing of bedrock and weathering crust, a lithogeochemical survey was carried out and the contents of platinum, palladium, gold and rare elements in secondary dispersion halos were determined.
\end{abstract}

Keywords: secondary dispersion halos, platinum group elements, rare elements, lithogeochemical survey, dunite, vein rocks, the Svetloborsky massif, the Ural Platinum belt

\section{INTRODUCTION}

The territory of the Svetloborsky massif is almost completely covered by a continuous cover of quaternary sediments, the thickness of which is 2-10 m, and in some areas the weathering crusts of dunites up to $25 \mathrm{~m}$ thick are developed, which greatly complicates the exploration work. In addition, the dunites of the massif are characterized by an almost complete absence of chromite schlieres, which are in other massifs of the Platinum belt of the Urals, for example, in Nizhny Tagil massif, a clear visual sign of the presence of platinum metal mineralization (Ivanov, 1997). Therefore, in addition to direct ore testing of bedrock, on the territory of the Svetloborsky massif, a lithogeochemical survey was carried out for the first time for the platinum-bearing mineralization of the Urals for the search for radical platinum-ore mineralization, according to the results of which the mineralized occurrence zone of Vysotsky was identified (Tolstykh et al., 2011, 2015).

Lithogeochemical work on the Svetloborsky massif was carried out by CJSC Ural-MPG in the period 2006-2009 in order to determine the contents of platinum, palladium, gold and a number of related elements, testing was carried out on a exploration network. 


\section{METHODOLOGY}

Within the central part of the Svetloborsky massif lithogeochemical survey using secondary halos showed only isolated abnormal samples, so it was necessary to identify anomalies extension exploration network and a re-sampling. In the central part of the Svetloborsky massif, the processes of recrystallization of dunites are developed, so the chromite formations and platinum are distributed extremely unevenly, therefore, lithogeochemistry can be effective only with a frequent sampling network.

During sampling, loose clay and sand-clay eluvial-deluvial material was selected from a subsoil layer weighing 200-300 g along a $200 \times 40$ m network with a network thickening in separate, most abnormal areas, to a cell size of $100 \times 40 \mathrm{~m}$. Separate profiles laid at a distance of $400 \mathrm{~m}$ from each other, they cross the massif, capturing not only the dunites of the massif core, but also the clinopyroxenites of the massif shell (Nikiforova et al., 2016).

During lithogeochemical survey, 1163 samples were obtained, of which 171 were taken directly at the Vysotsky ore occurrence. The sample processing process included drying the sampled material, sifting through an 80 mesh sieve, attritioning to $0.074 \mathrm{~mm}$, quarrying of the sample to obtain two batches weighing about 100-150 g. These samples were analyzed for the content of Pt, Pd, Au by an assay in a Lakefield laboratory (South Africa) and spectral analysis for a number of rare elements in OJSC Ural Central Laboratory. In interpreting the sampling data for secondary halos for a more detailed study, the Vysotsky ore occurrence site was selected, characterized by the wide development of dike and vein rocks.

Processing and interpretation of the initial geochemical data was carried out by methods of mathematical statistics using modern software, including the programs Statistica 12.6 and Surfer 15.0. The data obtained as a result of the analyzes were used to study the distribution characteristics of precious metals and rare elements in eluvial and deluvial-eluvial deposits.

\section{RESULTS AND DISCUSSION}

Table 1 presents the average contents of $\mathrm{Pt}, \mathrm{Pd}, \mathrm{Au}$ and rare elements in eluvial and deluvialeluvial deposits in comparison with the geochemical background calculated for the Svetloborsky massif. The geochemical background was calculated from 848 analyzes; the background concentrations of chemical elements were calculated as median values in the sample.

According to Table 1, for the eluvial and deluvial-eluvial deposits of the Vysotsky ore occurrence, elevated levels of platinum, palladium, chromium, manganese, nickel are characteristic, lower - barium, strontium and phosphorus, the content of other chemical elements (silver, cobalt, vanadium, titanium, copper, zinc, lead in the secondary halos of the Vysotsky ore occurrence are comparable with the geochemical background calculated for the Svetloborsky massif.

Among the group of precious metals, platinum has a maximum average content of $0.5 \mathrm{ppm}$, palladium $-0.08 \mathrm{ppm}$ and gold $-0.06 \mathrm{ppm}$. The $\mathrm{Pt} / \mathrm{Pd}$ ratio varies from 2 to 15 , in some cases reaching $30-50$, which is quite comparable with the data on the primary dunites of the Svetloborsky massif.

Most of the elements of the iron group are characterized by a relatively uniform distribution. Nickel contents vary from 7 to $150 \mathrm{ppm}$, cobalt from 2 to $70 \mathrm{ppm}$, manganese 70-600 ppm, with

Table 1. Average contents of $\mathrm{Pt}, \mathrm{Pd}, \mathrm{Au}$ and rare elements in eluvial and deluvial-eluvial deposits of the Vysotsky ore occurrence, $\mathrm{ppm}$.

\begin{tabular}{lllllllllllllll}
\hline Element & $\mathrm{Pt}$ & $\mathrm{Pd}$ & $\mathrm{Au}$ & $\mathrm{Ag}$ & $\mathrm{Cr}$ & $\mathrm{Mn}$ & $\mathrm{Ni}$ & $\mathrm{Co}$ & $\mathrm{V}$ & $\mathrm{Ti}$ & $\mathrm{Zn}$ & $\mathrm{Ba}$ & $\mathrm{Sr}$ & $\mathrm{Pb}$ \\
\hline $\begin{array}{l}\text { Vysotsky ore } \\
\text { occurrence }\end{array}$ & 0,05 & 0,01 & $<0,02$ & 0,01 & 600 & 250 & 60 & 10 & 17 & 600 & 7 & 50 & 1 & 0,9 \\
$\begin{array}{l}\text { Geochemical } \\
\text { background }\end{array}$ & 0,03 & $<0,02$ & $<0,02$ & 0,01 & 500 & 180 & 30 & 9 & 18 & 600 & 9 & 65 & 10 & 1 \\
\hline
\end{tabular}


the exception of several samples with contents of 700-900 ppm, vanadium 18-50 ppm, in single samples - more than $200 \mathrm{ppm}$. Chromium in samples from Vysotsky ore occurrence is characterized by a less uniform distribution with a change in contents from 30 to $1000 \mathrm{ppm}$, on average 600 ppm. It should be noted that, unlike the whole array, samples with high chromium content do not always correspond to samples with high platinum content. Cobalt content also varies from 2 to 70 ppm, titanium - from 60 to $1000 \mathrm{ppm}$. Cobalt content also varies from 2 to $70 \mathrm{ppm}$, titanium from 60 to $1000 \mathrm{ppm}$.

Transit elements in the eluvial-deluvial deposits of the Svetloborsky massif are characterized by an uneven distribution. Copper and phosphorus are contained in the initial samples in an amount of from 0.1 to $18 \mathrm{ppm}$ and from 7 to $180 \mathrm{ppm}$, respectively. Lead and zinc are characterized by maximums of 4 and $20 \mathrm{ppm}$. The analyzed large-ion lithophilic elements reach maxima of $100 \mathrm{ppm}$ (barium) and $60 \mathrm{ppm}$ (strontium).

Based on the calculation results for all the studied chemical elements, maps were constructed with the image of the positive and negative anomalies of the element contents (Figures 1-4). Maps of anomalies of elements within the entire Svetloborsky massif are presented in (Gayfutdinova et al. 2015), and in this work refined detailed maps of
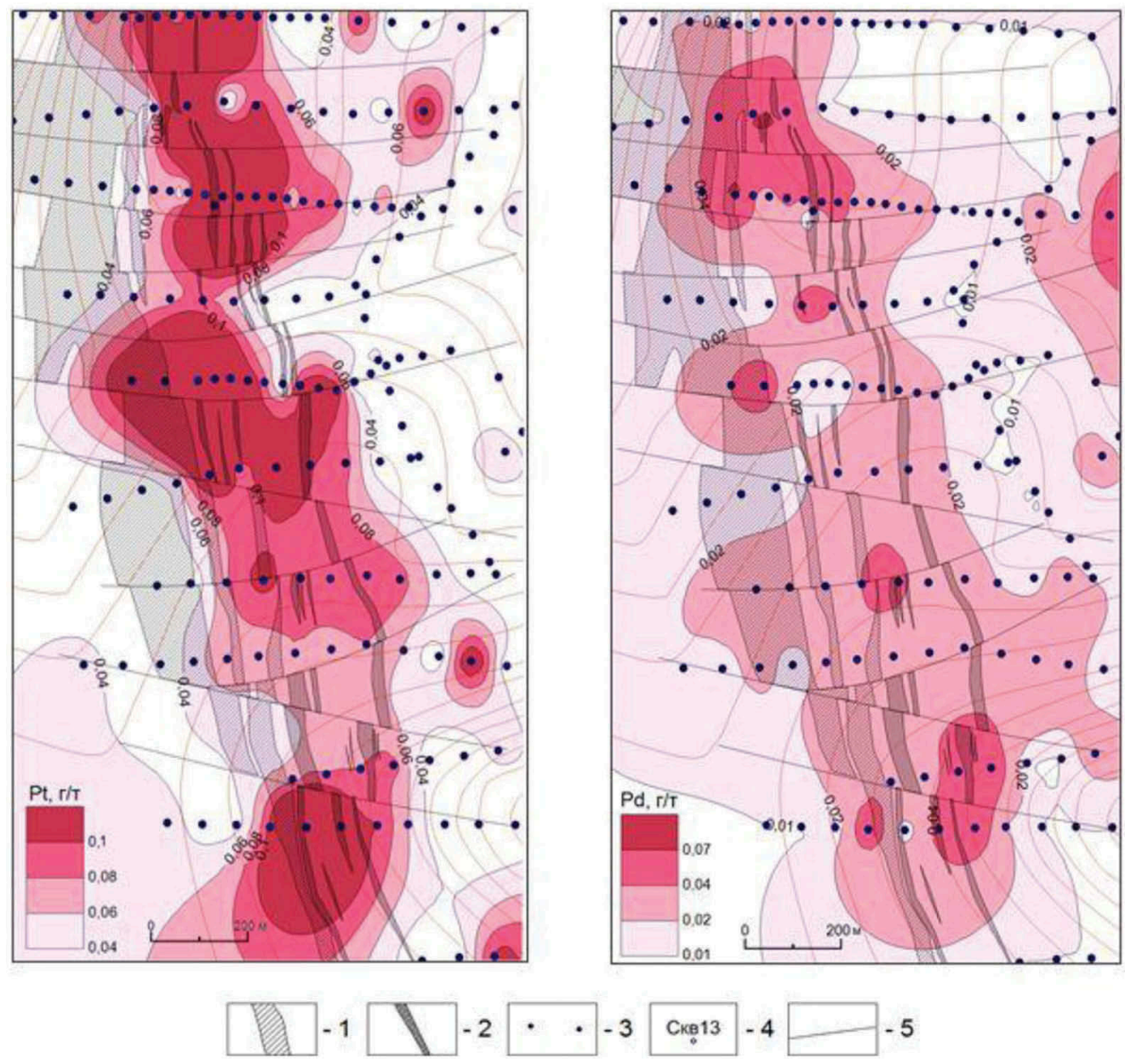

Figure 1. Secondary halos of dispersion of platinum and palladium.

1 - clinopyroxenite shell, 2 - hornblendite and diopside rock dikes, 3 - sampling points, 4 - wells, 5 - tectonic disturbances. 

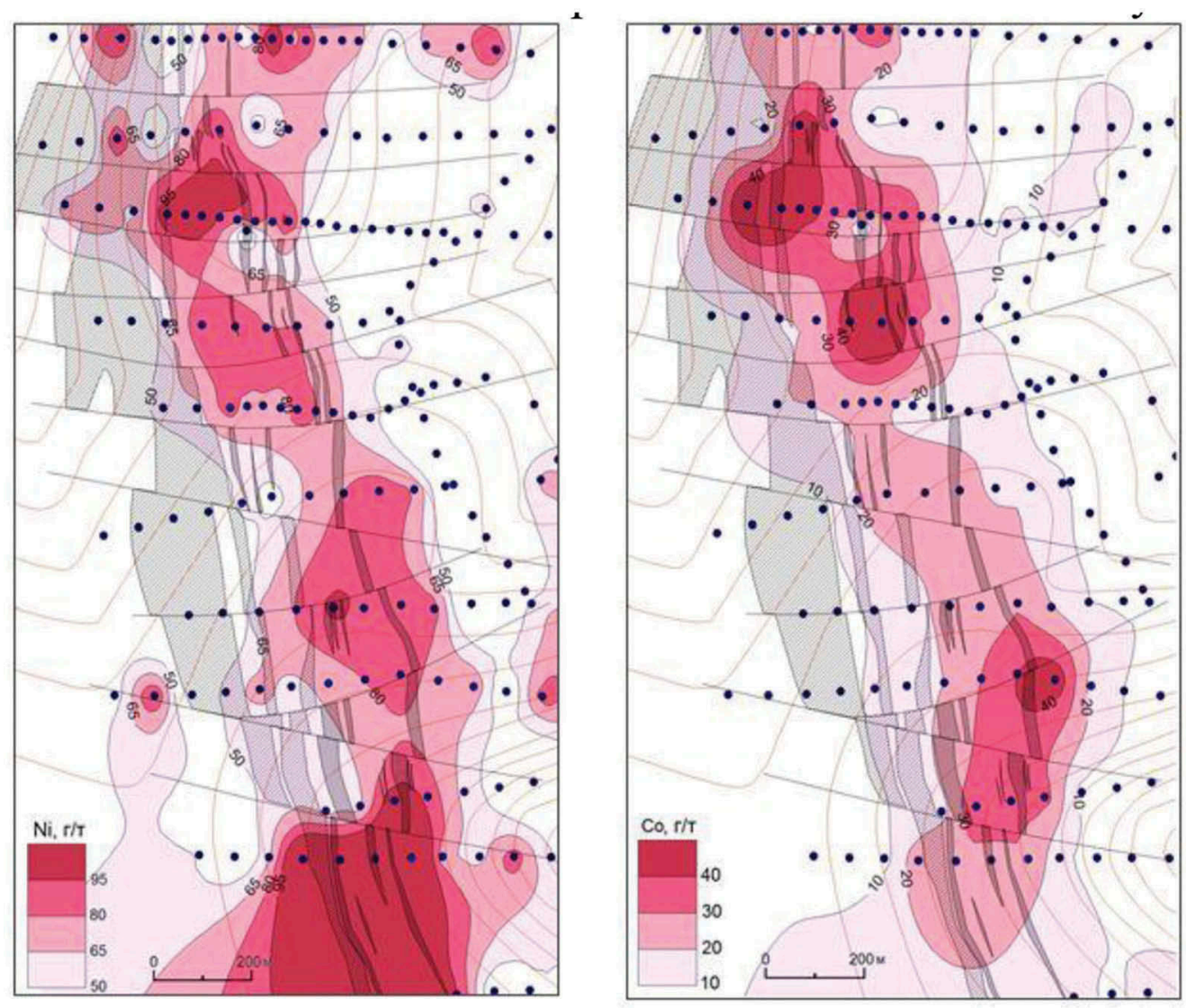

Figure 2. Secondary halos of dispersion of nickel and cobalt.

anomalies within the western contact of the massif, to which the Vysotsky ore occurrence is confined, are given.

\subsection{Platinum and palladium}

Within the Vysotsky ore occurrence platinum and palladium in secondary halos, several closely related positive elongated anomalies form (Figure 1).

The length of the platinum and palladium anomalies is from 400 to $900 \mathrm{~m}$, with an average width of about $400 \mathrm{~m}$. The platinum and palladium contents within the northern and southern positive anomalies exceed $0.23 \mathrm{ppm} 0.04 \mathrm{ppm}$, respectively, which is higher than the platinum and palladium in anomalies within the entire array.

As was shown by us in (Gayfutdinova et al. 2015), the platinum anomalies are generally confined to the western boundary of the dunite core of the massif in the zone of contact with the clinopyroxenite shell in the region of development of recrystallized medium- and coarsegrained dunites of the core center and fine-grained peripheral dunites. The construction of anomaly maps on the scale of Vysotsky's ore occurrence also revealed the spatial confinement of platinum and palladium anomalies to the areas of development of vein hornblendites and diopsides and their conformity to each other.

Despite the fact that the level of platinum content in scattering halos is relatively low, the shape of the anomalies and their confinement to the fields of development of dyke rocks, as well as to certain petrographic varieties of primary dunites, suggests a regular nature of their 

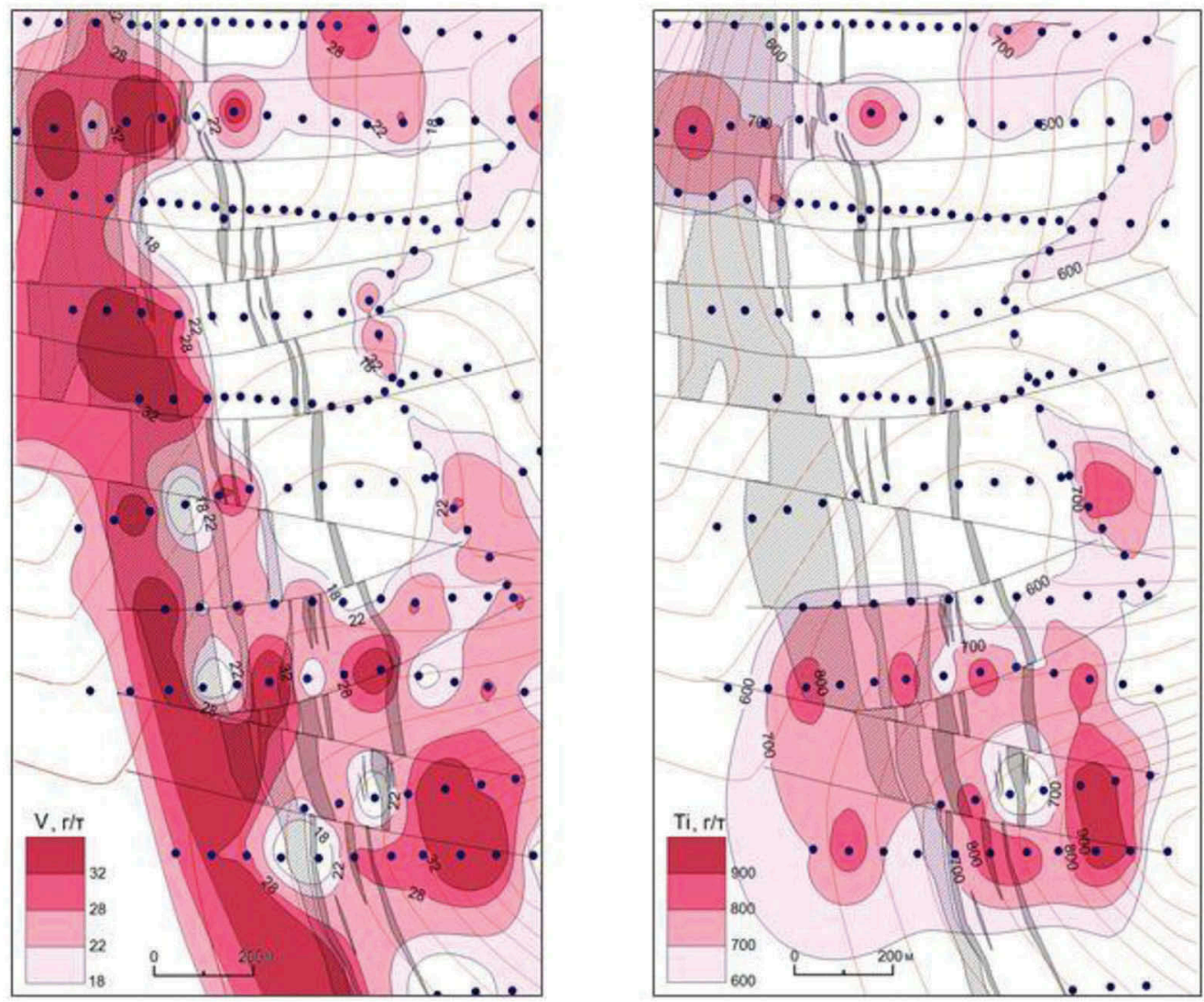

Figure 3. Secondary halos of dispersion of vanadium and titanium.

distribution, which is directly related to increased concentrations of platinum in the occurring under abnormalities of bedrock.

\subsection{Nickel and cobalt}

Among other rare elements, nickel and cobalt are distinguished by increased concentrations and contrasting anomalies (Figure 2). The positive anomalies of nickel and cobalt are partially spatially combined with the anomalies of platinum, but they are more widespread, while the promising positive anomalies of platinum $(>0.1 \mathrm{ppm})$ are characterized by a clear spatial confinement to the zones of vein rock development in the dunites of the Vysotsky ore occurrence.

A positive chromium anomaly is observed throughout the entire area of the ore occurrence, extending over more than $1.5 \mathrm{~km}$ in length with an average width of $400 \mathrm{~m}$.

Anomalies of manganese within the Vysotsky ore occurrence are weakly manifested and small in size (no more than $300 \mathrm{~m}$ in width and 200 to $400 \mathrm{~m}$ in length), all observed anomalies are elongated in the submeridional direction. In the northern part of the ore occurrence, several close anomalies are observed (Pilyugin et al., 2015).

\subsection{Vanadium and titanium}

Vanadium and titanium (Figure 3 ) is characterized by positive anomalies elongated in the submeridional direction. The association of the positive anomalies of vanadium to the 

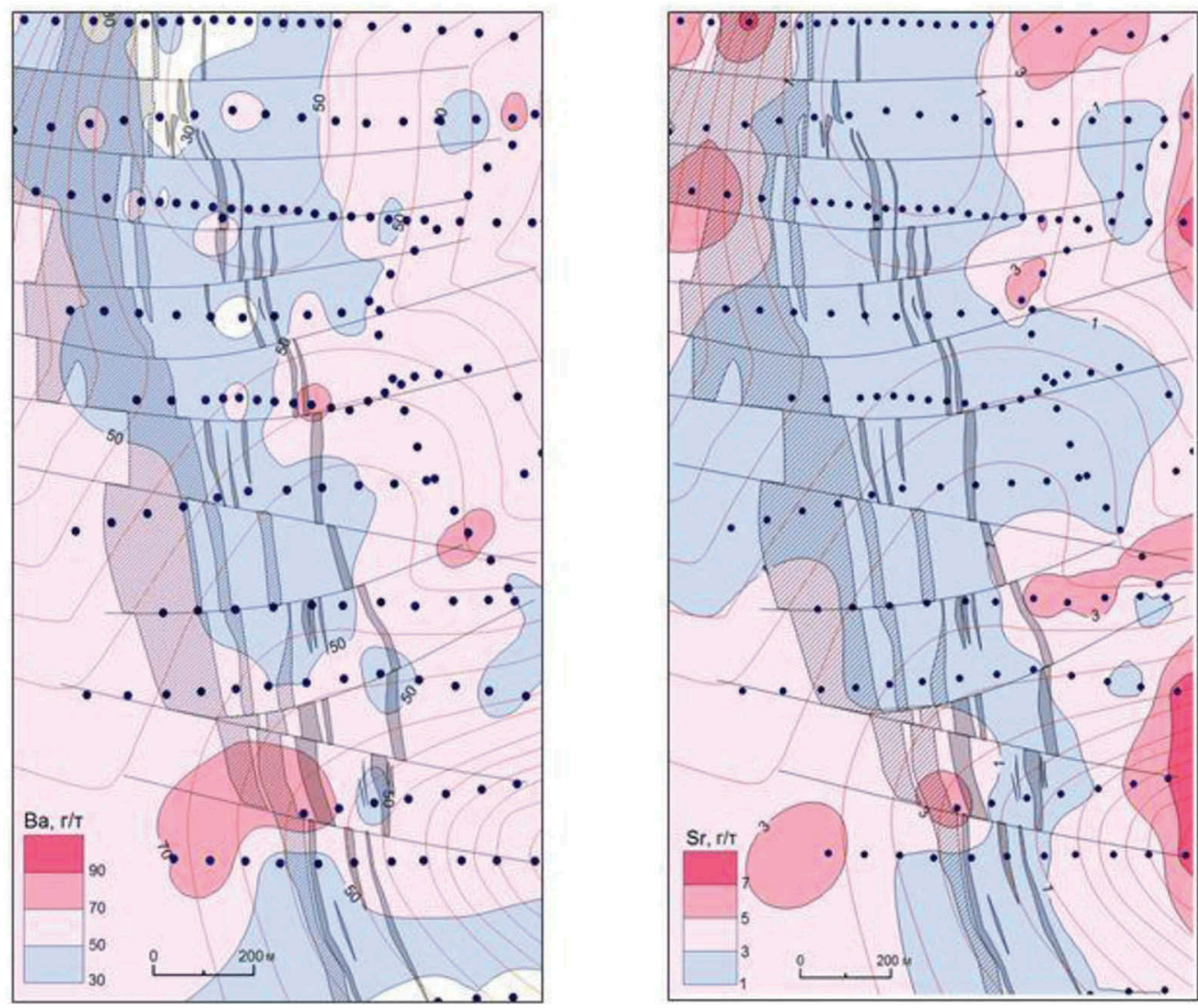

Figure 4. Secondary halos of dispersion of barium and strontium.

clinopyroxenite shell of the massif is noted, which is explained by the presence of vanadium in the composition of clinopyroxene (Lazarenkov et al., 2013).

Within the dunite core of the massif, the vanadium anomalies are less pronounced in the ore occurrence contour of the Vysotsky anomaly, but their confinement to dypsidite and gornblendite dikes is also noted.

\subsection{Barium and strontium}

Negative anomalies of barium and strontium spatially coincide with positive anomalies of platinum (Figure 4). Anomalies of barium are elongated in the submeridional direction, while there is a clear confinement of these anomalies to dikes of gornblendites and diopsides, but the reason for this is most likely the confinement of these concentrations to thick carbonate veins in the weathering crust of dunites, which in turn are confined to fracture zones at contacts by the rocks.

Negative anomalies of strontium are characterized by wider halos, while they are more manifested in the northern and central parts of the Vysotsky ore occurrence site.

Thus, in secondary scattering halos within the Vysotsky ore occurrence, positive anomalies of chromium, manganese, nickel and cobalt and negative anomalies of barium and strontium spatially coincide with positive anomalies of platinum and palladium. Anomalies of phosphorus, copper, zinc, lead and silver are less informative and cannot be used for search purposes. On the whole, the presence of sufficiently contrasting anomalies of chromium, manganese, nickel, and cobalt superimposed on each other allows us to recommend 
lithogeochemical surveys to refine, identify and predict the indigenous platinum mineralization within the Svetloborsky massif, as well as other poorly studied massifs of the Ural Platinum belt with the known the number of dike and vein rocks, such as Veresovoborsky, Kamenushinsky and others massifs.

To clarify the relationships between platinum and individual rare elements in the eluvialdeluvial deposits of the Svetloborsky massif for samples taken at the Vysotsky ore occurrence, we performed statistical processing of the data obtained, including correlation analysis and factor analysis using the principal component method. The source data array consists of 171 samples. When statistical processing of the results of testing with the contents of chemical elements in samples below the detection limit of the device were replaced by $1 / 2$ the detection limit. Since the contents of chemical elements are distributed lognormally, the prologarithmic values of the contents of elements were used for statistical analysis.

Based on the analysis of the matrix of correlation coefficients $(r=0.16,95 \%$ probability, 171 samples), the following conclusions can be drawn about the relationship between the contents of chemical elements in the secondary dispersion halos of the Vysotsky ore occurrence:

- platinum has significant positive correlation coefficients with palladium, chromium, manganese, nickel and cobalt and significant negative correlation with silver and barium;

- palladium, unlike platinum, has positive correlation with only chromium $(\mathrm{r}=0.18)$, nickel $(\mathrm{r}$ $=0.36)$, cobalt $(\mathrm{r}=0.55)$ and negative with silver $(\mathrm{r}=-0.25)$

Factor analysis carried out according to the logarithms of the contents of chemical elements in the overlying loose sediment massif allowed us to identify several elemental associations. Based on the results of factor analysis, we determined the main components of the indicator values, which were determined by the action of a particular factor, or a combination of both.

\section{CONCLUSIONS}

According to lithogeochemical surveys, the spatial distribution of anomalies of platinum and other rare metals, according to the results of correlation and factor analysis, the most informative from the point of view of searches for anomalies of platinum metals are data on $\mathrm{Cr}, \mathrm{Ni}$, $\mathrm{Co}, \mathrm{Mn}$, which can be considered indicator elements platinum-metal mineralization in eluvialdeluvial deposits of the Svetloborsky massif.

Thus, lithogeochemical surveys using secondary scattering halos are appropriate and can be recommended for other poorly studied massifs of the Platinum belt of the Urals with a developed platinum-dunite type of platinum-metal mineralization, for example, for Veresoborsky and Kamenushinskymassifs located a short distance from Svetloborsky massif.

The presence of secondary aureoles of platinum dispersion in the eluvial-deluvial deposits of the Svetloborsky massif serves as a reliable search sign of the indigenous platinum-metal mineralization.

1. Noble metal specialization in eluvial and deluvial-eluvial cover deposits monometallic platinum, inherited from indigenous sources.

2. In secondary scattering halos, the following associations of elements were distinguished: characteristic of dunites - $\mathrm{Pt}, \mathrm{Pd}, \mathrm{Cr}, \mathrm{Ni}, \mathrm{Co}, \mathrm{Mn}$, and characteristic of vein rocks - $\mathrm{V}$, Ti, $\mathrm{Cu}, \mathrm{Zn}, \mathrm{Pb}, \mathrm{Ba}, \mathrm{Sr}$.

3. It is noteworthy that the anomalies of individual elements are clearly confined to the areas of development of vein hornblendites and diopside rocks of the massif, as well as the anomalies of the elements themselves overlapping each other: within the Vysotsky ore occurrence, the positive anomalies of platinum and palladium spatially coincide with the positive anomalies of chromium, manganese, nickel and cobalt, as well as with negative anomalies of barium and strontium. Moreover, platinum has an average positive correlation coefficient with chromium, which indicates that platinum is associated not only with the platinum-chromite type of mineralization, but also with others. 
4. Peculiarities of the distribution of elements found in the secondary halo identified within the Vysotsky ore occurrence can be used in searches for platinum ore occurrences both within the Svetloborsky massif itself and in other zonal clinopyroxenite-dunite massifs of the Platinum-bearing belt of the Urals.

\section{REFERENCES}

Gayfutdinova A.M., Telegin Yu.M., \& Talovina I.V. 2015. Secondary dispersion halos of platinum group elements, gold and silver of the Svetloborsky dunite-clinopyroxenite massif, Platinum Belt of the Urals. Mining informational and analytical bulletin (1): 312-318.

Ivanov O.K. 1997. Concentrically-zoned pyroxenite-dunite massifs of the Urals, Ekaterinburg.

Lazarenkov V.G., Pilugin A.G., Vorontsova N.I. \& Talovina I.V. 2013. Rare earth elements in platinum bearing vein chromitites of Nizhni Tagil pyroxenite-dunite massif, Central Urals. Zapiski Gornogo instituta (200): 222-225.

Nikiforova V.S., Vorontsova N.I., Duryagina A.M. \& Talovina I.V. 2016. Vein rocks of the Svetloborsky massif and their petrochemical characteristics. Mining informational and analytical bulletin (2): 236-243.

Nikiforova V.S., Duryagina A.M., Telegin Yu.M. \& Talovina I.V. 2016. Rare elements in veined rocks of the Svetloborsky dunite-clinopyroxenite massif of the Ural Platinum Belt. Mining informational and analytical bulletin (2): 244-252.

Pilyugin A.G., Talovina I.V., Duryagina A.M. \& Nikiforova V.S. 2015. Geochemical features of platinum-bearing dunites of the Svetloborsky and Nizhny Tagil massifs of the Ural Platinum Belt. Zapiski Gornogo instituta (212): 50-61.

Tolstykh N.D, Kozlov A.P., Telegin Yu.M. 2015. Platinum mineralization of the Svetly bor and Nizhny Tagil intrusions, Ural Platinum belt. Ore Geology Reviews (67): 234-243.

Tolstykh N.D., Telegin Yu.M. \& Kozlov A.P. 2011. Platinum mineralization of the Svetloborsky and Kamenushinsky massifs (Urals Platinum belt). Russian Geology and Geophysics (6): 603-619. 


\title{
Hydrodynamic features of the formation and placement of thermal waters of the Eastern Ciscaucasia and their protection from surface pollution
}

\author{
M.M. Labazanov, Z.I. Gadaeva, P.U. Musaeva, T.Kh. Ozdieva \& Z.M-E. Damzaev \\ Grozny State Oil Technical University named after Acad. M.D. Millionschikov, Grozny, Russia
}

\begin{abstract}
Using the example of the Eastern Ciscaucasia, where there are extremely favorable and at the same time contrasting combinations of geological - tectonic, hydrodynamic, geothermal, and also hydro-hydrographic conditions, it seems possible to trace the main geological and physico-chemical processes that determine the formation and distribution of various types of groundwater associated with different zones and structural - hydrogeological floors and the dependence of the degree of their protection from surface pollution in connection with these especially features.

When considering this issue, first of all, it should be noted that all the main scientific hypotheses of the formation of groundwater are not groundless and depending on the geological conditions of the region, there are various options.

In particular, there is no doubt that the fresh and weakly mineralized warm groundwater of the Tersko-Kum artesian basin and groundwater of the aeration zone of the mountain-folded regions of Dagestan, in their overwhelming part, are waters of infiltration origin.

The processing of enormous factual material on hydrodynamics, hydrochemistry, gas geochemistry, geothermy, hydrological and climatic conditions, collected from the results of drilling about 3000 artesian wells, allowed us to conclude that the Tersko-Kum artesian basin of Pliocene and anthropogenic deposits is a hydrodynamically open flowing natural system with modern natural resources in the amount of $0.6 \mathrm{~km}^{3} / y e a r$ and potential resources of about $6.0 \mathrm{~km}^{3} /$ year.
\end{abstract}

\section{INTRODUCTION}

The problem of groundwater formation is complex and multifaceted and, depending on specific environmental conditions, has common and specific features.

The results of comprehensive studies indicate that low-mineralized thermal waters of the structural-hydrogeological floor (Miocene complex) also relate to a large part to waters of infiltration origin with a certain proportion of sedimentation and elizion waters from below and, in some cases, overlying horizons.

In the thickness of the Middle Miocene sediments, aquifers with a pore nature of groundwater circulation are distinguished, the formation of reserves of which occurs at the base by infiltration of atmospheric and surface waters, which is confirmed by actual material on the hydrodynamics of the aquifer. Actual hydrodynamic data make it possible to identify feeding, discharge and discharge areas for the Middle Miocene aquifer complex and, accordingly, areas more or less potentially susceptible to possible pollution.

The feeding areas are located within a fairly wide range of outcrops of Middle Miocene deposits to the surface, stretching from west to east along the Montenegrin monocline, the Narat-Tyubinsky zone; then the strip of exits turns in a southeast direction and stretches far south, where the Middle Miocene sediments overlap with the thickness of the Akchagyl deposits, which are mismatched on the underlying ones, down to the Jurassic (Andrushchuk, 
Dubinsky, Hain, 1968). The yields of Middle Miocene sediments are located at hypsometric elevations from 200 to $800 \mathrm{~m}$ in places and more, with individual peaks up to $1000 \mathrm{~m}$. The maximum elevations of $600-900 \mathrm{~m}$, correspond to the Black Mountains, decrease to 200 $400 \mathrm{~m}$ within the Narat-Tyubinskaya zone, slightly increase in Southern Dagestan is up to 300 - $500 \mathrm{~m}$ less often than $600 \mathrm{~m}$.

In the north, northeast direction from the areas of exits there is a regional subsidence of the strata. The roof of the Middle Miocene deposits is located at depths: in Makhachkala 800-1200 m, Ternair - 800-1000 m, Izberbash - 400-800 m, Karanai-Aul syncline $1600 \mathrm{~m}$, Bilgadi syncline - 400-600 m, in Derbent - $950 \mathrm{~m}$. V the zone of maximum subsidence in the Tersko-Caspian trough, the roof of the Middle Miocene deposits is located at depths of 3,500 - 3,700 m (Kurush, Karamay) i.e. the water of these deposits is almost completely protected from surface pollution (Figure 1).

Thus, based on the classical representations of artesian basins, the difference in the hydrostatic sets of supply areas and wellheads in the transit areas reaches the first tens of atmospheres, which should practically ensure water self-discharge in the overwhelming part of the distribution area of the Middle Miocene aquifers, taking into account hydraulic resistance. In fact, self-draining waters are ubiquitous.

The exception may be some areas where deep erosion valleys drain the Middle Miocene deposits, because of which natural depression extends to aquifers within the first tens of kilometers (Andrushchuk, Dubinsky, Hain, 1968). Such conditions are available in areas adjacent to the river valley. Sulak and other foothill rivers that drain these deposits at elevations of $100-300 \mathrm{~m}$, as well as near feeding areas.

In the areas of runoff and transit, which cover all the territories of the Forward Trough, the Kumskoy and Tersko-Sulak plains, the piezometric surface is characterized by a general drop in

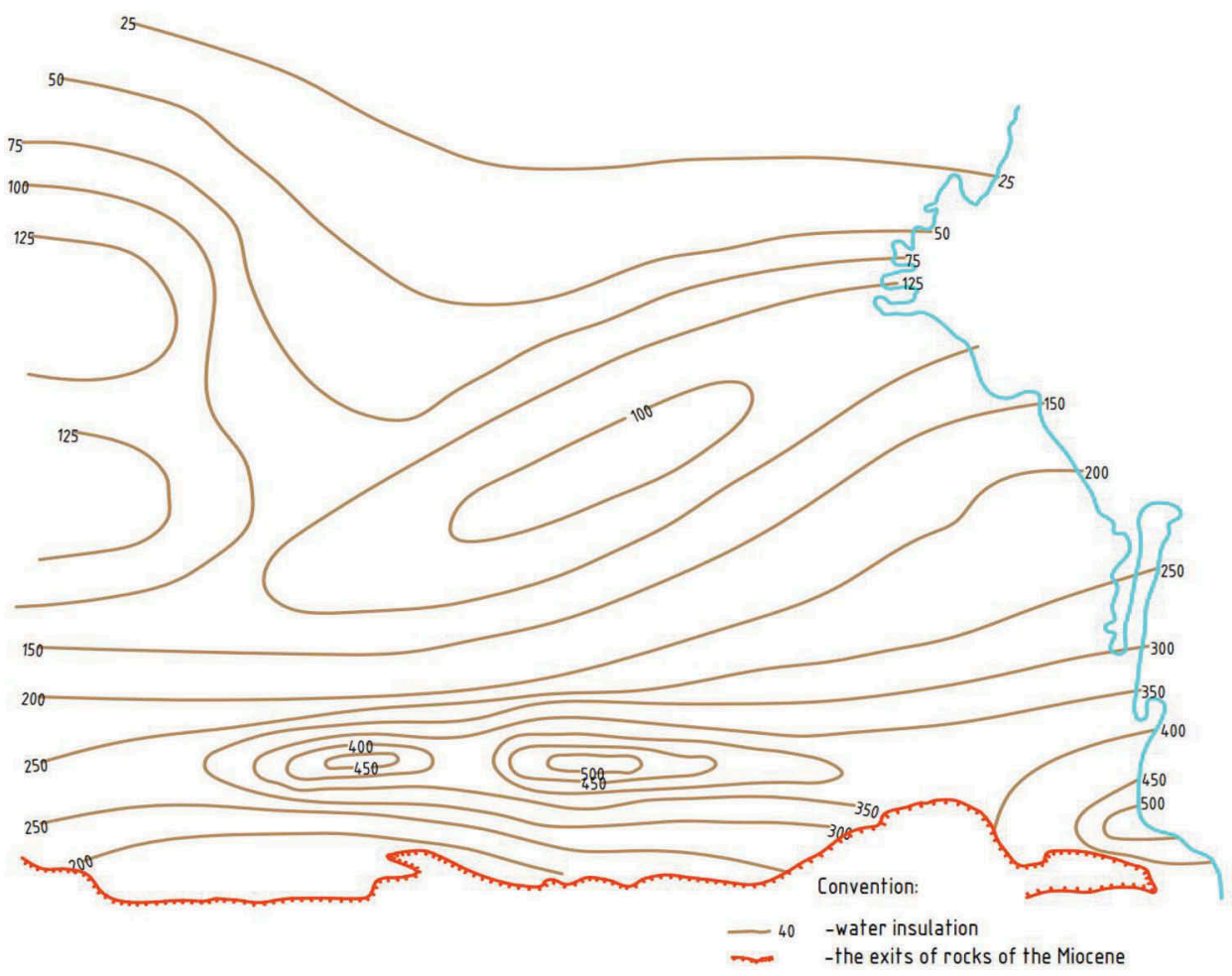

Figure 1. Schematic map of the conductivity of the Middle Miocene aquifer. 
the pressure of water in the directions from the feeding areas to the north and northeast towards the Caspian Sea, consistent with the regional dip in the north - east and east.

Absolute elevations of piezometric levels vary from $200-500 \mathrm{~m}$ in areas directly adjacent to food areas, to $10-150 \mathrm{~m}$ in areas remote to significant distances from them. (Table 1). The relative elevation of the hydrostatic level increases from the first units of meters to 14-16 atmospheres in the Makhachkala, Kizlyar, Northeast of Kizlyar in the areas of TerekliMekteb - Chervlennye Buruns, hydrostatic pressure at the mouths drops to 10-8 atmospheres.

Actual material on the hydrodynamics and hydrochemistry of Middle Miocene deposits allows us to distinguish three hydrodynamic zones - active, slow and very slow water exchange, which therefore are logically subdivided into three zones of protection from surface pollution.

The zone of active water exchange includes the piedmont regions of the Eastern Ciscaucasia, composed of middle-price deposits entering the day surface with hypsometric marks 200-600 mine and deep erosion valleys, which serve as local erosion bases. This zone is characterized by maximum hydraulic slopes of 0.01-0.03, filtration coefficients (average) of 4.0-5.5 m/day, and filtration rates of 4-17 cm/day. or 15-62 m/year. In hydrochemical terms, this is the zone of maximum washing with fresh and slightly mineralized waters of hydrocarbonate, sulfate and mixed chemical composition.

Of the cations that determine the chemical composition, $\mathrm{Ca}$ and $\mathrm{Mg}$ prevail, and the anions are sulfates and bicarbonates.

The high hypsometric position, the presence of a rather dense river network, rugged terrain, and an abundance of precipitation with favorable lithological-facies and geomorphologicaltectonic conditions contribute to intensive circulation and active groundwater exchange. In this case, the role of the distances from the supply area to the discharge area, which are minimal in this area, is significant. The upper hydrodynamic zone is represented by ground lowpressure and pressure fresh and low-mineralized waters. Numerous springs are confined to the Middle Miocene deposits in river valleys and natural relief depressions.

Numerous artesian and structural mapping wells have been drilled in the active water exchange zone, which reveal aquifers at depths from $50-60 \mathrm{~m}$ to $300-500 \mathrm{~m}$ and produce in most cases self-flowing waters with flow rates from fractions up to $2-151 / \mathrm{s}$. The reservoir properties of the sandstones of the active exchange zone are quite high. The porosity in the Sulak basin is from 14 to $23.6 \%$, an average of $18-20 \%$, the permeability is very high from units to 8-10 darsi. (Mironenko, 2001).

In general, the zone of active water exchange is characterized by significant groundwater circulation rates, hydrogeological flushing of rocks and, as a result, low water salinity, the

Table 1. Absolute elevations of piezometric levels.

\begin{tabular}{llllll}
\hline REGION & $\begin{array}{l}\text { №o } \\
\text { well }\end{array}$ & $\begin{array}{l}\text { Abs. Wellhead } \\
\text { marks }\end{array}$ & $\begin{array}{l}\text { Perforation } \\
\text { interval }\end{array}$ & $\begin{array}{l}\text { Deposits } \\
\text { age }\end{array}$ & $\begin{array}{l}\text { Abs. piezometric } \\
\text { level marks }\end{array}$ \\
\hline 1 & 2 & 3 & 4 & 5 & 6 \\
\hline Agach aul & 1 & 264,2 & $308-316$ & Karagan & 210,5 \\
Kaka-yurt & 7 & 207,1 & $203-215$ & “ & 213,6 \\
Ternair & 20 & 2,25 & $1085-1110$ & “ & 92,2 \\
Makhachkala & 160 & -20 & $1487-1518$ & “ & 70,0 \\
Bunaysk & $1-56$ & 557,0 & $77-93$ & “ & 558,65 \\
Gerga & $6-T$ & 50,8 & $1388-1405$ & “ & 53,1 \\
Manas Kent & $10-T$ & 36,18 & $1547-1561$ & Karanay & 51,18 \\
Manas Kultun & $9-\mathrm{T}$ & 10,6 & $1414-1448$ & “ & 32,6 \\
Kaspiysk & $2-\mathrm{T}$ & $-18,48$ & $1482-1492$ & “ & 32,78 \\
Derbent & $11-\mathrm{T}$ & $-14,77$ & $1260-1278$ & “ & 24,43 \\
Kizlyar & $4-\mathrm{T}$ & $-4,8$ & $2786-2824$ & “ & 135,2 \\
Kraynovka & 1 & $-20,0$ & $2146-2148$ & “ & 60,0 \\
\hline
\end{tabular}


predominance of calcium sulfates and bicarbonates, and a pronounced oxidative state. Flow rates, pressures, temperatures and composition of water, especially sources, are subject to seasonal fluctuations. The zone of active water exchange is the zone most susceptible to pollution.

The zone of delayed water exchange includes the water horizons of the Middle Miocene deposits located at depths from 400-500 to 2-3 thousand meters, which covers the vast majority of the study area. This zone includes the foothill and plain parts of the basin, which includes all thermal water deposits: Makhachkala, Izberbash, Kayakentsk, Kizlyarsk, Tarumovskoye, Terekli-Mektebskoye, Cherlennye Burun, Groznenskoye, Khankala and others. The regime of water horizons is characterized as a water head with estuary pressures 2-3 to 14-16 atm. Waters are self-draining throughout the territory, water flow rates are incomparably higher than in the first zone and reach up to $2-3$ thousand $\mathrm{m}^{3} /$ day.

In general, for the southern part of the basin, filtration rates are $2-3 \mathrm{~mm} /$ day or $0.7-1.0 \mathrm{~m} / \mathrm{year}$.

The fall of piezometric levels occurs in the northern, northeastern and eastern directions, from 180-200 m. Near nutrition areas to $10-30 \mathrm{~m}$ in Southern Dagestan and 80-100 m in Northern Dagestan. The gradients of the piezometric levels are maximum in the foothills of Southern Dagestan from 0.007 to 0.24 , in the foothill zone of Northern Dagestan from 0.012 to 0.05 . As you move north in the platform part, minimum speeds are noted and hydraulic gradients here are $0.001 \mathrm{~m}$ or less (Ovcharova, 2009).

As aquifers sink, formation pressures, hydrostatic pressure and water temperature increase. The zone of delayed exchange is hydrochemically characterized by the presence of chloridehydrocarbonate, chloride-sulfate sodium water. Mineralization of water gradually increases with depth to $10 \mathrm{~g} / \mathrm{l}$, and in some areas and formations to $30 \mathrm{~g} / \mathrm{l}$.

The zone of delayed water exchange is distinguished not only by the features of hydrodynamics and hydrochemistry of waters, but by the conditions of formation and regime of groundwater. The zone under consideration is characterized by relatively sustained thickness of aquifers, most often represented by small- and medium-grained sandstones of low cementation. As you move from the feeding areas deep into the flat part, the water regime gradually becomes stationary. Flow rates, pressures, chemical composition, temperatures are not subject to seasonal, annual and numerous fluctuations.

In general, the reserves and resources of this zone are incomparably large relative to the zone of active water exchange, which is explained by the maximum elastic reserves that can be exploited for apparently decades and are practically not subject to surface pollution.

The zone of a very slow water exchange includes the conditionally most submerged part of the Tersko-Caspian piedmont deflection, which is characterized by the presence of highly mineralized chlorine-sodium type in the Midiocene aquifer complex. Huge geostatic pressures contribute to a decrease in porosity, which determines the stagnant nature of the fluids. Unfortunately, this entire zone was not covered by drilling, and the only Karaman-I well drilled here in the southern geosynclinal board passed the very top of the Karagan Formation. This area is completely protected from surface contamination.

\section{CONCLUSION}

Thus, the underground waters of the Eastern Ciscaucasia according to their geological conditions of formation and occurrence are divided according to the degree of protection from surface pollution into 3 zones: unprotected; practically protected, but with the likelihood of contamination and fully protected.

The following tasks in the field of studying and developing the geothermal resources of the region, the authors consider:

- complex geological and geophysical, geochemical, geothermal, hydrogeological and experimental studies to prove and confirm the presence of depths of the hydrogeothermosphere, which should serve as a practically inexhaustible source of geothermal energy and valuable hydromineral raw materials;

- studies on practical confirmation and experimental proof of the possibility of implementing a self-circulating geothermal system and the growth of its effectiveness with depth. 
It is known that there are "hot spots" on Earth that are hotbeds of fresh mantle jets; therefore, there should also be "cold spots" that should serve as large foci of infiltration of water resources to great depths. Perhaps they are decompressed zones of spreading in mountain folded areas of land and ocean. In theoretical terms, the problem of heat and mass transfer of the upper horizons with deep bowels deserves attention the problem of finding "cold spots", the existence of which is evidenced by a number of factors.

In the scientific, methodological and applied respect, the creation of a bank of geological and all parameters of gas-oil, geothermal and artesian wells of the basin, the creation of a hydrogeological balance model for managing geothermal resources of the East Ciscaucasia basin based on geoinformation modeling is of great importance.

In the matter of further rational development of geothermal energy and raw material resources, scientific and methodological studies on the development of multilayer geothermal deposits, improvement of the designs of geothermal production and injection wells, and the development of a model geothermal heat supply system, including underground and all ground circuits, as well as water treatment and pumping them back into the reservoir.

\section{REFERENCES}

Andrushchuk V. L., Dubinsky A.Ya., Hain V. E. 1968. Geology of the USSR. Volume 9. Northern Caucasia Part 1. Moscow: Geological description of the Subsoil

Borovikov A. A. Vasilieva N.V., Leiko D. M. 2018. Engineering Geology and hydrology. Moscow: BGCKHA chute.

Davis S. de Whist R. 1970. World. Hydrogeology. Moscow

Dvorov I.M., Dvorov V.I. 1976. Enlightenment. Thermal waters and their use. Moscow

Everett L.G. 2004. Groundwater resources of the world and their use United Nations Educational Scientific and Cultural Organization. Paris.

Kartsev A.A., Vagin S.B. Shurygin V.P. 1992. Subsoil. Oil and gas hydrogeology. Moscow.

Kovyatkin L.A., Matusevich V.M. 2010. Oil and gas hydrogeology. Part 1. Theoretical foundations of oil and gas hydrogeology. Tsogu, Tyumen.

Mironenko V. A. 2001. Dynamics of underground waters. Moscow: Moscow state mining University.

Ovcharova T. A. 2009. Hydrogeology. Ukhta: UGTU.

Cherkashin V. I., Mamaev S. A., Magomedov R. A., Isaeva N.A. 2015. Geology and resources of Dagestan. Makhachkala.

Vagin S.B., Kartsev A.A., Shugrin V.P. 1992. Nedra, Oil and gas hydrogeology. Moscow.

Vsevolzhsky V.A. 2007. Tutorial. 2nd ed. MSU Publishing House. Fundamentals of hydrogeology.

Vsevolozhsky V.A. 2007. Moscow State University. Fundamentals of hydrogeology. Moscow 


\title{
Productive formations ranking methodology in order to select the optimal developing system
}

\author{
A.A. Farukshin \\ Postgraduate student, Saint-Petersburg Mining University, Saint-Petersburg, Russia
}

A.M. Zharkov

Doctor of geological and mineralogical Sciences, Saint-Petersburg Mining University, Saint-Petersburg, Russia

M.G. Ayrapetyan

Postgraduate student, Saint-Petersburg Mining University, Saint-Petersburg, Russia

\begin{abstract}
The article describes the methodology for ranking the objects of development of the Lower Cretaceous deposits of Western Siberia for their further development. The ranking is based on the degree of knowledge assessment of oil and gas deposits and allows us to predict the degree of uncertainty in determining the amount of reserves, which directly affects the field development system. The technique is universal, and its criteria are flexible. This allows us to adjust the estimate for deposits with varying degrees of knowledge.
\end{abstract}

Keywords: geological modeling, multivariate formation evaluation, geological uncertainties, formations ranking, saturation modeling

\section{INTRODUCTION}

In recent years, the majority of oil-producing regions (Volga-Ural, Western Siberia, etc.) have been characterized by the entry of the main pool of deposits into the late stage of development, where the extraction of residual hydrocarbon $(\mathrm{HC})$ reserves requires high unit costs. This, in turn, leads to a decrease in both the oil production rate and the efficiency of oilproducing enterprises. At the same time, the oil and gas industry still occupies one of the priority places in the Russian economy, contributing significantly to the development of other industries. One of the main ways to stabilize the rate of hydrocarbon production is to conduct exploratory work, the result of which is the discovery of new oil and gas fields.

However, in the "old" oil and gas producing regions, a decrease in the efficiency of prospecting is currently observed, which is associated with their relocation to areas with less prospects for oil and gas potential. In addition, work is being moved to areas with complex seismic and geological conditions with an increase in the number of small-scale deposits introduced into deep exploratory drilling. Obviously, drilling of unproductive facilities leads to economic losses. With this in mind, the task of prospecting for oil and gas is to obtain the most reliable information about the presence or absence of oil and gas-bearing object and its main characteristics.

This problem can be most rationally solved precisely by statistical methods based on a detailed study of the laws of structure and the criterion for evaluating small (1 to 5 million tonnes) and very small (less than 1 million ton) oil and gas deposits. Based on the analysis and systematization of factual material using multidimensional statistics, it is necessary to build geological models that provide the most rational choice of deposits for their input into further development. Ultimately, the effectiveness of prospecting will depend on the reliability of the economic planning of investment projects. The validity of the latter, first of all, is determined by the reliability 


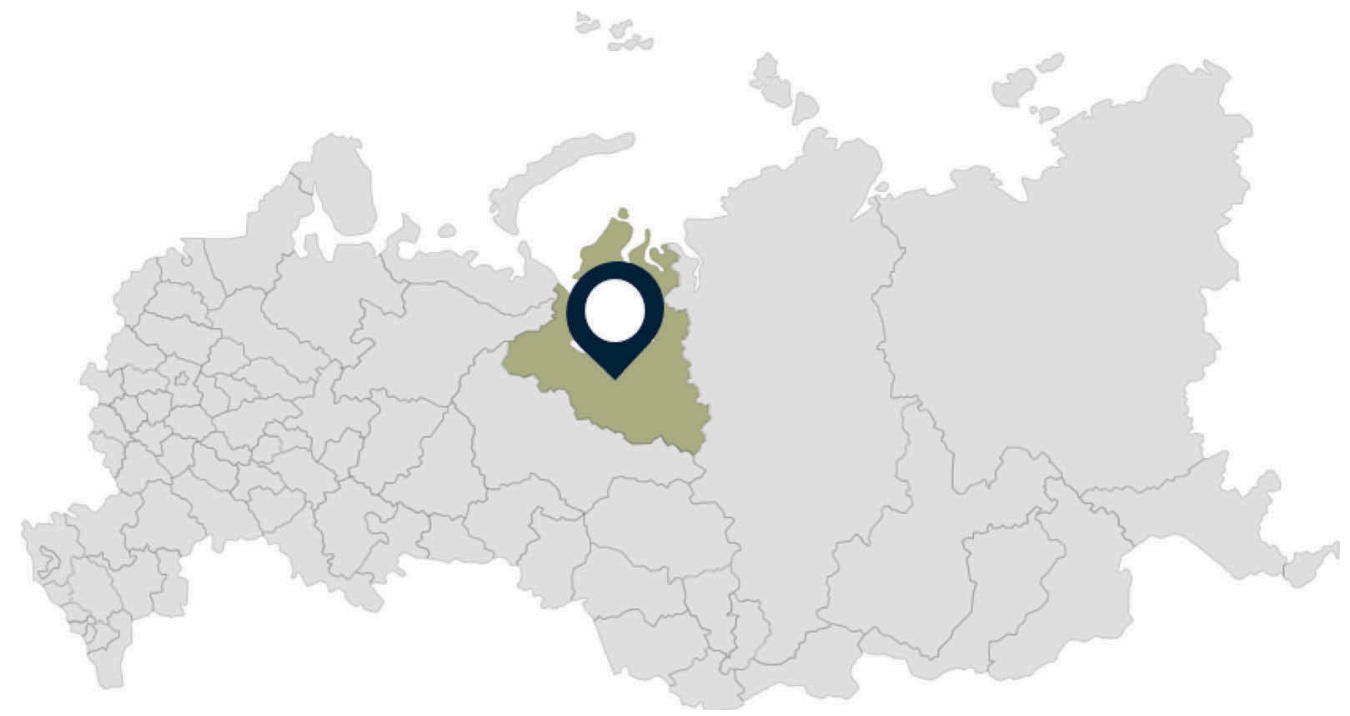

Figure 1. Research region.

of estimates of oil and gas reserves. The proposed approach allows even before significant investments to be made, to numerically assess the geological risks of exploration in Western Siberia, ensuring a reduction in the volume of exploration works by assessing uncertainties.

It is necessary either to discover new deposits, or to involve earlier discovered smaller deposits in the development, the commissioning of which is accompanied by large uncertainties in reserves, which causes concern when deciding on drilling or carrying out heavy geological and technical measures (GTM). Developers usually commission deposits from the bottom-up method; the choice is made according to the amount of residual recoverable reserves and the value of effective oil and gas saturated thicknesses. The same method accepts that, the value of reserves, this number is not fixed, but may vary within a certain interval.

Objects of research are undeveloped deposits of developed deposits and unexplored reserves of developed deposits of Lower Cretaceous deposits in Western Siberia (Figure 1).

\section{VERIFICATION OF GEOLOGICAL MODELS}

The goal of creating an algorithm for geological classification of formations was to create a unified scale for assessing the exploration of the hydrocarbon reservoir and forecasting the value of reserves with little exploration of hydrocarbon deposits. To compile a correctly working tool for ranking development objects, a geological analysis of all objects was carried out, as well as an analysis of their knowledge. For analysis, 12 deposits of the Snezhnoye field, which is at a late stage of development, were selected. All deposits are of the Lower Cretaceous age and are concentrated in the strata of the OK and AG groups. All deposits of the field are quite densely drilled by exploration and production wells. Detailed geological models were built for these deposits and hydrocarbon reserves (HC) were calculated. During the construction of geological models, data verification was carried out, which included: correlation of wells (Figure 2), construction of structural maps and thickness maps, derivation of the dependences of the permeability coefficient on the porosity coefficient, construction of a capillary model (Figure 3 ) for modeling oil saturation. Fluid contacts were also revised, because after drilling new wells the data were not updated. As a result, some substandard data were revealed, which were not taken into account when building dependencies and constructions.

The output was geological models that really reflected the structure of reserves, key uncertainties in their determination (Figure 4), as well as the distribution of hydrocarbon reserves. 


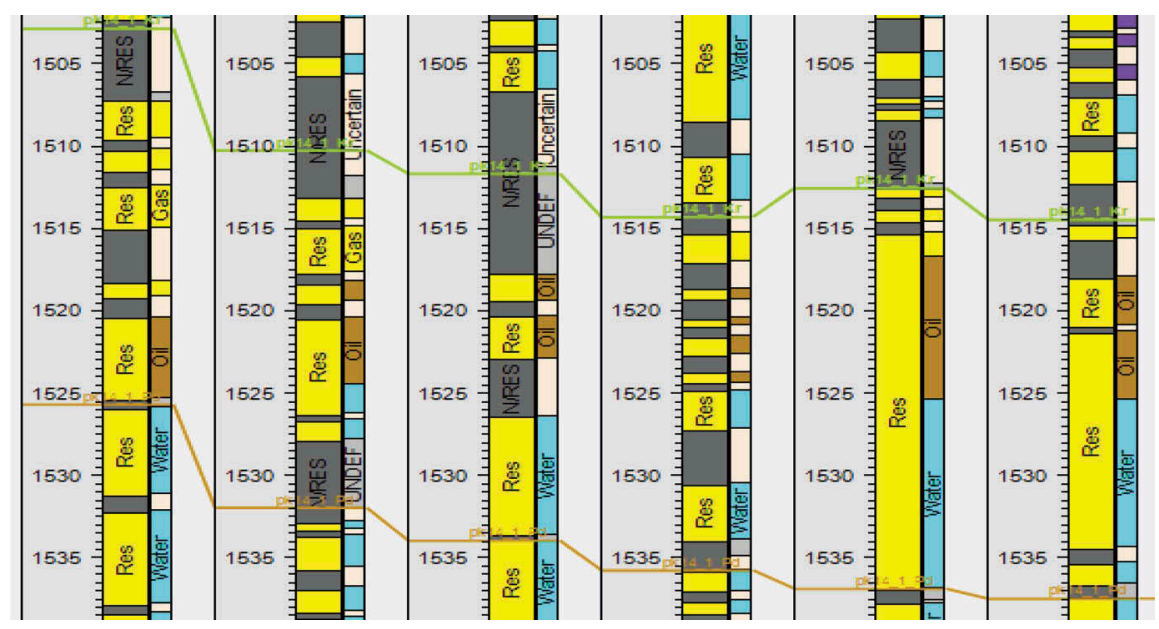

Figure 2. Correlation scheme of AK4 formation.

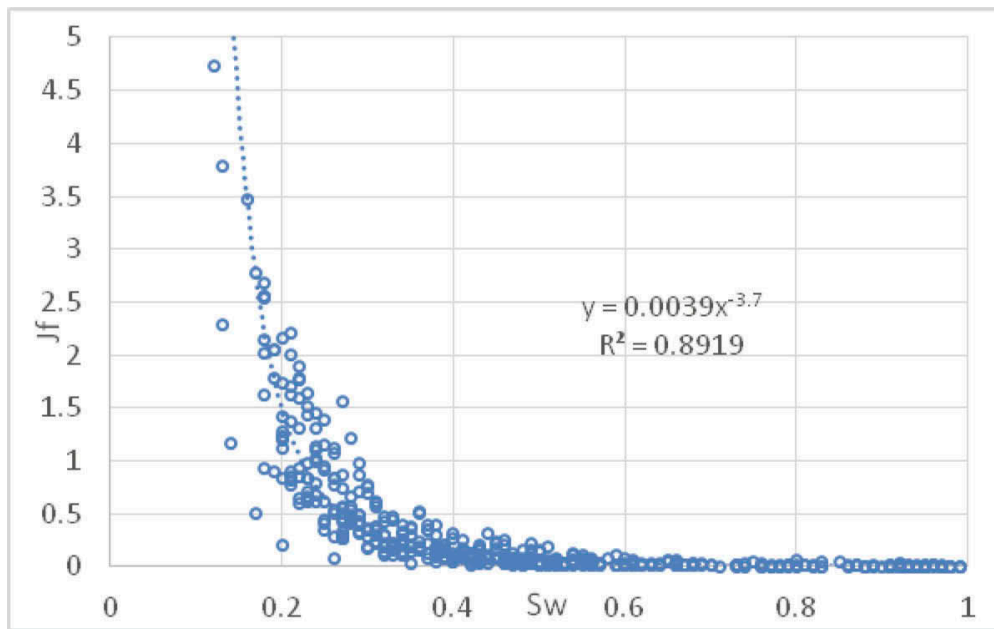

Figure 3. Capillary model (AK formations).

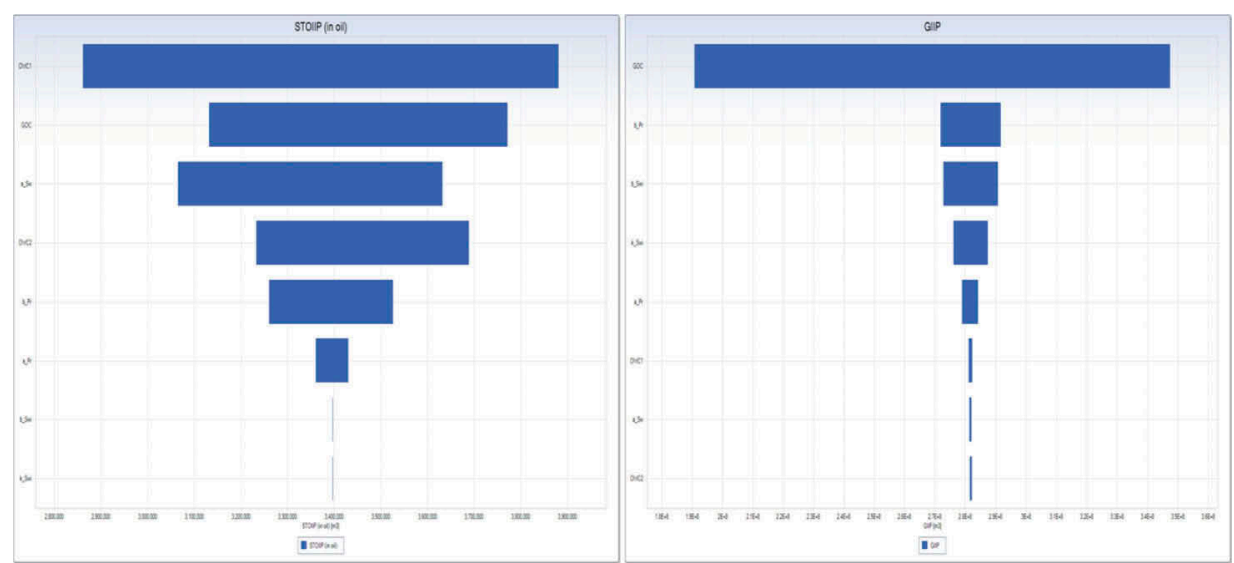

Figure 4. Sensitivity plot. OK2 formation reserves uncertainty decreases due to clarification of parameters. $\mathrm{HC}$ reserves more sensitive to varying of contacts and oil saturation. 

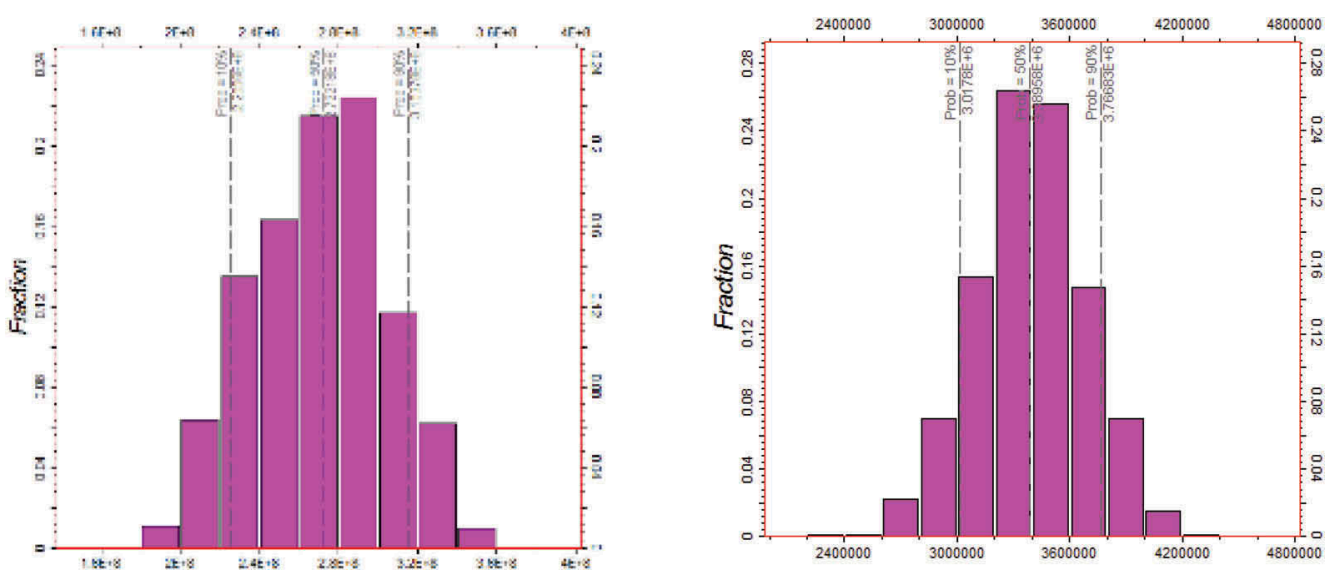

Figure 5. Clarification of initial oil reserves after remaking the geological model of OK2 formation.

The variability of reserves (Figure 5) was evaluated as a result of assessing the sensitivity of reserves to changes in the estimated parameters.

Thus, geological models were revised for all 12 sites. This was done to compile a reference sample that would allow us to develop a methodology for assessing the knowledge of development objects. Subsequently, all work was carried out on remade geological models with current data. For research, reserves of categories P10 (optimistic) and P90 (pessimistic) are useful.

\section{METHODOLOGY FOR THE KNOWLEDGE ASSESSMENT}

To assess the degree of knowledge of the development objects, a data pool was sorted, which somehow affects the uncertainties of hydrocarbon reserves. The study of deposits was considered as widely as possible and included:

1. Fluid studies

2. Petrophysical studies

3. Results of seismic data

4. Data from well tests and field geophysical data.

For each category of knowledge, parameters were described that describe the studies in detail. As a result, more than 80 parameters were collected that somehow contributed to the degree of knowledge of the reservoir. But it turned out that there are too many of these parameters to assess the degree of knowledge, since some of them strongly affect the calculated parameters, while others are not very. For example, the drilling density of a deposit affects the structure of the deposit, which in turn determines the area distribution and the size of reserves, and special geophysical studies, such as acoustic log data, do not affect the size of reserves so much.

Thus, directly related to the calculated parameters reservoir parameters were selected:

1. The structure of the deposits;

2. Fluid contact position;

3. Effective oil saturated thicknesses;

4. The coefficient of porosity $(\mathrm{Kp})$;

5. The coefficient of fluid saturation (So);

6. The formation volume factor (B);

Parameters for convenience are encoded with letters from A to F

The data characterizing the knowledge were grouped into categories and encoded from 0 to 5 :

1. Well stock;

2. Field geophysical surveys (FGS); 
3. Seismic surveys;

4. Well log data;

5. Petrophysical core studies;

6. Reservoir Fluid Studies;

As a result, a summary table was obtained for assessing the degree of exploration of deposits, on which the influence of studies on the determination of a particular parameter was analyzed (Table 1).

After compiling a summary table, evaluation criteria for each of its cells are developed. Cell A 0 - is determined by the degree of drilling density, A2 - by the correlation coefficient of the depth map with welltops. Cell B1 characterizes the knowledge of contacts by FGS, B3 - by well logs. $\mathrm{C} 0$ is determined by the drilling density (equal to A0), $\mathrm{C} 2$ is the correlation coefficient of the seismic data and thicknesses, C3 is the number of wells with a well logging. D2 - correlation coefficient of seismic data and Kp, D3 - correlation of core and well log data, D4 - presence of Kp core measurements. E3 - by correlation of the saturation parameter (Po) and So, E4 - by the presence of capillary studies and correlation of So with the capillary model.

To quantify the columns, the arithmetic mean for the parameters was calculated, but to take into account the weight of the studies, correction factors were also introduced:

$$
I=((a A 0+b A 2)+\ldots) / N
$$

where, I - knowledge, a and b - weighting factors.

All 12 deposits of the Snezhnoye field were estimated using this methodology (Figure 6).

Weight coefficients are independent.

Table 1. Criteria table for knowledge estimation. Green cells mean that study affects oil calculating parameters.

\begin{tabular}{lllllllll}
\hline & & Wells & Tests & Seismic data & Well log & Core & Fluids \\
\cline { 3 - 8 } Code & Parameter & 0 & 1 & 2 & 3 & 4 & 5 \\
\hline A & Structure & + & - & + & + & - & - \\
B & Contacts & - & + & - & + & - & - \\
C & Net thickness & + & - & + & + & + & - \\
D & Porosity & - & - & + & + & + & - \\
E & Saturation & - & - & - & + & + & - \\
F & B & + & - & - & - & - & + \\
\hline
\end{tabular}

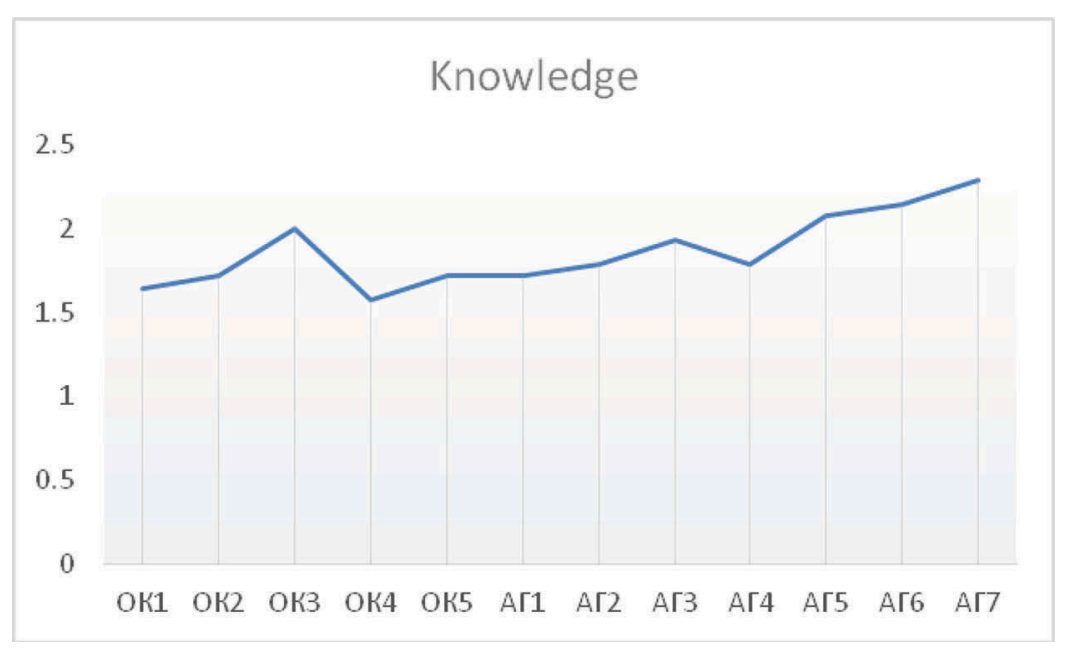

Figure 6. Formation knowledge. 


\section{RESULTS}

The weight coefficients for the studied deposits were selected automatically by solving the problem of multidimensional regression, when the degree of influence of each study on a particular parameter is calculated. The purpose of the selection was to obtain the maximum correlation coefficient of the degree of study and the ratio of reserves in the categories P10/ P90. This inventory ratio characterizes the uncertainty in the definition of reserves, that is, the wider the histogram of the distribution of reserves, the greater the uncertainty. As a result, a scattering diagram was obtained, the degree of correlation of which was 92\% (Figure 7). For 12 Snezhnoye deposits, the maximum weight factor was introduced for the So parameter and the contact position. Thus, all deposits are characterized by a strong sensitivity of the reserve uncertainty structure to these parameters.

\section{DISCUSSION}

This pattern of assessment of the degree of knowledge is universal for deposits. Depending on the degree of knowledge of the deposit for each cell in the table, you can set arbitrary numerical criteria, for example, for one field, the seismic data can describe the geological structure more detailed than for others.

This technique is designed to help the geologist in a number of tasks: the selection of the object of development from a variety of deposits for the purpose of priority, higher priority for further input into development, planning GTM; assessment the state of deposits knowledge allows assessing risks and uncertainties.

GTM planning on deposits with small and very small reserves is characterized by the presence of economic risk due to the possibility of a small economic effect.

The relevance of the method at the moment is that it allows the geologist to consider and type a new object in 1-2 hours. It can also be used for further studies of the object-timely update information in special checklists and get updated results instantly.

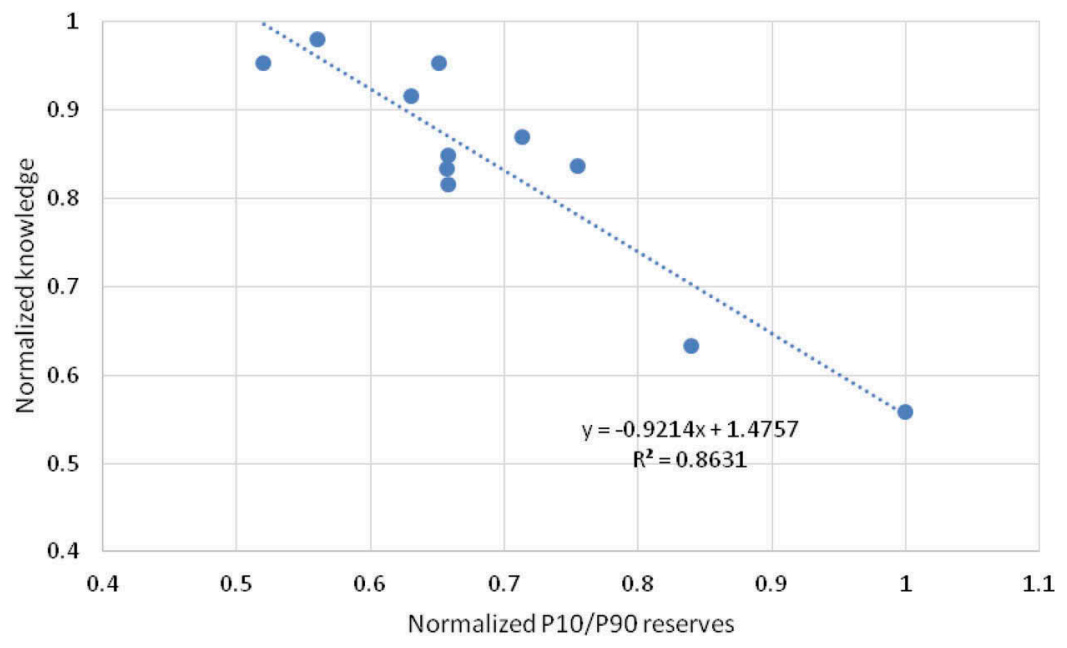

Figure 7. Normalized knowledge to P10/P90 reserves cross-plot. 


\section{CONCLUSIONS}

A method was developed for rapid assessment of the degree of knowledge of oil and gas deposits. The working tool is a table, which is a universal template for differentiating deposits depending on the availability, sufficiency, reliability and quality of input information. For a more accurate correlation of the study with the uncertainty in reserves, weight coefficients were automatically selected to determine the study that most affects them. The method was tested on 12 layers of the OK and AG group of the Snezhnoye field, the geological models of which were detailed in advance and the reserves of which were calculated by the probabilistic method. A high correlation coefficient $(92 \%)$ showed that the developed template accurately reflects the structure of uncertainty in hydrocarbon reserves. This means that after assessing the uncertainty of several deposits in detail, you can choose such criteria that can predict with high confidence the uncertainty of other deposits of the field of interest.

\section{REFERENCES}

Ababkov, K. (2010). Fundamentals of three-dimensional digital geological modeling. Ufa: "Oil and Gas business".

Bolshakov, M., Meynarands R., Naugunov M. V. "A new approach to the assessment of the index of complexity of development of deposits in Western Siberia". SPE-187780-RU

Disposal of the Ministry of Russia from 01.02.2016N 3-R (edition of 19. 04.2018) "On approval of methodological recommendations on application of Classification of reserves and resources of oil and combustible gases, approved by order of the Ministry of natural resources and ecology of the Russian Federation on 01.11.2013 N 477"

Gutman, I., Kuznetsova G. P. Classification of correlation of geological sections of wells in connection with the degree of study of oil and gas objects. Features of performance of comparison of geological sections of wells with use of the latest computer technologies. - Moscow: Gubkin Russian state University of oil and gas, 2006.

Matveev, V.P., Tarasenko, A.B. 2019. The study of the Berkha Island reef massif (Novaya Zemlya), based on lithological and geochemical data. - Chemie der Erde.

Prishchepa, O., Nefedov, Y., \& Grokhotov, E. 2019. Geochemical and petrophysical studies of hydrocarbon potential of domanic shale formation (Timan-Pechora petroleum province). EAGE/SPE Workshop on Shale Science 2019 - Shale Sciences: Theory and Practice

Rose, P. "Risk Analysis and management of oil and gas exploration projects" // SIC "RCD", "Izhevsk Institute of computer research", - Moscow-Izhevsk, 2011, - 304 p.

Sirotkin, A.N., Talovina, I.V., Duryagina, A.M. 2019. Mineralogy and geochemistry of alkaline lamprophyres of north-western Spitsbergen (Svalbard) - Chemie der Erde.

Zakrevsky, K. (2009). Geological 3D modeling. Moscow: LLC CPI Mask. 


\title{
Prospective petroleum accumulation areas in the non-structural traps in the Upper Permian sequences of the southern part of the Vilyuy Syneclise (Eastern Siberia)
}

\author{
G.A. Cherdancev \\ Postgraduate student, Saint-Petersburg Mining University, Russia
}

\author{
V.P. Semenov \\ Candidate of Geological and Mineralogical sciences, leading researcher, Joint-Stock company "All-Russia \\ Petroleum Research Exploration Institute» ( «VNIGRI»), Russia
}

I.A. Kushmar

Candidate of Geological and Mineralogical sciences, head of department, Joint-Stock company "All-Russia Petroleum Research Exploration Institute» ( $V V N I G R I »)$, Russia

\begin{abstract}
The article provides the updating of the petroleum potential forecast of the Permian formations in the southern part of the Vilyuy Syneclise, which is a promising territory for the petroleum exploration. Article includes a brief description of the Upper Permian sequences and justification of the oil and gas prospects of the Upper Permian Taragay Formation. Authors have performed updated scheme of the oil and gas potential prospects of the Permian section based on the data of new geological and geophysical studies carried out in the southern part of the syneclise.
\end{abstract}

\section{INTRODUCTION}

The current issue in the east of Russia - in Yakutia - is certain risks associated with the provision and refill of the energy and industrial sectors of the national economy with petroleum resources (Sivtsev, Chalaya et al., 2016). One solution to this problem is exploration of new accumulation areas in Central Yakutia.

Vilyuy Syneclise is one of the areas in Eastern Siberia, where researchers expect discovery of new petroleum accumulations in the Upper Paleozoic formations.

Vilyuy Syneclise is the largest depression in the east of the Siberian Platform. The syneclise is located on a large territory between the Anabar Anteclise in the north and Aldan Anteclise in the south; in the east the syneclise borders on the Pre-Verkhoyansk Trough. The geological structure of the sedimentary cover includes formations from the Upper Proterozoic to Cenozoic systems.

The petroleum potential of the Permian section of the Vilyuy Syneclise is confirmed by the presence of accumulations in the Upper Permian formations (gas and gas condensate fields in the central part of the syneclise - within the Khapchagay Uplift Area), as well as oil and gas occurrences within the syneclise.

Different researchers have repeatedly pointed out the possible oil and gas prospects of the Permian section in the south of the Khapchagay Uplift Area (Sitnikov et al., 2014, Vasiliev et al, 2018). The geological and geophysical studies recently conducted by JSC "Yakutskgeofizika" and JSC "VNIGRI" in the southern part of the syneclise confirm the prospects of Permian formations in this area. 


\section{BRIEF GEOLOGICAL CHARACTERISTICS OF THE STUDIED AREA AND UPPER PERMIAN FORMATIONS}

The studied area is about 12 thousand $\mathrm{km}^{2}$. In general, the Permian structural plan of this territory is the southern monoclinal slope of the Vilyuy Syneclise. It is complicated mainly by structural elements such as structural noses, flexures, etc. In the northeast of the territory there is the Tangnaryn Depression adjacent to the Khapchagay Uplift Area from the south. In the southwest of the studied area there are Ygyattin and Kempendyay depressions, which are separated by the Suntar Arch. The Arbaysk-Sinsk Uplift Area is located to the southeast from the Kempendyay Depression; from the southeast it is limited by the Sarsan Depression. To the east there is a northwest side of the Aldan Anteclise (Figure 1).

The Permian formations are widespread throughout the studied territory. Their thickness varies from $3.6 \mathrm{~km}$ in the central part of the Tangnaryn Depression to wedging-out closer to the sides of the syneclise. The subdivision of the Permian sequences is based on the presence or absence of coal layers.

The terrigenous-coal-bearing Permian section in the south and in the center of the syneclise is divided into the Lower Permian Mohsogolokh Formation and the Upper Permian Khomustah, Kharyass, Kyundey, and Taragay formations. A comparison of the time of their formation with the international stratigraphic chart and the general stratigraphic chart, used in the period of time when they were described, is presented in Figure 2. These formations are dominantly composed of sandstones, layers of interbedded siltstones and mudstones (Frolov et al, 2019). They were formed in continental sedimentation environments.

Gas-bearing reservoir rocks of the Upper Permian formations in the central part of the syneclise are confined to the Taragay Formation of the Tatarian series of the Permian system. The main type of deposits is lithologically screened roof deposit.

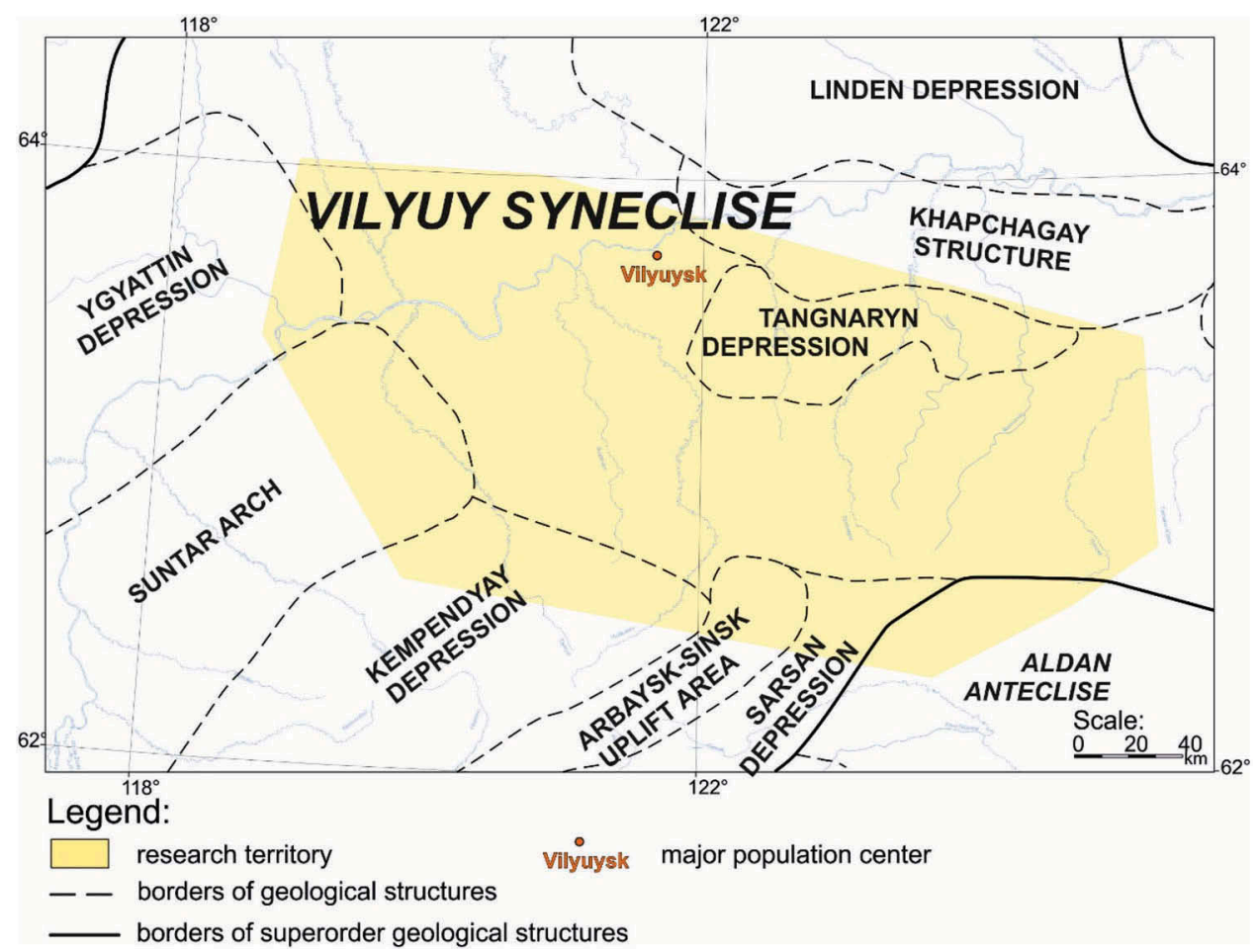

Figure 1. Structural and tectonic schematic view of the research territory. 

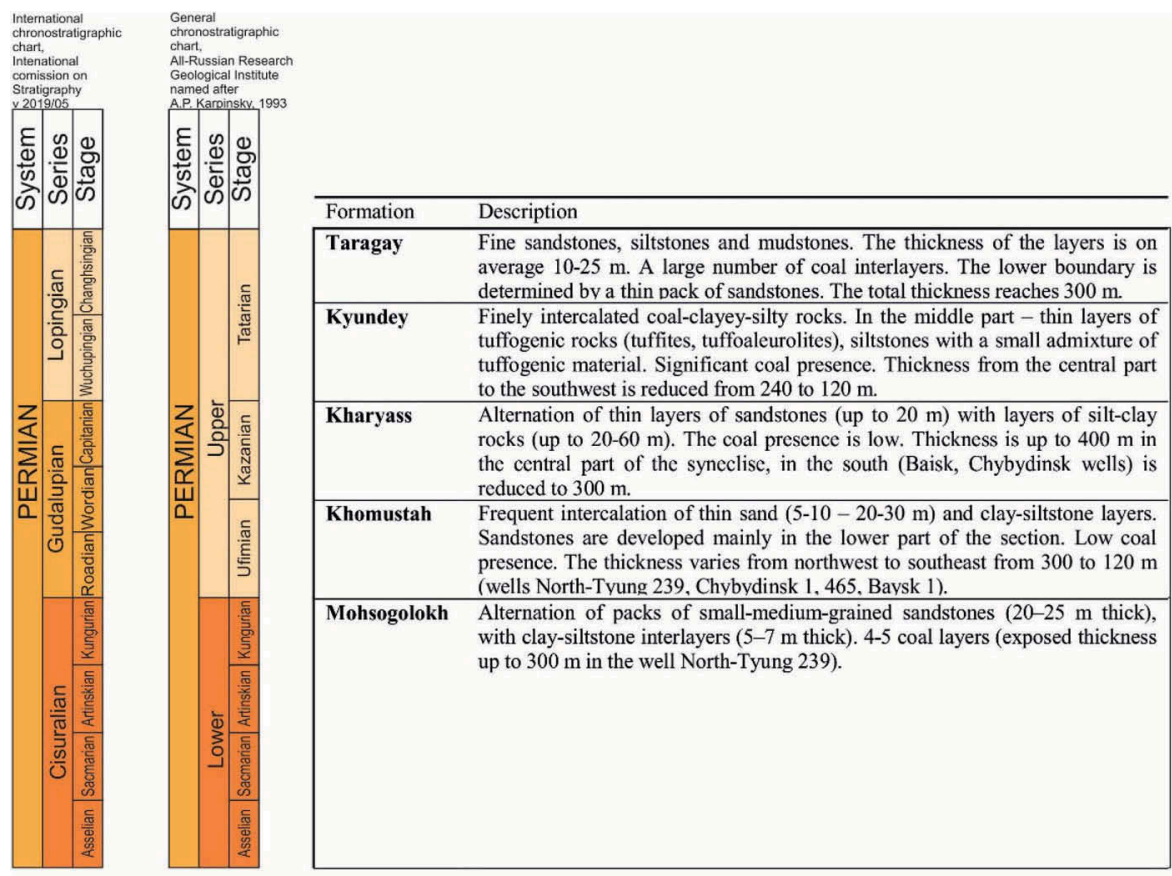

Figure 2. Description of the Permian formations of the southern part of the Vilyuy Syneclise.

The Taragay Formation was drilled by 26 wells within the studied territory; however, its full section was exposed only in wells of the Khapchagay Uplift Area. The formation is composed by thin layers of sandstones and carbon-bearing-clayey-siltstone rocks with thickness up to 10-15 m. Thin layers of tuffogenic rocks are exposed in the top of the formation. Taragay Formation on the southern side of the Vilyuy Syneclise was formed in the continental sedimentation environments. The section formed in the beds of meandering rivers, their floodplains, lakes and swamps, are widespread within the territory. The thickness of the formation within the site decreases from $304 \mathrm{~m}$ on the south (Middle Vilyuy 27 well (27_Sr-Vil)) to 85.9 m (Bappagay 1 well (1_Bapp)).

Permeable rocks of the upper part of the Permian section were discovered in the South Byrakan area (Byrakan wells (1184_Byr, 3_Byr, 2_Byr)). The porosity of the reservoirs reaches $14.2 \%$.

Satisfactory pore reservoirs are also discovered in Baysk 1 well (1_Bays) with a porosity of $14-15.8 \%$; during the tests the water inflow of $14.25 \mathrm{~m}^{3} /$ day was reached.

In the South Nedzhelinsk well (251_Y-Nedj) the natural gas inflow up to $1000 \mathrm{~m}^{3} /$ day was obtained from Permian formations (Sitnikov et al., 2017).

During tests in Hailakh 1213 well (1213_Hayl) the inflows of water with dissolved gas were obtained; core porosity of the reservoir rocks of the Taragay Formation was up to $9.4 \%$. The reservoir properties are also confirmed by the results of re-interpretation of well logs carried out by specialists of JSC "VNIGRI".

Reliable impermeable rocks for the potential Taragay Formation are the Lower Triassic Nedzhelinsk Formation, regionally developed on the territory of the Vilyuy Syneclise (Vasiliev et al, 2018). The Nedzhelinsk Formation is not distributed throughout the whole territory. On the remaining territory, the lower part of the Lower Jurassic Kyzylsyr Formation, which overlaps the Permian formations in the south where Triassic formations are absent, may serve as possible reservoir caprock due to its impermeable properties. In addition, there are impermeable layers of clay rocks within the Taragay Formation that can serve as local reservoir caprocks. 


\section{PERMIAN SOURCE ROCKS OF THE VILYUY SYNECLISE}

The Permian terrigenous structure is the main oil and gas producing formation for the Upper Paleozoic-Mesozoic sedimentary sequences of the basin (Zueva et al., 2014). Due to the high bio-productivity of the continental Permian landscapes, the large masses of organic matter are accumulated in this section.

The dispersed organic matter (DOM) of the Permian sequences has a mixed genetic nature with a different ratio of sapropelic and humic components, but is mainly represented by sapropelic and humic types (Zueva et al., 2014).

By the beginning of the Triassic, the Permian sequences entered the initial stage of the main phase of oil formation in the depressions in the south of syneclise. On the territory of the Linden Depression and the present-day Khapchagay Uplift Zone, they approached the main stage of gas generation. In subsequent eras, the Permian sequence continued to plunge unevenly. Subsidence depths were determined by the thickness of the overlying sections, which created various conditions for the generation and migration of hydrocarbons.

To the end of the Lower Cretaceous, the Permian sequences in most of the territory were located at the levels of the main gas generation zone, corresponding to the stage of maximum migration of gas hydrocarbons, while in the Linden Depression - to the stage of gas process attenuation.

At the present stage, corresponding to the depths of maximum deposits subsidence, the Permian formations are located almost throughout the territory within the gas generation zone. In the deepest parts of the depressions, the Permian section could have exhausted their gasproducing properties.

Thus, starting from the Triassic time, the hydrocarbon migration could occur from the most deepened part of the syneclise to its sides, where they could be accumulated in traps.

\section{OIL AND GAS PROSPECTS}

There are not many typical anticlinal traps in the studied area. They were identified earlier (Byrakan, Hailakh sites); wells were drilled within them, in which gas inflows were received during well tests. No other large anticlinal traps have been identified; therefore, the oil and gas accumulation zones within the studied area can be primarily confined to non-anticlinal traps. Favorable factors for their formation are the presence of interbedded sand and clay rocks, large regional Pre-Triassic and Pre-Jurassic erosion, on the surfaces of which the porous and impermeable rocks come into contact, the development of facial substitution areas and regional wedging out of sequences that are characterized by oil and gas potential. The positive impact of such factors on the oil and gas potential is also known in other oil and gas basins in Russia (Prishchepa et al, 2019; Borovikov and Volchenkova, 2018).

The identification of promising zones of oil and gas accumulation was preceded by a detailed correlation of productive levels, structural and tectonic studies based on seismic, electrical, and gravimetric surveys, which allow us to clarify the structural plans for prospective petroleum bearing areas within the territory and to update the pinch-out line of the Permian sequences.

As an example, the fragment of seismic survey interpretation performed by JSC «Yakutskgeofizika» specialists is provided in Figure 3, where the pinching out of the Permian sedimentary complex is presented.

Figure 4 shows the same seismic section with a possible petroleum prospect in the Upper Permian sedimentary rocks.

As a result of research, promising oil and gas zones were localized in the upper part of the Permian section (Figure 5).

In the eastern part of the research area, a promising prospecting object is limited from the northwest by tectonic fault traced along seismic sections. The level of oil and gas content was 


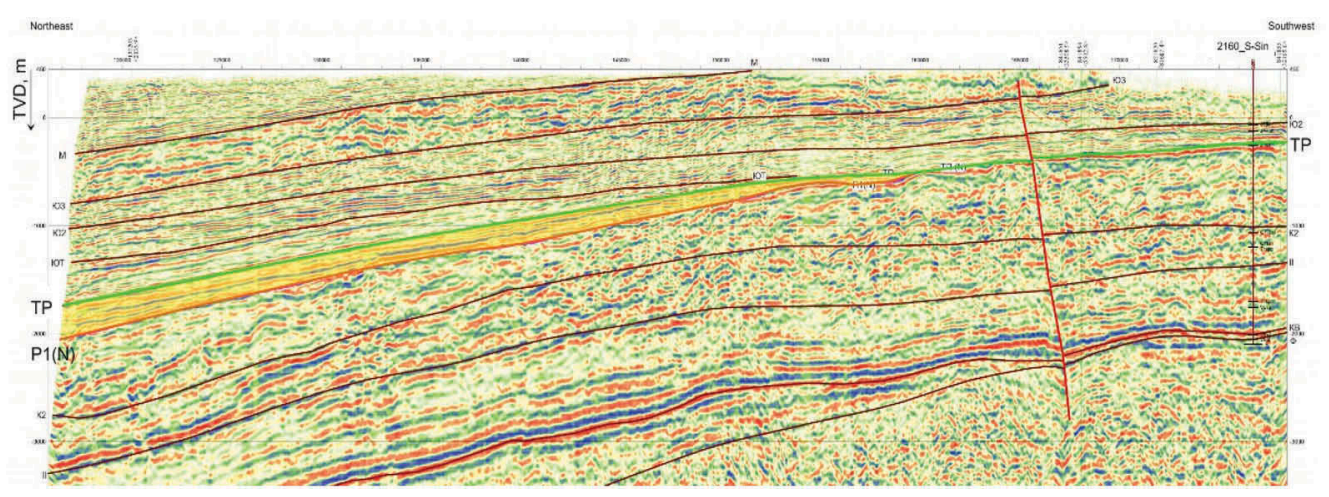

Figure 3. Fragment of the seismic section. TP (green) -top of the Upper Permian formation (Taragay Fm); P1(N) (orange) - bottom of the Upper Permian formations; the interval of the Upper Permian section is shown in yellow.

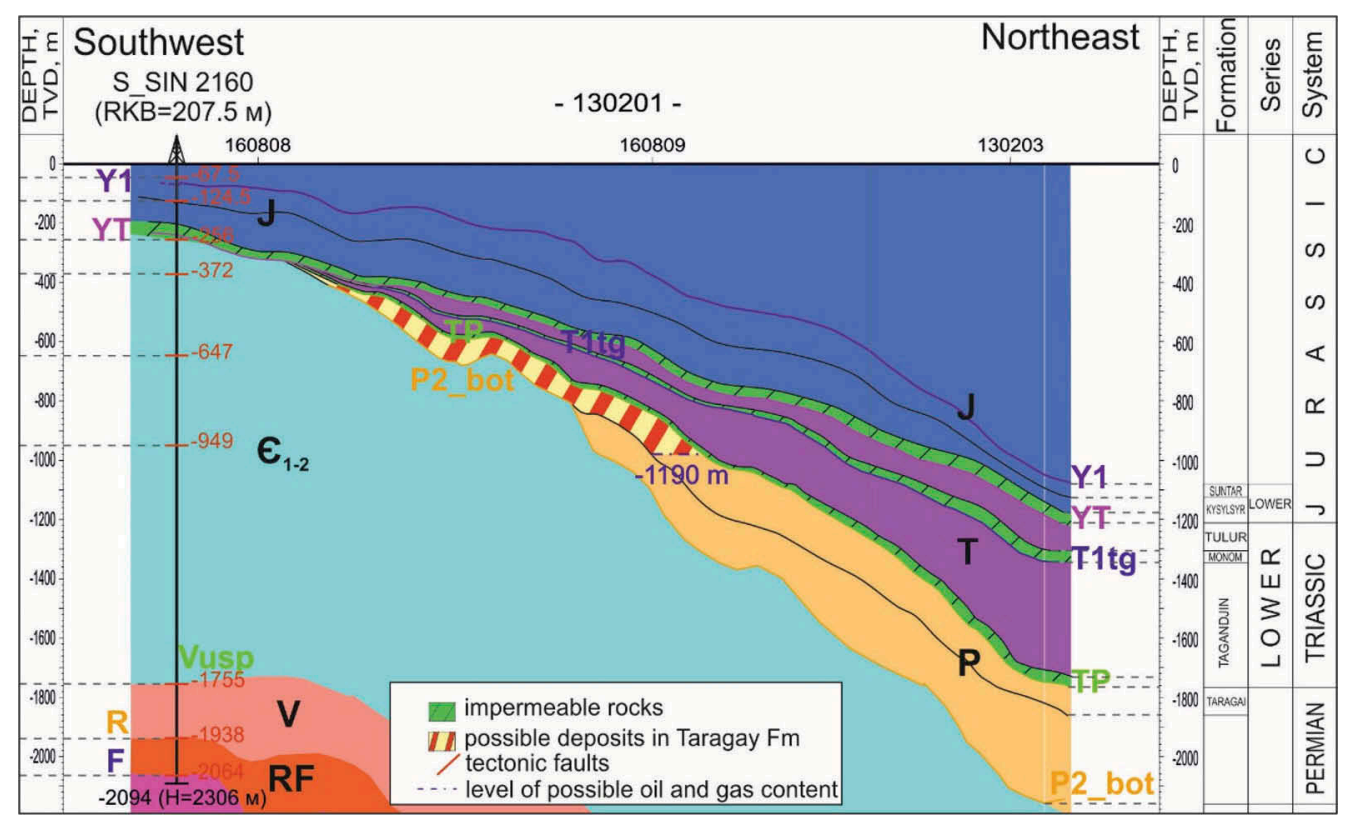

Figure 4. Fragment of the geological section.

Seismic horizons: Y1- top of Suntar Fm (J1sun); YT- top of Tulur Fm (T1t1); T1tg- top of Tagandjin Fm (T1tg); TP- top of Taragay (P2tr); P2_bot - bottom of Upper Permian formations; R- top of Riphean sequences; F - top of basement rocks

taken at an absolute depth (TVD) of $-1190 \mathrm{~m}$, corresponding to the top of water-saturated reservoirs according to well log data in Andreevsk 2 well (2_Andr) located nearby. In the south the perspective zone is limited by the wedging line of the Taragay Formation, traced on seismic surveys sections and deep well drilling data.

In the western part of the site, the prospecting object is bounded from the southwest by the pinch-out line of the Permian sequences, and by tectonic faults that limit the Suntar Arch from neighboring depressions. The probable oil and gas content level has an absolute depth $-1300 \mathrm{~m}$, which corresponds to the top of the water-saturated reservoir in the Nizhnetyukyan 311 well (311_N-Tuk). 


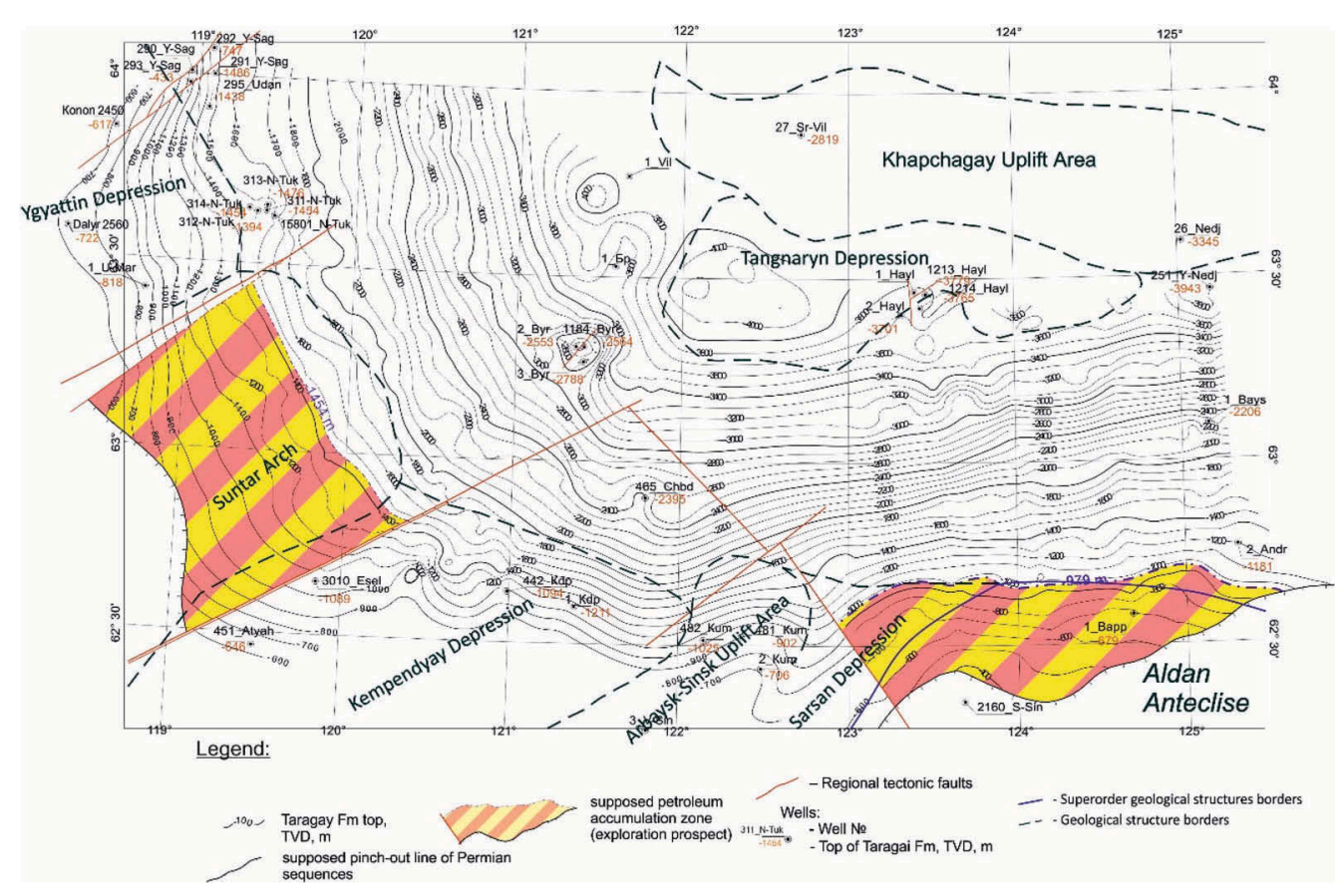

Figure 5. Scheme of oil and gas prospects of the Permian section in the southern part of the Vilyuy Syneclise.

\section{CONCLUSIONS}

The Permian oil and gas structure is associated with certain prospects for the discovery of hydrocarbon accumulations in the southern part of the Vilyuy Syneclise. Non-anticlinal traps are expected there. They are controlled by the surfaces of erosion, limiting the Permian sequence from below and above, as well as by the development of weakly permeable or impermeable rocks below the surface of the Pre-Permian erosion. Other factors are the distribution of clay rocks above the Triassic erosion surface and facial variability within the Permian section.

As a result of the studies conducted by VNIGRI specialists on the basis of complex geological and geophysical surveys, the perspective objects in the Upper Permian were localized within the research object and the pinching out boundaries of the Permian formations were clarified.

The traps in the selected zones are assumed to be of non-structural type and will be confined to the zones of pinch-out of productive reservoir rocks and controlled by regional lithological screens.

The types of deposits associated with these traps are stratigraphic, lithological and stratigraphic with elements of tectonic shielding.

The obtained geological results indicate the need for further study of this territory.

\section{REFERENCES}

Borovikov I.S., Volchenkova T.B. 2018. Model of forming hydrocarbon pools in the west of Melekess depression. Conference Proceedings, Innovations in Geosciences. Time for Breakthrough, Saint Petersburg, Apr 2018, (2018): 1-6. EAGE.

Frolov S.V., Karnyushina E.E., Korobova N.I., Bakay E.A., Kurdina N.S., Krylov O.V., Tarasenko A. A. 2019. Features of the structure, sedimentary complexes and hydrocarbon systems of the Leno-Vilyuisky oil and gas basin. Georesources 21(2): 13-30. 
Prishchepa, O., Nefedov, Y., \& Grokhotov, E. 2019. Geochemical and petrophysical studies of hydrocarbon potential of domanic shale formation (the timan-pechora petroleum province). Conference Proceedings, EAGE/SPE Workshop on Shale Science 2019, Apr 2019, (2019): 1-5. EAGE.

Sitnikov V.S., Alekseev N.N., Pavlova K.A., Pogodaev A.V., Sleptsova M.I. 2017. Newest forecast and development updating of Vilyuy Syneclise petroleum objects. Petroleum Geology - Theoretical and Applied Studies 12 (1).

Sitnikov V.S., Prishchepa O.M., Kushmar I.A., Pogodaev A.V. 2014. Petroleum potential prospects of southern part of Vilyusky syneclise. Prospect and protection of mineral resources 7: 22-28.

Sivcev A.I., Chalaya O.N., Zueva I.N. 2016. Prospects of oil and gas in the Central Yakutia as resource of energy security. Oil and Gas Business 2: 71-82.

Vasiliev S.A., Sobolev P.N., Taffarel E.S., Golovanova M.P., Garifullin I.I. 2018. Oil and gas potential of Vilyuiskaya syneclise and prospects of hydrocarbon deposits searching. Geology, geophysics and development of oil and gas fields 12: 14-26.

Zueva I.N., Chalaya O.N., Safronov A.F., Kashircev V.A. 2014. Oil Generated Potential of the Permian Deposits of the Vilyui Basin. Science and Education 2: 110-117. 


\title{
Bituminous sandstones of the Chechen Republic
}

\author{
Sh.Sh. Zaurbekov \\ Doctor of Economics, Professor, Vice-Rector, Grozny State Oil Technical University named after Acad. \\ M.D. Millionschikov, Grozny, Russia
}

M.M. Labazanov

Ph.D., Head of Scientific and Technical Center "Nedra", Grozny State Oil Technical University named after Acad. M.D. Millionschikov, Grozny, Russia

T.Kh. Ozdieva

Head of the laboratory "ILGEM" NTC "Nedra", Grozny State Oil Technical University named after Acad. M.D. Millionschikov, Grozny, Russia

P.U. Musaeva

Laboratory Assistant, ILGGP Scientific and Technical Center Nedra, Grozny State Oil Technical University named after Acad. M.D Millionshchikov, Grozny, Russia

Z.I. Gadaeva

Head of the laboratory "ILGGP" NTC "Nedra", Grozny State Oil Technical University named after Acad. M.D. Millionschikov, Grozny, Russia

\author{
A.A. Batukaev \\ Laboratory Assistant, Ecology and Nature Management, Grozny State Oil Technical University named \\ after Acad. M.D. Millionschikov, Grozny, Russia
}

Z.M-E. Damzaev

Junior Researcher, Scientific and Technical Center "Nedra", Grozny State Oil Technical University named after Acad. M.D. Millionschikov, Grozny, Russia

\begin{abstract}
The article gives a general description of tar sandstone deposits in the Chechen Republic. In total, nine areas of outcrops of sand and sandstones of the Karagansky and Chokraksky stages of the Neogene system, which are confined to two structural zones, are the zone of the Advanced Ranges and the zone of the Montenegrin monocline. Four zones were identified in each area.

All deposits of the Advanced Ridge zone are small, due to their local distribution of bituminosity and a steep occurrence of the host reservoirs. In addition to the volume of reserves, the deposits of the Montenegrin monocline are unpromising due to their remoteness from the main transport and energy highways.

When studying the bituminous strata of the promising sections, the following problems were solved: the geological structure of the section was studied; layers with industrial significance are highlighted in the context of the tar layers; bitumen content and the nature of its change are determined; the physicochemical characteristics of bituminous rocks and interposition with the host rocks are specified; qualitatively evaluated and determined technological parameters of bitumen; estimated mineral reserves are estimated.

The general characteristics of bituminous rocks include - the uneven distribution of bituminous in both individual intersections and in areas as a whole; are classified as - from low
\end{abstract}


bitumen to medium bitumen. By particle size distribution and particle size modulus, finely and medium-grained, by mineralogical composition, quartz sand.

All described areas of bituminous rocks can be attributed to promising development at the local regional level.

\section{INTRODUCTION}

Currently, the task has arisen of searching for additional resources of organic binders and developing methods for their rational use in the construction of roads. The source of reducing the deficit in oil bitumen is natural bituminous rocks, the deposits of which are widespread, including in the Chechen Republic. The conditions for the formation of natural bitumen in the host sedimentary formations are migration processes of fluids consisting of water and hydrocarbons with the obligatory access of air and specific microorganisms. In the process of this, this fluid mixture is differentiated on the fractured-pore surfaces of the rocks according to the fractional basis, i.e. heavy hydrocarbons, aspaltenes and resins.

An analysis of the available material obtained during geological exploration from the $30 \mathrm{~s}$ of the XX century, which includes specialized geological studies for oil and gas in the Grozny and Nozhay-Yurt districts, to the present (expedition of Chechenneftekhimprom OJSC) indicates that manifestations of bituminous rocks occur almost everywhere in the strip of outcrops on the surface of Karagan-Chokrak deposits. (Mitchin, 1992)

Deposits of the Jurassic, Cretaceous, Paleogene, Neogene, and Quaternary systems take part in the geological structure of the territory of the Chechen Republic. (Orel, Raspopov, Skripkin, 2001) Because bituminous sandstones have a clear stratigraphic and lithological confinement; in practice, we will only dwell on the characterization of these deposits only to the sandstones of the Chokrak and Karagans. (Khasanov, Shaipov, Zaurbekov, 2010)

The deposition of the Chokrak and Karagan strata together with the overlying layer of the Miocene and Pliocene belong to the Neogene system (N)

According to the scheme of N.A. Kozlova distinguishes 11 strata of sandstones of the Chokrak deposits (E1 - E11) of various thicknesses and lithology, including strike. The layers are separated by clays and marls of various thicknesses and lithology. (Orel, Raspopov, Skripkin, 2001) The lower boundary is drawn along the roof of the marls in accordance with the presented fauna. The thickness of the entire Chokrak tier reaches $1068 \mathrm{~m}$.

The rocks of the Karaganskian layer, according to the overlap of the deposits of the Chokrak layer and are represented by interbedded horizons of sandstones and packs of clay. The section of Karagan deposits is similar to the section of the Chokrak and differs from the latter only in fauna.

In total, 13 layers of sandstones, some of which are largely bituminized, were noted in the Karagan section. (Khasanov, Shaipov, Zaurbekov, 2010) These deposits are confined to the Grozny manifestation of tar stoves and some others (Bulgat-Irzu). The total thickness of the Karagansk deposits varies between 150-200 m.

Miocene sediments are undivided, according to overlap the formation of the Karagansian stage and are represented mainly by clays, with the appearance of sandstones, marls, shells and conglomerates in the upper part of the section.

Pliocene sediments are characterized by a wide range of lithological differences in rocks: sands, clays, sandstones, limestone, marls, and limestone.

The deposits of the Quaternary system (Q) are represented by clays, loams, sands, and pebbles.

In tectonic terms, the described region belongs to the zone of the Advanced Ranges and the Montenegrin monocline of the Northern slope of the Greater Caucasus.

In the zone of the Advanced Ranges, Tersky, Sunzhensky, Grozny, Bragunsky and Gudermes anticlinoria, as well as the Sunzhensky and Alkhanchurt synclinoria are distinguished. (Khasanov, Shaipov, Zaurbekov, 2010)

$\mathrm{He}$ anticlinoria are composed of a series of anticlinal brachisculides elongated in the sublatitudinal direction and complicated by a series of longitudinal reverse faults. As a rule, in the 
nuclei of these structures the rocks have a steep occurrence, noticeably flattening towards the northern and southern wings. In the zone of the Montenegrin monocline, the rocks have a stable northern fall at angles of 20-40. The eastern part of the Montenegrin anticline is complicated by the Benoic anticlinal ledge of sub-latitudinal strike with steep northern and flatter southern wings. The central part of the Benoy ledge is complicated by a series of transverse discontinuities. A significant gap was noted along the line of the village of Gilyana - Mount Eli Baving, called the Gilyansky reverse fault. There is an opinion that according to the throw-up in the area with. The Gilans are brought into contact with the Maykop and Karagan-Chokrak deposits, and oil flows from the former to the latter.

Within the described area there are a number of oil and gas fields. (Kerimov, Daukaev, 2003) In hydrological terms, the area can be divided into three zones: the zone of the Advanced Ranges, the lowland zone and the Black Mountains zone. In the zone of the Advanced Ranges, formation-fractured waters confined to the cover are developed. In the lowland zone, aquifers of the Pliocene, Pleistocene, and also underground waters of the terrace complex are noted. The Black Mountains zone is hydrologically poorly understood. Potentially aquifers are sandstones of Karaganchokrak deposits.

When studying promising areas of bituminous strata in the Chechen Republic, only 9 sites were covered: Grozny, Sernovodsky, Simsirsky, hkendatenn-Kort, Bulchat-Irzu, KurenBenoy, Gudermes, Bragunsky. (Mitchin, 1992) (Figure 1).

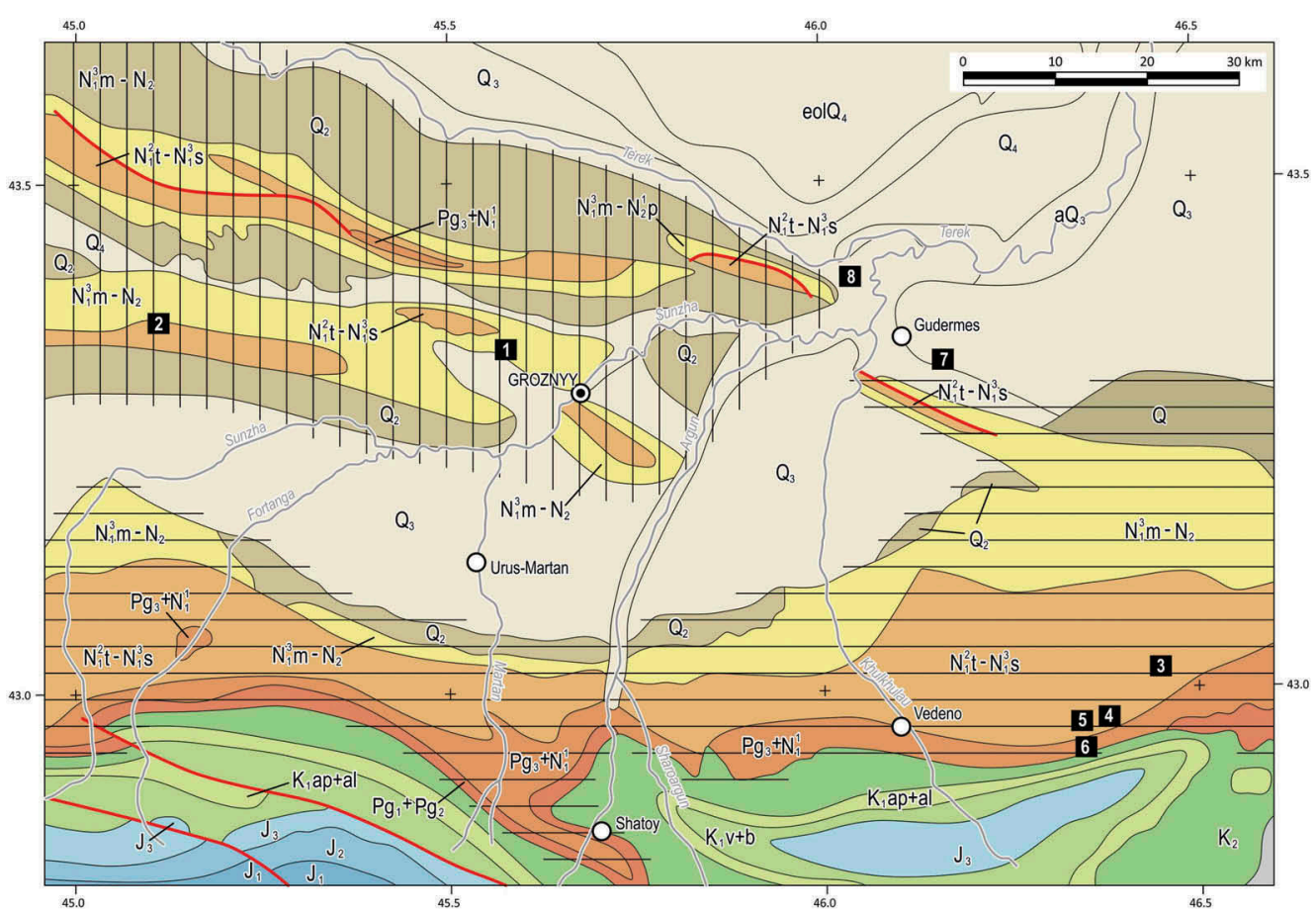

Legend:

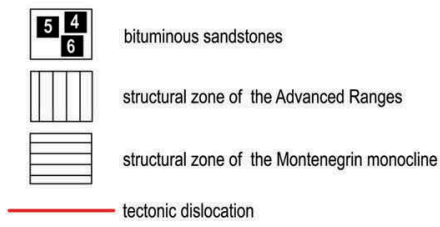

Figure 1. Schematic map of the manifestations of tar sandstones. 
The numbers on the map indicate

\begin{tabular}{|c|c|c|}
\hline № & Name & Location \\
\hline 1 & Grozny site & Starogroznensky ridge, Mamakaevskaya beam \\
\hline 2 & Sernovodsky site & $\begin{array}{l}\text { On the southern slope of the Sunzhensky ridge, between } \\
\text { the villages of Sernovodsk and Sleptsovskaya }\end{array}$ \\
\hline 3 & Simsirsky district & $\begin{array}{l}\text { District of the village of Simsir, the confluence of the } \\
\text { Yaryk-Su and small Yaryk-Su }\end{array}$ \\
\hline 4 & Section Mahkendatten & Court $2.5 \mathrm{~km}$ east of the village. Bulgat Irzu \\
\hline 5 & Plot Bulgat-Irzu & Western outskirts with. Bulgat Irzu \\
\hline 6 & 6 Section Kuren-Benoy & Northern outskirts of the village \\
\hline 7 & Gudermes & $\begin{array}{l}\text { section } 4-5 \mathrm{~km} \text { Southeast of Gudermes on the northern } \\
\text { slope of the Gudermes ridge }\end{array}$ \\
\hline 8 & Bragunsky site & $\begin{array}{l}4-5 \mathrm{~km} \text {. west of s. Braguns, on the northern slope of the } \\
\text { Bragun range }\end{array}$ \\
\hline
\end{tabular}

In these studies, the following tasks were solved:

- study of the geological structure of the site;

- the allocation in the context of tar packs, layers of "industrial" intervals;

- determination of the contour of productive intervals and assessment of their mining and geological conditions;

- determination of bitumen content and the nature of its change;

- clarification of the physico-chemical characteristics of bitumen-containing rocks and their interposition with the host rocks;

- a qualitative assessment of the mineral;

- determination of technological parameters and their compliance with the requirements for road construction.

The remaining sites were studied in less detail.

Grozny site. It is located on the northwestern outskirts of Grozny in the Mamakayevskaya beam (the Starogroznensky ridge is a spur of the Sunzhensky ridge). The size of the surveyed area is $1.1 \times 0.7 \mathrm{~km} 2$. Only part of the selected promising area measuring $100 \times 300 \mathrm{~m} 2$ was subjected to detailed examination.

The orographically studied site occupies the valley of the Mamakayevskaya beam, which has sides 30-40 m high, composed of sandstone layers. By age, sandstones belong to the Sarmatian and Karagansk layers. Overlap loams of Quaternary age, low power.

The mineral is confined to the Karagansky bituminous sandstones, which form an anticlinal fold, the core of which is opened by the Mamakayevsky beam incision.

Sandstones are heterogeneous, with a predominance of fine-grained and silty differences of massive texture, gray to black, depending on the intensity of bitumen saturation. In the absence of bitumen, sandstones are light gray to white in color with a slight yellowish tint. Visually, the bituminous intensity is heterogeneous, and it was not possible to establish any regularities in its distribution.

Productive sandstones are overlain by weak interbedded clays and marls of the Sarmatian stage, which reach up to $30 \mathrm{~m}$ in thickness to the north and south from the outcrops of the studied layers at a distance of 50-60 m.The Grozny site was studied by routes and five clearing, of which 65 laboratory and 1 laboratory and technological samples were selected. (Table 1.)

The table shows an extremely uneven distribution of bituminousness in the Grozny manifestation - from a practical absence to a high content. In general, according to the manifestation of bituminosity, sandstones and sands are characterized as having a low bitumen content.

According to the mineralogical composition, sands are essentially quartz; the silica content in them varies from $96.14 \%$ to $98.01 \%$.

Based on the ratio between water saturation and strength of water-saturated samples at $2000^{\circ} \mathrm{C}$, the optimum values of the amount of bitumen in the asphalt-concrete mixture were 
Table 1. Characterization of bituminous sandstones of the Grozny site.

\begin{tabular}{|c|c|c|c|c|c|}
\hline \multirow[b]{2}{*}{ № } & \multirow[b]{2}{*}{ № workings } & \multirow[b]{2}{*}{ Number of samples } & \multicolumn{3}{|c|}{ Bitumen content, $\%$} \\
\hline & & & from & to & from to weighted average \\
\hline 1 & Clearing 1 & 9 & 3,17 & 39,4 & 9,46 \\
\hline 2 & Clearing 2 & 17 & 0,19 & 3,66 & 1,61 \\
\hline 3 & Clearing 3 & 13 & 0,08 & 2,43 & 0,74 \\
\hline 4 & Clearing 4 & 11 & 0,89 & 3,08 & 2,15 \\
\hline 5 & Clearing 5 & 15 & 1,79 & 8,59 & 0,39 \\
\hline 6 & Manifestation & 65 & 0,08 & 39,4 & 2,95 \\
\hline 7 & Regulations & Not less $2 \%$ & & & \\
\hline
\end{tabular}

determined, which are 54\% for the sample. The knowledge of the manifestations allows us to classify reserves by $\mathrm{C} 2$.

The expected reserves of the Grozny manifestation with a deposit width of $100 \mathrm{~m}$, a length of $300 \mathrm{~m}$ and an optimal thickness of $6 \mathrm{~m}$ are: 100x300x6 $=180$ thousand $\mathrm{m} 3$.

Simsirsky site. Located $0.5 \mathrm{~km}$ north of the village of Sim-Sir Nozhai-Yurt district at the confluence of the rivers Yaryk-Su and Malaya Yaryk-Su. Erosion processes here formed an isolated isometric area, armored with a layer of tar sandstones. The size of the site is $500 \times 100$ $\mathrm{m} 2$. In geomorphological terms, it is an inclined plane in the northwest direction cut off from the north, west and east by a river cut.

Exceeding the maximum values of the site above the confluence of the rivers reaches $120 \mathrm{~m}$. The sides of the river valleys are gorges formed by cuts into sandstone packs.

The geological structure of the site is simple. It is composed of a rather powerful (up to $15 \mathrm{~m}$ ) pack of sandstones of the Chokrak stage, covered by an alluvial-deluvial cover of loam with detrital material and underlain by shaley argillite-like clays. The fall of bedrock (sandstones and shale clay) is measured in the north-western rumbas, the angle of incidence is 200 .

The mineral is represented by tar sandstone. Its thickness varies within $8-15 \mathrm{~m}$. The section of the sandstone layer from the roof to the bottom is presented in the following form:

- loose sandstone light gray to white - up to $4 \mathrm{~m}$,

- weakly bituminous banded sandstone - up to $4 \mathrm{~m}$,

- medium-bituminous banded sandstone - up to $6 \mathrm{~m}$,

- strongly bituminous banded sandstone - up to $2 \mathrm{~m}$.

Visually, the bituminous content of the rocks is uneven.

The upper part of the sandstones, especially in exposed areas, washed and sandstones become white with no signs of bitumen. Down the section of the sandstone formation, the degree of bituminousness increases, reaching its maximum at the bottom. (Table 2). Bitumen and crusts of bitumen are formed in this part, especially with the development of fracturing.

Table 2. Characterization of bituminous sandstones of Simsirsky site.

\begin{tabular}{llllll}
\hline & & \multicolumn{2}{l}{ Bitum contains, $\%$} \\
\cline { 5 - 5 } № & Clearings & Number of samples & from & to & average \\
\hline 1 & Clearing 20 & 10 & 0,91 & 6,57 & 4,39 \\
2 & Clearing 21 & 8 & 0,58 & 3,81 & 1,37 \\
3 & Clearing 23 & 12 & 3,72 & 6,61 & 4,82 \\
4 & Clearing 24 & 14 & 1,98 & 3,05 & 2,42 \\
5 & Clearing 25 & 13 & 2,28 & 6,05 & 4,60 \\
6 & Clearing 26 & 10 & 3,43 & 7,11 & 6,22 \\
7 & On site & 67 & 0,58 & 6,61 & 3,86 \\
8 & Regulations & Not least 2\% & & & \\
\hline
\end{tabular}


Table 3. Characteristics of bituminous sandstones of the Mahkendatten Cort.

\begin{tabular}{llllll}
\hline & & \multicolumn{2}{l}{ Bitum contains, \% } \\
\cline { 5 - 6 } № & Clearings & Number of samples & from & to & average \\
\hline 1 & Clearings 27 & 4 & 2,67 & 3,72 & 3,38 \\
2 & Clearings 28 & 5 & 0,01 & 4,30 & 2,41 \\
3 & Clearings 29 & 5 & 1,08 & 1,54 & 1,34 \\
4 & Clearings 30 & 5 & 0,72 & 2,01 & 1,59 \\
5 & Clearings 31 & 5 & 0,09 & 1,14 & 0,52 \\
6 & Clearings 32 & 5 & 0,83 & 1,43 & 1,18 \\
7 & Clearings 33 & 5 & 1,34 & 1,68 & 1,56 \\
8 & ON the site & 34 & 0,01 & 4,3 & 1,62 \\
9 & Regulations & Not least 2\% & & & \\
\hline
\end{tabular}

In hot weather, drops and streams of bitumen form on the surface of the rocks and a characteristic "asphalt" smell is felt at a considerable distance

It follows from the table that, as for individual intersections, and for the site as a whole, the distribution of bitumen saturation is heterogeneous and is classified from low contents (p. 21 , 24) to medium (p. 20,23,25,26), average bitumen content in the site characterized as low, close to average.

According to the grain size and size modulus, the sands are fine-grained, with a clear predominance of the 0.14 fraction.

By mineralogical composition - quartz sands, with silica content of 96, 34-98, 37\%.

The studied area has forecast reserves of categories $\mathrm{C} 2$ in accordance with the sizes $500 \times 100 \times 10 \mathrm{~m} 3-500$ thousand $\mathrm{m} 3$, i.e. the deposit is small.

Section Mahkendatten - Court. It is located $2.5 \mathrm{~km}$ east of the village of Bulgut - Irzu in Nozhai - Yurt district and is confined to a gentle hill with a mark of $1008.7 \mathrm{~m}$. On the northern and southern slopes, erosion processes in the form of a 10-15 meter ledge reveal tar sands of the Chokrak stage, which object of search work.

Judging by the elements of occurrence, two layers are recorded here, separated by a 10-15 meter pack of clay rocks. The bedding of the strata is north-western at angles of 200. An optimized section of sandstones, compiled from clearing, is presented as follows:

- uneven-grained sandstone - 1-4 m,

- fine-grained sandstone, silty - 4-7 m,

- uneven-grained sandstone - 7-11 m.

The observed bitumen saturation of the host rocks varies. More saturated rocks, exposed on the southern slope (clearing 28). In hot weather, a hydrocarbon consistency flows out of the formations, which is quite liquid and oily with the smell of oil.

The site is contoured along the perimeter by seven clearing sites (p. 27-33), of which 34 samples were taken. Bituminous rocks are characterized as follows (Table 3).

The table shows that this site is characterized by a fairly uniform, albeit low bitumen content.

The mineralogical composition of the sands is quartz, with a silica content of $97.28 \%$.

The Makhkendatten-Kort section has reserves of up to 325 thousand $\mathrm{m} 3$, in accordance with the dimensions $250 \times 130 \times 10 \mathrm{~m}$, which is characterized as a small field, in the presence of the likelihood of continuation of productive formations of the considered section along strike. Although the geomorphology of the region does not fully confirm these assumptions.

\section{CONCLUSION}

Thus, the available geological materials on the outputs of the bituminous sites allow us to say the following: all deposits promising for bituminousness are confined to two structural 
zones - the zone of the Advanced Ranges and the zone of the Montenegrin monocline. (Ganieva, Polovnyak, 2012)

The zone of advanced ranges (Tersky, Sunzhensky, Gudermes and Bragunsky) is represented by anticlinoria, folded brachiskladas of various orders and complicated by numerous fractures of the thrust nature. (Mitchin, 1992) The bedding here is mostly steep, productive horizons of bituminous rocks quickly "dive" under the deposits overlapping them. In this zone, the Grozny, Sernovodsky, Gudermes and Bragunsky sites were studied. In general, the zone of the Advanced Ranges should be classified as unpromising for the identification of deposits of bituminous rocks. (Zaurbekov, Mintsaev, Cherkasov, Labazanov M.M., Shaipov,Damzaev, 2015)

The zone of the Montenegrin monocline is composed of monoclinically falling to the north at angles of 20-400 rock strata, including bituminous. Theoretically, in this zone it is possible to identify deposits of bituminous rocks.

Within the Montenegrin monocline, the sections Simsirsky, Mahkendatten-Kort, BugatIrzu, Kuren-Benoi were studied. Only the Simsirsktä and Mahkendatten-Kort sections have certain prospects.

\section{REFERENCES}

Ganieva T.F., Polovnyak V.K. 2012 High viscosity oils, natural bitumen and bituminous rocks. Kazan: Kazan National Research Technological University

Kerimov I.A., Daukaev A.N. 2003 Minerals of the Chechen Republic. Terrible: GGNI

Khasanov M.A., Shaipov A.A., Zaurbekov Sh.Sh. 2010 Geology and oil and gas bearing Phanerozia of the Eastern Ciscaucasia. Terrible: GSTU named after Acad. M.D. Millionschikova; Stavropol: SevKavSTU; Service School

Mitchin A.D. 1992 Report on the results of prospecting for tar sands in the Chechen Republic. The terrible

Orel V.E., Raspopov Yu.V., Skripkin A.P. 2001 Geology and oil and gas potential of the Ciscaucasia. Moscow: GEOS

Zaurbekov Sh. Sh., Mintsaev M.Sh., Cherkasov S.V., Labazanov M.M., Shaipov A.A., Damzaev Z.M. E. 2015. Prospects for oil and gas potential and further areas of geological exploration within the Tersko-Sunzhenskoye oil and gas region. Moscow. Territory Neftegaz. 


\title{
The method of multivariate geological modeling and wells correlation of pashiysky horizon
}

\author{
M.G. Ayrapetyan \\ Postgraduate student, St. Petersburg mining University, St. Petersburg, Russia
}

\author{
A.A. Farukshin \\ Postgraduate student, St. Petersburg mining University, St. Petersburg, Russia \\ Y.V. Nefedov \\ PhD, Associate professor, St. Petersburg mining University, St. Petersburg, Russia
}

\begin{abstract}
This article describes the method of multivariate calculation of geological uncertainties and the first stage of the geological model construction - well correlation of the pashiysky horizon of Novosergievsky and Perevolotsky districts of the Orenburg region in the domestic tNavigator software product of RockFlowDynamics. This technique allows to construct geological models of the pashiysky horizon on variants P10 (optimistic), P50 (realistic), P90 (pessimistic), thereby to estimate risks and to carry out quality control of geological model. This method is used to construct structural maps of the roof and bottom of the pashiysky horizon.
\end{abstract}

\section{INTRODUCTION}

Against the background of the decrease in recoverable oil reserves of large deposits in the world and in Russia, the intensification of hydrocarbon production at current assets is a very urgent problem. One of the forced approaches to increase the production of hydrocarbons is the involvement in the development of small reserves and complex formations. A characteristic feature of field development in the oil and gas industry is the emphasis on the main object of development, while secondary layers may actually be no less profitable. Insufficient attention to secondary objects of development of oil and gas fields today is a challenge for oil and gas companies not only in Russia but also around the world.

One of such perspective layers is the pashiysky horizon of the Orenburg region. In the fields of the territory of Novosergievsky and Perevolotsky districts, the pashiysky horizon is a secondary potential object of development with a rather complex geological structure.

The problem of the object of research is the insufficiency of studying the formation, complex facies and tectonic structure, which leads to the impossibility of in-depth analysis of the filtration-capacitive properties of the horizon and its oil and gas potential. The interest to the object is caused by single wells producing oil from the pashiysky horizon, which indicates the confirmed oil and gas potential of the reservoir in the studied area. Thus, the identification of inhomogeneities and patterns of distribution of the filtration-capacitive properties of the pashiysky horizon will help to increase the understanding of the structure and geometry of the formation for further development.

This problem can be solved most rationally by methods of geological and hydrodynamic modeling on the basis of a detailed study of the regularities of the structure and properties of the formation. On the basis of data of geophysical researches of wells, their interpretation, core material, and also data on development it is possible to construct conceptual facies, structural and, as a result, geological model of a layer, as much as possible reflecting actual 
distribution of properties in a reservoir. And the first stage of the formation study is one of the tasks of this article - well correlation of the formation.

The second important task of the current article is the technique of multivariate modeling. The geologist's ideas about the geological structure of a deposit or formation are never exhaustive. Further decisions on field development depend on the reliability of the geological model. Due to the large number of uncertainties, the simulation will take place in a multivariate mode. In other words, each parameter or property of the formation and fluid will vary within certain boundaries already accepted by core studies and other data. At the final stage, this will determine the most likely model to make a decision and recommendations on drilling, geological and technical measures and production.

\section{WELL-TO-WELL CORRELATION}

In terms of petroleum Geology, the study area belongs to the East Orenburg oil and gas bearing area, which corresponds to the East Orenburg uplift in tectonic terms. The industrial oilbearing capacity of the area is associated with deposits of the pashiysky horizon, the Kolgan strata and the Tournai tier.

The Geology of Orenburg and the Orenburg region (Figure 1) includes sedimentary formations of the upper Proterozoic, Paleozoic and Mesozoic, which lie on igneous and metamorphic deposits of the Archean-early Proterozoic crystalline basement (Figure 2).

In the studied area, the main object of development is the Kolgan strata. However, a considerable number of vertical and directional wells opened pashiysky horizon (Figure 3)

Well-to-well correlation was carried out in the following stages (Figure 4, Figure 5):

1. The choice of the reference line, i.e., the reference horizon which can be traced in all the wells.

2. Selection of the reference section, that is, the most representative section, on which all reference layers are clearly well distinguished, sufficient power of the section is presented, a full complex of GIS is performed.

3. Comparison of well sections with reference section.

4. Well-to-well correlation according to different correlation schemes.

Well descriptions and core photos are attached to wells in the software simulator (Figure 6).

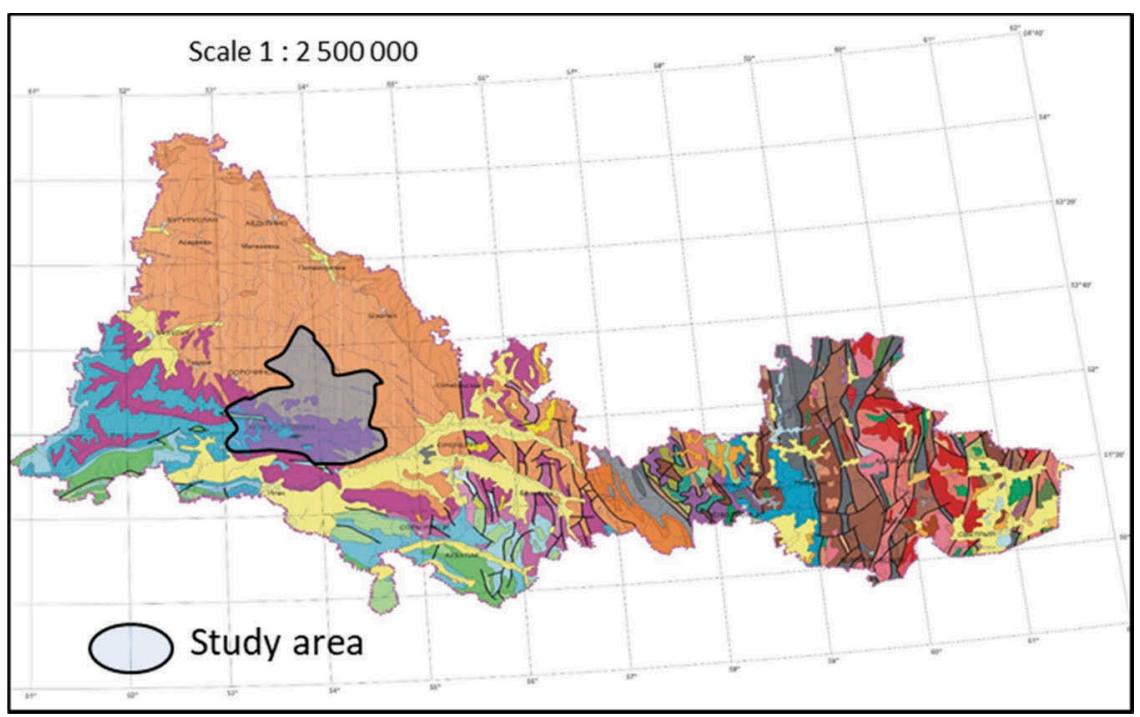

Figure 1. Map of pre-Quaternary formations of Orenburg region. 


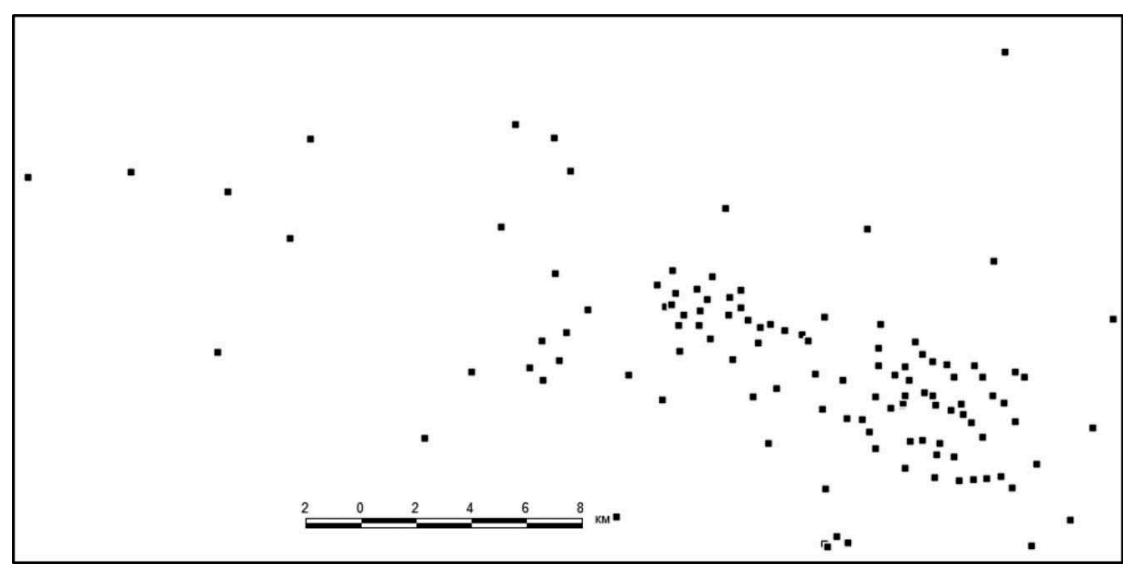

Figure 2. Wells, opening the main object of development in the study area.

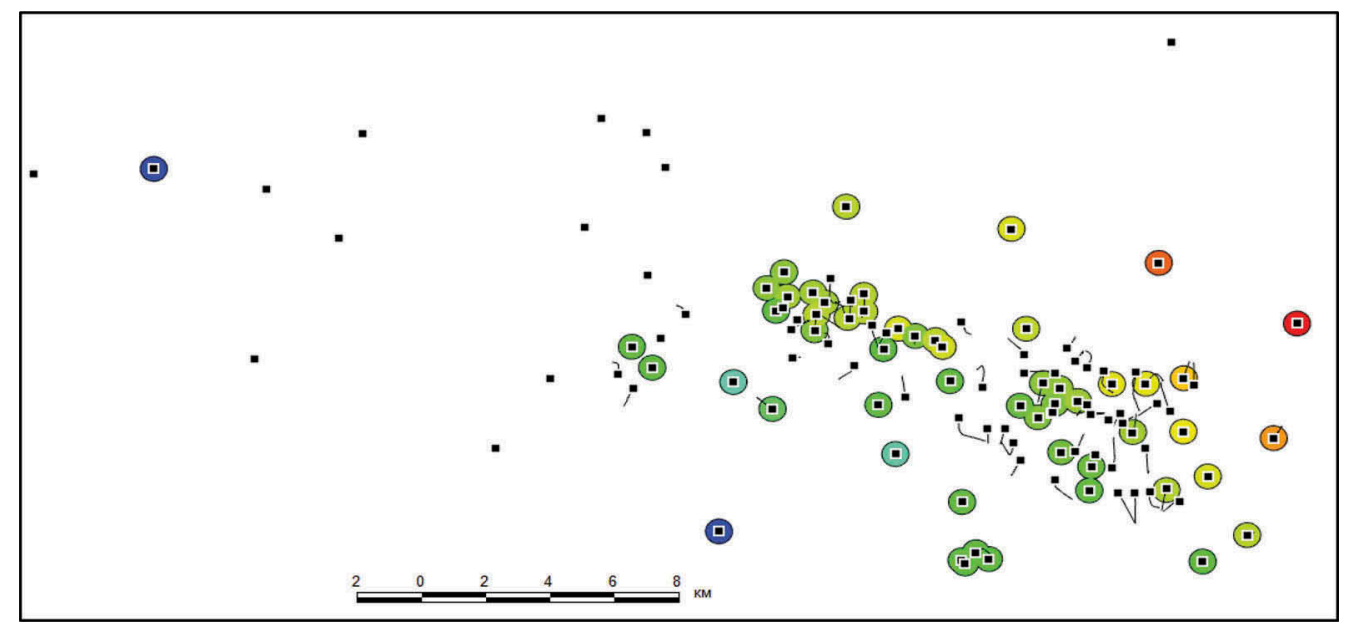

Figure 3. Wells that opened the roof of the pashiysky horizon.

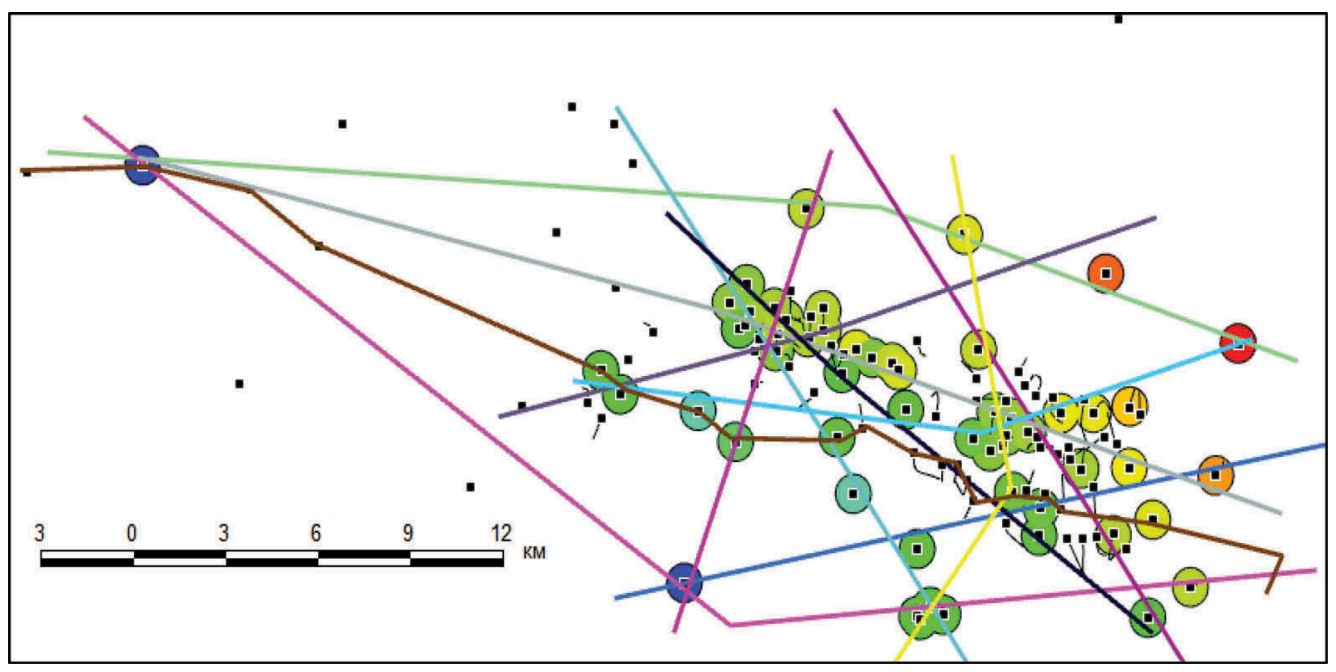

Figure 4. Correlation schemes. 


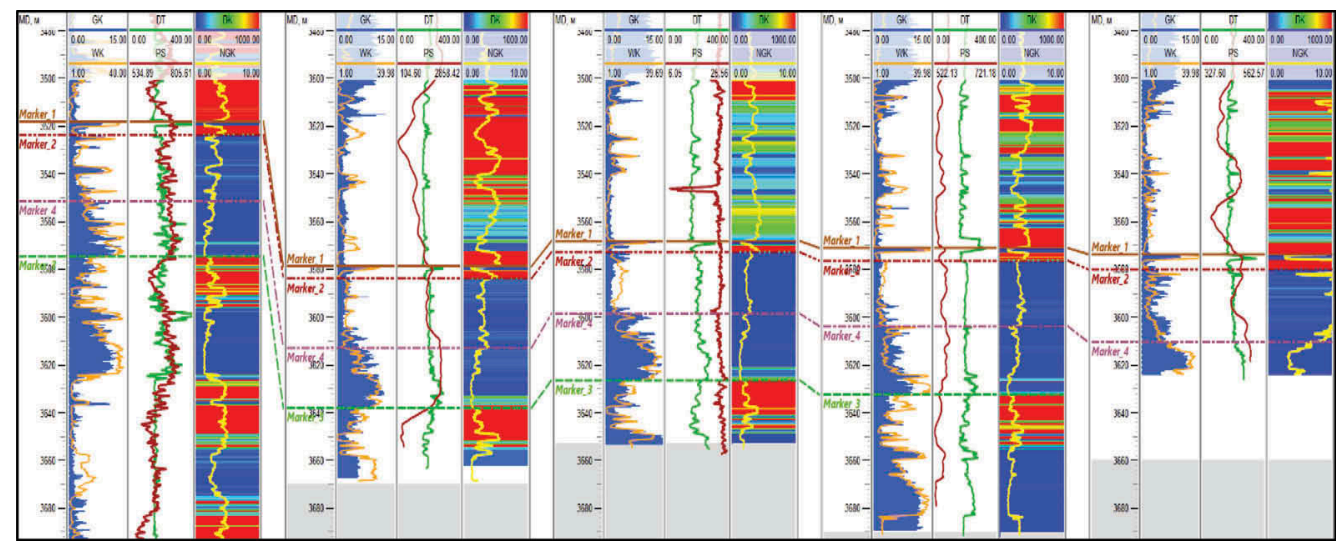

Figure 5. The correlation of the wells penetrated pashiysky horizon.

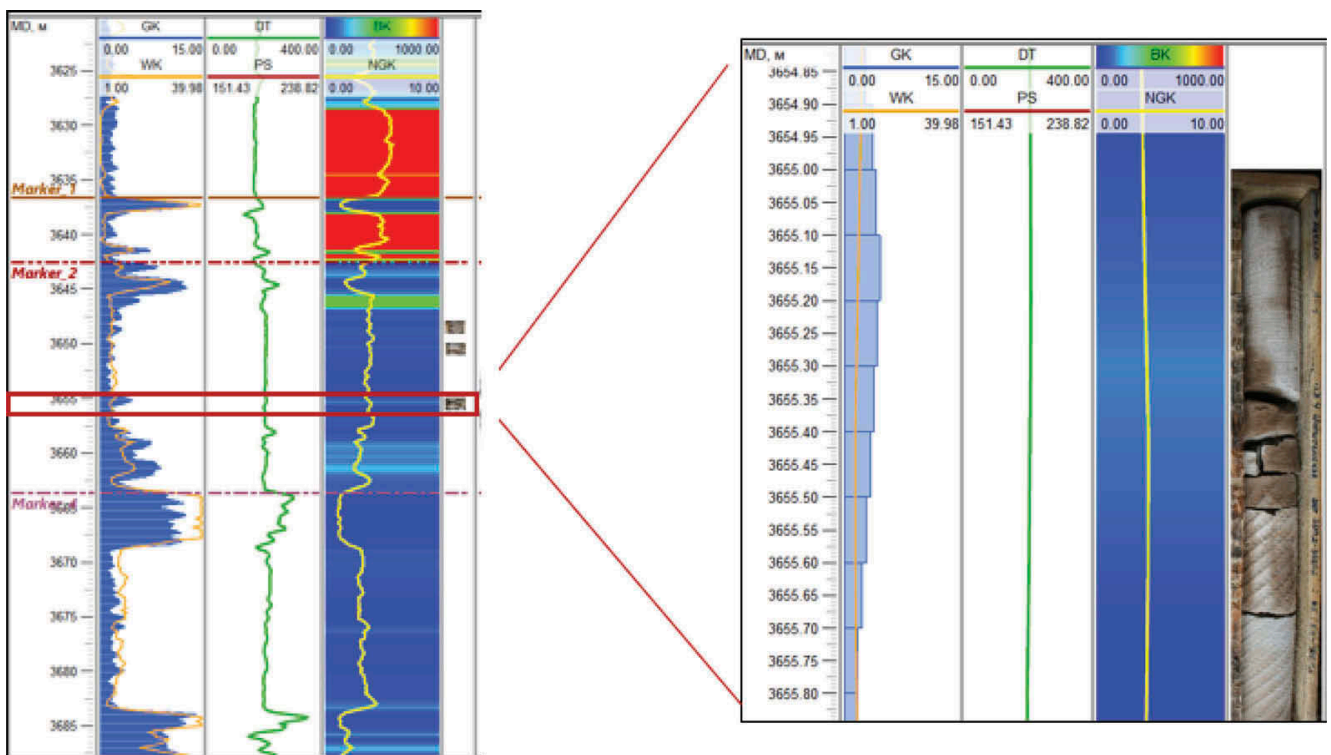

Figure 6. Snap photos and description of the core in the correlation scheme.

The peculiarity of the correlation of the pashiysky horizon was the inhomogeneous structure, which often causes difficulties when comparing well-logs curves. The lack of well data has become the reason for the interpolation of a formation over long distances. The pashiysky horizon is relatively constant in power in the area under study.

The pashiysky horizon is composed of fine - and fine-grained siltstone sandstones, with thin layers of siltstone and mudstone.

Reservoir rocks are sandstones light gray, light gray with a brownish tinge, quartz, porous, strong and medium strength, massive, lenticular-indistinctly layered, obliquely layered texture areas.

Dense clay sandstones, siltstones gray, dark gray, indistinctly layered, lenticular-layered and mudstones dark gray, thinly layered are common in the inefficient part of the formation.

The seal rock is a pack of mudstones of the roof part of the horizon, dark gray, dense, calcareous, with an uneven admixture of sand-silt material, thin-layered. 


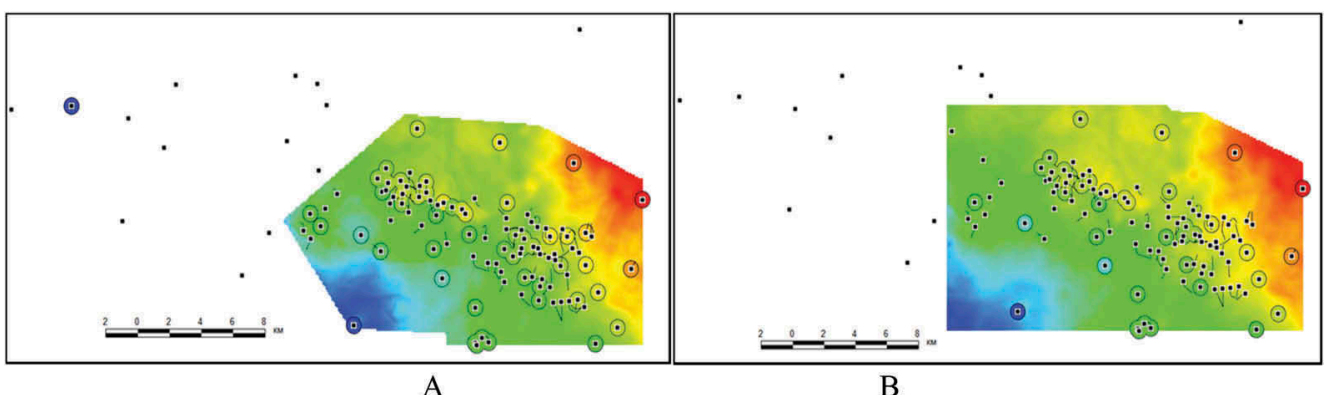

Figure 7. Map of the roof (A) and bottom (B) of the pashiysky horizon.

The deposits of the pashiysky horizon were formed in the conditions of the sea coast with mixed wave and river activity.

\section{MULTIVARIATE MODELING TECHNIQUE}

The technique of multivariate geological modeling is to vary the parameters and properties of the reservoir and fluid, in which there is no absolute value or there are doubts about their reliability. As a rule, dependencies and studies that are obtained in the process of processing the initial data, give a cloud of values and a significant spread with some trend.

As practice shows, deterministic methods of geological modeling give a figure of reserves, which can change during the development and updating of geological information.

The most important source of uncertainty in the construction of a geological model is the ambiguity of structural simulations.

Stages of multivariate modeling:

1. Estimation of the most probable depths of structural horizons in the inter-well space. The definition of the standard deviation of the depth.

2. Construction of structural horizons of the roof and the sole of the formation in the model.

3. Determination of lithological and genetic types of rocks and probability of distribution of sedimentary body morphology.

4. Filling of the structural framework with lithotypes based on borehole data, given forms of sedimentary body and probabilities of its size.

5. Reservoir filling with petrophysical properties based on probabilistic estimates of rock properties variability.

6. Calculation of hydrocarbon reserves by volumetric method for all possible variants of the geological model.

7. Choice of options P10 (optimistic), P50 (realistic), P90 (pessimistic)

Multivariate structural maps of the roof and sole of the formation were constructed on the basis of this technique and the correlation of the pashiysky horizon. Below are maps of the sole and roof of the pashiysky horizon according to the P50 variant (Figure 7).

\section{CONCLUSION}

As a result, the following conclusions were obtained:

- Correlation of the pashiysky horizon was carried out

- Snap photos and description of the core to the wells.

- Defines the uncertainty in the spacing layers

- The technique of multivariate geological modeling is proposed

- Maps of the roof and sole layers are constructed. 
It is important to use the multivariate approach in geological modeling, when a large amount of information is approximated.

The work showed an approach at the well correlation level. However, this approach is expected to be used at all stages of oil and gas field development.

\section{REFERENCES}

Ababkov K. V. (2010). Fundamentals of three-dimensional digital geological modeling. Ufa: "Oil and Gas business".

Bulgakov S. A. Investigation of layers of the pashiysky horizon by probabilistic-statistical Express method. Samara state technical University. "Oil and gas business" - Samara, 2011, 75 p.

Dudchenko, O.L., Fedorov, G.B., Andreev, A.A. (2018). Innovative method for the classification of coal slurries. "Ugol".

Gospodarikov, A.P., Zatsepin, M.A. (2019). Mathematical modeling of boundary problems in geomechanics. "Gornyi Zhurnal".

Gutman I. S., Balaban I. Yu., Isyangulova N. R., Potemkin G. N., et al. Modeling of complex oil and gas objects on the basis of detailed correlation of well sections in automatic and interactive modes// Neft. Gas.Innovations, No. 12, 2014. - Pp. 16-23.

Gutman I. S., Kuznetsova G. P. Classification of correlation of geological sections of wells in connection with the degree of study of oil and gas objects. Features of performance of comparison of geological sections of wells with use of the latest computer technologies. - Moscow: Gubkin Russian state University of oil and gas, 2006.

Zakrevsky K. E. (2009). Geological 3D modeling. Moscow: LLC CPI Mask.

Losheva Z. A., Magdeev M. sh., Agafonov S. G., Fedotov M. V., Magdeeva O. V. a New look at the geological structure of the pashiysky horizon (D3ps) of the Aznakaevskaya area of the Romashkinskoye oil field. Georesources. 2017. T.19. No. 1. Pp. 21-26.

Lyadsky P. V., Kvasnyuk L. N., Zhdanov A.V., Chechulina O. V. and others. State geological map of the Russian Federation. Scale 1:1,000,000 (third generation). A Series Of The Ural. Sheet M-40 (Orenburg) with valve M-41. Explanatory note. - SPb.: Map factory VSEGEI, 2013. 392 p. +1 incl.

Potemkin G. N. Features of geological structure and optimization of development of oil and gas potential of Devonian terrigenous deposits of the southern part of the Volga-Ural oil and gas province. Moscow: Gubkin Russian state University of oil and gas, 2016. - 137 c.

Prischepa, O., Nefedov, Y., Grokhotov, E. Geochemical and petrophysical studies of hydrocarbon potential of domanic shale formation (Timan-Pechora petroleum Province) EAGE/SPE Workshop on Shale Science 2019 - Shale Sciences: Theory and Practice DOI: 10.3997/2214-4609.201900475 ISBN: 978-946282281-8

Sinitsyn I. M., Sinitsyna G. I. State geological map of the Russian Federation. Scale 1: 200000. Series The Middle. Sheet O-40-XXXII (kuyeda). Explanatory note. - Moscow: Moscow branch of fsbi "VSEGEI", 2017. 81 PP.

Technical guide simulator "tnavigator". (2017). The Company "Rock Flow Dynamics". Moscow. 


\title{
Geological and economic assessment of resources of oil field of the West-Siberian oil and gas province
}

\author{
A.Kh. Ibatullin \\ Postgraduate student, Saint-Petersburg Mining University, Saint-Petersburg, Russia
}

A.M. Zharkov

Doctor of geological and mineralogical Sciences, Saint-Petersburg Mining University, Saint-Petersburg, Russia

O.E. Kochneva

PhD in Geology and Mineralogy, Associate Professor, Saint-Petersburg Mining University, Saint-

Petersburg, Russia

\begin{abstract}
The presence of a geological structure partially determines the formation of the field. In addition, experts need to analyze other parameters that affect the accumulation of hydrocarbons in prospective traps. In this article a feasibility study of geological exploration of West-Siberian deposit was carried out, within which structural maps were built for 24 layers and the profitability of the proposed project was estimated. This article describes different methods (geological and economic) of identifying prospective oil and gas zones and deciding whether to involve the territory in the geological study project.
\end{abstract}

\section{INTRODUCTION}

The oil field is geographically located in the Yamalo-Nenets Autonomous District of the Tyumen Region. In the northeast corner of the license area, structures are identified that could potentially contain hydrocarbon fields. Based on the calculation of the resource potential and the analysis of geological risks, an appraisal was made of the feasibility of prospecting work, a tree of scenarios was built, and an analysis of VOI (value of information) was executed.

Tasks:

1. Construction of 1D-2D geological model, which will be used to evaluate and analyze information;

2. Answer the question about the need for geological prospecting;

3. Assess the resources of field;

4. Assess the appropriateness of conducting geological prospecting in the north-eastern section.

\section{CHOICE OF RESEARCH FACILITIES}

The first stage of the study is the determination of reservoirs. Of the 31 strata of the Cretaceous age, available on the territory of the field, 24 are selected. They are presented in Table 1. The criterion for the selection of strata is a change in isohypses to lower depths in the northeastern part, which leads to the presence of promising positive dome-shaped structures. The main factor in the study of this area was the location of the tectonic structure of 
Table 1. Reservoirs with promising structures in the north-eastern part of the field.

\begin{tabular}{llll}
\hline & \multicolumn{2}{l}{ Age of collectors } & \\
\cline { 2 - 4 } № & Sukhududinskaya suite & Malohetskaya suite & Pokurskaya suite \\
\hline 1 & BU6-3 & MH1 & PC1-3 \\
2 & BU7 & MH3 & PC12-1 \\
3 & BU8 & MH4 & PC15 \\
4 & BU9 & MH5 & PC19 \\
5 & BU10-1 & MH71 & PC20-1 \\
6 & BU10-2 & MH8-9 & PC20-2 \\
7 & BU11-1 & & PC21-1 \\
8 & BU12-2 & & PC21-2 \\
9 & & & PC22-1 \\
10 & & & PC22-2 \\
\hline
\end{tabular}

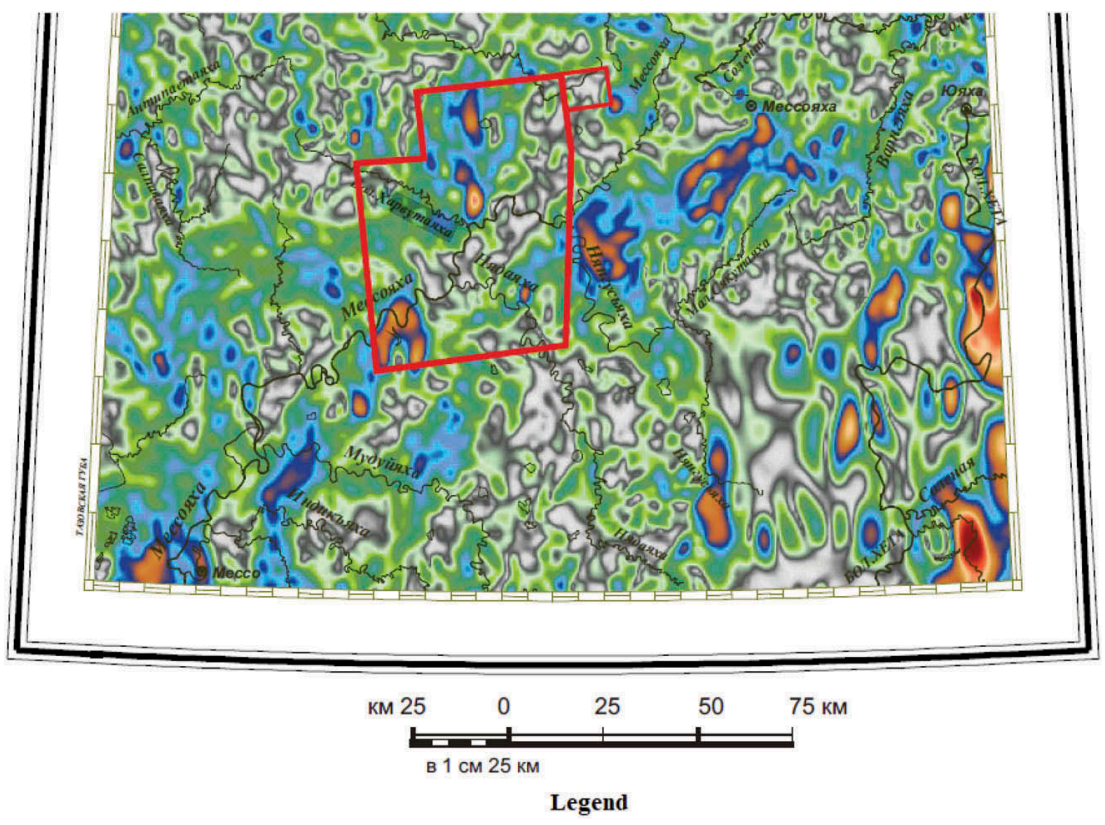

The scale of module full horizontal gradient of gravitional field (E)

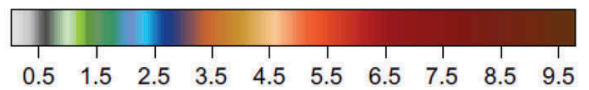

Figure 1. Fragment of map of full horizontal gradient module of gravitational field (Egorov T.N.).

the 3rd order (Figure 2) at the Ust-Port megaswell, adjacent to the Messoyakha megaswell (Egorov et al, 2016). Confirmation of the presence of hydrocarbons at the object of interest is a map of the module of the full horizontal gradient of the gravitational field (Figure 1), which shows abnormally low values in the north-eastern part of the field. When comparing detailed gravitational anomalies constructed from high-precision gravimetric measurements in oil and gas fields, it was found that oil and gas fields are displayed with relatively negative anomalies. 


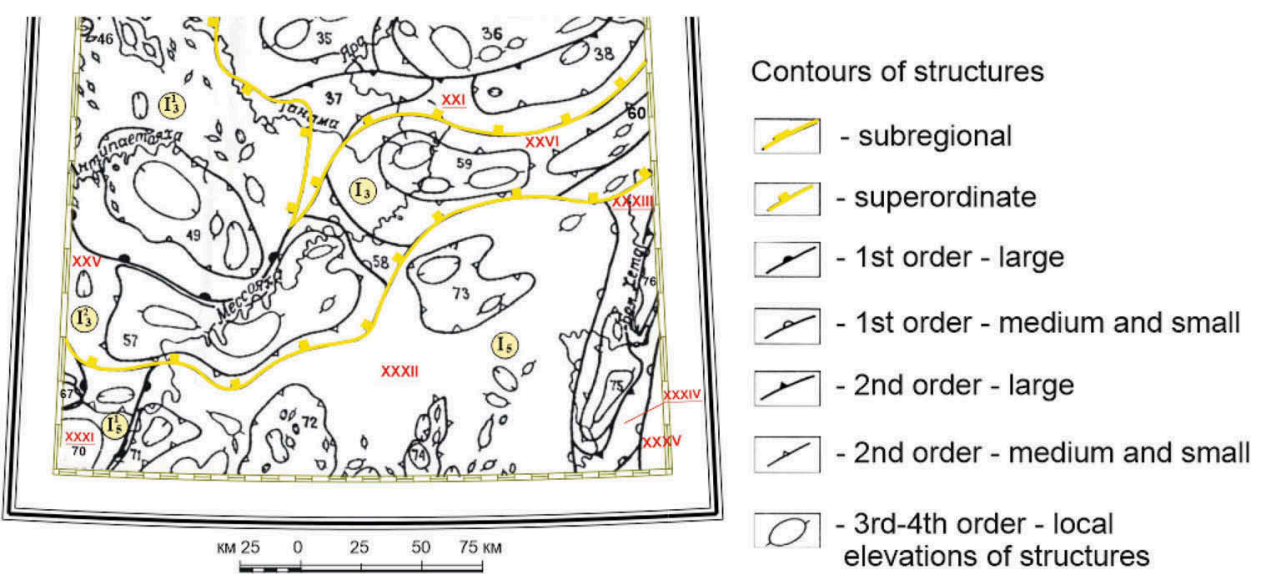

Figure 2. Fragment of tectonic map. $\mathrm{I}_{3}-$ Messoyakh-Antipayutin zone of liner structure; $\mathrm{I}_{3}^{2}-$ Messoyakha Belt magavals.

\section{CALCULATION AND SELECTION GEOLOGICAL PARAMETERS OF OBJECTS}

After selecting the reservoirs of interest, resources were calculated and the geometrical parameters of the fields were specified. As noted earlier, there are no seismic and borehole data outside the licensed area, which significantly complicates further calculations (Prishepa \& Nefedov, 2018; Cherepovitsyn et al, 2018). Using bicubic extrapolation, in Schlumberger Petrel software, structural maps were plotted for all collectors in the area of interest. Bicubic extrapolation is a method of calculating a parameter from two others beyond the area of available data (Gospodarikov \& Zatsepin, 2019). From a geological point of view, this means determining depths from coordinates outside the licensed area. The result was the allocation of 24 traps outside the license area, which are located on the area of $12.5 \mathrm{~km} \times 10 \mathrm{~km}$.

As a result, the geometrical parameters of promising traps were obtained, which are presented in Table 2 with the geological volumes of the traps.

\section{EVALUATION OF INITIAL RECOVERABLE RESOURCES}

Monte-Carlo simulation is a random selection method. The algorithm consists in selecting values from the indicated intervals, substituting them in the necessary formula. The advantage of this method is that it can be used by Microsoft Excel.

Initially, distribution type for each parameter should be specified. Two types of distribution were used in the work:

1. Uniform (GRV, NTG, density, conversion factor, oil recovery factor);

2. Normal (Kporo, Ko).

As a result of work, 8000 realizations were generated for each parameter and 1,344,000 values were obtained at the output. The parameters were taken according to the data of wells drilled at the field earlier (Table 4). The calculation of resources was carried out by the volumetric method according to the formula (1) (Gutman \& Sahakyan, 2017, Nedosekin et al, 2019):

$$
Q=G R V \times N T G \times \text { Kporo } \times K o \times \rho \times \theta \times O R F
$$

where GRV - gross rock volume; NTG - net to gross; Kporo - porosity factor; Ko - oil saturation factor; $\rho$ - density; $\Theta$ - the recalculation factor; ORF - oil recovery factor. Using 
Table 2. Geometric parameters of perspective traps.

\begin{tabular}{lll}
\hline & Gross rock volume & \\
\cline { 2 - 3 } Horizon & Max $\left(\right.$ P10), thous. $\mathrm{m}^{3}$ & Min $(\mathrm{P} 90)$, thous. $\mathrm{m}^{3}$ \\
\hline BU12-2 & 406887.000 & 2202.130 \\
BU11-1 & 398479.000 & 91846.400 \\
BU10-2 & 422400.000 & 18160.800 \\
BU10-1 & 423940.000 & 2643.580 \\
BU9 & 442589.000 & 25475.300 \\
BU8 & 289241.000 & 3510.220 \\
BU7 & 333590.000 & 1329.390 \\
BU6-3 & 392238.000 & 1994.120 \\
MH8-9 & 415825.000 & 18481.500 \\
MH7-1 & 82445.000 & 42239.000 \\
MH5 & 96548.000 & 151.769 \\
MH4 & 119869.000 & 22137.200 \\
MH3 & 168850.000 & 47274.400 \\
MH1 & 288077.000 & 26938.200 \\
PC22-2 & 262542.000 & 88.335 \\
PC22-1 & 305907.000 & 46030.300 \\
PC21-2 & 192563.000 & 4930.790 \\
PC21-1 & 160561.000 & 3417.710 \\
PC20-2 & 118530.000 & 891.833 \\
PC20-1 & 124591.000 & 42.546 \\
PC19 & 91821.800 & 738.545 \\
PC15 & 129476.000 & 4613.470 \\
PC12-1 & 139719.000 & 13031.400 \\
PC1-3 & 930820.000 & 4651.910 \\
\hline & & \\
\hline & & \\
\hline & & \\
MC &
\end{tabular}

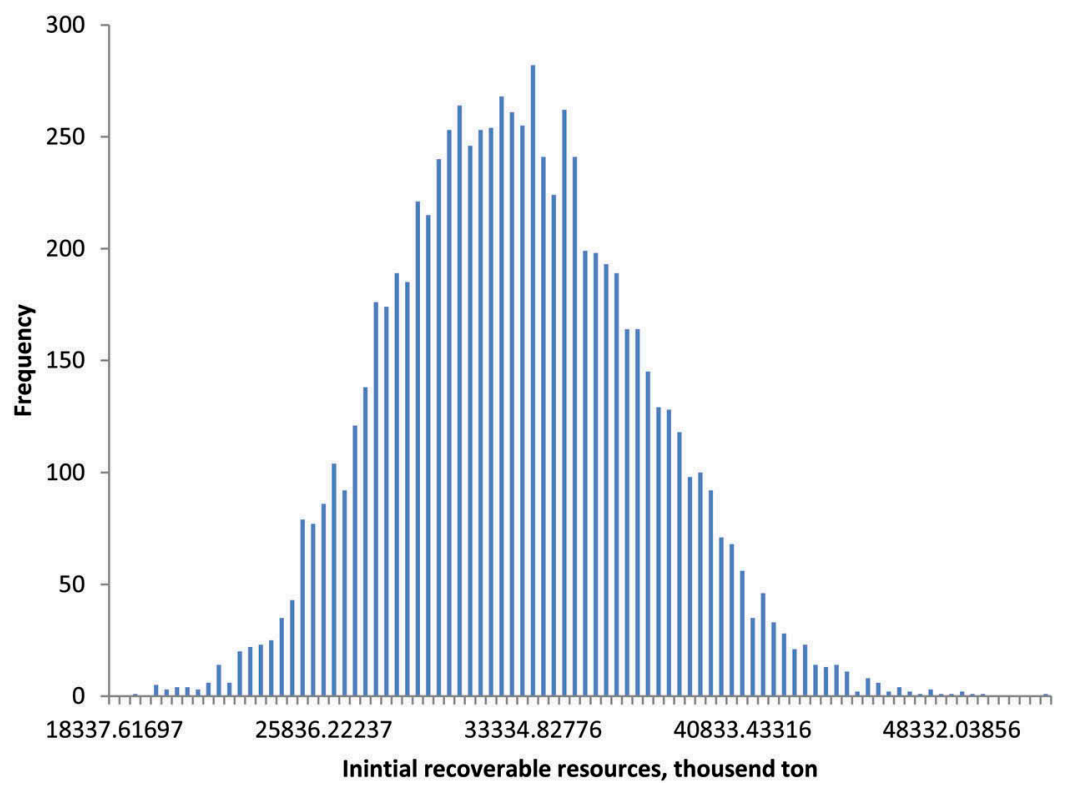

Figure 3. The distribution of resources in the north-eastern part of field No. 1 constructed by Monte-Carlo method. 
Table 3. Initial recoverable resources calculated by the Monte Carlo method.

\begin{tabular}{ll}
\hline Probability & Resources, million tons \\
\hline P90 & 26,97 \\
P50 & 32,42 \\
P10 & 38,29 \\
\hline
\end{tabular}

the Monte-Carlo method, we obtained the normal distribution of resources (Figure 3) calculated in Microsoft Excel and the volumes of initial recoverable resources presented in Table 3.

Additionally, the calculation was performed in the Oracle Crystal Ball software package, which allows to process large amounts of data than the mathematical apparatus of Microsoft Excel al-lows. The methodology for selecting a random distribution is similar to that described above. A feature of the Oracle Crystal Ball software package is that it allows to perform more than 40,000 realization at a time. At the end of the calculation, the distributions of the initial recoverable re-sources were obtained (Figure 4), descriptive statistics (Table 5) and the values of probable re-sources (Table 6).

Analysis of the obtained values of probable resources and descriptive distribution statistics showed similar calculation results, which indicates the reliability of the work performed. The result is also confirmed by the sensitivity value, in which the main contribution to the distribution is made by the values of the geological volume of the rocks $(75.9 \%)$.

\section{DETERMINING THE PROBABILITY OF GEOLOGICAL SUCCESS}

Geological Chance of Success (gCos, probability of geological success) - the probability which the discovery of an oil field will occur, estimated taking into account all existing uncertainties (Glebov, 2016).

This parameter is directly related to conditions for formation of hydrocarbon fields. The main probabilities reflect the result of a particular type of process, which form an accumulation of oil and gas in the reservoir (Shatrov, 2015). Depending on the method, the number of variables can vary from 4 to 6 (Gorbovskaya, 2017). In this work, five parameters were used that reflect the entire process of formation of the field and take into account the necessary conditions for this: Formation of the oil source reservoir (Posr); Migration of hydrocarbons $(\mathrm{Pm})$; The presence of a collector for the accumulation of hydrocarbons (Pc); The presence of traps (Pt); Safety (Ps).

The total probability of occurrence of independent events is equal to their product (2):

$$
g \operatorname{Cos}=\operatorname{Pos} r \times \mathrm{P} m \times \mathrm{P} c \times \mathrm{P} t \times \mathrm{P} s
$$

Probabilities of geological success for each formation are given in Table 7.

\section{BUILDING A DECISION TREE}

The decision tree is a graphical method of information analysis that displays the process of taking managerial decisions in the form of a set of sequential alternative actions and the realization of scenarios characterized by the presence of risks and uncertainties, combinations of which, at given probabilities, lead to the achievement of goals (Figure 5).

After the construction of the Decision Tree, information value (VOI) was estimated including NPV and probability for each outcome (Alekseeva et al, 2019), as well as EMV for all branches separated by probable events (Efimov \& Tashlitskaya, 2013). NPV (Net Present Value): net present value of free cash flow (calculated by formula (3)): 


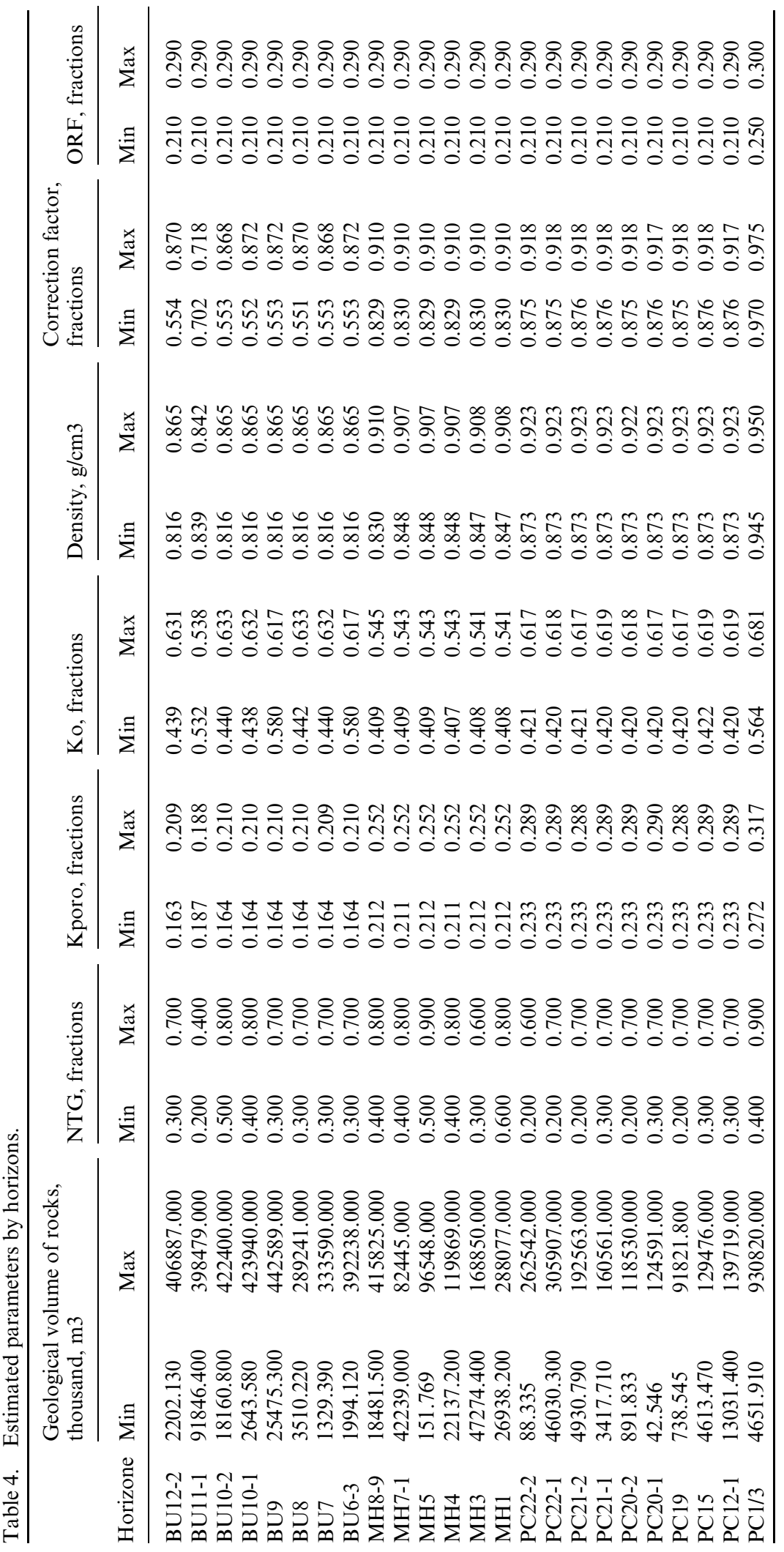




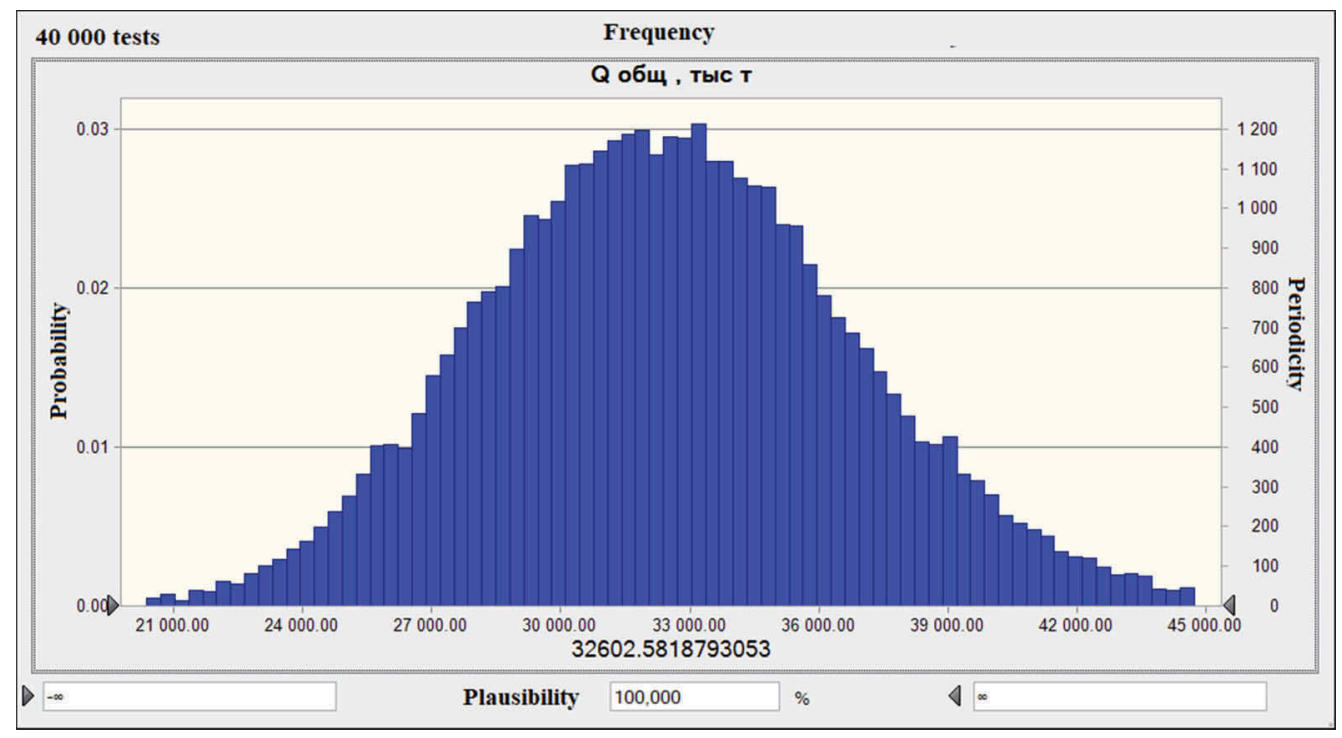

Figure 4. Calculation of the distribution of resources in the north-eastern part of field per-formed in the Oracle Crystal Ball software package.

Table 5. Descriptive statistics of resource allocation.

\begin{tabular}{ll}
\hline Statistics & Forecast values \\
\hline Test & 40000 \\
Base value & 32602,58 \\
Mean & 32550,68 \\
Average & 32439,68 \\
Standard deviation & 4342,53 \\
Discrepancy & 18857562,34 \\
Asymmetry ratio & 0,1797 \\
Excess ratio & 3,03 \\
Coefficient. Variations & 0,1334 \\
Minimum & 16195,62 \\
Maximum & 51952,11 \\
Average square error & 21,71 \\
\hline
\end{tabular}

$$
N P V=\text { Income }_{I}-\text { Consumption }_{I}
$$

EMV (Expected Monetary Value): expected cash value (calculated by formula (4)).

$$
E M V=\sum\left(N P V_{i} \times p_{i}\right)
$$

VOI (Value of Information): The value of Information (DI or VOI) is the increase or decrease in the value of an asset after acquiring information on its further study (Warren, 1983; Reidar, 2009; Whitney, 2010). The Value of Information is calculated by the formula (5):

$$
V O I=E M V_{1}-E M V_{2}
$$


Table 6. Probability resources.

\begin{tabular}{ll}
\hline Percentile & Forecast values, thousand tons \\
\hline P100 & 16195,62 \\
P90 & 27078,05 \\
P80 & 28860,11 \\
P70 & 30190,54 \\
P60 & 31338,40 \\
P50 & 32439,56 \\
P40 & 33521,78 \\
P30 & 34728,50 \\
P20 & 36133,22 \\
P10 & 38207,28 \\
P0 & 51952,11 \\
\hline
\end{tabular}

Table 7. Probability of geological success in studied formations.

\begin{tabular}{lllllll}
\hline Horizon & Oil & Migration & Collector & Trap & Safety & gCos \\
\hline PC1-3 & 1.00 & 1.00 & 0.64 & 0.4 & 0.7 & 0.182 \\
PC12-1 & 1.00 & 1.00 & 0.64 & 0.4 & 0.7 & 0.182 \\
PC15 & 1.00 & 1.00 & 0.65 & 0.4 & 0.68 & 0.178 \\
PC19 & 1.00 & 1.00 & 0.63 & 0.4 & 0.67 & 0.171 \\
PC20-1 & 1.00 & 1.00 & 0.67 & 0.4 & 0.71 & 0.19 \\
PC20-2 & 1.00 & 1.00 & 0.67 & 0.4 & 0.69 & 0.186 \\
PC21-1 & 1.00 & 1.00 & 0.65 & 0.4 & 0.68 & 0.178 \\
PC21-2 & 1.00 & 1.00 & 0.66 & 0.4 & 0.71 & 0.189 \\
PC22-1 & 1.00 & 1.00 & 0.63 & 0.4 & 0.69 & 0.174 \\
PC22-2 & 1.00 & 1.00 & 0.64 & 0.4 & 0.72 & 0.182 \\
MH1 & 1.00 & 1.00 & 0.66 & 0.4 & 0.71 & 0.186 \\
MH3 & 1.00 & 1.00 & 0.64 & 0.4 & 0.71 & 0.181 \\
MH4 & 1.00 & 1.00 & 0.68 & 0.4 & 0.7 & 0.191 \\
MH5 & 1.00 & 1.00 & 0.67 & 0.4 & 0.69 & 0.185 \\
MH7-1 & 1.00 & 1.00 & 0.66 & 0.4 & 0.7 & 0.185 \\
MH8-9 & 1.00 & 1.00 & 0.65 & 0.4 & 0.69 & 0.18 \\
BU6-3 & 1.00 & 1.00 & 0.64 & 0.4 & 0.69 & 0.18 \\
BU7 & 1.00 & 1.00 & 0.66 & 0.4 & 0.69 & 0.184 \\
BU8 & 1.00 & 1.00 & 0.65 & 0.4 & 0.71 & 0.185 \\
BU9 & 1.00 & 1.00 & 0.63 & 0.4 & 0.69 & 0.177 \\
BU10-1 & 1.00 & 1.00 & 0.64 & 0.4 & 0.69 & 0.175 \\
BU10-2 & 1.00 & 1.00 & 0.65 & 0.4 & 0.69 & 0.181 \\
BU11-1 & 1.00 & 1.00 & 0.66 & 0.4 & 0.71 & 0.189 \\
BU12-2 & 1.00 & 1.00 & 0.64 & 0.4 & 0.68 & 0.173 \\
\hline
\end{tabular}

Having analyzed the "Decision Tree", three values of EMV were calculated:

- In the case of the purchase of area (EMV1 $=9.989$ billion rubles)

- In the case of leasing of medical facilities and carrying out of construction and installation works (EMV2 $=9.934$ billion rubles)

- In the case of a leased asset rental without carrying out of construction works (EMV3 = 4.219 billion rubles)

Next, an EMV must be selected, which will be used to evaluate the value of the information. Priorities for further evaluation are EMV2 and EMV3. Since EMV2> EMV1, it is able to provide greater risk reduction.

VOI = EMV2 - EMV3 = 9.934-4 4.219 = 5.714 billion rubles 


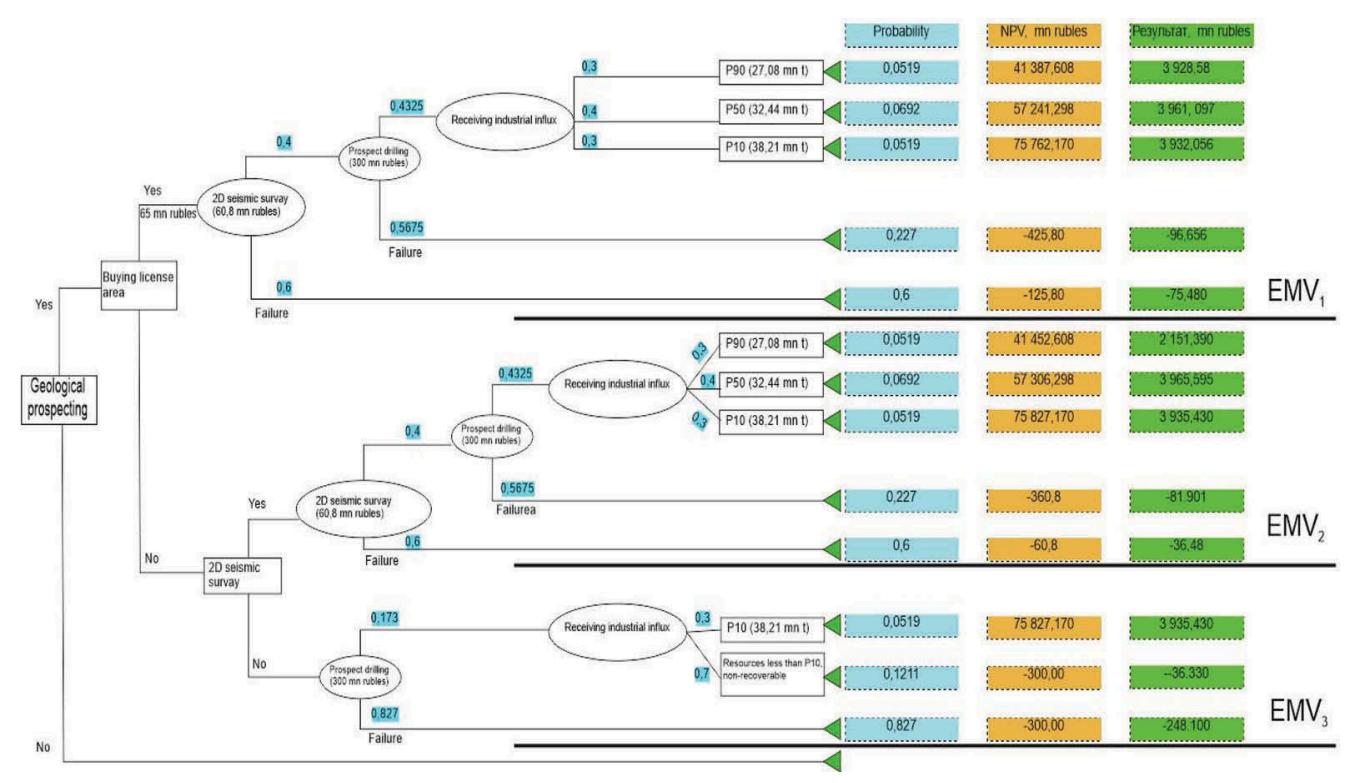

Figure 5. The decision tree.

A positive VOI determines the planning of a solution for $2 \mathrm{D}$ seismic survey and reduces our costs and risks when choosing this scenario by 5.714 billion rubles.

\section{DISCUSSION}

The described methodology for assessing resources allows to study the investigated object from two perspectives: geological and economic. The basis for this analysis is a geological model that defines all the factors and parameters designed to calculate resources and economic indicators. Calculation of the cost of information allows to assess the risks that are always present in the work of specialists. This technique is intended to help the geologist in choosing a priority object for further exploration and to assess risks and uncertainties in the study area. The relevance of the method lies in the fact that the specialist forms a decision on the work, which allows to explore the area with minimal cost and maximum profit.

\section{CONCLUSIONS}

A study of the available data on the area of the field was carried out, a 1D-2D geological model was built, a decision tree was built, an assessment and analysis of the value of information was performed. A feasibility study has been drawn up for geological prospecting. Design solutions for the placement of prospecting work are presented. An assessment of the initial recoverable resources was made, which showed that with a probability of $90 \%$ oil resources will be confirmed in the amount of 26.97 million tons, with a probability of $50 \%$ 32.42 million tons, and a probability of $10 \%$ - 38.29 million tons. Value of Information, amounting to 5.714 billion rubles. The project profitability calculation was estimated at 9.934 billion rubles. An assessment of the value of information, calculated on the basis of the constructed geological model, showed that the geological prospecting with 2D seismic surveys at the area is a reasonable option for choosing a company strategy in order to increase resource potential. 


\section{REFERENCES}

Alekseeva M.B., Bogachev V.F., Gorenburgov M.A. Systemic Diagnostics of the Arctic Industry Development Strategy.Journal of Mining Institute. 2019. Vol.238,p.450-458. DOI 10.31897/PMI.2019.4.450

Cherepovitsyn, A.E., Larichkin, F.D., Vorobiev, A.G., Ibrokhim, A., 2018. Economical prospects of advancement in liquefied natural gas production, Gornyi Zhurnal.

Efimov, A.V. \& Tashlitskaya, A.M. 2013. An example of economic evaluation of projects at the stage of geological prospecting taking into account risks and uncertainties, Oil industry (11): 94-96.

Egorov, A.S., Vinokurov, I.Y., Kalenich, A.P., Belevskaya, E.S., Ageev, A.S. 2016. Deep structure of the Barents-Kara region according to geophysical investigations along 1-AR and 2-AR geotravers, 7th EAGE Saint Petersburg International Conference and Exhibition: Understanding the Harmony of the Earth's Resources Through Integration of Geosciences: 728-732.

Glebov, A.F. 2016. Factor analysis of the geological and technological success and risks of oil and gas seismic survey in modern Russia for 20 years, Seismic survey technologies (4): 5-12.

Gorbovskaya, O.A. 2017. Probability Assessment of Geological Uncertainties: Lessons Learned, SPE Journal.

Gospodarikov, A.P., Zatsepin, M.A., 2019. Mathematical modeling of boundary problems in geomechanics, Gornyi Zhurnal.

Gutman, I.S. \& Sahakyan, M. I. 2017. Methods for calculating reserves and estimating oil and gas resources: textbook, Moscow: Nedra.

Nedosekin A.O., Rejshahrit E.I., Kozlovskij A.N. Strategic Approach to Assessing Economic Sustainability Objects of Mineral Resources Sector of Russia. Journal of Mining Institute. 2019. Vol.237, p.354-360. DOI: 10.31897/PMI.2019.3.354

Prischepa, O., Nefedov, Y., Grokhotov, E. 2019. Geochemical and petrophysical studies of hydrocarbon potential of domanic shale formation (Timan-Pechora petroleum Province), EAGE/SPE Workshop on Shale Science 2019 - Shale Sciences: Theory and Practice. DOI: 10.3997/2214-4609.201900475 ISBN: 978-946282281-8

Prishepa, O.M., Nefedov, Y.V., 2018. Methodical approaches to the allocation of oil and gas accumulation zones on the example of the timan-pechora OGP, Geomodel 2018-20th Conference on Oil and Gas Geological Exploration and Development.

Reidar, B. 2009. Value of Information in the Oil and Gas Industry: Past, Present, and Future, SPE Reservoir Evaluation \& Engineering.

Shatrov, S.V. 2015. Calculation of the probability of discovery of a field taking into account the mutual dependence of the parameters within the estimated formations and structures, Oil and gas geology. Theory and Practice.

Warren, J.E. 1983. The Development Decision: Value of Information, SPE Hydrocarbon Economics and Evaluation Symposium, Dallas, 3-4 March . DOI: 10.2118/11312-MS: SPE.

Whitney, J. T. 2010. On the value of information for spatial problems in the earth sciences. 


\title{
Mineral formation sequence in the hyperbasites of the Serovsko-Maukski ophiolite belt (the Northern Urals)
}

\author{
R.K. Ilalova \\ PhD in Geology and Mineralogy, assistant of the hystorical and dynamic geology Department, Mining \\ university, Saint-Petersburg, Russia
}

\author{
I.V. Talovina \\ Professor in Geology and Mineralogy, head of the hystorical and dynamic geology Department, Mining \\ university, Saint-Petersburg, Russia
}

\section{I.V. Vorontsovac}

PhD in Geology and Mineralogy, associate Professor of the geology and exploration of mineral deposits Department, Mining university, Saint-Petersburg, Russia

\begin{abstract}
: a comprehensive research of the geological structure and mineral composition features of the hyperbasites of the Serovsko-Maukski ophiolite belt and the weathering crust along them was carried out. Due to the complex geological history of formation of the weathering crust, a wide range of precision methods of investigation was used - optical-microscopic, $\mathrm{X}$-ray diffraction, thermal, micro-ray spectral and Raman methods. As a result, the sequence of mineral formation was revealed and the modern genetic classification of hyperbasite minerals and weathering crust was compiled. In the presented classification, all minerals of the weathering crust and hyperbasites of the Serovsko-Maukski ophiolite belt are divided into endogenous and exogenous ones. Among the endogenous ones there are four groups - magmatogenic-relikt minerals, oceanic weathering minerals, low-grade metamorphogenic-relikt and hydrothermalrelikt minerals; among the exogenous ones there are residual and infiltration-overlaid minerals. Residual minerals are divided into two subgroups - diffusion and infiltration. Thus, the results obtained allow us to identify the most important geological processes associated with the evolution of hyperbasite massifs of the Serovsko-Maukski ophiolite belt and the weathering crust along them. Moreover, the conclusions prove the appearance of hydrothermal processes and low-grade metamorphism in the history of massifs development and the weathering crust of the Serovsko-Maukski ophiolite belt, and can also be used for prediction and search for new ore nickel deposits.
\end{abstract}

\section{INTRODUCTION}

This study seems to be a topical subject because it allows us to identify the most important geological processes associated with the evolution of hyperbasite massifs of the SerovskoMaukski ophiolite belt and the weathering crust along them. And geological processes, in turn, are associated with the prediction and search for ore deposits, which also emphasize the importance of the research topic.

Aim of the research is complication of the modern genetic classification of minerals of the hyperbasites and weathering crust. Tasks of the research are: 1) to study the geological structure of hyperbasite massifs and weathering crust along them;2) to study the mineral composition of rocks of the weathering crust and hyperbasites; 3) to establish the zonation of the weathering profile; 4) to correlate the mineral composition of rocks and geological processes. 
The issue of the sequence of mineral formation of hyperbasites was first considered in the works of Ginzburg $(1946,1947,1953,1963)$. Later, some data on this issue were published by Nikitina (1956), Kukovsky (1961, 1963, 1966), Zhuravleva et al. (1971). The most recent data on the mineral composition of the weathering crust were presented in the works of Mezentseva (2011), Talovina (2012) \&Vorontsova (2013).

\section{METHODOLOGY}

During the 2015-2018 field seasons, the authors of this article carried out field work, collection of stone material, description and documentation of outcrops, ditch and well cores. A total of 150 geological sections and 500 samples of petrological differences in rocks were studied. The study of the material composition of rocks was conducted using digital technologies, which now occupy a special place in the world of science (Litvinenko, 2020; Zubov, 2017). Such as, Detection of altered rocks was carried out by means of petrographic study of transparent thin rock sections on the Leica DM2700 P microscope using domestic methods of studying these formations (400 pieces). In order to refine the diagnosis of minerals, micro-rays and Raman methods (300 definitions) were used - on the JSM-6510LA raster electron microscope with energy dispersive spectrometer JED-2200 (JEOL) in IGGD RAS (analyst O.L. Galankina) and ReactRaman 785 spectrometer (analyst E.A. Vasiliev), X-ray method (60 definitions) - on XRD 3000 TT and URD-6 X-ray diffractometers in the laboratory of the Freiberg Mining Academy (analyst R. Kleeberg), thermal method (40 definitions) - on the STA 429CD+QMS (ISC RAS, V.L. Ugolkov).

\section{RESULTS AND DISCUSSION}

The Kolskij, Ustaiskiy and Vagranskiy hyperbasite massifs $\left(\mathrm{O}_{1-2}\right)$ are located on the eastern slope of the Northern Urals and are a part of the Serovsko-Maukski ophiolite belt - the northern branch of the belt of the Urals ophiolite massifs (Vtorushin, 1969; Kononova, 1974; Vershinin, 1966). They are stretched in the meridional direction and occur among volcanogenicsedimentary formations of Middle Palaeozoic age - diabase porphyrites, tuff shales and tuff sandstones, contacting in the southwest with intrusive formations of porphyrites and quartz diorites. In the course of the Mesozoic-Cenozoic tectonic movements, the massifs were divided into large blocks and were covered by platform sediments of the Jurassic, Cretaceous and Paleogene ages. (Figure 1).

The ultramafic rocks of the massifs are almost completely serpentinized and bear the traces of intensive tectonic processing. Serpentinites are broken through by numerous dykes of basic and intermediate composition, in contact with which they are talked, chloritized and carbonated. Under the cover of the Meso-Cenozoic sediments are preserved aposerpentin rocks, which compose the ancient (T-J) weathering crust of the hyperbasites. The latter belongs to the linear-platform type and is divided into residual and transformed infiltration-metasomatic (chamosite) by genetic features. The residual crust is relict; initially it could form the lower horizons of a rather powerful primary weathering crust. During the Albian-Cenomanian period, the upper horizons of the latter were partially eroded, partially re-deposited, and underwent changes in the conditions of the recovery environment when the area was swamped and affected the laterites of $\mathrm{H}_{2} \mathrm{~S}$ и $\mathrm{CO}_{2}$ (Talovina et al., 2010; Mezentseva et al., 2011).

In the section (from bottom to top) the following zones are alternating (Table 1): 1) the zone of disintegrated serpentinite, chloritized and carbonated, weakly affected by weathering processes, 2) the zone of leached serpentinite (subjected to kerolitization, carbonation, siliconization, nontronitization, oxidation), 3) the hydration zone, 4) the oxidation zone and 5) the chamosite zone.

The mineral composition of the weathering crust of hyperbasites in the Serovsko-Maukski ophiolite belt is very complex and diverse due to the complex geological history of their formation (Stepanov et al., 2019; Aleksandrova et al., 2019; ElDeeb et al., 2019; Popov et al., 


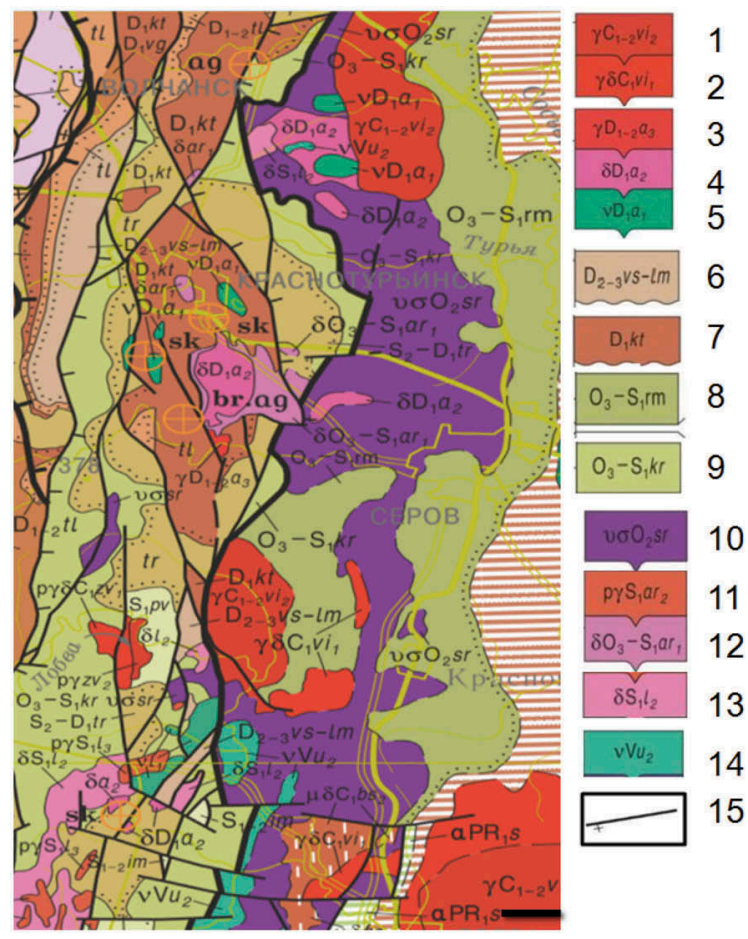

Figure 1. Geological map of the Daurian formations of the Northern Urals (A.P. Karpinsky Russian geological research institute, Uralian geological survey expedition. Map scale 1:1 000 000. Drawer: T.A. Petrova) 1-2 - Verhisetsky complex granodiorite-granite; 3-5 - Auerbach complex gabbro-diorite granite; 6 - undivided Wysotinsk and Limkin formations; 7 - Krasnoturyinsk formation; 8 - Romahinsk thick; 9 - Krasnouralsk formations; 10 - Serov complex dunite-harzburgite; 11-12 - Arbatsk complex dioriteplagiogranite; 13 - Levinsk complex gabbro-tonalit-plagiogranite; 14 - Usteysk complex dunite-verliteclinopyroxenite-gabbro; 15 - dislocations.

Table 1. Weathering profiles zoning.

\begin{tabular}{|c|c|c|c|}
\hline Weathering zone & Ongoing process & Rock varieties & Mineral varieties \\
\hline Shamosite & Shamositization & Chamosite rocks & $\begin{array}{l}\text { Chamosite, millerite-brindleyite- } \\
\text { chamosite, clinochloro-bertierine- } \\
\text { chamosite, chamosite-lizardite }\end{array}$ \\
\hline Oxide-iron & Oxidation & Goethite rocks & $\begin{array}{l}\text { Goethite, } \\
\text { quartz goethite, clinochloro goethite }\end{array}$ \\
\hline Nontronite & Hydration & Nontronite rocks & Nontronite, talc-chlorite-nontronite \\
\hline \multirow[t]{2}{*}{ Serpentinite } & Leaching & Lysardite rocks & $\begin{array}{l}\text { Clinochlore-talk-lizardite, nepuite-quartz- } \\
\text { lizardite, clinochlore-pennine lizardite }\end{array}$ \\
\hline & Disintegration & Chrysotile rocks & $\begin{array}{l}\text { Clinochlore-chrysotile, talc-chrysotile, dia- } \\
\text { bantite-brunsvigite-picnochlore-chrysotile }\end{array}$ \\
\hline
\end{tabular}

2020). Despite this fact, the authors have compiled a detailed genetic classification of weathering crust minerals and hyperbasites (Table 2). Moreover, the sequence of mineral formation was noted (Table 3).

In the presented genetic classification all minerals of the weathering crust of hyperbasites of the Serovsko-Maukski ophiolite belt are divided into endogenous and exogenous (Ilalova, 2019). Four groups are distinguished among the endogenous ones: magmatogenic-relict 
Table 2. Genetic classification of the basic minerals of the weathering crust of the hyperbasites of the Serovsko-Maukski ophiolite belt.

\begin{tabular}{|c|c|c|c|}
\hline \multicolumn{4}{|l|}{ Endogenous } \\
\hline Magmatogenic-relict minerals & $\begin{array}{l}\text { Oceanic weathering } \\
\text { minerals }\end{array}$ & $\begin{array}{l}\text { Low-grade meta- } \\
\text { morphogenic-relict }\end{array}$ & $\begin{array}{l}\text { Hydrothermal relict } \\
\text { minerals }\end{array}$ \\
\hline $\begin{array}{l}\text { Olivine, pyroxene, } \\
\text { chromspinelide }\end{array}$ & $\begin{array}{l}\text { Lysardite, chrysotile, } \\
\text { pecoraite, amphibole, } \\
\text { bastis, magnetite }\end{array}$ & Chlorite, talc & $\begin{array}{l}\text { Millerite, pyrite, chal- } \\
\text { copyrite, pyrrhotite, } \\
\text { chlorite, talc }\end{array}$ \\
\hline \multicolumn{4}{|l|}{ Exogenous } \\
\hline \multicolumn{4}{|l|}{ Residual } \\
\hline Diffusion & Infiltration & \multirow{2}{*}{\multicolumn{2}{|c|}{$\begin{array}{l}\text { Infiltration-overlay minerals } \\
\text { Shamosite, siderite, rhodochrosite, pyrite }\end{array}$}} \\
\hline $\begin{array}{l}\text { Nontronite, montmorillonite, } \\
\text { hydrochlorite, halloysite, } \\
\text { kaolinite }\end{array}$ & $\begin{array}{l}\text { Goethite, hydrogetite, } \\
\text { hematite, nontronite, } \\
\text { talc, quartz, opal, chal- } \\
\text { cedony, calcite, mag- } \\
\text { nesite, dolomite, } \\
\text { hydrargillite }\end{array}$ & & \\
\hline
\end{tabular}

Table 3. Genetic classification of the basic minerals of the weathering crust of the hyperbasites of the Serovsko-Maukski ophiolite belt.

\begin{tabular}{|c|c|c|c|c|}
\hline \multirow{2}{*}{$\begin{array}{l}\text { Minerals of the } \\
\text { hyperbasites }\end{array}$} & \multicolumn{4}{|c|}{ Profile zones of the weathering crust } \\
\hline & Disintegration & Leaching & Nontronite & Ochre \\
\hline Olivine & \multirow{2}{*}{\multicolumn{2}{|c|}{$\begin{array}{l}\text { Iron hydroxides } \\
\text { Initial stage of nontronite formation }\end{array}$}} & Nontronite & Iron hydroxides \\
\hline Serpentine & & & & $\begin{array}{l}\text { Nontronite } \\
\text { Quartz, chalcedony, opal } \\
\text { Oxides and hydroxides of } \\
\text { iron }\end{array}$ \\
\hline \multirow[t]{2}{*}{ Chlorite } & Hydrochlorite & & $\begin{array}{l}\text { Hydro } \\
\text { mica }\end{array}$ & $\begin{array}{l}\text { Kaolinite, quartz, chal- } \\
\text { cedony, opal }\end{array}$ \\
\hline & Hydrochlorite & $\begin{array}{l}\text { Montmorillonite, } \\
\text { halloysite, kaolinite }\end{array}$ & & $\begin{array}{l}\text { Hydrargillite, iron } \\
\text { hydroxides }\end{array}$ \\
\hline Piroxene & Hydrated piroxene & & Nontronite & $\begin{array}{l}\text { Iron hydroxides, silica } \\
\text { minerals }\end{array}$ \\
\hline Amphibole & Hydrochlorite & Montmorillonite & & $\begin{array}{l}\text { Kaolinite, iron hydrox- } \\
\text { ides, hydrargillite }\end{array}$ \\
\hline Bastite & $\begin{array}{l}\text { Hydrated } \\
\text { bastite }\end{array}$ & & Nontronite & $\begin{array}{l}\text { Iron hydroxides, silica } \\
\text { minerals }\end{array}$ \\
\hline Magnetite & Maghemit, hematite & & & Iron hydroxides \\
\hline Chromspinelids & Magnetite & Hematite & & Iron hydroxides \\
\hline
\end{tabular}

Note. The table does not include minerals of infiltration-overlaid genesis.

minerals, minerals of oceanic weathering, low-grade metamorphogenic and hydrothermal relict minerals; among the exogenous ones - residual and infiltration-overlay minerals. Residual minerals are divided into two subgroups - diffusion and infiltration minerals.

The following rock-forming minerals of hyperbasites are referred to as magmatogenicrelict minerals: olivine, pyroxene and chromspinelide. Minerals of oceanic weathering (at the spreading stage) are chrysotile, lysardite, pecoraite, bastite, amphiboles and magnetite. Olivine is transformed into serpentine, pyroxene into bastite and chromspinelide into 
magnetite. Chromspinelide and magnetite are found in all areas of the crust, and in the ochre zone, compared to the lower zones, the content of magnetite and chromspinelide is much higher. Low-grade metamorphogenic-relict minerals are formed at low-grade metamorphism of the hyperbasites at the stage of early Mesozoic tectonic-magmatic activation of the region, which appeared as a result of transregional riftogenesis and trap magmatism (Rapoport, 1998; Spiridonov, 2008). Serpentine, bastite, amphibole forms chlorite and talc. Chlorite in the weathering crust by composition belongs mainly to the ironmagnesia series. At microscopic study of thin section from zones of disintegration and leaching full or partial replacement of serpentine, bastite, amphiboles by chlorite is clearly visible. Talc forms pseudomorphoses over the chlorite and other earlier minerals. Iron, released from olivine and pyroxene, forms in serpentinite thin rash or chain-shaped clusters of tiny grains of magnetite. Hydrothermal relict minerals found in the cracks of chrysotile-lysardite metasomatites from the zone of disintegrated serpentinite, are formed in hydrothermal processes. Low-temperature hydrothermal solutions separated from the magmatic hearth and containing copper, nickel, iron and sulphur have deposited sulfide minerals such as pyrite, millerite, chalcopyrite and pyrrhotite in the tectonically disturbed serpentinite zones. Since these minerals are localized in the cracks of disintegrated serpentinite, their formation due to the serpentinization process is excluded. Chalcopyrite, pyrite, pirrotine in the form of grains up to $1 \mathrm{~mm}$ in irregular and cubic shape are associated with millerites, which have the form of needle crystals, often collected in radialbeam aggregates. In the ochre zone, sulfide minerals are hardly preserved, except for pyrite, which is formed here by infiltration. These sulfides quite often contain nickel, which is reflected in their chemical compositions.

Thus, at this stage, the transformation of relict minerals and the formation of new minerals occurring during low-grade metamorphism and hydrothermal processes are being completed. Subsequent transformations of minerals are the result of exogenous processes.

Residual minerals can occur in two ways:

1) as a result of direct metasomatic substitution of serpentinites during their weathering (diffusion);

2) as a result of deposition of cold solutions during their infiltration into the depths of tectonic disturbance zones and cracks in serpentinite (infiltration).

Depending on this, the residual minerals are subdivided into diffusion and infiltration minerals. Often the same mineral can be formed in different ways. Nontronite, montmorillonite, hydrochlorite, halloysite, and kaolinite are classified as diffusion residual minerals. Serpentine, being exposed to weathering agents (oxygen, carbon dioxide, humus acids and ground water) undergoes a complex successive process of changes. Weathering of serpentine minerals occurs under conditions of humid climate and strong cracking of rocks. In the disintegration zone, serpentine, absorbing water moving through the cracks or rock pores, begins to hydrate and partially turn into nontronite. Further removal of cations from serpentine minerals leads to destruction of the crystal lattice, reduction of volume weight, increase of porosity and change of other physical and optical properties, in particular the refractive index. If relict olivine remains in serpentinite, then in the disintegration zone, mainly in its upper part, it is destroyed with the formation of a residual grid, consisting of brown iron hydroxides.

Piroxene and amphibole in the upper horizons of the disintegration zone and in the lower horizons of the leaching zone turn into hydrogetite (as a fine mesh) and nontronite. Under the microscope it can be seen that this process begins with microcracks and gradually spreads to all grains.

There are several ways of chlorite weathering in the weathering crust, but the end products of their decomposition are the same minerals: halloysite, kaolinite and iron hydroxides (Lazarenkov et al., 2011; Ilalova et al., 2018). The stage of chlorite change can be represented by the following schemes: 
1. Chlorite $\rightarrow$ hydrochlorite $\rightarrow$ hydromica $\rightarrow$ halloysite $\rightarrow$ kaolinite $\rightarrow$

$\rightarrow$ quartz, opal, chalcedony

$\rightarrow$ iron hydroxides

$\rightarrow$ hydrargillite

2. Chlorite $\rightarrow$ hydrochlorite $\rightarrow$ montmorillonite $\rightarrow$ halloysite $\rightarrow$ kaolinite $\rightarrow$

$\rightarrow$ hydrargillite $\rightarrow$ iron hydroxides

During weathering, chlorite is converted to hydrochlorite, which is particularly characteristic of the upper crust areas of the weathering. Hydrochlorite under a microscope is usually observed as scaly grains or earthy masses of green, pale green color. During weathering of chlorite there is oxidation of $\mathrm{FeO}$ and hydrolysis of silicate, accompanied by silica release, and partial removal of $\mathrm{MgO}$. During $\mathrm{MgO}$ leaching, the coloration of the mineral turns pale and the refractive index decreases. If there are high concentrations of nickel in descending waters, it replaces $\mathrm{Mg}^{2+}$ and $\mathrm{Fe}^{2+}$ equivalent. Montmorillonite, in turn, decomposes to form kaolinite or halloysite and iron hydroxides.

Magnetite, maghemite and hematite occur as a result of oxidation of magmatogenic-relict chromspinelids, magnetite. Change of chromspinelids begins at the periphery of grains, then spreads through cracks, gradually covering the entire area of the grain. Magnetite formed during oceanic weathering (at the stage of spreading) during subsequent weathering also turns into magnetite, then into hematite.

Infiltration-resistant minerals are the most interesting and numerous. Goethite, hydrogethyte, hematite are formed as a result of the release of iron from iron-containing minerals at their destruction in various zones of the weathering crust. Thus, when magnetite, maghemite and other iron-containing minerals change further, iron is transferred from the crystal lattice to cold solutions as a result of the release of these minerals. These solutions seep into the loose ochre mass of the upper crust zone and move along the cracks of leached and disintegrated serpentinite and as the corresponding concentrations are reached, iron falls out of the solutions in the form of goethite, hydrogetite and hematite. When other chemical elements, such as $\mathrm{Mg}, \mathrm{Al}, \mathrm{Si}$ and $\mathrm{Ni}$, were introduced into the solutions together with iron, the formation of nontronite occurred.

Silicon entering the crust solutions due to the destruction of diorite minerals was used to form sedimentary quartz, chalcedony and opal. Some part of silicon precipitated together with magnesium, iron, aluminum and sometimes nickel to form talc, nontronite and other minerals. Calcite, magnesite and dolomite, as well as other minerals of this group, are sediment-newly formed. Magnesium and calcium were introduced into crust solutions as a result of plagioclases and pyroxenes destruction from dikes, serpentine and chlorites. Carbonate minerals were mostly precipitated in cracks of disintegrated and leached serpentinite, where $\mathrm{pH}>11$ and environment was reductive.

Infiltration-overlay minerals appeared after the formation of the weathering crust and its overlapping by precipitation from the Jurassic and Cretaceous periods. They are not connected with the destruction of hyperbasite massifs and dike rocks. Mineralized waters from lake and marsh water bodies penetrated downwards (into the upper zones of the weathering crust) and as a result of infiltration and overlaying replaced some previously formed minerals. In addition to metasomatic substitution, the minerals of this group were precipitated from cold solutions of cracks and rocks in the weathering crust. Infiltration-metasomatic chamosite was found in the weathering crust of serpentinite, which partially replaced both exogenous newly formed and endogenous relic minerals. Infiltration chamosite is distinguished by cracks and voids and belongs to the later generation. This group also includes pyrite, siderite and rhodochrosite. Pyritization and sideritization as infiltrationally superimposed processes are weaker in the weathering crust than chamositization. Pyrite in the form of crystals $0.5 \mathrm{~mm}$ in size is often found in the ochreous hydrogethyte mass of the upper area of the weathering crust. Siderite is in close paragenetic association with chamosite, rhodochrosite. It is observed in the form of rounded spherolite grains and clear crystalline aggregates in loose clayey chamosite rocks, cementing them. 


\section{CONCLUSIONS}

The sequence of mineral formation in the weathering crust does not have to be a fully developing process with inevitable and always defined transition minerals. It depends on physical and chemical conditions of the environment. Under favorable conditions this process occurs very quickly, in adverse conditions - slowly or even stops at some stage, not giving "final" products of rock decomposition. The "final" products are minerals resistant in the uppermost horizons of the weathering crust; most often these are hydro-oxides and oxides of iron, quartz, opal.

Thus, the weathering crust of the hyperbasite massifs of the Serovsko-Maukski ophiolite belt contains a large number of minerals of various genesis and carries the traces of various processes - oceanic weathering, low-grade metamorphism, hydrothermal and metasomatic processes. The obtained results allowed the authors provide evidence of the appearance of hydrothermal processes and lowgrade metamorphism in the history of development of massifs and weathering crust of the Serovsko-Maukski ophiolite belt.

The particular importance of this study is that the obtained knowledge allows reconstructing the processes of redistribution and accumulation of ore components in the weathering crust rocks, in particular, the results can be used in forecasting estimates of the territory for nickel.

It should be noted that rich nickel-rich weathering crusts occur due to overlapping processes of endogenous, thermal and eluvial origin (otherwise - a combination of hypergenic and hypogenic factors), which results in the formation of polychronous and polygenic formations. This suggests that surface eluvial formations can continue to the depth, especially in the zones of faults, contacts of intrusive bodies, wide development of dyke complex rocks and other tectonically weakened zones. Comprehensive geological data analysis shows that such deposits can be found on poorly studied areas of overlapping serpentinite melange of deep faults with a platform cover, in particular in the fracture zones framing the Tagilo-Magnitogorsky deflection and the East Ural Rise.

The study was performed as part of the Joint German-Russian Project No 20-55-12002 of the Russian Foundation for Basic Research.

\section{REFERENCES}

Aleksandrova, T.N., Talovina, I.V., Duryagina, A.M. 2019. Gold-sulphide deposits of the Russian Arctic zone: Mineralogical features and prospects of ore benefication. Chemie der Erde (144). DOI: 10.1016/j.chemer.2019.04.006.

ElDeeb A.B., Brichkin V.N., Kurtenkov R.V., Bormotov I.S. 2019. Extraction of alumina from kaolin by a combination of pyro- and hydro-metallurgical processes. Applied Clay Science (172): $146-154$.

Ilalova R. K. 2019. Geological structure, composition and conditions of formation of nickel-bared weathering crust of hyperbasites of the eastern slope of the Northern Ural: dissertation [Geologicheskoe stroenie, sostav i usloviya formirovaniya nikelenosnoj kory vyvetrivaniya: dis. . . kand. geol.-min. nauk], St. Petersburg: 173 p.

Ilalova R. K. \& Gulbin Y. L. 2018. Thermometry of nickel chlorites of the Kolskii massif (the Northern Urals). Proceedings of RMS (147): 1-17.

Lazarenkov V.G., Talovina I.V., Vorontsova N.I., Mezentseva O.P. \& Ryzhkova S.O. 2011. Nickel chlorites of oxide-silicate nickel deposits of the Urals. Lithology and mineral resources (3): 1-10.

Litvinenko V.S. 2020. Digital Economy as a Factor in the Technological Development of the Mineral Sector. Natural Resources Research (29): 1521-1541.

Mezenceva O. P. \& Talovina I. V. 2011. The value of ${ }^{\delta 34}$ S in millerite and the genesis of chamosite nickel ores of the Elovsky deposit, the Northern Ural. Journal of Mining Institute (189): 58-61.

Popov O., Talovina I., Lieberwirth H., Duryagina A. 2020. Quantitative microstructural analysis and x-ray computed tomography of ores and rocks - comparison of results. Minerals 10 (2),129. https:// doi.org/10.3390/min10020129.

Talovina I. V., Lazarenkov V. G., U. Kempe, Voroncova N. I., Mezenceva O. P., Ryzhkova S. O. \& Ugolkov V. L. 2010. Nickel serpentines of the lysardite - nepuit and karyopilite series in hypergene nickel deposits of the Urals. Proceedings of RMS (4): 80-94. 
Spiridonov E. M. 2008. In development of the idea of F.V. Chukhrova about late hydrothermal formations: low-grade metamorphism as ore preparation, ore-forming and ore-transforming processes. Institute of Geology of Ore Deposits, Petrography, Mineralogy and Geochemistry RAS: 206-209.

Stepanov S. Y., Palamarchuk R. S., Kozlov A. V., Khanin D. A., Varlamov D. A., Kiseleva D. V. 2019. Platinum-group minerals of Pt-placer deposits associated with the svetloborsky Ural-Alaskan type massif, middle urals, Russia. Minerals 9(2). https://doi.org/10.3390/min9020077.

Voroncova N. I., Talovina I. V., Lazarenkov V. G., Gajfutdinova A. M. \& Tihomirova M. 2013. ${ }^{87} \mathrm{Sr} /{ }^{86} \mathrm{Sr}$ isotopic ratios in the rocks and ores of the Sakharin and Ufaleysky hypergene nickel deposits of the Urals. Journal of Mining Institute (200): 179-185.

Zubov V.P. 2017. Status and directions of improvement of development systems of coal seams onperspective kuzbass coal mines. Journal of Mining Institute (225): 292-297. 


\title{
Granulite from the Bunger Hills, Eastern Antarctica: Mineral parageneses and terms of metamorphism
}

\author{
I.A. Abdrakhmanov \\ Postgraduate student, Saint-Petersburg Mining University, St. Petersburg, Russia \\ Yu.L. Gulbin \\ Doctor of geological and mineralogical Sciences, Saint-Petersburg Mining University, St. Petersburg, \\ Russia
}

\begin{abstract}
The article presents the results of mineral thermobarometry and physicochemical modeling of mineral parageneses in garnet-sillimanite-cordierite gneiss from the Mesoproterozoic metamorphic unit of the Bunger Hills, East Antarctica. Therefore, a clockwise $\mathrm{R}-\mathrm{T}$ path was inferred using petrograthic and mineralogical data. It is shown that peak temperature of metamorphism could exceed $900{ }^{\circ} \mathrm{C}$. Such temperature conditions in combination with post-peak decompression records the collision-related tectonic evolution of the studied area.
\end{abstract}

Keywords: thermobarometry, granulites, Bunger Hills, East Antarctica

\section{INTRODUCTION}

The problem of the generation of the continental crust in Precambrian is one of the leading ones in modern geology. Therefore, the reconstruction of processes of sedimentation magmatism, and subsequent metamorphism during the formation of Precambrian complexes are the most important tasks of the petrological study of the folded basement of the East Antarctic shield. The relevance of this kind of research is all the more undeniable in the light of the discussion of the evolution of the supercontinent Rodinia. One of the key sites capable for understanding the geological history is the Bunger Hills in the eastern part of the Antarctic Shield.

\section{GEOLOGICAL SETTING}

The Bunger Hills is a narrow strip of a land, free from ice, stretching along the Antarctic coast in the area of Wilkes Land. The geological structure of this territory was studied by Soviet and Australian geologists (Ravich et al., 1965; Sheraton et al., 1995).

A variety of plagiogneisses and crystalline gneisses, which are largely granitized and migmatized, take part in the geological structure of the Bunger Hill (Figure 1).

In the thickness of these rocks, there are concordant intrusions of metabasites and layers of silicate marbles and calciphyres, bored and weakly granitized. In addition to the most diverse migmatites, shadow granites and numerous veins of granite composition arise. Massifs of charnockites also occur among migmatites. Dolerite dikes cut through all other rocks. The thickness of migmatized plagiogneisses and crystalline gneisses are deformed into large folds, whose wings are complicated by smaller folds of higher orders. Three fault systems, along which there are zones of milonites and diaphthoritic schists, broke this section of the crystalline basement into separate blocks, mostly slightly moved relative to each other. 


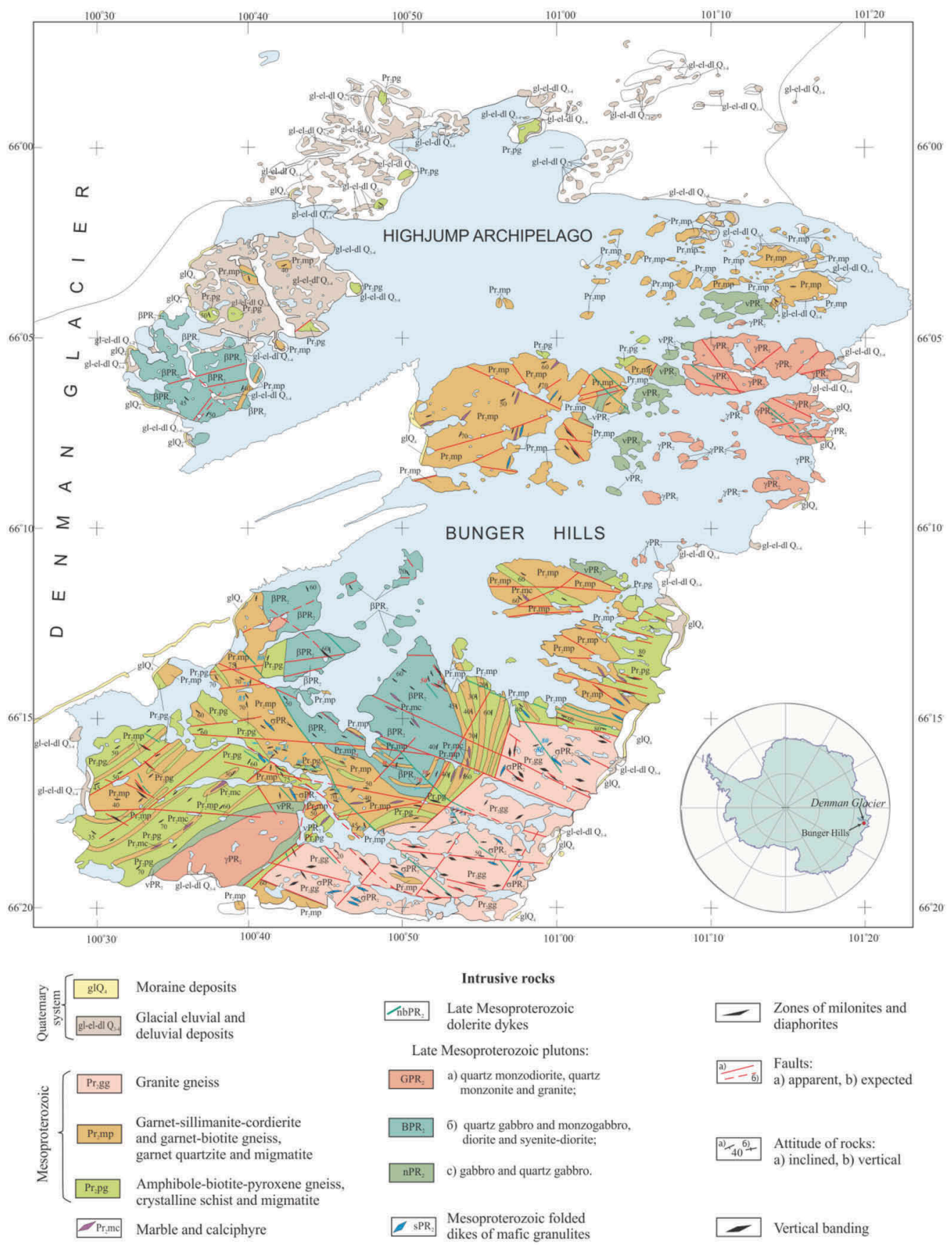

Figure 1. Geological map of the Bunger Hills, East Antarctica (Ravich et al., 1965).

According to the $\mathrm{U}-\mathrm{Pb}$ dating of syngenetic zircon, the igneous protolith of orthogneisses formed in the interval 1700-1500 Ma, while the appearance of plutons took place at the turn of 1170-1150 Ma (Sheraton et al., 1995). The age of metamorphism, according to in situ U-Pb dating of monazite from paragneisses, is 1240-1150 Ma (Tucker et al., 2016, 2017, 2018) and closely coincides with the formation of the Albany-Fraser orogenic belt (southwestern Australia) during the amalgamation of Rodinia. 


\section{SAMPLE DESCRIPTION AND ANALITICAL METHODS}

Samples utilized in this study were collected during the 2nd Soviet Antarctic Expedition of 1956-57. Sample 651a (from the Krylatyy peninsula) contains quartz (30 vol.\%), alkali feldspar (25), cordierite (20), garnet (10), biotite (7), sillimanite (5), ilmenite (2), albite (1), spinel (hercinite) $<1$, rutile, zircon $\ll 1$. The rock has a medium-fine-grained texture and banded structure due to the alternation of lenticular quartz layers with cordierite-garnet-sillimanitebiotite sections.

The bulk chemical composition of the rock was determined with the XRF method in VNNII-Okeangeologiya. Chemical compositions of minerals were obtained using JSM-6510LA elec-tron microprobe equipped with EDS JED-2200 (JEOL) at the Institute of Precambrian Geology and Geochronology of the Russian Academy of Sciences (Saint Petersburg, Russia).

The method of isochemical diagrams (pseudosection modeling) was applied to retrieve P-T history of the rock. This method implements the fundamental principle of metamorphic fa-cies. By this method, P-T phase diagrams are calculated that show which mineral assemblage stability field takes place for the rock of a given chemical composition under given temperature and pressure conditions. The modeling was done in the system NCKFMASHT using Theriak/Domino program (de Capitani, Petrakakis, 2010) with an internally consistent thermodynamic database tcdb55c2d (Holland, Powell, 1998, with changes) and different solid solution activity models for feldspars, garnet, biotite, cordierite, spinel, ilmenite, orthopyroxene, and osumilite. Quartz, sillimanite, kyanite, rutile, and titanite were considered as pure phases.

\section{RESULTS}

According to microprobe analysis, garnet is non-zonal and characterized by increased contents of almandine and pyrope end members $\left(X_{\mathrm{Fe}} 0.69-0.71, X_{\mathrm{Mg}} 0.27-0.29\right)$, low contents of $\mathrm{Ca}$ and $\mathrm{Mn}\left(X_{\mathrm{Ca}} 0.01-0.02, X_{\mathrm{Mn}} 0.01-0.02\right)$. In garnet rims next to the Crd-Bt aggregate (which replaces garnet) $X_{\mathrm{Mg}}^{\mathrm{Grt}}$ decreases (to 0.25 ), and $X_{\mathrm{Fe}}^{\mathrm{Grt}}$ increases (up to 0.74). This points to the partitioning of $\mathrm{Fe}$ and $\mathrm{Mg}$ between garnet, cordierite and biotite during retrograde metamorphism (Figure 2).

Sillimanite is characterized by a composition close to stoichiometric; it contains minor $\mathrm{FeO}$ (0.4-0.9 wt \%).

Alkali feldspar is a mesoperthite with K-rich feldspar host (Ort84-89Ab16-11An0) and almost pure albite lamellae Ab94-95An5-2Ort3-1 (Figure 3). It contains minor barium (BaO $0.3-1.3 \mathrm{wt} \%)$.
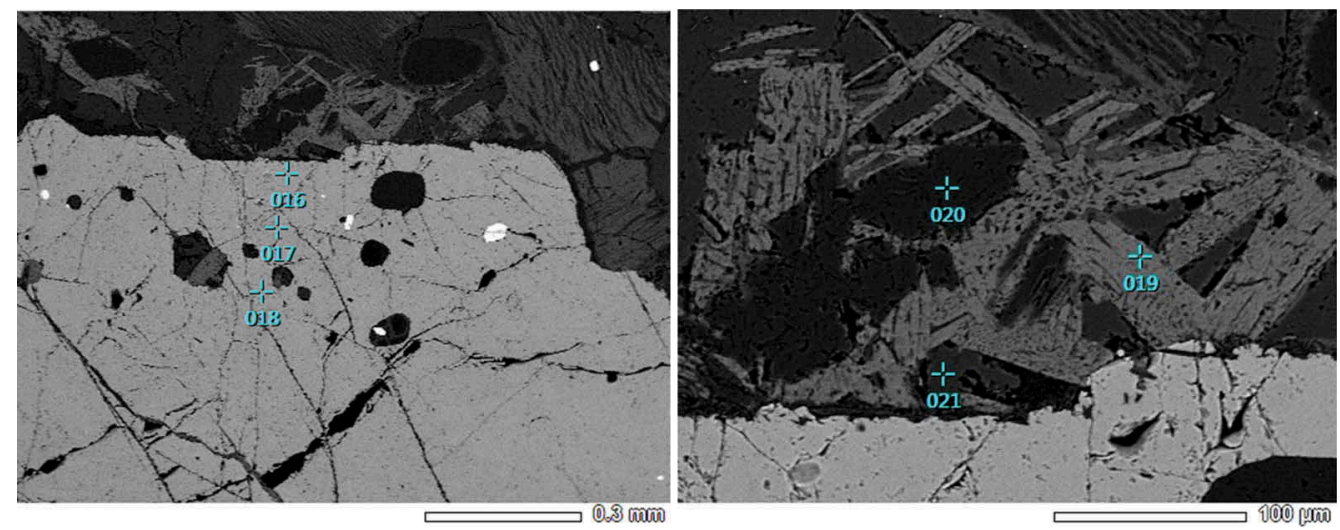

Figure 2. Change the composition of garnet rim next to the Crd-Bt aggregate. Points of analysis: point 19 is biotite, point 20 is sillimanite, point 21 is cordierite. 

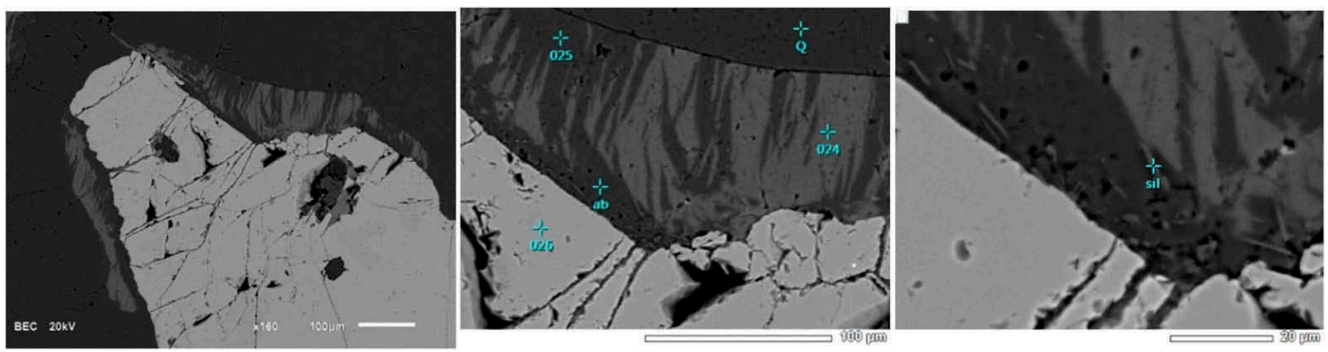

Figure 3. Mesopertite rims around garnet crystals with Sil (II) inclusions. BSE images.

Table 1. Chemical composition for sample 651a.

\begin{tabular}{lllllllllllll}
\hline $\mathrm{SiO}_{2}$ & $\mathrm{TiO}_{2}$ & $\mathrm{Al}_{2} \mathrm{O}_{3}$ & $\mathrm{Fe}_{2} \mathrm{O}_{3}$ & $\mathrm{FeO}$ & $\mathrm{MnO}$ & $\mathrm{MgO}$ & $\mathrm{CaO}$ & $\mathrm{Na}_{2} \mathrm{O}$ & $\mathrm{K}_{2} \mathrm{O}$ & $\mathrm{P}_{2} \mathrm{O}_{5}$ & $\mathrm{LOI}$ & $\Sigma$ \\
\hline 74.88 & 0.70 & 12.82 & 1.14 & 4.18 & 0.09 & 2.20 & 0.01 & 1.32 & 1.36 & 0.11 & 0.90 & 99.71 \\
\hline
\end{tabular}

The mineral of the spinel group corresponds to hercynite, which contains minor zinc ( $\mathrm{ZnO}$ 4.5-7.7 wt \%; 0.09-0.16 a.p.f.u.), chromium $\left(\mathrm{Cr}_{2} \mathrm{O}_{3} 0.3-7.8\right.$ wt \%; 0.01-0.19 a.p.f.u.) and nickel ( $\mathrm{NiO}$ up to $0.4-0.6 \mathrm{wt} \%$; Up to 0.01 a.p.f.u.). The content of the hercynite end-member in spinel varies from 0.52 to 0.65 , while the magnetite one does not exceed 0.04 . The average formula $(n=6)$ : $\left(\mathrm{Fe}^{2+}{ }_{0.61} \mathrm{Mg}_{0.28} \mathrm{Zn}_{0.12}\right)_{1.01}\left(\mathrm{Al}_{1.86} \mathrm{Fe}^{3+}{ }_{0.07} \mathrm{Cr}_{0.04} \mathrm{Si}_{0.01}\right)_{1.98} \mathrm{O}_{4}$.

Ilmenite contains minor magnesium ( $\mathrm{MgO}$ up to $0.4-1.2 \mathrm{wt} \%$ and up to $0.02-0.04$ a.p.f.u.) and manganese ( $\mathrm{MnO}$ up to $0.1-0.6 \mathrm{wt} \%$ and up to 0.01 a.p.f.u.). The content of ilmenite end member varies from 0.92 to 0.99 . Rutile contains minor $\mathrm{FeO}(0.3-2.9 \mathrm{wt} \%)$.

Cordierite is moderately magnesian with $X_{\mathrm{Mg}}$ in the range $0.68-0.77$. Biotite is characterized by low alumina content $\left(\mathrm{Al}_{2} \mathrm{O}_{3} 17.1-19.1 \mathrm{wt} \%\right)$ and high titanium content $\left(\mathrm{TiO}_{2}\right.$ up to $6.0 \mathrm{wt} \%$ ).

Bulk compositions of the studied sample are reported in Table 1.

During modeling, special attention was paid to the assessment of water activity in the system. To this end, P-T diagrams were constructed at different values of aH2O. As a result, water activity was limited by 0.2 because spinel observed in the rock disappears from the model assemblages at higher water activities (Figure 4, 5). In the diagram calculated for system with $\alpha_{H 2 O}=0.12$ (Figure 5), the Grt-Crd-Kfs-Qz-Ilm assemblage consists of spinel at a pressure of 5-6 kbar and a temperature exceeding $870^{\circ} \mathrm{C}$.

\section{DISCUSSIONS}

Pseudosection modeling and mineralogical analysis show the clockwise $\mathrm{P}-\mathrm{T}$ path that starts in the rutile stability field ( $\mathrm{P}>9 \mathrm{kbar}$ ) and records the pressure decrease to $6 \mathrm{kbar}$. The decompression temperature range is $850-950{ }^{\circ} \mathrm{C}$; it could occur against the background of a rise in temperature, or under conditions close to isothermal. This form of the P-T path follows from the assumption that at the early stage of metamorphism the assemblage Grt+Sill+Kfs+Qz+Rt \pm Ilm was stable in the studied rock. According to the GRAIL geobarome-ter (Bohlen et al., 1983), such equilibrium could take place in the pressure range of $6-8 \mathrm{kbar}$ at $900{ }^{\circ} \mathrm{C}$. As a result of the decompression, rutile was replaced by ilmenite and hercynite began to crystallize

The described scenario is consistent with the data of Tucker and Hand (2016), who also noted the presence of the high-pressure assemblage in the Bunger granulites. But at the same time, it cannot be ruled out that rutile in the studied sample was late and formed due to ilmenite oxidation at low temperatures at the retrograde stage (Bohlen et al., 1983), as indicated by the morphology of ilmenite-rutile intergrowths (Figure 6). 

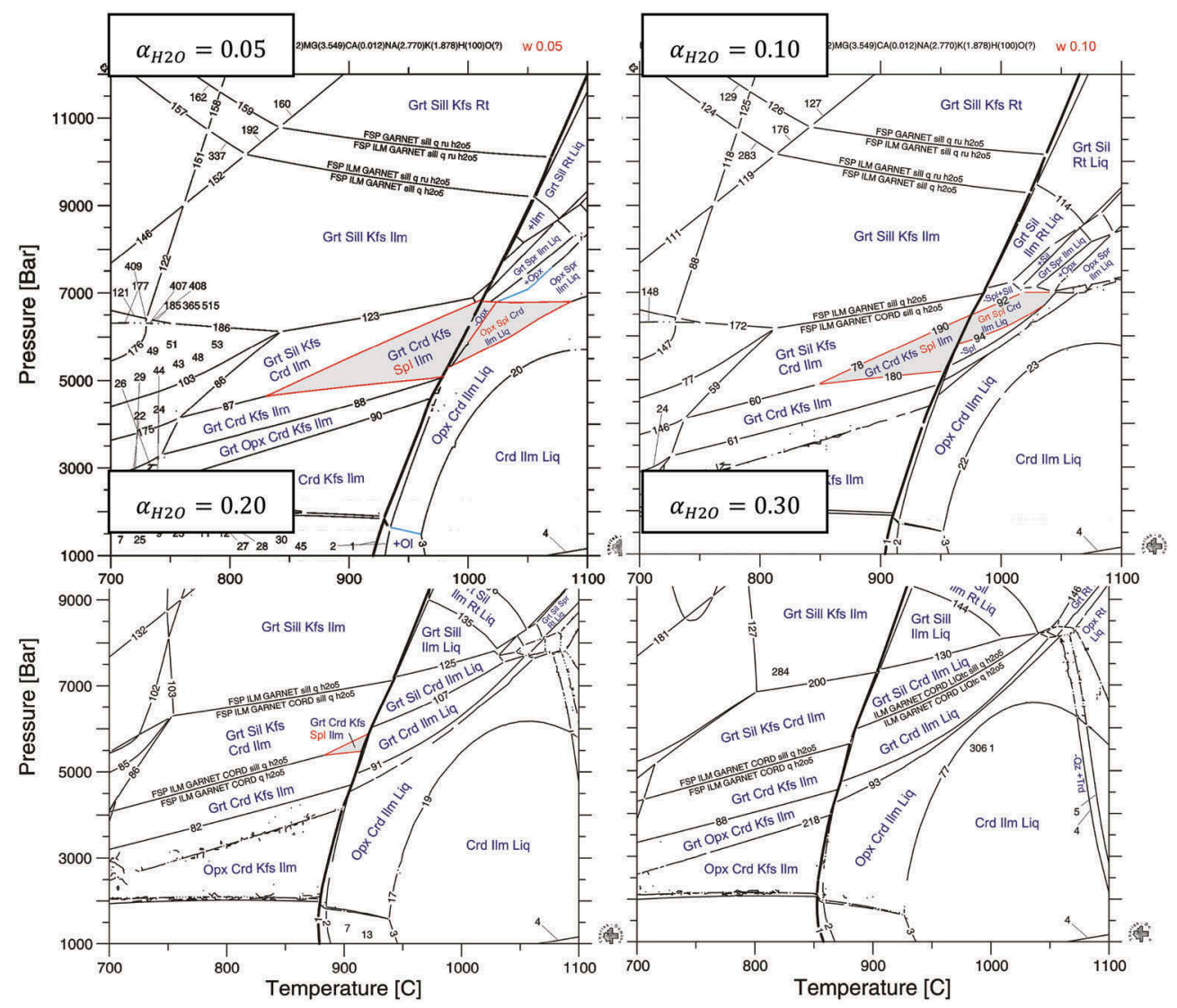

Figure 4. Isochemical P-T phase diagrams for sample 651a calculated for different values of $\alpha_{H 2 O}$. Quartz is in excess.

At the second stage, the Grt-Crd-Sp-Qz-Ilm assemblage stabilized and the rock experienced partial melting as a result of isobaric heating at $\mathrm{P}=5-6.5 \mathrm{kbar}$ and $\mathrm{T}>870 \mathrm{oC}$. The growth of garnet crystals during heating promoted capture of spinel inclusions. The calculated composition of spinel $\left(\mathrm{Hc}_{68-73} \mathrm{Sp}_{30-24} \mathrm{Usp}_{2-3}\right)$ agrees closely with the observed one $\left(\mathrm{Hc}_{60-83}\right.$ $\mathrm{Sp}_{40-17}$ ) without taking into account minor elements. Signs of partial melting in the rock (according to Holness et al., 2011) are intergranular quartz films and numerous mesoperthite rims around crystals of cordierite, sillimanite, and garnet (Figure 3, 7).

According to the modeling data, solidus temperature in the studied system is $960{ }^{\circ} \mathrm{C}$ at pressure of $6.2 \mathrm{kbar}$ and water activity of 0.12 . Partial melting is accompanied by the disappearance of alkali feldspar from the Grt-Crd-Sp-Qz-Ilm assemblage. The calculated composi-tion of the melt is $\mathrm{Qz}_{29} \mathrm{Ab}_{36} \mathrm{Kfs}_{24} \mathrm{Sil}_{10}$ whereby quartz, feldspar, and sillimanite are formed due to its crystallization. All these minerals are observed in the studied rock as melt crystallization products (Figure 3, 7). However, in contrast to the calculated composition of feldspar $\left(\mathrm{Ab}_{60} \mathrm{Kfs}_{40} \mathrm{An}_{0}\right)$, the reintegrated composition of mesoperthite observed in the sample is characterized by the predominance of the orthoclase mineral $\left(\mathrm{Ab}_{37-49} \mathrm{Kfs}_{62-50} \mathrm{An}_{1}\right)$.

It should be noted that the lower temperature limit of stability of hercynite, calculated in the NCKFMASHT system at a given water activity $\left(870{ }^{\circ} \mathrm{C}\right)$, can shift to lower temperatures in the case of spinel enriched with minor elements $\left(\mathrm{Fe}^{3+}, \mathrm{Zn}, \mathrm{Cr}\right)$.

At the third stage, isobaric cooling to $750-800{ }^{\circ} \mathrm{C}$ occurred. At these temperatures, garnet and cordierite were equilibrated. Evidences of the equilibrium are: (1) the intersection of 


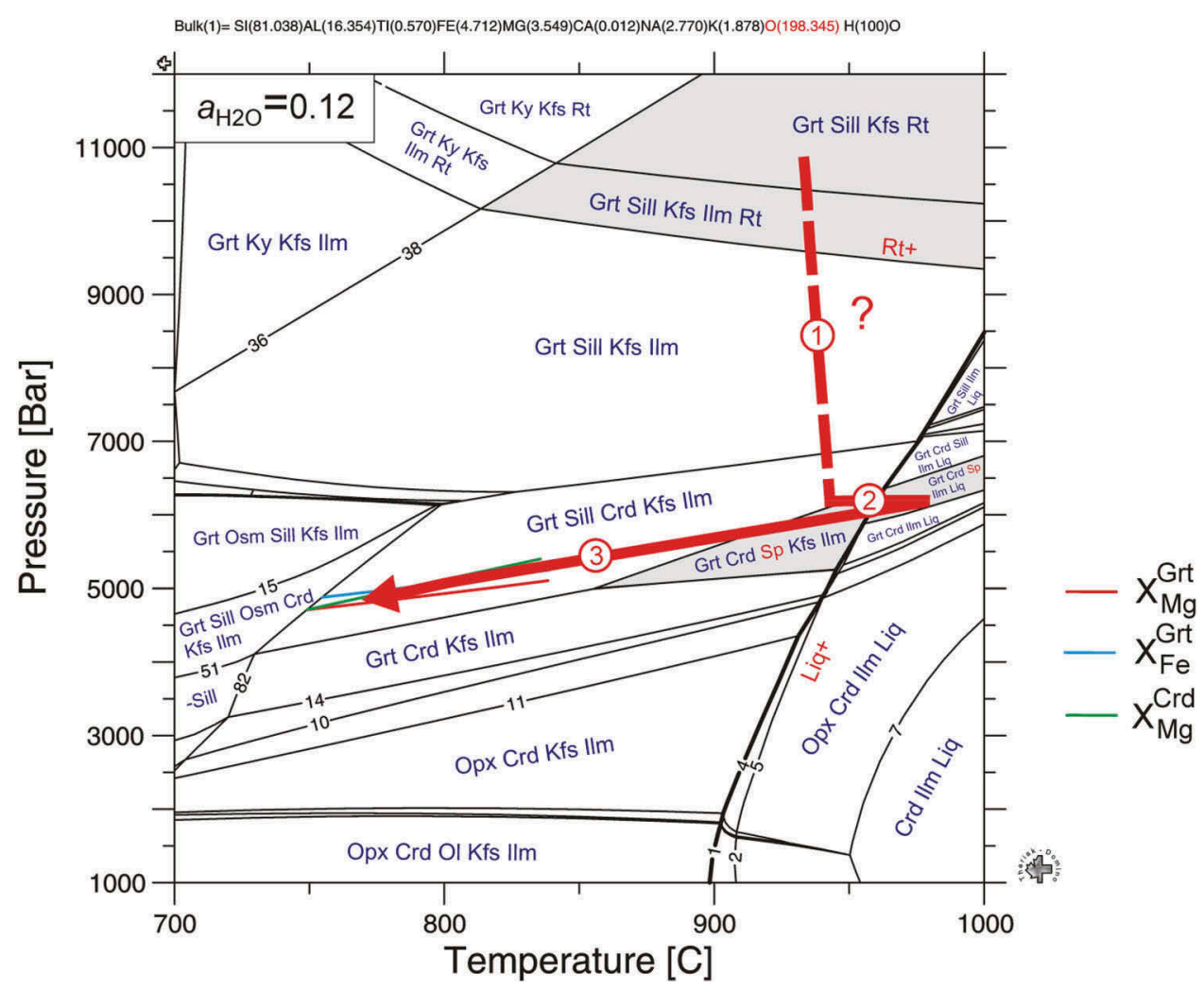

Figure 5. Isochemical P-T phase diagram for sample 651 calculated for $\alpha_{H 2 O}=0.12$. Quartz is in excess. Rutile and spinel stability fields are gray. The solidus line is marked in bold. Red arrow represents the $\mathrm{P}-\mathrm{T}$ path inferred on the basis of petrographic and mineralogical data.

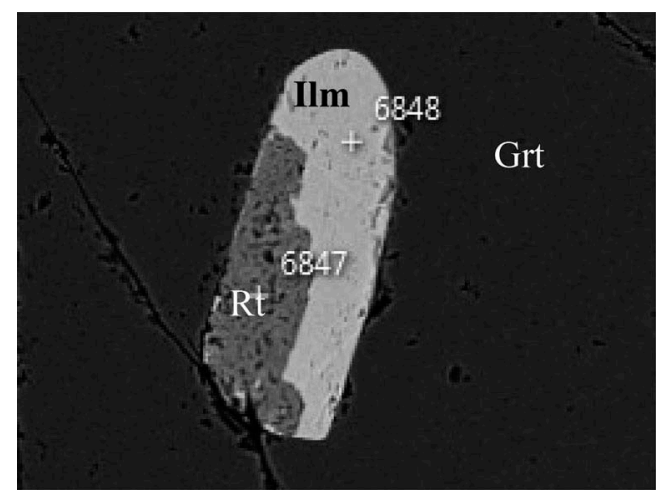

Figure 6. Intergrowth of ilmenite and rutile.

isopleths $X_{F e}^{G r t}, X_{M g}^{G r t}, X_{M g}^{C r d}$ corresponding to observed compositions of garnet and cordierite in the range of $750-800{ }^{\circ} \mathrm{C}$ at $5 \mathrm{kbar}$ (Figure 5), (2) temperature estimates obtained with the Grt-Crd geothermometer (Bhattacharya et al., 1988) which vary from 700 to $770{ }^{\circ} \mathrm{C}$ at 5 kbar. According to the Ti-in-biotite geothermometer (Henry et al., 2005), high-titanium biotite stabilized under similar conditions $\left(740-770{ }^{\circ} \mathrm{C}\right)$. The latter indicates an in-crease in water activity at the retrograde stage (as modeling shows biotite is stable up to a temperature of $760{ }^{\circ} \mathrm{C}$ at $\alpha_{\mathrm{H} 2 \mathrm{O}}=0.12$ and $\left.\mathrm{P}=5 \mathrm{kbar}\right)$. 

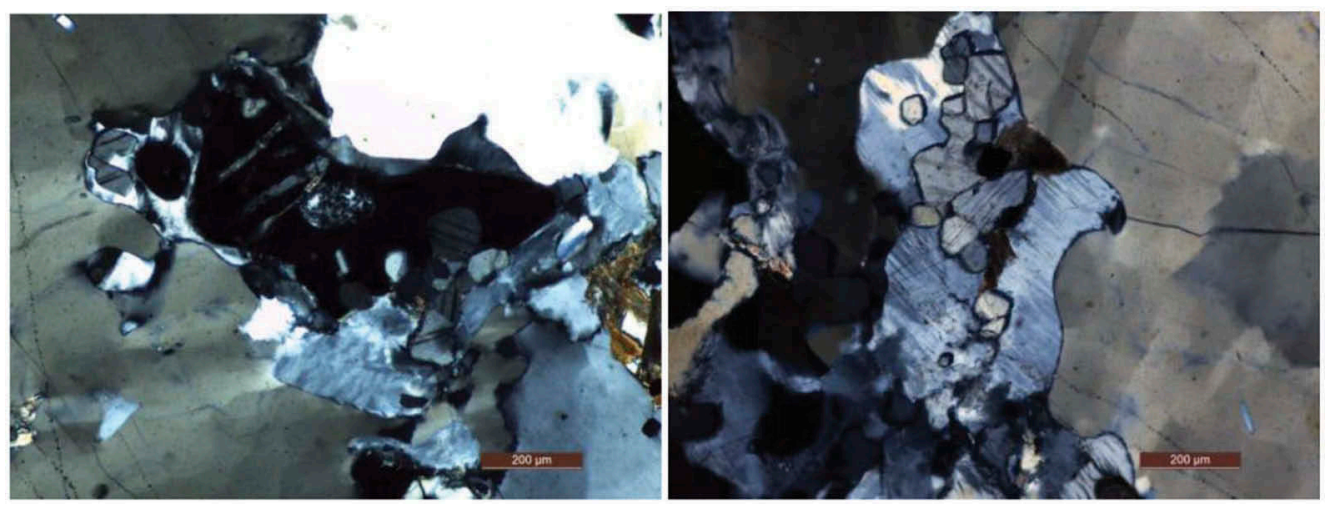

Figure 7. Mesoperthite rims around crystals of cordierite, sillimanite and garnet. Transmitted light, crossed polars.

\section{CONCLUSIONS}

The following results emerge from the study:

(1) it is shown that granulite metamorphism in the Bunger Hills undergoes at moderate pressure $(5-10 \mathrm{kbar})$, low water activity $(\mathrm{aH} 2 \mathrm{O}<0.2)$, and peak temperature possibly exceeding $900{ }^{\circ} \mathrm{C}$;

(2) the evolution of metamorphism is described by a clockwise P-T path with near-isothermal decompression in the early stage and near-isobaric cooling in the late stage of orogeny that is typical for P-T path associated with collision events

\section{REFERENCES}

Bhattacharya A. (1986), Some geobarometers involving cordierite in the $\mathrm{FeO}-\mathrm{Al}_{2} \mathrm{O}_{3}-\mathrm{SiO}_{2}\left( \pm \mathrm{H}_{2} \mathrm{O}\right)$ system: refinements, thermodynamic calibration and applicability in granulite facies rocks contribution // Mineralogy and Petrology, V. 94, pp. 387-394.

Bohlen, S. R., Wall, V. J., Boettcher, A. L. (1983), Experimental investigations and geological applications of equilibria in the system $\mathrm{FeO}-\mathrm{TiO}_{2}-\mathrm{Al}_{2} \mathrm{O}_{3}-\mathrm{SiO}_{2}-\mathrm{H}_{2} \mathrm{O} / /$ American Mineralogist, V. 68, pp. 1049-1058.

de Capitani, C., Petrakakis K. (2010), The computation of equilibrium assemblage diagrams with Theriak/Domino software // American Mineralogist, V. 95, pp. 1006-1016.

Gulbin, Y.L., Glazov, A.I. (2013), Morphological evidence for diffusion-controlled growth of garnet from metapelites // Geol. Ore Deposits, V. 55, pp. 686-691.

Gulbin, Y.L. (2013), Modeling of zoning patterns in garnet: Thermodynamic and kinetic aspects // Geol. Ore Deposits, V. 55, pp. 625-636.

Gulbin, Y.L. (2013), Compositional zoning in garnet and kinetics of metamorphic crystallization // Geol. Ore Deposits, V. 55, pp. 613-624.

Gulbin, Y.L. (2015), P-T paths and modeling the evolution of metapelitic mineral assemblages in the MnNCKFMASH system: A case of Northern Ladoga area // Geol. Ore Deposits, V. 57, pp. 699-711.

Gulbin Y.L., Mikhalsky E.V. (2019) Modeling of mineral parageneses and thermobarometry of metavolcanic rocks of the Ruker group in the southern Prince Charles Mountains, East Antarctica // Zapiski RMO (Proceedings of the Russian Mineralogical Society), V. 148, №5, pp. 24-44.

Henry D.J., Guidotti C.V., Thomson J.A. (2005), The Ti-saturation surface for low-to-medium pressure metapelitic biotites: Implications for geothermobarometry and Ti-substitution mechanisms // American Mineralogist, V. 90, pp. 316-328.

Holland T.J.B., Powell R. (1998), An internally consistent thermodynamic data set for phases of petrological interest // J. Metamorphic Geology, V. 16, P. 309-343.

Holness M. B., Cesare B., Sawyer E. W. (2011), Melted rocks under the microscope: microstructures and their intepretation // Elements, V. 7, P. 247252. 
Ravich M.G., Klimov L.V., Soloviev D.S. (1965), Precambrian of East Antarctica // M.: Nedra, 470 p.

Sheraton J.W., Tingey R.J., Oliver R.L., Black L.P. (1995), Geology of the Bunger Hills-Denman Glacier region, East Antarctica // AGSO Bull, No. 244, P. 1-136.

Tucker N.M., Hand M. (2016), New constraints on metamorphism in the Highjump Archipelago, East Antarctica // Antarctic Science, V. 28, P. 487-503.

Tucker N.M., Payne J. L., Clark C., Hand M., Taylor R.J.M., Kylander-Clark A.R.C., Martin L. (2017), Proterozoic reworking of Archean (Yilgarn) basement in the Bunger Hills, East Antarctica // Precambrian Research 298, p. 16-38.

Tucker N.M., Hand M., Kelsey D.E., Taylor R., Clark C., Payne J.L. (2018), A tripartite approach to unearthing the duration of high temperature conditions versus peak metamorphism: An example from the Bunger Hills, East Antarctica // Precambrian Research 314, p. 194-220. 


\title{
The principal characterized features of earth's crust within regional strike-slip zones
}

\author{
Aleksei Ageev \\ Ph.D, Assistant Professor, St. Petersburg Mining University, Saint-Petersburg, Russia \\ Aleksei Egorov \\ Doctor of Sciences, head of the Geological Department, St. Petersburg Mining University, \\ Saint-Petersburg, Russia \\ Nikita Krikun \\ Ph.D student, St. Petersburg Mining University, Saint-Petersburg, Russia
}

\begin{abstract}
Strike-slip zones are very important geological planet-scale structures. Scientific interest in studying these zones connects with frequent natural hazard (earthquakes, land-slides etc.). Moreover, active tectonics provide a high potential for mineral deposit surveys. This article is a first one in a series of articles and show the main result of modern surface structure of Earth's crust of Baikal-Stanovaya strike-slip zone. Before start, we examined results of geological and geophysical investigation of the earth's crust within most studied strike-slip zone all over the World (San Andreas and Upper-Rhine Graben). It helped us to create an algorithm of comprehensive research of crust investigated region. This algorithm consists from 3 stage. First step was accumulated geological-geophysical information about Earth's crust. At the next step we calculated transformation of geophysical potentional fields and conducted lineaments analysis. The final step was focused on compared individual lineament's schemes with geological maps and created a general tectonic scheme of Baikal-Stanovaya regional strike-slip zone.
\end{abstract}

\section{INTRODUCTION}

Regional Strike-slip Zones (RSZ) are geological structures of a planetary scale. The study of their modern structure, deep structure and evolution are fundamental tasks of modern geotectonics. High level of crust's destruction influences on minerogenic survey and metallogeny mapping (Nikolaeva, 2019). World experience in the study of new geological structures indicates that the analysis of the results of comprehensive work on the most studied strike-slip zones of the world plays an important role in the research process. Such comparison is possible only in the course of a model that considers the difference in the geodynamic parameters of the structures under study. In the research process, the authors chose a generalized "zonalblocking geotectonic model of the earth's crust" (Egorov A.S., Gulin V.D., 2014). The main structural units in this model are blocks with continental, oceanic and transitional types of crusts (areas of stationary geophysical parameters) and interblock zones (gradient zones of geophysical parameters, high seismicity and high heat flow). In that case, interblock zones correspond to suture zones, rifts, tectonic dislocations systems and main faults. The number of faults and the value of tectonic stresses within the interblock zones are several times higher than in the internal areas of relatively stationary blocks.

Nowadays, the most detail-studied by complex geological and geophysical methods is the San Andreas faults system. This tectonic zone is considered as the boundary between the North American craton and the Pacific lithospheric plate. Scientists attribute its foundation to a change in the geodynamic situation on the western edge of the North American continent 
from subduction to transform, which occurred in the Paleogene (Armstrong, Ward, 1991; Humphreys, 2003). Currently, the dextral strike-slip component predominates in the San Andreas fault system.

\section{DATA \& METHODS}

The results of comprehensive studies show that the highly seismic strike-slip zone of San Andreas is an extremely complex geological structure. The crust is characterized by a zonalblocking structure which was mapped during geological and geophysical investigations. The main tectonic units are large crustal blocks of the Pacific and North American plates: Great Valley, Mojave, Transverse Ranges, etc. (Figure 1) Their interaction occurs according to a well-developed system of tectonic dislocations which form 3 spatially joint interblock zones (San Andreas, Walker Lane, East California Shear Zone). The most structural controlling dislocation within San Andreas interblock zone is the San Andreas fault. The large part of tectonic stresses from the plate's interaction are indicating along the main fault. San Andreas fault is a very contrast structure. In potential geophysical fields it corresponds to highgradient zones. On LANDSAT images and 3D models of relief - straightened areas (10 $50 \mathrm{~km}$ length). Nearby the San Andreas fault develop numerous of secondary faults, which also seismogenic. Geological data show that these secondary faults play a key role in joining San Andreas zone with adjustments interblock zones. Results of detailed investigations of Walker Lane and ECSZ show well-developed fault systems with a network of spatially interconnected dislocations within zones. The main fault was not mapped in both structures.

The most studied trans-regional strike-slip zone in Europe is the Upper Rhine Graben (Germany). This tectonic zone bounds by the Rhine massif from the north and by the Swiss Alps

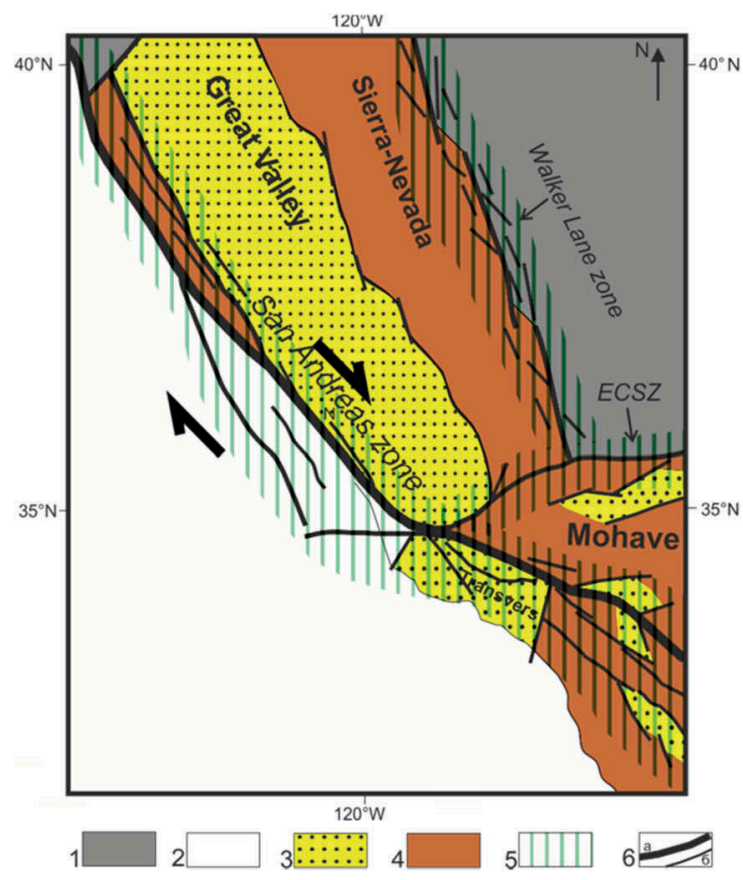

Figure 1. Tectonic scheme of the San Andreas zone.

Legend:1-2 - Lithospheric plates: 1 - North American continental plate; 2 - Pacific Ocean plate; 3-4 Alpine orogeny stationary blocks with transition type of crust: 3 - Basement covers Tretiary sediments, 4 - Basement covers volcanic sediments; 5 - Interblock zones; 6 - Faults. 
from the south (Grimmer, 2017). It is the most seismically active part of the European Cenozoic Rift System. Graben is located in its southern part of it.

The results of geological and geophysical studies show that the crust of this region can be interpreted by a zonal-blocking model. Large blocks of the continental crust are mapped: Moldanubian, Black Forest, Saxon-Thuringian and Swabian (Figure 2). The interblock zone is represented by two elongated "boundary" tectonic faults and a numerous of secondary dislocations (Fracassia, 2005). Researchers in this region identify "boundary" faults as the main structure controlling faults with dominant sinistral kinematics.

These faults mapped by geological surveys and characterize clearly visible structures on remote sensing data. Moreover, these faults correspond to high-gradient zones in potential geophysical fields. "Boundary" faults have a developed system of secondary dislocations. The fault branches extend outside the graben and to its inner region. Both "boundary" and intragraben faults are seismogenic but the intragraben faults mostly correspond normal-fault kinematics.

Scientific results of investigation earth's crust structure of San Andreas and Upper-Rhine Graben help us in studying of a strike-slip zone which develop in the territory of the Russian Federation.

The Neogene-Quaternary Baikal-Stanovaya regional strike-slip zone. It extends for more than 1,500 km east-northeast of Lake Baikal to coastline the Sea of Okhotsk (Ageev, 2016). Large crust geoblocks of the Siberian craton and the Ural-Mongolian ranges belt are most important geological structure of this region.

Research within the San Andreas and the Upper Rhine Graben showes that the first phase of a comprehensive study of the crust should be the spatial modelling of tectonic faults on the surface. In that case, authors formed a geospatial database of geological, geophysical seismological and remote sensing data. The geodatabase was created by ArcGIS 10.3 software, that provided more mobility sharing and updating the database during the research. Information was separated depend on physical properties which data contained. The scale of maps was

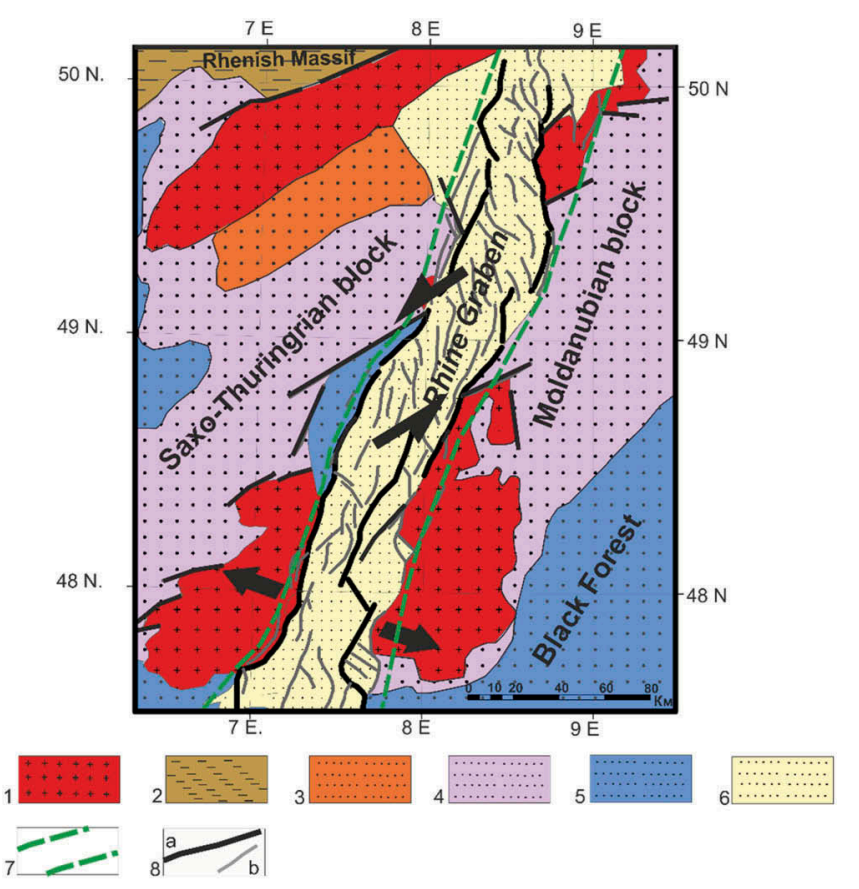

Figure 2. Tectonic scheme of the upper Rhine Graben zone.

Legend: 1 - Variscan crystalline basement; 2 - Devonian sediments; 3 - Permian sediments; 4 - Carboniferous sediments; 5 - Jurassic sediments; 6 - Tertiary sediments; 7 - Interblock zone; 8 -Faults: a - "borders", $\mathrm{b}$ - secondary faults. 
also important. In that case, we decided to divide all geodata for subdivisions: small-scale; middle-scale and large-scale formats. Small-scale format of data includes: Geological Map of Russia Federation and Adjacent Areas 1:2 500 000; Atlas of Geological Maps of Asia and Adjacent Areas; Tectonic Map of Northern, Central and Eastern Asia; The Atlas of summary maps of the territory of Russia; Map of Active Faults of Russia; In the second group were selected: Geological and Geophysical Maps 1:1 000000 (lists: O49 - O52; N49 - N52) from All-Russian Geological Institute (VSEGEI);

The main aspect in modeling the lateral distribution of tectonic dislocations were two types of independent lineament analysis: by user (visually) and by computer (PCI Geomatica software). The computer lineament analysis was used only in difficult geological situation and along geotraverses.

The whole complex of georeferenced and systematized geodata was involved in the data process. The most important source for lineaments analysis was satellite images (combined Landsat and visual model of relief). This image covers all investigated region from the lake of Baikal to coastline of the Okhotsk sea. The key features which we tried to identify were straight sections. Mostly it connected with rivers or specific landscape features. At the next step we conducted a lineament analysis of the initial potential geophysical fields (magnetic and gravity fields). The transformants (horizontal and full gradients) were also calculated and have been analyzed. Results of spatial distribution of the earthquake helped in lineament's quality. The catalog of seismic events in the south of the Siberian Platform for the period of instrumental observations from 1960 to 2019 was used in research (U.S. Geological Survey, 2019). The mistake in spatial position of earthquake estimates 1-3 km. In that case the earthquakes data plays secondary role in analysis.

At the first stage of data process we combined georeferenced individual lineaments patterns between each other. Lineaments that were not confirm at least two independent data sources removed from data process. Comparison of georeferenced lineament's schemes conducted in ArcGIS. These procedures led us to reduce a number of lineaments and helped in creation a general scheme of lineaments. The last step was focused on comparison a general lineament pattern with geological, tectonic and active faults schemes. In that case inconsistent lineaments were also deleted.

\section{RESULTS}

As a result of the studies, a tectonic scheme of the region was compiled. This map shows the zonal-blocking structure of the earth's crust. Several large crustal blocks are identified. A comparison of geophysical fields' linear features, other maps and diagrams made it possible to map and trace spatially interconnected systems of faults and independent faults through the area. Fault systems form an interblock zone, which develops from the southern end of Lake Baikal, then is mapped within the Baikal-Vitimskaya zone, and Khilock-Vitimskiy and Shilkinsky blocks and traces to the east, separating the Aldan and Stanovoy blocks. It should be noted that the main fault does not identified as a single structure. But, a large number of secondary faults are mapped. These faults mostly have echelon and linear form. It can be considered as tectonic "joints" between segments and systems of faults. Most of these faults system form Quaternary and Jurassic depressions. A general shape of interblock zone indicate a bend in a central part of it. In that area we mapped spatial connections with Mongol-Okhotskaya shear zone by group of faults. This situation is similar to San Andreas and adjacent interblock zones. The Mongol-Okhotskaya shear zone older than Baikal-Stanovaya but it also should be investigated in future research.

\section{DISCUSSION}

The results of the study show that using the model of the zonal-blocking structure of the earth's crust, it is possible to investigate different geodynamic regional strike-slip zones. The main geological units within these structures are blocks and interblock zones. The crust of the 


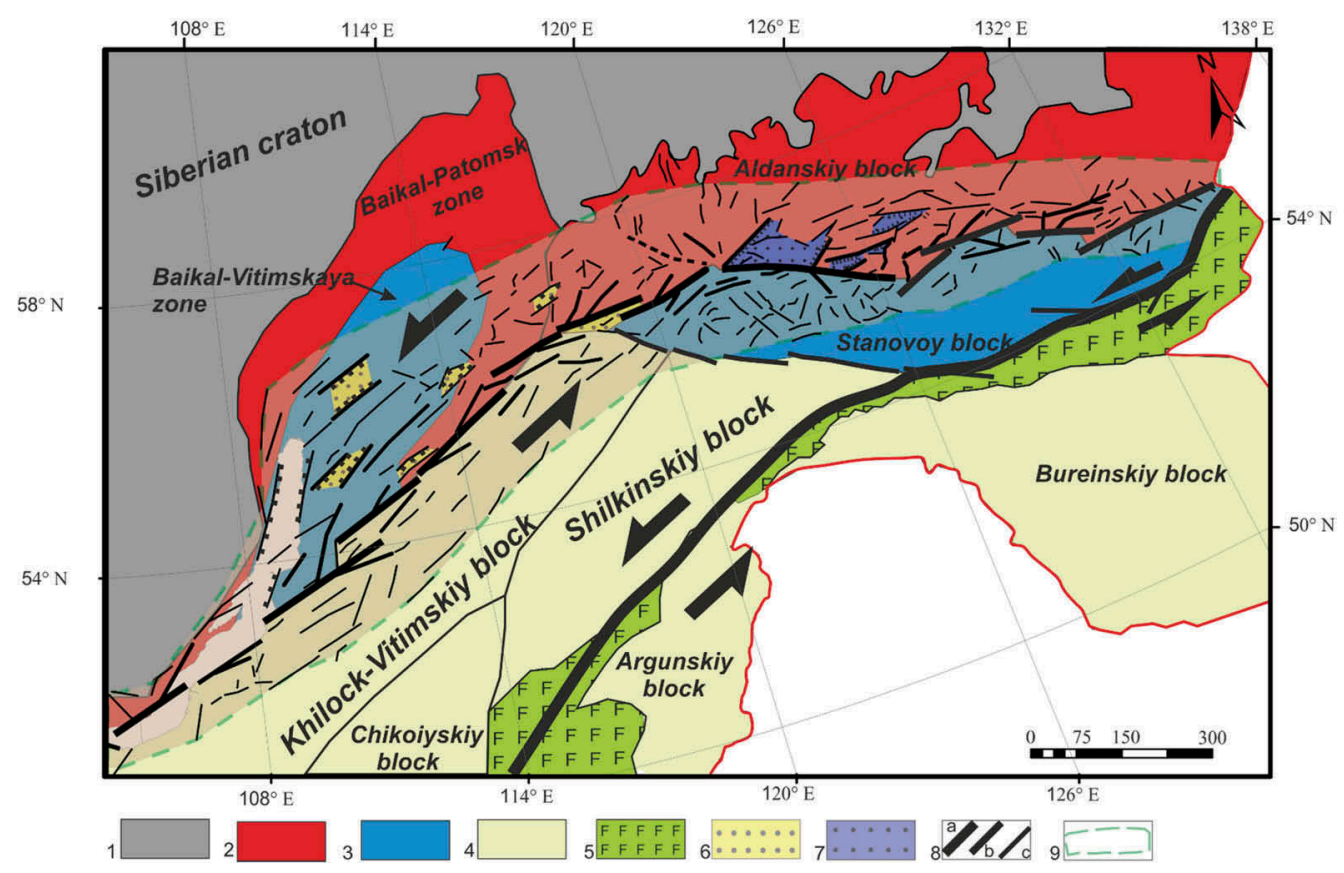

Figure 3. Tectonic scheme of Baikal-Stanovaya strike-slip zone.

Legend: 1 - Continental bocks with Archean basement; 2 - Deformed margins of Archean continental blocks; 3 - Blocks with Caledonian crystalline basement; 4 - Blocks with Cimmerian basement; 5 - Ophiolites; 6 - Neogene-Quaternary basins; 7 - Jurassic basins; 8 - Faults: a -segments of main fault, $b$-secondary faults with strike-slip kinematics, $\mathrm{c}$ - secondary faults with unknown kinematics; 9 - Interblock zone

interblock zones is characterized by the largest number of tectonic dislocations which form spatially interconnected fault systems. It was shown that the shape, quantity, and geographical distribution ensembles of tectonic dislocations within the strike-slip zones are different. These parameters depend on and mainly determined by a value and direction of the vectors of main and local tectonic stresses (Figure 3).

\section{REFERENCES}

Ageev, A.S., Ilalova, R.K., Duryagina, A.M. \& Talovina, I.V. 2019. A link between spatial distribution of the active tectonic dislocation and groundwater water resources in the Baikal-Stanovaya zone. Mining Informational and Analytical Bulletin V.5: 173-180. DOI: 10.25018/0236-1493-2019-050-173-180.

Armstrong, R.L \& Ward, P. 1991. Evolving geographic patterns of Cenozoic magmatism in the North America Cordillera: The temporal and spatial association of magmatism and metamorphic core complexes. J. Geophys. Res.V.96: P.13201-13224. DOI: 10.1029/91JB00412.

Egorov, A.S \& Gulin, V.D. 2014. Geological and geophysical deep structure researches of northern Eurasia in the zone-block model of the earth's crust. 6th Saint Petersburg International Conference and Exhibition on Geosciences: Investing in the Future 2014: 133-137. DOI: https://doi.org/10.3997/22144609.20140220.

Fracassia, U., Niviere, B. \& Winter, T.First. 2005. Appraisal to define prospective seismogenic sources from historical earthquake damages in southern Upper Rhine Graben. Quaternary Science Reviews V.24: 403-425.

Grimmer, J.C., Ritter, J.R., Eisbacher, G.H. \& Fielitz, W. 2017. The Late Variscan control on the location and asymmetry of the Upper Rhine Graben. International journal of Earth Sciences № 106: 827853. DOI: $10.1007 / \mathrm{s} 00531-016-1336-x$. 
Humphreys, E, Hessler, E., Dueker, K., Farmer, G., Erslev, E. \& Atwater, T. 2003. How Laramide-Age Hydration of North American Lithosphere by the Farallon Slab Controlled Subsequent Activity in the Western United States. In: The lithosphere of Western North America and its geophysical characterization. Klemperer S.L., Ernst W.G. (Eds.), Bellwether Publishing. Ltd. For the Geological Society of America. The George A. Thompson Volume International Book Series Volume 7: 524-544. DOI: $10.2747 / 0020-6814.45 .7 .575$.

Nikolaeva, E., Talovina, I, Duriagina, A., Vorontcova, N., Krikun, N. 2019. The Main Factors Influencing of Minor Intrusions on the Formation of Nickeliferous Weathering Crust on the Example of the Sakhara and the Elov Deposits (Urals). 19th International Multidisciplinary Scientific GeoConference SGEM 2019 Vol.18, Issue 1.1: 625-630. Bulgaria: SGEM 2019 Conference Proceedings. ISBN 978619-7408-76-8.

U.S. Geological Survey. 2018. 2017, Earthquake Facts and Statistics: accessed March 22 at URLhttps:// earthquake.usgs.gov/earthquakes/browse/stats.php (last accessed 20.01.2020). 


\title{
Dyke-like and veined bodies' complex of the Elov deposit (the Northern Urals)
}

\author{
E. Nikolaeva \\ Assist. Prof., Mining university, Saint-Petersburg, Russia \\ I.V. Talovina \\ Prof., Head of the Hystorical and dynamic geology department, Mining university, Saint-Petersburg, \\ Russia \\ G. Heide \\ Prof., Institutsdirektor, Technische Universität Bergakademie Freiberg, Freiberg, Germany
}

\begin{abstract}
The object of study is the Elov deposit, which is located in the Sverdlovsk region (the Northern Urals, Russia). Based on a comprehensive analysis of geological, mineralogical and petrographic data of the dyke-like and veined bodies of the Elov deposit, the patterns of influence of the veined rocks' composition and quality, as well as the distribution of ore mineralization in them has been researched. Further study of this topic will help to expand the region's prospects for the nickel mineralization's exploration.
\end{abstract}

Keywords: Elov deposit, Urals, nickeliferous weathering crust, minor intrusions of gabbros and granitoids, dykes, veined bodies

\section{INTRODUCTION}

The formation of nickel-bearing weathering crusts is the leading geological-industrial type in the world in terms of reserves and mining of nickel. In Russia the main deposits of nickelbearing weathering crusts are located in well-developed mining regions of the Urals and have been forming the raw material base of the cobalt-nickel industry developed in the Urals for many years.

The formation of nickel-bearing hypergenic weathering crusts is spatially confined to ultramafite formations, the bright examples of which are dunite-harzburgite complexes of the ophiolite formation type and dunite-clinopyroxenite massifs of the zonal formation type.

Nickel-bearing weathering crusts and nickel deposits associated with this type' crusts are mainly developed on ophiolite type' harzburgites and dunites, which in the Urals are represented by a considerable number of large, medium and small massifs confined to deep-seated faults and forming a series of meridional ultramafic belts. The formation of nickel-bearing weathering crusts occurs less often on the dunite-clinopyroxenite massifs of the zonal formation type, confined mainly to the Platiniferous Belt of the Urals.

The geological position and structure of many ultrabasic massifs of the Urals are interpreted ambiguously in the scientific literature despite the long period of study. In this regard, more detailed study of both the mineralogical and petrographic composition of the Urals' massifs' rocks is required. 


\section{GEOLOGY}

The Elov deposit is located on the eastern frontier area of the Kola (Serov) massif in that part of it where hyperbasites are on the border of large protrusion of gneiss-shaped diorites, which were classified by I.S. Lisov (1968) among Pre-cambrian (Figure 1).

The deposit has a very complex geological structure, it is composed of hyperbasites serpentinized to varying degrees or completely transformed into serpentinites and penetrated by dykes and dyke-like bodies of various compositions all over. The hyperbasites presented dunites, peridotites and pyroxenites. Peridotites are the predominant rocks. Dunites are spread less and often interspersed with peridotites. Pyroxenites are found in the eastern part of the deposit mainly, where they fringe the Kola (Serov) massif in the form of wide (100$300 \mathrm{~m}$ ) ribbon in contact with the Pre-cambrian gneiss-like diorites and granitoids.

Also pyroxenites were found in the southwestern part of the deposit among apoperidotite serpentinites in the form of bodies with thickness of up to 8-10 m.

In the northwestern part of the deposit the hyperbasites are on the border of diorites fresher in age, also numerous apophyses and dykes fall back into hyperbasites. These bodies have submeridional strike and steep mostly eastern pitch, their thickness of up to several tens of meters is.

In addition to the aforementioned dikes and apophyses there is a large number of weathered vein-like bodies having different compositions, a wide variety of shapes, differing thicknesses and various dips and strikes in the weathering crust of hyperbasites.

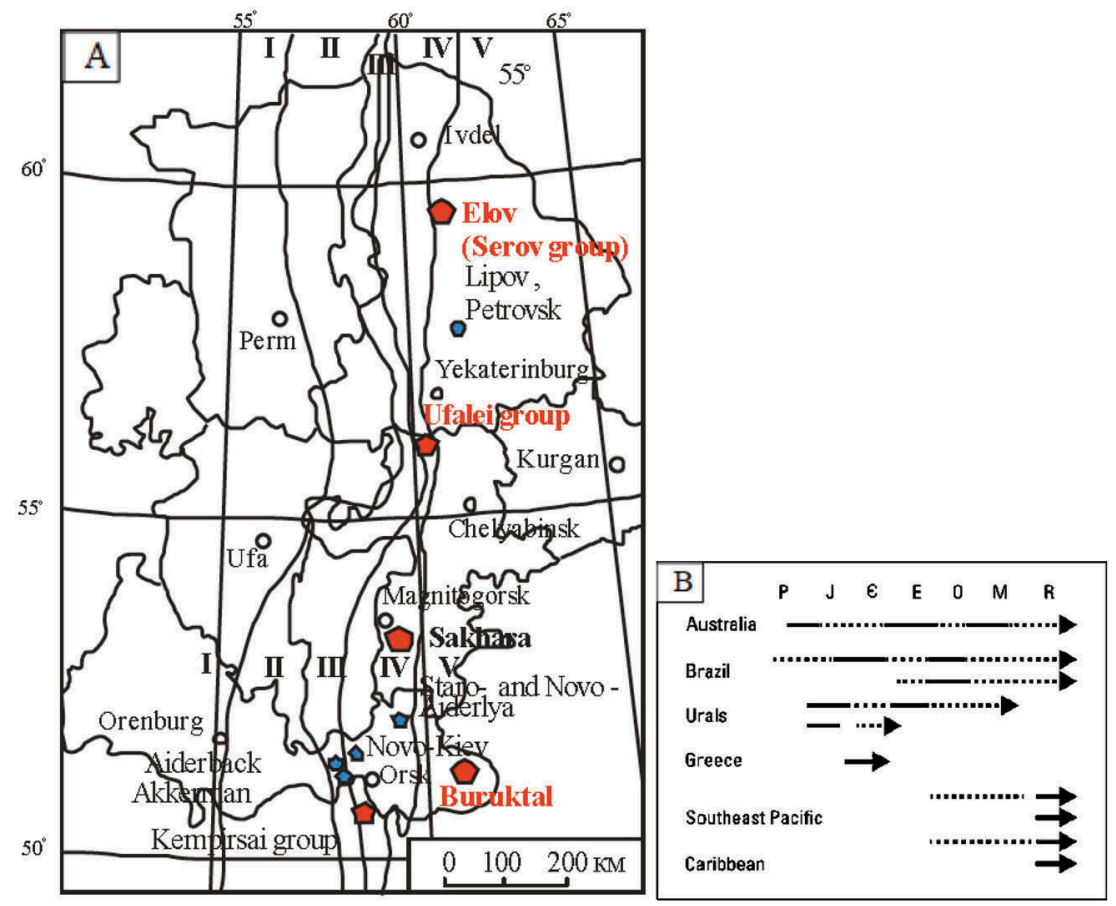

Figure 1. (A) Main tectonical units of the central and northern Urals with the nickelhydrosilicate ore deposits (after Mikhailov, 2002) and (B) Periods of nickel laterite formation in various provinces (after Marsh et al., 2013).

Tectonic zones: I, the East-European platform; II, the Fore-Ural megazone; III, the Central-Ural megazone; IV, the Tagil-Magnitogorsk megazone; V, the East-Ural megazone. Main supergene nickel deposits: the Buruktal deposit, the Ufalei group (the Cheremshanka, the Sinara, the Rogozha deposits), the Serov group (the Elov deposit). P, Paleozoic, J, Jurassic, C, Cretaceous, E, Eocene, O, Oligocene, M, Miocene, R, Recent. 
According to exploratory drilling's and mining works' data loose weathering products of vein-rocks in weathered hyperbasites are found in the upper part of the geological record much more often than vein-shaped bodies in fresh hyperbasites at depth.

Considering the data of measurements of dip and strike of vein-shaped bodies in prospect holes and cut acrosses, we can conclude that the vein-shaped bodies of southwestern strike in the central part of the Elov deposit prevail. The vein-shaped bodies of both northwestern and southeastern strike are equally spread. The vein-shaped bodies of northeastern strike are widespread in this area to a much lesser extent. The largest of them resemble "feathers" in shape with steeply going down "trunks". In the southern part of the deposit, the vein-shaped bodies are spread much less, the strike is mainly northwestern and southwestern, the pitch is steep.

In the east of the Elov deposit the shallow dipping apophyses of diorites are widespread and they form the lower parts of the geological record.

Nickel-bearing ore mineralization of the Elov deposit (Figure 2) is confined to the weathering crust of ultramafic rocks of peridotite's formation which all nickel deposits of the Urals and the North Kazakhstan are related with.

The Elov deposit (Figure 3) contains a large number of minor intrusions in contrast with all other Urals' deposits and for the formation of the weathering crust with equivalent nickel content as in other deposits with similar composition it could be required twice the amount of nickel in the source serpentinites or double expansion of decayed and weathered serpentinites, from which fully leached nickel was redeposited in orebodies.

According to calculations of the ratio of minor intrusions height to the seam height of serpentinites in the central part of the Elov deposit minor intrusions estimated $40 \%$ of total

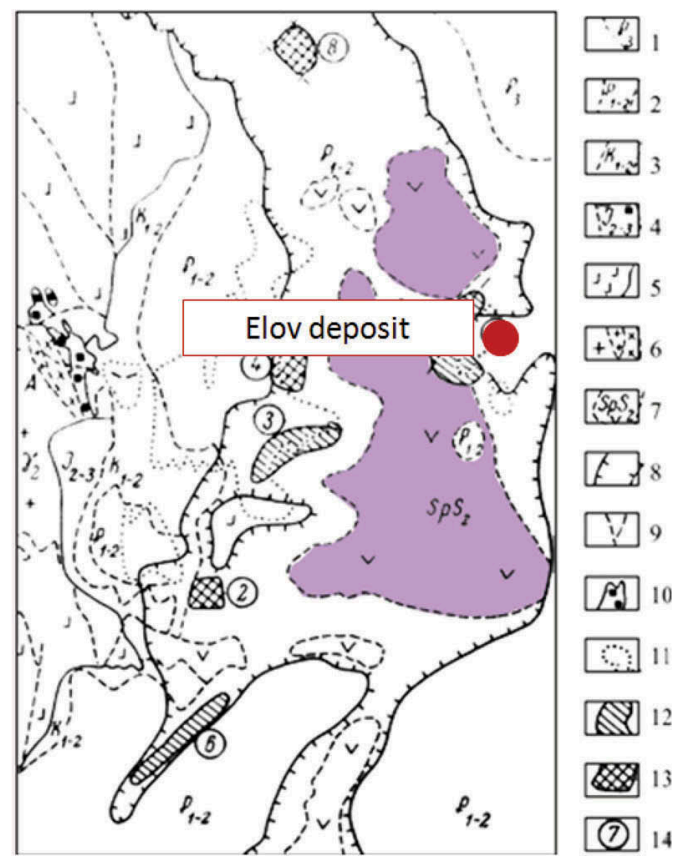

Figure 2. Schematic geological and technological map of deposits of the Serov group (after Vershinin et al., 1988).

1-4, Meso-Cenozoic deposits of the weathering crust; 5-6, Paleozoic formations; 7, day stones of serpentinites; 8, contours of serpentinites in accordance with magnetic survey and drilling; 9 , zones of tectonic dislocations; 10, chalcopyrite-magnetite skarns; 11, nodular-conglomerate sedimentary iron ores in the deposits of the Myssov suite; 12-14, deposits of supergene nickel ores of various technological types: 12, ores for alkaline hydrometallurgical process, 13 , ores for blast smelting process; 14, numbers of deposits. The Serov group of deposits: 7, Elov; 6, Katasmin; 8, Ustey; 2-4, others. 


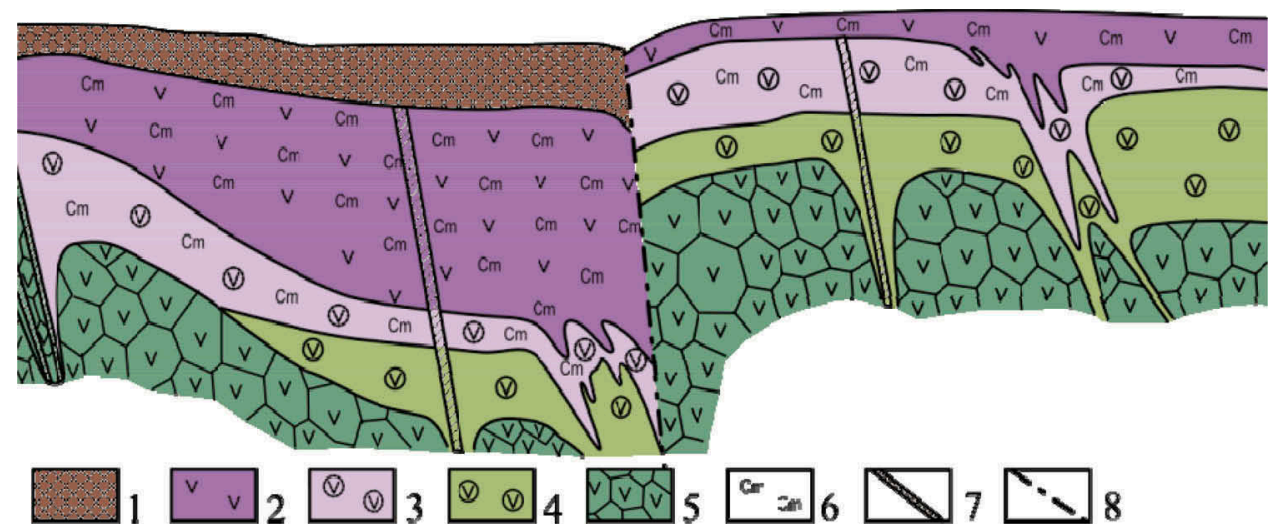

Figure 3. Geological record of the weathering crust of the Elov deposit (after Berkhin et al., 1970). 1 , nodular-conglomerate sedimentary iron ores $\left(\mathrm{K}_{1}\right) ; 2$, nontronited serpentinites; 3 , leached serpentinites; 4, disintegrated serpentinites; 5 , unaltered serpentinites; 6 , chamosites; 7 , chlorite vein-rock; 8 , fractures.

rocks thickness, sometimes in some small areas volume of vein-shaped bodies exceeds volume of the serpentinites.

\section{COMPOSITION AND STRUCTURE}

The composition of the vein-shaped bodies is different. Among them pyroxenites, gabbros, gabbro-porphyrites, odinites, spessartites, diorites and granitoids are noted. One part of the vein-shaped bodies is associated with hyperbasites, and the other part of them refers to granitoids derivatives. Some vein-shaped bodies may have a local contact-reaction-metasomatic genesis, i.e. they are the result of exposure to hyperbasites of post-magmatic liquids associated with granitoids.

The vein-shaped bodies of local contact-reaction-metasomatic genesis have a mutable composition, which varies from gabbroids to granitoids, and often a zonal structure. Zonation in most cases is asymmetric. The near-contact parts of the vein-shaped bodies are usually composed of amphibole rocks with relics of pyroxene and have different thicknesses (from a few centimeters to 1-2 meters). The following zones are represented by gabbroids, diorites, and, less commonly, granitoids sequentially to the center. Contacts between marked types can be either gradual or abrupt. Gabbroids in composition and structure resemble issites, hornblende microgabbros or metamorphic norites such as gabbro-amphibolites. They often have a banded structure, and the direction of banding coincides with the direction of contacts of the vein-shaped bodies with the surrounding hyperbasites. Gabbroids are sometimes represented by rocks of the amphibolite type, in which rocks of the diorites' and granitoids' composition are found in the form of vein-like aggregates and splices with tortuous outlines. In the vein rocks, all of the above varieties are not always present, and more often one or two varieties are absent. Amphibole rocks in the form of angular-shaped "detached masses" of up to 5-10 cm in size are observed in the diorite composition rocks. Narrow reaction rims of chlorite, tremolite and talc with a thickness of up to fractions of a meter, rarely up to 1 meter, are found at the contacts of the metasomatic vein bodies with the hyperbasites. Moreover, chlorite is formed mainly due to vein rocks, and tremolite and talc appear due to hyperbasites and serpentinites. The thickness of the contact-reaction rims depends on the thickness of the vein-shaped bodies. A thin biotite rim is occasionally present before the chlorite rim at the contacts of granitoids or quartz diorites with hyperbasites. Hyperbasites in the near-contact zones are transformed into antigorite serpentinites. The thickness of antigorite serpentinites is usually within a few meters. 
When compiling a geological map of the weathering crust of the Elov deposit, some of the many varieties of rocks described above were combined into several types:

1. the group of hyperbasites includes dunites, peridotites and serpentinites;

2. the group of gabbroids includes vein pyroxenites, gabbros, gabbro-porphyrites, amphibole near-contact rocks such as issits, also odinites and other amphibolites;

3 . the group of dioritoids includes diorites, quartz diorites, spessartites, granodiorites, plagiogranites, granites, plagiaplites and albitites.

\section{TECTONICS}

Paleozoic rocks of the deposit reflect traces of intense tectonic activity. Exploration work revealed a large number of joints and fractured zones of both submeridional and sublateral (East-West, EW) directions. Many of the largest tectonic faults, especially those with an EW trending, are controlled on the present surface of the relief by small rivers and narrows, and the largest submeridional faults in the eastern part of the deposit have steep stair-stepping benching towards the Sos'vin depression. The geological map shows mainly tectonic dislocations, renewed by adjustment movements immediately preceding the encrustation stage and later ones occurring in the Meso-Cenozoic period (cf. Ageev et al. 2019).

In Paleozoic age rocks a highly eroded weathering crust is well developed. The maximum crust thickness according to exploratory drilling wells data reaches 85 meters, and the thickness of nickel-bearing crust with industrial nickel contents in individual sections is up to $50 \mathrm{~m}$. It is represented mainly by the lower zones, i.e. the zones of leaching and integration. The weathering crust has been most fully preserved under Meso-Cenozoic deposits, especially along tectonic dislocations and joints, where strongly decomposed clay products and ochres developed after ultrabasic and basic rocks decomposition are also noted along with leached rocks.

Almost all products of ultrabasic rocks' weathering crust are nickel-bearing in the deposit, including the vein rocks under favorable conditions.

Ores associated with weathering products of ultrabasic rocks account for $76 \%$ of their total volume in the deposit. Of these, $18 \%$ are ochres and heavily ocherized leached nontronitized serpentinites. $24 \%$ of the total ore mass is associated with the weathering products of the vein rocks.

Initially, the weathering crust on the deposit had a wider development scale and greater thickness. Its upper clay and ocher products are mostly eroded at present. The erosion crust was eroded several times throughout the subsequent history of the development of the region, as a result of which the crust was almost completely eroded in some areas.

The free-open textured products of the weathering crust were transferred to the lower parts of the ancient relief of the deposit and were deposited at the bottom of lakes and swamps. They were a source of accumulation and formation of iron bean-conglomerate ores.

The Elov deposit is characterized by a shallow bedding of rocks in comparison with a number of other deposits of the Serov orefield.

In the western part of the deposit, the weathering crust directly lies under the Quaternary age deposits at a depth of the first tens of meters. Further east, as hyperbasites sink, the depth of nickel-bearing crust increases, reaching 80 meters. Meso-Cenozoic deposits appear in the geological record, at the base of which are bean-conglomerate ores. Up the geological record, bean-conglomerate ores are replaced by glauconite-quartz sands, mudstones (or argilites), silica gaizes and diatom earth.

\section{PROCESSING}

Currently, three different processes (Figure 4) are used to extract the nickel and cobalt elements from the mined rocks. The Caron process and high-pressure-acid leaching (HPAL) are mainly used for the oxide ore subtypes. For the nickel clay deposits, the HPAL method is also used with priority, whereas for the serpentine subtypes, a pure melting method is preferred. 


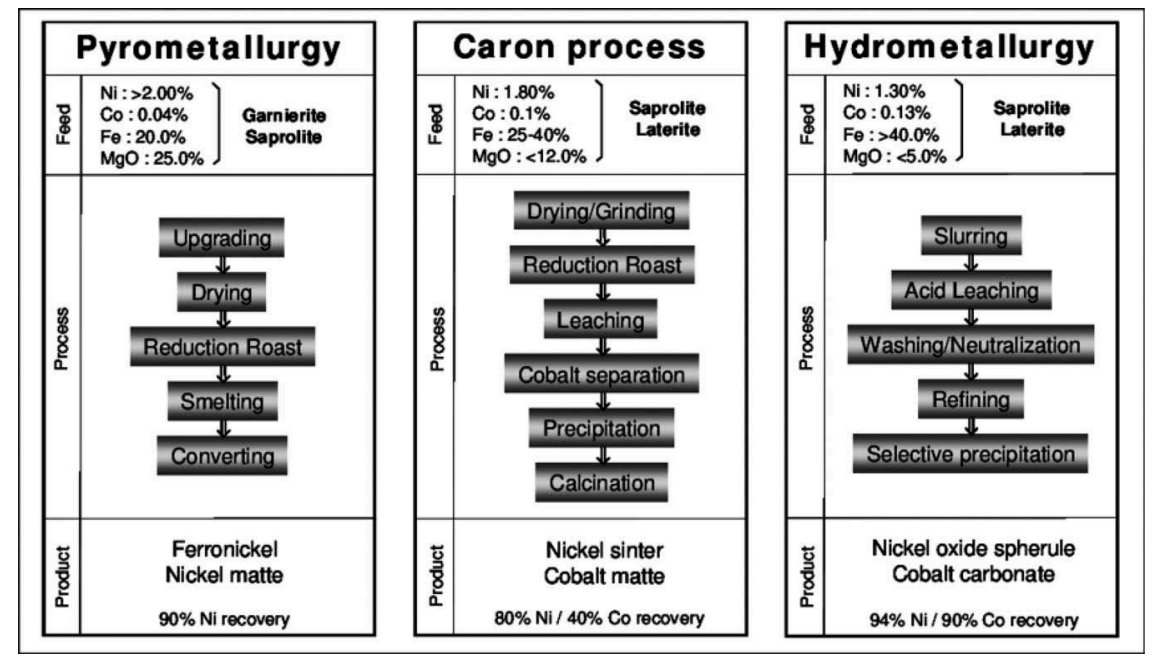

Figure 4. Main processes for the extraction of nickel out of lateritic rocks.

Ongoing research is developing new extraction methods, such as the Dni-Hydrometallurgy process developed by DirectNickel, which can also process the entire laterite profile without prior separation (cf. Kobylyanski et al. 2019). But because of the complexity needed to handle and process the nickel-cobalt laterites, much research has focused on ore delineation and mineralogical identification for distinguishing rocks. Thus it is important to characterize the mineralogy of the Elov deposit in more detail (cf. Lvov et al. 2017).

\section{MATERIALS AND METHODS}

\subsection{Samples}

For the investigation there were nine samples, which were sampled during an excursion by leading of Prof. Dr. Irina Talovina (Saint Petersburg Mining University) and Prof. Dr. Gerhard Heide (TU Bergakademie Freiberg) in the active open pit Elov nearby the town Serov in September 2014. The samples are crude ore as well as country rock that occur within the open pit area. In the following, the samples are listed in Table 1.

\subsection{Analytical methods}

The mineralogical composition of the samples was determined by using x-ray diffraction phase analysis. All samples were prepared as powder preparations. The rocks were crushed

Table 1. The investigated samples with Nickel content, $\%$.

\begin{tabular}{lll}
\hline Sample & Name & $\mathrm{Ni}$ \\
\hline SV 02 & Porphyritic serpentinite & 0.117 \\
SV 04 & Chromite ore & 0.056 \\
SV 06 & Talc-chlorite-schist & 0.542 \\
SV 07 & Limonite ore & 1.160 \\
SV 08 & Gangue rock & 0.199 \\
SV 09 & Contact-zone of SV08 & 0.163 \\
SV 10-1 & Silicate nickel ore & 0.101 \\
SV 10-2 & Silicate nickel ore & 0.979 \\
SV 11 & Oxide nickel ore & 1.030 \\
\hline
\end{tabular}


with a hammer down to a grain size $<400 \mu \mathrm{m}$. The bulk samples were subsequently divided using quarter cross. Further crushing was done using the ball mill XRD-Mill McCrone with $\mathrm{ZrO} 2$-grinding bodies. Technical ethanol $(96 \%)$ was used for cooling and to guarantee careful grinding. After drying, the samples were homogenized by means of an Ardenne vibrator and finally sieved with a $200 \mu \mathrm{m}$ sieve into an aluminum cuvette using the side-loading procedure. The measurements were executed with URD 6 (Mineralogical laboratory TU Bergakademie Freiberg) with Co-radiation.

To investigate the swelling capable minerals which show mainly wide reflexes in the $14 \AA$ area, texture preparations were produced in the traditional way. The selected samples were first measured in an air-dried state, afterwards they were saturated in ethylene glycol vapor and then measured again. The ethylene glycol accumulates in the interlayers of the minerals and causes a widening of the structure, thereby increases the layer distance. After the second measurement, all texture preparations were annealed at $400{ }^{\circ} \mathrm{C}$ and measured again. The last measurement was executed after an annealing process at $550{ }^{\circ} \mathrm{C}$.

Thermal analyses were carried out in the mineralogical laboratory of the TU Bergakademie Freiberg by Dipl.-Chem. Margitta Hengst. All measurements were realized by means of the STA 409 PC, and a heating rate of 10 kelvin per minute, up to a maximum temperature of $1200{ }^{\circ} \mathrm{C}$. As carrier gas, purified air was used for all analyses. The reference material for the DTA analyses was corundum (cf. Földvari 2011).

The observations on the scanning electron microscope (SEM) were mainly examined on polished thin sections of the solid rocks. Individual measurements were also carried out on strewn slides. For the investigations it was possible to use the CarryScope JCM-5700 from the museum "Terra Mineralia Freiberg". This SEM is equipped with a Bruker EDX (133eV). The focus of this analytical method was the determination of the spinel group minerals. Further questions arose with regard to the distribution of the various valuable elements inside the rock units, primarily nickel. As far as possible, this method allowed the investigation of the local coupling of nickel to the various minerals.

\subsection{Results}

The chemical analyses show a significant accumulation of nickel in various rocks of the open pit. Most of the silicate dominated areas of the deposit contain higher nickel concentrations, however, they are not high enough to reach economic relevance. The rocks display nickel contents between $0.101 \%$ and $0.542 \%$. An exception is the major amount of silicate nickel ore (SV $10-2$ ), which at $0.979 \%$ shows significantly increased nickel contents of economic importance. It is note-worthy that only the unaltered areas of the silicate nickel ore have significantly elevated contents, while the secondary silicified zone has only a very low nickel content of $0.101 \%$. Since the biggest difference lies in the mineral composition, in this case the increased content of serpentine and especially smectite in the non-silicified areas, the nickel must be linked to exactly these minerals. It can be assumed that these are typical nickel-containing nontronites (cf. Brindley 1984b, Brindley et al. 1973).

The highest nickel contents were detected in the oxidic type nickel ore of SV $11(1.03 \%)$ and in the limonite ore of SV $07(1.16 \%)$. Thus, these areas are most enriched when considering the absolute contents. As far as the limonite ore is concerned, it can be assumed that the nickel is primarily coupled to nickel-rich goethite and very occasionally to nickel sulphides. The rock contains neither smectite nor talc, and the serpentine branch veins (apophysis) in which EDX analyses did not show any major nickel content, are the result of later secondary formation. According to the elevated position of the dehydroxilation peak, the thermal analyses of goethite indicate a significant foreign metal substitution, further substantiating the thesis of nickel-rich goethite (cf. Talovina 2012, Talovina et al. 2008, 2010, 2011, 2012). Although nickel sulphides have been detected in limonite ore, their absolute contents are negligible compared to the substitutional placement in the goethite structure. This is corroborated by the missing peaks in the powder diffraction pattern as well as by the low sulphur content of the sample. It merely amounts to $0.10 \%$ sulphur content compared to the $1.16 \%$ nickel content. In the oxidic type nickel ore (SV 11), the nickel carrier cannot be reliably determined. 
However, enrichment in the silicate components seems to be plausible, especially in chlorite and smectite as well as in goethite, which also has increased d values. Also in this particular rock the serpentines showed no relevant nickel content throughout the EDX measurements.

\section{CONCLUSION}

The Serov group of deposits is one of the sedimentary-infiltration formations. The OrskKhalilovsk, Aydyrlinsk and other deposits, except the Elov deposit, belong to this kind of formations in the Urals. In this type a significant role belongs to the nickel-containing ore-forming ferruginous chlorite, i.e. shamosite $(\mathrm{Fe} 5 \mathrm{Al})(\mathrm{AlSi3O})(\mathrm{OH}) 8$. The deposits of this type had experienced a rather complex history of formation, including the stage of epigenesis (destruction, transportation and deposition with the formation of ferrous sedimentary rocks) in addition to the lateritogenesis stage (cf. Yudovich et al. 2011).

The vertical zonal profile in the nickel weathering crust of the Elov deposit is observed (from the bottom up): serpentinized ultramaficites (substrate) - serpentinite zone - nontronite zone - oxide-iron zone. Separately, it is worth noting the shamosite zone, which belongs to the converted part of the weathering crust of the Elov deposit, has a limited distribution and replaces serpentinite, nontronite and oxide-iron zones in part or completely.

The research displays a very diverse mineralogy in the rocks of the Elov deposit. It was shown that different types of rocks from variously weathered areas of the deposit have relevant nickel contents. Due to the different mineralogy of the nickel-bearing minerals between laterite and saprolite, both a selective mining and a selective processing of the individual types of ore should be considered.

\section{ACKNOWLEDGEMENTS}

The work is carried out with financial support of Ministry of Education and Science of Russian Federation according to grant program "Research and development in priority areas of development of Russia's scientific and technical complex for 2014 - 2020", the project RFMEFI61620X0127.

\section{REFERENCES}

Ageev A. S., Ilaliva R. K., Duryagina A. M., Talovina I. V. A link between spatial distribution of the active tectonic dislocation and groundwater water resources in the Baikal-Stanovaya shear zone. Gornyy informatsionno-analiticheskiy byulleten'. 2019;5:173-180. [In Russ]. DOI: 10.25018/0236-14932019-05-0-173-180.

Bugelskiy, J. J., I. V. Vitovskaya, A.P. Nikitina. 1990. Ekzogennye rudoobrazujushhie sistemy kor vyvetrivanija (Exogenic Ore-forming Systems of Weathering Crusts). Moscow, Nauka, 365 p. (in Russian).

Földvari M. 2011. Handbook of thermogravimetric system of minerals and its use in geological practice. In Occasional Papers of the Geological Institute of Hungary, Vol. 2, 180 p.

Gottman, I. A., E. V. Pushkarev. 2009. Geologicheskie dannye o magmaticheskoi prirode gornblenditov v gabbroul'tramafitovyh kompleksah Uralo-Alyaskinskogo tipa (Geological data on the magma nature of hornblendites in gabbroultramafic complexes of the Ural-Alaskan type). Litosfera, 2, 78-86 (in Russian).

Kobylyanski, A., Zhukova, V., Petrov, G., Boduen, A.Y. 2019. Challenges in processing copper ores containing sulfosalts. DOI: 10.1201/9781003017226-18. In book: Scientific and Practical Studies of Raw Material Issues, pp.120-128.

Lazarenkov, V. G., I. V. Talovina, I. N. Beloglazov, V. I. Volodin. 2006. Platinovye metally $v$ gipergennyh nikelevyh mestorozhdenijah i perspektivy ih promyshlennogo izvlechenija (Platinum metals in supergene nickel deposits and prospects for their commercial extraction). St Petersburg, Nedra, 188 p. (in Russian).

Lvov V., Sishchuk J., Chitalov L. Intensification of Bond ball mill work index test through various methods//17th International multidisciplinary scientific geoconference and expo SGEM - 2017, Vol. 17, Issue 11, pp. 857-864. DOI: 10.5593/sgem2017/11/S04.109. 
Marsh, E., E. Anderson, F. Gray. 2013. Nickel-Cobalt Laterites - A Deposit Model Chapter H of Mineral Deposit Models for Resource Assessment. - In: Scientific Investigations Report 2010-5070-H. Reston, USGS, $38 \mathrm{p}$.

Mikhailov, B. M. 1999. Nickel ores in the Urals. Lithology and Mineral Resources, 35, 4, 351-364.

Mikhailov, B .M. 2002. Perspective of mineral base of nickel industry in Urals. Regionalnaya Geologiya i Metallogeniya, 15, 97-109.

Marin, Y .B., V. G. Lazarenkov. 1992. Magmatic formations and their ore-bearing. St. Petersburg, Mining University (SPbGGI), $166 \mathrm{p}$.

Nikolaeva, E.; Talovina, I.; Duriagina, A.; Vorontcova, N.; Krikun, N. 2019. The main factors influencing of minor intrusions on the formation of nickeliferous weathering crust on the example of the Sakhara and the Elov deposits (Urals). 19th International Multidisciplinary Scientific GeoConference SGEM 2019: SGEM; Sofia Vol. 19, Issue 1.1,: 625-630. Sofia: Surveying Geology \& Mining Ecology Management (SGEM). (2019) DOI:10.5593/sgem2019/1.1/S01.077.

Nikolaeva, E.S., Talovina, I.V., Nikiforova, V.S., Heide, G. 2019. Chemical composition and genesis of serpentinite group minerals in nickeliferous weathering crust of the Elov deposit (Urals). DOI: 10.1201/9781003017226-1. In book: Scientific and Practical Studies of Raw Material Issues, pp.3-10.

Talovina, I. V., G. Heide. 2016. Serpentines of Chrysotile-pecoraite series as genesis indicators of nickel deposits in the Urals weathering crusts. Journal of Mining Institute, 221, 629-637. DOI 10.18454/ PMI.2016.5.629.

Talovina, I. V., V. G. Lazarenkov, S. O. Ryzhkova, V. L. Ugolkov, N. I. Vorontsova. 2008. Garnierite in Nickel Deposits of the Urals. St. Petersburg State Mining Institute (Technical University), Lithology and Mineral Resources, 43, 6, 588-595.

Talovina, I. V. 2012. Geohimija uralskih oksidno-silikatnyh nikelevyh mestorozhdenij (Geochemistry of the Uralian oxide-silicate nickel deposits). St. Petersburg, Natsionalnyi mineralno-syrevoi universitet "Gornyi". 270 p. (in Russian).

Talovina, I. V., N.I. Vorontsova, S. O. Ryzhkova O. P. Mezentseva, A. G. Pilugin. 2012. Harakter raspredelenija redkozemel'nyh jelementov v rudah Elovskogo i Buruktalskogo gipergennyh nikelevyh mestorozhdenij (Pattern of rare earth element distribution in ores of the Elov and Buruktal supergene nickel deposits). Zapiski Gornogo Instituta, 196, 31-35 (in Russian).

Talovina, I. V., V. G.Lazarenkov, N. I. Vorontsova, O. P. Mezentseva, S. O. Ryjkova, A. G. Pilugin. 2010. Geochemistry of impurity elements in Buruktal supergene nickel deposit, South Urals. FreibergSt. Petersburger interdisziplinares Kolloquium junger Wissenschaftler. Technische Universitat Bergakademie Freiberg. 40-43.

Talovina, I.V., V. G. Lazarenkov, U. Kempe, M. Tichomirowa, N. I. Vorontsova, A. G. Pilugin. 2011. Value in Millerite and Genesys of Chamosite Nickel Ores in the Elov Supergene Deposit (Serov Group), North Urals. Scientific Reports on Resource Issues. Vol.1: Latest Developments in Mineral Industry Geology, Mining, Metallurgy and Management. TU Bergakademie Freiberg. 30-34.

Talovina, I. V. 2012. Geochemistry of supergene nickel deposits of the Urals. PhD Thesis, G.-M. Sciences: 25.00.09., St. Petersburg, 270 p.

Volchenko, Y. A., K. S. Ivanov, V. A. Koroteev, T. Auger. 2007. Strukturno-veshhestvennaja evoljuciya kompleksov Platinonosnogo pojasa Urala pri formirovanii hromit-platinovyh mestorozhdenii uralskogo tipa (Structural-compositional evolution of the Ural Platinum Belt complexes during the formation of platinum-chromite deposits of the Ural type). Part 1. - Litosfera, 4, 73-101 (in Russian).

Yudovich, Y. E., M. P. Ketris. 2011. Geochemical indicators of lithogenesis (lithological geochemistry). Syktyvkar, Geoprint, 742 p. 


\title{
Longwall panel width optimization
}

\author{
D. Belova \\ Postgraduate student, St. Petersburg mining University, St. Petersburg, Russia
}

A. Sidorenko

PhD, Associate professor, St. Petersburg mining University, St. Petersburg, Russia

\author{
A. Meshkov \\ «SUEK-Kuzbass»
}

\begin{abstract}
The article discusses the issues encountered by mining companies in Russia when extracting coal through the use of fully mechanized longwalls. The article presents the results of an analysis of coal mining operations in the world's largest coal producers (USA, Australia, and Russia). As a result of the analysis, it has been determined that longwall panel width depends on a range of geological and engineering factors, such as average annual production, panel length, working height, depth of cover, etc. Using the cases of several Australian mines, the authors examine the influence of longwall panel dimensions on water inflows in the longwall face and mine faces taking into account the influence of overburden pressure and fracture density. The issue of massive water inflows at the thick-seam coal mine named after V. D. Yalevsky in the Kuznetsk Basin is considered. The results of mathematical modelling and economic evaluation for different longwall panel dimensions presented in the article make it possible to determine the range of optimal longwall panel dimensions with due consideration of working heights.
\end{abstract}

\section{INTRODUCTION}

When facing volatility and tough competition in the global coal market, one of the key issues for coal mining companies is to reduce their production costs. The main cost-reducing method in underground coal mining is to deploy a fully mechanized longwall system, which delivers excellent results in terms of productivity and economic performance if there are no mining constraints. However, as the main coal-mining regions in Russia are characterized by complicated geological settings, it negatively influences equipment performance indicators. This is why searching for optimal engineering solutions for the effective use of advanced equipment is an important practical task for Russian mines. The longwall method is the most popular method of underground coal mining in Russia. Such parameters of longwalls as panel width and length have a significant impact on productivity and safety. It should be noted that Russia has not yet accumulated any experience in using longwall faces with a length of more than $400 \mathrm{~m}$ (only one mine has been operating with a panel width of $400 \mathrm{~m}$ since 2017), which makes analyzing the experience accumulated by the top coal-producing countries of particular interest.

\section{LITERATURE REVIEW}

One of the global coal mining leaders is the United States of America in terms of not only production indicators but also the state of technology used in mining operations. When analyzing data on American longwall mining operations over the last 35 years, it can be noted 
that over this period the share of panels with widths ranging from 122 to $183 \mathrm{~m}$ decreased from $81 \%$ in 1984 to $5 \%$ in 2018 , with a large share taken by panels having a width over $305 \mathrm{~m}$ (Figure 1). It should be stressed that there is a common upward trend in panel width seen in all the top coal-mining countries and the number of longwalls being operated in the U.S. almost halved over the same period due to the use of state-of-the-art equipment in favourable geological settings and an increased concentration of production.

If we look at how longwall panel width influenced average annual production in U.S. coal mines over a period from 2013 to 2018 (Figure 2), it becomes obvious that longwalls with panel widths exceeding $400 \mathrm{~m}$ are characterized by the highest production rates in each of the years analyzed (Fiscor, 2014-2019).

It should be kept in mind that the choice of longwall panel dimensions depends on geological settings and engineering parameters, such as working height and depth of cover.

Based on the analysis of data on U.S. mines operating in 2018, it can be argued that, as a rule, thick coal seams are mined using panel widths of up to $350 \mathrm{~m}$, whereas medium-thick seams are mined using bigger panel widths.

The influence of the depth of cover on the choice of panel width is the following: the greater the depth, the less likely the use of panel widths exceeding 300-350 m.

Each of the above factors influencing the choice of panel width is, in its turn, influenced by overburden pressure and face ventilation conditions.

At the same time, panel dimensions are undoubtedly interrelated, which makes it necessary to find the optimal panel length when determining the optimal panel width. This requirement is based on the fact that geological data on the block of the seam being mined is unevenly distributed. In 2018, panels with widths ranging from 350 to $400 \mathrm{~m}$ had the biggest length

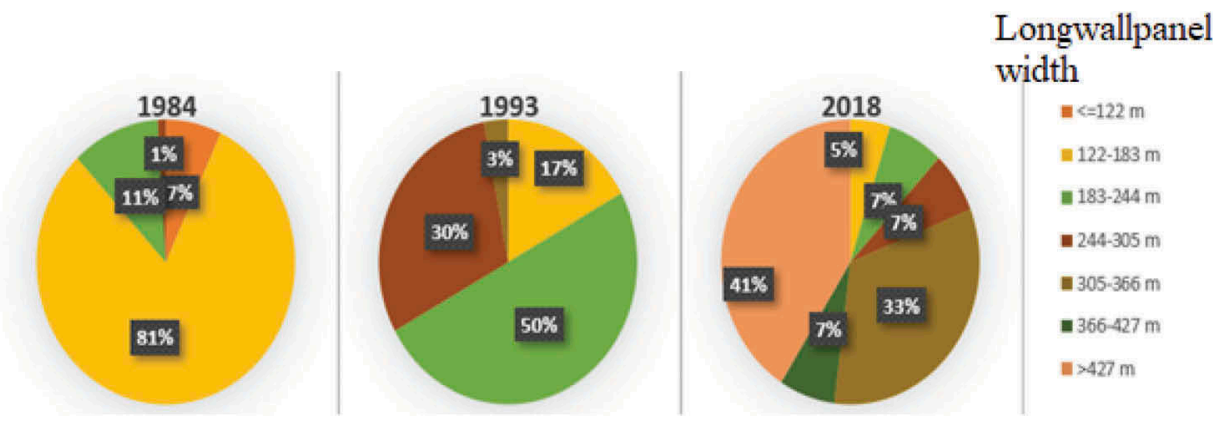

Figure 1. Shares of U.S. mines active in 1984, 1993, and 2018 based on longwall panel width.

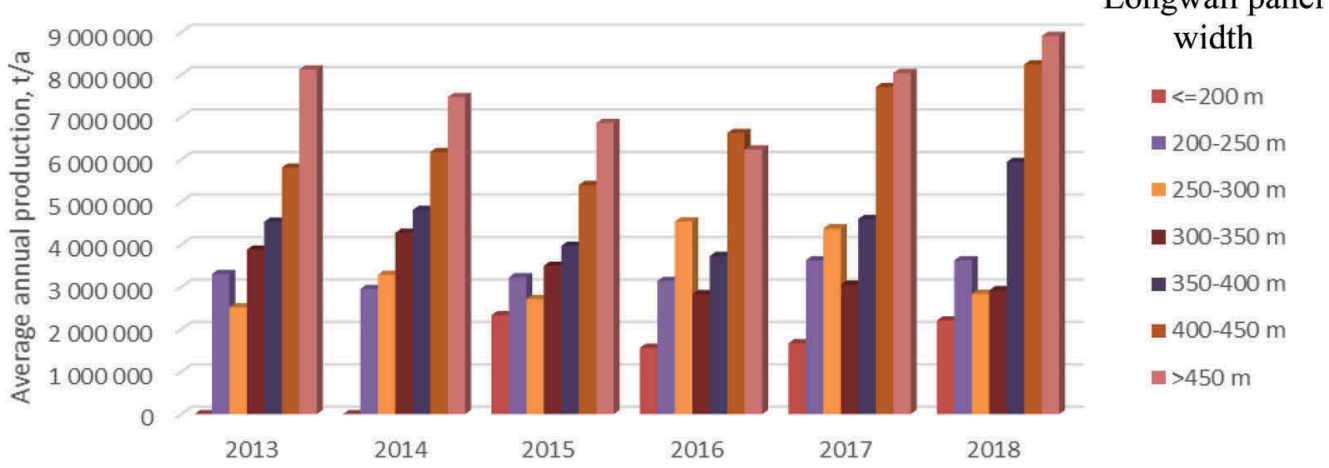

Figure 2. The dependence of average annual production on longwall panel width at U.S. mines for years 2013 to 2018 . 


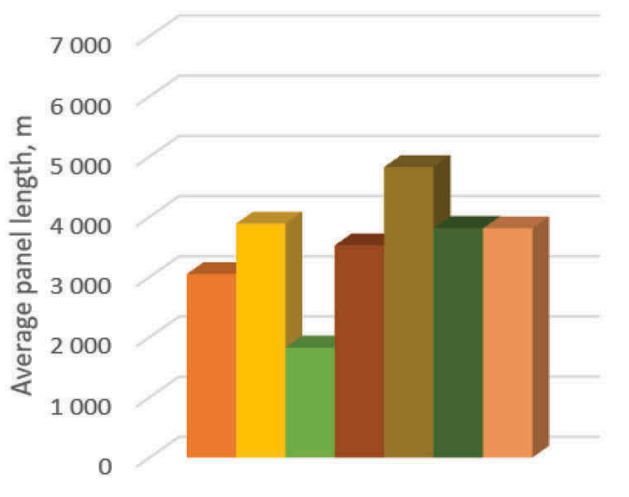

E $<=200 \mathrm{~m} \quad 200-250 \mathrm{~m}=250-300 \mathrm{~m} \square 300-350 \mathrm{~m}$ - $350-400 \mathrm{~m} \square 400-450 \mathrm{~m} \square>450 \mathrm{~m}$

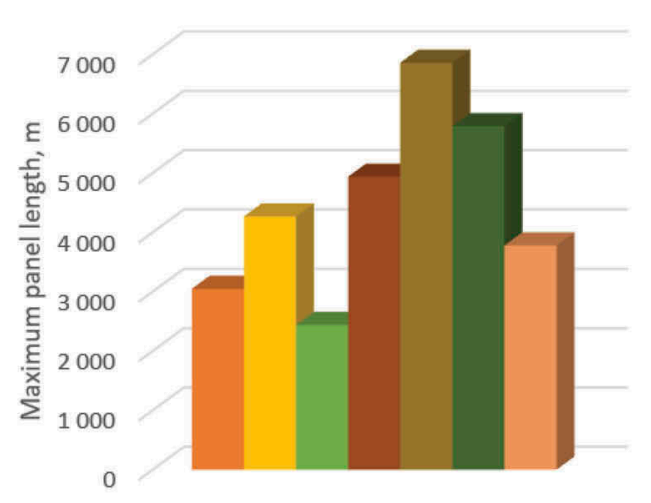

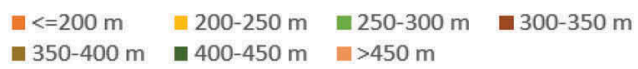

Figure 3. The dependence of average and maximum panel lengths on panel width in the U.S. in 2018.

(about $7 \mathrm{~km}$ ) along with the biggest average length (Figure 3). Based on these figures, it can be assumed that an increase in panel length sets the stage for an increase in panel width.

Under ideal geological settings, i.e. when the coal seam is flat-lying and free of such geologic structures as faults and joints, the methane content is low, and water inflows are regular as mining operations are conducted far enough from river valleys or lake basins or other sources of massive water inflows, an increase in panel dimensions undoubtedly leads to an increase in equipment utilization efficiency and a growth in the concentration of production at minimum cost. However, when geological settings are not ideal, the feasibility of increasing panel length should be studied from an economic perspective. The main questions arising in this process are: what restrictions are there on increasing panel dimensions and how much do these restrictions affect the productivity indicators of one or another mining sequence?

The positive results of increasing panel dimensions (a decrease in the number of assembly and disassembly operations in the mine, a decrease in the unit cost of panel preparation, an increase in face productivity, more regular methane emissions, and a decrease in coal loss due to chain pillars) in real-life geological settings should be considered along with negative consequences (an increase in absolute methane emissions from the seam being mined into the working area, an increase in methane emissions from adjacent seams into the mined-out areas, an increase in the length of assembly and disassembly operations in the working area, an increase in initial capital costs due to the cost of equipment, an increase in the variability of geological settings within one panel, as well as an increase in loads on load-bearing elements and, as a result, a bigger influence of overburden pressure).

An example of a mine characterized by negative results of an increase in panel dimensions is the mine named after V. D. Yalevsky (the Kuznetsk Basin). The section of coal seam No. 52 being mined is affected by the Srednyaya Salanda River valley causing massive water inflows into the longwall face and the mine faces. As a rule, when there are massive water inflows, it is recommended that reserves should be mined in a bottom-up sequence to prevent water from flooding the faces (Chemezov, 2019). However, an increase in panel dimensions has resulted in the fact that the geological and geometrical characteristics of the coal seam within one panel are so different on the up-dip and down-dip sides that the extraction sequence has to be changed. When mining in a top-down sequence, there is a sharp drop in face productivity.

It is considered that the main reason causing massive water inflows is an increase in panel dimensions. For example, in a report on one of the Australian mines dated October 29, 2008 (Gale, 2008), the author analyzes the effect of changes in panel width on water inflows into working areas. Using computer modelling tools, the author shows that with an increase in panel width, there is a bigger zone of destressed strata, which causes stress redistribution and, as a consequence, a growing zone of high rock pressure resulting in extra fracturing. An 
increase in fractre density entails an increase in water inflows at the face ends. However, such a parameter as the depth of cover should also be taken into account. At shallow depths, the influence of these processes is especially great, since the river valley, as a rule, is impacted by mining operations even if there are impermeable layers. However, with an increase in the depth of cover, the impact of mining operations on the layers located closer to the surface diminishes, which suggests that there is such a depth of cover at which an increase in panel dimensions does not have a significant impact on water inflows into the longwall face and the mine faces.

According to the results of studies conducted at another Australian mine in 2015 (Skorulis\& Minchin, 2015), the impact of longwall mining operations can be graphically represented in the following way (Figure 4):

The dimensions of each zone are calculated individually for each kind of geological settings and each set of panel dimensions. The results of calculations make it possible to predict, to some degree, the intensity of water inflows into longwall faces, which, in turn, enables engineers to take precautions against water inflows and tackle the issue of a drop in face productivity.

\section{MATERIALS AND METHODS}

In order to find the optimal panel width, mathematical modelling and economic evaluation of the dependence between panel width and performance indicators were carried out. In the model, the total unit costs for the main items as well as the net present value (NPV) were taken into account. A range of panel widths from 200 to $450 \mathrm{~m}$ with a step of $50 \mathrm{~m}$ was analyzed. The model was built using the parameters of geological settings at the mine named after V. D. Yalevsky (SUEK-Kuzbass).

Mathematical modelling and economic evaluation were carried out taking into account the following cost items: unit production costs, unit development costs, total unit costs. As the next step, the price for coal as of the moment of modelling was taken to calculate the income based on different production volumes, which was later discounted.

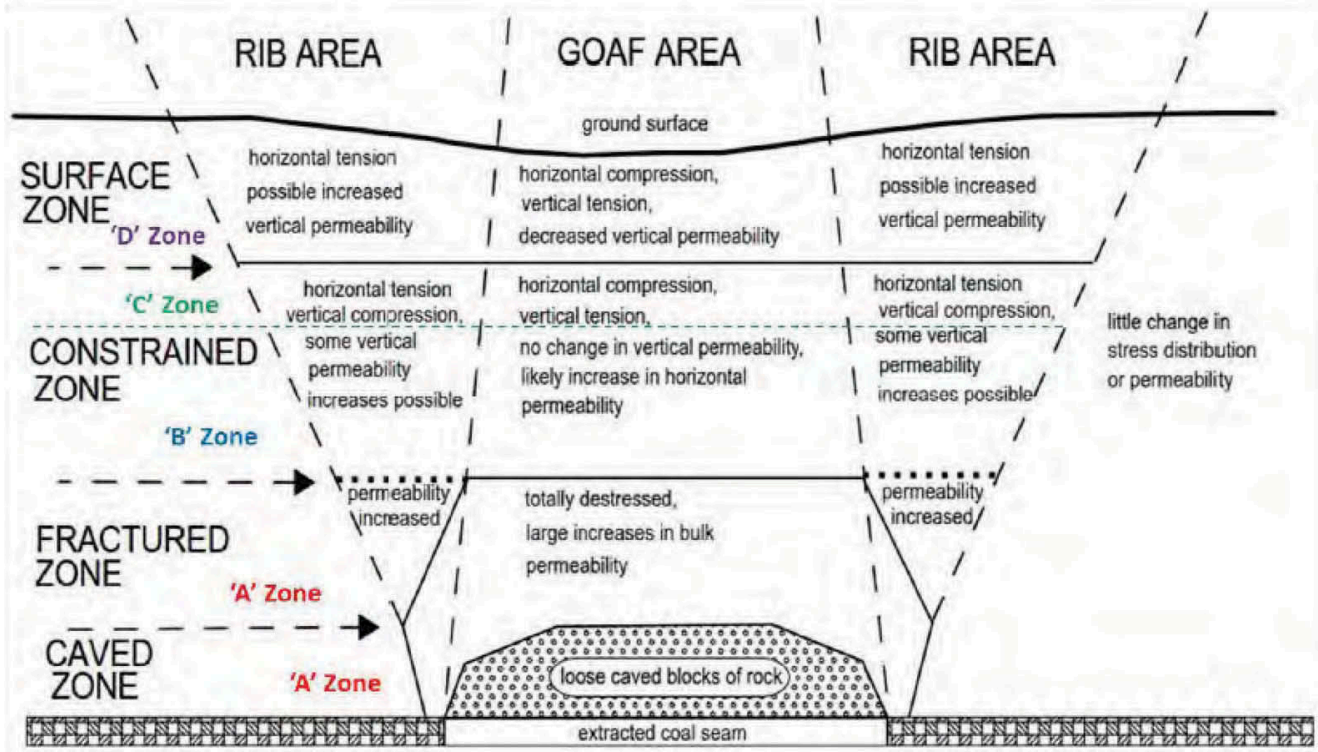

Figure 4. Zones of disturbance and hydrogeological effects following longwall mining (Skorulis\& Minchin, 2015). 


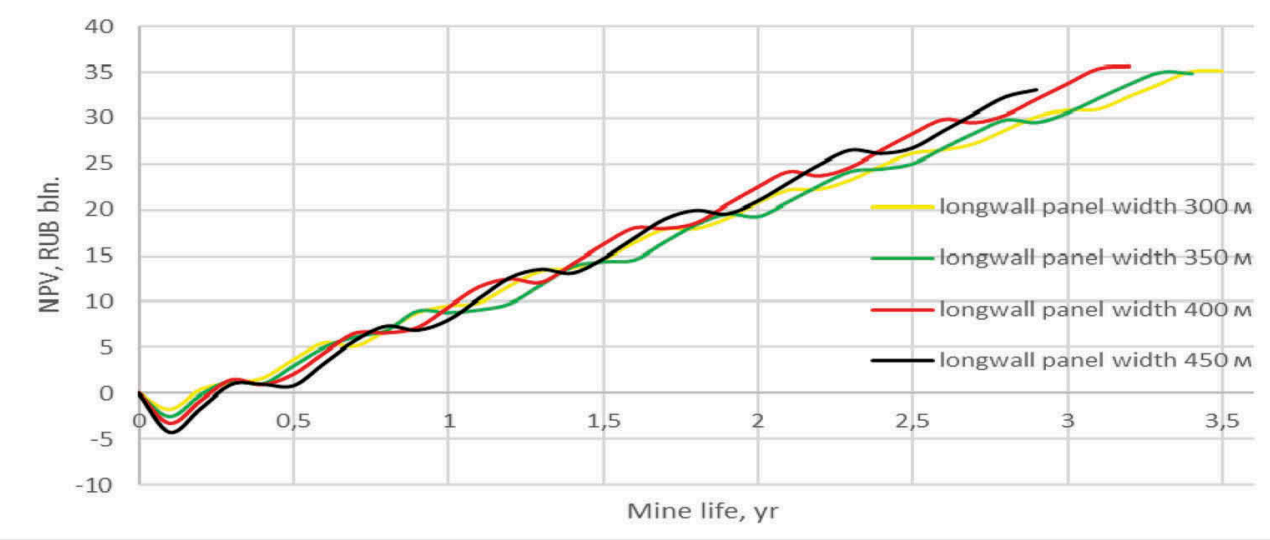

Figure 5. Changes in NPV over time depending on longwall panel width.

\section{RESULTS}

As a result of mathematical modelling and economic evaluation, unit development costs and unit production costs were calculated for each panel width option, based on which the net present value for the most cost-effective options was found (Figure 5).

\section{DISCUSSION}

Assuming that the calculation error associated with the inaccuracy of the initial data and other factors is $10 \%$, the optimal panel width ranges from 300 to $450 \mathrm{~m}$. This is a range within which the total unit costs are at a minimum.

After calculating the net present value for this range of longwall panel widths and analysing its change over time, it becomes clear that a panel width of $400 \mathrm{~m}$ is the optimal one, since it results in the highest net present value over the shortest period possible (Figure 5). However, a panel width of $450 \mathrm{~m}$ could also be an optimal solution but for the fact that there are dimension limits, which, when exceeded, result in an increase in coal loss.

\section{CONCLUSION}

The analysis of longwall mining practices in the top coal-producing countries has revealed that there is a global upward trend in longwall panel dimensions, with panel width reaching 400 to $500 \mathrm{~m}$ and panel lengths reaching 6 to $8 \mathrm{~km}$, which is a result of utilizing reliable highperformance equipment. However, there is a range of factors limiting the use of such panels. Among them are significant methane emissions, and limited panel length. The main factors limiting panel length are the limited size of the area being mined, the presence of faults and joints, as well as complex geometry and geological settings accompanied by massive water inflows. It has also been revealed that longwall panel dimensions are interrelated: an increase in panel length sets the stage for an increase in panel width. In addition, longwall panel width is greatly affected by working height, since an increase in panel width results in an increase of coal volume within the panel and, consequently, a decrease in unit development costs. The results of mathematical modelling and economic evaluation show that using longwall panels with widths bigger than $400 \mathrm{~m}$ in thick coal seams is impractical, which is also confirmed by the fact that no such panels are used in the top coal-producing countries. 
Further research will be conducted with the view to solving the issue currently relevant to Russian mines, which is finding optimal longwall panel dimensions in mines characterized by complex seam geometry and geological settings and influenced by massive water inflows.

\section{REFERENCES}

Skorulis A., Minchin W., 2015. Report «Estimated Height of Connected Fracturing above Dendrobium longwalls», https://www.south32.net

Chemezov E.N. Industrial safety principles in coal mining. Journal of Mining Institute. 2019. Vol. 240, p. 649-653. DOI: 10.31897/PMI.2019.6.649

Fiscor, S. February 2014. The Landscape for U.S. Longwalls changes. Coal Age, The Magazine for Coal Mining and Processing Professionals: 26-32.

Fiscor, S. February 2015. US Longwall Operators Ramp Up Production. Coal Age, The Magazine for Coal Mining and Processing Professionals: $30-38$.

Fiscor, S. February 2016. U.S. Longwall Operators Scale Back Production. Coal Age, The Magazine for Coal Mining and Processing Professionals: 18-22.

Fiscor, S. January-February 2017. U.S. Longwall Operations: How slow can we go? Coal Age, The Magazine for Coal Mining and Processing Professionals: 26-32.

Fiscor, S. January-February 2018. Longwall Production Rebounds in 2017. Coal Age, The Magazine for Coal Mining and Processing Professionals: 24-28.

Fiscor, S. January-February 2019. Longwall Production Remains Steady. Coal Age, The Magazine for Coal Mining and Processing Professionals: 24-28.

Gale, W., 2008. Report «Assessment of Longwall Panel Widths and Potential Hydraulic Connection to Bowmans Creek - Ashton Mine», http://www.ashtoncoal.com.au

Ralston, J.C., Hargrave C.O., Dunn M.T., August 2017. Longwall automation: trends, challenges, and opportunities. International Journal of Mining Science and Technology: 733-739.

Ordin, A.A., Metelkov, A.A., Kolenchuk, S.A., 2014. Instructional guidelines on optimization of fully mechanized production face length and output in flat coal seam mining. Fundamental and engineering questions of mining sciences: 266-272.

Trackemas J.D., 2013. Factors considered for increasing longwall panel width. Graduate Theses, Dissertations, and Problem Reports. 175.

Mills K.W., O'Grady P., 1998. Impact of longwall width on overburden behavior. Coal Operators' Conference, University of Wollongong\& the Australian Institute of Mining and Metallurgy: 147-155.

McMillan, D., December 2014. Selecting a longwall panel. RPMGlobal PERSPECTIVES: 4.

Kazanin O.I., Sidorenko A.A. \& Meshkov A.A. Organizational and technological principles of realization of the modern high productive longwall equipment capacity. Ugol' - Russian Coal Journal, 2019, no. 12., pp. 4-13.

Singh T.N., B. Singh. 1985. Model simulation study of coal mining under riverbeds in India. International Journal of Mine Water 4, no. 3: 1-10.

Jeffery, R.I., J.W. Summers, and M.D. North. 1991. The numerical analysis of subsurface deformation in relation to minewater ingress at Wistow Colliery. In 4th International Mine Water Congress, Ljubljana, Slovenia, Yugoslavia, September.

Golubev D. D., April 2018. Development of the technological schemes of the extraction of coal seams for modern mines. Topical Issues of Rational Use of Natural Resources: Proceedings of the International Forum-Contest of Young Researchers, ed. Litvinenko, St. Petersburg, Russia: 55-60.

Nguyen, K.L., Gabov, V.V., Zadkov, D.A., Le, T.B., 2018. Justification of process of loading coal onto face conveyors by auger heads of shearer-loader machines. IOP Conference Series: Materials Science and Engineering, № 327: 1-6. 


\title{
Design of seismic-resistant linings for rock burst conditions
}

\author{
Vitalii V. Glinskii \\ Postgraduate student, Saint-Petersburg Mining University, Saint-Petersburg, Russian Federation \\ V.L. Trushko \\ D.E.Sc., full professor, Saint-Petersburg Mining University, Saint-Petersburg, Russian Federation
}

\begin{abstract}
In the deep horizons development of deposits, mining and geological and technical conditions are significantly complicated. In mine workings dynamic phenomena are appeared, therefore they lead to performance decline of mining enterprises and injuries of miners. Actual task is the development of designs and justification of the rational parameters of seismic-resistant reinforcing linings, ensuring the stability of the mine workings throughout the entire period of their exploitation and the safety of mining. An analysis of the experience of using reinforcing rockbolt linings in Russian and foreign mining enterprises and a comparative assessment of seismic resistance and the effectiveness of using various types of rockbolts. The basic requirements for reinforcing rockbolt linings are formulated to ensure the stability of mine workings in the conditions with dynamic phenomena. As a result of research, it was found that the most effective application of frictional rockbolts, since they come into operation immediately after installation, retain high bearing capacity under dynamic stresses $(75-110 \mathrm{kN})$.
\end{abstract}

\section{INTRODUCTION}

In the development of deep horizons of deposits, geological and mining and technical conditions are greatly complicated. Dynamic phenomena such as rock bump reduce the efficiency and productivity of the mining enterprise and lead to injuries to miners. Proceeding from this, the development of rational parameters of seismic-resistant reinforcing linings, which ensure the stability of the mine workings, the reliable maintenance throughout the entire period of their exploitation, the safety of mining operations and the constancy of the mining enterprise's work, becomes an actual task in the development of deep deposits.

Mainly combined seismic-resistant rockbolt linings in mine workings with the manifestation of dynamic phenomena from rock bump and mass explosions in preparatory mine workings and used coupling (Chunlin $\mathrm{Li}, \mathrm{C}$. 2010). The relatively recent studies have shown that friction-type rockbolt linings have the highest strength and deformation indicators.

Exploitation reliability in mine workings, which liable to dynamic loads and in areas, which affected by mass explosions is low. The wooden lining in this case has low efficiency, because the beams are destroyed, the legs are pressed inside the output contour. Dumps and the zone of destroyed rocks in the roof, depending on the type of rock, reach 2-3 $\mathrm{m}$. The arch malleable lining doesn't provide the necessary stability of mine workings, because such phenomena as deflection of the upper part of the lining, breaks of clamps, and destruction of the tie lead to a loss of stability of the lining structure with increasing deformations.

The main reason for the low efficiency of the considered lining constructions under dynamic phenomena is the discrepancy between the work mechanism of the deformation processes arising in rocks under the action of seismic waves. 


\section{REQUIREMENTS FOR ROCKBOLT LININGS}

The designed rockbolt lining must satisfy the following requirements (Trushko V.L., Protosenya A.G., Matveev P.F., Sovmen H.M. 2000) to ensure the stability of mine workings in the conditions of dynamic forms of rock pressure manifestations:

- providing functional purpose in economic and technological ways;

- starting working in a short time after installation (up to 3-6 hours);

- assumption of a change in the shape and size of the cross section of the mine when it's position in space deviates from the initial one,

- assumption of a change in the direction and magnitude of the maximum static and dynamic stresses in the rock mass, without a significant change in the construction of the elements and the technology of erection lining;

- maximum use of the own load-bearing capacity of the rock mass, including due to it's hardening to the level necessary to perceive the total influence of static and dynamic loads for the required period;

- providing the possibility of reinforcing the originally selected lining in zones of influence of increased seismic effects, tectonic disturbances, couplings of mine workings stoping without significantly changing the constructional elements of the lining;

- ensuring the stability of the mine workings in conditions with genesis of oscillatory processes in the border zone of rock mass;

- preservation of the load-bearing capacity and stability of the lining interaction with the rock mass under periodic exposure to dynamic phenomena.

The peculiarities of the work of rockbolt linings are determined by the variability of the distribution of stress fields in the tectonically active rock mass, the random character of the dynamic influences on the lining, and the frequent change of geological conditions during mining works.

Based on this, the type and parameters of lining are chosen for typical mining, geological and technological conditions of the designed mine working, providing for the possibility of changing both the shape of its cross section and the parameters of the lining during the period of mining works.

Rockbolt linings must satisfy the following technological and design requirements for implementation these conditions:

- ensuring the stability of production and the safety of work in it throughout the entire service life;

- quick entry into work, preservation of the calculated load-bearing capacity and resistance to dynamic influences throughout the entire service life of the lining;

- assumption of changing the shape of the cross section of the mine working without changing the construction of the lining;

- possession of an effective reinforcing effect on the rock mass;

- increasing the load-bearing capacity of the border zone of the rock mass in order to prevent loss of stability of the mine working in areas of possible dynamic manifestations of rock pressure;

- possession of the necessary amortizing properties (compliance) during the development of oscillatory processes in the rock mass under the influence of dynamic phenomena;

- the possession of increased load-bearing capacity, necessary in conditions of highly weakened rocks around the output contour of mine working;

- the lining construction must be technologically advanced in the manufacture and construction, transportable, accessible for monitoring the load-bearing capacity and maintenance during exploitation.

\section{ROCKBOLT LINING GROUPS}

In the mining industry of the Russian Federation are mainly classical types of linings such as shotcrete and rockbolt lining from supporting structures - compliant metal lining and monolithic concrete lining are used. 
As seismic-resistant linings it's recommended to use reinforcing constructions of rockbolt linings and combined linings, which preserve the calculated load-bearing capacity and stability under the influence of seismic effects and throughout the entire period of exploitation (Wen, J., Yang, C., Su, H., \& Ning, D. 2015). The rockbolts should come into work quickly after installation and have contact with the rock mass along the entire length of the rockbolt (Gospodarikov, A. P., \& Zatsepin, M. A. 2019).

Consider the traditional types of rockbolt constructions used in the mining industry of the Russian Federation which have been successfully tested in domestic mines.

As a seismic-resistant rockbolt constructions were fastened, which are retaining the loadbearing capacity under the influence of seismic effects (Li, C. C., Stjern, G., \& Myrvang, A. 2014). This condition is most satisfied with the rockbolt, which had the presence of continuous contact with a massive. Based on this in this work two groups are considered: first group is rockbolts which are entering into work immediately or shortly after installation; second group is rockbolts which are entering into work after several hours of installation (Li, C. C. 2017).

The first group includes following rockbolts:

(1) Combined cemented roof rockbolt (CCRR). This slot-and-wedge rockbolt (Figure 1) is a structure that has a wedge-slot metal rockbolt with a modified wedge as reinforcement, which is fixed in the array by both the wedge itself and the cement-sand mortar that fills the well along the entire length before the rockbolt is inserted into it. Designs of this rockbolt are selected to specific conditions, changing the length of the rockbolts, the diameter of the rockbolts, the density of their placement, the diameter of the wire mesh, the thickness of the shotcrete and the backlog of the lining from the face of mine working (Small, J. C. 2016).

(2) Frictional rockbolt type Swellex (FR). This frictional rockbolt (Figure 2) consists of a special hollow pipe with a C-shaped cross section with plugs at the ends, which is fixed in the well by the pressure of a special fluid pumped into the pipe (Li, D., Masoumi, H., Saydam, S., \& Hagan, P. C. 2018).

(3) Resin-grouted roof rockbolt (RGRR). Steel and polymer rockbolt (Figure 3) are lock and solid, consisting of a reinforcing bar, ampoules with polymer concrete components, a nut and a base plate (Protosenya A.G., Kolosova O.V., Ogorodnikov Y.N. 2003).

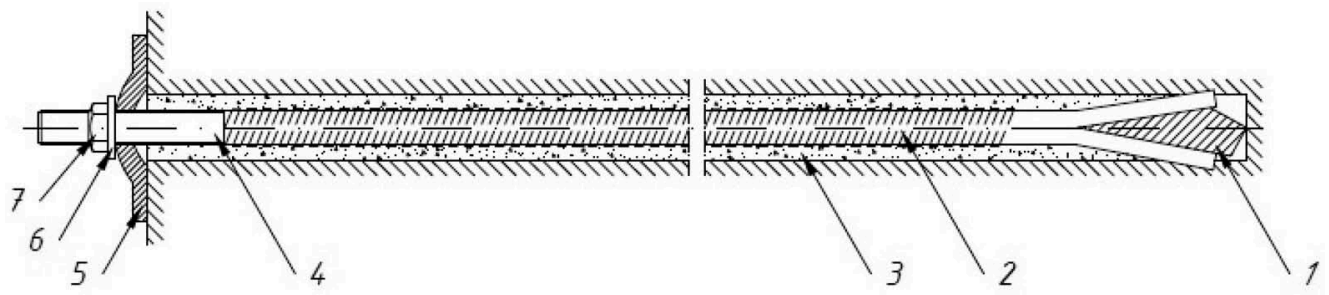

Figure 1. Combined cemented roof rockbolt (1 - metal wedge, 2 - rod of circular or periodic profile, 3 cement-sand mortar, 4 - section of the rod with thread, 5 - base plate, 6 - spacing washer, 7 - tension nut).

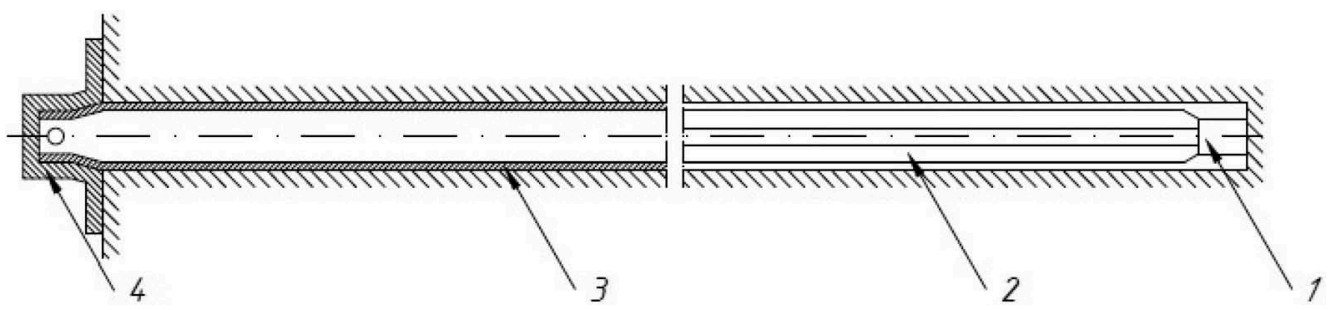

Figure 2. Frictional rockbolt type Swellex (1 - a sealed rockbolt shank, 2 - a special section hollow pipe before liquid injection, 3 - a special section hollow pipe after liquid injection, 4 - a special type base plate). 

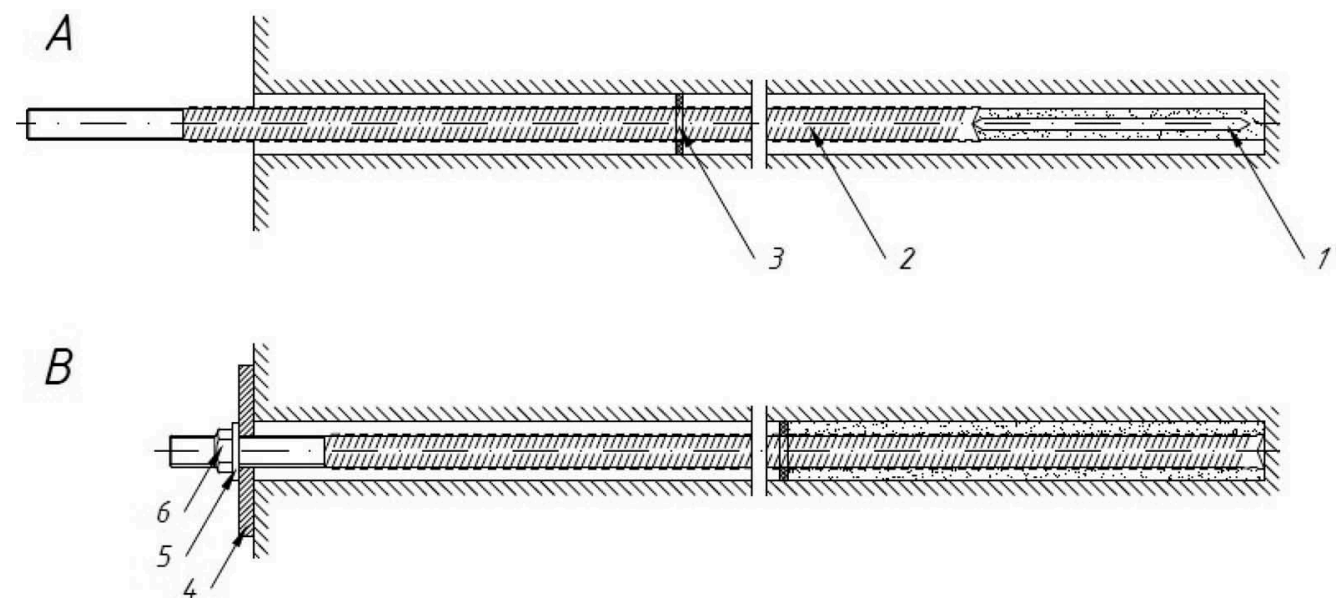

Figure 3. Resin-grouted roof rockbolt during installation (a) and after it (b) (1 - a steel rod of a periodic profile, 2 - quick-hardening composition based on synthetic resins, 3 - a rubber ring, 4 - a base plate, 5 spacing washer, 6 - a tension nut).
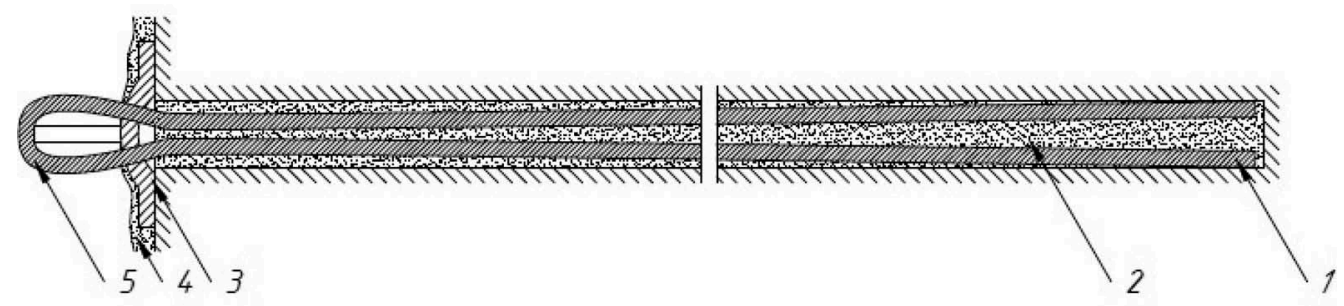

Figure 4. Cable rockbolt (1 - wire rod, 2 - cement-sand mortar, 3 - special wedge-shaped supporting element, 4 - shotcrete, 5 - hinge of wire rod).

The second group includes following rockbolt:

(1) Cable rockbolt (CR). This rockbolt (Figure 4) consists a loop end, an oval-type base plate with a notch and a special locking wedge (Trushko O.V. 2016).

\section{TASKS OF WORK}

The first task is determination of the load-bearing capacity of seismic resistant rockbolts in rock mass, exposed to dynamic effects.

The second task is testing construction technologies of seismic resistant rockbolts and the estimation of their labor intensity.

\section{METHODOLOGY}

The tests were carried out in the conditions of the Severouralsk bauxite mines in the limestone rocks with a compressive strength of 62-75 MPa at a depth of 200-400 m. Each type of rockbolt had a length of $2.5 \mathrm{~m}$. and a diameter of $36 \mathrm{~mm}$.

The tests were as follows:

(1) One rockbolt of each type was installed in a specific mining area; 
(2) Measurements were made of the installation time of each of the rockbolts to determine the complexity of the work and the average time for each type of rockbolt was displayed;

(3) Throughout the day, data on the bearing capacity of each of the rockbolts were recorded. The first measurements were made at the installation stage if it was possible to make the installation technology of the rockbolt. Then the measurements were made after 1 hour, 2 hours and 24 hours.

\section{ANALYSIS OF RESULTS}

Average results of mining tests in Table 1 are presented.

Table 1. Average results of mining tests.

\begin{tabular}{|c|c|c|c|c|c|c|}
\hline \multirow[b]{2}{*}{ Rockbolt type } & \multirow{2}{*}{$\begin{array}{l}\text { Number of } \\
\text { tested } \\
\text { structures }\end{array}$} & \multicolumn{4}{|c|}{$\begin{array}{l}\text { Average load-bearing capacity of the rockbolt } \\
(\mathrm{kN}) \text { from the moment of installation (hour) }\end{array}$} & \multirow{2}{*}{$\begin{array}{l}\text { Unit labor for installa- } \\
\text { tion of one rockbolt } \\
\text { (person per hour) }\end{array}$} \\
\hline & & 0 & 1 & 2 & 24 & \\
\hline $\begin{array}{l}\text { Combined } \\
\text { cemented roof } \\
\text { rockbolt (CCRR) }\end{array}$ & 3 & 69 & - & - & 110 & 0,16 \\
\hline $\begin{array}{l}\text { Cable rockbolt } \\
\text { (CR) }\end{array}$ & 4 & 0 & - & - & $60-85$ & 0,18 \\
\hline $\begin{array}{l}\text { Resin-grouted } \\
\text { roof rockbolt } \\
\text { (RGRR) }\end{array}$ & 3 & $0-60$ & 80 & 140 & 180 & 0,18 \\
\hline $\begin{array}{l}\text { Frictional rock- } \\
\text { bolt (FR) }\end{array}$ & 2 & $100-110$ & $100-110$ & $100-110$ & $100-110$ & 0,10 \\
\hline
\end{tabular}

When analyzing the results, the following conclusions were generated:

(1) The load-bearing capacity of the CCRR ensures normal exploitation and it may apply as a permanent lining;

(2) RGRR tests have shown high performance. Due to the application of polymer concrete with high-strength fast-acting composition, it was possible to achieve rapid entry into work. RGRR has a high resistance to seismic effects and can be used such as temporary and permanent linings;

(3) Experimental data showed that FR is the most effective of the common constructions. FR come into exploitation immediately after installation and have high load-bearing capacity $(100-110 \mathrm{kN})$. FR has contact with the rock along the entire length and it is technological in installation (the average installation time of the rockbolt was not more than $1 \mathrm{~min}$, excluding drilling of the hole);

(4) The technology of CR construction and their load-bearing capacity are less than CCRR, which ensures their normal exploitation and it may apply as a permanent support. However, the slow curing of concrete strength does not allow the use of CR such as a temporary lining.

\section{CONCLUSION}

Due to the high seismic resistance of FR, high and constant load-bearing capacity, workability, this rockbolt construction can be recommended as rockbolt in difficult mining and geological conditions with exposed to dynamic forms of rock pressure.

It can be used both as temporary and as permanent lining. 


\section{REFERENCES}

Chunlin Li, C. 2010. A new energy-absorbing bolt for rock support in high stress rock masses. International Journal of Rock Mechanics and Mining Sciences, 47(3), pp.396-404. https://doi.org/10.1016/ j.ijrmms.2010.01.005

Gospodarikov, A. P., \& Zatsepin, M. A. 2019. Mathematical modeling of boundary problems in geomechanics. Gornyi Zhurnal, 2019(12), 16-20. doi:10.17580/gzh.2019.12.03

Li, C. C., Stjern, G., \& Myrvang, A. 2014. A review on the performance of conventional and energy-absorbing rockbolts. Journal of Rock Mechanics and Geotechnical Engineering. Chinese Academy of Sciences. https://doi.org/10.1016/j.jrmge.2013.12.008

Li, C. C. 2017. Principles of rockbolting design. Journal of Rock Mechanics and Geotechnical Engineering, 9(3), 396-414. doi:10.1016/j.jrmge.2017.04.002

Li, D., Masoumi, H., Saydam, S., \& Hagan, P. C. 2018. Mechanical Characterisation of Modified Cable Bolts Under Axial Loading: An Extensive Parametric Study. Rock Mechanics and Rock Engineering, 51 (9), pp. 2895-2910. https://doi.org/10.1007/s00603-018-1475-4

Protosenya A.G., Kolosova O.V., Ogorodnikov Y.N. 2003. Seismic-resistant designs of lining of mine workings in the development of shock-hazardous deposits. Journal of Mining Institute, 154, pp. 153-156.

Small, J. C. 2016. Geomechanics in soil, rock, and environmental engineering. Geomechanics in soil, rock, and environmental engineering, pp. 1-535

Trushko V.L., Protosenya A.G., Matveev P.F., Sovmen H.M. 2000. Geomechanics of massifs and dynamics of deep mine workings. Saint-Petersburg Mining Institute, p. 396.

Trushko O.V. 2016. Types and designs of antiseismic lining a used in the development of ore deposits. "Izvestiya Tula State University" (Izvestiya TulGU), pp. 120-130.

Wen, J., Yang, C., Su, H., \& Ning, D. 2015. Theoretical analysis and application of composite arch for bolt-shotcrete steel frame supported tunnel in weak and fractured rock mass. Tumu Gongcheng Xuebao/China Civil Engineering Journal, 48(5), 115-122. 


\title{
Results of plasma-impulse technology application at uranium Inkay deposit, Kazakhstan
}

\author{
A.V. Chekulaev \\ Geophysic Engineer of Scientific-production center «GeoMIR», Saint-Petersburg, Russia
}

\begin{abstract}
A.S. Egorov
Doctor of Geological and Mineralogical Scienses, Head of the Department of Geophysical and Geochemical Methods of Prospecting and Exploration of Mineral Deposits, Saint-Petersburg Mining University, SaintPetersburg, Russia
\end{abstract}

\begin{abstract}
A.A. Molchanov
Doctor of Engineering Sciences, Proffessor at the Department of Geophysical and Geochemical Methods of Prospecting and Exploration of Mineral Deposits, Saint-Petersburg Mining University, Saint-Petersburg, Russia
\end{abstract}

\begin{abstract}
This article discusses the methodology for increasing the uranium extraction, in the process of development of hydrogen type uranium deposits of the Republic of Kazakhstan. The analysis of the effectiveness of the standard repair work and methods was applied. The plasma-impulse technology (PIT) using is proposed to increase the permeability of the ore-layer decolmatate the well filters and as a result, intensify the leaching process. The article reviews the physical impact of PIT on the reservoir. Due to the resonant effects in the reservoir as a result of the elastic impact, the process of uranium transition to the mobile form is intensified. A schematic model of the elastic resonance action on a uranium-containing ore-layer using PIT is presented. Positive results were obtained on the application of the proposed technology on some uranium ore deposits of the Republic of Kazakhstan at all stages of their development while the opening of a deposit, blocks acidification and leaching. Based on the results of testing the technology, a combination of PIT with standard methods of repair and restoration work was developed. The application of the author's methodology intensifies the process of uranium transition to the mobile form due to resonance at dominant frequencies and stabilizes the metal yield. High flow rates of pumping wells with an increased or stable metal yield will increase uranium production, its extraction rate and, accordingly, shorten the life of the deposit.
\end{abstract}

\section{INTRODUCTION}

The method of the drillhole in situ leaching (ISL) in uranium deposits was developed and widely used in the Republic of Kazakhstan. It is characterized by high environmental safety, low costs and simplification of technological operations (Turaev. N. \& Zherin. I. 2005). ISL development system is considered to be the specified mode of technological wells. The principal operations of the ISL technological system are the well injecting, pumping and monitoring (Figure 1).

Sulfuric acid solution with a concentration of 5-30 grams per liter, less often up to 50 grams per liter, is used as a leaching reagent (acid solution). The acid solution is supplied through injection wells and penetrated into ore horizons, where selective transfer of natural uranium ions to a productive solution takes place. The productive solution with dissolved uranium rises to the surface through pumping wells. Monitoring wells are used for observation and process control. 


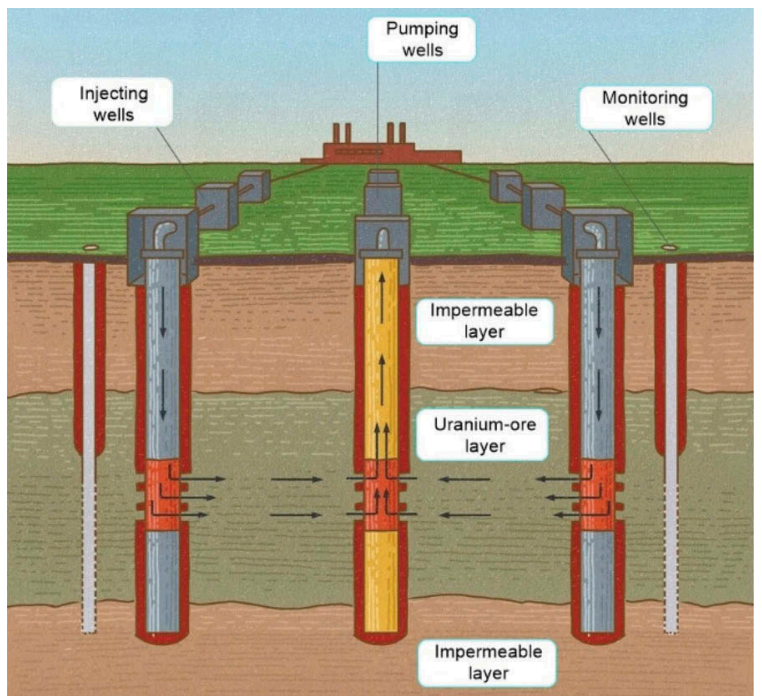

Figure 1. Technological scheme of drillhole in situ leaching of hydratogenous uranium deposits.

\section{PROBLEM DEFINITION}

It should be noted that the leaching rate in beds depends on many geological and technological parameters. There are two principal parameters - the coefficient of permeability of ore horizons and the uranium concentrations. Due to high permeability of the sedimentary reservoirs at a low metal values of hydratogenous uranium deposits, the drillhole in situ leaching method is the only possible method for their efficient and profitable development.

The decreasing of productive intervals permeability is one of the principal problems of ISL method application to the due to the clogging (colmatation) of well-filters (Evteeva L., 2002) and near-well zones of technological wells (Gorbatenko O. et al, 2018). A similar problem is observed in the process of development of uranium deposits in Kazakhstan in depths more than 500 meters. It is necessary to achieve high production rates of pumping wells, to ensure a stable metal yield, to increase the interrepair cycles (IRC) in technological wells, and to reduce the number and time of repair and restoration works (RRW). Therefore, the solution of this problem is of significant technological and economic interest.

Currently, there are standart technologies increasing well productivity. There are three principial types of RRW applied to recover the permeability:

- physical methods of RRW - flushing, pumping by airlift, hydrodynamic and pneumatic treatments;

- chemical methods of RRW based on the using of highly concentrated sulfuric acid or ammonium fluoride;

- physicochemical (complex) methods of RRW.

Each of the RRW methods has its advantages and disadvantages, however, the average interrepair cycle of wells achieves 20 - 25 days, sometimes achieves $1.5-2.0$ months. Besides, application of standart RRW methods requires the shutdown of wells and the additional expenses.

Our investigations have shown that the main well colmatant is drilling clay. The clay content in the solid phase varies from 42 to $98.2 \%$ and on average is of $76 \%$. The rest part of the colmatant is represented by the sand of various fractions, mainly from 0.1 to $0.5 \mathrm{~mm}$, destroyed in the process of ion exchange in the injecting wells and insignificant amounts of gypsum. 


\section{METHODOLOGY}

To increase the uranium extraction, the authors developed and patented plasma-impulse technology (PIT) for creating a series of high - power electrohydraulic impulses in the hydrosphere of the well (Molchanov A. et al, 2014). The manufactured equipment "Pritok-1M" (Figure 2) can be used for decalmation of the well-filter, wellbore zone, and interwell space to restore the permeability of the reservoir and increase the mobility of the acid solution (RU Pat. No. 2685381 to LLC SPC «GeoMIR»). This technology has been successfully tested in the Inkai uranium field.

This process of plasma - impulse action occurs due to the expansion of the plasma channel and its subsequent "collapse", which has alternating stresses on the filter, near the wellbore zone and on the reservoir as a whole (Molchanov A. \& Chekulaev A., 2019). As a result of repeating repression-depression cycles, elastic hydraulic waves propagate along with the bedlayer skeleton and in its porous medium, improve the capacitive and filtration properties of this bed-layer. At the same time, the filter intervals and the near-well zone are cleared from the clay and mud slush colmatant particles, as well as the precipitation of salts.

Pressure impulses open the natural channels in the reservoir and contribute to the formation of new ones that have increased hydraulic conductivity (Figure 3). Due to the resonant effects in the reservoir as a result of the elastic impact, the process of transition of uranium to the mobile form is intensified (Molchanov A. \& Chekulaev A.,, 2019). The penetration depth of
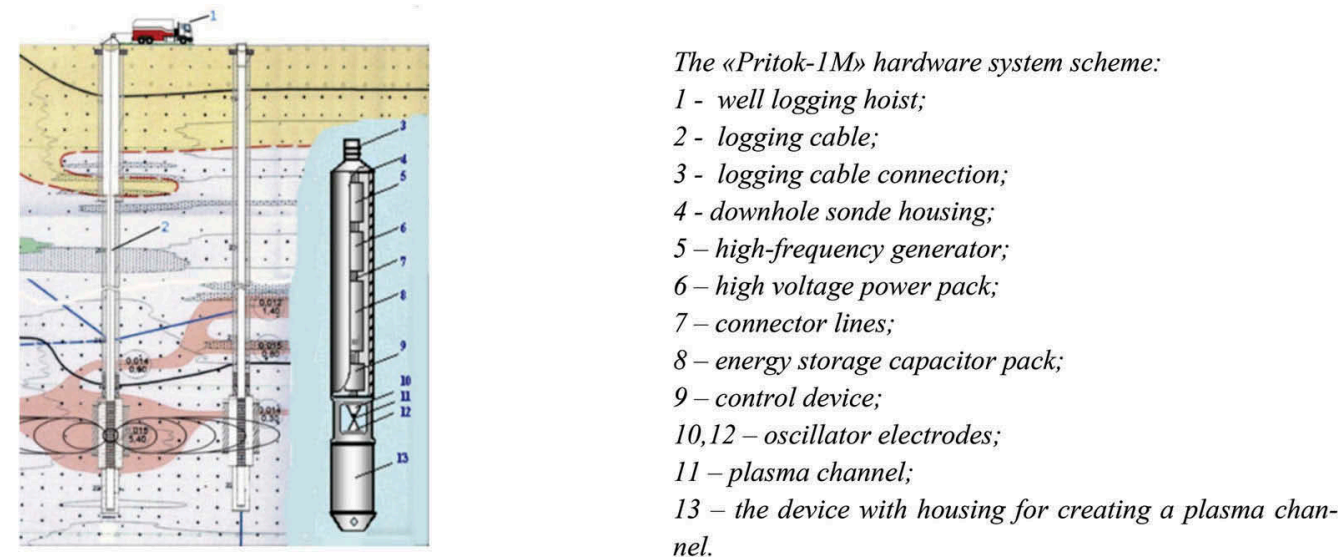

Figure 2. Construction of the «Pritok-1M» hardware system.

$A$
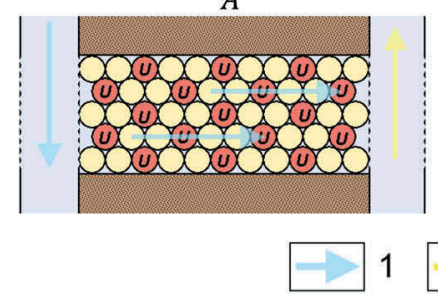
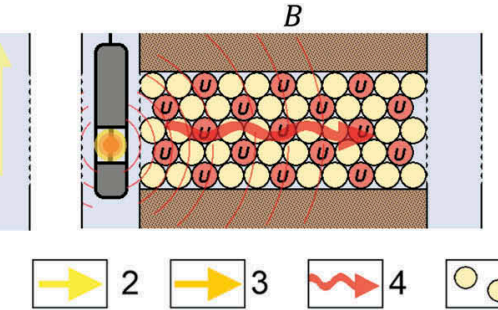
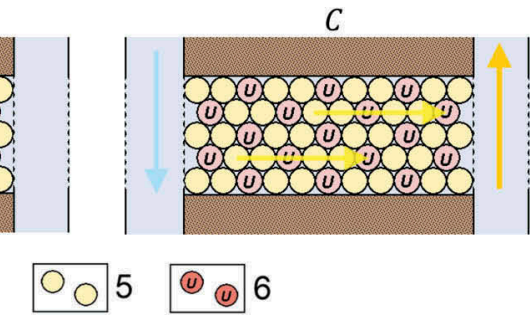

Figure 3. Schematic model of the plasma-impulse impact on the ore-layer. A- the usual model of uranium leaching. B- the ore-layer treatment by PIT. C - intensified leaching process. 1 - direction of injected acid solution; 2- direction of acid solution with a low concentration of uranium; 3- direction of acid solution with a high concentration of uranium; 4- elastic wave exposure of PIT; 5- rock grains; 6-uraniumcontaining rock grains. 
elastic energy due to directional radiation achieves 50-75 meters or more, which significantly exceeds the exposure range of the traditionaly applied RRW methods and, in combination with acid treatment, contributes to deeper leaching of metal from wells of long-operating cells with low uranium extraction (Molchanov A. \& Demekhov., 2014).

\section{RESULTS}

Application of PIT in the period of the blocks acidification provides reducing the time of uranium transition to the mobile form and to intensify the leaching process due to the deep penetration of the acid solution into the interwell space. It also provides the uranium extraction and high production rates of pumping wells for a long time with an IRC of 80 - 120 days. (Table 1).

Table 1. Operating mode of wells after the PIT application (LLP "JV"Inkai" 2016-2017 y.).

\begin{tabular}{|c|c|c|c|c|c|c|c|}
\hline № & $\begin{array}{l}\text { Number } \\
\text { of well }\end{array}$ & Date of RRW & $\begin{array}{l}\text { production rate after } \\
\text { PIT, } \mathrm{m}^{3} / \text { hour }\end{array}$ & $\begin{array}{l}0.7 \text { production rate } \\
\text { after } \mathrm{PIT}, \mathrm{m}^{3} / \text { hour }\end{array}$ & $\begin{array}{l}\text { IRC, } \\
\text { days }\end{array}$ & $\begin{array}{l}\mathrm{Q} / \mathrm{Q}_{\max } \\
\%\end{array}$ & $\mathrm{U}, \mathrm{mg} /$ \\
\hline 1. & $30-6-3$ & 10.05 .16 & $8.30-1.84$ & 5,81 & 50 & 22 & 15 \\
\hline 2. & $30-6-4$ & 11.05 .16 & 8,89 & 6,22 & 65 & 63 & 17,4 \\
\hline 3. & $32-0 \mathrm{~d}-1$ & 26.11 .16 & 8,01 & 5,60 & 45 & 48 & 34,3 \\
\hline 4. & $32-2-2$ & 24.11 .16 & 11,04 & 7,728 & 120 & 55 & $31-23$ \\
\hline 5. & $32-4-4$ & 14.12 .16 & 7,88 & 5,51 & 120 & 42 & $44,4-31$ \\
\hline 6. & $32-6-3$ & 22.11 .16 & 9,53 & 6,671 & 50 & 57 & 42,6 \\
\hline 7. & $80-6-1$ & 08.08 .16 & 9,23 & 6,46 & 30 & 62 & 84,3 \\
\hline 8. & $80-6-4$ & 05.05 .16 & 9,82 & 6,87 & 75 & 78 & 47,4 \\
\hline 9. & $80-8-3$ & 26.11 .16 & 7,35 & 5,14 & 180 & 77 & 55 \\
\hline 10. & $16-18 d-3$ & 06.12 .16 & \multicolumn{5}{|c|}{ The bottom of the well filter after the PIT was filled with sand } \\
\hline 11. & $16-20 d-5$ & 11.12 .16 & 11,33 & 7,93 & 240 & 71 & 45,6 \\
\hline 12. & $16-26 \mathrm{~d}-2$ & 16.12 .16 & 5,01 & 3,50 & 120 & 23 & $90-64$ \\
\hline 13. & $81-6-3$ & 19.12 .16 & 12,63 & 8,84 & 240 & 80 & 274 \\
\hline 14. & $81-4-1$ & $\begin{array}{l}\text { Without PIT } \\
\text { treatment } \\
\text { (control) }\end{array}$ & 10.25 & 7,17 & 230 & 96 & 162 \\
\hline
\end{tabular}

To study the effectiveness of the PIT treatment in wells in the period of their acidification, the commissioned well No.81-6-3 was treated with a complex of PIT and pneumatic pumping. The control well No.81-4-1 (without any treatment) was located in the same cell. The increase in metal extraction in No.81-6-3 well occurred in 12 days earlier than in the control well No.81-4-1. The metal extraction in the samples stabilized at the value of $264 \mathrm{mg}$ per liter and lasted more than 150 days. In the control well: output - $174 \mathrm{mg}$ per liter. Over the period from January 20 to June 9 in the No.81-6-3 well treated by PIT, the metal extraction was $43.2 \%$ higher than in the untreated control well 81-4-1 (Figure 4).

Moreower, this technology has been successfully tested at the Akdala uranium field, Central and East Mynkuduk uranium fields of the Republic of Kazakhstan. So, RRW applying PIT in the mynkuduk and inkuduk-horizons were carried out in 36 pumping and 54 injection wells. During development after drilling, acidification and leaching of technological blocks No. 30 , No. 32 , No. 16 , No. 80 , No. 81 , No. 83 and No. 66, the IRC increased from 15-20 days to $80-150$ days, with the flow rates of pumping wells within $10-11 \mathrm{~m}^{3} / \mathrm{h}$, an increase, and stabilization of the metal yield are observed. 


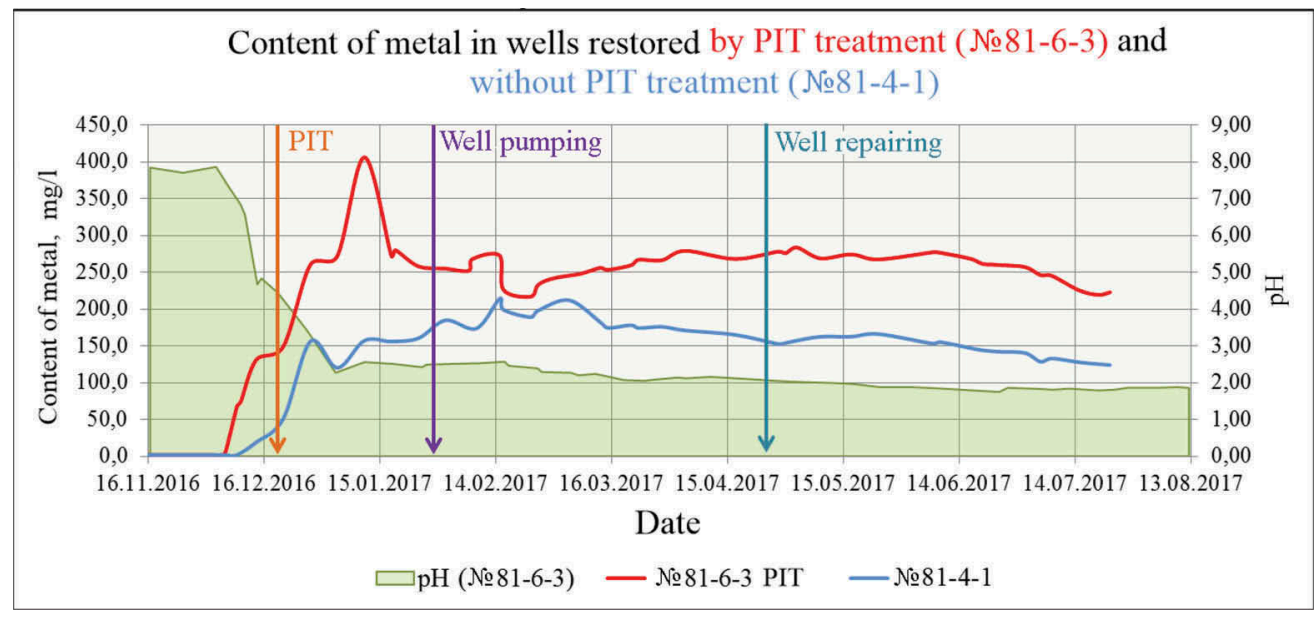

Figure 4. Comparison of metal extraction in wells No. 81-6-3 and No. 81-4-1.

\section{CONCLUSION}

1. The author's plasma-impulse technology (PIT) accelerates the transition of uranium in sedimentary layers to the mobile form due to the parametric resonance of layers at dominant frequencies.

2. Applying the PIT in combination with standard methods of repair and restoration works (RRW) provides deep cleaning of the filter and the near-wellbore zone, as well as intensify the operating modes of technological wells at all stages in the process of uranium deposits development.

3. Experience in the application of PIT at the Inkai uranium field demonstrated opportunities of the efficiency increasing of uranium development. It was justified by our investigations of 36 pumping and 54 injection wells of the inkuduk and mynkuduk horizons in the Inkai uranium field at various stages of it's development. At the same time, the interrepair cycle of pumping wells increases in several times, which allows reducing the number of RRW and, accordingly, reduce the production expenses.

\section{REFERENCES}

Gorbatenko, O. 2018. The results and prospects of applying plasma impulse technology for increasing of efficiency of technological wells operating mode of uranium from deposits which are developed by the method of drillhole in situ leaching (Inkay deposit, republic of Kazakhstan). A.Molchanov \& A.Chekulaev. 25 World Mining Congress. 2018. Kazakhsatn, Astana.

Evteeva, L. 2002. Types of well collation during underground uranium leaching and methods of struggle. II International Scientific and Practical Conference "Actual problems of uranium industry", JSC "NAC Kazatomprom", Almaty, 2002.

Molchanov, A. \& Demekhov, Y. 2014. Increasing the efficiency of uranium mining from deposits of hydrogenous type, developed by the method of underground well leaching of the Republic of Kazakhstan (on the example of the Vostochny Mynkuduk deposit). VII International Scientific and Practical Conference. "Actual problems of uranium industry", Almaty, 92-98. September 25-27, 2014.

Molchanov, A. 2018. Plasma-impulse technology applying for intensification of hydratogenous uranium deposits. Y.Demekhov \& A. Chekulaev «Ecology and social development». № 4. 34 42. 2018.

Molchanov, A. 2014. Plasma-impulse technology application for increasing the efficiency of uranium extraction from hydrogenous type deposits, developed by the drillhole in situ leaching". D.Dmitriev \& V.Sidora. Scientific and technical bulletin "Karotaznik", No. 3, 29-40. 2014. 
Molchanov. A. \& Chekulaev. A. 2019. Efficiency of parametric resonance application to the process of mining ore deposits developed by the method of underground well leaching. Scientific and technical bulletin "Karotaznik" No. 295, 3-14. 2019.

Patent of the Russian Federation, No. 2685381 "Method of uranium and related elements extraction on the technology of drillhole in situ leaching with plasma-impulse effect on the hydrosphere of the well" (priority 15.05.2018), patentee: LLC SPC “GEOMIR" (RU).

Turaev. N. \& Zherin. I. 2005. Chemistry and Technology of Uranium: A Textbook for Universities/Moscow. Federal state unitary enterprise central scientific research institute of economics of information of "ROSATOM", 2005. p. 83-89. 


\title{
Geomechanical issues in the development of the Udachnaya diamondiferous pipe
}

\author{
K.A. Anisimov \\ Postgraduate student, Saint-Petersburg mining university, Saint-Petersburg, Russian Federation \\ D.G. Sokol \\ Postgraduate student, Saint-Petersburg mining university, Saint-Petersburg, Russian Federation \\ V.P. Zubov \\ Professor, Saint-Petersburg mining university, Saint-Petersburg, Russian Federation
}

\begin{abstract}
The data of researches and observations of the geological settings on the Udachnaya kimberlite pipe since the commissioning of the underground mine was considered in this article. The main geomechanical parameters that complicate mining were studied; recommendations on the future researches were given.
\end{abstract}

\section{INTRODUCTION}

Nowadays, Udachny Mining and Processing Division (MPD) develops two primary diamond deposits: Udachnaya and Zarnitsa, as well as Dellyuvialnaya and Ruchey Piropovy placer deposits of the Udachnaya kimberlite pipe (Brief report by independent experts on the reserves and resources of diamond deposits of the ALROSA group of companies, 2018).

The Udachnaya kimberlite pipe has a crucial meaning to the development of the Udachny MPD. This deposit is located in the Daldino Alakit diamondiferous area, close to the city of the same name. The pipe can be traced as a single ore body from the surface to a depth of $250 \mathrm{~m}$. Downstream it splits into two independent ore bodies - East (EOB) and West (WOB), separated by a block of host secondary rocks of the upper-Cambrian period (Figure 1) (Drozdov, 2015).

For a long time, the pipe had been mined as an open-pit. Udachny open-pit was put into production in 1971, and it has been functioning for over 40 years. Open-pit mining was completed in 2016; the depth of the open-pit was 640 meters at the time of the completion.

The Udachny underground mine was put into production in 2014. The development of the ore reserves, which lie below the bottom of the open-pit with absolute elevation of $-320 \mathrm{~m}$, is provided by three vertical shafts located south of the pit: cage shaft, air shaft and skip shaft. Moreover, main opening adits are driven into the sides of the open-pit at $-170 \mathrm{~m}$ and $-290 \mathrm{~m}$ levels, and they are connected with West and East airway crosscuts at $-380 \mathrm{~m}$ level through the runaway No.1 (Nikitin, 2017).

\section{RESEARCH}

The development of the underground reserves of the Udachnaya pipe was started at the level of 260/-320 m WOB and EOB. There were ore reserves left in the pit sides on these levels. Mining method, which was applied to develop these reserves: sublevel caving with the side ore drawing, showed excellent results providing a sufficiently high volume of ore mass production with low rates of loss and dilution. More than half of the ore mined on the pit sides was dumped at the 


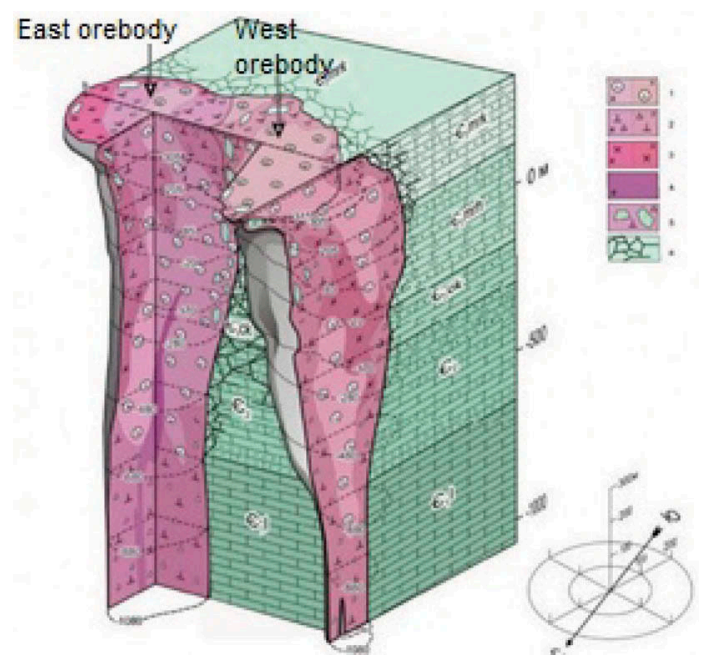

Figure 1. Geological structure of the kimberlite pipe (G.S. Von der Flaas representation). 1 - autolithic kimberlite breccia (phase III); 2 - kimberlite breccia (II); 3 - kimberlite breccia of the massive structure (phase I); 4 - porphyritic kimberlite (phase IV); 5 - kimberlite breccia with large xenoliths of host rocks; 6 - crushing area of host rocks.

bottom of the pit; some of the reserves were transported to the Processing Plant No. 12 (PP No. 12) in the city of Udachny. The bottom of the pit at $-320 \mathrm{~m}$ and $-365 \mathrm{~m}$ levels was also destroyed to create a movable and friable safety cushion. This ore safety cushion is a three-dimensional moving rock mass with a designed height of up to 65 meters, which provides a seal between the underground mining and the open-pit space. The safety cushion is going to be slowly lowered following a decrease in the level of mining operations in accordance with the designed mining method of the kimberlite pipe (Drozdov, 2015; Piven', 2011).

A high-performance method of combined shrinkage stoping and caving with one-stage stoping and areal ore drawing is implemented (Figure 2) to develop primary reserves, located below the bottom of the pit up to the level of $600 \mathrm{~m}$. This mining method is unique for diamondiferous deposits of the Far North, since earlier such methods had not been used in such difficult climatic conditions. There has also been a significant change in technology for creating a safety cushion between the open pit and the underground mine. Traditionally, the bottom of the pit is either left forming a pillar of kimberlite rocks of the sufficient thickness, or artificial filling mass is made (Aikhal, Mir, Internatsionalny mines), when designing the development of a diamondiferous deposit. The movable and friable ore safety cushion was designed at the Udachny mine. Lowperformance cut-and-fill mining methods are commonly implemented in the fields of the Far North. These methods allow reducing the negative climate impact on the underground mining, reducing the influence of hydrological parameters and increasing the safety of personnel in mining zones (Kovalenko, Tishkov, 2017). The method of combined shrinkage stoping and caving with a friable safety cushion is used in the countries of the African continent (Finsh and Kimberly mines). This method has a higher productivity rate: it was possible to achieve and maintain the mine's productivity at the same level as in open-pits with the introduction of these mining methods in the mines of South Africa at a cost-per-ton of ore much less than that of the cut-and-fill mining methods (Chadwick, 2012).

Diesel load-haul-dumpers and self-propelled drillers are used at the drawing-off levels. It is planned to use electrical equipment on the main haulage levels, in particular, a belt conveyer is used on the main haulage level at the elevation of $-480 \mathrm{~m}$, ore gets onto it from an underground crushing facility. The projected production rate for 2018 was 2.7 million tons. The mine was supposed to reach full production capacity by 2019 , ensuring the production of 


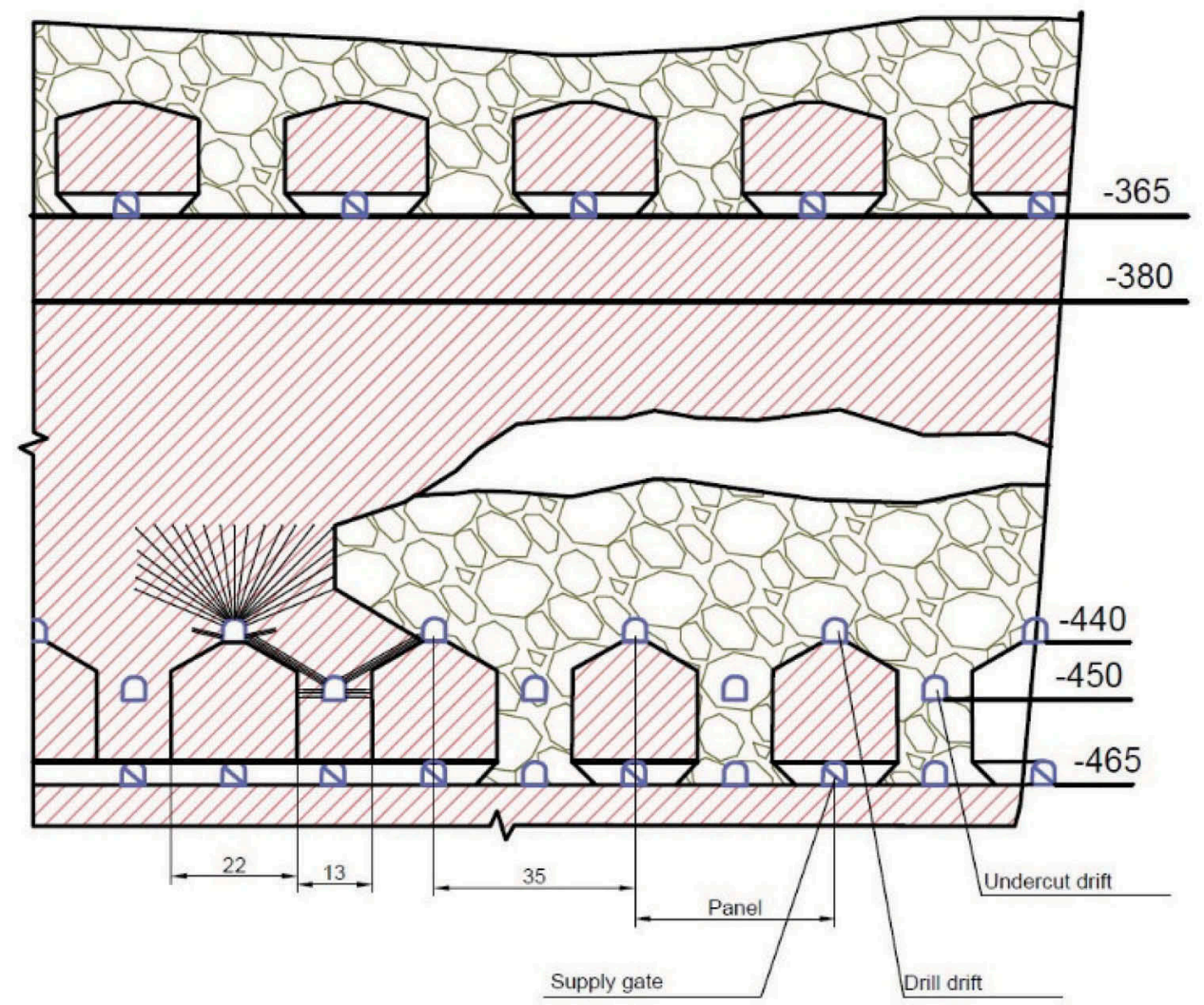

Figure 2. Part of the combined shrinkage stoping and caving method; the lay out of the workings on the $-450 \mathrm{~m}$ level (undercutting level).

4.0 million tons of ore annually, however, as for the III quarter of 2019, 1836 thousand tons of ore were mined, ensuring that the plan was not fulfilled almost twice (The quarterly report of ALROSA PJSC for the 3rd quarter of 2019, 2019).

The development of the Udachnaya kimberlite pipe is extremely difficult, climatic and geological conditions have a significant impact on the development process. The main factors that have a critical value for the operation of the underground mine are the following:

- Kimberlite pipe is located in the extreme climatic conditions of the Far North, almost at the level of the Arctic Circle. The pipe is located in the permafrost area with a large frost depth of rocks. Sharply continental climate is described by large daily temperature swings, which negatively affect the stability of rock masses (Balek, Sashurin, 2016);

- Water cut is distributed highly uneven in the developed rock masses, the geological structure of the pipe and surrounding rocks is formed without natural aquicludes, which leads to the free promotion of aggressive and high-salinity brines with a total salinity of up to $400 \mathrm{~g} / \mathrm{l}$ (Balek, Sashurin, 2016);

- The rock mass, which surrounds the pipe, is extremely disturbed, host rocks and kimberlite rocks have a network of deep (up to 50 meters) fractures and various disturbances located randomly. Cases of groundwater breakthroughs in mines due to penetration of fractures during drilling wells, etc., were recorded (Balek, Efremov, 2016; Kovalenko, Tishkov, 2016);

- Ore and rock masses have low stability; the dependence of the kimberlite's stability on the time of its contact with the mine's air has been established: it drops significantly over the year, increasing the cost of fastening and maintaining mine workings (Bokiy, Zoteev, 
Pul, 2019). The most disturbed mass is the mass of waste rocks in the space between the WOB and EOB; it contains many disturbances and manifestations of fracturing;

- Many zones of increased fracturing, hazardous places of low coherence, caused by various hydro-geomechanical, geomechanical and other factors were particularly highlighted. Special timbering plans are often designed for such zones and there is special monitoring of the state of the underground mines (according to PJSC ALROSA);

- The mine is hazardous in terms of gas emission; there have been cases of oil and gas occurrences during mining on the levels of $-260 \mathrm{~m} /-380 \mathrm{~m}$ that negatively affect the development of the field (Brief report by independent experts on the reserves and resources of diamond deposits of the ALROSA group of companies, 2018).

The development of the Udachnaya kimberlite pipe is a big challenge for Russian science, forming a certain number of extremely unique and often advanced solutions. The Yakutniproalmaz Institute was initially involved in the development of all design decisions; part of the work was carried out in Saint-Petersburg at the Institute GIPRONIKEL LLC, the Institute of Mining of Ural Branch of RAS carried out the research work and technical solutions. Therefore, technological parameters of the development process of the Udachnaya kimberlite pipe have been studied for a long time taking into consideration the wishes of the direct customer PJSC ALROSA.

However, the following negative factors that affect mining process were noted in the first few years of the mine's operations:

1. A methane-air mixture exploded during the driving of the runaway due to the strong gas contamination of the mine and insufficient ventilation. Gas manifestations were repeatedly recorded in the mine atmosphere during further mining operations, there were also oil products ignitions after the production cycle of the blast hole drilling (according to the regional department of the Russian Ministry of Emergency Situations).

These negative factors are caused by the content of petroleum bitumen in the host rocks. Its content on different mining depth varies from 0.6 to $2.35 \%$, and lower in the section (level $-480 \mathrm{~m} /-1080 \mathrm{~m}$ ) decreases to $0.01 \%$. According to group analysis, bitumen contains about $50-60 \%$ oils, $40-45 \%$ resins, and in the lower part of the section the oil content decreases to $15-20 \%$. Oil in the area of the Udachnaya pipe contains less resins $(30-35 \%)$ compared to bitumen, and its asphaltene content does not exceed $4 \%$. The gas content of the field is due to the presence of gases dissolved in oil and brines, however, the rocks themselves have almost no sorption capacity. The gas content of the field was assessed to a depth of $800 \mathrm{~m}$; the main gases are hydrocarbon mixtures with predominant methane content. Petroleum bitumen in kimberlites complicates the ore processing, and their presence in rocks have a great impact on the conduction of blasting operation in the underground conditions;

2. Multiple rock falls were observed both from the roof and from the sides of the workings, this is especially typical for the ore body - kimberlite ores are very easy to flake and crumble, starting their destruction in an extremely short time. Moreover, kimberlites of the East ore body are different from the ones of the West ore body in their characteristics (Balek, Efremov, 2016; Drozdov, 2009).

These phenomena are mostly observed either in the ore body or in zones of increased fracturing and at contacts with the ore body. Kimberlites of the EOB and WOB change the values of all physical and mechanical properties by 1.1-1.6 times with the increase in depth. The average bulk density varies through the blocks in the upper levels of the field (elevation of $+300 \mathrm{~m} /-280 \mathrm{~m}$ ) from 2.34-2.37 to 2.48-2.6 t/m $\mathrm{m}^{3}$, and on "deep" levels (elevation of $-280 \mathrm{~m} /-1080 \mathrm{~m}$ ) - from $2.52-2.62$ to $2.62-2.69 \mathrm{t} / \mathrm{m}^{3}$. In terms of unconfined compressive strength, kimberlites of the EOB and WOB are considered soft $(\sigma=10-35 \mathrm{MPa})$ and very soft $(\sigma=4-10 \mathrm{MPa})$ rocks. Hardness coefficient of the host rocks on the Protodyakonov's scale of hardness ranges from 1 to 8 , and the coefficient of kimberlites varies from 5 to 7 . The lowest values of the hardness coefficient are recorded in crushing zones, less often in zones of hydrothermal changes, and its maximum values coincide with intensely silicified rocks; 


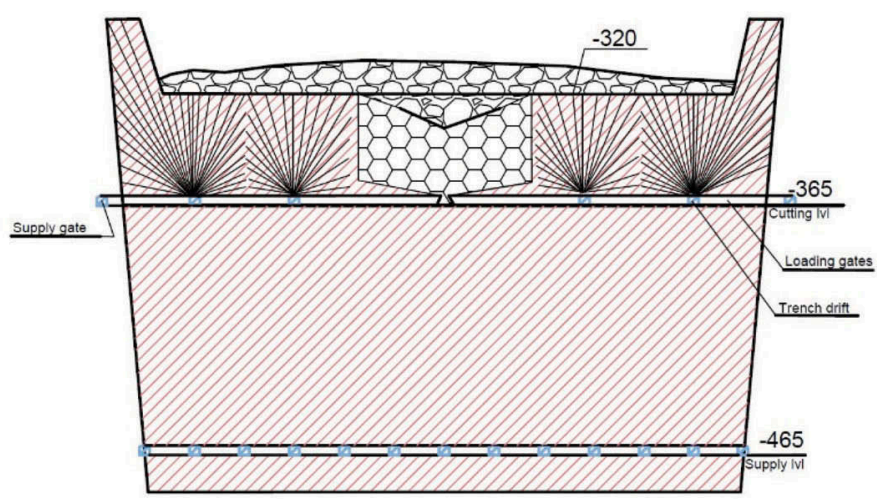

Figure 3. Part of the mining method with the creation of the safety cushion.

3. Increased wear of machinery and equipment associated with the aggressive type of brines, which penetrate underground mines, was observed during the operation of the mine. There have been cases of breakthroughs of brines into the interior of the mine due to the bursting through fractures or disintegration of the underground cavities filled with them (Kovalenko, Tishkov, 2017; Bokiy, Zoteev, Pul, 2019; Sokolov, Smirnov, Antipin, Nikitin, Tishkov, 2018).

Groundwater is represented by calcium chloride brines with an average salinity of 300-400 $\mathrm{g} / \mathrm{l}$. The total gas saturation of brines can reach up to $1.2 \mathrm{~m}^{3} / \mathrm{m}^{3}$. The chemical composition of the aquifer is abnormal: sodium chloride brines have a high content of sodium, sulfates, and bromine. Hydrogen ion concentration $(\mathrm{pH})$ value is 7.75. Filtration properties of kimberlites are variable: water conductivity varies from $1-2$ to $70 \mathrm{~m}^{2} /$ day (average conductivity is $40 \mathrm{~m}^{2} /$ day), however, it always exceeds equivalent parameters of the host rocks. The negative impact of the water inflow in the underground mine will increase with further development of the kimberlite pipe;

4. Numerous safety violations have been recorded since the beginning of the operation of the mine to the present moment, resulting in personnel injuries, including deaths at the mine (according to the regional department of the Russian Ministry of Emergency Situations) The management of the Udachny MPD was faced with the lack of personnel trained to work in the underground conditions of the mine during the period of transition to the underground operation of the enterprise. At the same time, method of combined shrinkage stoping and caving with one-stage stoping and areal ore drawing requires the highest quality of the conducted mining operations and high professionalism of personnel. Moreover, there are no similar mines which use combined shrinkage stoping and caving method among underground mines in the territory of Russian Federation;

5. It is planned to extract mineral resources in the WOB and EOB simultaneously in a descending order by the flow-sheet of the mine. The friable safety cushion is supposed to be gently lowered with the lowering of the mining, conducting work on two levels of the working $-480 \mathrm{~m}$ and $-580 \mathrm{~m}$ (Figure 3). At the same time, the destroyed bottom of the open-pit formed into the ore friable safety cushion should go down, increasing the depth of the pit, as well as forming and exposing the mass of the host rocks located between the East and West ore bodies.

\section{RESULTS}

Mass of the host rocks located between the East and West ore bodies consists of extremely disturbed rocks, especially in the contact zone. The mass at the elevation of $-580 \mathrm{~m}$ is 
comparable in volume with the volume of both ore bodies. It becomes impossible to control the state of the inner-pipe mass as the mining operations deepen. Active processes of flattening of the sides, which gradually come down onto the ore cushion, are already taking place in the pit, further ensuring the inability to safely come to the bottom of the pit and restricting visual observation of the smoothly exposing mass.

The parameters of the safety cushion were calculated by the specialists of the Institute of Mining of Ural Branch of RAS, taking into consideration the collapse of the known volume of the sides with the known geometry and location (Sokolov, Smirnov, Antipin, Nikitin, Tishkov, 2018). However, in the case of uncontrolled destruction of the inner-pipe mass, it is impossible to give an accurate estimation of the volume of collapsed rocks on the safety cushion, including giving a reliable prediction of the height and the place of the collapse. At the same time, if the thickness of the safety cushion is insufficient, there is a real threat of transfer of the impact energy through the safety cushion to the underground mines. This transfer can cause dangerous deformations of the underground mines, up to creating emergency situation at the field.

The results of the analysis of the actual state and development prospects of mining operations in the EOB and WOB indicate that ensuring a cost-effective and safe extraction of reserves of the Udachnaya Pipe is problematic without developing measures to eliminate dangerous geomechanical situations caused by an increase the depth of mining operations. Initial data for predicting such situations can be obtained using the modeling method on models of equivalent materials of large-scale geomechanical processes in block rock masses developed at St. Petersburg Mining University (Zuev B.Yu., Zubov V.P., Smychnik A.D., 2019; Zuev B. Yu., Zubov V. P., Fedorov A. S., 2019). This method allows you to study the stress-strain state of the rock mass located between the EOB and WOB for various stages of development of mining operations, and on this basis to take preventive measures aimed at increasing the efficiency of mining ore bodies.

\section{CONCLUSION}

The current state of the Udachny mine can be called steady and stable. The production capacity required by the engineering design is achievable with the existing mining technology. It is suggested based on the analysis of the geological conditions of the pipe to adjust the parameters of the mining methods as mining operations are deepened to maintain the production volume. There is a steady tendency to the degradation of the mining conditions:

- An increase in the volume of underground brines penetrating into the workings directly affects mining operations, the safety of the underground workings, and the condition of the machinery and equipment;

- The process of destruction of the access crosscut of the bottom of the blocks composed of kimberlite, which will experience high loads, is going to begin after the start of the extraction process using combined shrinkage stoping and caving method. Open access to mine air is going to accelerate the destruction of walls of the workings;

- Geomechanical issues will occur associated with the weakening of the sides of the open-pit and with the violation of the initial state of the rock mass during the mining of the West and East ore bodies. The mass located between the ore bodies is extremely disturbed. There is a possibility of partial relaxation, and fracturing, and sudden uncontrolled collapses of rocks on the safety cushion with a decrease in level of the mining operations and exposure of this rock mass. In case of uncontrolled collapse of the rock mass, there is a possibility of exceeding the maximum allowable stability of the cushion up to serious dynamic impacts on the underlying workings.

These factors, which impact the mining of the kimberlite pipe, require further scientific research. At the same time, the inner-pipe mass requires special attention, including field studies and research operations to identify and prevent dangerous uncontrolled collapses. 


\section{REFERENCES}

Balek A. E., Efremov E. Yu. Justification of the geomechanical conditions of the underground mining of the diamond pipe "Udachnaya pipe". Innovative geotechnologies in the development of ore deposits, 2016, pp. 173-176.

Balek A. E., Sashurin A. D. The problem of assessing the natural stress-strain state of a rock mass during subsurface development. Mining Information and Analytical Bulletin, special issue, 2016, pp. 9-23.

Bokiy I. B, Zoteev O. V, Pul V. V. Analysis of the process of subsidence of the rock pillow during mining of the western ore body of the Udachnaya pipe using a collapse system, Mining Journal, No. 2, 2019, pp. 43-46;

Brief report by independent experts on the reserves and resources of diamond deposits of the ALROSA group of companies, Micon International Co Limited, 2018, http://www.alrosa.ru/wp-content/ uploads/2013/11/Alrosa-Summary-Report-Final-RUS.pdf

Chadwick J., Automated Finsch, International Mining, 2012, pp. 10-13.

Drozdov A.V. Geotechnological problems of developing the deep horizons of the Udachnaya pipe. Subsoil use problems: issues of integrated development of deep-seated mineral deposits, 2009, pp. $110-121$.

Drozdov A.V. Mining and geological features of the deep horizons of the Udachnaya pipe. Mining Information and Analytical Bulletin, No. 1, 2011, pp. 153-165.

Drozdov A.V. Mining, geological and technological problems in the construction of the Udachny underground mine. Mining Information and Analytical Bulletin, No. 2, 2015, pp. 125-131;

Kovalenko A. A., Tishkov M. V. Assessment of the underground method of mining the Udachnaya pipe field using a self-collapsing system. Mining Information and Analytical Bulletin, No. 4, 2017, pp. $117-128$.

Kovalenko. A.A., Tishkov M.V. Evaluation of development of the Udachnaya pipe field. Mining Information and Analytical Bulletin, No. 12, 2016, pp. 173-174

Nikitin I.V. Optimization of opening parameters during underground mining of open-pit reserves of a kimberlite deposit. Topical Issues of Rational Use of Natural Resources, No. 1, 2017, pp. 21-28;

Piven' G.F. Technologies for the development of sub-quarry reserves of the Udachnaya pipe. Notes of the Mining Institute, No. 1, 2011, pp. 359-361.

Sokolov I.V., Smirnov A.A., Antipin Yu.G., Nikitin I.V., Tishkov M.V. Justification of the thickness of the safety cushion when working out the quarry reserves of the Udachnaya pipe with caving systems. Technology mining operations, FTRPRI, No. 2, 2018, pp. 52-62.

The quarterly report of ALROSA PJSC for the 3rd quarter of 2019, ALROSA PJSC, 2019, http://www. alrosa.ru/wp-content/uploads/2019/11/3-квартал-2019-года.pdf.

Trushko V.L., Protosenya A.G., Prospects of geomechanics development in the context of new technological paradigm. Journal of Mining Institute, Vol. 236, 2019, pp. 162-166.

Yakubovskiy M.M., Sankovsky A.A., Drilling and blasting design based on invariable mining parameters. Journal of Industrial Pollution Control, Vol. 33, 2017, pp. 931-936.

Zuev B.Yu., Zubov V. P., Fedorov A. S. Application prospects for models of equivalent materials in studies of geomechanical processes in underground mining of solid. Eurasian mining, No. 1, 2019, pp. $8-12$.

Zuev B.Yu., Zubov V.P., Smychnik A.D. Determination of static and dynamic stresses in physical models of layered and block massifs. Mountain Journal, No. 7, 2019, pp. 61-66. 


\title{
Increasing the degree of nepheline raw materials use based on the conversion of sludge from alumina production
}

\author{
M.A. Gorbachev \\ Postgraduate student, Saint-Petersburg Mining University, Saint-Petersburg, Russia \\ V.M. Sizyakov \\ Professor, Metallurgy Department, Saint-Petersburg Mining University, Saint-Petersburg, Russia \\ R.V. Kurtenkov \\ PhD, Associate professor, Saint-Petersburg Mining University, Saint-Petersburg, Russia
}

I.S. Bormotov

Student, Saint-Petersburg Mining University, Saint-Petersburg, Russia

\begin{abstract}
A modern approach to metallurgical production requires the implementation of technological solutions to reduce the amount of waste generated. The possibility of processing nepheline sludge into a calcareous component by means of combined conversion is proposed. The product of sludge disposal in this case is calcium carbonate, silica gel and soda solution. The developed methods for processing nepheline sludge are simple, low cost of implementation and can be carried out on typical equipment for alumina production, that will allow to diversify production. The described approach allows to increase the economic efficiency of production.
\end{abstract}

\section{INTRODUCTION}

Modern metallurgical production is characterized by the use of technologies that ensure the extraction of a significant amount of valuable components in the processing of ore raw materials of natural and technogenic origin. At the same time, low-value impurity components and minerals of waste rock are released into the sludge products in their original or chemically modified form, followed by storage in sludge storages (Lainer 1961, Eremin et al. 1980). Currently, these processes are on a global scale, which pose a serious problem for the industrial and environmental safety of existing enterprises and adjacent territories. This problem is especially acute in relation to the processing of aluminum-containing raw materials (ElDeeb et al. 2019, Sizyakov et al. 2016, Brichkin et al. 2019). For example, in the processing of bauxite per 1 ton of the final product (aluminum), at least 2 tons of waste sludge is formed, and in the processing of nepheline, this amount is already 12 or more tons, depending on the quality of the feedstock. The existing integrated method of processing nepheline into alumina and associated products allows the disposal of nepheline sludge in the production of cement and cementitious components, however, in the current situation in the market of building materials and the economic inexpediency of transporting cement over long distances leads to the accumulation of solid waste in sludge storages Figure 1.

Thus, it is of interest to develop a cost-effective technology aimed at separating the calcareous component into an independent product with its subsequent application in the alumina production cycle, obtaining products of the carboaluminate series for the chemical industry and the production of materials with high added value. 
a)

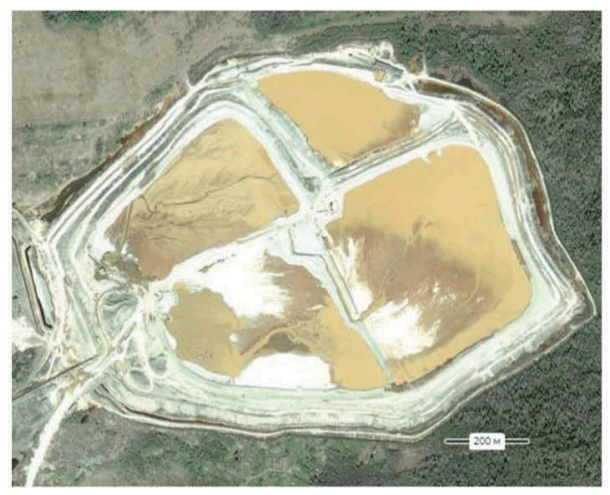

b)

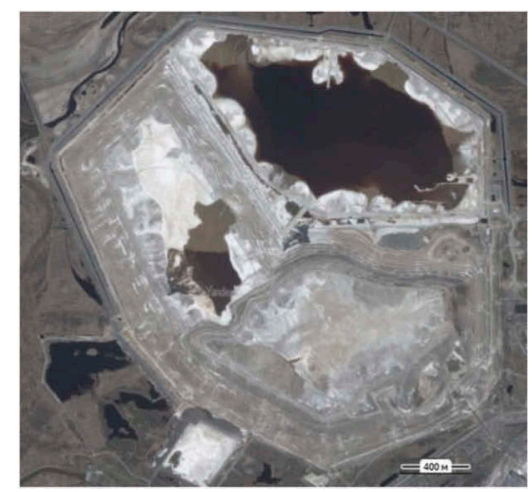

Figure 1. Sludge storage facilities for alumina refineries in Pikalevo (a) and Achinsk (b).

\section{MATERIALS AND RESEARCH METHODS}

Nepheline sludge is a multicomponent system, the composition of which depends on the chemical interactions during sintering, leaching of nepheline concentrate and subsequent washing, the chemical composition of the sludge is presented in Table 1 . The solid waste obtained during production has a physical density of $3150-3200 \mathrm{~kg} / \mathrm{m} 3$, bulk density in the range of $1000-1500 \mathrm{~kg} / \mathrm{m} 3$. According to its mineralogical composition, it is $80 \%$ composed of $\beta$-modification of dicalcium silicate (belite).

In the works of P.I. Bozhenov (Bozhenov \& Kavalerova 1966), the dependence of the activity of dicalcium silicate $\mathrm{C}_{2} \mathrm{~S}$ in the nepheline sludge on the alkaline module (molar ratio $\mathrm{R}_{2} \mathrm{O}: \mathrm{Al}_{2} \mathrm{O}_{3}$ ) of the nepheline-limestone charge was determined. This dependence is shown in Figure 2.

Thus, taking into account the production requirements for the alkaline module of the nepheline-limestone charge, it can be concluded that the activity obtained at the Russian production facilities of nepheline sludge is in the optimal region for its processing. At the same time, it should be remembered that in the production of alumina from nepheline, one of the key tasks of sintering is the binding of silicon to dicalcium silicate in the form of a low-active $\beta$ modification $\left(\beta-\mathrm{C}_{2} \mathrm{~S}\right)$. In turn, $\alpha$-modification is more preferable and would greatly simplify the processing of sludge due to its activity, but this solution is not practical, since it will lead to significant contamination of aluminate solutions during leaching, and additional heat treatment of the sludge to transfer dicalcium silicate from $\beta$-modification to the $\alpha$-modification is economically disadvantageous, since it requires heating the material. Therefore, comprehensive approaches to hydrochemical treatment are needed, which make it possible to utilize nepheline sludge without additional heat treatment.

The fundamental possibility of the soda-carbon dioxide conversion of nepheline sludge to calcium carbonate and the separation of silicon in the form of a silicate solution was previously shown and are associated with the thermodynamic instability of calcium silicates formed under high-temperature sintering processes in relation to hydration, hydrolysis, and ion exchange (Abramov et al. 1990, Shmorgunenko \& Korneev 1982). Soda and carbon dioxide conversion is characterized by the following stoichiometric ratios, respectively:

$$
\mathrm{Ca}_{2} \mathrm{SiO}_{4}+2 \mathrm{Na}_{2} \mathrm{CO}_{3}=2 \mathrm{CaCO}_{3}+\mathrm{Na}_{4} \mathrm{SiO}_{4}
$$

Table 1. The chemical composition of nepheline sludge, \% (mass.) (Abramov et al. 1990).

\begin{tabular}{llllllll}
\hline Refinery & Loss on calcination & $\mathrm{SiO}_{2}$ & $\mathrm{Al}_{2} \mathrm{O}_{3}$ & $\mathrm{Fe}_{2} \mathrm{O}_{3}$ & $\mathrm{CaO}$ & $\mathrm{R}_{2} \mathrm{O}$ & Others \\
\hline Pikalevo & 2,6 & 29,6 & 2,6 & 3,0 & 56,8 & 1,8 & 3,6 \\
Achinsk & 3,4 & 28,8 & 4,2 & 3,6 & 54,6 & 2,6 & 2,8 \\
\hline
\end{tabular}




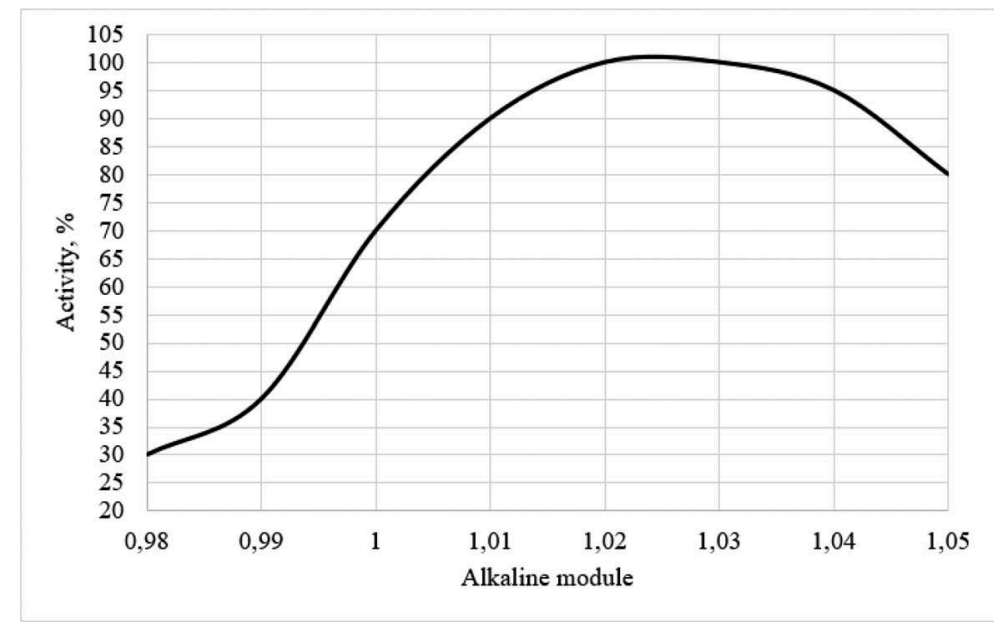

Figure 2. The dependence of the activity of $\mathrm{C}_{2} \mathrm{~S}$ in nepheline sludge on the alkaline module of charge.

$$
\begin{gathered}
\mathrm{Ca}_{2} \mathrm{SiO}_{4}+2 \mathrm{Na}_{2} \mathrm{CO}_{3}+\mathrm{H}_{2} \mathrm{O}=2 \mathrm{CaCO}_{3}+\mathrm{Na}_{2} \mathrm{SiO}_{3}+2 \mathrm{NaOH} \\
2 \mathrm{CaO} \cdot \mathrm{SiO}_{2}+2 \mathrm{CO}_{2}=2\left(\mathrm{CaO} \cdot \mathrm{CO}_{2}\right)+2 \mathrm{SiO}_{2} .
\end{gathered}
$$

However, the proposed methods and technical solutions do not allow a high degree of conversion and can be used mainly to obtain a single-component cement mixture, which necessitates further studies aimed at achieving the conversion of belite in the composition of nepheline sludge to $95-100 \%$, and increasing the efficiency and the complexity of its processing.

The main indicators of the soda conversion of nepheline sludge were determined in laboratory conditions using a factory sample of a nepheline sludge of an average composition and synthetic soda solutions. The chemical composition is presented in Table 1 .

\section{EXPERIMENTAL}

The methodology for experimental research includes the preparation of synthetic solutions of soda, repulpation of nepheline sludge with a soda solution with a given concentration (from $52,5-233,8 \mathrm{~g} / \mathrm{l}$ ) at a constant concentration of solid in the pulp, corresponding to Liquid: Solid $=1 \div 10$. The conversion was carried out in a single reactor AutoLAB system for $0,5-6$ hours. After completion of the process, the pulp was filtered off on a laboratory vacuum filter to obtain technological products. The liquid phase was analyzed for the content of total and caustic alkali by the titrimetric method in accordance with the accepted industry method and silicon dioxide by the photometric method. The degree of conversion was calculated by determining the carbonate carbon content in solid products by spectral analysis using a TOC-L analyzer.

During the experiment, the influence of various technological factors on the soda leaching of unmilled nepheline sludge (processing time, soda solution concentration) was studied. Graphic processing of the results of the study at the indicators of soda conversion of unmilled nepheline sludge $\mathrm{L}: \mathrm{S}=10$, process temperature $50-95^{\circ} \mathrm{C}$, the concentration of soda solution 52,5-233.8 g/l, is presented in Figures 3, 4.

The results obtained suggest that the temperature and concentration of soda solution are factors that have a significant effect on the change in the phase and chemical composition of the products. The dependence of the degree of conversion on the concentration of soda solution reflects the effects of stoichiometric, kinetic and thermodynamic nature. The shape of the kinetic curves suggests a noticeable diffusion inhibition of the conversion of belite, presumably due to 


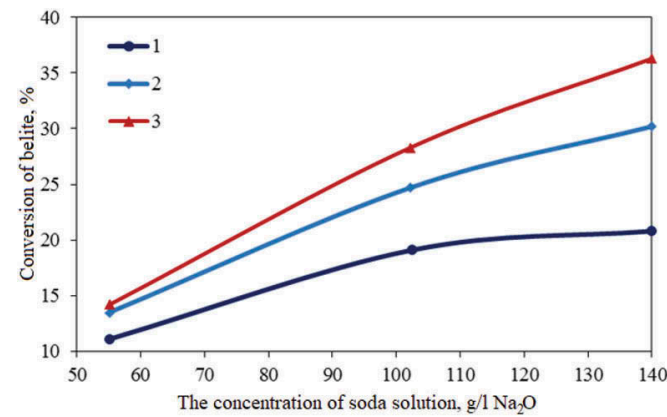

Figure 3. Effect of soda solution concentration on the decomposition of unmilled sludge at various temperatures: $1-50^{\circ} \mathrm{C}, 2-75^{\circ} \mathrm{C}, 3-95^{\circ} \mathrm{C}$.

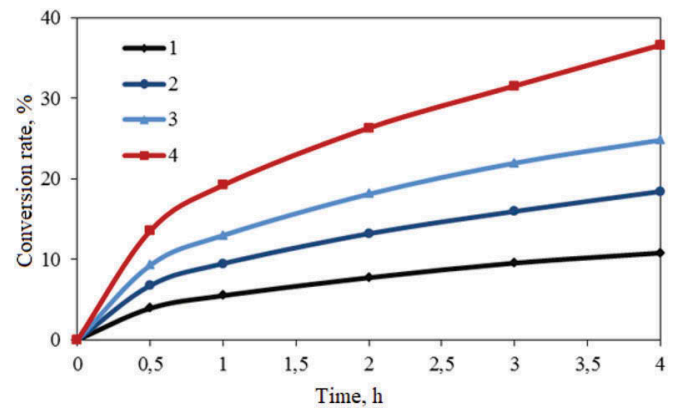

Figure 4. Kinetics of soda conversion of unmilled nepheline sludge at a temperature of $95{ }^{\circ} \mathrm{C}$ and a concentration of $\mathrm{Na}_{2} \mathrm{CO}_{3}: 1-52,5 \mathrm{~g} / 1,2-110,3$ $\mathrm{g} / \mathrm{l} ; 3$ - 187,1 g/l; 4 - 233,8 g/l.

the formation of solid products on the surface of the initial solid phase. The calculated values of the Pilling-Bedwards test for conversion products by reactions (1) and (2) are 1,27 and 1,33, which also indicates the possibility of the formation of stable passivating films.

To intensify the conversion process and achieve higher values, an experiment was carried out for a three-stage hydrochemical treatment of nepheline sludge based on the transition to the region of pearsonite $\left(\mathrm{Na}_{2} \mathrm{CO}_{3} \cdot \mathrm{CaCO}_{3} \cdot 2 \mathrm{H}_{2} \mathrm{O}\right)$ formation using soda solutions with a $\mathrm{Na}_{2} \mathrm{O}$ concentration of more than $220 \mathrm{~g} / \mathrm{l}$ according to the reaction:

$$
\mathrm{CaCO}_{3}+\mathrm{Na}_{2} \mathrm{CO}_{3}+2 \mathrm{H}_{2} \mathrm{O}=\mathrm{Na}_{2} \mathrm{CO}_{3} \cdot \mathrm{CaCO}_{3} \cdot 2 \mathrm{H}_{2} \mathrm{O}
$$

To carry out the research, a laboratory setup based on the AutoLAB single-reactor system was assembled (Figure 5). The experimental design is shown in Figure 6.

The selection of technological parameters and processing methods was carried out on the basis of the analysis of scientific and technical literature in the field of processing of nepheline

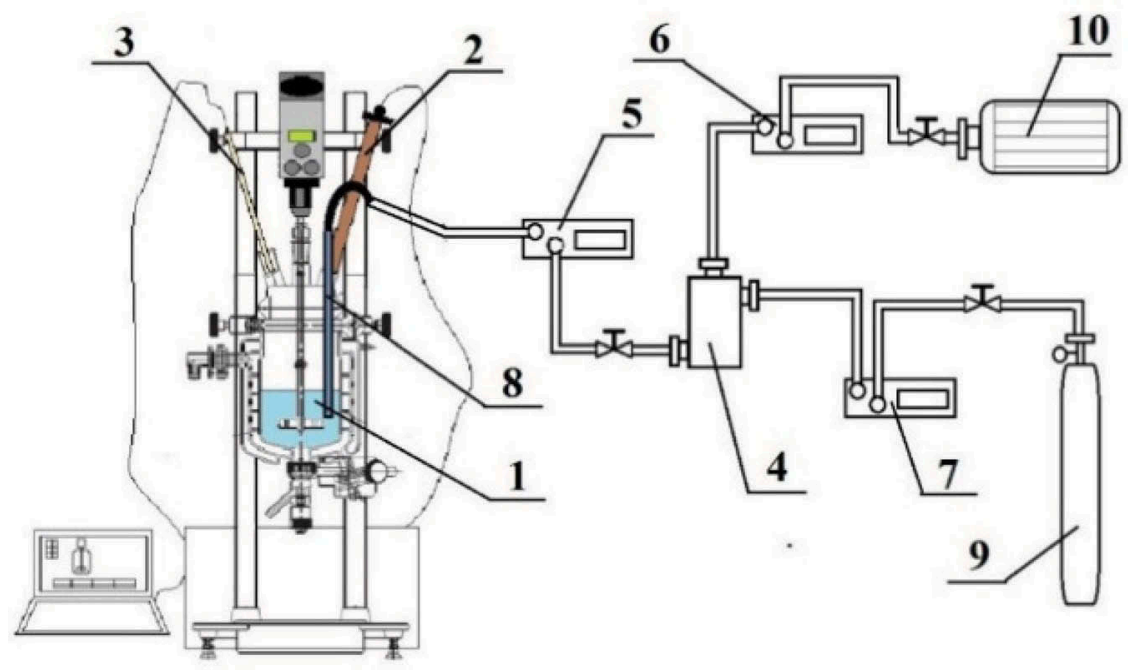

Figure 5. Scheme of a laboratory setup for a three-stage hydrochemical treatment. 1 - steel reactor 2,0 1. Single reactor AutoLab system (HEL); 2- pH electrode; 3 - temperature sensor; 4 - gas mixer; 5, 6, 7 gas meter RGS-1; 8 - gas supply pipe; 9 - a cylinder with technical carbon dioxide; 10 - compressor. 


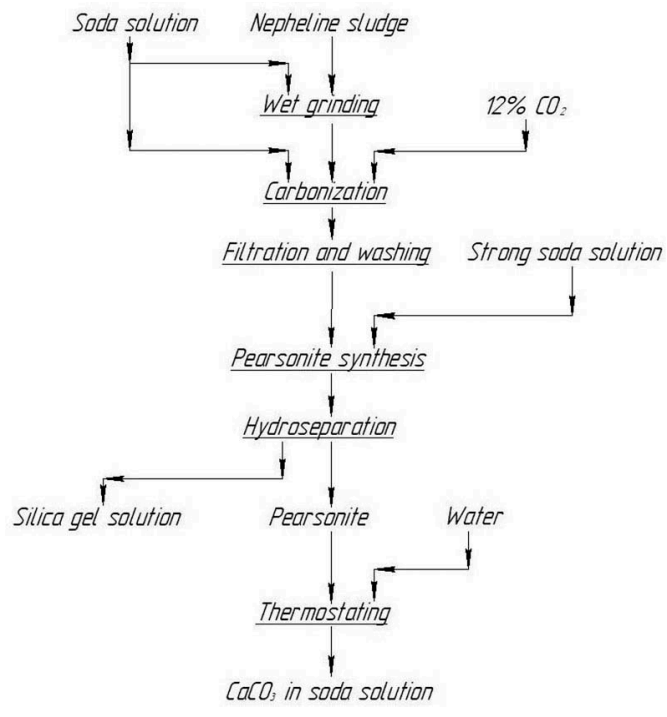

Figure 6. Scheme of the experiment.

and its sludges. In order to intensify the decomposition process, mechanical activation of nepheline sludge particles in a ball mill Pulverisette 6 (Fritsch) is built into the beginning of the scheme. As a result of the action of the balls and soda solution, the particles of the sludge are destroyed (hence, the increase in the reaction surface) and the process of its decomposition by reaction 1 begins. Wet grinding was carried out with the ratio $\mathrm{L}: \mathrm{S}=1$. After grinding, the size of the sludge corresponded to the residue on a sieve of $80 \mu \mathrm{m}-5-6 \%$. The concentration of soda solution during grinding was $120 \mathrm{~g} / \mathrm{l} \mathrm{N} \mathrm{N}_{2} \mathrm{O}$. After grinding, the suspension was brought with a soda solution with a concentration of $120 \mathrm{~g} / 1 \mathrm{Na}_{2} \mathrm{O}$ to the ratio $\mathrm{L}: \mathrm{S}=10$ in pulp and was sent for further carbonization at a temperature of $85^{\circ} \mathrm{C}$ for 5 hours. The composition of the gas phase corresponded to $12 \%$ vol. $\mathrm{CO}_{2}$, the flow rate of the gas mixture was maintained at $2.0 \mathrm{l} / \mathrm{min}$. At this stage, the formation of the first pearsonite crystals, which subsequently at the stage of synthesis, act as seeds.

Due to inactivity of stale nepheline sludge, it was determined that a precondition for the creation of a working scheme is pearsonite transformation, i.e. transition of the calcareous component to the double carbonate salt state according to reaction 4 . The main reason for this solution is the need to separate the calcareous component from the silica gel solution. For this, at the second stage, the obtained slurry after washing was subjected to additional treatment with a strong soda solution with a concentration of $220 \mathrm{~g} / 1 \mathrm{Na}_{2} \mathrm{O}$ for 6 hours at $\mathrm{L}: \mathrm{S}=4$ and a temperature of $90{ }^{\circ} \mathrm{C}$. Due to this operation, the synthesis of pearsonite in the field of its stable state is carried out. Then, the resulting pulp was separated on a laboratory vacuum filter and the solid phase was washed.

The third stage of the experiment consisted in thermostating of the solid residue in water to go into the region of metastable state of pearsonite and its decomposition to produce calcium carbonate and soda solution.

According to the results of the experiment, the resulting material was analyzed for inorganic carbon using a TOC-L analyzer. The calculated degree of conversion was $72 \%$, a rather low rate is associated with incomplete decomposition of sludge, however, it shows the possibility of their processing by the considered method. Additional confirmation that during the conversion of nepheline sludge decomposes pearsonite with the formation of calcium carbonate and alkali is the result of a titrimetric analysis of the solution after filtration to total alkali which showed an alkali content of $130 \mathrm{~g} / \mathrm{l}$. 


\section{CONCLUSION}

The results showed the fundamental possibility of modifying nepheline sludges to produce a calcareous component. Further research should be aimed at studying the influence of the parameters of mechanochemical activation of nepheline sludge, the processes of carbonization and synthesis of pearsonite to achieve a degree of nepheline sludge conversion at the level of $95-100 \%$. Presumably, an increase in the concentration of soda solution and the time of the carbonization process will increase the degree of decomposition of nepheline sludge due to a deeper hydrochemical preparation for the synthesis of pearsonite. The gas mixture used in the experiment in terms of carbon dioxide content is similar to the composition of the exhaust gases from sintering furnaces, which reduces the emission of carbon dioxide into the environment.

The application of this approach allows to increase the economic efficiency of the technology by obtaining new products, as well as reducing the cost of measures to protect the environment from the effects of industrial wastes.

\section{ACKNOWLEDGMENTS}

The study was carried out with the financial support of the Ministry of Education and Science of the Russian Federation (registration number of the project 11.4098.2017/ПЧ of 01.01.2017).

\section{REFERENCES}

Abramov, V.Y. \& Alekseev, A.I. \& Badalyants, Ch.A. 1990. Complex processing of apatite-nepheline raw materials. Moscow: Metallurgy.

Bozhenov, P.I. \& Kavalerova, V.I. 1966. Nepheline sludges. Moscow: Stroyizdat.

Brichkin, V.N. \& Kurtenkov, R.V. \& ElDeeb, A.B. \& Bormotov, I.S. 2019. State and development options for the raw material base of aluminium in non-bauxite regions. Obogashchenie Rud 4: 31-37. St.-Petersburg: Ore\&Metals.

ElDeeb, A.B. \& Brichkin, V.N. \& Kurtenkov, R.V. \& Bormotov, I.S. 2019. Extraction of alumina from kaolin by a combination of Pyro- and hydrometallurgical Processes. Applied Clay Science 172: 146-154. Amsterdam: Elsevier Science Publishing Company, inc.

Eremin, N.I. \& Naumchik, A.N. \& Kazakov, V.G. 1980. Processes and apparatuses of alumina production. Moscow: Metallurgy.

Lainer A.I. 1961. Alumina production. Moscow: Metallurgy.

Shmorgunenko N.S. \& Korneev V.I. 1982. Complex processing and use of slime dump alumina production, Moscow: Metallurgy.

Sizyakov, V.M. \& Brichkin, V.N. \& Kurtenkov, R.V. 2016. Increasing all-round utilization of nepheline raw materials through belite sludge soda conversion. Obogashchenie Rud 1: 54-59. St.-Petersburg: Ore\&Metals. 


\title{
Development of methods for calculating non-stationary heat transfer between multilayer structures
}

\author{
A. Gorshkov \\ Saint Petersburg State University of Industrial Technologies and Design, Saint Petersburg, Russia
}

A. Demidov

Rector, Saint Petersburg State University of Industrial Technologies and Design, Saint Petersburg, Russia

A. Makarov

Vice-Rector of Science, Saint Petersburg State University of Industrial Technologies and Design, Saint

Petersburg, Russia

\begin{abstract}
When solving various problems of heat transfer between multilayer structures separating physical media with different temperature characteristics, various heat exchangers or devices are used (Gorshkov et al., 2018; Korniyenko et al., 2016; Gorshkov et al., 2015). Examples of heat exchange devices may include a heater and various heat utilization appliances. In real operating conditions of multilayer structures separating media with different temperatures, the heat transfer behaviour through their boundaries is almost always unsteady (Gorshkov et al., 2014; Grinfeldi et al., 2014; Vatin et al., 2014). However, for the overwhelming majority of practical problems, as a rule, a quasi-stationary heat transfer mode is considered, characterized by the time constancy of the heat flux through the structure. The quasi-stationary heat transfer mode can only be established in very short time intervals. The convenience of such a mode of heat transfer is stipulated by the fact that when considering it, all thermotechnical calculations that are used in design practice are greatly simplified (Gorshkov et al., 2013a; Gorshkov et al., 2013b; Zimin et al., 2013). Unsteady heat transfer also occurs when solving problems of heating and cooling objects, damping temperature fluctuations in structures and some others. However, their practical use is often happens to be limited.
\end{abstract}

\section{INTRODUCTION}

To solve a number of practical problems of heat transfer between multilayer structures separating physical media with different temperature characteristics, the existing calculation methods have a number of significant inconveniences. For example, when considering a structure of several layers, differing in temperature characteristics, in order to determine the temperature fields at each boundary of the corresponding layer, it becomes necessary to merge solutions, which leads to unnecessary complication of calculations (Gorshkov et al., 2013c; Romanova et al., 2007; Romanova et al., 2005a). Moreover, the direct input from each layer is often far from obvious. There are also known problems with the setting of boundary conditions, and the constructions of some formulas when solving problems of unsteady heat transfer are so voluminous that their use for engineering calculations is difficult (Romanova et al., 2005b; Perevoznikov et al., 2004; Gorshkov et al., 2003). In the stationary mode of heat transfer, the equations and calculation methods are greatly simplified, however the reserves of energy saving when considering them, especially when considering multilayer rather massive material structures, are largely exhausted. In this respect at the present stage of the development of constructional thermal physics, reserves of energy savings should be sought with considering 
engineering problems in the non-stationary heat transfer mode (Makarov et al., 2015). Therefore, the search for optimal solutions with considering modes of non-stationary heat transfer is relevant when creating engineering calculation methods. The authors propose a description of the processes of heat transfer through multilayer structures in a non-stationary mode in the terms of the transport theory (Makarov et al., 2016).

\section{DEVELOPMENT OF A METHODOLOGY FOR SOLVING PROBLEMS OF NON-STATIONARY HEAT TRANSFER}

The process of heat transfer from the standpoint of the theory of transport can be considered as the diffusion of an additive scalar property - thermal energy. Let the heat transfer be carried out along some axis Ox. Since thermal energy propagates both along and against the Ox axis, it is expedient to introduce the corresponding heat flow densities $q_{\leftrightarrow}(x, t)$ as a local characteristic which can be considered as vectors in two-dimensional space As one of the local characteristics of the medium we can introduce the rate of propagation of thermal energy c (x) (Pereborova et al., 2018e; Makarov et al., 2018a; Pereborova et al., 2019).

It is obvious that the heat current density $-q(x, t)=q_{\rightarrow}(x, t)+q \quad(x, t)$. The transferred part of the internal energy can be interpreted as a nonequilibrium phonon gas, diffusing in a general way by different mechanisms. The density of the transferred part of the energy $U(x, t)=1 / c \cdot\left[q_{\rightarrow}(x, t)+q(x, t)\right]$. Moreover, it can be assumed that $U=c_{\nu} \rho T$ where $c_{v}-$ specific heat, $\rho$ - local density of the medium, $T(x, t)$ - desired temperature field $\left(d U=c_{\nu} \rho d T\right) \leftarrow$ (Demidov et al., 2006a; Demidov et al., 2006b; Demidov et al., 2007a).

From the general view of the theory of transport, the spread of the additive property is determined not only by the property itself, but also by the properties of one-dimensional space, which we will call the medium. The characteristics of the medium can be determined by the distribution of other properties (for example, moisture transfer, mechanical loads, etc.), and they can also depend (in the general case, nonlinearly) on the distribution of the studied property itself (thermal energy) (Stalevich et al., 2003; Makarov et al., 2002; Stalevich et al., 2002a).

Let us consider a section of the Ox axis - $\left[x_{1} ; x_{2}\right]$, which we will call a layer of the medium. Let us assume that a heat current $\left[x_{1} ; x_{2}\right]$ "falls" on the layer $q_{0}\left(x_{1}-0, t\right)$. First we consider the case when $q_{0}=\delta\left(t^{\prime}-t\right)$, where $t^{\prime}$ - current time, $t$ - fixed point in time. Let us introduce the following characteristics of the medium layer (Stalevich et al., 2002b; Stalevich et al., 2000):

- transmission coefficient $-\Lambda\left(t, x_{1} \mid x_{2}, \tau\right)=q_{\rightarrow}\left(x_{2}-0, t+\tau\right)$ - heat current density passing through the layer $\left(x_{1} ; x_{2}\right)$ in time $\tau$; it is being understood that outside the boundaries of the layer $\left[x_{1} ; x_{2}\right]$ there are screens completely absorbing heat;

- reflection coefficient - $\mathrm{P}\left(t, x_{1} \mid x_{2}, \tau\right)=q\left(x_{1}+0, t+\tau\right)$ - the density of the heat current reflected from the layer $\left(x_{1} ; x_{2}\right)$ in time $\tau$; i.e, the first reflection without a preceding crossing boundaries $x=x_{1}$ and $x=x_{2}$ earlier;

- absorption coefficient - $R\left(t, x_{1} \mid x_{2}, \tau\right)$ - heat current absorbed (born) in the layer $\left(x_{1} ; x_{2}\right)$ in time $(t+\tau)$.

Note that the introduced coefficients and the currents themselves $q_{\leftrightarrow}$ will be considered complex numbers (in terms of multichannel theory the coefficients $\Lambda, P, R$ will be square matrices). The absorption coefficient $R$ introduced above does not imply that there are permanent sources (leaks) of heat in the medium. By the heat source we understand the generation of heat energy $U$ at the moment $t>t_{0}$, if it was absent before, and the interval is completely limited by screens. The introduction of the properties of absorbing, reflecting, semitransparent screens has a simple meaning and serves only as a way of visual description (Pereborova et al., 2020a).

All coefficients (distributions) $\Lambda, \mathrm{P}, R$ are assumed to be zero for $\tau \prec 0$ (principle of causality). For distributions $\Lambda, \mathrm{P}, R$ we can compose recurrence relations.

In the most general case in terms of the ring $R_{\bar{\otimes}}[4]$ these relations have the form: 


$$
\begin{aligned}
& \Lambda\left(x_{1} \mid x_{3}\right)=\Lambda\left(x_{1} \mid x_{2}\right) \bar{\otimes}\left[\delta-\mathbf{P}\left(x_{2} \mid x_{3}\right) \bar{\otimes} \mathbf{P}\left(x_{2} \mid x_{1}\right)\right]^{\bar{\otimes}-1} \bar{\otimes} \Lambda\left(x_{2} \mid x_{3}\right) \\
& \mathbf{P}\left(x_{1} \mid x_{3}\right)=\mathbf{P}\left(x_{1} \mid x_{2}\right)+\Lambda\left(x_{1} \mid x_{2}\right) \bar{\otimes}\left[\delta-\mathbf{P}\left(x_{2} \mid x_{3}\right) \bar{\otimes} \mathbf{P}\left(x_{2} \mid x_{1}\right)\right]^{\bar{\otimes}-1} \bar{\otimes} \mathbf{P}\left(x_{2} \mid x_{3}\right) \bar{\otimes} \Lambda\left(x_{2} \mid x_{1}\right), \\
& R\left(x_{1} \mid x_{3}\right)=R\left(x_{1} \mid x_{2}\right)+\Lambda\left(x_{1} \mid x_{2}\right) \bar{\otimes}\left[\delta-\mathbf{P}\left(x_{2} \mid x_{3}\right) \otimes \mathbf{P}\left(x_{2} \mid x_{1}\right)\right]^{\otimes-1} \bar{\otimes} \\
& \bar{\otimes}\left[\mathbf{P}\left(x_{2} \mid x_{3}\right) \otimes R\left(x_{2} \mid x_{1}\right)+R\left(x_{2} \mid x_{3}\right)\right]
\end{aligned}
$$

The mathematical apparatus is based on non-commutative multiplication. To clarify the introduced symbols let us consider the set of functions $C_{t, \tau}$ of two real variables $t$ and $\tau$, which are definite and piecewise continuous for $\tau \geq 0$ and analytic with respect to the variable $t \in(-\infty ;+\infty)$ (Pereborova et al., 2020b).

Let $a(t, \tau), b(t, \tau), c(t, \tau) \in C_{t, \tau}$ Let us define the product of functions in the form:

$$
c(t, \tau)=a(t, \tau) \bar{\otimes} b(t, \tau) \stackrel{D e f}{=} \int_{0}^{\tau} a\left(t, \tau_{1}\right) b\left(t+\tau_{1}, \tau-\tau_{1}\right) d \tau_{1}
$$

Let us denote $R_{\bar{\otimes}}$ - the ring of functions $C_{t, \tau}$ with natural definite addition and multiplication in the sense of (2).

Let us see an ordered sequence of functions $a, b, c \ldots \in R_{\bar{\Phi}}$. In some problems $a(t, \tau)$ can be interpreted as a distribution function of some event $A$, that started at time $\mathrm{t}$ and distributed over the duration of the event $\tau \geq 0$. In this case, we will call the above sequence of functions a process consisting of sequential execution of events $A, B, C, \ldots$

The need to use a ring $R_{\bar{\otimes}}$ means that most of the natural phenomena around us are some ordered chains of certain events (Pereborova et al., 2020c).

In the simplest case if $a, b, c, \ldots$ do not depend on a variable $t$ expressly (for example, the start time of an event), then integral (2) represents the usual convolution of functions, i.e. $c(\tau)=a(\tau) * b(\tau)$. Consequently, $R_{*} \subset R_{\bar{\otimes}}$. To describe specific processes, it is more convenient to use not the ring $R_{\bar{\otimes}}$, itself, but the ring $R_{\bar{\otimes}}$. Isomorphism between $\operatorname{rings} R_{\bar{\otimes}}$ and $R_{\bar{\otimes}}$ is determined using the Laplace transformation

$$
A(t, S)=\int_{0}^{\infty} a(t, \tau) e^{-S \tau} d \tau
$$

where $A(t, S)$ - analytic function in both variables (real $t$ and complex $S$ ) (Pereborova et al., 2020d).

We define the product of functions $A(t, S) \otimes B(t, S)=C(t, S) ; A, B, C \in R_{\otimes}$, describing the multiplicative semigroup of the ring $R_{\otimes}$ as follows:

$$
C(t, S) \stackrel{\text { Def }}{=} \sum_{n=0}^{\infty} \frac{(-1)^{n}}{n !} \cdot \frac{\partial^{n} A(t, S)}{\partial S^{n}} \cdot \frac{\partial^{n} B(t, S)}{\partial t^{n}}=A(t, S) \otimes B(t, S)
$$

The associativity of the ring $R_{\otimes}$ follows from the associativity of the ring $R_{\bar{\otimes}}$. Multiplication in the sense of (3) is associated with addition due to the laws of distributivity. $R_{\otimes}$ - a ring with a unit element, while the unit element of the ring $R_{\otimes}$ is the function $E(t, S) \equiv 1$.

We will consider the physical meaning of equations (1) using the example of the first equation of this system. Event - the passage of a heat carrier (phonon) through the layer $\left[x_{1} ; x_{3}\right]$ is possible only by crossing the imaginary boundary an odd number of times (Pereborova et al., 2018a).

Then, according to theorems on addition and multiplication of probabilities for distributions, we have 


$$
\begin{aligned}
& \Lambda\left(t, x_{1} \mid x_{2}, \tau\right)=\int_{0}^{\tau} \Lambda\left(t, x_{1} \mid x_{2}, \tau_{1}\right) \cdot \Lambda\left(t+\tau_{1}, x_{2} \mid x_{3}, \tau-\tau_{1}\right)+ \\
& +\Lambda\left(x_{1} \mid x_{2}\right) \bar{\otimes} \mathbf{P}\left(x_{2} \mid x_{3}\right) \bar{\otimes} \mathbf{P}\left(x_{2} \mid x_{1}\right) \bar{\otimes} \Lambda\left(x_{2} \mid x_{3}\right)+\ldots= \\
& =\Lambda\left(x_{1} \mid x_{2}\right) \bar{\otimes}\left[\delta-\mathbf{P}\left(x_{2} \mid x_{3}\right) \bar{\otimes} \mathbf{P}\left(x_{2} \mid x_{1}\right)\right]^{\bar{\otimes}-1} \bar{\otimes} \Lambda\left(x_{2} \mid x_{3}\right)
\end{aligned}
$$

Instead of distributing $\Lambda, \mathrm{P}, R$ it is advisable to immediately use their Laplace images, that is $\bar{\Lambda}, \overline{\mathrm{P}}, \bar{R}$. In this case, instead of the symbol $\bar{\otimes}$ it is necessary to use multiplication $\otimes$ in the sense of (4) (Makarov et al., 2018b).

The theory of transfer formulates the transition from one ring to another in the form of the "non-stationary principle". The essence of it is as follows. Let some additive quantity $M$, that has no structure be described by coefficients $\bar{\Lambda}, \overline{\mathrm{P}}, \bar{R}$, and one with a structure - by analogous elements $\widetilde{\Lambda}, \widetilde{\mathrm{P}}, \widetilde{R}$, while $\widetilde{\Lambda}, \widetilde{\mathrm{P}}, \widetilde{R}$ belong to a more complex ring $R_{0}$. Then the transition from the description of the propagation of the property $M$ to the description of the propagation of the property $\widetilde{M}$ is reduced to replacing the operation $\otimes$ with the operation of multiplication and replacing 1 by the unit element of the ring $R_{0}$ without changing the form of equations (Pereborova et al., 2019a; Pereborova et al., 2018b; Makarov et al., 2014a). In other words, system (1) is also valid for the multichannel case with the corresponding substitution of symbols.

Accordingly, in a general way, system (1) will take the form:

$$
\begin{aligned}
& \bar{\Lambda}\left(x_{1}, t \mid x_{3}, S\right)=\bar{\Lambda}\left(x_{1} \mid x_{2}\right) \otimes\left[I-\overline{\mathrm{P}}\left(x_{2} \mid x_{3}\right) \otimes \overline{\mathrm{P}}\left(x_{2} \mid x_{1}\right)\right]^{\otimes-1} \otimes \widetilde{\Lambda}\left(x_{2} \mid x_{3}\right) \\
& \overline{\mathrm{P}}\left(x_{1}, t \mid x_{3}, S\right)=\overline{\mathrm{P}}\left(x_{1} \mid x_{2}\right)+\bar{\Lambda}\left(x_{1} \mid x_{2}\right) \otimes\left[I-\overline{\mathrm{P}}\left(x_{2} \mid x_{3}\right) \overline{\mathrm{P}}\left(x_{2} \mid x_{1}\right)\right]^{\otimes-1} \otimes \\
& \otimes \overline{\mathrm{P}}\left(x_{2} \mid x_{3}\right) \otimes \Lambda\left(x_{2} \mid x_{1}\right) \\
& \bar{R}\left(x_{1}, t \mid x_{3}, S\right)=\bar{R}\left(x_{1} \mid x_{2}\right)+\bar{\Lambda}\left(x_{1} \mid x_{2}\right) \otimes\left[I-\overline{\mathrm{P}}\left(x_{2} \mid x_{3}\right) \otimes \overline{\mathrm{P}}\left(x_{2} \mid x_{1}\right)\right]^{\otimes-1} \otimes \\
& \otimes\left[\overline{\mathrm{P}}\left(x_{2} \mid x_{3}\right) \otimes \bar{R}\left(x_{2} \mid x_{1}\right)+\bar{R}\left(x_{2} \mid x_{3}\right)\right]
\end{aligned}
$$

The relations (6) make it possible to successively determine the properties of a system of layers, with knowing the properties of each layer, i.e. give a constructive way to solve the problems of heat transfer (Demidov et al., 2006c).

The non-commutativity of the rings $R_{\bar{\otimes}}$ and $R_{\otimes}$ is essential for strongly non-stationary processes, when the properties of the medium change over the mean time of heat passage, i.e., each time the "wandering" phonon enters a new medium. If all the coefficients do not depend on time $t$ explicitly or this dependence can be neglected, then the multiplication " $\otimes$ " is an ordinary multiplication, i.e.

$$
\begin{aligned}
\bar{\Lambda}\left(x_{1} \mid x_{3}, S\right) & =\frac{\bar{\Lambda}\left(x_{1} \mid x_{2}\right) \bar{\Lambda}\left(x_{2} \mid x_{3}\right)}{1-\overline{\mathrm{P}}\left(x_{2} \mid x_{3}\right) \overline{\mathrm{P}}\left(x_{2} \mid x_{1}\right)} \\
\overline{\mathrm{P}}\left(x_{1} \mid x_{3}, S\right) & =\overline{\mathrm{P}}\left(x_{1} \mid x_{2}\right)+\frac{\bar{\Lambda}\left(x_{1} \mid x_{2}\right) \bar{\Lambda}\left(x_{2} \mid x_{1}\right) \overline{\mathrm{P}}\left(x_{2} \mid x_{3}\right)}{1-\overline{\mathrm{P}}\left(x_{2} \mid x_{3}\right) \overline{\mathrm{P}}\left(x_{2} \mid x_{1}\right)} \\
\bar{R}\left(x_{1} \mid x_{3}, S\right) & =\bar{R}\left(x_{1} \mid x_{2}\right)+\frac{\bar{\Lambda}\left(x_{1} \mid x_{2}\right)\left[\overline{\mathrm{P}}\left(x_{2} \mid x_{3}\right) \bar{R}\left(x_{2} \mid x_{1}\right)+\bar{R}\left(x_{2} \mid x_{3}\right)\right]}{1-\overline{\mathrm{P}}\left(x_{2} \mid x_{3}\right) \overline{\mathrm{P}}\left(x_{2} \mid x_{1}\right)}
\end{aligned}
$$

Non-commutativity is also essential in those cases when the medium is inhomogeneous or there are inclusions in the medium layer. In this case, it is necessary to introduce the concept of a propagation channel and all coefficients $\bar{\Lambda}, \overline{\mathrm{P}}, \bar{R}$ are square matrices. In reality, Fourier's law is rather approximate and functions well only for the stationary case. This is explained by the fact that heat transfer even in a homogeneous medium does not follow just one mechanism (there are also internal heat transfer channels) (Rymkevich et al., 2013). 
The existence of several mechanisms of heat conduction leads to a slightly different system of equations describing the process of heat transfer (Pereborova et al., 2019b; Pereborova et al., 2018c; Pereborova et al., 2018d).

For the majority of engineering calculations all these "subtleties" may be disregarded and the above relations (7) can be used.

The described method of heat transfer makes it possible to establish correlations between energy densities (i.e., temperature) and heat currents at different points in space. Indeed, let us consider the two-point identity for heat fluxes. Given $x=x_{1}$ we know the heat currents $q_{1 \leftrightarrow}(S)$ Let us define these heat currents at an arbitrary point $x_{2}$ (for greater certainty let it be $\left.x_{2}>x_{1}\right)$.

Using the developed method, we have:

$$
\begin{aligned}
& \overline{q_{\rightarrow}}\left(x_{2} \mid S\right)=\left[\underset{\rightarrow}{\overline{q_{0}}}+\underset{\leftarrow}{q_{0}} \otimes \overline{\mathrm{P}}\left(x_{1} \mid-\infty\right)\right] \otimes\left[I-\overline{\mathrm{P}}\left(x_{1} \mid+\infty\right) \otimes \overline{\mathrm{P}}\left(x_{1} \mid-\infty\right)\right]^{\otimes-1} \otimes \\
& \otimes \bar{\Lambda}\left(x_{1} \mid x_{2}\right) \otimes\left[I-\overline{\mathrm{P}}\left(x_{2} \mid+\infty\right) \otimes \overline{\mathrm{P}}\left(x_{2} \mid x_{1}\right)\right]^{\otimes-1}, \\
& \overline{q_{\rightarrow}}\left(x_{2} \mid S\right)=\overline{q_{\rightarrow}}\left(x_{2} \mid S\right) \otimes \overline{\mathbf{P}}\left(x_{2} \mid+\infty\right)
\end{aligned}
$$

It is not difficult to express currents $q_{1}$ by means of $q_{2}$. In particular, with $x_{2}=x_{1}=x$ we obtain a true identity that connects $\bar{\Lambda}$ and $\overline{\mathrm{P}}$ with each other. In general, by splitting a certain layer in different ways, we can get useful results, sometimes greatly simplifying the solution of specific problems. Thus, the property currents at one point in one-dimensional space completely determine the property currents for all other points. The method of accounting for multiple border crossings can be generalized to the three-dimensional case (Makarov et al., 2017b).

For continuous space, it is advisable to consider an infinitely thin layer $d x$. We have $\bar{\Lambda}(x \mid x) \equiv 1, \overline{\mathrm{P}}(x \mid x)=\bar{R}(x \mid x) \equiv 0$, if there are no singularities (the existing singularities will be called screens). Expanding $\overline{\mathrm{P}}(x \mid x \pm d x)$ and $\bar{R}(x \mid x \pm d x) d x>0$ in a series and leaving the first terms of the expansion, we will have:

$$
\begin{aligned}
& \overline{\mathrm{P}}(x \mid x \pm d x)=a(x, t) d x+0(d x) \\
& \bar{R}(x \mid x \pm d x)=\chi(x, t) d x+0(d x)
\end{aligned}
$$

where $a(*, t)$ and $\chi(*, t)$ will be called reflection and absorption indices respectively. Thus, $a$ and $\chi$ are the local characteristics of the medium in relation to the propagation of heat (Demidov et al., 2017).

Let us introduce the notion of the average time for the passage of heat by the layer $\Delta x$ as follows:

$$
t_{\lambda} \Delta x \stackrel{D e f}{=}-\frac{\partial}{\partial S}[\ln \bar{\Lambda}(x \mid x+\Delta x)]_{S=0}
$$

For a homogeneous medium $\bar{\Lambda}, \overline{\mathrm{P}}, \bar{R}$ have a simple form:

$$
\begin{aligned}
\bar{\Lambda}(z, S) & =\frac{2 \mu(S-\mu) e^{-\mu z}}{a^{2}-(S-\mu)^{2} e^{-2 \mu z}}, \infty \\
\overline{\mathrm{P}}(z, S) & =\frac{a(S-\mu)\left[1-e^{-2 \mu \mathrm{z}}\right]}{a^{2}-(S-\mu)^{2} e^{-2 \mu \mathrm{z}}}, \\
\bar{R}(z, S) & =\frac{\sqrt{2} \chi \sqrt{S-\mu}}{\sqrt{S-a}} \cdot \frac{\left[1-e^{-\mu \mathrm{z}}\right]}{\left[a+(S-\mu) e^{-\mu \mathrm{z}}\right]}
\end{aligned}
$$


Here we introduce the symbols $z=x_{2}-x_{1}, \quad \mu=\sqrt{\widetilde{S}^{2}-a^{2}}, \quad \widetilde{S}=\frac{S}{c}+(a+\chi)$.

\section{NON-STATIONARY HEAT TRANSFER THROUGH MULTILAYER TEXTILES}

One of the problems that arises when solving problems of unsteady heat transfer through multilayer textiles is the correct setting of the boundary conditions at the media interface. Another problem is limiting the rate of transfer of thermal energy, that is, heat is transferred with some delay (Makarov et al., 2017b). The calculations of the delay in heat transfer between textiles lead to equations of the form:

$$
\begin{aligned}
& \tau_{\mathrm{P}} \frac{\partial \vec{q}}{\partial t}+\vec{q}=-\lambda \vec{\nabla} \vec{T} \\
& \tau_{\mathrm{P}} \frac{\partial^{2} T}{\partial t^{2}}+\frac{\partial T}{\partial t}=\operatorname{div}\left[a_{T} \operatorname{grad} T\right]
\end{aligned}
$$

Here $T(x, y, z, t)$ - is the required temperature field; $\vec{q}$ - heat flux density; $\lambda$ - coefficient of thermal conductivity, $a_{T}=\frac{\lambda}{c_{V} \rho}$ - coefficient of heat diffusion (coefficient of thermal diffusivity); $c_{V}$ and $\rho$ accordingly, the specific heat and density of the material; $\tau_{\mathrm{P}}$ - relaxation time. The equations (12) characterize most of the heat transfer phenomena between textiles. Nevertheless, theoretical estimates show that the relaxation time $\tau_{\mathrm{P}}$ for most textile materials is very short, although the empirically introduced $\tau_{\mathrm{P}}$ corrects non-stationary thermal fields (Makarov et al., 2015a).

The polymeric materials that the studied textiles are composed of have a heterogeneous structure. However, even for a homogeneous medium, there is more than one heat transfer mechanism. The transferred part of the internal energy can be interpreted as a nonequilibrium phonon gas diffusing in the general case by different mechanisms (longitudinal and transverse waves) (Makarov et al., 2015b).

The process of transferring heat between textiles can be viewed as the diffusion of an additive scalar property - thermal energy with an internal structure.

Let us assume that heat energy propagates through $N$ various mechanisms, which we will call heat propagation channels. It is the amount of heat energy on each channel that determines the structure of the heat flow. The transferred part of the internal energy $U(x, t)$ is equal to the sum of the energies on each channel (internal energy reservoirs) (Demidov et al., 2009).

$$
U(x, t)=\sum_{n=1}^{N} \frac{1}{c_{n}}\left[q_{\vec{n}}(x, t)+q_{\overleftarrow{n}}(x, t)\right]=\sum_{n=1}^{N}\left[U_{\vec{n}}(x, t)+U_{\overleftarrow{n}}(x, t)\right]
$$

It should be noted that $T(x, t)$ - some average temperature over a physically small volume. Since the transfer of heat is an irreversible and nonequilibrium process, it is more accurate to talk about the local temperature on each channel (the principle of local equilibrium). Therefore, in the case of non-stationary heat transfer, two physical processes take place: the first is the transfer of energy from a more heated body to a less heated one; the second is the exchange of energy between different distribution channels, i.e. relaxation processes. Part of the electromagnetic energy is absorbed according to the well-known exponential Bouguer law, i.e. passes to other channels of heat propagation (Makarov et al., 2014b).

The heat flux density $q(x, t)$ is

$$
q(x, t)=\sum_{n=1}^{N} q_{n}(x, t)=\sum_{n=1}^{N}\left[q_{\vec{n}}(x, t)-q_{\vec{n}}(x, t)\right]
$$


To derive the heat transfer equations generally it is sufficient to write $2 \mathrm{~N}$ equations of continuity for the linear energy density on each channel in accordance with the law of conservation of energy (Demidov et al., 2007a).

Thereat we will have

$$
\begin{aligned}
& \frac{\partial U_{\vec{n}}(x, t)}{\partial t}=-\frac{\partial}{\partial x}\left[U_{\vec{n}}(x, t) c_{n}\right]-\sum_{k=1}^{N}\left[\tilde{a}_{\overrightarrow{n k}}+\tilde{b}_{\overrightarrow{n k}}\right] U_{\vec{n}}(x, t)+\sum_{k=1}^{N} \tilde{a}_{\leftarrow n} U_{\leftarrow}(x, t)+\sum_{k=1}^{N} \tilde{b}_{\vec{k}} U_{\vec{k}}(x, t)
\end{aligned}
$$

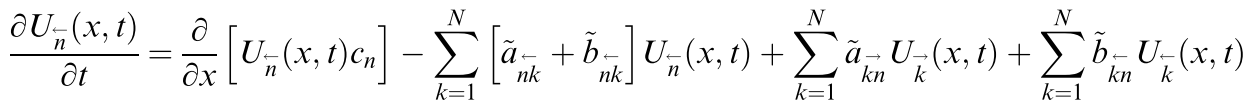

Here $\widetilde{a}_{n k}(x, t) \leftarrow$ is the reflection rate constant, i.e. the share of thermal energy per unit oftime that has passed from channel $n$ to channel $k$ with a change in the direction of propagation; $\widetilde{a}_{n k}(x, t)=\frac{\widetilde{a}_{n k}}{c_{n}}$ - is called the matrix element of the heat flux dissipation indicators; $\widetilde{b}_{n k}(x, t)$ - matrix of constants of transition rate from channel $n$ to channel number $k$, i.e. the proportion of thermal energy per unit of time $\left(\widetilde{q}_{n k} \equiv 0\right)$, that has passed from channel number $n$ to channel number $k$ without changing the direction of movement; the quantity $\left(\widetilde{\theta}_{n k}=\frac{\widetilde{b}_{n k}}{c_{n}}\right.$ is called the matrix element of the transition indicators (Demidov et al., 2007b).

The system equations express the law of conservation of energy transfer with taking into account the internal exchange between the channels. The distribution channel can also be understood as a homogeneous part of a heterogeneous system. In the absence of asymmetry: i.e. without the presence of external fields, fluxes of quantities of the same nature,

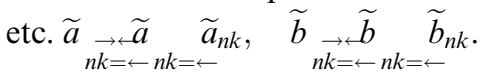

We restrict ourselves to considering the case of a quasi-homogeneous medium whose properties do not change with time (for example, aging). Such a medium will be described by the following constants: $\widetilde{a}_{n k}-N^{2}$ - quantities, $\widetilde{b}_{n k}-N(N-1)$ quantities and $c_{n}-N$ - quantities, i.e. totally $2 N^{2}$ material characteristics. In reality there are much less of them due to the presence of equilibrium equations (Demidov et al., 2006d).

Let us rewrite system (6) in a slightly different form, adding and subtracting the equations of the system term by term, introducing the matrix elements

$$
\begin{aligned}
\theta_{k n} & =\frac{1}{c_{n}} \sum_{n=1}^{N}\left[\tilde{a}_{k n}+\tilde{b}_{k n}\right] \delta_{k n}+\frac{1}{c_{k}}\left[\tilde{a}_{k n}-\tilde{b}_{k n}\right] \\
G_{k n} & =\sum_{m=1}^{\infty}\left[\tilde{a}_{k m}+\tilde{b}_{k m}\right] \delta_{k n}-\left[\tilde{a}_{k n}+\tilde{b}_{k n}\right]
\end{aligned}
$$

In this case, system (5) will be rewritten as follows:

$$
\begin{aligned}
& \frac{\partial U_{n}}{\partial t}+\frac{\partial q_{n}}{\partial x}+\sum_{k=1}^{N} U_{k} G_{k n}=0 \\
& \frac{1}{c_{n}} \frac{\partial q_{n}}{\partial t}+c_{n} \frac{\partial U_{n}}{\partial x}+\sum_{k=1}^{N} q_{k} \theta_{k n}=0
\end{aligned}
$$

The first $N$ of equations are equations of continuity with internal energy transfers from channel to channel. The second $N$ of equations express the generalized Fourier law. From the system of equations $N=1$ hyperbolic heat conductivity equations follow (12) (Leusheva et al., 2019). 
If the thickness of the medium layer is sufficiently large, then in the stationary case (steady state) the Fourier law is fulfilled, i.e.

$$
\begin{aligned}
& \sum_{k=1}^{N} U_{k}^{p} G_{k n}=0 \\
& c_{n} \frac{\partial U_{k}^{p}}{\partial x}+\sum_{k=1}^{N} q_{k}^{p} \theta_{k n}=0
\end{aligned}
$$

The index " $p$ " means that equilibrium has been established between the channels and the principle of local equilibrium is in effect, i.e. the system has a local temperature $T(x)$ and other local characteristics. Let $\omega_{k}^{p}$ - is the fraction of thermal energy propagating through the channel number $n\left(\sum_{n=1}^{N} \omega_{k}^{p}=1\right)$, then the system (Nikolaev et al., 2018)

$$
\begin{aligned}
& \sum_{k=1}^{N} \omega_{k}^{p} G_{k n}=0 \\
& \sum_{n=1}^{N} \omega_{k}^{p}=1
\end{aligned}
$$

uniquely determines the value $\omega_{k}^{p}$ (Lapshin, 2014).

In addition, for such a stationary quasi-equilibrium, the principle of detailed equilibrium can be applied - the amount of energy passing from channel number $k$ to channel $n$ is equal to the amount of energy passing from channel $n$ to channel number $k$.

This way

$$
\begin{aligned}
& \omega_{k}^{p} \tilde{a}_{k n}=\omega_{n}^{p} \tilde{a}_{n k} \\
& \omega_{k}^{p} \tilde{b}_{k n}=\omega_{n}^{p} \tilde{b}_{n k}
\end{aligned}
$$

that significantly reduces the number of linearly independent characteristics of the environment. In particular, for the stationary case, we have the following equality:

$$
\frac{1}{a_{T}} c_{n} \omega_{n}^{p}-\omega_{k}^{p} \theta_{k n}=0
$$

With additional $\mathrm{N}$ - constraint equations (Gryazev et al., 2017)

\section{CONCLUSION}

As a result, a mathematical model has been developed for calculating multilayer structures in the non-stationary heat transfer mode. In engineering problems, when assessing the energy saving potential, equations and models obtained in a stationary heat transfer mode are usually considered. The reserves of thermal energy savings for them are well studied, and their potential at the present stage of development of science in the area of knowledge under consideration is largely realized. In this regard, an additional potential for energy saving can be identified when considering the heat transfer process in a nonstationary mode.

The developed mathematical model is based on the methods of the general transport theory. An equation is obtained to determine the difference in the average transit times of a heat flux through a multilayer structure that separates media with different temperatures for 
a different sequence of layers arrangements. The influence of the order of the layers on its thermal stability is shown. An expression is obtained that shows the difference in the average transit times of a heat flux through a multilayer structure with different arrangements of its layers. The obtained equations can be used, inter alia, when describing the process of heat transfer through multilayer textiles.

\section{FUTURE RESEARCH AND ACKNOWLEDGEMENTS}

The study was funded within the framework of the state assignment of the Ministry of Science and Higher Education of the Russian Federation, Project No. FSEZ-2020-0005.

\section{REFERENCES}

Demidov, A.V., Makarov, A.G., Stalevich, A.M. (2006a) Methods of computer analysis of viscoelasticity of technical materials. Izvestiya Vysshikh Uchebnykh Zavedenii, Seriya Teknologiya Tekstil'noi Promyshlennosti, Vol. 291, No 3, pp. 13-17. eid=2-s2.0-37849188658

Demidov, A.V., Makarov, A.G., Stalevich, A.M. (2006b) Definition of the mechanical characteristics of textile stuffs at variable temperature. Izvestiya Vysshikh Uchebnykh Zavedenii, Seriya Teknologiya Tekstil'noi Promyshlennosti, Vol. 291, No 3, pp. 13-17. eid=2-s2.0-37849188658

Demidov, A.V., Makarov, A.G., Stalevich, A.M. (2006c) The criteria of optimal selection of mathematical model of textile materials viscoelasticity. Izvestiya Vysshikh Uchebnykh Zavedenii, Seriya Teknologiya Tekstil'noi Promyshlennosti, Vol. 293, No 5, pp. 21-25. eid=2-s2.0-34247548784

Demidov, A.V., Makarov, A.G., Stalevich, A.M., Petrova, L.N., Chelishev, A.M. (2006d) Research of changes of deformation properties of polyester threads depending on twist amount. Izvestiya Vysshikh Uchebnykh Zavedenii, Seriya Teknologiya Tekstil'noi Promyshlennosti, Vol. 292, No 4, pp. 9-13. eid=2-s2.0-33845499474

Demidov, A.V., Makarov, A.G., Stalevich, A.M. (2007a) Definition of the computer forecasting trends of deformation properties of textile stuffs. Izvestiya Vysshikh Uchebnykh Zavedenii, Seriya Teknologiya Tekstil'noi Promyshlennosti, Vol. 297, No 2, pp. 14-17. eid=2-s2.0-38849203122

Demidov, A.V., Makarov, A.G., Stalevich, A.M. (2007b) Predicting the nonlinear hereditary viscoelasticity of polymers. Journal of Applied Mechanics and Technical Physics, Vol. 48, No 6, pp. 897-904. DOI: $10.1007 / \mathrm{s} 10808-007-0114-8$

Demidov, A.V., Makarov, A.G., Stalevich, A.M. (2007c) System analysis of viscoelasticity of textile stuffs. Izvestiya Vysshikh Uchebnykh Zavedenii, Seriya Teknologiya Tekstil'noi Promyshlennosti, Vol. 298, No 3, pp. 11-14. eid=2-s2.0-34648822922

Demidov, A.V., Makarov, A.G., Stalevich, A.M. (2009) A version of modeling of nonlinear-hereditary viscoelasticity of polymer materials. Mechanics of Solids, Vol. 44, No 1, pp. 122-130. DOI: 10.3103/ S0025654409010130

Demidov, A.V., Makarov, A.G., Pereborova, N.V., Egorova, M.A. (2017) Forecasting of deformation-relaxation properties of poly amide fabric used to make the canopy. Izvestiya Vysshikh Uchebnykh Zavedenii, Seriya Teknologiya Tekstil'noi Promyshlennosti, Vol. 367, No 1, pp. 250-258. eid=2-s2.0-85033239149

Gorshkov, A.S. (2003) 75 years Soyuzteplostroi. Montazhnyei Spetsial'nye Raboty v Stroitel'stve, 9, pp. 15-19. eid=2-s2.0-0142041513

Gorshkov, A.S., Vatin, N.I. (2013a) Properties of the wall structures made of autoclaved cellular concrete products on the polyurethane foam adhesive. Magazine of Civil Engineering, Vol. 40, No 5, pp. 5-19. DOI: $10.5862 / \mathrm{MCE} .40 .1$

Gorshkov, A.S., Sokolov, N.A. (2013b) Inconsistency in Russian and international standards in the determination of the design values of thermal conductivity of building materials and products. Magazine of Civil Engineering, Vol. 42, No 7, pp. 7-14+78-80. DOI: 10.5862/MCE.42.2

Gorshkov, A.S., Makarov, A.G., Romanova, A.A., Rymkevich, P.P. (2013c) Modelling of directed polymers deformation processes based on the description of the kinetics of supramolecular structures separated by energy barriers. Magazine of Civil Engineering, Vol. 44, No 9, pp. 76-83+103-104. DOI: 10.5862/MCE.44.10

Gorshkov, A.S., Rymkevich, P.P., Vatin, N.I. (2014) Simulation of non-stationary heat transfer processes in autoclaved aerated concrete-walls. Magazine of Civil Engineering, Vol. 52, No 8, pp. 38-48 and 65-66. DOI: 10.5862/MCE.52.5 
Gorshkov, A.S., Rymkevich, P.P. (2015) A diagram method of describing the process of non-stationary heat transfer. Magazine of Civil Engineering, Vol. 60, No 8, pp. 68-82. DOI: 10.5862/MCE.60.8

Gorshkov, A.S., Vatin, N.I., Rymkevich, P.P., Kydrevich, O.O. (2018) Payback period of investments in energy saving. Magazine of Civil Engineering, Vol. 78, No 2, pp. 65-75. DOI: 10.18720/MCE.78.5

Grinfeldi, G.I., Gorshkov, A.S., Vatin, N.I. (2014) Tests results strength and thermophysical properties of aerated concrete block wall samples with the use of polyurethane adhesive. Advanced Materials Research, 941-944, pp. 786-799. DOI: 10.4028/www.scientific.net/AMR.941-944.786

Gryazev, M.V., Kachurin, N.M. and Vorob'ev, S.A. (2017) Mathematical models of gas-dynamic and thermophysical processes in underground coal mining at different stages of mine development. Journal of Mining Institute, 223, p. 99. DOI: 10.18454/pmi.2017.1.99.

Korniyenko, S.V., Vatin, N.I., Gorshkov, A.S. (2016) Thermophysical field testing of residential buildings made of autoclaved aerated concrete blocks. Magazine of Civil Engineering, Vol. 64, No 4, pp. 10-25. DOI: $10.5862 / \mathrm{MCE} .64 .2$

Lapshin, A. A. (2014) "Mathematical modeling of mine air conditioning in the zone of mine works", Journal of Mining Institute, 210, p. 53. Available at: http://pmi.spmi.ru/index.php/pmi/article/view/ 5265 (Accessed: 18 August 2020).

Leusheva, Ekaterina \& Morenov, Valentin \& Martel, A.S. (2019). Combined cooling heat and power supplying scheme for oil and gas fields development. 10.1201/9780429327070-53.

Makarov, A.G. (2002) Determining the analytical correlation between the standardized nuclei of relaxation and creep in textile materials. Izvestiya Vysshikh Uchebnykh Zavedenii, Seriya Teknologiya Tekstil'noi Promyshlennosti, Vol. 266, No 2, pp. 13-17. eid=2-s2.0-0036931214

Makarov, A.G., Pereborova, N.V., Egorova, M.A., Wagner, V.I. (2014a) Modeling and forecasting viscoelastic properties of textile materials with a complex structure. Izvestiya Vysshikh Uchebnykh Zavedenii, Seriya Teknologiya Tekstil'noi Promyshlennosti, Vol. 354, No 6, pp. 120-124. eid=2-s2.0 $-84937439497$

Makarov, A.G., Pereborova, N.V., Egorova, M.A., Wagner, M.A. (2014b) Ways of modeling deformation and relaxation properties of textile materials with a complex structure. Izvestiya Vysshikh Uchebnykh Zavedenii, Seriya Teknologiya Tekstil'noi Promyshlennosti, Vol. 351, No 3, pp. 110-115. eid=2-s2 $.0-84937410003$

Makarov, A.G., Demidov, A.V., Pereborova, N.V., Egorova, M.A. (2015a) Modeling and prediction of estimated relaxation and deformation properties of the polymer parachute line. Izvestiya Vysshikh Uchebnykh Zavedenii, Seriya Teknologiya Tekstil'noi Promyshlennosti, Vol. 360, No 6, pp. 194-205. eid=2-s2.0-84976560627

Makarov, A.G., Pereborova, N.V., Wagner, V.I., Vasileva, E.K. (2015b) Development of methodology for the comparative analysis of deformation and relaxation properties of aramid yarns and textile materials based on them. Izvestiya Vysshikh Uchebnykh Zavedenii, Seriya Teknologiya Tekstil'noi Promyshlennosti, Vol. 359, No 5, pp. 48-58. eid=2-s2.0-84971636036

Makarov, A.G., Slutsker, G.Y., Drobotun, N.V. (2015c) Creep and fracture kinetics of polymers. Technical Physics, Vol. 60, No 2, pp. 240-245. DOI: 10.1134/S1063784215020152

Makarov, A.G., Slutsker, G.Y., Gofman, I.V., Vasil'eva, V.V. (2016) Initial stage of stress relaxation in oriented polymers. Physics of the Solid State, Vol. 58, No 4, pp. 840-846. DOI: 10.1134/ S1063783416040132

Makarov, A.G., Pereborova, N.V., Egorova, M.A., Egorov, I.M. (2017a) Quality analysis of deformation-relaxation properties of aramid cords mountain rescue appointments. Izvestiya Vysshikh Uchebnykh Zavedenii, Seriya Teknologiya Tekstil'noi Promyshlennosti, Vol. 368, No 2, pp. 309-313. eid=2-s2.0-85035207042

Makarov, A.G., Pereborova, N.V., Egorova, M.A., Egorov, I.M. (2017b) Mathematical modeling of deformation-relaxation processes polymeric materials in conditions of variable temperatures. Izvestiya Vysshikh Uchebnykh Zavedenii, Seriya Teknologiya Tekstil'noi Promyshlennosti, Vol. 370, No 4, pp. 287-292. eid=2-s2.0-85057142312

Makarov, A.G., Pereborova, N.V., Vagner, V.I., Egorova, M.A., Klimova, N.S. (2018a) Spectral Analysis of Viscoelastic Creep of Geotextiles. Fibrie Chemistry, Vol. 50, No 4, pp. 378-382. DOI 10.1007/ s10692-019-09993-4

Makarov A.G., Pereborova N.V., Kozlov A.A., Shvankin A.M. (2018b) Computer-Assisted Prediction and Qualitative Analysis for Polymer Parachute Cords. Fibre Chemistry, Vol. 50, No. 3, pp. 239-242. DOI 10.1007/s10692-018-9968-1

Nikolaev, A \& Dokoukin, V \& Lykov, Yuri \& Fetisov, Vadym. (2018). Research of processes of heat exchange in horizontal pipeline. IOP Conference Series: Materials Science and Engineering. 327. 032041. 10.1088/1757-899X/327/3/032041. 
Pereborova N.V., Demidov A.V., Makarov A.G., Klimova N.S. (2018a) Modeling of DeformationRelaxation Processes of Aramid Textile Materials - the Foundation for Analyzing Their Operational Properties. Fibre Chemistry, Vol. 50, No. 2, pp. 104-107. DOI 10.1007/s10692-018-9941-z

Pereborova, N.V., Makarov, A.G., Egorova, M.A., Kozlov, A.A., Konovalov, A.S. (2018b) Methods of simulation and comparative analysis of shadow and deformation-reducing properties of aramide textile materials. Izvestiya Vysshikh Uchebnykh Zavedenii, Seriya Teknologiya Tekstil'noi Promyshlennosti, Vol. 375, No 3, pp. 253-257. eid=2-s2.0-85059766891

Pereborova, N.V., Makarov, A.G., Egorova, M.A., Klimova, N.S. (2018c) Methods of increasing the competitiveness of domestic aramid textile materials based on complex analysis of their functional properties. Izvestiya Vysshikh Uchebnykh Zavedenii, Seriya Teknologiya Tekstil'noi Promyshlennosti, Vol. 378, No 6, pp. 267-272. eid=2-s2.0-85072335464

Pereborova, N.V., Demidov, A.V., Makarov, A.G., Klimova, N.S., Vasileva, E.K. (2018d) Methods of mathematical modeling and qualitative analysis of relaxation-deformation processes of aramide textile materials. zvestiya Vysshikh Uchebnykh Zavedenii, Seriya Teknologiya Tekstil'noi Promyshlennosti, Vol. 374, No 2, pp. 251-255. eid=2-s2.0-85056451197

Pereborova, N.V., Makarov, A.G., Kozlov, A.A., Vasil'eva, E.K. (2018e) Development of Integral Optimality Criteria for Mathematical Modeling of Relaxation/Recovery Processes in Polymer Textile Materials. Fibrie Chemistry, Vol. 50, No 4, pp. 306-309. DOI 10.1007/s10692-019-09981-8

Pereborova N.V., Makarov A.G., Vasil'eva E.K., Shvankin A.M., Egorov I.M. (2019a) Mathematical Modeling and Computed Prediction of Viscoelastic Creep in Geotextile Nonwoven Fabrics. Fibre Chemistry, Vol. 50, No 6, pp. 487-490. DOI 10.1007/s10692-019-10015-6

Pereborova N.V., Makarov A.G., Egorova M.A., Klimova N.S. (2019b) Improving the Competitiveness of Aramid Textile Materials Based on Mathematical Modeling and Analysis of Their Performance Properties. Fibre Chemistry, Vol. 50, No 6, p. 569-572. DOI 10.1007/s10692-019-10030-7

Pereborova, N.V., Makarov, A.G., Egorova, M.A., Kozlov, A.A. (2019c) Mathematical Modeling and Comparative Analysis of Deformation/Recovery Properties and Shrinkage of Aramid Textile Materials. Fibre Chemistry, Vol. 50, No 5, pp. 468-472. DOI 10.1007/s10692-019-10010-x

Pereborova, N.V., Makarov, A.G., Shvankin, A.M., Egorova, M.A., Abramova, I.V. (2020a) Modeling and Qualitative Analysis of Creep Processes of Geotextile Nonwovens -A Foundation for Enhancing their Competitiveness. Fibre Chemistry, Vol. 51 No. 5, pp. 397-400. DOI 10.1007/s10692-020-10119-4

Pereborova, N.V., Makarov, A.G., Shvankin, A.M., Egorova, M.A., Korobovtseva, A.A. (2020b) Predicting Creep and Deformation and Recovery Processes of Geotextile Nonwovens. Fibre Chemistry, Vol. 51, No. 5, pp. 401-403. DOI 10.1007/s10692-020-10120-x

Pereborova, N.V., Makarov,A.G., Egorova,M.A., Egorov,I.M. (2020c) Methods of Modeling and Computer-Aided Prediction of Relaxation of Medical-Purpose Textile Elastomers. Fibre Chemistry, Vol. 51, No. 6, pp.467-470. DOI 10.1007/s10692-020-10136-3

Pereborova, N.V.,Makarov,A.G., Egorova,M.A., Egorov,I.M. (2020d) Methods modeling and Computer-Aided Prediction of Strain and Relaxation Processes of Medical-Purpose Textile Elastomers. Fibre Chemistry, Vol. 51, No. 6, pp.471-474. DOI 10.1007/s10692-020-10137-2

Perevoznikov, E.N., Gorshkov, A.S. (2004) Amplitude modulation mechanism of the free longitudinal vibrations in stressed filament yarns. Izvestiya Vysshikh Uchebnykh Zavedenii, Seriya Teknologiya Tekstil'noi Promyshlennosti, Vol. 280, No 5, pp. 73-76. eid=2-s2.0-19344363321

Romanova, A.A., Rymkevich, P.P., Gorshkov, A.S., Stalevich, A.M. (2005a) Dynamic relaxation of synthetic fibres. Khimicheskie Volokna, No 4, pp. 44 46. eid=2-s2.0-29144510616

Romanova, A.A., Rymkevich, P.P., Gorshkov, A.S., Stalevich, A.M. (2005b) Dynamic relaxation of synthetic fibres. Fibre Chemistry, Vol. 37, No 4, pp. 289-292. DOI: 10.1007/s10692-005-0097-2

Romanova, A.A., Rymkevich, P.P., Gorshkov, A.S., Stalevich, A.M. (2007) Young relaxing modulus of synthetic threads. Izvestiya Vysshikh Uchebnykh Zavedenii, Seriya Teknologiya Tekstil'noi Promyshlennosti, Vol. 299, No 4, pp. 3-5. eid=2-s2.0-36148930530

Rymkevich, P.P., Romanova, A.A., Golovina, V.V., Makarov, A.G. (2013) The energy barriers model for the physical description of the viscoelasticity of synthetic polymers: Application to the uniaxial orientational drawing of polyamide films. Journal of Macromolecular Science, Part B: Physics, Vol. 52, No 12, pp. 1829-1847. DOI: 10.1080/00222348.2013.808906

Stalevich, A.M., Makarov, A.G. (2000) Determining the inherent viscoelastic relaxation spectrum for synthetic filaments. Izvestiya Vysshikh Uchebnykh Zavedenii, Seriya Teknologiya Tekstil'noi Promyshlennosti, Vol. 255, No 3, pp. 8-12. eid=2-s2.0-0034436083

Stalevich, A.M., Makarov, A.G. (2002a) Forecasting the deformation recovery process and the reverse relaxation in polymer materials. Izvestiya Vysshikh Uchebnykh Zavedenii, Seriya Teknologiya Tekstil'noi Promyshlennosti, Vol. 268, No 4-5, pp. 15-18. eid=2-s2.0-0037742684 
Stalevich, A.M., Makarov, A.G., Saidov, E.D. (2002b) Elastic components in the stress/strain curve for a synthetic fibre yarn. IzvestiyaVysshikh Uchebnykh Zavedenii, Seriya Teknologiya Tekstil'noi Promyshlennosti, (4-5), pp. 15-18. eid=2-s2.0-0037742684

Stalevich, A.M., Makarov, A.G., Saidov, E.D. (2003) Relaxation spectrometry of synthetic yarns. Izvestiya Vysshikh Uchebnykh Zavedenii, Seriya Teknologiya Tekstil'noi Promyshlennosti, Vol. 270, No 1, pp. 16-22. eid=2-s2.0-2642532049

Vatin, N.I., Gorshkov, A.S., Nemova, D.V., Staritcyna, A.A., Tarasova, D.S. (2014) The energy-efficient heat insulation thickness for systems of hinged ventilated facades. Advanced Materials Research, 941944, pp. 905-920. DOI: 10.4028

Zimin, Z.S., Orlovich, R.B., Gorshkov, A.S. (2013) Application of stones of high voidage in the facing layer of the multilayer walls. Magazine of Civil Engineering, Vol. 43, No 8, pp. 14-23+77-78. DOI: 10.5862/MCE.43.3 


\title{
Effect of sintering temperature on the alumina extraction from kaolin
}

\author{
A.B. ElDeeb \\ Ph.D. student, Metallurgy Department, Saint-Petersburg Mining University, Saint-Petersburg, Russia \\ Assistant lecturer, Mining and petroleum department, Faculty of Engineering, Al-Azhar University in Cairo, \\ Egypt \\ V.M. Sizyakov \\ Professor, Metallurgy Department, Saint-Petersburg Mining University, Saint-Petersburg, Russia \\ V.N. Brichkin \\ Professor, Head of Metallurgy Department, Saint-Petersburg Mining University, Saint-Petersburg, Russia \\ R.V. Kurtenkov \\ Assistant, Metallurgy Department, Saint-Petersburg Mining University, Saint-Petersburg, Russia
}

\begin{abstract}
Solid state, phase transformation mechanism during the thermal decomposition of kaolin-limestone mixture sintered at different temperatures were investigated. The effect of sintering temperature on the phase transformation and alumina extraction efficiency were studied. Sintering of the mixture was carried out in the temperature range $800-1400^{\circ} \mathrm{C}$, followed by leaching with sodium carbonate solution. Leaching was carried out under the following conditions; sodium carbonate solution concentration of $120 \mathrm{~g} / 1$ at a temperature of $70^{\circ}$ $\mathrm{C}$ for 30 minutes and at a stirring speed of $600 \mathrm{rpm}$. During sintering, kaolinite decomposes and transferred into the metakaolinite phase, which in turn reacts with the decomposed calcium carbonate and forms at a certain temperature calcium aluminate phases $\left(12 \mathrm{CaO} .7 \mathrm{Al}_{2} \mathrm{O}_{3}\right)$ that are readily soluble in sodium carbonate solution. The obtained results indicate that is the sintering temperature has a significant effect on the phase transformation and the efficiency of alumina extraction. Low sintering temperatures are not enough for the main phase transformations and the formation of readily soluble forms of calcium aluminate. It is clear that, increasing the temperature to $1360^{\circ} \mathrm{C}$ increases the degree of extraction of alumina in the solution to $80.49 \%$. At the same time, the increase in the sintering temperature has a positive effect on the degree of completion of the self-disintegration process.
\end{abstract}

Keywords: alumina extraction, kaolin, solid state transformation, sintering temperature, kaolin-limestone mixture, self-disintegration process, microstructure composition

\section{INTRODUCTION}

Alumina is an important industrial material, which can be used as an abrasive material and as adsorbent (Salahudeen et al., 2015). Alumina has been widely used in advanced technological applications including its use for the processing of high-quality insulators (Ueki et al., 2010), semiconductors (Lee et al., 2013), microelectronics (Imanaka, 2015), high-strength materials (Lee et al., 2009), ceramics, refractories (Andrews et al., 2014), biofuel and cell-fuel (Phung et al., 2014), fireproof plastics, high-grade polishes (Lei et al., 2012), catalysts (Osman et al., 2017), electrochemical anodic oxidation (Wan et al., 2018), metal-matrix composites (Garg et al., 2019), the production of aluminum metal (Kvande, 2014) and a plurality of other uses. 
The aluminum industry is one of the fastest growing global sectors in the world, especially among developing countries. Increased worldwide demand for aluminum oxide, currently at more than 160 million tons per year, is expected to lead to a gradual global decline of highgrade bauxite, the ore from which alumina is mainly produced using the Bayer process. Many aluminum-producing countries have thus become increasingly interested in the investigation of producing alumina from non bauxitic sources (ElDeeb et al., 2019, Cohen \& Mercier, 2016, Protosenya \& Trushko, 2007).

Low-grade bauxites and non-bauxite resources such as nepheline, coal fly ash, clays and red mud are widely distributed in the world (Brichkin, et al., 2019, ElDeeb \& Brichkin, 2018, Dubovikov \& Brichkin, 2016, Sizyakov \& Brichkin, 2018, Sizyakov, 2005).

Clay is one of the numerous aluminous raw materials that are distributed on a large scale in the world. Among the clay group kaolin and kaolinite-based solid wastes such as coal fly ash and oil shale have attracted considerable attention for alumina extraction due to the high content of alumina in these ores (Brichkin et al., 2019, ElDeeb \& Brichkin, 2018, Olaremu, 2015, Seyed, et al., 2011, Sizyakov et al., 2019, Guo et al., 2014, Lima et al., 2014, Suss et al., 2014; Xiao et al., 2015).

Among the different clays, kaolin seems to be a more attractive candidate for alumina production and an aluminum resource alternative to bauxite, due to its high aluminium content $(35-38 \%)$ and the reactivity of kaolin increases after the dehydration transformation of the kaolin to amorphous metakaolinite, which is more reactive and from which alumina can be easily extracted by acidic or alkaline leaching agents (ElDeeb \& Brichkin, 2018, Seyed et al., 2011).

The lime sinter process for processing clay consists of the following sequential steps: 1) mixing the ground clay and calcium carbonate in proportions to give after sintering at a suitable temperature a mixture corresponding to the composition of $\left(2 \mathrm{CaO} \cdot \mathrm{SiO}_{2}\right)$, $\left(12 \mathrm{CaO} \cdot 7 \mathrm{Al}_{2} \mathrm{O}_{3}\right)$ and $\left(\mathrm{CaO} \cdot \mathrm{Al}_{2} \mathrm{O}_{3}\right)(2)$ leaching of the calcium aluminate compounds by dilute sodium carbonate solution to extract alumina in the form of sodium aluminate, (3) treating the sodium aluminate solution with carbon dioxide to precipitate alumina trihydrate (gibbsite) and (4) calcining the gibbsite at $1350^{\circ} \mathrm{C}$ to produce alumina $\left(\alpha \mathrm{Al}_{2} \mathrm{O}_{3}\right)$ phase (Al Ajeel et al., 2014, Sizyakov, 2016).

Thermal treatments at a controlled temperature range were generally applied to increase the activity of kaolin before the acidic and alkaline extraction procedure due to the low chemical reactivity of kaolinite (Sizyiakov et al., 2013). The process is generally thought to increase clay reactivity by affecting dehydration transformation of the kaolin to amorphous metakaolinite $\left(\mathrm{Al}_{2} \mathrm{Si}_{2} \mathrm{O}_{7}\right)$, which is known to be more reactive and from which alumina can be easily extracted by acidic or alkaline leaching agents (Cohen \& Mercier, 2016, Sizyiakov, 2006).

In this work, the effect of sintering temperature, solid state and phase transformation mechanism on the alumina extraction efficiency from kaolin ore processed using lime-sinter process were investigated. The efficiency of the self-disintegration process as a result of the sintering process was also studied. The micro structure changes in the produced sinters and sludges due to the sintering process were investigated.

\section{MATERIALS AND METHODS}

The current study was carried out using kaolin ore which was obtained from Irkutsk mining site, while limestone ore sample was obtained from Pikalevo region, Russia. Chemically pure grade up to $99.8 \%$ sodium carbonate was used for the leaching process.

The chemical composition of the kaolin and limestone ores was determined using XRF1800 sequential X-ray fluorescence spectrometer $(40 \mathrm{kV}, 90 \mathrm{~mA}, \mathrm{Re}$ anode) (USA) in order to estimate the chemical composition of the raw materials and the chemical changes that took place after the sintering and the leaching processes. Structural phase analysis of the kaolin ore was carried out using a bruker D8 focus X-ray diffractometer having siemens diffractometer 7000 with $\mathrm{Cu}-\mathrm{K} \alpha$ radiation $(40 \mathrm{kV}, 30 \mathrm{~mA}, \lambda=1.5406 \AA$ ) (USA). 
Differential scanning calorimetry (DSC) and thermal gravimetric analysis (TGA) for kaolin-limestone mixture were investigated using simultaneous DSC-TGA instrument (SDT Q600) (USA) in the temperature range from ambient to $1300^{\circ} \mathrm{C}$ and heating rate of $20^{\circ} \mathrm{C} / \mathrm{min}$ in the air conditions in order to clarify the thermal decomposition behavior of kaolinlimestone mixture. The particle size analysis for the produced sinter and sludge was carried out by laser microanalysis using the domestic microsizer $201 \mathrm{C}$ analyzer and the range of analysis was 0.2 to $600 \mu \mathrm{m}$.

The microstructure changes of the sintered kaolin-limestone mixture as a result of the sintering process at different temperatures and the sludge produced as a result of the subsequently leaching were characterized using a tescan TS 5130MM scanning electron microscope equipped with an X-ray energy dispersive detector (manufactured by Oxford Instruments, active crystal area $-50 \mathrm{MM}^{2}$ ) with the INCA energy microanalysis system and YAG crystal as a reflected electron detector.

The kaolin-limestone mixture was prepared according to the stoichiometric calculations on the basis of the molar ratios of oxides $\left[\mathrm{CaO} / \mathrm{SiO}_{2}=2, \mathrm{CaO} / \mathrm{Al}_{2} \mathrm{O}_{3}=1.8\right.$ and $\left.\mathrm{CaO} / \mathrm{Fe}_{2} \mathrm{O}_{3}=1\right]$ and the prepared charge according to this stoichiometry composed of $265.8 \mathrm{~g}$ limestone and $100 \mathrm{~g}$ kaolin. These ratios provide the required phases suitable for the leaching process and the higher recovery of alumina (Al-Ajeel et al., 2014, ElDeeb et al., 2019).

The kaolin-limestone mixture was effectively mixed in a drum mixer for $4 \mathrm{hr}$ then formed on the form of cylindrical briquettes. Briquetting was carried out on the hydraulic press "Laptuls" using the press mould of $30 \mathrm{~mm}$ diameter and $30 \mathrm{~mm}$ height at $5 \mathrm{MPa}$ briquetting pressure (ElDeeb et al., 2019). The produced briquettes was sintered in a laboratory high-temperature chamber furnace in closed air conditions in the temperature range from $800^{\circ} \mathrm{C}$ to $1400^{\circ} \mathrm{C}$ and for $1 \mathrm{hr}$. In the sintering process, the briquettes were inserted in the furnace then the furnace started to heat at the predetermined temperature with a rate of $10^{\circ} \mathrm{C} /$ minute. After reaching the desired temperature, the duration of the isothermal holding at the given temperature was $1 \mathrm{hr}$. After finishing the sintering time, the furnace was allowed to cool down to the room temperature in order to allow the sintered material to be annealed and achieve the self-disintegration process. The obtained sintered material was characterized chemically using XRF analysis in order to determine the oxides content in the produced sinter and mineralogically using XRD analysis in order to determine the new phases as a result of the sintering process at different temperatures. The microstructure changes of the sintered kaolin-limestone charge as a result of the sintering process and the sludge produced as a result of the subsequently leaching were characterized using scanning electron microscope (SEM-EDX).

The sinters obtained from the sintering process were leached using $\mathrm{Na}_{2} \mathrm{CO}_{3}$ solution. The leaching process was carried out in the HEL Auto-Mate II reactor system equipped with mechanical stirring. All leaching experiments for the produced sinter at differant temperatures were carried out under the following conditions: $70^{\circ} \mathrm{C}$ leaching temperature, $\mathrm{Na}_{2} \mathrm{CO}_{3}$ solution with a concentration $120 \mathrm{~g} / \mathrm{l}$ solution, $1 / 5$ solid to liquid ratio, $30 \mathrm{~min}$. leaching time and $600 \mathrm{rpm}$ stirring speed according to the best condition obtained before (ElDeeb et al., 2019). The produced pulp from the leaching process was filtered out using a vacuum and the obtained sludge was washed with hot distilled water then dried in the draying furnace. The obtained sludge's were analyzed chemically by XRF analysis in order to determine the oxides content in the sludge. The alumina extraction degree was calculated using the following formula: $\mathrm{Al}_{\text {extracted }}=\left(\mathrm{A} 1_{\text {sinter }}-\mathrm{Al}_{\text {sludge }}\right) / \mathrm{A} 1_{\text {sinter. }}$

\section{RESULTS AND DISCUSSION}

\subsection{The physical and chemical characterization of the used raw materials}

The mineralogical analysis of the kaolin ore sample using XRD analysis shown in Figure 1, revealed that the kaolin ore composed mainly from kaolinite mineral $\left(\mathrm{Al}_{2} \mathrm{O}_{3} \cdot 2 \mathrm{SiO}_{2} \cdot 2 \mathrm{H}_{2} \mathrm{O}\right)$ barring aluminium oxide and silica contributions, which were also detected as quartz mineral. The chemical analysis of the kaolin ores using XRF analysis shown in Table 1 indicates that is 


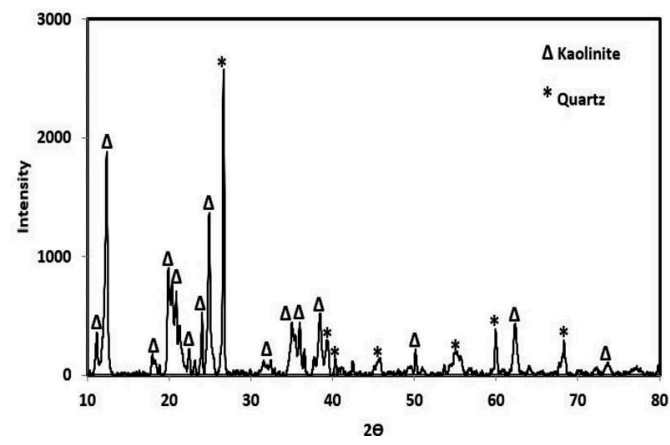

Figure 1. XRD analysis of the kaolin ore.

Table 1. The chemical analysis of the kaolin and limestone ores.

\begin{tabular}{lcclcccccc}
\hline Materials & $\mathrm{SiO}_{2}$ & $\mathrm{Al}_{2} \mathrm{O}_{3}$ & $\mathrm{Fe}_{2} \mathrm{O}_{3}$ & $\mathrm{TiO}_{2}$ & $\mathrm{CaO}$ & $\mathrm{Na}_{2} \mathrm{O}$ & $\mathrm{K}_{2} \mathrm{O}$ & others & L.O.I \\
\hline Kaolin ore & 52.2 & 31.9 & 1.4 & 0.58 & 0.59 & 0.15 & 0.15 & 0.03 & 13 \\
Limestone & 2.01 & 0.41 & 0.56 & 0.58 & 53.3 & - & - & - & 43.14 \\
\hline
\end{tabular}

the kaolin ore contains $31.9 \% \mathrm{Al}_{2} \mathrm{O}_{3}$ and $52.2 \% \mathrm{SiO}_{2}$ which represent the main components of the kaolin ore in addition to other oxides. The loss on ignition of $13 \%$ in the chemical analysis is as a result of organic matter, some non-metals and the chemical and physical water lost. This alumina content in kaolin ore is considered as economic percentage for the extraction of alumina in comparison with bauxite ore (Brichkin et al., 2019).

The TGA and DSC analysis for the kaolin-limestone mixture is shown in Figure 2. The TGA curve of the kaolin-limestone mixture sample show three well-defined weight loss regions, the first is below $200^{\circ} \mathrm{C}$ and the endothermic peak in the DSC curve at $111.20^{\circ} \mathrm{C}$ is due to the loss of physisorbed water. The seconded weight loss region in the TGA curve is above $450^{\circ} \mathrm{C}$ and the endothermic peak in the DSC curve at $507.51^{\circ} \mathrm{C}$ is due to the dehydroxylation of coordinated and structural water with a weight loss of $3.27 \%$. The third weight loss regions in the TGA curve is in the range $\left(650-850^{\circ} \mathrm{C}\right)$ and the endothermic peak in the DSC curve at $844.43^{\circ} \mathrm{C}$ can be attributed to the complete dissociation of the limestone and the further release of $\mathrm{CO}_{2}$ from $\mathrm{CaCO}_{3}$ with a weight loss of $29.69 \%$. Compared with the

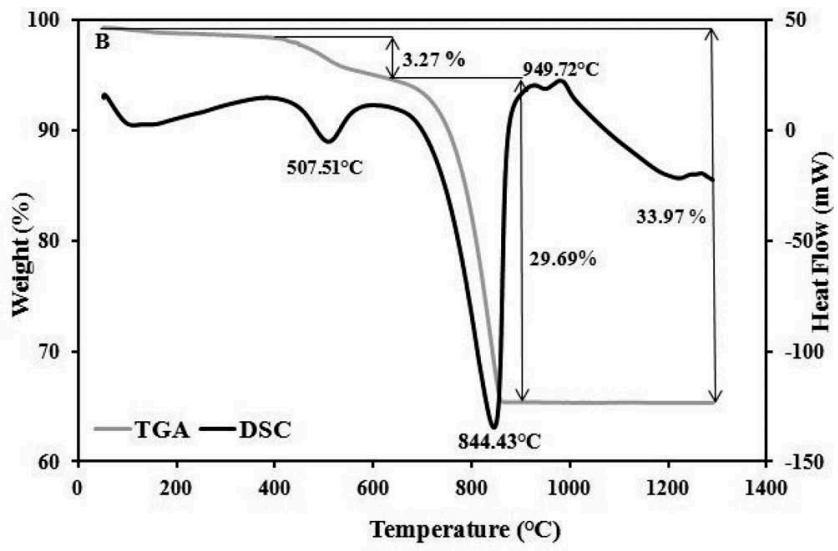

Figure 2. DSC and TGA analysis for the kaolin-limestone mixture. 
decomposition temperature of pure $\mathrm{CaCO}_{3}\left(650-900^{\circ} \mathrm{C}\right)$, the existence of kaolinite obviously decreased the decomposition temperature of $\mathrm{CaCO}_{3}$ in the mixture, which suggested that the solid-state reaction between kaolinite and $\mathrm{CaCO}_{3}$ occurred during the heating process (Tian et al., 2016, Yan et al., 2017, Zhang et al., 2015). The sharp exothermic peak at $949.52^{\circ} \mathrm{C}$ could be assigned to the phase transformation from metakaolinite to Al-Si spinel or mixture of $\gamma$-alumina, amorphous silica and mullite and the total weight loss is $33.97 \%$ at $1300^{\circ} \mathrm{C}$ (Zhang et al., 2015, ElDeeb et al., 2019). Also it is clear that the existence of calcite $\left(\mathrm{CaCO}_{3}\right)$ obviously decreased the phase transformation temperature from metakaolinite to Al-Si spinel or the mixture of $\gamma$-alumina, amorphous silica and mullite compared to this temperature for the TGA and DSC analysis of the kaolin ore.

\subsection{The effect of sintering temperature on the percent recovery of alumina}

The most important factor affecting on the physico-chemical transformation of the kaolinlimestone mixture and hence the extraction of alumina from kaolin ore is the sintering temperature. The effect of the sintering temperatures on the percent recovery of alumina from kaolin ore was investigated in the range from 800 to $1400^{\circ} \mathrm{C}$. The obtained sinters at different sintering temperatures and the sludges as a result of the subsequently leaching of these sinters were characterized chemically using XRF analysis in order to determine the oxides content in both the sinters and sludges. The effect of the sintering temperatures on the oxides content in the sinters is shown in Figure 3A. The oxides content in the sludges produced from the subsequently leaching of the sinter is shown in Figure 3B. The chemical composition indicates that both the sinter and sludge composed mainly from the following oxides $\mathrm{CaO}, \mathrm{SiO}_{2}, \mathrm{Al}_{2} \mathrm{O}_{3}$ in addition to other oxides. The difference between the alumina content in the sinter and its content in the sludge represent the percent recovery of alumina in the solution and the alumina extraction degree was calculated using the following formula: $\mathrm{Al}$ extracted $=\left(\mathrm{Al}_{\text {sinter }}-\mathrm{Al}_{\text {sludge }}\right) / \mathrm{Al}_{\text {sinter }}$ as shown in Figure 4.

It is clear that is the percent recovery of alumina increases with increasing the sintering temperature from 800 to $1360^{\circ} \mathrm{C}$ and then with more increasing of the sintering temperature up to
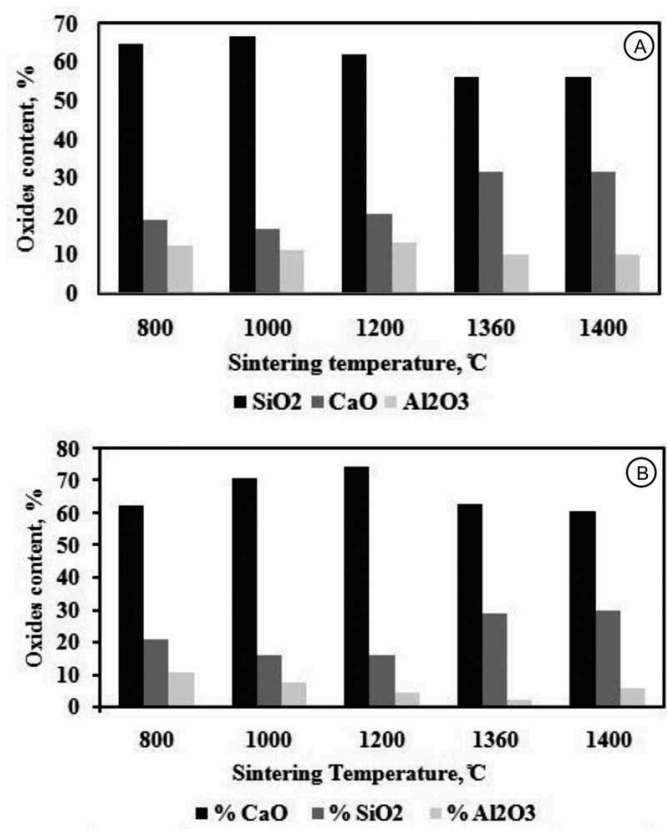

Figure 3. The effect of the sintering temperature on the oxides content obtained in a) the sintered kaolin-limestone mixture and $\mathrm{b}$ ) the sludge produced from the leaching process. 


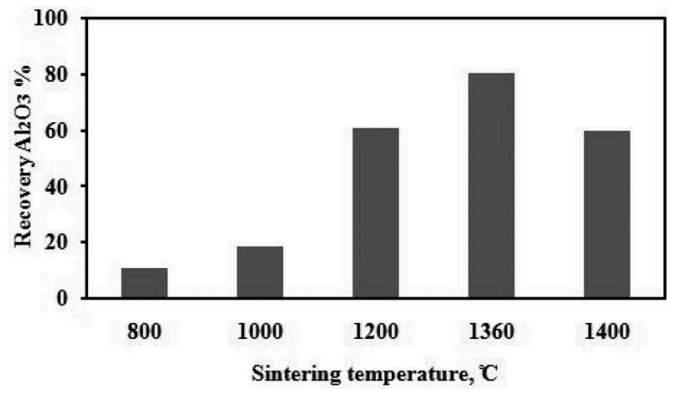

Figure 4. The effect of sintering temperature on the percent recovery of alumina.

$1400^{\circ} \mathrm{C}$ the percent recovery of alumina decreases. The percentage recovery of alumina increases from $10.51 \%$ at $800^{\circ} \mathrm{C}$ to 80.49 at $1360^{\circ} \mathrm{C}$ then decrease to $59.70 \%$ at $1400^{\circ} \mathrm{C}$. This can be attributed to that is the sintering temperature of $1360^{\circ} \mathrm{C}$ is the most suitable temperature for the formation of $\mathrm{C}_{2} \mathrm{~S}$ and $\mathrm{C}_{12} \mathrm{~A}_{7}$ compounds in the sinter at which alumina can be extracted easily from the $\mathrm{C}_{12} \mathrm{~A}_{7}$ using sodium carbonate solution. The low temperature isn't sufficient for the complete decomposition of the calcium carbonate and the formation of the $\mathrm{C}_{2} \mathrm{~S}$ and $\mathrm{C}_{12} \mathrm{~A}_{7}$ compounds hence the lost of alumina in the form of $\mathrm{Al}_{2} \mathrm{SiO}_{5}$ and $\mathrm{Ca}_{2} \mathrm{Al}_{2} \mathrm{SiO}_{7}$. On the other hand, decreasing the percent recovery of alumina with more increasing of the sintering temperature up to $1400^{\circ} \mathrm{C}$ can be attributed to the high temperature which leads to the formation of mullite $\left(\mathrm{Al}_{2} \mathrm{O}_{3} \cdot \mathrm{SiO}_{2}\right)$ phase from which alumina is difficulty extracted (Qiao, et al., 2008).

\subsection{The effect of sintering temperature on the solid state and phase transformation mechanism}

The effect of the sintering temperature on the phase transformation mechanism of kaolin- limestone mixture was carried out by studying the microstructure changes in both the sinters and sludges produced at differant temperatures. The main structural components of both the sinter produced at $800^{\circ} \mathrm{C}$ and the sludge obtained from its subsequently leaching are shown in Figure 5 . The results indicate that the main structural components in both the sinter and sludge include: relics of the original charge minerals including kaolinite and calcite. Other components including particles of silicon dioxide, magnetite, rutile, ilmenite, iron-chromium spinels and calcite which are strictly subordinate. In addition, traces of the sludge contain traces of finely dispersed highly porous carbonate mass surrounding the relics of kaolin particles.
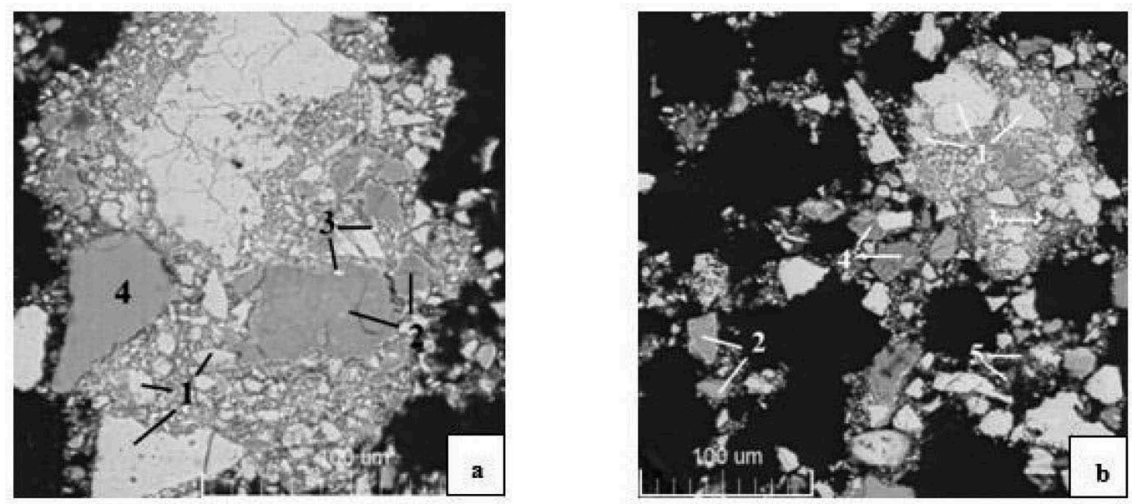

Figure 5. The main structural components of (a) the sinter and (b) the sludge samples produced at $800^{\circ} \mathrm{C}$ where, 1- calcium carbonate, 2- relics of kaolin, 3- particles of magnetite/rutile/other heavy impurities components of the charge, 4- silicon dioxide and 5- fine carbonate mass. 
It can be concluded, that is the sintering temperature of $800^{\circ} \mathrm{C}$ is not sufficient to the decomposition and dissociation of the calcium carbonate. There for, there is no solid state reaction between metakaolinite produced from the dehydroxylation of kaolin ore and the calcium carbonate. It was also noted that the formation of calcium aluminates in the sintered material is not marked and this means that this temperature is not sufficient to the formation of this phase from which alumina can be extracted easily. This explains the lower recovery of alumina from the sinter produced at this temperature as shown in Figure 4 and this means that is the extraction of alumina is carried out from the metakaolinite particles. It was also detected that is the aluminum in the samples of both sinter and sludge produced at $800^{\circ} \mathrm{C}$ is concentrated in kaolin relics.

The main structural components of both the sinter and sludge produced at $1000^{\circ} \mathrm{C}$ are illustrated in Figure 6. It Indicate that both of them have mainly the same composition of relics of calcium carbonates, relics of kaolin, secondary aluminosilicate rims, and silicon dioxide except the sludge contains fine carbonate mass. It was found that the degree of change of these structures are much higher than that occurred at $800^{\circ} \mathrm{C}$. It can be seen that; nearly most of calcium carbonates is characterized by a high degree of decomposition up to complete destruction. On the other hand for kaolin, it is shown that secondary aluminosilicate rims of a wide range of composition are present on the surface.

The main structural components of the sinter produced at $1360^{\circ} \mathrm{C}$ are illustrated in Figure $7 \mathrm{a}$. The most common components in the sinter are aluminosilicate components of a wide range of composition, calcium silicate and calcium aluminate. These components are presented both in the form of free particles and in association with each other and the other components. The main structural components of the sludge produced at $1360^{\circ} \mathrm{C}$ are illustrated in Figure $7 \mathrm{~b}$. It is clear that the most common components in the sludge are aluminosilicate components of a wide range of composition. It was also noted that the main structural components of the sludge is nearly the same for the sinter in addition to the presence of $\mathrm{CaCO}_{3}$ as a result of the leaching process. Also in the structural components of the sinter and sludge it was noted that, in addition to aluminosilicates, calcium silicates and calcium aluminates of variable composition with noticeable admixtures of other elements are subordinate to the samples. It was noted that the content of aluminates in the sample of sludge is significantly lower than its content in the sinter sample that explains the higher recovery of alumina at this sintering temperature (ElDeeb et al., 2019).

\subsection{The effect of sintering temperature on the efficiency of the self-disintegration process}

The sintering temperature has also a significant effect on the efficiency of the selfdisintegration process and the completeness of the phase transformations, hence the
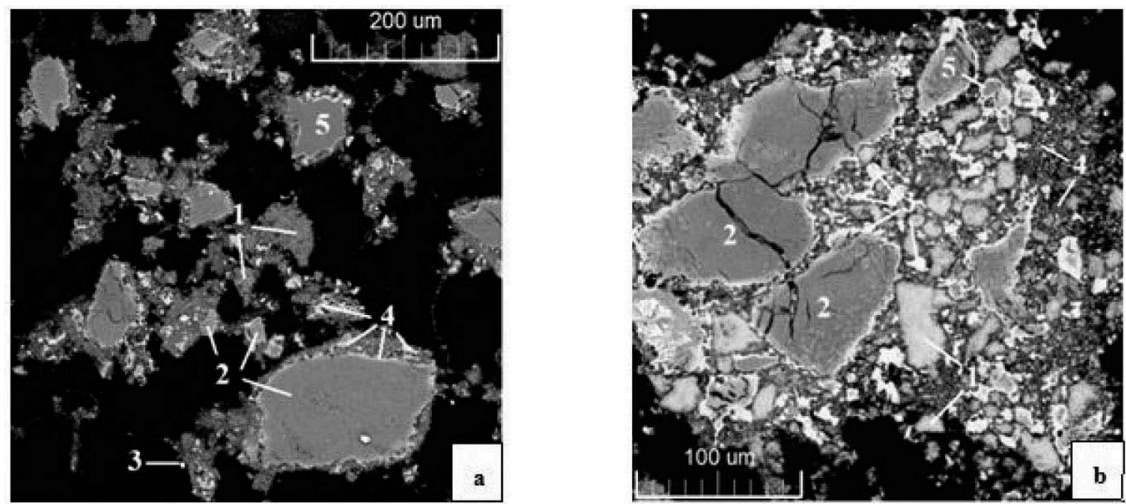

Figure 6. The main structural components of the (a) sinter produced at $1000^{\circ} \mathrm{C}$ where, 1- relics of calcium carbonate, 2- relics of kaolin, 3- particles of magnetite/rutile/other heavy impurities of the charge, 4- secondary aluminosilicate rims and 5- silicon dioxide. (b) the sludge sample where, 1- relics of carbonates, 2- relics of kaolin, 3- secondary aluminosilicate rims, 4- fine carbonate mass and 5- silicon dioxide. 

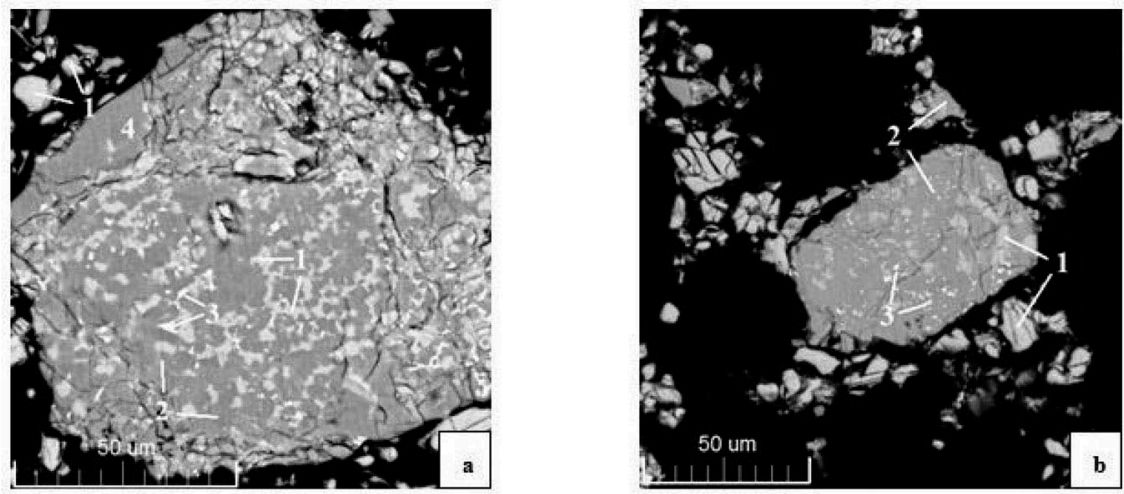

Figure 7. The main structural components of the sinter sample produced at $1360^{\circ} \mathrm{C}$ where, 1 - calcium silicates, 2- aluminosilicates, 3- particles of magnetite/rutile/other heavy impurity components of the charge, 4- calcium aluminates and 5- carbonate components. (b) the sludge sample where, 1- calcium silicates, 2- aluminosilicates of a wide range of composition, 3- particles of magnetite/rutile/other heavy impurity components of the charge, 4- carbonate components and 5-calcium aluminates.

extraction of alumina. The lower sintering temperatures $\left(800-1200^{\circ} \mathrm{C}\right)$ are not sufficient for the formation of calcium silicates $\left(\mathrm{C}_{2} \mathrm{~S}\right) . \mathrm{C}_{2} \mathrm{~S}$ undergoes a crystallographic transformation on cooling with an increase in the molar volume due to the transformation of $2 \mathrm{CaO} \cdot \mathrm{SiO}_{2}$ from $\beta$ to $\gamma$ form as shown in following equation. In contrast, high sintering temperatures $\left(1300-1400^{\circ} \mathrm{C}\right)$ are sufficient for the formation of $\mathrm{C}_{2} \mathrm{~S}$ in sufficient amounts that leads to the transformation of the sintered briquettes into fine powder, which increases the solubility of the alumina containg compounds without any need for further grinding (Stange et al., 2017).

$$
\beta-\mathrm{Ca}_{2} \mathrm{SiO}_{4} \stackrel{675^{\circ} \mathrm{C}}{\longrightarrow} \gamma-\mathrm{Ca}_{2} \mathrm{SiO}_{4}
$$

The results of the particle size analysis of the produced sinter and sludge using the domestic microsizer $201 \mathrm{C}$ analyzer is shown in Figure 8. It is clear that there is an enlargement in the particle size of the sludge obtained after the leaching process compared to the size of the sinter. The agglomeration and the increase in particle size of the produced sludge can be attributed to the formation of $\mathrm{CaCO}_{3}$ at the surface of the produced sludge (Zhang, et al., 2015).
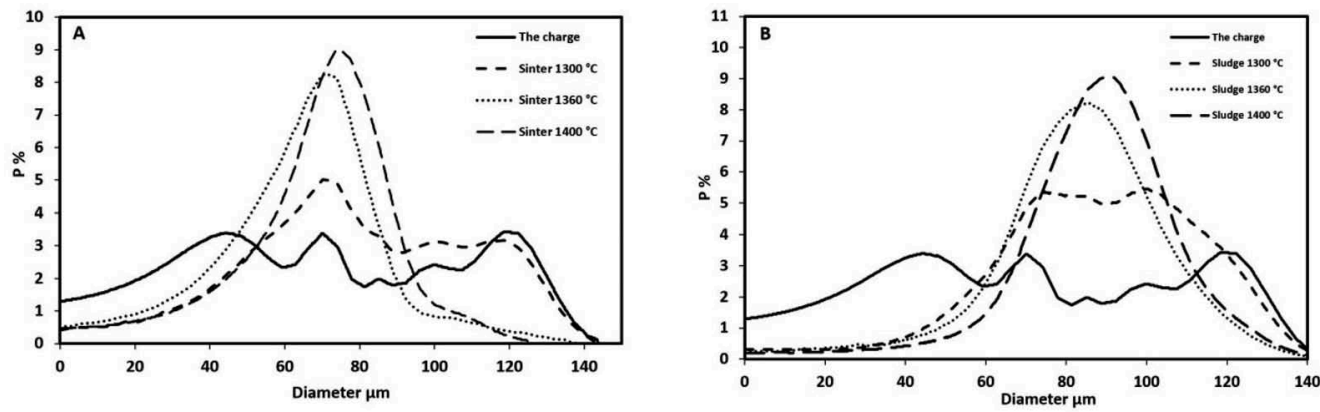

Figure 8. The effect of the sintering temperature on the particle size of the (A) sinter and (B) sludge obtained at different sintering temperature. 


\section{CONCLUSION}

The obtained results indicate that is the sintering temperature has a significant effect on the solid state, phase transformation mechanism and hence the efficiency of alumina extraction from kaolin ore processed using lime-sinter process. The lower sintering temperatures are not enough for the melting of the original compounds of the charge and the solid state reaction between the metakaolinite and calcium carbonate doesn't occur. The extraction of alumina is carried out only from metakaolinite that explains the lower recovery of alumina at this temperature of about $10.51 \%$ at $800^{\circ} \mathrm{C}$. The higher sintering temperatures are enough for the complete dehydroxylation of kaolinite and decomposition of calcium carbonate and at the same time the melting of the original constituents with the formation of calcium aluminates and calcium silicates in different forms. These temperatures enhancing the extraction of alumina to be $60.74 \%$ at $1000^{\circ} \mathrm{C}$ and $80.49 \% \%$ at $1360^{\circ} \mathrm{C}$. The more increase in the sintering temperature more than $1360^{\circ} \mathrm{C}$ leads to the formation of mullite phase $\left(3 \mathrm{Al}_{2} \mathrm{O}_{3} \cdot 2 \mathrm{SiO}_{2}\right)$ with higher percentage from which it is difficult to extract alumina which explains the decreasing of alumina extraction at $1400^{\circ} \mathrm{C}$ to about $59.70 \%$. Thus, it is obvious that is the sintering temperature of $1360^{\circ} \mathrm{C}$ is the most suitable temperature for the higher extraction of alumina from kaolin. The agglomeration of secondary $\mathrm{CaCO}_{3}$ particles on the surface of the insoluble particles is the dominant mechanism of increasing the particle size of the produced sludge compared to the original particle size of the obtained sinter.

\section{ACKNOWLEDGMENT}

The work was carried out with the financial support of the Russian Science Foundation under the agreement No. 18-19-00577 of April 262018 of grant for fundamental scientific research and exploratory scientific research.

\section{REFERENCES}

Al-Ajeel, A.A. \& Abdullah, S.Z. \& Muslim, W.A. \& Abdulkhader, M.Q. \& Al-Halbosy, M.K. \& AlJumely, F.A. 2014. Extraction of Alumina from Iraqi colored kaolin by lime-sinter process. Iraqi Bull. Geol. Min. 10 (3): 109-117.

Andrews, A. \& Nsiah-Baafi, E. \& Gawu, S.K.Y. \& Olubambi, P.A. 2014. Synthesis of high alumina refractories from lithomargic clay. Ceramics International 40 (4): 6071-6075.

Brichkin, V.N. \& Kurtenkov, R.V. \& ElDeeb, A.B. \& Bormotov, I.S. 2019. State and development options for the raw material base of aluminum in non-bauxite regions. Obogashchenie Rud 4: 31-37.

Cohen, J. \& Mercier, H. 2016. Recovery of alumina from Non-Bauxite aluminum-bearing raw materials. In: Donaldson D., Raahauge B.E. (eds.) Essential Readings in Light Metals. Springer, Cham. 1057-1064.

Dubovikov, O.A. \& Brichkin, V.N. 2016. Directions and prospects of using low grade process fuel to produce alumina. Journal of Mining Institute 220: 587-594.

ElDeeb, A.B.S. \& Brichkin, V.N. 2018. Egyptian aluminum containing ores and prospects for their use in the production of Aluminum. Int. J. Sci. Eng. Res. 9 (5): 721-731.

ElDeeb, A.B. \& Brichkin, V.N. \& Kurtenkov, R.V. \& Bormotov, I.S. 2019. Extraction of alumina from kaolin by a combination of Pyro- and hydrometallurgical Processes. Applied Clay Science 172: 146-154.

Imanaka Y., 2015. Materials and processes of microelectronic packing including low temperature cofired ceramics technology (past, present and future). J. Ceram. Sci. Tech. 6 (4): 291-300.

Garg, P. \& Jamwal, A. \& Kumar, D. \& Sadasivuni, K.K. \& Hussain, C.M. \& Gupta, P. 2019. Advance research progresses in aluminium matrix composites: manufacturing \& applications. Journal of Materials Research and Technology 8 (5): 4924-4939.

Kvande, H. 2014. The Aluminum Smelting Process. Journal of Occupational and Environmental Medicine 56: S2-S4.

Lee, J.S. \& Kim, H.S. \& Park, N.-K. \& Lee, T.J. \& Kang, M. 2013. Low temperature synthesis of $\alpha-$ alumina from aluminum hydroxide hydrothermally synthesized using $\left[\mathrm{Al}\left(\mathrm{C}_{2} \mathrm{O}_{4}\right) \mathrm{x}(\mathrm{OH}) \mathrm{y}\right]$ complexes. Chemical Engineering Journal 230: 351-360.

Lee, S.O. \& Jung, K.H. \& Oh, C.J. \& Lee, Y.H. \& Tran, T. \& Kim, M.J. 2009. Precipitation of fine aluminum hydroxide from Bayer liquors. Hydrometallurgy 98 (1-2): 156-161. 
Lei, H. \& Wu, X. \& Chen, R. 2012. Preparation of porous alumina abrasives and their chemical mechanical polishing behavior. Thin Solid Films 520 (7): 2868-2872.

Lima, P.E.A. \& Angélica, R.S. \& Neves, R.F. 2014. Dissolution kinetics of metakaolin in sulfuric acid: comparison between heterogeneous and homogeneous reaction methods. Applied Clay Science 88-89 (3): $159-162$.

Olaremu, A.G. 2015. Sequential leaching for the production of alumina from a Nigerian clay. Int. J. Eng. Technol. Manag. Appl. Sci. 3 (7): 103-109.

Osman, A.I. \& Abu-Dahrieh, J.K. \& Rooney, D.W. \& Thompson, J. \& Halawy, S.A. \& Mohamed, M. A. 2017. Surface hydrophobicity and acidity effect on alumina catalyst in catalytic methanol dehydration reaction. Journal of Chemical Technology \& Biotechnology 92 (12): 2952-2962.

Phung, T.K. \& Lagazzo, A. \& Rivero Crespo, M.Á. \& Sánchez Escribano, V. \& Busca, G. 2014. A study of commercial transition aluminas and of their catalytic activity in the dehydration of ethanol. Journal of Catalysis 311: 102-113.

Protosenya A.G. \& Trushko O.V., 2007. Problems of the development of the raw material base of the aluminum industry in Russia and the organization of production in a market economy. Journal of Mining Institute 172: 132-137.

Qiao, X.C. \& Si, P. \& Yu, J.G. 2008. A Systematic Investigation into the Extraction of Aluminum from Coal Spoil through Kaolinite. Environ. Sci. Technol., 42 (22): 8541-8546.

Salahudeen, N. \& Ahmed, A.S. \& Al-Muhtaseb, A.H. \& Dauda, M. \& Waziri, S. M. \& Jibril, B. Y. 2015. Synthesis of gamma alumina from Kankara kaolin using a novel technique. Applied Clay Science 105-106: 170-177.

Seyed, A.H. \& Aligholi N. \& Dariush S. 2011. Production of $\gamma-\mathrm{Al}_{2} \mathrm{O}_{3}$ from Kaolin. Open Journal of Physical Chemistry 1: 23-27.

Sizyakov, V.M. \& Brichkin, V.N. \& ElDeeb, A. B. \& Kurtenkov, R.V. 2019. Egyptian aluminumcontaining raw materials and the prospects for its integrated processing to produce alumina and byproducts. XI International Congress \& Exhibition Non-Ferrous Metals \& Minerals, Proceedings of 37th International ICSOBA Conference, Krasnoyarsk, Russia, 16-20 September, 2019, http://nfmsib. ru/wp-content/uploads/2019/08/spisok-dokladov-Alyuminij-Sibiri_6.08.pdf.

Sizyakov, V.M. \& Brichkin, V.N. 2018. About the role of Hydrafed calcium carboaluminates in improving the technology of complex processing of nephelines. Journal of Mining Institute 231: 292-298.

Sizyakov, V.M. 2016. Chemical and technological mechanisms of a alkaline aluminum silicates sintering and a hydrochemical sinter processing. Journal of Mining Institute 217: 102-112.

Sizyiakov, V.M. \& Dubovikov, O.A. \& Nikolaeva, N.V. \& Kalashnikova, M.I. 2013. The role of mineralized additivies in the alumina phase transformation process. Journal of Mining Institute 202: 48-55.

Sizyiakov V.M. 2006. Influence of nepheline and limestone dispersion on the quality of aluminate sinter. Journal of Mining Institute 169: 35-40.

Sizyakov, V.M. 2005. Current status and problems of the Russian aluminum industry. Journal of Mining Institute 165: 163-169.

Stange, K. \& Lenting, C. \& Geisler, T. 2017. Insights into the evolution of carbonate-bearing kaolin during sintering revealed by in situ hyperspectral Raman imaging. Journal of the American Ceramic Society:1-14.

Suss, A.G. \& Damaskin, A.A. \& Senyuta, A.S. \& Panov, A.V. \& Smirnov, A.A. 2014. The influence of the mineral composition of low-grade aluminum ores on aluminium extraction by acid leaching. In: Grandfield J. (eds) Light Metals 2014, Springer, Cham,:105-109.

Tian, Y. \& Pan, X. \& Yu, H. \& Han, Y. \& Tu, G. \& Bi, S. 2016. An improved lime sinter process to produce $\mathrm{Al}_{2} \mathrm{O}_{3}$ from low-grade Al-containing resources. In: Williams E. (eds) Light Metals. Springer, Cham: $5-9$.

Ueki, Y. \& Kunugi, T. \& Morley, N.B. \& Abdou, M.A. 2010. Electrical insulation test of alumina coating fabricated by sol-gel method in molten PbLi pool. Fusion Engineering and Design 85 (10-12): $1824-1828$.

Wan, Ye \& Wang, Huan \& Zhang, Yundian \& Wang, Xiumei \& Li, Yanbo. 2018. Study on Anodic Oxidation and Sealing of Aluminum Alloy. Int. J. Electrochem. Sci. 13: 2175-2185.

Xiao, J. \& Li, F. \&, Zhong, Q. \& SS Bao, H. \& Wang, B. \& Huang, J. \& Zhang, Y. 2015. Separation of aluminum and silica from coal gangue by elevated temperature acid leaching for the preparation of alumina and $\mathrm{SiC}$. Hydrometallurgy 155: 118-124.

Yan, K. \& Guo, Y. \&, Fang, Li \& Cui, Li \& Cheng, F. \& Li, T. 2017. Decomposition and phase transformation mechanism of kaolinite calcined with sodium carbonate. Applied Clay Science 147: 90-96.

Zhang, S. \& Ou, X. \& Qiang, Y. \& Niu, J. \& Komarneni, S. 2015. Thermal decomposition behavior and de-intercalation mechanism of acetamide intercalated into kaolinite by thermoanalytical techniques. Applied Clay Science 114 (10): 309-314. 


\title{
New approaches in mineral raw materials comminution tests modelling
}

\author{
L.S. Chitalov \\ Postgraduate student, St. Petersburg mining University, St. Petersburg, Russia \\ V.V. Lvov \\ PhD, Associate professor, St. Petersburg mining University, St. Petersburg, Russia
}

\begin{abstract}
The paper discusses a model of ore particles crushing with a JK Drop Weight Tester, created using the method of discrete elements in the Rocky DEM software. The mathematical relationship between output parameters of the JK Drop Weight Test (JK DWT) and parameters of the breakage model in Rocky DEM is shown. A JK DWT was performed on a technological sample of copper-nickel ore. The JK DWT results were used in Rocky DEM to calibrate its breakage model by factorial experiment using two parameters that are not related to the results of the JK DWT. The achieved accuracy of the resulting model is $\pm 3.1 \%$ of the $t_{10}$ value. The resulting model can be used to obtain the particle size distribution of crushing products for various comminution machines, as well as for determination the parameters for calibrating mathematical models of crushers, autogenous and semi-autogenous mills in the JKSimMet.
\end{abstract}

\section{INTRODUCTION}

In the practice of mineral processing, comminution processes are the most expensive due to their high energy consumption. Today, the main way of reducing energy costs for crushing and grinding is optimizing these processes through mathematical modeling. At the same time, no modeling can be carried out without the strength characteristics of mineral raw materials (Gospodarikov \& Zatsepin, 2019, Zuev et al., 2019). Obtaining such characteristics is closely related to laboratory tests, which describe the relationship between the change in the size of the material and the energy expended on this change. The JK Drop Weight Test is one of the most used worldwide comminution test. Its results may be used as inputs parameters for calibration different kind of breakage models. One of them, constructed with the discrete element method, was calibrated in this study (Taranov et al., 2013).

\section{$1.1 \quad J K$ drop weight test}

JK Drop Weight Test (JK DWT) (Nikolaeva et al., 2017, Andreev et al., 2012) of JKTech (Australia) is developed by the Julius Kruttschnitt Mineral Research Centre. Power measurements in the range of size (from 13 to $63 \mathrm{~mm}$ ) at different energy levels (from 0.1 to $2.5 \mathrm{kWh} /$ t) were obtained in the test for copper-nickel ore. The equipment for determining the breakage function is called the JK Drop Weight Tester (JK DW). Test results were reduced to three parameters - $A, b$ and $t_{a}$ for subsequent use in the JKSimMet software.

\section{$1.2 \mathrm{JKSimMet}$}

When modeling in JKSimMet, the ore parameters are combined with the comminution equipment details and operating conditions, which allow to predict the performance of autogenous 
grinding and semi-autogenous grinding mills (AG/SAG), crushers and other comminution equipment, as well as to obtain information on the particle size distribution. Using JKSimMet in conjunctions with the JKSimFloat software it is possible to optimize existing or design new flowsheets for comminution circuits and flowsheets that include flotation operations (Alexandrova et al., 2019).

Despite the fact that JKSimMet is a leader in its field, its computational system is fixed; the simulation itself is static and does not take into account all the factors that affect the process. So, as the parts of the ore dressing machine wear out, there are modifications in the technological processes occurring. Such changes are not taken into account when modeling in JKSimMet.

\subsection{Discrete Element Method (DEM)}

The discrete element method as applied in mining is a method of modeling physical processes in which step-by-step calculation of particles kinetics of their motions and collisions with other particles and machine construction is carried out for individual particles. DEM simulations are widely used for AG/SAG processes, but as a rule only with a qualitative assessment of the dynamics of mill load (Cleary et al., 2003, Weerasrkara et al., 2013). Recently, the Rocky DEM software (Rocky) has the ability to model particle breakage processes (Beloglazov, 2018), in which the parameters obtained by JK DWT are basic. However, due to a number of limitations of DEM modeling, direct input of JK DWT results into the Rocky interface is not possible. At the same time, Rocky's mathematical model is easy to control, and the modeling process is dynamic.

\section{MATERIALS AND METHODS}

\subsection{The subject, tasks and the aim of the study}

The aim of this work is to combine the mathematical aspects of the breakage model of mineral raw materials in Rocky DEM software in line with the results of the drop weight test for the material (model verification). The object of the study was a copper-nickel ore sample.

The tasks include carrying out laboratory tests according to the JK DWT method on a technological sample of copper-nickel ore; comparing the theoretical foundations of JK DWT and the mathematical apparatus of breakage model in Rocky; verification of mineral breakage modeling by the JK DWT using the discrete element method in Rocky DEM software by means of a complete model factor experiment.

Subsequently, a calibrated fracture model in Rocky can be used to obtain data that allows the calibration of mathematical models of hand-held apparatuses in JKSimMet, as well as to clarify the effect of abrasive wear of the apparatuses construction on the course of the technological process.

\subsection{Methods}

The output parameters of the JK DWT are $A$ and $b$ characterizing the strength properties of the tested ore. These constants are found after obtaining all the results of sieve analyses of the fracture products and bringing them to the exponential dependence of the following form (see Figure 1):

$$
t_{10}=A \cdot\left(1-\exp ^{-b \cdot E_{c s}}\right)
$$

where $t_{10}$ is the percentage finer than $1 / 10$ th of the original particle size $\% ; A$ - constant (asymptotic, Figure 1); $b$ - constant (controls the shape of the curve); $E_{c s}$ - specific energy, $\mathrm{kWh} / \mathrm{t}$, in JK DWT $E_{c s}$ is regulated by the mass of the drop weight and the drop height (equation 2). 


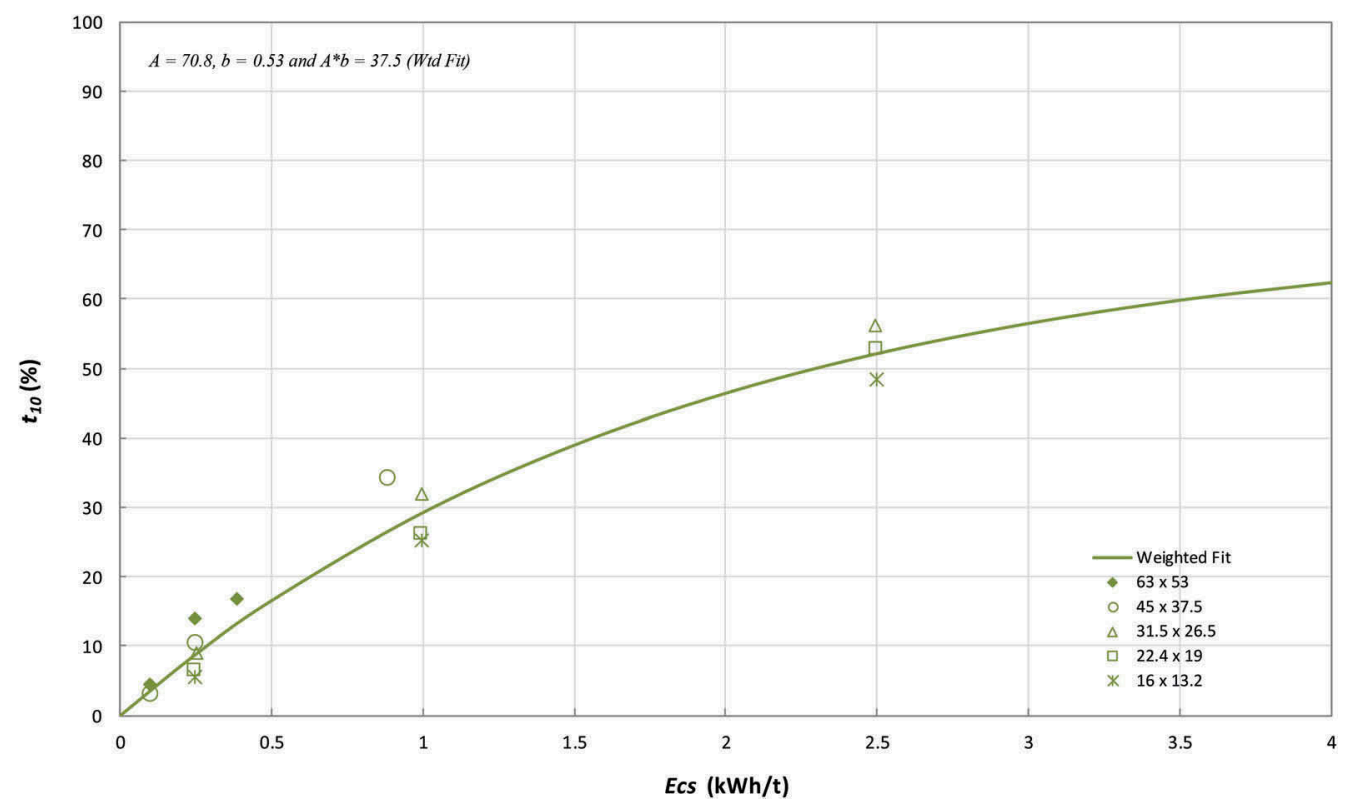

Figure 1. The dependence of the parameter $t_{10}$ on the specific energy Ecs obtained from the JK DWT results for the sample of copper-nickel ore.

$$
E_{c s}=\frac{m g h}{3,6 m_{y}}
$$

where $m$ is the mass of the weight, $\mathrm{kg} ; m_{u}$ - particle mass, $\mathrm{g} ; g$ is the force due to gravity, $m / s^{2} ; h$ - "clean" drop height (difference between final $h_{2}$ and initial $h_{1}$ position of the steel weight, $h_{2}$ varies as it depends on the residue after breakage.), $\mathrm{m}$.

In Rocky, the model multi-step events of destruction is transformed considering the probability of an act of particle breaking:

$$
P\left(e_{\text {cum }}\right)=1-\exp ^{- \text {SecumL } / \text { Lref }},
$$

where $P\left(e_{\text {cum }}\right)$ - probability of breakage at the current value of the total specific energy applied to the particle $\left(e_{\text {cum }}\right), S$ - constant for the material, called the coefficient of the selection function or the selective coefficient, $\mathrm{kg} / \mathrm{J} ; L$ - particle size, $\mathrm{m} ; L_{r e f}$-reference particle size, $\mathrm{m}$.

In this case, $e_{c u m}$ is the sum of the energies applied to the particle in the current and previous calculation steps $t$ :

$$
e_{c u m}^{t}=e_{c u m}^{t-\Delta t}+\left(e_{c}^{t}-e_{c}^{t-\Delta t}\right)
$$

where $e_{c u m}^{t-\Delta t}$ and $e_{c}^{t-\Delta t}$ - total specific contact energy and instantaneous specific contact energy at the previous time step $t$, respectively.

In addition, in Rocky, for the act of breakage to occur, the specific energy applied to the particle must be greater than the minimum specific energy of destruction, $e_{\text {min }}$, which is determined by the expression:

$$
e_{\min }=e_{\min \cdot r e f} \frac{L_{r e f}}{L}
$$


where $e_{\text {min.ref }}$ - reference minimum specific energy for the reference particle size of this material. This parameter, among others, is introduced into the fracture model when it is configured in the Rocky interface.

When a particle breaks, fragments are generated in accordance with the Voronoi breakage algorithm (Aurenhammer \& Klein, 2000) in accordance with the minimum size of the generated particles, which is set by the user. The value of the parameter $t_{10}$, which will eventually be generated by the model, is calculated by the expression:

$$
t_{10}=A\left[1-\exp \left(-S e_{c u m} L / L_{r e f}\right)\right]
$$

The expression $\left(e_{c u m} L / L_{r e f}\right)$ in equation 5 corresponds to the $E_{c s}$ from equation 1 taking into account the size of a particular destructible particle. Thus, to obtain a similar final fracture result in the Rocky JK DW model (see Figure 2, a), the parameters of the minimum specific energy $e_{\min }$ from equation 4 and the selective fracture function $S$ from equations 2 and 5 were calibrated.

$$
b=\frac{S L e_{c u m}}{L_{r e f} E_{c s}}=\frac{S e_{c u m} e_{\min . r e f}}{E_{c s} e_{\min }}
$$

To solve this problem, a complete factorial model experiment was conducted on the values of the coefficients $S$ and $e_{\text {min }}$ comparing the parameter $t_{10}$ obtained on their basis with the results of JK DWT carried out on a sample of the studied copper-nickel ore. To carry out a factor experiment, ANSYS Workbench software was performed, which partially automates the input parameters to the Rocky JK DW model, among which were:

- The mass of the drop weight (8 values for 15 experiments),

- Drop height (15 values for 15 experiments),

- The particle size (5 values for 15 experiments), it was also used as $L_{r e f}$,

- Particle mass (15 values for 15 experiments),

Among the varied parameters of the fracture model for each of the 15 experiments were:

- The reference minimum value of specific energy $e_{\text {min }}$ from equation 4 (7 values),

- Selective coefficient $S$ from equations 2 and 5 (7 values).

a)
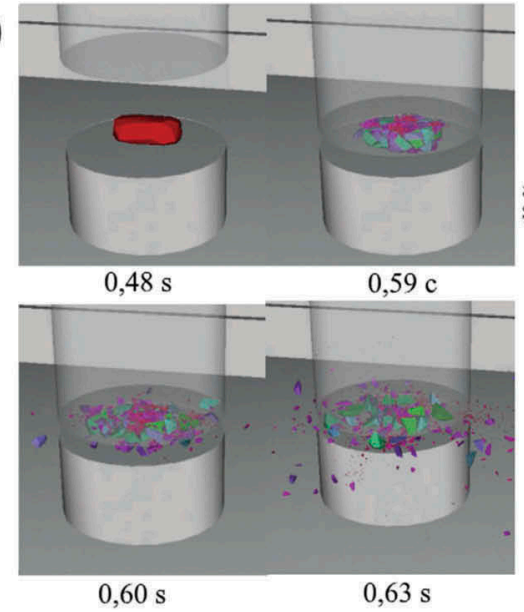

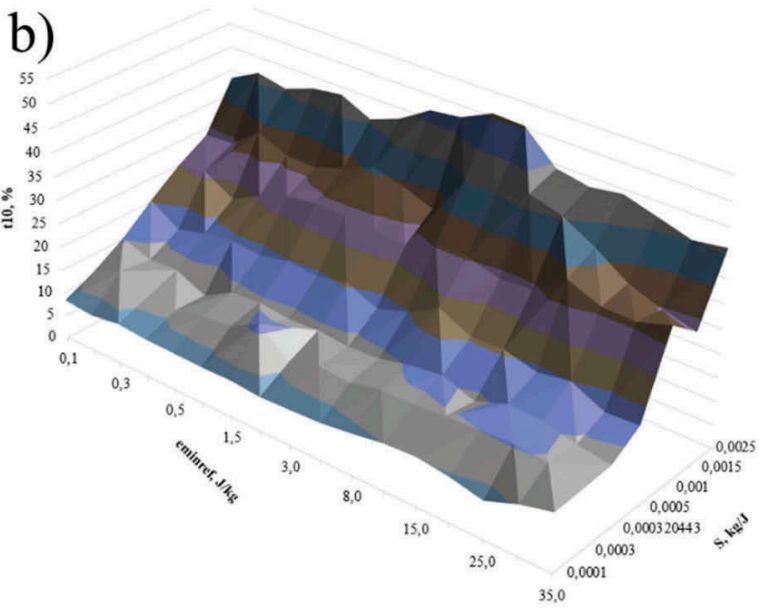

Figure 2. JK DWT modeling: a) a tester in the form of a 3D model; b) a surface diagram for the values of the obtained parameter $t_{10}$ when varying the studied factors. 
The constant $A$ form equation 5 was introduced directly into the Rocky model from the results of a JK DWT. The size of the smallest generated particles in each experiment was introduced as $1 / 50$ of the arithmetic mean particle size of the destructible particle size class.

\section{RESULTS AND DISCUSSION}

A series of experiments was simulated with 49 models for each of 15 sets of JK DWT (735 models in total). The output was reduced to surface diagrams of parameter $t_{10}$ for each of the 15 sets (one of such diagrams is shown in Figure 2, b).

It was established that the influence of the input reference minimum specific energy emin. ref on the value of the output parameter $t_{10}$ is insignificant in comparison with the influence of the selective coefficient $\mathrm{S}$ (see Figure 2, b). This is explained by the specificity of the destruction of the material using the JK DW installation, aimed at creating a single act of destruction by each of the particles included in the set.

The results obtained for equation 7 are presented in Table 1.

Figure 3 shows the initial dependence $t_{10}=f(A, b)$ and the same dependence obtained from the DEM simulation of the JK DW installation in Rocky.

Table 2 presents the initial strength parameters $A$ and $b$ obtained from Rocky models.

Table 1. The absolute error in determining the value $t_{10}, \%$.

\begin{tabular}{llllll}
\hline Specific energy, kWh/t & Sizes, $\mathrm{mm}$ & & & \\
\cline { 2 - 6 } & $-63+53$ & $-45+37,5$ & $-31,5+26,5$ & $-22,4+19$ & $-16+13,2$ \\
\hline 0,10 & $-0,31$ & 0,13 & - & - & - \\
0,25 & 1,17 & 1,01 & $-1,20$ & 0,01 & 0,15 \\
0,40 & 0,13 & - & - & - & - \\
1,00 & - & $-2,70$ & 2,12 & $-0,90$ & $-1,43$ \\
2,50 & - & - & 3,07 & $-3,06$ & 1,81 \\
\hline
\end{tabular}

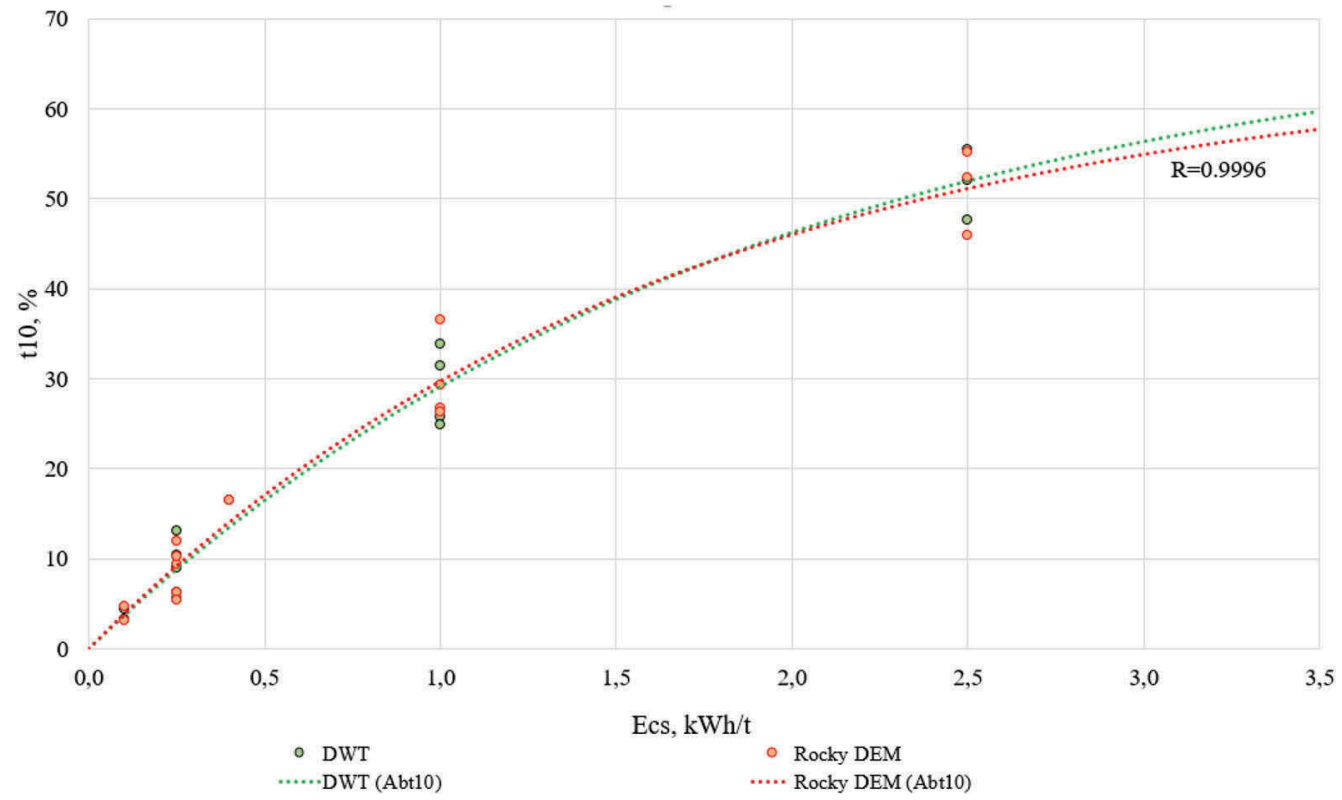

Figure 3. The dependence obtained from the results of DEM modelling. 
Table 2. Strength parameters obtained by the

DEM model.

\begin{tabular}{lcc}
\hline Parameter & JK DWT & Rocky DEM \\
\hline $\mathrm{A}$ & 70,8 & 65,7 \\
$\mathrm{~b}$ & 0,53 & 0,60 \\
$\mathrm{Ab}$ & 37,5 & 39,6 \\
\hline
\end{tabular}

\section{CONCLUSIONS}

According to the results of the work, the coefficients of the mathematical model in Rocky, making it possible to predict the parameter t10 obtained in the JK DWT experiments for various values of the specific breakage energy for all studied particle size fractions with an accuracy of $\pm 3.1 \%$ at a confidence interval of $95 \%$. The repeatability of the model has not been estimated with many tests. Despite this, the resulting model allows to calibrate mathematical models in JKSimMet software for such ore dressing equipment as crushers and AG/SAG mills according to the power parameters developed under load and particle size distribution of the feed and crushing product taking into account the lining wear rate.

The calibrated breakage Rocky DEM model may be used for analysis of particle size distribution changes during dry crushing and grinding processes of the studied nick-el-copper ore sample and during JKSimMet equipment settings:

- When making structural changes to ore preparation machines (using non-standard discharge gratings in AG mills, using non-standard lining in crushers, etc.);

- With the abrasive wear of the constructions of comminution equipment;

- To analyze the equipment which is not included in the list of supported in JKSimMet software.

- The research was carried out under the grant received from Russian Foundation of Fundamental Research № 20-55-12002

\section{REFERENCES}

Aleksandrova T. N., Nikolaeva N.V., Lvov V.V., Romashev A.O. 2019. Ore processing efficiency improvements for precious metals based on process simulations. Obogashchenie rud, No. 2: 8-13. DOI: 10.17580 /or.2019.02.02.

Andreev Ye.Ye., Zakhvatkin V.V., Lvov V.V., Nikolaeva N.V. 2019. Application of falling weight test for estimation of ore strength properties. Obogashchenie rud, No. 3: 19-22.

Aurenhammer F., Klein R. 2000. Voronoi Diagrams. Handbook of Computational Geometryю In J. R. Sack and J. Urrutia (ed.) Amsterdam, Holland: North-Holland: 201-290.

Beloglazov I.I., Stepanyan A.S., Feoktistov A.Yu., Yusupov G.A. 2018. Disintegration process modeling for a jaw crusher with complex jaws swing. Obogashchenie rud, No. 2: 3-8. DOI: 10.17580/ or.2018.02.01.

Cleary P.W., Morrisson R., Morrell S. 2003. Comparison of DEM and experiment for a scale model SAG mill. Mineral Processing, No. 68: 129-165.

Gospodarikov A.P. \& Zatsepin, M.A. 2019. Mathematical modeling of boundary problems in geomechanics. Gornyi Zhurnal, Issue 12: 16-20.

Nikolaeva N.V., Aleksandrova, T.N., Taranov, V.A. 2017. Determination of the degree of impact destruction of gold-bearing ore particles in the layer. Information (Japan), 20(9): 6605-6613.

Taranov, V.A., Baranov V.F., Aleksandrova T.N. 2013. Review of software for modeling and calculation of ore preparation flowsheets. Obogashchenie rud, No. 5: 3-7.

Weerasekara N.S., Powell M.S., Cleary P.W., Tavares L.M., Evertsson M., Morrison R.D., Quist J., Carvalho R.M. 2013. The contribution of DEM to the science of comminution. Powder Technology no. 248: 3-24.

Zuev B.Y., Zubov V.P., Smychnik A.D. 2019. Determination of static and dynamic stresses in physical models of layered and block rock masses. Gornyi Zhurnal, Issue 7: 61-66. 


\title{
Research on the patterns of structure formation processes of a clinker-free alkaline stone
}

\author{
S-A.Yu. Murtazaev, M.Sh. Salamanova \& M.Sh. Mintsaev \\ FSFEI HE "Millionschikov Grozny State Oil Technical University”, Kh. Ibragimov Complex Institute of \\ the Russian Academy of Sciences, Grozny, Russia \\ D.K-S. Bataev \\ Kh. Ibragimov Complex Institute of the Russian Academy of Sciences, Grozny, Russia
}

\begin{abstract}
Resource- and energy-consuming Portland cement is currently considered the most popular material in construction, but its production is classified as harmful due to the large amount of emissions into the environment. Therefore, the development of a clinker-free technology for the production of binders based on mineral fine-dispersed powders of aluminosilicate nature, activated by an alkaline grouting fluid, is an urgent and promising direction.

The research presents the results of a study on the laws of processes occurring during the structure formation of clinker-free binder systems of alkaline activation on alkaline cements using blast furnace granulated slags in a finely dispersed state. Formulations are given and the properties of clinker-free binders of alkaline activation based on mineral finely dispersed powders from rocks of sedimentary and magmatic origin are investigated. Electron probe analysis and X-ray phase analysis revealed the presence of hydrated amorphous compounds close in composition to zeolites in cement stone. An analysis of the results allowed us to determine the optimal composition of clinker-free binder of alkaline activation "silicified marl + volcanic tuff $(70: 30 \%)+\mathrm{Na}_{2} \mathrm{SiO}_{3}+\mathrm{NaOH}$ " with activity ranging from $42.0-54.5 \mathrm{MPa}$, depending on the conditions under which the hardening of the samples was implemented.

This work was carried out as part of research on the implementation of scientific project No. 05.607.21.0320. "Development of technology for new building composites on clinkerless alkaline binders using substandard natural and secondary raw materials" that received support from the federal target program "Research and Development in Priority Directions for the Development of the Russian Science and Technology Complex for 2014-2020”. Unique Agreement Identifier RFMTFI60719X0320.
\end{abstract}

Keywords: High-strength concrete, super concrete, local raw materials, products of buildings and constructions demolition and dismantling, concrete scrap, brick rubble, recycling, secondary or recycled filler (sand), filled binder, concrete

\section{INTRODUCTION}

The fundamental factor in the formation of structure-forming elements, both of various dense rocks, and for all traditional mineral binders is the presence of an alkaline environment created by alkaline and alkaline earth metals. Minerals such as zeolites and feldspars in the $\mathrm{Na}_{2}$ $\mathrm{O}-\mathrm{Al}_{2} \mathrm{O}_{3}-\mathrm{SiO}_{2}-\mathrm{H}_{2} \mathrm{O}$ system were formed as a result of metamorphic processes in the earth's crust, under conditions of high temperatures, humidity, pressures, weathering and cementation with alkaline compounds of aluminosilicate rocks. But it must be taken into account that in alkaline cements, the main astringent function is performed by com-pounds of alkali metals with silicates, aluminates, and water, which are much more active than alkaline 
earth oxides and create a stronger alkaline environment (Glukhovsky et al., 1981, Glukhovsky et al., 1980).

The mechanism for creating durable compositions from traditional cements is based on the synthesis of calcium salts, which, when hydrated, give an alkaline environment saturated with calcium hydroxide, which will subsequently become a component of crystallization formations. Having located the elements of alkali-containing compounds in basicity: $\mathrm{Cs}, \mathrm{Kb}$, $\mathrm{K}, \mathrm{Na}, \mathrm{Li}, \mathrm{Ba}, \mathrm{Sr}, \mathrm{Ca}, \mathrm{Mg}$, we observe a decrease in activity and $\mathrm{pH}$ of the medium from left to right, therefore, caustic alkalis of sodium and potassium are strong bases, and will allow to obtain multicomponent cement systems with hydraulic properties (Glukhovsky et al., 1981, Krivenko et al., 1993, Salamanova \& Murtazaev et al., 2017, Murtazaev \& Salamanova et al., 2018).

\section{LITERATURE REVIEW}

A study of the issues related to the reactivity of the studied compounds showed that the minerals of alkaline-earth aluminosilicates, silicates, aluminates do not react with water, and for the hydration interaction to occur, it is necessary to increase the basicity of the dispersion phase, which is possible by introducing an alkaline component into the hardener, which will lead to the formation of a system with a clear increase in strength indicators.

In the works of Glukhovsky (Glukhovsky et al., 1981, Glukhovsky et al., 1980) it is proposed to classify the hydration characteristics of alkaline compounds depending on the chemical and mineralogical compositions:

- caustic alkali solutions of ROH type;

- soft acids salts of non-siliceous nature, such as $\mathrm{R}_{2} \mathrm{CO}_{3}, \mathrm{R}_{2} \mathrm{SO}_{3}, \mathrm{R}_{2} \mathrm{~S}$, RF, etc.;

- siliceous salt of the $\mathrm{R}_{2} \mathrm{O}-(0,5-4,0)-\mathrm{SiO}_{2}$ composition;

- aluminate salts of the $\mathrm{R}_{2} \mathrm{O}-\mathrm{Al}_{2} \mathrm{O}_{3}$ composition;

- aluminosilicate salts of the $\mathrm{R}_{2} \mathrm{O}-\mathrm{Al}_{2} \mathrm{O}_{3}-(2-6) \mathrm{SiO}_{2}$ type;

- salts of strong acids of non-siliceous nature such as $\mathrm{RCl}, \mathrm{R}_{2} \mathrm{SO}_{4}$.

The hydration ability was studied (Davidovitz et al., 2008, Duxson et al., 2007, Nikiforov et al., 2011, Krivenko et al., 2006) on samples of normal consistency, from blast furnace granulated slag of aluminosilicate nature, mixed with the corresponding alkaline solutions, with $\mathrm{Na}_{2} \mathrm{O}$ content in a binder (up to $3 \%$ ). Table 1 shows a comparative analysis of slag-alkali compositions.

The dependence of the strength index of the studied alkaline compositions on the type of alkaline solution showed that the activity of binders is determined by the nature of the grouting fluid, and reaches its highest index in compounds with alkali metals + silicates of high basicity (Rakhimova et al., 2009). Therefore, the strength indicators of alkaline systems depend on the degree of their solubility and dissociation in water.

Aluminosilicate alkaline groutings, as we know, do not dissolve in water, but as a result of interaction with it, they break off a weak concentration of caustic soda. Aluminates and sodium silicates are readily soluble in water and the results of studies (Murtazaev \& Salamanova et al., 2019) confirm their hydration hardening inherent in alkaline earth compounds. Consequently, the dispersed alkaline phase, necessary for hydration processes to form cement

Table 1. The results of determining the activity of blast surface slag compositions (slag compositions in short) (Glukhovsky et al., 1980).

Compressive strength, MPa

\begin{tabular}{lllllllllll}
\hline Water & $\mathrm{NaOH}$ & $\mathrm{Na}_{2} \mathrm{CO}_{3}$ & $\mathrm{NaNO}_{3}$ & $\mathrm{NaF}$ & $\mathrm{Na}_{2} \mathrm{~S}$ & $\mathrm{Na}_{2} \mathrm{SiO}_{3}$ & $\begin{array}{l}\mathrm{Na}_{2} \mathrm{O} \\
2 \mathrm{SiO}_{2}\end{array}$ & $\begin{array}{l}\mathrm{Na}_{2} \mathrm{O} \\
4 \mathrm{SiO}_{2}\end{array}$ & $\begin{array}{l}\mathrm{Na}_{2} \mathrm{O} \mathrm{Al}_{2} \mathrm{O}_{3} \\
2 \mathrm{SiO}_{2}\end{array}$ & $\begin{array}{l}\mathrm{Na}_{2} \mathrm{O} \\
\mathrm{Al}_{2} \mathrm{O}_{3}\end{array}$ \\
\hline 7,5 & 80 & 63 & 55 & 85 & 60 & 130 & 160 & 23 & 10 & 67 \\
\hline
\end{tabular}


stone, will be an indispensable condition, and the previously known (Glukhovsky et al., 1980, Duxson et al., 2007, Nikiforov et al., 2011, Krivenko et al., 2006, Bataev \& Salamanova et al., 2019) scientific, theoretical and experimental approaches to creating hydraulic binders based on calcium oxide will help to model the algorithm obtaining clinker-free bindings with mineral powders of alkaline mixing.

\section{RESEARCH METHODS AND MATERIALS}

The regularities and laws of the processes occurring during the formation of the structure of clinker-free binder systems of alkaline activation were studied on slag-alkali cements using blast furnace granulated slags in a finely dispersed state (Rakhimova et al., 2009, Davidovitz et al., 2008, Krivenko et al., 2006, Murtazayev \& Alaskhanov et al., 2019). It has been established that compounds of the Si-O-Si and Al-O-Si type in a solution of alkali metals of high concentration are first destroyed, but after a certain time they become denser, trans-forming into a colloidal state.

The mechanism of the structure formation process is quite long and complex. At the first stage of hardening, the dispersed slag particles spontaneously dissolve in the alkali metal solution with the formation of dispersion-coagulative solutions necessary for the formation of the initial structure. Primary neoplasms formed as a result of cationic ex-change of $2 \mathrm{Na}^{+} \leftrightarrow \mathrm{Ca}^{2+}$ are variable in nature.

At the next stage, the formed condensation structure transforms due to mass transfer processes in the colloidal dispersed system, and the transition of hydrosols to the solid phase, which intensifies the crystallization of the structure. A particular alkaline system was studied in a few research papers and it was represented by the following system " $\mathrm{Ca}(\mathrm{OH})_{2}-\mathrm{SiO}_{2}-\mathrm{H}_{2}$ $\mathrm{O}-\mathrm{NaOH}$ ", and so with the molar ratio $\mathrm{Ca}(\mathrm{OH})_{2} / \mathrm{SiO}_{2}=1$, the development of phase formation can be traced:

at $\mathrm{NaOH} / \mathrm{SiO}_{2}<1$, the tobermorite phase is $11.3 \AA$ with silicon-oxygen anions;

at $\mathrm{NaOH} / \mathrm{SiO}_{2}=1-5$, the tobermorite phase is $11.3 \AA$ with the chain structure of siliconoxygen anions;

at $\mathrm{NaOH} / \mathrm{SiO}_{2}>5$, sodium cation in the tobermorite phase is $\mathrm{NaCaHSiO}_{4}$ with $\mathrm{SiO}_{4}$ being isolated.

And at the last stage of structure formation, the primary solid phases of an unstable composition develop, leading to the formation of a strong crystalline intergrowth. The crystallization phases are unstable, and depend on many factors, chemical and mineralogical compositions that make up the system, the nature of the alkaline solution, the dispersion of the components, hardening conditions, etc. Alkaline medium of high basicity promotes the formation of compounds such as tobermorite like low basic calcium hydrosilicates CSH (B), variable hydrogranates, silicic acid gel, alkaline hydroaluminosilicates such as natural zeolites and hydromica, and other alkaline-alkaline earth compounds of variable composition (Rakhimova et al., 2009).

The process of forming the structure of multicomponent systems "mineral powder - alkaline activator" requires a careful analysis, since the characteristics of the binder, its nature, degree of dispersion, alkaline curing agent (alkaline grouting fluid), their dissolution rate, crystallization conditions, interfacial contact zone, and other factors as a whole affect hardening and a cement stone's strength gain. Undoubtedly, the material and quantitative compositions of the components of this complex system will have a direct impact on the process at all stages of structure formation (Rakhimova et al., 2009, Krivenko et al., 2006, Murtazayev \& Alaskhanov et al., 2019).

This paper presents its view on the development of clinker-free technology for producing building composites. Considering the fact that in many regions of our vast country there are no reserves of ferrous metallurgy wastes, and transportation of this valuable raw material over long distances is economically disadvantageous, our efforts were aimed at finding materials that mutually substitute (or fill place of) blast furnace granulated slags. And this is no coincidence, the slag of ferrous metallurgy in their chemical composition is identical to the composition of clinker minerals, therefore, the processes of structure formation of cement 
stone will be similar for both types of binder. Due to the lack of slag, we made attempts to obtain alkaline mixing binders using finely dispersed mineral powders of various origins.

It becomes possible since the North Caucasus has huge natural potential for the development of the cement industry. In mountainous regions, stocks of cement marls, lime-stones, gaize (silica clay), dolomites, large deposits of mortar and glass sands, coquinoid limestone, sandstone (malmrock), natural sand dunes of the Terskaya lowland are concentrated (Salamanova \& Murtazaev et al., 2017).

To develop clinker-free cements of alkaline activation, mineral finely dispersed powders were prepared from rocks of sedimentary and magmatic origin: silicified marl and volcanic tuff from the Kabardino-Balkarian Republic.

\section{RESULTS}

The energy-dispersive microanalysis of the powders studied using a Quanta 3D 200 i scanning electron microscope showed a significant difference in the chemical composition of the mineral additives:

$\square$ Volcanic tuff, $\%: \mathrm{MgO}=0,20 ; \mathrm{Al}_{2} \mathrm{O}_{3}=13,57 ; \mathrm{SiO}_{2}=73,67 ; \mathrm{K}_{2} \mathrm{O}=6,00 ; \mathrm{CaO}=1,79 ; \mathrm{Fe}_{2}$ $\mathrm{O}_{3}=1,52 ; \mathrm{TiO}_{2}=2,85 ;$ other $=0,40$.

$\square$ Silicified marl, \%: $\mathrm{MgO}=1,64 ; \mathrm{Al}_{2} \mathrm{O}_{3}=6,42 ; \mathrm{SiO}_{2}=28,6 ; \mathrm{K}_{2} \mathrm{O}=1,33 ; \mathrm{CaO}=16,90 ; \mathrm{Fe}_{2}$ $\mathrm{O}_{3}=1,08 ; \mathrm{TiO}_{2}=0,47 ; \mathrm{SO}_{3}=0,29 ;$ other $=43,2$.

To study the structure formation processes of cement stone made with clinker-free binders of alkaline activation (CFBAA), electron-probe studies were carried out using a VEGA II LMU scanning electron microscope of the INCA ENERGY 450/XT energy dispersive microanalysis system while X-ray phase analysis was performed on an ARLX'TRA diffractometer. For research, samples were obtained from finely dispersed silicified marl, thermally activated at a temperature of $700{ }^{\circ} \mathrm{C}$, with a specific surface area of $1150 \mathrm{~m}^{2} / \mathrm{kg}$ and a finely ground volcanic tuff with a specific surface area of $905 \mathrm{~m}^{2} / \mathrm{kg}$, which were mixed in a predetermined ratio and subsequently tempered with an alkaline solution of salable liquid sodium glass with a silicate module of 2,8 and a density of $1,42 \mathrm{~g} / \mathrm{cm}^{3}$. The prepared samples solidified on the first day under normal conditions at a temperature of $20 \pm 2{ }^{\circ} \mathrm{C}$, but after 2 days the samples were being placed into a chamber drier for 2 hours at a temperature of $50{ }^{\circ} \mathrm{C}$ every day for the next 28 days.

The studied sample of cement stone is characterized by a thin-crystalline non-uniformly crystalline structure (Figure $1 \mathrm{c}$ ) with rounded closed pores with a diameter of up to $0,5 \mathrm{~mm}$ (Figure $1 \mathrm{a}, \mathrm{b}$ ). A commonly dense aggregation of cement mass with particles of sand aggregate is presented.

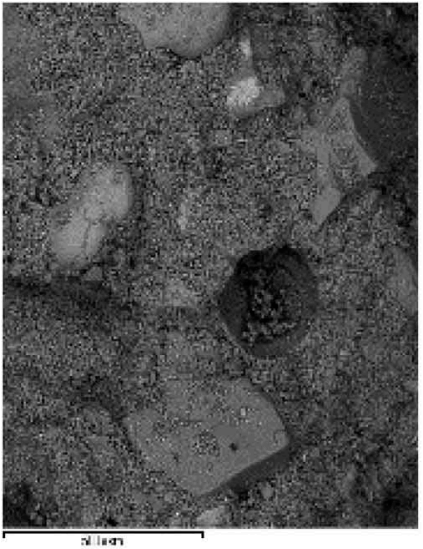

a)

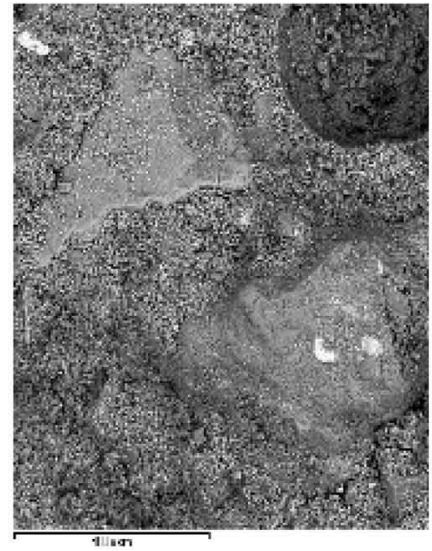

b)

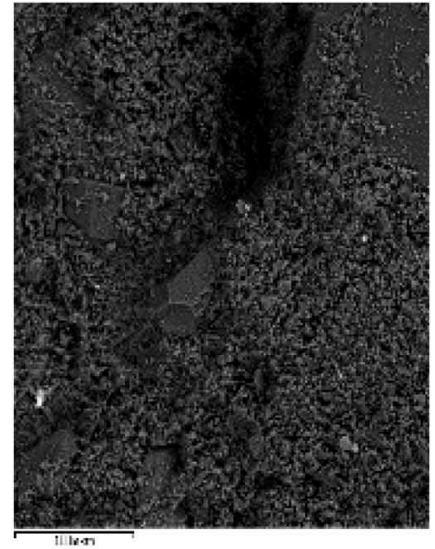

c)

Figure 1. The microstructure of CFBAA cement stone based on volcanic tuff and thermally activated marl. 


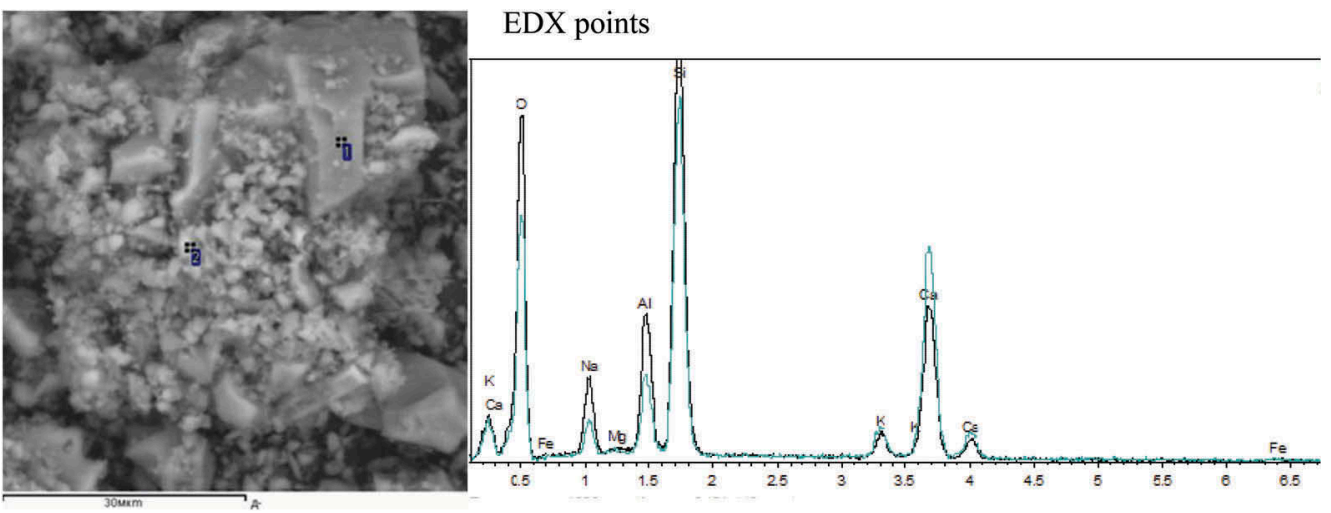

Figure 2. Hydrates of the fragments' mass $(1,2)$.

Table 2. The composition of the hydrates of the presented fragments' mass, in weight. \% (points [phases] of analysis are indicated in Figure 2).

\begin{tabular}{lllllllll}
\hline Point & $\mathrm{Na}_{2} \mathrm{O}$ & $\mathrm{MgO}$ & $\mathrm{Al}_{2} \mathrm{O}_{3}$ & $\mathrm{SiO}_{2}$ & $\mathrm{~K}_{2} \mathrm{O}$ & $\mathrm{CaO}$ & $\mathrm{FeO}$ & Total \\
\hline 1 & 8,19 & 0,22 & 12,51 & 46,98 & 2,05 & 17,71 & 0,43 & 88,09 \\
2 & 4,13 & 0,21 & 6,72 & 35,82 & 2,58 & 24,42 & 0,52 & 74,41 \\
\hline
\end{tabular}

Table 3. The composition of the crystals of the presented fractions' mass, in weight. \% (points [or phases] of analysis are indicated in Figure 3).

\begin{tabular}{lllrrrrrr}
\hline Point & $\mathrm{Na}_{2} \mathrm{O}$ & $\mathrm{MgO}$ & $\mathrm{Al}_{2} \mathrm{O}_{3}$ & $\mathrm{SiO}_{2}$ & $\mathrm{~K}_{2} \mathrm{O}$ & $\mathrm{CaO}$ & $\mathrm{FeO}$ & Total \\
\hline 1 & 8,66 & 0,00 & 18,76 & 61,65 & 1,66 & 7,61 & 0,40 & 98,74 \\
2 & 4,24 & 0,23 & 12,12 & 71,43 & 5,03 & 5,57 & 0,28 & 98,91 \\
3 & 0,92 & 0,21 & 1,14 & 5,98 & 0,23 & 44,52 & 0,00 & 53,00 \\
4 & 2,36 & 0,54 & 1,25 & 4,35 & 0,27 & 43,17 & 0,00 & 57,44 \\
5 & 0,74 & 0,00 & 1,03 & 4,06 & 0,33 & 42,55 & 0,00 & 48,70 \\
\hline
\end{tabular}

The main structure-forming layers are hydrates of sodium calcium aluminum silicates, often forming dense intergrowths of crystals up to 10-20 $\mu \mathrm{m}$ in size (Figure 2), the composition of which according to the results of a semi-quantitative analysis is shown in Tables 2, 3 (analyzes 1,2), which are associated with calcite and, apparently, thin layers of $\mathrm{Ca}(\mathrm{OH})_{2}($ Table 3, analyzes 3-5), as well as thin mica flakes.

Minerals of mica according to x-ray phase and electron probe analyzes correspond to muscovite; the measured flake composition $(\sim 20 \mu \mathrm{m}$ in size $)$ is on average close to the formula $\left(\mathrm{Na}_{0.14} \mathrm{~K}_{0.63}\right)_{0.8}\left(\mathrm{Fe}^{2+}{ }_{0.05} \mathrm{Mg}_{0.02} \mathrm{Al}^{\mathrm{VI}}{ }_{2.01} \mathrm{Ti}_{0.01}\right)_{2.1}\left(\mathrm{Si}_{3.01} \mathrm{Al}^{\mathrm{IV}}{ }_{0.99}\right)_{4.0} \mathrm{O}_{10}\left(\mathrm{OH}_{2.00}\right)_{2.0}$ reflecting the enrichment of sodium and aluminum.

According to the results of X-ray phase analysis, the presence of quartz, feldspars close to albite and orthoclase, mica, calcite, zeolites (Figure 4) was established.

\section{DISCUSSION}

According to $\mathrm{X}$-ray diffraction data, zeolite is identified as close to garronite. $\mathrm{Na}_{2} \mathrm{Ca}_{5} \mathrm{Al}_{12} \mathrm{Si}_{20}$ $\mathrm{O}_{64} \cdot 27\left(\mathrm{H}_{2} \mathrm{O}\right)$ distinctly expressed main reflex at this point (phase) $(2 \Theta-12,4(7,10 \AA))$. Electron probe studies reveal the presence of $\mathrm{Na}-\mathrm{Ca}-\mathrm{Si}$ hydrated amorphous compounds with a high 

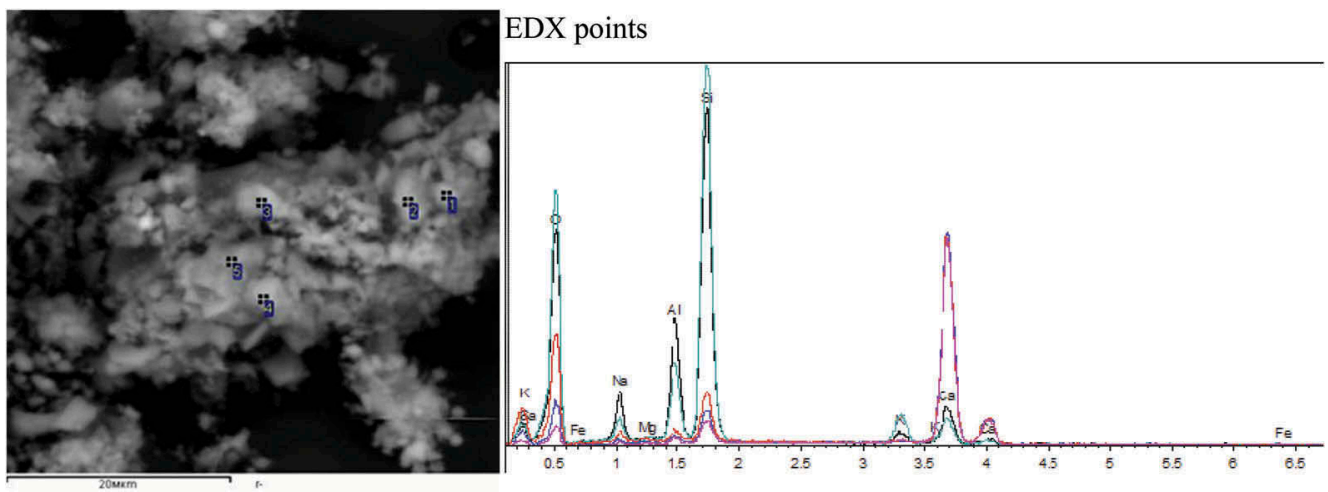

Figure 3. Points of the fragments' mass.

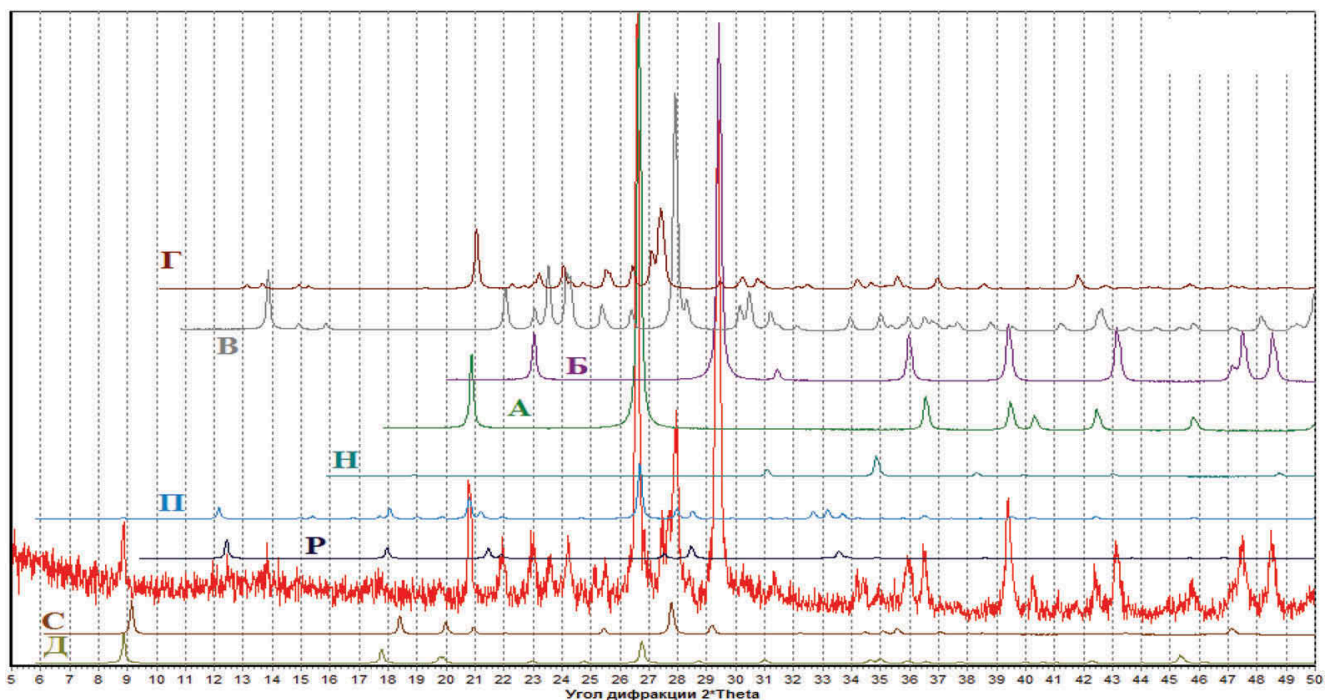

Figure 4. X-ray diffraction pattern of sample 1 in comparison with the data base PDF-2. The comparison points (phases) are as follows (the bracketed letters are Cyrillic Alphabet letters from Figure 4): A (A) - quartz, B (Б) - calcite, C (B) - albite, G (Г) - potassium feldspar, D (Д) - muscovite, $\mathrm{N}(\mathrm{H})$ - analcime, $\mathrm{P}(\Pi)$ - jismondite, $\mathrm{R}(\mathrm{P})$ - garronite, $\mathrm{S}(\mathrm{C})$ - paragonite.

water content (Figure 5, Table 4) and points (phases) similar to them in composition and also containing aluminum. Additionally, these points (phases) are similar to zeolites in elemental composition (Figure 6; 7, Tables 6 and 7).

The size and surface roughness of the preparations do not allow measurements by quantitative methods, but it can be stated that the composition is close to Ca-phillipsite or garronite (which are characterized by the ratio $-\mathrm{SiO}_{2} / \mathrm{Al}_{2} \mathrm{O}_{3} \sim 2$ ).

According to the results of X-ray phase analysis in a cement stone of the multicomponent system "mineral powder - alkaline activator" using finely dispersed volcanic tuff powders and thermally activated marl at $700{ }^{\circ} \mathrm{C}$, the presence of quartz, feldspars close to albite and orthoclase, mica, calcite, zeolites has been established. Electron probe studies also reveal the presence of hydrated amorphous Na-Ca-Si compounds of similar compositional phases containing aluminum and close in elemental composition to zeolites. 


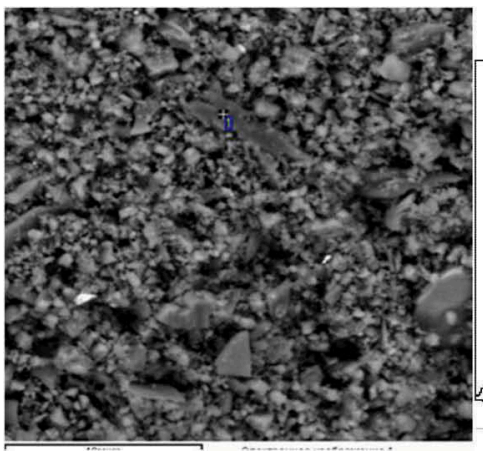

Figure 5. Hydrated Na-Ca-Si compounds in the structure of the material.

Table 4. The composition of the mica crystals, in weight. $\%$.

\begin{tabular}{llllllllll}
\hline Point & $\mathrm{Na}_{2} \mathrm{O}$ & $\mathrm{MgO}$ & $\mathrm{Al}_{2} \mathrm{O}_{3}$ & $\mathrm{SiO}_{2}$ & $\mathrm{~K}_{2} \mathrm{O}$ & $\mathrm{CaO}$ & $\mathrm{TiO}_{2}$ & $\mathrm{FeO}$ & Total \\
\hline 1 & 1,08 & 0,53 & 37,45 & 44,22 & 8,19 & 1,00 & 0,21 & 1,13 & 77,58 \\
\hline
\end{tabular}

Table 5. Composition of hydrated Na-Ca-Si compounds (points [or phases] of analysis are indicated in Figure 6), in weight. \%.

\begin{tabular}{lllllllll}
\hline Point & $\mathrm{Na}_{2} \mathrm{O}$ & $\mathrm{MgO}$ & $\mathrm{Al}_{2} \mathrm{O}_{3}$ & $\mathrm{SiO}_{2}$ & $\mathrm{~K}_{2} \mathrm{O}$ & $\mathrm{CaO}$ & $\mathrm{FeO}$ & Total \\
\hline 1 & 13,52 & 0,04 & 1,43 & 11,80 & 0,55 & 12,31 & 0,72 & 40,36 \\
\hline
\end{tabular}

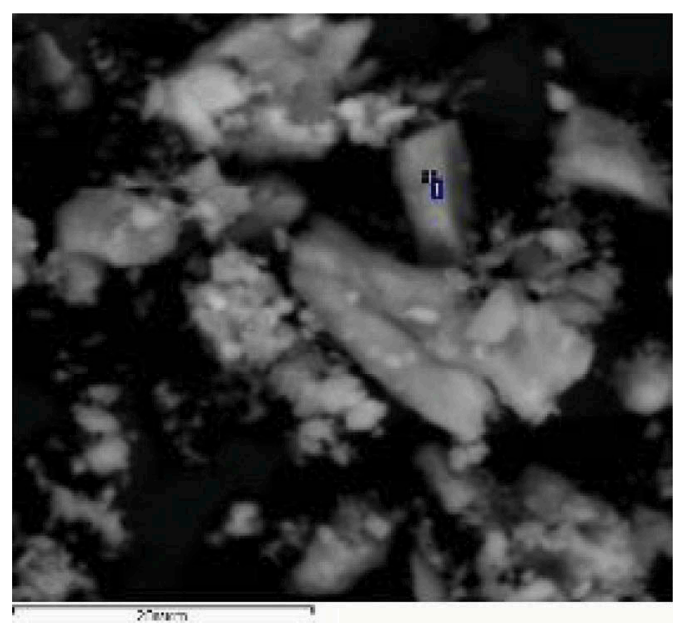

Figure 6. Hydrated Na-Ca-Si compounds in the structure of the material.

To study the kinetics of strength development of the clinker-free binder of alkaline activation, various compositions were prepared from finely dispersed silica marl thermally activated at a temperature of $700{ }^{\circ} \mathrm{C}$ with a specific surface of $1150 \mathrm{~m}^{2} / \mathrm{kg}$ and finely ground volcanic tuff with a specific surface of $905 \mathrm{~m}^{2} / \mathrm{kg}$, activated with an alkaline solution; the test results are given in Table 7. 

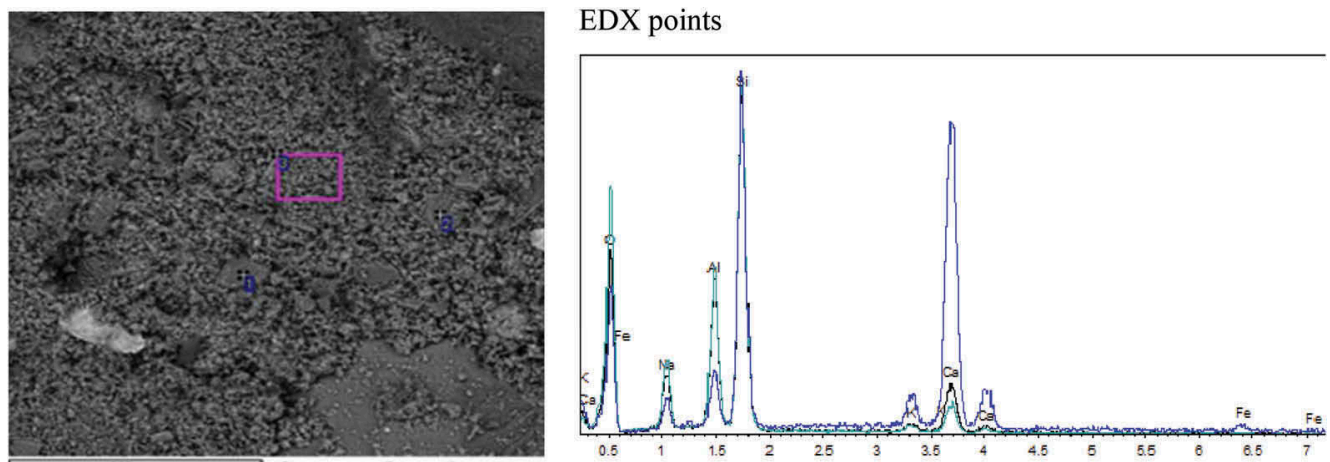

Figure 7. Points of EDX crystals close to zeolites $(1,2)$ и fragments' main mass (3).

Table 6. The composition of the zeolite point (phase) (points [or phases] of analysis are indicated in Figure 7), in weight. \%.

\begin{tabular}{llllllll}
\hline Point & $\mathrm{Na}_{2} \mathrm{O}$ & $\mathrm{Al}_{2} \mathrm{O}_{3}$ & $\mathrm{SiO}_{2}$ & $\mathrm{~K}_{2} \mathrm{O}$ & $\mathrm{CaO}$ & $\mathrm{FeO}$ & Total \\
\hline 1 & 5,12 & 17,07 & 40,91 & 0,39 & 6,47 & 0,13 & 71,09 \\
\hline
\end{tabular}

Table 7. Kinetics of strength development of the alkaline activation binder.

\begin{tabular}{|c|c|c|c|c|c|c|c|c|c|}
\hline \multirow[b]{3}{*}{ Alkaline activator } & \multicolumn{9}{|c|}{ The compressive strength, MPa per day } \\
\hline & \multicolumn{3}{|c|}{ after thermal treatment } & \multicolumn{3}{|c|}{ in water } & \multicolumn{3}{|c|}{ normal conditions } \\
\hline & 28 & 90 & 180 & 28 & 90 & 180 & 28 & 90 & 180 \\
\hline \multicolumn{10}{|c|}{ silicified marl + volcanic tuff $(30: 70 \%)$} \\
\hline $\mathrm{Na}_{2} \mathrm{SiO}_{3}+\mathrm{NaOH}$ & 24,5 & 25,1 & 26,0 & 18,3 & 23,4 & 24,5 & 18,3 & 18,4 & 19,5 \\
\hline $\mathrm{Na}_{2} \mathrm{SiO}_{3}$ & 20,1 & 20,5 & 22,3 & 16,5 & 17,3 & 18,5 & 16,6 & 17,2 & 17,6 \\
\hline $\mathrm{NaOH}$ & 15,0 & 15,1 & 15,3 & 12,4 & 13,3 & 13,4 & 12,2 & 13,0 & 13,3 \\
\hline \multicolumn{10}{|c|}{ silicified marl + volcanic tuff $(50: 50 \%)$} \\
\hline $\mathrm{Na}_{2} \mathrm{SiO}_{3}+\mathrm{NaOH}$ & 43,0 & 47,5 & 49,7 & 41,8 & 43,8 & 44,7 & 38,0 & 41,8 & 42,7 \\
\hline $\mathrm{Na}_{2} \mathrm{SiO}_{3}$ & 34,3 & 35,8 & 36,9 & 30,2 & 31,4 & 32,7 & 31,5 & 32,3 & 33,6 \\
\hline $\mathrm{NaOH}$ & 25,2 & 27,8 & 28,6 & 24,8 & 26,1 & 27,6 & 27,5 & 27,4 & 27,9 \\
\hline \multicolumn{10}{|c|}{ silicified marl + volcanic tuff $(70: 30 \%)$} \\
\hline $\mathrm{Na}_{2} \mathrm{SiO}_{3}+\mathrm{NaOH}$ & 46,5 & 52,4 & 54,5 & 45,6 & 47,6 & 49,6 & 42,0 & 43,7 & 44,3 \\
\hline $\mathrm{Na}_{2} \mathrm{SiO}_{3}$ & 37,2 & 38,6 & 40,8 & 35,4 & 38,4 & 39,9 & 34,1 & 36,3 & 37,5 \\
\hline $\mathrm{NaOH}$ & 30,0 & 31,6 & 32,7 & 30,4 & 31,2 & 33,1 & 28,7 & 28,8 & 30,9 \\
\hline
\end{tabular}

\section{CONCLUSIONS}

The results showed that clinker-free binder of alkaline activation of the "silicified marl + volcanic tuff $(70: 30 \%)-\mathrm{Na}_{2} \mathrm{SiO}_{3}+\mathrm{NaOH}$ " composition can be considered as an optimal one. The activity of cement stone varies from 42.0 to $54.5 \mathrm{MPa}$ depending on hardening conditions affecting the samples. It can be noted that heat treatment favorably affects the kinetics of the strength development of cement stone. Activation of the investigated multi-component systems with sodium hydroxide solution is inferior to sodium metasilicate. 
Thus, the obtained research results will significantly expand the scope of application of clinker-free cements of alkaline activation in regions experiencing a shortage of ferrous metallurgy waste, and become an alternative to energy and resource-consuming Portland cement, and, of course, it will be possible, if necessary, to replace it in the construction industry as the studies have confirmed the presence of hydrated amorphous Na-Ca-Si compounds, similar in composition of studied fragments' masses to zeolites, capable of facilitating the production of effective modern concrete composites.

\section{REFERENCES}

Bataev D.K-S., Murtazayev S- A. Yu., Salamanova M.Sh., Viskhanov S.S. 2019. Utilization of Cement Kiln Dust in Production of Alkali-Activated Clinker-Free Binders/Proceedings of the International Symposium "Engineering and Earth Sciences: Applied and Fundamental Research" dedicated to the 85th anniversary of H.I. Ibragimov (ISEES 2019). Atlantis Highlights in Material Sciences and Technology (AHMST). April 2019. Vol.1.

Davidovitz, J. 2008. Geopolymer. Chemistry and applications. Saint-Quentin: Institute Geopolymer.

Duxson, P. 2007. Geopolymer technology: The current state of the art//P. Duxson, A. Fernandez, J. Provis/J. Mater. Sci. - V. 42.

Glukhovsky, V.D. Slag-alkali concrete on fine-grained aggregates [Text]/V.D. Glukhovsky//Kiev: Vishcha school. Head Publishing House, 1981.- 224 p.

Glukhovsky, V.D. 1980. Complex use of blast furnace and electrothermophosphoric slag in the production of high-strength cements and concrete/ V.D. Glukhovsky, I.A. Pashkov, B.C. Grigoryev / University News: Construction and Architecture, - No. 5.

Krivenko, P.V. 1993. The durability of slag-alkali concrete/P.V. Krivenko, K.K. Pushkareva//- Kiev: Budivelnik.

Krivenko, P.V. 2006. Physicochemical fundamentals of the durability of slag stone/P.V. Krivenko// Cement. - 1990. - No. 11. - S. 2-4.10. Lecomte, I. Microstructural comparison between geopolymers, alkali-activated slag cement and Portland cement/I. Lecomte, C. Henrist, M. Liegeois//J. Eur. Cer. Soc. -2006 . - Vol. 26.

Murtazaev, S-A.Yu. 2017. The effect of surface active sites on the reactivity of mineral additives/S-A.Yu. Murtazaev, M.Sh. Salamanova, M.S. Saidumov, Z.Kh. Ismailova//Scientific journal "Modern Science and Innovation" (Stavropol - Pyatigorsk). - 2017. - No. 2 (18).

Murtazaev, S-A.Yu. 2018. Prospects for the use of thermally activated raw materials of aluminosilicate nature/C-A.Ю. Murtazaev, M.Sh. Salamanova//Volga Scientific Journal. - 2018. - No. 2 (T.46).

Murtazayev S- A. Yu., Salamanova M.Sh., Alaskhanov A.Kh, Ismailova Z.Kh 2019. Development of Multicomponent Binders Using Fine Powders/Proceedings of the International Symposium "Engineering and Earth Sciences: Applied and Fundamental Research" dedicated to the 85th anniversary of H.I. Ibragimov (ISEES 2019). Atlantis Highlights in Material Sciences and Technology (AHMST). April 2019. Vol.1.

Nikiforov, E.A. 2011. The effect of alkaline activation on the structure and properties of diatomite/E.A. Nikiforov, V.I. Loganina, E.E. Simonov//Bulletin of BSTU named after V.G. Shukhov. 2011. - No. 2.

Rakhimova, N.R. 2009. Properties of the slag-alkaline bindings - specific surface and granulometric of ground blast furnace slags relation/N.R. Rakhimova, R.Z. Rakhimov//17. Internationale Baustofftagung, Tagungsbericht. Band 1.Weimar.

Salamanova, M.Sh. 2019. Obtaining liquid glass silicate-sodium alkaline solutions from silica-containing additives/M.Sh. Salamanova, St. A.Yu. Murtazaev//Scientific and technical journal Vestnik GGNTU. Technical science. - 2019 .- No. 1(15). 


\title{
Energy estimates of relaxation and creep deformation processes of polymeric materials
}

\author{
A. Makarov \\ Vice-Rector of Science, Saint Petersburg State University of Industrial Technologies and Design, Saint \\ Petersburg, Russia
}

\section{A. Demidov}

Rector, Saint Petersburg State University of Industrial Technologies and Design, Saint Petersburg, Russia

N. Pereborova

PhD, Associate Professor, Associate Professor of the Department of Intelligent Systems and Information Security Saint Petersburg State University of Industrial Technologies and Design, Saint Petersburg, Russia

\section{Egorova}

PhD, Associate Professor, Associate Professor of the Department of Intelligent Systems and Information Security Saint Petersburg State University of Industrial Technologies and Design, Saint Petersburg, Russia

\begin{abstract}
The article considers energy estimates of nonlinear hereditary relaxation and creep processes. Polymeric materials have pronounced rheological properties including the flexible-chain structure of macromolecules that are in an oriented state and have an amorphous-crystalline structure at the supramolecular level (Pereborova et al., 2020a). According to the current views of structural physicists, at this level, the rheological properties of polymers, as a combination of elasticity, viscoelasticity and plasticity, are formed (Pereborova et al., 2020b). The decomposition of the total deformation value into the corresponding three parts is considered to be a difficult task due to their simultaneous occurrence and further development. Information about the complex pattern of distribution of material particles over relaxation and delay times can be obtained only through a physically-based analytical description of polymeric materials rheology in combination with the measurement of various deformation processes (Pereborova et al., 2020c). The accumulated experience of working with polymeric materials shows that the viscoelastic and plastic components of their deformation depend in a certain way on the level of applied mechanical action (Pereborova et al., 2020d). Hence, it follows that one creep or relaxation curve cannot be used to get any information on the delay or relaxation times (Pereborova et al., 2018a).
\end{abstract}

\section{THE METHODS FOR DETERMINING THE ACTIVATION ENERGY OF RELAXATION AND CREEP DEFORMATION PROCESSES OF POLYMERIC MATERIALS}

The main deformation processes of polymeric materials are relaxation and creep. To determine the activation energy of deformation processes, it is necessary to develop their mathematical models. The parameters of these processes, the relaxation and delay (creep) times, implicitly contain information about energy (Makarov et al., 2018a).

The physical meaning of the relaxation and delay time is the minimum time of conformational transition during which the assumed 'relaxing' or 'delaying' particle passes from one energy state to another overcoming some potential energy barrier (Pereborova et al., 2019a). 
The authors proposed mathematical models of relaxation and creep processes based on the Cauchy probability distribution of the relaxation and delay times. It is physically feasible as this distribution has an additivity property, i.e. the sum of random variables distributed according to the Cauchy law, is also distributed according to this law (Pereborova et al., 2018b).

To illustrate the above-noted statement, it is proposed to consider a woven polymer fabric which consists of threads made up of fibres. Experimental studies confirm that complex (composite) polymeric materials behave in a similar way in the relaxation and creep processes and these processes can be described by the same mathematical models (Makarov et al., 2016).

The second convenience of the Cauchy probability distribution is in its close similarity to the normal distribution on the basis of which many physical principles can be described.

And finally, the third advantage of the Cauchy distribution is that its cumulative distribution function is an elementary function normalized arctangent (Makarov et al., 2015).

$$
\varphi_{t}=\frac{1}{2}+\frac{1}{\pi} \operatorname{arctg}\left(\frac{1}{b} \ln \frac{t}{t_{1}}\right)
$$

in contrast to the probability integral for the normal distribution.

Here, the dimensionless logarithmic time is taken as an argument $\frac{t}{t_{1}}\left(t_{1}\right.$ - some value of base time), $b$ - the coefficient of the intensity of relaxation or creep processes.

The elementary character of this function considerably simplifies the rearrangement in mathematical modelling of relaxation and creep.

The simplest model of the relaxation process for the case of constant deformation $\varepsilon=$ const is given by (Pereborova et al., 2018c)

$$
E_{\varepsilon t}=E_{0}-\left(E_{0}-E_{\infty}\right) \varphi_{\varepsilon t}
$$

where $E_{0}$ and $E_{\infty}$ - asymptotic values of the relaxation modulus

$E_{\varepsilon t}=\frac{\sigma_{t}}{\varepsilon}, \sigma_{t}$ - time varying $\mathrm{t}$ stress.

Similarly, the simplest model of the creep process for the case of constant stress $\sigma=$ const is given by (Makarov et al., 2018b).

$$
D_{\sigma t}=D_{0}+\left(D_{\infty}-D_{0}\right) \varphi_{\sigma t}
$$

where $D_{0}$ and $D_{\infty}$ - aasymptotic compliance values $D_{\sigma t}=\frac{\varepsilon_{t}}{\sigma}$.

The simplest mathematical model of relaxation (1), (2) has an important advantage over other similar models as it has the smallest possible number of physically based parameters: three constants $\left(E_{0}, E_{\infty}, b_{\varepsilon}\right)$ and deformation-time function

$$
f_{\tau_{\varepsilon}}=\ln \frac{t_{1}}{\tau_{\varepsilon}}
$$

characterising the relaxation times $\tau_{\varepsilon}$ (Pereborova et al., 2019d).

The same can be said about the mathematical model of creep (1), (3). It also contains three physically based constants $\left(D_{0}, D_{\infty}, b_{\sigma}\right)$ and force-time function

$$
f_{\tau_{\sigma}}=\ln \frac{t_{1}}{\tau_{\sigma}}
$$

characterising the delay times $\tau_{\sigma}$ (Rymkevich et al., 2013)

Sufficient reliability and technical convenience follows from the analysis of the applicability of the considered simplest mathematical models of relaxation and creep used for the analytical description of the rheological properties of polymeric materials and the subsequently calculated prediction of loaded or deformable states of these materials. Due to the smallest number of 
parameters-characteristics, the simplicity of their determination from short-term experiments, and clarity of their physical interpretation, the developed methods seem to be promising not only for polymers but also for a number of other solid materials (Pereborova et al., 2019c).

The simplest mathematical models of relaxation (1), (2) and creep (1), (3) can be easily generalised for the case of complex relaxation $(\varepsilon \neq$ const $)$ and complex deformation $(\sigma \neq c o n s t)$ processes by using the Boltzmann-Volterra integral constitutive relations whose integral kernels are derivatives of the relaxation function or the delay function, respectively (Pereborova et al., 2018d). The mathematical model of a complex relaxation process is given by (Pereborova et al., 2018e),

$$
\sigma_{t}=E_{0} \varepsilon_{t}-\left(E_{0}-E_{\infty}\right) \cdot \int_{0}^{t} \varepsilon_{\theta} \cdot \varphi_{\varepsilon ; t-\theta}^{\prime} d \theta
$$

where $\varphi_{\varepsilon t}^{\prime \leftarrow}$ - relaxation kernel:

$$
\begin{gathered}
\varphi_{\varepsilon t}^{\prime}=\frac{\partial \varphi_{\varepsilon t}}{\partial t}=\frac{1}{\pi} \cdot \frac{1}{b_{\varepsilon}} \cdot \frac{1}{1+W_{\varepsilon t}^{2}} \cdot \frac{1}{t}, \\
\varphi_{\varepsilon t}=\frac{1}{2}+\frac{1}{\pi} \cdot \operatorname{arctg}\left(W_{\varepsilon t}\right) \\
W_{\varepsilon t}=\frac{1}{b_{\varepsilon}} \cdot \ln \frac{t}{\tau_{\varepsilon}}=\frac{1}{b_{\varepsilon}} \cdot\left(\ln \frac{t}{t_{1}}+\ln \frac{t_{1}}{\tau_{\varepsilon}}\right)
\end{gathered}
$$

Similarly, the mathematical model of a complex deformation process is given by (Gorshkov et al., 2013)

$$
\varepsilon_{t}=D_{0} \sigma_{t}-\left(D_{\infty}-D_{0}\right) \cdot \int_{0}^{t} \sigma_{\theta} \cdot \varphi_{\sigma ; t-\theta}^{\prime} d \theta
$$

where $\varphi_{\sigma t}^{\prime}$ - delay kernel:

$$
\begin{gathered}
\varphi_{\sigma t}^{\prime}=\frac{\partial \varphi_{\sigma t}}{\partial t}=\frac{1}{\pi} \cdot \frac{1}{b_{\sigma}} \cdot \frac{1}{1+W_{\sigma t}^{2}} \cdot \frac{1}{t} \\
\varphi_{\sigma t}=\frac{1}{2}+\frac{1}{\pi} \cdot \operatorname{arctg}\left(W_{\sigma t}\right), \\
W_{\sigma t}=\frac{1}{b_{\sigma}} \cdot \ln \frac{t}{\tau_{\sigma}}=\frac{1}{b_{\sigma}} \cdot\left(\ln \frac{t}{t_{1}}+\ln \frac{t_{1}}{\tau_{\sigma}}\right)
\end{gathered}
$$

At the same time, the set of assumptions on which these mathematical models are built should be considered. First of all, the governing equations (6) and (10) of the elastic-hereditary type have a phenomenological origin (Makarov et al., 2017a). Despite the achieved success in the modelling of elastic-hereditary and more general rheological media with a stable structure, it seems to be obvious that almost any mathematical model greatly simplifies the properties of a polymer material (Demidov et al., 2017). The essence of the alternativeness of two consistent equations of nonlinear hereditary viscoelasticity (6) and (10) is in the simultaneous use of two analogies, which are deformation-time (in the case of relaxation) and force-time (in the case of creep) (Makarov et al., 2017b). There are no direct contradictions to modern kinetic views in this approach. Although, it is unusual to simultaneously use two contradicting analogies at once. The approximate nature of both analogies can be the only physical justification of this approach (Makarov et al., 2015a). 
The accepted hypothesis about the feasibility of simultaneous consistent use of two logarithmically symmetric delay and relaxation kernels has an approximate nature and makes all sorts of calculation procedures easier because of a noticeable reduction in the number of parameters-characteristics. The question of preference of one kernel over another remains unclear and is subject to further research. The possibility of considering at least one of these kernels logarithmically symmetric is also not obvious (Makarov et al., 2015b).

In addition to the reduction of the number of parameters-characteristics, the simplest version of generalisation by introducing force-time and deformation-time analogies into the hereditary kernels in the normalized version plays a pivotal role.

The obtained force function of the delay times (5) and the deformation function of the relaxation times (4) in general qualitatively correspond to the modern approaches to kinetic thermofluctuation nature of 'behaviour' of the oriented amorphous-crystalline polymers (Makarov et al., 2014a).

\section{CALCULATION OF THE ACTIVATION ENERGY OF RELAXATION AND CREEP DEFORMATION PROCESSES OF POLYMERIC MATERIALS}

In order to verify the quantitative correspondence to these views on the curves obtained from a set of creep and relaxation of a polyester thread 83 tex., the activation energies were calculated using the well-known Arrhenius-Boltzmann formula which is given by (Demidov et al., 2006a).

$$
\begin{aligned}
& U_{\sigma}=R T \cdot\left(\ln \frac{t_{1}}{\tau_{0}}-\ln \frac{t_{1}}{\tau_{\sigma}}\right), \\
& U_{\varepsilon}=R T \cdot\left(\ln \frac{t_{1}}{\tau_{0}}-\ln \frac{t_{1}}{\tau_{\varepsilon}}\right),
\end{aligned}
$$

where $\tau_{0}$ - the parameter that has the meaning of the duration of the elementary rearrangement of 'relaxing' particles of the material $t_{1}=1$ minutes; $f_{\tau_{\sigma}}=\ln \frac{t_{1}}{\tau_{\sigma}}$ - force-time function, $\tau_{\sigma}$ delay time; $f_{\tau_{\varepsilon}}=\ln \frac{t_{1}}{\tau_{\varepsilon}}$ - deformation-time function, $\tau_{\varepsilon}$ relaxation time; $T$ - temperature ${ }^{o} \mathrm{~K}$; $R=k A, k$ - the Boltzmann constant, $A$ - the Avogadro number; $U_{\sigma}$ - activation energy as a function of stress; $U_{\varepsilon}$ - activation energy as a function of deformation.

In the calculation of the relaxation and creep activation energy of a polyester thread 83 tex., the following values were used: $R=8,31 \mathrm{~kJ} / \mathrm{mol}^{*} \operatorname{grad}$ and $\tau_{0} \cong 5 \cdot 10^{-12} \mathrm{c}$, whence it follows that $\ln \frac{t_{1}}{\tau_{0}} \cong 30$.

The calculation results are shown in Figure 1 and Figure 2. It is evident that the calculated dependencies are linear. In equations (Demidov et al., 2009)

$$
\begin{gathered}
U_{\sigma}=U_{0}-\gamma \\
U_{\varepsilon}=U_{0}-\gamma \cdot E_{\tau} \varepsilon
\end{gathered}
$$

according to Figure 1 and Figure 2, it is obtained that $U_{0}=100 \mathrm{~kJ} / \mathrm{mol}$ and $\gamma \cong 4 \cdot 10^{-22} \mathrm{~cm}^{3}$.

In the calculation of $\gamma$ according to Figure 2, the mean value of the viscoelastic modulus was used $E_{\tau}=8,5 \mathrm{GPa}$. These values correspond to the molecular mobility of the segments or the destruction of van der Waals cross-links between the side groups.

The proximity and stability of the lines obtained in Figure 1 and Figure 2 with reference to temperature changes confirms the concept validity of the micromechanism of delay or relaxation unity in the considered temperature range, as well as, the physical validity of the analogies used. In this case, it is assumed that with a change in temperature, the physical meaning of the used parameters-characteristics is preserved but their numerical values may change. 


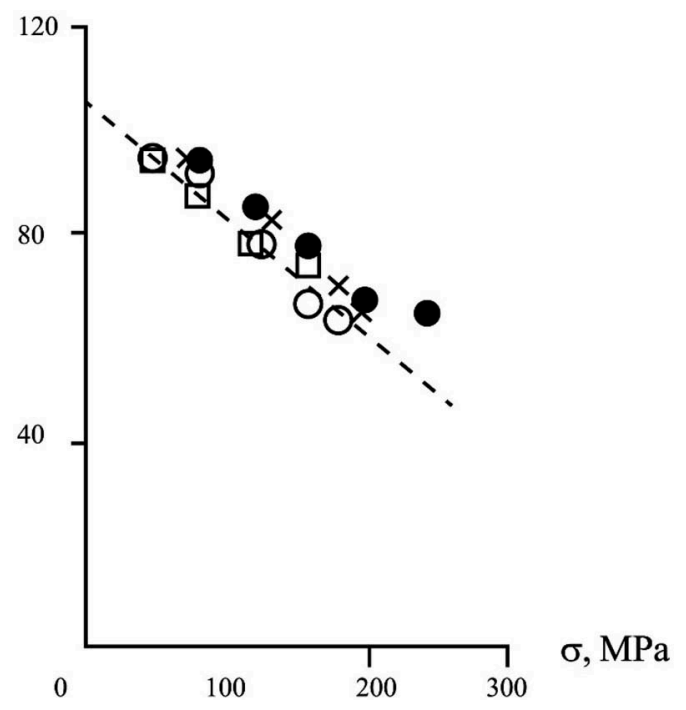

Figure 1. The dependence of activation energy on stress at temperatures $20^{\circ} \mathrm{C}(\bullet) ; 40^{\circ} \mathrm{C}(\mathrm{x}) ; 60^{\circ} \mathrm{C}(\mathrm{o})$; $80^{\circ} \mathrm{C}(\square)$ of a polyester thread 83 tex.

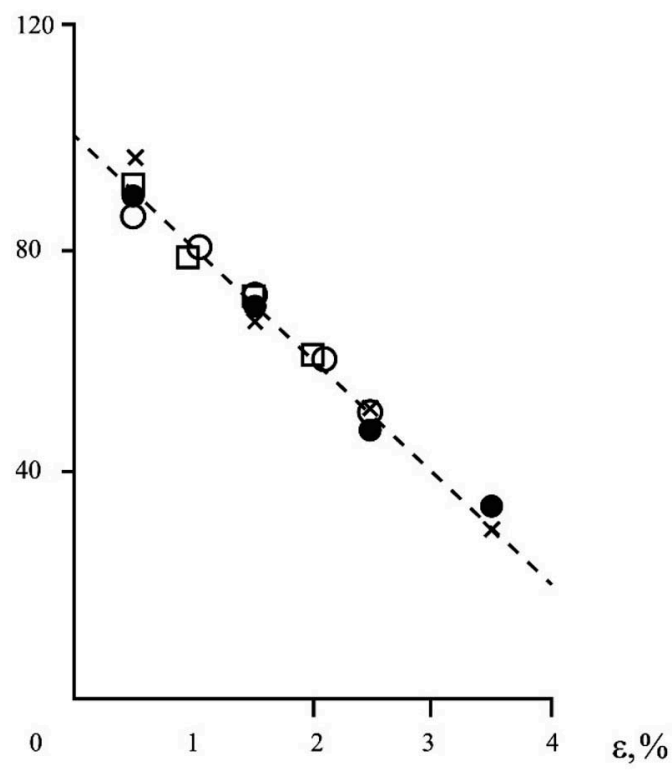

Figure 2. The dependence of the activation energy on deformation at temperatures $20^{\circ} \mathrm{C}\left(\bullet^{\circ}\right) ; 40^{\circ} \mathrm{C}(\mathrm{x})$; $60^{\circ} \mathrm{C}(\mathrm{o}) ; 80^{\circ} \mathrm{C}(\square)$ of a polyester thread 83 tex.

Consequently, in the investigated temperature range the isothermal force-time and deformation-time analogies are generalised into the temperature-force-time and temperaturedeformation-time analogies, respectively (Makarov et al., 2014b). It should be emphasised that the assumptions made in the mathematical description of the hereditary-rheological properties of polymeric materials did not affect the calculation of the activation energies of the delay times (14) and the relaxation times (15). The obtained decreasing character of the 
activation energy (16), (17) corresponds to the modern approaches to the activating character of mechanical action and the leading role of thermal fluctuations at the molecular level.

\section{CALCULATION OF THE COMPONENTS OF DEFORMATION OF POLYMERIC MATERIALS}

The process of deformation of polymeric materials at a constant speed $\dot{\varepsilon}$ at the initial stage of the stress-strain diagram (Figure 3 ) is analytically described by a phenomenological integral equation of the nonlinear-hereditary type (6) which by changing the variable $s=t-\theta$ is reduced to the form

$$
\sigma_{t}=E_{o} \varepsilon_{t}-\left(E_{o}-E_{\infty}\right) \cdot \int_{0}^{t} \varepsilon_{t-s} \cdot \varphi_{\varepsilon s}^{\prime} d s
$$

Let's take a closer look at the stress-strain diagram (Figure 3). Where $\varepsilon_{t}=\dot{\varepsilon} \cdot \mathrm{t}$ and $\sigma_{t}$ are the coordinates of a point; $\varepsilon_{t-\mathrm{s}}=\dot{\varepsilon} \cdot(\mathrm{t}-\mathrm{s})$ is the deformation under the integral sign in the formula (18).

Due to the fact that all parameters and functions included in (18) have a well-defined physical meaning, equation (18) can be considered as the mathematical model of the mechanical properties of a polymeric material with a specific spectral interpretation (Demidov et al., 2007a).

Both in the general case when $\dot{\varepsilon} \neq$ const and in the special case when $\dot{\varepsilon}=$ const, elastic $\left(\varepsilon_{t o}\right)$ and absorbed $\left(\varepsilon_{t t}\right)$ deformation components can be obtained using the formulas (Demidov et al., 2007b).

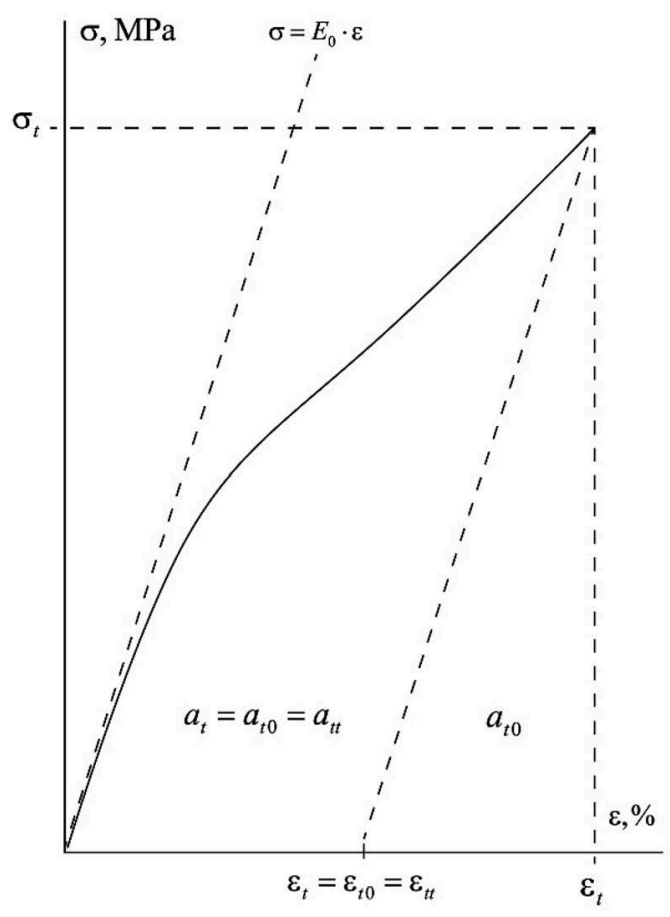

Figure 3. The decomposition scheme of the total deformation $\varepsilon_{t}$ and mechanical work $a_{t}$ of a polymer material into elastic $\left(\varepsilon_{t o}, a_{t o}\right)$ and absorbed $\left(\varepsilon_{t t}, a_{t t}\right)$ components. 


$$
\begin{gathered}
\varepsilon_{t o}=E_{o}^{-1} \sigma_{t} \\
\varepsilon_{t t}=\varepsilon_{t}-\varepsilon_{t o}
\end{gathered}
$$

or a calculated prediction based on (18) taking into account (19) and (20) (Demidov et al., 2006b).

$$
\begin{gathered}
\varepsilon_{t t}=\left(1-E_{\infty} E_{o}^{-1}\right) \int_{o}^{t} \varepsilon_{t-s} \varphi_{\varepsilon s}^{\prime} d s \\
\varepsilon_{t o}=\varepsilon_{t}-\varepsilon_{t t}
\end{gathered}
$$

Obtaining of elastic and absorbed deformation components for a polyester thread 83 tex. $T=40^{\circ} \mathrm{C}, \dot{\varepsilon}=0,083 c^{-1}$ is shown in Figure 4 .

The calculated values of the deformation components of a polyester thread 83 tex. $T=40^{\circ} \mathrm{C}$, $\dot{\varepsilon}=0,083 c^{-1}$ are given in Table 1 .

The relative fractions of elastic and absorbed deformation components are equal (Demidov et al., 2006c)

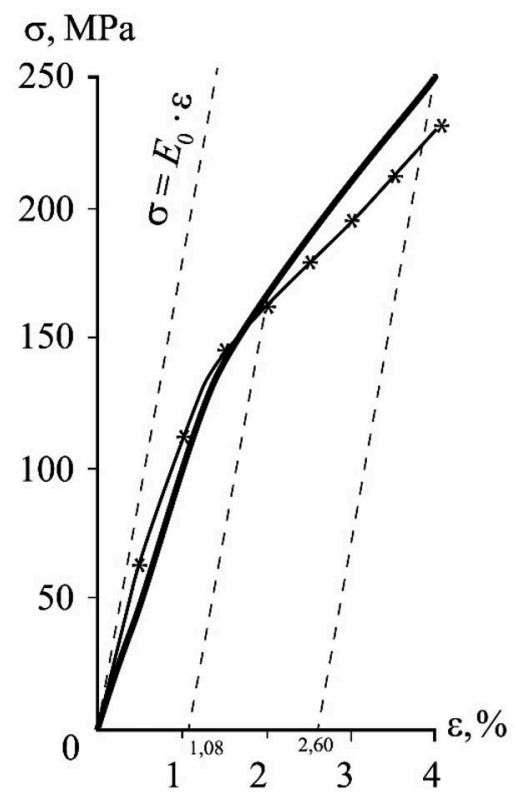

Figure 4. The stress-strain diagram of a polyester tread 83 tex., $T=40^{\circ} \mathrm{C}, \dot{\varepsilon}=0,083 c^{-1}$ (solid line experiment, - * - - calculation).

Table 1. The values of the deformation components of a polyester thread 83 tex., $T=40^{\circ} \mathrm{C}$.

\begin{tabular}{lll}
\hline$\varepsilon_{t}$ & $\varepsilon_{t o}$ & $\varepsilon_{t t}=\varepsilon_{t}-\varepsilon_{t o}$ \\
\hline 2,00 & 0,92 & 1,08 \\
4,00 & 1,40 & 2,60 \\
\hline
\end{tabular}




$$
\begin{gathered}
\varepsilon_{t o} \varepsilon_{t}^{-1}=E_{o}^{-1} \sigma_{t} \varepsilon_{t}^{-1} \\
\varepsilon_{t o} \varepsilon_{t}^{-1}=1-\left(1-E_{\infty} E_{o}^{-1}\right) \varepsilon_{t}^{-1} \int_{o}^{t} \varepsilon_{t-s} \varphi_{\varepsilon s}^{\prime} d s
\end{gathered}
$$

In the calculations using (19) - (24) the corresponding viscoelastic parameterscharacteristics are used $E_{o}, E_{\infty}, f_{\tau_{\varepsilon} \varepsilon}, A_{\varepsilon}$.

Thus, the decomposition of the total deformation into elastic and absorbed components can be carried out either using the experimental stress-strain diagram (19), (20) or by the calculated prediction (21), (22).

\section{CALCULATION OF THE ENERGY COMPONENTS OF THE DEFORMATION MECHANICAL WORK OF POLYMERIC MATERIALS}

By analogy with the method of the total deformation of polymeric materials decomposition $\varepsilon_{t}$ into elastic $\varepsilon_{t o}$ and absorbed $\varepsilon_{t t}$ components, the decomposition of the specific (per unit volume) mechanical deformation work $a_{t}$ into elastic $a_{t o}$ and absorbed $a_{t t}$ components can be considered (Demidov et al., 2006d).

For a given point of the stress-strain diagram (Figure 3) with coordinates $\varepsilon_{t}$ and $\sigma_{t}$ the specific mechanical work is calculated by the formula

$$
a_{t}=\int_{o}^{\varepsilon_{t}} \sigma_{t} d \varepsilon
$$

Taking into account (18), from (25) the prediction formula is developed (Demidov et al., 2007c).

$$
a_{t}=0,5 E_{o} \varepsilon_{t}^{2}-\dot{\varepsilon}\left(E_{o}-E_{\infty}\right) \int_{o}^{t} \int_{o}^{t} \varepsilon_{t-s} \varphi_{\varepsilon s}^{\prime} d s d t
$$

The elastic component of specific mechanical work (Stalevich et al., 2003).

$$
a_{t o}=0,5 E_{o}^{-1} \sigma_{t}^{2}
$$

and, accordingly, the elastic fraction of mechanical work $\left(a_{t o} / a_{t}\right)$ is obtained for a given point of the diagram with coordinates $\varepsilon_{t}$ and $\sigma_{t}$ or directly using the formula (25) (Makarov, 2002)

$$
\frac{a_{t o}}{a_{t}}=\frac{\sigma_{t}^{2}}{2 E_{o} \int_{o}^{\varepsilon_{t}} \sigma_{\mathrm{t}} d \varepsilon}
$$

or by the prediction using the formula (28) with the help of (18) (Stalevich et al., 2002a) 


$$
\begin{aligned}
& \frac{a_{t o}}{a_{t}}=\frac{E_{o}^{2} \varepsilon_{t}^{2}+\left(\int_{o}^{t} \varepsilon_{t-s} E_{\varepsilon s}^{\prime} d s\right)^{2}+2 \varepsilon_{t} E_{o} \int_{o}^{t} \varepsilon_{t-s} E_{\varepsilon s}^{\prime} d s}{E_{o}^{2} \varepsilon_{t}^{2}+2 \dot{\varepsilon} E_{o} \int_{o}^{t} \int_{o}^{t} \varepsilon_{t-s} E_{{ }_{\varepsilon s}} d s d t}= \\
& =\frac{\varepsilon_{t}^{2}+(1-c)^{2}\left(\int_{o}^{t} \varepsilon_{t-s} \phi_{\varepsilon s}^{\prime} d s\right)^{2}+2 \varepsilon_{t}(1-c) \int_{o}^{t} \varepsilon_{t-s} \phi^{\prime}{ }_{\varepsilon s} d s}{\varepsilon_{t}^{2}+2 \dot{\varepsilon}(1-c) \int_{o}^{t} \int_{o}^{t} \varepsilon_{t-s} \phi^{\prime}{ }_{\varepsilon s} d s d t}
\end{aligned}
$$

where $c=\frac{\mathrm{E}_{\infty}}{E_{o}}$.

The absorbed part of the specific mechanical work (Stalevich et al., 2002b)

$$
a_{t t}=a_{t}-a_{t o}
$$

or its relative part

$$
\frac{a_{t t}}{a_{t}}=1-\frac{a_{t o}}{a_{t}}
$$

are also obtained in any of the two mentioned ways (Stalevich et al., 2000).

For example, the values of the specific work and its elastic and absorbed components for a polyester thread 83 tex., $t=40^{\circ} \mathrm{C}$, at a deformation speed $\dot{\varepsilon}=0,083 \mathrm{c}^{-1}$ are given in Table 2 .

The calculation results of the fraction of elastic component of mechanical work $\frac{a_{t o}}{a_{t}}$ depending on the deformation $\varepsilon$ according to (28) - (31) are shown in Figure 5.

As it is evident from the graph (Figure 5), the fraction of the component $\mathrm{a}_{\mathrm{tt}}$ in mechanical work increases, the fraction of the component $a_{t o}$ decreases with increasing deformation $\varepsilon$ (Makarov et al., 2014c). This means that in order to return to its original state, according to the law of conservation of energy, the material needs to transfer from the external environment the more (in percentage) energy, the more it is deformed. On the other hand, this fact indicates the emerging role of the viscoelastic factor with the increase of deformation (Potapov et al., 2018).

As the result, the methods for obtaining the elastic component of mechanical work from the stress-strain diagrams or using the calculated prediction at the stage of nondestructive mechanical action are proposed (Blinov te al., 2018). The proximity of elastic components values obtained from the measured or predicted stress-strain diagram confirms the quite satisfactory reliability of physical and mechanical properties modelling of a thread in the form of a nonlinear hereditary equation (18) (Vasil'eva et al., 2016).

Table 2. The values of the specific deformation work $\left(a_{t}\right)$, its elastic $\left(a_{t o}\right)$ and absorbed $\left(a_{t t}\right)$ components for the deformation values $\varepsilon_{t}$ of a polyester thread 83 tex., $t=40^{\circ} \mathrm{C}$ at a deformation speed $\underline{\varepsilon}=0,083 c^{-1}$.

\begin{tabular}{llll}
\hline$\varepsilon_{t}, \%$ & $a_{t}, \mathrm{MPa}$ & $a_{t o}, \mathrm{MPa}$ & $a_{t t}, \mathrm{MPa}$ \\
\hline 2,00 & 1,86 & 0,76 & 1,10 \\
4,00 & 5,42 & 1,75 & 3,67 \\
\hline
\end{tabular}




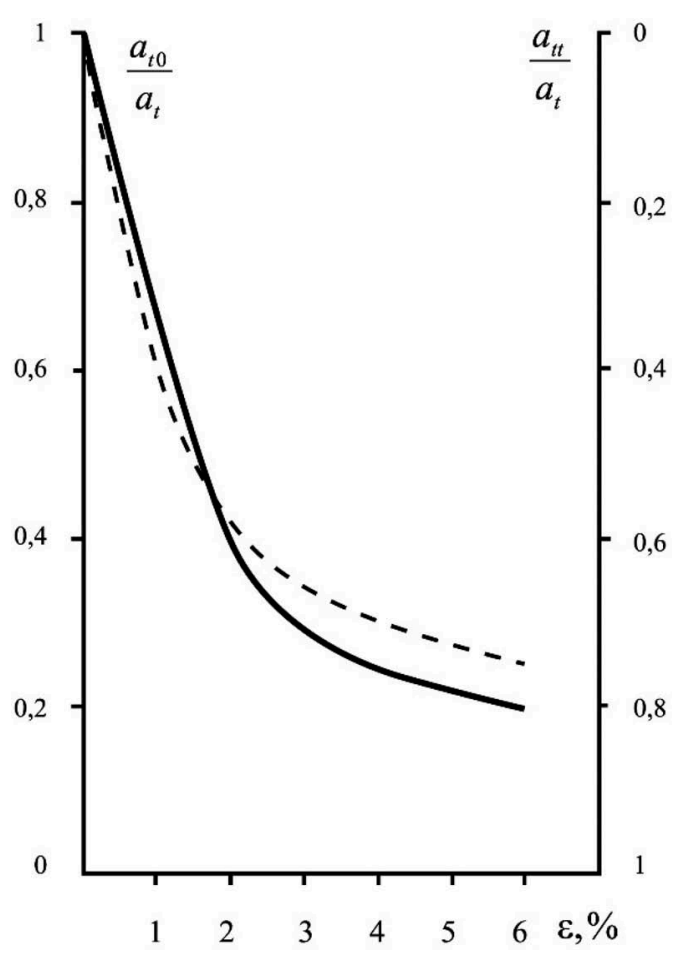

Figure 5. The fraction of elastic component $\frac{a_{t o}}{a_{t}}$ and absorbed component $\frac{a_{t t}}{a_{t}}$ of mechanical work during deformation of a polyester thread 83 tex., $T=40^{\circ} \mathrm{C}$ depending on the deformation $\varepsilon, \%$ (solid line - experiment, - - - calculation).

\section{CONCLUSION}

In sum, the energy characteristics of relaxation and creep processes were considered. Specifically, the methods for decomposition of the deformation mechanical work into two elasticreversible and viscoelastic-plastic components are developed. The proximity of the values of elastic components obtained from the measured and predicted stress-strain diagram confirms the reliability of the mechanical properties modelling of a polymeric material in the form of a nonlinear hereditary governing equation.

The methods for decomposition of deformation of polymeric materials into their components: elastic deformation, highly elastic deformation and plastic deformation allows to better understand the nature of deformation processes. Taking into account the plastic component of deformation helps to improve the accuracy and, consequently, the reliability of predicting both simple and complex nonlinear hereditary viscoelastic processes.

The proximity of the energy parameters calculated from the delay times and from the relaxation times, their invariability in the temperature range, and the decreasing nature of the activation energy confirm the thermofluctuation interpretation of the viscoelastic nonlinearity of the delay and relaxation kernels at the level of intermolecular interaction and internal rotation in chemical bonds.

The analysis of the activation parameters calculated from the obtained delay times and relaxation times confirms the consistency of the hypothesis about the activating nature of mechanical action at the level of intermolecular interactions and internal rotation. It also confirms the consistency of the thermofluctuation interpretation of viscoelastic nonlinearity of the used delay and relaxation kernels. This substantiates the proposed methods for the analytical description of the hereditary rheological properties of polymeric materials. 


\section{FUTURE RESEARCH AND ACKNOWLEDGEMENTS}

The study was funded within the framework of the state assignment of the Ministry of Science and Higher Education of the Russian Federation, Project No. FSEZ-2020-0005.

\section{REFERENCES}

Blinov, P.A., Dvoynikov, M.V. (2018) Rheological and Filtration Parameters of the Polymer Salt Drilling Fluids Based on Xanthan Gum. Journal of Engineering and Applied Sciences, 13: 5661-5664. DOI: $10.36478 / 2018.5661 .5664$

Demidov, A.V., Makarov, A.G., Stalevich, A.M. (2006a) The criteria of optimal selection of mathematical model of textile materials viscoelasticity. Izvestiya Vysshikh Uchebnykh Zavedenii, Seriya Teknologiya Tekstil'noi Promyshlennosti, Vol. 293, No 5, pp. 21-25. eid=2-s2.0-34247548784

Demidov, A.V., Makarov, A.G., Stalevich, A.M., Petrova, L.N., Chelishev, A.M. (2006b) Research of changes of deformation properties of polyester threads depending on twist amount. Izvestiya Vysshikh Uchebnykh Zavedenii, Seriya Teknologiya Tekstil'noi Promyshlennosti, Vol. 292, No 4, pp. 9-13. eid=2-s2.0-33845499474

Demidov, A.V., Makarov, A.G., Stalevich, A.M. (2006c) Methods of computer analysis of viscoelasticity of technical materials. Izvestiya Vysshikh Uchebnykh Zavedenii, Seriya Teknologiya Tekstil'noi Promyshlennosti, Vol. 291, No 3, pp. 13-17. eid=2-s2.0-37849188658

Demidov, A.V., Makarov, A.G., Stalevich, A.M. (2006d) Definition of the mechanical characteristics of textile stuffs at variable temperature. Izvestiya Vysshikh Uchebnykh Zavedenii, Seriya Teknologiya Tekstil'noi Promyshlennosti, Vol. 294, No 6, pp. 15-18. eid=2-s2.0-34250009041

Demidov, A.V., Makarov, A.G., Stalevich, A.M. (2007a) Definition of the computer forecasting trends of deformation properties of textile stuffs. Izvestiya Vysshikh Uchebnykh Zavedenii, Seriya Teknologiya Tekstil'noi Promyshlennosti, Vol. 297, No 2, pp. 14-17. eid=2-s2.0-38849203122

Demidov, A.V., Makarov, A.G., Stalevich, A.M. (2007b) System analysis of viscoelasticity of textile stuffs. Izvestiya Vysshikh Uchebnykh Zavedenii, Seriya Teknologiya Tekstil'noi Promyshlennosti, Vol. 298, No 3, pp. 11-14. eid=2-s2.0-34648822922

Demidov, A.V., Makarov, A.G., Stalevich, A.M. (2007c) Predicting the nonlinear hereditary viscoelasticity of polymers. Journal of Applied Mechanics and Technical Physics, Vol. 48, No 6, pp. 897-904. DOI: $10.1007 / \mathrm{s} 10808-007-0114-8$

Demidov, A.V., Makarov, A.G., Stalevich, A.M. (2009) A version of modeling of nonlinear-hereditary viscoelasticity of polymer materials. Mechanics of Solids, Vol. 44, No 1, pp. 122-130. DOI: 10.3103/ S0025654409010130

Demidov, A.V., Makarov, A.G., Pereborova, N.V., Egorova, M.A. (2017) Forecasting of deformation-relaxation properties of poly amide fabric used to make the canopy. Izvestiya Vysshikh Uchebnykh Zavedenii, Seriya Teknologiya Tekstil'noi Promyshlennosti, Vol. 367, No 1, pp. 250-258. eid=2-s2.0-85033239149

Gorshkov, A.S., Makarov, A.G., Romanova, A.A., Rymkevich, P.P. (2013) Modelling of directed polymers deformation processes based on the description of the kinetics of supramolecular structures separated by energy barriers. Magazine of Civil Engineering, Vol. 44, No 9, pp. 76-83+103-104. DOI: 10.5862/MCE.44.10

Makarov, A.G. (2002) Determining the analytical correlation between the standardized nuclei of relaxation and creep in textile materials. Izvestiya Vysshikh Uchebnykh Zavedenii, Seriya Teknologiya Tekstil'noi Promyshlennosti, Vol. 266, No 2, pp. 13-17. eid=2-s2.0-0036931214

Makarov, A.G., Pereborova, N.V., Egorova, M.A., Wagner, V.I. (2014a) Modeling and forecasting viscoelastic properties of textile materials with a complex structure. Izvestiya Vysshikh Uchebnykh Zavedenii, Seriya Teknologiya Tekstil'noi Promyshlennosti, Vol. 354, No 6, pp. 120-124. eid=2-s2.0 $-84937439497$

Makarov, A.G., Pereborova, N.V., Egorova, M.A., Wagner, M.A. (2014b) Ways of modeling deformation and relaxation properties of textile materials with a complex structure. Izvestiya Vysshikh Uchebnykh Zavedenii, Seriya Teknologiya Tekstil'noi Promyshlennosti, Vol. 351, No 3, pp. 110-115. eid=2-s2 $.0-84937410003$

Makarov, A.G., Pereborova, N.V., Wagner, V.I., Rymkevich, P.P., Gorshkov, A.S. (2014c) The Basis of Spectral-Temporal Analysis of Relaxation and Deformation Properties of Polymeric Materials in Textile and Ligt Industry. Izvestiya Vysshikh Uchebnykh Zavedenii, Seriya Teknologiya Legkoi Promyshlennosti. Vol. 23, No 1. pp. 24-29. 
Makarov, A.G., Slutsker, G.Y., Drobotun, N.V. (2015) Creep and fracture kinetics of polymers. Technical Physics, Vol. 60, No 2, pp. 240-245. DOI: 10.1134/S1063784215020152

Makarov, A.G., Demidov, A.V., Pereborova, N.V., Egorova, M.A. (2015a) Modeling and prediction of estimated relaxation and deformation properties of the polymer parachute line. Izvestiya Vysshikh Uchebnykh Zavedenii, Seriya Teknologiya Tekstil'noi Promyshlennosti, Vol. 360, No 6, pp. 194-205. eid=2-s2.0-84976560627

Makarov, A.G., Pereborova, N.V., Wagner, V.I., Vasileva, E.K. (2015b) Development of methodology for the comparative analysis of deformation and relaxation properties of aramid yarns and textile materials based on them. Izvestiya Vysshikh Uchebnykh Zavedenii, Seriya Teknologiya Tekstil'noi Promyshlennosti, Vol. 359, No 5, pp. 48-58. eid=2-s2.0-84971636036

Makarov, A.G., Slutsker, G.Y., Gofman, I.V., Vasil'eva, V.V. (2016) Initial stage of stress relaxation in oriented polymers. Physics of the Solid State, Vol. 58, No 4, pp. 840-846. DOI: 10.1134/ S1063783416040132

Makarov, A.G., Pereborova, N.V., Egorova, M.A., Egorov, I.M. (2017a) Quality analysis of deformation-relaxation properties of aramid cords mountain rescue appointments. Izvestiya Vysshikh Uchebnykh Zavedenii, Seriya Teknologiya Tekstil'noi Promyshlennosti, Vol. 368, No 2, pp. 309-313. eid=2-s2.0-85035207042

Makarov, A.G., Pereborova, N.V., Egorova, M.A., Egorov, I.M. (2017b) Mathematical modeling of deformation-relaxation processes polymeric materials in conditions of variable temperatures. Izvestiya Vysshikh Uchebnykh Zavedenii, Seriya Teknologiya Tekstil'noi Promyshlennosti, Vol. 370, No 4, pp. 287-292. eid=2-s2.0-85057142312

Makarov, A.G., Pereborova, N.V., Kozlov, A.A., Shvankin, A.M. (2018a) Computer-Assisted Prediction and Qualitative Analysis for Polymer Parachute Cords Fibre Chemistry, Vol. 50, No. 3, pp. 239-242. DOI 10.1007/s10692-018-9968-1

Makarov, A.G., Pereborova, N.V., Vagner, V.I., Egorova, M.A., Klimova, N.S. (2018b) Spectral Analysis of Viscoelastic Creep of Geotextiles. Fibrie Chemistry, Vol. 50, No 4, pp. 378-382. DOI 10.1007/ s10692-019-09993-4

Pereborova, N.V., Demidov, A.V., Makarov, A.G., Klimova, N.S. (2018a) Modeling of DeformationRelaxation Processes of Aramid Textile Materials - the Foundation for Analyzing Their Operational Properties. Fibre Chemistry, Vol. 50, No. 2, pp. 104-107. DOI 10.1007/s10692-018-9941-z

Pereborova, N.V., Makarov, A.G., Egorova, M.A., Kozlov, A.A., Konovalov, A.S. (2018b) Methods of simulation and comparative analysis of shadow and deformation-reducing properties of aramide textile materials. Izvestiya Vysshikh Uchebnykh Zavedenii, Seriya Teknologiya Tekstil'noi Promyshlennosti, Vol. 375, No 3, pp. 253-257. eid=2-s2.0-85059766891

Pereborova N.V., Makarov A.G., Kozlov A.A., Vasil'eva E.K. (2018c) Development of Integral Optimality Criteria for Mathematical Modeling of Relaxation/Recovery Processes in Polymer Textile Materials. Fibrie Chemistry, Vol. 50, No 4, pp. 306-309. DOI 10.1007/s10692-019-09981-8

Pereborova, N.V., Makarov, A.G., Egorova, M.A., Klimova, N.S. (2018d) Methods of increasing the competitiveness of domestic aramid textile materials based on complex analysis of their functional properties. Izvestiya Vysshikh Uchebnykh Zavedenii, Seriya Teknologiya Tekstil'noi Promyshlennosti, Vol. 378, No 6, pp. 267-272. eid=2-s2.0-85072335464

Pereborova, N.V., Demidov, A.V., Makarov, A.G., Klimova, N.S., Vasileva, E.K. (2018e) Methods of mathematical modeling and qualitative analysis of relaxation-deformation processes of aramide textile materials. Izvestiya Vysshikh Uchebnykh Zavedenii, Seriya Teknologiya Tekstil'noi Promyshlennosti, Vol. 374, No 2, pp. 251-255. eid=2-s2.0-85056451197

Pereborova, N.V., Makarov, A.G., Vasil'eva, E.K., Shvankin, A.M., Egorov, I.M. (2019a) Mathematical Modeling and Computed Prediction of Viscoelastic Creep in Geotextile Nonwoven Fabrics. Fibre Chemistry, Vol. 50, No 6, pp. 487-490. DOI 10.1007/s10692-019-10015-6

Pereborova, N.V., Makarov, A.G., Egorova, M.A., Kozlov, A.A. (2019b) Mathematical Modeling and Comparative Analysis of Deformation/Recovery Properties and Shrinkage of Aramid Textile Materials. Fibre Chemistry, Vol. 50, No 5, pp. 468-472. DOI 10.1007/s10692-019-10010-x

Pereborova, N.V., Makarov, A.G., Egorova, M.A., Klimova, N.S. (2019c) Improving the Competitiveness of Aramid Textile Materials Based on Mathematical Modeling and Analysis of Their Performance Properties. Fibre Chemistry, Vol. 50, No 6, pp. 569-572. DOI 10.1007/s10692-019-10030-7

Pereborova, N.V., Makarov, A.G., Shvankin, A.M., Egorova, M.A., Abramova, I.V. (2020a) Modeling and Qualitative Analysis of Creep Processes of Geotextile Nonwovens -A Foundation for Enhancing their Competitiveness. Fibre Chemistry, Vol. 51, No. 5, pp. 397-400. DOI 10.1007/s10692-020-10119-4

Pereborova, N.V., Makarov, A.G., Shvankin, A.M., Egorova, M.A., Korobovtseva, A.A. (2020b) Predicting Creep and Deformation and Recovery Processes of Geotextile Nonwovens. Fibre Chemistry, Vol. 51, No. 5, pp. 401-403. DOI 10.1007/s10692-020-10120-x 
Pereborova, N.V., Makarov, A.G.,Egorova, M.A., Egorov, I.M. (2020c) Methods of Modeling and Computer-Aided Prediction of Relaxation of Medical-Purpose Textile Elastomers. Fibre Chemistry, Vol. 51, No. 6, pp. 467-470. DOI 10.1007/s10692-020-10136-3

Pereborova, N.V., Makarov, A.G.,Egorova, M.A., Egorov, I.M. (2020d) Methods modeling and Computer-Aided Prediction of Strain and Relaxation Processes of Medical-Purpose Textile Elastomers. Fibre Chemistry, Vol. 51, No. 6, pp. 471-474. DOI 10.1007/s10692-020-10137-2

Potapov, A., Makhov, V. (2018) Methods for Nondestructive Testing and Diagnostics of Durability of Articles Made of Polymer Composite Materials. Russian Journal of Nondestructive Testing. 54. 151-163. 10.1134/S1061830918030087.

Rymkevich, P.P., Romanova, A.A., Golovina, V.V., Makarov, A.G. (2013) The energy barriers model for the physical description of the viscoelasticity of synthetic polymers: Application to the uniaxial orientational drawing of polyamide films. Journal of Macromolecular Science, Part B: Physics, Vol. 52, No 12, pp. 1829-1847. DOI: 10.1080/00222348.2013.808906

Stalevich, A.M., Makarov, A.G. (2000) Determining the inherent viscoelastic relaxation spectrum for synthetic filaments. Izvestiya Vysshikh Uchebnykh Zavedenii, Seriya Teknologiya Tekstil'noi Promyshlennosti, Vol. 255, No 3, pp. 8-12. eid=2-s2.0-0034436083

Stalevich, A.M., Makarov, A.G. (2002a) Forecasting the deformation recovery process and the reverse relaxation in polymer materials. Izvestiya Vysshikh Uchebnykh Zavedenii, Seriya Teknologiya Tekstil'noi Promyshlennosti, Vol. 267, No 3, pp. 10-13. eid=2-s2.0-0038128574

Stalevich, A.M., Makarov, A.G., Saidov, E.D. (2002b) Elastic components in the stress/strain curve for a synthetic fibre yarn. Izvestiya Vysshikh Uchebnykh Zavedenii, Seriya Teknologiya Tekstil'noi Promyshlennost $i$, Vol. 268, No 4-5, pp. 15-18. eid=2-s2.0-0037742684

Stalevich, A.M., Makarov, A.G., Saidov, E.D. (2003) Relaxation spectrometry of synthetic yarns. Izvestiya Vysshikh Uchebnykh Zavedenii, Seriya Teknologiya Tekstil'noi Promyshlennosti, Vol. 270, No 1, pp. 16-22. eid=2-s2.0-2642532049

Vasil'eva, M.A., Feit, S. (2016) Investigation of polymer material of the working camera-channel of the magnetic pumps for heavy oil. Journal of Mining Institute, 221, p. 651. DOI: 10.18454/pmi.2016.5.651 


\title{
Increasing the corrosion resistance of tubular furnace elements at temperature range $400-700^{\circ} \mathrm{C}$ in accelerated testing for real operational conditions
}

\author{
Bashar Issa \\ PhD student, Faculty of Mineral Raw Materials Processing, Saint-Petersburg Mining University, Saint- \\ Petersburg, Russia \\ Vladimir Yu. Bazhin \\ Doctor of Engineering, Professor, Saint-Petersburg Mining University, Saint-Petersburg, Russia \\ Tatiana A. Aleksandrova \\ Candidate of Engineering Sciences, Saint-Petersburg Mining University, Saint-Petersburg, Russia
}

\begin{abstract}
The presence of impurities in the crude oil especially trace metals and chlorides are the primary responsible for the deterioration of the coiled-pipes of the tubular furnaces, and therefore for their premature failure. Mainly as a result of the acceleration of different types of corrosion processes in addition to the catalyst poisoning reaction. The small quantities of such these impurities which are existed in the heavy crude oils are large enough to cause significant industrial problems annually, environmental hazards and economic losses. Coiled-pipes of tubular furnaces are subject to extreme operating conditions from the prolonged exposure to the high temperatures and the aggressive environments on their alloys, because of these types of furnaces are constantly working ( 24 hours a day -7 days a week). The inevitable consequences for the coiled-pipes utilization (or other elements) of the tubular furnaces can be summarized as; the reducing of the corrosion resistance of the coiled-pipes alloys, the increasing of the tendency to unexpected coiled-pipes ruptures, releasing flammable materials, fires, explosions, injuries and unfortunately deaths. As long as corrosion is the most dangerous process, which can negatively affect the elements of the tubular furnaces and especially on the coiled-pipes, this research is devoted to find a solution for very important industrial problem of the premature failure of the coiled-pipes of the tubular furnaces of the dewatering and desalting installation at oil refinery "ELOY» which is located in Syria by using two furnaces to make a closed small-scale heating cycle with temperature range 400 $700^{\circ} \mathrm{C}$. Role of different kinds of chlorides which are existed in the Syrian heavy crude oil is carefully studied due to their high concentrations; accordingly, a whole mechanism for chloride corrosion cycle inside the coiled-pipes of tubular furnaces is suggested. Roles of trace metals which are existed in the Syrian heavy crude oil are also studied in deep in addition to their possible roles in the resulting corrosion types. The responsible mechanisms for each type of corrosion are proposed too.
\end{abstract}

\section{GENERAL INSTRUCTIONS}

\subsection{Introduction}

After an accident occurred at the studied oil refinery in Syria because of the corrosion of the coiled-pipes of the tubular furnace, this led to cease the production for few months, which led to import of oil-products from abroad, which in turn exacerbated the economic burden. Scientific research about corrosion and corrosion resistance at temperature range $400-700^{\circ} \mathrm{C}$ and 
about the role of trace metals which are existed in both phases of crude oil on scales and deposits forming (corrosion products) in the inner surface of the coiled-pipes of the tubular furnace are almost rare in the literatures, which reflects the importance of this research.

Spontaneous physicochemical destruction and premature failure of the coiled-pipes of the tubular furnaces at oil refineries, leading to irretrievable loss of their alloys, due to their chemical or electrochemical interaction with the flowing crude oil can be defined as corrosion. As a result of the corrosion processes, the inner surface of the coiled-pipes is visibly destroyed (Saakyan et al. 1982, Isaev1997 \& Goldobina et al. 2019, Ivanik et al. 2017). A large amount of crude oil as well as natural gas is lost annually from through defects and the premature failures in oil- and/or gas-pipelines and coiled-pipes of tubular furnaces, which leads to environmental pollution, emergency situations, oil and/or gas shortages to consumers, and penalties (Bakesheva et al. 2019). For the purpose of coiled-pipes, trunks and oil and/or gas pipelines safe operation, two types of wall metal anticorrosion protection can be generally used - the passive (insulation coating) protection and the active (electrochemical) protection (Tsenev et al. 2017). Corrosion processes require annually huge repair and maintenance expenses to the oil, gas and petrochemical industry (Bobritsky \& Yufin 1988, Kondrasheva et al. 2014 \& Volovikov 2010), which can cause serious injuries and unfortunately deaths, explosions, fires, catastrophic disasters, environmental pollution and economical losses every year; due to the mutual effect of both crude oil impurities and the temperature on the coiled-pipes of the tubular furnaces (Alekseev \& Smirnov 1955, Alekseev 1972 \& Baratov et al. 1990).

Syria is a relatively small oil producer, according to global or even regional standards, that accounted for just $0.5 \%$ of the global production in 2010, falling to less than $0.05 \%$ by 2016 according to the International Monetary Fund, i.e. the Syrian oil production has fallen by ten times in six years due to the consequences of the devastating war, the accompanying international sanctions and the deterioration of installations and equipments.

\subsection{Aims of study}

The aims of this research are: to determine the possible roles of metals and/or metallic components in the crude oil on the severe corrosion at the studied temperature range; to determine the most possible corrosion types; and to determine the effectiveness of a specific inhibitor in reducing the corrosion rate of the coiled-pipe of tubular furnaces.

\subsection{Used methods}

Chemical analysis for determination the metals content in Syrian heavy crude oils is done by burning the Syrian heavy crude oil sample and then by analyzing the obtained carbon residual by using sequential X-ray fluorescence spectrometer XRF-1800; Chemical and microstructural analysis for determination the metals content in coiled-pipes is done by using an analytical scanning electron microscope - VEGA3 TESCAN; X-ray microanalysis for the determination of phase's composition in coiled-pipe is done by using oxford INCA energy EDS; Determination of corrosion ability of the coiled-pipe and the effectiveness of studied inhibitor in reducing the corrosion rate of the coiled-pipes at the studied temperature range is done by using weight loss method.

\section{RESULTS}

\subsection{Closed small-scale heating cycle}

The closed small-scale heating cycle consists of four basic elements, as shown in Figure 1: horizontal tube furnace, pump (air-cooled thermic fluid pump - AT. DIN24256), silit (silicon carbide) furnace and system filling valve (VF06 Sealed System Filling Valve). Inside the horizontal (ceramic) tube furnace (with the dimensions $30 \mathrm{~cm}$ (length)* $3.3 \mathrm{~cm}$ (diameter)), we put 


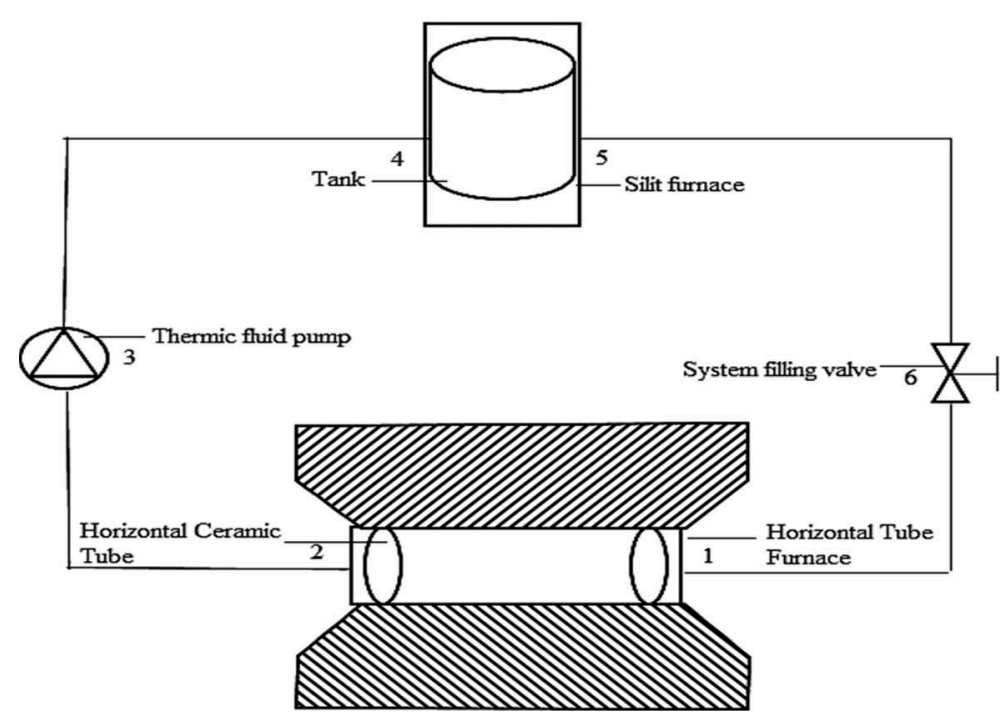

Figure 1. Closed small-scale heating cycle.

a stainless steel tube (AISI 321 grade) (with the dimensions $30 \mathrm{~cm}$ length $* 2.8 \mathrm{~cm}$ diameter $*$ $0.5 \mathrm{~cm}$ thickness) and inside this stainless tube we fixed a coupon (with the dimensions $3 \mathrm{~cm}$ length $* 1 \mathrm{~cm}$ width $* 0.5 \mathrm{~cm}$ thickness) from the same alloy of the coiled-pipe of the tubular furnace between two obstacles (barriers/pieces) of the same alloy of the stainless steel alloy in order to stay in the horizontal (ceramic) tube and not to move with circulating (flowing) emulsion. Inside the silit furnace (heating camera with the dimensions $250 \mathrm{~mm}$ height $* 160 \mathrm{~mm}$ length $* 160 \mathrm{~mm}$ width), we put tank (with the dimensions $23 \mathrm{~cm}$ height $* 14 \mathrm{~cm}$ length $* 14 \mathrm{~cm}$ width) and we put inside the tank $4 \mathrm{~L}$ of the flowing emulsion. The flowing emulsion consists of a mixture of laboratory prepared salt electrolyte $(90 \%=3.6 \mathrm{~L})$ (with the composition shown in the Table 5) and Syrian heavy crude oil $(10 \%=400 \mathrm{~mL})$ ) (with metal composition shown in the Table 4). The two furnaces were set at the same studied temperature. Tests were performed with and without the studied inhibitor by applying weight loss method.

The surface of each coupon was abraded mechanically with (320, 400 and 600) grades of $\mathrm{SiC}$ (silicon carbide) abrasive paper, washed with distilled water, dried with clean tissue paper, immersed in ethanol, dried with clean tissues paper and weighted before and after the experiment, then the weight loss was determined. The corrosion rate and the effectiveness of the inhibitor in reducing the corrosion rate were calculated by using the following equation:

$$
\begin{gathered}
C R_{i}, m d d=\frac{\Delta m, g}{A, C m^{2} \cdot t, \sec }\left(10^{5}\right)(86400) \\
\%_{i}=\frac{C R_{0}-C R_{i}}{C R_{0}}(100)
\end{gathered}
$$

Where: $\mathrm{CR}_{\mathrm{i}}$ - Corrosion rate with the studied inhibitor; $\mathrm{CR}_{0}-$ Corrosion rate without inhibitor; $\mathrm{mdd}=\mathrm{mg} / \mathrm{dm}^{2} /$ day; $\Delta \mathrm{m}-$ Weight loss of the coupon of the coiled-pipe; $\mathrm{A}-$ Surface area of the coupon; $\% \%_{i}$ - Inhibitor effectiveness in reducing the corrosion rate.

The studied emulsion enters the stainless-steel tube at point 1 , which is placed inside the horizontal tube furnace, where the coupon of the coiled-pipe is fixed between two obstacles of the same alloy of the stainless steel. The emulsion exits from the stainless-steel tube at point 2 to enter the thermic fluid pump at point 3 in order to continue to reach the silit furnace to enter the tank at point 4 and to exit at point 5 to continue to enter the filling valve at point 6 . All the connecting lines were made of thick wall copper tubing. 
The two furnaces ensure that the temperature of the flowing emulsion will be constant inside the stainless-steel tube, where the coupon is placed in. The filling valve (VF06 Sealed System Filling Valve) and the thermic fluid pump (AT. DIN24256) control the flow through the stainless-steel tube (flow rate $1 \mathrm{~L} / \mathrm{min}$ ) and to assure proper performance of the closed small-scale heating cycle. The filling valve for closed heating systems (VF06) is a combinationfilling valve for sealed heating systems, incorporating a pressure-reducing valve, stop valve, a non-return valve and hose connections. The thermic fluid pump -(AT. DIN 24256) with no additional cooling required (air-cooled).

It should be noted that the composition of the flowing emulsion under the experimental condition is $90 \%$ laboratory prepared salt electrolyte: 10\% heavy Syrian crude oil, while the percentage of the formation water (salt electrolyte) of the flowing emulsion under the real operative condition inside the coiled-pipes of the tubular furnace is only $0.5 \%$ formation water according to the Syrian standards (and according to the Russian requirements $0.2 \%$ formation water), because of that; the real corrosion rates can be calculated by multiplying the accelerated corrosion rates by $0.5 / 90$ for the Syrian requirements (and by $0.2 / 90$ for the Russian requirements).

The cause of use laboratory prepared salt electrolyte instead of the formation water and the cause of use the ratio (90\% laboratory prepared salt electrolyte: $10 \%$ heavy Syrian crude oil) instead of the ratio ( $99.5 \%$ heavy Syrian crude oil: $0.5 \%$ formation water (salt electrolyte)) are due to two reasons: Firstly, to accelerate the process of corrosion, since the effectiveness of the studied inhibitor in reducing the corrosion rate will not change. Secondly, to follow the safety procedures because the crude oil is a flammable liquid and the experiments required high temperatures.

\subsection{Microstructure and elemental composition of coiled-pipe}

The alloy grade of coiled-pipes of tubular furnaces which is used in the studied oil refinery is «10X17H13M2T» - austenitic steel, its chemical composition is shown in Table 1.

The structure of the coiled-pipe is shown under the scanning electron microscope in spectra, as shown in figures (2 - For non-affected (clean) areas (sites), without any signs of corrosion and 3 - For affected (corroded) (transitional) areas (sites)) and their composition are shown in tables (2 and 3 ).

Table 1. Chemical composition of steel «10X17H13M2T».

\begin{tabular}{llllllllll}
\hline $\mathrm{C}, \%$ & $\mathrm{Si}, \%$ & $\mathrm{Mn}, \%$ & $\mathrm{Ni}, \%$ & $\mathrm{~S}, \%$ & $\mathrm{P}, \%$ & $\mathrm{Cr}, \%$ & $\mathrm{Mo}, \%$ & $\mathrm{Cu}, \%$ & $\mathrm{Fe}, \%$ \\
\hline$\leq 0.1$ & $\leq 0.8$ & $\leq 2$ & $12-14$ & $\leq 0.02$ & $\leq 0.035$ & $16-18$ & $2-3$ & $\leq 0.3$ & Balance \\
\hline
\end{tabular}

Table 2. Analytical composition of eight spectra of coiled-pipe in non-affected (clean) areas (sites).

\begin{tabular}{lllllllll}
\hline № Spectrum & $\mathrm{O}, \%$ & $\mathrm{Si}, \%$ & $\mathrm{Ni}, \%$ & $\mathrm{Mn}, \%$ & $\mathrm{Mo}, \%$ & $\mathrm{Cr}, \%$ & $\mathrm{Fe}, \%$ & Total \\
\hline Spectrum 1 & 1.01 & 0.2 & 9.18 & 0.1 & 0.61 & 8.54 & 80.36 & 100 \\
Spectrum 2 & 0.25 & 0.44 & 6.41 & 0.54 & 1.25 & 11.39 & 79.72 & 100 \\
Spectrum 3 & 0.36 & 0.59 & 10.25 & 1.05 & 0.96 & 14.11 & 72.68 & 100 \\
Spectrum 4 & 1.95 & 0.32 & 12.15 & 0.35 & 2.01 & 13.56 & 69.66 & 100 \\
Spectrum 5 & - & 0.41 & 9.73 & 0.12 & 1.85 & 11.03 & 76.86 & 100 \\
Spectrum 6 & 2.47 & 0.26 & 4.26 & 1.36 & 1.31 & 14.73 & 75.61 & 100 \\
Spectrum 7 & - & 0.11 & 7.12 & 0.34 & 0.31 & 12.67 & 79.45 & 100 \\
Spectrum 8 & 1.65 & 0.61 & 11.54 & 0.21 & 0.97 & 11.93 & 73.09 & 100 \\
Min. & - & 0.11 & 4.26 & 0.1 & 0.31 & 8.54 & 69.66 & \\
Max. & 2.47 & 0.61 & 12.15 & 0.54 & 2.01 & 14.73 & 80.36 & \\
\hline
\end{tabular}


Table 3. Analytical composition of three spectra of coiled-pipe in affected (corroded) (transitional) areas.

\begin{tabular}{llllllllllllll}
\hline & $\begin{array}{l}\mathrm{Fe} \\
\%\end{array}$ & $\begin{array}{l}\mathrm{V} \\
\%\end{array}$ & $\begin{array}{l}\mathrm{Cl} \\
\%\end{array}$ & $\begin{array}{l}\mathrm{O} \\
\%\end{array}$ & $\begin{array}{l}\mathrm{Mn} \\
\%\end{array}$ & $\begin{array}{l}\mathrm{Cr} \\
\%\end{array}$ & $\begin{array}{l}\mathrm{Co} \\
\%\end{array}$ & $\begin{array}{l}\mathrm{Ni} \\
\%\end{array}$ & $\begin{array}{l}\mathrm{Cu} \\
\%\end{array}$ & $\begin{array}{l}\mathrm{Zn} \\
\%\end{array}$ & $\begin{array}{l}\mathrm{Sn} \\
\%\end{array}$ & $\begin{array}{l}\mathrm{Si} \\
\%\end{array}$ & $\begin{array}{l}\mathrm{S} \\
\%\end{array}$ \\
\hline Spec.11 & 7.85 & 11.24 & 4.13 & 4.58 & - & 0.73 & - & 22.96 & 41.37 & 2.14 & 4.39 & 0.61 & - \\
Spec.12 & 3.98 & - & - & - & - & - & 0.82 & 37.64 & 50.21 & 5.5 & 1.86 & - & - \\
Spec.15 & 7.84 & 13.43 & 9.71 & 5.01 & 1.36 & 2.61 & 17.03 & 20.05 & 21.76 & 1.25 & 11.39 & 0.57 & 0.63 \\
Min. & 3.98 & - & - & - & - & - & - & 20.05 & 21.76 & 1.25 & 1.86 & - & - \\
Max. & 7.85 & 13.43 & 9.71 & 5.01 & 1.36 & 2.61 & 17.03 & 37.64 & 50.21 & 5.5 & 11.39 & 0.61 & 0.63 \\
\hline
\end{tabular}

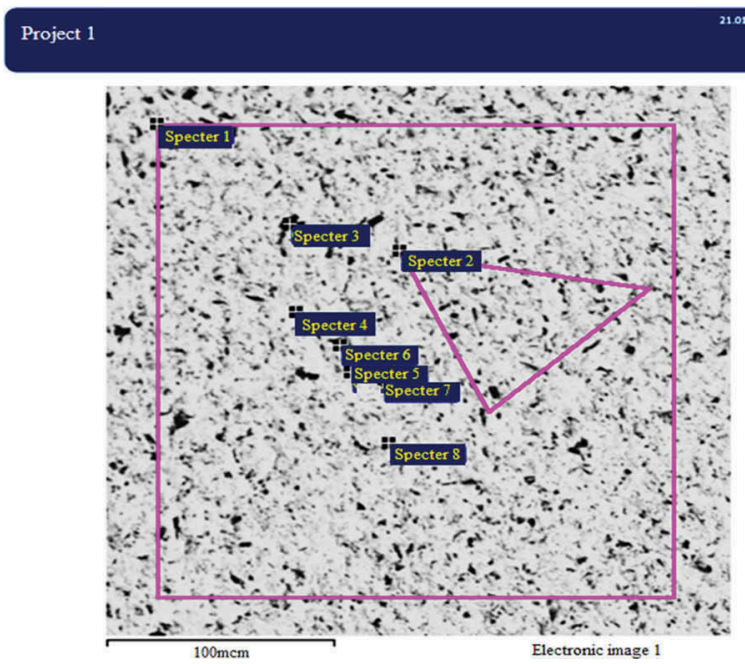

Figure 2. Electronic image-position of eight spectra of coiled-pipe in non-affected area — scale 1: 100.

In Figure 3 the left side is the material of the coiled-pipe, and the right side is the scale, formed as a result of the long stay of the coiled-pipes under the influence of the burners of the tubular furnace in addition to the effects of different types of corrosion processes. Between the material of the coiled-pipe and the resulting scale there is the transitional zone of corrosion.

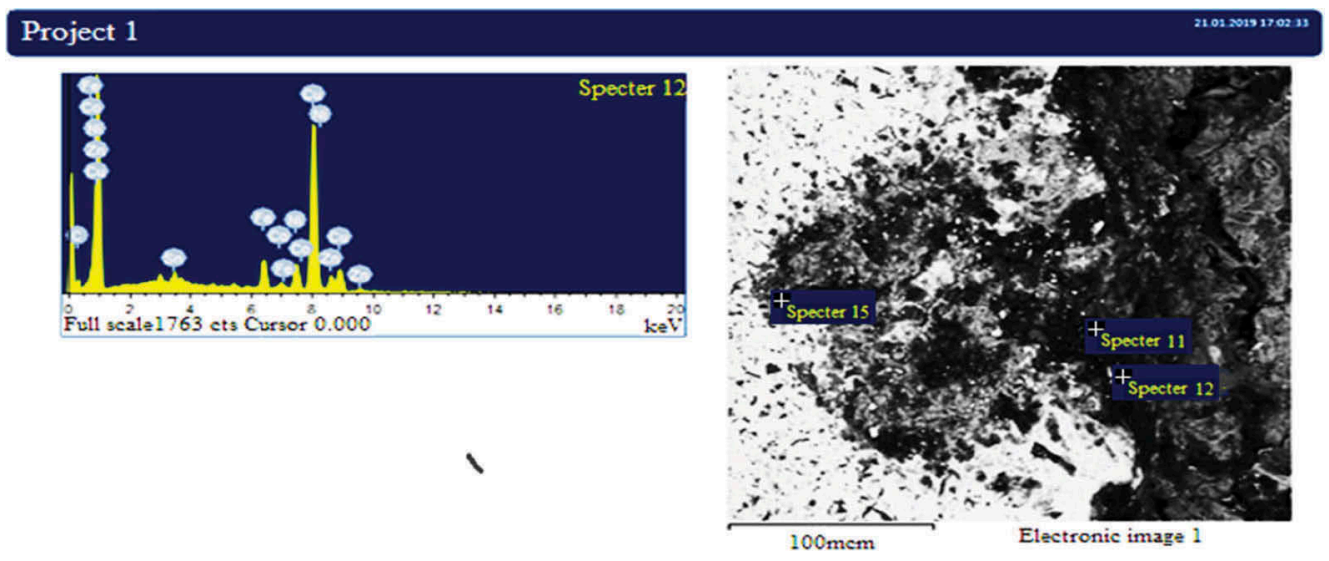

Figure 3. Electronic image-position of three spectra of coiled-pipe in affected (transitional) zone scale 1: 100 . 


\subsection{Trace metals in Syrian heavy crude oil}

$6.0259 \mathrm{~g}$ of Syrian heavy crude oil was placed in a crucible, the crucible was placed inside the heating chamber of the silit furnace, where the Syrian heavy crude oil was burned at $350^{\circ} \mathrm{C}$ and the furnace was turned-off immediately after the self-ignition is stopped, the crucible was kept inside the turned-off furnace to cool down to room temperature, after that it weighted again and the weight of the carbon residual was $1.1451 \mathrm{~g}$, the weight percentages of the elements inside the carbon residual was analyzed by XRF as shown in Table 4.

Where: $\% \mathrm{M}_{\mathrm{C}}-$ Weight percentage of element in the carbon residual; $\% \mathrm{M}_{0}-$ Weight percentage of element in crude oil.

\subsection{Corrosion experiments}

Inorganic salt precipitation is one of the main problems in oilfield operations and many factors can affect scale and fouling formation and their inhibition (Khormali et al. 2018). The availability of abrasive sand particles in the flowing crude oil inside the coiled pipes of the tubular furnaces is considered to be a factor that contribute to the emergence of grooving corrosion (Popov et al. 2019). To prevent the destruction processes and premature failures for reliable operation of oil and coiled-pipes, tanks and oil and/gas pipelines caused by metal corrosion some solutions are needed (Sultanbekov et al. 2019). Using of coiled-pipes made of high-strength composite corrosion resistant materials it must be an intuitive solution (Nikolaev et al. 2017). For an example, using of Ni-resist cast-iron alloys for critical elements of tubular furnaces operating in oil refineries (Bevza et al. 2018) should be a wise decision. Despite the development of corrosion-resistant alloys over the past few decades, cheap and nonresistant alloys are still used in oil, gas and petrochemical industries (Alec 2010 \& Nesic 2005) especially in Syria - taking into account the bad economic circumstances as a result of the war consequences - then the only possible way to protect the coiled-pipes of tubular furnace is by adding a corrosion inhibitor, (Achour et al. 2010 \& Jevremović et al. 2013).

Corrosion experiments on coiled-pipes coupons were made by using an emulsion $(90 \%$ laboratory prepared salt electrolyte: $10 \%$ Syrian heavy crude oil). The laboratory prepared salt electrolyte $(\mathrm{pH}=5.5)$ having the composition which is shown in Table 5 is used; firstly, without inhibitor, and secondly, with the studied inhibitor (SNPCH-6030«b») in three

Table 4. Metal content in Syrian heavy crude oil.

\begin{tabular}{lll}
\hline Element & $\% \mathrm{M}_{\mathrm{C}} * 10^{4}$ & $\% \mathrm{M}_{0} * 10^{4}$ \\
\hline $\mathrm{S}$ & 5.42 & 1.03 \\
$\mathrm{~V}$ & 94.19 & 17.90 \\
$\mathrm{Ni}$ & 41.99 & 7.98 \\
$\mathrm{Fe}$ & 30.89 & 5.87 \\
$\mathrm{Zn}$ & 19.84 & 3.77 \\
$\mathrm{Mn}$ & 14.05 & 2.67 \\
$\mathrm{Cu}$ & 4.79 & 0.91 \\
$\mathrm{~Pb}$ & 3.68 & 0.70 \\
$\mathrm{Co}$ & 3.31 & 0.63 \\
$\mathrm{Cr}$ & 2.74 & 0.52 \\
$\mathrm{C}$ & balance & balance \\
\hline
\end{tabular}

Table 5. The composition of the laboratory prepared salt electrolyte.

\begin{tabular}{llllll}
\hline Chem. compounds & $\mathrm{NaCl}$ & $\mathrm{MgCO}_{3}$ & $\mathrm{CaCl}_{2}$ & $\mathrm{MgSO}_{4}$ & $\mathrm{HCl}$ \\
\hline $\mathrm{C}, \mathrm{M}$ & $8.5\left(10^{-3}\right)$ & $1.6\left(10^{-6}\right)$ & $5.5\left(10^{-4}\right)$ & $5.7\left(10^{-4}\right)$ & $3.2\left(10^{-6}\right)$ \\
\hline
\end{tabular}


different concentrations 100ppm, 150ppm and 200ppm. The main characteristics of this inhibitor are shown in Table 6.

- Influence of the temperatures on the accelerated corrosion rates (table 7):

From Figure 4, we can notice that at the lowest studied temperature $400^{\circ} \mathrm{C}$, the curves are so close to each other because of the relatively close accelerated corrosion rates. By increasing the temperature, the curves move away from each other because of the diverging accelerated corrosion rates. The highest differential corrosion rates are recorded at the highest temperature $700^{\circ} \mathrm{C}$.

- Influence of the inhibitor concentrations on the accelerated corrosion rates (Table 8):

Table 6. The main characteristics of the used inhibitor (SNPCH$6030 \ll \mathrm{b} »)$.

\begin{tabular}{ll}
\hline Parameter & Parameter value \\
\hline Mass fraction of active substance, $\%$ & $33-37$ \\
Mass fraction of phosphorus, $\%$ & $0.15-0.32$ \\
Mass fraction of nitrogen, $\%$ not less than & 0.13 \\
Pour point, ${ }^{\circ} \mathrm{C}$ not higher than & -50 \\
\hline
\end{tabular}

Table 7. The relationship between the temperatures and the accelerated corrosion rates.

\begin{tabular}{llll}
\hline $\mathrm{T},{ }^{\circ} \mathrm{C}$ & $\mathrm{CR}_{\mathrm{i}}, \mathrm{mdd}\left(10^{5}\right)-100 \mathrm{ppm}$ & $\mathrm{CR}_{\mathrm{i}}, \mathrm{mdd}\left(10^{5}\right)-150 \mathrm{ppm}$ & $\mathrm{CR}_{\mathrm{i}}, \mathrm{mdd}\left(10^{5}\right)-200 \mathrm{ppm}$ \\
\hline 400 & 43128.75 & 32053.02 & 12985,3 \\
500 & 89582,74 & 43073,15 & 18884,4 \\
600 & 115533,14 & 59817,07 & 16176,03 \\
700 & 151752,20 & 103168,4 & 19373,14 \\
\hline
\end{tabular}

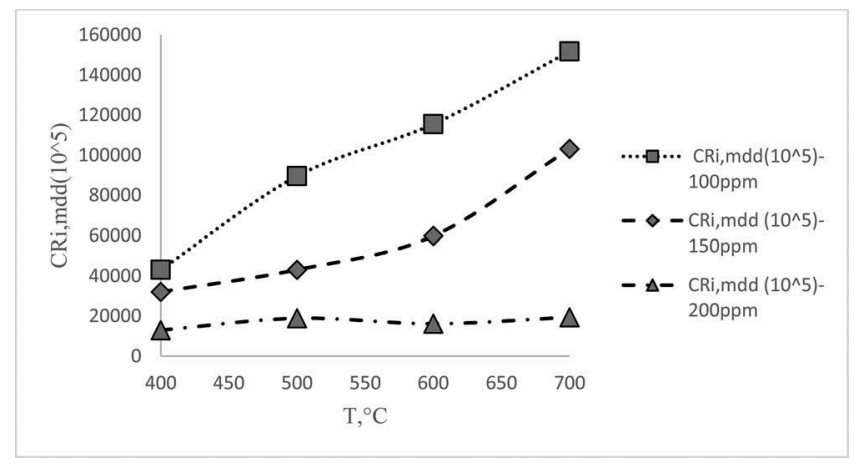

Figure 4. The relationship between the temperatures and the accelerated corrosion rates.

Table 8. The relationship between the inhibitor concentrations and the accelerated corrosion rates.

\begin{tabular}{lllll}
\hline (i),ppm & $\mathrm{CR}, \mathrm{mdd}\left(10^{5}\right)-400^{\circ} \mathrm{C}$ & $\mathrm{CR}, \mathrm{mdd}\left(10^{5}\right)-500^{\circ} \mathrm{C}$ & $\mathrm{CR}, \mathrm{mdd}\left(10^{5}\right)-600^{\circ} \mathrm{C}$ & $\mathrm{CR}, \mathrm{mdd}\left(10^{5}\right)-700^{\circ} \mathrm{C}$ \\
\hline 0 & 71623,31 & 153158,02 & 207651,24 & 301293,01 \\
100 & 43128,75 & 89582,74 & 115533,14 & 151752,20 \\
150 & 32053,02 & 43073,15 & 59817,07 & 103168,4 \\
200 & 12985,3 & 18884,4 & 16176,03 & 19373,14 \\
\hline
\end{tabular}


From the Figure 5, it can be seen that the accelerated corrosion rate decreases with the increasing of the inhibitor concentration. In general, as the temperature increases, the corrosion rate (with/without inhibitor) increases; these increases of the corrosion rates are increased by decreasing inhibitor concentration to reach the maximum corrosion rates without the inhibitor at all studied temperatures, comparing with the accelerated corrosion rates with inhibitor, which indicates that the studied inhibitor (SNPCH-6030 «b») has an effective role in slowing down the corrosion of the coiled-pipes.

In the range of inhibitor concentration $(0-100 \mathrm{ppm})$, the accelerated corrosion rate is reduced linearly for the four studied temperatures $\left(400^{\circ} \mathrm{C}, 500^{\circ} \mathrm{C}, 600^{\circ} \mathrm{C}\right.$ and $\left.700^{\circ} \mathrm{C}\right)$ with their slopes $\left(-28494.56\left(10^{-5}\right),-63575.28\left(10^{-5}\right),-92118.1\left(10^{-5}\right)\right.$ and $\left.-149540.81\left(10^{-5}\right)\right)$ respectively. The $700^{\circ} \mathrm{C}$-line inside the linear range $(0-100 \mathrm{ppm}$ inhibitor concentration) decreases more rapidly by $\left[-149540.81\left(10^{-5}\right) /-28494.56\left(10^{-5}\right)=\right] 5.2$ times, and $600^{\circ} \mathrm{C}$-line by [-92118.1 $\left(10^{-5}\right) /-$ $\left.28494.56\left(10^{-5}\right)=\right] 3.2$ times, and $500^{\circ} \mathrm{C}$-line by $\left[-63575.28\left(10^{-5}\right) /-28494.56\left(10^{-5}\right)=\right] 2.2$ times by comparison with $400^{\circ} \mathrm{C}$-line.

- Influences of inhibitor concentrations on the inhibitor effectiveness in reducing the accelerated corrosion rates (Table 9):

As shown from Table 9, the highest inhibitor effectiveness in reducing the accelerated corrosion rate was recorded for $200 \mathrm{ppm}$ inhibitor concentration, at $400^{\circ} \mathrm{C}$ was $81.87 \%$, while was $87.67 \%$ at $500^{\circ} \mathrm{C}$, and was $92.21 \%$ at $600^{\circ} \mathrm{C}$, and was $93.57 \%$ at $700^{\circ} \mathrm{C}$ (which is the highest inhibitor effectiveness ever recorded while the lowest inhibitor effectiveness ever recorded is $39.8 \%$ for $100 \mathrm{ppm}$ inhibitor at $400^{\circ} \mathrm{C}$ ).

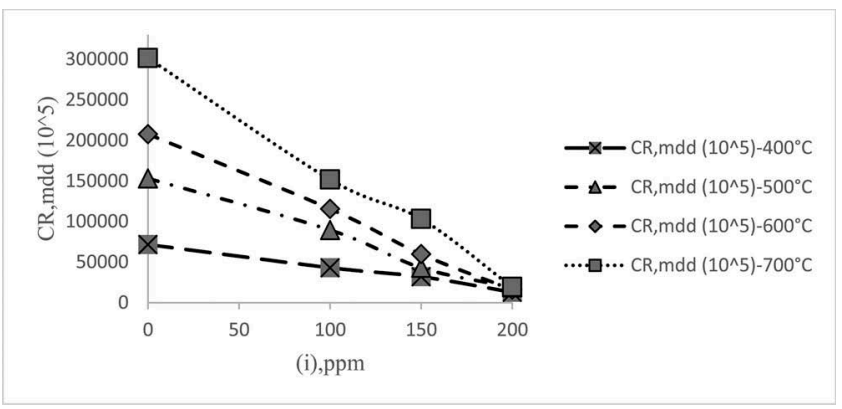

Figure 5. The relationship between the inhibitor concentrations and the accelerated corrosion rates.

Table 9. Impact of temperature on the relationship between inhibitor concentrations and inhibitor effectiveness.

\begin{tabular}{llll}
\hline $\mathrm{T},{ }^{\circ} \mathrm{C}$ & ${ }{ }_{100 \mathrm{ppm}}$ & ${ }{ }_{150 \mathrm{ppm}}$ & ${ }{ }_{200 \mathrm{ppm}}$ \\
\hline 400 & 39.8 & 55.2 & 81.87 \\
500 & 41.5 & 71.9 & 87.67 \\
600 & 44.4 & 71.2 & 92.21 \\
700 & 49.6 & 65.7 & $\mathbf{9 3 . 5 7}$ \\
\hline
\end{tabular}




\section{RESULTS INTERPRETATION}

Taking into consideration that «ELOU» installation - electrical desalting and dewatering installation, $\mathrm{NaOH}$ and $\mathrm{NH}_{3}$ are added in «ELOU» installation before heat exchangers by $(2-4 \%)$ of the amount of crude oil to be refined individually and separately. $\mathrm{NaOH}_{(1)}$ is added to the «ELOU» installation (as anti-hydrolysis agent) to control $\mathrm{HCl}_{(\mathrm{l})}$ (hydrochloric acid) by converting acidic metal chlorides salts (especially $\mathrm{CaCl}_{2}$ and $\mathrm{MgCl}_{2}$ ) to $\mathrm{NaCl}$ and by converting $\mathrm{HCl}_{(1)}$ (hydrochloric acid) - which is generated from the hydrolysis process of the acidic chlorides salts - to $\mathrm{NaCl} . \mathrm{NH}_{3(\mathrm{~g})}$ is added to the «ELOU» installation (as a neutralizer) to control $\mathrm{HCl}_{(\mathrm{g})}$ (hydrogen chloride) by converting $\mathrm{HCl}_{(\mathrm{g})}$ into $\mathrm{NH}_{4} \mathrm{Cl}_{(\mathrm{s})}$. It should be noted that the amount of ammonia should be controlled carefully because: the under-dosing of $\mathrm{NH}_{3(\mathrm{~g})}$ amount can lead to acid corrosion, while over-dosing of $\mathrm{NH}_{3(\mathrm{~g})}$ can cause localized underdeposit corrosion, because the excessive formation of $\mathrm{NH}_{4} \mathrm{Cl}_{(\mathrm{s})}$ salt, which can cause fouling and later sublimation, and the cycle goes on.

\subsection{Role of chlorides}

The chlorides are always existed in the crude oil (water-in-oil type emulsion), which are considered one of the most dangerous and aggressive components at the studied temperature range, because of the high conductivity of chlorides and therefore of their high tendency to form more stable emulsion, which can lead to presence higher concentrations of chlorides in the dewatered and desalted crude oil after the «ELOU» installation, this possible functional failure or at least low efficiency of the «ELOU» installation definitely can accelerate the corrosion rate of the coiled-pipe leading to the premature failure. Because of that, the corrosion control in the tubular furnaces of «ELOU» installation is very difficult to achieve. The following points can explain the possible roles of chlorides:

- Role of inverse solubility salts

It is a well-known fact that by increasing the temperature, the dissolution of all salts, which are existed in the flowing emulsion inside the coiled-pipes, can be increased but their solubility at the studied temperature range is determined only by Le Chatelier's principle. Calcium and magnesium salts can play a role in the deterioration of the coiled-pipe because of their inverse solubility, which can lead to their sedimentation, which in turn can lead to form hard impermeable scale that eventually can lead to overheating and burning-out (thermal failure) of the coiled-pipes of the tubular furnace.

- Role of acidic salts

Acidic salts like chlorides (in the first place) and sulfates (in the second place) are harmful due to their hydrolysis processes at the studied temperature range to their derivatives acids, which can lead to increase the local acidity of the medium, which in turn can lead to severe local corrosion in the forms of deep pits, crevices and cracks (Rogachèv \& Mukhametshin 2018).

\section{- Role of volatile metallic chlorides}

The $\mathrm{HCl}_{(\mathrm{g})}$ (hydrogen chloride) in the coiled-pipes at the studied temperature range can cause localized corrosion as a result of the formation and sublimation of volatile metallic chlorides, especially iron chloride and copper chloride $\mathrm{FeCl}_{3}=318.4^{\circ} \mathrm{C}, \mathrm{CuCl}_{2}=523.6^{\circ} \mathrm{C}$ (Maier 1925).

\section{- Role of molten metallic chlorides}

In spite of molten metallic chlorides are corroding salts and strong ionic electrolytes, which can play an effective role in the electrochemical corrosion but this role is secondary at the studied temperature range $\left(400-700^{\circ} \mathrm{C}\right)$ due to their higher melting temperatures (melting point of metallic chlorides $\mathrm{MgCl}_{2}=714^{\circ} \mathrm{C}, \mathrm{KCl}=772^{\circ} \mathrm{C}=\mathrm{CaCl}_{2}, \mathrm{NaCl}=808^{\circ} \mathrm{C}$ ) (Maier1925).

\section{- Possible mechanism of the chloride corrosion cycle}

The most common source of $\mathrm{HCl}_{(\mathrm{g})}$ vapor/condensate inside the coiled-pipes of tubular furnace comes from hydrolysis process of acidic chloride salts. Eventually all chloride salts in 
crude oil will be converted to hydrogen chloride $\mathrm{HCl}_{(\mathrm{g})}$ as a result of the high temperature and hydrolysis processes inside the coiled-pipes of the tubular furnace. $\mathrm{NaCl}$ is more common in desalted crude oil feeds than $\mathrm{MgCl}_{2}$ and $\mathrm{CaCl}_{2}$ but it is more resistant to hydrolysis. $\mathrm{MgCl}_{2}$ and $\mathrm{CaCl}_{2}$ start to hydrolyze above $\left(121^{\circ} \mathrm{C}\right)$ and $\left(204^{\circ} \mathrm{C}\right)$ respectively while $\mathrm{NaCl}$ is more stable and will not hydrolyze under $\left(232^{\circ} \mathrm{C}\right)$ (Bagdasarian et al. 1996, Valenzuela \& Dewan 1999 \& Kapusta et al. 2001).

Hydrogen chloride $\mathrm{HCl}_{(\mathrm{g})}$ can move quickly inside the coiled-pipes, and one part of hydrogen chloride can easily dissolve in water vapor (water condensate), resulting in local mediums with very low $\mathrm{pH}$ values it can reach to $1-1.5 \mathrm{pH}$ (Rogachèv \& Mukhametshin 2018), which can lead to dissolve the protecting films/scales or corrosion products to reach the bare metal surface and make deep pits, crevices and even cracks. The second part of hydrogen chloride can react with ammonia vapor $\mathrm{NH}_{3(\mathrm{~g})}$ to form $\mathrm{NH}_{4} \mathrm{Cl}_{(\mathrm{s})}$ ammonium hydrochloride salt (exothermic reaction). If $\mathrm{NH}_{4} \mathrm{Cl}_{(\mathrm{s})}$ salt deposits become wet, they can be very corrosive to the alloy of the coiled-pipe and cause localized under-deposit corrosion because of the hydrolysis of $\mathrm{NH}_{4} \mathrm{Cl}$. If $\mathrm{NH}_{4} \mathrm{Cl}$ salt deposits do not become wet, under the influence of the high temperatures they can be sublimated to form $\mathrm{NH}_{3(\mathrm{~g})}$ and $\mathrm{HCl}_{(\mathrm{g})}$, which lead to under-deposit corrosion (endothermic reaction). The third part of hydrogen chloride can react easily with active metals and their oxides, hydroxides, and carbonates to produce chlorides with the presence of moisture in the transitional zones or in the scales or corrosion products.

Thus, as a result, the cycle of chloride corrosion will continue endlessly and will lead eventually to total premature failure of the coiled-pipes. Since the concentrations of chlorides in the emulsion will considerably affect the corrosion rate, thus developing the suitable technology to reduce the concentration of chlorides in pre-treatment of the oil before entering the furnace will have great effect on reducing the corrosion rate.

\subsection{Role of metals}

Metals can accelerate corrosion and can also cause catalyst poisoning, fouling and catalyzing undesired side reactions. Impurities like nickel, copper and cobalt in the transitional zones are nobler metals than iron. They can play a negative role through electrochemical corrosion, especially according to their relatively high concentrations in the transitional zones (which needs further research). Vanadium compounds can form vanadium pentoxide $\mathrm{V}_{2} \mathrm{O}_{5}$, which is conditioned by oxygen availability (most of the spectra of the affected zones proved the oxygen availability of about $5 \%$ ). Vanadium pentoxide $\mathrm{V}_{2} \mathrm{O}_{5}$ has relatively low melting point $690^{\circ} \mathrm{C}$; this liquid (melted) vanadium pentoxide is strongly corrosive for the coiled-pipes alloy (Bakirova et al. 1984 \& Qasim 2017). As shown in the following reaction, where hydrochloric acid $\mathrm{HCl}_{(1)}$ is oxidized to the corresponding halogen by $\mathrm{V}_{2} \mathrm{O}_{5}$, which in turn, is reduced to ionic form of vanadium compound, thus vanadium is also responsible for the deterioration of the coiled-pipe alloy as a result of $\mathrm{V}_{2} \mathrm{O}_{5}$ forming.

$$
\mathrm{V}_{2} \mathrm{O}_{5}+6 \mathrm{HCl}+7 \mathrm{H}_{2} \mathrm{O} \rightarrow 2\left[\mathrm{VO}\left(\mathrm{H}_{2} \mathrm{O}\right)_{5}\right]^{2+}+4 \mathrm{Cl}^{-}+\mathrm{Cl}_{2}
$$

Since manganese is existed in the Syrian heavy crude oil up to more than $2.5 \mathrm{~g} / \mathrm{t}$ and in the coiled-pipe alloy up to $2 \%$, maybe it has a possible role in promoting the formation of $\mathrm{Cr}_{2} \mathrm{O}_{3}$ scale (Sudhangshu 2018) (which needs a further research). $\mathrm{Cr}_{2} \mathrm{O}_{3}$ scale which has good resistant to hot, acidic and electrochemical corrosion, but its low amount makes its role in corrosion resistance limited. Chrome (which is a corrosive-resistant metal) has high resistant for hot, acidic and electrochemical corrosion. Since coiled-pipe alloy of grade «10X17H13M2T» contains $16-18 \% \mathrm{Cr}$ and $2-3 \% \mathrm{Mo}$ as corrosion-resistant alloying elements, this alloy shows better corrosion resistance comparing with other alloys containing low content of chrome, because of the formation and accumulation of thin, chemical stable and passive oxide film of $\mathrm{Cr}_{2} \mathrm{O}_{3}$. Without chrome as an alloying element, the corrosion rates of the coiled-pipes alloy it would be much worse. However, further corrosion protection is needed for coiled-pipe alloy in the «ELOY» installation against hot, acidic and electrochemical corrosion, due to the high 
temperatures and the aggressive medium by applying inhibitor as was suggested in our research (SNPCH-6030 «b») for its considered role in slowing the corrosion rate of the coiledpipes.

\section{CONCLUSIONS}

The highest inhibitor effectiveness (SNPCH-6030 «b») in reducing the accelerated corrosion rate was recorded for $200 \mathrm{ppm}$ inhibitor concentration, at $400^{\circ} \mathrm{C}$ was $81.87 \%$, while was $87.67 \%$ at $500^{\circ} \mathrm{C}$, and was $92.21 \%$ at $600^{\circ} \mathrm{C}$, and was $93.57 \%$ at $700^{\circ} \mathrm{C}$ (which is the highest inhibitor effectiveness ever recorded while the lowest inhibitor effectiveness ever recorded is $39.8 \%$ for $100 \mathrm{ppm}$ inhibitor at $400^{\circ} \mathrm{C}$ ). Despite the positive role of chrome as an alloying element in coiled-pipe alloy to protect from corrosion but it is still not enough according to the high temperatures and the aggressiveness of the medium, because of that further corrosion protection (additional protection) is needed for coiledpipe alloy in the "ELOY» installation against hot, acidic and electrochemical corrosion by applying the studied inhibitor (SNPCH-6030 «b») as we suggested in our research for its significant role in slowing the corrosion rate of the coiled-pipes. The high contents of vanadium and chloride in Syrian heavy crude oil, in addition to the high content of nickel, copper and cobalt in the transitional zones and of course the high temperature inside the coiled-pipe of the tubular furnaces are the main reasons for the severe corrosion of the coiled-pipe which led to the premature failure. Mixed mechanism between sedimentation - sublimation and redox reactions was proposed to interpret the hot corrosion of the coiled-pipe. Mixed mechanism between dissolution - sedimentation reactions and hydrolysis reactions was proposed to interpret the acid corrosion of the coiledpipe. Mechanism of electrochemical reactions (galvanic effect) was proposed to interpret the electrochemical corrosion of the coiled-pipe in the transitional zone with the presence of nobler metals than iron, mainly in the water vapor/condensate inside the coiled-pipe and less possibly in molten salts (due to their higher melting points than the studied temperature range).

\section{REFERENCES}

Achour, M., Blumer, D., Baugh, T., Lane, C., Humble, Ph., Waters, J.,Wilcher, J.\& Hudgins, R. 2010. A novel method to mitigate top of the line corrosion in wet gas pipelines: part I - proof of concept, CORROSION, paper no. 11332 .

Alec, Groysman. 2010. Corrosion for Everybody. Springer-Verlag, Dordrecht. p 346-159.

Alekseev, M.V. 1972. Basics of fire prevention in technological processes of production. M., Higher School of the Ministry of Internal Affairs of the USSR, NIIRIO. p 89-132, 143-159.

Alekseev, M.V.\& Smirnov, V.M. 1955. Fire prevention in the technological processes connected with the circulation of flammable and flammable liquids. M.: Ministry of Communal Services of the RSFSR. $p$ $17-49$.

Bagdasarian, A., Feather, J., Hull B., Stephenson R. \& Strong, R. 1996. Crude Unit Corrosion and Corrosion Control. Corrosion/96, Paper No. 96615, NACE International, Houston, TX.

Bakesheva, A.T., Fetisov, V.G. \& Pshenin, V.V. 2019. A refined algorithm for leak location in gas pipelines with determination of quantitative parameters. International Journal of Engineering Research and Technology. Volume 12, Issue 12, Pages 2867-2869.

Bakirova, S.F.,Kotova, A.V.,Yagyayeva, S.,Fedorova, N. \& Nadirov, N.K.1984. Structural Features of Vanadyl Porphyrins of Petroleum of West Kazakhstan, Petroleum Chemistry U.S.S.R., 24, 196-202.

Baratov, A.N., Korolchenko, A.Ya. \& Kravchuk, G.N. 1990. Fire and explosion hazard of substances and materials and means of extinguishing them; M., Chemistry. p 25-39.

Bevza, V.F., Grusha, V.P. \& Krasnyy, V.A. 2018. Improvement of structure and properties of ni-resist cast-iron part blanks for mining and petroleum refining machine industry. Mining Informational and Analytical Bulletin. Vol. 2018, Issue 2, Pages156-167.

Bobritsky, N.V. \& Yufin, V.A. 1988. Basics of the oil and gas industry. M.: Nedra. p 174-189. 
Goldobina, L. A. \& Orlov, P. S. 2019. Analysis of the corrosion destruction causes in underground pipelines and new solutions for increasing corrosion steel's resistance. ZapiskiGornogoinstituta. Volume 219.

Isaev, N.I. 1997. Theory of corrosion processes. M.: Metallurgy. p 289-321.

Ivanik, S.A. \& Lyubin V, E.A. 2017. Chemical and electrochemical methods of protection from corrosion of gas and oil pipelines pipelinesand storage tanks. International Multidisciplinary Scientific GeoConference Surveying Geology and Mining Ecology Management, SGEM. Vol. 17, Issue 14, Pages579-584.

Jevremović I., Singer M., Achour M., Blumer D., Baugh T., Misković-Stanković V. \& Nešić S. 2013. A Novel Method to Mitigate the Top-of-the-Line Corrosion in Wet Gas Pipelines by Corrosion Inhibitor within a Foam Matrix. Corrosion. p 144-167.

Kapusta, S., Ooms, A., Buijis, J.W., Fan, D. \& Fort, W. 2001. Systematic Approach to Controlling Fouling and Corrosion in Crude Unit Overheads and Hydrotreater Reactor Effluents. Corrosion/01, Paper No. 01535, NACE International, Houston, TX,

Khormali, A., Sharifov, A.R. \& Torba, D.I. 2018. Increasing efficiency of calcium sulfate scale prevention using a new mixture of phosphonate scale inhibitors during waterflooding. Journal of Petroleum Science and Engineering. Vol. 164, Pages 245-258.

Kondrasheva, N. K., Dubovikov, O. A., Ivanov, I. I. \& Zyr'yanova, O. V. 2014. Preliminary preparation of oil for primary processing. ZapiskiGornogoinstituta. Volume 210.

Maier, C. G. 1925. Vapor pressures of the common metallic chlorides and a static method for high temperatures. University of Utah. Department of Metallurgical Research, Washington, D.C.: U.S. Dept. of the Interior, Bureau of Mines: U.S. Govt. Print. Off. P.53

Nesic, S. 2005. Key Issues related to modeling of internal corrosion of oil and gas pipelines - A review, 16th International corrosion congress.

Nikolaev, A.K. \& Velazquez, A.L.C. 2017. Modelling of fiberglass pipe destruction process. Journal of Mining Institute. Vol. 223, Pages 93-98.

Popov, G., Kasyanov, A., Bolobov, V. \& Krivokrysenko, E. 2019. Study of factors enabling initiation and behavior of grooving corrosion. E3S Web of Conferences. Vol. 121.

Qasim, Y Mohammed. 2017. Determination of salt content in crude oil, turbine oil and some refinery products volumetrically, Journal of Chemical and Pharmaceutical Sciences, volume 10 (issue 1).

Rogachèv, M.K. \& Mukhametshin, V. V. 2018. Control and regulation of the process of hydrochloric acid effect on the well bottom zone according to geological field data. ZapiskiGornogoinstituta. T. 231. p.275-280.

Saakyan, L.S. \& Efremov, A.P. 1982. Protection of oilfield equipment against corrosion. M.: Nedra. p $186-211$.

Sudhangshu, Bose. 2018. High Temperature Coatings (second edition). Butterworth-Heinemann. P. 416

Sultanbekov, R. \& Nazarova, M. 2019. The influence of total sediment of petroleum products on the corrosiveness of the metal of the tanks during storage. E3S Web of Conferences. Vol. 121.

Tsenev, A.N., Nosov, V.V.\& Akimova, E.V. 2017. Fault location method for unexposed gas trunk line insulation at stray current constant effect area. IOP Conference Series: Earth and Environmental Science. Vol. 87, Issue 9.

Valenzuela, D. \& Dewan A. 1999. Refinery Crude Column Overhead Corrosion Control, Amine Neutralizer Electrolyte Thermodynamics, Thermochemical Properties, and Fluid Phase Equilibria., $p$ 829-834.

Volovikov, A. Yu. 2010. Problems and prospects of the exploration of the primary oil refining. ZapiskiGornogoinstituta. Volume 186. 


\title{
Technogenic byproduct filler-based earthquake-resistant super concrete
}

\author{
M.S. Saidumov \& A.Kh. Alashkhanov \\ FSFEI HE "Millionschikov Grozny State Oil Technical University”, Grozny, Russia
}

\author{
S-A.Yu. Murtazaev \\ FSFEI HE "Millionschikov Grozny State Oil Technical University", Kh. Ibragimov Complex Institute of \\ the Russian Academy of Sciences, Grozny, Russia
}

T.S-A. Murtazaeva

Academy of Sciences of the Chechen Republic, Grozny, Russia

\begin{abstract}
The article presents an analysis of domestic and foreign experience in the production and use of high-strength concrete (HSC) and studies raw material resource base, both natural and secondary, for their production. The test results of filled binders obtained with the use of concrete scrap and brick rubble processing are given. The compositions of earthquake-resistant HSC, classified to be up to B80 in compressive strength, are obtained and the results of their tests are presented.

This work was carried out as part of research on the implementation of scientific project No. 18-48-200001 "High-quality concrete with enhanced performance properties based on local natural and secondary (processed) raw materials," which received support from the Russian Foundation for Fundamental Research (RFFR).
\end{abstract}

Keywords: High-strength concrete, super concrete, local raw materials, products of buildings and constructions demolition and dismantling, concrete scrap, brick rubble, recycling, secondary or recycled filler (sand), filled binder, concrete

\section{INTRODUCTION}

Currently, for the construction of cast-in-situ buildings and constructions, along with traditional concrete of grade B7.5-B30, new effective concrete composites are becoming widely used: highstrength, non-shrinking, expanding, straining and others, that are also made with the use of new composite or filled binders, which significantly expand the range and capacity of product units (Kaprielov et al., 2017, Bazhenov, 1995, Bazhenov et al., 2011). Specifically, according to the American Association of Cement Manufacturers, in 2012 alone, the world's leading industrial powers produced more than 13 billion cubic meters of concrete (Volkov, 2004).

It is a common knowledge that high-rise construction lead to increased demands placed on the quality of raw materials, the uniformity and stability of the compositions, the reliability and stability of the construction, etc. For concretes operating in seismically active regions, the issue of selecting the composition and designing the properties of the future composite requires even more attention. Such concretes must possess increased strength, ductility and enviable longevity (Bataev et al., 2017, Kuprina, 2014).

An analysis of scientific papers (Lesovik et al., 2012, Volodchenko et al., 2016) on highstrength concrete technology shows that their production is usually associated with the use of high-quality natural raw materials affecting the cost and increasing the energy and resource consumption of composites based on them. 
With a rational approach of using such elements as modern chemical modifiers of the concrete structure, mineral additives of various nature, as well as effective equipment for activating raw materials and homogenizing the mixture, high-strength concrete compositions based on secondary raw materials can be recommended.

First of all, concrete and reinforced concrete scrap, as well as crushed brick (rubble), which make up more than $60 \%$ of the total waste of dismantling buildings and structures, are of great interest for concrete technology (Murtazaev et al., 2009, Salamanova \& Murtazaev, 2018). According to the authors, this interest is caused by the possibility of their use as a finely ground mineral component in mixed or so-called filled binders, characterized by improved technological and physico-mechanical properties, based on which, high-strength concrete can be obtained suitable for cast-in-situ high-rise construction in seismically active regions of the country and the world.

\section{LITERATURE REVIEW}

In foreign practice, high-strength concrete (or considered to be high-strength at that time) began to appear at the beginning of the second half of the twentieth century, when concrete of classes B30 and higher began to be developed in the USA, Norway and some other countries. Later, in the 70s and 80s, analogues of modern high-strength concrete of B70-B80 compressive strength classes were known (Bazhenov et al., 2006).

Scientific works of Kim J.-K., Aitcin P.C., Skazlic M., Shi C., Talebinejad I., Strunge T., Wille K., Soutsos M., Ma J. are internationally recognised for their contribution to the development of HSC practice. Works of these researchers and of a number of other scientists, highlight the features of the technology for producing high-strength concrete and the role of mineral additives in the process of their structure formation.

According to Kim J.-K. (Kim \& Kim, 1996) and Aitcin P.C. (Aitcin, 1998) it was proved that the presence of finely dispersed fillers and additives helps to reduce the amount of portlandite and ettringite and fill capillary pores with hydration products, as a result of which a decrease in porosity and the obtainment of high concrete strength are observed.

The raw materials requirements to obtain HSC presented in the works of Aitcin P.C. (Aitcin, 1998), Skazlic M. (Skazlic \& Bjegovic, 2005) and Shi C. (Shi et al., 2015), are mainly associated with a limitation of the amount of water $(\mathrm{W} / \mathrm{C}=0.22-0.4)$, high cement content (about 450-560 kg/m3), optimization of the grain composition of aggregates (sand size modulus $\mathrm{Mk}=2.5-3$, the recommended crushed stone fraction is $10-15 \mathrm{~mm}$, the absence of flaky grains, etc.), the use of mineral fillers (finely ground additives of various nature, which reduce the porosity of cement stone), etc.

The fragility and the pattern of deterioration of high-strength concrete was investigated in the works of Richard P. and Cheyrezy M. (Richard \& Cheyrezy, 1995), where it is recommended to use fiber reinforcement in order to increase the fracture toughness of concrete. In addition, in order to obtain concrete with a strength of about $150 \mathrm{MPa}$, Cheyrezy M., Shi C. and other scientists outside of Russia suggest reducing the W/C ratio to 0.13 and argue that in this case the maximum density of the concrete composite can be achieved.

Yu.M. Bazhenov (Bazhenov, 1995), S.S. Kaprielov (Kaprielov et al., 2017), D.K.-S. Bataev (Bataev et al., 2017), V.S. Lesovik (Lesovik et al., 2012), B.C. Demyanova (Demyanova \& Gusev, 2013), V.I. Kalashnikov (Bazhenov et al., 2006), G.V. Nesvetaev (Nesvetaev et al., 2003), O.Ya. Berg (Berg et al., 2012) and others have actively contributed to the development of Russian science in the field of obtaining HSC.

Until recent times, the low demand for high-strength concrete in Russia has led to the fact that the concrete used in Russia at the end of the twentieth century secured much lower index in strength (almost 2 times) in comparison with concrete developed in the USA and Europe. The production and development of high-strength concrete in Russia is mainly associated with the development of binders of low water demand (LWD) and their modified analogues developed by Russian scientists Yu.M. Bazhenov and his students (Bazhenov et al., 2011), due to the fact that the potential for using binding ability and properties in such binders is $1.5-2.0$ 
times greater in comparison with traditional factory grinding cements. Currently, due to the development of a market economy and the development of domestic scientists in Russia, there is practically no gap in the physical, mechanical and other indicators of modern concrete used in Russia and abroad.

Kaprielov S.S., Sheinfeld A.V. and Dondukov V.G. (Kaprielov et al., 2017) studied binders for high-strength concrete and proposed optimal compositions of effective high-strength concrete for cast-in-situ construction based on the use of the MB series concrete modifier.

Works of Lesovik V.S. and his students (Lesovik et al., 2012, Volodchenko et al., 2016) develop methodological foundations for the use of energy-saving raw materials and effective technologies for the production of building composite materials, considering the genesis of the raw materials and the sustainability of the "man - material - environment" system. V.S. Lesovik is the author of a new transdisciplinary scientific field - geonics, and his scientific school solve engineering problems considering the knowledge gained during the study of natural processes and view rocks as natural analogues of building materials. Therefore, they obtained ultra-high-strength concrete using the theoretical principles of geonics and raw materials of the Kursk magnetic anomaly, which, according to the author, will be in demand in the development of the North and the Arctic, in the construction of fortifications and in the field of other anomalous conditions for the operation of materials."

Thus, the experience of researchers, both Russian and international, shows that HSC currently is and in the foreseeable future will be in great demand in the manufacture of a wide range of structural elements of civil buildings and special structures, both in earthquake-safe areas and in areas with sites for increased seismic activity (Kim \& Kim, 1996, Aitcin, 1998).

Therefore, the development of compositions of high-strength concrete based on the integrated use of secondary raw materials for their (compositions') use in concreting structural elements of high-rise cast-in-situ earthquake-resistant buildings is an urgent problem in the field of concrete technology that needs to be addressed in order to increase the efficiency of the waste recycling process resulting from dismantling buildings and structures.

\section{RESEARCH METHODS AND MATERIALS}

They are constituted by mineral fillers of technogenic nature (MFTN) for producing highquality concrete mixtures using mechanical activation and ceramic brick rubble (CBR) in a laboratory vibrating ball mill of the MV-20-EKS type to obtain a specific gravity of 450$600 \mathrm{~m}^{2} / \mathrm{kg}$. The average grinding time was $4-6$ minutes.

The chemical composition of the feedstock, as well as the macro- and microstructure of concrete samples, were studied using a Quanta 3D 200i scanning electron microscope.

The natural sand of the Chervlenskoye deposit in the Chechen Republic with the following characteristics was used as a fine aggregate: fineness modulus $\mathrm{Fm}=1.7-1.8$; the content of flour and clay particles is $1.7-1.9 \%$; void coefficient $-40.8 \%$; density $\rho_{\mathrm{s} .}=2617 \mathrm{~kg} / \mathrm{m}^{3}$; density $\rho_{\text {p. }}=1512 \mathrm{~kg} / \mathrm{m}^{3}$.

Local gravel from gravel fractions of 5-20 mm fractions of the Argun and Sernovodsky deposits of the Chechen Republic was used as a coarse aggregate.

In experimental studies, a plain Portland cement of the PC 500 D0 grade produced by the State Unitary Enterprise "Chechencement" (Chechen Republic, village of Chiri-Yurt) with normal consistency $(\mathrm{NC})=25.5 \%$, specific surface area of $3252 \mathrm{~cm}^{2} / \mathrm{g}$, water segregation (bleeding) $\leq 18 \%$ and the setting time of 2 hours and 15 minutes (start) and 3 hours 40 minutes (end) was used as a binder. The content of clinker minerals characterizing the mineralogical composition of the binder: $\mathrm{C}_{3} \mathrm{~S}=59 \% ; \mathrm{C}_{2} \mathrm{~S}=16 \% ; \mathrm{C}_{3} \mathrm{~A}=8 \% ; \mathrm{C}_{4} \mathrm{AF}=13 \%$.

Modern additives of the following manufacturers of construction chemicals were used as fluidizing agents:

1. POLYPLAST company - "Linamix PK" (liquid) superplasticizing agent (SP) and "Linamix RS" (liquid) hardening retardant based on polyoxyethylene derivatives of polymethacrylic acid; 
2. TOKAR LLC (Vladikavkaz) offers a complex multifunctional additive "D-5" (in a dry powder form) that meets the requirements of State All-Union Standard (SAUS) No. 24211-2008.

The choice between the proposed additives is due to their accessibility and cheapness, although their analogues with equal effectiveness are known in the world for instance plasticizer additives from manufacturers such as "MC-Bauchemie" ("MC-PowerFlow" hyperplasticizer based on the latest polycarboxylate ester technology MS), "Sika" company ("Sika ViscoCrete 5-600 SK" superplasticizer based on polycarboxylate esters), etc.

\section{RESULTS}

In order to obtain optimal formulations of high-strength concrete with the integrated use of the secondary raw material, compositions of filled binders (FB) with a fine-ground mineral filler of technogenic nature (MFTN - filler made of recyclables) were developed, allowing to obtain a high-strength cement stone with significantly smaller pores and less shrinkage (Table 1).

Two brands of FB with a finely ground MFTN (developed by the authors) were studied, the formulations of which are included, \% by weight:

- The brand of FB:

$\begin{array}{ll}\text { FB-75:25 } & \text { FB-60:40 } \\ 75 & 60 \\ 16 & 27 \\ 7 & 11 \\ 2 & 2\end{array}$

- PC M500 D0 «Chechencement» $75 \quad 60$

- MFTN of concrete scrap $\quad 16 \quad 27$

- Same, of CBR 7 1

- D-5 Additive 22

The compositions were developed in relation to the technology for constructing cast-in-situ bored piles of the 435-meter multi-functional high-rise complex "Akhmat Tower", erected in the city of Grozny on a site with a seismicity of 9-10 points.

Due to the fact that concrete of various strength grades (B40, B75-B80, etc.) were laid down for the design of the underground part the complex, the task of designing optimal formulations of high-strength concrete was indicated in this work, including mediumgrade concrete of compressive strength B30-B40 and high-strength - B50-B80 all of which were produced with the integrated use of secondary raw materials. At the same time, the formulations were designed to obtain highly mobile (pumpable castables) concrete mixtures with a standard cone slump of $22 \pm 2 \mathrm{~cm}$, which corresponds to the P5 workability grade, which are used in modern cast-in-situ construction field, as more efficient concrete mixtures requiring less energy for pumping through a concrete pump pipeline and subsequent vibrocompaction.

The compositions and properties of high-quality concrete mixtures with increased durability and longevity are presented in Table 2 .

Table 1. Properties of FB with fine-ground (floured) MFTN.

\begin{tabular}{|c|c|c|c|c|c|c|c|}
\hline \multirow[b]{2}{*}{ Name of a binder } & \multirow{2}{*}{$\begin{array}{l}\text { Normal } \\
\text { density } \\
\text { ND, } \%\end{array}$} & \multirow{2}{*}{$\begin{array}{l}\mathrm{S}_{\mathrm{ssa}} \text { of a }- \\
\text { binder, } \mathrm{m}^{2} / \mathrm{kg}\end{array}$} & \multirow{2}{*}{$\begin{array}{l}\text { True } \\
\text { density, } \mathrm{kg} / \mathrm{m}^{3}\end{array}$} & \multirow{2}{*}{$\begin{array}{l}\text { Water segre- } \\
\text { gation } \\
\text { (bleeding), \% }\end{array}$} & \multicolumn{2}{|c|}{$\begin{array}{l}\text { Setting time, } \\
\text { hour. - min }\end{array}$} & \multirow{2}{*}{$\begin{array}{l}\text { Activity, } \\
\text { MPa }\end{array}$} \\
\hline & & & & & Start & End & \\
\hline FB-75:25 & 17 & 558 & 2986 & 15,5 & $3-40$ & $5-30$ & 71,3 \\
\hline FB-60:40 & 19 & 577 & 2905 & 14,7 & $3-55$ & $5-35$ & 60,7 \\
\hline $\begin{array}{l}\mathrm{PC} \text { M } 500 \text { D0 SUE } \\
\text { «Chechencement» } \\
\text { (for reference) }\end{array}$ & 26 & 325 & 3115 & 18,0 & $2-15$ & $3-40$ & 52,6 \\
\hline
\end{tabular}




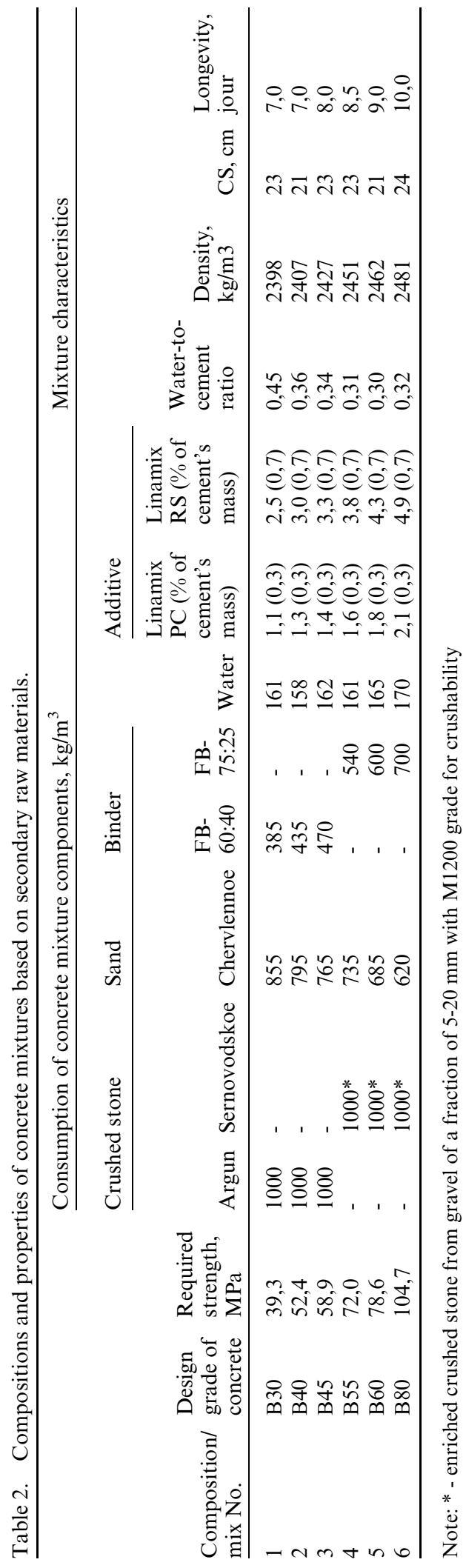


The Linamix PK superplasticizer was introduced into FB concrete mixes together with mixing water in a small amount (from 0.3 to $0.4 \%$ of the binder's weight), since the complex polyfunctional additive D-5 already has plasticizing properties in the composition of FB.

The hardening retarder "Linamix RS" was dosed in an amount of $0.7 \%$ by weight of the binder in order to ensure increased workability retaining capacity of concrete mixtures (7-8 hours or more).

The obtained experimental data on the study of the properties of HSC based on secondary raw materials of technogenic nature are presented in Table 3.

When comparing the obtained experimental results of testing concrete based on filled binders (Table 3) with known indicators of concrete strength on traditional Portland cement, you can notice the difference in the dynamics of the concrete strength gain (Figure 1).

In order to analyze the degree of homogeneity of the studied concretes based on secondary raw materials, the dependences of the prismatic strength coefficient of concretes on their compositions and on the type of binders used were studied. In addition, the proportion of the clinker part and the finely ground filler of technogenic nature in the used binders varied.

The obtained data reflecting the experimental dependencies of the prism strength $R_{P R}$ of the developed concrete using binders of various nature on their cubic strength $\mathrm{R}$, were compared with the known data of Russian scientists (Figure 2).

It was established that with an increase of the prismatic strength of concrete, its modulus of elasticity increases as well (Figure 3). Moreover, the dependence curve is slightly different from the known data obtained by prof. G.V. Nesvetaev and his students.

\section{DISCUSSION}

Based on the analysis of the results obtained, it can be stated that concretes containing filled binders that use finely ground fillers of technogenic nature are characterized by distinctive features of properties compared to traditional Portland cement concretes. In particular, this relates to retaining workability parameters of the concrete mixtures, the dynamics of curing during the first days of hardening, the strain (deformation) properties of concrete, etc. (Figures 1-3).

Therefore, the development process of FB concrete's strength characteristics at 1-3 days of age is accelerated by 1.5-2 times: on the first day FB concrete develops a strength about 33$36 \%$ higher compared to the design strength, and on the 3 -day, the strength is $65-75 \%$. Moreover, at the age of 7 days, the strength of this concrete completely exceeds $85-90 \%$ of the design strength. This differs significantly from the performance of conventional formulations that use traditional Portland cement. Thereby, these characteristics when relating to the traditional concrete at the age of 1,3 and 7 days correspond to $23-26,34-37$ and $65-70 \%$ of the design strength, respectively. Such dynamics of concrete hardening is explained by the complex effect of chemical modifiers that form the concrete as well as filled binder. Additive D-5 in concrete, which exhibits plasticizing properties during the first hours after mixing the concrete with water, begins to act as an accelerator since day one, to a certain extent. A similar effect of D-5 on the properties of concrete mix and concrete itself turn it into a multifunctional additive that positively affects both the rheological and technological characteristics of the mixture, as well as the physical-mechanical and operational characteristics of the concrete. Identically, the properties of the concrete mixes and concrete are also affected by the addition of Linamix PK, which accelerates the hardening of concrete at an early age. Such a sufficiently fast dynamics of the strength development allows you to load constructional elements at an early age (1...7 days after construction).

As is commonly known, among the most important indicators of the quality of concrete mix for cast-in-situ construction is the ability of the concrete to retain the parameters of its workability (mobility, composition stability, etc.) for a long time. In this regard, the rheological and technological properties of concrete mixtures were studied, in particular their mobility, durability, ability to retain workability, water segregation (bleeding), segregation of concrete, etc. As can be seen from Table 3, the compositions studied and proposed in this work (special concrete compositions) based on filled binders and special additives are characterized by increased capacity to retain 


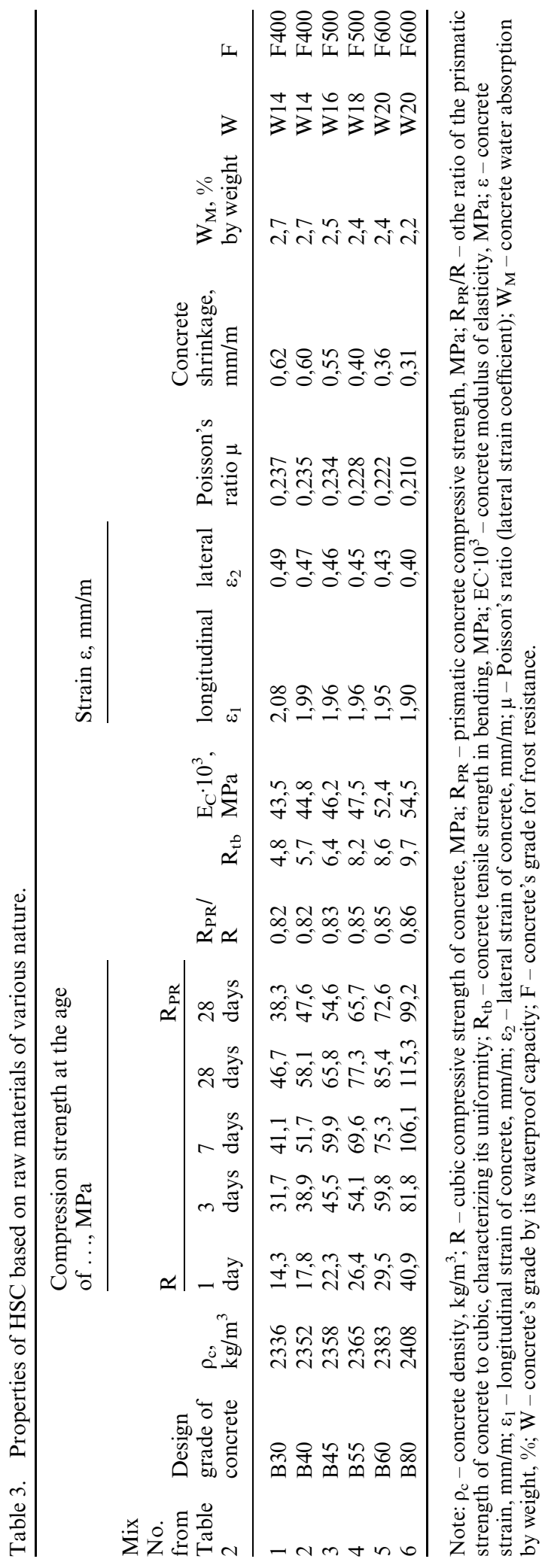




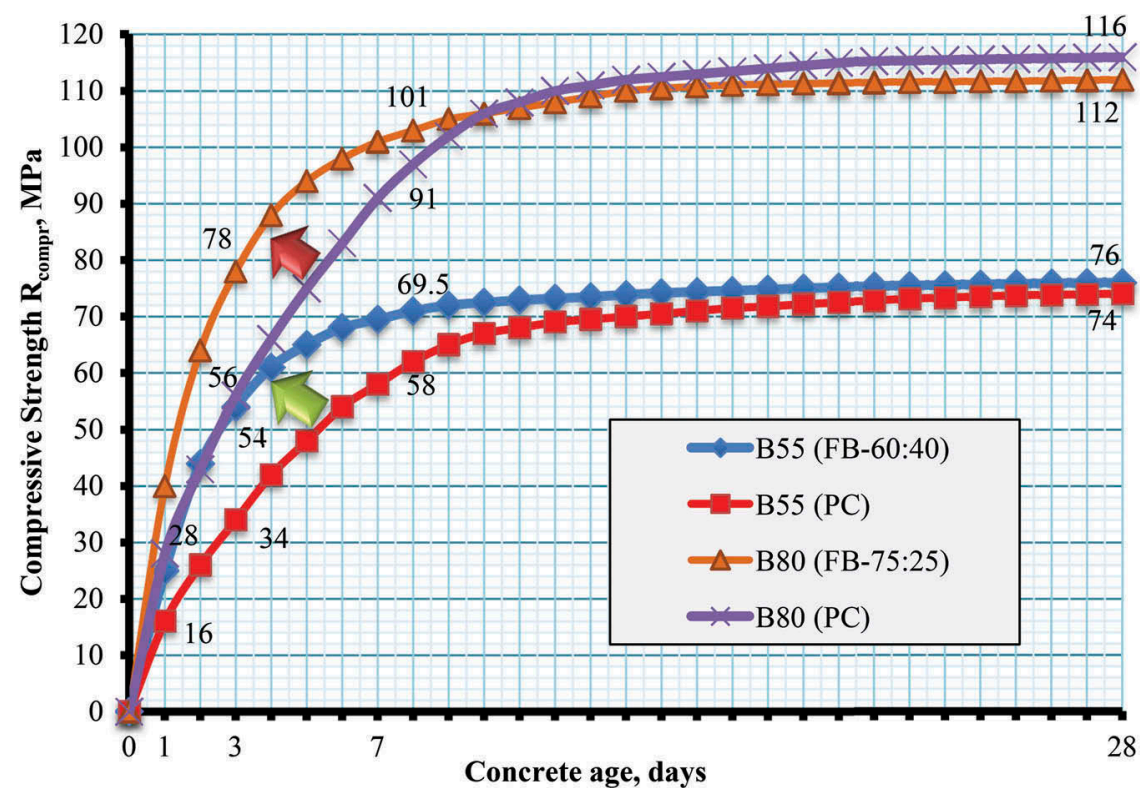

Figure 1. Assessment of the concrete strength characteristics growth (over time), depending on the type of binder.

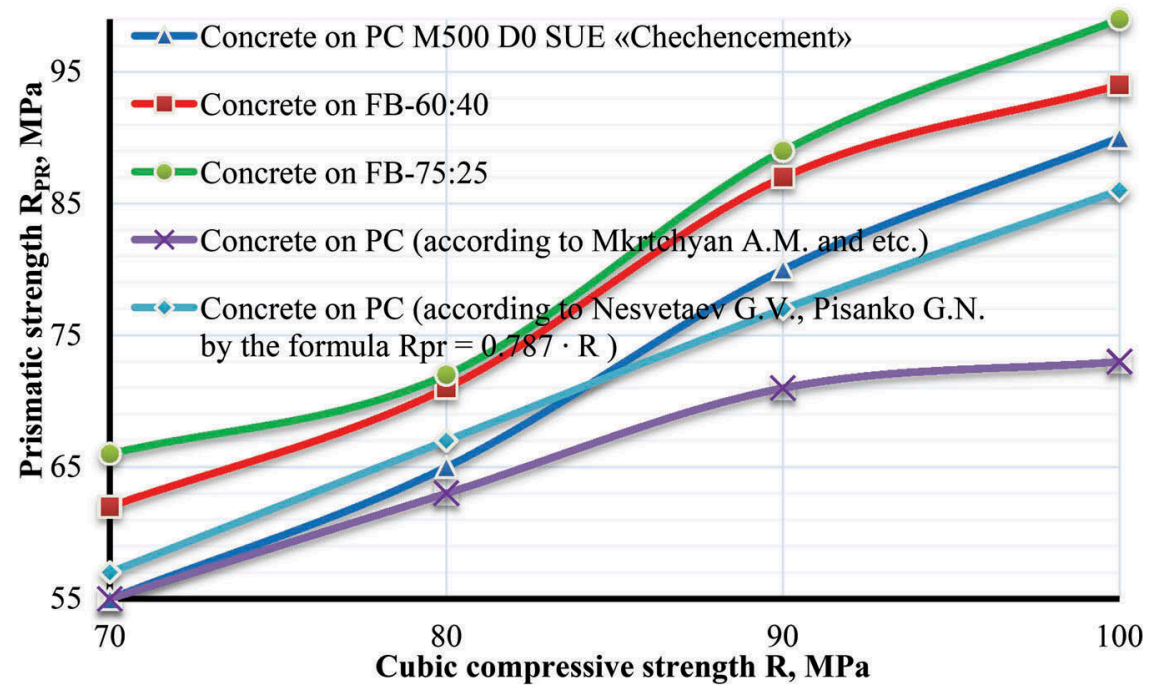

Figure 2. Dependence of the prism strength $\mathrm{R}_{\mathrm{PR}}$ on cubic $\mathrm{R}$ when using binders of various nature.

workability (8-10 hours). High rates of workability parameters preservation of concrete mixtures contribute to the production of an integral in-situ construction without the formation of "cold joints" in case of unforeseen circumstances associated with breakdown of equipment and tools, failure to supply the mixture, etc. And after the end of the inhibitory effect of the additive, these mixtures quickly gain strength at an early age (1-3 days), which increases the efficiency of form reuses and, as a result, drastically reduces the construction time, which is very important in modern cast-in-situ construction. For elements of the precast reinforced construction industry, 


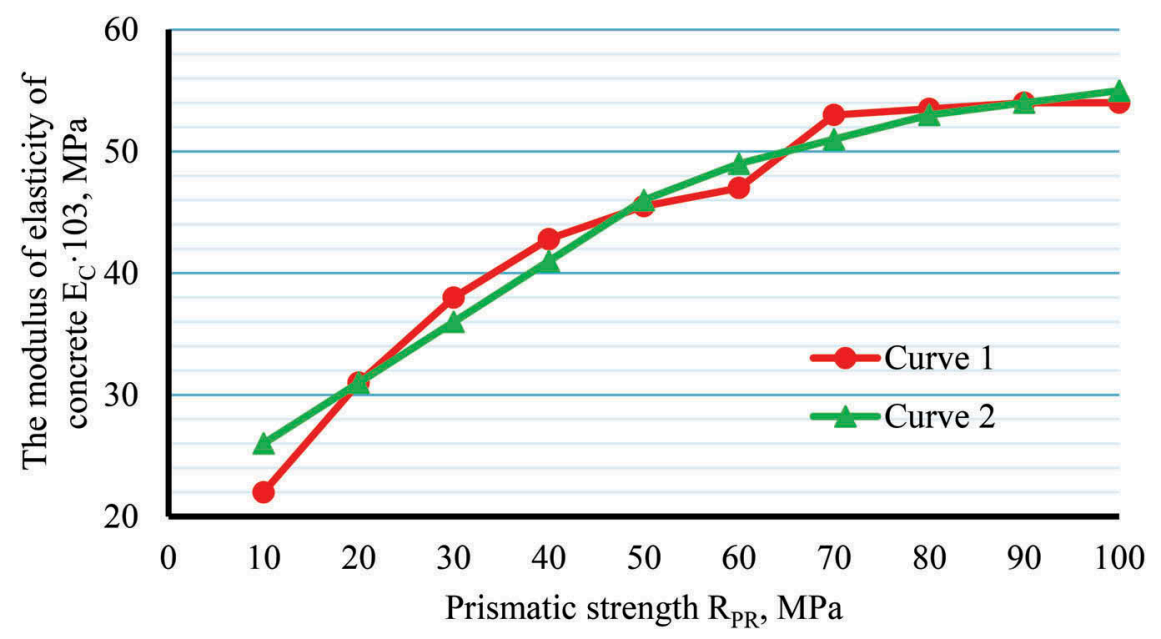

Figure 3. Dependence of the elastic modulus of HSC produced with a finely ground MFTN (curve 1) and ordinary concrete (curve 2, according to G.V. Nesvetaev) on its prism strength.

such a feature of the proposed concrete formulations (high durability, rapid strength development, etc.) will slash the manufacturing time of constructions, and in some cases, partially or completely eliminate the cost of concrete steaming.

\section{CONCLUSIONS}

Formulations of filled binders (FB) with an activity of 60-71 MPa with finely dispersed mineral fillers of technogenic origin (MFTO), including concrete scrap and ceramic brick (CBK) with a ratio of $70: 30 \%$, respectively, were developed and studied, with the proportion of the filler mixture in FB amounted to 25 and $40 \%$ by weight of the binder.

Using secondary raw materials, optimal formulations of concrete mixtures with a grade of P5 in cone slump along with its capacity to retain workability for more than 8 hours were designed to produce HSC.

The physical-mechanical characteristics of HSC made of secondary raw materials of B60B80 grades were studied, and the development of their strength characteristics over a period of time depending on the type of binder was evaluated. It was found that the process of strength development of FB concrete is accelerated by 1.5-2 times at an early age (1-3 days). So, FB concrete at the age of 1 day has a strength of about $33-36 \%$ of the design, and at the age of 3 days - it reaches up to $70 \%$. The 7-day strength of concrete obtained using FB is about $85-90 \%$ of the design, which is significantly higher than the performance of traditional "PortlandCement" (PC) compositions.

It is proved that the prismatic strength coefficient (i.e., the RPR/R ratio) for FB concrete is in the range of $0.82-0.86$, whereas the traditional PC concrete shows only 0.78 or lower.

The stress-related (deformational) properties of HSC based on secondary raw materials were studied. It was found that the concrete modulus of elasticity of the proposed compositions of HSC, prepared on the basis of secondary raw materials, is in the range of $40,2 \times 10^{3}-$ $54,5 \times 10^{3} \mathrm{MPa}$, depending on the strength of concrete and the type of filler. Moreover, the higher the strength of concrete, the higher its modulus of elasticity.

It is experimentally proved that the ultimate longitudinal $\varepsilon_{1}$ and lateral $\varepsilon_{2}$ strains of the HSC on finely dispersed MFTN are $1.93-2.32 \mathrm{~mm} / \mathrm{m}$ and $0.41-0.66 \mathrm{~mm} / \mathrm{m}$, respectively. For straight cement concrete of traditional composition, they usually reach $\varepsilon_{1}=3.2-3.6 \mathrm{~mm} / \mathrm{m}$ and $\varepsilon_{2}=1.9-2.0 \mathrm{~mm} / \mathrm{m}$. It is discovered that with an increasing concrete strength and higher proportion of finely ground MFTN the longitudinal and lateral strains decrease. 
It was found that the Poisson's ratio $\mu$ (lateral strain coefficient) for HSC with a finely ground MFTN is in the range of 0.21-0.285. It was found that with an increase in concrete strength, the Poisson's ratio of HSC decreases, which indicates a more fragile nature of the structure of such concrete with an increase in their compressive strength grade.

Thus, the given deformation characteristics of the developed HSC testify to their high resistance to dynamic influences, including seismic ones.

It has been proved that HSC based on FB with fine-ground MFTN are characterized by high grades in frost resistance (F300-F500) and waterproof (W14 and higher), demonstrating a solid evidence of high durability and longevity of such concrete.

\section{REFERENCES}

Aitcin, P.C. 1998. High-performance concrete. London: E\&FN SPON.

Bazhenov, Yu.M. 2011. Fine-grained concrete from recycled materials for the repair and restoration of damaged buildings and structures: scientific publication / Yu.M. Bazhenov, D.K.-S. Bataev, St. A.Yu. Murtazaev, H.N. Mazhiev. - Grozny: IE "Sultanbegova H.S.".

Bazhenov, Yu.M. 1995. Concrete of the 21st Century/Yu.M. Bazhenov // Resource- and energy-saving technologies of building materials, products and structures: Sat. scientific tr Int. conf. -Belgorod.

Bazhenov, Yu.M. 2006. Modified high-quality concrete: scientific publication / Yu.M. Bazhenov, B.C. Demyanova, V.I. Kalashnikov. - M.: Publishing house of the Association of construction universities.

Bataev, D.K.-S. 2017. Recipes of high-strength concrete based on technogenic and natural raw materials / D.K-S. Bataev, M.S. Saydumov, T.S.-A. Murtazaeva, D.M. Dudaev, M.K. Salgiriev // Actual problems of modern building science and education: materials of the All-Russian scientific-practical conference dedicated to the 60th anniversary of the building faculty of FSBEI HE "GSTU named after Acad. M.D. Millionschikova", October 12-13, 2017 - Grozny: P. Bisultanova.

Berg, O.Ya. 2012. High-strength concrete/O.Ya. Berg, E.N. Shcherbakov, G.N. Pysanko. -M.: Stroyizdat.

Demyanova, V.S. 2013. Effective building materials using industrial waste/V.S. Demyanova, A.D. Gusev. -Penza: PGUAS.

Kaprielov, S. S., Scheinfeld, A. V., Dondukov, V. G. 2017. Cements and additives for the production of high-strength concrete // Building materials. - No. 11.

Kim, J.-K., Kim, Y.-Y. 1996. Experimental study of the fatigue behavior of high strength concrete // Cement and Concrete Research. -Vol. 26, -Issue 10.

Kuprina, A.A., Lesovik, V.S., Zagorodnyk, L.H., Elistratkin, M.Y. 2014. Anisotropy of materials properties of natural and man-triggered origin // Research Journal of Applied Sciences. -Vol. 9.- Issue 11.

Lesovik, B.C. 2012. Building composites based on screenings for crushing concrete scrap and rocks: scientific publication/B.C. Lesovik, St. A.Yu. Murtazaev, M.S. Saydumov. -Grozny: Municipal Unitary Enterprise "Printing House".

Murtazaev, S-A.Yu. 2009. Fine-grained concrete based on fillers from recycled materials [Text]: scientific publication / S-A.YU. Murtazaev, D.K.-S. Bataev, Z.K. Ismailov, Kh.N. Mazhiev, St. M.K. Khubaev. -M.: Komtekhprint.

Nesvetaev, G.V. 2003. Evaluation of the effectiveness of superplasticizers for high-strength and high-quality concrete / G.V. Nesvetaev, A.V. Nalimova, G.V. Bumblebee // Proceedings of universities. Construction, -№ 9.

Richard, P., Cheyrezy, M. 1995. Composition of reactive powder concretes // Cement and Concrete Research. -No. 25.

Salamanova, M.Sh. 2018. Clinker-free binders based on finely dispersed mineral components/Murtazaev S.A. Yu., Salamanova M.Sh. // Collected: ibausil conference proceedings. - -FROM. 707-714.

Shi, C., Wu, Z., Xiao, J., Wang, D., Huang, Z., Fang, Z. 2015. A review on ultra high performance concrete: Part 1. Raw materials and mixture design // Construction and Building Materials. -No. 101.

Skazlic, M., Bjegovic, D. 2005. Perspectives of designing with new concrete types. Zagreb: Annual 2005 of the Croatian Academy of Engineering.

Volkov, Yu. 2004. Concrete basis for modern skyscrapers / Yu. Volkov, A. Zvezdov // Construction. - No. 5.

Volodchenko, A.A., Lesovik, V.S., Zagorodnjuk, L.H., Volodchenko, A.N., Aleksandrovna, K.A. 2016. The control of building composite structure formation through the use of multifunctional modifiers // Research Journal of Applied Sciences -№ 10 (12). 


\title{
Recent technologies in selective removal of arsenic in copper ore processing
}

\author{
A. Kobylyanski \\ Postgraduate student, Saint-Petersburg Mining University, Saint-Petersburg, Russian Federation \\ V. Zhukova \\ Master student, Saint-Petersburg Mining University, Saint-Petersburg, Russian Federation \\ V. Grigoreva \\ Student, Saint-Petersburg Mining University, Saint-Petersburg, Russian Federation
}

\author{
A.Ya. Boduen \\ PhD, Associate professor, Saint-Petersburg Mining University, Saint-Petersburg, Russian Federation
}

\begin{abstract}
The changes of raw material's characteristic and challenges of processing copper ores containing high concentration of arsenic and antimony was considered. The analysis of the main methods shows that alkaline sulphide leaching is the most effective way to process off-grade copper concentrates. Leaching of concentrates' samples containing approximately $1,36 \%$ As and $19.2 \% \mathrm{Cu}$ was studied in alkaline sulphide solutions containing sodium hydroxide and sodium sulphide

Experiments were carried out with the assistance of the laboratory base of St. Petersburg mining university's Common Use Centre. Experimental results of concerning the selective removal of arsenic are presented here.
\end{abstract}

Keywords: copper, arsenic, tennantite, enargite, sulphides, sulfosalt, alkaline leaching, ore processing

\section{INTRODUCTION}

For the copper industry it is the time of chances and challenges. The industry and the market have to face these challenges now, for seizing the chances coming its way in the future. The European Copper Institute predicts (the ECI 2017 Annual Report) the growth in copper consumption in the short term, taking into account the development of industries and expansion of the number of copper products applications.

However, one of the serious challenges for mining companies is the increase of the off-grade mineral reserves in the deposits. This situation is common for many companies of the mining industry including copper sector. Statistical database of the International Copper Study Group and the recent researches indicate that producers are exploiting deposits with low valuable components concentration in the ores.

In this situation copper deposits are being developed by mining companies, and valuable component content in the ore is ranging between 0.5 and $0.8 \%$. This problem is further complicated by the fact that the relatively low-grade mineral resources being extracted are often unconventional and contain more than one valuable component. This leads to unavoidable losses of the valuable components in ore concentration processes and conversion into mining and mineral processing waste (Nevskaya et al., 2019) Consequently, the effective processing 
and the utilisation of the raw materials with various quality characteristics became much more important for industrial companies.

In details, the changes in quality characteristic of the raw materials (especially steady decrease of the content of the valuable component in the ores) lead to the drop of the processing indicators of raw materials. The chemical and mineralogical compositions of the processed concentrates get worse. All these factors have influence on the final metallurgical product's cost.

High concentration of impure elements in the ore composition is also the problem for metallurgical companies. There are many orebodies or materials, which have significant value but also contain arsenic, throughout the world. Processing of copper ores (or any other ores) that contain arsenic is challenging. Arsenic is considered to be a human carcinogen with high mobility in aqueous streams, which in time may lead to increased arsenic concentrations in rivers (Oyarzun et al., 2004, 2006) and drinking water.

The presence of arsenic minerals in copper concentrates complicates their treatment by the conventional smelting-converting process. The sulphides and oxides of arsenic are highly volatile. Thus, in the pyrometallurgical treatment of copper concentrates with high arsenic content, there is a high risk of producing arsenic emissions to the atmosphere. Therefore, the smelters impose heavy penalties on copper concentrates that contain more than $0.5 \%$ arsenic (Ruiz M.C. et al., 2015).

Hydrometallurgical methods can be involved in treatment processes of arsenic containing materials, concentrates and ores as well as complex ones containing any number of metals. Industrial experience of these methods is known worldwide, in CIS, China and the United States the methods are employed for the production of antimony.

Despite the prevalence of pyrometallurgical processes, the global copper production by implementing hydrometallurgical approach increases (Fedoseev et al., 2018; Boduen et al., 2019). Amongst current technologies, an alkaline sulphide hydrometallurgical process has been demonstrated successful results in selective dissolution of arsenic and antimony from a copper concentrate containing enargite and tennantite (Prada et al., 2014; Tongamp et al., 2009; Baláž et al., 2006). In this paper, the process undertakes an alkaline sulphide leaching with a concentrated solution for transformation the arsenic sulphides into soluble compounds. The alkaline sulphide system is essentially a mixture of sodium sulphide and sodium hydroxide. It is an exclusive hydrometallurgical system - very selective lixiviant for the alkaline leaching of tin, gold, antimony, arsenic and mercury.

\section{THE ROLE OF ARSENIC IN COPPER ORE PROCESSING}

Copper production from the copper ores (or any ores) that contain arsenic is challenging due to certain factors. The common copper-arsenic bearing minerals in copper ores are enargite $\left(\mathrm{Cu}_{3} \mathrm{AsS}_{4}\right)$ and tennantite $\left(\mathrm{Cu}_{12} \mathrm{As}_{4} \mathrm{~S}_{13}\right)$. It should be noted that enargite and tennantite contain significant amounts of copper: $48.4 \%$ and $51.6 \%$ respectively. Chalcopyrite, which is employed more for copper production, has $34.5 \%$ of copper content. Removal of enargite and tennantite minerals from the concentrate means valuable metal losses, hence production income. Moreover, according to environmental and plant ecological concerns, pyrometallurgical operations will penalise concentrates that contain arsenic over $0.5 \%$ by weight (sometimes less). The presence of arsenic can also increase concentrates' shipping costs, since concentrates are commonly imported/exported overseas (Castro, 2008; Filippou et al., 2007).

Enargite and tennantite are part of the sulfosalt minerals' class. Sulfosalt minerals differ from sulphides in that semimetal elements such as antimony, arsenic or bismuth in sulphides substitute the sulphur positions, but in sulfosalts they substitute for the metal ions and bond with the sulphur.

There is a dearth of industrial experience and literature concerning the selective removal of arsenic from the copper ores during the processing. The up-to-date methods of processing copper-sulphide ores with mixture of sulfosalt minerals encompass a number of technological problems that significantly complicate the production process. In other words, at the stage of 
ore preparation sulfosalt minerals are usually over grinded due to the very thin mutual germinating of the main ore-forming minerals: pyrite, chalcopyrite, and sphalerite and sulfosalt minerals.

Besides the similarity of the flotation properties of the minerals and over crushing of sulfoarsenides, the process of selective flotation is complicated, because of the main copper sulphides combined with tennantite might be easily turned to sludge, and that leads to higher losses of copper with processing tails as well as challenges in obtaining a conditioned copper concentrate.

Methods and experiments carried out by other researches (Prada et al., 2014; Tongamp et al., 2009; Baláž et al., 2006) have shown the results of arsenic extraction up to $97 \%$. These results can be achieved by using the alkaline sulphide process for processing ores containing enargite and tennantite. In the presence of sulphide, arsenic is believed to transform and to form sodium thioarsenate as shown in the Equation 1:

$$
\begin{aligned}
& \mathrm{Cu}_{12} \mathrm{As}_{4} \mathrm{~S}_{13}+6 \mathrm{NaOH}+6 \mathrm{NaOH} \rightarrow 5 \mathrm{Cu}_{2} \mathrm{~S}+2 \mathrm{CuS}+ \\
& 4 \mathrm{Na}_{3} \mathrm{AsS}_{3}+6 \mathrm{H}_{2} \mathrm{O}
\end{aligned}
$$

Studying these methods and achievement the same arsenic extraction results for processing copper-arsenic concentrates and middling products were one of the key of this research work.

\section{MATERIALS AND METHODOLOGY}

\subsection{Sample preparation}

The samples of middling product and copper concentrate were received from the Uchalinskiy mining and processing plant (JSC «Uchalinsky GOK»), which is one of the largest industrial companies of Southern Ural, (production specialisation - zinc and copper concentrates).

The ores of the region demonstrate a decrease in the average content of valuable components (on average 10.0-15.0\%), as well as a constant grow in the content of related elements such as arsenic, antimony, lead, mercury, fluorine. These raw materials are characterised as difficult to process, multicomponent, with unfavourable texture and structural features. Oreforming minerals have similar processing properties (Nikolaeva, E.S. et al., 2019).

The samples of the study were the concentrate and middling product provided by the JSC «Uchalinsky GOK». The chemical analyses results (ICP) of the samples are presented in the Table 1.

The samples of middling product and copper concentrate were prepared in laboratory conditions by coning and quartering followed by splitting through a 10-channel splitter, obtaining 50 gram of leaching samples. A sample with $\mathrm{P}_{80}$ of approximately $50 \mu \mathrm{m}$ was used for kinetic experiments at different temperatures. The particle size distribution for this sample is shown in Figure 1.

\subsection{Apparatus and procedure}

Experiments were carried out batch-wise in a $300 \mathrm{ml}$ glass jacket cell under atmospheric pressure. Temperature was controlled by a thermostated water bath throughout the process.

Table 1. Chemical analysis of the copper concentrate and middling product (basic elements).

\begin{tabular}{lllllllllllll}
\hline & \multicolumn{1}{l}{ Content (wt. \%) } \\
\cline { 2 - 12 } Sample & $\mathrm{Cu}$ & $\mathrm{Pb}$ & $\mathrm{Zn}$ & $\mathrm{Fe}$ & $\mathrm{Co}$ & $\mathrm{SiO}_{2}$ & $\mathrm{Al}_{2} \mathrm{O}_{3}$ & $\mathrm{Cd}$ & $\mathrm{As}$ & $\mathrm{Sb}$ & $\mathrm{Ag}$ \\
\hline Copper concentrate UGOK & 16.0 & 23.8 & 0.8 & 5.3 & 0.1 & 1.94 & 0.82 & 0.03 & 1.36 & 0.21 & 0.009 \\
Middling UGOK & 6.22 & 0.74 & 7.3 & 24.4 & 0.1 & 4.02 & 1.32 & 0.03 & 1.36 & 0.19 & 0.009 \\
\hline
\end{tabular}




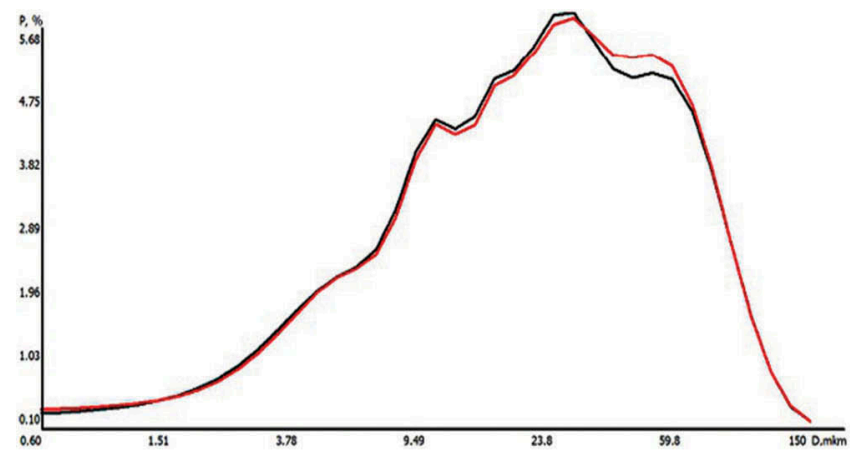

Figure 1. Particle size distribution for the enargite sample used for determination of the rate controlling process, $\mathrm{P} 80=50 \mu \mathrm{m}$.

Agitation was provided by a mechanical paddle agitator during tests. All chemicals were of analytical grade and were used as received. In order to avoid evolution of hydrogen sulphide, leach solutions were prepared separately by dissolving sodium hydroxide in distilled water and dissolving sodium sulphide in distilled water in separate glass cell. Thereafter both solutions were mixed together in the glass jacket cell. It should be noted that all $\mathrm{NaOH}$ concentrations written below also include the $\mathrm{NaOH}$ produced by the hydrolysis of $\mathrm{Na}_{2} \mathrm{~S}$ according to the Equation 2.

$$
\mathrm{Na}_{2} \mathrm{~S}_{(a q)}+\mathrm{H}_{2} \mathrm{O}_{(l)} \leftrightarrow \mathrm{NaOH}_{(a q)}+\mathrm{NaHS}_{(a q)}
$$

The samples for analysing, approximately $10 \mathrm{ml}$ of pulp, were drawn from the leaching reactor periodically (in some test - only in the final stage), filtered and sent for analysis. The remaining pulp that was not used for analysis was immediately returned to the reactor. In this experimental work the studied parameters included concentration of sodium sulphide and sodium hydroxide, temperature, agitation, $\mathrm{P}_{80}$ and pulp density and their effect on the dissolution behaviour of arsenic, antimony, iron and copper.

\section{RESULTS AND DISCUSSION}

During the experimental work certain parameters were determined, studied and described. The effects of temperature and hydroxide concentration are important for the leaching kinetics. In general, Figure 2 shows that there is a clear improvement in the kinetics of arsenic removal as temperature is increased.

The best results were observed when both reagents were taken in high concentrations (4 $\mathrm{M} \mathrm{NaOH}$ and $1.5 \mathrm{M} \mathrm{Na}_{2} \mathrm{~S}$ ) - almost $100 \%$ of arsenic extraction. This strong concentration and temperature dependence is very clear evidence that the controlling mechanism is a chemical reaction taking place on the surface of the particles (Levenspiel, 1999; Petrov, G. et al., 2018).

The decrease of the reagents' concentration declines the leaching rate significantly. Results of experiments 1 and 2 confirm that the concentration of both sodium hydroxide and sulphide has immediate impact on the leaching process (Table 2).

The temperature impact was studied in the range of 85,90 и $95^{\circ} \mathrm{C}$. In this group of experiments other parameters were kept constantly:

- process time -4.5 hours;

- agitation rate $-600 \mathrm{rpm}$;

- reagents concentration $-3,5 \mathrm{M} \mathrm{NaOH}$ и 1,5 $\mathrm{M} \mathrm{Na}_{2} \mathrm{~S}$. 


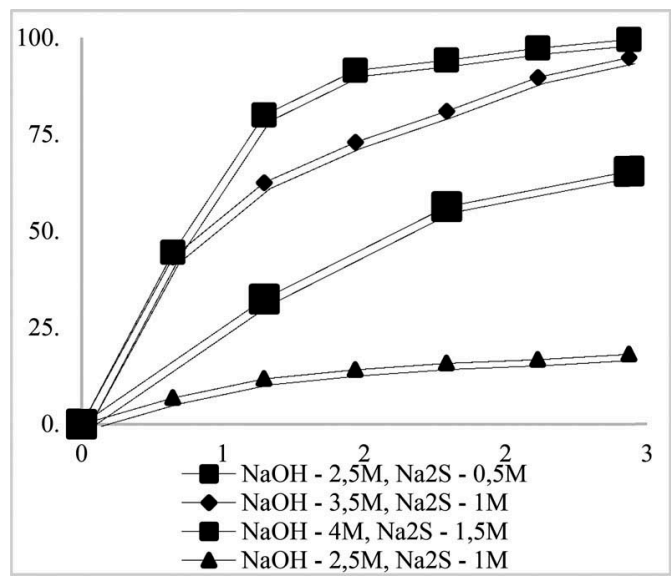

Figure 2. Effect of $\mathrm{NaOH}$ and $\mathrm{Na}_{2} \mathrm{~S}$ on the arsenic extraction at $95^{\circ} \mathrm{C}$ in $250 \mathrm{ml}$ of solution.

Table 2. Parameters and results of experiments - the concentration influence.

\begin{tabular}{lllllll}
\hline & & & \multicolumn{3}{l}{ Concentration } & \\
\cline { 5 - 6 } Experiment & Temperature $\left({ }^{\circ} \mathrm{C}\right)$ & Liquid/solid rate & Time $(\mathrm{h})$ & $\mathrm{NaOH}$ & $\mathrm{Na}_{2} \mathrm{~S}$ & As removal (\%) \\
\hline 1 & 95 & 10 & 3 & 2.5 & 0.5 & 18.10 \\
2 & & & 2.5 & 1.0 & 65.44 \\
3 & & & 3.5 & 1.0 & 92.86 \\
4 & & & 4.0 & 1.5 & 99.56 \\
\hline
\end{tabular}

The results of experiments follow the same trend as previous ones. The highest temperature level provides the best arsenic removal rate (Figure 3; Table 3).

According to the results of experiments' analysis, copper and iron was found in leaching solutions in concentrations $12 \times 10^{-4}(\mathrm{~g} / \mathrm{l})$ and $78 \times 10^{-4}(\mathrm{~g} / \mathrm{l})$ respectively. This trend indicates high selectivity of leaching process.

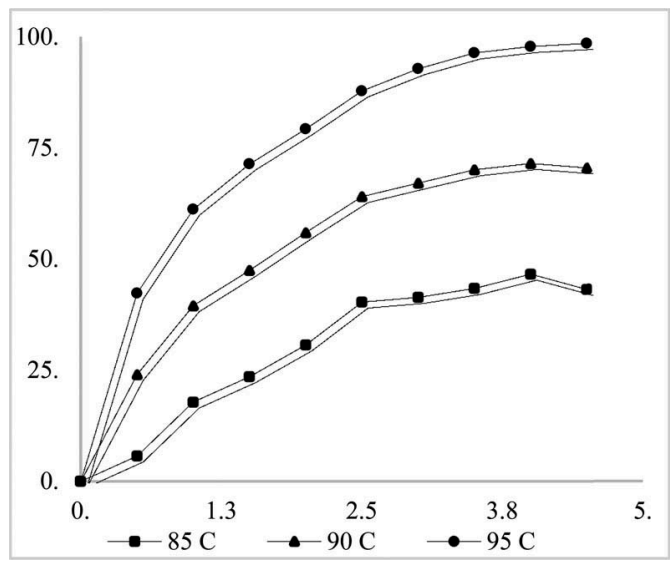

Figure 3. Effect of temperature on the arsenic extraction in $250 \mathrm{ml}$ of solution with concentration 3,5 M $\mathrm{NaOH}$ и $1,5 \mathrm{M} \mathrm{Na}_{2} \mathrm{~S}$. 
Table 3. Parameters and results of experiments of the temperature impact.

\begin{tabular}{lllllll}
\hline & & & \multicolumn{3}{l}{ Concentration } & \\
\cline { 5 - 6 } Experiment & Temperature $\left({ }^{\circ} \mathrm{C}\right)$ & Liquid/solid rate & Time $(\mathrm{h})$ & $\mathrm{NaOH}$ & $\mathrm{Na}_{2} \mathrm{~S}$ & As removal $(\%)$ \\
\hline 1 & 85 & 10 & 4.5 & 3.5 & 1.0 & 43.21 \\
2 & 90 & & & & & 70.54 \\
3 & 95 & & & & 98.57 \\
\hline
\end{tabular}

\section{CONCLUSION}

The existing industrial and scientific experience in technologies of arsenic extraction from copper concentrates and middling products does not provide appropriate solutions for the industry.

The existing methods of flotation cannot separate copper and zinc sulphides from sulfosalt minerals completely, that increases the concentration of arsenic in the product.

Therefore, the smelters impose heavy penalties on copper concentrates that contain more than $0.5 \%$ arsenic. All this factors makes this area of research very relevant.

The alkaline sodium sulphide leaching of copper concentrates and middling products efficiently removes arsenic, and produces a "pure" copper product. Due to this fact the selective leaching of arsenic and antimony using sodium sulphide in the alkaline solutions is a prospective way of upgrading copper-gold-silver concentrates to make them suitable for smelting. This fact creates an opportunity for the mining companies to extend the raw materials base for the production from off-grade mineral reserves.

At the moment, the main direction of modern research in this area is focused on the identification of effective reagent regime and influences of the mechanical activation on the process.

The reported study was funded by RFBR according to the research project 18-29-24103.

\section{REFERENCES}

Anderson, C.G. \& Twidell, L.G. 2008. The alkaline sulphide hydrometallurgical separation, recovery and fixation of tin, arsenic, antimony, mercury and gold. Lead and Zinc 2008: 121-132.

Baláž, P., Achimovičová, M. 2006. Selective leaching of antimony and arsenic from mechanically activated tetrahedrite, jamesonite and enargite. International Journal of Mineral Processing 81: 44-50.

Boduen, A. \& Fokina, S. \& Petrov, G. \& Andreev, Yu. (2019). Ammonia autoclave technology for the processing of low-grade concentrates generated in flotation concentration of cupriferous sandstones. Obogashchenie Rud. 33-38. 10.17580/or.2019.02.06.

Fedoseev, I. V., Barkan, M. S., Kornev, A. V., and Danilov, A. S. (2018). Theoretical Foundations and Technological Capabilities of Hydrocarbonyl Process of Recovering Copper from Technogenic Wastes. Journal of Ecological Engineering, 19(5), pp.33-37.

Filippou, D., St-Germain, P., Grammatikopoulos, T., 2007. Recovery of metal values from copperarsenic minerals and other related resources. Miner. Process. Extr. Metall. Rev. 28 (4): 247-298.

Nadkarni, R.M \& Kusik, C.L. 1988. Hydrometallurgical removal of arsenic from copper concentrates. Arsenic Metallurgy Fundam. Appl. Proc. Symp: 263-286.

Nevskaya, M.A.; Seleznev, S.G.; Masloboev, V.A.; Klyuchnikova, E.M.; Makarov, D.V. Environmental and Business Challenges Presented by Mining and Mineral Processing Waste in the Russian Federation. Minerals 2019, 9, 445.

Nikolaeva, E.S., Talovina, I.V., Nikiforova, V.S., Heide, G. 2019. Chemical composition and genesis of serpentinite group minerals in nickeliferous weathering crust of the Elov deposit (Urals). Scientific and Practical Studies of Raw Material Issues: 3-10.

Oyarzun, R., Guevara, S., Oyarzun, J., Lillo, J., Maturana, H., Higueras, P. 2006. The Ascontaminated Elqui river basin: a long lasting perspective (1975-1995) covering the initiation and development of $\mathrm{Au}-\mathrm{Cu}-\mathrm{As}$ mining in the high Andes of northern Chile. Environ. Geochem. Health 28 (5): 431-443.

Oyarzun, R., Lillo, J., Higueras, P., Oyarzun, J., Maturana, H. 2004. Strong arsenic enrichment in sediments from the Elqui watershed, northern Chile: industrial (gold mining at El Indio-Tambo district) vs. geologic processes. J. Geochem. Explor. 84 (2): 53-64. 
Parada, F., Jeffrey, M.I., Asselin, E. 2014. Leaching kinetics of enargite in alkaline sodium sulphide solutions. Hydrometallurgy 146: 48-58.

Petrov, G. V. \& Fokina, S. B. \& Boduen, A.Y. \& Zotova, I.E. \& Fidarov, B.F. 2018. Arsenic behavior in the autoclave-hydrometallurgical processing of refractory sulfide gold-platinum-bearing products. International Journal of Engineering and Technology (UAE) 7: 35-39.

Tongamp, W., Takasaki,Y. \& Shibayama, A. 2009. Arsenic removal from copper ores and concentrates through alkaline leaching in NaHS media. Hydrometallurgy 98: 213-218. 


\title{
Spectral-time analysis of relaxation and creep processes of polymeric materials
}

\author{
N. Pereborova \\ PhD, Associate Professor, Associate Professor of the Department of Intelligent Systems and Information \\ Security Saint Petersburg State University of Industrial Technologies and Design, Saint Petersburg, Russia \\ A. Makarov \\ Vice-Rector of Science, Saint Petersburg State University of Industrial Technologies and Design, Saint \\ Petersburg, Russia
}

A. Demidov

Rector, Saint Petersburg State University of Industrial Technologies and Design, Saint Petersburg, Russia

V. Wagner

PhD, Associate Professor of the Department of Intelligent Systems and Information Security Saint Petersburg State University of Industrial Technologies and Design, Saint Petersburg, Russia

\begin{abstract}
The article investigates into the type of distributions of relaxing and delay particles over their relaxation and delay times built upon the mathematical models of relaxation and creep of polymeric materials. The relaxation and delay times characterise the transition times of relaxing or delay particles from one stable energy state to another (Makarov et al., 2016).

The nature of such transitions can be different. It depends on both the rheology of a polymer material and the applied deformation or load value. It can be explained, on the one hand, by conformational energy transfers within the macromolecules of material when their shape changes during rearrangement, and on the other hand, there are shears of macromolecules and other changes caused by energy (Makarov et al., 2015a). The most satisfactory results considering the processes of deformation of polymeric materials can be obtained using rather complex models such as a consequent combination of a number of the Maxwell and the Kelvin-Voigt models (Pereborova et al., 2020a). The application of modelling for an accurate quantitative description of deformation or relaxation in the study of the properties of polymers encounters certain difficulties (Pereborova et al., 2020b). Different operational behaviour of polymers, structural changes during deformation depending on the sample background, temperature, duration of action, and stress-strain values, make it difficult to obtain the exact rheological characteristics of the process (Pereborova et al., 2020c). However, the relevance of modelling for a qualitative or approximate quantitative description of mechanical properties is obvious.
\end{abstract}

\section{THE METHODS FOR DETERMINING THE SPECTRA OF RELAXATION AND DELAY}

One of the methods for describing deformation and relaxation processes of polymer materials is the use of mechanical models. The limits and prospects of application of deformation processes modelling of polymers were considered in a number of studies carried out by V. A. Kargin (Pereborova et al., 2020d), G. L. Slonimskiy (Pereborova et al., 2020e), A .A. Askadskiy (Makarov et al., 2018a), I. Ward (Pereborova et al., 2019a) and other authors.

The study of relationships between various viscoelastic functions often deals with the relaxation and delay (creep) spectra. The essence of these spectra can be shown on the example of 
the Generalised Maxwell model (for relaxation) and on the example of the Generalised Kelvin-Voigt model (Pereborova et al., 2018a).

The Generalised Maxwell model represents an infinite parallel set of Maxwell elements consisting of a dashpot and a spring connected in series (Figure 1.).

Consider the element at the $i$-th place. If the stiffness of a spring is denoted by $E_{i}$, and the viscosity of the liquid where a dashpot $\eta_{i}$ is located, then the relaxation time of the $\mathrm{i}$-th element is obtained by $\tau_{i}=\frac{\eta_{i}}{E_{i}}$ and is a measure of the time required for stress relaxation.

Any number of Maxwell's elements connected in series has the properties of both the element itself and other more complex properties. This fact leads to a discrete spectrum of relaxation times $\left\{\tau_{i}\right\}$ (Pereborova et al., 2018b).

A similar statement can be made for the delay (creep) spectrum on the example of the Generalised Kelvin-Voigt model which is an infinite parallel set of Kelvin-Voigt elements consisting of a dashpot and a spring connected in series (Figure 2.) (Egorov et al., 2020).

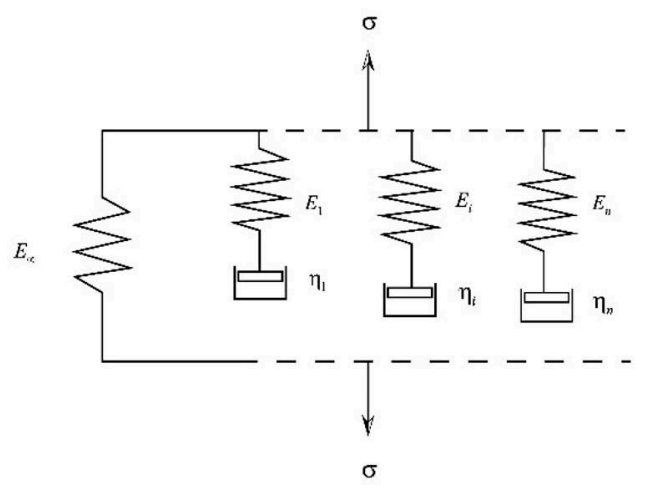

Figure 1. The Generalised Maxwell model.

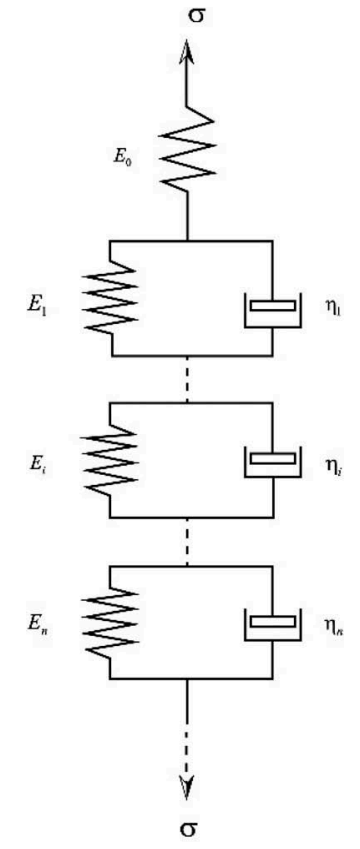

Figure 2. The Generalised Kelvin-Voigt model. 
If the element is at the $i$-th place consists of a spring with stiffness $E i$, and the viscosity of the liquid where a dashpot is located $\eta_{i}$, then the delay time of the $i$-th element is obtained by $\tau_{i}=\frac{\eta_{i}}{E_{i}}$ and is a measure of the time required for the spring to strain to its equilibrium length in the presence of the viscous element braking forces (Pereborova et al., 2019b).

\section{OBTAINING OF THE RELAXATION SPECTRA OF POLYMERIC MATERIALS}

Sufficient approximations of the relaxation and delay spectra can be found by processing the experimental sets of relaxation and creep, respectively. Obtaining the relaxation and delay spectra means finding the distribution of the relaxation times and delay times that cannot be found experimentally.

To obtain the analytical form of the relaxation spectrum of polymeric materials, a variant of the mathematical model of the relaxation process can be used in the form (Rymkevich et al., 2013).

$$
\sigma_{t}=E_{0} \varepsilon_{t}-\left(E_{0}-E_{\infty}\right) \cdot \int_{0}^{t} \varepsilon_{\theta} \cdot \varphi_{\varepsilon ; t-\theta}^{\prime} d \theta
$$

where

$\varepsilon_{t}$ - time-dependent deformation $t$,

$\sigma_{t}$ - time-dependent stress $t$,

$E_{0}$ - elastic modulus,

$E_{\infty}$ - viscoelastic modulus,

$$
\varphi_{\varepsilon t}=\frac{1}{2} \cdot\left(1+\operatorname{th}\left(\frac{A_{\varepsilon}}{2} \cdot \ln \left(\frac{t}{\tau_{\varepsilon}}\right)\right)\right)
$$

normalised relaxation function that forms the basis of the mathematical model of relaxation (Pereborova et al., 2019c),

$$
\begin{aligned}
& \varphi_{\varepsilon t}^{\prime}=\bar{r}_{\varepsilon t}=\frac{\partial \varphi_{\varepsilon t}}{\partial(\ln t)}=\frac{A_{\varepsilon}}{4} \cdot \frac{1}{c h^{2}\left(W_{\varepsilon t}\right)}= \\
& =\frac{A_{\varepsilon}}{4} \cdot\left(1-t h^{2}\left(W_{\varepsilon t}\right)\right)=A_{\varepsilon} \cdot \varphi_{\varepsilon t} \cdot\left(1-\varphi_{\varepsilon t}\right)
\end{aligned}
$$

integral relaxation kernel,

$$
W_{\varepsilon t}=\frac{A_{\varepsilon}}{2} \cdot \ln \frac{t}{\tau_{\varepsilon}}=\frac{A_{\varepsilon}}{2} \cdot\left(\ln \left(\frac{t}{t_{1}}\right)+\ln \left(\frac{t_{1}}{\tau_{\varepsilon}}\right)\right)
$$

$A_{\varepsilon}$ - parameter of the intensity of relaxation processes,

$$
f_{\varepsilon, \tau_{\varepsilon}}=\ln \left(\frac{t}{\tau_{\varepsilon}}\right)
$$

logarithmic function of the relaxation times.

The analytical form of the relaxation spectrum $\bar{H}_{\varepsilon \tilde{\tau}}$ can be obtained by the known formula (Pereborova et al., 2018c) 


$$
\int_{0}^{\infty} \bar{H}_{\varepsilon \tilde{\tau}} \cdot e^{-t x} \cdot d x=\frac{d \varphi_{\varepsilon t}}{d t}=r_{\varepsilon t}
$$

by successive approximations.

The given formula (6) is the Laplace transform in which the relaxation spectrum $\bar{H}_{\varepsilon \tilde{\tau}}$ plays the role of the original, and the relaxation kernel $r_{\varepsilon t}$ plays the role of the figure in terms of operator calculus. This dependence (6) is obtained on the basis of the properties of the Generalised Maxwell model (Pereborova et al., 2018d).

The application of the hyperbolic tangent function as the normalised relaxation function (2) leads to the following logarithmic relaxation kernel

$$
E_{\varepsilon t}^{\prime}=\frac{\partial E_{\varepsilon t}}{\partial \ln t}=-\left(E_{0}-E_{\infty}\right) \cdot \bar{r}_{\varepsilon t}=-\frac{A_{\varepsilon}}{4} \cdot\left(E_{0}-E_{\infty}\right) \cdot\left(1-t h^{2}\left(W_{\varepsilon t}\right)\right)
$$

The deformation-time argument (4) of the relaxation kernel (3) takes into account the current time factor and the characteristically average internal relaxation times. In the known approximation, the relaxation kernel (3) characterises the distribution of relaxing particles over their micromechanical relaxation times (Pereborova et al., 2020f).

In order to obtain approximations of the normalised relaxation spectrum, the known recurrence formulas can be used (Gorshkov et al., 2013a) if $k=1$

$$
\bar{H}_{1}=\frac{\partial \varphi_{\varepsilon \mathrm{t}}}{\partial \ln t}=\varphi_{\varepsilon \mathrm{t}}^{\prime}=\left.\bar{r}_{\varepsilon \mathrm{t}}\right|_{t=\tilde{\tau}}
$$

and if $k \quad 2$

$$
\bar{H}_{k}=\bar{H}_{k-1}-\left.\frac{1}{k-1} \cdot \frac{d \bar{H}_{k-1}}{d \ln \tilde{\tau}}\right|_{t=(k-1) \tilde{\tau}}
$$

For calculating the values of the derivatives $\bar{r}_{\varepsilon t}=\frac{\partial \varphi_{\varepsilon t}}{\partial \ln t}, \ldots, \frac{\partial^{k} \varphi_{\varepsilon t}}{\partial \ln t^{k}}, \ldots$, where for the relaxation function $\varphi_{\varepsilon t}=\varphi$ the hyperbolic tangent (2) is chosen and $\mathrm{W}_{\varepsilon \mathrm{t}}=W$ is the structuredeformation-time argument-functional (4), we obtain

$$
\begin{gathered}
\varphi_{\varepsilon t}=\frac{1}{2} \cdot\left(1+t h\left(\frac{A_{\varepsilon}}{2} \cdot \ln \left(\frac{t}{\tau_{\varepsilon}}\right)\right)\right) \\
\varphi_{\varepsilon t}^{\prime}=\bar{r}_{\varepsilon t}=\frac{\partial \varphi_{\varepsilon t}}{\partial(\ln t)}=\frac{A_{\varepsilon}}{4} \cdot \frac{1}{c h^{2}\left(W_{\varepsilon t}\right)}=\frac{A_{\varepsilon}}{4} \cdot\left(1-t h^{2}\left(W_{\varepsilon t}\right)\right)=A_{\varepsilon} \cdot \varphi_{\varepsilon t} \cdot\left(1-\varphi_{\varepsilon t}\right) \\
\varphi^{\prime \prime}{ }_{\varepsilon t}=\frac{\partial^{2} \varphi_{\varepsilon t}}{\partial(\ln t)^{2}}=A_{\varepsilon}^{2} \cdot \varphi_{\varepsilon t} \cdot\left(1-\varphi_{\varepsilon t}\right) \cdot\left(1-2 \cdot \varphi_{\varepsilon t}\right) \\
\varphi^{\prime \prime \prime}{ }_{\varepsilon t}=\frac{\partial^{3} \varphi_{\varepsilon t}}{\partial(\ln t)^{3}}=A_{\varepsilon}^{3} \cdot \varphi_{\varepsilon t} \cdot\left(1-\varphi_{\varepsilon t}\right) \cdot\left(1-6 \cdot \varphi_{\varepsilon t}+6 \cdot \varphi_{\varepsilon t}^{2}\right) \\
\varphi_{\varepsilon t}^{\iota v}=\frac{\partial^{4} \varphi_{\varepsilon t}}{\partial(\ln t)^{4}}=A_{\varepsilon}^{4} \cdot \varphi_{\varepsilon t} \cdot\left(1-\varphi_{\varepsilon t}\right) \times\left(1-14 \cdot \varphi_{\varepsilon t}+36 \cdot \varphi_{\varepsilon t}^{2}-24 \cdot \varphi_{\varepsilon t}^{3}\right) \\
\varphi_{\varepsilon t}^{v}=\frac{\partial^{5} \varphi_{\varepsilon t}}{\partial(\ln t)^{5}}=A_{\varepsilon}^{5} \cdot \varphi_{\varepsilon t} \cdot\left(1-\varphi_{\varepsilon t}\right) \times\left(1-30 \cdot \varphi_{\varepsilon t}+150 \cdot \varphi_{\varepsilon t}^{2}-240 \cdot \varphi_{\varepsilon t}^{3}+120 \cdot \varphi_{\varepsilon t}^{4}\right)
\end{gathered}
$$




$$
\begin{gathered}
\varphi_{\varepsilon t}^{v \iota}=\frac{\partial^{6} \varphi_{\varepsilon t}}{\partial(\ln t)^{6}}=A_{\varepsilon}^{6} \cdot \varphi_{\varepsilon t} \cdot\left(1-\varphi_{\varepsilon t}\right) \cdot\left(1-62 \cdot \varphi_{\varepsilon t}+\right. \\
\left.+510 \cdot \varphi_{\varepsilon t}^{2}-1560 \cdot \varphi_{\varepsilon t}^{3}+1800 \cdot \varphi_{\varepsilon t}^{4}-720 \cdot \varphi_{\varepsilon t}^{5}\right) \\
\varphi_{\varepsilon t}^{v v l}=\frac{\partial^{7} \varphi_{\varepsilon t}}{\partial(\ln t)^{7}}=A_{\varepsilon}^{6} \cdot \varphi_{\varepsilon t} \cdot\left(1-\varphi_{\varepsilon t}\right) \cdot\left(1-126 \cdot \varphi_{\varepsilon t}+1716 \cdot \varphi_{\varepsilon t}^{2}-\right. \\
\left.-8280 \cdot \varphi_{\varepsilon t}^{3}+16800 \cdot \varphi_{\varepsilon t}^{4}-15120 \cdot \varphi_{\varepsilon t}^{5}+5040 \cdot \varphi_{\varepsilon t}^{6}\right)
\end{gathered}
$$

Using the recurrence formulas (8), (9) that in expanded form are given by

$$
\begin{gathered}
\bar{H}_{1}=\frac{\partial \varphi}{\partial \ln t}=\varphi^{\prime}=\left.\overline{r_{\varepsilon t}}\right|_{t=\tilde{\tau}} \\
\bar{H}_{2}=\frac{\partial \varphi}{\partial \ln t}-\frac{\partial^{2} \varphi}{\partial \ln t^{2}}=\varphi^{\prime}-\left.\varphi^{\prime \prime}\right|_{t=\tilde{\tau}} \\
\bar{H}_{3}=\varphi^{\prime}-\frac{3}{2} \varphi^{\prime \prime}+\left.\frac{1}{2} \varphi^{\prime \prime \prime}\right|_{t=2 \tilde{\tau}} \\
\bar{H}_{4}=\varphi^{\prime}-\frac{11}{6} \varphi^{\prime \prime}+\varphi^{\prime \prime \prime}-\left.\frac{1}{6} \varphi^{\iota v}\right|_{t=3 \tilde{\tau}} \\
\bar{H}_{5}=\varphi^{\prime}-\frac{25}{12} \varphi^{\prime \prime}+\frac{35}{24} \varphi^{\prime \prime \prime}-\frac{5}{12} \varphi^{\iota v}+\left.\frac{1}{24} \varphi^{v}\right|_{t=4 \tilde{\tau}} \\
\bar{H}_{6}=\varphi^{\prime}-\frac{137}{60} \varphi^{\prime \prime}+\frac{15}{8} \varphi^{\prime \prime \prime}-\frac{17}{24} \varphi^{\iota v}+\frac{3}{24} \varphi^{v}-\left.\frac{1}{120} \varphi^{v \iota}\right|_{t=5 \tilde{\tau}} \\
\bar{H}_{7}=\varphi^{\prime}-\frac{49}{20} \varphi^{\prime \prime}+\frac{203}{90} \varphi^{\prime \prime \prime}- \\
-\frac{49}{48} \varphi^{\iota v}+\frac{35}{144} \varphi^{v}-\frac{7}{240} \varphi^{v \iota}+\left.\frac{1}{720} \varphi^{v \iota l}\right|_{t=6 \tilde{\tau}}
\end{gathered}
$$

we obtain expressions for approximations of the normalised relaxation spectrum

$$
\begin{aligned}
& \bar{H}_{1}=\left.\frac{\partial \varphi_{\varepsilon t}}{\partial(\ln t)}\right|_{t=\tilde{\tau}}=\left.\varphi_{\varepsilon t}^{\prime}\right|_{t=\tilde{\tau}}=\left.A_{\varepsilon} \cdot \varphi_{\varepsilon t} \cdot\left(1-\varphi_{\varepsilon t}\right)\right|_{t=\tilde{\tau}} \\
& \bar{H}_{2}=\varphi_{\varepsilon t}^{\prime}-\left.\varphi^{\prime \prime}\right|_{\varepsilon t=\tilde{\tau}}=\left.A_{\varepsilon} \cdot \varphi_{\varepsilon t} \cdot\left(1-\varphi_{\varepsilon t}\right) \cdot\left(1-A_{\varepsilon}\left(1-2 \cdot \varphi_{\varepsilon t}\right)\right)\right|_{t=\tilde{\tau}} \\
& \bar{H}_{3}=\varphi_{\varepsilon t}^{\prime}-\frac{3}{2} \varphi^{\prime \prime}{ }_{\varepsilon t}+\left.\frac{1}{2} \varphi^{\prime \prime \prime}{ }_{\varepsilon t}\right|_{t=2 \tilde{\tau}}=A_{\varepsilon} \cdot \varphi_{\varepsilon t} \cdot\left(1-\varphi_{\varepsilon t}\right) \times \\
& \times\left.\left(1-\frac{3}{2} \cdot A_{\varepsilon} \cdot\left(1-2 \cdot \varphi_{\varepsilon t}\right)+\frac{1}{2} \cdot A_{\varepsilon}^{2} \cdot\left(1-6 \cdot \varphi_{\varepsilon t}+6 \cdot \varphi_{\varepsilon t}^{2}\right)\right)\right|_{t=2 \tilde{\tau}} \\
& \bar{H}_{4}=\varphi_{\varepsilon t}^{\prime}-\frac{11}{6} \varphi^{\prime \prime}{ }_{\varepsilon t}+\varphi^{\prime \prime \prime}{ }_{\varepsilon t}-\left.\frac{1}{6} \varphi^{\prime \prime \prime \prime}{ }_{\varepsilon t}\right|_{t=3 \tilde{\tau}}=A_{\varepsilon} \cdot \varphi_{\varepsilon t} \cdot\left(1-\varphi_{\varepsilon t}\right) \times \\
& \times\left(1-\frac{11}{6} \cdot A_{\varepsilon} \cdot\left(1-2 \cdot \varphi_{\varepsilon t}\right)+A_{\varepsilon}^{2} \cdot\left(1-6 \cdot \varphi_{\varepsilon t}+6 \cdot \varphi_{\varepsilon t}^{2}\right)-\right. \\
& \left.-\frac{1}{6} \cdot A_{\varepsilon}^{3} \cdot\left(1-14 \cdot \varphi_{\varepsilon t}+36 \cdot \varphi_{\varepsilon t}^{2}-24 \cdot \varphi_{\varepsilon t}^{3}\right)\right)\left.\right|_{t=3 \tilde{\tau}}
\end{aligned}
$$




$$
\begin{aligned}
& \bar{H}_{5}=\varphi_{\varepsilon t}^{\prime}-\frac{25}{12} \varphi_{\varepsilon t}^{\prime \prime}+\frac{35}{24} \varphi^{\prime \prime \prime}{ }_{\varepsilon t}-\frac{5}{12} \varphi_{\varepsilon t}^{\prime \prime \prime \prime}+\left.\frac{1}{24} \varphi^{\prime \prime \prime \prime \prime}\right|_{t=4 \tilde{\tau}}= \\
& =A_{\varepsilon} \cdot \varphi_{\varepsilon t} \cdot\left(1-\varphi_{\varepsilon t}\right) \cdot\left(1-\frac{25}{12} \cdot A_{\varepsilon} \cdot\left(1-2 \cdot \varphi_{\varepsilon t}\right)+\frac{35}{24} \cdot A_{\varepsilon}^{2} \times\right. \\
& \times\left(1-6 \cdot \varphi_{\varepsilon t}+6 \cdot \varphi_{\varepsilon t}^{2}\right)-\frac{5}{12} \cdot A_{\varepsilon}^{3} \cdot\left(1-14 \cdot \varphi_{\varepsilon t}+36 \cdot \varphi_{\varepsilon t}^{2}-24 \cdot \varphi_{\varepsilon t}^{3}\right)+ \\
& \left.+\frac{1}{24} \cdot A_{\varepsilon}^{4} \cdot\left(1-30 \cdot \varphi_{\varepsilon t}+150 \cdot \varphi_{\varepsilon t}^{2}-240 \cdot \varphi_{\varepsilon t}^{3}+120 \cdot \varphi_{\varepsilon t}^{4}\right)\right)\left.\right|_{t=4 \tilde{\tau}} \\
& \bar{H}_{6}=\varphi_{\varepsilon t}^{\prime}-\frac{137}{60} \varphi^{\prime \prime}{ }_{\varepsilon t}+\frac{15}{8} \varphi^{\prime \prime \prime}{ }_{\varepsilon t}-\frac{17}{24} \varphi_{\varepsilon t}^{\iota v}+\frac{1}{8} \varphi_{\varepsilon t}^{v}-\left.\frac{1}{120} \varphi_{\varepsilon t}^{v \iota}\right|_{t=5 \tilde{\tau}}= \\
& =A_{\varepsilon} \cdot \varphi_{\varepsilon t} \cdot\left(1-\varphi_{\varepsilon t}\right) \cdot\left(1-\frac{137}{60} \cdot A_{\varepsilon} \cdot\left(1-2 \cdot \varphi_{\varepsilon t}\right)+\frac{15}{8} \cdot A_{\varepsilon}^{2} \times\right. \\
& \times\left(1-6 \cdot \varphi_{\varepsilon t}+6 \cdot \varphi_{\varepsilon t}^{2}\right)-\frac{17}{24} \cdot A_{\varepsilon}^{3} \cdot\left(1-14 \cdot \varphi_{\varepsilon t}+36 \cdot \varphi_{\varepsilon t}^{2}-24 \cdot \varphi_{\varepsilon t}^{3}\right)+ \\
& +\frac{1}{8} \cdot A_{\varepsilon}^{4} \cdot\left(1-30 \cdot \varphi_{\varepsilon t}+150 \cdot \varphi_{\varepsilon t}^{2}-240 \cdot \varphi_{\varepsilon t}^{3}+120 \cdot \varphi_{\varepsilon t}^{4}\right)-\frac{1}{120} \cdot A_{\varepsilon}^{5} \times \\
& \left.\times\left(1-62 \cdot \varphi_{\varepsilon t}+510 \cdot \varphi_{\varepsilon t}^{2}-1560 \cdot \varphi_{\varepsilon t}^{3}+1800 \cdot \varphi_{\varepsilon t}^{4}-720 \cdot \varphi_{\varepsilon t}^{5}\right)\right)\left.\right|_{t=5 \tau} \\
& \bar{H}_{7}=\varphi_{\varepsilon t}^{\prime}-\frac{49}{20} \varphi_{\varepsilon t}^{\prime \prime}+\frac{203}{90} \varphi_{\varepsilon t}^{\prime \prime \prime}-\frac{49}{48} \varphi_{\varepsilon t}^{\iota v}+\frac{35}{144} \varphi_{\varepsilon t}^{v}-\frac{7}{240} \varphi_{\varepsilon t}^{v l}+ \\
& +\left.\frac{1}{720} \varphi_{\varepsilon t}^{v u}\right|_{t=6 \tilde{\tau}}=A_{\varepsilon} \cdot \varphi_{\varepsilon t} \cdot\left(1-\varphi_{\varepsilon t}\right) \cdot\left(1-\frac{49}{20} \cdot A_{\varepsilon} \cdot\left(1-2 \cdot \varphi_{\varepsilon t}\right)+\right. \\
& +\frac{203}{90} \cdot A_{\varepsilon}^{2} \cdot\left(1-6 \cdot \varphi_{\varepsilon t}+6 \cdot \varphi_{\varepsilon t}^{2}\right)-\frac{49}{48} \cdot A_{\varepsilon}^{3} \cdot\left(1-14 \cdot \varphi_{\varepsilon t}+36 \cdot \varphi_{\varepsilon t}^{2}-\right. \\
& \left.-24 \cdot \varphi_{\varepsilon t}^{3}\right)+\frac{35}{144} \cdot A_{\varepsilon}^{4} \cdot\left(1-30 \cdot \varphi_{\varepsilon t}+150 \cdot \varphi_{\varepsilon t}^{2}-240 \cdot \varphi_{\varepsilon t}^{3}+120 \cdot \varphi_{\varepsilon t}^{4}\right)- \\
& -\frac{7}{240} \cdot A_{\varepsilon}^{5} \cdot\left(1-62 \cdot \varphi_{\varepsilon t}+510 \cdot \varphi_{\varepsilon t}^{2}-1560 \cdot \varphi_{\varepsilon t}^{3}+\right. \\
& \left.+1800 \cdot \varphi_{\varepsilon t}^{4}-720 \cdot \varphi_{\varepsilon t}^{5}\right)+\frac{1}{720} \cdot A_{\varepsilon}^{6} \cdot\left(1-126 \cdot \varphi_{\varepsilon t}+1760 \cdot \varphi_{\varepsilon t}^{2}-\right. \\
& \left.\left.-8280 \cdot \varphi_{\varepsilon t}^{3}+16800 \cdot \varphi_{\varepsilon t}^{4}-15120 \cdot \varphi_{\varepsilon t}^{5}+5040 \cdot \varphi_{\varepsilon t}^{6}\right)\right)\left.\right|_{t=6 \tilde{\tau}}
\end{aligned}
$$

The obtained results (25) - (31) can be represented by a single formula (Makarov et al., 2017a).

$$
\bar{H}_{k}=\left.\bar{r}_{\varepsilon t} \cdot \sum_{i=1}^{k}\left(A_{\varepsilon}^{i-1} \cdot P_{k i}\left(\varphi_{\varepsilon t}\right)\right)\right|_{t=(k-1) \tilde{\tau}}
$$

where $P_{k i}\left(\varphi_{\varepsilon t}\right)$ - polynomials of a degree $i-1$ from $\varphi_{\varepsilon t}$. The type of the polynomials $P_{k i}\left(\varphi_{\varepsilon t}\right) \leftarrow$ is shown in Table 1.

Therefore, the relaxation spectrum obtained on the basis of the mathematical model of the relaxation process (1) using the hyperbolic tangent (2) as the normalised relaxation function is completely determined by the structural coefficient $A_{\varepsilon}$ depending on a polymer material and a type of the polynomials $P_{k i}\left(\varphi_{\varepsilon t}\right)$ that do not depend on a polymer material but are characteristics of the mathematical model itself (Demidov et al., 2017).

From the analytical form of the relaxation spectrum approximations $\bar{H}_{k}$, it is evident that these approximations converge rather quickly to their limiting value $\bar{H}$ which characterises the stability of the chosen mathematical model of the relaxation process (1) based on the 
Table 1. The type of polynomials $P_{k i}\left(\varphi_{\varepsilon t}\right)$ included in the formulas for approximations of the relaxation spectra of polymer materials.

\begin{tabular}{llllll}
\hline $\mathrm{i} \mid \mathrm{k}$ & 1 & 2 & 3 & 4 & 5 \\
\hline 1 & 1 & 1 & 1 & 1 & 1 \\
2 & - & $2 \varphi-1$ & $3 \varphi-\frac{3}{2}$ & $\frac{11}{3} \varphi-\frac{11}{6}$ & $\frac{25}{6} \varphi-\frac{25}{12}$ \\
3 & - & - & $3 \varphi^{2}-3 \varphi+\frac{1}{2}$ & $6 \varphi^{2}-6 \varphi+1$ & $\frac{35}{4} \varphi^{2}-\frac{35}{4} \varphi+\frac{35}{24}$ \\
4 & - & - & - & $4 \varphi^{3}-6 \varphi^{2}+\frac{7}{3} \varphi-\frac{1}{6}$ & $10 \varphi^{3}-15 \varphi^{2}+\frac{35}{6} \varphi-\frac{5}{12}$ \\
5 & - & - & - & - & $5 \varphi^{4}-10 \varphi^{3}+\frac{25}{4} \varphi^{2}-\frac{5}{4} \varphi+\frac{1}{24}$ \\
\hline
\end{tabular}

\begin{tabular}{lll}
\hline ilk & 6 & 7 \\
\hline 1 & 1 & 1 \\
2 & $\frac{137}{30} \varphi-\frac{137}{60}$ & $\frac{49}{10} \varphi-\frac{49}{20}$ \\
3 & $\frac{45}{4} \varphi^{2}-\frac{45}{4} \varphi+\frac{15}{8}$ & $\frac{203}{15} \varphi^{2}-\frac{203}{15} \varphi+\frac{203}{90}$ \\
4 & $17 \varphi^{3}-\frac{51}{2} \varphi^{2}+\frac{119}{12} \varphi-\frac{17}{24}$ & $\frac{49}{2} \varphi^{3}-\frac{147}{4} \varphi^{2}+\frac{343}{24} \varphi-\frac{49}{48}$ \\
5 & $15 \varphi^{4}-30 \varphi^{3}+\frac{75}{4} \varphi^{2}-\frac{15}{4} \varphi+\frac{1}{8}$ & $\frac{175}{6} \varphi^{4}-\frac{175}{3} \varphi^{3}+\frac{875}{24} \varphi^{2}-\frac{175}{24} \varphi+\frac{35}{144}$ \\
6 & $6 \varphi^{5}-15 \varphi^{4}+13 \varphi^{3}-\frac{17}{4} \varphi^{2}+\frac{31}{60} \varphi-\frac{1}{120}$ & $21 \varphi^{5}-\frac{105}{2} \varphi^{4}+\frac{91}{2} \varphi^{3}-$ \\
7 & & $-\frac{119}{8} \varphi^{2}+\frac{217}{120} \varphi-\frac{7}{240}$ \\
& - & $7 \varphi^{6}-21 \varphi^{5}+\frac{70}{3} \varphi^{4}-\frac{23}{2} \varphi^{3}+$ \\
\hline
\end{tabular}

hyperbolic tangent (2). This means that, with a small permissible error, as the relaxation spectrum its first approximation can be accepted, which is given by (Makarov et al., 2017b).

$$
\bar{H}_{1}=\left.A_{\varepsilon} \cdot \varphi_{\varepsilon t} \cdot\left(1-\varphi_{\varepsilon t}\right)\right|_{t=\tilde{\tau}}
$$

and depends only on the structural coefficient $A_{\varepsilon}$ and on the relaxation function $\varphi_{\varepsilon t}$ (2).

Taking into account that the approximations of the spectrum of relaxation times $\bar{H}_{\varepsilon \tilde{\tau}}$ are obtained by the logarithmic time scale derivatives of the normalised relaxation function (2) and knowing the type of the relaxation spectrum, the inverse problem can be solved. It is possible to obtain the corresponding normalised relaxation function by integrating. That is the basis of the mathematical model of viscoelastic properties of polymeric materials (Pereborova, $2020 \mathrm{~g}$ ).

The example of the relaxation spectrum of a polyester thread 83 tex. is shown in Figure 3 . And the corresponding spectrum of the relaxation times of a polyester fabric made from polyester threads 83 tex. is shown in Figure 4.

Analysing the graphs of the relaxation times spectra of a polyester thread 83 tex. and a polyester fabric made of polyester threads 83 tex., it can be noted that the intensity parameter corresponds to a polyester thread $A_{\varepsilon}=0,14$, while in a polyester fabric it is much higher $A_{\varepsilon}=0,92$ which leads to a more pronounced shape of the relaxation spectrum curve (Figure 3 ., Figure 4.) (Makarov et al., 2015b).

It should be noted that the modified logarithmic time scale contains the deformation-time function

$$
\ln \frac{t}{\tau_{\varepsilon}}=\ln \frac{t}{t_{1}}+\ln \frac{t_{1}}{\tau_{\varepsilon}}
$$




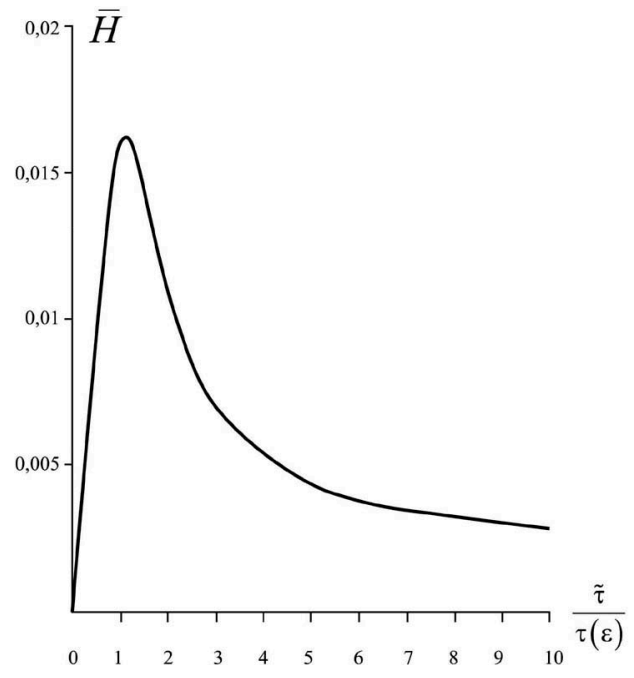

Figure 3. The graph of the spectrum of relaxation times of a polyester thread 83 tex., $T=40^{\circ} \mathrm{C}$.

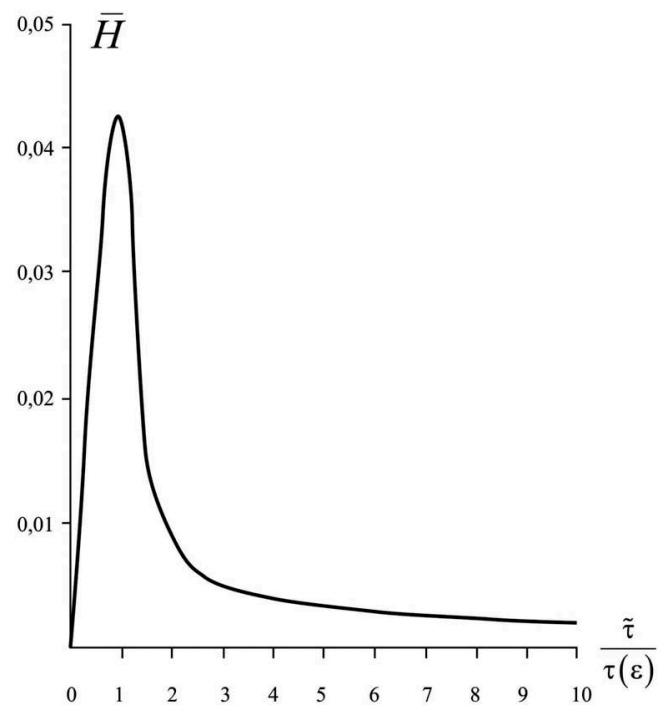

Figure 4. The graph of the spectrum of relaxation times of polyester fabric for technical purposes, $T=40^{\circ} \mathrm{C}$.

reflecting the deformation-time analogy. Due to this time modification, the obtained relaxation spectra are generalised, that means, they extend to the entire initial range of nondestructive deformation (Makarov et al., 2014a).

\section{OBTAINING OF THE DELAY SPECTRA OF POLYMERIC MATERIALS}

To obtain the analytical form of the delay spectrum of polymeric materials, a variant of the mathematical model of the creep process can be used in the form (Demidov et al., 2006a). 
where

$$
\varepsilon_{t}=D_{0} \sigma_{t}+\left(D_{\infty}-D_{0}\right) \cdot \int_{0}^{t} \sigma_{\theta} \cdot \varphi_{\sigma ; t-\theta}^{\prime} d \theta
$$

$\varepsilon_{t}$ - time-dependent deformation $t$,

$\sigma_{t}$ - time-dependent stress $t$,

$D_{0}$ - initial elastic compliance,

$D_{\infty}$ - finite quasiequilibrium compliance,

$$
\varphi_{\sigma t}=\frac{1}{2} \cdot\left(1+\operatorname{th}\left(\frac{A_{\sigma}}{2} \cdot \ln \left(\frac{t}{\tau_{\sigma}}\right)\right)\right)
$$

normalised delay function that forms the basis of the mathematical model of creep (Demidov et al., 2009),

$$
\varphi_{\sigma t}^{\prime}=\bar{r}_{\sigma t}=\frac{\partial \varphi_{\sigma t}}{\partial(\ln t)}=\frac{A_{\sigma}}{4} \cdot \frac{1}{c h^{2}\left(W_{\sigma t}\right)}=\frac{A_{\sigma}}{4} \cdot\left(1-t h^{2}\left(W_{\sigma t}\right)\right)=A_{\sigma} \cdot \varphi_{\sigma t} \cdot\left(1-\varphi_{\sigma t}\right)
$$

integral delay kernel,

$$
W_{\sigma t}=\frac{A_{\sigma}}{2} \cdot \ln \frac{t}{\tau_{\sigma}}=\frac{A_{\sigma}}{2} \cdot\left(\ln \left(\frac{t}{t_{1}}\right)+\ln \left(\frac{t_{1}}{\tau_{\sigma}}\right)\right)
$$

$A_{\sigma}$ - parameter of the intensity of creep processes,

$$
f_{\sigma, \tau_{\sigma}}=\ln \left(\frac{t}{\tau_{\sigma}}\right)
$$

logarithmic function of the delay times.

The analytical form of the delay spectrum $\bar{Q}_{\sigma \tilde{\tau}}$ can be obtained by the known formula (Makarov et al., 2014b).

$$
\int_{0}^{\infty} \bar{Q}_{\sigma \tilde{\tau}} \cdot e^{-t x} \cdot d x=\frac{d \varphi_{\sigma t}}{d t}=r_{\sigma t}
$$

by successive approximations.

The given formula (41) is the Laplace transform in which the delay spectrum $\bar{Q}_{\sigma \tilde{\tau}}$ plays the role of the original, and the delay kernel $r_{\sigma t}$ plays the role of the figure in terms of operator calculus. This dependence (40) is obtained on the basis of the properties of the Generalised Kelvin-Voigt model (Demidov et al., 2007a).

The application of the hyperbolic tangent function as the normalised delay function (36), leads to the following logarithmic delay kernel (Makarov et al., 2020).

$$
D_{\sigma t}^{\prime}=\frac{\partial D_{\sigma t}}{\partial \ln t}=\left(D_{\infty}-D_{0}\right) \cdot \bar{r}_{\sigma t}=\frac{A_{\sigma}}{4} \cdot\left(D_{\infty}-D_{0}\right) \cdot\left(1-t h^{2}\left(W_{\sigma t}\right)\right)
$$

The force-time argument (38) of the delay kernel (37) takes into account the current time factor and the characteristically average internal delay times. In the known approximation, the delay kernel (37) characterises the distribution of relaxing particles over their micromechanical delay times (Demidov et al., 2006b). 
In order to obtain approximations of the normalised delay spectrum, the known recurrence formulas can be used (Demidov et al., 2006c) if $k=1$

$$
\bar{Q}_{1}=\frac{\partial \varphi_{\sigma \mathrm{t}}}{\partial \ln t}=\varphi_{\sigma \mathrm{t}}^{\prime}=\left.\bar{r}_{\sigma \mathrm{t}}\right|_{t=\tilde{\tau}}
$$

and if $k 2$

$$
\bar{Q}_{k}=\bar{Q}_{k-1}-\left.\frac{1}{k-1} \cdot \stackrel{d \bar{Q}_{k-1}}{d \ln \tilde{\tau}}\right|_{t=(k-1) \tilde{\tau}}
$$

For calculating the values of the derivatives $\bar{r}_{\sigma t}=\frac{\partial \varphi_{\sigma t}}{\partial \ln t}, \ldots, \frac{\partial^{k} \varphi_{\sigma t}}{\partial \ln t^{k}}, \ldots$, where for the delay function $\varphi_{\sigma t}=\varphi$ the hyperbolic tangent is chosen (36) and $\mathrm{W}_{\sigma \mathrm{t}}=W$ is the structure-force-time argument-functional (38), we obtain

$$
\begin{aligned}
& \varphi_{\sigma t}=\frac{1}{2} \cdot\left(1+t h\left(\frac{A_{\sigma}}{2} \cdot \ln \left(\frac{t}{\tau_{\sigma}}\right)\right)\right) \\
& \varphi_{\sigma t}^{\prime}=\bar{r}_{\sigma t}=\frac{\partial \varphi_{\sigma t}}{\partial(\ln t)}=\frac{A_{\sigma}}{4} \cdot \frac{1}{c h^{2}\left(W_{\sigma t}\right)}= \\
& =\frac{A_{\sigma}}{4} \cdot\left(1-t h^{2}\left(W_{\sigma t}\right)\right)=A_{\sigma} \cdot \varphi_{\sigma t} \cdot\left(1-\varphi_{\sigma t}\right) \\
& \varphi^{\prime \prime}{ }_{\sigma t}=\frac{\partial^{2} \varphi_{\sigma t}}{\partial(\ln t)^{2}}=A_{\sigma}^{2} \cdot \varphi_{\sigma t} \cdot\left(1-\varphi_{\sigma t}\right) \cdot\left(1-2 \cdot \varphi_{\sigma t}\right) \\
& \varphi^{\prime \prime \prime}{ }_{\sigma t}=\frac{\partial^{3} \varphi_{\sigma t}}{\partial(\ln t)^{3}}=A_{\sigma}^{3} \cdot \varphi_{\sigma t} \cdot\left(1-\varphi_{\sigma t}\right) \cdot\left(1-6 \cdot \varphi_{\sigma t}+6 \cdot \varphi_{\sigma t}^{2}\right) \\
& \varphi_{\sigma t}^{\iota v}=\frac{\partial^{4} \varphi_{\sigma t}}{\partial(\ln t)^{4}}=A_{\sigma}^{4} \cdot \varphi_{\sigma t} \cdot\left(1-\varphi_{\sigma t}\right) \times \\
& \times\left(1-14 \cdot \varphi_{\sigma t}+36 \cdot \varphi_{\sigma t}^{2}-24 \cdot \varphi_{\sigma t}^{3}\right) \\
& \varphi_{\sigma t}^{v}=\frac{\partial^{5} \varphi_{\sigma t}}{\partial(\ln t)^{5}}=A_{\sigma}^{5} \cdot \varphi_{\sigma t} \cdot\left(1-\varphi_{\sigma t}\right) \times \\
& \times\left(1-30 \cdot \varphi_{\sigma t}+150 \cdot \varphi_{\sigma t}^{2}-240 \cdot \varphi_{\sigma t}^{3}+120 \cdot \varphi_{\sigma t}^{4}\right) \\
& \varphi_{\sigma t}^{v \iota}=\frac{\partial^{6} \varphi_{\sigma t}}{\partial(\ln t)^{6}}=A_{\sigma}^{6} \cdot \varphi_{\sigma t} \cdot\left(1-\varphi_{\sigma t}\right) \cdot\left(1-62 \cdot \varphi_{\sigma t}+\right. \\
& \left.+510 \cdot \varphi_{\sigma t}^{2}-1560 \cdot \varphi_{\sigma t}^{3}+1800 \cdot \varphi_{\sigma t}^{4}-720 \cdot \varphi_{\sigma t}^{5}\right) \\
& \varphi_{\sigma t}^{v u \iota}=\frac{\partial^{7} \varphi_{\sigma t}}{\partial(\ln t)^{7}}=A_{\sigma}^{6} \cdot \varphi_{\sigma t} \cdot\left(1-\varphi_{\sigma t}\right) \cdot\left(1-126 \cdot \varphi_{\sigma t}+1716 \cdot \varphi_{\sigma t}^{2}-\right. \\
& \left.-8280 \cdot \varphi_{\sigma t}^{3}+16800 \cdot \varphi_{\sigma t}^{4}-15120 \cdot \varphi_{\sigma t}^{5}+5040 \cdot \varphi_{\sigma t}^{6}\right)
\end{aligned}
$$

and using the recurrence formulas (42), (43), that in expanded form are given by 


$$
\begin{gathered}
\bar{Q}_{1}=\frac{\partial \varphi}{\partial \ln t}=\varphi^{\prime}=\left.\overline{r_{\sigma \tau}}\right|_{t=\tilde{\tau}} \\
\bar{Q}_{2}=\frac{\partial \varphi}{\partial \ln t}-\frac{\partial^{2} \varphi}{\partial \ln t^{2}}=\varphi^{\prime}-\left.\varphi^{\prime \prime}\right|_{t=\tilde{\tau}} \\
\bar{Q}_{3}=\varphi^{\prime}-\frac{3}{2} \varphi^{\prime \prime}+\left.\frac{1}{2} \varphi^{\prime \prime \prime}\right|_{t=2 \tilde{\tau}} \\
\bar{Q}_{4}=\varphi^{\prime}-\frac{11}{6} \varphi^{\prime \prime}+\varphi^{\prime \prime \prime}-\left.\frac{1}{6} \varphi^{\iota v}\right|_{t=3 \tilde{\tau}} \\
\bar{Q}_{5}=\varphi^{\prime}-\frac{25}{12} \varphi^{\prime \prime}+\frac{35}{24} \varphi^{\prime \prime \prime}-\frac{5}{12} \varphi^{\iota v}+\left.\frac{1}{24} \varphi^{v}\right|_{t=4 \tilde{\tau}} \\
\bar{Q}_{6}=\varphi^{\prime}-\frac{137}{60} \varphi^{\prime \prime}+\frac{15}{8} \varphi^{\prime \prime \prime}-\frac{17}{24} \varphi^{\iota v}+\frac{3}{24} \varphi^{v}-\left.\frac{1}{120} \varphi^{v \iota}\right|_{t=5 \tilde{\tau}} \\
\bar{Q}_{7}=\varphi^{\prime}-\frac{49}{20} \varphi^{\prime \prime}+\frac{203}{90} \varphi^{\prime \prime \prime}-\frac{49}{48} \varphi^{\iota v}+\frac{35}{144} \varphi^{v}-\frac{7}{240} \varphi^{v \iota}+\left.\frac{1}{720} \varphi^{v \iota \iota}\right|_{t=6 \tilde{\tau}}
\end{gathered}
$$

we obtain expressions for approximations of the normalised delay spectrum

$$
\begin{gathered}
\bar{Q}_{1}=\left.\frac{\partial \varphi_{\sigma t}}{\partial(\ln t)}\right|_{t=\tilde{\tau}}=\left.\varphi_{\sigma t}^{\prime}\right|_{t=\tilde{\tau}}=\left.A_{\sigma} \cdot \varphi_{\sigma t} \cdot\left(1-\varphi_{\sigma t}\right)\right|_{t=\tilde{\tau}} \\
\bar{Q}_{2}=\varphi_{\sigma t}^{\prime}-\left.\varphi^{\prime \prime}{ }_{\sigma t}\right|_{t=\tilde{\tau}}=\left.A_{\sigma} \cdot \varphi_{\sigma t} \cdot\left(1-\varphi_{\sigma t}\right) \cdot\left(1-A_{\sigma}\left(1-2 \cdot \varphi_{\sigma t}\right)\right)\right|_{t=\tilde{\tau}} \\
\bar{Q}_{3}=\varphi_{\sigma t}^{\prime}-\frac{3}{2} \varphi^{\prime \prime}{ }_{\sigma t}+\left.\frac{1}{2} \varphi^{\prime \prime \prime}{ }_{\sigma t}\right|_{t=2 \tilde{\tau}}=A_{\sigma} \cdot \varphi_{\sigma t} \cdot\left(1-\varphi_{\sigma t}\right) \times \\
\times\left.\left(1-\frac{3}{2} \cdot A_{\sigma} \cdot\left(1-2 \cdot \varphi_{\sigma t}\right)+\frac{1}{2} \cdot A_{\sigma}^{2} \cdot\left(1-6 \cdot \varphi_{\sigma t}+6 \cdot \varphi_{\sigma t}^{2}\right)\right)\right|_{t=2 \tilde{\tau}} \\
\bar{Q}_{4}=\varphi^{\prime}{ }_{\sigma t}-\frac{11}{6} \varphi^{\prime \prime}{ }_{\sigma t}+\varphi^{\prime \prime \prime}{ }_{\sigma t}-\left.\frac{1}{6} \varphi^{\prime \prime \prime \prime}{ }_{\sigma t}\right|_{t=3 \tilde{\tau}}=A_{\sigma} \cdot \varphi_{\sigma t} \cdot\left(1-\varphi_{\sigma t}\right) \times \\
\times\left(1-\frac{11}{6} \cdot A_{\sigma} \cdot\left(1-2 \cdot \varphi_{\sigma t}\right)+A_{\sigma}^{2} \cdot\left(1-6 \cdot \varphi_{\sigma t}+6 \cdot \varphi_{\sigma t}^{2}\right)-\right. \\
\left.-\frac{1}{6} \cdot A_{\sigma}^{3} \cdot\left(1-14 \cdot \varphi_{\sigma t}+36 \cdot \varphi_{\sigma t}^{2}-24 \cdot \varphi_{\sigma t}^{3}\right)\right)\left.\right|_{t=3 \tilde{\tau}} \\
\bar{Q}_{5}=\varphi_{\sigma t}^{\prime}-\frac{25}{12} \varphi_{\sigma t}^{\prime \prime}+\frac{35}{24} \varphi^{\prime \prime \prime}{ }_{\sigma t}-\frac{5}{12} \varphi^{\prime \prime \prime \prime}{ }_{\sigma t}+\left.\frac{1}{24} \varphi^{\prime \prime \prime \prime \prime}{ }_{\sigma t}\right|_{t=4 \tilde{\tau}}= \\
=A_{\sigma} \cdot \varphi_{\sigma t} \cdot\left(1-\varphi_{\sigma t}\right) \cdot\left(1-\frac{25}{12} \cdot A_{\sigma} \cdot\left(1-2 \cdot \varphi_{\sigma t}\right)+\frac{35}{24} \cdot A_{\sigma}^{2} \times\right. \\
\times\left(1-6 \cdot \varphi_{\sigma t}+6 \cdot \varphi_{\sigma t}^{2}\right)-\frac{5}{12} \cdot A_{\sigma}^{3} \cdot\left(1-14 \cdot \varphi_{\sigma t}+36 \cdot \varphi_{\sigma t}^{2}-24 \cdot \varphi_{\sigma t}^{3}\right)+ \\
\left.\frac{1}{24} \cdot A_{\sigma}^{4} \cdot\left(1-30 \cdot \varphi_{\sigma t}+150 \cdot \varphi_{\sigma t}^{2}-240 \cdot \varphi_{\sigma t}^{3}+120 \cdot \varphi_{\sigma t}^{4}\right)\right)\left.\right|_{t=4 \tilde{\tau}}
\end{gathered}
$$




$$
\begin{aligned}
& \bar{Q}_{6}=\varphi_{\sigma t}^{\prime}-\frac{137}{60} \varphi_{\sigma t}^{\prime \prime}+\frac{15}{8} \varphi_{\sigma t}^{\prime \prime \prime}-\frac{17}{24} \varphi_{\sigma t}^{\iota v}+\frac{1}{8} \varphi_{\sigma t}^{v}-\left.\frac{1}{120} \varphi_{\sigma t}^{v L}\right|_{t=5 \tilde{\tau}}= \\
& \left.\times\left(1-62 \cdot \varphi_{\sigma t}+510 \cdot \varphi_{\sigma t}^{2}-1560 \cdot \varphi_{\sigma t}^{3}+1800 \cdot \varphi_{\sigma t}^{4}-720 \cdot \varphi_{\sigma t}^{5}\right)\right)\left.\right|_{t=5 \tilde{\tau}} \\
& =A_{\sigma} \cdot \varphi_{\sigma t} \cdot\left(1-\varphi_{\sigma t}\right) \cdot\left(1-\frac{137}{60} \cdot A_{\sigma} \cdot\left(1-2 \cdot \varphi_{\sigma t}\right)+\frac{15}{8} \cdot A_{\sigma}^{2} \times\right. \\
& \times\left(1-6 \cdot \varphi_{\sigma t}+6 \cdot \varphi_{\sigma t}^{2}\right)-\frac{17}{24} \cdot A_{\sigma}^{3} \cdot\left(1-14 \cdot \varphi_{\sigma t}+36 \cdot \varphi_{\sigma t}^{2}-24 \cdot \varphi_{\sigma t}^{3}\right)+ \\
& +\frac{1}{8} \cdot A_{\sigma}^{4} \cdot\left(1-30 \cdot \varphi_{\sigma t}+150 \cdot \varphi_{\sigma t}^{2}-240 \cdot \varphi_{\sigma t}^{3}+120 \cdot \varphi_{\sigma t}^{4}\right)-\frac{1}{120} \cdot A_{\sigma}^{5} \times \\
& \bar{Q}_{7}=\varphi_{\sigma t}^{\prime}-\frac{49}{20} \varphi^{\prime \prime}{ }_{\sigma t}+\frac{203}{90} \varphi^{\prime \prime \prime}{ }_{\sigma t}-\frac{49}{48} \varphi_{\sigma t}^{\iota v}+\frac{35}{144} \varphi_{\sigma t}^{v}-\frac{7}{240} \varphi_{\sigma t}^{v l}+ \\
& +\left.\frac{1}{720} \varphi_{\sigma t}^{v u t}\right|_{t=6 \tilde{\tau}}=A_{\sigma} \cdot \varphi_{\sigma t} \cdot\left(1-\varphi_{\sigma t}\right) \cdot\left(1-\frac{49}{20} \cdot A_{\sigma} \cdot\left(1-2 \cdot \varphi_{\sigma t}\right)+\right. \\
& +\frac{203}{90} \cdot A_{\sigma}^{2} \cdot\left(1-6 \cdot \varphi_{\sigma t}+6 \cdot \varphi_{\sigma t}^{2}\right)-\frac{49}{48} \cdot A_{\sigma}^{3} \cdot\left(1-14 \cdot \varphi_{\sigma t}+36 \cdot \varphi_{\sigma t}^{2}-\right. \\
& \left.-24 \cdot \varphi_{\sigma t}^{3}\right)+\frac{35}{144} \cdot A_{\sigma}^{4} \cdot\left(1-30 \cdot \varphi_{\sigma t}+150 \cdot \varphi_{\sigma t}^{2}-240 \cdot \varphi_{\sigma t}^{3}+120 \cdot \varphi_{\sigma t}^{4}\right)- \\
& -\frac{7}{240} \cdot A_{\sigma}^{5} \cdot\left(1-62 \cdot \varphi_{\sigma t}+510 \cdot \varphi_{\sigma t}^{2}-1560 \cdot \varphi_{\sigma t}^{3}+\right. \\
& \left.+1800 \cdot \varphi_{\sigma t}^{4}-720 \cdot \varphi_{\sigma t}^{5}\right)+\frac{1}{720} \cdot A_{\sigma}^{6} \cdot\left(1-126 \cdot \varphi_{\sigma t}+1760 \cdot \varphi_{\sigma t}^{2}-\right. \\
& \left.\left.-8280 \cdot \varphi_{\sigma t}^{3}+16800 \cdot \varphi_{\sigma t}^{4}-15120 \cdot \varphi_{\sigma t}^{5}+5040 \cdot \varphi_{\sigma t}^{6}\right)\right)\left.\right|_{t=6 \tilde{\tau}}
\end{aligned}
$$

The obtained results (59) - (65) can be represented by a single formula (Demidov et al., 2006d).

$$
\bar{Q}_{k}=\left.\bar{r}_{\sigma t} \cdot \sum_{i=1}^{k}\left(A_{\sigma}^{i-1} \cdot P_{k i}\left(\varphi_{\sigma t}\right)\right)\right|_{t=(k-1) \tilde{\tau}}
$$

where $P_{k i}\left(\varphi_{\sigma t}\right) \leftarrow$ polynomials of a degree $i-1$ from $\varphi_{\sigma t}$. The type of the polynomials $P_{k i}\left(\varphi_{\sigma t}\right)$ is shown in Table 2.

Therefore, the delay spectrum obtained on the basis of the mathematical model of the creep process, using the hyperbolic tangent (36) as the normalised delay function is completely determined by the structural coefficient $A_{\sigma}$, depending on a polymer material and the type of the polynomials $P_{k i}\left(\varphi_{\sigma t}\right)$ that do not depend on a polymer material but are the characteristics of the mathematical model itself (Demidov et al., 2007b).

From the analytical form of the delay spectrum approximations $\bar{Q}_{k}$, it is evident that these approximations converge rather quickly to their limiting value $\bar{Q}$ which characterises the stability of the chosen mathematical model of the creep process based on the hyperbolic tangent (36). This means that, with a small permissible error, as the relaxation spectrum its first approximation can be accepted, which is given by (Stalevich et al., 2003)

$$
\bar{Q}_{1}=\left.A_{\sigma} \cdot \varphi_{\sigma t} \cdot\left(1-\varphi_{\sigma t}\right)\right|_{t=\tilde{\tau}}
$$

and depends only on the structural coefficient $A_{\sigma}$ and on the delay function $\varphi_{\sigma t}$ in the form of the hyperbolic tangent (36).

Taking into account that the approximations of the spectrum of delay times $\bar{Q}_{\sigma \tilde{\tau}}$ are obtained by the logarithmic time scale derivatives of the normalised delay function (36), and knowing the type of the delay spectrum the inverse problem can be solved. It is possible to 
Table 2. The type of polynomials $P_{k i}\left(\varphi_{\sigma t}\right)$, included in the formulas for approximations of the relaxation spectra of polymer materials.

\begin{tabular}{llllll}
\hline $\mathrm{ilk}$ & 1 & 2 & 3 & 4 & 5 \\
\hline 1 & 1 & 1 & 1 & 1 & 1 \\
2 & - & $2 \varphi-1$ & $3 \varphi-\frac{3}{2}$ & $\frac{11}{3} \varphi-\frac{11}{6}$ & $\frac{25}{6} \varphi-\frac{25}{12}$ \\
3 & - & - & $3 \varphi^{2}-3 \varphi+\frac{1}{2}$ & $6 \varphi^{2}-6 \varphi+1$ & $\frac{35}{4} \varphi^{2}-\frac{35}{4} \varphi+\frac{35}{24}$ \\
4 & - & - & - & $4 \varphi^{3}-6 \varphi^{2}+\frac{7}{3} \varphi-\frac{1}{6}$ & $10 \varphi^{3}-15 \varphi^{2}+\frac{35}{6} \varphi-\frac{5}{12}$ \\
5 & - & - & - & - & $5 \varphi^{4}-10 \varphi^{3}+\frac{25}{4} \varphi^{2}-\frac{5}{4} \varphi+\frac{1}{24}$ \\
\hline
\end{tabular}

\begin{tabular}{lll}
\hline $\mathrm{i} \mathrm{k}$ & 6 & 7 \\
\hline 1 & 1 & 1 \\
2 & $\frac{137}{30} \varphi-\frac{137}{60}$ & $\frac{49}{10} \varphi-\frac{49}{20}$ \\
3 & $\frac{45}{4} \varphi^{2}-\frac{45}{4} \varphi+\frac{15}{8}$ & $\frac{203}{15} \varphi^{2}-\frac{203}{15} \varphi+\frac{203}{90}$ \\
4 & $17 \varphi^{3}-\frac{51}{2} \varphi^{2}+\frac{119}{12} \varphi-\frac{17}{24}$ & $\frac{49}{2} \varphi^{3}-\frac{147}{4} \varphi^{2}+\frac{343}{24} \varphi-\frac{49}{48}$ \\
5 & $15 \varphi^{4}-30 \varphi^{3}+\frac{75}{4} \varphi^{2}-\frac{15}{4} \varphi+\frac{1}{8}$ & $\frac{175}{6} \varphi^{4}-\frac{175}{3} \varphi^{3}+\frac{875}{24} \varphi^{2}-\frac{175}{24} \varphi+\frac{35}{144}$ \\
6 & $6 \varphi^{5}-15 \varphi^{4}+13 \varphi^{3}-\frac{17}{4} \varphi^{2}+\frac{31}{60} \varphi-\frac{1}{120}$ & $21 \varphi^{5}-\frac{105}{2} \varphi^{4}+\frac{91}{2} \varphi^{3}-\frac{119}{8} \varphi^{2}+\frac{217}{120} \varphi-\frac{7}{240}$ \\
7 & - & $7 \varphi^{6}-21 \varphi^{5}+\frac{70}{3} \varphi^{4}-\frac{23}{2} \varphi^{3}+\frac{110}{45} \varphi^{2}-\frac{31}{180} \varphi+\frac{1}{720}$ \\
\hline
\end{tabular}

obtain the corresponding normalised relaxation function by integrating. That is the basis of the mathematical model of viscoelastic properties (Makarov 2002).

The example of the delay spectrum of a polyester thread 83 tex. is shown in Figure 5. And the corresponding spectrum of the delay times of a polyester fabric made from polyester threads 83 tex. is shown in Figure 6.

Analysing the graphs of the delay times spectra of a polyester thread 83 tex. and polyester fabric made of polyester threads 83 tex., it can be noted that the intensity parameter corresponds to a polyester thread $A_{\sigma}=0,30$, while in a polyester fabric it is much higher $A_{\sigma}=1,45$ which leads to a more pronounced shape of the relaxation spectrum curve (Figure 5., Figure 6.)

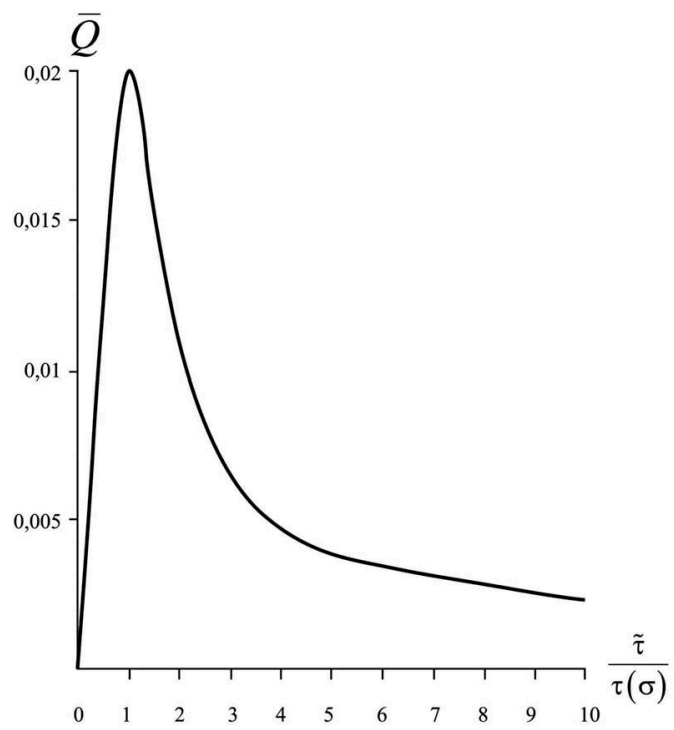

Figure 5. The graph of the spectrum of the delay times of a polyester thread 83 tex., $T=40^{\circ} \mathrm{C}$. 


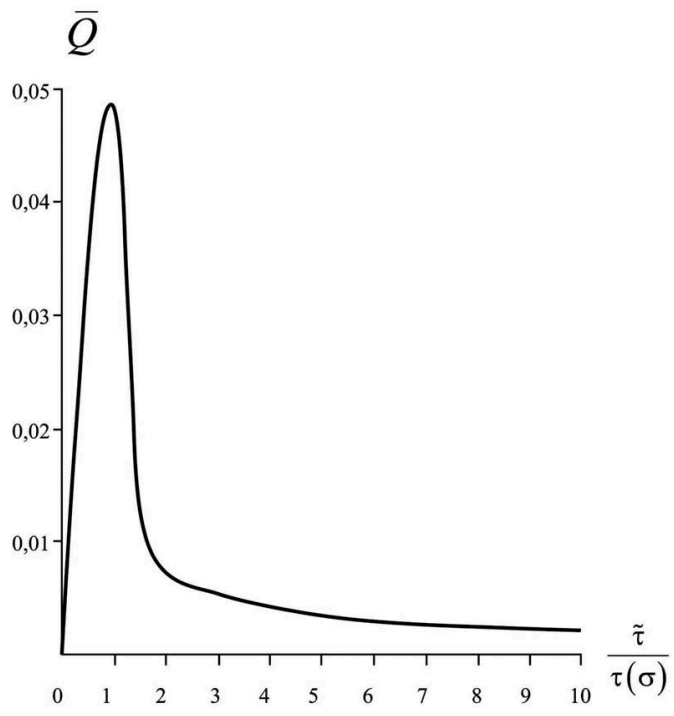

Figure 6. The graph of the spectrum of the delay times of polyester fabric made from polyester threads 83 tex., $T=40^{\circ} \mathrm{C}$.

It should be noted that the modified logarithmic time scale contains the force-time function

$$
\ln \frac{t}{\tau_{\sigma}}=\ln \frac{t}{t_{1}}+\ln \frac{t_{1}}{\tau_{\sigma}}=\ln \frac{t}{t_{1}}+f_{\sigma_{1} \sigma}
$$

reflecting the force-time analogy. Due to this time modification, the obtained delay spectra are generalised, that means, they extend to the entire initial range of non-destructive deformation (Stalevich et al., 2002a).

\section{THE INTERRELATION OF VISCOELASTIC PARAMETERS-CHARACTERISTICS AND THE SPECTRA OF RELAXATION AND DELAY}

As it is obvious from the previous study ( 2 and 3 ), the spectra of relaxation times and delay times are completely determined by the tasks of the mathematical model of relaxation and the mathematical model of creep, respectively, as well as the values of the intensity parameters $A_{\varepsilon}$ and $A_{\sigma}$ of these processes.

The approximations of the spectra of relaxation and delay times converge rather quickly to their limiting values. Therefore, according to its physical meaning, the normalised relaxation function is obtained by integrating the relaxation spectrum which characterises the distribution of particles over relaxation times and is completely determined by the average value of the relaxation times and the value of the structural coefficient $A_{\varepsilon}$. Similar results were achieved by obtaining the delay spectrum from the measured creep processes. If the preference is given to the average relaxation time $\tau_{\varepsilon}$, depending on the deformation $\varepsilon$ and the relaxation spectrum, this physical approach to nonlinear hereditary viscoelasticity can be called geometric (Stalevich et al., 2002b). If the average delay time $\tau_{\sigma}$ and the spectrum of the delay $\overline{\mathrm{Q}}_{\sigma \tilde{\tau}}$ are taken as a basis, i.e. the distribution of the number of particles over the delay time, then this approach can be called the force one (Stalevich et al., 2000).

For complex deformation modes, these approaches correspond to equations of the hereditary type written in a logarithmic time scale as (Makarov et al., 2014c) 


$$
\begin{gathered}
\sigma_{\mathrm{t}}=E_{o} \cdot \varepsilon_{t}+\int_{-\infty}^{\ln t} \varepsilon_{t-s} \cdot \frac{\partial E_{\varepsilon s}}{\partial \ln s} \cdot d \ln s \\
\varepsilon_{\mathrm{t}}=E_{o}^{-1} \cdot \sigma_{t}+\int_{-\infty}^{\ln t} \sigma_{t-s} \cdot \frac{\partial D_{\sigma s}}{\partial \ln s} \cdot d \ln s
\end{gathered}
$$

The equation (69) describes a complex relaxation process when $\varepsilon \neq$ const, and the equation (70) describes a complex creep process when $\sigma \neq$ const.

The first approximations of the relaxation spectrum (Pereborovaet al., 2018e; Makarov et al., 2018b)

$$
\begin{gathered}
\left.\frac{\partial \mathrm{E}_{\varepsilon \mathrm{s}}}{\partial \operatorname{lns}} \cong\left(E_{o}-E_{\infty}\right) \bar{H}_{\varepsilon \tilde{\tau}}\right|_{\tilde{\tau}=s} \\
\left.\frac{\partial \mathrm{D}_{\sigma \mathrm{s}}}{\partial \operatorname{lns}} \cong\left(E_{\infty}^{-1}-E_{o}^{-1}\right) \bar{Q}_{\tilde{\sigma} \tilde{\tau}}\right|_{\tilde{\tau}=s}
\end{gathered}
$$

characterise the spectral meaning of the equations kernels (69) and (70) and, as a result, the preferred type of notation (69) and (70) for practical analysis and calculations. For example, analysis or calculation of the stress-strain diagram by the formula (69) and the recovery deformation process by the formula (70) (Makarov et al., 2015c).

The physical validity of using the equations of state in the form (69) and (70) is also confirmed by the observed proportionality between the logarithm of the statistical relaxation or delay time and the activation energy according to the classical Arrhenius-Boltzmann formula (Demidov et al., 2007c)

$$
\begin{aligned}
& U_{\sigma}=R T \cdot\left(\ln \frac{t_{1}}{\tau_{0}}-\ln \frac{t_{1}}{\tau_{\sigma}}\right) \\
& U_{\varepsilon}=R T \cdot\left(\ln \frac{t_{1}}{\tau_{0}}-\ln \frac{t_{1}}{\tau_{\varepsilon}}\right)
\end{aligned}
$$

where $\tau_{0}$ - the parameter that has the meaning of the duration of the elementary rearrangement

of 'relaxing' particles of the material; $t_{1}=1$ minutes; $\ln \frac{t_{1}}{\tau_{\sigma}}=f_{\sigma_{1} \sigma}$ - force function

where $\tau_{\sigma}$ - delay time; $\ln \frac{t_{1}}{\tau_{\varepsilon}}=f_{\varepsilon_{1} \varepsilon}$ - deformation function where $\tau_{\varepsilon}$ - relaxation time;

$T$ - temperature $T^{\circ} K ; R \stackrel{\tau_{\varepsilon}}{=} k A$ where $k$ is the Boltzmann constant, $A$ - the Avogadro number;

$U_{\sigma}$ - activation energy as a function of stress; $U_{\varepsilon}$ - activation energy as a function of deformation (Romashev et al., 2018).

This proportionality and equality of the initial values of the activation energies correspond to the adequacy of the equations (69) and (70), therefore, to the considered spectra in certain conditions (Blinov et al., 2018). The operability of the equations (69) and (70) means that the considered spectra of the distribution of particles over the relaxation or delay times reflects the nonlinear hereditary viscoelasticity of the considered polymer materials (Krasnyi et al., 2020).

\section{CONCLUSION}

The research showed that the relaxation spectra of polymeric materials are with satisfactory accuracy characterised by their first approximations which are the relaxation kernels, and the subsequent approximations quickly converge to the exact values of the spectra. 
The same can be said about the delay spectra of polymeric materials which are also with satisfactory accuracy characterised by their first approximations, that are the delay kernels, and the subsequent approximations quickly converge to the exact values of the spectra.

The solution to the problem of analytical relationship between the nonlinear hereditary relaxation kernel and the deformation-time relaxation spectrum, as well as between the nonlinear hereditary creep kernel and the force-time creep spectrum, was substantiated by plotting the relaxation function and the delay function in the form of the hyperbolic tangent (2) and (36).

The features of the analysed polymeric materials, from the point of view of the considered mathematical models of viscoelasticity and their properties, include the fact that the relaxation kernel as a function of the logarithm almost coincides with the relaxation spectrum in a similar invariant form with reference to the deformation value, and the delay kernel as a function of time coincides with the delay spectrum in an invariant form with reference to the stress value.

It was found that the relaxation and delay spectra are completely determined by the average value of the relaxation and delay times, and the form of the corresponding curves is determined by the value of the structural coefficients $A_{\varepsilon}$ and $A_{\sigma}$ characterising the intensity of relaxation and creep processes.

According to the physical meaning, the normalised relaxation function and the delay function are obtained by integrating the relaxation spectrum and the delay spectrum, respectively.

The problems of determining the types of the relaxation spectra and delay spectra were reduced to obtaining the coefficients $A_{\varepsilon}$ and $A_{\sigma}$ depending on the structure of polymeric materials, the values of which can be found by express processing of the corresponding experimental sets of relaxation and delay. Therefore, it can be concluded that the relaxation and delay spectra are obtained by experimental data processing.

It should be mentioned that the relaxation and delay spectra are with satisfactory accuracy characterised by their first approximations which are the relaxation kernel and the delay kernel, and the subsequent approximations quickly converge to the limiting values of the spectra.

\section{FUTURE RESEARCH AND ACKNOWLEDGEMENTS}

The study was funded within the framework of the state assignment of the Ministry of Science and Higher Education of the Russian Federation, Project No. FSEZ-2020-0005.

\section{REFERENCES}

Blinov, P., Dvoynikov V., (2018) Rheological and Filtration Parameters of the Polymer Salt Drilling Fluids Based on Xanthan Gum. Journal of Engineering and Applied Sciences, 13: 5661-5664. DOI: $10.36478 / 2018.5661 .5664$

Demidov, A.V., Makarov, A.G., Stalevich, A.M. (2006a) The criteria of optimal selection of mathematical model of textile materials viscoelasticity. Izvestiya Vysshikh Uchebnykh Zavedenii, Seriya Teknologiya Tekstil'noi Promyshlennosti, Vol. 293, No 5, pp. 21-25. eid=2-s2.0-34247548784

Demidov, A.V., Makarov, A.G., Stalevich, A.M., Petrova, L.N., Chelishev, A.M. (2006b) Research of changes of deformation properties of polyester threads depending on twist amount. Izvestiya Vysshikh Uchebnykh Zavedenii, Seriya Teknologiya Tekstil'noi Promyshlennosti, Vol. 292, No 4, pp. 9-13. eid=2-s2.0-33845499474

Demidov, A.V., Makarov, A.G., Stalevich, A.M. (2006c) Methods of computer analysis of viscoelasticity of technical materials. Izvestiya Vysshikh Uchebnykh Zavedenii, Seriya Teknologiya Tekstil'noi Promyshlennosti, Vol. 291, No 3, pp. 13-17. eid=2-s2.0-37849188658

Demidov, A.V., Makarov, A.G., Stalevich, A.M. (2006d) Definition of the mechanical characteristics of textile stuffs at variable temperature. Izvestiya Vysshikh Uchebnykh Zavedenii, Seriya Teknologiya Tekstil'noi Promyshlennosti, Vol. 294, No 6, pp. 15-18. eid=2-s2.0-34250009041

Demidov, A.V., Makarov, A.G., Stalevich, A.M. (2007a) Definition of the computer forecasting trends of deformation properties of textile stuffs. Izvestiya Vysshikh Uchebnykh Zavedenii, Seriya Teknologiya Tekstil'noi Promyshlennosti, Vol. 297, No 2, pp. 14-17. eid=2-s2.0-38849203122 
Demidov, A.V., Makarov, A.G., Stalevich, A.M. (2007b) Predicting the nonlinear hereditary viscoelasticity of polymers. Journal of Applied Mechanics and Technical Physics, Vol. 48, No 6, pp. 897-904. DOI: 10.1007/s10808-007-0114-8

Demidov, A.V., Makarov, A.G., Stalevich, A.M. (2007c) System analysis of viscoelasticity of textile stuffs. Izvestiya Vysshikh Uchebnykh Zavedenii, Seriya Teknologiya Tekstil'noi Promyshlennosti, Vol. 298, No 3, pp. 11-14. eid=2-s2.0-34648822922

Demidov, A.V., Makarov, A.G., Stalevich, A.M. (2009) A version of modeling of nonlinear-hereditary viscoelasticity of polymer materials. Mechanics of Solids, Vol. 44, No 1, pp. 122-130. DOI: 10.3103/ S0025654409010130

Demidov, A.V., Makarov, A.G., Pereborova, N.V., Egorova, M.A. (2017) Forecasting of deformation-relaxation properties of poly amide fabric used to make the canopy. Izvestiya Vysshikh Uchebnykh Zavedenii, Seriya Teknologiya Tekstil'noi Promyshlennosti, Vol. 367, No 1, pp. 250-258. eid=2-s2.0-85033239149

Egorov, I.M., Makarov, A.G., Pereborova,N.V., Kiselev, S.V. (2020) Development of methods of system analysis of viscoelastic-plastic properties of polymeric ropes of marine purpose. Vestnik of Saint Petersburg State University of Technologies and Design. Series 4. Industrial Technologies, No 1, pp. 65-74. DOI 10.46418/2619-0729_2020_1_8

Gorshkov, A.S., Makarov, A.G., Romanova, A.A., Rymkevich, P.P. (2013a) Modelling of directed polymers deformation processes based on the description of the kinetics of supramolecular structures separated by energy barriers. Magazine of Civil Engineering, Vol. 44, No 9, pp. 76-83+103-104. DOI: $10.5862 / \mathrm{MCE} .44 .10$

Krasnyi, V. A., Maksarov, V. V. and Ol't, Y. (2020) "The use of polymer composite materials in the friction nodes downhole oil pumps", Journal of Mining Institute, 211, p. 71. Available at: http://pmi. spmi.ru/index.php/pmi/article/view/5250 (Accessed: 19 August 2020).

Makarov, A.G. (2002) Determining the analytical correlation between the standardized nuclei of relaxation and creep in textile materials. Izvestiya Vysshikh Uchebnykh Zavedenii, Seriya Teknologiya Tekstil'noi Promyshlennosti, Vol. 266, No 2, pp. 13-17. eid=2-s2.0-0036931214

Makarov, A.G., Pereborova, N.V., Egorova, M.A., Wagner, V.I. (2014a) Modeling and forecasting viscoelastic properties of textile materials with a complex structure. Izvestiya Vysshikh Uchebnykh Zavedenii, Seriya Teknologiya Tekstil'noi Promyshlennosti, Vol. 354, No 6, pp. 120-124. eid=2-s2.0 $-84937439497$

Makarov, A.G., Pereborova, N.V., Egorova, M.A., Wagner, M.A. (2014b) Ways of modeling deformation and relaxation properties of textile materials with a complex structure. Izvestiya Vysshikh Uchebnykh Zavedenii, Seriya Teknologiya Tekstil'noi Promyshlennosti, Vol. 351, No 3, pp. 110-115. eid=2-s2 .0-84937410003

Makarov, A.G., Pereborova, N.V., Wagner, V.I., Rymkevich, P.P., Gorshkov, A.S. (2014c) The Basis of Spectral-Temporal Analysis of Relaxation and Deformation Properties of Polymeric Materials in Textile and Ligt Industry. Izvestiya Vysshikh Uchebnykh Zavedenii, Seriya Teknologiya Legkoi Promyshlennosti, Vol. 23, No 1. pp. 24-29.

Makarov, A.G., Slutsker, G.Y., Drobotun, N.V. (2015a) Creep and fracture kinetics of polymers. Technical Physics, Vol. 60, No 2, pp. 240-245. DOI: 10.1134/S1063784215020152

Makarov, A.G., Pereborova, N.V., Wagner, V.I., Vasileva, E.K. (2015b) Development of methodology for the comparative analysis of deformation and relaxation properties of aramid yarns and textile materials based on them. Izvestiya Vysshikh Uchebnykh Zavedenii, Seriya Teknologiya Tekstil'noi Promyshlennosti, Vol. 359, No 5, pp. 48-58. eid=2-s2.0-84971636036

Makarov, A.G., Demidov, A.V., Pereborova, N.V., Egorova, M.A. (2015c) Modeling and prediction of estimated relaxation and deformation properties of the polymer parachute line. Izvestiya Vysshikh Uchebnykh Zavedenii, Seriya Teknologiya Tekstil'noi Promyshlennosti, Vol. 360, No 6, pp. 194-205. eid=2-s2.0-84976560627

Makarov, A.G., Slutsker, G.Y., Gofman, I.V., Vasil'eva, V.V. (2016) Initial stage of stress relaxation in oriented polymers. Physics of the Solid State, Vol. 58, No 4, pp. 840-846. DOI: 10.1134/ S1063783416040132

Makarov, A.G., Pereborova, N.V., Egorova, M.A., Egorov, I.M. (2017a) Quality analysis of deformation-relaxation properties of aramid cords mountain rescue appointments. Izvestiya Vysshikh Uchebnykh Zavedenii, Seriya Teknologiya Tekstil'noi Promyshlennosti, Vol. 368, No 2, pp. 309-313. eid=2-s2.0-85035207042

Makarov, A.G., Pereborova, N.V., Egorova, M.A., Egorov, I.M. (2017b) Mathematical modeling of deformation-relaxation processes polymeric materials in conditions of variable temperatures. Izvestiya Vysshikh Uchebnykh Zavedenii, Seriya Teknologiya Tekstil'noi Promyshlennosti, Vol. 370, No 4, pp. 287-292. eid=2-s2.0-85057142312 
Makarov, A.G., Pereborova N.V., Kozlov A.A., Shvankin A.M. (2018a) Computer-Assisted Prediction and Qualitative Analysis for Polymer Parachute Cords Fibre Chemistry, Vol. 50, No. 3, pp. 239-242. DOI 10.1007/s10692-018-9968-1

Makarov, A.G., Pereborova, N.V., Vagner, V.I., Egorova, M.A., Klimova, N.S. (2018b) Spectral Analysis of Viscoelastic Creep of Geotextiles. Fibrie Chemistry, Vol. 50, No 4, pp. 378-382. DOI 10.1007/ s10692-019-09993-4

Makarov, A.G., Busygin, K.N. (2020) System analysis of functional properties of special application aramid materials. Vestnik of Saint Petersburg State University of Technologies and Design. Series 4. Industrial Technologies, No 2, pp. 84-94. DOI: 10.46418/2619-0729_2020_2_10

Pereborova, N.V., Makarov, A.G., Egorova, M.A., Kozlov, A.A., Konovalov, A.S. (2018a) Methods of simulation and comparative analysis of shadow and deformation-reducing properties of aramide textile materials. Izvestiya Vysshikh Uchebnykh Zavedenii, Seriya Teknologiya Tekstil'noi Promyshlennosti, Vol. 375, No 3, pp. 253-257. eid=2-s2.0-85059766891

Pereborova, N.V., Makarov, A.G., Kozlov, A.A., Vasil'eva, E.K. (2018b) Development of Integral Optimality Criteria for Mathematical Modeling of Relaxation/Recovery Processes in Polymer Textile Materials. Fibrie Chemistry, Vol. 50, No 4, pp. 306-309. DOI 10.1007/s10692-019-09981-8

Pereborova, N.V., Makarov, A.G., Egorova, M.A., Klimova, N.S. (2018c) Methods of increasing the competitiveness of domestic aramid textile materials based on complex analysis of their functional properties. Izvestiya Vysshikh Uchebnykh Zavedenii, Seriya Teknologiya Tekstil'noi Promyshlennosti, Vol. 378, No 6, pp. 267-272. eid=2-s2.0-85072335464

Pereborova, N.V., Demidov, A.V., Makarov, A.G., Klimova, N.S., Vasileva, E.K. (2018d) Methods of mathematical modeling and qualitative analysis of relaxation-deformation processes of aramide textile materials. Izvestiya Vysshikh Uchebnykh Zavedenii, Seriya Teknologiya Tekstil'noi Promyshlennosti, Vol. 374, No 2, pp. 251-255. eid=2-s2.0-85056451197

Pereborova, N.V., Demidov, A.V., Makarov, A.G., Klimova, N.S. (2018e) Modeling of DeformationRelaxation Processes of Aramid Textile Materials - the Foundation for Analyzing Their Operational Properties. Fibre Chemistry, Vol. 50, No. 2, pp. 104-107. DOI 10.1007/s10692-018-9941-z

Pereborova, N.V., Makarov, A.G., Vasil'eva, E.K., Shvankin, A.M., Egorov, I.M. (2019a) Mathematical Modeling and Computed Prediction of Viscoelastic Creep in Geotextile Nonwoven Fabrics. Fibre Chemistry, Vol. 50, No. 6, pp. 487-490. DOI 10.1007/s10692-019-10015-6

Pereborova, N.V., Makarov, A.G., Egorova, M.A., Kozlov, A.A. (2019b) Mathematical Modeling and Comparative Analysis of Deformation/Recovery Properties and Shrinkage of Aramid Textile Materials. Fibre Chemistry, Vol. 50, No 5, pp. 468-472. DOI 10.1007/s10692-019-10010-x

Pereborova, N.V., Makarov, A.G., Egorova, M.A., Klimova, N.S. (2019c) Improving the Competitiveness of Aramid Textile Materials Based on Mathematical Modeling and Analysis of Their Performance Properties. Fibre Chemistry, Vol. 50, No 6, pp. 569-572. DOI 10.1007/s10692-019-10030-7

Pereborova, N.V., Makarov, A.G., Shvankin, A.M., Egorova, M.A., Abramova, I.V. (2020a) Modeling and Qualitative Analysis of Creep Processes of Geotextile Nonwovens -A Foundation for Enhancing their Competitiveness. Fibre Chemistry, Vol. 51, No. 5, pp. 397-400. DOI 10.1007/s10692-020-10119-4

Pereborova, N.V., Makarov, A.G., Shvankin, A. M., Egorova, M. A., Korobovtseva, A.A. (2020b) Predicting Creep and Deformation and Recovery Processes of Geotextile Nonwovens. Fibre Chemistry, Vol. 51, No. 5, pp. 401-403. DOI 10.1007/s10692-020-10120-x

Pereborova, N.V., Makarov, A.G., Egorova, M.A., Egorov, I.M. (2020c) Methods of Modeling and Computer-Aided Prediction of Relaxation of Medical-Purpose Textile Elastomers. Fibre Chemistry, Vol. 51, No. 6, pp. 467-470. DOI 10.1007/s10692-020-10136-3

Pereborova, N.V., Makarov, A.G., Egorova, M.A., Egorov, I.M. (2020d) Methods modeling and Computer-Aided Prediction of Strain and Relaxation Processes of Medical-Purpose Textile Elastomers. Fibre Chemistry, Vol. 51, No. 6, pp. 471-474. DOI 10.1007/s10692-020-10137-2

Pereborova, N.V., Makarov, A.G., Kiselev, S.V., Egorov, I.M. (2020e) System analysis of relaxation processes of polymeric textile materials of special purpose. Vestnik of Saint Petersburg State University of Technologies and Design. Series 4. Industrial Technologies, Vol. 47, No 1, pp. 53-64. DOI 10.46418/ 2619-0729_2020_1_7

Pereborova, N.V., Wagner, V.I., Kiselev, S.V., Kozlov, A.A. (2020f) Computer forecasting of relaxation processes of polymeric textile materials. Vestnik of Saint Petersburg State University of Technologies and Design. Series 4. Industrial Technologies, No 1, pp. 89-100. DOI 10.46418/2619-0729_2020_1_12

Pereborova, N.V. (2020g) Application of criteria for qualitative evaluation of relaxation properties of polymeric textile materials for evaluation of their functionality. Vestnik of Saint Petersburg State University of Technologies and Design. Series 4. Industrial Technologies, No 1, pp. 101-110. DOI 10.46418/ 2619-0729_2020_1_13 
Romashev, A.O., Aleksandrova, T.N., Aleksandrov, A.V. (2018) Modelling of the relaxation properties of petroleum-bitumen suspension. Information, No 20, Vol. 9, pp. 6595-6603

Rymkevich, P.P., Romanova, A.A., Golovina, V.V., Makarov, A.G. (2013) The energy barriers model for the physical description of the viscoelasticity of synthetic polymers: Application to the uniaxial orientational drawing of polyamide films. Journal of Macromolecular Science, Part B: Physics, Vol. 52, No 12, pp. 1829-1847. DOI: 10.1080/00222348.2013.808906

Stalevich, A.M., Makarov, A.G. (2000) Determining the inherent viscoelastic relaxation spectrum for synthetic filaments. Izvestiya Vysshikh Uchebnykh Zavedenii, Seriya Teknologiya Tekstil'noi Promyshlennosti, Vol. 255, No 3, pp. 8-12. eid=2-s2.0-0034436083

Stalevich, A.M., Makarov, A.G. (2002a) Forecasting the deformation recovery process and the reverse relaxation in polymer materials. Izvestiya Vysshikh Uchebnykh Zavedenii, Seriya Teknologiya Tekstil'noi Promyshlennosti, Vol. 267, No 3, pp. 10-13. eid=2-s2.0-0038128574

Stalevich, A.M., Makarov, A.G., Saidov, E.D. (2002b) Elastic components in the stress/strain curve for a synthetic fibre yarn. Izvestiya Vysshikh Uchebnykh Zavedenii, Seriya Teknologiya Tekstil'noi Promyshlennosti, Vol. 268, No 4-5, pp. 15-18. eid=2-s2.0-0037742684

Stalevich, A.M., Makarov, A.G., Saidov, E.D. (2003) Relaxation spectrometry of synthetic yarns. Izvestiya Vysshikh Uchebnykh Zavedenii, Seriya Teknologiya Tekstil'noi Promyshlennosti, Vol. 270, No 1, pp. 16-22. eid=2-s2.0-2642532049 


\title{
Ecotoxicological assessment of underwater welding impact during the construction of marine pipelines
}

\author{
K.Y. Kirichenko, K.S. Pikula, A.M. Zakharenko \& A.V. Gridasov \\ Far Eastern Federal University, Vladivostok, Russian Federation \\ S.G. Parshin \\ Peter the Great St. Petersburg Polytechnic University, Saint Petersburg, Russian Federation
}

S.A. Medvedev

Stock Company «Izumrud», Vladivostok, Russian Federation

I.A. Vakhniuk

Far Eastern Federal University, Vladivostok, Russian Federation

K.S. Golokhvast

Far Eastern Federal University, Vladivostok, Russian Federation

N.I. Vavilov All-Russian Institute of Plant Genetic Resources, Saint-Petersburg, Russian Federation

Pacific Geographical Institute FEB RAS, Vladivostok, Russian Federation

\begin{abstract}
Underwater welding is commonly used in joining pipelines and in underwater construction. Harmful and hazardous compounds are added to many flux cored wires for underwater welding and cutting, which can have a negative impact on marine life. This study is the first attempt to determine the influence of underwater welding on marine organisms using a standard model for assessing the changes in the early development of embryos of the sea urchin Scaphechinus mirabilis during short-term cultivation with the postulated toxicant.

Particles emitted during underwater welding pose toxicological threat to marine ecosystems. This fact requires the development of regulatory documents in the field of environmental protection and the introduction of compensatory measures to reduce the impact on marine organisms.
\end{abstract}

\section{INTRODUCTION}

The construction of long-distance subsea oil and gas pipelines has become a trend in the development of networks of large corporations. To date, several major underwater projects have been completed or currently are under development worldwide, including the Russian Federation:

1. Nord Stream $(1,224 \mathrm{~km})$ and Nord Stream $2(1,200 \mathrm{~km})$ - gas pipelines between Russia and Germany running over the bottom of the Baltic Sea;

2. The Blue Stream $(1,213 \mathrm{~km})$ and the Turkish Stream $(1,100 \mathrm{~km})$ - gas pipelines between Russia and Turkey running over the bottom of the Black Sea;

3. The Langeled pipeline $(1,200 \mathrm{~km})$ connecting the Norwegian Ormen Lange natural gas field with the U.K. Easington Gas Terminal;

4. Dzhubga - Lazarevskoye - Sochi $(166 \mathrm{~km})$ - a system of gas pipelines for energy supply in Sochi.

Underwater welding is commonly used in joining of the pipelines and in underwater construction (Labanowski et al., 2008). Underwater welding was first demonstrated in 1932 by the Soviet engineer K.K. Khrenov (Khrenov \& Livshiz,1934). 
The compositions, electrodes and methods of this technology are being improved till this day (Han et al., 2020; Park \& Moon, 2020). Commonly, various additives are introduced to the flux cored wire to improve the technology (Xing et al., 2020). For working in deep water, toxic materials, for instance, chromium oxides, metallic chromium, and potassium dichromate $\left(\mathrm{K}_{2} \mathrm{Cr}_{2} \mathrm{O}_{7}\right)$ are added. The introduction of dichromate, for example, reduces the ionization potential and improves the stability of arcing under water, as well as increases the mechanical properties of welded joints during the underwater welding (Grishanov \& Pankov, 1994a; Yushchenko et al., 1995; Duo et al., 2014).

As is known, $\mathrm{K}_{2} \mathrm{Cr}_{2} \mathrm{O}_{7}$ is a strong oxidizing agent with a pronounced genotoxic effect and it is used as a reference toxicant in aquatic toxicity testing (Kikuchi et al., 2017; Patlolla et al., 2009; Pikula et al., 2019). When welding, potassium dichromate, as well as oxidizing metallic chromium, form toxic chromium oxides in a gas-vapor bubbles. Metal fluorides (lithium and cobalt) are also added to the composition of flux cored wire and electrodes for underwater welding (Grishanov \& Pankov, 1994b).

A flux cored wire for welding steels under water is known, which includes a powder mixture containing loparite concentrate, cadmium oxide and nickel. The wire improves the quality and corrosion resistance of weld joints, however, it contains cadmium oxide and radioactive thorium oxide $\mathrm{ThO}_{2}$ (in loparite concentrate) (Grishanov \& Pankov, 1994c). Barium peroxide (Wang et al., 2012) and potassium chlorate $\mathrm{KClO}_{3}$ (Duo et al., 2015) are also among the components of flux cored wire for underwater arc cutting. In summary, many flux cored wires for underwater welding and cutting contain harmful and hazardous compounds that can have a negative effect on marine life.

Previously we have shown a dependence of aquatic toxicity of welding fume particles on the welding electrode type and the welding regime parameters using a microalgae growth-inhibition approach (Kirichenko et al., 2019). In this study, we assessed the environmental impact of the SEAWELD electrode (Arcair) used for underwater welding on early development of the sea urchin embryos Scaphechinus mirabilis during short-term cultivation.

\section{MATERIALS AND METHODS}

\subsection{Sample preparation}

The practical application of underwater welding is complicated by several factors, including poor visibility, which in turn makes it difficult to make butt joints as the welding path is easily lost. In this regard, during the experiment, a fillet weld of lap joint was performed, and the edges of plates were used as guides for the electrode.

As it known, water-cooled electrode covering melts slower than the core wire forming a "fingernail" at the end of the electrode, which, in turn, ensures the stability of gas bubble and arc burning. Therefore, the welding was done by supported electrode while moving the electrode along the weld line and touching the metal surface with the protruding edge of the "fingernail" at the end of electrode. We moved the electrode along the welding path without lateral oscillations and with the speed that provided the desired cross section of weld metal.

In the welding experiment, we used 5-mm thick metal plates from commercial quality carbon steel, Russian standard VSt3sp according to GOST 19903-74. Chemical composition of used steal represented in Table 1.

The welding was done in the lower position at direct-current straight polarity $\left(\mathrm{I}_{\text {welding }}=120\right.$ A) with the Arcair Sea-Weld electrodes (Victor Technologies, USA), $3.2 \mathrm{~mm}$ in diameter, $356 \mathrm{~mm}$ in length (1/8 “x14"). The electrode covering has three layers: iron oxide, aluminum, and plasticized vinyl (Figure 1).

Seawater for the experiment was taken in the Ajax Bay (Russky Island, Vladivostok) in 40liter sterile containers. We filtered the collected water through $0.45 \mu \mathrm{m}$ filters and poured it into a 160-liter glass aquarium (Figure 2). 
Table 1. Chemical composition (\%) of steel VSt3sp.

\begin{tabular}{llllllllll}
\hline $\mathrm{C}$ & $\mathrm{Si}$ & $\mathrm{Mn}$ & $\mathrm{Ni}$ & $\mathrm{S}$ & $\mathrm{P}$ & $\mathrm{Cr}$ & $\mathrm{Cu}$ & $\mathrm{As}$ & $\mathrm{Fe}$ \\
\hline $0.14-0.22$ & $0.12-0.3$ & $0.4-0.65$ & $<0.3$ & $<0.05$ & $<0.04$ & $<0.3$ & $<0.3$ & $<0.08$ & $<100$ \\
\hline
\end{tabular}

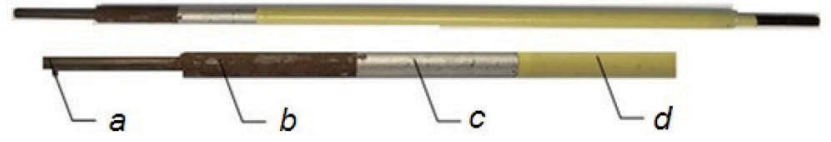

Figure 1. The structure of the Arcair Sea-Weld electrode; $a$ - electrode core wire, $b$ - iron oxide layer, $\mathrm{c}$-aluminum covering, $\mathrm{d}$ - plasticized vinyl.
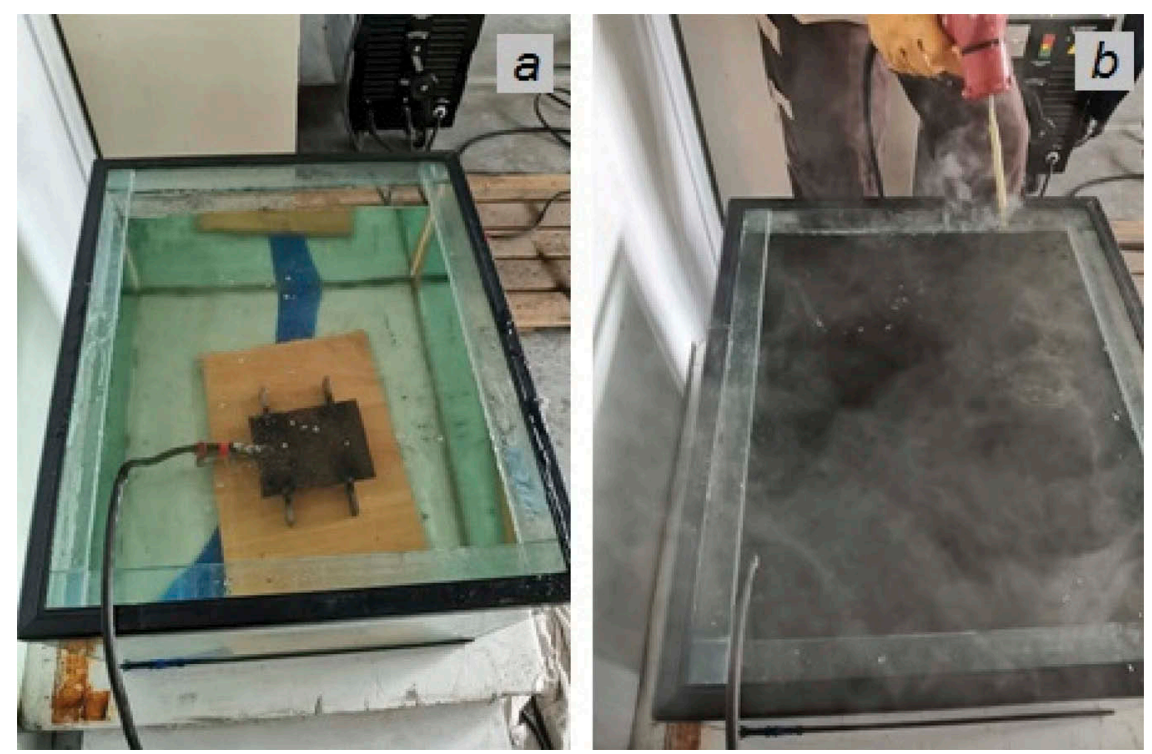

Figure 2. The experimental aquarium used for simulating underwater welding; $\mathrm{a}$ - before burning of an electrode, $\mathrm{b}$ - after burning of an electrode $(60 \mathrm{sec})$.

We measured the particle size distribution of the welding fume generated above the aquarium using a TSI 9306 V2 particle counter (Aerotrack, USA) at time intervals of 15, 30, 45, and 60 seconds.

We collected sea water samples from the experimental aquarium at 15, 30, 45, and 60 seconds after the start of the underwater welding experiment. The particle size analysis of the obtained sea water samples was performed in the particle range of 1-700 $\mu \mathrm{m}$ using the Analysette 22 NanoTec plus laser particle sizer (Fritsch GmbH, Germany). Additionally, we carried out particle size analysis of seawater in the range of 100-900 nm by the CytoFLEX flow cytometer (Beckman Coulter, USA) using the data of forward scattering of violet laser (405 $\mathrm{nm})$.

The experiments were carried out in the Department of Welding and in the Education and Scientific Center of Nanotechnology, School of Engineering of the Far Eastern Federal University.

\subsection{Aquatic toxicity assessment}

Aquatic toxicity of underwater welding suspensions was evaluated by standard early embryo growth toxicity test (Nacci et al., 1986) using the sea urchin S. mirabilis A. Agassiz, 1864 
(Kroh and Mooi, 2015). Sea urchin embryos were incubated in 24 -well plates at $17-17.5^{\circ} \mathrm{C}$, water salinity of $33.7 \%$, and $\mathrm{pH}$ of 8.18 . The aliquot of embryonic cells in seawater was $1000 \mu \mathrm{l}$. We added the welding suspension, which was obtained after 60 seconds of simulating the underwater welding, in volumes of $1,10,100,250,500$, and $1000 \mu \mathrm{l}$. In all cases, the volume of added liquid was brought to $1000 \mu$ using seawater filtered by the method described above. Accordingly, at the maximum concentration, only welding suspension was added to the aliquot of sea urchin embryos, and seawater without welding suspension was used as a control.

We observed early changes in the development of sea urchin embryos using the Axio Observer A1 optical microscope (Carl Zeiss, Germany) for 48 hours. Control points were recorded after 2, 4, 6, 24, and 48 hours of exposure of the eggs and sperm of the sea urchin in the tested suspensions of underwater welding particles.

\section{RESULTS AND DISCUSSION}

One of the drawbacks of the model used is the small depth of the aquarium compared to the real underwater welding conditions. As a result, a certain amount of welding aerosol was emitted into the air, which obviously would remain in the water medium when welding at great depths. The particle size composition of the welding aerosol emitted into the air above the aquarium during the experiment presented in Table 2.

According to the data presented in Table 2, there was a significant increase in the concentration of particles with the diameter of 0.3 to $3 \mu \mathrm{m}$ in the air above the underwater welding process. The concentration of $0.3 \mu \mathrm{m}$ particles increased 100 times in 60 seconds after the start of the experiment compared to the control concentration. At the same time, the concentrations of $0.5 \mu \mathrm{m}$ and $1 \mu \mathrm{m}$ particles increased 500 times. Obviously, when welding at a depth, all these particles will remain in the water.

Even though a part of the welding aerosol was emitted into the air, most of the solid particles emitted during the underwater welding remained in sea water. The particle size distribution of the welding suspensions in the range of 1-700 $\mu \mathrm{m}$ represented in Table 3 .

As we can see, seawater is an extremely heterogeneous and complex system. The laser diffraction method does not allow us to clearly verify the nano- and microparticles of welding suspension, therefore we additionally used flow cytometry to identify the particle sizes with higher precision. The particle size distribution of suspensions obtained using the CytoFLEX flow cytometer is shown in Figure 3.

Firstly, we can draw a preliminary conclusion about the necessity to create a combined precision method for measuring the dimensions, concentration and fractional ratio of welding aerosol particles in sea water. Since, to date, none of the methods can accurately determine both the concentration and dimensions of nanoparticles in sea water.

Table 2. Particle size composition of the aerosol emitted during the simulation of underwater welding.

\begin{tabular}{llrrrr}
\hline & $\begin{array}{l}\text { Control (air before } \\
\text { the experiment), } \\
\text { particles in } \mathrm{m}^{3}\end{array}$ & \multicolumn{3}{l}{ Welding aerosol during the experiment, particles in $\mathrm{m}^{3}$} \\
\cline { 3 - 6 } & $15 \mathrm{sec}$ & $30 \mathrm{sec}$ & $45 \mathrm{sec}$ & $60 \mathrm{sec}$ \\
\hline 0.3 & 22880 & 90598 & 263575 & 720336 & 2302992 \\
0.5 & 3406 & 16091 & 146790 & 488030 & 1750635 \\
1 & 1365 & 7615 & 26060 & 100030 & 715639 \\
3 & 376 & 2742 & 785 & 1541 & 54096 \\
5 & 201 & 1467 & 366 & 568 & 9424 \\
10 & 35 & 351 & 63 & 100 & 71 \\
\hline
\end{tabular}


Table 3. Particle size composition of the welding aerosol suspension in sea water obtained using the Fritch laser particle sizer.

\begin{tabular}{lccccc}
\hline & $\begin{array}{l}\text { Control (sea } \\
\text { water), } \% \text { of } \\
\text { particles }\end{array}$ & \multicolumn{4}{l}{$\begin{array}{l}\text { The distribution of solid particles in the welding sus- } \\
\text { pension during the experiment, } \%\end{array}$} \\
\cline { 3 - 6 } Particle size, $\mu \mathrm{m}$ & $15 \mathrm{sec}$ & $30 \mathrm{sec}$ & $45 \mathrm{sec}$ & $60 \mathrm{sec}$ \\
\hline$<1$ & 0.3 & 1.9 & 2.7 & 3.5 & 3.4 \\
10 & 11.9 & 21.1 & 9.4 & 8.1 & 6.5 \\
50 & 0.3 & 9.7 & 9.8 & 11.9 & 38.3 \\
100 & 0 & 3.8 & 0.5 & 0.7 & 0.8 \\
400 & 0.9 & 15.6 & 2.7 & 19.8 & 18 \\
700 & 37 & 23.8 & 36.2 & 22.8 & 22.5 \\
$>700$ & 49.6 & 24.1 & 38.7 & 23.2 & 10.7 \\
\hline
\end{tabular}

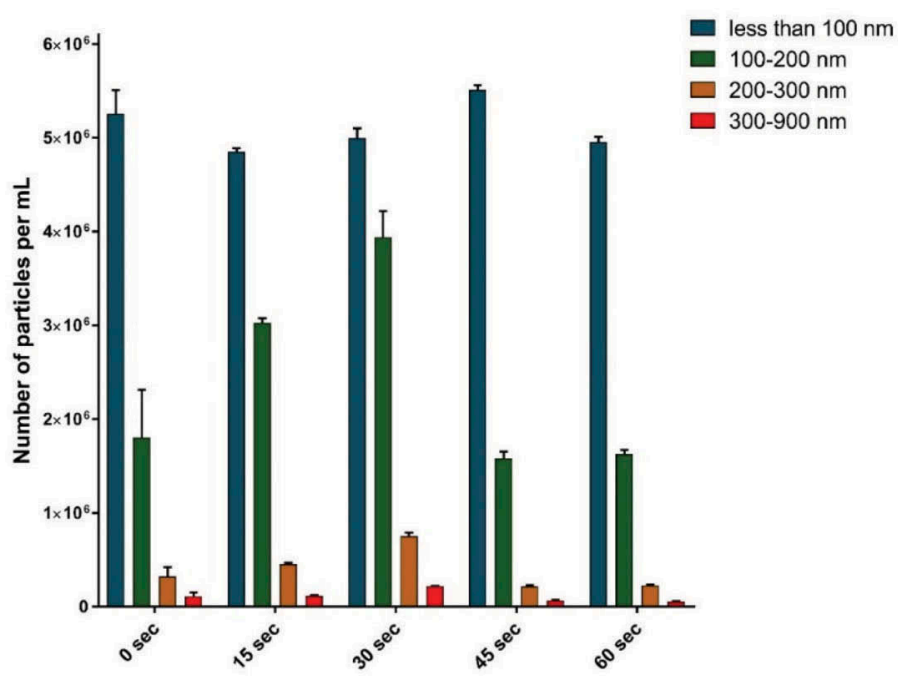

Figure 3. Particle size composition of the welding aerosol suspension in sea water obtained using the CytoFLEX flow cytometer.

Secondly, we can highlight the prevalence of $50 \mu \mathrm{m}$ and $400 \mu \mathrm{m}$ particles in the micron range (Table 3) and the intensive formation of the most toxic 100-200 nm particles (Engin et al., 2017) in the submicron range (Figure 3).

We assumed that underwater welding emission may be toxic to aquatic organisms, and we verified the assumption using the classic embryotoxicity test on sea urchin larvae. The data on the effect of the welding suspension on changes in the development and the viability of sea urchin embryos is presented in Figure 4.

The results demonstrate a linear increase in toxicity of the welding suspension for embryos of sea urchins $S$. mirabilis. We should note an intensive stimulation of development disorders of the embryos that does not lead to a significant increase in mortality up to 24 hours of exposure (Figure $4 \mathrm{a}-\mathrm{c}$ ). After 48 hours of exposure to the maximum concentration of the welding suspension, about a third of the cells died (Figure 4e). Visually, it can be seen in Figure 5. 

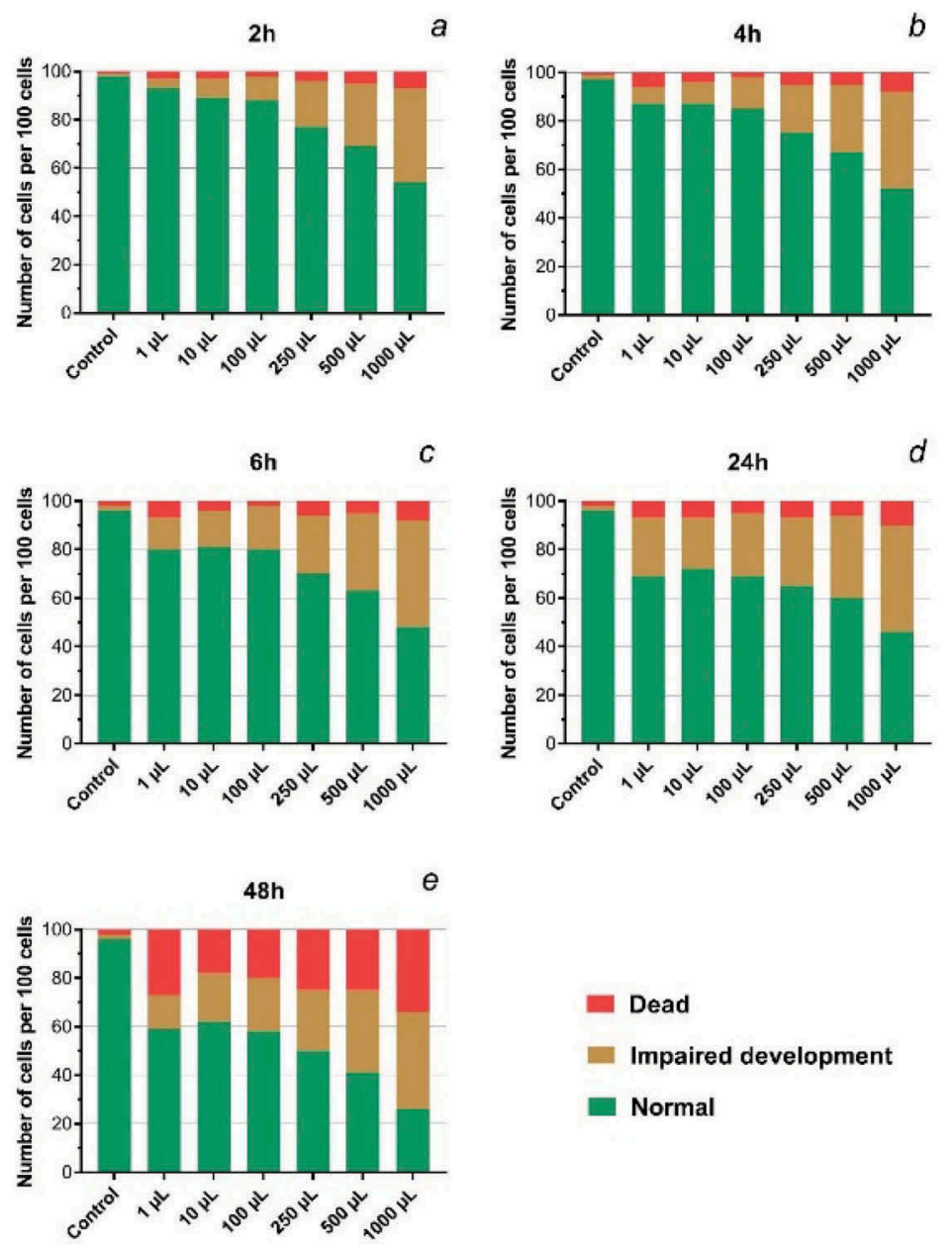

Figure 4. The changes in the development and viability of $S$. mirabilis embryos after the exposure to the welding suspension; $\mathrm{a}-2$-hours treatment, $\mathrm{b}$ - 4-hours treatment, $\mathrm{c}-6$-hours treatment, $\mathrm{d}$ - 24-hours treatment, e-48-hours treatment.
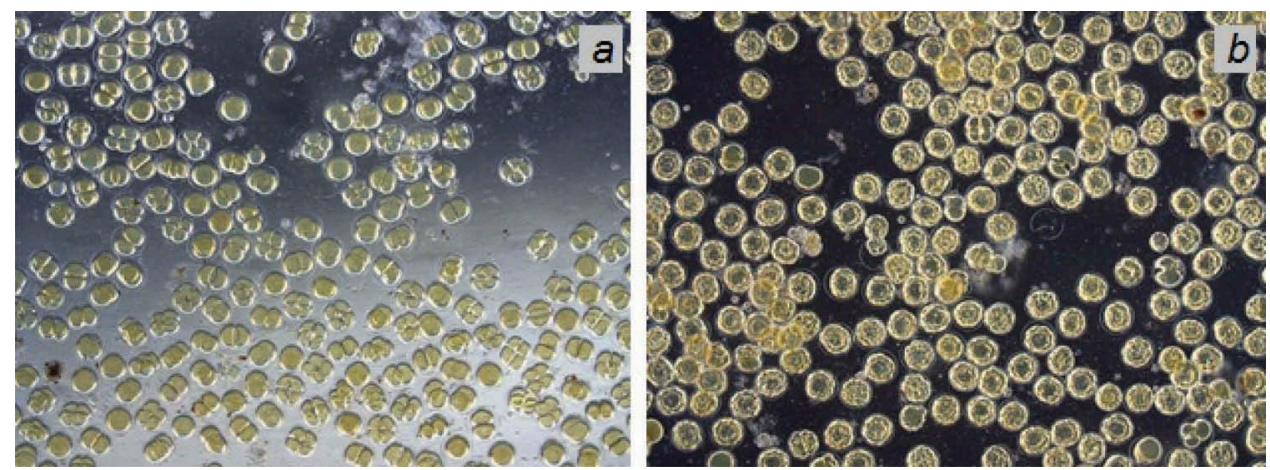

Figure 5. The effect of underwater welding suspension at the concentration of $1000 \mathrm{mg} / \mathrm{L}$ on the embryos of S. mirabilis; a -2-hours treatment, b-48-hours treatment. 


\section{CONCLUSIONS}

The results of this study enable us to state with confidence that underwater welding poses a serious threat to marine ecosystems. Given the growing volume of work on underwater pipelines, which are used for the transportation of natural resources, one should predict an increase of the negative impact on representatives of aquatic organisms. Therefore, this fact requires a timely response. The process of underwater welding needs to be further studied in order to develop ecological standards and effective measures that will ensure safety for the environment and humans.

\section{ACKNOWLEDGEMENTS}

The study was funded by RFBR, project number 19-05-50010, and by the grant from the President of the Russian Federation for young candidates of sciences (PhD) MK-2461.2019.5.

\section{REFERENCES}

Duo, L., Hongliang, L. \& Jical, F. 2015. Chemical core cutting wire for underwater wet method electric arc cutting. Patent $\mathrm{CN} 104858565$ (A).

Duo, L., Ning, G., Yibo, L., Jical, F. \& Xin, Y. 2014. Self-protection flux-cored wire for underwater wetmethod welding. Patent $\mathrm{CN} 104057214$ (A).

Engin, A.B., Neagu, M., Nikitovic, D., Henrich-Noack, P., Docea, A.O., Shtilman, M.I. Golokhvast, K. S. \& Tsatsakis, A.M. 2017. Mechanistic understanding of nanoparticles' interactions with extracellular matrix: the cell and immune system. Particle and Fibre Toxicology 14(1): 22. doi: 10.1186/s12989-0170199-z

Grishanov, A.A. \& Pankov V.I. 1994b. Flux cored wire for welding steels. Patent of the Russian Federation No. 2012469, B23K35/368 (In Russian).

Grishanov, A.A. \& Pankov, V.I. 1994a. Flux cored wire for welding steels. Patent of the Russian Federation No. 2012471, B23K35/368 (In Russian).

Grishanov, A.A. \& Pankov, V.I. 1994c. Flux cored wire for welding steels. Patent of the Russian Federation No. 2012470, B23K35/368 (In Russian).

Han, Y., Dong, S., Zhang, M., Jia, C., Zhang, M. \& Wu, C. 2020. A novel underwater submerged-arc welding acquires sound quality joints for high strength marine steel. Materials Letters 261: 127075. doi:10.1016/j.matlet.2019.127075.

Khrenov, K.K. \& Livshiz, M.L. 1934. Underwater electric arc welding. Svarshchik 6: 26-31. (In Russian).

Kikuchi, M., Syudo, A., Hukumori, M., Naito, C. \& Sawai, J. 2017. Changes in aquatic toxicity of potassium dichromate as a function of water quality parameters. Chemosphere 170: 113-117. doi: 10.1016/j. chemosphere.2016.11.158.

Kirichenko, K., Zakharenko, A., Pikula, K., Chaika, V., Markina, Z., Orlova, T., Medvedev, S., Waissi, G., Kholodov, A., Tsatsakis, A. \& Golokhvast, K. 2019. Dependence of welding fume particle toxicity on electrode type and current intensity assessed by microalgae growth inhibition test. Environmental research 179: 108818. doi: 10.1016/j.envres.2019.108818.

Kroh, A. \& Mooi, R. 2015. The World Echinoidea Database. http://www.marinespecies.org/Echinoidea/.

Labanowski, J., Fydrych, D. \& Rogalski, G. 2008. Underwater welding-a review. Advances in Materials Sciences 8(3): 11-22. doi: 10.2478/v10077-008-0040-3.

Nacci, D., Jackim, E. \& Walsh, R. 1986. Comparative evaluation of three rapid marine toxicity tests: sea urchin early embryo growth test, sea urchin sperm cell toxicity test and Microtox. Environmental Toxicology and Chemistry: An International Journal 5(6): 521-525. doi: 10.1002/etc.5620050603.

Park, J. H., \& Moon, H. S. 2020. Advanced Automatic Welding System for Offshore Pipeline System with Seam Tracking Function. Applied Sciences 10(1): 324. doi: 10.3390/app10010324.

Patlolla, A.K., Barnes, C., Hackett, D. \& Tchounwou, P.B. 2009. Potassium dichromate induced cytotoxicity, genotoxicity and oxidative stress in human liver carcinoma (HepG2) cells. International Journal of Environmental Research and Public Health 6(2): 643-653. doi: 10.3390/ijerph6020643.

Pikula, K.S., Zakharenko, A.M., Chaika, V.V., Stratidakis, A.K., Kokkinakis, M., Waissi, G., Rakitskii, V.N., Sarigiannis, D.A., Hayes A.W., Coleman, M.D., Tsatsakis, A. \& Golokhvast, K.S., 
2019. Toxicity bioassay of waste cooking oil-based biodiesel on marine microalgae. Toxicology Reports 6: 111-117. doi: 10.1016/j.toxrep.2018.12.007.

Wang J., Li W. \& Zhu J. 2012. Flux-cored cutting wire for underwater wet-type arc cutting and preparation method thereof. Patent CN102554520 (A).

Xing, C., Jia, C., Han, Y., Dong, S., Yang, J. \& Wu, C. 2020. Numerical Analysis of the Metal Transfer and Welding Arc Behaviors in Underwater Flux-cored Arc Welding. International Journal of Heat and Mass Transfer 153, 119570. doi: 10.1016/j.ijheatmasstransfer.2020.119570.

Yushchenko, K.A., Fadeeva, G.V., Kakhovsky, Yu.N. \& Savchenko V.S. 1995. Composition of cored wire. Patent of the Russian Federation No. 1605451, bull. No. 3. (In Russian). 


\title{
Assessment of coal dust particles influence on marine mollusk Modiolus modiolus
}

\author{
K.Y. Kirichenko, K.S. Pikula, V.V. Chaika, A.M. Zakharenko, A.S. Kholodov, \\ V.V. Chernyshev, M.O. Tretyakova \& K.S. Golokhvast \\ Far Eastern Federal University, Vladivostok, Russian Federation
}

\author{
A.S. Kholodov \\ Far East Geological Institute Far Eastern Branch RAS, Vladivostok, Russian Federation
}

K.S. Golokhvast

N.I. Vavilov All-Russian Institute of Plant Genetic Resources, Saint-Petersburg, Russian Federation

\begin{abstract}
Among the multiple anthropogenic factors, air pollution is associated with the influence of pedosphere and its components on humans and environment. The disturbance of natural balance is facilitated by large-scale development of mineral deposits and associated environmental pollution by harmful components. The increasing anthropogenic impact require scientific and technical examination, introduction of air pollution monitoring systems, amendments to state regulatory acts, and practical solutions to the problems of mineral resources management. This study deals with the ecotoxicological assessment of the influence of coal dust microparticles on a typical representative of marine biota, namely mollusk Modiolus modiolus. We did not detect acute toxicological hazard of coal dust particles to the representatives of marine biota, however, the observed changes in the state of hemocytes of mollusk M. modiolus suggest that there is a chronic exposure.
\end{abstract}

\section{INTRODUCTION}

The port complex of Nakhodka city is located in thse southwestern part of Primorsky Krai on the shores of Nakhodka Bay and Vostok Bay, Sea of Japan. This port complex ranks first in the Russian Far East and second in Russia in terms of cargo turnover (Naumov, 2016). There is a steady dynamic in cargo turnover, from 59.6 million tons in 2012 to 80 million tons in 2015. Vostochny Port, the largest in the Far East, demonstrates annual growth in coal transshipment volumes (http://www.vostport.ru/company/statistics). Continuously growing volumes of coal transshipment (tens of millions of tons) through the port infrastructure of the Nakhodka city district, which is not designed for these purposes (no sanitary protection zones or dust suppression systems), have led to the increased emissions of coal dust into the atmosphere and degradation of the environment in the region.

The state of ambient air is one of the most significant environmental factors affecting the health of people in urban areas (Lelieveld et al., 2015; Zhang et al., 2017). However, the data on the content of nano- and microparticles of coal dust in the air of cities is insufficient. It is commonly known that particles with aerodynamic diameter of less than $200 \mathrm{~nm}$ settle at low speed (in $\mathrm{mm}$ or $\mathrm{cm}$ per hour), and particles less than $100 \mathrm{~nm}$ practically do not obey the law of gravity remaining suspended for a long time (Christian et al., 2008; Kumar et al., 2010).

The circulation of suspended particles of coal dust on the territory of enterprises and in the adjacent coastal sea water area leads to their accumulation and redistribution in the "air-human -biota-sea" system, where the air migration plays a leading role (Johnson and Bustin, 2006). The content of toxic elements in the rocks of coal-bearing strata largely determines the nature and the level of pollution of atmospheric air and water area adjacent to the transport terminals. The 
most common pollutants of coals are water-soluble compounds of heavy metals, including nickel, cobalt, lead, copper, arsenic, vanadium, manganese, chromium, beryllium, molybdenum, bismuth, zinc, niobium, lithium, and fluorine (Tang et. al., 2017; Kurilenko, 2019). In earlier study, a significant content of coal dust particles was found in seawater samples from Nakhodka Bay, ranging from $7 \%$ to $53 \%$ depending on the distance from the coal terminal (Lebedev et al., 2017). The research of Pacific Oceanology Institute of the Far Eastern Branch RAS revealed that the content of petroleum products and heavy metals in the marine area of Nakhodka Bay exceeded the threshold limit values (Naumov, 2016).

Water contamination by coal cause mortality and growth inhibition of marine organisms (Gibson, 2005; Berry et al., 2016; Berry et al., 2017). A disturbance in early embryogenesis and growth inhibition of embryos and larvae were observed in all samples of developing embryos of marine mussels in Nakhodka Bay under the influence of coal-dust particles (Naumov and Naidenko, 1997). Given the continuous increase of anthropogenic pressure on the environment, practical steps are needed to timely solve the problems of pollution of the atmosphere, hydrosphere, and pedosphere by nano- and microparticles (Golokhvast et al., 2017; Honarvar and Sami, 2019; Pikula et al., 2020a).

The aim of this work is a comprehensive study of the quantitative and qualitative composition of coal dust microparticles in Nakhodka city, and assessment of the environmental impact of coal dust microparticles on representatives of marine biota. In this study, we evaluated the toxicological effects of coal dust particles on representatives of marine aquatic organisms, namely the hemocytes of marine mollusks Modiolus modiolus.

\section{MATERIALS AND METHODS}

The samples of lignite coal (grade 1B) were collected at the Novoshakhtinsk open pit mine (seam IV PK64) located in Primorsky Krai, Mikhailovsky district, Novoshakhtinsky settlement. This lignite coal is used at energy enterprises of the Primorsky Krai during the heating season and it is exported to the Asia-Pacific region countries.

Morphological analysis of coal dust particles was performed using the Malvern Morphologi G3-ID equipment (Malvern Instruments Ltd., UK). The unit features sample dispergation system and automated static imaging with chemical identification of individual particles using morphologically directed Raman spectroscopy at the resolution of $4 \mathrm{~cm}^{-1}$. The analysis was performed using the diode laser with a wavelength of $785 \mathrm{~nm}$ and the resulting laser power of $4 \mathrm{~mW}$ in the low power mode. The use of micro-Raman spectroscopy made it possible to determine the size and basic chemical composition of each individual particle in samples (Kholodov, Golokhvast, 2016). Additionally, we analyzed the particle size distribution of coal in solution with the CytoFLEX flow cytometer (Beckman Coulter, USA): in the submicron range with direct light scattering of the violet laser $(405 \mathrm{~nm})$, and in the micron range with light scattering of the blue laser $(488 \mathrm{~nm})$. The cytometer was pre-calibrated with sets of particles in the ranges of $0.1-1 \mu \mathrm{m}$ and $1-50 \mu \mathrm{m}$ (Molecular Probes, USA).

We collected marine mollusks M. modiolus for the experiment in the Fedorov Bay (Vladivostok). The hemocytes of molluscs were isolated using a standard technique and incubated in 96-well plates with the addition of coal suspension. The suspension prepared by diluting a coal sample in artificial seawater was added to the mollusk hemocytes to obtain the concentrations of coal particles of $1,10,100$, and $1000 \mathrm{mg} / \mathrm{L}$. The control group consisted of cells in sea water without the coal particles. The experiment was repeated three times for each concentration and for the control group. All measurements were carried out after 2, 4, and 6 hours from the start of mollusk hemocytes incubation with the coal suspension.

We measured the changes in the state of cells exposed to the coal particles by the CytoFLEX flow cytometer (Beckman Coulter, USA) using fluorescent dyes. We recorded the change in the viability and integrity of cell walls, the change in the enzyme activity, and the changes in cell membrane polarization of $M$. modiolus hemocytes. The blue laser of the flow cytometer with a wavelength of $488 \mathrm{~nm}$ was used as a source of fluorescence excitation with all dyes. Cell size was determined by measuring the intensity of the forward scatter of blue laser ( $488 \mathrm{~nm})$. 
Table 1. Bioassay conditions measured by flow cytometry.

\begin{tabular}{lll}
\hline Endpoint & Fluorescent Dye & Cytometer Emission Filter \\
\hline Viability & Propidium iodide (PI) & ECD, $610 \mathrm{~nm}$ \\
Esterase activity & Fluorescein diacetate (FDA) & FITC, $525 \mathrm{~nm}$ \\
Membrane potential & $3,3^{\prime}$-dihexyloxacarbocyanine iodide $\left(\right.$ DIOC $\left._{6}\right)$ & FITC, $525 \mathrm{~nm}$ \\
\hline
\end{tabular}

The used fluorescent dyes and measured parameters are shown in Table 1. The features of using this set of biomarkers for determining the aquatic toxicity of particulate matter on marine organisms were described in our previous works (Pikula et al., 2019; Pikula et al., 2020b).

The morphological changes in the cells were monitored by the Axio Observer A1 optical microscope (Carl Zeiss, Germany).

\section{RESULTS AND DISCUSSION}

The particle size distribution of coal used in the study was represented by a fine fraction, most susceptible to dusting under the influence of external factors. Altogether, 300 thousand particles from the coal sample were examined by micro-Raman spectroscopy and 1 million particles by flow cytometry. Particles, in general, have oval elongated and broken shapes. The diameter of majority of particles ranges from $150 \mathrm{~nm}$ to $10 \mu \mathrm{m}$. As shown in Figure 1a, b, the predominant amount of coal particles is in the diameter range of about $300 \mathrm{~nm}$. In the micrometer range, the predominant diameter is $1-2 \mu \mathrm{m}$ (Figure 1a, c).

It should be noted that the analyzed coal samples taken from the coal seam are represented by a finer size fraction than coal, which was transported, stored, and then sampled directly at the territory of the coal terminal (Kirichenko et al., 2019).

a
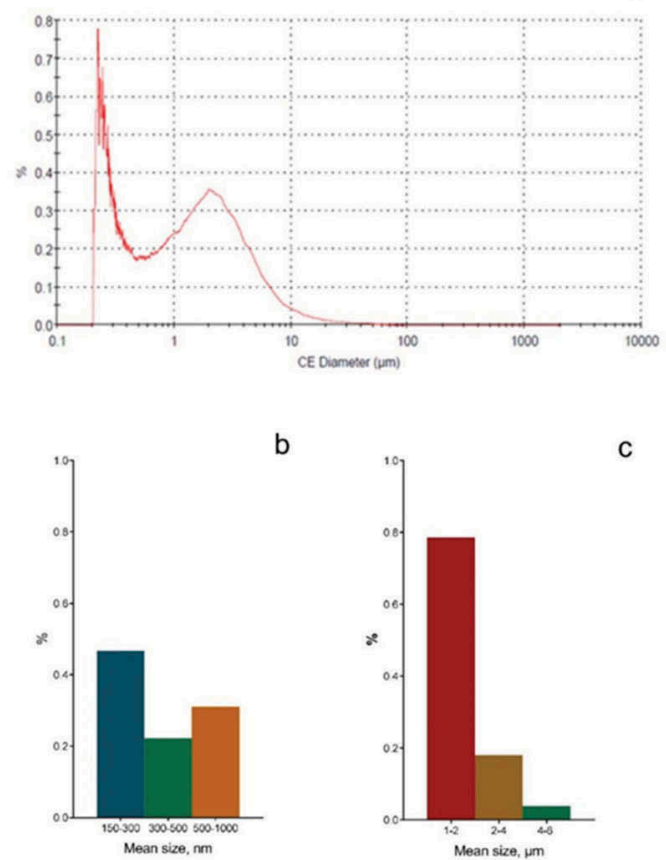

b

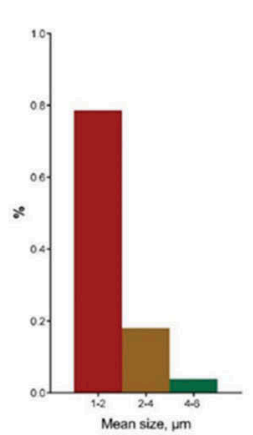

Figure 1. Particle size composition of the coal sample. a) micro-Raman spectroscopy data; b) and c) flow cytometry data. 
The results of the exposure of the mollusk M. modiolus hemocytes to the coal suspension are presented in Figure 2.

The viability was assessed by the absence of DNA cells staining with PI dye (Ostrander, 2005) registered by the absence of changes in the level of cell fluorescence in the ECD emission channel (Table 1). Dead cells were excluded from the count. According to the results of the tests, we can conclude that the investigated coal sample did not have a significant effect on the viability of the mollusk M. modiolus hemocytes. The proportion of alive cells in each measurement series after 2, 4, and 6 hours of exposure to the highest concentration of coal suspension $(1000 \mathrm{mg} / \mathrm{L})$ was almost at the same level as the proportion of alive cells in the control group for each series (Figure 1a). The greatest fluctuation and spread of values in different series of measurements was observed for the concentration of coal suspension of $100 \mathrm{mg} / \mathrm{L}$.

The change in the hemocyte esterase activity level after exposure to coal suspension was recorded as the fluorescence intensity of fluorescein formed due to the cleavage of FDA dye with cell esterases (Figure 2b). This index makes it possible to assess the enzyme activity and, therefore, the level of cell metabolism (Fontvieille et al., 1992). We can note that the cell metabolism activity increased slightly when exposed to coal suspension at concentrations of 1 and $10 \mathrm{mg} / \mathrm{L}$, while concentrations of 100 and $1000 \mathrm{mg} / \mathrm{L}$ caused the inhibition of cell metabolism. The increase in the time of exposure to coal suspension from 2 to 6 hours did not cause any further decrease in the cell metabolism level, since each series of measurements $(2,4$, and 6 hours) had a similar exposure level.

Maintaining the polarization level of cell membranes is an important indicator characterizing the ability of cells to perform barrier and metabolic functions that ensure cell activity.

a
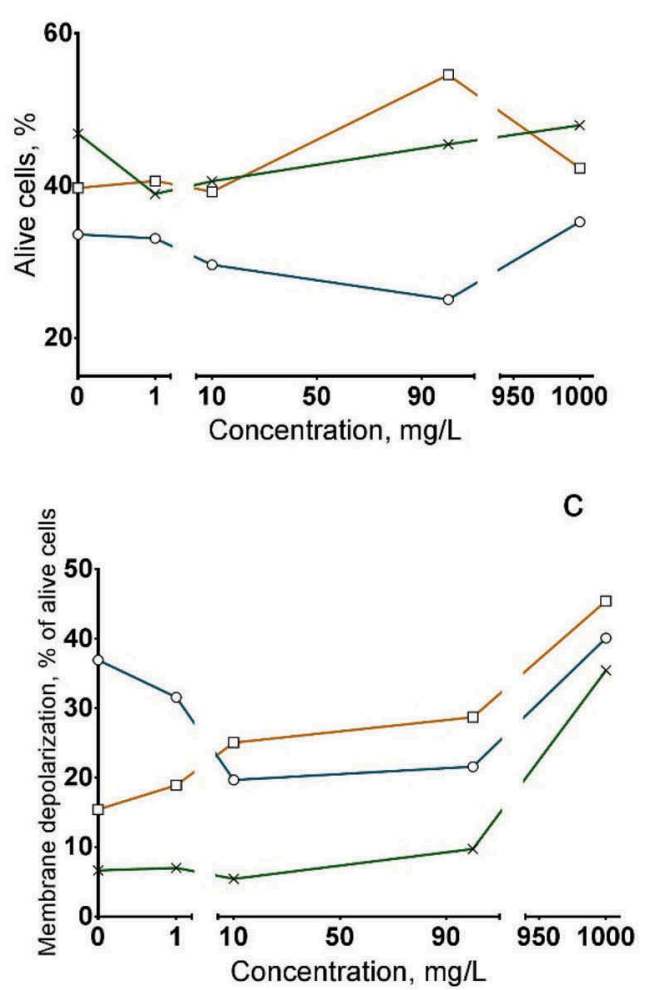
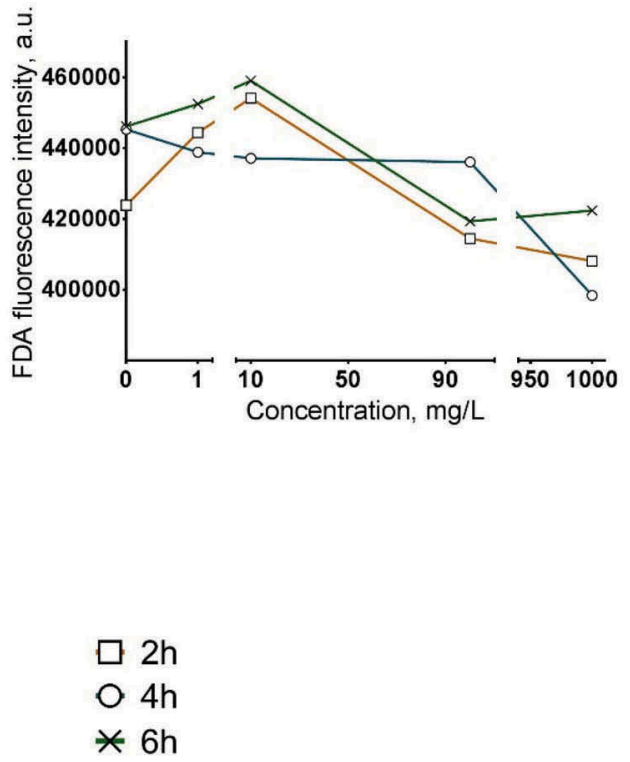

Figure 2. The change in the state of hemocytes of mollusk M. modiolus after 2, 4, and 6 hours of exposure to coal suspension at concentrations of $1,10,100$, and $1000 \mathrm{mg} / \mathrm{L}$. a) percentage of alive cells, b) change in esterase activity of cells, c) change in polarization of cell membranes; a.u. - arbitrary units. 

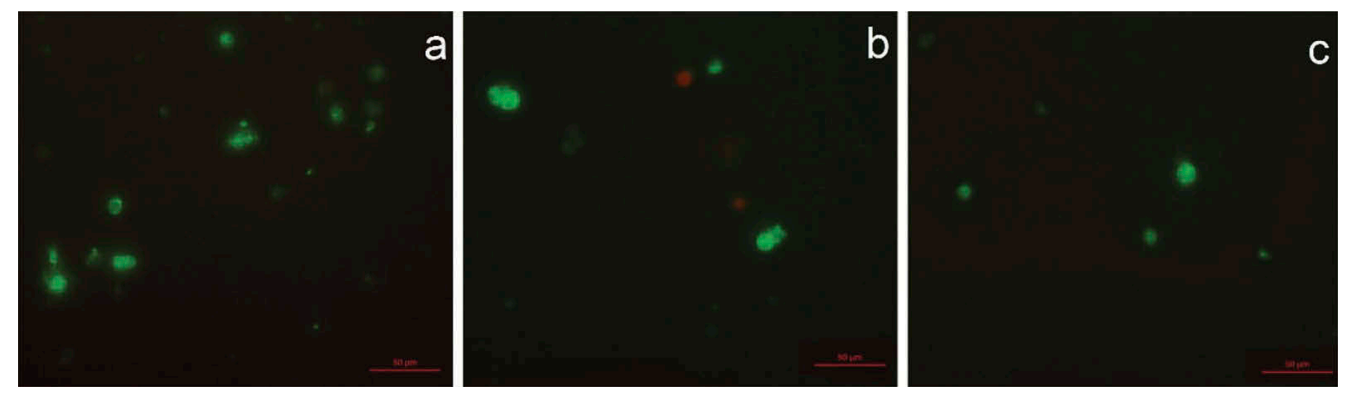

Figure 3. The hemocytes of mollusk M. modiolus after 6 hours of exposure. a) control group, b) $100 \mathrm{mg} / \mathrm{L}$, c) $1000 \mathrm{mg} / \mathrm{L}$.

Negatively charged cell membranes bind to the positively charged $\mathrm{DiOC}_{6}$ dye (Sabnis et al., 1997). When cell membrane functions are impaired, their charge decreases and, accordingly, the bound $\mathrm{DiOC}_{6}$ dye is released into the medium (Grégori et al., 2003). As a result of the mollusk M. modiolus exposure to the coal suspension, no significant effects were observed at coal suspension concentrations up to $100 \mathrm{mg} / \mathrm{L}$. (Figure 2c). At the coal suspension concentration of $1000 \mathrm{mg} / \mathrm{L}$, membrane depolarization of about $20 \%$ of alive cells of hemocytes was observed. A change in the fluorescence level of cell membranes is shown in Figure 3.

It should be noted that the change in polarization of cell membranes during the exposure for 2, 4, and 6 hours has a common trend, which indicates the absence of an increase in the negative effect over time in the measurement range.

\section{CONCLUSIONS}

We did not detect acute toxicological hazard of coal dust particles to the representatives of marine biota even at extremely high concentrations. There is a decrease in the enzyme activity and partial depolarization of membranes (an average of 20\%) exposed to coal particles. The observed changes in the state of hemocytes of mollusk $M$. modiolus suggest that there is a chronic exposure. Further long-term toxicological studies are needed to identify the effects of coal dust on marine aquatic organisms.

This study will be continued using the environmental monitoring system which is planned to be set up at various locations in Nakhodka city.

\section{ACKNOWLEDGEMENTS}

The study was funded by RFBR, project number 19-05-50010, and by the grant from the President of the Russian Federation for young candidates of sciences (PhD) MK-2461.2019.5.

\section{REFERENCES}

Berry, K., Hoogenboom, M., Flores, F., Negri, A.P. 2016. Simulated coal spill causes mortality and growth inhibition in tropical marine organisms. Scientific Reports 6: 25894. doi:10.1038/srep25894.

Berry, K. L., Hoogenboom, M. O., Brinkman, D. L., Burns, K. A., Negri, A. P. 2017. Effects of coal contamination on early life history processes of a reef-building coral, Acropora tenuis. Marine pollution bulletin 114(1): 505-514. doi:10.1016/j.marpolbul.2016.10.011.

Christian, P., Von der Kammer, F., Baalousha, M., Hofmann, Th. 2008. Nanoparticles: structure, properties, preparation and behaviour in environmental media. Ecotoxicology 17: 326-343. https://doi.org/ 10.1007/s10646-008-0213-1.

Fontvieille, D.A., Outaguerouine, A., Thevenot, D.R., 1992. Fluorescein diacetate hydrolysis as a measure of microbial activity in aquatic systems- Application to activated sludges. Environmental Technoogy 13(6): 531-540. doi: 10.1080/09593339209385181. 
Gibson, R., Atkinson, R., Gordon, J. (ed.). 2005. Oceanography and Marine Biology. Boca Raton: CRC Press. doi:10.1201/9781420037449.

Golokhvast, K.S., Kupriyanov, A.N., Manakov, Yu.A., Agoshkov, A.I., 2017. Environmental characteristic of air suspensions at coal production objects: From extraction to combustion. Gornyi Zhurnal 4: 87-90. doi:10.17580/gzh.2017.04.18 (In Russian).

Grégori, G., Denis, M., Lefèvre, D., Beker, B., 2003. A flow cytometric approach to assess phytoplankton respiration. Advanced Flow Cytometry: Applications in Biological Research. Springer Netherlands, Dordrecht: 99-106. doi:10.1007/978-94-017-0623-0_15

Honarvar, A.R., Sami, A. 2019. Towards sustainable smart city by particulate matter prediction using urban big data, excluding expensive air pollution infrastructures. Big data research 17: 56-65. doi:10.1016/j.bdr.2018.05.006.

Johnson, R., Bustin, R.M. 2006. Coal dust dispersal around a marine coal terminal (1977-1999), British Columbia: The fate of coal dust in the marine environment. International Journal of Coal Geology 68 (1-2): 57-69. doi:10.1016/j.coal.2005.10.003.

Kholodov, A.S., Golokhvast, K.S. 2016. Complex research of the particles which cause air pollution by laser granulometry, Raman-spectrometry and IR-spectrometry. Proc. SPIE 10176: 101760N1-101760N-6, doi:10.1117/12.2268229.

Kirichenko, K.Yu., Kholodov, A.S., Vakhniuk, I.A., Gusev, D.S., Kiryanov, A.V., Drozd, V.A., Golokhvast, K.S., 2019. Research of air pollution with fine coal dust (Nakhodka, Primorsky krai). Bulletin of Kamchatka State Technical University 50: 6-13. doi:10.17217/2079-0333-2019-50-6-13 (In Rusian).

Kumar, P., Fennell, P., Robins, A. 2010. Comparison of the behaviour of manufactured and other airborne nanoparticles and the consequences for prioritising research and regulation activities. Journal of Nanoparticle Research 12: 1523-1530. doi:10.1007/s11051-010-9893-6.

Kurilenko, V.V. 2019. Fundamentals of environmental geochemistry. V.V. Kurilenko (ed.), Ecological Problems Geology: Proceedings of XIX International Youth Scientific Conference-school; SaintPetersburg, 2-7 June 2019. Saint-Petersburg: Saint-Petersburg State University (In Russian).

Lebedev, A.A., Tikhonova, O.A., Blinovskaya, Ya.Yu., Chaika, V.V., Kirianov, A.V., Khristophorova, N.K., Pikula, K.S., Shevchenko, V.P., Golokhvast, K.S. 2017. Coal terminal impact on marine suspention composition: Nakhodka Gulf (Japan Sea). Proceedings of the Russian State Hydrometeorological University 48: 195-201 (In Russian).

Lelieveld, J., Evans, J. S., Fnais, M., Giannadaki, D., Pozzer, A. 2015. The contribution of outdoor air pollution sources to premature mortality on a global scale. Nature 525: 367-371. doi:10.1038/ nature15371.

Naumov, Yu.A., Naidenko, T.Kh. 1997. The ecological state of Nakhodka Bay. Izvestiâ Tihookeanskogo naučno-issledovatel'skogo rybohozâjstvennogo centra 122: 524-537 (In Russian).

Naumov, Yu.A. 2016. Sea ports and their water areas state of the environment (through the example of Nakhodka Bay port complex on the Sea of Japan). International journal of applied and fundamental research 10(4): 623-626. (In Russian).

Ostrander, G.K. (ed.) 2005. Techniques in aquatic toxicology. Boca Raton: CRC Press.

Pikula, K.S., Chernyshev, V.V., Zakharenko, A.M., Chaika, V.V., Waissi, G., Hai, L.H., Hien, T.T., Tsatsakis, A.M., Golokhvast, K.S. 2019. Toxicity assessment of particulate matter emitted from different types of vehicles on marine microalgae. Environmental research 179: 108785. doi:10.1016/j. envres.2019.108785.

Pikula, K.S., Zakharenko, A.M., Chaika, V.V., Kirichenko, K.Y., Tsatsakis, A.M., Golokhvast, K.S. 2020a. Risk assessment in nanotoxicology: Bioinformatics and computational approaches. Current Opinion in Toxicology 19: 1-6. doi:10.1016/j.cotox.2019.08.006.

Pikula, K., Chaika, V., Zakharenko, A., Markina, Z., Vedyagin, A., Kuznetsov, V., Gusev, A, Park, S, Golokhvast, K. 2020b. Comparison of the level and mechanisms of toxicity of carbon nanotubes, carbon nanofibers, and silicon nanotubes in bioassay with four marine microalgae. Nanomaterials 10 (3): 485. doi:10.3390/nano10030485.

Sabnis, R.W., Deligeorgiev, T.G., Jachak, M.N., Dalvi, T.S., 1997. DiOC(6)(3): a useful dye for staining the endoplasmic reticulum. Biotech. Histochem. 72(5),253-258. doi:10.3109/10520299709082249.

Tang, Z., Chai, M., Cheng, J., Jin, J., Yang, Y., Nie, Z., Huang, Q., Li, Y. 2017. Contamination and health risks of heavy metals in street dust from a coal-mining city in eastern China. Ecotoxicology and Environmental Safety 138: 83-91. doi:10.1016/j.ecoenv.2016.11.003.

Zhang, Q., Jiang, X., Tong, D.,Davis, S.J., Zhao, H., Geng, G., Feng, T., Zheng, B., Lu, Z., Streets, D. J., Ni, R., Brauer, M., Donkelaar, A., Martin, R.V., Huo, H., Liu, Z., Pan, D., Kan, H., Yan, Y., Lin, J., He, K., Guan, D. 2017. Transboundary health impacts of transported global air pollution and international trade. Nature 543: 705-709. doi:10.1038/nature21712. 


\title{
Air sample system optimization for the raw materials industry objects monitoring
}

\author{
M.V. Volkodaeva \\ Professor, Saint-Petersburg Mining University, Saint-Petersburg, Russia \\ Ya.A. Volodina \\ Postgraduate student, Saint-Petersburg Mining University, Saint-Petersburg, Russia \\ V.A. Kuznetsov \\ Postgraduate student, Saint-Petersburg Mining University, Saint-Petersburg, Russia
}

\begin{abstract}
The raw material industry has a negative impact on the environment. In particular, it is an air pollution source. In order to improve the air sampling procedure, it is suggested to use lavsan sample bags. A distinctive feature of these devices is the ease of their use, regeneration and transportation, the possibility of their multiple application and averaging air samples for any period of time. Due to structural features and technical characteristics of bags, the procedure of their delivery to laboratories from remote observing sites is simplified, as well as air samples analysis. To establish the feasibility of using proposed sample bags and to assess the impact of the phosphorite mining enterprise the research was conducted, results of which allow us to conclude that it is advisable to use these devices for sample collection and transportation.
\end{abstract}

\section{INTRODUCTION}

Mineral resources are a complex of raw material stocks in the bowels that can ensure the stable development of the country's economy for a significant future (Boyko et al. 2019, Kozlov et al. 2018). Exploitation of natural resources by a mineral resource sector is associated with the extraction, removal of overburden, ore, coal, oil, gas, groundwater, etc. from geosystems. Attendant problems of the use of natural resources are man-made impacts on environmental compartments that cause their changes (Mammadov et al. 2019, Nevskaya et al. 2019). In this regard, the mineral resource complex has a negative impact on the environment (Krutskikh 2019, Pashkevich et al. 2019), in particular, as a source of emission of a wide range of pollutants into the atmospheric air. The main pollutants in the air basin are particulate pollutants, sulfur dioxide, carbon monoxide, nitrogen oxides and volatile organic compounds (State report 2018).

In the total volume of pollutant emissions into the atmosphere from stationary sources, which amounted to $17,476.2$ thousand tons in 2017 , the largest contribution was made by sources (by type of economic activity): "Manufacturing" - 5802.2 thousand tons, or $33.2 \%$ of all emissions from stationary sources; "Mining" - 4,918.9 thousand tons, or 28.1\%; "Provision of electric energy, gas and steam; air conditioning"- 3,542.6 thousand tons, or 20.3\% (State report 2018).

Therefore, in order to carry out effective environmental protection activities, it is necessary to be provided with sufficient information about the state of the environment, take into account spatial and temporal factors, the degree of anthropogenic impact, anticipate the possible consequences of human intervention in the course of natural processes. The tool for obtaining such information is environmental monitoring (State report 2018). 


\section{ENVIRONMENTAL MONITORING SAMPLING}

Monitoring conducted by enterprises to assess the impact of their activities on the natural environment (and, first of all, on the most sensitive component of ecosystems - atmospheric air) can be both instrumental and calculated. Calculated monitoring allows you to determine the level of pollution based on the data on emissions of pollutants. Thanks to this approach, it is possible to estimate the level of pollution not only at its source, but also at any distance from the industrial facility. Instrumental monitoring involves sampling on the ground (usually in the area of greatest pollution) and subsequent laboratory analysis, allowing you to obtain data on the level of air pollution in the zone of a particular enterprise influence. However, it should be noted that the largest measurement errors occur at the stage of sampling of atmospheric air (Watson et al. 2011). Also carrying out full-fledged instrumental monitoring is associated with a number of difficulties, for example, the inability to quickly obtain data from remote areas, the operation of obsolete equipment, as well as sampling methods and devices (Yakunina \& Popov 2009).

Basically, sampling methods are divided into 2 groups: aspiration (air suction through absorption solutions, filters, sorption tubes or grain sorbents placed in the absorber) and sampling in vessels (bottles, gas pipettes and other containers) that are delivered for the further analysis to the laboratory (Woolfenden 2010).

Air sampling is most often carried out by the aspiration method in order to determine the concentration of chemical compounds. The method is based on aspiration of a known volume of air through an absorption material capable of retaining substances to be determined. This method is used when it is necessary to concentrate the microimpurities in the absorber and to increase the sensitivity of the analysis method.

As an absorption solution, distilled water or special liquids that dissolve toxic substances or interact with them are used. Absorbers with solid sorbents are also used: silica gel, activated carbon, and others. They have a different design: in them, solid sorbents can be stationary or set in motion by an air current, forming a "fluidized bed", which contributes to a greater contact of the sorbents with air and improves the absorption of the substance of interest. Sorption tubes are also used to take and analyze air samples. They are filled with glass powder, impregnated with special solutions for trapping toxic substances. This type of sampling suction systems is most common for environmental monitoring tasks.

For quick sampling with the availability of sensitive research methods, sampling into various vessels and containers is used. The type of gas sampling vessel is determined by the nature of the gas being analyzed and the volume of the sample. It is noteworthy that the volume of the gas sample should be sufficient for analysis by the selected method and for repeated determinations.

Sample storage conditions are an important factor in the analysis of environmental component. For example, air samples taken on active solid sorbents can be stored for a limited time, in some cases cooling is necessary. Air samples taken in vessels are not recommended to be stored for a long time, since reactions with oxygen, water vapor, adsorption of the vessel walls and so on are possible. One of the main problems in determining the concentrations of volatile substances is associated with this.

Typically, gas samples are taken into the device in which the analysis is performed. If the analysis cannot be performed at the sampling site, air samples are delivered to the laboratory. Gas diffusion through some connecting tubes may cause a change in the composition of the gas sample. The composition of the average sample may vary in the sampling device itself. Another important factor is the temperature - a significant temperature difference at the time of selection and during storage can significantly affect the final result of the analysis. Therefore, when optimizing sampling methods, various aspects should be considered that affect the concentration of pollutants in the sample.

Currently, various devices are used in the Russian Federation for air sampling: direct sorption and indicator tubes, various types of absorption vessels (for example, Zaitsev, Richter vessels with a porous plate), cooled traps, syringes, gas pipettes and others. Most of these devices have several disadvantages. For example, when using sorption tubes, the concentration of substances in the sample decreases as a result of adsorption by the tube material, and during subsequent analysis of the sample, false peaks may appear on the gas chromatogram (as a result of desorption of 
previously adsorbed substances). The use of syringes and gas pipettes does not comply with the regulatory and technical documentation for sampling (due to the time of sampling), as well as these devices do not allow storing air samples. Moreover, many sampling devices require considerable time for their regeneration, as well as the preliminary preparation of special sorbents and absorption solutions. These shortcomings indicate the need for modernization of the monitoring network, in particular, the introduction of new methods and devices for air sampling for the subsequent determination of the pollutant content in the air.

It should be noted that in recent years, sample bags have increasingly been used for sampling around the world (Watson et al. 2011). They are devices for sampling air, which are used both for basic gases and for specific substances. These bags can be made of various materials (teflon, lavsan, fluoroplastic, polyvinylidene fluoride, fluoroethylene propylene, aluminum film, etc.). The leaders in the production of sampling bags are considered to be Restek (USA), SKC (USA), ColeParmer (USA), Merck (Germany), GL Sciences (The Netherlands).

In support of the feasibility and advisability of using these sampling devices, many studies have been carried out around the world. For instance, some scientists consider the problem of storage stability (Akdeniz et al. 2011, Laor et al. 2010); in other works the question regarding the sample loss is raised (Sironi et al. 2014, Kim \& Kim 2012); there are also some works on the different types of bags (Kim et al. 2012, Laor et al. 2010) and materials (Salo \& Makinen 2019) comparison. Of particular interest is the study of comparing commercial and homemade bags (Parker et al. 2010, Abruzzi et al. 2019). All in all, the results allowed concluding that air sample bags can be an alternative to the widely used sampling devices and are suitable for many areas, including industrial hygiene, landfill (biogas), ambient air, indoor air and stationary source testing. The disadvantage of these devices is their high cost, often the inability to reuse, as well as the inability to store some volatile organic compounds.

For the needs of industrial environmental control and atmospheric air monitoring in the Russian Federation, which includes the regular determination of the pollutant concentrations over immense territories and in remote areas, as well as for studying the content of specific compounds in samples, there is no universal sampling device. This is due to the need to fulfill a number of conditions: ease of sampling, ease of the device regeneration, a low background level of substances in the device, economic affordability, the possibility of long-term storage of samples and comparisons with established environmental standards.

In order to improve the atmospheric air sampling procedure, the authors propose the use of lavsan sample bags, which allow subsequent determining of the concentrations of pollutants that are characteristic of mineral resource complex enterprises. Due to the design features and technical characteristics of the bags, the procedure of their delivery to laboratories from remote observation points and analysis of air samples is simplified, and the cost of devices is reduced.

To establish the feasibility and advisability of using the proposed sample bags with the participation of the authors numerous studies were carried out: the concentrations of pollutants at control points without sampling were determined and also in laboratory conditions with preliminary sampling of atmospheric air into the lavsan bags (Volkodaeva \& Volodina 2017); the optimal methods for the sample bags regeneration were identified (Volkodaeva et al. $2019 \mathrm{~b}$ ); the possibility of using these devices at the border of the sanitary protection zone was demonstrated (Volkodaeva et al. 2019a).

\section{SAMPLE BAGS APPLICATION}

Sample bags made of polymer films are intended to be used for the collection and storage of gaseous samples for subsequent analysis on laboratory equipment (chromatographs, stationary gas analyzers, etc.). The bags can be used to control the pollution of the atmosphere, air of the working area, industrial emissions, as well as to control production processes in the chemical, petrochemical, pharmaceutical, food industries, medicine, agriculture, etc.

Sampling in bags is carried out by means of portable sampling pumps or vacuum samplers. The capacity of the packages can vary from 0.5 to 100 liters. The bags are equipped with 
various fittings: stainless steel, polypropylene, teflon, designed both for sampling from the bag with a syringe, and using an external pump. The number of fittings may also vary.

Compared to other sampling devices (gas pipettes, gas syringes, etc.), bags of polymer films have several advantages:

- flexibility: a variety of organic and inorganic compounds can be sampled and stored in bags;

- high stability of sample storage;

- the ability to automatically average samples over a 20-minute (or other) time interval;

- the ability to automatically adapt the sample to the conditions of analysis (temperature and pressure);

- the variety of fitting types and their quantity;

- lightness, strength and durability.

A study of a great variety of sample bags produced by world leaders, as well as Russian manufacturers, showed that there is no appropriate device for the collection, storage and transportation of samples of volatile organic compounds (control of such compounds is mandatory in large cities and near enterprises-sources of these substances) for the purpose of environmental monitoring of atmospheric air. Some samples are disposable and cannot be regenerated, others are not able to hold the specific contaminants necessary for determination, and others are equipped with fittings that are inconvenient to use. Thus, the absence of a suitable sampling device leads to the search for technical solutions to optimize the procedure of sample collection, storage, transportation, as well as the procedure of bags regeneration.

Currently, the monitoring of the content of volatile organic compounds in the air is carried out over vast territories. It implies sampling on site and delivering air samples to specialized laboratories. Due to the remoteness of some observation points, as well as the load of analytical equipment in laboratories, the solution is to increase the storage time of samples in bags.

The authors propose to make some changes to the design of the sample bag, namely, to improve the seams and fittings of the device. The use of reinforced double seams has a positive effect on the duration of storage of samples and less diffusion of pollutants through the seams of the bag - the most fragile part of the sampling device. There is also a need for better cleaning of devices, which can be achieved by identifying the optimal regeneration method, as well as placing an additional fitting on the opposite side of the bag.

\section{SAMPLE BAG DESIGN OPTIMIZATION}

The authors propose to make changes to the design of the sample bags, as well as to use the identified effective ways of regenerating these devices.

The manufacture of sample bags from an ultra-pure lavsan film with a thickness of $50 \mu \mathrm{m}$ can be considered the optimal solution, because with the small weight of the bag the barrier functions necessary for storing the samples are performed. The material prevents the diffusion of gases through the walls of the bag, which is similar to preserving the air sample inside the device. The usage of double seams increases the storage time of volatile organic compounds in atmospheric air samples. Seams are made by the agency of a welding machine.

Moreover, it is also possible to place a fluoroplastic tube with a diameter of $1-2 \mathrm{~mm}$ in the space between two seams (Figure 1). This tube, located around the entire perimeter of the bag, will make it possible to make a kind of frame and at the same time reduce the likelihood of deformation of the device and, as a result, loss of atmospheric air sample.

The use of two polypropylene fittings increases the "flexibility" of the sampling. In other words, it allows taking samples in different conditions, varying the way the bag is attached to the sample feeder and the sampling speed, and also improves the quality of the bag regeneration by the through-bag purging.

Another feature of lavsan sample bags is the possibility of their multiple use. For the purpose of this, devices should be regenerated properly. The authors propose the use of ozone and nitrogen as gases for cleaning bags. The choice of a regeneration method is based on the physicochemical characteristics of substances acting as purifiers (Volkodaeva et al. 2019b). 


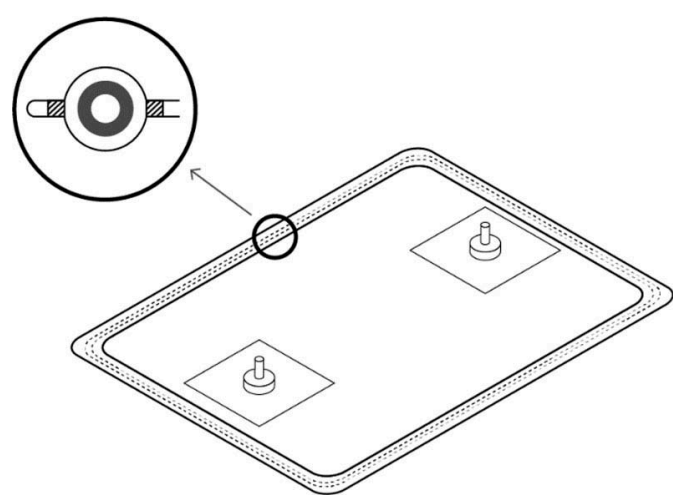

Figure 1. Sample bag with a fluoroplastic tube.

From an environmental point of view, lavsan material can be recycled and disposed of. There are two main ways of processing polyethylene terephthalate: mechanical and physicochemical; biological methods are actively developing (Yoshida et al. 2016). Moreover, polypropylene processing is practiced. It includes the stages of sorting, crushing and temperature exposure, granulation.

Thus, the proposed characteristics of the sample bags make it possible to obtain reliable data from remote areas (relevant for objects of the mineral resource complex), as well as to conduct numerous sampling while monitoring air quality at the border of the sanitary protection zone. It should be noted that there are various ways to recycle and dispose of the material from which the bags are made.

\section{FIELD STUDY}

To assess the impact of the phosphorite mining enterprise, measurements were made on site and 20-minute air samples with an hourly interval during the active phase of the production process were taken. As a part of the study, the concentrations of the following pollutants were determined: benzene, toluene, ethylbenzene, isomers of xylene, styrene, acetone.

In order to obtain more complete and representative environmental information about the state of the air basin, as well as to conduct a comparative experiment, the authors decided to use several different devices for sampling (in addition to direct measurements on site). Such devices were sorption tubes (filled with Carbopack ${ }^{\mathrm{TM}} \mathrm{B}$ ), Tedlar ${ }^{\circledR}$ sample bags (manufactured by SKC) and homemade lavsan sample bags. The measurements on site were carried out by the agency of portable gas chromatograph FGH (manufactured by Research and Production Company Ekan).

Samples were taken in an open field, without obstacles to capture pollutants from the leeward side of the source of pollution at the border of the sanitary protection zone.

After sampling, all samples were delivered to the laboratory within three hours for further analysis (by means of a gas chromatograph FGH).

The averaged results of determining the pollutant concentrations in different ways are presented in Table 1 and Figure 2.

The results of direct measurements made on site should be considered as reference, since such measurements do not have factors affecting the sample such as its storage and transportation. Moreover, background concentrations of sampling devices can also distort the final result.

According to the research, all the devices used provide fairly good stability of the samples during their transportation and preservation of volatile organic compounds. However, there is a decrease in the concentration of pollutants in the samples due to 
Table 1. Averaged results of determining the pollutant concentrations in samples of atmospheric air.

\begin{tabular}{lllll}
\hline Pollutant & $\begin{array}{l}\text { Direct measurements } \\
\text { (on site) }\end{array}$ & $\begin{array}{l}\text { Preliminary } \\
\text { sampling in } \\
\text { sorption tubes }\end{array}$ & $\begin{array}{l}\text { Preliminary } \\
\text { sampling in } \\
\text { Tedlar }^{B} \text { bags }\end{array}$ & $\begin{array}{l}\text { Preliminary } \\
\text { sampling in } \\
\text { lavsan bags }\end{array}$ \\
\hline benzene $(\mathrm{mg} / \mathrm{m} 3)$ & 0.023 & 0.011 & 0.015 & 0.018 \\
toluene $(\mathrm{mg} / \mathrm{m} 3)$ & 0.091 & 0.124 & 0.065 & 0.071 \\
ethylbenzene $(\mathrm{mg} / \mathrm{m} 3)$ & 0.018 & 0.009 & 0.012 & 0.015 \\
m-xylene $(\mathrm{mg} / \mathrm{m} 3)$ & 0.184 & 0.104 & 0.122 & 0.151 \\
p-xylene $(\mathrm{mg} / \mathrm{m} 3)$ & 0.159 & 0.113 & 0.135 & 0.142 \\
o-xylene $(\mathrm{mg} / \mathrm{m} 3)$ & 0.078 & 0.043 & 0.061 & 0.068 \\
styrene $(\mathrm{mg} / \mathrm{m} 3)$ & 0.002 & $<0.001$ & 0.001 & 0.002 \\
acetone $(\mathrm{mg} / \mathrm{m} 3)$ & 0.016 & 0.007 & 0.004 & 0.011 \\
\hline
\end{tabular}

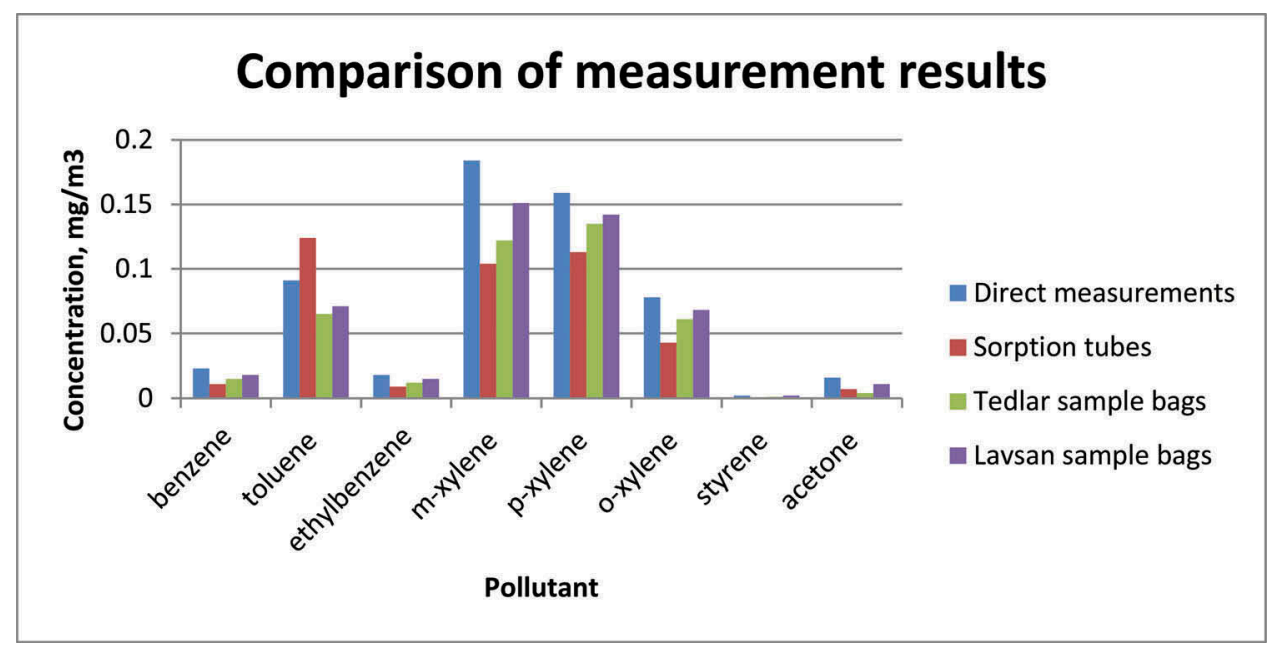

Figure 2. Comparison of results of a quantitative measurement of pollutants.

volatilization, adsorption (in the case of tubes) or deposition (on the inner walls of the bags). An exception is the result of the determination of toluene, collected using sorption tubes, which may be caused by the desorption of previously adsorbed substances. The correlation coefficient between the results of direct measurements and measurements using sorption tubes amounted to 0.86 , Tedlar ${ }^{\circledR}$ bags -0.98 , lavsan bags -0.99 . The discrepancies between the values obtained during measurements on site and during the analysis of samples taken in bags under laboratory conditions vary within a few tens of percent, which is acceptable when conducting such studies.

All in all, the results obtained during the research allow us to conclude that it is possible and advisable to use devices for sampling and transportation of samples, in particular, lavsan sample bags, in order to control the quality of atmospheric air. Despite a slight decrease in pollutant concentrations in lavsan bags, the use of these devices for the purposes of environmental monitoring is a good alternative to outdated methods.

It should also be noted that the results of this study, similar to the results reflected in the Abruzzi's research (Abruzzi et al. 2019), show that homemade containers are a good alternative to commercial ones for storing air samples and further analysis by chromatographic method. The Abruzzi's work also says about the possibility of stable storage of samples in homemade borosilicate glass containers for up to 96 hours, while in our lavsan bags the time of stable storage is about 72 hours. However, lavsan bags are also suitable for volatile organic compounds sampling and it is easier to transport and store them due to their light weight and shape. 
Moreover, Kim's research (Kim et al. 2012) on the storage of volatile organic compounds in polyester aluminum (PEA) and polyvinyl fluoride (PVF) sample bags showed more stable storage of substances in PEA containers than in PVF ones. Homemade lavsan sample bags showed similar results in our research.

\section{CONCLUSION}

The raw material industry has a significant negative impact on the environment and atmospheric air, in particular. In this regard, it is mandatory to conduct continuous air quality monitoring both at the facilities themselves and at the border of the sanitary protection zone, which implies sampling. Since widely used methods and devices have certain drawbacks, the authors propose the use of lavsan sample bags. When using these bags, it becomes possible to average the air samples over different time intervals, to deliver the samples from distant observation points to the laboratory for subsequent analysis. Bags can be used multiply, which is also a cost-effective solution for monitoring systems of different levels. In support of the feasibility and advisability of using these sampling devices, many studies have been carried out around the world.

In a similar vein authors conducted an experiment in order to compare different sampling devices - sorption tubes, manufactured and homemade sample bags. According to the research, all the devices used provide fairly good stability of the samples during their transportation and volatile organic compounds preservation. The discrepancies between the values obtained during measurements on site and during the analysis of samples taken in bags vary within a few tens of percent, which is acceptable when conducting such studies. Homemade lavsan sample bags also showed good results and, consequently, could be used for environmental monitoring purposes despite a slight decrease in pollutant concentrations in them.

Thus, the optimization of the sampling system through the introduction of specialized bags will improve the quality and speed of obtaining reliable information necessary for decision-making on environmental protection, as well as assessing effectiveness of nature protection measures.

\section{REFERENCES}

Abruzzi, R.C., Bonetti, B., Marçal, J.R.P., Berenice, A.D. \& Bitencourt, A.K. 2019. Artifacts in the analysis and assessment of low-cost containers for sampling and storing greenhouse gases. Quimica Nova 42(1): 84-94.

Akdeniz, N., Janni, K.A., Jacobson, L.D. \& Hetchler, B.P. 2011. Comparison of gas sampling bags to temporarily store hydrogen sulfide, ammonia, and greenhouse gases. Transactions of the ASABE 54: 653-661.

Boyko, N.A., Chvileva, T.A. \& Romasheva, N.V. 2019. The impact of coal companies on the socio-economic development of coal mining regions and its assessment. Ugol 11(1124): 48-53.

Kim, Y.-H. \& Kim, K.-H. 2012. Experimental approach to assess sorptive loss properties of volatile organic compounds in the sampling bag system. Journal of Separation Science 35(21): 2914-2921.

Kim, Y.-H., Kim, K.-H., Jo, S.-H., Jeon, E.-C., Sohn, J. R. \& Parker, D. B. 2012. Comparison of storage stability of odorous VOCs in polyester aluminum and polyvinyl fluoride Tedlar ${ }^{\circledR}$ bags. Analytica Chimica Acta 712: 162-167.

Kozlov, A.V., Teslya, A.B. \& Chernogorsky, S.A. 2018. Game Theory Model of State Investment into Territories of Advanced Development in the Regions of Mineral Resources Specialization. Journal of Mining Institute 234: 673-682.

Krutskikh, N.V. 2019. Assessment of nature transformation in the mining influence zone by earth remote sensing data. Gornyi Zhurnal 3: 88-93.

Laor, Y., Ozer, Y., Ravid, U., Hanan, A. \& Orenstein, P. 2010. Methodological aspects of sample collection for dynamic olfactometry. Chemical Engineering Transactions 23: 55-60.

Mammadov, V.A., Salamov, A.M. \& Khalilova, H.Kh. 2019. Study of the anthropogenic impact on the change of geoecological conditions of the Khojahasan lake, Azerbaijan. Journal of Mining Institute 239: 603-610. 
Nevskaya, M.A., Seleznev, S.G., Masloboev, V.A., Klyuchnikova, E.M. \& Makarov, D.V. 2019. Environmental and business challenges presented by mining processing waste in the Russian Federation. Minerals 9(7): 445.

Parker, D.B., Perschbacher-Buser, Z.L., Cole, N.A. \& Koziel, J.A. 2010. Recovery of agricultural odors and odorous compounds from polyvinyl fluoride film bags. Sensors 10(9): 8536-8552.

Pashkevich, M.A., Matveeva, V.A. \& Danilov, A.S. 2019. Migration of pollutants from the mining waste disposal territories on the Kola Peninsula. Gornyi Zhurnal 1: 17-21.

Salo, H. \& Makinen, J. 2019. Comparison of traditional moss bags and synthetic fabric bags in magnetic monitoring of urban air pollution. Ecological indicators 104: 559-566.

Sironi, S., Eusebio, L., Capelli, L., Boiardi, E., Del Rosso, R. \& Guillot, J.M. 2014. Ammonia diffusion phenomena through Nalophan bags used for olfactometric analyses. Journal of Environmental Protection 5: 949-961.

State report. 2018. On the State and Environmental Protection of the Russian Federation in 2017. Moscow: Ministry of Natural Resources and Environment of the Russian Federation, Research and Production Enterprise Kadastr.

Volkodaeva, M.V. \& Volodina, Y.A. 2017. Comparing the results of measurements of concentrations of volatile organic compounds using different sampling methods. Ecological systems and devices 7: 3-6.

Volkodaeva, M.V., Volodina, Y.A. \& Kuznetsov, V.A. 2019a. Development of industrial environmental control methods. IOP Conf. Series: Earth and Environmental Science 378(2019) 012108.

Volkodaeva, M.V., Volodina, Y.A. \& Kuznetsov, V.A. 2019b. On the selection of the lavsan sample bags regeneration for their repeated use. Danish Scientific Journal 21(1): 65-68.

Watson, N., Davies, S., Wevill, D. 2011. Air Monitoring: New Advances in Sampling and Detection. Scientific World Journal 11: 2582-2598.

Woolfenden, E. 2010. Sorbent-based sampling methods for volatile and semi-volatile organic compounds in air - part 1: sorbent-based air monitoring options. Journal of Chromatography A. 1217(16): $2674-2684$

Yakunina, I.V. \& Popov, N.S. 2009. Methods and instruments for environmental control. Environmental Monitoring: A Training Manual. Tambov: Publishing house of Tambov State technical university.

Yoshida, S., Higara, K., Takehana, T., Taniguchi, I., Yamaji, H., Maeda, Y., Toyohara, K., Miyamoto, K., Kimura, Y. \& Oda, K. 2016. A bacterium that degrades and assimilates poly(ethylene terephthalate). Science 351: 1196-1199. 


\title{
Method of MSW landfill reclamation using waste conversion products
}

\author{
N.O. Milyutina \\ Postgraduate student, Saint Petersburg State University, Saint Petersburg, Russia \\ N.A. Averianova \\ PhD, Chief process engineer, JSC Avtopark №1 «Spectrans», Saint Petersburg, Russia \\ E.S. Velikoselsksya \\ Ecologist, LLC Novyj Svet.EKO, Saint Petersburg, Russia \\ D.M. Malyuhin \\ Deputy general Director, LLC Novyj Svet-EKO, Saint Petersburg, Russia \\ N.A. Politaeva \\ DSc, Professor, Peter the Great Saint Petersburg Polytechnic University, Saint Petersburg, Russia
}

\begin{abstract}
Mostly, municipal solid waste in Russia is disposed of in landfills. It is known that the main problems in landfill reclamation are the leachate purification and the application of a fertile layer. The most commonly used technology of leachate purification nowadays is reverse osmosis, but the result of this method are two substances: clean water and new waste - concentrate. The creation of a fertile layer is related to the destruction of natural land. A new method of leachate utilization without the generation of new waste is presented in this paper. Also, it is proposed to use the biological potential of the organic waste fraction to create a fertile layer. As a result, a resource-saving scheme for landfill reclamation using waste potential has been developed.
\end{abstract}

\section{INTRODUCTION}

About 35 to 40 million tons of municipal solid waste (MSW) are annually generated in Russia. Only $4-5 \%$ of them are sent for recycling while the remaining waste is disposed of in landfills and dumps. However, this type of waste management is the least preferred according to the hierarchy of accepted methods (Wilson, 1999, Umanets, 2014, Yousefloo, 2020).

Under the influence of biological, physical and chemical factors, the processes of substance transformation occur in the body of MSW landfill. The formed leachate and biogas determine the polluting effect of MSW landfills on the environment (Gourc, 2010, Popovych, 2020, Wilson, 1999). MSW landfills remain sources of pollutants despite the observance of protective measures on the spot. Problems associated with the emission of MSW transformation products remain even after the closure of landfills. Therefore, it is necessary to conduct landfill reclamation.

Reclamation is a combination of engineering, technical and sanitary-hygienic measures that allow to restore the ecological balance of the environment near landfills. Reclamation is divided into technical and biological stages. The technical stage includes the selection of technologies for collecting, purifying and utilizing biogas and leachate as well as slopes formation and application of recultivation layers, the final of which is a fertile soil layer. The biological stage is a set of agrotechnical and phytomeliorative measures to restore the territory of closed 
landfills. The main economic and environmental problems in landfill reclamation are related to purification and disposal of the leachate, as well as the creation of a fertile layer (Lassini, 1999, Weng, 2015).

\section{LITERATURE REVIEW}

Most of the MSW landfills currently operating in Russia are not equipped with a local leachate treatment station. The most common way to reduce leachate during landfill operation is its recirculation. However, this does not solve the problem completely and becomes impossible to use after landfill reclamation (He, 2005). Therefore, an important issue in the technical stage of reclamation is the selection and installation of a treatment plant.

The main methods for purifying the leachate can be divided into biological (aerobic and anaerobic), mechanical (sedimentation, filtration, separation) and physicochemical (coagulation, flocculation, flotation, ion exchange, sorption, micro and ultrafiltration, reverse osmosis, ozonation, electrolysis, ultraviolet radiation) (Henze, 1995, Renou, 2008, Salem, 2008, Silva, 2004, Trebouet, 2001). To achieve a high degree of purification, a combination of these methods is necessary. The most commonly used technology nowadays is reverse osmosis with preliminary mechanical and/or physicochemical treatment of the leachate. The permeate (purified water) obtained as a result of such a purification scheme corresponds to the quality required for its discharge to surface water (Renou, 2008). On the other hand, the use of reverse osmosis leads to the formation of a concentrate representing $25-50 \%$ of the raw leachate, which is itself a new form of waste that must be disposed of.

The second problem of the technical stage of reclamation is applying the fertile layer which is necessary for the realization of the biological stage. The creation of this reclamation layer is an environmental and economic problem due to the shortage of soil. It is estimated that up to $10000 \mathrm{~m}^{3}$ of fertile soil is required for the reclamation of 1 hectare of landfill, which corresponds to the destruction of 5 hectares of natural land. It should be kept in mind that when using mineral loam soils as a recultivation layer, the processes of humus formation occur very slowly. In fact, in 15 years, only $1.5-2 \mathrm{~cm}$ of a continuous humus horizon is formed. In order to save natural resources and accelerate biological processes during reclamation work, the soil can be replaced with organogenic substrates from MSW (Ilinykh, 2015, Awasthi, 2020). The high biological potential of these substrates that are due to their rich plant nutrients and humified organic matter content is universally recognized (Bolan, 2013, Gauhey, 1953).

Waste composting can be carried out in biodrums or in storage pits by the field method. Before composting, it is necessary to sort waste. The activation of biological processes based on the microflora contained in the compostable mass is ensured by aeration using a compost turner (Werf, 2000). The rotating shaft of the turner mixes the mass of the storage pits in such a way that it keeps its trapezoidal shape.

The processes that occur during composting of waste can be divided into 3 phases. The first is characterized by the rapid reproduction of mesophilic microorganisms at an optimal temperature of $20-35^{\circ} \mathrm{C}$. Easily biodegradable organic compounds, mainly found in food waste (carbohydrates, organic acids, proteins), serve as an energy source for bacteria. As a result of their vital activity, thermal energy is released, which contributes to the heating of the composted material to a temperature of $50{ }^{\circ} \mathrm{C}$. In the second phase, this increase in temperature creates favorable conditions for the development of thermophilic microorganisms, which, as a result of their vital activity, increases even more the heat generation and accelerate the decomposition of organic substances. The temperature of the composted material rises to $55-60{ }^{\circ} \mathrm{C}$. The third phase is a slow drop in temperature, indicating the exhaustion of easily decomposable organic compounds. At this stage, a part of the thermophilic microflora dies and the other part goes into a state of spore formation. The mesophilic microflora begins to multiply again due to its more diverse and powerful enzymatic system, with the help of which more stable organic compounds (fiber, lignin) are decomposed. Antibiotic substances with bactericidal properties produced by the biothermal process inhibit the development or cause the death of pathogenic microflora (zhu, 2019, Jain, 2020, Ilinykh, 2015, Liwarska-Bizukoje, 2001). 


\section{METHODS AND MATERIALS OF INVESTIGATION}

The objects of this study consisted of the leachate from one of the MSW landfills of the Leningrad Region, the stabilized leachate and the technogenic soil. The leachate stabilized by solidification was obtained at different periods of time (six samples). The technogenic soil (ten samples) was produced by field composting of sorted municipal solid waste.

In the course of this research, the heavy metals content and agrochemical indicators of the studied objects have been determined. The analysis of the heavy metals content was carried out by Inductively Coupled Plasma Optical Emission Spectroscopy (ICP OES). The toxicity of the stabilized leachate was determined by biotesting. The organic carbon content was determined by the Tyurin method. The active forms of phosphorus were determined by the Denizha colorimetric method after effectuating a Kirsanov extraction. The analysis of the active forms of potassium was carried out using a PAZh-2 flame analyzer from a Kirsanov extract. The active forms of nitrogen were determined by the colorimetric method; nitrate nitrogen with disulfophenolic acid and ammonium with the Nessler reagent.

\section{THE RESULTS AND DISCUSSION}

\subsection{Leachate utilization}

In the course of this research, a new technology for the leachate utilization based on a change in the aggregation state of a liquid into a solid product has been developed. This new product is obtained by the mechanical mixing of the leachate with special reagents. The process is divided in two main stages: the first stage consists of water coagulation, the result of which is the basis for the activation of the second stage - hardening of the mixture due to the formation of mineral components. Various known compounds widely used for MSW leachate purification (Trebouet, 2001) serve as coagulation activators in the present technology. The selection of a particular coagulant depends on the chemical composition of the raw leachate. The main binder additive is the mineral residue from the burning of oil shale in thermal power plants.

The high porosity of the particles of the binder additive leads to the sorption of neutralization reaction soluble products and other soluble impurities of the leachate. Also, as a consequence of chemical reactions, poorly soluble humates of heavy metals are formed. During the mixing of the components, gases are released and are sent to a gas purification filter based on fibrous composite material. The composition of the resulting gases includes nitrogen dioxide $\left(\mathrm{NO}_{2}\right)$, carbon monoxide $(\mathrm{CO})$, hydrogen sulfide $\left(\mathrm{H}_{2} \mathrm{~S}\right)$, nitric oxide $(\mathrm{NO})$ and methane $\left(\mathrm{CH}_{4}\right)$. A plastic paste-like mass of material obtained after mixing components is formed, which hardens and gains strength within 21 days.

The chemical composition of the leachate depends on a number of factors. The main ones are the morphological composition of the deposited waste and the landfill stage of life, which corresponds to a certain stage of biochemical and physicochemical transformation of the waste. The leachate is conditionally divided into "young" and "old" according to its chemical composition. The "young" leachate is formed at the first stages of waste decomposition in the acetogenic phase after the 2-7 years of waste storage. The "old" leachate is formed at the methanogenic stages (salem, 2008). Depending on the amount of organic carbon (COD and BOD), basic anions and heavy metals (HM) in the leachate, the ratio of the main components when converting the leachate to a solid product can be varied for obtaining a high-quality product.

The studied leachate was determined as "old" and the appropriate ratio of components and mixing have been selected, after which, a product of solidification was obtained. The content of the active forms of HM in the new product is presented in Table 1.

The total content of HM in this product is presented in Table 2. These concentrations represent the average contents in the six samples.

From the data obtained, it follows that the content of heavy metals in the solid product does not exceed permissible concentrations for settlement soils. 
Table 1. Active form of heavy metals content in the solid product.

\begin{tabular}{lll}
\hline Heavy metal (active form) & Concentration, $\mathrm{mg} / \mathrm{kg}$ & LOC*, mg/kg \\
\hline $\mathrm{Ni}^{2+}$ & $1.1 \pm$ & 4.0 \\
$\mathrm{Co}^{2+}$ & $<1.0$ & 5.0 \\
$\mathrm{Cu}^{2+}$ & $<1.0$ & 3.0 \\
$\mathrm{Mn}^{2+}$ & $28.0 \pm 4,2$ & 80.0 \\
$\mathrm{Cr}^{3+}$ and $\mathrm{Cr}^{6+}$ & $1.7 \pm$ & 6.0 \\
$\mathrm{~Pb}^{2+}$ & $2.7 \pm$ & 6.0 \\
$\mathrm{Zn}^{2+}$ & $5.3 \pm$ & 23.0 \\
\hline
\end{tabular}

* Level of concern from the Hygienic Standards 2.1.7.2041-06.

Table 2. Total heavy metals content in the solid product.

\begin{tabular}{lll}
\hline Heavy metal (total) & Concentration, $\mathrm{mg} / \mathrm{kg}$ & $\mathrm{LOC}, \mathrm{mg} / \mathrm{kg}$ \\
\hline $\mathrm{Hg}$ & $0.068 \pm 0.0078$ & 2.1 \\
$\mathrm{As}$ & $10.02 \pm 0.83$ & 10.0 \\
$\mathrm{Ni}$ & $3.60 \pm 0.32$ & 80.0 \\
$\mathrm{Co}$ & $1.43 \pm 0.14$ & - \\
$\mathrm{Cu}$ & $2.21 \pm 0.17$ & 132.0 \\
$\mathrm{Mn}$ & $72.0 \pm 4.3$ & 1500 \\
$\mathrm{Cr}$ & $6.02 \pm 0.54$ & - \\
$\mathrm{Pb}$ & $7.98 \pm 0.61$ & 130.0 \\
$\mathrm{Zn}$ & $16.0 \pm 1.1$ & 220.0 \\
$\mathrm{Cd}$ & $0.162 \pm 0.015$ & 2.0 \\
\hline
\end{tabular}

* Level of concern from the Hygienic Standards 2.1.7.2511-09.

The toxicological studies carried out on white rats and guinea pigs as well as the bioassays realized on Daphnia magna Straus and Chlorella vulgaris did not show any toxic effects of the product (Table 3,4$)$.

The resulting solid product is proposed to be used during reclamation as a leveling layer (when grinded to a fraction of 1-5 mm diameter), and also as a drainage layer under a fertile soil (when crushed to a fraction of 20-40 mm diameter). Moreover, this product can be used as an inert material when refilling waste during the operation of the MSW landfills and for building roads to the facility. Thus, the leachate is converted into a solid product without receiving new waste and can be implemented directly at its production site.

\subsection{Creation of the fertile layer}

In the course of this work, it was confirmed that 180 days are needed for obtaining the product of waste field composting in Saint-Petersburg climate. However, the use of additional biological additives can reduce the ripening time of the product, i.e. the technogenic soil, to 90 days. Currently, due to the relevance of using the potential of MSW landfills, various modifications of biological additives with antimicrobial effects have been designed to accelerate the decomposition of organic substances. Tests on the influence of several Russian brands of biological additives on the raw mass of sorted waste have revealed a more rapid humus formation and, consequently, a faster ripening of technogenic soil.

The chemical composition of the technogenic soil obtained after field composting of sorted waste is presented in Table 5.

According to the obtained data, the technogenic soil is a very agrochemically favorable substrate for plant growth and significantly exceeds the sod-podzolic soil in terms of nutrient content. The total content of heavy metals does not exceed the normative indicators for composts 
Table 3. Toxicological studies of the new solid product on laboratory animals.

\begin{tabular}{|c|c|c|c|}
\hline Indicator & Units & Research results & $\begin{array}{l}\text { Russian normative document on } \\
\text { the research method }\end{array}$ \\
\hline $\begin{array}{l}\text { Acute toxicity by intragas- } \\
\text { tric gavage } \mathrm{DL}_{50} \text { (white } \\
\text { rats) }\end{array}$ & $\mathrm{mg} / \mathrm{kg}$ & $\mathrm{DL}_{50}>5000$ & $\begin{array}{l}\text { Instruction 1.1.11-12-35-2004 } \\
\text { "Experimental research require- } \\
\text { ments for primary toxicological } \\
\text { evaluation and hygienic regula- } \\
\text { tion of substances" }\end{array}$ \\
\hline $\begin{array}{l}\text { Inhalation hazard by static } \\
\text { inhalation inoculation, } \\
\text { (n.c.), exposure for } 2 \text { hours, } \\
\text { (white rats) }\end{array}$ & - & $\begin{array}{l}\text { The volatile components did not } \\
\text { cause irritation of the mucous } \\
\text { membranes of the eyes and } \\
\text { upper respiratory tract. The } \\
\text { death of animals was not } \\
\text { recorded. }\end{array}$ & $\begin{array}{l}\text { "Recommendations for prelim- } \\
\text { inary assessment of chemical } \\
\text { substance toxicity by accelerated } \\
\text { method" }\end{array}$ \\
\hline $\begin{array}{l}\text { Skin-irritant effect (white } \\
\text { rats) } \\
\text {-singly } \\
\text {-repeatedly }\end{array}$ & $\begin{array}{l}\text { points } \\
\text { points }\end{array}$ & $\begin{array}{l}0 \\
0\end{array}$ & $\begin{array}{l}\text { Methodical guidelines №2102-79 } \\
\text { "Assessment of the impact of } \\
\text { harmful chemical compounds } \\
\text { on the skin and the justification } \\
\text { of extremely acceptable levels of } \\
\text { skin contamination" }\end{array}$ \\
\hline $\begin{array}{l}\text { Irritation of the mucous } \\
\text { membranes of the eyes } \\
\text { (guinea pigs) }\end{array}$ & points & 0 & $\begin{array}{l}\text { Methodical guidelines № } 2196- \\
80 \text { "Setting up studies of irritat- } \\
\text { ing properties and justification } \\
\text { of maximum permissible con- } \\
\text { centrations of selectively acting } \\
\text { irritating substances in the air of } \\
\text { the working area" }\end{array}$ \\
\hline
\end{tabular}

Table 4. Toxicological studies of the new solid product by bioassays.

\begin{tabular}{|c|c|c|c|c|c|c|c|}
\hline Indicator & Units & Resec & ch res & & & $\begin{array}{l}\text { Permissible } \\
\text { level }\end{array}$ & $\begin{array}{l}\text { Russian normative document on the } \\
\text { research method }\end{array}$ \\
\hline \multirow{5}{*}{$\begin{array}{l}\text { Dilution of the } \\
\text { extract tested on } \\
\text { the hydrobionts: } \\
\text {-without dilution } \\
\text {-control } \\
\text { Sensitivity of } \\
\text { Chlorella at mul- } \\
\text { tiple rates of } \\
\text { dilution: } \\
\text {-without dilution } \\
\text {-control }\end{array}$} & $\%$ & $24 \mathrm{~h}$ & $48 \mathrm{~h}$ & $72 \mathrm{~h}$ & $96 \mathrm{~h}$ & \multirow[t]{3}{*}{$\mathrm{A} \leq 10$} & \multirow{5}{*}{$\begin{array}{l}\text { FR 1.39.2007.03222 "Methods for } \\
\text { determining water toxicity and water } \\
\text { extracts from soil, sewage sludge, } \\
\text { waste on mortality and fertility } \\
\text { changes of Daphnia" } \\
\text { FR 1.39.2015.20001 "Method of the } \\
\text { measurement of the optical density of } \\
\text { cultures of Chlorella algae for the } \\
\text { determination of drinking, fresh, nat- } \\
\text { ural and waste water, water extracts } \\
\text { from soil, sewage sludge, and waste } \\
\text { toxicity" }\end{array}$} \\
\hline & & 0 & 0 & 0 & 0 & & \\
\hline & & 0 & 0 & 0 & 0 & & \\
\hline & $\%$ & $+9,6$ & & & & $-30<\mathrm{I}<+20$ & \\
\hline & & 0 & & & & & \\
\hline
\end{tabular}

from MSW. It should be noted that the bioavailable forms of HM are even less (KabataPendias, 2001). Despite that it is not planned to use the plants that naturally sprouted on the technogenic soil for feed, results have shown that these plants were within the standards of fodder crops of farm animals. 
Table 5. Chemical composition of the technogenic soil.

\begin{tabular}{lll}
\hline Elements & Concentration & Measurement units \\
\hline $\mathrm{C}$ total & $11.3 \pm 0.8$ & $\%$ \\
$\mathrm{~N}$ total & $0.54 \pm 0.07$ & $\%$ \\
$\mathrm{C}: \mathrm{N}$ & 20.9 & $\mathrm{unit}$ fraction \\
$\mathrm{N}-\mathrm{NH}_{4}$ (active form) & $22.4 \pm 1.3$ & $\mathrm{mg} / \mathrm{kg}$ \\
$\mathrm{N}-\mathrm{NO}_{3}$ (active form) & $31.2 \pm 2.5$ & $\mathrm{mg} / \mathrm{kg}$ \\
$\mathrm{P}$ (active form) & $343 \pm 31$ & $\mathrm{mg} / \mathrm{kg}$ \\
$\mathrm{K}$ (active form) & $339 \pm 20$ & $\mathrm{mg} / \mathrm{kg}$ \\
$\mathrm{Cu}$ (total) & $103 \pm 7$ & $\mathrm{mg} / \mathrm{kg}$ \\
$\mathrm{Zn}$ (total) & $208 \pm 9$ & $\mathrm{mg} / \mathrm{kg}$ \\
$\mathrm{Pb}$ (total) & $134 \pm 8$ & $\mathrm{mg} / \mathrm{kg}$ \\
$\mathrm{Cd}$ (total) & $3.32 \pm 0.28$ & $\mathrm{mg} / \mathrm{kg}$ \\
$\mathrm{Ni}$ (total) & $31.4 \pm 2.3$ & $\mathrm{mg} / \mathrm{kg}$ \\
$\mathrm{Mn}$ (total) & $4.50 \pm 0.39$ & $\mathrm{mg} / \mathrm{kg}$ \\
$\mathrm{Hg}$ (total) & $4.21 \pm 0.33$ & $\mathrm{mg} / \mathrm{kg}$ \\
As (total) & $2.13 \pm 0.17$ & $\mathrm{mg} / \mathrm{kg}$ \\
\hline
\end{tabular}

Thus, the technogenic soil obtained from the organic part of MSW is a rational and affordable method for replacing the fertile layer during reclamation.

\subsection{Use of the MSW potential in landfill reclamation}

During landfill reclamation, the following layers are used: a drainage layer to collect biogas, a waterproof layer to isolate the landfill body, a drainage layer to drain surface water and a fertile soil layer (Figure 1).

According to the obtained data, a method for landfill reclamation using the potential of waste coming to landfill is proposed. The product of the leachate solidification can serve as a drainage layer and technogenic soil as a fertile soil. The scheme of using waste transformation products during reclamation is presented in Figure 2.

Today, many landfills of the Russian Federation created at the end of the last century need to be reclaimed, and therefore the development of a landfill reclamation scheme using the potential of waste is relevant and opportune.

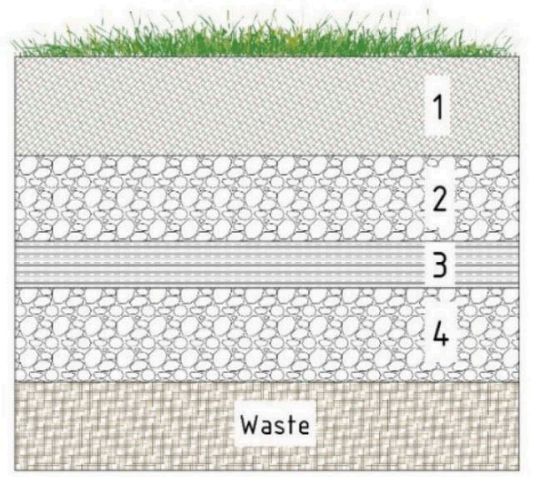

Figure 1. Reclamation layers of landfill: 1 - fertile layer, 2 - drainage layer for water, 3 - waterproof layer (clay), 4 - drainage layer for biogas. 


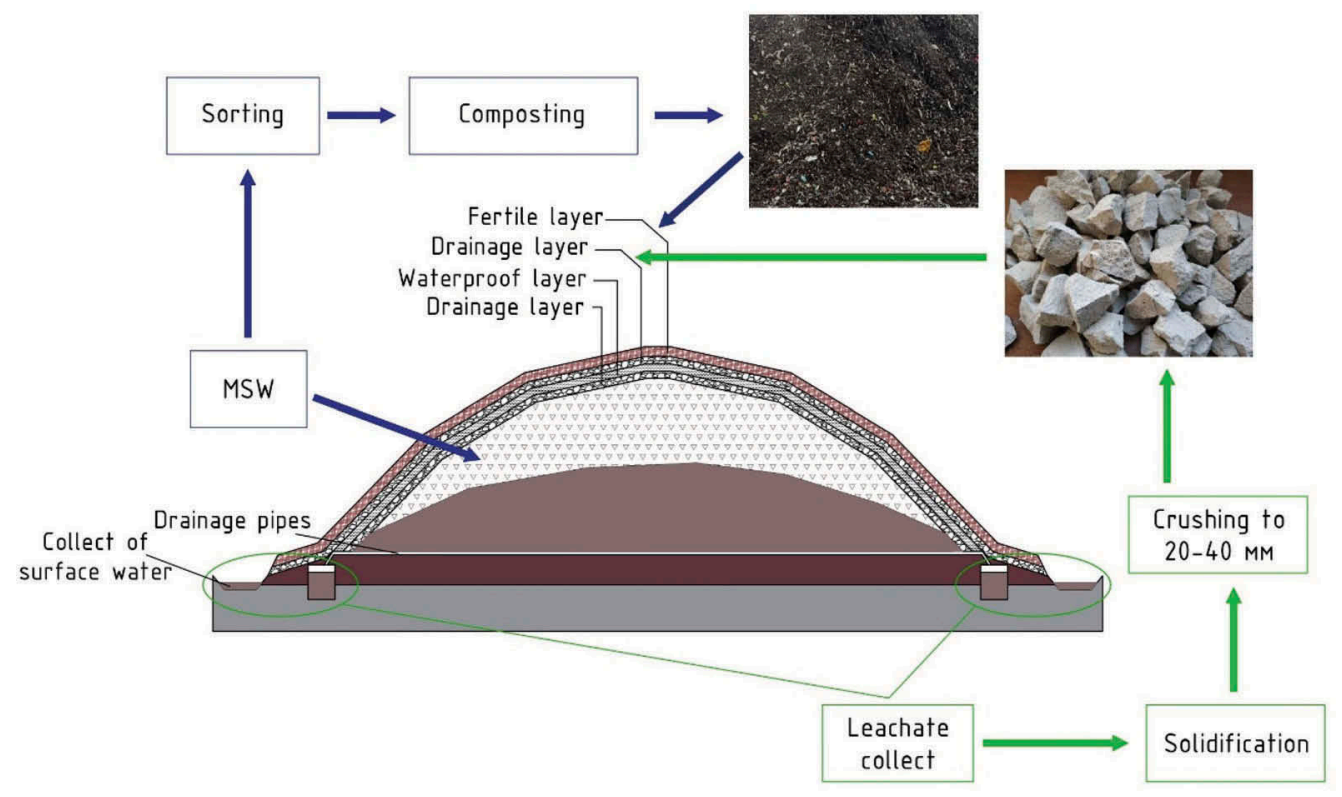

Figure 2. Scheme of using waste transformation products during reclamation.

\section{CONCLUSIONS}

1. A new method for the utilization of leachate has been developed, which allows the leachate to be converted into a solid product without generating new waste;

2. The content of heavy metals in the solid product did not exceed permissible concentrations for settlement soils and thus, does not represent a secondary source of pollution. Moreover, the toxicological studies confirmed the safety of this product;

3. It was confirmed that the technogenic soil obtained from the organic fraction of MSW has the necessary agrochemical parameters for its use as a fertile layer;

4. A resource-saving scheme for landfill reclamation using waste transformation products as reclamation layers was presented, which is economically and environmentally friendly.

\section{REFERENCES}

Awasthi, S.K., Sarsaiya, S., Awasthi, M.K. et al. 2020. Changes in global trends in food waste composting: Research challenges and opportunities. Bioresource Technology 299: 122555.

Bolan, N.S., Thangarajan, R., Seshadri, B. et al. 2013. Landfills as a biorefinery to produce biomass and capture biogas. Bioresource Technology 135: 578-587.

Gauhey, P., Golueke, C. 1953. Reclamation of Municipal Refuse by Composting. Berkeley: Univ. of Calif.

Gourc, J. P., Staub, M. J., Conte, M. 2010. Decoupling MSW settlement into mechanical and biochemical processes - Modelling and validation on large-scale setups. Waste Management 30: 1556-1568.

He, R., Shen, D., Wang, J., He, Y., Zhu, Y. 2005. Biological degradation of MSW in a methanogenic reactor using treated leachate recirculation. Process Biochemistry 40: 3660-3666.

Henze, M. 1995. Wastewater treatment. Biological and chemical processes. Berlin: Springier.

Ilinykh, G.V., Visman, YA.I., Slyusar, N.N., Korotaev, V.N. 2015. Municipal solid waste composition of the city of Perm, Russia: main changes over time. Intern. multidisciplinary scientific geoconference surveying geology and mining ecology management. Albena: SGEM.

Jain, M.S., Paul, S., Kalamdhad. A.S. 2020. Kinetics and physics during composting of various organic wastes: Statistical approach to interpret compost application feasibility. Journal of Cleaner Production 255: 120324.

Kabata-Pendias, A., Pendias, H. 2001. Trace elements in soils and plants. Boca Raton: CRC Press. 
Lassini, P., Sala, G., Sartori, F. 1999. Reclamation of old and new landfills and their integration with the invironment. Environmental impact, aftercare and remediation of landfills; 7 th intern. waste management and landfill symp. Sardinia: SIWMLS.

Liwarska-Bizukoje, E., Ledakowicz, S. 2001. Elemental balance for the biodegradation process of the organic fraction of municipal solid waste. Lodz: Technical university of Lodz.

Popovych, V., Telak, J., Telak, O. et al. 2020. Migration of hazardous components of municipal landfill leachates into the environment. Journal of Ecological Engineering 21: 52-62.

Renou, S., Givaudan, J.G., Poulain, S. et al. 2008. Landfill leachate treatment: review and opportunity. Journal of Hazardous Materials 150: 468-493.

Salem, Z., Hamouri, K., Djemaa, R., Allia, K. 2008. Evalution of landfill leachate pollution and treatment. Desalination 220: 108-114.

Silva, A. C., Dezotti, M., Sant'Anna, G. L. 2004. Treatment and detoxitation of a sanitary landfill leachate. Chemosphere 55: 207-214.

Trebouet, D., Schlumpf, J. P., Jaouen, P., Quermeneur, F. 2001. Stabilized landfill leachate treatment by combined physicochemicalnanofiltration process. Water Research 35: 2935-2945.

Umanets, V.N., Chusov, A.N., Umanets, E.V. 2014. Solution approach to historical pollution and accumulated production wastes. Ecology \& environmental protection: 607-614.

Weng, Y., Fujiwara, T., Houng, H.J. et al. 2015. Management of landfill reclamation with regard to biodiversity preservation, global warming mitigation and landfill mining: experiences from the AsiaPacific region. Journal of Cleaner Production 1041: 364-373.

Werf, P. 2000. Assessment and evaluation of outlets of compost produced from municipal waste. Wexford: Environmental Protection Agency.

Wilson, I.M., Garlick, C. 1999. Management and statistical analysis of landfill monitoring data. Environmental impact, aftercare and remediation of landfills; 7th intern. waste management and landfill symp. Sardinia: SIWMLS.

Yousefloo, A., Babazadeh, R. 2020. Designing an integrated municipal solid waste management network: A case study. Journal of Cleaner Production 244: 118824.

Zhu, L., Zhao, Y., Zhang, W. et al. 2019. Roles of bacterial community in the transformation of organic nitrogen toward enhanced bioavailability during composting with different wastes. Bioresource Technology 285: 121326. 


\title{
Microalgae biotechnology multiple use of Chlorella sorokiniana
}

\author{
N.A. Politaeva, Y.A. Smyatskaya \& I.V. Dolbnya \\ Peter the Great St. Petersburg Polytechnic University, St. Petersburg, Russia \\ D.S. Sobgaida \\ Saratov State Medical University named after V.I. Razumovsky, Saratov, Russia
}

\begin{abstract}
This study is dedicated to realization closed biotechnology using Chlorella sorokiniana microalgae. It is a new source of valuable components for various kinds of industry and for obtaining energy such as biofuel and biogas. This technology includes several main stages: microalgae cultivation; extraction of lipids, pigments, pectic substances and carotenoids from the biomass; creation sorption materials based on residual biomass of microalgae for water treatment; using residual biomass and saturated sorbents as a fuel, as a co-substrate for organic waste fermentation and as fertilizers. It is shown that the realization of presented biotechnology allows to use each product on every step of the technology.
\end{abstract}

\section{INTRODUCTION}

Nowadays, biomass of different microalga species is used widely in various industries such as: the ecological industry, in water purification, biotechnology, pharmacy, in the food industry and for biofuel production. Green microalgae grow fast. They do not require large soil territories like in the case of conventional food crops and they can be cultivated in closed or open cultivation systems (cultivators and photobioreactors) (Azad, 2019). And they need provision of light, nutrients and aeration. Microalgae is a source of many valuable components such as: lipids, proteins, pigments, carotenoids, pectic substances. These components are extracted from the biomass and can be used in different fields of production.

One of the main ecological problems is water pollution by organic and inorganic substances. Fresh water is widely used in different fields of industry, for agricultural and domestic needs; after technological processes wastewater is formed. They contain various kinds of pollutants including suspended particles and dissolved ones. Often, they are toxic, for example heavy metal ions (Afroze, 2018). Microalgae are good sorption materials for water purification (Abdel-Raouf, 2012). It is possible to grow them with the use of wastewater as a nutrient medium or to use their residual biomass which is formed after extraction valuable components.

Sorption is the one of the effective methods for water treatment. It is a process of concentration pollutants on the surface or the porous area of the material (sorbent). If it occurs on the surface of solid material, the adsorption arises. If liquid or gas phase is used as a sorbent, and in this case, contaminants are concentrated in the volume of the phase, the absorption occurs (Gregg, 1982; Dąbrowski, 2001). At the same time, sorption is a complicated method. Therefore, it is important to develop research in this field, accumulate new knowledge, find new materials which can be used as sorbents, establish modern modification methods for sorption materials creation. Herewith, technologies which are invented for a solution of some problems have not to be the reason of other difficulties, it is important to apply them in a complex way.

Thus, innovative biotechnology multiple use of Chlorella sorokiniana microalgae was developed. It includes stages from biomass cultivation, extraction of pigments, lipids and pectic substances, creation sorption materials based on residual biomass for water treatment, and 
end up with biogas production by organic waste fermentation with residual biomass and saturated sorbents as co-substrate. The realization of this biotechnology allows to use of each component on every step and totally avoid waste accumulation, because all materials are considered as the resources.

\section{LITERATURE REVIEW}

\subsection{Microalgae biomass and its cultivation}

Microalgae are cultivated in cultivators and photobioreactors with different constructions; they can be closed or open, Figure 1.

All cultivation technics are divided into two categories: the first one is laboratory conditions and a controlled environment, Figure 2; the second one is outdoor conditions which allow to produce large amount of biomass (Vonshak, 1985; Brennan, 2010). Each type of this technic has advantages and disadvantages. The closed system prevents contamination by other microalgae species and some pollutants, but the open pond should be controlled to avoid such problems. Some construction of the cultivator has a special electro and mechanical providing which allows to move panels with cultivators in the direction of sunlight, Figure $1 \mathrm{~b}$.

Microalgae are living microorganisms, for their growth they need in nutrients medium supply. The nutrients medium should consist of following elements: carbon, hydrogen, oxygen, calcium, potassium, magnesium, nitrogen, iron, phosphorus, sulfur, and copper, manganese, zinc or selenium as trace elements. But three elements such as carbon, nitrogen and
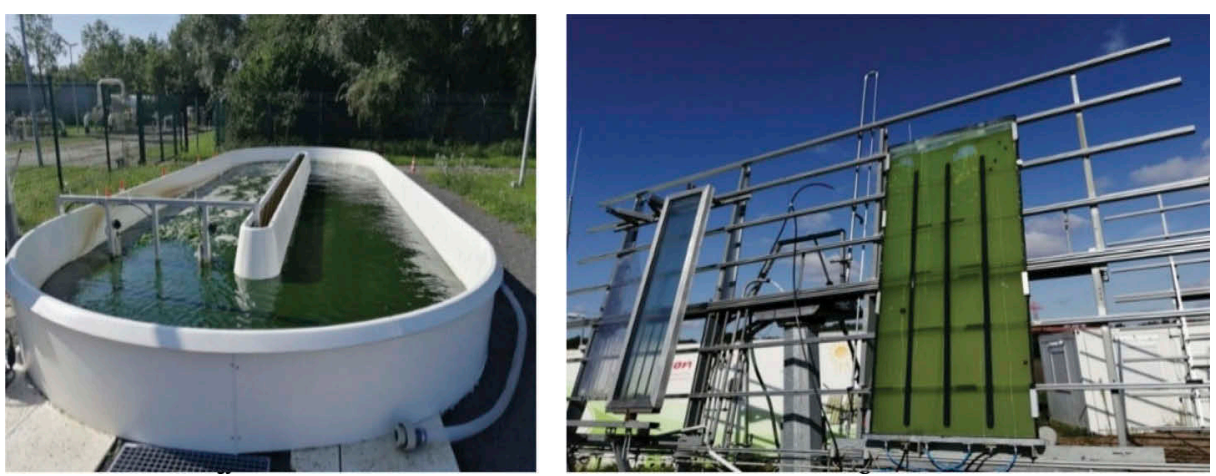

Figure 1. Types of cultivation systems (outdoor conditions): $a-$ open raceway pond; $b$ - closed photobioreactor.
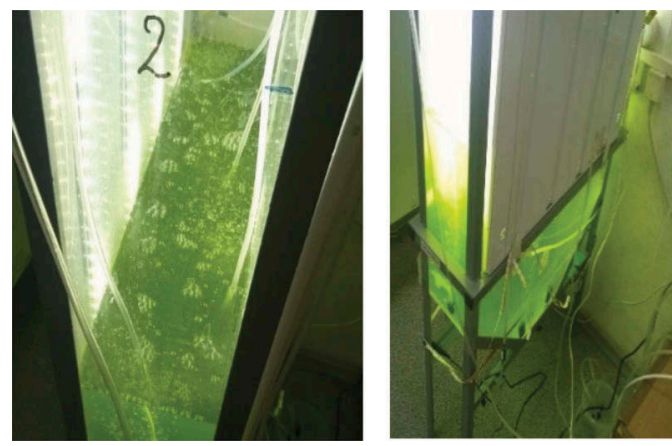

Figure 2. Microalgae cultivation in laboratory conditions (closed photobioreactors). 
phosphorus are the most important for growth (Geada, 2017; Richmond, 2013). The use of additional external physical actions (e.g. laser radiation, magnetic field) allows to maximize biomass growth in the shortest time (Politaeva, 2018; Smyatskaya, 2019).

Microalgae represent green carbon as an alternative to fossil carbon (fuels); these microorganisms capable to produce biomass enriched with valuable components using sun energy. As all green plants they absorb $\mathrm{CO}_{2}$ and convert it into $\mathrm{O}_{2}$. Thus, they provide decrease of $\mathrm{CO}_{2}$ concentration in the air and take part in minimization of global warming. So, the use of microalgae as a new source of energy has a lot of advantages and perspectives (Geada, 2017).

Chlorella sorokiniana is widely used to obtain the biomass containing lipids and proteins. It is a singlecelled green microalga characterized by its small size $(2-10 \mu \mathrm{m}$ in diameter $)$ and high division rate (1division every 17 to 24 hours). It is non-flagellated and has thick cell wall. These microalgae contain high amounts of valuable compounds: $40 \%$ protein, 30-38 \% carbohydrate, 18-22\% lipid, pigments (lutein), etc. (Niccolai, 2019; De Andrade, 2017).

\subsection{Wastewater treatment}

Water contamination is the main ecological problem in the world. Industry and agriculture use a large amount of fresh water for production needs. And after technological processes wastewater are formed, which include in their composition various kinds of substances specific for certain activity. In the most cases these substances are hazardous even in small concentrations and have the ability to accumulate in body tissues of living organisms and then can reach the human body by movement along the food chain. It is extremely important to apply special technological methods and equipment to get purified water. Even for now the planet has such territories with lack of fresh water and for some people it is very hard to have it in a sufficient amount.

Water treatment technology consists from following methods: physical, chemical, physicochemical, biological. The choice of one method or another or their group depends on initial water contamination and purposes of its further usage. Wastewater containing suspended substances go through a stage of pretreatment; during this process large particles such as wood, rags, fecal material and others are removed. Then sewage flow in sedimentation tanks, where sedimentation of settleable solids occurs by gravity. Water prepared in this way is directed on a stage of more deep sorption purification where dissolved impurities are removed. At the end of the process purified water flows on biological treatment, then its disinfection is curried out and after this water can be used again.

Microalgae widely used in the process of water purification. As they capable to actively accumulate biomass by transformation of sun energy it is possible to use of wastewater as nutrient medium for their growth (De la Noüe, 1988; Abdel-Raouf, 2012).

Algae have a good accumulation ability in relation to different heavy metal ions: $\mathrm{Cu}^{2+}, \mathrm{Pb}^{2+}$, $\mathrm{Cr}^{3+}, \mathrm{Ni}^{2+}, \mathrm{Cd}^{2+}, \mathrm{Co}^{2+}, \mathrm{Fe}^{2+}, \mathrm{Mn}^{2+}, \mathrm{Zn}^{2+}$. And these elements are included in the biological process of microalgae growth, at the same time metal detoxication occurs. Different mechanisms lead to reducing heavy metals concentration by microalgae. It depends on the algae species, the type of metal ion and its valency, the condition of aqueous solution and the state of algae cells, which can be living or nonliving (Abdel-Raouf, 2012). And it is possible to use a residual biomass of microalgae which is formed after extraction of valuable components for water treatment as sorption materials.

\subsection{Sorption process and sorption materials}

Sorption is surface phenomenon when accumulation of substances near an interface takes place. This process may be defined as partitioning of chemical species between bulk phase and interface. It can be a contact of such systems as solid-liquid, liquid-liquid, liquid-gas and solid-gas. The possibility of change in concentration of a given substance at the interface in comparison with bulk phase underlies many directions of technology including purification nature environments such as water, gas, soil (Dąbrowski, 2001; Bajpai, 1999). 
Sorption is the general determination of the process, but when this phenomenon caries out on a surface or porous space of solid phase, adsorption occurs. But in the case of concentration of the substances in the volume of liquid or gas phase, absorption arises. It is important to distinguish these specific terms. Also, sorption has different types; when physical interactions caused by Van der Waals forces take place, the process is called physical sorption; when interactions between two phases are caused by chemical mechanisms with formation of new substances, in this case sorption has the chemical type.

Now, a lot of different materials are used as sorbents for water treatment. The most famous is activated carbon. This material is widely used as adsorbent for the removal of different kinds of contaminants, which have organic and inorganic origin. Activated carbon has good sorption properties, high values of adsorption capacity and surface area (Rodriguez-Reinoso, 2016). But it also has some disadvantages in application as difficulties with regeneration after sorption and this is expansive material. Because of it, there are many research dedicated to development of new materials with the same properties like activated carbon has; and now in the most cases researches pay attention on the use of waste to create sorption materials based on them. It can be agricultural waste such as wheat and millet husk, sunflower husk, nuts shells, rice straw; also, it can be chitosan, zeolites, waste of food production and other kinds of industry (Crini, 2018; Jagruti, 2015; Khalil, 2018; Politaeva, 2019a). Due to the use of waste for these purposes another one urgent ecological problem related to this can be solved. As it was previously mentioned the biomass of microalgae is the good sorbent for many substances in aqueous solutions; and it is possible to use residual biomass for water purification, because of the composition of this natural material consisting of cellulose, hemicellulose, lignin, etc. On practice in the most cases row materials have such sorption characteristics which are not so good enough. Therefore, various kinds of modification are applied to improve sorption properties (thermal and chemical modification). In order to increase the sorption capacity composite sorption materials can be created with different composition. As a binder substance chitosan can be used in obtaining of granulated sorbents. It is a biopolymer and it has good sorption properties in relation to contaminants in water solutions. And in water treatment technology it is also used as a sorbent, but because of its high cost, chitosan doesn't find a wide application. But residual microalgae biomass included in the composition with chitosan increases sorption characteristics of a new created granulated sorbent and leads to improvement of chitosan resistance to dissolution in acid environment.

\subsection{Biogas production with the use of microalgae}

Another advantage to develop the biotechnology of microalgae treatment is biogas production. Nowadays it is third generation biofuel. Microalgae produce an oil that can be refined into biodiesel. It is a renewable one and it includes methane, carbon dioxide and biohydrogen. The grow rate of microalgae is very high; large land territories for biomass production is not needed. Because of it, microalgae as a source of energy is more profitable in comparison with materials used as a basis for first and second generation fuels. In general, the process of biogas production from microalgae biomass is commercially viable, when firstly all by-products are extracted from the initial biomass. And after that for the purposes of biogas production the residual biomass is applied (Alam, 2015; Brennan, 2010; Azad, 2019; Tang, 2016). Converting the biomass into biogas components (methane, hydrogen and $\mathrm{CO}_{2}$ ) carries out at anaerobically digested conditions (Chusov, 2019). Thus, the complex use of microalgae potential through all stages of the biotechnology allows to get a lot of useful by-products, new materials and energy.

During implementation of international project entitled «Development and implementation of innovative biotechnologies for treatment of microalgae Chlorella sorokiniana and the duckweed Lemna minor» a closed loop biotechnology using Chlorella sorokiniana microalgae biomass has been developed. It includes following stages: cultivation microalgae in bioreactors; harvesting; extraction lipids and fatty acids, and pigments; obtaining sorption materials based on residual biomass for water treatment; producing biogas by fermentation of used sorbents and other waste which are formed. 


\section{MATERIALS AND METHODS}

\subsection{Cultivation of Chlorella sorokiniana microalgae in laboratory conditions and its harvest}

Chlorella sorokiniana microalgae were cultivated in closed photobioreactors which are presented in Figure 2. For its growth nutrition medium was prepared based on modified Hoagland solution including composition of macro- and micronutrients, which are important for microalgae cell formation (Richmond, 2004). Specific growth conditions were provided such as illumination of photobioreactors using fluoriscence lamps with duration 18 hours per day in the regime of day/night with constant aeration by air. This aeration was conducted by bubbling Xilong AP-003 device ( $5 \mathrm{~W}, 2 \mathrm{Kh} 2,5 \mathrm{l} / \mathrm{mines})$. The optical density of the biomass from the beginning of the cultivation was measured by spectrophotometer Shimadzu UV-1280 at $\lambda=750 \mathrm{~nm}$. It allows to control cells culture accumulation. And after 10 days the biomass growth reaches maximum amounts at the stationary phase of the growth (Politaeva, 2018b).

The next step after cultivation is harvest. Biomass concentration was carried out by microfiltration through membrane filters or by centrifugation. After this step, the biomass was dried by freeze-drying.

\subsection{Extraction of valuable components}

Chlorella sorokiniana biomass is the source of many valuable components such as: lipids including fatty acids which can be used for Omega - 3 and biofuel production; carotenoids which are widely used in pharmaceutic industry; green pigments which can be used in the fields of cosmetology and in the food industry as dietary pigments; pectic substances which are useful ingredients in the food production. The extraction of lipids and this process are described in following scientific article (Politaeva, 2019b).

\subsection{Sorption material for water treatment based on residual biomass and chitosan}

After the extraction of valuable components, a residual biomass is formed. It is a kind of waste, but at the same time it is a material with useful properties. Therefore, it can be used for obtaining sorption material for water treatment from heavy metal ions. It is known that these substances are toxic and are often contained in wastewater, so it is relevant to look for new methods to remove these heavy metal ions and get purified water. So, the technology of obtaining sorption material based on carbonized residual biomass and chitosan as a binder substance consists of following steps. First, the residual biomass is carbonized at high temperatures in order to be activated. The second step is the dissolution of chitosan in a $3 \%$ solution of acetic acid. Then all components are mixed and the next, the granulation step is carried out by the addition of the mixture drop by drop to a $5 \%$ solution of sodium hydroxide. The granules are then left to soak in this solution for 24 hours. Then the granules are washed using distilled water until reaching neutral $\mathrm{pH}$ values. After this, the material is by ambient air drying.

The determination of the sorption properties of the obtained sorbent was conducted. Sorption isotherms were experimentally obtained. The initial and equilibrium concentrations of heavy metal ions in the modal water solution have been measured with the use of TA-Lab device (Russia, LLC Research production enterprise Tom'analit) which work based on inversion voltammetric method of analysis, using standard Russian method Environmental Protection Regulation 14.1:2:4.222-06. The inaccuracy of measuring technique is $25 \%$. Experimental conditions of purification model water solutions consisted of $\mathrm{Zn}^{2+}, \mathrm{Cd}^{2+}$ and $\mathrm{Cu}^{2+}$ ions: $\mathrm{m}_{\text {sorbent }} / \mathrm{V}_{\text {solution }}=$ $2 \mathrm{~g} / \mathrm{l} ; \mathrm{t}_{\text {sorption }}=24$ hours; $\mathrm{T}=20 \pm 2{ }^{\circ} \mathrm{C} ; \mathrm{pH}=4.0 \pm 0.2$. The experiment accuracy is within the limits of 5-10\%. The sorption capacity was calculated using Equation 1:

$$
q=\frac{\left(C_{i}-C_{e}\right) \cdot V}{m}
$$


where $\mathrm{C}_{\mathrm{i}}$ and $\mathrm{C}_{\mathrm{e}}$ - initial and equilibrium concentrations of heavy metal ions (mmol/l); V solution volume (1); and $\mathrm{m}$ - mass of the sorbent (g).

To describe sorption process two sorption models were applied: Lengmuir (Equation 2) and Freundlich (Equation 3) isotherm models. Equation 2 is a linearized form of Lengmuir sorption model (Ayawei, 2017).

$$
\frac{1}{q}=\frac{1}{q_{\max }}+\frac{1}{K q_{\max } C_{e}}
$$

where $\mathrm{q}$ - sorption capacity $(\mathrm{mmol} / \mathrm{g}) ; \mathrm{q}_{\max }$ - maximum sorption capacity of the sorbent ( $\mathrm{mmol} / \mathrm{g}) ; \mathrm{C}_{\mathrm{e}}$ - equilibrium heavy metal ions concentration in the solution (mmol/l); $\mathrm{K}$ - Langmuir constant which notices on sorption rate and it is also a coefficient or constant of sorption equilibrium $(1 / \mathrm{mmol})$.

Equation 3 is a logarithmic form of Freundlich sorption model (Ayawei, 2017).

$$
\log q=\log K+1 / n \log C_{e}
$$

where $\mathrm{q}$ - sorption capacity (mmol/g); $\mathrm{K}$ and $\mathrm{n}$ - constants of Freundlich sorption model; $\mathrm{C}_{\mathrm{e}}-$ equilibrium heavy metal ions concentration ( $\left.\mathrm{mmol} / \mathrm{l}\right)$.

In order to establish sorption character (physical or chemical mechanism) Gibbs free energy has been calculated by Equation 4 (Gautam, 2016):

$$
\Delta G=-R \cdot T \cdot \ln K
$$

where $\mathrm{R}$ - universal gas constant which equal to $8,314(\mathrm{~J} / \mathrm{mol} \cdot \mathrm{K})$; $\mathrm{T}$ - absolute temperature (K); K - coefficient or constant of sorption equilibrium $(1 / \mathrm{mmol})$.

If $\Delta \mathrm{G}<0$, there is an absence of energy consumption during sorption process, therefore the physical mechanism of interaction between sorbate and sorbent is observed. In that case if $\Delta \mathrm{G}>0$, chemisorption caries out, some amounts of energy are expended on interactions between dissolved substance with sorbent with formation of tough chemical bond or new compound. If $\Delta \mathrm{G}=0$, a system is in equilibrium. The results are presented in Table 3 .

Microstructure of obtained sorption material was identified by scanning electron microscopy with the use of JSM 7001F (JEOL, Japan) equipment. The graphs of the sorption isotherms and all data of the experiment were statistically calculated with the help of Microsoft Office Excel 2019 software (Politaeva, 2019b).

The process of biogas production using Chlorella sorokiniana microalgae residual biomass is presented and described in detail in following article (Chusov, 2019).

\section{RESULTS AND DISCUSSION}

Obtained sorption material (carbonized residual biomass + chitosan $(\mathrm{CRB}+\mathrm{Chitosan})$ ) has a shape of granules and it is presented in Figure 3a. The sorbent microstructure (1000) is shown on Figure 3b.

The structure of the material has roughness, porous and cracks which determine the sorption of contaminants from aqueous solution. Studying the surface of the sorbent it is possible to presume the physical adsorption. To establish the sorption mechanism more accurately sorption isotherms have been obtained by conducting of the bunch of the experiments with certain conditions, Figure 4. They have the shape of Langmuir type of isotherm or the first type of isotherm of BET classification (Abebe, 2018). It is the first sign of sorption conducted by physical mechanisms. After mathematical conversion the isotherms were linearized. The constants of Langmuir and Freundlich sorption models have been graphically determined. A suitability of the isotherms in relation to studied sorption models was established by values of correlation coefficient ( $\mathrm{r}$ ) and approximation coefficient $\left(\mathrm{R}^{2}\right)$, Table 1 and Table 2 . If they 


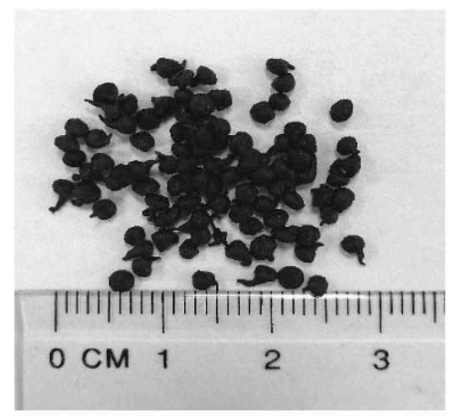

a

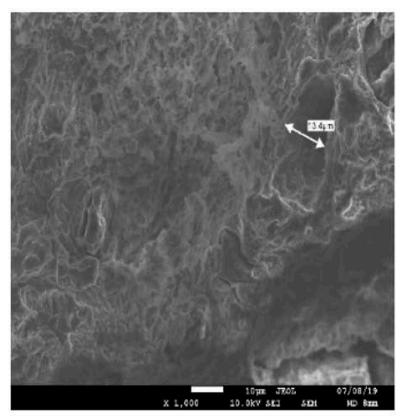

b

Figure 3. Sorption material CRB+Chitosan.

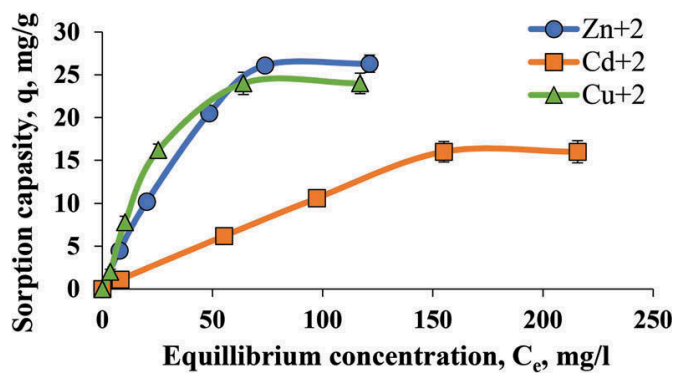

Figure 4. Sorption isotherms.

Table 1. Application of Langmuir sorption model.

\begin{tabular}{lllllll}
\hline Sorbent & Heavy metal ions & $\mathrm{q}_{\max }, \mathrm{mmol} / \mathrm{g}$ & $\operatorname{tg} \alpha=1 / \mathrm{q}_{\max }$ & $\mathrm{K}, 1 / \mathrm{mmol}$ & $\mathrm{r}$ & $\mathrm{R}^{2}$ \\
\hline CRP+Chitosan & $\mathrm{Zn}^{+2}$ & 0.78 & 1.28 & 0.8 & 0.999 & 0.998 \\
& $\mathrm{Cd}^{+2}$ & 0.12 & 8.67 & 1.4 & 0.995 & 0.871 \\
& $\mathrm{Cu}^{+2}$ & 7.23 & 0.14 & 0.1 & 0.991 & 0.981 \\
\hline
\end{tabular}

Table 2. Application of Freundlich sorption model.

\begin{tabular}{lllllll}
\hline Sorbent & Heavy metal ions & $\mathrm{K}$ & $1 / \mathrm{n}$ & $\mathrm{n}$ & $\mathrm{r}$ & $\mathrm{R}^{2}$ \\
\hline CRP+Chitosan & $\mathrm{Zn}^{+2}$ & 0.33 & 0.682 & 1.5 & 0.978 & 0.956 \\
& $\mathrm{Cd}^{+2}$ & 0.10 & 0.860 & 1.2 & 0.994 & 0.989 \\
& $\mathrm{Cu}^{+2}$ & 0.35 & 0.712 & 1.4 & 0.949 & 0.900 \\
\hline
\end{tabular}

Table 3. Gibbs free energy and type of sorption.

\begin{tabular}{llll}
\hline Sorbent & Heavy metal ions & $\Delta \mathrm{G}, \mathrm{kJ} / \mathrm{mol}$ & Type of sorption \\
\hline CRP+Chitosan & $\mathrm{Zn}^{+2}$ & 0.5 & Chemisorption \\
& $\mathrm{Cd}^{+2}$ & -0.8 & Physical sorption \\
& $\mathrm{Cu}^{+2}$ & 5.6 & Chemisorption \\
\hline
\end{tabular}




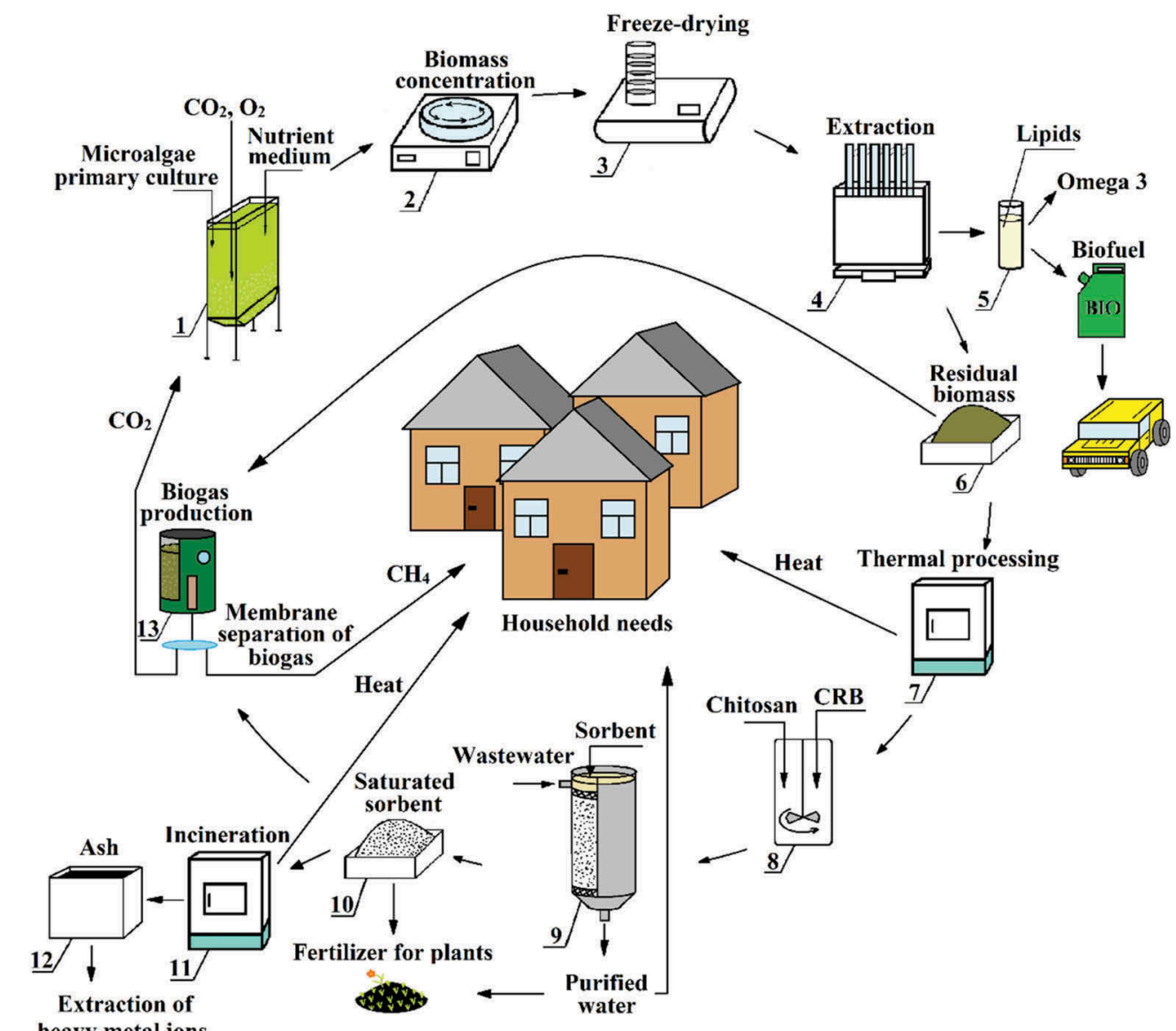

heavy metal ions and rare earth elements

"CRB - carbonized residual biomass

Figure 5. Microalgae biotechnology multiple use of Chlorella sorokiniana (general scheme).

1 - photobioreactor; 2 - centrifuge; 3 - freeze-dryer; 4 - Soxhlet extractor; 5 - lipids extracted from mi-croalgae; 6 - storage tank for residual biomass; 7, 11 - muffle furnace; 8 - mixing apparatus; 9 - appa-ratus for water treatment (adsorber); 10 - storage tank for saturated sorbent; 12 - storage tank for ash; 13 - bioreactor.

are close to 1.0, experimental results are described in an appropriate way, and this or that isotherm refers to one of two studied models or even both of them.

Thus, the results indicate the possibility to use obtained sorption material in the fields of industry where wastewater are formed containing heavy metal ions including the mining industry.

After a sorption process saturated sorbents can be utilized by three ways such as: use it as a fuel, as a co-substrate for organic waste fermentation and as fertilizers.

The general scheme of cyclic ecotechnology is presented on Figure 5. It includes all steps which have been reviewed previously. The main idea is the complex use of each component on every step of the technology.

\section{CONCLUSIONS}

To conclude, Chlorella sorokiniana biomass presents several promising applications. It is the source of valuable components which can be used in different fields of industry. Sorption material based on residual biomass and chitosan have been proved effective for water 
purification from heavy metal ions. The realization of this closed loop biotechnology using microalgae biomass allows to get new resources, products, materials, energy, that can be used in a complex way.

\section{ACKNOWLEDGEMENTS}

The research was performed within the implementation of Federal Target Program for Research and Development in Priority Areas of the Russian Scientific and Technological Complex for 2014 - 2020, the project «Development and implementation of innovative biotechnologies for treatment of microalgae Chlorella sorokiniana and the duckweed Lemna minor» (Agreement № 14.587.21.0038 of 17.07.2017), the unique project identifier is RFMEFI58717X0038.

\section{REFERENCES}

Abdel-Raouf, N., Al-Homaidan, A.A. \& Ibraheem, I.B.M. 2012. Microalgae and wastewater treatment. Saudi Journal of Biological Sciences 19(3): 257-275.

Abebe, B., Ananda Murthy, H.C. \& Amare, E. 2018. Summary on Adsorption and Photocatalysis for Pollutant Remediation: Mini Review. Journal of Encapsulation and Adsorption Sciences 8: 225-255.

Alam, F., Mobin, S. \& Chowdhury, H. 2015. Third generation biofuel from Algae. 6th BSME International Conference on Thermal Engineering (ICTE 2014); Procedia Engineering 105: 763-768.

Afroze, S. \& Kanti Sen, T. 2018. A Review on Heavy Metal Ions and Dye Adsorption from Water by Agricultural Solid Waste Adsorbents. Water, Air \& Soil Pollution 229:225.

Ayawei, N., Ebelegi, A.N. \& Wankasi, D. 2017. Modelling and Interpretation of Adsorption Isotherms: Review Article. Hindawi Journal of Chemistry vol. 2017: 11 pages.

Azad, K. 2019. Advances in eco-fuels for a sustainable environment. Woodhead publishing series in energy. Elsivier.

Bajpai, A.K. \& Rajpoot, M. 1999. Adsorption Techniques - A Review. Journal of Scientific \& Industrial Research 58: 844-860.

Brennan, L. \& Owende, P. 2010. Biofuels from microalgae - A review of technologies for production, processing, and extractions of biofuels and co-products. Renewable and Sustainable Energy Reviews 14: $557-577$.

Chusov, A. et al. 2019. Determination of biogas potential of residual biomass of microalgae Chlorella sorokiniana. IOP Conf. Series: Earth and Environmental Science 403012225.

Crini, G. \& Litchfouse, E. 2018. Green adsorbents for pollutant removal: Fundamentals and Design. Environmental chemistry for a sustainable world. Springer.

Dąbrowski, A. 2001. Adsorption from theory to practice. Advances in Colloid and Interface Science 93: $135-224$.

De Andrade, C.J. \& De Andrade, L.M. 2017. An overview on the application of genus Chlorella in biotechnological processes. Journal of Advanced Research in Biotechnology 2(1): 1-9.

De la Noüe, J. \& De Pauw, N. 1988. The potential of microalgal biotechnology. A review of production and uses of microalgae. Biotechnol. Adv. 6: 725-770.

Gautam, R.K. \& Chattopadhyaya, M.C. 2016. Kinetics and Equilibrium Isotherm Modeling: Graphene-Based Nanomaterials for the Removal of Heavy Metals From Water: Chapter 5. Nanomaterials for Wastewater Remediation: 79-109.

Geada, P. et al. 2017. Microalgal Biomass Cultivation: Chapter 13. Algal Green Chemistry: 257-284.

Gregg, S.J. \& Sing, S.W. 1982. Adsorption, Surface Area and Porosity. London: Academic Press.

Jadava, J.N., Maindb, S.D. \& Bhaleraoa, S.A. 2015. Competitive biosorption of lead (II) ions from aqueous solutions onto Terminalia Catappa l. leaves as a cost effective biosorbent. Octa Journal of Environmental Research 3(1): 067-079.

Khalil, A., Sergeevich N. \& Borisova, V. 2018. Removal of ammonium from fish farms by biochar obtained from rice straw: Isotherm and kinetic studies for ammonium adsorption. Adsorption Science and Technology 36(5-6): 1294-1309.

Niccolai, A. et al. 2019. Microalgae of interest as food source: Biochemical composition and digestibility. Algal Research 42101617.

Politaeva, N. et al. 2018a. Effect of laser radiation on the cultivation rate of the microalga Chlorella sorokiniana as a source of biofuel. IOP Conf. Series: Earth and Environmental Science 115012001. 
Politaeva, N. et al. 2018b. Chlorella Microalga Biomass Cultivation for Obtaining Energy in Climatic Conditions of St. Petersburg. V. Murgul and Z. Popovic (eds.), International Scientific Conference Energy Management of Municipal Transportation Facilities and Transport EMMFT 2017, Advances in Intelligent Systems and Computing 692: 555-562.

Politaeva, N. et al. 2019a. Research of $\mathrm{pH}$ influence on sorption properties of sorbents on a basis of residual biomass of microalgae Chlorella sorokiniana and duckweed Lemna minor. E3S Web of Conferences 12401050.

Politaeva, N., Smyatskaya, Yu. \& Toumi, A. 2019b. Influence of SHF Treatment on Lipid Output from Microalga Chlorella sorokiniana. IOP Conference Series: Earth and Environmental Science 272032056.

Richmond, A. 2013. Biological principles of mass cultivation of photoautotrophic microalgae: Chapter 11. A. Richmond, Q. Hu (eds.), Handbook of Microalgal Culture. Oxford: John Wiley \& Sons.

Richmond, A. 2004. Handbook of Microalgal Culture: Biotechnology and Applied Phycology. Hoboken: Blackwell Science.

Rodriguez-Reinoso, F. \& Silvestre-Albero, J. 2016. Activated Carbon and Adsorption. Reference Module in Materials Science and Materials Engineering. Elsivier.

Smyatskaya, Y.A. et al. 2019. Study of chemical composition and properties of biomass of Chlorella sorokiniana under influence of different physical factors. Izvestiya Vysshikh Uchebnykh Zavedenii, Seria Khimia i Khimicheskaya Tekhnologiya 62(2): 72-78.

Tang, Y. et al. 2016. Microalgae as a feedstock for biofuel precursors and value-added products: green fuels and golden opportunities. BioResources 11(1): 2850-2885.

Vonshak, A. 1985. Micro-algae: laboratory growth techniques and outdoor biomass production: Chapter 15. Techniques in bioproductivity and photosynthesis: 188-200. 


\title{
Geochemical traits of urban landscapes
}

\author{
V.A. Alekseenko \\ Doctor of geological and mineralogical Sciences, Institute for Water and Environmental Problems of Siberian \\ Branch of the Russian Academy of Sciences, Barnaul, Russia; \\ Southern Federal University, Rostov-on-Don, Russia; \\ Admiral Ushakov Maritime State University, Novorossiysk, Russia
}

N.V. Shvydkaya

Kuban State Agrarian University, Krasnodar, Russia

\begin{abstract}
A.V. Puzanov
Institute for Water and Environmental Problems of Siberian Branch of the Russian Academy of Sciences, Barnaul, Russia
\end{abstract}

A.V. Nastavkin

Southern Federal University, Rostov-on-Don, Russia

\begin{abstract}
The study examines environmental quality in residential landscapes. From the point of view of the migration of elements, urban landscapes are almost identical to industrial ones located beyond the city's borders. The greater impact on all residents - not only on the employees of an enterprise - is the key environmental difference that should be emphasized. In addition, pollutants, especially aerosols, are dispersed less effectively in cities than outside them. Considering these landscapes, it should be borne in mind that very peculiar pollution types like electromagnetic, thermal, sound (noise), and radioactive can occur in the course of life activities within a city. These pollution types cause certain environmental changes as well. For large-scale studies conducted in megacities, as well as for ecological and geochemical certification, a more detailed classification of landscapes is required. Patterns of technogenic migration and concentration of chemical elements are still the basis of division in these cases.
\end{abstract}

\section{INTRODUCTION}

Classification of urban geochemical landscapes is carried out taking into account the characteristics of the leading type of migration of chemical elements, i.e. the technogenic patterns. On this basis, first of all, landscapes of industrial, residential, and recreational areas, streets, military zones, wastelands, and cemeteries are distinguished. Industrial landscapes include territories located within localities and occupied by various production enterprises (factories and their separate workshops, transport parks, power plants, etc.), and in certain cases quarries and underground mines (Ajmone-Marsan \& Biasioli 2010; Bech et al. 2015; Ermolin et al. 2017; Gallagher et al. 2008; Ngun et al. 2018; Tepanosyan et al. 2019). The same landscapes include territories occupied by buildings necessary for the operation of the named enterprises.

First of all, it is advisable to separate out the landscapes of quarries and underground mines, dumps of mine workings, various factories, power plants, garages, tram and trolleybus parks, gas stations, waste processing facilities, bazaars, as well as the landscapes of automobile and railway stations, airports, and river and seaports. All of them differ from each other in the composition, occurrence form and amount of pollutants, both distributed within their limits, and in neighboring landscapes of a locality. 
Landscapes of residential areas normally take a major part of settlements (Grebenshchikova et al. 2017; Naylo et al. 2019; Seleznev et al. 2019; Timofeev et al. 2019). In addition, a significant share of residents spends most of their lives there. Therefore, the assessment of the ecological and geochemical situation of such zones and its improvement are among the most important environmental issues.

Quite often, biological cycles of elements play a significant role in the evolution of landscapes in residential areas. This is especially true for small settlements with one-story houses and homesteads. However, the biological cycles in residential areas of cities differ significantly from those in neighboring industrial, recreational and other urban landscapes (KabataPendias \& Pendias 2001).

The building height in residential areas, directly and indirectly, affects the pathways of numerous chemical elements and compounds that end up being accumulated or removed from the urban environment. Wind direction and speed, as well as the ratio of turbulent and laminar air flows, are also often dependent on the number of stories. All other things being equal, these indicators become decisive for the content of many substances, including toxic ones, in the air, and consequently for the ingress from it into soils, plant and animal organisms (including humans).

The number of floors alters the density of the population in a residential area; the volume of municipal waste and ways of disposal are associated with it too. Stories largely determine water supply and heating, which, in turn, control the input and removal of not only elements in the form of solutions and gas mixtures, but also elements in other forms. Species diversity and the number of domestic animals also largely depend on this indicator, and consequently, the features of migration, and often the forms of chemical elements in the landscapes of residential areas. The number of floors in residential areas also affects the level of comfort of residents living in them, as well as the speed and level of spread of various infections and even specific diseases (often mental disorders). These features largely determine the ecological status of many areas.

\section{MATERIALS AND METHODS}

Field studies in urban areas were carried out during the summer seasons with sampling the upper $(0-5 \mathrm{~cm})$ horizon of soils and technogenic superficial formations, which is the most indicative part of the soil cover from the point of view of pollution - the depositing geochemical environment. The work was carried out following a regular grid with a step of $1 \mathrm{~km}$, which is the most representative in the field research conditions, covering all the main geochemical landscapes of the research area. Soil sections were studied within the residential urban parts, with a description of the horizons and sampling. The full list of the studied urban areas categorized by population or primary component of the local economy includes cities with the number of citizens equal to over 1 million, half a million, over 100 thousand, and less than 100 thousand, as well as resort towns and villages of agricultural specialization (Alekseenko \& Alekseenko 2014).

The combination of buildings of different height in the landscapes of residential zones can be considered as a main ecological and geochemical indicator for them. In accordance with this indicator, the considered landscapes should be divided more detailed for special studies. It should be noted that in recent years, in many cities, development is conducted on the principle of creating neighborhoods with a specific combination and mutual location of buildings of different stories. When detailing these areas, it is advisable to consider them as separate landscapes. Their ecological and geochemical features should be taken into account when developing the research methodology.

The study of surface horizons of soils was carried out according to the method of an averaged sample: the soil was collected at least three times from the laid-down digs with a depth of $0-5 \mathrm{~cm}$ on a plot of approximately $10 \mathrm{sq} . \mathrm{m}$, samples were placed in a single package, their total weight was about $3 \mathrm{~kg}$. Mixing and averaging were performed in the laboratory. The analyses of soil and plant samples were carried out in the certified and accredited Central Testing Laboratory at Kavkazgeolsyomka using emission spectral analysis. 


\section{RESULTS}

Streets are the closest in geochemical features to roads that are allocated outside of localities, and also have no natural analogs. These include roadways and sidewalks (often with plantings of various bushes and trees) near residential buildings, industrial enterprises or barriers that fence off homesteads or other landscapes of the locality. Despite the usual plantings along sidewalks, biological cycles are low-developed in the considered landscapes, since all the fall and dry branches of trees and shrubs, as a rule, are taken out of a city or burned, and the ash is most often dispersed, not concentrating in the street landscapes.

As in other landscapes of settlements, a significant part of the elements in the street comes through the atmosphere. At the same time, unlike neighboring landscapes, car exhaust gases play a significant role in the atmospheric air of streets. They are also the most toxic compounds that are constantly present in the atmospheric gases on the streets. Their concentration is related to the traffic intensity. The latter is largely responsible for the dustiness and receipt of specific compounds in the described landscapes due to the wear of tires, engines, tram tracks, etc.

Indirectly, the traffic intensity is related to the type of road surface (paved, unpaved, etc.). Special cases are streets where railway traffic occurs; in such landscapes, the flow of chemical elements is unpredictable, in various forms: although in relatively small quantities due to spilling out of the cars.

There is usually no significant accumulation of substances from neighboring landscapes on the streets. They themselves are a source of numerous compounds that enter the surrounding landscapes through the atmosphere. The height of buildings that limit streets, as well as the plantings and the type of plants that make up them, have a great influence on this movement of elements. A significant share of different substances is removed from the streets by surface and underground water. They can be concentrated on certain geochemical barriers, creating technogenic anomalies (Table 1) that are not associated with any enterprises, which must be taken into account when making special maps for ecological and geochemical studies.

Table 1. Comparison of the average contents of a number of chemical elements in the soils of various groups of settlements.

\begin{tabular}{|c|c|c|c|c|}
\hline \multirow{2}{*}{$\begin{array}{l}\text { Categories of urban areas } \\
\text { by population or primary } \\
\text { component of the local } \\
\text { economy }\end{array}$} & \multicolumn{2}{|c|}{ Heightened average contents } & \multicolumn{2}{|c|}{ Decreased average contents } \\
\hline & $\begin{array}{l}\text { Number of } \\
\text { elements }\end{array}$ & Elements & $\begin{array}{l}\text { Number of } \\
\text { elements }\end{array}$ & Elements \\
\hline Over 1 million population & 17 & $\begin{array}{l}\mathrm{Ag}, \mathrm{As}, \mathrm{Be}, \mathrm{Bi}, \mathrm{Cd}, \\
\mathrm{Co}, \mathrm{Cr}, \mathrm{Cu}, \mathrm{Ga}, \mathrm{Mn}, \\
\mathrm{Ni}, \mathrm{P}, \mathrm{Pb}, \mathrm{Sn}, \mathrm{Ti}, \mathrm{V}, \\
\text { and } \mathrm{Zn}\end{array}$ & 2 & $\mathrm{Li}$ and $\mathrm{W}$ \\
\hline Half a million population & 4 & $\mathrm{Ba}, \mathrm{La}, \mathrm{Li}$, and $\mathrm{W}$ & 11 & $\begin{array}{l}\mathrm{Ag}, \mathrm{As}, \mathrm{Mo}, \mathrm{Nb}, \mathrm{P}, \mathrm{Sc}, \\
\mathrm{Sn}, \mathrm{Ti}, \mathrm{Tl}, \mathrm{V}, \text { and } \mathrm{Yb}\end{array}$ \\
\hline $\begin{array}{l}\text { Over } 100 \text { thousand } \\
\text { population }\end{array}$ & 11 & $\begin{array}{l}\mathrm{Ag}, \mathrm{Bi}, \mathrm{Mo}, \mathrm{Nb}, \mathrm{P}, \mathrm{Sn} \\
\mathrm{Sr}, \mathrm{W}, \mathrm{Y}, \mathrm{Yb} \text {, and } \mathrm{Zr}\end{array}$ & 10 & $\begin{array}{l}\mathrm{Ba}, \mathrm{Cd}, \mathrm{Co}, \mathrm{Cr}, \mathrm{Cu} \text {, } \\
\mathrm{Ga}, \mathrm{Ge}, \mathrm{Mn}, \mathrm{Ni} \text {, and } \\
\mathrm{Ti}\end{array}$ \\
\hline $\begin{array}{l}\text { Less than } 100 \text { thousand } \\
\text { population }\end{array}$ & 7 & $\begin{array}{l}\mathrm{Ge}, \mathrm{Nb}, \mathrm{Se}, \mathrm{Tl}, \mathrm{Y}, \mathrm{Yb} \text {, } \\
\text { and } \mathrm{Zr}\end{array}$ & 10 & $\begin{array}{l}\mathrm{Be}, \mathrm{Bi}, \mathrm{Cu}, \mathrm{Ga}, \mathrm{Li}, \\
\mathrm{Mn}, \mathrm{Ni}, \mathrm{Pb}, \mathrm{Sr} \text {, and } \mathrm{Zn}\end{array}$ \\
\hline Resort towns & 16 & $\begin{array}{l}\mathrm{As}, \mathrm{Ba}, \mathrm{Cd}, \mathrm{Co}, \mathrm{Cr} \\
\mathrm{Cu}, \mathrm{Ge}, \mathrm{Li}, \mathrm{Mn}, \mathrm{Ni} \\
\mathrm{Pb}, \mathrm{Sc}, \mathrm{Sr}, \mathrm{Tl}, \mathrm{V} \text {, and } \\
\mathrm{Zn}\end{array}$ & 6 & $\begin{array}{l}\text { Mo, P, W, Y, Yb, and } \\
\mathrm{Zr}\end{array}$ \\
\hline $\begin{array}{l}\text { Villages of agricultural } \\
\text { specialization }\end{array}$ & 4 & $\mathrm{Be}, \mathrm{Ga}, \mathrm{Mo}$, and $\mathrm{Ti}$ & 18 & $\begin{array}{l}\mathrm{Ag}, \mathrm{As}, \mathrm{Ba}, \mathrm{Bi}, \mathrm{Cd}, \mathrm{Co}, \\
\mathrm{Cr}, \mathrm{Ge}, \mathrm{Nb}, \mathrm{Pb}, \mathrm{Sc}, \mathrm{Sn}, \\
\mathrm{Sr}, \mathrm{Tl}, \mathrm{V}, \mathrm{Y}, \mathrm{Zn} \text {, and } \mathrm{Zr}\end{array}$ \\
\hline
\end{tabular}


In the case of special and detailed studies, it is advisable to separate street landscapes taking into account the traffic intensity, the prevailing mode of transport, and the characteristics of the road surface.

Landscapes of recreation areas are located both in the center and on the outskirts of settlements. These include parks, stadiums, squares, sports fields, alleys, recreation lines along banks of rivers, reservoirs, seas, etc. Biological properties of some of them (parks, squares, etc.) are close to the forest-engineering landscapes that are allocated outside of settlements. The landscapes under consideration do not receive any specific compounds, except for oxygen and various solid, liquid and gaseous products of life activity of organisms. Most of the substances entering the recreation areas are transported by air from nearby localities (Mazhari et al. 2018). In recent years, pollution of these landscapes by exhaust fumes from cars and motorboats has become widespread.

For urban areas, especially large ones, very important environmental indicators are the percentage of city's territory occupied by recreation areas, and the uniformity of distribution of the latter over the entire area of the city.

The landscapes of zones occupied by military departments are currently among the least studied. The specific environmental pollution caused by them and the need for their ecological and geochemical study has been discussed only recently, in connection with the withdrawal of troops from Eastern Europe.

In addition to the actual environmental and geochemical pollution, they can cause radiation, electromagnetic, noise, heat, and other types of environmental pollution. Therefore, such landscapes should be highlighted even if they are small and impossible to study. Their classification has not been developed yet for large-scale and detailed studies.

\section{DISCUSSION}

The relationship between the content of most chemical elements in soils - including metals with the development of living organisms and the concentration of these elements in them is considered in several works (Bourotte et al. 2019; Lenoir et al. 2019; Tepanosyan et al. 2017). We note only that, as when studying other landscapes, the following factors must be taken into account in urban areas at this level:

- redox conditions, oxidizing with free oxygen and reducing with either gley or sulfides;

- alkaline-acid conditions, which are best divided as strongly acidic, acidic, neutral, and highly alkaline;

- a set of typomorphic elements and, as a result, a class of water migration of chemical elements.

Quite often, especially for detailed work, in the conditions of urban landscapes, the considered selection is not enough. In such cases, a set of typomorphic elements in groundwater should be considered at the same level. It is advisable to note the alkaline-acid properties of groundwater and the acid-sulfur regime, since these indicators in the waters and soils of different parts of settlements may differ very significantly and represent significant ecological and geochemical changes.

Urban landscapes are combined taking into account the geomorphological features of a territory. In terms of the land topography, it is convenient to combine eluvial, trans-eluvial, trans-accumulative, and accumulative positions. First of all, they differ from each other in the features of the mechanical migration of elements and their compounds. Moreover, additional maps of the material's surface drift are often required.

Wasteland landscapes have been developed in many localities. Their appearance is usually associated either with the demolition of old buildings, or with the reconstruction of cities, or with uneven development of certain areas, which usually leave empty areas for a short time. In the first case, landscapes (especially in old cities) may have a large geochemical diversity. However, as a rule, the main ecological and geochemical impact on neighboring urban landscapes is not caused by them, but by the construction waste that is brought from them. Quite 
often, vacant lots themselves become temporary storage areas for a variety of garbage - from household waste to construction debris. In this case, they should be given great attention, studying them as a kind of social geochemical barriers.

Cemetery landscapes can be divided into old and operating ones. Old cemeteries are usually located next to a city center and are similar to the landscapes of recreation areas in terms of their ecological and geochemical features. When designing new cemeteries, first of all, one should pay attention to the surface and underground water flow from them. It should not take place in the direction of existing or projected urban districts.

Among the urban landscapes of almost all localities, there are various educational institutions, kindergartens, hospitals, and public baths (Bourotte et al. 2019; Famuyiwa et al. 2019). When assessing the overall environmental situation in localities, special attention should be paid to both their number and the uniformity of distribution. On maps of urban geochemical landscapes, all these institutions should be marked with extra-scale signs.

The second taxonomic level is not less important. At this level, despite the practical poor development of biological cycles in localities, it is advisable to combine urban landscapes based on the characteristics of plant communities and their preservation. There are two main reasons for this.

First, plants are very sensitive to changes not only in the complex of ecological and geochemical conditions but also in such important indicators for normal human life as radiation conditions, thermal pollution, etc. Based on the state (or even survival) of certain plant species (Bezel' et al. 2015; Drozdova et al. 2019; Yalaltdinova et al. 2018), it is often possible to pre-judge changes in the urban environment without analyses, which are sometimes rather expensive.

Secondly, in many localities, especially with a small number of residents, a significant part of agricultural products (fruits, vegetables, and various herbs for vegetable seasonings) is supplied from homesteads. In order to avoid poisoning and to obtain environmentally friendly products, areas with certain agricultural crops located within the boundaries of a city should be identified and their geochemical features studied in detail.

Detailed and special ecological and geochemical studies often require a more fractional division of landscapes. In these cases, one can select separate landscapes with certain agricultural crops, both perennial and annual, ornamental plants, or with their various combinations. In addition, for special studies, separate maps of the sanitary state of plantings should usually be drawn up (Famuyiwa et al. 2019; Grebenshchikova et al. 2017; Tume et al. 2018).

\section{CONCLUSIONS}

Geochemical traits of natural landscapes are constantly affecting the urban environment. The study of landscapes is performed following the developed scheme, depending on the composition of the rocks. However, when compiling ecological and geochemical maps of localities at the considered level, it is necessary to take into account the thickness of loose formations located between bedrock and soil, as well as the position of zones of discontinuous disturbances. These factors can be crucial in the design of residential and industrial buildings, especially in unstable environments.

The certain associations of plants were also affected by the background elements concentrations in soils of several cities. The increased concentrations of elements were more often detected other things being equal - in the landscapes with mixed decorative fruit and berry plant association $(\mathrm{Cu}, \mathrm{Pb}, \mathrm{Co}, \mathrm{Mn}, \mathrm{Ti}, \mathrm{Sr})$, less often - with agricultural fruit and berry plant association ( $\mathrm{Zn}, \mathrm{Ag}, \mathrm{Sn}, \mathrm{Ba}, \mathrm{Cr}$ ). In parks with just decorative kinds of plants, the increased concentrations of $\mathrm{V}$ and $\mathrm{Sc}$ were identified. The traffic intensity could also have some influence in this case.

\section{ACKNOWLEDGMENTS}

The analyses of soil and plant samples were carried out in the certified and accredited Central Testing Laboratory at Kavkazgeolsyomka using emission spectral analysis. 


\section{REFERENCES}

Ajmone-Marsan, F. \& Biasioli, M. 2010. Trace elements in soils of urban areas. Water Air and Soil Pollution $213,121-143$.

Alekseenko, V. \& Alekseenko, A. 2014. The abundances of chemical elements in urban soils. Journal of Geochemical Exploration 147 (B), 245-249.

Bech, J., Tume, P., Roca, N. \& Reverter, F. 2015. Geochemical distribution of potentially harmful elements in periurban soils of a Mediterranean region: Manresa (Catalonia, Spain). Fresenius Environmental Bulletin 24(12A), 4379-4389.

Bezel', V.S., Zhuikova, T.V. \& Gordeeva, V.A. 2015. Geochemistry of grass biocenoses: Biogenic cycles of chemical elements at contamination of the environment with heavy metals. Geochemistry International 53(3), 241-252.

Bourotte, C.L.M., Sugauara, L.E., De Marchi, M.R.R. \& Souto-Oliveira C.E. 2019. Trace metals and PAHs in topsoils of the university campus in the megacity of São Paulo, Brazil. Anais da Academia Brasileira de Ciencias 91(3), 20180334.

Drozdova, I., Alekseeva-Popova, N., Dorofeyev, V., Bech, J., Belyaeva, A. \& Roca, N. 2019. A comparative study of the accumulation of trace elements in Brassicaceae plant species with phytoremediation potential. Applied Geochemistry 108, 104377.

Ermolin, M.S., Fedotov, P.S., Ivaneev, A.I., Fedyunina, N.N. \& Eskina, V.V. 2017. Isolation and quantitative analysis of road dust nanoparticles. Journal of Analytical Chemistry 72(5), 520-532.

Famuyiwa, A.O., Davidson, C.M., Oyeyiola, A.O., Lanre-Iyanda, Y. \& Babajide, S.O. 2019. Pollution characteristics and health risk assessment of potentially toxic elements in school playground soils: A case study of Lagos, Nigeria. Human and Ecological Risk Assessment 25(7), 1729-1744.

Gallagher F.J. 2008. Soil metal concentrations and vegetative assemblage structure in an urban brownfield. Environ Pollut 153, 351-361.

Grebenshchikova, V.I., Efimova, N.V. \& Doroshkov, A.A. 2017. Chemical composition of snow and soil in Svirsk city (Irkutsk Region, Pribaikal'e). Environmental Earth Sciences 76(20), 712.

Grebenshchikova, V.I., Gritsko, P.P., Kuznetsov, P.V. \& Doroshkov, A.A. 2017. Uranium and thorium in soil cover of the Irkutsk-Angarsk industrial zone (Baikal region). Bulletin of the Tomsk Polytechnic University, Geo Assets Engineering 328(7), 93-104.

Kabata-Pendias, A. \& Pendias, H. 2001. Trace elements in soils and plants. CRC Press LLC, Boca Raton.

Lenoir, T., Duc, M., Lassabatere, L. \& Bellagh, K. 2019. Identification of the artifact contribution to two urban Technosols by coupling a sorting test, chemical analyses, and a least absolute residual procedure. Journal of Soils and Sediments 19(2), 683-701.

Mazhari, S.A., Bajestani, A.R.M., Hatefi, F., Aliabadi, K. \& Haghighi, F. 2018. Soil geochemistry as a tool for the origin investigation and environmental evaluation of urban parks in Mashhad city, NE of Iran. Environmental Earth Sciences 77(13), 492.

Naylo, A., Almeida Pereira, S.I., Benidire, L., Schwartz, C. \& Boularbah, A. 2019. Trace and major element contents, microbial communities, and enzymatic activities of urban soils of Marrakech city along an anthropization gradient. Journal of Soils and Sediments 19(5), 2153-2165.

Ngun, C.T., Pleshakova, Y.V. \& Reshetnikov, M.V. 2018. Soil diagnosis of an urban settlement with low levels of anthropogenic pollution (Stepnoe, Saratov region). IOP Conference Series: Earth and Environmental Science 012067.

Seleznev, A., Yarmoshenko, I., Malinovsky, G., Kiseleva, D. \& Gulyaeva, T. 2019. Snow-dirt sludge as an indicator of environmental and sedimentation processes in the urban environment. Scientific Reports 9(1), 17241.

Tepanosyan, G., Sahakyan, L., Belyaeva, O., Maghakyan, N. \& Saghatelyan, A. 2017. Human health risk assessment and riskiest heavy metal origin identification in urban soils of Yerevan, Armenia. Chemosphere 184, 1230-1240.

Tepanosyan, G., Sahakyan, L., Zhang, C. \& Saghatelyan A. 2019. The application of Local Moran's I to identify spatial clusters and hot spots of $\mathrm{Pb}, \mathrm{Mo}$ and $\mathrm{Ti}$ in urban soils of Yerevan. Applied Geochemistry $104,116-123$.

Timofeev, I., Kosheleva, N. \& Kasimov, N. 2019. Health risk assessment based on the contents of potentially toxic elements in urban soils of Darkhan, Mongolia. Journal of Environmental Management 242, 279-289.

Tume, P., Roca, N., Rubio, R., King, R. \& Bech, J. 2018. An assessment of the potentially hazardous element contamination in urban soils of Arica, Chile. Journal of Geochemical Exploration 184, 345-357.

Yalaltdinova, A., Kim, J., Baranovskaya, N. \& Rikhvanov L. 2018. Populus nigra L. as a bioindicator of atmospheric trace element pollution and potential toxic impacts on human and ecosystem. Ecological Indicators 95, 974-983. 


\title{
Soil evolution and reclamation of technogenic landscapes in Siberia
}

\author{
V.A. Androkhanov \\ Doctor of Biological Sciences, Acting Director, Institute of Soil Science and Agrochemistry, Novosibirsk, \\ Russian Federation \\ D.A. Sokolov \\ Candidate of Biological Sciences, Senior Researcher, Institute of Soil Science and Agrochemistry, Novosibirsk, \\ Russian Federation
}

\begin{abstract}
Specific features of soil evolution were revealed as a result of the longterm studies of soils developing on the coal mining spoils in Siberia. The evolutionary trends and transformation rates of young soils were shown to be determined by the spoil parent rock material, as well as by the environmental and climatic conditions of the area. Biological reclamation carried out taking into account regional soil evolution features provides the possibility a) to use the parent rock lithogenic resources more efficiently and economically, b) to avoid unfavorable combinations of parent rock properties, climate and biota species, used at the biological stage of recultivation, and c) to increase technogenic landscape diversity due to scientifically based alternation of parent rocks in spoil surface layers.
\end{abstract}

\section{INTRODUCTION}

Currently the impact of industrial production on natural landscapes of some regions in Russia reached such a level when negative consequences exert significant influence on natural processes and environment. Continuous development of mining industry, wide use of surface mining, as well as other aspects of economy increase the areas used for waste dumping. Reclamation or revegetation due to natural succession (Shrestha, Lal, 2010; 2011; Huot et al., 2015; Ahirwal et al., 2016; Feng et al., 2019) can minimize such negative consequences. Transformation of ecological functions of technogenic landscapes under both approaches result in soil cover evolution alongside with biogeocenoses succession and changes in microclimate and parent rock material. Soil evolution from the initial parent rock towards the state of equilibrium with environmental conditions is usually referred to as ontogenesis. The specificity of soil ontogenesis in technogenic landscapes is manifested by continuous changes taking place over short time spans (Ivanov et al., 2015). Following the ontogenetic one, the post-ontogenetic stage of soil evolution results in meta-stable, i.e. relatively equilibrated, soil state.

Assessing the above-mentioned soil formation features from the practical aspect makes it obvious that soil evolution process in technogenic landscapes should be aimed at spoil rock substrate transformation in such a way as to increase its beneficial soil ecological functions. The combination of such functions in the short term, i.e. at the ontogenetic stage, ensures surface compaction and vegetation cover, whereas in the medium and long term, i.e. at the post ontogenetic stage, promotes sustainability of biotic communities, able to reproduce their main components.

So the aim of the study was to reveal the regularities and specific features of soil evolution in the technogenic landscapes with the view to use the findings for increasing efficiency of reclamation approaches. 


\section{METHODS}

The soils developed on the coal mining spoils of the major coal mining areas in Siberia were used at the objects of the study. We studied the soil cover of the coal mining spoils located in the montane taiga (humid) and forest-steppe (sub-humid) areas of the Kemerovo region, in the steppe (semi-arid) areas of Khakassia and dry steppe (arid and extra continental) areas of the Tyva Republic. Some brown coal and anthracite mining sites in the Krasnoyarsk and Novosibirsk regions, where spoil parent rocks differ in metamorphosis, were also studied. The parent rock material of all spoils was not phytotoxic.

To reveal specifics of soil evolution we examined soil cover by using macromorphometry description, widely used in pedology (Rosanov, 1983). Soil identification was performed using soil classification of technogenic landscapes, a methodology developed by the Institute of Soil Science and Agrochemsitry of the Siberian Branch of the Russian Academy of Sciences (Gadzhiev, Kurachev, 1992) and then further improved by V.M.Kurachev and V.A.Androkhanov (2002). According to this classification, the identification of a corresponding diagnostic horizon allows to discriminate four types of embryozems on the surface of coal mining spoils. The so called initial embryozems do not have any diagnostic horizons that are morphologically well expressed. The OM-accumulating embryozems are distinguished by the presence of horizons where accumulation of non-specific organic matter (represented by plant material) occurs. Soddy and humus-accumulating embryozems are diagnosed by the presence of respective horizons. According to the World Reference Base for Soil Resources (World Reference..., 2015), embryozems are classified as Technosols.

The study was carried out on the horizontally leveled sites, differing in age and parent rock material.

\section{RESULTS}

The results showed that soil cover formation at the ontogenetic stage of soil evolution in different climatic environments and parent rock materials is going at different rates. All four embryozem types, i.e. initial, OM-accumulating, soddy and humus-accumulating (Table 1), were found in the studied areas. Each embryozem type corresponds to a certain stage of soil evolution, identified by the degree of visualization of OM-accumulating, soddy and humusaccumulating processes in an embryozem profile (Sokolov et al., 2015). The rate of transformation from initial into OM-accumulating and further into soddy and humus-accumulating embryozems was found to be determined by parent rock properties and climate of the regions.

Soil cover of technogenic surface layers, consisting of sandstone, is characterized by minimal diversity of soil types as compared with the soil cover developed on other dense

Table 1. Ontogenetic differentiation of soil cover composition at different technogenic substrates as dependent on environmental and climatic conditions.

\begin{tabular}{|c|c|c|c|c|c|}
\hline \multirow[b]{2}{*}{ Climate type } & \multirow[b]{2}{*}{ Sandstone } & \multirow[b]{2}{*}{ Siltstone } & \multirow{2}{*}{$\frac{\text { Parent rock material }}{\text { Mudstone }}$} & \multirow[b]{2}{*}{ Sand } & \multirow[b]{2}{*}{ Loams and clays } \\
\hline & & & & & \\
\hline Humid & EI, EOA & EI, EOA, ES & EI, EOA, ES, EHA & EOA & EOA, ES, EHA \\
\hline Sub-humid & EI, EOA, ES & $\begin{array}{l}\text { EI, EOA, ES, } \\
\text { EHA }\end{array}$ & $\begin{array}{l}\text { EI, EOA, ES, } \\
\text { EHA }\end{array}$ & EOA, ES & EOA, ES, EHA \\
\hline Semiarid & EI, EOA, ES & $\begin{array}{l}\text { EI, EOA, ES, } \\
\text { EHA }\end{array}$ & $\begin{array}{l}\text { EI, EOA, ES } \\
\text { EHA }\end{array}$ & EI, EOA & EOA, ES, EHA \\
\hline Arid & EI & EI, EOA & EI, EOA, ES & EI, EOA & EOA, ES \\
\hline Arid Extracontinental & EI & EI, EOA & EI, EOA & EI & EI, EOA \\
\hline
\end{tabular}

EI - initial embryozem; EOA - organic matter accumulating embryozem; ES - soddy embryozem; EHA humus-accumulating embryozem. 
sedimentary rocks. Such situation is due to a) significant resistance of sandstone to hypergenic transformation, and b) low (5-20\%) contribution of swelling minerals in rock cement (Ragimzade, 1992); both factors impede the formation of humus-accumulating embryozems on such surfaces and, consequently, sustainable grass communities (Glebova, 2005). As a result, in all climatic regions during 20-25 years of technogenic landscapes' existence initial embryozems comprise substantial fraction of soil cover. Under climatic conditions ranging from humid to semi-arid ones initial embryozems are accompanied by OM-accumulating embryozems, and in sub-humid regions soddy embryozems are also present in the soil cover. Notably, the same sandstone properties that limit multicomponent composition of soil cover, under humid climate promote eluvial processes in embryozems and hence the formation of woody plant communities.

More favorable conditions for soil cover differentiation occur in those technogenic landscapes, where surface layers consist of silt- or mudstone. These materials are more susceptible for hypergenic transformation as compared with sandstone and are often of laminated texture, impeding eluvial processes in embryozems. At the same time relatively high content of expansive minerals in rock cement (15-35\% in siltstone and 55-65\% in mudstone) together with carbonaceous inclusions promote formation of sustainable grass communities. All these facilitate the formation of OM-accumulating embryozems in the studied regions, with soddy embryozems developing under less arid climatic conditions (Table 1). Humus-accumulating embryozems can also develop on such parent rocks, i.e. on siltstone under sub-humid climate and mudstone under humid and semiarid climate.

Alongside with soils of the later stages of embryozem genesis, initial and OM-accumulating embryozems persist in the surface layers composed of silt- and mudstone. Such soil cover differentiation results from the differential content of stone fractions and differential metamorphosis of parent rock material.

Ontogenetic differentiation of soil cover on sands is similar to the one on sandstone. However, as soil formation on loose parent material is not accompanied by disintegration of fragments, sufficient precipitation results in practically no initial embryozems in soil cover developed over 20-25 yrs.

The best conditions for transformation of sandy substrate by pedogenic and biotic processes occur in regions with humid climate, where from the first years of phytocenoses' development soil environment benefits predominance of woody vegetation and OM-accumulating embryozems in soil cover. Under sub-humid climate due to low intensity of eluvial processes soddy embryozems contribute significantly into the soil cover. In arid regions there is minimal differentiation of soil cover, developed on sand material. This is also facilitated by deflation processes, increasing with the increased climate aridity. Frequent denudation renewal of surface sandy layers also leads to predominance of initial embryozems in the soil cover.

Clay and clay loams are the most common loose sedimentary materials of the coal mining spoils in Siberia. Transformation of such surface spoil layers, similar to the sandy ones, by pedogenic and biogenic processes begins in the substrate, most favorable for soil formation. High content of fine-sized fractions results in formation of soddy and humus accumulating embryozems over 20-25 years of revegetation.

Soil cover differentiation at the post ontogenetic stage of evolution occurs after embryozems reach meta-stable stage of development. At this stage soil transformation occurs mainly as changes in properties of organogenic horizons. The main driver of the process is substitution of the successional stages of phytocenoses with climax communities, adequate for the surrounding natural environment and climatic conditions. In different regions such substitution does not occur in a similar way. Under moderate arid and humid conditions the meta-stable state as a result of soil evolution is reached at the stage of a closed phytocenosis (Glebova, 2005). In arid conditions the meta-stable state is reached when various sagebrush species become predominating over legumes (Titlyanova, Sambuu, 2016). In humid conditions the meta-stable state of soils is reached when tree crowns close and surface illumination regime changes.

The described changes in phytocenoses directly affect the properties of the upper part of soil profile, allowing more detailed diagnostics of surface differentiation according to soil 
formation conditions. In embryozems with the same sequence of genetic horizons it becomes possible to diagnose processes in order to ascribe soils to a certain subtype. There was a need to identify soil subtypes on the old (20-25 yrs) coal mining spoils in Siberia. So among initial embryozems, along the usually identified typical subtype, common at the initial stages of parent substrate transformation by pedogenic and biogenic processes, a cryptopedogenic subtype was distinguished. Such initial cryptopedogenic subtypes are formed after initial embryozems reach the meta-stable state, and thus usually develop on substrates with low lithogenic potential for soil formation. Similar to initial ones, the cryptopedogenic embryozems do not visually manifest genetic horizons, the presence of which more often results from the absence of conditions for preservation, rather than formation.

The soil type of OM-accumulating embryozems can be differentiated into three subtypes according to soil forming environment. For example, the soils with their type-identifying horizon represented by herbs and grasses' residues, are referred to as OM-accumulating felt embryozems; in litter and peat subtypes this horizon is represented by tree litter and moss phytomass.

The identification of soddy embryozem subtypes is more complicated. A combination of features is used to discriminate between xerophytic and hygrophytic subtypes, including the character of interaction between the type-diagnostic horizon with the underlying mineral soil, as well as the composition of the horizon above the soddy one, with sedge residues contributing significantly into the litter of the latter one.

Because humus-accumulating embryozems can form in a quite narrow range of climatic and lithogenic conditions, their differentiation into subtypes according to soil formation conditions is rather problematic. Identified earlier as an individual soil type (Gadzhiev, Kurachev, 1992), currently coarse humus-accumulating embryozems are considered to be a subtype of humus-accumulating embryozems. We believe their development results from the transformation of humus-accumulating horizon, developed during the preceding stage of grass vegetation, rather than from specific humus accumulation in technogenic forest ecosystems.

As post ontogenetic stage of soil evolution starts simultaneously with establishment of constant phytocenotic structure, its specific moment of establishment varies due to conditions, determining the syngenetic transformation of substrate by pedogenic and biogenic processes. It was shown to take 25-26 years under the most favourable conditions in Siberia, i.e. on clay loamy spoils in Kansk-Achinsk coal mining region in Central Siberia (MironychevaTokareva, 1998). On substrates formed by dense sedimentary rocks sustainable soil cover can be developed over 50 years or more (Kurachev, Androkhanov, 2002).

Alongside with soil cover features, mentioned above, another characteristic feature of metastable soil cover is not only its temporal stability, but also its constant composition irrespective of heat- and water supply in some years or over a period of several years. This peculiarity results in low soil cover differentiation on territories composed of the same parent rock material. Such stability of soil cover can best be seen in pedogenesis under humid conditions on sandstone material (Table 2). Development and closinging of tree crowns ensures plant litter input practically on entire soil surface. Similar situation can be observed under sub-humid climate with an exception that the sites with herb and grass communities are dominated by the subtype of soddy xerophytic embryozems. Pedogenesis under arid conditions on sandstone results in formation of OM-accumulating felt embryozems. With increasing climate aridity the contribution of this subtype into soil cover becomes less than the one of the initial cryptopedogenic embryozem subtype.

On siltstone surface layers soil cover differentiation at the stage of its stabilization is mostly driven by the same factors as on sandstone spoils. However, due to the production of finesized particles from siltstone material via its destruction, the formation of humusaccumulating and soddy xerophytic embryozems becomes possible in sub-humid and semiarid climatic conditions, respectively. In regions with typical arid climate this siltstone characteristic results in the dominance of the OM-accumulating felt embryozems.

In regions where spoil parent rock material is mudstone (Table 2), soil cover in technogenic landscapes is the most differentiated. High variability of mudstone properties resulted in the prevalence of OM-accumulating litter embryozems and coarse humus accumulating 
Table 2. Post ontogenetic differentiation of soil cover developed on different substrates in the technogenic landscapes under different climatic conditions.

\begin{tabular}{|c|c|c|c|c|c|}
\hline \multirow[b]{2}{*}{ Climate type } & \multirow[b]{2}{*}{ Sandstone } & \multirow[b]{2}{*}{ Siltstone } & \multirow{2}{*}{$\frac{\text { Parent rock material }}{\text { Mudstone }}$} & \multirow[b]{2}{*}{ Sand } & \multirow[b]{2}{*}{ Loams and clays } \\
\hline & & & & & \\
\hline Humid & EOAl & EOAl & $\begin{array}{l}\text { EOAl, EOAp, } \\
\text { EHAch }\end{array}$ & EOAl & $\begin{array}{l}\text { EOAl, ESh, } \\
\text { EHAch }\end{array}$ \\
\hline Sub-humid & EOAl, ESx & ESx, EHA & ESx, ESh, EHA & ESx & EHA \\
\hline Semiarid & EOAf & $\begin{array}{l}\text { EOAf, } \\
\text { ESx }\end{array}$ & EOAf, ESx, EHA & $\begin{array}{l}\text { EOAf, } \\
\text { ESx }\end{array}$ & EHA \\
\hline Arid & $\begin{array}{l}\text { EIC, } \\
\text { EOAf }\end{array}$ & EOAf & EOAf, ESx & EOAf & ESx \\
\hline $\begin{array}{l}\text { Arid } \\
\text { extracontinental }\end{array}$ & EIc & EIc, EOAf & EIc, EOAf & EIc & EOAf \\
\hline
\end{tabular}

EIc- initial cryptopedogenic embryozem; EOAl - organic matter accumulating litter embryozem; EOAf organic matter accumulating felt embryozem; EOAp - organic matter accumulating peat embryozem; ESx soddy xerophytic embryozem; ESh - soddy hygrophytic embryozem; EHA - humus accumulating embryozem; EHAch - coarse humus accumulating embryozem.

embryozems in soil cover of the humid regions. OM-accumulating peat embryozems develop on highly compacted surface layers, composed of highly metamorphosed mudstone. Under sub-humid climate the dominant OM-accumulating embryozems are substituted by humus accumulating and soddy xerophytic and hygrophytic ones. With further increase in aridity the share of the above-mentioned soils in the soil cover decreases, whereas the share of OMaccumulating felt embryozems increases. Under arid extra continental climate the contribution of initial cryptopedogenic embryozems becomes more pronounced.

Soil cover composition on sand rock is similar to the one on sandstone. However, high dispersion, resulting in the relatively high water-holding capacity of sands, shifts pedogenesis towards prevailing formation of soddy xerophytic embryozems in sub-humid and semi-arid regions and towards $\mathrm{OM}$-accumulating felt embryozems in arid regions.

Soil cover differentiation at the post ontogenetic evolution stage is less pronounced in loamy and clay surface layers, as their properties promote quick implementation of specific zonal soil formation. Thus more than 20-years-old areas of coal mining spoils, composed of such parent rock material, display similar soil cover composition in most climatic regions except for the humid ones, where soddy hygrophytic embryozems are widely spread alongside with OM-accumulating litter embryozems, with" residual" coarse humus accumulating embryozems being often identified as well.

\section{CONCLUSION}

Thus our studies showed different potential of parent rock substrates for pedogenesis and differentiated soil cover formation in technogenic landscapes, as related to embryozem types and subtypes. Taking into account that each soil type and subtype under different climatic conditions develops under certain vegetation formation, one can design adequate approaches for technical and biological reclamation. The latter, based on the revealed features of soil evolution, allows to 1) use lithogenic resources more efficiently and economically; 2) to minimize or avoid those combinations of parent rocks, climatic conditions and plant species, which are unfavourable for pedogenesis; 3 ) to increase biological diversity of technogenic landscapes by reasonably alternating parent rock materials in surface layers.

Overall it can be concluded that parent rock substrates with higher content of physical clay or that are able to produce it due to weathering, i.e. clays, loams, mudstone, are more beneficial for greenery landscaping. The less metamorphised the parent rocks are, the higher their 
capacity to release fine-sized fractions is, and hence better the chances to reach the reclamation goals. Mechanic fixing of a surface, i.e. providing geomorphologic stability for a landscape, requires other parent rock substrates. In such cases dense sedimentary materials, resistant to hypergenic transformation (sandstone, strongly metamorphised siltstone and mudstone) are better. The mentioned features enable development of efficient and economically relevant reclamation actions. Their implementation is possible by employing selective spoil formation by using loose or alternating dense sedimentary parent materials for surface layer construction in technogenic landscapes.

\section{REFERENCES}

Ahirwal, J. \& Maiti S.K. 2016. Assessment of soil properties of different land uses generated due to surface coal mining activities in tropical Sal (Shorea robusta) forest, India. Catena 140: 155-163.

Feng, Y., Wang J., Bai Z. et al. 2019. Effects of surface coal mining and land reclamation on soil properties: A review. Earth-Science Reviews 191: 12-25.

Gadzhiev, I.M. \& Kurachev V.M. 1992. Genetic and environmental aspects of the study and classification of soils of technogenic landscapes. In V.G. Mordkovich, V.I. Volkovintser \& T.P. Slavlina (eds), Ecology and remediation of technogenic landscapes: 6-15. Novosibirsk: Science. Sib. Br. [in Russian]

Glebova, O.I. 2005. Biogeographic diagnosis of Kuzbass embryozems. Novosibirsk: Institute of Soil Science and Agrochemistry SB RAS. [in Russian]

Huot, H., Morel J.L. \& Simonnot, M.-O. 2015. Pedogenetic trends in soils formed in technogenic parent materials. Soil Sciences 180 (4-5): 182-192.

Ivanov, I.V. \& Kudeyarov, V.N. 2015. Evolution of soils and soil cover. Theory, diversity of natural evolution and anthropogenic transformations of soils. Moscow: GEOS. [in Russian]

Kurachev, V.M. \& Androkhanov, V.A. 2002. Classification of soils of technogenic landscapes. Siberian Journal of Ecology 9 (3): 255-261. [in Russian]

Mironycheva-Tokareva, N.P. 1998. Dynamics of vegetation during overgrowing of dumps (on the example of KATEK). Novosibirsk: Science. Sib. Br. [in Russian]

Ragim-zade, F.K. 1992. Soil-forming rocks of technogenic landscapes. In V.G. Mordkovich, V. I. Volkovintser \& T.P. Slavlina (eds), Ecology and remediation of technogenic landscapes: 15-45. Novosibirsk: Science. Sib. Br. [in Russian]

Rozanov, B.G. 1983. Soil morphology. Moscow: MSU Pubs. [in Russian]

Shrestha, R.K. \& Lal, R. 2010. Carbon and nitrogen pools in reclaimed land under forest and pasture ecosystems in Ohio, USA. Geoderma 157 (3): 196-205.

Shrestha, R.K. \& Lal, R. 2011. Changes in physical and chemical properties of soil after surface mining and reclamation. Geoderma 161 (3-4): 168-176.

Sokolov, D.A., Androkhanov, V. A., Kulizhskii, S. P. et al. 2015. Morphogenetic diagnostics of soil formation on tailing dumps of coal quarries in Siberia. Eurasian Soil Science 48 (1): 95-105.

Titlyanova, A.A. \& Sambuu, A.D. 2016. Succession in grasslands. Novosibirsk: Publishing house of the SB RAS. [in Russian]

World reference base for soil resources 2015. International soil classification system for naming soils and creating legends for soil maps. Update 2015. World soil resources reports, 106. Food and agricuture organization of the United Nations. Rome. 


\title{
Lightning exposure of oil tanks with changing roof position
}

\author{
A.I. Adekitan \& M. Rock \\ Group for Lightning and Overvoltage Protection, Technische Universität Ilmenau, Germany
}

\begin{abstract}
Crude oil and related petroleum products are major fossil fuels for the supply of energy globally. Floating Roof Tanks (FRTs) are used for storing crude oil after production to ensure product stability before product export, but FRTs are susceptible to lightning strikes. Lightning is a major threat to operational safety in crude oil storage terminals, particular in the tropics with a very high number of thunderstorm days per year $(\mathrm{Td} / \mathrm{yr})$. Protecting crude oil storage tanks against the high-energy lightning current with a continuing current charge of 200 Coulomb requires the design and implementation of a purpose-specific lightning protection system. An evaluation of the probability of a lightning strike to a FRT using the dynamic electro-geometrical model (DEGM) was performed using numerical techniques. The results for the cases considered show that the total probability of a direct strike to the circular tip of the tank shell at its topmost height varies from about $85 \%$ to $99 \%$ depending on the dimension of the tank and the position of the floating roof within the tank.
\end{abstract}

Keywords: Floating roof tank, lightning strike probability, dynamic electro-geometrical model, lightning protection system, lightning current distribution, numerical methods, oil and gas facility, fire, process safety

\section{INTRODUCTION}

Lightning is a natural phenomenon that is as old as the earth itself. Lightning strikes to structures on earth may be very dangerous to facilities, and equipment depending on the level of risk associated with the structure as a function of the geographic location, nature and dimension of the structure, and adjoining facilities. The geographic location determines the number of lightning flashes that the structure is exposed to annually. Lightning strike can either be direct i.e. when the flash terminates on a structure or indirect, when the flash terminates near the structure and connected services. Out of 102 floating roof tank fires studied in China by Ren et al. (2012), it was discovered that $65 \%$ of these were due to direct lightning strikes (Wei et al., 2018). Lightning strike to structures and equipment can result in damage, fire, and even injury to living beings. A lightning flash can either be negative or positive, and fact as shown that about $90 \%$ of lightning flashes are of the negative type while positive flashes carry about six times more current than the negative type (Afa, 2012, Akinyemi et al., 2014).

A number of lightning-induced floating roof tank and facility fire incidents, and equipment damage have occurred across the globe resulting in equipment and facility destruction, expensive repair cost, loss of production time, and man-hours expended on incident reviews. An external floating roof tank has a floating roof that moves with the level of the liquid within the tank in order to limit the vapor space above the liquid crude oil. This helps to reduce the evaporation of light oil fractions and petroleum products by $90-98 \%$ (Kulikov \& Chekardovskiy, 2018). The roofs are made of pontoons which aid the buoyancy of the roof. The gap between the floating roof and the tank shell is covered by rim seals which prevent crude oil from leaking onto the roof. Also, it limits vapor escape from the shell-roof gap. The rim seal region of a floating roof tank is the most likely starting point for a lightning-induced tank fire during a thunderstorm (Chang \& Lin, 2006, Adekitan \& Rock, 2019a). 
Any vapor that escapes from the crude oil during service will bubble to the surface, and escape to the atmosphere through breather valves that are set at atmospheric pressure. High-pressure liquids should not be diverted to a floating roof tank because it can generate sufficient vapor pressure to jam the roof. High crude-oil true vapor pressure (TVP) coupled with inefficient safety barriers from the production end can result in excessive vapor release on the floating roof tank (Adekitan \& Rock, 2019b). The accumulation of escaped flammable vapor around the tank, and the rim seal region can be ignited when lightning strikes.

\subsection{Modes of FRT ignition by lightning}

A floating roof tank can be ignited by lightning in three ways, and these are:

a. Roof surface electrostatic charging due to the charge separation occurring in the clouds which creates a pre-strike electromagnetic field that setup transient currents.

b. When lightning strikes, sparks can easily be generated between intended and unintended gaps existing on the floating roof tank. Sparks can either be a thermal spark resulting from the formation of incendiary materials at a spark point, or a voltage spark that results in the electrical breakdown of air-vapor mixture within the gap.

c. Heating due to the flow of heavy lightning current which can cause thin tank materials that are less than $5 \mathrm{~mm}$ in thickness to melt.

A floating roof tank is a massive structure with a large diameter and tall height, and a gap at the shell-roof interface where flammable fuel vapor may accumulate, and this makes it difficult to design a simple and effective conventional lightning protection system for a floating roof tank. To ensure continuity for the flow of lightning current from the tank shell to the roof during lightning strike, the shell-roof linkage provided by the roof stairs, the use of bypass conductors, and shunts have all been considered, and each has been found to be defective in one way or the order, as they do not continuously provide the optimal low resistance shell-roof connection that can effectively prevent sparks at the rim seal region of the floating roof tank [7]. For example, bypass conductors create dangling cables on the roof, shunts can be easily coated with crude oil which increases its contact resistance. Also, floating roof tank may lose its perfect roundness over time, or when tank subsidence occurs the shunts become disconnected from the tank shell creating a gap it was installed to prevent.

A device called a retractable grounding array (RGA) was developed in order to address the issues created by the extensive length of bypass cables. RGA is made of retractable weaved cable strands that adjust its length based on the position of the roof. Although the RGA may be better than the bypass cable which conducts the continuing, and the intermediate components of the lightning current by ensuring minimal length at any roof position (Hu \& Liu, 2012), but its sufficiency as a replacement for shunts which are meant to conduct the fast (rising) lightning current pulse needs to be determined. Also, due to continuous extension and retraction of the RGA with the changing floating roof position, a number of RGAs tend to snap off from the roof over time, as observed on some tanks. The roof of the floating roof tank constantly changes its vertical position within the tank based on the level of the liquid content, and as such, the portion of the roof exposed to direct lightning strike varies depending on the position of the roof.

Currently, there is no approved air termination design based on conventional lightning protection system for FRT. This is due to the intricacies of how direct and indirect lightning strikes interact with FRT. In this study, the interaction of lightning with FRT is investigated by evaluating the probability of lightning strikes to different points on a FRT using the dynamic electro-geometrical model. Based on the result of the numerical model, an air termination configuration that can adequately intercept and safely dissipate the high energy lightning current while preventing sparking at the shunt-shell interface can now be developed. 


\section{MATERIALS AND METHODS}

The methodology applied in this study has three key aspects. First, a volume from which lightning can strike a FRT is defined as the attractive volume as discussed in section 2.1, while section 2.2 highlights the details of a numerical model termed the dynamic electro-geometrical model (DEGM) for computing the probability of a direct lightning strike to structures within the defined volume. Finally, the DEGM model is applied to various dimensions of a FRT as described in section 2.3.

\subsection{The attractive volume of a FRT}

The risk of a lightning strike to a structure can be evaluated using the concept of the attractive volume. The attractive volume defines a space volume around a structure to be protected within which lightning strikes can hit the object. The object is deemed naturally protected from all lightning downward leaders which do not enter the attractive volume of the protected object. The concept was developed to explain the stochastic nature of the descent of a downward leader, and the orientation point at which the object to be struck by lightning is determined (Horváth, 1991). The distance between the orientation point, and the object to be struck or the ground is known as the striking distance. It is a function of the lightning-induced electrical field strength on the ground, and this also depends on the magnitude of the electric charge in the lightning leader channel.

By applying increasing striking distance, various rolling sphere radii that can touch the FRT and the ground were computed, the centers of such spheres as shown by the curved black line in Figure 1 represent the boundary of the interception volume of the FRT on the "right" side of the structure. The same concept applies on all sides around the structure, and this will generate a volume within which downward leaders can orientate towards the floating roof tank.

\subsection{The dynamic electro-geometrical model (DEGM)}

The peak value of lightning current has been measured and recorded at different regions of the world, and this has been used to develop a distribution function for the striking distance (r) using logarithm normal functions (Horváth, 2006). In terms of the striking distance, the probability density function (PDF) is defined by Equation 1. By applying the median value of lightning current distribution and the standard deviation for positive and negative lightning, the distribution obtained is shown in Figure 2. Also, the effective probability distribution

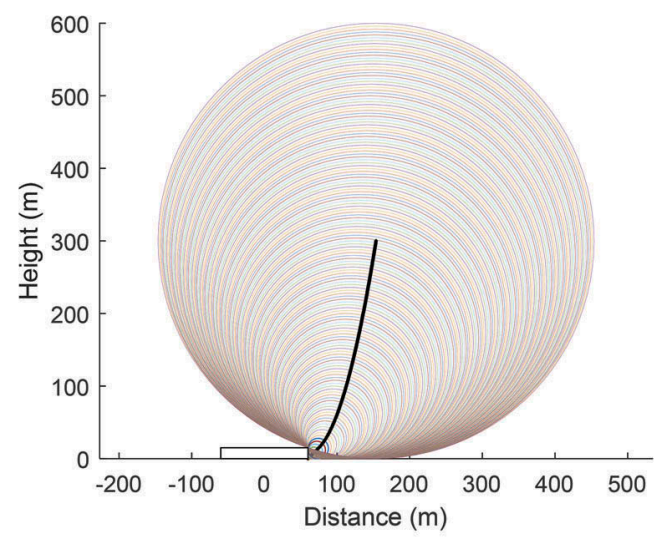

Figure 1. Interception boundary at one side of FRT. 


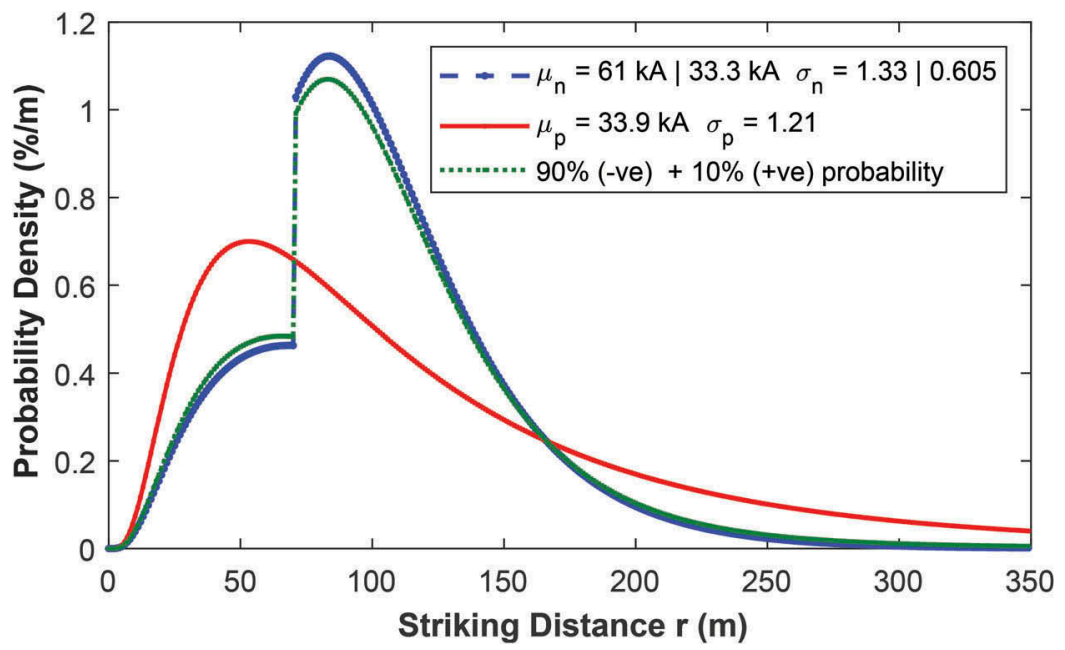

Figure 2. Striking distance probability density (blue, $\mathrm{n}-$ negative lightning, red, $\mathrm{p}-$ positive lightning).

resulting from the summation of $90 \%$ of the PDF for negative lightning and $10 \%$ for positive lightning is also plotted in comparison in Figure 2. From lightning observations over time, about $90 \%$ of all lightning strikes have negative polarity, and as such, the effective probability distribution will be applied in the numerical computation of the dynamic electro-geometrical model (Hannig et al., 2014).

The DEGM applies the concept of probability weighted collection volume (Horváth, 2006), which modulates collection volume by the probability density function i.e. the striking distance density. To apply the DEGM concept to a floating roof tank (FRT), the surface of the FRT is first discretized into various surface points, and the associated interception volume enclosed by the circle centers as shown in Figure 1 is also discretized into multiple orientation points from which lightning can orientate towards the FRT. For each orientation point in space, the distance to various points on the FRT is computed, and the point(s) on the FRT having distances equal to the lowest geometric distance are determined as the final strike point(s) from that specific orientation point in space above the FRT (Adekitan \& Rock, 2020). The associated probability is computed using Equation 1, and the process is repeated for all the orientation points within the interception volume. The probability of a strike to the same point on the FRT from different orientation points is cumulated. Finally, the overall probability for all the points on the FRT is summed, and from this value, the percentage of the probability of a strike for each point on the FRT can be computed. This is a numerical computation which has also been applied by Kern et al. (Kern et al., 2010) for various structures.

$$
P D F(r)=\frac{10^{\frac{-1}{0.65}}}{0.65} r^{\frac{0.35}{0.65}} \frac{1}{\sigma\left(\frac{r}{10}\right)^{\frac{1}{0.65}} \sqrt{2 \pi}} e^{-\left\{\ln \frac{\left(\frac{r}{10}\right)^{\frac{1}{0.65}}}{\mu}\right\}^{2}}{ }^{2 \sigma^{2}}
$$

Where $r$ is the striking distance, $\mu$ is the median value and $\sigma$ is the standard deviation $(\sigma)$ of the lightning current distribution.

\subsection{Numerical simulation of various FRT dimensions and roof positions}

Large floating tanks are more susceptible to lightning induced ignition and fires. This is due to the increased surface area that is exposed to direct lightning strikes, and the consequences 
of indirect strikes as charges accumulate on, and around the tank. The position of the floating roof changes within a FRT based on the level of the liquid in the tank. Due to the changing roof position, the exposed area of the roof that can be struck by lightning from above the tank, and within the interception volume of the FRT i.e. cloud-to-ground strikes (Wang et al., 2018), varies with the position of the roof (Adekitan \& Rock, 2019b).

In this study, the effect of tank height and the position of the roof within the tank on the probability of lightning strike to different points on a FRT is examined. Three different tank heights were considered; $10 \mathrm{~m}, 15 \mathrm{~m}$, and $20 \mathrm{~m}$ high FRTs with a diameter of $60 \mathrm{~m}$. The roof positions were simulated to determine the effect of changing roof position. The first roof position is at the top, when the roof is most exposed to direct lightning strikes. The middle position, at half the height of the tank was also considered, and the bottom position which for this simulation was set at $0.5 \mathrm{~m}$ from the ground. Usually, the roof does not get to $0 \mathrm{~m}$ on the ground. At the base of the tank, the roof sits on adjustable legs, that may be as high as $2 \mathrm{~m}$ to allow for man-entry for maintenance checks.

\section{RESULTS AND DISCUSSION}

The results of the numerical analysis for the various roof positions are presented in this section.

In Figure 3, the floating roof of the $30 \mathrm{~m}$ radius tank with $20 \mathrm{~m}$ in height is at the topmost position, and at this point, the roof has the highest exposure to direct lightning strikes. In Figure 4 , the roof is at half the height of the tank and only a small portion of the tank roof

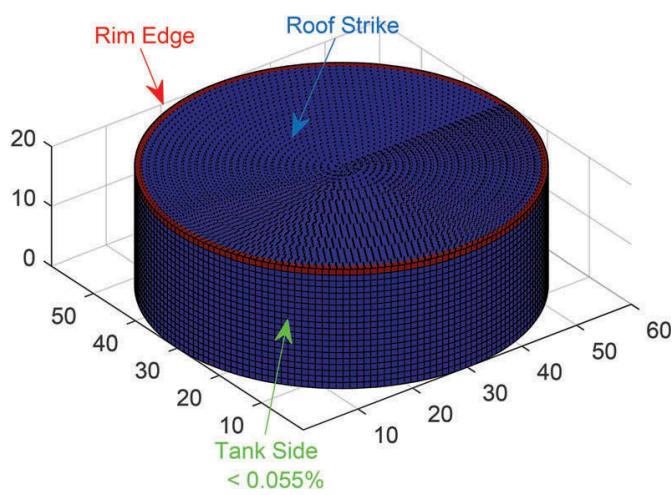

Figure 3. Floating roof at the highest position within the tank.

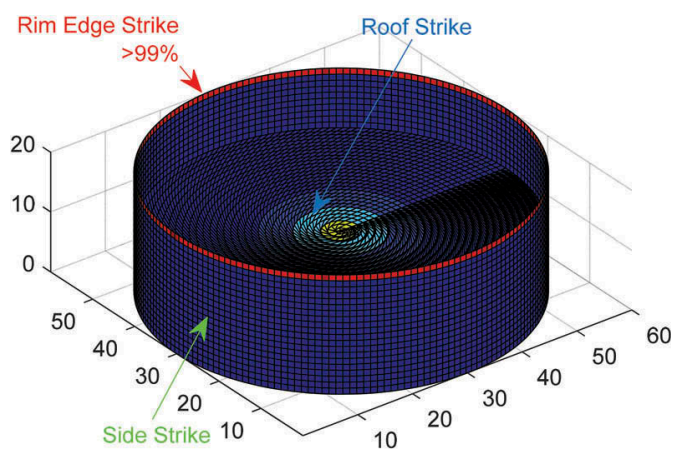

Figure 4. Floating roof at the middle height of the tank. 
around the center is exposed to direct cloud-to-ground strikes. In Figure 5, the roof is shown at the base of the tank, and at this position the risk of a direct lightning strike to the roof is extremely small.

The surface of the FRT is categorized into three: the roof, the rim edge which refers to the topmost circular portion of the cylindrical tank shell, and the side of the tank which encompasses the remaining cylindrical wall of the tank below the rim edge. The probability of a strike to each of these three parts is presented for the $10 \mathrm{~m}, 15 \mathrm{~m}$, and $20 \mathrm{~m}$ high FRT in Figure 6, Figure 7, and Figure 8 for the various roof positions (top, middle, and bottom).

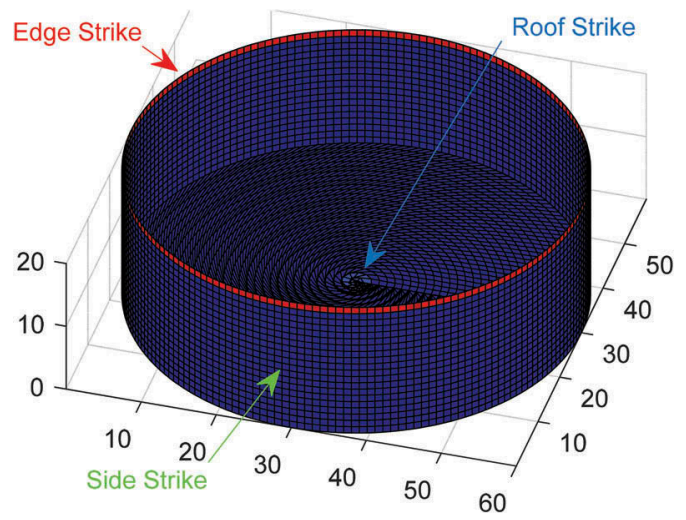

Figure 5. Floating roof at the base of the tank.

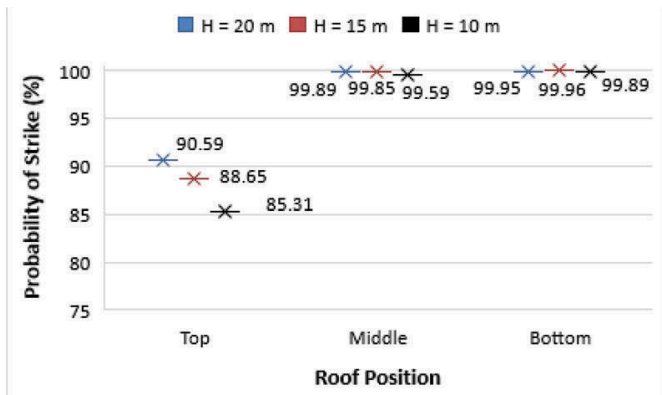

Figure 6. Probability of a lightning strike to the rim edge of the tank cylinder.

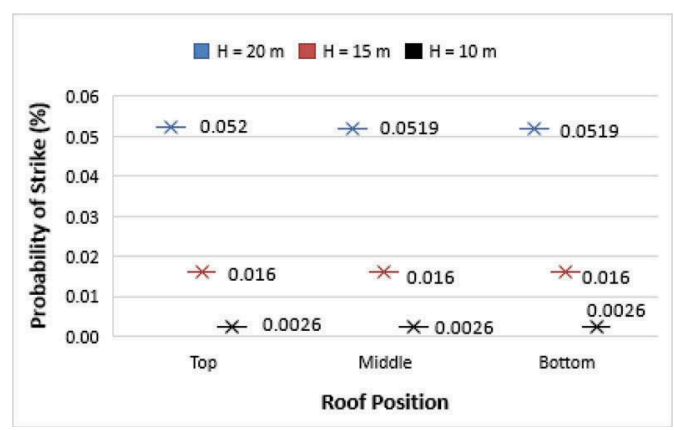

Figure 7. Probability of a lightning strike to the side of the tank. 


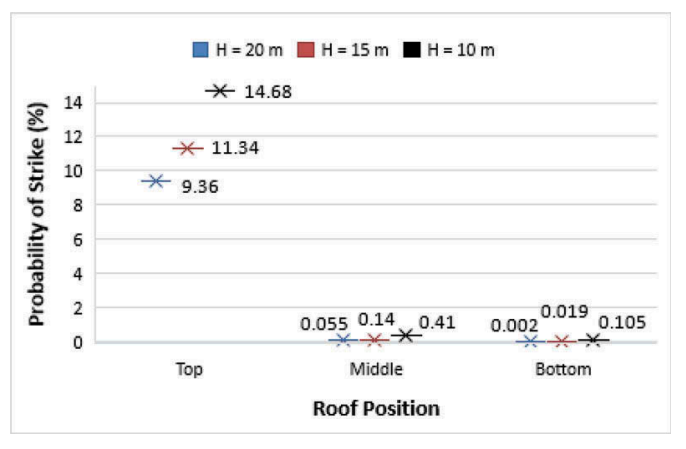

Figure 8. Probability of a lightning strike to the roof of the FRT.

The probability of a lightning strike to the rim edge of the tank cylinder for the three different tank heights considered is shown in Figure 6. It was observed that the probability of a strike to the rim of the cylindrical tank shell increased with tank height at the topmost roof position. At other roof positions i.e. midway, and at the bottom, the probability of a strike to the rim edge is greater than $99 \%$, and this did not change significantly with tank height.

As shown in Figure 7, the probability of a strike to the remaining part of the tank cylindrical shell referred to as tank side increases with tank height (i.e. more exposed tank wall surface area), but the probability of a strike is relatively constant with changing roof position.

For the floating roof as shown in Figure 8, the probability of a direct lightning strike reduces with increasing tank height when the roof is at the topmost height. At the middle position, the probability of a strike to the roof reduces slightly with increasing height, and at the bottom, the probability of a strike is relatively constant irrespective of tank height.

The highest probability of a direct strike occurs when the roof is at the topmost position. The probability of a direct strike to the rim edge, i.e. the rim-seal area of the tank where shunts are positioned, with a high probability of flammable vapor presence is highest as compared with the risk of a strike to the side of the tank or the floating roof. When heavy currents flow through the shunt-shell contact within the rim-seal region, the risk of spark formation is high. Hence, it is necessary to ensure that lightning currents flowing down to the rim edge is minimal. This may be achieved by using interconnected, parallel air termination arrangements, which create multiple flow paths for the lightning current and associated energy. This cannot be achieved by using vertical air termination rods on the FRT shell that will only intercept strikes and conduct the full currents down to a single point on the tank shell.

From the simulated results, the frequency of lightning strike $\left(N_{i}\right)$ can be computed for the rim edge, the roof, and the side of the tank by applying Equation 2.

Frequency of lightning strike $\left(N_{i}\right)=$ ground flash density $\left(N_{G}\right) \times$ probability modulated collection volume $(C P)$

$$
N_{i}=N_{G} \times C P
$$

Where $N_{G}$ is the ground flash density in flashes $/ \mathrm{km}^{2} / y e a r$, and $C P$ is the computed probability using DEGM for the rim seal, the roof, and the side of the tank. Assuming, the tank is located in the Niger Delta region of Nigeria; the analysis is therefore based on a ground flash density of 16 flashes $/ \mathrm{km}^{2} /$ year. The estimated frequency of a lightning strike to the three categorized areas of the FRT is computed for the different tank heights and roof positions. The result is presented in Table 1 for the $10 \mathrm{~m}$ high FRT, Table 2 for the $15 \mathrm{~m}$ high FRT, and Table 3 for the $20 \mathrm{~m}$ high FRT. The variation in the estimated frequency of lightning strikes for the different roof positions is because of the changing total exposed area of the FRT that is susceptible to direct lightning strike as the roof changes position. 
Table 1. The frequency of lightning strike per year for the $10 \mathrm{~m}$ high FRT.

\begin{tabular}{llll}
\hline & Rim Edge & Side Wall & Roof \\
\hline Top & 0.2479 & 0.000008 & 0.0427 \\
Middle & 0.2929 & 0.000008 & 0.0012 \\
Bottom & 0.2943 & 0.000008 & 0.0003 \\
\hline
\end{tabular}

Table 2. The frequency of lightning strike per year for the $15 \mathrm{~m}$ high FRT.

\begin{tabular}{llll}
\hline & Rim Edge & Side Wall & Roof \\
\hline Top & 0.3336 & 0.00006 & 0.0427 \\
Middle & 0.3796 & 0.00006 & 0.0005 \\
Bottom & 0.3802 & 0.00006 & 0.0001 \\
\hline
\end{tabular}

Table 3. The frequency of lightning strike per year for the $20 \mathrm{~m}$ high FRT.

\begin{tabular}{llll}
\hline & Rim Edge & Side Wall & Roof \\
\hline Top & 0.4129 & 0.00024 & 0.0427 \\
Middle & 0.4593 & 0.00024 & 0.0003 \\
Bottom & 0.4596 & 0.00024 & 0.0000 \\
\hline
\end{tabular}

\section{CONCLUSIONS}

The risk of a strike to various points on a floating roof tank (FRT) is dynamic, and it is influenced by the position of the roof within the tank. The dimension of a FRT plays a significant role in the manner of exposure of such tanks to direct lightning strikes. The dynamic electrogeometrical model simulations carried out in this study reveals that the height of a FRT and the position of the floating roof determines the risk of a direct lightning strike to the roof. The numerical simulation shows that when the roof is at the uppermost point, the risk of a strike to the rim edge (around the rim seal region) where flammable vapor concentration is often present, increases with increasing tank height for the same diameter tank. As the roof descends into the tank, the probability of a lightning strike to the rim edge increases with reducing roof height. By the time the roof is at half the height of the tank, the probability of a strike to the rim edge of the tank shell is around $99 \%$.

In line with the realities of the result of this simulation, conventional air terminations positioned on the FRT must be designed, not only to be able to intercept lightning strikes e.g. by using air termination rods, but also, it must be able to divide the lightning current into multiple flow parts in order to reduce the risk of sparking when the current gets to the rim seal region of the tank shell where arcing may occur at the shunt-shell region. This study as revealed the likelihood of lightning strikes to various parts of a FRT with respect to floating roof position. The knowledge provided here, will serve as bases for the design and investigation of various conventional air termination arrangements for reliably protecting a FRT from direct strikes while also preventing arcing at the rim-seal region.

\section{ACKNOWLEDGMENT}

This is to appreciate the support of the Nigerian Petroleum Technology Development Fund (PTDF) through the Overseas Scholarship Scheme in partnership with the German Academic Exchange Service (DAAD). 


\section{REFERENCES}

Adekitan, A. I. \& Rock, M. 2019a. Lightning induced fires: A case study of floating roof tanks. XII Russian-German Raw Materials Forum: Youth Day, St Petersburg, Russia. Saint-Petersburg Mining University, 156-157.

Adekitan, A. I. \& Rock, M. 2019b. Performance investigation of Lightning Protection Systems for Floating Roof Tanks in Nigeria. 13. VDE Blitzschutztagung, 24. - 25. Oktober 2019 Aschaffenburg. VDE Fachberichte, 71-77.

Adekitan, A. I. \& Rock, M. 2020. The impact of space point definition on dynamic electro-geometrical model of lightning strike probability. Electric Power Systems Research.

Afa, J. T. 2012. Lightning Activities and Ground Flash Density in Niger Delta Coast. Journal of Engineering and Applied Sciences, 7, 339-341.

Akinyemi, M., Boyo, A., Emetere, M., Usikalu, M. \& Olawole, O. 2014. Lightning a Fundamental of Atmospheric Electricity. International Conference on Environment Systems Science and Engineering, $47-52$.

Chang, J. I. \& Lin, C. 2006. A study of storage tank accidents. Journal of Loss Prevention in the Process Industries, 19, 51-59.

Hannig, M., Hinrichsen, V., Hannig, R., \& Brocke, R. 2014. An analytical consideration on the striking probability and the total amount of strikes to simple structures according to standardized regulations. 32nd International Conference on Lightning Protection (ICLP). IEEE.

Horváth, T. 1991. Computation of lightning protection. Cargese Lectures in Physics.

Horváth, T. 2006. Interception of lightning air termination systems constructed with rolling sphere method. Proc. 28th International Conference on Lightning Protection (ICLP).

Hu, H. \& Liu, Q. 2012. Research on lightning sparks discharge and protection measures of large floating roof tank. 31st International Conference on Lightning Protection (ICLP). IEEE, 1-4.

Kern, A., Schelthoff, C. \& Mathieu, M. 2010. Probability of lightning strikes to air-terminations of structures using the electro-geometrical model theory and the statistics of lightning current parameters. 30th International Conference on Lightning Protection (ICLP). IEEE.

Kulikov, A. M. \& Chekardovskiy, S. M. 2018. Improving the safety of operation of tanks with a floating roof in the winter period. IOP Conference Series: Materials Science and Engineering, IOP Publishing, 445012010.

Ren, X., Fu, Z., Yan, N., \& Sun, W. 2012. Analysis and experimental investigation of direct lightning protection for floating roof oil tanks. Electric Power Systems Research, 94 134-139.

Wang, C., Sun, Z., Jiang, R., Tian, Y. \& Qie, X. 2018. Characteristics of downward leaders in a cloud-toground lightning strike on a lightning rod. Atmospheric Research, 203, 246-253.

Wei, T., Qian, X., \& Yuan, M. 2018. Quantitative risk assessment of direct lightning strike on external floating roof tank. Journal of Loss Prevention in the Process Industries, 56, 191-203. 


\title{
Simulating the formation of wax deposits in wells using electric submersible pumps
}

\author{
A.N. Aleksandrov \\ Engineer, Saint Petersburg Mining University, Saint Petersburg, Russia \\ M.A. Kishchenko \\ Master student, Saint Petersburg Mining University, Saint Petersburg, Russia \\ Thang Nguyen Van \\ Postgraduate student, Saint Petersburg Mining University, Saint Petersburg, Russia
}

\begin{abstract}
In this paper, based on the known physicochemical characteristics and the component composition of the reservoir high-wax oil from $\mathrm{D}_{2 \mathrm{ef}}$ formation of the Kirtaelsky field, a phase behavior model of the studied high-wax oil was developed through the Multiflash Wax module, which allows us to determine the conditions for phase transition of paraffinic hydrocarbons in the gas-liquid mixture. It is established that for the given conditions, the closest to the actual value of the depth of organic deposit formation was obtained through the complex mechanistic model of the vertical multiphase flow OLGAS. The nature of the change in WAT along the wellbore was determined. The changes were highly noticeable when creating a depression in the reservoir and increasing the pressure in the electric submersible pumps (ESP) together with the degassing process of well products. A study focused on the influence of operating parameters of a well equipped with an ESP on conditions leading to the wax formation was conducted. Practical recommendations for the conditions under consideration were obtained.
\end{abstract}

\section{INTRODUCTION}

A principal challenge in many oil industry production situations is paraffin wax. Up to $75 \%$ of the world's oil suffers when wax precipitates out and solidifies in formation pores and fluid flow channels, at the wellbore, on the sidewalls of wells, in the tubing, casings, pump strings, and processing system. Wax deposition is costly and one of the oil industry's most expensive inconveniences, leading to dramatic reductions in production, equipment failures, loss of storage and transport capacity, and loss of efficiency.

Wax is a complicated blend of n-paraffin, i-paraffin and c-paraffin with carbon numbers from 18 to 65 (Lake et al. 2006). Fadairo et al. (2010) and Kasumu et al. (2013) showed that waxes are precipitated as solids with the changing thermodynamic equilibrium when the oil temperature cools down lower than the wax appearance temperature (WAT). In other words, the temperature at which the first organic wax crystalizes in oil as a deposit is referred to as the WAT. Berne-Allen et al. (1938) and Paso et al. (2009) suggested that the WAT is one of the main factors, which needs to be taken into account when developing preventative strategies for handling wax deposition in oil wells.

For a scientifically-based method to the prevention and removal of wax, it is important to take into account the conditions that cause a phase transition of paraffin to a solid-state. This process is influenced concurrently by several factors (Glushchenko et al. 2009, Ibragimov et al. 2010, Rogachev et al. 2006):

- geological, physical and technological conditions of field production;

- physicochemical properties and component composition of reservoir oil; 
- changes in thermobaric conditions along the wellbore;

- violation of hydrodynamic equilibrium;

- changes in the structure and flow rate;

- the intensity of oil degassing;

- the amount of solid contained in oil;

- water-cut;

- condition of the internal surface of the equipment (roughness).

The intensity of the wax formation depends on the predominance of one or more factors, which might vary in time and depth, hence, the amount and nature of organic deposits are not constant (Struchkov et al. 2018).

Regarding the analysis of the prevailing situation on the dewaxing of a well of the studied production object, it was found that the measures taken to remove wax deposits, for one reason or another, have low efficiency. Solving the problem of preventing the formation and removing wax deposits will reduce current and capital costs in the exploitation of high-wax oil.

One of the acknowledged methods to reduce the intensity of the formation of organic deposits in the well is to choose the optimal technological regime of its operation. During the production of the high-wax oil well using ESP, the most important operating parameters affecting the conditions for the formation of wax deposits are the changes in the ESP rotation frequency and the number of stages, as well as the buffer pressure.

Despite the fact that wax formation simulation is one of the more challenging questions facing engineers, owing to the extremely complicated and limited data, there are a number of wax simulation programs developed to predict and control wax formation, the amount of precipitated wax, and wax deposition rates.

Detailed design of production systems is required to improve the efficiency of oil production and exploitation. There are a tremendous number of software packages used to predict the crystallization process of high-molecular components of oil such us the PVTsim software package (developed by the Calsep company), the PVTP software package (developed by the Petroleum Experts company), and the OLGA and PIPESIM software packages (developed by the Schlumberger company).

One of the leading software systems in the field of analysis and optimization of oil production systems is the product of the Schlumberger Company - PIPESIM. For the most part, this software package is a wax simulation used for building and calculation of a static model of steadystate multiphase flow moving from the reservoir to the objects of the collection and preparation system. PIPESIM allows for the solution of many complicated problems with the help of numerous modules included in this package (Schlumberger PIPESIM [Electronic resource]).

The novelty of this paper is to provide a detailed study of the effect of parameters of the electric submersible pump on wax formation. In addition, this work also proposes practical recommendation for given conditions, which play a pivotal role in predicting and measuring wax formation.

\section{MATERIALS AND METHODS}

In this work, we used the results of laboratory studies of the physicochemical properties of the high-wax oil in the Kirtaelskoe field, as well as the results from modeling the movement of the specified high-wax oil along the wellbore of a well using electric submersible pump through the Schlumberger PIPESIM software package.

\section{RESULTS AND DISCUSSION}

\subsection{Initial data}

The object of the study is a hypothetical well, simulating the conditions of the Timan-Pechora oil and gas province with geometric, geological and physical parameters characterized for the 
Table 1. Well parameters.

\begin{tabular}{|c|c|}
\hline Parameter & Value \\
\hline Flow rate of the fluid at standard conditions, $\mathrm{m}^{3} / \mathrm{d}$ & 85 \\
\hline Productivity Index, $\mathrm{m}^{3} / \mathrm{d}^{*} \mathrm{MPa}$ & 15 \\
\hline Gas/oil ratio, $\mathrm{m}^{3} / \mathrm{m}^{3}$ & 72 \\
\hline Surface pressure, $\mathrm{MPa}$ & 1.8 \\
\hline Oil bubble point pressure, $\mathrm{MPa}$ & 8.8 \\
\hline Well depth, m & 3000 \\
\hline Perforation depth, m & 2925 \\
\hline Tubing depth, m & 2400 \\
\hline Average angle of inclination of the well, ${ }^{\circ}$ & 2 \\
\hline Internal diameter of the production string, $\mathrm{m}$ & 0.144 \\
\hline Internal diameter of tubing, $\mathrm{m}$ & 0.062 \\
\hline Temperature of the neutral layer, ${ }^{\circ} \mathrm{C}$ & 4 \\
\hline Depth of the neutral layer, $\mathrm{m}$ & 30 \\
\hline
\end{tabular}

Table 2. Physical and chemical properties of degassed oil from the $\mathrm{D}_{2 \mathrm{ef}}$ pool.

\begin{tabular}{lc}
\hline Main properties & Value \\
\hline Density at $20{ }^{\circ} \mathrm{C}, \mathrm{kg} / \mathrm{m}^{3}$ & 802 \\
The pour point, ${ }^{\circ} \mathrm{C}$ & 39 \\
WAT, ${ }^{\circ} \mathrm{C}$ & 43.5 \\
Hydrocarbon group composition, \% by mass: \\
Wax content $(\mathrm{wt} \%)$ & 32.3 \\
Asphaltene content $(\mathrm{wt} \%)$ & 0.7 \\
Resin content $(\mathrm{wt} \%)$ & 4.7 \\
Reservoir temperature, ${ }^{\circ} \mathrm{C}$ & 62 \\
Reservoir pressure, $\mathrm{MPa}$ & 29.1 \\
\hline
\end{tabular}

conditions of the developed oil reservoir $\mathrm{D}_{2 \mathrm{ef}}$ (given in Table 1). The temperature for the specified reservoir is $62{ }^{\circ} \mathrm{C}$, and the current reservoir pressure is $19.6 \mathrm{MPa}$.

The results of laboratory studies of the physical-chemical properties of the wellhead nonwater oil sample are shown in Table 2. Degassed oil is extremely light (density $802 \mathrm{~kg} / \mathrm{m}^{3}$ ). The pour point is $39^{\circ} \mathrm{C}$.

In terms of group analysis, the oil has a high wax content ( $32.3 \%$ by mass), and is resinous (resin content is $4.7 \%$ and asphaltene content is $0.7 \%$ by mass). Physical and chemical properties of degassed oil from the $\mathrm{D}_{2 \text { ef }}$ pool are given in Table 2.

\subsection{Pump selection}

At the first stage, a method of well productivity evaluation was applied in the form of nodal analysis. It allows us to divide the system "reservoir-well-pump" into components connected by nodal points (Guo et al. 2009), to visually evaluate the influence of various parameters on the formation productivity and the performance of the lift and submersible pump. The behavior of the well is determined by the energy of the reservoir ensuring the flow of fluid to the well and the ability of the fluid to rise to the surface. The intersection point of the inflow curve (indicator curve) and the outflow curve is called the working point of the system. Modeling of fluid flow at the bottom of the well, which determines the flow rate of the reservoir at the depression established on it was carried out by setting the well productivity index, taking into account the Vogel correction. In the developed model, the nodal point is located opposite the perforated interval. 


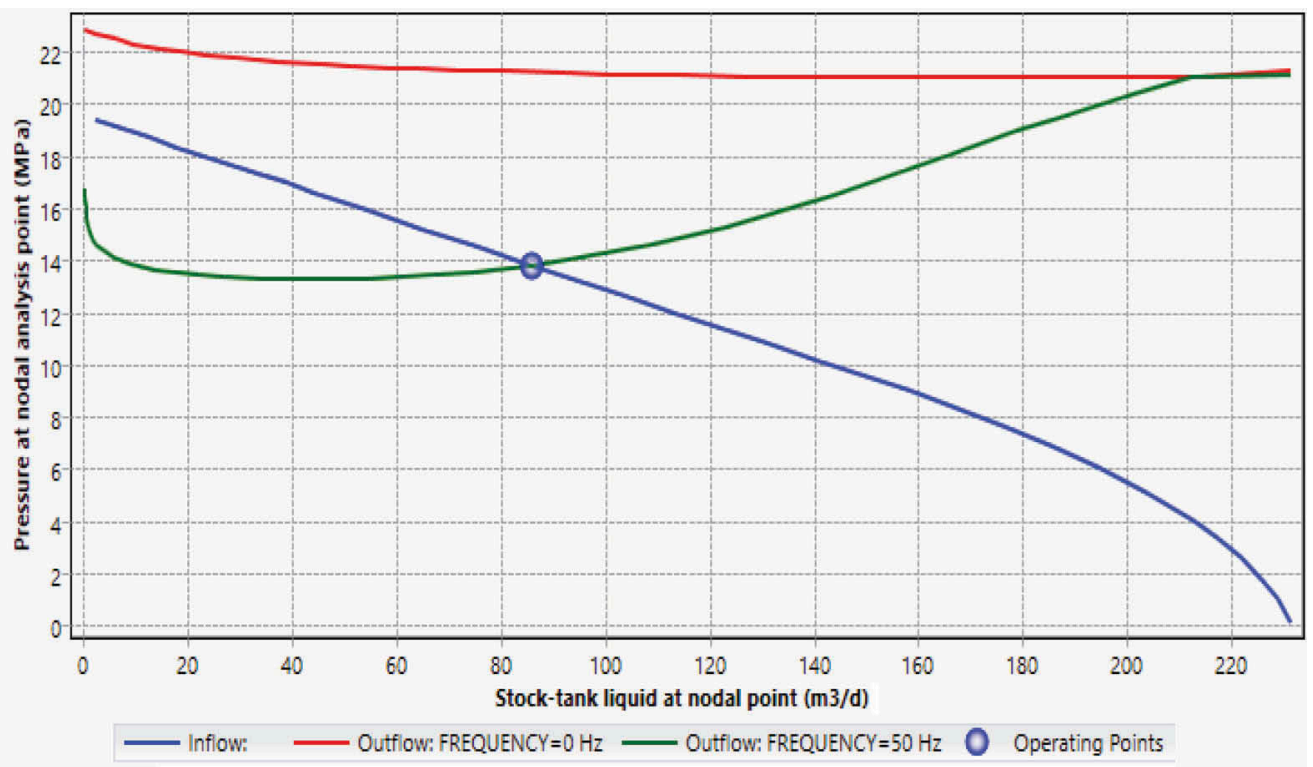

Figure 1. Combined characteristic of the reservoir-well system without a pump and with its use.

During production, the initial reservoir pressure dropped to $19.6 \mathrm{MPa}$. The use of nodal analysis makes it possible to establish that the energy for lifting the well is not enough to move the fluid from the downhole to the wellhead - well blowout is impossible (red line, Figure 1).

In order to provide the well with sufficient energy to lift fluid to the surface and achieve the planned flow rate $\left(85 \mathrm{~m}^{3} / \mathrm{day}\right)$, an ESP TD600 was chosen. The green line in Figure 1 represents the characteristic of the well with a working pump. The most suitable pump is selected from the vast database with the highest efficiency, which is made for the selected pump model $65 \%$. When choosing a pump, losses between steps, viscosity correction, and downhole separation effects were taken into account.

\subsection{Phase equilibrium diagram}

With regard to the known physical-chemical characteristics and component composition, a model of high-wax oil was developed, which allows us to determine the conditions for the wax formation in a gas-liquid mixture. The wax formation line shown on the phase diagram corresponds to the temperature of the studied wax appearance temperature $-44{ }^{\circ} \mathrm{C}$. According to the graph, at the temperature of $20^{\circ} \mathrm{C}$, the wax content is $32.3 \%$ by mass. The values of the WAT and wax mass content in the presented model are quite close to the experimentally obtained data at $20^{\circ} \mathrm{C}$ and the atmospheric pressure, given in Table 2 .

Under normal conditions, different hydrocarbon components contained in the oil form a three-phase system. At reservoir conditions (high temperature and pressure), all the components form one phase which is a liquid mixture. Oil is a multicomponent system, so the phase equilibrium diagram in the "temperature-pressure" coordinates, unlike in individual substances, is not a single curve, but an area limited by condensation line and evaporation line.

The first stage of the simulation is to plot a phase diagram of the hydrocarbon system for the $\mathrm{D}_{2 \mathrm{ef}}$ pool (Figure 2). To the left of the critical point $(\mathrm{C})$ and above the evaporation line (area 1) hydrocarbons are in a liquid state; to the right and below the condensation line (area 2) hydrocarbons are in a gaseous state. Inside the two-phase boundary between the 


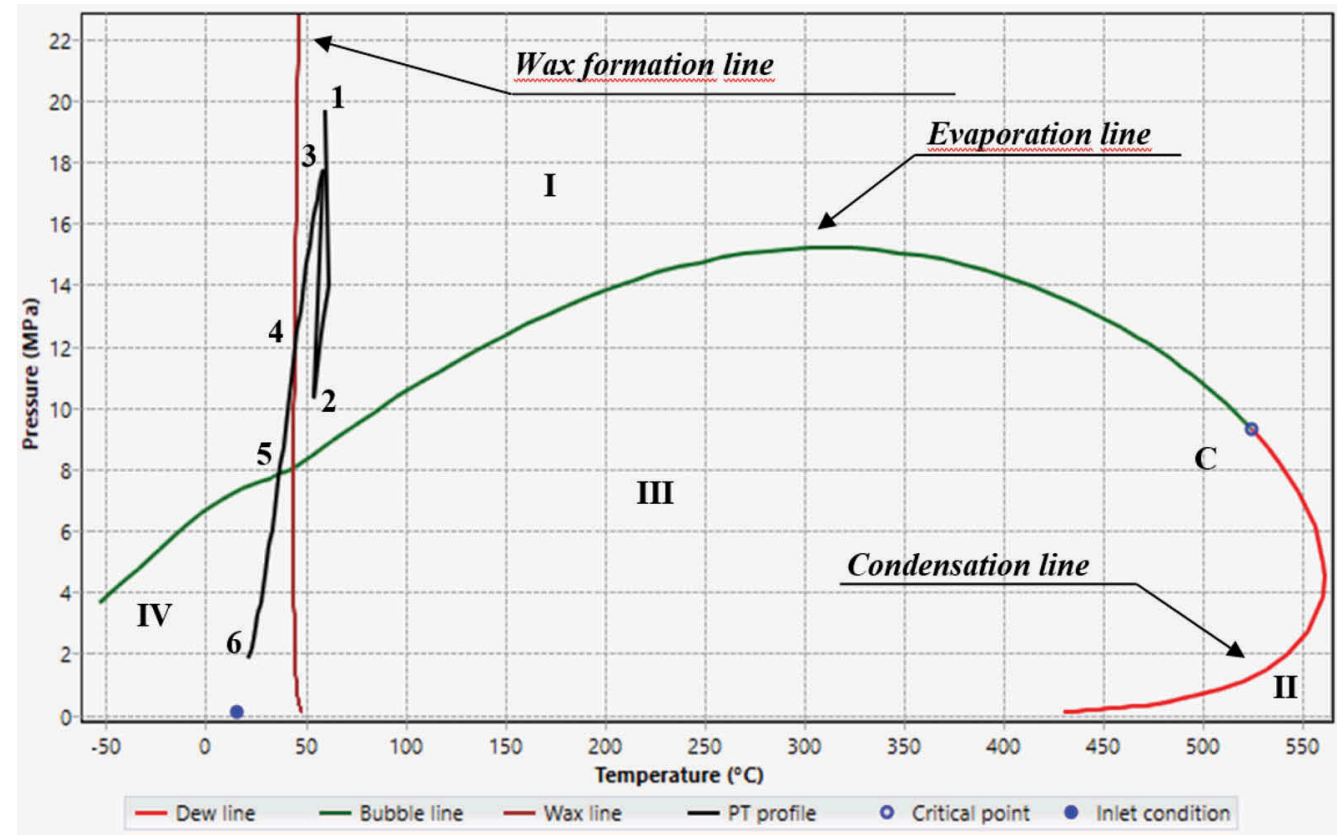

Figure 2. Phase equilibrium diagram for the $\mathrm{D}_{2 \mathrm{ef}}$ pool hydrocarbon system.

evaporation and condensation line (area 3 ) gas and liquid can coexist. When the temperature drops below the wax formation line, the system turns into a three-phase state (area 4) with an additional solid phase - wax.

Additionally, the phase diagram is a simulated PT (pressure and temperature) - profile during fluid movement from the reservoir to the wellhead. The beginning of the calculation of the model occurs at point 1 , which illustrates the reservoir conditions. Points 2 and 3 correspond to the thermobaric conditions at the intake, discharge of the ESP, and illustrate the pressure and temperature rise occurring in the pump. When moving along the tubing string, the flow temperature decreases to the WAT (point 4), which contributes to the beginning of wax formation. Then the pressure decreases to the point of oil saturation with gas (bubble point, point 5), which initiates the loss of light hydrocarbon fractions and contributes to the extensive formation of wax deposits. In the area between points 5 and 6 (wellhead), there is a movement of a 3-phase system (liquid, gas and solid particles).

\subsection{Determination of the depth of wax formation}

Figure 3 shows a comparison of the real (actual) temperature log with temperature distribution profiles along the wellbore, which is calculated by using formulas 1,2, 3 and through complex mechanical model of the vertical multiphase flow OLGAS. In this model, two types of correlations are observed: the two-phase model considering the gas-liquid flow and the three-phase model additionally counting solid particles.

The complex mechanical flow model OLGAS is applied for all tilt angles, pipe diameters, and fluid properties. In this model, we used independent continuity equations for gas and liquid droplets, which are related to interfacial mass transfer.

The wax appearance temperature curve obtained using the Coutinho model in the Multiflash module was shown in Figure 3, which allows us, when crossing with temperature profiles, to determine the depth of the formation of wax deposits in the well (Table 3).

The model Coutinho is a thermodynamic model based on the concept of predicting the formation of a solid phase. The use of this model in combination with the state equation 


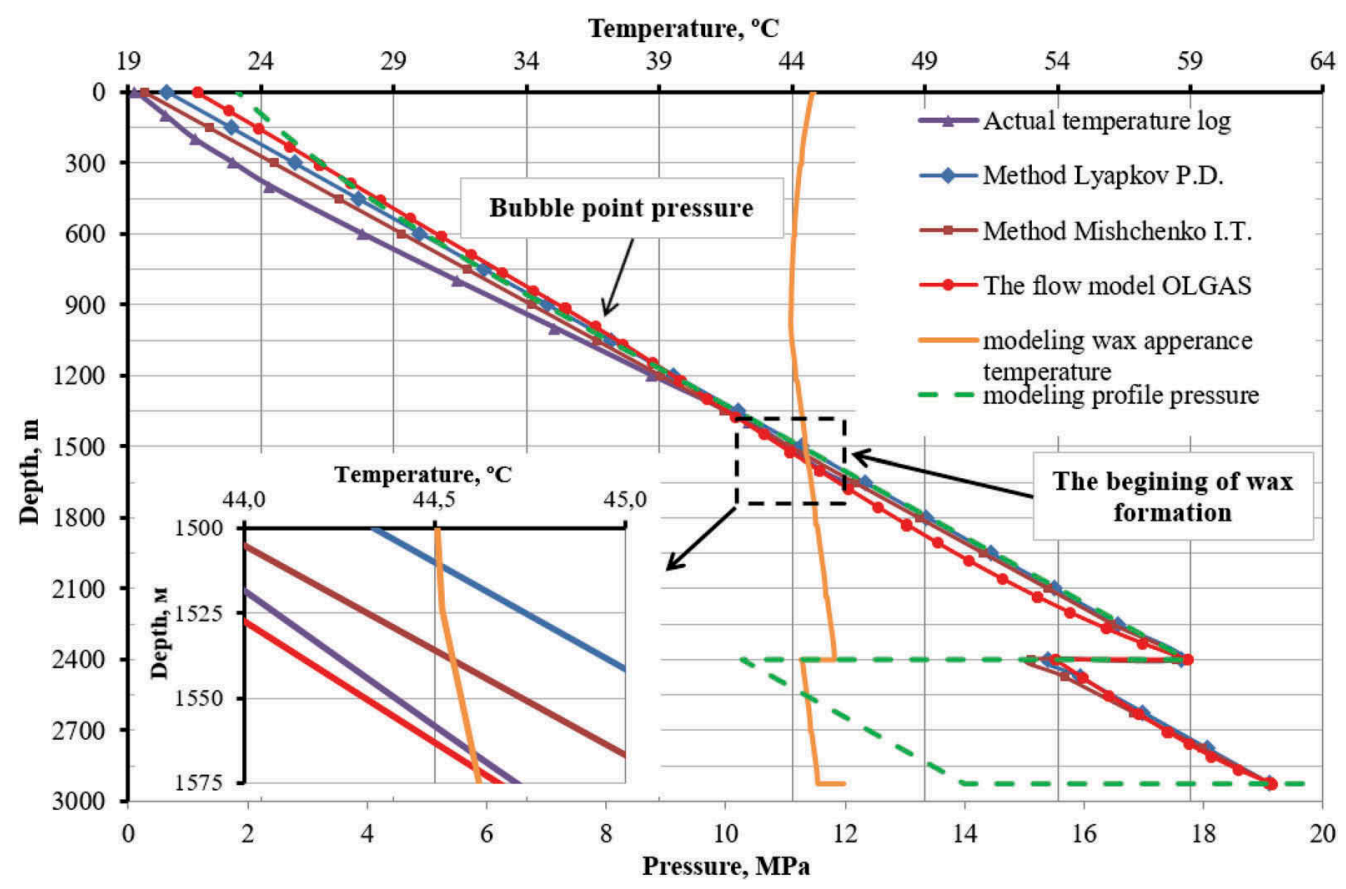

Figure 3. Determination of the depth of the formation of wax deposits.

Table 3. Determination of the depth of wax formation.

\begin{tabular}{lll}
\hline Method & WAT, ${ }^{\circ} \mathrm{C}$ & $\mathrm{H}_{\text {wax formation, }} \mathrm{m}$ \\
\hline According to Lyapkov P.D. & 44,51 & 1510 \\
According to Mishchenko I.T. & 44,55 & 1540 \\
According to actual temperature log & 44,59 & 1566 \\
According to the flow model OLGAS & 44,62 & 1572 \\
\hline
\end{tabular}

(UNIQUAC model) makes it possible to predict the behavior of oil and its model solutions at low temperatures with high accuracy (Coutinho J. et al. 2001).

Temperature distribution at the wellbore using the method of Lyapkov P.D. (Lyapkov P.D. 1987):

$$
T(H)=T_{r}-\left(L_{c}-H\right) \cdot \frac{0.0034+0.79 \cdot \omega \cdot \cos \alpha}{10 \frac{q}{86400 \cdot 20 \cdot d^{2.67}}}
$$

where $T_{r}$ is the reservoir temperature, $\mathrm{K} ; L_{c}$ is the well depth, $\mathrm{m} ; H$ is the current depth, which is measured from the wellhead, $\mathrm{m} ; \omega$ is the average geothermal gradient in the well, $\mathrm{K} / \mathrm{m}$; $\alpha$ is the angle of deviation of the well from the vertical, degree; $q$ is the flow rate, $\mathrm{m}^{3} / \mathrm{s}$; $d$ is the diameter of the lift, $\mathrm{m}$.

Temperature distribution at the wellbore using the method of Mishchenko I.T. (Mishchenko I.T. 2003):

- For tubing

$$
t(h)=t_{r}\left\{1-\frac{h}{c}\left[0.544\left(623.7 \frac{d_{t}}{Q_{m}}+1\right)\right]\right\},
$$


- For the casing string

$$
t(h)=t_{r}\left\{1-\frac{h}{c}\left[0.544\left(311.85 \frac{d_{c}}{Q_{m}}+1\right)\right]\right\}
$$

where $t_{r}$ is the reservoir temperature, ${ }^{\circ} \mathrm{C} ; h$ is the depth, which is measured from the bottom hole, $\mathrm{m} ; Q_{m}$ is the mass flow rate, $\mathrm{t} / \mathrm{d} ; d_{t}$ is the internal diameter of the tubing, $\mathrm{m} ; d_{c}$ is the internal diameter of casing string, $\mathrm{m} ; c$ is the specific heat of well product, $\mathrm{J} / \mathrm{kg} \cdot{ }^{\circ} \mathrm{C}$.

Thus, the comparison of the actual temperature log with the temperature distribution profiles along the wellbore, which was calculated according to the methods of Lyapkov P.D., Mishchenko I.T. and built using the complex mechanical model of the vertical multiphase flow OLGAS, showed that the study has an excellent result. For the given conditions, the greatest convergence with field study results of the temperature distribution along the wellbore and the actual depth of the beginning of the wax formation is given by using the multiphase flow model OLGAS.

\subsection{The nature of the change in the wax appearance temperature}

As previously noted, the WAT is known as the temperature at which wax from the dissolved state transfers to the solid phase (the first wax crystal is deposited in the oil). This parameter is influenced by many factors, which are: physical-chemical properties, component composition of reservoir oil, wax content, degassing intensity, pressure gradient along the wellbore (Kamenshchikov F.A. 2005).

Figure 4 Shows the joint profile of the wax appearance temperature and pressure along the wellbore. It is important to notice that the nature of changes in these parameters corresponds to the phase equilibrium diagram of the hydrocarbon system (Figure 3).

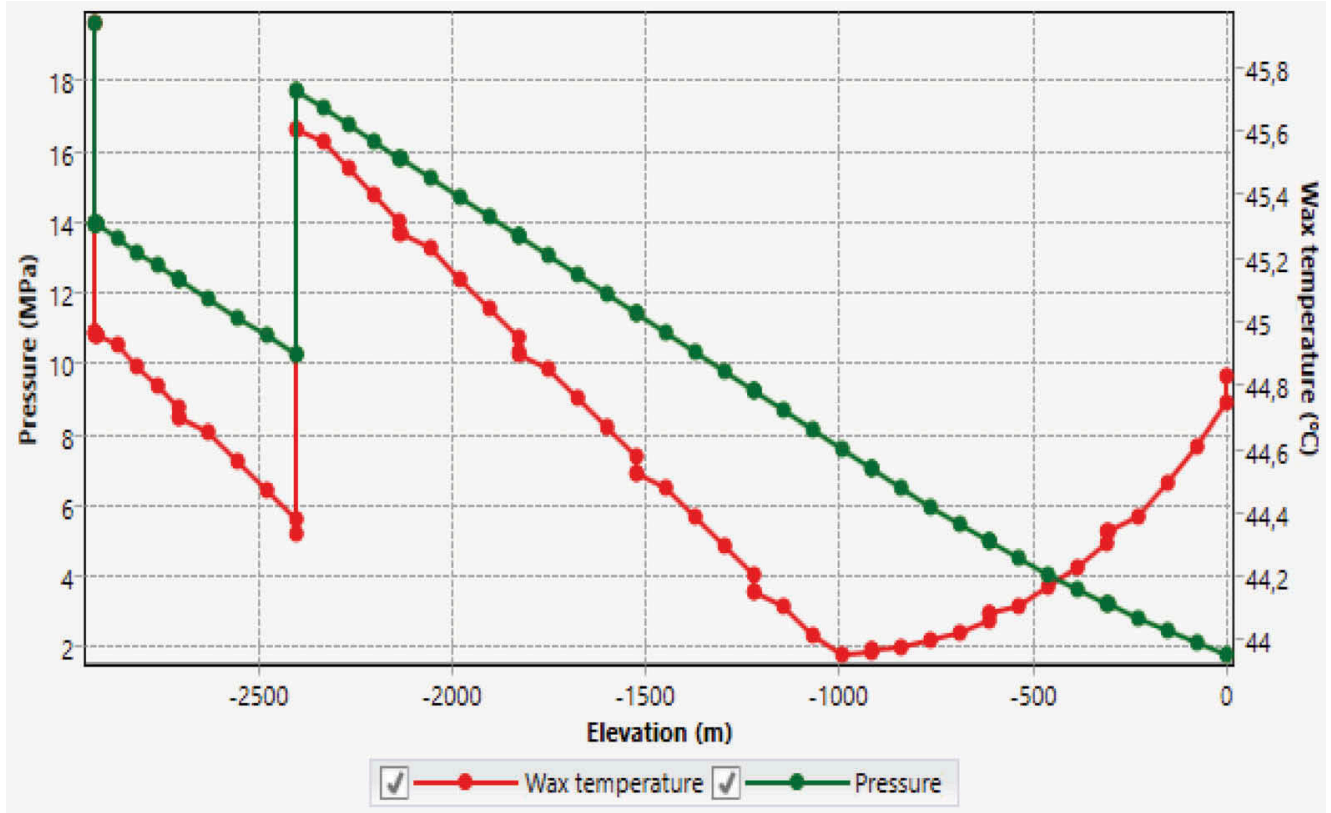

Figure 4. The pressure profile and the wax appearance temperature. 
The decrease in the WAT as it moves to the bottom of the well is due to the manifestation of the throttle effect when creating a depression on the reservoir. Moreover, a significant increase in the WAT occurs in the pump, which is caused by a sharp increase in the pressure in the system. In the sections from the perforation interval to the pump intake $(2925-2400 \mathrm{~m})$ and from the pump discharge to the "bubble point" $(2400-1000 \mathrm{~m})$, there is a linear dependence of the decline in wax appearance temperature with decreasing pressure in the system. Starting from a depth of 1000 meters, an increase in the wax appearance temperature is observed, which is due to the intensive release of light oil fractions and, consequently, a decrease in the solvent capacity of oil relative to (compared to) wax, as well as due to the cooling of the oil flow in the wellbore. It should be noted that the gas globules arising in this process are mass-exchange promoters of the growth of wax crystals (Pashali A.A. et al. 2011 \& Tronov V.P. 1970).

\subsection{The effect of the water cut of the test oil on the depth of wax formation}

The study of Glushchenko V.N. (Glushchenko V.N. et al. 2009) presents a thorough analysis of the literature and field material focused on the effect of water-cut on the formation of organic solids. In many works, a decrease in the intensity of the wax formation with an increase in water-cut of wells production was demonstrated. This owes to a decrease in adhesion to the hydrophilic steel surface, a decrease in the rate of cooling due to the greater heat capacity of water compared to oil. In Figure 5, it can be seen that with an increase in water cut, the wellhead temperature increases due to a decrease in the rate of cooling of the flow.

Additionally, in the work (Glushchenko V.N. et al. 2009), a number of researchers were highlighted, whose studies showed the negative effect of water cut. This is explained by the general decrease in the temperature of the watering fields, a significant gas absorption by water with a decrease in the wax solubility in oil, and an increase in the WAT by several degrees.

The simulation results showed that with an increase in the water cut of well production, there is a decrease in the depth of wax formation in the tubing string (Figure 6).

Thus, reducing the interval of wax formation in the well for the given conditions is caused by a decrease in the portion of high-molecular hydrocarbons in the well production during the field development, hydrophilization of the internal surface of the tubing string, as well as a decrease in the rate of flow cooling.

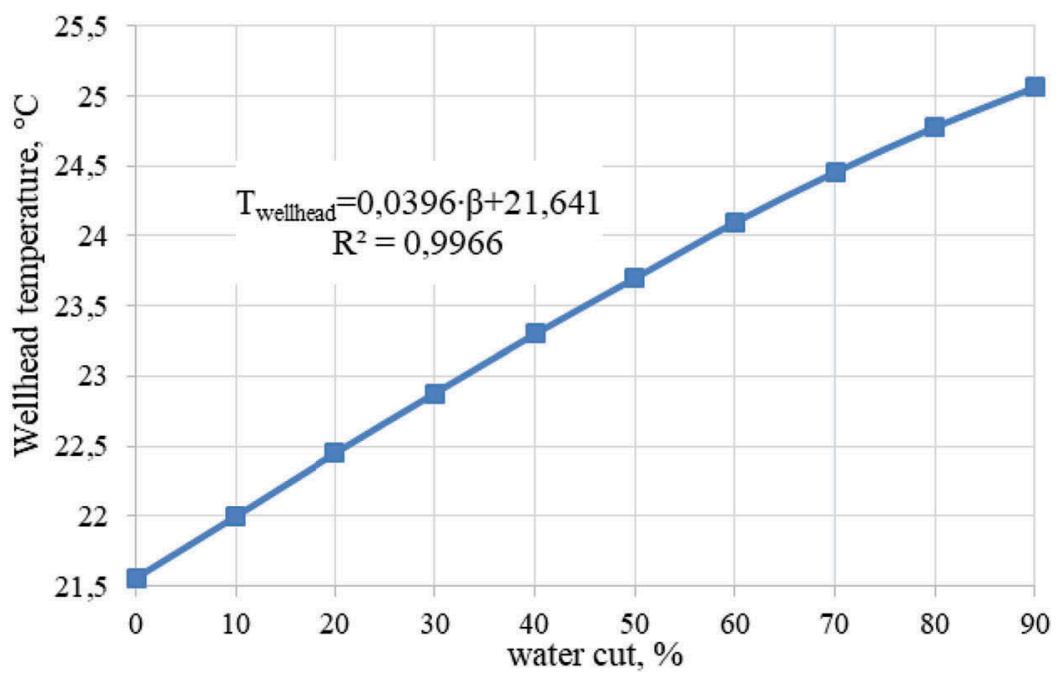

Figure 5. The dependence of wellhead temperature on water cut. 


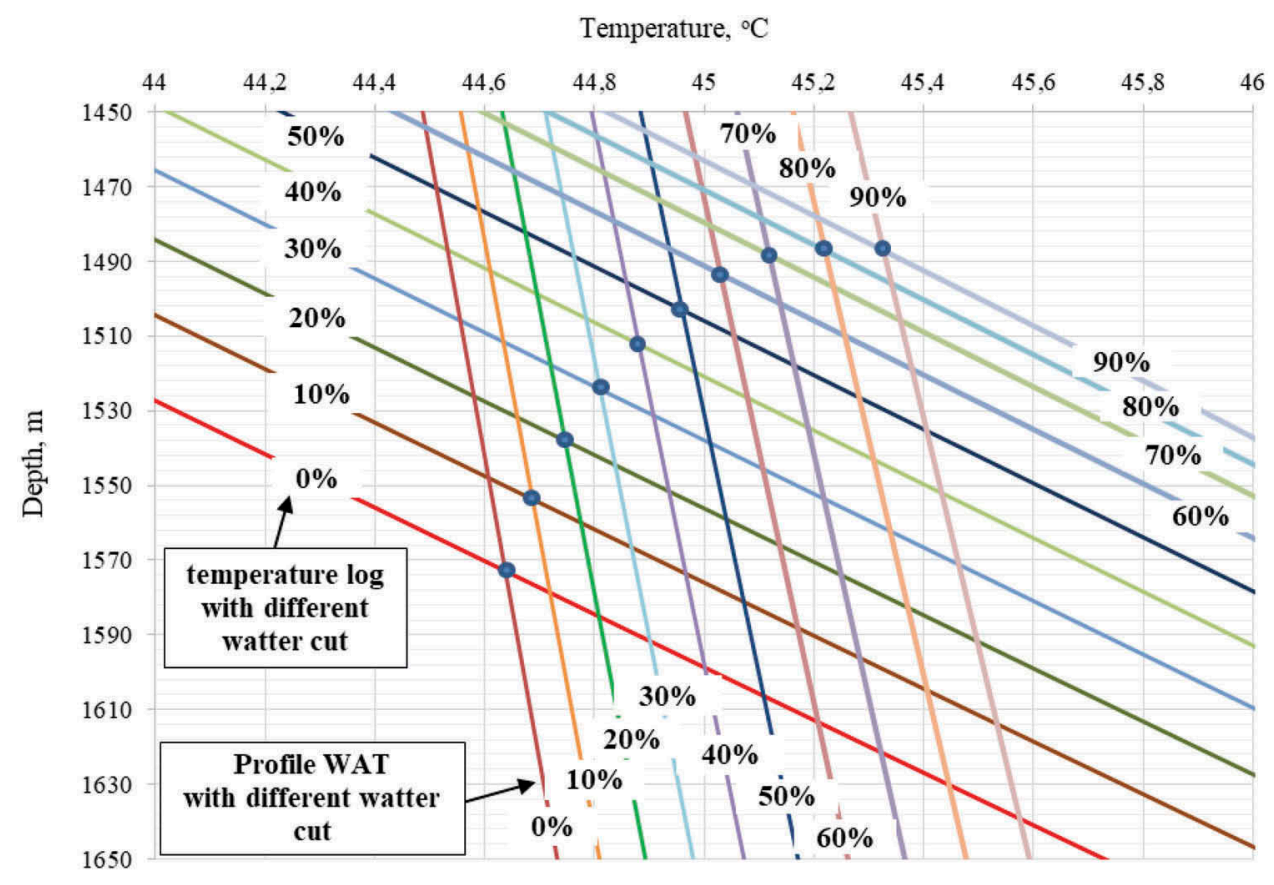

Figure 6. Dependence of the wax formation depth in the well with an increase in water cut.

\subsection{The influence of the buffer pressure on the depth of wax formation}

A considerable amount of field data demonstrates a reverse dependence of the residual gas saturation value of oil to the depth of wax formation in the wellbore (Glushchenko V.N. et al. 2009). For instance, in the Zhanazhol field, an increase in wellhead pressure prevented a sharp degassing, which led to a sharp decrease in the wax formation. Another example is the production of high-wax oil in the Tengutinskaya area in Kazakhstan. At the beginning of field operation with a high gas factor, there were no complications with the formation of wax deposits. During the development of the reservoir, the reservoir, buffer pressures, and the gas factor decrease, which led to intensive waxing of underground and surface equipment.

Hence, one of the effective methods to handle wax formation is to prevent the negative impact of the released gas by using the choke restriction method to increase the buffer pressure (Glushchenko V.N. et al. 2009). The positive effect is to reduce the time finding wells with a simultaneous increase in their flow rates.

The obtained simulation results confirmed that an increase in backpressure at the wellhead leads to a shift in the depth of the start of degassing up along the wellbore (Figure 7). From this point of view, an increase in the buffer pressure at the wellhead can serve as one of the methods for preventing wax formation in the tubing on the condition that the wax formation interval is located above the point of initial degassing.

For the given conditions, when the formation of organic deposits in the wellbore occurs before the start of oil degassing, a negative result is observed, at which point an increase in buffer pressure leads to an increase in the WAT and, therefore, an earlier onset in the formation of organic deposits in the wellbore (Figure 8). Thus, the area of effective application of the choke restriction method as a way to cope with the formation of ARPD has been identified.

In the above example, a sensitivity assessment tool was used for the boundary conditions of the model. It is necessary to consider that when changing one parameter in the model, all the others remain unchanged. 


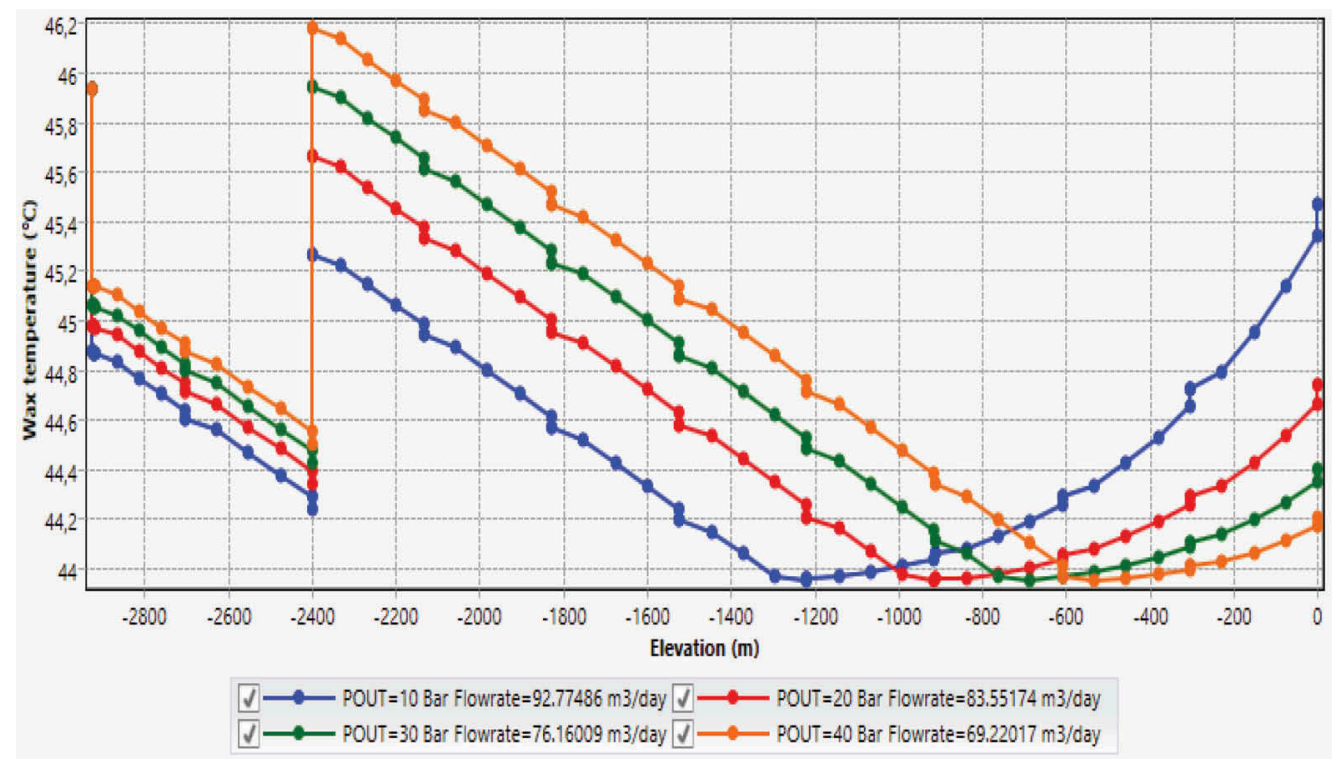

Figure 7. Change in the WAT when creating different buffer pressure.

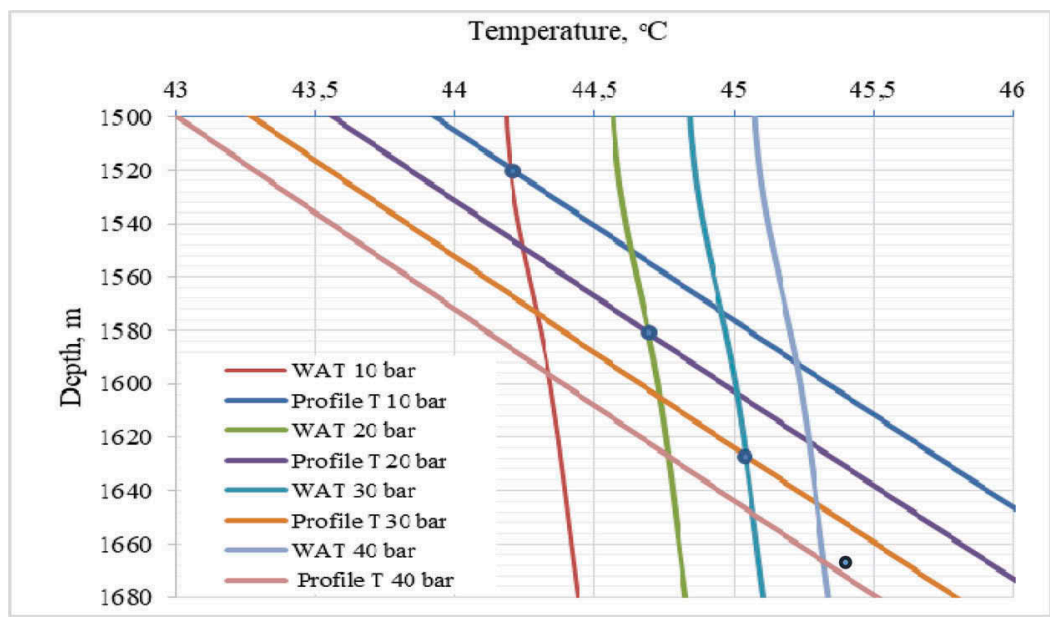

Figure 8. The influence of buffer pressure on the depth of wax formation.

\subsection{The effect of the rotational frequency of the ESP on the depth of wax formation}

One of the most important parameters that affect the intensity of the wax formation of the downhole equipment is the flow rate. Acceleration of the oil flow leads to a decrease in fluctuation of temperature along the wellbore, a change in the structure and dispersion of the gasliquid flow as well as a decrease in the rate of solid deposits accumulation. In general, a positive effect of the parameter under consideration is perceived when it changes to a certain critical value, corresponding the transition from a laminar to a turbulent flow regime (Glushchenko V.N. et al. 2009, Ibragimov N.G. et al. 2010 \& Coutinho J. et al. 2001).

Figure 9 Shows the change in the depth of wax formation in the well depending on the rotation frequency of the ESP. Furthermore, the flow rate can be influenced by change in the 


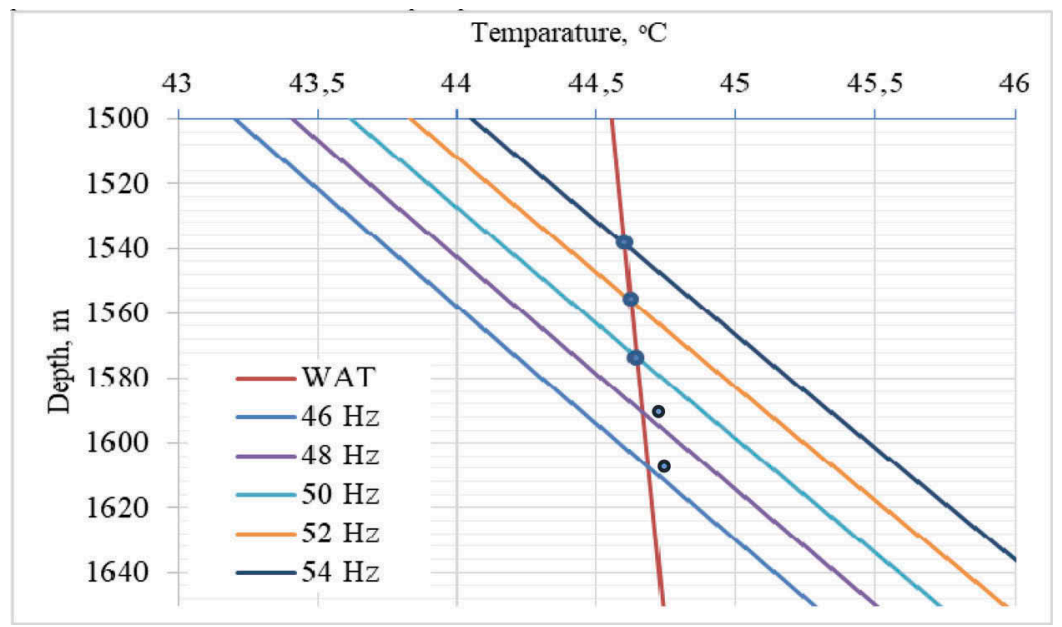

Figure 9. Effect of ESP rotation frequency on the depth of wax formation in the well.

number of stages in the pump and the diameter of the tubing, which also leads to change in the pressure-flow characteristics of the pump.

\section{CONCLUSIONS}

1. By modeling the movement of high-wax oil in wellbores, we are be able to study the influence of various factors affecting the depth of the formation of organic deposits.

2. High convergence of the actual temperature log with the calculated temperature profiles with regard to the methods of Lyapkov P.D. and Mishchenko I.T. was obtained. This allows us to rely on the accuracy of these methods on the condition that the results of field studies of the temperature distribution in the wellbore are not available. Nevertheless, for the given conditions, the closest to actual value of the depth of organic deposit formation was obtained through the complex mechanistic model of the vertical multiphase flow OLGAS.

3. The nature of the change in WAT along the wellbore was determined. It is important to note that those changes were highly noticeable when creating a depression on the reservoir and increasing the pressure in the ESP. During degassing, the WAT increases due to a decrease in the content of light fractions.

4. Temperature is considered as one of the key factors affecting wax formation in wells. It is recommended to use a nominal size ESP with higher productivity than that, which is required to achieve the planned flow rate, which will provide additional heating to the production of the well.

5. The influence of ESP rotation frequency on the depth of wax formation was established. On top of the increase in frequency, it is possible to influence the growth of the flow rate by reducing the internal diameter of the tubing and adding the number of stages, which also leads to a change in the pressure-flow characteristics of the pump.

6. The dependence of the depth of wax formation along the wellbore on the water content of the high-wax oil was established. The decrease in the interval of wax formation in the well is the result of the reduction in the proportion of high-molecular hydrocarbons in the well production during the development of the field, the hydrophilization of the internal surface of the tubing string, and the decrease in the rate of flow cooling.

7. Identified the area of effective application of the choke restriction method (an increase in buffer pressure) as a way to handle wax formation. A positive effect is observed when the formation of deposits in the well occurs after the start of degassing. Contrarily, a negative 
result is observed, when an increase in the buffer pressure leads to an increase in the WAT and consequently, an earlier onset in the formation of organic deposits in the wellbore.

\section{ACKNOWLEDGMENTS}

We acknowledge Evgeny A. Kibirev, head of oil production technology, technology and methods of the oil production department (Gazpromneft-NTC LLC, Saint Petersburg, Russian Federation), for his assistance during the experiments. We acknowledge Dr. M.K. Rogachev for his assistance during the experiments. Finally, we would like to thank Saint-Petersburg mining university (Saint-Petersburg, Russian Federation) for providing laboratory equipment, support and samples for this research.

\section{REFERENCES}

Bern, P.A., Withers, V.R., \& Cairns, R.J. 1980. Wax deposition in crude oil pipelines. In European offshore technology conference and exhibition. Society of Petroleum Engineers.

Berne-Allen, Jr.A., \& Work, L.T. 1938. Solubility of refined paraffin waxes in petroleum fractions. Industrial \& Engineering Chemistry, 30(7): 806-812.

Brown, T.S., Niesen, V.G., and Erickson, D.D., 1993, "Measurement and Prediction of the Kinetics of Paraffin Deposition", $68^{\text {th }}$ Annual Conference of the Society of Petroleum Engineers, paper no. SPE 26548.

Creek, J.L., Lund, H.J., Brill, J.P., \& Volk, M. 1999. Wax deposition in single phase flow. Fluid Phase Equilibria, 158, 801-811.

Fadairo, A.S. A., Ameloko, A., Ako, C.T., \& Duyilemi, O. 2010. Modeling of wax deposition during oil production using a two-phase flash calculation. Petroleum \& Coal, 52(3): 193-202.

Glushchenko, V.N., Silin, V.N., \&\#x0026; Gerin, Yu.G. 2009. Prevention and elimination of asphaltene-resin-paraffin deposits. Oilfield chemistry: $480 \mathrm{p}$.

Guo, B., Song, S., Chacko, J. and Ghalambor, A. "Offshore Pipelines”, Elesvier Inc., Oxford, UK, 2005.

Guozhong, Z., \& Gang, L. 2010. Study on the wax deposition of waxy crude in pipelines and its application. Journal of Petroleum Science and Engineering, 70(1-2), 1-9.

Huang, Z, Zheng, S., \& Fogler, H.S. 2016. Wax Deposition: Experimental Characterizations, Theoretical Modeling, and Field Practices. CRC Press, Boca Raton.

Ibragimov, N.G., Tronov, V.P., \& Guskova, I.A. 2010. Theory and practice of methods for controlling organic deposits in the late stages of oil field development. - $240 \mathrm{p}$.

Jennings, D.W., \& Weispfennig, K. 2005. Experimental solubility data of various n-alkane waxes: effects of alkane chain length, alkane odd versus even carbon number structures, and solvent chemistry on solubility. Fluid phase equilibria, 227(1), 27-35.

Jung, S.Y., Lee, D.G., \& Lim, J.S. 2014. A simulation study of wax deposition in subsea oil production system. In The Twenty-fourth International Ocean and Polar Engineering Conference. International Society of Offshore and Polar Engineers.

Kamenshchikov, F.A. 2005. Thermal dewaxing wells. Izhevsk: 254 p.

Kasumu, A.S., Arumugam, S., \& Mehrotra, A. K. 2013. Effect of cooling rate on the wax precipitation temperature of "waxy" mixtures. Fuel, 103, 1144-1147.

Kohse, B.F., \& Nghiem, L.X. 2006. Asphaltene and waxes. Petroleum. Engineering Handbook. Society of Petroleum Engineering, Richardson Texas, USA.

Lake, L.W., Kohse, B.F., Fanchi, J.R., \& Nghiem, L.X. 2006. Petroleum Engineering Handbook: Volume I General Engineering. SPE, Texas, USA: 397-453.

Leontaritis, K.J., \& Geroulis, E. 2011. Wax Deposition Correlation-Application in Multiphase Wax Deposition Models. In Offshore Technology Conference. Offshore Technology Conference.

Lyapkov, P.D.1987. Selection of the installation of a submersible centrifugal pump to the well. M.: MING.

Mishchenko, I.T. 2003. Oil Well Production: A Textbook for High Schools. M.: FSUE Publishing House "Oil and Gas" Russian State University of Oil and Gas named after IM Gubkin. - 816 p.

Pan, H., Firoozabadi, A., \& Fotland, P. 1997. Pressure and composition effect on wax precipitation: experimental data and model results. SPE Production \& Facilities, 12(04), 250-258.

Pashali, A.A., Mikhailov, V.G., \& Petrov, P.V. 2011. Investigation of the effect of the concentration of gas bubbles on the value of the coefficient of natural separation//Bulletin of the Ufa State Aviation Technical University, T. 15. - No. 1 (41). 
Paso, K., Kallevik, H., \& Sjoblom, J. 2009. Measurement of wax appearance temperature using near-infrared (NIR) scattering. Energy \& Fuels, 23(10), 4988-4994.

Rogachev M.K., Strizhnev K.V. Fighting complications in oil production. Nedra, 2006, 296 p.

Schlumberger PIPESIM [Electronic resource]. - Access mode: http://www.sis.slb.ru/pipesim/(accessed date $04 / 15 / 18$ ).

Struchkov, I.A., \& Rogachev, M.K. 2018. The challenges of waxy oil production in a Russian oil field and laboratory investigations. Journal of Petroleum science and Engineering, 163, 91-99.

Tronov, V.P. 1970. Mechanism of the formation of resin-paraffin deposits and the fight against them/I M.: Nedra, T. 192. - p. 5. 


\title{
Separation of water-oil emulsions in device with enlarged throughflow capacity
}

\author{
O.S. Dmitrieva \\ Candidate of Technical Sciences, Associate Professor of the Department of Processes and Devices of \\ Chemical Technology, Kazan National Research Technological University, Kazan, Russia
}

\author{
I.I. Sharipov \\ Candidate of Technical Sciences, Associate Professor of the Department of Theoretical Foundations of \\ Heat Engineering, Kazan State Power Engineering University, Kazan, Russia
}

\author{
V.E. Zinurov \\ Master's Student of the Department of Theoretical Foundations of Heat Engineerin, Kazan State Power \\ Engineering University, Kazan, Russia
}

\begin{abstract}
The growth of production capacities of industrial enterprises leads to an increase in emission concentration of pollutants and requires the use of separators. This scientific paper includes the research of separation of emulsions with similar densities. The emulsions with similar properties are separated very slowly, so it is necessary to use special inserts to accelerate the separation process. The authors have chosen inserts with corrugated baffles, located at an angle of $45^{\circ}$, inserts with corrugated baffles, located at an angle of $135^{\circ}$, as well as inserts with cross-corrugated baffles. As a result of experimental research, it was found that with an increase in the emulsion rate inside of apparatus, the separation efficiency decreases, upon the condition that all the studied inserts are installed. When the concentration of hydrocarbons in the original mixture is less than $25 \%$, it is most appropriate to use inserts with corrugated baffles, located at an angle of $45^{\circ}$.
\end{abstract}

\section{INTRODUCTION}

In recent years, the separation of oil and water was considered as one of the main problems all around the world due to an increased production of industrial oil-containing wastewaters. Nowadays, the separation of oil and water is still considered as a critical technical problem due to a complex composition and a high content of oily hydrocarbons in wastewaters. The traditional separation methods have low efficiency, high cost, and other types of pollution take place when these methods are implemented (Jiang et al., 2019, Li et al., 2020, Patterson, 1985).

The separators are usually the first stage between the oil source (for ex. oil field well) and oil process pipeline. When being transported inside the pipeline, the crude oil, byproduced water and gas move in a complex multiphase mode, and a finely dispersed emulsion usually creates a number of difficulties. The gas phase can be quite easily separated from the liquid flow; emulsions are usually stable and more difficult to be separated. As a rule, emulsions of "water in oil" type are very common for the oil production (Chen et al., 2009, Harpura et al., 1997, Sadeghi et al., 2013, Wang et al., 2012, Wang et al., 2016). They are mainly formed due to availability of amphiphilic hydrocarbons in the crude oil, such as asphaltenes, resins, and acids. Moreover, some chemical additives or solid particles, used inside of production piping network, contribute to the formation of stable emulsion. The stability of oil emulsified systems is highly dependent on the crude 
oil composition. Due to a wide range of compounds in the crude oil, the mathematical modeling of separation processes often gives significant errors, that's why some problems can be solved only by conducting experimental studies. When producing the crude oil, the emulsions are mostly separated by gravity in vertical or horizontal apparatuses. Since the difference in the density of emulsion components is small, the apparatuses are usually designed with very large dimensions (Berman \& Tamir, 2003, Cambiella et al., 2006, Sadeghi et al., 2011, Yang, 2007). Thus, the development, study and application of new apparatuses for the separation of stable emulsions are critical tasks.

In most cases, the choice of a particular type of design is based on a technical and economic analysis and takes into account local conditions, for example, the vertical settling tanks are used at low ground water level. Also, the choice of design is significantly affected by throughput capacity. The vertical, horizontal and radial settling tanks are used at the following throughput capacity of sewage treatment plants: not more than $10000,15000-20000$ and from $20000 \mathrm{~m}^{3} /$ day, respectively. As of today, one of the most promising ways to increase the efficiency of water-oil emulsion separation at the oil fields is to study different methods of improving the settling tanks. One of these methods is to study various inserts, to be installed inside the settling tanks, which have the form of webs, shields and other geometric bodies that increase the rate of water-oil emulsion stratification into components by changing the flow structure when moving along the obstacles. It should be noted that currently the flow rate of water-oil emulsions inside the settling tanks does not exceed a few millimeters per second, since at higher rates, the separation efficiency decreases significantly due to the phase mixing. Increasing the efficiency and separation rate of water-oil emulsions will reduce the costs for obtaining the finished petroleum products. Thus, the research and the use of new devices for the separation of stable emulsions is a relevant task. The purpose of this research paper is to study the increase in efficiency and separation rate of oil-water emulsions inside of continuously operating settling tanks.

\section{RESEARCH PROBLEM}

The purpose of this paper is to study the extraction of liquid oily hydrocarbon compounds from the emulsion. Two methods are usually used to separate the water-oil emulsions: reagent, using a demulsifies, and reagent-free.

The chemical method includes adding of various chemical reagents into the water to react with it. As a result of chemical reaction, the water is settled out as insoluble residues. This method helps to purify the emulsion by $95 \%$. With a further increase in purification degree due to the use of chemical reagents, the water is contaminated with these chemical reagents. That is disadvantage of this method. The root of reagent-free method is to remove oil and oil products from the water by water settling out with the subsequent collection of oil by special devices: settling tanks, hydrocyclones, oil traps, etc. The main disadvantage of these apparatuses is a low degree of separation of water-oil emulsions (Diederen et al., 1998, Kou et al., 2019, Vanhoutte et al., 2011, Young et al., 1994, Zeng et al., 2016, Zhou et al., 2010,). In some cases, it is advisable to use the membranes for separation of water-oil emulsions (Babiker et al., 2019). However, if oil emulsions contain the components that can form a precipitate on the surfaces, then the membranes are very difficult to be used.

In order to improve the efficiency and to speed up the separation of water-oil emulsions, the authors developed several models of inserts, designed for continuously operating devices (settling tanks, separators), which are to be installed inside of these apparatuses. The research tasks also included the evaluation of possibility of developed inserts by experimental method to increase the efficiency of water-oil emulsion separation, to speed up its stratification, to determine the most effective rate ranges for each insert model, as well as to analyze the process of emulsion separation when it directly contacts with a certain model of insert. 


\section{RESEARCH METHODS}

The experimental apparatus (Figure 1) consisted of separator (Dmitriev et al., 2019) with a cross-section of $60 \times 60 \mathrm{~mm}$ with experimental inserts (Figure 2), valves for adjusting the flow rates of light and heavy phases, samplers for determining the concentration of hydrocarbon compounds after separation of emulsion, flowmeters LOUCHEN ZM FS300A G3/4" with an error of $\pm 5 \%$ to calculate the rate of separated flows, tanks with a stirrer for remixing the separated emulsion and pump OASIS CRP 15/9 for feeding the emulsion into the separator.

In the course of experimental research, the following parameters were assumed to be constant: ambient temperature $t_{0}=20^{\circ} \mathrm{C}$; water density $\rho_{b}=998.2 \mathrm{~kg} / \mathrm{m}^{3}$; coefficient of water dynamic viscosity $\mu_{b}=0.001003 \mathrm{~kg} /(\mathrm{m} \cdot \mathrm{s})$; density of oily hydrocarbon compounds $\rho=883 \mathrm{~kg} /$ $\mathrm{m}^{3}$; coefficient of dynamic viscosity of hydrocarbon compounds $\mu_{c}=0.0198 \mathrm{~kg} /(\mathrm{m} \cdot \mathrm{s})$. The concentration of oily hydrocarbons at the inlet of apparatus varied from $15 \%$ to $25 \%$.

Various inserts were studied (Figure 2): $a$-insert with corrugated baffles, located at an angle of $45^{\circ} ; b$ - insert with corrugated baffles, located at an angle of $135^{\circ} ; c$-insert with cross corrugated baffles. The depth of corrugations was equal to $10 \mathrm{~mm}$. Along the entire length of plate, the holes were executed with a diameter of $1 \mathrm{~mm}$ and a uniform two-way pace of $3.5 \mathrm{~mm}$. The holes were executed in such a way so that the sharp edges formed around them.

In the course of experimental research, the prepared emulsion was mixed in a tank by means of stirrer and the separated emulsion was fed into the apparatus by means of pump. When the tank was filled, the valves were opened to adjust the required flow rates of emulsion components, which were measured by flowmeters and after that, the emulsion, separated into

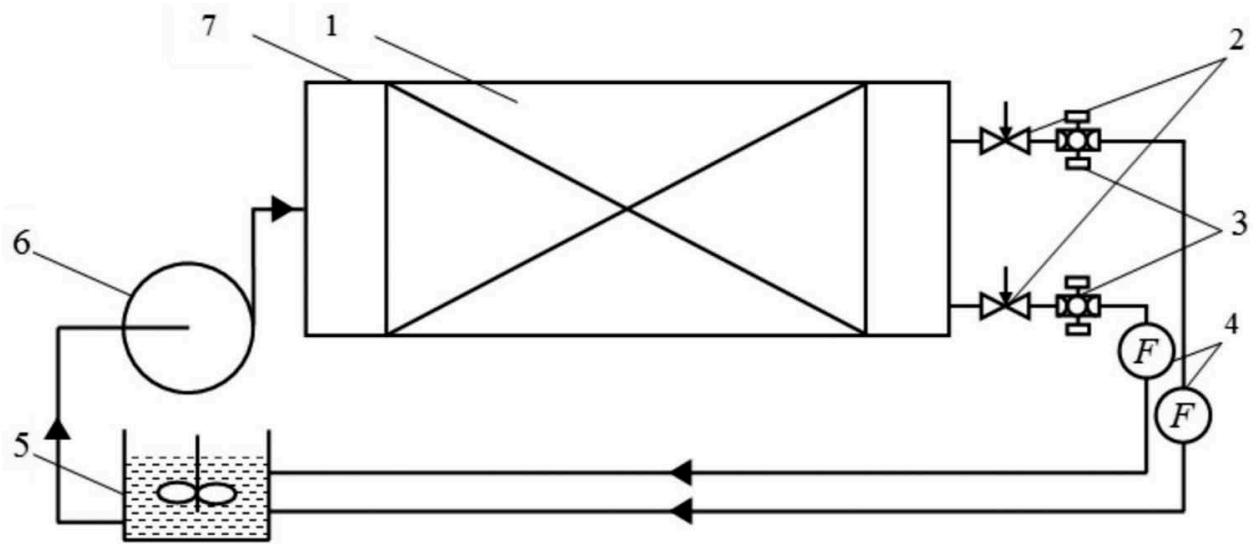

Figure 1. Experimental apparatus: 1 - experimental insert; 2 - control valves; 3 - samplers; 4 - flowmeters LOUCHEN ZM FS300A G3/4; 5 - tank for re-mixing of separated emulsion; 6 - pump OASIS CRP 15/9; 7 - experimental unit.
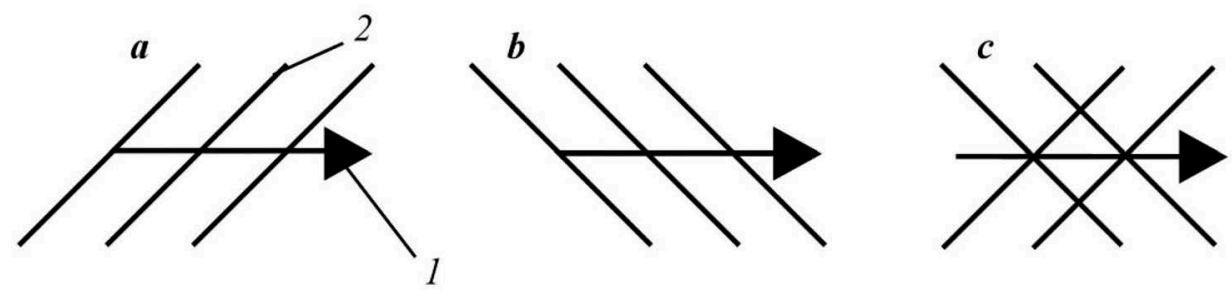

Figure 2. Models of experimental inserts: $a$ - insert with corrugated baffles, located at an angle of $45^{\circ} ; b$-insert with corrugated baffles, located at an angle of $135^{\circ} ; c$-insert with cross corrugated baffles; 1 - direction of liquid flow movement inside of apparatus; 2 - corrugations. 
light and heavy phases, was again fed into the tank. The concentration of hydrocarbon compounds at the outlet of apparatus was determined by the weight method. For this purpose, the sampling was carried out (at least 3 times, every 30 minutes) by samplers, on the scales R-25 with an error of \pm 0.05 .

\section{RESULTS}

The results of experimental research are shown graphically in Figures 3-5. With an increase in the emulsion flow rate, entering the experimental apparatus, the efficiency of extracting the liquid oily hydrocarbon compounds from the emulsion decreases. This is due to the fact that an increase in the input rate leads to an increase in the flow turbulence, resulting in a large number of vortex points that prevent the separation of oily hydrocarbon compounds from the emulsion. In order to intensify the processes of extraction of hydrocarbon compounds from the emulsion, it is necessary to use various inserts that are located inside of apparatus, contributing to the stratification of multiphase emulsion, i.e. arrangement of flow structure, contributing to the separation of compounds with different than the water has density.

In the course of research, it was found that the greatest efficiency of separator is achieved when using inserts with corrugated baffles, located at an angle of $45^{\circ}$. Such design increases the efficiency of stratification of oily compounds from the emulsion due to the orientation of corrugated surfaces, which shift the flow direction of lighter oily components against the water i.e. these components move upwards inside of apparatus, thereby intensifying the stratification process.

It should be noted that when the corrugated baffles are located at an angle of $135^{\circ}$, the emulsion separation efficiency is lower than when the baffles are located at an angle of $45^{\circ}$, because the orientation angle of baffles is almost coincident with the emulsion flow direction, that does not allow additionally affect the emulsion separation into different fractions. In the case of cross-corrugated baffles, an unordered emulsion flow is observed, resulting in two simultaneous processes throughout the whole insert, i.e. separation and mixing of mixture that leads to the lower efficiency.

The apparatuses without inserts provide the lowest efficiency of emulsion separation. This is caused by lack of elements inside of apparatus for intensification of separation of oily hydrocarbon compounds from the emulsion. The efficiency of extraction of liquid oily

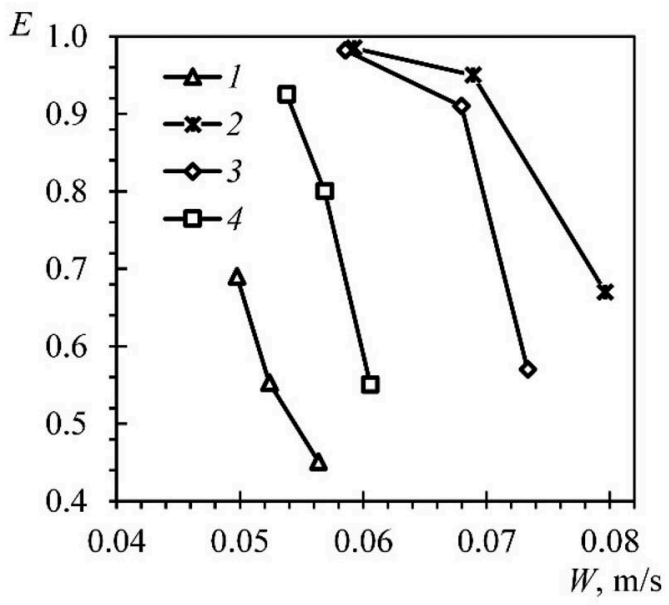

Figure 3. Dependency of liquid oily hydrocarbon compounds extraction efficiency from an emulsion, having $15 \%$ concentration of hydrocarbons in the original mixture, on the input rate with various experimental inserts: 1 - without inserts; 2 - inserts with corrugated baffles, located at an angle of $45^{\circ} ; 3$-inserts with corrugated baffles, located at an angle of $135^{\circ} ; 4$ - inserts with cross corrugated baffles. 


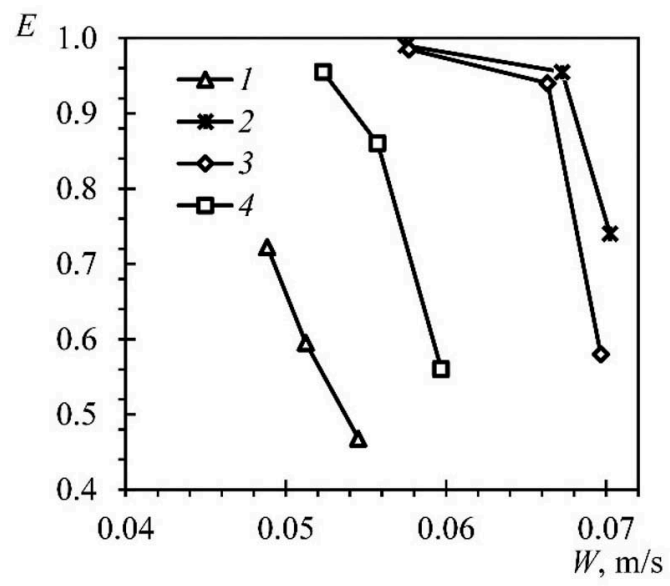

Figure 4. Dependency of liquid oily hydrocarbon compounds extraction efficiency from an emulsion, having $20 \%$ concentration of hydrocarbons in the original mixture, on the input rate with various experimental inserts: 1 - without inserts; 2 - inserts with corrugated baffles, located at an angle of $45^{\circ} ; 3$ inserts with corrugated baffles, located at an angle of $135^{\circ} ; 4$ - inserts with cross corrugated baffles.

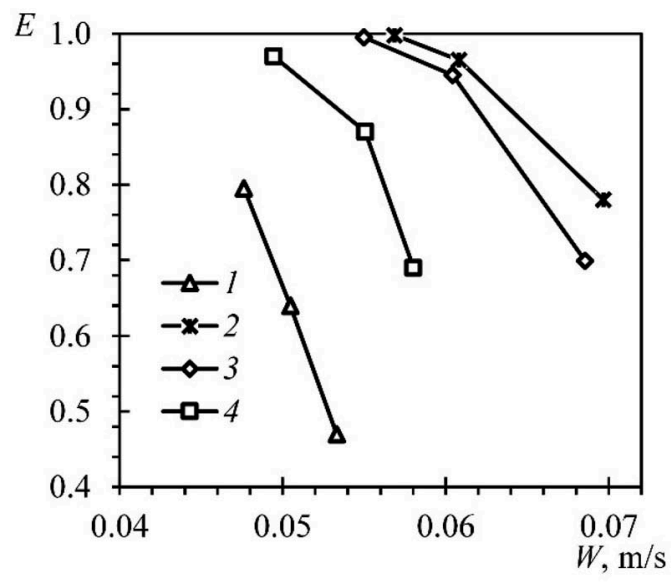

Figure 5. Dependency of liquid oily hydrocarbon compounds extraction efficiency from an emulsion, having $25 \%$ concentration of hydrocarbons in the original mixture, on the input rate with various experimental inserts: 1 - without inserts; 2 - inserts with corrugated baffles, located at an angle of $45^{\circ} ; 3$-inserts with corrugated baffles, located at an angle of $135^{\circ} ; 4$-inserts with cross corrugated baffles.

hydrocarbon compounds from the emulsion, with the concentration of them in original mixture of not more than $25 \%$, on average is equal to $89.2,84.5,79.8$ and $59.8 \%$ - when using the inserts with corrugated baffles, located at an angle of $45^{\circ}$, at an angle of $135^{\circ}$, inserts with cross corrugated baffles and without inserts, respectively, at the input rate within the range of $0.047-0.08 \mathrm{~m} / \mathrm{s}$.

\section{DISCUSSION}

When extracting the liquid oily compounds from the emulsion, with $15 \%$ concentration of them in the original mixture, the efficiency of apparatus on average was equal to $56.4,86.8$, 
82.1 and $75.8 \%$ - when using the apparatus without inserts, with inserts with corrugated baffles, located at an angle of $45^{\circ}$, at an angle of $135^{\circ}$, and inserts with cross corrugated baffles, respectively. With an increase in the emulsion flow rate inside of apparatus, the separation efficiency decreased: when using the apparatus without inserts, an increase in the flow rate by $10 \%$ resulted in a decrease in efficiency by $52 \%$; when using inserts with corrugated baffles, located at an angle of $45^{\circ}$, an increase in the flow rate by $25 \%$ decreased the separation efficiency by $32 \%$; when using inserts with corrugated baffles, located at an angle of $135^{\circ}$, an increase in the flow rate by $20 \%$ decreased the separation efficiency by $42 \%$, when using inserts with cross corrugated baffles, an increase in the flow rate by $11 \%$ decreased the separation efficiency by $41 \%$. The highest efficiency of emulsion separation was equal to $69.1,98.5,98.2$ and $92.5 \%$ - when using an apparatus without inserts, with inserts with corrugated baffles, located at an angle of $45^{\circ}$, at an angle of $135^{\circ}$, and inserts with cross corrugated baffles, respectively (Figure 3).

When extracting the liquid oily compounds from the emulsion, with $20 \%$ concentration of them in the original mixture, the efficiency of apparatus on average was equal to 59.5, 89.5, 83.5 and $79.2 \%$ - when using the apparatus without inserts, with inserts with corrugated baffles, located at an angle of $45^{\circ}$, at an angle of $135^{\circ}$, and inserts with cross corrugated baffles, respectively. An increase in the emulsion flow rate inside of apparatus on average by $0.006 \mathrm{~m} / \mathrm{s}$ resulted in a decrease in the emulsion separation efficiency on average by $33.8 \%$. An increase of liquid oily hydrocarbon compounds concentration in the emulsion from 15 to $20 \%$ led to an increase in the separation efficiency on average by $2.7 \%$ (Figure 4 ).

When extracting the liquid oily compounds from the emulsion, with $25 \%$ concentration of them in the original mixture, the efficiency of apparatus on average was equal to 63.5, 91.4, 87.9 and $84.3 \%$ - when using the apparatus without inserts, with inserts with corrugated baffles, located at an angle of $45^{\circ}$, at an angle of $135^{\circ}$, and inserts with cross corrugated baffles, respectively. An increase in the emulsion flow rate inside of apparatus on average by $0.008 \mathrm{~m} / \mathrm{s} \mathrm{resulted}$ in a decrease in the emulsion separation efficiency on average by $31.8 \%$. The highest efficiency of emulsion separation was equal to 79.5, 99.8, 99.5 and 91.7\% - when using the apparatus without inserts, with inserts with corrugated baffles, located at an angle of $45^{\circ}$, at an angle of $135^{\circ}$, and inserts with cross corrugated baffles, respectively. An increase of liquid oily hydrocarbon compounds concentration in the emulsion from 20 to $25 \%$ led to an increase in the separation efficiency on average by $4.9 \%$ (Figure 5).

\section{CONCLUSIONS}

The conducted research shows that in order to intensify the processes of extracting the liquid oily compounds from emulsions, various inserts, increasing the efficiency of apparatus at least by $17 \%$ in comparison with the apparatus without any inserts, shall be used. In the course of research, it was found that the most effective are the inserts with corrugated baffles, located at an angle of $45^{\circ}$, providing the most qualitative process of emulsions separation as a result of inhibition of liquid oily components by the surfaces of corrugations, moving upwards inside of apparatus due to a lower density than the water has. An obligatory requirement for achieving the highest possible efficiency of emulsion separation is to provide the relatively low flow rates. The highest efficiency of emulsions separation with a concentration of liquid oily hydrocarbon compounds in it within the range of $15-25 \%$ was on average equal to $73.1,98.7,99.1$ and $94.3 \%$ - when using an apparatus without inserts, with inserts with corrugated baffles, located at an angle of $45^{\circ}$, at an angle of $135^{\circ}$, and inserts with cross corrugated baffles, respectively at minimum flow rates, which correspond to the following values: for an apparatus without inserts $-0.047 \mathrm{~m} / \mathrm{s}$, inserts with corrugated baffles, located at an angle of $45^{\circ}-$ $0.057 \mathrm{~m} / \mathrm{s}$, inserts with corrugated baffles, located at an angle of $135^{\circ}-0.055 \mathrm{~m} / \mathrm{s}$, inserts with cross corrugated baffles $-0.049 \mathrm{~m} / \mathrm{s}$. The advantages of apparatus are high efficiency of liquid oily hydrocarbon compounds separation from emulsions, design simplicity, minimum capital and operating costs. 


\section{ACKNOWLEDGMENTS}

The reported study was funded by grant of the President of the Russian Federation, project number MK-616.2020.8.

\section{REFERENCES}

Babiker, D.M.D., Zhu, L., Yagoub, H., Xu, X., Zhang, X., Shibraen, M.H.M.A. \& Yang, S. 2019. Hydrogen-bonded methylcellulose/poly(acrylic acid) complex membrane for oil-water separation. Surf. Coat. Technol. 367: 49-57.

Berman, Y. \& Tamir, A. 2003. Kinetics of droplets' sedimentation in a continuous gravity settler. Chem. Eng. Sci., 58: 2089-2102.

Cambiella, A., Benito, J.M., Pazos, C. \& Coca, J. 2006. Centrifugal separation efficiency in the treatment of waste emulsified oils. Chem. Eng. Res. Des. 84: 69-76.

Chen, W., Peng, J., Su, Y., Zheng, L., Wang, L. \& Jiang, Z. 2009. Separation of oil/water emulsion using Pluronic F127 modified polyethersulfone ultrafiltration membranes. Sep. Purif. Technol. 66(3): 591-597.

Diederen, A.M., Zee, G.van, Veenman, A.W. \& Graauw, J.de. 1998. A novel apparatus for countercurrent sorption separation processes using fibrous sorbents. Chem. Eng. Process.: Process Intensification 37(3): 217-221.

Dmitriev, A.V., Zinurov, V.E., Vinh, D. \& Dmitrieva, O.S. 2019. Removal of moisture from contaminated transformer oil in rectangular separators. E3S Web Conf. 110: 01026.

Harpura, I.G., Wayth, N.J., Bailey, A.G., Thew, M.T., Williams T.J. \& Urdahl O. 1997. Destabilisation of water-in-oil emulsions under the influence of an A.C. electric field: Experimental assessment of performance. J. Electrost. 40-41: 135-140.

Jiang, W., Chen, Y., Chen, M., Liu, X., Liu, Y., Wang, T. \& Yang J. 2019. Removal of emulsified oil from polymer-flooding sewage by an integrated apparatus including EC and separation process. Sep. Purif. Technol. 211: 259-268.

Kou, J., Chen, Y. \& Wu, J. 2019. Numerical study and optimization of liquid-liquid flow in cyclone pipe. Chem. Eng. Process.: Process Intensification 107725.

Li, X., Shan, H., Zhang, W. \& Li, B. 2020. 3D printed robust superhydrophilic and underwater superoleophobic composite membrane for high efficient oil/water separation. Sep. Purif. Technol. 237: 116324.

Patterson, J.W. 1985. Industrial wastewater treatment technology. 2nd ed., Butterworths, Stoneham: MA.

Sadeghi, I., Aroujalian, A., Raisi, A., Dabir, B. \& Fathizadeh, M. 2013. Surface modification of polyethersulfone ultrafiltration membranes by corona air plasma for separation of oil/water emulsions. J. Membr. Sci. 430: 24-36.

Sadeghi, R., Mohebbi, A., Sarrafi, A., Soltani, A., Salmanzadeh, M. \& Daneshpojooh, S. 2011. CFD simulation and optimization of the settler of an industrial copper solvent extraction plant: A case study. Hydrometallurgy 106: 148-158.

Vanhoutte, D.J.D., Eeltink, S., Kok, W.Th. \& Schoenmakers, P.J. 2011. Construction and initial evaluation of an apparatus for spatial comprehensive two-dimensional liquid-phase separations. Anal. Chim. Acta 701(1): 92-97.

Wang, S., Qin, W. \& Dai, Y. 2012. Separation of oil phase from dilute oil/water emulsion in confined space apparatus. Chin. J. Chem. Eng. 20(2): 239-245.

Wang, X., Yu, J., Sun, G. \& Ding, B. 2016. Electrospun nanofibrous materials: a versatile medium for effective oil/water separation. Mater. Today 19(7): 403-414.

Yang, C.L. 2007. Electrochemical coagulation for oily water demulsification. Sep. Purif. Technol. 54: 388-395.

Young, G.A.B, Wakley, W.D., Taggart, D.L., Andrews, S.L. \& Worrell J.R. 1994. Oil-water separation using hydrocyclones: An experimental search for optimum dimensions. J. Pet. Sci. Eng. 11 (1): $37-50$.

Zeng, Q., Wang, Z., Wang, X., Zhao, Y. \& Guo, X. 2016. A novel oil-water separator design and its performance prediction. J. Pet. Sci. Eng. 145: 83-94.

Zhou, N., Gao, Y, An, W. \& Yang, M. 2010. Investigation of velocity field and oil distribution in an oil-water hydrocyclone using a particle dynamics analyzer. Chem. Eng. J. 157(1): 73-79. 


\title{
Increasing the efficiency of pipeline transport of viscous oil based on rheological features
}

\author{
N.A. Zaripova \\ Postgraduate student, Saint Petersburg Mining University, St. Petersburg, Russia \\ A.K. Nikolaev \\ Professor, Saint Petersburg Mining University, St. Petersburg, Russia \\ Y.G. Matveeva \\ Engineer, Saint Petersburg Mining University, St. Petersburg, Russia
}

\begin{abstract}
This article discusses existing methods for increasing the efficiency of pipeline transport of viscous oils. In more detail, the authors considered a method for transporting viscous oil using various additives. It is known that the rheological properties of oil are the basic initial data for the selection of a rational method of transportation. In this regard, an analysis of rheological models of viscous fluids is presented. Also, this paper considers the calculation of the effectiveness of the use of additives and their influence on the rheological properties of viscous oil. Taking into account the parameters of the studied pipeline, an anti-turbulent additive was chosen. This additive reduces the coefficient of hydraulic resistance and increases the throughput of the pipeline. The results of experimental studies of the rheological properties of viscous oil are presented. Based on the results of the experiments, the authors obtained the dependence of the shear stress on the shear rate in the temperature range of $10-30{ }^{\circ} \mathrm{C}$ at different concentrations of the additive used and without it. Taking into account the obtained dependences, conclusions were drawn about the presence of non-Newtonian properties in the investigated oil. In addition, an analysis is made of the change in the rheological model when the concentration of the additive and the temperature of the transportation change. Based on the results of the studies, the authors performed the selection of the optimal pumping regime for the investigated oil.
\end{abstract}

\section{INTRODUCTION}

Currently, the issue of increasing the efficiency of pipeline transport of viscous and highviscosity oils is discussed in the works of many scientists.

The rheological properties of hard-to-recovery oil are the main initial data for the solution of design and operational tasks in field development and further pipeline transport. In this regard, the task of studying the rheological properties of high-viscosity oil is topical.

For the correct choice of technological regimes of various processes of extraction, transportation and processing of oil, it is necessary to know the rheological properties of the oil, as well as oil products and working fluids involved in these processes (Martinez-Palou, 2011).

For the efficient pumping of viscous oil, several basic methods are used (Hart, 2014):

- oil heating;

- using of hydrocarbon diluents;

- hydrotransport;

- construction of loopings and inserts;

- increasing of the number of pumping stations (PS) along the pipeline;

- Increasing of the station capacity;

- Using of additives. 


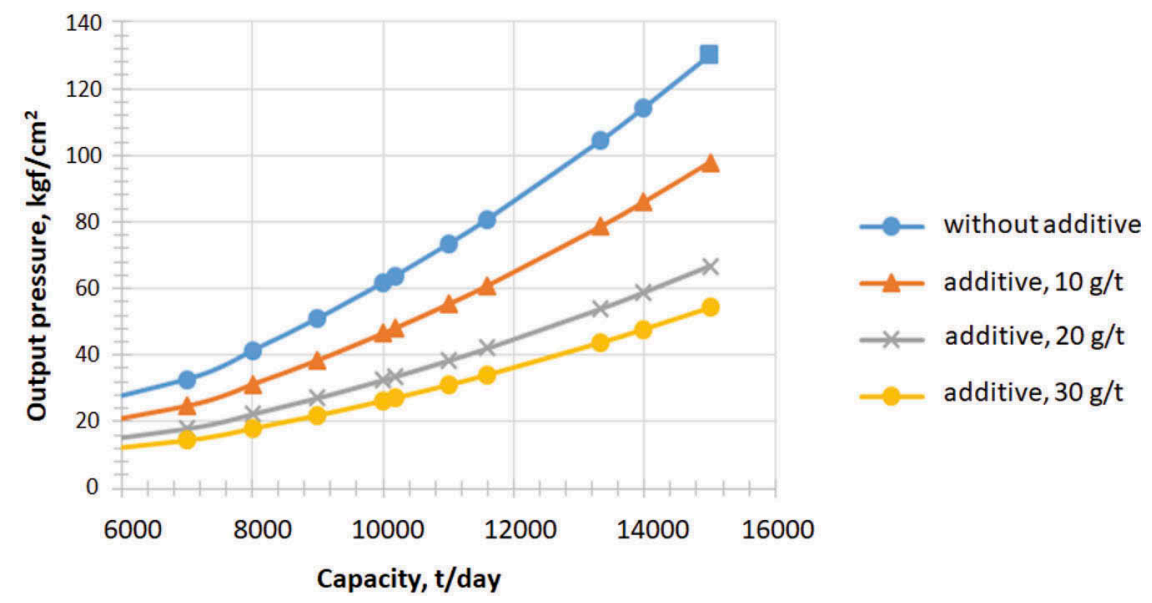

Figure 1. Head capacity curve of the pipeline, transporting oil with the anti-turbulent additive at various concentrations and without it.

The most common method for transporting viscous oil by pipelines is to pump preheated oil. This method consists in preheating oil before the enter to the main oil pipeline. Then oil heating stations are installed on the route at a certain distance, where the oil is heated (Nikolaev. 2016).

Previously, the authors conducted studies on the use of the M-FLOWTREAT grade C antiturbulent additive in sections of a pressure oil pipeline (Nikolaev et al. 2019).

According to the results of the study, the head-capacity curves of the pipeline pumping oil without additives and with an additive concentration of 10, 20 and $30 \mathrm{~g} / \mathrm{t}$ were obtained (Figure 1).

In this paper authors provided theoretical and experimental studies of methods for transporting high-viscosity oil. They also got necessary rheological dependencies and calculated effectiveness of using additive.

\section{METHODOLOGY}

The rheological properties of oil are the main source data for solving design and operational problems in the development of the field and further pipeline transport.

The initial data is a pipeline, the route of which runs under conditions of water-flooded and marshy area and eternal congelation along the territory of the Yamalo-Nenetskiy and Khanty-Mansiisk Autonomous District of the Tyumen Region. In addition to the Arctic climate, the construction area is characterized by unique geological and hydrological conditions. It is not rational to increase throughput only by heating, in order to avoid environmental impact (Nikolaev et al. 2018). In this regard, the authors have suggested the use of additives. An analysis of the using the various additives in domestic and foreign practice was made.

The additives used by the type of commodity form. We can divide additives into two groups: dispersion and gel (Muratova. 2014).

Additives of the first type are a suspension of the polymer in various liquids that do not enter into a chemical reaction with it. Alcohols, glycols and their esters are usually used as such liquids. The content of the active polymer in these additives reaches $25 \%$. Such antiturbulent additives include Necadd 447, Liquid Power, FLO XL, FLO MXA, M-FLOWTREAT, Alfacauchuk-S, Koltek PTN 3170, TurbulentMaster 8010.

Gel additives (CDR 102, FLO, Necadd 547, Viol, X-PAND, HIPR) are made in the form of a polymer solution in any hydrocarbon liquid (gasoline, kerosene, etc.). The active polymer in such additives contains about $10 \%$. 
The use of gel additives is especially beneficial for pipelines, where the processes of speed of their dissolution are important. These can be short pipelines of offshore fields, loading and shipping terminals.

Recently, work has been underway on the development and implementation of suspensionemulsion additives, designed for use in oil and gas production in field pipelines.

Due to the variety of physicochemical properties of the pumped oil and oil products through pipeline systems, in each case the use of chemical reagents is an individual feature of the pipeline.

Taking into account the parameters of the studied pipeline, an anti-turbulent additive was chosen, which reduces the coefficient of hydraulic resistance and increases the throughput of the pipeline (Avksentiev. 2017, Khudyakova et al. 2018).

The effectiveness (\%) of anti-turbulent additive in a stationary mode of operation of the pipeline (Nikolaev et al. 2018):

$$
D R=\left[1-\frac{\Delta P_{f}}{\Delta P_{0}} \cdot\left(\frac{Q_{0}}{Q_{f}}\right)^{2-m} \cdot\left(\frac{\nu_{0}}{v_{f}}\right)^{m}\right] \cdot 100 \%
$$

where $\mathrm{f}$ and 0 correspond to the flow of crude oil with and without additives; $\Delta \mathrm{P}=$ friction pressure loss, $\mathrm{kg} / \mathrm{cm}^{2} ; \mathrm{Q}=$ volume flow rate, $\mathrm{m}^{3} / \mathrm{h} ; \mathrm{v}=$ kinematic viscosity with average temperature, $\mathrm{m}^{2} / \mathrm{c} ; \mathrm{m}=$ criteria of flow mode. Turbulent in zone hydraulically smooth pipe $\mathrm{m}=0,25$, zone of mixed friction $\mathrm{m}=0,123$.

One of the main tasks of rheological research is to determine the correlation between the forces acting on the investigated fluid and the deformations caused by these forces.

Fluids called Newtonian are described by the following equation:

$$
\tau=\mu \cdot \dot{\gamma}
$$

where $\tau=$ the shear stress, $\mathrm{Pa} ; \mu=$ the coefficient of dynamic viscosity, $\mathrm{Pa}$ c; $\dot{\gamma}=$ the velocity gradient, $\mathrm{c}^{-1}$.

The hypothesis of linear correlations between shear stresses and the velocity gradient proposed by Newton is not valid for all liquids.

Liquids whose rheological behavior differs from the equation are called non-Newtonian. Non-Newtonian fluids are divided into three groups (Mirzajanzade. 1999, Rogachev. 2000):

1. nonlinearly viscous fluids (shear stress is a nonlinear function of shear rate);

2. liquids with unsteady rheological characteristics (the functional relationship between shear stress and shear rate depends on the time or process history);

3. viscoelastic fluids (exhibit elastic restoration of shape after stress relief).

The studied oil sample can be attributed to nonlinearly viscous liquids.

A general classification of rheological models of nonlinearly viscous fluids proposed by various researchers was given in (Mirzajanzade. 1999.).

\section{RESULTS AND DISCUSSION}

Experimental studies were carried out at the Center for Engineering Surveys (Mining University), on a Kinexus ultra + rotational rheometer. The principle of operation of the Kinexus ultra + rotational rheometer is to apply an adjustable shear strain to the test sample in order to measure the flow properties.

As a result of experimental studies, the main rheological dependencies were obtained. The obtained dependences show the presence of non-Newtonian properties in oil transported without additives (Figure 2) and in oil samples transported with an additive of $20 \mathrm{~g} / \mathrm{t}$ (Figure 3 ) in the temperature range $10-30{ }^{\circ} \mathrm{C}$. 


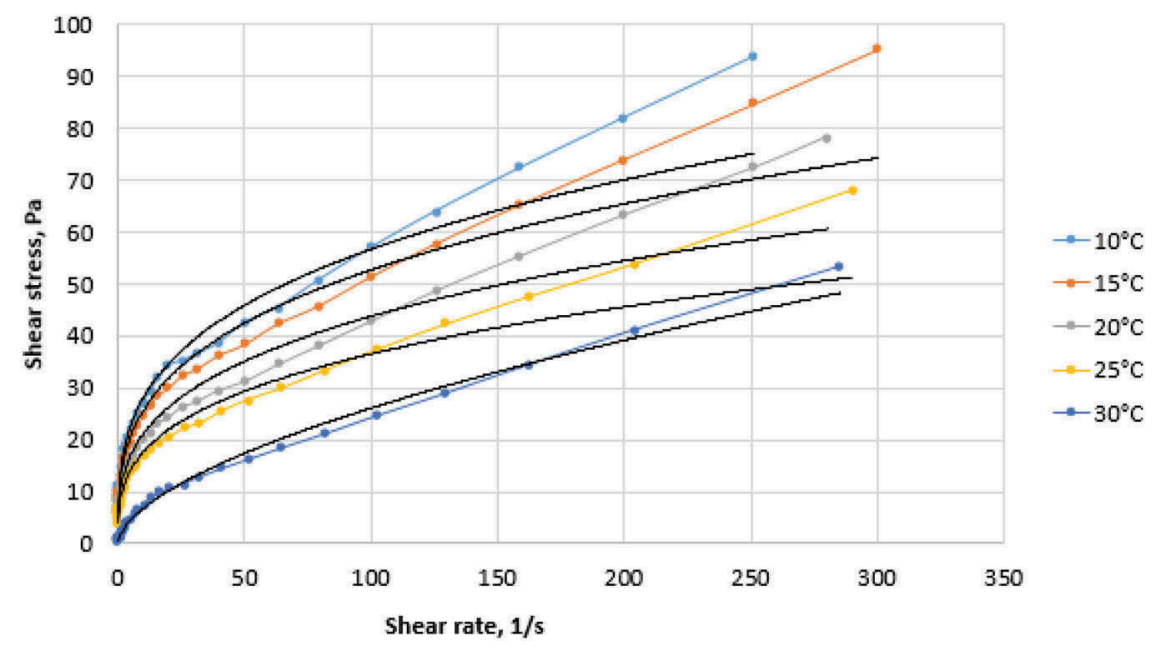

Figure 2. The dependence of shear stress on shear rate without additive.

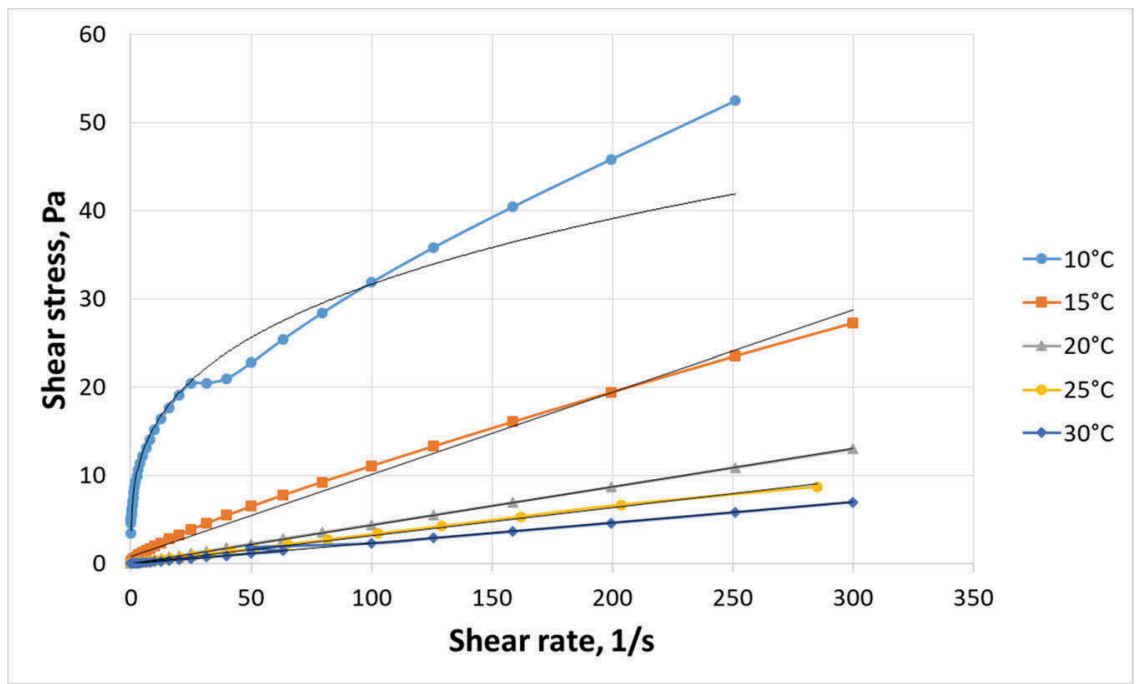

Figure 3. The dependence of shear stress on shear rate with an additive concentration of $20 \mathrm{~g} / \mathrm{t}$.

During data processing the authors obtained the following dependences for a sample of oil transported without the use of an anti-turbulent additive:

Sample heating to $10^{\circ} \mathrm{C}$ :

$$
\tau=13,863 \dot{\gamma}^{0,3057}
$$

Sample heating to $15^{\circ} \mathrm{C}$ :

$$
\tau=12,5 \dot{\gamma}^{0,3123}
$$


Sample heating to $20^{\circ} \mathrm{C}$ :

$$
\tau=10,197 \dot{\gamma}^{0,3161}
$$

Sample heating to $25^{\circ} \mathrm{C}$ :

$$
\tau=8,4988 \dot{\gamma}^{0,3168}
$$

Sample heating to $30^{\circ} \mathrm{C}$ :

$$
\tau=1,7589 \dot{\gamma}^{0,5857}
$$

According to the results of dependences (3-7) and according to the data in Table 1, the oil corresponds to the Ostwald - de Waal model. During the pumping oil without using an additive, the oil sample belongs to nonlinearly viscous liquids and shows the presence of nonNewtonian properties when heated to $30^{\circ} \mathrm{C}$.

During data processing, authors obtained the following dependences for oil sample transported with an anti-turbulent additive with a concentration of $20 \mathrm{~g} / \mathrm{t}$.

Sample heating to $10^{\circ} \mathrm{C}$ :

$$
\tau=7,7621 \dot{\gamma}^{0,3052}
$$

Sample heating to $15^{\circ} \mathrm{C}$ :

$$
\tau=0,0931 \dot{\gamma}+0,8074
$$

Sample heating to $20^{\circ} \mathrm{C}$ :

$$
\tau=0,0435 \dot{\gamma}+0,0241
$$

Sample heating to $25^{\circ} \mathrm{C}$ :

$$
\tau=0,0318 \dot{\gamma}+0,0372
$$

Sample heating to $30^{\circ} \mathrm{C}$ :

$$
\tau=0,0232 \dot{\gamma}+0,0183
$$

According to the obtained dependence 8 and the data of Table 1 the oil corresponds to the Ostwald - de Waal model. According to the obtained dependence of 8 , the oil corresponds to the Shvedov-Bingham model. But we can notice that it has a transitional form. According to dependences 9-12, it is clear that when transported with an additive of $20 \mathrm{~g} / \mathrm{t}$ and when heated to $20^{\circ} \mathrm{C}$, oil acquires Newtonian properties.

Table 1. The results of calculating the effectiveness of anti-turbulent additive «M-FLOWTREAT» brand $\mathrm{C}$.

\begin{tabular}{lllllll}
\hline Stage & $\begin{array}{l}\text { Rate of addi- } \\
\text { tive, } \mathrm{g} / \mathrm{t}\end{array}$ & $\begin{array}{l}\text { Output pressure, } \\
\mathrm{kgf} / \mathrm{cm}^{2}\end{array}$ & $\begin{array}{l}\text { Inlet pressure, } \\
\mathrm{kgf} / \mathrm{cm}^{2}\end{array}$ & $\begin{array}{l}\text { Volume flow } \\
\text { rate, } \mathrm{m}^{3} / \mathrm{h}\end{array}$ & $\begin{array}{l}\text { Effectiveness } \\
\mathrm{DR}, \%\end{array}$ & $\begin{array}{l}\text { Increase in } \\
\text { capacity, \% }\end{array}$ \\
\hline 1 & - & 63.8 & 2.8 & 535.00 & - & - \\
2 & 10 & 63.7 & 2.4 & 610.24 & 21.59 & 14.06 \\
3 & 20 & 53.9 & 3.2 & 700.50 & 49.86 & 30.93 \\
4 & 30 & 47.7 & 2.6 & 734.79 & 59.08 & 37.34 \\
\hline
\end{tabular}

\section{CONCLUSION}

Based on the results obtained during the studying of viscous oil samples at various concentrations of additive from 0 to $20 \mathrm{~g} / \mathrm{t}$ and heating oil samples from $10^{\circ} \mathrm{C}$ to $30^{\circ} \mathrm{C}$, the following conclusions and recommendations can be made: 
At a certain content and temperature of oil, its properties change slightly. Therefore, increasing the cost of regulation of the temperature and the content of the additive is not rational, because efficiency during pumping does not change significantly.

With an increase in additive concentration and temperature, oil with non-Newtonian properties begins to correspond to the model described by Newton.

The optimal mode for pumping this oil is pumping at $20^{\circ} \mathrm{C}$ with an additive concentration of $20 \mathrm{~g} / \mathrm{t}$. Moreover, increasing in additive concentration will not lead to efficiency improvement.

\section{REFERENCES}

Abarasi Hart. 2014. A review of technologies for transporting heavy crude oil and bitumen via pipelines. Journal of Petroleum Exploration and Production Technology - Vol. 4, 327-336.

Avksentiev S.Y., Nikolaev A.K. 2017. Influence of Rheology on Pressure Losses in Hydrotransport System of Polymetallic Ores Tailings. IOP Conference Series: Earth and Environmental Science Volume 87, Issue 5: 6.

Grachev S.I., Korotenko V.A., Kushakova N.P. Study on influence of two-phase filtration transformation on formation of zones of undeveloped oil reserves. Journal of Mining Institute. 2020. Vol.241, p. 68-82. DOI: 10.31897/PMI.2020.1.68

Dolgii I.E. Methods to Enhance Oil Recovery in the Process of Complex Field Development of the Yarega Oil and Titanium Deposit. Journal of Mining Institute. 2018. Vol.231, p.263-267. DOI: 10.25515/PMI.2018.3.263

Khudyakova, I.N. et al. 2018. Raw peat production and processing from flooded fields and approaches to maintain dehydration IOP Conference Series: Earth and Environmental Science.

Martinez-Palou R, Maria de Lourdes M, Beatriz Z-R, Elizabeth M-J, Cesar B-H, Juan de la Cruz C-L, Jorge A. 2011. Transportation of heavy and extra-heavy crude oil by pipeline: a review. J Pet Sci Eng 75:274-282

Mirzajanzade A.H. 1999. Studies on the modeling of complex oil production systems. Nonlinearity, nonequilibrium, heterogeneity. Ufa, Russia.

Muratova V.I. 2014. Assessment of the effect of anti-turbulent additives on the hydraulic efficiency of oil pipelines. Ufa, Russia: 462

Nikolaev A K, Klimko V.I., 2016. Selection of rational heating temperature for pipeline pumping high-viscosity and high pour point crude oil, Journal of Mining Institute, T. 217, 50-54.

Rogachev M.K., Kondrasheva N.K. 2000. Rheology of oil and oil products. Ufa, Russia: 89. 


\title{
Development of detergent for drilling muds while directional drilling
}

\author{
R.R. Gizatullin \\ Postgraduate student, Saint-Petersburg Mining University, Saint-Petersburg, Russia \\ M.E. Budovskaya \\ Postgraduate student, Saint-Petersburg Mining University, Saint-Petersburg, Russia
}

M.V. Dvoynikov

Doctor of technical sciences, Saint-Petersburg Mining University, Saint-Petersburg, Russia

\begin{abstract}
Research is devoted to the development of formulations detergent for drilling muds in order to reduce the adhesion of clay particles to drill pipes while deepening complex sections of the trajectory of a directional well in the intervals composed of clay rocks. Three types of glycerol-based additive composition with the addition of emulsifiers and water repellents were investigated in various concentrations in the range of $0.5-2 \%$. As a result of complex studies which including measurements of the rheological parameters of drilling fluids and bench tests on the model according to the methodology presented in the report, the optimal formulation of detergent was determined. The best results were determined for the additive at a concentration of $1 \%$ for all test samples of the presented drilling fluids. The effectiveness of the detergent is estimated in the mass reduction degree of oil seal which formed on the simulator. It amounted to $65-71 \%$ in the experiments.
\end{abstract}

\section{INTRODUCTION}

The main part of graphic log in Russia (especially Western Siberia) is made up of plastic rocks, in the total mass of which prevail clays. Drilling rocks of this kind with waterbasedmuds is often accompanied by various complications, such as bit balling leads, column tacking. Oil seal formation is the process of sticking of soft sticky rocks (usually clays) on the cutting edges of the bit, which leads to their temporary inefficiencies on the elements of the drill string in the places of transition from a large diameter to a smaller one (Guseynova et al. 2016). This process leads to a decrease in the rate of penetration, an increase in the forces of resistance to movement of the tool in the well, the occurrence of talus and rockfall due to the effect of pistoning at lifting the drill string with the oil seal (Nikolaev et al. 2014; Idress et al. 2020). The cause of oil seal formation is insufficient breed inhibition, in particular hydration and drilling of granular highly permeable formations.

Resistance forces to tool movement in wells largely depend on the quality of the drilling fluid and, above all, on the level of its antifriction and adhesive properties (Durkin et al. 2013; Petrov et al. 2015). It should be noted that the worsening of the structure, thixotropic and rheological properties of the drilling mud causes the bit balling. In this case, the bit balling leads to an increase in uncontrolled hydrodynamic pressures in the wellbore and possibility of oil and gas shows and hydraulic fracturing (Morenov et al. 2017; Petrov et al. 2015). In this regard, relevant is the development of formulations detergent and lubricant additives to reduce friction between the borehole walls and the drill string and to reduce bit and elements of the bottom hole assembly balling (BHA) (Alsaba et al. 2017; Nikolaev et al. 2016). 
Currently, research is underway in the field of lubricating and anti-oil additives. There are Russian and foreign production. For example, SONBUR manufactured by CJSC "PETROCHEM EXPERIMENTAL PLANT" (Russia), K-LUBE (KEM-TRON INC, USA), TORQ-TRIM II (Halliburton), OPTIBUR ("BURINTEKH", Ltd, Russia). All of these anti-oil additives are successfully used in production, but they all have approximately the same component composition. A distinctive feature of the developed detergent is the replacement of an water base with glycerin (anhydrous), which currently has no analogues in the production of additives for drilling fluids.

Three types of additive compositions (COMPOSITION 1, COMPOSITION 2, COMPOSITION 3), each of which consists of glycerol (glycerol) $\mathrm{C} 3 \mathrm{H} 5(\mathrm{OH}) 3$, monoalkyl ether of polyethylene glycol based on fatty acid with the addition of oxyethylene and monoalkylamine in different volume fraction, were studied in order to solve the task of developing formulations of detergent additives for drilling muds. To determine the effectiveness of the fight against bit balling, these COMPOSITIONS (1-3) in concentrations of $0.5-2.0 \%$ were added to the basic drilling muds. Further measurements of rheological parameters and comparison of bench tests on the model were made. It was carried out to find the best additive composition in the muds at which the mass reduction degree of oil seal will be noticed.

\section{MATERIALS AND METHODS}

Together with the company "Service Center SBM" for the experiment, a technique was developed that simulates the process of the bit balling leads. A laboratory stirrer was used as the basis for an experimental setup in which the standard polished rod with blades for mixing the solution was replaced with an unpolished steel rod of equal diameter (the layout and appearance of the stirrer are shown in Figure $1 \mathrm{a}, \mathrm{b}$ ).

This was done in order to bring the experimental conditions closer to real ones, since drill pipes and BHA elements have a higher roughness than polished metal parts of laboratory devices (Bulatov 1977; Ganjumyan et al. 2000; Kalinin 2008). The rod is wetted with the solution while it is in it for 5 minutes before the start of the experiment. The rod rotates in a solution with a frequency close to standard conditions of rotation of a drilling tool with rotary drilling - $50 \mathrm{rpm}$.

Installation elements simulate a well with a diameter $D$, a drill string with a diameter $d_{l}$, a calibrator with a diameter $d_{2}$. In this case, these values will accordingly have values $D=40 \mathrm{~mm}$, $d_{1}=20 \mathrm{~mm}, d_{2}=30 \mathrm{~mm}$, taking into account the proportional reduction of the actual dimensions.

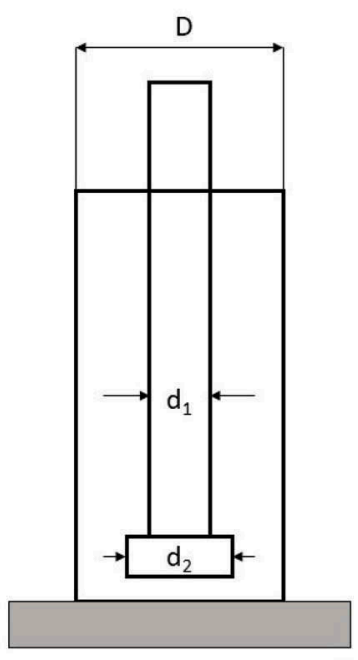

a

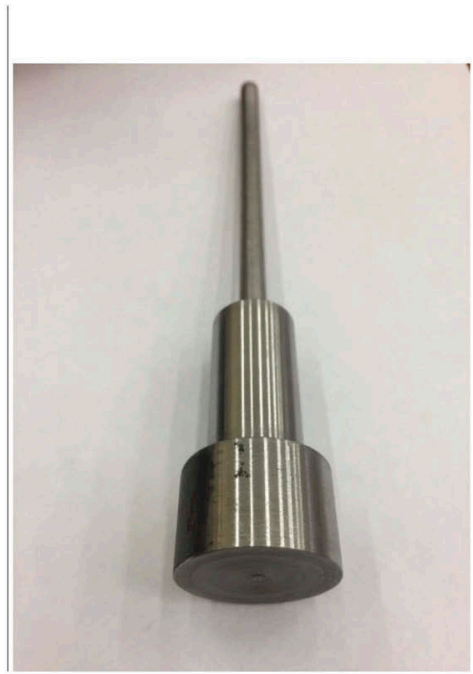

b

Figure 1. Scheme and type of experimental setup. 
The choice of the calibrator as the bottom element of the BHA is due to a small difference in its diameter with the bit and a large role in the danger of the formation of an oil seal in the transition zone from the calibrator in the drill string. The cavernosity coefficient is 1.3 (Idress et al. 2020).

The application of this technique makes it possible to see the process of the bit balling leads during the rotation of a metal rod in the test drilling mud. Researches were carried out using a polymer solution.

\section{RESULTS AND DISCUSSION}

The grade of clay powder for COMPOSITION 1 was selected after a comparative analysis of the ability of clay powders of various grades to form an oil seal in a polymer solution, as well as taking into account the availability of material (Litvinenko 2007; Chubik 1999; Leusheva et al. 2017). We also recommend the use of dried clay sludge obtained from the interval in which intensive an oil seal is observed.

For example, consider research conducting with COMPOSITION 2. Pour 350 grammes a polymer solution into a $500 \mathrm{ml}$ glass, then use a paddle stirrer with a stirring speed of 100$150 \mathrm{rpm}$ and add the detergent reagent gradually to the solution. Mixing is carried out until the component is completely dissolved. Then 42 grammes of clay powder is gradually dispersed into a glass at a stirring speed of $400-500 \mathrm{rpm}$. It is necessary to ensure that the minimum amount of clay is dispersed on the mixer blades when dispersing. Dispersion is carried out within 10-12 seconds. Next, pour the suspension into metal cups into which the rods are lowered for subsequent rotation at a speed of $50 \mathrm{rpm}$. An oil seal is formed within 20 minutes then the rod is washed in distilled water for 20 minutes. Weigh the rods, calculate the average weight of the oil seal in 3 parallel experiments. The effectiveness of the reagent is determined by reducing the weight of the oil seal in comparison with a dummy experiment (without additives).

The optimal formulation of the detergent additive was determined as a result of comprehensive researches which included measurements of the rheological parameters of drilling fluids and bench tests on the model according to the presented methodology. The best results were determined for the additive COMPOSITION 2 with a concentration of $1 \%$.

The graphs (Figures 2-5) show the correlation between two values: the degree of decrease in plastic viscosity and mass reduction degree of oil seal for: gypsum-lime drilling mud, clay drilling mud, biopolymer saline inhibited mud, non-clay mud. Detergent additive COMPOSITION 2 was introduced into all samples at concentrations of $0.5-2 \%$.

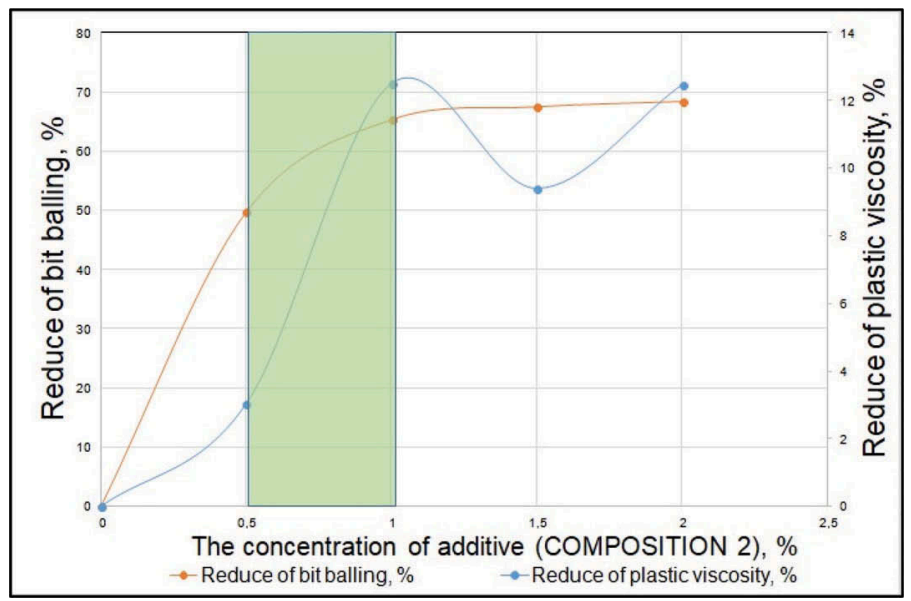

Figure 2. The effect of additives on the reduction the bit balling leads and changes in the viscosity of gypsum-lime mud. 


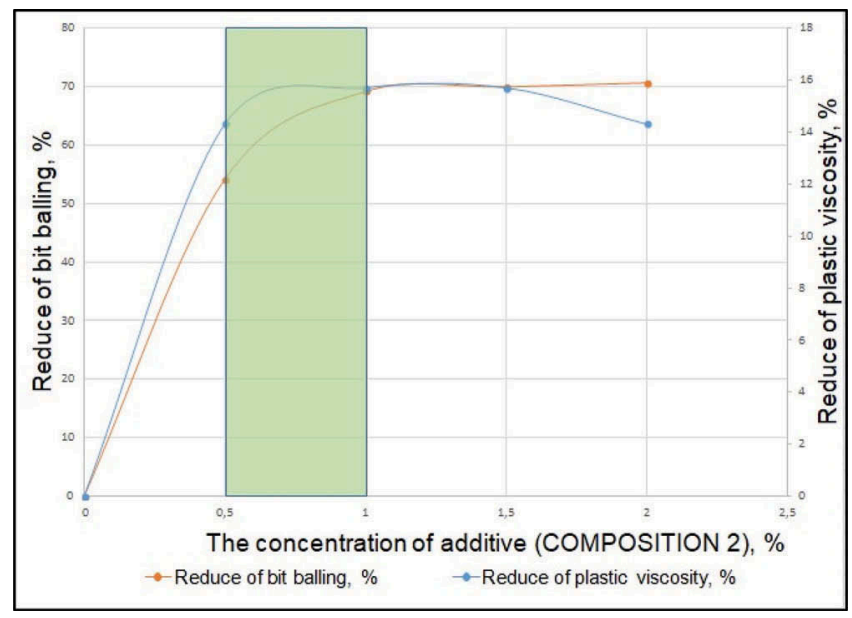

Figure 3. The effect of additives on the reduction the bit balling leads and changes in the viscosity of biopolymer saline inhibited mud.

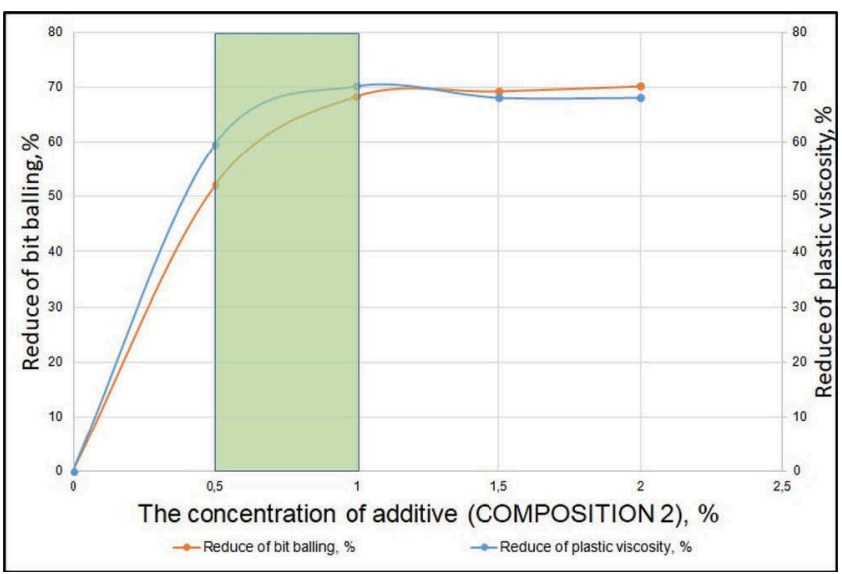

Figure 4. The effect of additives on the reduction the bit balling leads and changes in the viscosity of clay mud.

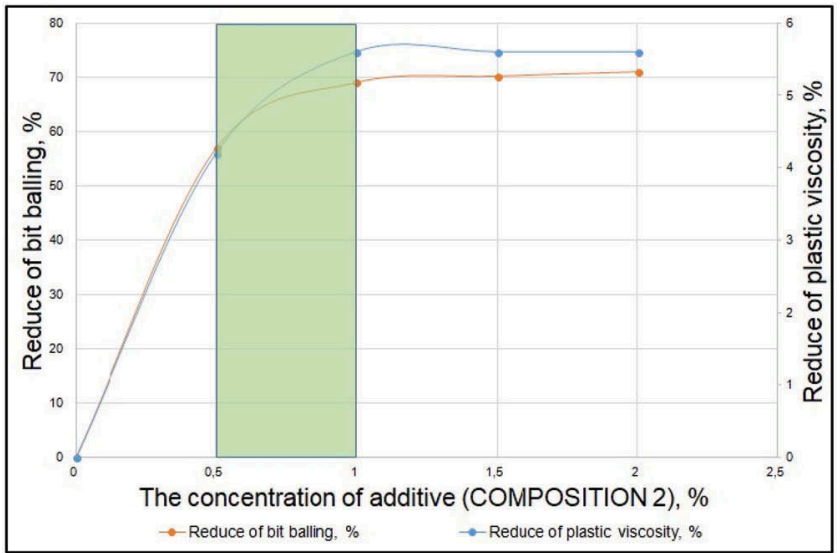

Figure 5. The effect of additives on the reduction the bit balling leads and changes in the viscosity of non-clay mud. 
The criterion for the success of detergent additives is the achievement of an effect in which mass reduction degree of oil seal is reduced by more than $50 \%$. An increase in the content of introduced additives of more than $1 \%$ does not have a noticeable effect on the elimination of oil seals on BHA elements. The zones of dependence of the change in mass of oil seal with the introduction of additives for each solution are highlighted in green in Figures 2-5. Researches have shown a mass reduction degree of oil seal with the introduction of additives by $67-71 \%$ and a decrease in plastic viscosity - up to $15 \%$.

\section{CONCLUSION}

The use of a new detergent additive leads to a decrease in oil seal formation on the elements (BHA) and bit due to a decrease in the adhesion of clay particles to metal surfaces. This detergent additive improves the rheological properties of the drilling fluid and increases the lubricating properties. A regulation has been developed for regulating the technological properties of the system on the basis of the studies as well as a draft instruction for the use of detergent additives.

\section{REFERENCES}

Alsaba, M, Al Dushaishi, MF., Nygaard, R., Nes O-M \& Saasen, A. 2017. Updated criterion to select particle size distribution of lost circulation materials for an effective fracture sealing. Journal of Petroleum Science and Engineering 149: 641-648.

Bulatov, A.I. 1977. Grouting materials and well cementing technology. Moscow: Nedra.

Chubik, P.S. 1999. Qualimetry of drilling fluids. Tomsk: NTL.

Durkin, V. V. \& Ionov, I. V. 2013. Integrated solution of the problem relating to bit packing prevention during wells' upper intervals drilling. Journal Construction of oil and gas wells on land and sea, (4): 13-22. Moscow: Russia.

Ganjumyan, R.A., Kalinin, A.G. \& Nikitin, B.A. 2000. Engineering calculations when drilling deep wells: A reference guide under the general. Moscow: Nedra.

Guseynova, E. L. \& Zernov, M. N. 2016. Application of lubricant and antiadhesive additives to drilling fluids. Collection of scientific papers of the 43rd International Scientific and Technical Conference of young scientists, post graduate students and students, dedicated to the 60th anniversary of the branch of USTU: 141-145. Oktyabrsky: Russia.

Idress, M. \& Hasan, M.L 2020. Investigation of different environmental-friendly waste materials as lost circulation additive in drilling fluids. Journal of Petroleum Exploration and Production Technology 10: 233-242. Bandar Seri Iskandar, Perak Darul Ridzuan: Malaysia.

Kalinin, N.G. 2008. Drilling oil and gas wells (lecture course): Textbook Russian State Geological Exploration University. Moscow: TsentrLitNefteGaz.

Litvinenko, V.S. \& Kalinin, A.G. 2007. Basics of drilling oil and gas wells: a Training manual. Moscow: Higher School.

Leusheva, E. \& Morenov, V. 2017. Research of clayless drilling fluid influence on the rocks destruction efficiency. International Journal of Applied Engineering Research, 12(6): 945-949. India.

Morenov, V. \& Leusheva, E. 2017. Development of drilling mud solution for drilling in hard rocks. International Journal of Engineering, Transactions A: Basics, 30(4): 620-626. Iran.

Nikolaev, N.I. \& Leusheva, E.L. 2016. Increasing of hard rocks drilling efficiency. Neftyanoe Khozyaystvo - Oil Industry, 3: 68-71. Russia.

Nikolaev, N.I., Liu, T., Wang, Z., Jiang, G., Sun, J., Zheng, M. \& Wang, Y. 2014. The experimental study on a new type low temperature water-based composite alcohol drilling fluid. Procedia Engineering, 73: 276-282. Netherlands.

Petrov, N.A., Yangirov, F.N., \& Davydova, I.N. 2015. Research of domestic and foreign lubricant additives of drilling fluids. Network publication "Oil and Gas Business", 5: 150-171. Russia. 


\title{
Stress-stain state of a vertical steel tank affected by bottom sediments in conditions of extreme temperature differences
}

\author{
R.R. Sultanbekov \\ Postgraduate student, Saint-Petersburg Mining University, Saint-Petersburg, Russian Federation \\ R.D. Terekhin \\ Student, Saint-Petersburg Mining University, Saint-Petersburg, Russian Federation \\ M.N. Nazarova \\ PhD, Associate professor, Saint-Petersburg Mining University, Saint-Petersburg, Russian Federation
}

\begin{abstract}
This article describes the analysis of the stress-strain state of the tank taking into account bottom sediments of oil products and the influence of the temperature of the oil product and the environment using the Ansys software package. Effects that oil product has separately and oil product with bottom sediments have on a stress-stain state are compared. Oil products having different temperatures of $20,30,40,50{ }^{\circ} \mathrm{C}$ are examined in different series. Calculations at various ambient temperatures $\left(-60,-50,-40{ }^{\circ} \mathrm{C} ;-20{ }^{\circ} \mathrm{C} ; 0{ }^{\circ} \mathrm{C} ;+20^{\circ} \mathrm{C}\right.$; $+40{ }^{\circ} \mathrm{C}$ ) are presented in each series. Different densities of oil product and bottom sediment were considered. Based on the analysis of the stress-strain state using finite element modeling on the example of a vertical steel tank, it was shown that the stresses in the zone of the miter weld, as well as in the places of installation of the receiving-distributing branch pipe and the manhole, are maximum. It is in these zones that the influence of bottom sediment and temperature is significant, since they form local elevated stress zones, which increase significantly when the walls are thinned.
\end{abstract}

\section{INTRODUCTION}

The subject of this work is vertical steel tank of the PBC series, and bottom sediments which can appear during normal operation.

Actuality of the work is dictated by absence of scientific research on the theme and by need in increasing reliability, efficiency and safety of oil tank operation.

The study is aimed on testing the following hypothesis: temperature of the bottom sediment affects the stress-stain state of a steel tank; more accurately, the higher change in temperature of a bottom sediment is, the greater stress values are observed in the wall of the tank. This statement is based on the fact that the density of a liquid depends on its temperature. Moreover, temperature stresses appear when the metal wall is heated by bottom heaters of a reservoir. However, it is unclear whether these phenomena can lead to serious consequences, up to reservoir destruction, and is there a significant interplay between temperature changes and the presence of bottom sediments.

The theme of this study is new and is uncovered in previous works. There are a number of studies related to stress-stain study of a steel tank in correlation with cyclic operation loads (Prokopov \& Tkachyova., 2015), in correlation with temperature changes (Kuzeev et al., 2013).

The first work considers the same oil tank series as in the current study, but with a different volume, and uses finite element method. Results show influence of loads on the bottom part of the tank and especially its foundation. The second work shows the stress in the zone of 
a nozzle using the same finite element method. However, none of these studies consider the affect that bottom sediments can have on a stress-stain state of a tank.

The only work on the theme is made by the authors of this work. Authors have been doing research on the theme for quite a long time, and have articles published (Sultanbekov et al., 2019). In this work temperature changes are greater; moreover, environment temperature is also taken into account. The previous work did not take this aspect into consideration.

In this article authors model the stress-stain state of a vertical steel tank in ANSYS software package, figure out the value of stresses in the wall in different temperatures, make conclusion about connection between stress level and sediment temperature.

\section{THEORY AND METHOD}

\subsection{Theoretical background}

Tanks for oil and oil product storage are one of the main technological objects of oil depots and trunk oil pipelines (Sherstobitova et al., 2008). The ecology of the area where tank farms and human safety are located depends on their reliability. Ensuring the required level of reliability of the steel vertical cylindrical tank is carried out at the operation stage. In case of tank accidents, oil products pollute adjacent territories and water basins (Bykova et al., 2019). The economic damage from accidents involving leakage of petroleum products includes not only direct losses, but also the costs of environmental measures to restore the environment, as well as the costs of replenishing the stock of petroleum products.

Modern regulatory documents, (GOST R 52910 - 2008) do not establish the maximum service life of tanks. Tank dismantling is done only according to the results of a diagnostic examination - instrumental and calculated (Kuzeev et al., 2013). The tank is a vertical shell with a bottom; however, the presence of geometric features significantly changes the symmetry of the structure, the distribution of stresses and strains in local zones, which is difficult to take into account when performing analytical calculations.

Thanks to the use of software systems for finite element calculations, such as Ansys, it becomes possible to determine the most dangerous zones and predict the stress-stain state (SSS) during operation, taking into account additional factors. One of such is bottom sediment, which is formed during storage and mixing of oil products (Sultanbekov \& Nazarova, 2019). Especially active sedimentation is observed when different types of residual oil products are mixed due to their incompatibility (Mitusova et al., 2018). Sedimentation occurs due to imbalance and instability of fuels, when the amount of aromatic hydrocarbons decreases, so the proportion of paraffin and asphaltenes in the mixture increases (Kondrasheva et al., 2019). Cases of "incompatibility" during the mixing of petroleum products are associated with the emergence of strong intermolecular interactions caused by changes in the structural group composition and the mutual ratio of the concentrations of high molecular weight compounds of petroleum products (Karimov \& Mastobaev, 2012), which leads to the formation of molecular associates, bulk colloidal particles of various shapes and structures (Kondrasheva et al., 2018). The problem of "incompatibility" of oil products is extremely urgent, since due to the precipitation of sediment on the tanks during operation, the useful volume decreases and the need to clean the tanks arises, and when mixing fuels because of the "incompatibility", the quality of the whole product deteriorates in the first place, the subsequent use of which increases the risk of equipment wear (ISO 8217, 2017).

When there is a big temperature difference, especially in zones of extremely low temperatures, the problem of reservoir operation is quite important (YUhtorov et al., 2018). Such conditions can be found in some northern regions, in the Arctic zone. Tank's wall metal is exposed to greater loads, and this fact should be taken into consideration during tank design to ensure its safe and reliable operation (Bondarev et al., 2017). 


\subsection{Method}

To determine the effect of bottom sediment, mainly consisting of asphaltene-tar paraffin deposits, on SSS diagram, we consider vertical steel tank PBC-20000, which stores a mixture of residual fuels of the RMK-700 grade with a density of $958 \mathrm{~kg} / \mathrm{m} 3$ at $15{ }^{\circ} \mathrm{C}$ and has a viscosity of $550 \mathrm{sSt}$ at $50{ }^{\circ} \mathrm{C}$. Liquid surface height is 12 meters, the material of the tank is Steel 3. There is a fixed roof, the weight with the equipment installed on it is 10,000 N. Laboratory tests of viscosity were performed using a Stabinger SVM 3000 laboratory instrument, and Anton Paar DMA 4100 M equipment used to measure density. The results are shown in Table 1.

The reservoir model was created and the tank SSS calculations were performed in the Ansys software package, taking into account the stored residual fuel and total sediments at a temperature of $20^{\circ} \mathrm{C}$ (Figure 1).

Table 1. Density of the residual fuel and total sediment depending on the measurement temperature.

\begin{tabular}{lll}
\hline Temperature, ${ }^{\circ} \mathrm{C}$ & Total sediment, $\mathrm{kg} / \mathrm{m} 3$ & Residual fuels RMK-700, $\mathrm{kg} / \mathrm{m} 3$ \\
\hline 15 & 1090.0 & 958.0 \\
20 & 1087.2 & 954.8 \\
25 & 1084.4 & 951.6 \\
30 & 1081.5 & 948.4 \\
35 & 1078.7 & 945.1 \\
40 & 1075.9 & 941.9 \\
45 & 1073.0 & 938.7 \\
50 & 1070.2 & 935.4 \\
55 & 1067.4 & 932.2 \\
60 & 1064.5 & 928.9 \\
65 & 1061.6 & 925.7 \\
70 & 1058.8 & 922.4 \\
\hline
\end{tabular}

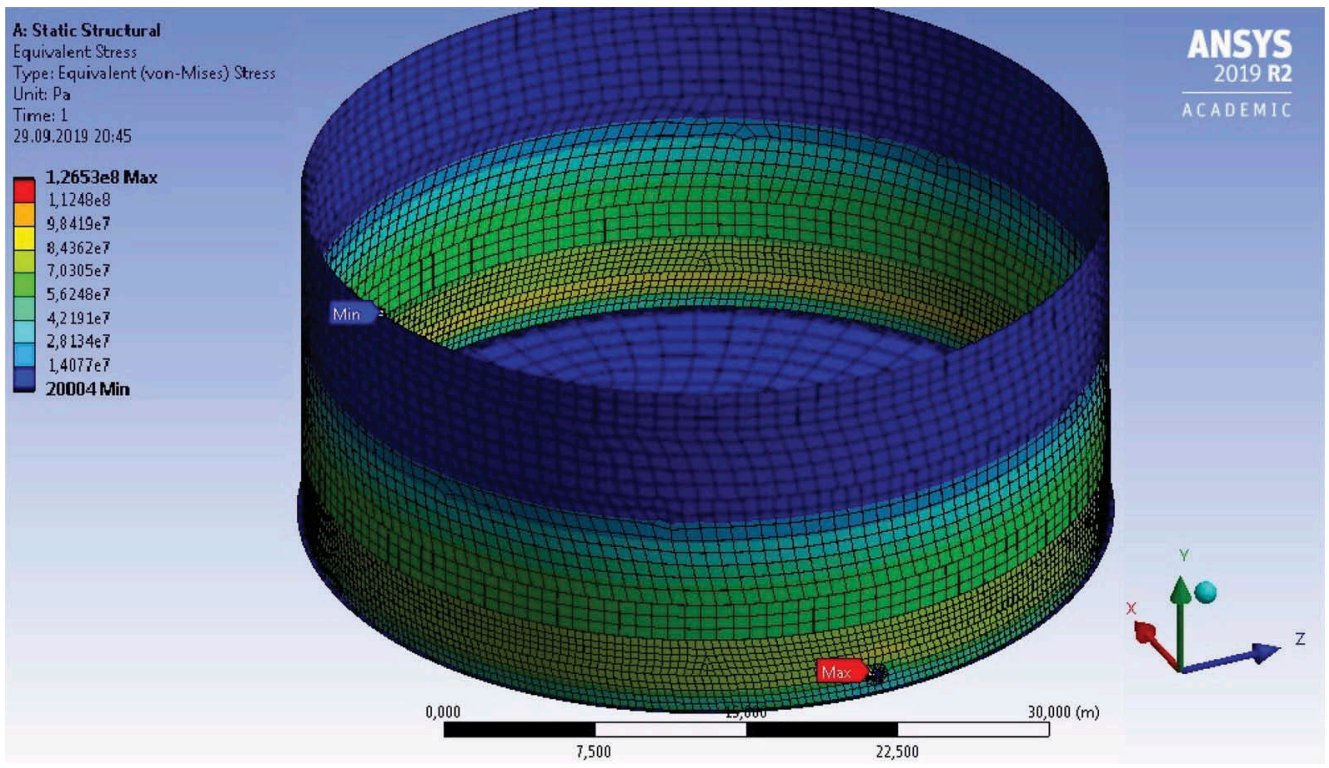

Figure 1. SSS of a reservoir without bottom sediment, $20^{\circ} \mathrm{C}$. 


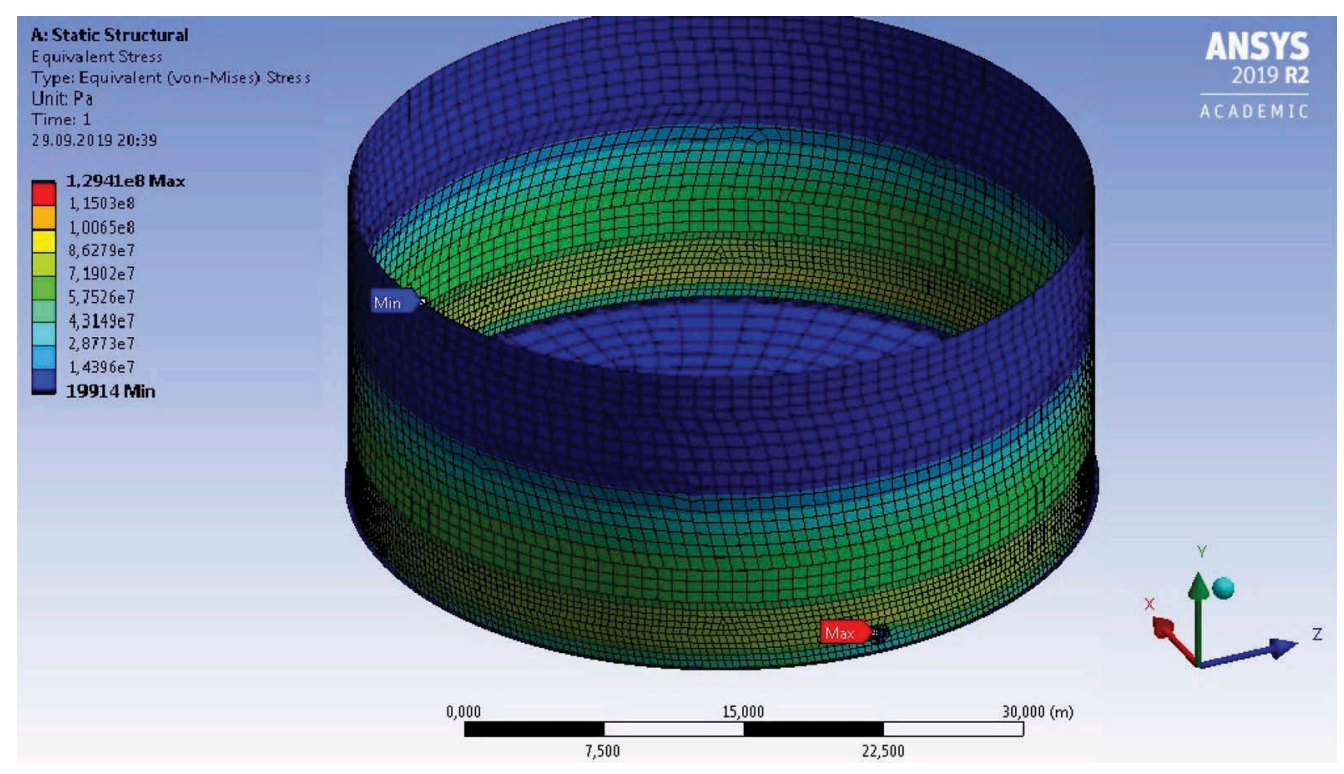

Figure 2. SSS of a reservoir, 1,3 meter of bottom sediment, $20^{\circ} \mathrm{C}$.

In the absence of sediments, the maximum stresses of $126 \mathrm{MPa}$ are observed in the zone of the masonry weld, as well as in the places of installation of the dispensing nozzle and manhole.

Another calculation is made with bottom sediment with a height of 1.3 meters. The density of sediments is $1090 \mathrm{~kg} / \mathrm{m}^{3}$ at $15^{\circ} \mathrm{C}$. (Figure 2).

Attention should be paid to an increase in the maximum stresses created by the liquid column. Unaccounted stress in the metal can lead to negative consequences, especially under bad circumstances. Especially when you consider that the tank is loaded cyclically, and metal failure may occur earlier than anticipated. Especially when you consider that the tank is loaded cyclically, and metal failure may occur earlier than anticipated.

The ambient temperature changes, so does the magnitude of the stresses in the tank wall. This is due to the thermal expansion of the metal. Bottom sediments also affect the stress experienced on the tank wall. So, with a large temperature difference, the maximum stress in the metal can exceed the yield strength, which leads to the destruction of the tank.

Several series are to be calculated. Let the fluid in the tank be heated, its density and temperature are constant during one series. Totally there are four series for each temperature of the stored product $-20,30,40,50{ }^{\circ} \mathrm{C}$. Calculations for different ambient temperatures $(-60$, $-40,-20,0,20,40^{\circ} \mathrm{C}$ ) are made in one series.

\subsection{Product's temperature is $50^{\circ} \mathrm{C}$.}

Results are shown on Figure 3. Calculation is present for six different ambient temperatures and the same product temperature, which is constant and is $50{ }^{\circ} \mathrm{C}$.

As expected, maximum stress values are obtained with greater temperature difference, and are located in the zones of nozzle and manhole. As the temperature gets higher, stress is lowered at first and gets bigger then, but its distribution is almost the same. Points of max and min values in these cases differ because of low mesh resolution due to free license limitations. Results of calculations are in the Table 2. 


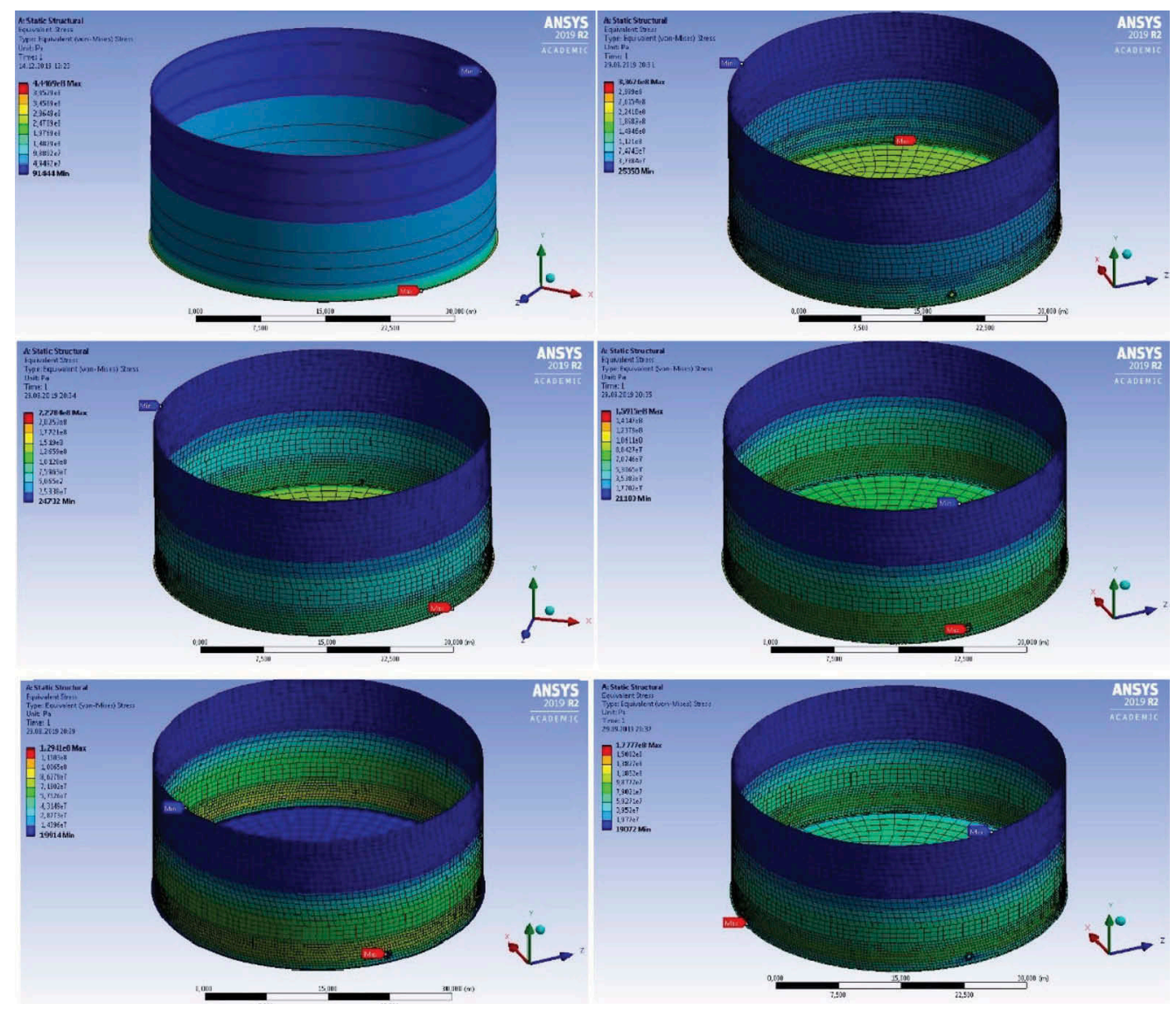

Figure 3. SSS of a reservoir, 1.3 meter of bottom sediment, different ambient temperatures, product at $50{ }^{\circ} \mathrm{C}$.

Table 2. Stress depending on the temperature, product at $50^{\circ} \mathrm{C}$.

\begin{tabular}{ll}
\hline Ambient temperature, ${ }^{\circ} \mathrm{C}$ & Maximum stress in a wall, Mpa \\
\hline-60 & 444 \\
-40 & 336 \\
-20 & 227 \\
0 & 159 \\
20 & 129 \\
40 & 177 \\
\hline
\end{tabular}

\subsection{Series representing product at $40^{\circ} \mathrm{C}$}

As well as in the previous set of calculations, product temperature is constant while ambient temperature is changing. SSS remains almost the same while values change dramatically (Figure 4).

Slight increase in stress due to increased densities of product and sediment is worth mentioning.

Results are shown in the Table 3. Some values representing stress in nozzle or manhole (the bigger one) are shown separately. Theoretically such different values are caused 


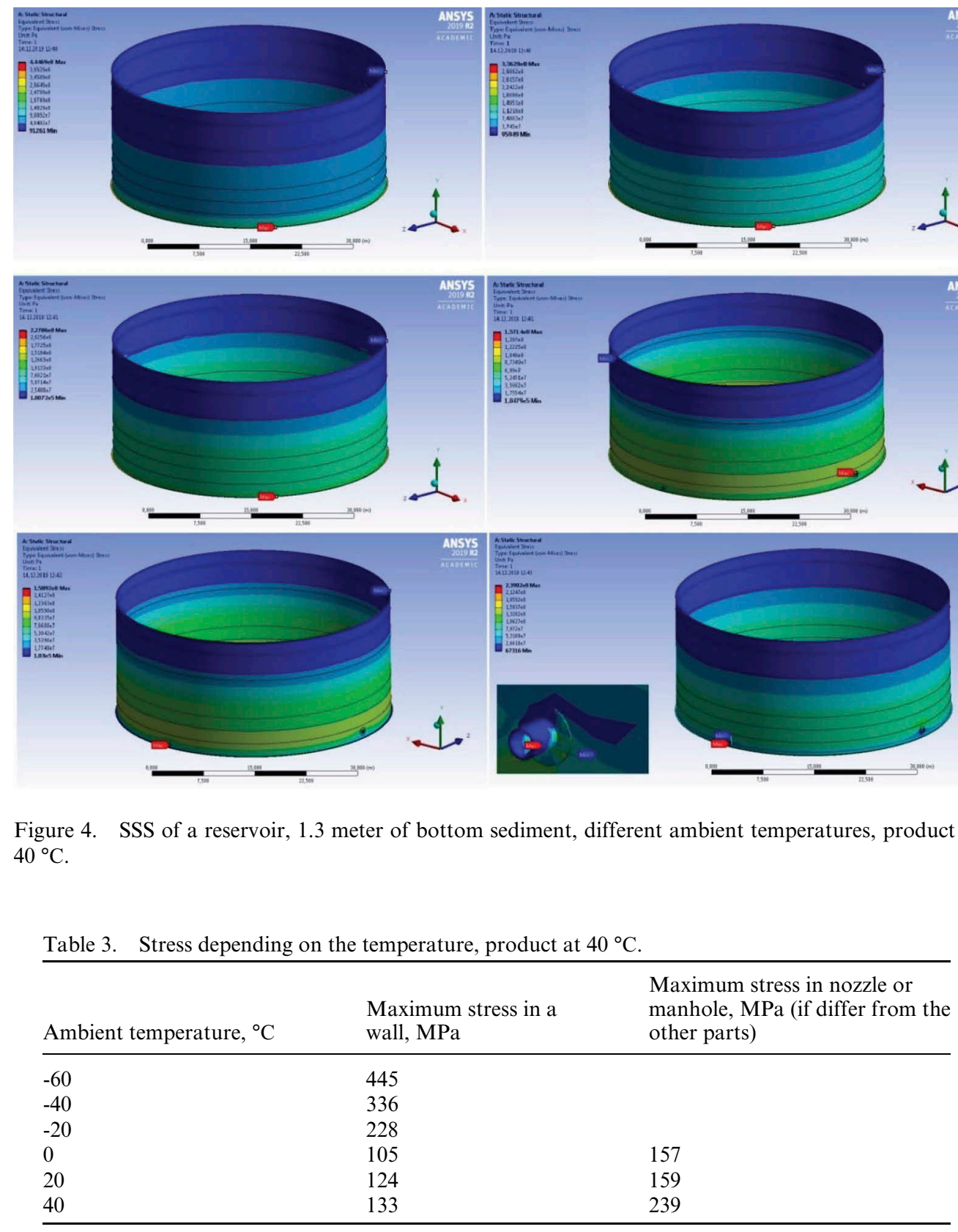

by low-resolution mesh rather than actual load on the part. It can be understood while closely examining the results: only one mesh node has such great values.

\subsection{Series representing product at $30^{\circ} \mathrm{C}$}

The same as above. Calculation results are shown on Table 4.

Stress measured in manhole and nozzle zones doesn't necessarily represent actual stresses in a real reservoir. Calculation results are shown in Table 4. 
Table 4. Stress depending on the temperature, product at $30^{\circ} \mathrm{C}$.

\begin{tabular}{lll}
\hline Ambient temperature, ${ }^{\circ} \mathrm{C}$ & $\begin{array}{l}\text { Maximum stress in a } \\
\text { wall, MPa }\end{array}$ & $\begin{array}{l}\text { Maximum stress in nozzle or manhole, } \\
\text { MPa (if differ from the other parts) }\end{array}$ \\
\hline-60 & 446 & \\
-40 & 337 & \\
-20 & 229 & 158 \\
0 & 106 & 160 \\
20 & 125 & 240 \\
40 & 133 & \\
\hline
\end{tabular}

Table 5. Stress depending on the temperature, product at $20^{\circ} \mathrm{C}$.

\begin{tabular}{lll}
\hline Ambient temperature, ${ }^{\circ} \mathrm{C}$ & $\begin{array}{l}\text { Maximum stress in a } \\
\text { wall, MPa }\end{array}$ & $\begin{array}{l}\text { Maximum stress in nozzle or manhole, } \\
\text { MPa (if differ from the other parts) }\end{array}$ \\
\hline-60 & 447 & \\
-40 & 337 & \\
-20 & 229 & 159 \\
0 & 107 & 162 \\
20 & 126 & 242 \\
40 & 135 & \\
\hline
\end{tabular}

\subsection{Series at $20^{\circ} \mathrm{C}$}

In previous cases the product was heated. Now let's consider the situation without heating. Product density reaches its maximum, so the highest values of stress are expected.

As expected, stresses are mostly to the thermal expansion of wall metal. The most dangerous points are again the nozzle and the manhole. Stress values change while the distribution remains the same. Results are shown in Table 5.

\section{CONCLUSIONS}

As a result of the analysis of the stress-strain state of the tank, taking into account the operational loads of the reservoir models, it was established that the stress in the casing increases during the operation of the reservoir.

Analysis of SSS using finite element methods showed that with active sedimentation and an increase in the temperature of the stored product, an increase and redistribution of stresses occurs in the lower zone. Also, calculations of the influence of ambient temperature and bottom sediment on SSS showed the highest stresses in the lower zone at the most negative values, namely $-60 \mathrm{C}$. As a result, stress concentration zones arise that are located directly in the zone of the weld seam and in the places of installation of the receiving-distributing branch pipe and manhole, which are not taken into account when calculating by standard methods.

\section{REFERENCES}

Bondarev E., Rozhin I., and Argunova K. 2017 Features of mathematical modeling of natural gas production and transportation systems in the Arctic zone of Russia. Journal of Mining Institute, 228 (6), 705. DOI: http://dx.doi.org/10.25515/pmi.2017.6.605.

Bykova M.V., Pashkevich M.A., Matveeva V.A., Sverchkov I.P. 2019. Assessment and abatement of the soil oil-contamination level in industrial areas. In: Litvinenko V. (ed.), Topical Issues of Rational Use 
of Natural Resources - Proceedings of the International Forum-Contest of Young Researchers, pp. 347-359.

GOST R 52910-2008. Rezervuary vertikal'nye cilindricheskie stal'nye dlja nefti i nefteproduktov. Obshhie tehnicheskie uslovija. M.: Standartinform. 56 c. [in Russian].

ISO 8217 Fuel Standar. - 2017. - URLhttps://https://www.wfscorp.com/sites/default/files/ISO-8217-2017Tables-1-and-2-1-1.pdf (date of the application10.01.2019).

Karimov R M, Mastobaev B N. 2012. Vliyanie soderzhaniya parafinov, smol i asfal'tenov na tovarnye kachestva neftej//Bashkirskij himicheskij zhurnal.-Tom 19.

Kondrasheva N. K., Eremeeva A. M., \& Nelkenbaum K. S. 2018. Development of domestic technologies of produsing high quality clean diesel fuel. Izvestiya vysshikh uchebnykh zavedenii Khimiya Khimicheskaya Tekhnologiya, 61(9-10), 76-82. https://doi.org/10.6060/ivkkt.20186109-10.5651.

Kondrasheva N. K., Eremeeva A. M., Nelkenbaum K. S., Baulin O. A. \& Dubovikov O. A. 2019. Development of environmentally friendly diesel fuel, Petroleum Science and Technology, 37:12, 1478-1484, DOI: $10.1080 / 10916466.2019 .1594285$.

Kondrasheva N K, Rudko V A, Kondrashev D O, Konoplin R R, Smyshlyaeva K I, and Shakleina V S. 2018. Functional influence of depressor and depressor-dispersant additives on marine fuels and their distillates components. Petroleum Science and Technology 36 (24), 2099-2105. DOI: 10.1080/ 10916466.2018.1533858.

Kondrasheva N K, Rudko V A, Kondrashev D O, Shakleina V S, Smyshlyaeva K I, Konoplin R R, Shaidulina A A, Ivkin A S, Derkunskii I O, Dubovikov O A. 2019. Application of a Ternary Phase Diagram to Describe the Stability of Residual Marine Fuel /// Energy \& Fuels. Vol. 33, № 5. P. 4671-4675.

Kuzeev I.R., Tlyasheva R.R. and others. 2013. Technique of definition the stress-strain state of the steel cylindrical tank. FSBEI HPE "Ufa state petroleum technological university", Ufa, Russian Federation. - №4 - pp. 339-347. http://ogbus.ru/article/view/metodika-opredeleniya-napryazhenno-deformir ovannogo-sostoyaniya-stalnogo-cilindricheskogo-rezervuara.

Mitusova T N, Kondrasheva N K, Lobashova M M, Ershov M A, and Rudko V A. 2017. Influence of dispersing additives and blend composition on stability of marine high-viscosity fuels. Journal of Mining Institute 228, 722-725. DOI: 10.25515/PMI.2017.6.722.

Mitusova T N, Kondrasheva N K, Lobashova M M, Ershov M A, and Rudko V A and Titarenko M A. 2018. Determination and Improvement of Stability of High-Viscosity Marine Fuels. Chemistry and Technology of Fuels and Oils 53 (6), 842-845. DOI: 10.1007/s10553-018-0870-.

Prokopov A.Y., Tkachyova K.E. 2015. A study of stress-strain state of foundation of vertical vessel subject to dynamic operating loads. Inzhenerniy vestnik Duna, №3. https://ivdon.ru/ru/magazine/archive/ n3y2015/3200 [in Russian].

Sherstobitova R T, et al. 2008. Povyshenie bezopasnosti RVS, dlitel'no jekspluatiruemyh v uslovijah nizkih temperature, Ufa: UGNTU, $131 \mathrm{c}$. [in Russian].

Sultanbekov R. R., Nazarova M. N. 2019. Determination of compatibility of petroleum products when mixed in tanks. EAGE., Tyumen, DOI: 10.3997/2214-4609.201900614. Available at: http://earthdoc. eage.org/publication/publicationdetails/?publication=96369 (Accessed 30 March 2019).

Sultanbekov R.R., Terekhin R.D., Nazarova M.N. 2019. Effect of temperature fields and bottom sediments of oil products on the stress-strain state of the design of a vertical steel tank. Journal of Physics Conference Series, 1431:012055, DOI: 10.1088/1742-6596/1431/1/012055.

YUhtorov V. N., Korol'chenko I. A., Ulanin S E., Sokolov D. N. 2018. Obosnovanie sposoba prognozirovaniya sohranyaemosti kachestva nefteproduktov pri dlitel'nom hranenii (Substantiation of method for forecasting of preserved quality of oil products during long storage).//Mir nefteproduktov. Vestnik neftyanyh kompanij. - №3. - S. 20-27 [in Russian]. 


\title{
Modification of sodium lignosulfonate with reagent obtaining for drilling fluids
}

\author{
R.A. Fedina \\ Applicant of the Department of Physical and Organic Chemistry, Federal State Budgetary Educational \\ Institution of Higher Education Ufa State Petroleum Technological University, Ufa, Russia
}

\begin{abstract}
A.D. Badikova
Doctor of Engineering Sciences, Professor, Head of the Department of Physical and Organic Chemistry, Federal State Budgetary Educational Institution of Higher Education Ufa State Petroleum Technological University, Ufa, Russia

I.N. Kulyashova

Candidate of Engineering Sciences, Head of laboratory of the Department of Physical and Organic Chemistry, Federal State Budgetary Educational Institution of Higher Education Ufa State Petroleum Technological University, Ufa, Russia
\end{abstract}

\section{D.A. Dubovtsev}

Master's Degree Student of the Department of Oil and Gas Technology, Federal State Budgetary Educational Institution of Higher Education Ufa State Petroleum Technological University, Ufa, Russia

\section{M.A. Tsadkin}

Doctor of Engineering Sciences, Professor of the Department of High-molecular Compounds and General Chemical Technology, Federal State Budgetary Educational Institution of Higher Education Bashkir State University, Ufa, Russia

\begin{abstract}
Analysis of lignosulfonate drilling reagents showed that the reagents based on modified lignosulfonates, that is ferrochrome lignosulfonates (FCLS) are part of most drilling fluids. However, the content of toxic chromium $(2.0-3.5 \% \mathrm{wt})$, high bottomhole temperatures $\left(150-190^{\circ} \mathrm{C}\right)$, as well as a decrease in the volume and quality of sulfite lignosulfonate, which is the main source of raw materials, limits the possibility to use them. To obtain an effective drilling reagent capable of regulating the properties of the drilling fluid, the basic method for modifying the neutral sulfite lignosulfonate to produce drilling reagents with high qualitative characteristics has been improved - the liquefaction index is up to $60 \%$, the filtration index is $6.0-6.5 \mathrm{~cm}^{3} / 30 \mathrm{~min}$, the nominal viscosity is $24 \mathrm{~s}$, and to increase the stability and resistance of the washing (drilling) liquid to temperature aggression, additional modifiers containing phosphonic compounds are introduced.
\end{abstract}

Keywords: sodium lignosulfonate, neutral sulfite liquor, modification, phosphonic compounds, drilling reagent, infrared spectroscopy (IR spectroscopy), X-ray fluorescence (XRF)

\section{INTRODUCTION}

In drilling, a group of reagents based on lignosulfonates is widely used, i.e. oxidized and chromium-substituted lignosulfonate (oxyl), ferrochrome lignosulfonate (FCLS), spent sulfitealcohol liquor (SSAL), sulfite yeast mash (SYM), condensed spent sulfite-alcohol liquor 
(CSSAL), etc. The main disadvantage of these reagents is the weak effect under conditions of high bottomhole temperatures.

Acrylic polymers, in particular, gipan, metas, K-4, M-14, Lacris-20, and others, are very resistant to heat. However, their use is not always effective because of their instability to polyvalent metal salts, for example, to the effect of calcium ions; the high cost of imported macromolecular substances and the scarcity of domestic ones (the needs for polymer reagents are satisfied only by $40-50 \%$ ) (Komkova, 2011).

Tretyak A.Ya. proposed a drilling fluid containing $0.5-2.0 \%$ carboxymethyl cellulose, dextrin crumb, which is a mixture of hydrocarbons formed during the hydrolysis of potato and maize starch $0.5-3.0 \%$ and water (Pat. RF 2038362, 1995). Dextrin crumb is a colmatation filler, and the rest of the solution is very sensitive to polysalt mineralization, so the use of this solution is limited, it can be used only in fresh systems.

The same author proposed the composition of the solution containing $0.5-3.0 \%$ dextrin groats, $0.5-2.0 \% \mathrm{CMC}, 0.1 \%$ sodium hydroxide and water (Bulatov et al., 1999). The presence of caustic soda creates an increased $\mathrm{pH}$ value of the medium (up to 14), which limits their use under conditions of using aluminum pipes and adversely affects the stability of the borehole walls (Kulyashova, 2016).

An analysis of the papers of domestic and foreign researchers showed that the most optimal stabilizing reagents for mineralization conditions and high temperatures may be linear polymeric substances containing non-ionic functional groups that provide optimal adsorption on the solid phase (Komkova, 2011).

A method of obtaining a reagent for processing drilling fluids (Levik, 1982) is known, including the oxidation of spent sulfite-alcohol liquor with alkali metal dichromates, followed by condensation, where the oxidation and condensation being carried out for 1-2 hours at 20$30^{\circ} \mathrm{C}$ at $\mathrm{pH}$ 6.0-6.5 of the initial raw mixture in the presence of fatty acids of vegetable oils. The disadvantage is that due to high $\mathrm{pH}$ and reaction medium dilution, a low degree polycondensation reagent is formed and as a sequence of this, with lower stabilization efficiency and reduced filtration of drilling fluids. In addition, the reagent is used in overdosages.

A method of obtaining a reagent is also known (Pat. RF 2152419, 2000), which is constant in composition and qualitative characteristics, with high performance properties, obtained by polycondensation of lignosulfonates with formaldehyde and a co-condensing agent in an aqueous medium with an acid catalyst when heated, followed by neutralization of the reaction mass with alkali metal hydroxides, characterized in that polycondensation is carried out stepwise: initially, lignosulfonates interact with formaldehyde, then into the reaction mass a co-condensing reagent is introduced and additional polycondensation is carried out, and the neutralized reaction mass is dried. The disadvantage of this production method is that it is proposed to use highly toxic phenol, phenolsulfonic acid, etc., as a co-condensing reagent, which increases the environmental risks when using this drilling reagent.

In the structure of lignosulfonates, there are active centers capable of entering into the polycondensation reaction (of the phenolaldehyde type) with the enlargement of the starting substances (Bulatov et al., 1999). This leads to an increase in the antifiltration and thermostabilizing properties of condensed lignosulfonates as reagents for drilling fluids. Condensed lignosulfonates are obtained, for example, by their interaction with formaldehyde in an aqueous medium when heated with an acid catalyst (Badikova, 2014). The disadvantage is condensed lignosulfonates (CSSAL) are ineffective in the presence of sodium chloride and at high temperatures (Pat. RF 2098447, 1997).

Lignosulfonate macromolecules are disordered, branched helices with varying degrees of compaction. Low molecular fractions can be of a linear structure. Polydispersity, the presence of ionogenic groups, and a high degree of molecular dissociation indicate that strongly associated highly hydrophilic polyions should prevail in the solution. The structure of lignosulfonates in the shape of polyaromatic chains with functional groups included in them, determines their diphilic nature, surface activity, and high adsorption activity (Badikova et al., 2014).

The qualitative and quantitative composition of lignosulfonates obtained during the wood delignification process depends on the main chemical processes timing during various cooking 
methods, on the properties of the wood components with which cooking solutions react, as well as on the composition of cooking solutions and cooking conditions (Kulyashova, 2016).

The problem for the further use of lignosulfonate reagents today is a decrease in the production of sulfite lignosulfonates due to a change in the raw material base and the consistent transition of pulp and paper mills to neutral sulfite methods of technical lignosulfonate production. The resulting products are characterized by a reduced content of the main component, that is lignosulfonate (not more than $49 \%$ of the mass, unlike sulfite $-60 \%$ of the mass), consisting mainly of low molecular fractions, and also containing insoluble components in the composition (Pat. RF 2038362, 1995). Neutral sulfite liquor is of undoubted interest, since a large proportion of organic substances in it are carbohydrates and salts of low molecular organic acids. However, the possibility of individual use of neutral sulfite liquor requires its modification to obtain a reagent that is stable during electrolyte and temperature aggression and does not adversely affect other properties of the working solution (Badikova et al., 2014). A distinctive feature of drilling reagents obtained by the modification of lignosulfonates is the dependence of their physical and chemical and technological parameters on the quality of the raw material base (Komkova, 2011; Badikova et al., 2016).

In industry, obtaining the ferrochrome lignosulfonate (FCLS) is carried out by modifying the technical lignosulfonate with iron and chromium compounds, followed by neutralization with caustic soda, and then dried to a powder state (Levik, 1982).

However, the industrial obtaining of chrome lignosulfonates is associated with a number of issues, such as the formation of a chromic production waste, incomplete reduction of anionic chromium compounds in the composition of the resulting drilling reagent (Kulyashova, 2016; Badikova et al., 2016)

In this regard, the aim of this paper was to obtain and study the properties of a modified lignosulfonate drilling reagent for effective drilling fluids.

\section{MATERIALS AND METHODS}

In this paper, lignosulfonates of various cooking methods were used as raw materials for obtaining drilling reagents: sulfite STO (Corporate Standard) 43508418-022-2010 and neutral sulfite TU (Technical Standards) 2455-101-72197712-2013; modifiers, that is iron sulfate as per GOST (State Standard) 6981, sodium dichromate, as per GOST (State Standard) 2651; NTF (nitrilotrimethylphosphonic acid) modifiers TU (Technical Standards) 2439-34705763441-2001 and TPF (sodium tripolyphosphate) GOST (State Standard) 13493-86 containing phosphonic groups (Badikova et al., 2016).

A drilling reagent based on lignosulfonate modified with salts of polyvalent metals (iron and chromium), manufactured under the trade name of FCLS (ferrochrome lignosulfonate), corresponding to quality indicators, was chosen as an industrial analogue.

Quality indicators of a FCLS reagent are as follows: mass fraction of water is no more than $10 \%$; solubility in water is at least $90 \%$; $\mathrm{pH}$ of a $1 \%$ aqueous solution is in the range of $4.0-5.0$; a dilution rate is at least $50 \%$.

The process of obtaining sulfite liquors, until today, has been predominant and met all the necessary requirements: cheap starting chemicals, high yield of cellulose, the ability to easily obtain from by-products while complying with environmental requirements. However, at present, the standards for the content of pollution in wastewater and gas emissions are tightened, there is a decrease in the quality of the raw materials used for the sulfite cooking method. As a result, pulp and paper mills switch to the processing of low-grade raw materials in a neutral sulfite method that meets environmental safety requirements and contributes to the production of technical lignosulfonates with a reduced content of the main component, that is lignosulfonate (not more than $49 \%$ of the mass, unlike sulfite - $60 \%$ of the mass), and consists mainly of low molecular fractions (up to $7500 \mathrm{amu}$, in contrast to sulphite, up to 20,000 amu), and also contains insoluble substances, which makes it impossible to obtain reagents of appropriate quality. 
In this regard, additional modification of the lignosulfonate was carried out with compounds containing phosphonic groups (Kulyashova, 2016; Pat. RF 2574659).

Modification of the lignosulfonate feed was carried out as follows: iron (II) sulfate was introduced into the mass of technical lignosulfonate. The mass was maintained with constant stirring for 1.0-1.5 hours at a temperature of $30-40^{\circ} \mathrm{C}$. Sodium dichromate was introduced into the resulting mass in the form of an aqueous $15-20 \%$ solution. The mass was maintained with constant stirring for 1 hour at a temperature of $30-40^{\circ} \mathrm{C}$. Then, a modifying agent was introduced, in the form of an aqueous solution, and again kept for 1 hour under the same conditions. The finished liquid product was neutralized with caustic soda to $\mathrm{pH}=3.5-5.0$. The finished mass was dried to a powder state, first at atmospheric pressure at a temperature of $65 \div 85^{\circ} \mathrm{C}$, then in a vacuum oven to a constant weight (Kulyashova, 2016). The obtained experimental drilling reagents were analyzed according to the requirements of analytical control adopted in the production of reagents that regulate the quality of a drilling fluid (Badikova et al., 2014).

\section{RESULTS AND DISCUSSION}

As raw materials for obtaining experimental modified lignosulfonate drilling reagents, technical aqueous solutions of lignosulfonates of various cooking methods were used: sulfite and neutral sulfite.

As shown in the references (Badikova et al., 2016; Teptereva et al., 2015), the qualitative characteristics of the obtained drilling reagents are directly conditioned by the chemical composition of the sources of raw materials (sulfite and neutral sulfite lignosulfonate) and modifiers containing phosphophonic groups.

A comparative analysis of the content of functional groups in lignosulfonate feedstock and modified drilling reagents based on it has been carried out. The determination has been carried out by IR spectrometry. The spectra were recorded on a FTIR-8400S (Shimadzu) FT-IR spectrometer in the range $700-4000 \mathrm{~cm}^{-1}$ with a device resolution of $4 \mathrm{~cm}^{-1}$.

The obtained IR spectra (Figure 1) of lignosulfonates are characterized by the following absorption bands: $1039-1089 \mathrm{~cm}^{-1}$ (SO3 groups); 3200-3600 $\mathrm{cm}^{-1}$ (OH groups); 1521 and $1558 \mathrm{~cm}^{-1}$ (substituted aromatic lignin ring); $1379 \mathrm{~cm}^{-1}$ relate to symmetric vibrations of the terminal methyl group; $1456,1458 \mathrm{~cm}^{-1}$ is the total content of methylene and methyl groups (Kazitsyna et al., 1971).

Figure 1 shows the IR spectrum of the experimental lignosulfonate sample modified with a compound containing phosphonic groups.

The presence of sulfogroups in the lignosulfonate macromolecule gives hydrophilic properties to a water-insoluble polymer.

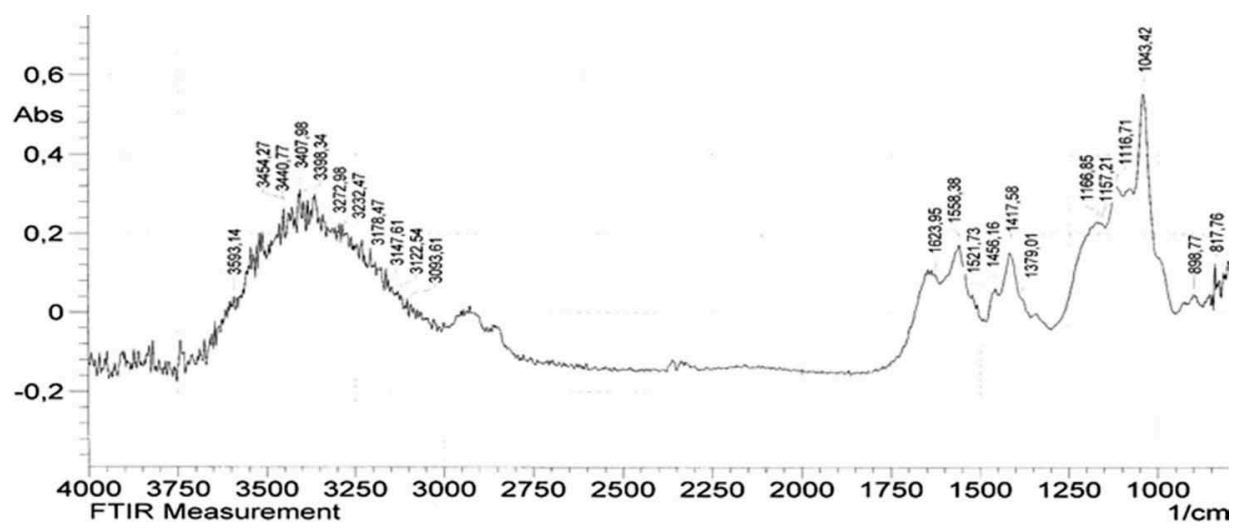

Figure 1. IR spectra of the ferrochrome lignosulfonate sample + TPF (sodium tripolyphosphate). 
According to the obtained analysis data by IR spectrometry, it was shown that the samples of modified lignosulfonate reagents were almost identical in the content of functional groups. In the infrared spectrum of the lignosulfonate modified with compounds containing phosphonic groups, absorption bands of the associated $\mathrm{P}=\mathrm{O}$ bond are observed in the region of $1157-1166 \mathrm{~cm}^{-1}$, which is presumably illustrative of the formation of an additional complex between the phosphonic group introduced into the carboxyl group of the phenylpropane unit of the lignosulfonate, and mainly iron cation (Kazitsyna et al., 1971).

To determine the thermal stability of the reagents tested, a clay mud prepared from Serpukhov mud powder of ПБМВ (PВМV) brand with the following parameters was taken as the basis: NV (nominal viscosity) $=64 \mathrm{~s}$, FI (filtration index $)=18 \mathrm{~cm}^{3} / 30 \mathrm{~min}, \eta_{\mathrm{pl}}\left(\eta_{\text {plastic viscosity }}\right)$ $=16 \mathrm{mPas}, \tau_{0}=68 \mathrm{dPa}$ (dynamic shear stress), SSS (static shear stress) ${ }_{1 / 10}=50 / 64 \mathrm{dPa}$. The obtained modified drilling reagents were introduced into the clay drilling mud and analyzed according to the GOST analysis methods (Kister, 1972; Darley et al., 1988). The results are presented in Table 1.

The influence of temperature in the range from $20^{\circ} \mathrm{C}$ up to $190^{\circ} \mathrm{C}$ on the change in technological parameters of the clay mud was determined when the sample was kept for 3 hours in the aging cell 'BOMBA A-B-05' (BOMB A-B-05).

Based on the results obtained in Table 1, it was found that an industrial sample of a drilling reagent, ferrochrome lignosulfonate, is able to effectively reduce the nominal viscosity from 64 up to $30 \mathrm{~s}$, filtering from 18 up to $6 \mathrm{~cm}^{3} / 30 \mathrm{~min}$, plastic (from 16 up to $12 \mathrm{mPas}$ ) and dynamic viscosity from 68 up to $52 \mathrm{dPa}$, static shear stress from 50/64 up to 15/45 dPa of No. 2 drilling mud with respect to No. 1 initial clay drilling mud. However, drilling fluids are used in a wide variety of mining and geological conditions, for example, when drilling wells at elevated bottomhole temperatures. The influence of temperature on No. 3 drilling fluid in the range up to $190^{\circ}$ leads to a decrease in qualitative indicators.

When a drilling reagent based on neutral sulfite liquor modified with TPF (sodium tripolyphosphate) is introduced into No. 5 drilling mud, the nominal viscosity decreases from $64 \mathrm{~s}$ up to $36 \mathrm{~s}$ and at the same time the heat resistance increases up to $190^{\circ} \mathrm{C}$.

When nitriletrimethylenephosphonic acid is modified with a ferrochrome lignosulfonate reagent based on neutral sulfite liquor in No. 4 drilling fluid, the nominal viscosity decreases from $64 \mathrm{~s}$ up to $34 \mathrm{~s}$, and it was found that at a concentration of $1 \%$ of the mass of introduced modifiers with complex containing properties, the best qualitative indicators were determined, filtration index: $6.5 \mathrm{~cm}^{3} / 30 \mathrm{~min}$. The addition of FCLS based on sulfite liquor, modified NTF and TPF to drilling fluids No. 6 and 7, reduces the nominal viscosity of No. 1 initial clay

Table 1. The effect of reagents on the parameters of clay drilling mud.

\begin{tabular}{|c|c|c|c|c|c|c|c|c|c|c|}
\hline \multirow[b]{3}{*}{ № } & \multirow[b]{3}{*}{ Solution composition } & \multirow[b]{3}{*}{$\begin{array}{l}\mathrm{T},{ }^{\circ} \mathrm{C} \\
3 \mathrm{~h}\end{array}$} & \multicolumn{8}{|c|}{ Solution Properties } \\
\hline & & & \multirow[b]{2}{*}{$\begin{array}{l}\rho, \\
\mathrm{g} / \mathrm{cm}^{3}\end{array}$} & \multirow[b]{2}{*}{$\mathrm{NV}, \mathrm{s}$} & \multirow[b]{2}{*}{$\begin{array}{l}\eta_{\mathrm{pl}}, \\
\mathrm{mPas}\end{array}$} & \multirow[b]{2}{*}{$\begin{array}{l}\tau_{0} \\
\mathrm{dPa}\end{array}$} & \multicolumn{2}{|c|}{$\mathrm{SSS}, \mathrm{dPa}$} & \multirow{2}{*}{$\begin{array}{l}\mathrm{FI}, \\
\mathrm{cm}^{3} / 30 \\
\min \end{array}$} & \multirow[b]{2}{*}{$\mathrm{pH}$} \\
\hline & & & & & & & $1 \mathrm{~min}$ & $10 \mathrm{~min}$ & & \\
\hline 1 & Initial clay mud (ICM) & 20 & 1.08 & 64 & 16 & 68 & 50 & 64 & 18.0 & 9.0 \\
\hline 2 & $\mathrm{ICM}+1 \% \mathrm{FCLS}^{*}$ & 20 & 1.09 & 30 & 12 & 52 & 15 & 45 & 6.0 & 9.0 \\
\hline 3 & ICM+1\% FCLS* & 190 & 1.08 & 64 & 14 & 98 & 87 & 105 & 9.0 & 9.1 \\
\hline 4 & $\mathrm{ICM}+1 \% \mathrm{FCLS}^{*}+\mathrm{NTF}$ & 190 & 1.07 & 34 & 14 & 57 & 15 & 44 & 6.5 & 9.0 \\
\hline 5 & $\mathrm{ICM}+1 \%$ FCLS $*+\mathrm{TPF}$ & 190 & 1.08 & 36 & 14 & 55 & 17 & 45 & 6.5 & 9.0 \\
\hline 6 & $\mathrm{ICM}+1 \%$ FCLS $* *+\mathrm{NTF}$ & 195 & 1.06 & 25 & 14 & 57 & 15 & 44 & 18.0 & 9.0 \\
\hline 7 & $\mathrm{ICM}+1 \% \mathrm{FCLS} * *+\mathrm{TPF}$ & 195 & 1.04 & 30 & 15 & 56 & 15 & 42 & 16.0 & 9.0 \\
\hline
\end{tabular}

* based on NSC (neutral sulfite liquor),

** based on SC (sulfite liquor),

Note: $\rho, \mathrm{g} / \mathrm{cm} 3$ - density; NV, s - nominal viscosity; $\eta_{\mathrm{pl}}$, mPas - plastic viscosity; $\tau_{0}$, mPas - relative viscosity; $\mathrm{SSS}, \mathrm{dPa}$ - static shear stress; FI, $\mathrm{cm}^{3} / 30 \mathrm{~min}$ - filtration index; $\mathrm{pH}-\mathrm{pH}$ (hydrogen) index. 
drilling mud from 64 up to $25-30 \mathrm{~s}$, and the filtration indexes remain almost unchanged compared to ICM No. 1.

According to the research results the influence of drilling reagents on the parameters of clay drilling mud, it was shown that the introduction of modifying agents made it possible to preserve, and in some cases improve the main qualitative characteristics, i.e. nominal viscosity and filtration index, and, among the modifiers used, the best results were achieved with the introduction of NTF or TPF containing phosphonic groups in a drilling reagent based on neutral sulfite liquor, preserving the parameters of drilling fluids No. 4 and 5, even at a temperature up to $190^{\circ} \mathrm{C}$.

Modification of lignosulfonates by cations of polyvalent metals that are part of iron sulfate and sodium dichromate in order to obtain ferrochrome lignosulfonates results reagent obtaining, that is a viscosity reducing agent, which is used in a wide range of temperatures and under various conditions (Hornof et al., 1981).

The main qualitative characteristics proved that modified drilling reagents based on neutral sulfite liquor can preserve the property of drilling fluids even at elevated temperatures up to $190^{\circ} \mathrm{C}$.

In this regard, a thermogravimetric analysis of a modified drilling reagent sample for thermal stability was carried out on a TGA-DSC instrument ('Mettler Toledo' company). For this, a weighed portion of the test sample $(5-15 \mathrm{mg})$ was placed in an alumina crucible with a volume of $70 \mu \mathrm{l}$. The measurements were carried out in the temperature range from $25^{\circ} \mathrm{C}$ up to $220^{\circ} \mathrm{C}$ at a heating rate of $5 \mathrm{deg} / \mathrm{min}$, the atmosphere - air, nitrogen. According to the results of a thermogravimetric analysis of lignosulfonate raw materials and reagents obtained on its basis, it was shown that the temperature of the beginning of decomposition in the raw materials in a neutral sulfite cooking method was $150^{\circ} \mathrm{C}$; and in modified drilling reagents was $190^{\circ} \mathrm{C}$ and $200^{\circ} \mathrm{C}$, respectively.

The content of iron and chromium compounds was determined by an energy dispersive $\mathrm{X}$-ray fluorescence analysis.

The elemental composition of the drilling reagent samples was determined on an EDX-800 Shimadzu energy dispersive X-ray fluorescence spectrometer with an X-ray tube with a rhodium anode under the following conditions: voltage $15-50 \mathrm{kV}$, current $20-1000 \mu \mathrm{A}$, in vacuum atmosphere, collimator $5 \mathrm{~mm}$, measurement time $15 \mathrm{~min}$. The analysis was carried out by the method of fundamental parameters, provided by software support of the device, using the measurement channels [Ti-U], [C-Sc], [S-K].

Samples for determining the elemental composition undergo minimal preliminary preparation. The sample powder is pressed into tablets on a boric acid substrate by the press at the pressure of 10-15 t (Badikova et al., 2016).

As an example, the results of the analysis of FCLS (industrial analogue) and FCLS + NTF (modified experimental reagent based on neutral sulfite liquor) are shown (Table 2).

The analysis shows that the composition is represented by 10 components. It should be noted that the calculation of the content of elements in the samples is carried out by the

Table 2. Results of comparative laboratory tests of the elemental composition.

\begin{tabular}{lrr}
\hline Analit & FCLS industrial & FCLS + NTF \\
\hline $\mathrm{S}$ & $21.482 \pm 0.04$ & $13.324 \pm 0.65$ \\
$\mathrm{Na}$ & $9.094 \pm 0.84$ & $3.877 \pm 0.44$ \\
$\mathrm{Fe}$ & $0.998 \pm 0.01$ & $0.849 \pm 0.01$ \\
$\mathrm{P}$ & $0.986 \pm 0.02$ & $2.754 \pm 0.11$ \\
$\mathrm{Cr}$ & $2.089 \pm 0.01$ & $0.450 \pm 0.02$ \\
$\mathrm{~K}$ & $0.579 \pm 0.03$ & $0.091 \pm 0.12$ \\
$\mathrm{Ca}$ & $0.241 \pm 0.17$ & $0.138 \pm 0.01$ \\
$\mathrm{Si}$ & $0.256 \pm 0.03$ & $0.191 \pm 0.02$ \\
$\mathrm{Cl}$ & $0.107 \pm 0.09$ & $0.072 \pm 0.05$ \\
$\mathrm{C}$ & $64.167 \pm 0.26$ & $78.159 \pm 1.35$ \\
\hline
\end{tabular}


method of fundamental parameters; the determination of elements in the form of oxides without the possibility of indicating valence is carried out formally according to the spectrometer software. C content should be considered as an organic component of the sample. The iron content in FCLS is $0.998 \%$ wt., and in the experimental sample is $0.849 \% \mathrm{wt}$.; chromium in FCLS is $2.089 \%$ wt., experimental reagent is $0.450 \% \mathrm{wt}$. The results are confirmed by the spectra.

According to the spectra, the elemental composition of the drilling reagents presented is consistent with tabular photon energies of the main lines of $\mathrm{K}$-series $(\alpha, \beta)$ and L-series $(\alpha, \beta)$.

According to the data obtained, it was found that the samples are comparable in terms of the basic elemental composition, but a decrease is observed in the chromium content in the developed modified reagent up to $0.450 \%$ wt. as compared with the industrial analogue of FCLS $(2.089 \%$ wt.), which contributes to a significant reduction in environmental risks when using an experimental reagent.

\section{CONCLUSIONS}

It was found that when modifying a ferrochromolignosulfonate reagent based on neutral sulfite liquor and/or sulfite liquor with phosphonic compounds, a drilling reagent with improved quality characteristics was obtained: the nominal viscosity is $34 \mathrm{~s}$ and $25-30 \mathrm{~s}$, the filtration index is $6.5 \mathrm{~cm}^{3} / 30 \mathrm{~min}$ and $16-18 \mathrm{~cm}^{3} / 30 \mathrm{~min}$, respectively.

The presented methodology for the modification of the lignosulfonate reagent makes it possible to obtain a drilling reagent, which is stable at high bottomhole temperatures $\left(190-195^{\circ} \mathrm{C}\right)$ and meet the environmental safety requirements by reducing the content of iron to $0.85 \%$ by weight. and chromium up to $0.45 \%$ by weight.

\section{REFERENCES}

Badikova A.D., Kulyashova I.N., Teptereva G.A., Kudasheva F.Kh., Konstantinov K.N. 2009. The effect of lignosulfonate tannidity on the rate of drilling fluid reagent dilution Series: Chemistry and Chemical Technology, V. 52, No. 4, pp. 69-70.

Badikova A.D., Yalalova R.A., Kulyashova I.N., Alekhina I.E., Tashbulatova V.F. 2016. Determination of chromium and iron in the composition of modified lignosulfonate drilling reagents by X-ray fluorescence analysis, Bulletin of the University of Bashkir, T. 21, No. 4, S. 931-934.

Badikova A.D., Yalalova R.A., Kulyashova I.N., Kudasheva F.Kh., Tsadkin M.A., Mortikov E.S. 2016 Modification of neutral sulfite liquors to obtain lignosulfonate drilling reagents, Chemistry and Technology of Fuels and Oils, 2016, No. 6 (598), P. 21-24.

Badikova A.D., Kulyashova I. N., Kudasheva F. Kh. 2014 Lignosulfonates of the neutral sulfite cooking method as a promising raw material for producing drilling reagents, Bashkir Chemical Journal, 2014, V. 21, No. 1, P. 64-66.

Bulatov, A.I., Makarenko P.P., Proselkov Yi. N. 1999. Drilling flushing and grouting solutions: a textbook for universities, M. Nedra, 1999, 424 pp.

Darley H.C.H., Gray G.R., 5th edition. Houston, TX: Gulf Professional Publishing, 1988, 643 p.

Hornof V., Neal G., Bourgeois P., Canad. J., Chem. Engng, 1981, Vol. 59, No. 8, p. 554

Kazitsyna L.A., Kupletskaya N.B. 1971. The use of UV, IR, NMR and mass spectroscopy in organic chemistry: a textbook for universities, M. Higher School, $240 \mathrm{pp.}$

Kister E.G. 1972. Chemical treatment of drilling fluids, M. Nedra, 392 P.

Komkova, L.P. 2011. Improving the quality of drilling drilling fluids using modified lignosulfonates: Abstract. dis. ... cand. tech. Sciences: 25.00.15.: 1-24.

Kulyashova, I.N. 2016. Improving the quality of drilling drilling fluids with modified neutral sulfite lignosulfonates: Abstract. dis. ... cand. tech. Sciences: 25.00.15.: 1-23.

Levik N.P. 1982. A.S. 956537 USSR. 1982, No. 33, 1 p.

Lurie Yu. Yu. 1984. Chemical analysis of industrial wastewater, M. Chemistry, $142 \mathrm{pp.}$

Lurie Yu. Yu. 1971. Unified methods of water analysis, M. Chemistry, 375 pp.

Pat. 2098447 Russian Federation, IPC C09K 7/00 (1995.01) A method for producing a lignosulfonate reagent for drilling fluids. 95109485/03 Decl. 06/06/1995, publ. 12/ 10/1997. 
Pat. 2038362 Russian Federation, IPC C09K 7/02 (1995.01) Drilling fluid. 93014619/03 Declared 03/ 22/ 1993,publ. 06/27/1995.

Pat. 2574659 Russian Federation, IPC C09K 8/03 (2006.01) A method for producing reagents for processing drilling fluids. 2015100383/03 Declared 01/ 12/2015,publ. 02/ 10/2016.

Pat. 2152419 Russian Federation, IPC C09K 7/02 (2000.01) A method for producing a lignosulfonate reagent for drilling fluids. 98116713/03 Decl. 09/ 07/1998,publ. 07/10/2000.

Teptereva G.A., Kulyashova I.N., Asfandiyarov L.Kh., Konesev G.V., Badikova A.D., Chetvertneva I. A. 2015. Reactivity of sulfite liquors as the basis of drilling reagents, Oil and Gas Business, No. 3, P. 91 


\title{
Improving the technical and economic efficiency of the Reservoir Pressure Maintenance system (RPM)
}

\author{
Sh.Sh. Zaurbekov \\ Doctor of Economics, Professor, Vice-Rector, Grozny State Oil Technical University named after Acad. M. \\ D. Millionschikov, Grozny, Russia \\ M.M. Labazanov \\ Ph.D., Head of Scientific and Technical Center "Nedra", Grozny State Oil Technical University named \\ after Acad. M.D. Millionschikov, Grozny, Russia \\ P.U. Musaeva \\ Laboratory Assistant, ILGGP Scientific and Technical Center Nedra, Grozny State Oil Technical Univer- \\ sity named after Acad. M.D Millionshchikov, Grozny, Russia
}

Z.I. Gadaeva

Head of the laboratory "ILGGP” NTC "Nedra", Grozny State Oil Technical University named after Acad. M.D. Millionschikov, Grozny, Russia

T.Kh. Ozdieva

Head of the laboratory "ILGEM" NTC "Nedra", Grozny State Oil Technical University named after Acad. M.D. Millionschikov, Grozny, Russia

I.R. Masarov

Assistant driller, production and exploration wells for oil and gas of the 5th category, Tomsk, Russia

Damzaev

Junior Researcher, Scientific and Technical Center "Nedra", Grozny State Oil Technical University named after Acad. M.D. Millionschikov, Grozny, Russia

ABSTRACT: Waterflooding of oil fields is undoubtedly the most effective way to develop them, providing high rates of oil recovery, significant periods of well flowing and an increase in oil recovery coefficient. Suffice it to say that $95 \%$ of all oil produced in the country is accounted for by fields developed using various modifications of waterflooding systems. At the same time, the amount of water pumped into the reservoirs on average doubles the volume of the selected oil.

Naturally, such volumes of injection are associated with huge investments and operating costs, determined by the need to drill injection and water wells, the construction of water intakes, pumping stations, long-term pressure pipelines, commissioning of sewage treatment plants, etc.

So, for example, 381 injection wells were drilled at one of the largest oil fields in the country - Mamontovskoye, 20 water wells from which Apt-Cenomanian water was extracted mechanically, 17 cluster pumping stations were built, each of which owed 7-10 bushes.

The total length of high-pressure pipelines in the field is $656 \mathrm{~km}$. The vast majority of the country's oil fields are equipped with similar RPM systems. The functioning and maintenance of such a complex economy is associated with the large operational costs of small oil production resources should be an increase in the technical and economic efficiency of the reservoir pressure maintenance system. The aforementioned will be caused by an increase in the injectivity of injection wells associated with a decrease in viscosity, both when using directly thermal water for flooding, and when heating injected surface water due to deep heat. 
Such an increase in the acceptability of injection wells allows decreasing wellhead injection pressures while maintaining injection volumes, or increasing injection volumes while maintaining these pressures, or reducing the number of injection wells while maintaining wellhead pressures and injection volumes.

\section{INTRODUCTION}

The most important task in the development and operation of oil fields is the maximum extraction of oil from productive formations. As was shown, the completeness of oil recovery from the reservoirs is characterized by the reservoir recovery coefficient, which varies widely over different fields. Various methods are used to maintain reservoir pressure and increase the coefficient of reservoir recovery, but methods such as injection of water or gas under pressure into productive formations have found the greatest application in practice. (Ozdoeva, Labazanov, Shaipov, Damzaev, 2017).

A system for maintaining reservoir pressure is the process of naturally or artificially maintaining pressure in productive formations of oil deposits at the initial or projected value in order to achieve high rates of oil production and increase the degree of oil recovery. The RPM system during the development of an oil reservoir can be implemented due to the natural active water pressure or water pressure elastic mode, artificial water pressure created as a result of injection of water into reservoir reservoirs during outflow or outflow, as well as during outflow flooding. Depending on the geological conditions and economic development indicators, one or another method of PPD or a combination of them is chosen.

For many decades of development of the oil industry, field development was carried out by drilling only production wells and extracting oil from them through the use of resources of all natural types of reservoir energy. After depletion of reservoir energy and a decrease in bottomhole pressure in production wells, sometimes fields were abandoned to zero when extracting no more than $25-30 \%$ of the initial oil reserves in the reservoir.

Artificial water flooding is widespread. At the fields developed with flooding, about $90 \%$ of the total oil production is currently produced, more than 2 billion $\mathrm{m} 3$ per year is pumped into the reservoirs. The popularity of artificial waterflooding of oil deposits is due to its following advantages:

- availability and free water;

- the relative simplicity of water injection;

- relatively high efficiency of oil displacement by water.

Initially, the use of water flooding was mainly associated with the injection of water into injection wells located in the marginal part of the field (marginal flooding). The principles of near-water flooding - multi-stage development, transfer of injection, shut-off of low-water wells and others - are not widespread. (Shupik 2013).

At present, block systems of in-circuit flooding are justified. With these systems, it is necessary to cut the oil field into blocks of optimal sizes, which exclude the conservation of oil reserves in the inner zones.

The oil industry at the present stage is the most powerful and highly efficient consumer of thermal waters, although for unknown reasons the volumes of thermal waters used in oil production are not taken into account when assessing the consumption of geothermal energy in the country as a whole.

With the use of water flooding, more than 350 fields are developed, providing $96 \%$ of the country's total oil production. Water flooding is the main method of developing oil fields. This allows the country to ensure the highest level and rate of oil production in the world.

In recent years, certain difficulties have been outlined in the development of the oil industry, a tendency to reduce the technical and economic indicators of field development, and the pace of development of the industry.

These difficulties and trends are due to modern features of the industry, the main of which can be summarized as follows: 
- The deterioration of the structure of reserves, which occurs both in the developed fields, due to their natural depletion and the accelerated development of highly productive parts, and in new fields due to the fact that the latter are characterized by low permeability of reservoirs, high viscosity of oil, high paraffin content in it, small oil-saturated thicknesses, occurrence of oil in the sub-gas parts and oil-water zones, etc. The above complicates the development process, leads to a decrease in oil recovery rates and oil production rates, requires an increase in the efficiency of existing development systems, the use of more active systems with tight well networks in new fields, necessitates the maintenance of not only reservoir pressure, but also temperature, and the use of new, more complex and expensive technologies, etc.

- Depletion and flooding of the country's main developed fields. Almost all of the large fields that provide the main oil production have entered the late stage of development. The commissioning of new capacities in the industry in recent years has been mainly spent on compensating for the increasing losses of production in fields entering the late stage of development, which are characterized by a significant drop in oil production, a rapid increase in water cut in well production, and the transfer of almost the entire stock to mechanized methods of raising the liquid, retirement of some of them from operation, increase in flow rates of wells by fluid, and withdrawal of fluid from the entire facility.

Due to the depletion and watering of the main developed fields from 1980 to 2010. there was an increase in the average water cut of well production from 57.5 to 74.6 , a water-oil factor from 1.35 to 2.91 , a decrease in fountain production from $45 \%$ to $25-30 \%$, an increase in the mechanized well stock from 64.4 to 149.9 thousand., an increase in the volume of injected water from 1.400 to 2 billion $\mathrm{m}^{3}$.

Field development under these conditions often requires a number of such capital-intensive technological and technical measures to further intensify the development and involve previously uncovered, worse in productivity and operating conditions parts of the deposits, such as additional cutting, creating foci of waterflooding, the transition to areal systems, the formation of fluid withdrawals from individual wells and fields, changing the direction of formation flows, conducting insulating work, etc.

The implementation of these measures requires the drilling of a significant number of additional wells, reconstruction of field facilities, waterflooding capacities, oil treatment and utilization of associated water, and energy re-equipment of the fields.

- Increasing the depth of well drilling in both the "old" and relatively new areas of oil production. Prospects for oil production, especially in the "old" oil producing areas, are associated with access to great depths (about 6000-7000 m). Deposits at these depths are characterized by high initial formation pressure and temperature, a high content of corrosive components (sulfur, hydrogen sulfide, carbon dioxide) in the formation fluids, and the possible manifestation of the plastic properties of oil-bearing rocks. The aforementioned features pose great challenges for science and industry in creating special methods for developing such deposits, and for the necessary drilling and technological equipment.

- A sharp increase in the stock of injection and production wells, especially requiring the use of more labor-intensive and expensive mechanized methods of operation.

- Relocation of the main volumes of oil production to areas with severe climatic conditions. If in 1990 these areas accounted for only about half of the country's oil production in 2010, more than $2 / 3$ of all production falls on these areas. With the aforementioned half-time increase in the stock of producing wells in the country as a whole, a three-fold increase is expected in these areas. The development of oil fields and the operation of wells under these conditions are associated with significant expenditures of fuel and energy resources for own needs. It is clear that the above main features of the current state of oil field development lead to a decrease in the efficiency of their development processes, technical and economic indicators of the development of the industry as a whole. The indicated tendency for their regular decrease is likely to continue in the future. Under these conditions, any positive step towards increasing the marked indicators will be a significant contribution to 
solving the most important tasks of the energy program. (Shaipov, Labazanov, Batukaev, Gadaeva, Damzaev, 2017).

In addition to injecting water or gas into the reservoirs, other methods of maintaining reservoir pressure are also used in practice: treating the injected water with surface-active substances (surfactants), injecting carbon dioxide into the reservoirs, and thermal methods. The use of surfactants for additives in injected water in small quantities (0.05-0.1\%) significantly reduces the surface tension at the border with oil and with a solid rock surface, reduces the necessary pressure drop for moving oil through the capillaries and contributes to better leaching of oil from the capillaries. According to laboratory studies, oil recovery when using surfactants can increase by $15-16 \%$.

One of the possible ways to maintain reservoir pressure, increase the efficiency and technical and economic indicators of oil field development is to more actively engage and use for this purpose thermal water resources, huge reserves of which are concentrated in the areas where oil production is located, especially in the Tersko-Sunzhenskoye oil and gas region. Some of the promising features of this method of reservoir pressure maintenance are described in this article.

The initial value of the reservoir temperature and its distribution are determined by the geothermal conditions in which the field is located. Typically, the reservoir temperature of oil fields corresponds to the geometric mean gradient in a given geological region. However, significant deviations of formation temperature from this value are also observed. Then it is believed that the reservoir temperature is increased or decreased. High temperature crust zones are called geothermal zones. (Grattoni Carlos, 2003).

In the process of developing an oil field, its reservoir temperature can change significantly. This occurs when substances, mainly water, are injected into the formation with a different temperature than the initial formation, as well as during exothermic reactions in the formation. To a much lesser extent, the reservoir temperature changes due to the throttling of the extracted liquids and gases and hydraulic friction against the formation rocks of the substances filtered in it.

The distribution of reservoir temperature underground and its change in time is called the temperature regime of the field. Temperature changes in oil reservoirs occur mainly due to thermal conductivity and convection.

Oil reservoirs are not thermally insulated from surrounding rocks and from other reservoirs. Therefore, any change in temperature in any section compared to other sections entails its redistribution and heat transfer due to thermal conductivity. The injection into the reservoir of water with a different temperature than the reservoir, and the extraction of oil from the reservoir with reservoir temperature lead to a change in the heat content in the reservoir and, consequently, the reservoir temperature.

Consider the process of oil displacement by water from a homogeneous rectilinear reservoir under conditions when the injected water has a different temperature than the reservoir. For simplicity, we assume that the displacement of oil by water is reciprocating, and the residual oil saturation decreases with increasing temperature according to a certain law.

An increase in the injectivity of the injection well with a decrease in the viscosity of the injected water follows from Darcy's law.

A significant decrease in the viscosity of water with increasing temperature, especially in the range of relatively low reservoir temperatures, causes a significant effect of this factor on the filtration resistance of the bottom-hole zone of the well. The dependence of the viscosity of mineralized water $\mu \mathrm{v}$ on temperature is quite accurately described by the following empirical formula:

$$
\mu_{v}=\left(35+0.7 M+0.22 M^{2}\right) /(+15.7)
$$

where $\mathrm{T}$ and $\mathrm{M}$ are the temperature and salinity of the water for which the viscosity value is determined.

Bottom water temperature is a function of flow rate, deep wells, geothermal gradient, wellhead temperature, etc. Theoretical assumptions and experience in thermal and per well shows 
that at fairly high costs in excess of $300-400 \mathrm{~m}^{3} /$ day. The change in water temperature along the wellbore at steady state is about $3^{\circ} \mathrm{C} / 1000 \mathrm{~m}$ depthTherefore, without resorting to complex solutions of the heat transfer equations in the wellbore, to assess the increase in injectivity of the well, we take the dependence of the bottomhole temperature in the injection well (with an average depth of $3000 \mathrm{~m}$ ) on its value at the wellhead, in the following simple form:

$$
t_{c}=t_{y}+10
$$

where $t_{c}$ and $t_{y}$ are the temperature of the injected water at the bottom and at the mouth.

Then, for the axisymmetric flow in the near-well zone of the injection well, for the flow rates of the wellhead temperatures $t_{\mathrm{y} 1}$ and $\mathrm{t}_{\mathrm{y} 2}$, one can obtain:

$$
\frac{\mathrm{q}_{2}}{\mathrm{q}_{1}}=\frac{\frac{1}{\mathrm{t}_{\mathrm{y}}+25.7} \ln \frac{10}{\mathrm{r}_{\mathrm{c}}}+\frac{1}{\mathrm{t}_{\mathrm{p}}+15.7} \ln \frac{\mathrm{R}_{\mathrm{k}}}{10}}{\frac{1}{\mathrm{t}_{\mathrm{y}}+25.7} \ln \frac{10}{\mathrm{r}_{\mathrm{c}}}+\frac{1}{\mathrm{t}_{\mathrm{p} 1}+15.7} \ln \frac{\mathrm{R}_{\mathrm{k}}}{10}}
$$

where $\mathrm{q}_{2}$ and $\mathrm{q}_{1}$ are flow rates at temperatures ty $\mathrm{y}_{1}$ and $\mathrm{ty}_{2} ; \mathrm{Rk}$ and $\mathrm{r}_{\mathrm{c}}$ are the radii of the drainage zone and the well; $\mathrm{t}_{\mathrm{pl}}$ - reservoir temperature.

When deriving formula (3), it was assumed that the radius of the zone around the bottom of the injection well cooled to a temperature $t_{c}$ is $10 \mathrm{~m}$.

The results of estimates for $R_{k}=500$ and $r_{c}=0.1 \mathrm{~m}$ at reservoir temperatures of 80 and $120^{\circ} \mathrm{C}$ (Figure 1).

The calculations were performed for the ranges of temperature changes of cold and hot (thermal) water characteristic of the conditions of deposits in Western Siberia. From the graph it follows that the increase in flow rate due to the injection of water at a higher temperature depends on the absolute values of wellhead temperatures.

So, for example, if, as a result of injection, thermal waters instead of normal, the temperature on the spine rises from four to $20^{\circ} \mathrm{C}$ at a reservoir temperature of $80^{\circ} \mathrm{C}$, the injectivity increases by $35 \%$. In the case of lifting and pumping thermal Cenomanian water through the same well, due to a decrease in heat loss during the transport of water, we can assume that a temperature of about $45^{\circ} \mathrm{C}$ is provided at the mouth.

With an increase in the water temperature at the wellhead from 4 to $45^{\circ} \mathrm{C}$ at a reservoir temperature of $80^{\circ} \mathrm{C}$, the injectivity of the well increases by $85 \%$. Thus, an increase in the injectivity of injection wells as a result of an increase in the temperature of the injected water (due to the transition to the injection of thermal water instead of the usual one), contributes to

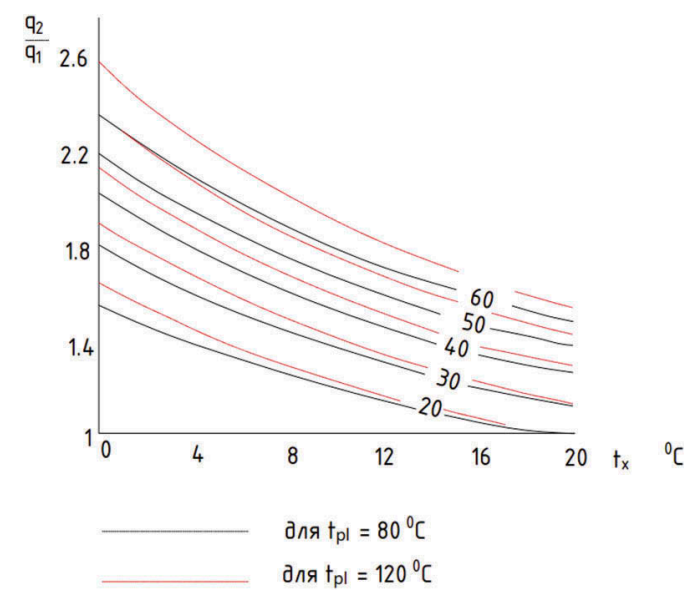

Figure 1. The dependence of the relative increase in the flow rate of the injection well from changes in the temperature of the injected water. 
a significant improvement in the technical and economic indicators of the pressure maintenance systems.

The increase in the technical and economic efficiency of RPM systems during the transition to thermal waterflooding, instead of the usual one, is largely associated with the acceleration of the development of RPM systems, with the exception or postponement of large investments in the construction of water intakes, structures and low pressure water pipelines at a later date.

In addition to the noted effects, the transition to flooding with warmer thermal water or surface water heated by deep heat will significantly reduce the pressure loss when pumping water from the pumping station to the bushes. In Western Siberia, pressure losses in high pressure waterways (3-10 km long), especially in winter, reach $15-30 \mathrm{~kg} / \mathrm{cm}^{2}$. Increasing the temperature of the water used for waterflooding is also important for the reliable operation of RPM systems at low temperatures. The noted significant reduces the likelihood of accidents associated with freezing of the mouths in the injection wells of their shafts in the intervals of permafrost distribution.

One of the promising directions of increasing the efficiency of waterflooding is the injection of formation water without lifting them to the surface. A well-known type of such injection is the transfer of water from water reservoirs into a drained oil reservoir. The simplicity of the technology and the exclusion of the aforementioned high costs associated with all ground structures of the RPM systems make this method especially valuable. However, the low filtration characteristics of real reservoir systems, the relatively small pressure differences created by the bypass and the hydrodynamic imperfection of the wells usually determine insufficient volumes of bypassed water. (Gabitov, Safonov, Strizhnev 2005).

The efficiency of the bypass in these cases can be significantly increased by taking measures to increase the pick-up coefficient.

In addition to the noted cost savings associated with the surface structures of the RPM system, it is obvious that in this case all the advantages that are characteristic of flooding the formations with thermal water are retained.

An even more promising and perfect method of flooding without raising the thermal formation water to the surface is the forced downhole pumping of water from the thermal formation into the oil one.

This method is based on the use of submersible pumps of the required capacity, installed directly in the wellbore in such a way as to take the required amount of water from the thermal reservoir and pump it into the water-filled oil reservoir.

Despite the lack of reliable experimental research in downhole injection, it can be assumed that this method, due to its great advantages, will find wide application in the near future.

\section{CONCLUSION}

The use of formation water instead of surface water, in addition to the listed advantages, allows saving large volumes of fresh water used for PPD systems. There is a shortage of fresh water in many, especially in the newly developed oil producing regions of Western Kazakhstan, the Caspian lowland, and Central Asia. Providing these areas with fresh water is associated with the laying of water pipelines of considerable length.

The volumes of water used to maintain reservoir pressure, as noted above, are huge. So, for example, at one of the largest oil fields of the Soyuz-Mamontovskoye, the annual injection in 1981 reached 49 million $\mathrm{m}^{3}$ (or 160,000 $\mathrm{m}^{3} /$ day). At the same time, 10 million $\mathrm{m}^{3}$ of Apt-Cenomanian reservoir water, about 5 million $\mathrm{m}^{3}$ of wastewater and about 35 million $\mathrm{m}^{3}$ of fresh water are ending. In total, since 1975, about 252 million $\mathrm{m}^{3}$ were pumped, of which 150 million $\mathrm{m}^{3}$ are fresh water. Even larger injection volumes are characterized by the largest oil field - Samotlor.

Currently, water injection at this field has reached 1.5 million $\mathrm{m}^{3} /$ day.

Obviously, the maximum use of thermal water instead of fresh water from surface sources, at such a scale of water flooding, saves huge amounts of fresh water.

It is known that both water from surface sources and associated water must be treated at special facilities before injection into oil reservoirs in order to reduce the content of solids and prevent infection of the reservoirs with sulfate-reducing bacteria 
This is associated with significant costs due to the need to use expensive equipment, scarce antiseptics and other reagents.

The use of formation water in the PPD system is usually possible without chemical treatment and purification. For example, for flooding productive formations of oil fields in Western Siberia, thermal waters of powerful water complexes of Apt-Cenomanian and Alb-Cenomanian deposits are used, which lie above productive horizons.

In terms of their physicochemical properties, these waters are close to the waters of productive formations; their displacement does not lead to the formation of precipitation and a decrease in the injectivity of injection wells; they do not require treatment and construction of treatment facilities. One of the drawbacks of surface water sources used for water supply to oil production is the development of microorganisms and algae in the bottom-hole zone of injection wells. In this case, sulfate-reducing bacteria pose the greatest danger. Propagation of these bacteria in the formation leads to the formation of sulfate ions $\left(\mathrm{SO}_{4}{ }^{-}\right)$, clogging the formation as a result of the activity of these bacteria in the formation, sulfides (FeS) are also formed, which in turn react with free iron. In this case, iron sulfide $\mathrm{FeS}$ itself is a blocking agent, and the hydrogen sulfide $\mathrm{H}_{2} \mathrm{~S}$, which is formed in this case, is a corrosive agent. The noted negative factors are completely eliminated when deep thermal formations are injected into the injection wells of thermal waters.

\section{REFERENCES}

Farkhutdinov A.M., Khamitov I.Sh., Cherkasov S.V., Mintsaev M.Sh., Zaurbekov Sh.Sh., Shaipov A. A., Labazanov M.M. 2017. Thermal groundwater of the East Ciscaucasia artesian basin: economic aspects of use on the example of the Khankalsky deposit. Tomsk. News of Tomsk Polytechnic University. Geo-Resource Engineering.

Gabitov G.Kh., Safonov E.H., Strizhnev V.A. and others. 2005. Improving the reservoir pressure maintenance system is the basis of the effective development of an oil field. Moscow. Oil industry.

Grattoni Carlos (Great Britain). 2003. Alternate water and gas injection, gas injection: Proceedings of the 12th European Symposium Enhancing Oil Recovery. Moscow.

Gumerov A.G., Bazhaikin S.G., Bagmanov A.A. and other. 2006. The technique of choosing pumping equipment for pumping water into the reservoir in the reservoir pressure maintenance system. Moscow. Enterprise Standard.

Edited by Kozlovsky E.A. 2001. Mountain encyclopedia. Moscow. Soviet Encyclopedia.

Lysenko V.D., Graifer V.I. 2001. Development of unproductive oil fields. Moscow. Nedra-Business Center LLC.

Ozdoeva L.I., Labazanov M.M., Shaipov A.A., Damzaev Z.M.E. 2017. The oil and gas potential of some areas in the Chechen Republic is promising. Grozny. In the collection: GEOTECHNOLOGIES OF THE XXI CENTURY Materials of the All-Russian Scientific and Practical Conference dedicated to the 100th anniversary of FSBEI HE "GSTU named after Acad. M.D. Millionschikova". Grozny State Oil Technical University named after academician M.D. Millionschikova.

Shaipov A.A., Labazanov M.M., Batukaev A.A., Gadaeva Z.I., Damzaev Z.M.E. 2017. Prospects for the development of thermal deposits in the Chechen Republic. Grozny. In the collection: FUNDAMENTAL AND APPLIED RESEARCH: PROBLEMS AND RESULTS Materials of the I International scientific-practical conference dedicated to the 100th anniversary of the FSBEI HE "GSTU named after academician MD Millionschikov": in 2 volumes. Grozny State Oil Technical University named after academician M.D. Millionschikova.

Shupik N.V. 2013. Improving reservoir pressure maintenance based on leading water flooding. Moscow. Oil and gas technology.

Zakharova EF, Pashanina O.D., Tronov V.P. 2003. Improving the reservoir pressure maintenance system at the Berezovsky field. Moscow. Electronic scientific journal "Oil and Gas Economy".

Zaurbekov Sh. Sh., Mintsaev M.Sh., Labazanov M.M., Shaipov A.A., Batukaev A.A. 2015. Improving the efficiency of well development in the oil fields of the Tersko-Sunzhenskoye oil and gas region. Grozny. Territory Neftegaz.

Zaurbekov Sh. Sh., Mintsaev M.Sh., Cherkasov S.V., Labazanov M.M., Shaipov A.A., Damzaev Z.M. E. 2015. Prospects for oil and gas potential and further areas of geological exploration within the TerskoSunzhenskoye oil and gas region. Grozny. Territory Neftegaz.

Zeigman, Yu.V. 2007. The operation of reservoir pressure maintenance systems in the development of oil fields: a training manual. USTU. - Ufa. Oil and gas business. 


\title{
Effective axial load as a function of the ultimate stress state of rocks to be drilled
}

\author{
L.K. Gorshkov \\ Saint-Petersburg military space Academy A. F. Mozhaysky, Saint-Petersburg, Russia
}

\author{
A.N. Dmitriev \\ St. Petersburg mining University, St. Petersburg, Russia
}

\begin{abstract}
This paper presents the study of the mechanism of well deepening in diamond drilling. Destruction of rocks under diamond drilling is represented by a set of deformation processes arising in rocks when destroying efforts are applied. Modern requirements to the technology and economic feasibility of drilling operations suggest continuous improvement in the field of the mechanism of bottom rock breaking. The article proposes a procedure to analyze situations at well bottom drilling deeper per a revolution of the diamond rock cutting tool. On the basis of the proposed procedure the authors analyze and operating influences to preserve the set and optimum deepening per a revolution are revealed under effective destruction of firm rocks. The estimation method of stress-strain state of rocks to be drilled and the choice of the maximum axial load in diamond drilling of rocks with different physical and mechanical properties.
\end{abstract}

\section{INTRODUCTION}

Optimization of drilling modes, improvement and creation of new high-performance rock destruction tools should play a big role in solving the problem of increasing drilling speed. Successful development of drilling technique and technology requires in-depth knowledge of patterns of the rock behavior at the well opening, patterns of rock destruction by the rockdestroying tool, structures, operation and wear of this tool. Thus, the study of the mechanics of bottomhole processes, methods of describing and calculating these processes will allow to develop an effective technology of the rock destruction.

The actual task in the current drilling conditions is to predict the drilling strength of rocks, to determine the concepts of choosing the drilling method and the rock-destroying tool in each individual case. The search for new ways to improve the efficiency and quality of drilling operations without increasing the energy consumption and resource of the rock-destroying tool by modernizing the drilling technology on the example of the method of optimizing the axial load is important for scientific and practical significance.

The problem of evaluating the limit state of rocks to be drilled can be categorized to the group of problems, where the main criteria for the solid body state are excessive crack opening or its complete destruction.

The main resistance parameter of rocks to be drilled is its normative resistance (tensile strength, yield strength, critical resistance, etc.), which determine the level of the maximum axial load on the rock-cutting tool.

\section{MATERIALS AND METHODS}

To assess the stress-strain state of rocks to be drilled and select the maximum permissible axial load for effective rock destruction in the drilling process, the flat problem solution (one of the 
main stresses is zero) of elasticity theory is most often used, at the same time the rocks at the bottom of the well experience normal vertical stress $\sigma_{x}$ (Figure 1), normal lateral compression stress $\sigma_{y}$ in the horizontal direction and shear stresses $\tau_{x y}$ that determine the adhesion of rocks during their destruction.

The above-mentioned normal stresses relate to each other according to the dependence:

$$
\sigma_{y}=\frac{1-\mu}{\mu} \cdot \sigma_{x}=\lambda \cdot \sigma_{x}
$$

where $\mu$ is the Poisson's ratio for the rock to be drilled; $\lambda$ is the lateral compression ratio.
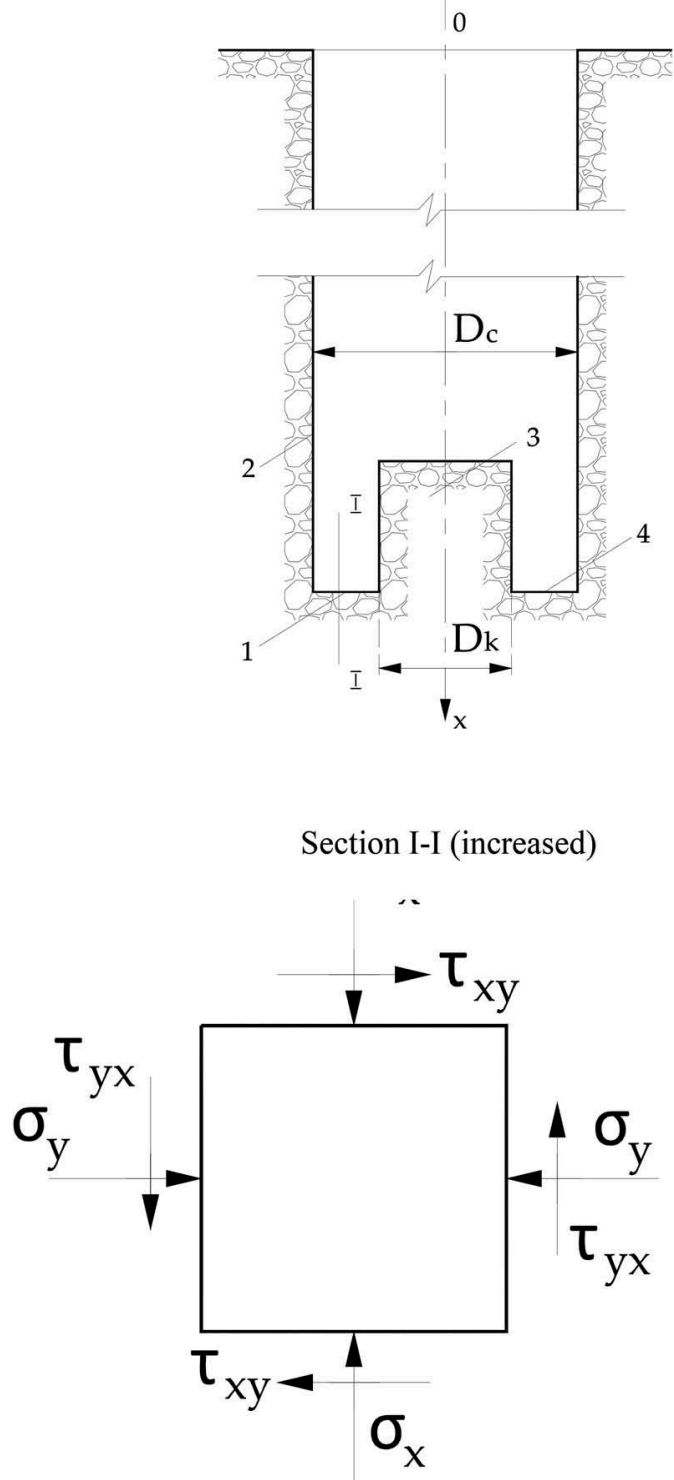

Figure 1. Calculation scheme for determining bottom-hole rock stresses, where: 1-the element of the array to be drilled allocated to the bottom; 2-the walls of the well; 3-the core column; 4-the bottom of the well; $\sigma_{x}$ and $\sigma_{y}$ normal stresses; $\tau_{x y}$ and $\tau_{y x}$ tangential stresses on the surfaces of the array element to be drilled. 


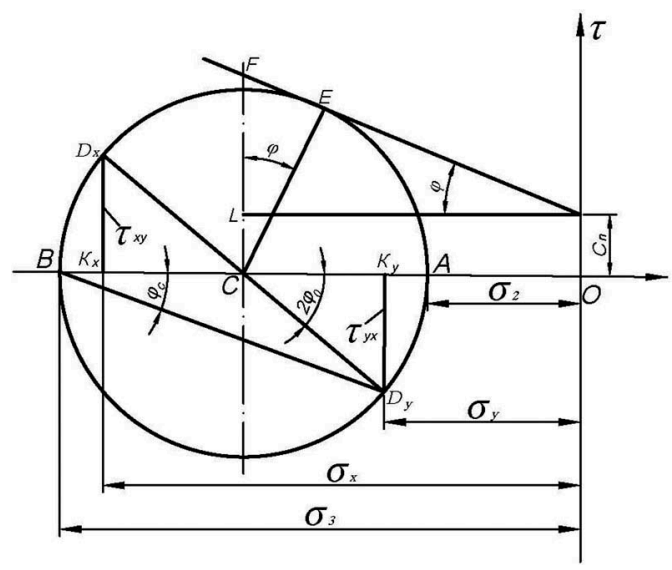

Figure 2. Graphical representation of stress distribution (Mohr circle) on the surfaces of an array element from the well bottom, where: $\sigma_{2}$ and $\sigma_{3}$-the main tension.

The relationship between the stresses $\sigma_{x}, \sigma_{x}$ and $\tau_{x y}$ can be obtained by constructing-for the case in question (see Figure 1) the corresponding Mohr circle (Figure 2), from which its understood that the envelope of the circle at the maximum level of the shear stress is spaced from the center of the circle at a distance

$$
\overline{F C}=C_{n}+\overline{F L}
$$

where $C_{n}$ the grip or the shifting strength of rocks.

If we take into account that

$\overline{F L}=\overline{O C} \cdot \operatorname{tg} \varphi$ and $O C=\frac{\sigma_{x}+\sigma_{y}}{2}$

we will have

$$
\overline{F C}=C_{n}+\frac{\sigma_{x}-\sigma_{y}}{2} \cdot \operatorname{tg} \varphi
$$

The radius of the Mora circle

$$
\overline{C D_{x}}=\overline{E X}
$$

then

$$
\overline{C D}_{x}=\overline{F C} \cdot \cos \varphi=C_{n} \cdot \operatorname{Cos} \varphi+\frac{\sigma_{x}+\sigma_{y}}{2} \cdot \sin \varphi
$$

where $\varphi$ is the angle of internal friction of the target rock.

From a triangle $C D_{x} K_{x}$ (see Figure 2) it follows that, in turn,

$$
\overline{C D_{x}}=\frac{\overline{D_{x} K_{x}}}{\sin 2 \varphi_{0}}=\frac{\left(\sigma_{x}-\sigma_{y}\right) \cdot \operatorname{tg} 2 \varphi_{0}}{2 \cdot \sin 2 \varphi_{0}}=\frac{\sigma_{x}-\sigma_{y}}{2} \cdot \cos 2 \varphi_{0},
$$

where $\varphi_{0}$-the angle of inclination of the area on which the stress acts $\sigma_{x}$, to the greatest main stress; $0<\varphi_{0}<0,8$ on average, $0.3 \mathrm{rad}$ for most cases of drilling in hard rocks are used $\varphi_{0}=$. 
Equating the right parts of expressions (2) and (3), we obtain

$$
\sigma_{x}=\frac{2 C_{n} \cos \varphi+\sigma_{y}\left(\sin \varphi+\cos 2 \varphi_{0}\right)}{\cos 2 \varphi_{0}-\sin \varphi}
$$

Or

$$
\sigma_{x}=\frac{2 C_{n}+\sigma_{y}(K+2 \operatorname{tg} \varphi)}{K}
$$

where $K$ is the reducing factor:

$$
K=\frac{\cos 2 \varphi_{0}-\sin \varphi}{\cos \varphi}
$$

Substituting the value $\sigma_{y}$ of the dependence (1) in the expression (4) and after some transformations we finally get

$$
\sigma_{x}=\frac{2 C_{n}}{K-\lambda(K+2 \operatorname{tg} \varphi)}
$$

The area of the contact surface on which the stress acts $\sigma_{x}$ is equal to

$$
f_{k}=\alpha \frac{\pi}{4}\left(D_{c}^{2}-D_{k}^{2}\right)
$$

Where $\alpha$-the coefficient characterizing the size of the cutters contact total area ratio with the cross-sectional area of the annular face of the well; for crowns with a diameter of 59 and $76 \alpha=0,06 \div 0,10 \mathrm{~mm}$, i.e. on average it is possible to use $\alpha=0,08 ; D_{c} \Pi D_{k}$-diameters of the well and core respectively.

Taking into account the expressions (6) and (7), we can write the expression for the maximum axial load on the well bottom during core drilling

$$
P_{n p}=\sigma_{x} \cdot f_{k}
$$

Or

$$
P_{n p}=\frac{\alpha \cdot \pi \cdot C_{n}\left(D_{c}^{2}-D_{k}^{2}\right)}{2[K+2 \operatorname{tg} \varphi]}
$$

The adhesion of rocks $C_{n}$ in the formula (8) can be expressed through the strength of rocks on uni-axial compression $\sigma_{\mathrm{cж}}$ and the coefficient of internal friction $\varphi$ (Bock, 1983):

$$
C_{n}=\frac{\sigma_{\text {сж }}}{2 \operatorname{tg}\left(\frac{\pi}{4}+\frac{\varphi}{2}\right)} .
$$

\section{RESULTS AND DISCUSSION}

Using the given calculation method, it is possible to determine the maximum axial loads during drilling of rocks with different physical and mechanical properties and different drilling capacity. 
Table 1. Physical and mechanical properties of rocks.

\begin{tabular}{|c|c|c|c|c|c|c|c|}
\hline № & $\begin{array}{l}\text { Formation } \\
\text { rock }\end{array}$ & $\begin{array}{l}\text { modulus of elasti- } \\
\text { city } E, 10^{5} \mathrm{MPa}\end{array}$ & $\begin{array}{l}\text { Poisson's } \\
\text { ratio, } \\
\mu\end{array}$ & $\begin{array}{l}\text { coefficient of } \\
\text { lateral } \\
\text { compression, } \\
\lambda\end{array}$ & $\begin{array}{l}\text { One-axial com- } \\
\text { pressive strength } \\
\sigma_{\text {сж⿱ }}, M P A\end{array}$ & $\begin{array}{l}\text { Internal } \\
\text { friction } \\
\text { angle } \\
\varphi, \text { grad. }\end{array}$ & $\begin{array}{l}\text { Rock } \\
\text { adhesion } \\
C_{n}, M P a\end{array}$ \\
\hline 1. & Basalt & 1,0 & 0,28 & 0,39 & 290 & 50 & 52,7 \\
\hline 2. & Granit & $0,55-0,9$ & 0,25 & 0,33 & 210 & 48 & 40,3 \\
\hline 3. & Gabbro & 1,05 & 0,34 & 0,51 & 200 & 46 & 40,4 \\
\hline 4. & Limestone & $0,2-0,9$ & 0,22 & 0,28 & 110 & 50 & 20,0 \\
\hline 5. & Sandstone & $0,1-0,7$ & 0,30 & 0,43 & 105 & 47 & 20,7 \\
\hline 6. & Hard shale & 0,4 & 0,25 & 0,33 & 75 & 45 & 15,6 \\
\hline 7. & Siltstone & 0,3 & 0,26 & 0,35 & 60 & 43 & 13,0 \\
\hline 8. & Argillite & 0,2 & 0,24 & 0,32 & 45 & 42 & 10,0 \\
\hline
\end{tabular}

Table 2. Ultimate axial loads of some rocks during drilling by diamond crowns with diameters of 59 and $76 \mathrm{~mm}$.

\begin{tabular}{|c|c|c|c|c|c|c|}
\hline \multirow[b]{2}{*}{ № } & \multirow[b]{2}{*}{$\begin{array}{l}\text { Formation } \\
\text { rock }\end{array}$} & \multirow{2}{*}{$\begin{array}{l}\text { Category of } \\
\text { rocks by } \\
\text { drillability }\end{array}$} & \multirow{2}{*}{$\begin{array}{l}\text { Shorthand } \\
\text { multiplier } \\
\mathrm{K}\end{array}$} & \multirow[b]{2}{*}{$\begin{array}{l}\sigma_{x} \\
\mathrm{MPa}\end{array}$} & \multicolumn{2}{|c|}{$\begin{array}{l}\text { Maximum axial loading, } \\
\mathrm{kN}\end{array}$} \\
\hline & & & & & $\begin{array}{l}\text { Calculation results } \\
\mathrm{P}_{\text {пр }}\end{array}$ & Recommendations [4] \\
\hline 1. & Basalt & $\mathrm{X}$ & 0,71 & 127,9 & $7-15 / 11-19$ & $8-15 / 12-17$ \\
\hline 2. & Granit & IX - X & 0,199 & 134,3 & $8-16 / 12-21$ & $8-15 / 12-17$ \\
\hline 3. & Gabbro & IX & 0,233 & 85,8 & $6-11 / 8-14$ & $6-12 / 8-13$ \\
\hline 4. & Limestone & VII - VIII & 0,171 & 73,5 & $5-9 / 7-12$ & $6-8 / 8-12$ \\
\hline 5. & Sandstone & VII & 0,213 & 51,8 & $4-7 / 5-9$ & $4-8 / 5-10$ \\
\hline 6. & Hard shale & VII & 0,239 & 62,4 & $4-8 / 6-10$ & $4-8 / 5-10$ \\
\hline 7. & Siltstone & VI & 0,265 & 54,0 & $4-7 / 5-9$ & $4-8 / 5-10$ \\
\hline 8. & Argillite & V - VI & 0,279 & 51,8 & $4-7 / 5-8$ & $4-7 / 5-8$ \\
\hline
\end{tabular}

As an example, Table 1 shows the data of physical and mechanical properties (Bulychev, 1989; Gorshkov, 1992) calculations of some rocks, drilled by diamond crowns, and in Table 2-values of limit axial loads for the same rocks drilled with crowns of $59 \mathrm{~mm}$ (in the numerator) and $76 \mathrm{~mm}$ (in the denominator) diameters in comparison with other data (Gorshkov, 2000).

From Table 2 conclusions can be made that the limiting axial loads calculated by the proposed method are satisfactorily correlated with their values obtained experimentally from the device "ВИТР". Some deviations of the compared data are explained by inaccuracies in determining the coefficient of internal friction of rocks and the value of the lateral compression coefficient, depending both on the depth of the well in the drilling interval and on geological and tectonic conditions, as well as a fairly rough averaging of the coefficient $\alpha$ in formula (7), which is determined by the level of bulky diamond saturated crowns (Gorshkov, 1992).

\section{CONCLUSIONS}

Using of the described technique, it is possible to determine the most optimal operating conditions of the rock-destroying tool.

The validity of the technique is confirmed by the close convergence of the results of the theoretical and experimental studies. The statistical evaluation of the results of the experimental 
studies showed that the error is not more than 5\%. Nevertheless, the calculation showed sufficient simplicity and practical applicability of the proposed method for determining the maximum permissible axial loads in diamond drilling, at least at the preliminary stage, which is confirmed by the results of the study (Blinov et al., 1983).

\section{REFERENCES}

Bock H. Introduction to the mechanics of rocks. - M .: Mir, 1983.

Bulychev N.S. Mechanics of underground structures in the examples and tasks. - M .: Nedra, 1989.

Gorelikov V.G. The classification and analysis of the methods of determining the diamond's number involved in the destruction of rock/Yu.V. Lykov, Baatarkhuu Gantulga. The collection of the master and postgraduate student's research, 2014. № 9/156, - pp. 115-117.

Gorshkov L.K. Temperature modes of diamond drilling/L.K. Gorshkov, V.G. Gorelikov.- M.: Nedra, 1992. - p. 73.

Gorshkov L.K. Assessment of the stress-strain state of the diamond crown matrix during dynamic interaction with a mountain massif/L.K. Gorshkov, V.I. Spirin// Collection of "Geological study and use of the subsoil", Vol. 3. - M .: Geoinformmak, 2000. - p. 3-14.

Neskoromnykh V.V. Rock destruction in geological survey. [Razrushenie gornyh porod pri provedenii geologo-razvedochnyh rabot]. Uchebnik-Textbook. Krasnoyarsk: Publ.H. SFU, 2012, 297 p.

Reference guide of the master exploration drilling/ G.A. Blinov, V.I. Vasiliev, Yu.V. Baklanov and others. - L .: Nedra, 1983. 


\title{
Polymer compositions for well killing operation in fractured reservoirs
}

\author{
S.R. Islamov \\ Postgraduate student, Saint Petersburg Mining University, St. Petersburg, Russia
}

A.V. Bondarenko

Student, Saint Petersburg Mining University, St. Petersburg, Russia

A.F. Gabibov

Student, Saint Petersburg Mining University, St. Petersburg, Russia

D.V. Mardashov

PhD, Associate professor, Saint Petersburg Mining University, St. Petersburg, Russia

\begin{abstract}
This article describes the results of physical, chemical and rheological properties of the frame and gel forming compositions, which are crosslinked systems prepared based on soluble silicates. The aim of this work is to increase the well killing efficiency during well service operations in the conditions of fractured carbonate reservoirs, high gas-oil ratio and abnormally low reservoir pressure. The technology of well killing during well service operation involves sequential injection into the well. The considered compositions showed that they could be used in conditions of reservoir temperatures from $20^{\circ} \mathrm{C}$ to $90^{\circ} \mathrm{C}$, which consists in the possibility of injection these compositions into a typical well and selling them into the bottom-hole formation zone due to their low viscosity after preparation and slow cross-linking speed. Laboratory tests showed the high efficiency of the use of blocking polymer compositions, and opened new directions for further research, namely, the need for a cycle of laboratory and field tests of the considered compositions, which will allow us to choose and justify the optimal technological and economic parameters of the operation. The results can be applied to increase the well killing efficiency of oil and gas wells in complicated conditions during well service operations.
\end{abstract}

\section{INTRODUCTION}

Currently, based on the assessment of reserves, the share of carbonate reservoirs accounts for about $60 \%$ of hydrocarbon fields and about the same amount of oil production in the world. The development of such reservoirs is complicated by the presence of an extensive network of natural and artificial (as a result of hydraulic fracturing) fractures, high heterogeneity, complex structure of the pore space, hydrophobic properties of reservoir rocks and abnormally low reservoir pressure.

The considered characteristic features of carbonate reservoirs can lead to low coverage of the formation impact, low displacement efficiency, quick well flooding, gas breakthrough, and, as a result, a rapid decline in oil production (Bouts et al. 1997; Dorman \& Udvary 1996; Rogachev \& Strizhnev 2006).

The presence of reservoirs with similar characteristics in the field requires a special, differentiated approach to planning well killing operations related to the development and selection of blocking composition. The correct selection of blocking compositions for well killing requires careful laboratory tests for specific objects of the planned application. 
Failure to comply with the above conditions when planning activities at the well may lead to the loss of significant volumes of process fluids, increase the repair and response time, which, ultimately, will lead to an increase in the cost of well service operations (Dandekar 2013; Jouenne et al. 2006).

An advanced solution in the development of blocking fluids is the use of cross-linked polymer compositions with time-controlled gelation. The rate of change of viscosity can be adjusted to more efficiently carry out technological operations.

Technologies using the described polymer compositions have proven to be a reliable method for isolating highly permeable reservoir intervals in order to prevent water and gas breakthrough into production wells (Gumerova \& Yarkeyeva 2017).

As part of this work, the physical, chemical and rheological properties of the frame and gel forming compositions were selected and studied as blocking polymer fluids for well killing.

These compositions are crosslinked systems based on soluble silicates. In this case, a silicate gel is formed when an aqueous solution with a relatively high $\mathrm{pH}$, containing a sufficient amount of orthosilicic acid ester monomer or orthosilicic acid oligomers, experiences a decrease in its $\mathrm{pH}$, or is exposed to hardness cations (Volkov et al. 2019; Musabirov et al. 2019; Tokunov \& Saushin 2004).

The technology for well killing during well service operation involves sequential injection of frame and gel forming compositions into the well.

The procedure for conducting laboratory physical, chemical and rheological tests of compositions consisted of several consecutive stages:

1) determination of density;

2) assessment of thermal stability;

3) assessment of destruction;

4) determination of effective viscosity and static shear stress;

5) determination of the gelation time of cross-linked compositions.

\section{MATERIALS AND METHODS}

\subsection{Investigation of physical and chemical properties of compositions}

The frame-forming composition is an opaque non-uniform white liquid. When injected into the reservoir, the liquid phase is separated, and the dry residue is "baked" at elevated temperatures, forming a strong frame-forming screen for isolating intervals with increased fracturing. This feature of the composition allows to reduce the fluid loss into the well during well killing operation.

In turn, the gel-forming compositions are a transparent homogeneous liquid, which due to its high viscosity has a low filtration index in the reservoir, and is also able to prevent gas breakthrough in high gas-oil ratio conditions. At the same time, the gel-forming composition was prepared in two versions with a gel-forming agent for low $\left(20^{\circ} \mathrm{C}\right)$ and high $\left(90^{\circ} \mathrm{C}\right)$ temperatures.

The density of the frame and gel forming compositions was determined by the pycnometric method according to (GOST 3900-85 2006) and amounted to $1045 \mathrm{~kg} / \mathrm{m}^{3}$ and $1015 \mathrm{~kg} / \mathrm{m}^{3}$ for low temperatures, and for high temperatures $-1022 \mathrm{~kg} / \mathrm{m}^{3}$ ), respectively. This value of the density of the studied compositions allows them to be used at normal and reduced values of reservoir pressure (Galimkhanov et al. 2019; Rogachev \& Kondrashev 2016).

To assess the thermal stability, the prepared composition fulfilled in a thermostat at a temperature of $20^{\circ} \mathrm{C}$ or $90^{\circ} \mathrm{C}$ for 3 days (average duration of well service operation). Then the state of the composition under study and the change in its appearance were visually evaluated. The composition was considered unstable when the water phase was isolated, stratified, and precipitated.

The destructibility of the frame and gel forming compositions was evaluated visually at temperatures of $20^{\circ} \mathrm{C}$ and $90^{\circ} \mathrm{C}$ for 24 hours by mixing the destructor with the studied blocking compositions in 1:1 ratios. A $10 \%$ aqueous solution of sodium hydroxide was used as the 
destructor of the gel-forming composition, and a mixture of $12 \%$ hydrochloric and $5 \%$ hydrofluoric acids was used for the destruction of the frame-forming composition.

\subsection{Determination of the rheological properties of the compositions}

The study of rheological properties of the frame and gel forming compositions consisted in determining the following parameters:

- effective viscosity at $300 \mathrm{rpm}$;

- "viscosity curves" (dependence of the effective viscosity on the shear rate or rotor speed);

- Static shear stress after gelation of cross-linked compositions in the controlled shear rate mode by plotting the dependence of the shear stress $\tau$ on the shear rate $\mathrm{D}$, determining the shear stress at which the structure of the composition begins to collapse and move;

- time of gelation of cross-linked compositions in the "dynamic" mode by measuring the effective viscosity $\mu_{\text {eff }}$ of the composition in time at a given shear rate equal to the rate of injection of the composition into the well, and in the "static" mode of oscillating stresses by measuring the complex viscosity in time.

The construction of the "viscosity curve" and the determination of the static shear stress was carried out for the frame and gel forming compositions. Static shear stress characterizes the initial pressure gradient at which the structure of the composition collapses and moves (Strizhnev 2010).

Experiments to determine the gelation time were performed only for cross-linked compositions that are nonlinear gels.

Determination of rheological characteristics is carried out according to (GOST 1929-87 2002) with the use of automated rotary viscometer Rheotest RN 4.1 (Figure 1). Measurements were made using a cylindrical measuring system.

I. Sequence of studies of linear (non-crosslinked) compositions:

1. Modeling the process of starting the movement of the composition (destruction of the structure of the composition). The static shear stress is determined by plotting the dependence of the shear stress on the shear rate in the controlled shear stress mode. The static shear stress is equal to the value of the shear stress $\tau$, preceding the destruction of the structure of the composition, and characterizes the beginning of the movement of the composition. The conditions of the experiment:

- pre-exposure of the composition in the measuring cell for 15 minutes;

- experiment time $\mathrm{t}=0-500 \mathrm{~s}$;

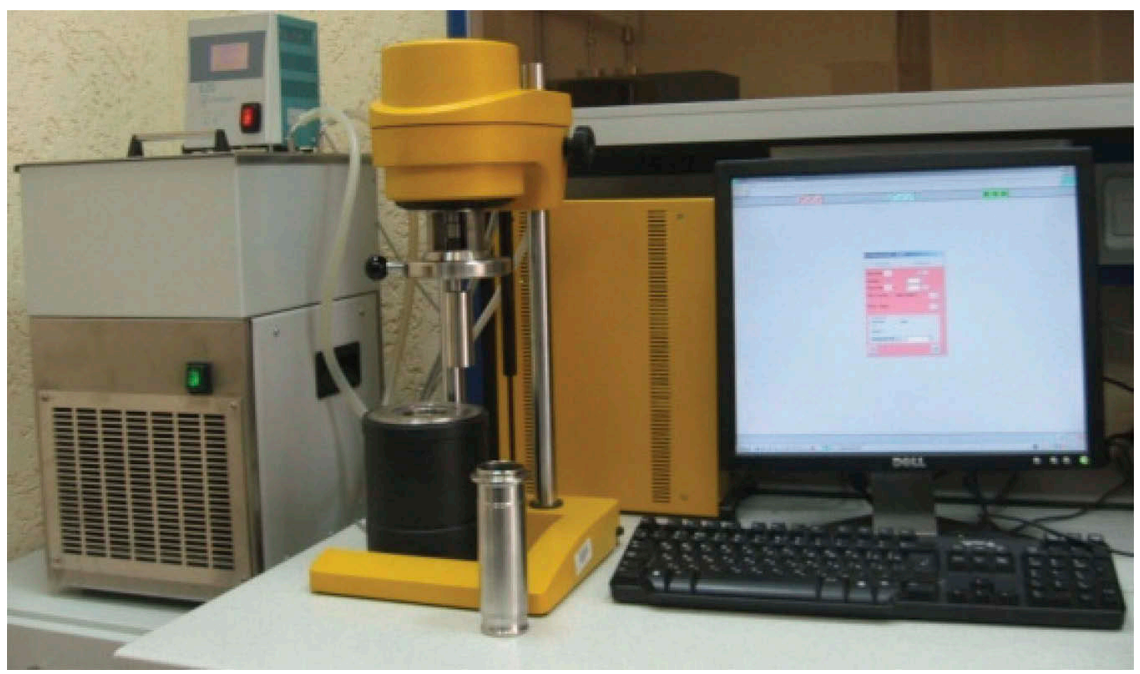

Figure 1. Rotational automated viscometer Rheotest RN 4.1. 
- shear stress $\tau=0-2000 \mathrm{~Pa}$;

- temperature $\mathrm{T}=20-90^{\circ} \mathrm{C}$, respectively.

2. Determination of the effective viscosity was carried out in the controlled shear rate "viscosity curve" (CR test - Controlled Rate). The essence of the research method was to obtain the dependence of the effective viscosity (shear stress) on the shear rate (rotational speed) with a gradual increase in the last parameter from 0 to $300 \mathrm{~s}^{-1}$. The conditions of the experiment:

- experiment time $\mathrm{t}=0-300 \mathrm{~s}$;

- shear rate $\gamma=0-300 \mathrm{~s}^{-1}$;

- temperature $\mathrm{T}=20-90^{\circ} \mathrm{C}$, respectively.

II. Due to the fact that the gel-forming composition changes the viscosity over time, it was decided to conduct a step-by-step study of rheological characteristics according to the following scheme (Raupov \& Oprikova 2018; Ryabokon 2009):

1. Modeling the state of the composition immediately after preparation at the wellhead to assess filterability in the inter-tube space or in a column of tubing. The effective viscosity of the composition at different shear rates is determined by removing the "viscosity curve". The conditions of the experiment:

- experiment time $\mathrm{t}=0-300 \mathrm{~s}$;

- shear rate $\gamma=0-300 \mathrm{~s}^{-1}$;

- temperature $\mathrm{T}=20^{\circ} \mathrm{C}$.

2. Modeling the process of pumping the composition through the tube space into the well, taking into account the uniform temperature change along the well bore. The gelation time is determined at a constant shear rate. The conditions of the experiment:

- experiment time $\mathrm{t}=85 \mathrm{~min}$;

- shear rate $\gamma=21.8 \mathrm{~s}^{-1}$;

- temperature $\mathrm{T}=20-90^{\circ} \mathrm{C}$ (for the composition applicable at $20^{\circ} \mathrm{C}$, the experiment temperature $\mathrm{T}=20^{\circ} \mathrm{C}$ ).

3. Modeling the process of pumping the composition into the space of the production string. The determination of the gelation time at a constant shear rate continues. The conditions of the experiment:

- experiment time $\mathrm{t}=15$ min;

- shear rate $\gamma=7.1 \mathrm{~s}^{-1}$;

- temperature $\mathrm{T}=90^{\circ} \mathrm{C}$ (for a composition applicable at $20^{\circ} \mathrm{C}$, the experiment temperature $\mathrm{T}=20^{\circ} \mathrm{C}$ ).

4. Modeling the process of holding the composition for the reaction time (the end of the crosslinking process) at the reservoir temperature. The time of gelation in the static mode of oscillating stresses is determined (Elchin et al. 2019; Quintero et al. 2017). The conditions of the experiment:

- experiment time $\mathrm{t}=3 \mathrm{~h}$;

- the oscillation frequency of the rotor $\mathrm{f}=1 \mathrm{~Hz}$;

- voltage modulus $\mathrm{G}=10 \mathrm{~Pa}$;

- temperature $\mathrm{T}=90^{\circ} \mathrm{C}$ (for a composition applicable at $20^{\circ} \mathrm{C}$, the experiment temperature $\mathrm{T}=20^{\circ} \mathrm{C}$ ).

5. Modeling the process of starting the movement of the composition (destruction of the structure of the composition). The static shear stress is determined by plotting the dependence of the shear stress on the shear rate in the controlled shear stress mode. The conditions of the experiment:

- experiment time $\mathrm{t}=0-500 \mathrm{~s}$;

- shear stress $\tau=0-2000 \mathrm{~Pa}$;

- temperature $\mathrm{T}=90^{\circ} \mathrm{C}$ (for the composition used at $20^{\circ} \mathrm{C}$, the experiment temperature $\mathrm{T}=20^{\circ} \mathrm{C}$ ).

6. Modeling the state of the composition after injection into the well to assess changes in its effective viscosity. The effective viscosity of the composition at different shear rates is determined by removing the "viscosity curve". The conditions of the experiment: 
- experiment time $\mathrm{t}=0-300 \mathrm{~s}$;

- shear rate $\gamma=0-300 \mathrm{~s}^{-1}$;

- temperature $\mathrm{T}=90^{\circ} \mathrm{C}$ (for the composition used at $20^{\circ} \mathrm{C}$, the experiment temperature $\left.\mathrm{T}=20^{\circ} \mathrm{C}\right)$.

\section{RESULTS AND DISCUSSION}

The evaluation of thermal stability of frame-forming composition (Table 1) revealed that 15 min after preparation of the composition at $20^{\circ} \mathrm{C}$ and $90^{\circ} \mathrm{C}$ of the composition is given up to 20 and $25 \%$ of water, respectively. When further thermostating, the amount of water released remains virtually unchanged. At the same time, the producer of the frame-forming composition allows the release of water in a small amount from the volume of the composition. Therefore, it was decided that the frame-forming composition is thermal stable at $20^{\circ} \mathrm{C}$ and $90^{\circ} \mathrm{C}$ and is able to maintain its physical and chemical properties during well service and workover operations.

At the same time, when the gel-forming composition was thermostated, no visible changes in appearance were observed during the entire period time.

It is worth noting that the requirement for such a type of composition in well killing operation is their complete or partial destructibility when exposed to a destructor. Compositions that do not meet these conditions cannot be recommended for use. Since this entails a deterioration of the reservoir's filtration and reservoir properties, as well as difficulties in developing and bringing the well back to normal after well service and workover operations.

The destructibility of the frame and gel forming compositions was evaluated visually at temperatures $20-90^{\circ} \mathrm{C}$ for 24 hours by mixing the destructor with the studied blocking compositions in 1:1 ratios. A 10\% aqueous solution of sodium hydroxide was used as the destructor of the gel-forming composition, and a mixture of $12 \%$ hydrochloric and $5 \%$ hydrofluoric acids was used for the destruction of the frame-forming composition.

As a result of evaluating the destruction of the frame and gel forming compositions (Table 2) it was found that these compositions can be recommended for use in the well-killing process. The results of evaluating the destruction of the frame and gel compositions showed the following:

- the gel-forming composition is completely destroyed within 1 and 3 hours with a $10 \%$ aqueous $\mathrm{NaOH}$ solution at 90 and $20^{\circ} \mathrm{C}$, respectively;

- the frame-forming composition is destroyed by $75 \%$ within 24 hours with a mixture of $12 \%$ hydrochloric and $5 \%$ hydrofluoric acids (mud acid) at 90 and $20^{\circ} \mathrm{C}$, respectively. The future observation showed insignificant changes because when reacting with a frame-forming composition, mud acid loses reactivity.

Summarized results of rheological tests of the compositions are presented in Table 3.

The results of determining the gelation time under the conditions of injection of crosslinked compounds are shown in Figures 2-3.

Based on the results presented in (William et al. 1996), the higher the static shear stress, the greater the pressure gradient blocking composition is able to withstand without collapsing. The same conclusions are valid when the effective viscosity increases, since it increases its structural strength.

Table 1. Results of determining the thermal stability of the frame and gel forming compositions.

\begin{tabular}{|c|c|c|c|c|}
\hline No. & $\begin{array}{l}\text { Composition } \\
\text { name }\end{array}$ & $\begin{array}{l}\text { Thermal stability at } \\
20^{\circ} \mathrm{C} \text { for } 3 \text { days }\end{array}$ & $\begin{array}{l}\text { Thermal stability at } \\
90^{\circ} \mathrm{C} \text { for } 3 \text { days }\end{array}$ & Remark \\
\hline 1 & Frame-forming & + & + & \multirow{2}{*}{$\begin{array}{l}\text { Allocation of up to } 20 \text { and } 25 \% \\
\text { of water, respectively } \\
\text { - }\end{array}$} \\
\hline 2 & Gel-forming & + & + & \\
\hline
\end{tabular}


Table 2. Results of evaluation of the destruction processes of the frame and gel forming compositions.

\begin{tabular}{lllllll}
\hline No. & $\begin{array}{l}\text { Composition } \\
\text { name }\end{array}$ & $\begin{array}{l}\text { Temperature, } \\
{ }^{\circ} \mathrm{C}\end{array}$ & $\begin{array}{l}\text { Destruction } \\
\text { results }\end{array}$ & $\begin{array}{l}\text { Destruction } \\
\text { time, } \mathrm{h}\end{array}$ & Destructor & $\begin{array}{l}\text { Recommendation } \\
\text { for use }\end{array}$ \\
\hline 1 & $\begin{array}{l}\text { Frame- } \\
\text { forming }\end{array}$ & 20 & Partially & $\begin{array}{l}1(50 \%) \\
24(75 \%)\end{array}$ & $12 \% \mathrm{HCl}+5 \% \mathrm{HF}$ & Recommended \\
2 & $\begin{array}{l}\text { Frame- } \\
\text { forming }\end{array}$ & 90 & Partially & $\begin{array}{l}1(50 \%) \\
24(75 \%)\end{array}$ & $12 \% \mathrm{HCl}+5 \% \mathrm{HF}$ & Recommended \\
3 & $\begin{array}{l}\text { Gel-forming } \\
4\end{array}$ & 20 & Completely & $3(100 \%)$ & $\begin{array}{l}10 \% \text { aqueous } \\
\mathrm{NaOH} \text { solution }\end{array}$ & Recommended \\
& Gel-forming & 90 & Completely & $1(100 \%)$ & $\begin{array}{l}10 \% \text { aqueous } \\
\mathrm{NaOH} \text { solution }\end{array}$ & Recommended \\
\hline
\end{tabular}

Table 3. Results of rheological studies of the frame and gel forming compositions.

\begin{tabular}{lllll}
\hline & $\begin{array}{l}\text { Effective viscosity (mPa's) } \\
\text { after preparation at }\end{array}$ & $\begin{array}{l}\text { Effective viscosity (mPa's) } \\
\text { after crosslinking at } \\
\mathrm{N}=300 \mathrm{rpm}\end{array}$ & $\begin{array}{l}\text { Static } \\
\text { shear } \\
\text { stress, Pa }\end{array}$ \\
\hline 1 & Frame-forming at $20^{\circ} \mathrm{C}$ & 27 & - & 2.66 \\
2 & Frame-forming at $90^{\circ} \mathrm{C}$ & 64 & - & 3.38 \\
3 & Gel-forming at $20^{\circ} \mathrm{C}$ & 10.7 & 17.4 & 126 \\
4 & Gel-forming at $90^{\circ} \mathrm{C}$ & 8 & 600 & 648 \\
\hline
\end{tabular}

Notes:

"-"means that the effective viscosity for these compositions was not measured, since these compositins are not "cross-linked" and their viscosity does not depend on time

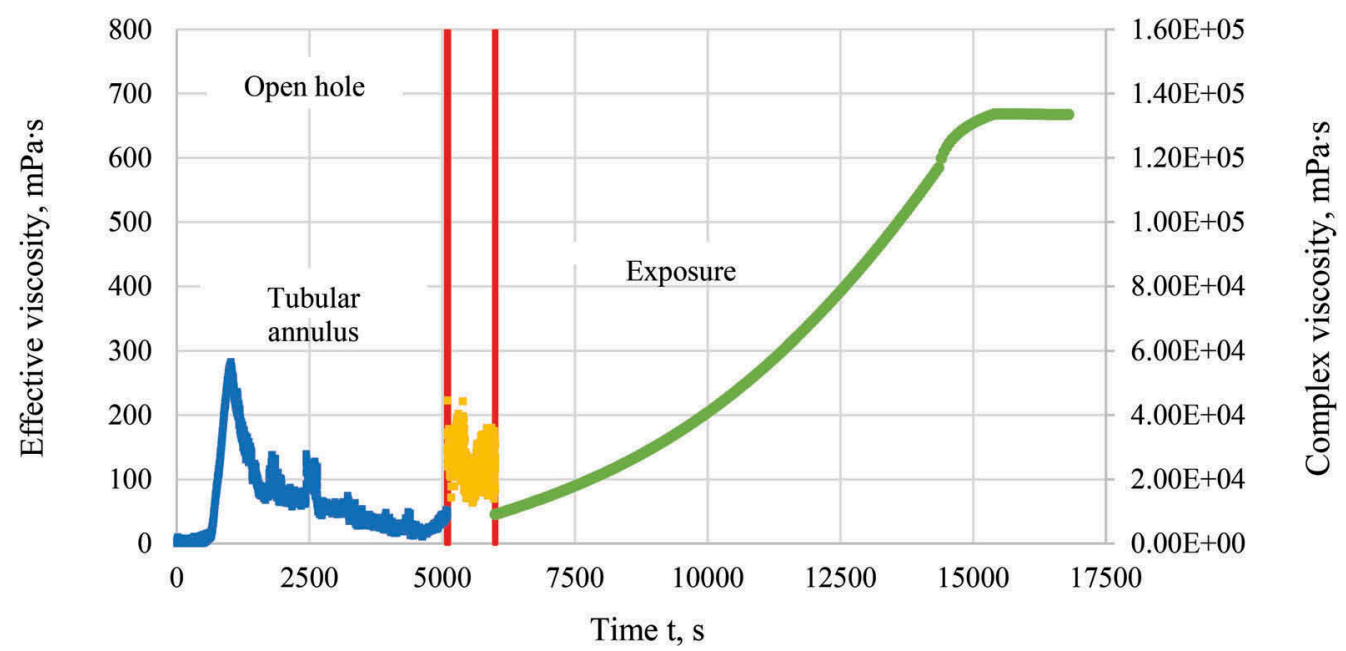

Figure 2. Dynamics of effective and complex viscosity of the gel-forming composition $\left(90^{\circ} \mathrm{C}\right)$.

Based on the results of determining the crosslinking time in the process of modeling the injection of a gel-forming composition (used for $20^{\circ} \mathrm{C}$ ) into a conditional well, it was found that: 


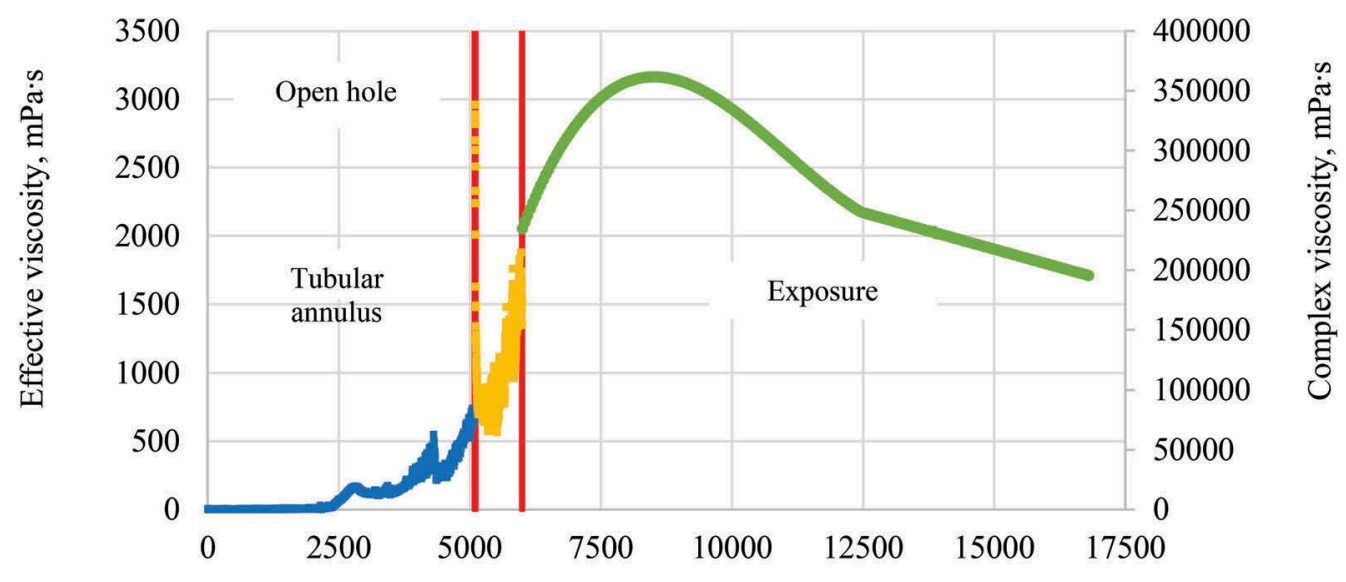

Time $t, s$

Figure 3. Dynamics of effective and complex viscosity of the gel-forming composition $\left(20^{\circ} \mathrm{C}\right)$.

- the crosslinking process begins during the injection of the compound into the inter-tube space. The induction period of the beginning of gelation is about 40 minutes after the preparation of the composition.

- the process of crosslinking the composition ends after its injection into the well, during the technical settling of the well. The induction period of the end of gelation is about $2 \mathrm{~h} 20$ min after preparation of the composition.

Based on the results of determining the crosslinking time in the process of modeling the injection of a gel-forming composition (used for $90^{\circ} \mathrm{C}$ ) into a conditional well, it was found that:

- the crosslinking process begins during the injection of the compound into the inter-tube space. The induction period of the beginning of gelation is about 12 minutes after the preparation of the composition.

- the process of crosslinking the composition ends during its injection into the inter-tube space.

The induction period of the end of gelation is about 18 minutes after the preparation of the composition. After injection of the composition into the well, during the technical settling of the well, structure formation is observed, characterized by an increase in the complex viscosity, which ends after 4 hours from the moment of preparation of the composition. In order to increase the technological efficiency (for example, to prevent mechanical destruction of the gel during its injection into the well) of the silencing process using the gel-forming composition used for $90^{\circ} \mathrm{C}$, it is recommended to adjust the content of the components so that the gelforming process ends after the composition is fully injected into the well.

\section{CONCLUSION}

Based on the laboratory tests of physical, chemical and rheological properties of the frame and gel forming compositions, the following findings have been established:

1. Compositions in the conditions of low $\left(20^{\circ} \mathrm{C}\right)$ and high $\left(90^{\circ} \mathrm{C}\right)$ temperatures are thermostable during the entire researched period ( 3 days).

2. The results of evaluating the destruction of the frame and gel compositions showed the following: 
- the gel-forming composition is completely destroyed within 1 and 3 hours with a $10 \%$ aqueous $\mathrm{NaOH}$ solution at 90 and $20^{\circ} \mathrm{C}$, respectively;

- the frame-forming composition is destroyed by $75 \%$ within 24 hours with a mixture of $12 \%$ hydrochloric and 5\% hydrofluoric acids (mud acid) at 90 and $20^{\circ} \mathrm{C}$, respectively. The future observation showed insignificant changes because when reacting with a frame-forming composition, mud acid loses reactivity.

3. The gel (8 and $10.7 \mathrm{mPa} \cdot \mathrm{s})$ and frame (64 and $27 \mathrm{mPa} \cdot \mathrm{s})$ forming compositions at 20 and $90^{\circ} \mathrm{C}$, respectively, have a low effective viscosity after preparation, which allows us to conclude that they are technologically efficient when injected into the well;

4. Gel-forming composition can have a high blocking capacity, since their static shear stress is $648 \mathrm{~Pa}$ at low temperatures $\left(20^{\circ} \mathrm{C}\right)$ and $126 \mathrm{~Pa}$ at high temperatures $\left(90^{\circ} \mathrm{C}\right)$.

The results of physical, chemical and rheological studies of frame and gel forming compositions have shown that they can be used in conditions of reservoir temperatures from $20^{\circ} \mathrm{C}$ to $90^{\circ} \mathrm{C}$, which consists in the possibility of injection these compositions into a typical well and selling them into the bottom-hole formation zone due to their low viscosity after preparation and slow cross-linking speed. However, based on the results of the conducted studies, it is recommended to adjust the content of the components of the gel-forming composition (used for $90^{\circ} \mathrm{C}$ ) so that the gel-forming process ends after the composition is injected into the well in full.

In addition, the use of destruction allows to reduce the negative impact of this technology on filtration characteristics of the bottomhole formation zone after well killing due to the reduction of the coefficient of relative changes in permeability and pressure gradient the start of oil flow when "development" wells.

To address the problem of well killing in complicated conditions, it is necessary to conduct a cycle of laboratory and field tests of the considered compositions, which will allow to select and justify the optimal technological and economic parameters of the operation.

\section{REFERENCES}

Bouts, M.N., Ruud, A.T. \& Samuel, A.J. 1997. Time Delayed and Low-Impairment Fluid-loss Control Using a Succinoglycan Biopolymer with an Internal Acid Breaker. SPE Journal, doi: 10.2118/31085PA, 21-23 December. Texas: Houston.

Dandekar, A.Y. 2013. Petroleum Reservoir Rock and Fluid Properties. Boca Raton: CRC press.

Dorman, J. \& Udvary, F. 1996. Comparative Evaluation of Temporary Blocking Fluid Systems for Controlling Fluid Loss Through Perforations. SPE Formation Damage Control Symposium, doi: 10.2118/ 31081-MS, 14-15 February. Louisiana: Lafayette.

Elchin, F.V., Azizagha, A.A., Vugar, V.G. \& Nurana, V.N. 2019. Water Shutoff Using Crosslinked Polymer Gels. SPE Annual Caspian Technical Conference, doi: 10.2118/198351-MS, 16-18 October. Azerbaijan: Baku.

Galimkhanov, A., Okhotnikov, D., Ginzburg, L., Bakhtin, A., Sidorov, Y., Kuzmin, P., Kulikov, S., Veliyev, G. \& Badrawi, M. 2019. Successful Implementation of Managed Pressure Drilling Technology Under the Conditions of Catastrophic Mud Losses in the Kuyumbinskoe Field. SPE Russian Petroleum Technology Conference, doi: 10.2118/196791-MS, 22-24 October. Russia: Moscow.

GOST 3900-85. 2006. Oil and Oil products. Density Determination Methods. Moscow: Publishing Standards.

GOST 1929-87. 2002. Oil Products. Methods for Determination of Dynamic Viscosity on a Rotational Viscometer. Moscow: Publishing Standards.

Gumerova, G.R. \& Yarkeyeva, N.R. 2017. Technology of using cross-linked polymer compositions. Journal of Oil \& Gas Business, 2, 63-79.

Jouenne, S., Klimenko, A. \& Levitt, D. 2016. Tradeoffs Between Emulsion and Powder Polymers for EOR. SPE Improved Oil Recovery Conference, doi: 10.2118/179631-MS, 11-13 April. Oklahoma: Tulsa.

Musabirov, M.Kh., Kuryashov, D.A., Garifov, K.M., Dmitriyeva, A.Y. \& Abusalimov E.M. 2019. Developing structure-forming colloidal systems for matrix acidizing of porous-fractured carbonate reservoirs. Oil Industry Journal, 6, 71-73. 
Quintero, L., Ponnapati, R. \& Felipe, M. 2017. Cleanup of Organic and Inorganic Wellbore Deposits Using Microemulsion Formulations: Laboratory Development and Field Applications. Offshore Technology Conference, doi: 10.4043/27653-MS, 1-4 May. Texas: Houston.

Raupov, I.R. \& Oprikova, V.Y. 2018. The results of laboratory studies of the rheological characteristics of the crosslinked polymer composition. Bulatovskie chteniya, 2, 63-66.

Rogachev, M.K. \& Strizhnev, K.V. 2006. Complication Control During Oil Production. Moscow: Nedra Business Center.

Rogachev, M.K. \& Kondrashev, A.O. 2016. Substantiation of the technology of in-situ waterproofing in low-permeability reservoirs. Journal of Mining Institute, 217, 55-60.

Ryabokon, S.A. 2009. Technological Fluids for Completion and Well Service Operations. Krasnodar: Prosveshcheniye-Yug.

Strizhnev, K.V. 2010. Repair and Insulation Works in Wells: Theory and Practice. St. Petersburg: Nedra.

Tokunov, V.I. \& Saushin, A.Z. 2004. Process Fluids and Compositions for Increasing the Productivity of Oil and Gas Wells. Moscow: Nedra.

Volkov, V., Turapin, A., Ermilov, A., Vasyutkin, S., Fomin, D. \& Sorokina, A. 2019. Experience of Gas Wells Development in Complex Carbonate Reservoirs in Different Stages of Development. SPE Russian Petroleum Technology Conference, doi:10.2118/196915-MS, 22-24 October. Russia: Moscow.

William, E., Syed, A. \& Mingjie, K. 1996. Effects of Completion Fluid Loss on Well Productivity. SPE Formation Damage Control Symposium, doi: 10.2118/31137-MS, 14-15 February. Louisiana: Lafayette. 


\title{
Paper methodology for pipe steels in hydrogen containing environments. Review
}

\author{
A.B. Arabey \\ Gazprom, St. Petersburg, Russia \\ V.A. Egorov, K.B. Konischev \& Semenov \\ Gazprom VNIIGAZ LLC, Moscow reg., Russia
}

\begin{abstract}
The review article provides test methods for pipe steels in environments containing hydrogen. The authors analyze test procedures designed for determination of pipe steel properties to provide further estimation of their serviceability for transmission of hydrogen-containing natural gas. The fatigue properties of the pipe metal decrease with increasing hydrogen content in the gas mixture. The method of determining the of the fatigue crack growth rate is promising for pipe metal in gas mixture containing hydrogen.It has been established that hydrogen impacts gas mixture compression. This fact should be taken into account when selecting operation modes for compressor stations.
\end{abstract}

Keywords: hydrogen embrittlement, hydrogen-methane gas mixture, fatigue damage, crack growth rate, strength properties

\section{INTRODUCTION}

Hydrogen can be considered as a clean energy carrier, similar to electricity (Nitsh \& Voigt, 1988), (Aksyutin et al., 2017). Using the existing natural gas (NG) grid for the hydrogen service has been being considered over the past decades.It has been found, that transporting hydrogen using an existing natural gas network is technically feasible (Bedel \& Junker, 2006). Existing gas transmission system (GTS) can be used for hydrogen-containing natural gas as well. Hydrogen embrittlement of carbon steels that the major pipelines are made of can impose restrictions on transmission of hydrogenmethane gas mixtures through GTS. Hydrogen embrittlement of steels has been investigated by a number of scientists (Nanninga et al., 2010), (Marhi \& Somerday, 2008), (Kolachev, 1985), (Nagumo, 2016). These studies analyze hydrogen impact only on metal that stays tensile enough after exposure to hydrogen. At the same time, most of metallic materials have reduced resistance to fatigue damage and high fatigue crack growth rate in hydrogen environments (Marhi \& Somerday, 2012). Changing the hydrogen concentration in the gas mixture leads to unsteady operation of the GTS (Guandalini et al., 2015). Recently, the American Society of Mechanical Engineers (ASME) has adopted a code specifically for hydrogen piping and pipelines: ASME Pressure Piping Code B31.12. Additionally, ASME has adopted new language in the Boiler and Pressure Vessel Code (Section VIII, Division 3, Article KD-10) for qualifying pressure vessels for hydrogen service. These rules can be adopted for pipelines as well, as part of a fitnessfor-service management program (Baek et al., 2017). This work is motivated by a desire to describe the approach of fracture mechanics to serviceability for pipelines distributing mixed hydrogen and natural gas. 


\section{MATERIAL AND TEST METHODS}

A hydraulic servo controlled testing machine Instron with an autoclave was used to measure the mechanical properties of specimens in mixtures natural gas and hydrogen (ASTM G1422016). Chamber material is insensitive to hydrogen embrittlement and is able to resist up to 20 $\mathrm{MPa}$ gaseous hydrogen pressure. Tests were conducted with API-5L X80 pipe samples (Figure 1) (ASTM G142 2016), (ASTM E647 2000).

Mechanical properties of the pipe metal have been determined by standard specimens. Fatigue crack growth tests have been carried out within this study on the compact tension specimens in accordance with (ISO 7539-6 2018).

Test environment: hydrogen-methane gas mixture with hydrogen content varying from $0 \%$ to $50 \%$. Tests have been performed under $12 \mathrm{MPa}$. For safety reasons methane was replaced by nitrogen.

\section{TEST RESULTS}

Authors (Meng et al., 2017) were determined that the change in hydrogen content in gas mixture didn't influence tensile properties (Figure 2).

The influence of added hydrogen on tensile behavior of thesmooth specimens is shown in Figure 3.

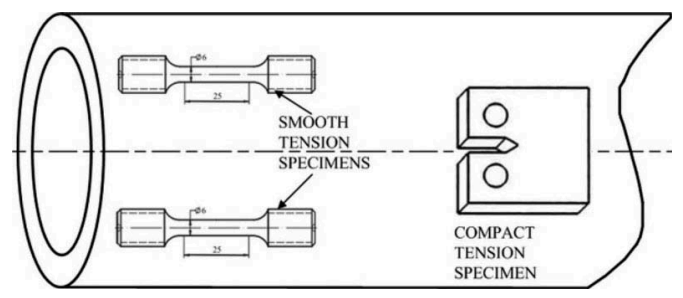

Figure 1. Specimens for tests from API-5L X80 pipe.

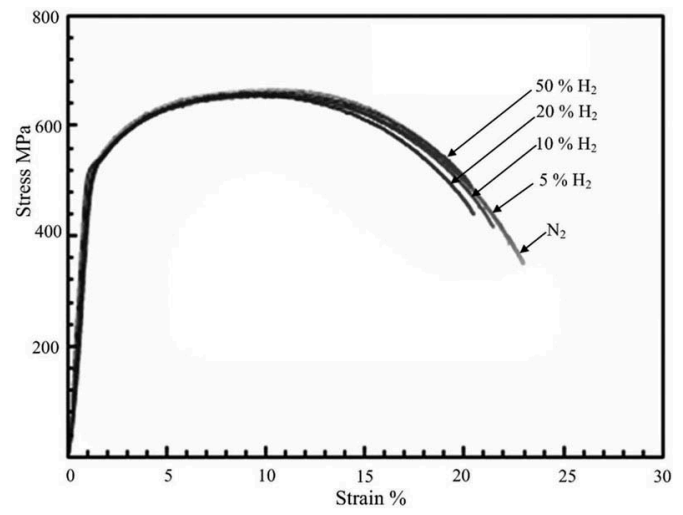

Figure 2. Influence of added hydrogen on the tensile of the smooth tension specimens. 


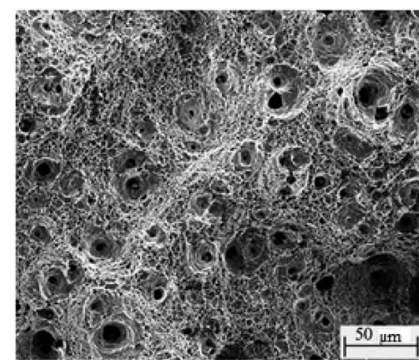

a)

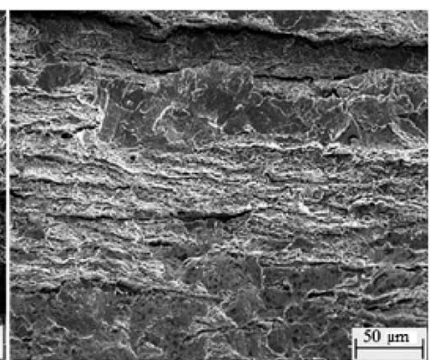

b)

Figure 3. Fractured surfaces of the smooth specimens in: a) nitrogen and; b) hydrogen blend $20 \%$.

The reduction of area specimens and hydrogen embrittlement index is calculated as follows:

$$
\begin{gathered}
R_{A}=1-\left(S_{k} / S_{0}\right) \\
E_{I}(\%)=\frac{R_{A}^{N_{2}}-R_{A}^{H_{2}}}{R_{A}^{N_{2}}} \times 100
\end{gathered}
$$

where $R_{A}=$ the reduction of area specimen in $\mathrm{N}_{2}$ and $\mathrm{H}_{2}$ blends; $S_{k}=$ cross-section area of the specimen after failure; $S_{0}=$ cross-section area of the specimen before failure; $E_{I}=$ specimen hydrogen embrittlement index $\left(E_{I}=0\right.$ means no hydrogen embrittlement $E_{I}=100 \%$ is value for maximum embrittlement).

The indexes for various hydrogen blends are shown in Table 1.

Authors (Meng et al., 2017) have suggested that gaseous hydrogen content increasing in gas mixture from $0 \%$ to $50 \%$ results in metal embrittlement of high-strength API-5L X80 pipes. Fatigue crack growth rate escalates by an order of magnitude when moving from neutral nitrogen to gaseous mixtures of nitrogen and hydrogen. Fatigue crack growth rate also builds up with hydrogen content increase in gas mixture from $5 \%$ to $50 \%$. Simultaneous hydrogen exposure and mechanical loads on pipe steel can lead to hydrogen embrittlement. For this reason there is a need to understand the problem of reversed pipeline loads in hydrogencontaining environments. The influence of cyclic loads on crack growth rate of API-5L X80 pipe steel in pure nitrogen and hydrogen blends is shown in Figure 4.

The effect of hydrogen on the properties of API-5L X80 was investigated by similar methods (Briottet et al., 2011). It has been established that «fatigue crack growth rate» parameter is more sensitive to alternation of hydrogen content, than to any changes in mechanical properties of pipe steel. For air and hydrogen environments fatigue crack growth rates in shown in Figure 5.

The fatigue crack growth rate increases by at least an order of magnitude in hydrogen compared to air. This difference explained by interaction between hydrogen and dislocations in API-5L X80 steel.

Specialists of the Institute of Standards and Technologies (the USA) were engaged in the study of hydrogen embrittlement and simulated fatigue crack growth processes on API-5L

Table 1. Hydrogen embrittlement of API-5L X80 steel.

\begin{tabular}{llllll}
\hline $\mathrm{H}_{2}$ content, $\%$ & 0 & 5 & 10 & 20 & 50 \\
\hline $\mathrm{E}_{\mathrm{I}}$ index, $\%$ & 0 & 3,39 & 4,32 & 15,88 & 16,77 \\
\hline
\end{tabular}




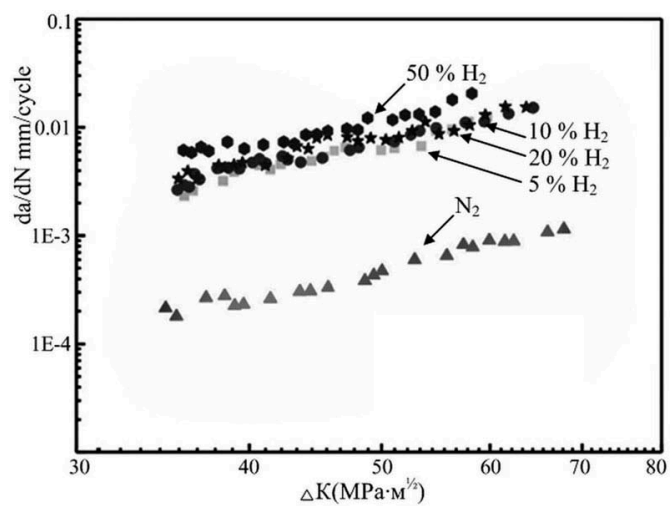

Figure 4. $\mathrm{Da} / \mathrm{dN}$ versus $\Delta \mathrm{K}$ curves in nitrogen gas and hydrogen blends.

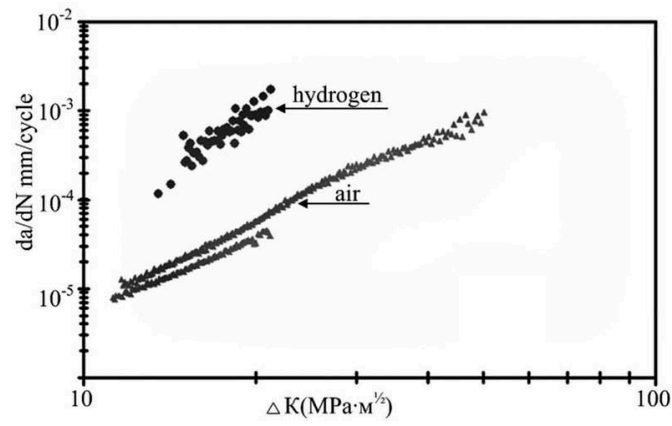

Figure 5. Fatigue crack growth rate behavior in air and hydrogen gas.

X100 steel (Amaro et al., 2014). Studies have shown that the fatigue crack growth rate in air and in environments with different hydrogen pressure varied (Figure 6).

Authors determined that fatigue crack growth rate depended on hydrogen content. Upgrading of hydrogen pressure from 1.72 MPa to $20.68 \mathrm{MPa}$ can double the growth rate.

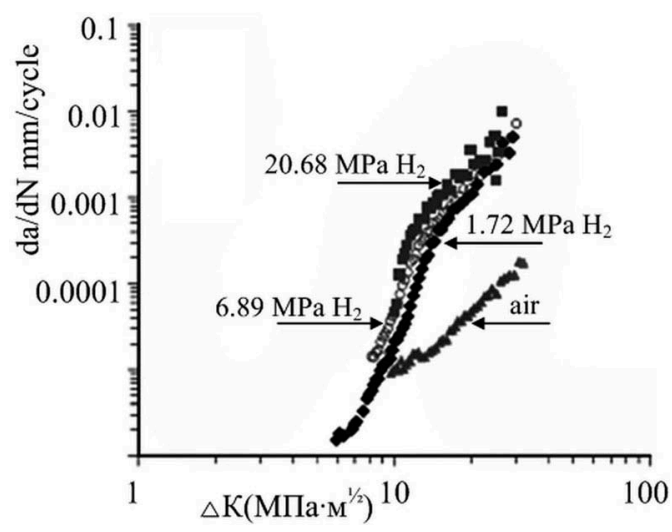

Figure 6. Fatigue crack growth rate behavior in air and hydrogen gas. 


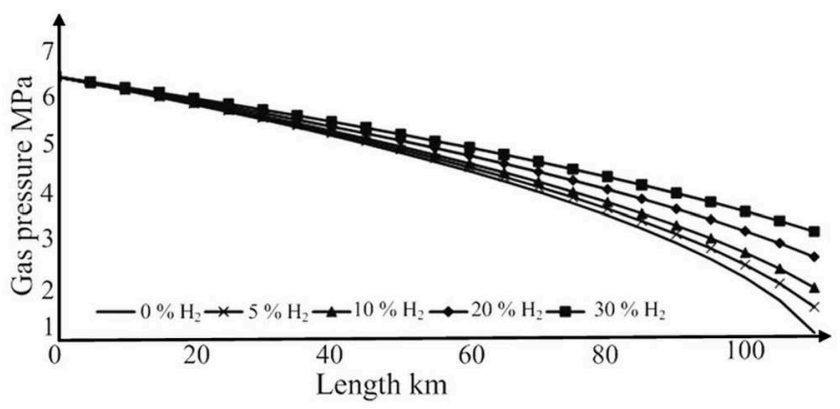

Figure 7. Gas pressure drop in pipeline for different hydrogen fractions in mixture with natural gas.

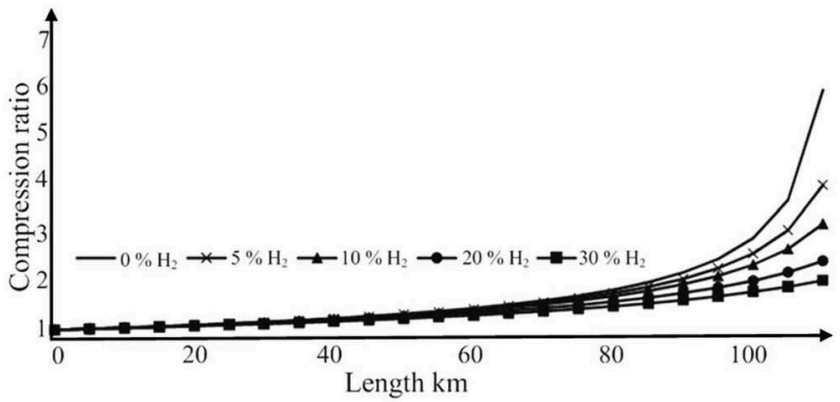

Figure 8. Compression ratio for mixture gas depending from the pipeline length.

In addition to pipes, compressor station, belong to GTS. Therefore, should be paid attention to physic parameters hydrogen transportation by pipeline GTS (Zabrzeski et al., 2017). For example hydrogen is much less viscous, and thus it can decrease Joule-Thompson effect in terms of pressure drop (Shimko, 2005). A mixture of natural gas and hydrogen in the pipeline $600 \mathrm{~mm}$ was investigated. The hydrogen content in natural gas modified from $0 \%$ to $30 \%$. The gas temperature was to be $7^{\circ} \mathrm{C}$ and initial gas pressure 6.4 MPa (Zabrzeski et al., 2019). Correlation between gas pressure, hydrogen content and pipeline length is shown in Figure 7.

Simulated conditions for hydrogen-containing natural gas transmission through existing GTS must take into account operation of compressor stations. Figure 8 shows relationship of compression and the length of a pipeline that transmits hydrogen-containing natural gas.

Thus, hydrogen strongly influences variation of the process of natural gas compression.

\section{CONCLUSIONS}

Increase in hydrogen content in gas mixtures from $5 \%$ to $50 \%$ does not have significant impact on traditional mechanical properties of high-strength API-5L X80 pipe steels. Variation of fatigue crack growth rate depends on hydrogen content in pipe steel and is sensitive to the level of hydrogen content in metal. Fatigue crack growth rate determination method can be prospective in terms of selection of the best chemical composition of the pipe steel that is not exposed to negative hydrocarbon impact during transmission of methane-hydrogen mixtures.It is necessary to give consideration to physical properties of hydrogen when selecting compression and transmission modes for methane-hydrogen mixtures via existing GTS. 


\section{REFERENCES}

Aksyutin O.E., Ishkov A.G., Romanov K.V., Teterevlev R.V., Khloptsov V.G., Kazaryan V.A., Stolyarevsky A. Ya. Power content of methane-hydrogen fuel under the conditions of transition to lowcarbon economy. Gazovaya promyshlennost = Gas industry. Special edition №1/750/2017, 82-85.

Amaro R.L., Rustagi N., Findley K.O., Drexler E.S., Slifka A.J. Modeling the fatigue crack growth of X100 pipeline steel in gaseous hydrogen. International Journal of Fatigue 59 (2014) 262-271.

ASTM E647-00 Standard test method for measurement of fatigue crack growth rates.

ASTM G142-2016 Standard test method for determination of metals to embrittlement in hydrogen containing environments at high pressure, high temperature, or both.

Baek U.B., Nahm S.H. Kim W.S. Ronevich, J.A. and San M. Compatibility and suitability of existing steel pipelines for transport of hydrogen-natural gasblendshttps://hysafe.info/wp-content/uploads/ 2017_papers/228.pdf

Bedel L., Junker M. Naturel gas pipelines for hydrogen transportation WHEC 16/ 13-16June 2006-Lyon France.

Briottet L., Moro I., Lemoine, P. Quantifying the hydrogen embrittlement of pipe steel for safety considerations. Available from: http://conference.ing.unipi.it/ichs2011/papers/186.pdf

Guandalini G., Colbertaldo P., Campanari S. Dynamic Quality Tracking of Natural Gas and Hydrogen Mixture in a Portion of Natural Gas Grid Energy Procedia 75 (2015) 1037-1043.

ISO 7539-6:2018 Corrosion of metals and alloys-Stress corrosion testing-Part 6: Preparation and use of pre-cracking specimens for tests under constant load or constant load or constant.

Kolachev B.A. Hydrogen embrittlement of metals. Moscow. Metallurgy. 1985.

Marhi C.S. and Somerday B.P. Technical reference on hydrogen compatibility of materials: plain carbon ferritic steels: C-Mn alloys. Sandia National Laboratories Report No. SAND2008-1163.

Marhi C.S. and Somerday B.P. Technical reference on hydrogen compatibility of materials. Sandia National Laboratories Report No. SAND2012-7321, Livermore CA, 2012.

Meng B., Gu C., Zhang L., Zhou C., Li X., Zhao Y., Zheng J., Chen X., Han Y. Hydrogen effects on X80 pipeline steel in high-pressure natural gas/hydrogen mixtures. International Journal of Hydrogen Energy 42(2017) 7404-7412.

Nagumo M., Fundamentals of hydrogen embrittlement ISBN 978-981-10-0160-4, 2016.

Nanninga N.E., Slifka A.J., Levy Y.S. and White C. A review of fatigue crack growth for pipeline steels exposed to hydrogen. Journal of Research of the National Institute of Standards and Technology, 115 No.6, 2010, 437-452.

Nitsh J. and Voigt C. Launch concepts for non-fossil hydrogen, 1988, Springer, Berlin.

Shimko M.A. V.E.1 Combined Reverse-Brayton Joule Thompson hydrogen liquefaction cycle. Available from: http://www.hydrogen.energy.gov/pdfs/progress05/v_e_1_shimko.pdf

Zabrzeski Ł., Janusz P., Liszka K., Laciak M. and Szurlej A. The effect of hydrogen transported through gas pipeline on the functioning of gas compression station work AGH Drilling, Oil, Gas 2017/34.

Zabrzeski L., Janusz1 P., Liszka K., Laciak M., Szurlej A. Hydrogen-natural gas mixture compression in case of transporting through high-pressure gas pipelines. Available from: https://iopsciennce.iop.org/ article/10.1088/1755-1315/214/1/012137/pdf 


\title{
Investigation of pump-ejector systems characteristics for water alternating gas injection
}

\author{
A.N. Drozdov \\ Doctor of Engineering Sciences, Professor, Peoples Friendship University of Russia, Moscow, Russia \\ S.D. Karabaev \\ Post-graduate student of Peoples Friendship University of Russia, Moscow, Russia \\ N.P. Olmaskhanov \\ Post-graduate student of Peoples Friendship University of Russia, Moscow, Russia \\ Y.A. Gorbyleva \\ Post-graduate student of Peoples Friendship University of Russia, Moscow, Russia \\ I.M. Narozhnyy \\ Senior lecturer of Peoples Friendship University of Russia, Moscow, Russia \\ E.I. Gorelkina \\ Post-graduate student of Peoples Friendship University of Russia, Moscow, Russia
}

\begin{abstract}
In this article, the experiments conducted to increase the efficiency of the use of pumping-ejector systems used for the enhanced oil recovery metod. This method is the water alternating gas injection. Water alternating gas injection implies the injection of alternately water and gas, or a water-gas mixture - simultaneous water alternating gas. The purpose of these experiments is to study the jet apparatus characteristics at high pressures at the ejector's intake $(0-0.3 \mathrm{MPa})$, as well as to develop a new calculation methodology for the rheometer. Studies were conducted on a laboratory bench, allowing research at various gas flow rates. The article presents new dependencies for the three possible stand designs that allow recalculation of gas flow. The new rheometer calculation methodology can reduce the inaccuracy from $20 \%$ to $1.8 \%$. The results of experiments that, the maximum value of the ejector efficiency is equal to $32.5 \%$, and the injection rate varies from $1-1.14$, under these experiments conditions.
\end{abstract}

Keywords: pump-ejector systems, characteristic of liquid-gas ejector, water alternating gas injection

\section{INTRODUCTION}

Simultaneous water alternating gas (SWAG) injection is a combination of conventional waterflooding and gas injection techniques. Unlike water, which takes up small hydrophilic pores and bottleneckings in the flooded zone of the reservoir, pumped gas as a non-wetting phase takes large hydrophobic pores, and the top of the reservoir under the action of gravitational forces (Drozdov et al. 2006). These aspects of oil displacement have led to reasonability of maintaining reservoir pressure by water and gas injection. At the same time, the displacement profile is also aligned, and the formation coverage is increased. Various authors carried out laboratory filtration experiments on the displacement of oil and hydrocarbon liquids from the reservoir by water, gas and various combinations of these agents. The results of experiments (Piyakov et al. 1992) on the use of water alternating gas (WAG) injection showed that the 
injection of gas and water, regardless of the type of gas used and the stage of flooding, contributes to an increase in the displacement efficiency. The value of the increase of displacement efficiency is a function of the gas agent composition. The minimum increase of $7-8 \%$ was obtained in experiments using nitrogen; upon injection of dry hydrocarbon gas, the increase was $15-16 \%$; with an increase in the content of intermediate components $\mathrm{C}_{2}-\mathrm{C}_{4}$ in a hydrocarbon gas, the displacement efficiency increased. The series of experiments on core samples (Fatemi et al. 2013), taking into account the wettability of the reservoirs, proves the effectiveness of the use of WAG compared to injecting water or gas separately.

Experiments (Stepanova 2003) suggested that the most significant effect of WAG was observed for media with mixed wettability, when hydrophobic surfaces form through paths along large pores, while smaller ones remain hydrophilic. The direct observation of physical processes occurring in a porous medium during WAG was carried out on the water-wet glass micromodel (Sohrabi et al. 2000). Various water alternating gas technologies over the past decades have been applied at almost a hundred fields in the world, both abroad and in our country. The successful ratio of using WAG according to data in foreign practice exceeds $90 \%$ (Berge 2002).

With the simultaneous injection of water and gas, the greatest effect according to the data (Egorov 2006, Liskevich 1973, Drozdov 2006) is achieved when the gas content of the watergas mixture is in the range of $25-75 \%$. Now abroad, dry or enriched hydrocarbon gases, as well as carbon dioxide, are usually injected into WAG technologies. The most commonly reported increase in oil recovery during WAG is approximately $5 \%$, but, as noted in some fields, oil recovery may increase by $20 \%$. Studies (Lei et al. 2016) have shown the efficiency of WAG $\mathrm{CO}_{2}$ for multilayer formation.

In the article (Christensen et al. 2001) extensive review of the WAG injection process has been presented. The increase in oil production of the considered fields is about $5-10 \%$. To obtain the effect of WAG and to avoid early breakthrough of the injection gas, it is necessary to have a good idea of the phase of the behavior of the reservoir oil and injection gas mixtures, as well as the heterogeneity of the reservoir.

The experimental study of WAG and SWAG injection schemes with $\mathrm{CO}_{2}$ (Kamali 2017) is aimed at determining the function of co-optimization function for $\mathrm{CO}_{2}$ storage and incremental oil production. Experiments are run to represent immiscible, near-miscible, and miscible displacements. Numerical simulations show a remarkable reduction in gas relative permeability for the WAG and SWAG displacements compared with continuous-gas-injection displacements, as a result of which the vertical-sweep efficiency of $\mathrm{CO}_{2}$ is improved.

A comprehensive review of WAG field displacements and their effect on oil recovery and produced-gas/water ratio has been presented in the literature (Stalkup 1983; Christensen et al. 2001).

The vast simulation study (Nygård \& Andersen 2020) has been performed investigating immiscible WAG injection focusing on mechanisms such as mobility, gravity, injected volume fractions, reservoir heterogeneity, gas entrapment, and relative permeability hysteresis.

Scientists (Hoare \& Coll 2018, Kumar et al. 2017, Khorsandi et al. 2017; Alzayer \& Sohrabi 2018) note the influence of hysteresis relative permeability on the effectiveness of WAG. It is often expected that the gas phase will show large hysteresis effects (Hoseini et al. 2011). Hysteresis lowers gas mobility and hence improves the gas/oil mobility ratio and reduces gravity segregation. The first effect is always positive, but the second is mainly positive in more uniform reservoirs where gravity segregation has a negative effect on recovery. In heterogeneous reservoirs, reducing gravity segregation can lead to the oil in low-permeability layers remaining unswept. (Nygård \& Andersen 2020)

Most foreign fields with WAG technologies are located in Canada, the USA and Norway (Skauge \& Stensen 2003, Christensen et al. 2001, Cone 1970, Quale et al. 2000, Righi \& Pascual 2007, Shi et al. 2008, Stoisits et al. 1995, Choudhary et al. 2011, Gbadamosi et al. 2018, Olalotiti-Lawal et al.2018).

In Russia, experimental work on the WAG was carried out at the Sovetskoye and Vakhskoye (Kryuchkov 2002), Ilishevskoye (Shuvalov et al. 2008), Alekseevskoye (Vafin 2008, Zaripov 2006), Novogodnee (Zakirov et al. 2006), Vostochno-Perevalnoye (Zatsepin \& Chernikov 2007, Chubanov et al. 2008) and at the Sredne-Hulymskoye fields (Chubanov et al. 2008). 
In foreign practice, complex and expensive equipment that requires large capital investments, high-quality maintenance and competent operation - gas treatment units, pumps and high pressure compressors - is used to implement gas and water exposure. Attempts to apply the WAG compressor technology at the Samotlorskoye and Novogodnoye fields under Russian conditions, despite the enormous costs, were ultimately discontinued.

So the traditional technology of SWAG injection is not widely used in domestic oil fields. The main problem is the absence of effective processes and technologies for water and gas pumping into injection wells. In this situation, the use of jet technology, in particular pumpejector systems, may turn out to be a very attractive solution.

In previously published papers (Krasilnikov 2010, Drozdov et al. 2008), laboratory studies of pump-ejector systems were carried out at constant pressure at the jet apparatus intake $\mathrm{P}_{\text {in }}$ $(0 ; 0.5 \mathrm{MPa})$ with different values of relative power pressure drop created in the ejectors working nozzle $\Delta \mathrm{P}_{\mathrm{p}}$. In this article, the characteristics of an ejector with a constant $\Delta \mathrm{P}_{\mathrm{p}}$ with a relative outlet pressure drop $\Delta \mathrm{P}_{\mathrm{o}}$ created by a jet apparatus were considered.

\section{PURPOSE}

The purpose of this work is to characterize the pump-ejector system at high pressures at the jet apparatus intake within $0-0.3 \mathrm{MPa}$. Additionally, the differential pressure gauge should be calibrated with the creation of a new calculation methodology.

\section{MATERIALS AND METHODS}

Investigations of the pump-ejector system was carried out on the laboratory bench (Figure 1) which worked in the following way. The power liquid (water) from the tank 1 enters the intake of a multistage centrifugal pump 2. Next, the power fluid is forced to the nozzle of the jet apparatus 3 and injects, depending on the experimental conditions, either gas from tank 1 or gas from the atmosphere, which is regulated by valves 12 and 13 .

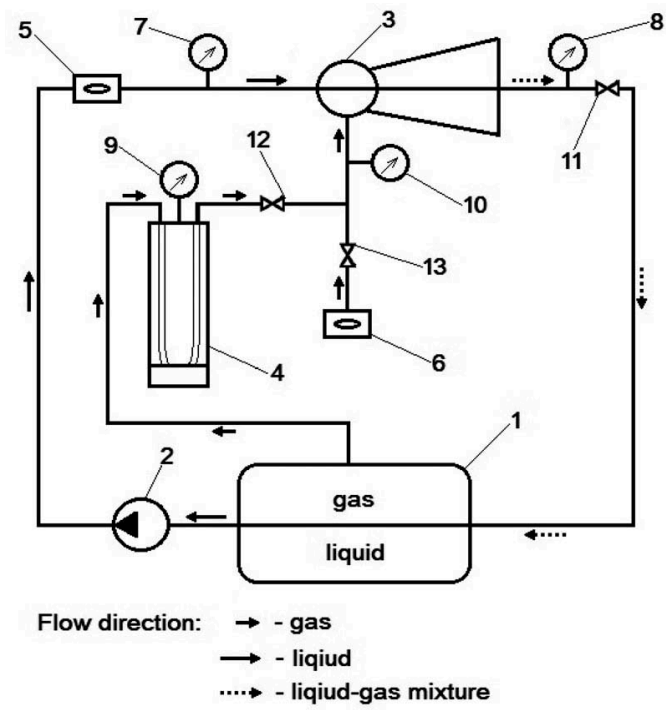

Figure 1. Diagram of the stand for the pump-ejector system investigation: 1 - liquid-gas tank; 2 - multistage centrifugal pump; 3 - ejector; 4 - differential pressure gauge; 5 - fluid meter; 6 - gas meter; 7, 8, 9 manometers; 10 - pressure-vacuum meter; 11, 12, 13 - control valves and gate valves. 
The flow rate of the power fluid injected into the nozzle is measured by a fluid meter 5 . Depending on the conditions, the flow rate of the injected gas is measured by a differential pressure gauge 4 when high pressure gas is injected, or by a gas meter 6 when atmospheric air is injected. The pressures in front of the working nozzle of the jet apparatus and at the output from its diffuser were measured using manometers 7 and 8 . The pressure at the ejector's intake was measured with a pressure - vacuum meter 10. Different operating modes and pressures were generated by a control valve 11 .

Measured parameters during the experiment: fluid rate, gas rate from the tank, gas rate from the atmosphere, power pressure in front of the nozzle, pressure at the ejector's intake and output pressure. The efficiency of the ejector $\eta_{g}$ during gas injection is determined by the ratio of the effective power $N_{e}$ to total power $N_{t}$ (Drozdov 2014):

$$
\begin{aligned}
& \eta_{g}=\frac{N_{e}}{N_{t}}=\frac{\mathrm{Q}_{g . i n} P_{i n} \ln \frac{\mathrm{P}_{\mathrm{o}}}{\mathrm{P}_{\text {in }}}}{\mathrm{Q}_{p}\left(P_{o}\right)} \\
& =\frac{\mathrm{u}_{\mathrm{g}} p_{\text {in }} \ln \frac{\mathrm{P}_{\mathrm{o}}}{\mathrm{P}_{\text {in }}}}{\left(P_{p}-P_{0}\right)}
\end{aligned}
$$

where $\mathrm{Q}_{\mathrm{g} . \mathrm{in}}$ - volumetric gas rate in the suction chamber;

$p_{\text {in }}$ - pressure in the suction chamber (intake chamber);

$\mathrm{P}_{\mathrm{o}}$ - outlet pressure of the ejector;

$P_{p}$ - power pressure in front of the nozzle;

$\mathrm{Q}_{p}$ - volumetric power fluid rate;

$\mathrm{u}_{\mathrm{g}}=\mathrm{Q}_{\mathrm{g} \text {.in }} / \mathrm{Q}_{p}$ is the volumetric injection coefficient in the suction chamber.

Technical water is used as a power liquid and air as a gas. Relative pressure drop:

$$
\frac{\Delta \mathrm{P}_{\mathrm{c}}}{\Delta \mathrm{P}_{\mathrm{p}}}=\frac{P_{c}-P_{\pi \mathrm{p}}}{P_{p}-P_{\pi \mathrm{p}}}
$$

where $\Delta \mathrm{P}_{\mathrm{c}}, \Delta \mathrm{P}_{\mathrm{p}}$ - pressure drops created by the jet apparatus and the working nozzle of the ejector respectively.

Differential pressure gauge DT-50 was used to determine the gas rate from the tank. Generally, it is used to measure the flow rate of non-aggressive gases, vapors and liquids by determining the pressure drop across the orifice plate or other throttle body.

Additional tubes were used for the accuracy and to increase the measurement range for gas rate (Figure 2). Were used 3 schemes of gas flow which dependences on the degree of gas rate.

The "right" scheme is used at pressures $\mathrm{P}<0.18 \mathrm{MPa}$, which is activated by opening the valve 7 and closing the valve 6 . The "left" scheme is used at pressures of $0.18<\mathrm{P}<0.26 \mathrm{MPa}$, where the valves open vice versa to the "right" scheme. The "general" scheme is used when $\mathrm{P}>0.26 \mathrm{MPa}$, where both valves open. Theoretically, after getting the calibration curve at any pressure level, other pressure values can be obtained using the following equation:

$$
Q_{2}=Q_{1} \sqrt{\frac{\lambda_{1}}{\lambda_{2}} \frac{P_{1}}{P_{2}}}
$$

where $Q_{1}, Q_{2}$ - the gas rates in the rheometer at pressures $P_{1}$ and $P_{2}$ respectively; $\lambda_{1}, \lambda_{2}-$ resistance values at $P_{1}$ and $P_{2}$ respectively.

For a quadratic zone of gas flow in a tube, as is well known $\lambda_{1}=\lambda_{2}$, where at the same water level difference in the differential pressure gauge, we obtain: 


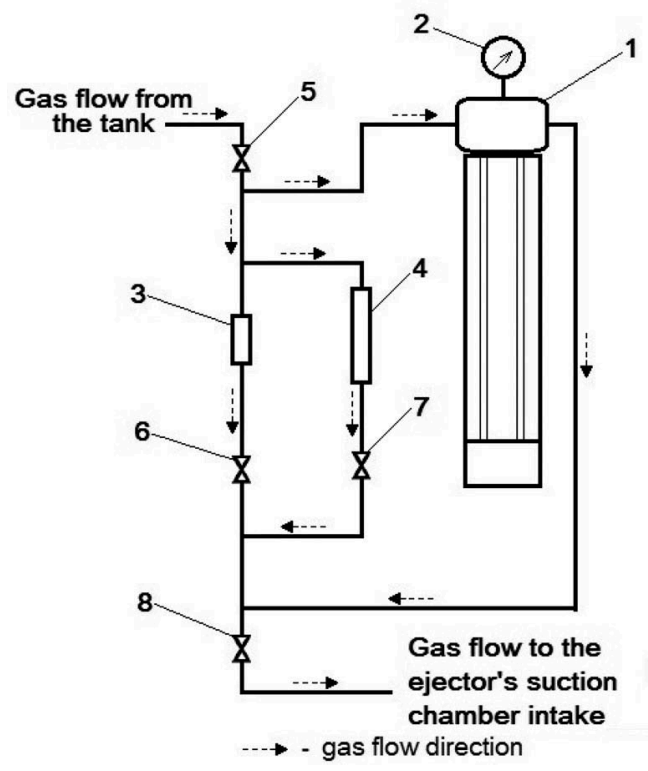

Figure 2. Diagram of a differential pressure gauge with variable parameters of the measurement range: 1 - differential pressure gauge; 2 - manometer; 3 - copper tube (shortened); 4 - copper tube (elongated); 5, $6,7,8$ - valves and gate valves.

$$
Q_{2}=Q_{1} \sqrt{\frac{P_{1}}{P_{2}}}
$$

In article (Drozdov 1982) it is pointed out that in the calibration process where brass tubes with an internal diameter of 4-6 $\mathrm{mm}$ was used at pressure under 0.6 MPa, the resistance values are not equal $\lambda_{1} \neq \lambda_{2}$. Analytical determination of $\lambda$ with the required accuracy depending on pressure and flow rate by formula (3) is difficult to perform. Due to it, the calibration dependencies were built at the same pressures as in the experiments pressures values. Since our studies are carried out with $6 \mathrm{~mm}$ tubes at pressures below $0.6 \mathrm{MPa}$, it is necessary to introduce correction factors for formula (2).

Calibration of the differential pressure gauge was carried out in this way. Calibration curves were registered at pressures of $0.1 ; 0.14 ; 0.18 ; 0.22 ; 0.26 ; 0.3 \mathrm{MPa}$. Gas rates at appropriate pressures were calculated based on $0.1 \mathrm{MPa}$ by the formula (4). After that, the deviations between the calculated and actual values were estimated. According to the deviations, correction factors were found, and flow rates based on new formula were calculated. Next will be presented the results.

\section{RESULTS AND DISCUSSION}

This section presents the results of experimental studies of the pump-ejector system and calibration of the differential pressure gauge.

\subsection{Differential pressure gauge}

Because of the calibration carried out, it was possible to achieve sufficient accuracy of the new calculation methodology (Table 1, Table 2, Table 3). The following formula was obtained for the "right" scheme: 
Table 1. The results of the calibration of the differential pressure gauge for the "right" scheme.

\begin{tabular}{lll}
\hline $\mathrm{P}, \mathrm{MPa}$ & Old method $(\Delta, \%)$ & New method $(\Delta, \%)$ \\
\hline 0,14 & 9,9 & 1,14 \\
0,18 & 16,8 & 1,78 \\
0,22 & 22,7 & 1,71 \\
0,26 & 26,3 & 1,62 \\
0,3 & 28,7 & 1,35 \\
\hline
\end{tabular}

Table 2. The results of the calibration of the differential pressure gauge on the "left" scheme.

\begin{tabular}{lll}
\hline $\mathrm{P}, \mathrm{MPa}$ & Old method $(\Delta, \%)$ & New method $(\Delta, \%)$ \\
\hline 0,14 & 9,1 & 1,37 \\
0,18 & 15,4 & 1,11 \\
0,22 & 18,9 & 0,99 \\
0,26 & 23,1 & 1,01 \\
0,3 & 25,4 & 1,15 \\
\hline
\end{tabular}

Table 3. The results of the calibration of the differential pressure gauge on the "common" scheme.

\begin{tabular}{lll}
\hline $\mathrm{P}, \mathrm{MPa}$ & Old method $(\Delta, \%)$ & New method $(\Delta, \%)$ \\
\hline 0,14 & 9,7 & 1,86 \\
0,18 & 14,7 & 1,5 \\
0,22 & 20,0 & 1,66 \\
0,26 & 23,0 & 1,83 \\
0,3 & 25,2 & 1,44 \\
\hline
\end{tabular}

$$
\mathrm{Q}_{2}=\mathrm{Q}_{1} * \sqrt{\frac{\mathrm{P}_{1}}{\mathrm{P}_{2}}} *\left(-5,04 *(\Delta P)^{2}+2,38 *(\Delta P)+1,01\right)
$$

where $\mathrm{Q}_{1}, \mathrm{Q}_{2}$ - volumetric gas rates in differential pressure gauge at pressure $\mathrm{P}_{1}, \mathrm{P}_{2}$ respectively;

$$
\Delta P=P_{2}-P_{1}
$$

During the calibration of the differential pressure gauge on the "right" scheme, the following results are obtained:

- according to the old method, the averaged inaccuracy is $20.88 \%$;

- according to the new method, the averaged inaccuracy does not exceed $1.8 \%$.

The next formula was obtained for "left" scheme: 


$$
\mathrm{Q}_{2}=\mathrm{Q}_{1} \times \sqrt{\frac{\mathrm{P}_{1}}{\mathrm{P}_{2}} \times\left(-3,08 *(\Delta P)^{2}+1,75 *(\Delta P)+1,03\right)},
$$

During the calibration of the differential pressure gauge on the "right" scheme, received the following indicators:

- according to the old method, the averaged inaccuracy is $18.52 \%$;

- according to the new method, the averaged inaccuracy does not exceed $1.9 \%$.

The next formula was obtained for "common" scheme:

$$
\mathrm{Q}_{2}=\mathrm{Q}_{1} \times \sqrt{\frac{\mathrm{P}_{1}}{\mathrm{P}_{2}} \times\left(-3,53 *(\Delta P)^{2}+1,83 *(\Delta P)+1,03\right),}
$$

During the calibrating for the "common" system, we obtained the following indicators:

- according to the old method, the averaged inaccuracy is $18.52 \%$

- according to the new method inaccuracy does not exceed $1.9 \%$.

\subsection{Characteristics of the pump-ejector system}

After the calibration of the differential pressure gauge, the pressure-energy characteristics of the ejector were obtained (Figure 3, Figure 5). The maximum efficiency of ejector $\eta_{g}$ during gas injection is obtained 0.325 , where the relative pressure drop is $\Delta \mathrm{P}_{\mathrm{o}} / \Delta \mathrm{P}_{\mathrm{p}}=0.315$, injection coefficient $\mathrm{u}_{\mathrm{g}}$ in the suction chamber is 1.13 at intake pressure $\mathrm{P}_{\text {in }}=0.26 \mathrm{MPa}$ and outlet pressure $\mathrm{P}_{\mathrm{o}}=0.636 \mathrm{MPa}$. The minimum efficiency of ejector $\eta_{g}$ during gas injection is obtained 0.245 , where the relative pressure drop is $\Delta \mathrm{P}_{\mathrm{o}} / \Delta \mathrm{P}_{\mathrm{p}}=0.294$, injection coefficient in the suction chamber is $u_{g}=1.14$ under intake pressure $P_{\text {in }}=0.05 \mathrm{MPa}$ and outlet pressure $\mathrm{P}_{\mathrm{o}}=0.397$ $\mathrm{MPa}$. It can also be noted that in the pressure range $\mathrm{P}_{\text {in }}=0.05-0.3 \mathrm{MPa}$ the injection coefficient in the suction chamber is varies from 1 to 1.14 .

After that, a graph of maximum efficiencies $\eta_{g}$ was plotted to the function of intake pressures $\mathrm{P}_{\text {in }}$ (Figure 4.). This graph shows that the difference between the maximum and

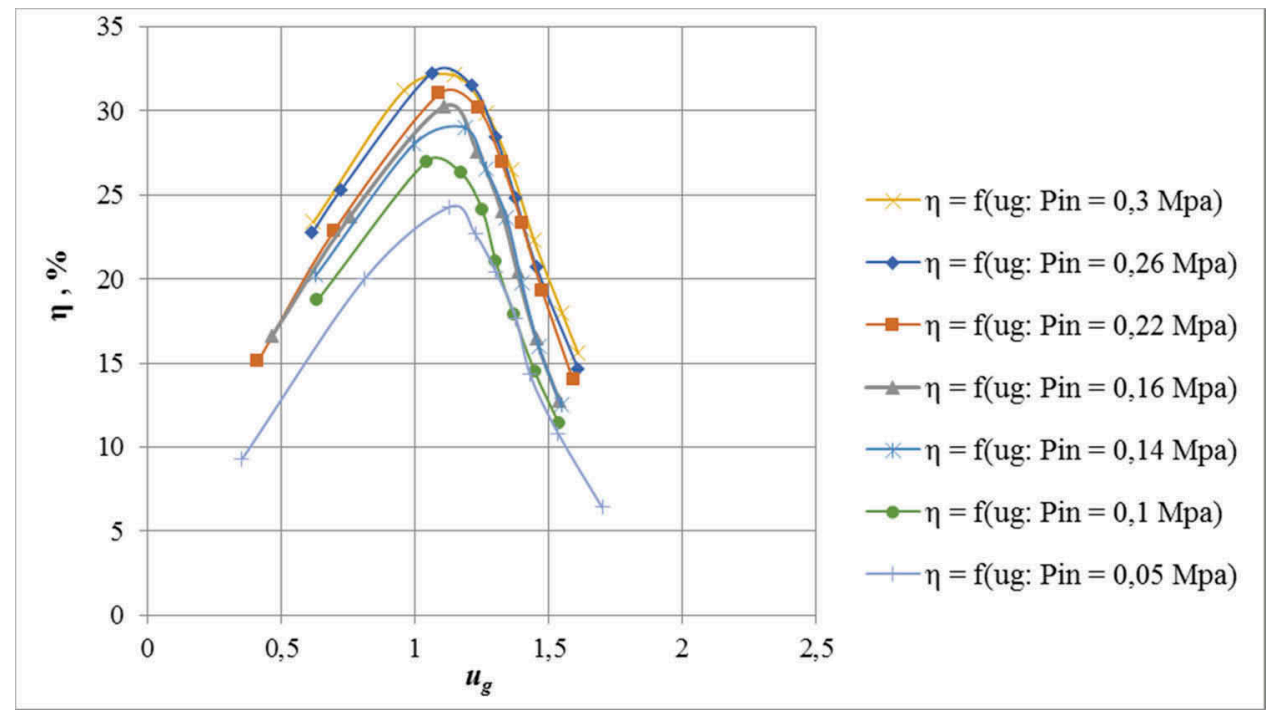

Figure 3. The ejector efficiencies $\eta_{g}$ to the function of injection coefficient $u_{g}$. 


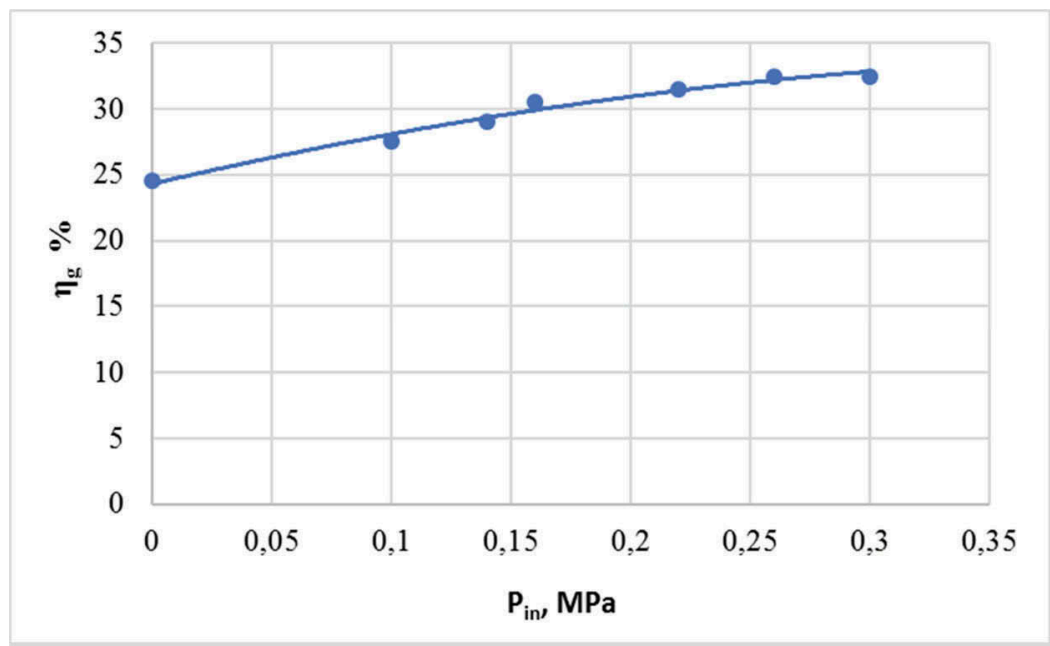

Figure 4. The maximum efficiencies $\eta_{g}$ to the function of intake pressure $\mathrm{P}_{\mathrm{in}}$.

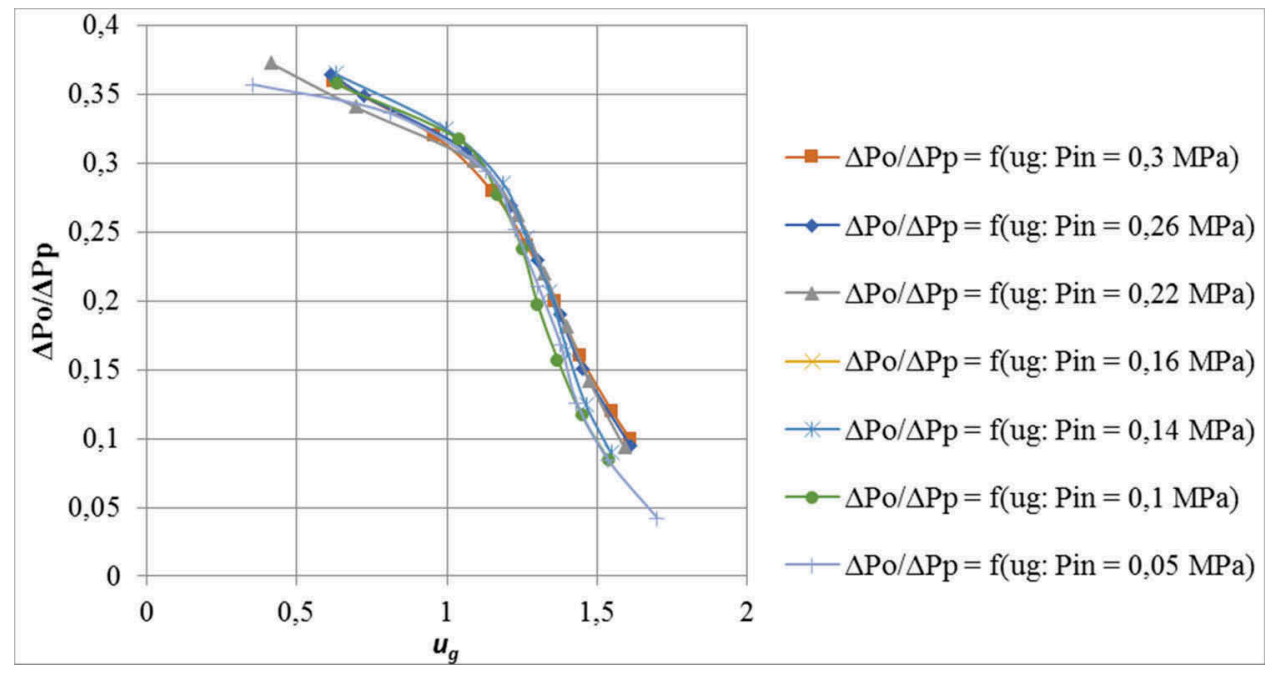

Figure 5. The relative pressure drop $\Delta \mathrm{P}_{\mathrm{o}} / \Delta \mathrm{P}_{\mathrm{p}}$ to the function of injection coefficient $u_{g}$.

minimum values is 0.078 . The value of $\eta_{g}$ gradually increases to $\mathrm{P}_{\text {in }}=0.26 \mathrm{MPa}$ and after this point some decline is observed.

\section{CONCLUSION}

Research and calculations have shown that, the new calculation methodology of the differential pressure gauge makes it possible to calculate gas rates with an inaccuracy of no more than $1.8 \%$.

The obtained pressure-energy characteristics for high pressures at the ejector's intake in the range from 0.05 to $0.3 \mathrm{MPa}$ allow us to conclude that the maximum efficiency at this condition, do not exceed $32.5 \%$. The volumetric injection coefficient rates range from 1 to 1.14 . It is 
worth noting that after the intake pressure of $0.26 \mathrm{MPa}$, there is some decrease in the efficiency, which can be assessed in further studies at higher intake pressure $\mathrm{P}_{\text {in }}$.

\section{ACKNOWLEDGMENT}

The publication has been prepared with the support of the «RUDN University Program 5-100».

\section{REFERENCES}

Alzayer, H. \& Sohrabi, M. 2018. Water-Alternating-Gas Injection Simulation-Best Practices SPE EOR Conference at Oil and Gas West Asia, 26-28 March: SPE-190346-MS Oman: Muscat

Berge, L.I., Stensen, J.A., Crapez, B. \& Quale, E.A. 2002. SWAG Injectivity Behavior Based on Siri Field DataImproved Oil Recovery Symposium, 13-17 April: SPE 75126 Oklahoma: Tulsa.

Choudhary, M.K., Dezabala, E., Solis, H.A. \& Narvaez, J. Z. Z. 2011. Design, Implementation and Performance of a Down-Dip WAG Pilot International Petroleum Technology Conference, 15-17 November: IPTC-14571-MS Thailand: Bangkok

Christensen, J. R., Stenby, E. H. and Skauge, A. 2001. Review of WAG Field Experience. SPE Res Eval \& Eng 4 (2): 97-106.

Chubanov, O.V., Harlanov, S.A. \& Nurgaliev, R.G. 2008. Development and implementation of water alternating gas injection methods for enhanced oil recovery at RITEK Territory of NEFTEGAZ vol. 9: $42-48$

Cone, C. 1970. Case history of the University Block-9 (Wolfcamp) field - a gas-water injection secondary recovery project Journal of Petroleum Technology XII, vol. 22:1485-1491.

Drozdov, A.N. 1982. Development of methods for calculating the characteristics of a submersible centrifugal pump for the operation of wells with low pressures at the entrance to the pump Cand. Sci. Dissertation Moscow p 212

Drozdov, A.N., Egorov, Yu.A., Verbitsky, V.S., Dengaev, A.V. \& Lambin, D.N. 2006. Methods and technology of water alternating gas injection influence to oil reservoirs Territory NEFTEGAZ vol 2: 54-58

Drozdov, A.N., Krasilnikov, I.A. \& Verbitsky V.S. 2008. Investigation of the characteristics of pumping-ejector systems for water-gas impact on the formation Territory NEFTEGAZ vol 2: 60-63

Drozdov, A.N. 2014. Problems of simultaneous water alternating gas injection and its solutions Oil industry vol 2: 2-6

Egorov, Yu.A. 2006 Development of water-alternated-gas technology using pump-ejector systems to increase oil recovery Cand. Sci. Dissertation Moscow p 169

Fatemi, S.M. \& Sohrabi, M. 2013. Experimental investigation of near-miscible water-alternating-gas injection performance in water-wet and mixed-wet systems SPE Journal vol. 18(1): 114-123.

Gbadamosi, A. O., Kiwalabye, J., Junin, R. \& Augustine, A. 2018. A review of gas enhanced oil recovery schemes used in the North Sea Journal of Petroleum Exploration and Production Technology vol. 8:1373-1387

Hoare, G. \& Coll, C. 2018. Effect of Small/Medium Scale Reservoir Heterogeneity on the Effectiveness of Water, Gas and Water Alternating Gas WAG Injection. SPE Europec featured at the 80th EAGE Conference and Exhibition, 11-14 June: SPE-190855-MS Denmark: Copenhagen

Hoseini, J., Masoudi, R., Mousavi Mirkalaei, S. M. et al. 2011. Investigating the Effect of Hysteresis Modelling on Numerical Simulation of Immiscible WAG Injection. International Petroleum Technology Conference, 15-17 November: IPTC-15055-MS. Thailand: Bangkok

Kamali, F., Hussain, F. \& Cinar, Y. 2017. An Experimental and Numerical Analysis of Water-Alternating-Gas and Simultaneous-Water-and-Gas Displacements for Carbon Dioxide Enhanced Oil Recovery and Storage SPE Journal vol. 22 (2): 18

Khorsandi, S., Li, L., \& Johns, R. T. 2017. Equation of State for Relative Permeability, Including Hysteresis and Wettability Alteration SPE Journal vol. 22 (6):1915-1928.

Krasilnikov, I.A. 2010. Development of methods for calculating the characteristics of liquid-gas ejectors for well operation and water alternating gas influence on the reservoir using pump-ejector systems Cand. Sci. Dissertation Moscow p 144

Kryuchkov, V.I. 2002. The use of water-gas systems based on petroleum gas to increase oil recovery. Cand. Sci. Dissertation Bugulma p 193 
Kumar, J., Agrawal, P. \& Draoui, E. 2017. A Case Study on Miscible and Immiscible Gas-Injection Pilots in a Middle East Carbonate Reservoir in an Offshore Environment. SPE Res Eval \& Eng 20 (1): 19-29. SPE-181758-PA.

Lei, H., Yang, S., Zu, L., Wang, Z. \& Li, Y. 2016. Oil recovery performance and $\mathrm{CO}_{2}$ storage potential of $\mathrm{CO}_{2}$ water-alternating-gas injection after continuous $\mathrm{CO}_{2}$ injection in a multilayer formation Energy \& fuels vol. 30 (11): 8922-8931.

Liskevich, E.I. \& Ostrovsky, Yu.M. 1973. Oil displacement by gas-water mixtures Oil field development, proceedings of UkrNIIIPND vol. 11-12: 233-240.

Nygård, J. I. \& Andersen, P. Ø. 2020. Simulation of Immiscible Water-Alternating-Gas Injection in a Stratified Reservoir: Performance Characterization Using a New Dimensionless Number SPE Journal SPE-200479-PA

Olalotiti-Lawal, F., Onishi, T., Datta-Gupta, A., Fujita, Y., Watanabe, D. \& Hagiwara, K. 2018. PostCombustion $\mathrm{CO}_{2}$ WAG Pilot in a Mature Field: Model Calibration and Optimization SPE Annual Technical Conference and Exhibition, 24-26 September: SPE-191472 Texas: Dallas

Piyakov, G.N., Yakovlev, A.P., Kudashev, R.I. \& Romanova, E.I. 1992. The study of the efficiency of water alternating gas injection (on the example of the $\mathrm{Yu}_{1}$ layer of the Kogalymskoye field) Oil industry vol. 1: 38-39.

Quale, E.A., Crapez, B., Stensen, J.A. \& Berge, L.I.B. 2000. SWAG Injection on the Siri Field - An Optimized Injection System for Less Cost, SPE 65165, SPE European Petroleum Conference held in Paris, France, October, 24-25 France: Paris

Righi, E.F. \& Pascual, M. 2007. Water-Alternating-Gas Pilot in the Largest Oil Field in Argentina: Chihuido de la Sierra Negra, Neuquen Basin. SPE Latin American and Caribbean Petroleum Engineering Conference, 15-18 April 2007: SPE 108031. Argentina: Buenos Aires.

Shi, W., Corwith, J., Bouchard, A., Bone, R. \& Reinbold E. 2008. Kuparuk MWAG Project after 20 Years SPEIDOE Improved Oil Recovery Symposium, 19-23 April 2008: SPE 113933. Oklahoma: Tulsa.

Shuvalov, A.V., Samigullin, I.F. \& Suleymanov, A.A. 2008. Pilot-industrial work at JSOC Bashneft related to the introduction of gas and water alternating gas injection Materials of the VII Interregional Conference "Geology, Minerals, and Geoecology Problems of Bashkortostan, the Urals and Neighboring Territories", 2008, November: 239-241

Skauge, A. \& Stensen, J.O. 2003. A review of field experience in water alternating gas injection. Reports of the 1st International Conference "Oil Recovery - 2003", May 19-23: 119-120. Russia: Moscow

Sohrabi, M., Henderson, G.D., Tehrani, D.H \& Danesh A. 2000. Visualisation of oil recovery by water alternating gas (WAG) injection using high pressure micromodels-water-wet system SPE Annual Technical Conference and Exhibition.

Stalkup, F. I. 1983. Miscible Displacement. Richardson, Texas: Monograph Series, Society of Petroleum Engineers.

Stepanova, G.S. 2003 New methods of gas and water-alternated-gas injection of oil reservoirs Drilling and Oil, vol. 9: 18-20.

Stoisits, R.F., Krist, G.J., Ma, T.D., Rugen, J.A., Kolpak, M.M. \& Payne, R.L. 1995. Simultaneous Water and Gas Injection Pilot at the Kuparuk River Field, Surface Line Impact SPE Annual Technical Conference, Oct. 1995: SPE 30645

Vafin, R.V. 2008. Improving the efficiency of water-alternated-gas technology on the reservoir at the Alekseevskoye field Neftepromyslovoe delo vol. 2: 33-35

Zakirov, S.N., Indrupsky, I.M., Levochkin, V.V., Fakhretdinov, R.N. \& Ostapchuk, S.S. 2006. Wateralternated-gas injection on the Novogodnee field Oil industry, vol.12: 40-43.

Zaripov, M.S. 2006. Improving the technology of water alternating gas injection, preparation and injection of working agents into the reservoir Abstract of Cand. Sci. Dissertation Ufa p 24

Zatsepin, V.V. \& Chernikov, E.V. 2007. Some issues of the implementation of water alternating gas injection at the Vostochno-Perevalnoye field Oil Industry vol. 2: 44-47. 


\title{
The choice of fluid and thermal grid of the organic Rankine cycle in the conditions of its application at the oil refineries
}

\author{
M.A. Peretyatko \\ Ph.D. student, Saint-Petersburg Mining University, Saint-Petersburg, Russia \\ P.V. Yakovlev \\ Professor, Saint-Petersburg Mining University, Saint-Petersburg, Russia
}

V.A. Lebedev

Professor, Saint-Petersburg Mining University, Saint-Petersburg, Russia

\author{
A.S. Deev \\ Postgraduate student, Saint-Petersburg Mining University, Saint-Petersburg, Russia
}

\begin{abstract}
The article discusses the problem of choosing the working fluid for the Rankine organic cycle. This is done by analyzing the parameters of the ORC unit on these Freon's. It is proposed to use low-grade heat of technological units for oil refining as a heat source for the organic Rankine cycle unit. Currently, a significant part of the available lowgrade heat from oil refineries is lost into the atmosphere. The installation of the organic Rankine cycle allows the use of this heat to generate an expensive energy resource - electricity. This is the advantage of this installation over other methods of utilizing low-grade heat. At the moment, there is no clear methodology for choosing a working fluid for the organic Rankine cycle, that used at an oil refinery. For comparison, the following freons were selected: $245 \mathrm{fa}$, r152a and r404a. To solve this problem, a model that calculates such indicators as thermal efficiency, coolant flow rate and electric power of the installation, for the simplest scheme of the organic Rankine cycle was built. The article also provides an analysis of the results obtained by modeling the comparison of the considered working bodies. To assess the feasibility of using the unit with selected coolant, the economic effect of its implementation was evaluated.
\end{abstract}

\section{INTRODUCTION}

In the modern world, more and more attention is paid to the problem of improving energy efficiency. One of the tasks of increasing energy efficiency is the development of methods for recycling of low-grade heat. Low-potential heat sources include flows of various substances and gases with a temperature of not more than $300^{\circ} \mathrm{C}$. Such sources are very common in the oil, metallurgical chemical and other industries.

Consider the refining industry in more detail. The technological process of oil refining is not perfect in terms of the full use of thermal energy. Thermal energy supplied to oil at refineries is used only by $30 \%$. About $35 \%$ of it discharged into the atmosphere using circulation water system or air-cooling units, about $10-15 \%$ released into the atmosphere from surfaces of equipment and about 15\% released into the atmosphere with flue gases (Burdygina, 2003). According to estimates, at refineries with a capacity of 5-6 million tons per year of crude oil, at least $15 \mathrm{MW}$ of low potential heat with a temperature of at least $150^{\circ} \mathrm{C}$ are discharged into the atmosphere.

One of the modern ways of recycling this low-grade heat is organic Rankine cycle (ORC). $\mathrm{ORC}$ is used to generate electricity. The schematic diagram of the OCR unit is shown in Figure 1. 


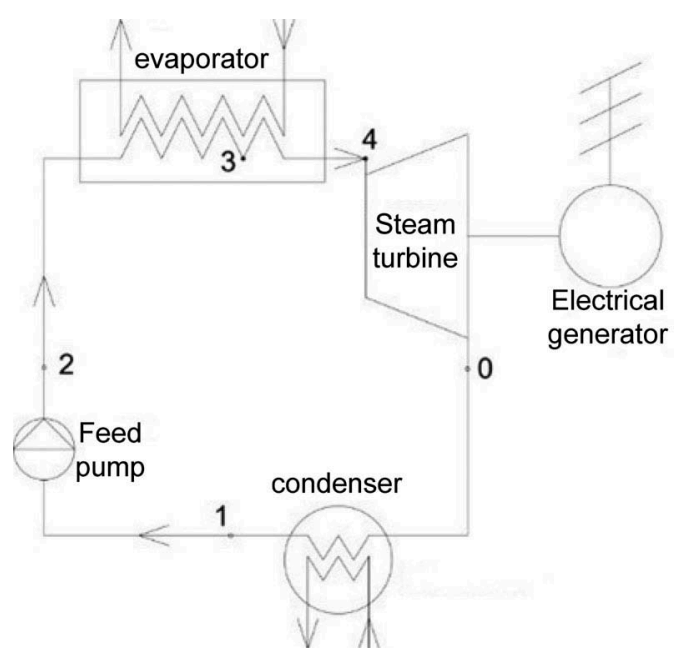

Figure 1. Schematic diagram of the OCR unit.

OCR works on the same principle as the classical Rankine cycle with water as a fluid. The main difference between organic fluid and water is a low boiling point, which allows steam to be generated at low temperatures of heat sources.

For the normal operation of a steam turbine, it is necessary, to have a large pressure difference, which is different for various fluids. In this regard, depending on the temperature conditions of the thermal scheme of the organic Rankine cycle, it is necessary to determine the compound that will be used as a working fluid. When choosing different compounds, you must follow rules:

- Work, done by steam in the turbine, should be as much as possible;

- Thermal conductivity of the fluid should be as large as possible for more efficient heat transfer in the evaporator and condenser;

- Fluid must be stable at high temperatures;

- Fluid should be environmentally friendly and safe.

Based on these criteria, for further consideration, the following freons were selected: $245 \mathrm{fa}$, r152a, r404a. The parameters of the considered working fluid are presented in Table 1.

These freons have already been used as a coolant for ORC, but under other conditions. It is advisable to consider them for specific conditions of use at a refinery.

One of the main indicators of the effectiveness of the Rankine cycle is the thermal efficiency of the cycle. In this case, the thermal efficiency of the cycle will depend on the selected compound. Based on this fact, the choice of the working fluid will be made according to the highest thermal efficiency of the cycle. Further in the work, an unit working on the selected fluid will be considered.

Consider freon $\mathrm{r} 245 \mathrm{fa}$ as a working fluid for the proposed heat recovery unit at oil refineries. The p-h diagram of the ORC with r $245 \mathrm{fa}$ is shown in Figure 2.

Table 1. Parameters of the considered working fluid.

\begin{tabular}{llll}
\hline & \multicolumn{2}{l}{ Value } & \\
\cline { 2 - 4 } Parameter & r245fa & r152a & r404a \\
\hline Molar mass, g/mol & 134,1 & 66,1 & 97,6 \\
Boiling point, ${ }^{\circ} \mathrm{C}$ & 15,3 & -24 & $-46,3$ \\
Specific thermal capacity in a liquid state at normal pressure, $\mathrm{kJ} / \mathrm{kg} \mathrm{K}$ & 1,36 & 1,8 & 1,62 \\
Ozone depletion potential & 0 & 0 & 0 \\
Global warming potential & 1030 & 140 & 3750 \\
\hline
\end{tabular}




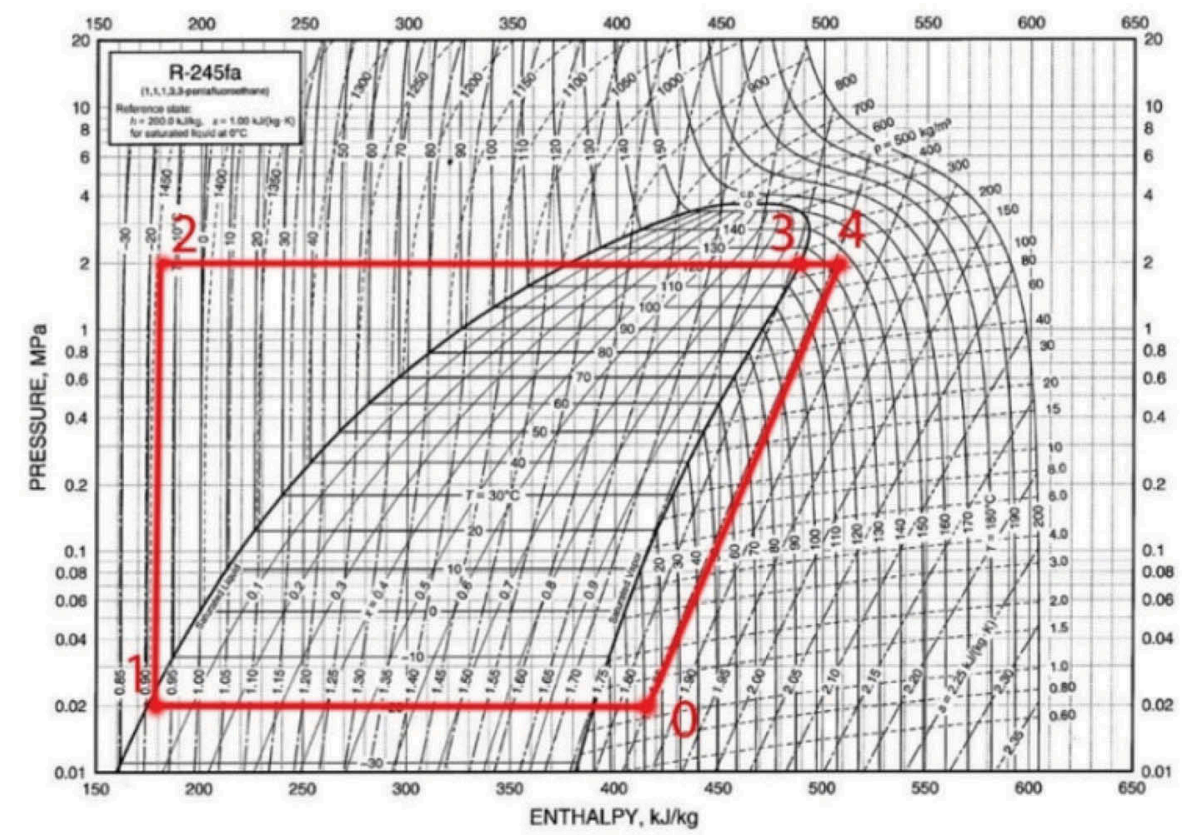

Figure 2. P-h diagram of the ORC with r245fa.

The following algorithm was used to determine the installation efficiency:

- The value of the temperature of the quenching compound in the condenser and power of the low-potential heat source and its temperature are set. The temperature of the lowgrade heat source determines the maximum attainable temperature of the organic fluid;

- The enthalpies of the fluid at the characteristic points of the cycle are determined. The characteristic points of the cycle on r245fa are presented in Table 2;

- Further, the thermal efficiency of the unit, the work done by steam in the turbine and its adiabatic power are determined from the values of enthalpies in the evaporator and condenser;

- Then, the power of the feed pump is determined. Power of the ORC unit, taking into account the operation of the feed pump, the energy loss in the generator and the internal efficiency of the turbine is determined.

Then, in a similar way, calculation was performed for the remaining freons. To facilitate the calculations, a model of the OCR unit was built in Microsoft Excel. This model automatically calculates all parameters of the cycle after entering the initial data. ${ }^{\circ} \mathrm{C}$

For comparison, several freons as a working fluid in the ORC, the temperature range of the quenching compound is assumed to be the same (from $-20^{\circ} \mathrm{C}$ to $20^{\circ} \mathrm{C}$ ), as well as the values of the internal efficiency of the turbine $(86 \%)$ and the efficiency of the generator $(95 \%)$. Then we

Table 2. Characteristic points of the cycle on r245fa.

\begin{tabular}{lll}
\hline Point & Enthalpy, $\mathrm{KJ} / \mathrm{kg}$ & Note \\
\hline 0 & 410 & End of expansion in a turbine \\
1 & 175 & At the exit of the condenser \\
2 & 185 & At the entrance to the evaporator \\
3 & 480 & At the exit of evaporator \\
4 & 505 & At the exit of the superheater \\
\hline
\end{tabular}


compare technical performance of the unit with different fluids. The most suitable compound is the one at which the power of the unit is greatest.

One of the problems of ORC is low efficiency. Thermal efficiency of these installations usually does not exceed 28\% (Casati, 2014). One of the methods for increasing efficiency is the improvement of the cycle arrangement. However, this method leads to a complication of the design of the unit and an increase in its cost. For this reason, we built computer model that allows you select the most optimal cycle diagram of the ORC unit. The selection is made according to the following principle:

- The technical parameters of three cycle diagrams are calculated (simple circuit, circuit with economizer, circuit with intermediate steam overheating and economizer);

- Economical indicators of each circuit are determined;

- The optimal cycle diagram is selected based on the economic performance.

The calculation of the technical indicators of the unit without intermediate overheating of the steam and with economizer was carried out similarly to the algorithm for choosing the working fluid. The difference is that in this calculation the power of the feed pump is not taken into account.

Consider the OCR unit with an economizer. The thermal circuit of this unit is shown on Figure 3.

This scheme is used to increase the efficiency of the cycle. Economizer is installed between the turbine and the condenser and it heat the condensate after the feed pump in front of the evaporator by cooling the steam leaving the turbine to a condensation temperature $20^{\circ} \mathrm{C}$.

The calculation of the technical indicators of the unit with an economizer was carried out similarly to the above algorithm; however, the calculation is complicated due to the need to make the heat balance of the economizer. From the heat balance equation, the enthalpy of the heated refrigerant at the outlet of the economizer is determined.

Next, a thermal circuit is calculated with an intermediate superheat of the steam and an economizer (Figure 4).

The calculation of the technical indicators of the unit operating according to this thermal scheme was carried out similarly to the calculation of the scheme with the economizer; however, the calculation is complicated by adding two characteristic points of the cycle: after high-pressure section and before low pressure section. It is necessary to set the value of the pressure of steam after the high-pressure section ( $0.6 \mathrm{MPa}$ in this case), as well as to compile the heat balance of the intermediate superheater of the steam. The initial enthalpy of steam in the low pressure section is calculated from the heat balance equation.

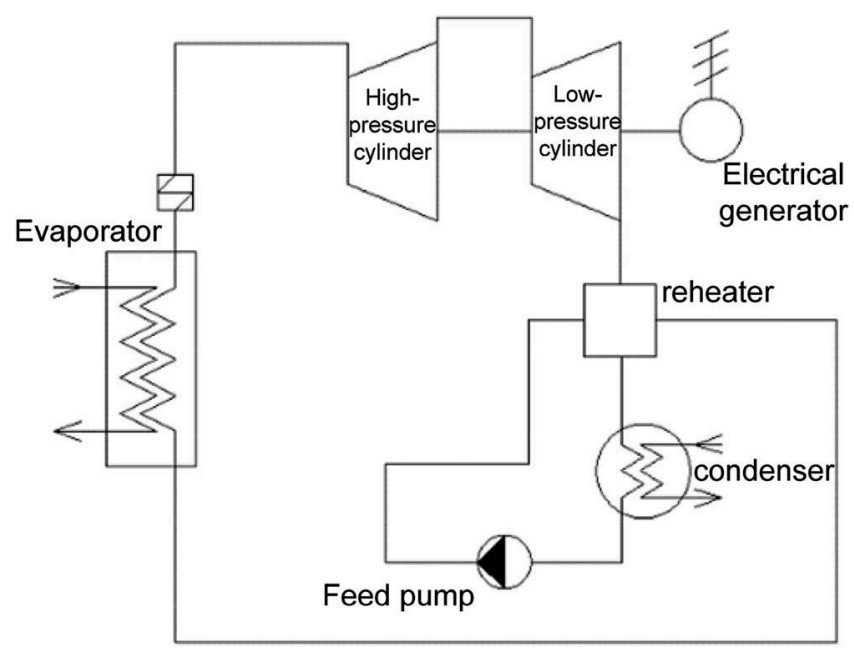

Figure 3. Thermal circuit of OCR unit with an economizer. 


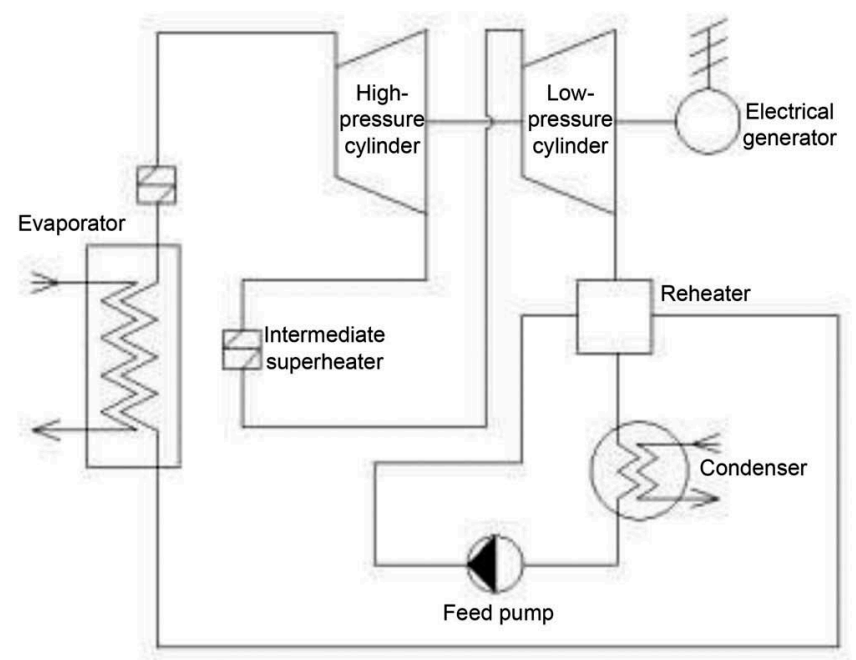

Figure 4. Thermal circuit of OCR unit with an intermediate superheat of the steam and an economizer.

Next, the economic indicators of the installation are determined. The calculation formulas for determining the indicators of economic efficiency are presented in Table 3.

The main indicators of economic efficiency is discounted payback period, discounted Profitability Index, internal rate of return and net present value.

Table 3. Calculation formulas for determining the indicators of economic efficiency.

\begin{tabular}{ll}
\hline Calculation period (T), years & 15 \\
\hline Depreciation (A), thousand rubles a year & $A=C / T^{1}$ \\
Cash Flows (cost of saved electricity), $\mathrm{CF}_{\mathrm{t}}$, thou- & $C F_{t}=c_{k h} T_{\text {work }} N^{2}$ \\
sand rubles a year & \\
Operating expenses (O), thousand rubles a year & $O=0,05 C$ \\
Average employee wages (w), thousand rubles & 600 \\
a year & \\
Number of employers, n & 8 \\
Wages expenses (W), thousand rubles a year & $W=w n$ \\
Social expenses (S), thousand rubles a year & $S=0,3 W$ \\
Cost of equipment (PE), thousand rubles & $P E=C-A t^{3}$ \\
Property tax (WT), thousand rubles a year & $W T=0,022 P E$ \\
Balance (B), thousand rubles a year & $B=C F-C-C I W-D S W-A-O-W-S-W T$ \\
Profit tax (PT), thousand rubles a year & $P T=0,2 B$ \\
Net cash flow (NCF $),$ thousand rubles a year & $N C F_{t}=B-P T$ \\
Discount rate (i) & $i=i_{0}+i_{r}{ }^{4}$ \\
Net present value (NPV), thousand rubles & $N P V=\sum_{t=0}{ }^{N} \frac{N C F_{t}}{(1+i)^{t}}$ \\
Internal rate of return (IRR) & IRR=i, wherein $N P V=0$ \\
Discounted profitability Index (DPI) & $D P I=N P V+C$ \\
Discounted payback period (DPP) & DPP=t, wherein $N P V=0$ \\
\hline
\end{tabular}

1 Where C - capital expenses

2 Where $c_{k h}$-cost kilowatt hour, $T_{\text {work }}$-Time of work, $N$-power

3 Where t- period number

4 Where: $i_{0}=0,07$ - risk-free rate, $i_{r}=0,02$-risk rate 


\section{RESULTS}

The dependences of thermal efficiency and electric power on the temperature of the cooling medium, which were obtained as a result of calculations (Figure 5).

The obtained dependences of electric power on the temperature of the cooling medium are presented in Figure 6.

As we can see from the Figure 5 and 6, efficiency and electric power are highly dependent on temperature of the cooling medium: power decreases with average speed $40 \mathrm{~kW} /{ }^{\circ} \mathrm{C}$; efficiency decreases with average rate of $0.27 \% /{ }^{\circ} \mathrm{C}$. Unit with freon $\mathrm{r} 245 \mathrm{fa}$ as a fluid, have the greatest power and efficiency rate.

Thermal efficiency and electric power for each of the three considered thermal circuits were determined. These indicators are presented in Figure 7.

As expected, a thermal circuit with an economizer and intermediate steam superheating has the highest energy efficiency. However, it should be noted that the easiest way to increase the efficiency of the ORC unit is to add an economizer. This method increases the thermal efficiency by $2.2 \%$ and the unit power by $300 \mathrm{~kW}$.

Indicators of economic efficiency of the project are presented in table 4. NPV for the periods of operation is presented in Figure 8.

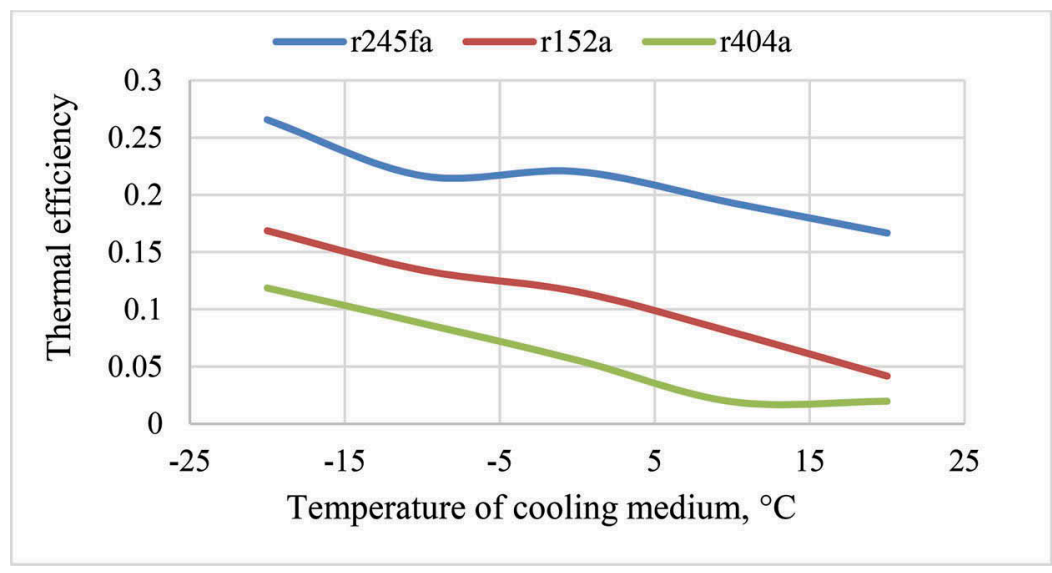

Figure 5. The dependences of thermal efficiency and electric power on the temperature of the cooling medium.

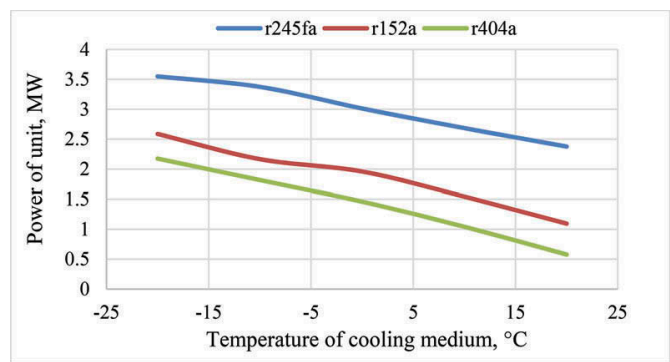

Figure 6. Dependences of electric power on the temperature of the cooling medium. 


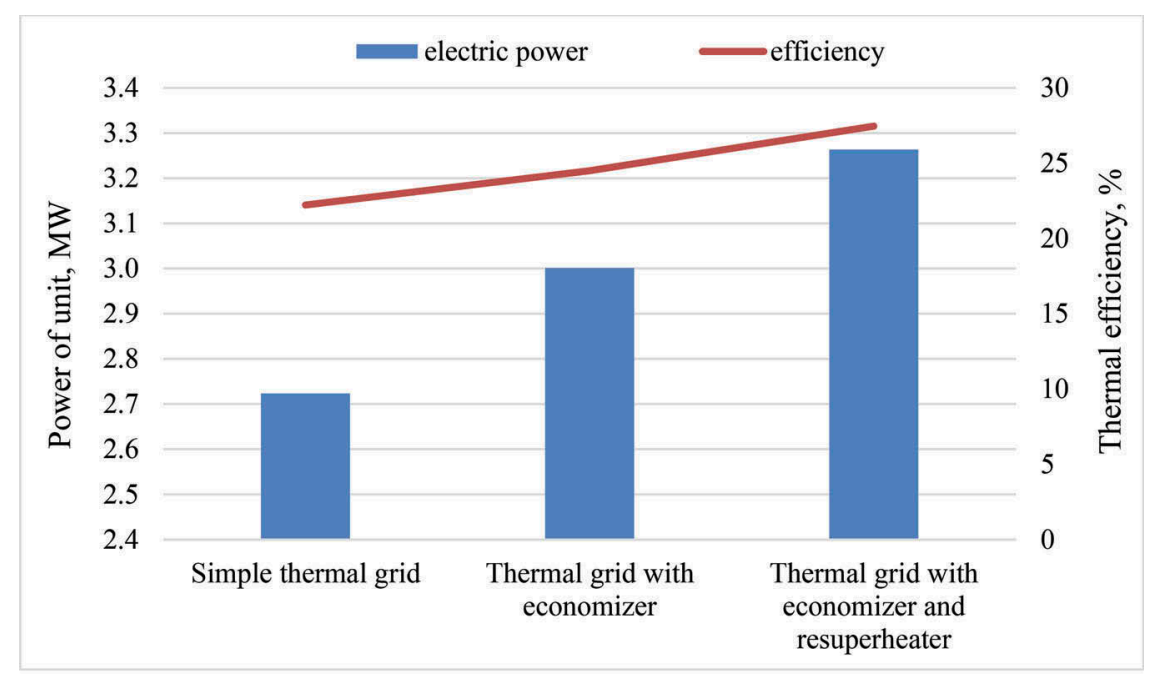

Figure 7. Indicators of energy efficiency each of the three considered thermal circuits.

Table 4. Indicators of economic efficiency.

\begin{tabular}{llll}
\hline Variant & $\begin{array}{l}\text { Without economizer, without } \\
\text { intermediate superheater }\end{array}$ & $\begin{array}{l}\text { With economizer, without } \\
\text { intermediate superheater }\end{array}$ & $\begin{array}{l}\text { With economizer, with } \\
\text { intermediate superheater }\end{array}$ \\
\hline NPV, thou- & 124887 & 158630 & 138413 \\
sand rubles & $24,94 \%$ & $24,29 \%$ & $23,59 \%$ \\
IRR & 1,55 & 1,55 & 1,49 \\
DPI & 6,69 & 7,15 \\
DPP, year & 6,69 & & \\
\hline
\end{tabular}

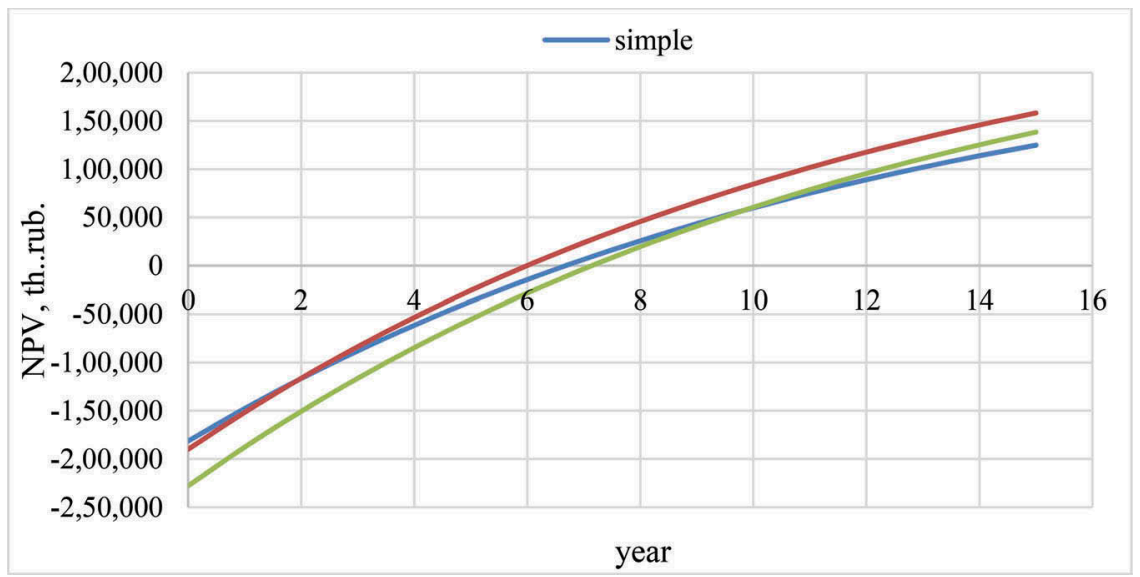

Figure 8. Indicators of economic efficiency. 


\section{DISCUSSION OF THE RESULTS}

From Figures 5 and 6, we can see that the cycle on $\mathrm{r} 245 \mathrm{fa}$ freon has the highest values of thermal efficiency and electric power (in the temperature range of the cooling medium from $-20^{\circ}$ $\mathrm{C}$ to $20^{\circ} \mathrm{C}$ ), thus, we find that it turned out to be the most suitable fluid for given initial conditions.

Figure 7 shows that the thermal circuit with an intermediate superheater and economizer is expected to be better than the other considered options for thermal circuits in terms of the full use of the heat of the source. The thermal efficiency of this option is 3.0\% higher than that of a thermal circuit with an economizer and 5.2\% higher than that of thermal circuit without auxiliary equipment. It should also be noted that installation of the economizer increases the thermal efficiency of the unit by $2.3 \%$ with the relatively low cost of this element, the simplicity of its installation and operation.

Now we are comparing the economic indicators of the unit options under consideration. As it can be seen from Table 4 and Figure 8, despite the greatest energy efficiency, a thermal circuit with an intermediate superheater and economizer is the least profitable in terms of economic indicators. This thermal scheme has the worst values of DPI, DPP and IRR. The reason for the economic inexpediency of using this thermal scheme is the high cost of the system components (a significant increase capital expenses, the cost of installation and operation of a turbine unit with intermediate superheater).

Interesting results are obtained by comparing the economic indicators of units without an economizer and superheater with the unit with an economizer and without superheater. As can be seen from Table 4 and Figure 8, despite the lower efficiency of the first variant (thermal efficiency is lower by $2.3 \%$ ), the economic performance indicators for this variant are not much worse than the option with the economizer installed. However, if we consider the dependence of NPV on the lifetime, you can also notice that with an increase in the operating life, the most energy-efficient variant begins to approach two other variants and, starting from the 9 th year of operation, surpasses the least energy-efficient variant.

\section{CONCLUSION}

In this paper, we considered the problem of choosing a working fluid and the thermal circuit of the OCR for refinery industry. For this, an algorithm was developed that allows you to choose the most effective variant from the point of view of its technical and economic parameters.

The described method can also be used to select a working fluid for the ORC under other initial conditions. It is universal for all ranges of powers and temperatures of low-grade heat sources.

With the help of this algorithm, the most acceptable variant of the Thermal circuit of OCR was chosen for the given initial conditions. This is a variant of the thermal circuit of the OCR with an economizer, despite its lower energy efficiency compared to the variant of the thermal circuit with an economizer and intermediate steam overheating. Also, based on the analysis of the results obtained, an assumption was made: with an increase in the power of the lowpotential heat source and the working lifespan, the most energy-efficient option will be more and more economically feasible. This statement is due to the following: the NPV of this variant will increase faster than that of other options with an increase in the working lifespan, and also an increase in the unit capacity of the unit will lead to a decrease in the unit cost of equipment.

Economic indicators from the implementation of the proposed technology prove the feasibility of its use. This technology allows the most efficient use of the energy resources of the plants, which ultimately leads to a reduction in the cost of finished products. 


\section{REFERENCES}

Burdygina, E.V. 2003. Improving the energy efficiency of heat engineering equipment for crude oil distillation. Authors abstract. Ufa: Ufa State Petroleum Technological University.

Chen, H. \& Goswami, D.Y. \& Stefanakos, E.K. 2010. A rewiew of thermodynamic cycles and working fluids for the conversion of low-grade heat. Renewable and Sustainble Energy Reviews Vol. 14: pp. 3059-3067.

Emiliano, I.M. Casati. 2014. New concepts for Organic Rankine cycle power systems. Milan: Politecnico di Milano

Fitsak, V.V. \& Boguslavskiy, E.I. 2017. Technology and economics of near-surface geothermal resources exploitation. Journal of Mining Institute Vol. 224: pp. 189-198.

Kang, S. 2012. Design and experimental study of ORC and radial turbine using R245fa working fluid. Energy №41: pp. 514-524.

Kirsanova, N.Y. \& Lenkovets, O.M. \& Nikulina, A.Y. 2018. Renewable energy sources (RES) as a factor determining the social and economic development of the arctic zone of the Russian Federation. International Multidisciplinary Scientific GeoConference Surveying Geology and Mining Ecology Management, SGEM Vol. 18: pp. 679-686.

Makhovikov, A.B. \& Katuntsov, E.V. \& Kosarev, O.V. \& Tsvetkov, P.S. 2018. Digital transformation in oil and gas extraction. Innovation-Based Development of the Mineral Resources Sector: Challenges and Prospects - 11th conference of the Russian-German Raw Materials Vol. 1: pp. 531-538.

Russian Federation Federal Law No. 261-FZ of November 23, 2009. On Energy Saving and Increase of Energy Efficiency and Introduction of Changes into Separate Legislative Acts of the Russian Federation

Smirnova, N.N. \& Izotov, E.A. 2017. Methodology for estimating heat losses due to heat effects on a heterogeneous oil reservoir. Journal of Industrial Pollution Control Vol. 33: pp. 950-958.

Smirnova, N.V. \& Rudenko, G.V. 2017. Tendencies, problems and prospects of innovative technologies implementation by Russian oil companies. Journal of Industrial Pollution Control Vol. 33: pp. 937-943.

Tartiere, T. \& Astolfi, M.A. 2017. World overview of the organic Rankine cycle market. Energy Procedia Vol. 129: pp. 2-9. 


\title{
Cluster analysis of electric energy consumption in metallurgy enterprises
}

\author{
R.V. Klyuev \\ Grand PhD in Engineering sciences, Head of Department, North-Caucasian Institute of mining and metallurgy \\ (State Technological University), Vladikavkaz, Professor, Moscow Polytechnic University, Moscow, Russia
}

\author{
I.I. Bosikov \\ PhD in Engineering sciences, Associate Professor, North-Caucasian Institute of mining and metallurgy \\ (State Technological University), Vladikavkaz, Russia
}

O.A. Gavrina

PhD in Engineering sciences, Associate Professor, North-Caucasian Institute of mining and metallurgy (State Technological University), Vladikavkaz, Russia

\begin{abstract}
To increase the efficiency of energy use at non-ferrous metallurgy enterprises, an integrated approach is required to assess energy consumption. Therefore, the urgent issue is the development of a methodology that most fully reflects the specifics of the non-ferrous metals production, based on the methods of expert evaluations, cluster and rank analysis, which allows us to evaluate and implement energy management. The objectives of the research in this work are: development of a methodology for expert assessments, which allows to assess the influence degree of technological production indicators of the hard alloys on the consumption of electricity; conducting a statistical analysis of expert assessments for a number of null hypotheses; development of a methodology for cluster analysis of the main indicators of technocenosis, which allows one to build histograms and mathematical models of the distribution of the sums of ranks of expert assessments for all castes of rank distribution. The formation of clusters and the construction of a dendrogram of weakly correlated indicators among themselves, the influence of which for individual castes on the consumption of electric energy is quantified by the values of the weighted average fuzzy numbers. Cluster analysis made it possible to clarify for the non-ferrous metallurgy enterprise significant weakly correlated indicators that have the greatest impact on electricity consumption. An analysis of significant weakly correlated indicators showed that they are all divided into two main groups on the basis of their possible use to obtain the regression equation.
\end{abstract}

\section{INTRODUCTION}

Non-ferrous metallurgy enterprises for the production of hard alloys are large consumers of electricity. The operation mode of these enterprises is determined by the specifics of technological processes. Electricity consumption is influenced by a large number of rather vague factors. Therefore, to solve the important and urgent task of increasing the efficiency of electricity use, it is necessary to first determine the factors themselves and assess the degree of their influence on electricity consumption using expert assessment methods and cluster analysis.

The use of expert assessment methods and cluster analysis in various industries is the focus of the work of Russian scientists (Beshelev \& Gurvich. 1980), (Frenkel. 1977), (Vartazarov, Gorlov, Minaev, \& Khvastunov. 1981) and foreign scientists (Bann \& Farmer. 1987), (Draper \& Smith. 1973), (Duran \& Odell. 1977), (Kendall. 1975), (Lee \& Deb. 2018), (Liao \& He. 2018), (Ioppolo, Boffardi \& Ar-bolino. 2019), (Meschede, Esparcia, Holzapfel \& Bertheau. 2019). 


\section{RESEARCH METHODS AND MATERIALS}

In present work, to solve the problem of improving the efficiency of use at non-ferrous metallurgy enterprises, a research method based on expert assessments is used. As experts, professionals in the field of carbide production at a non-ferrous metallurgy enterprise were involved.

The developed methodology for expert assessments of the influence degree of technological evaluated indicators on electricity consumption is based on the analysis of rank correlation, which allows formalizing a priori information of experts.

As experts, professionals in the field of technology of production processes, power plants and researchers associated with the production of hard alloy were involved. Due to the heterogeneity of experts, a "weight" coefficient is assigned to each of them to obtain a more objective average assessment. The proposed differentiated scale of "weight" coefficients $\beta_{j}$, taking into account the qualifications of the expert, the length of service in the specialty, is shown in Table 1.

The expert qualifications are reflected in their "weight" $\beta_{j}=(0.7 \div 1.3)$. The greatest "weight" $\left(\beta_{j}=1.3\right)$ was assigned to the chief metallurgist with a work experience of more than 40 years, and the smallest $\left(\beta_{j}=0.7\right)$ to the senior power engineer of the workshop with work experience of up to 10 years.

Initial assessments of experts were obtained on the basis of developed questionnaires evaluating the influence of technological indicators of workshops on electricity consumption on a 5-point scale (Table 2).

Based on representative expert assessments for the workshop for the recovery and sintering of molybdenum from a non-ferrous metallurgy enterprise, the following main factors were identified, presented in Table 3 (Klyuev, Bosikov \& Gavrina. 2018).

Based on expert assessments, an initial matrix of ranks and a matrix of related ranks of indicators are formed (Table 4).

Table 1. Differentiated scale of experts "weight" $\beta_{j .}$

\begin{tabular}{lllll}
\hline & \multicolumn{4}{l}{ The numerical value of the "weight" of the $j$-th expert $\beta_{j}$} \\
\cline { 2 - 5 } Expert Position & \multicolumn{4}{l}{ Work experience in the specialty } \\
\cline { 2 - 5 } & up to 10 years & 10 - 20 years & 20-30 years & 30 -40 years \\
\hline Chief Metallurgist of Plant & 1.2 & 1.3 & 1.4 & 1.5 \\
Chief Technologist of Plant & 1.1 & 1.2 & 1.3 & 1.4 \\
Chief Engineer of Plant & 1.0 & 1.1 & 1.2 & 1.3 \\
Chief Power Engineer of Plant & 0.9 & 1.0 & 1.1 & 1.2 \\
Doctor, Candidate of Technical Sciences & 0.8 & 0.9 & 1.0 & 1.1 \\
Workshop Technologist & 0.7 & 0.8 & 0.9 & 1.0 \\
Senior Power Engineer & 0.6 & 0.7 & 0.8 & 0.9 \\
\hline
\end{tabular}

Table 2. The scale of expert's numerical ratings $a_{\mathrm{i}}$ the dependence of electricity consumption $(y)$ on the performance of the workshop of a non-ferrous metallurgy enterprise $\left(x_{i}\right)$.

Experts opinion on how electricity consumption (y) depends on indica- The numerical value of the tors $x_{i}$ assessment

I'm not quite sure that energy consumption depends on $x_{i}$, maybe it depends, but very weakly

I think that power consumption depends on $x_{i}$, but it does not depend much

I think that energy consumption depends on $x_{i}$, about $50 \%$ 
Table 3. The list of indicators $\left(x_{i}\right)$ for the enterprise and assessment of their impact on electricity consumption $(y)$.

\begin{tabular}{lll}
\hline $\mathrm{x}_{\mathrm{i}}$ The list of key indicators for the enterprise & Assessment of the impact of indicators on $y$ \\
\hline & Temperature in reduction, sintering and calcining & 1 \\
$x_{1}$ furnaces & 1 \\
$x_{2}$ Hydrogen quality & 3 \\
$x_{3}$ Hydrogen consumption & 5 \\
$x_{4}$ Voltage drops & 5 \\
$x_{5}$ Thermal insulation of furnaces & 1 \\
$x_{6}$ Uniform promotion of boats in the furnace & 4 \\
$x_{7}$ Loading mass of material into the boat & 2 \\
$x_{8}$ Irregular operation of equipment &
\end{tabular}

Table 4. Matrix of related ranks of indicators for the enterprise.

\begin{tabular}{|c|c|c|c|c|c|c|c|c|c|c|c|c|c|c|}
\hline \multirow[b]{2}{*}{$\mathrm{x}_{\mathrm{i}}$} & \multicolumn{13}{|c|}{ The experts, $m$} & \multirow{2}{*}{$-\sum_{i=1}^{m} \sum_{j=1}^{n} a_{j i}^{(2)}$} \\
\hline & 1 & 2 & 3 & 4 & 5 & 6 & 7 & 8 & 9 & 10 & 11 & 12 & 13 & \\
\hline$x_{1}$ & 2 & 4.5 & 7.5 & 3.5 & 3.5 & 1 & 4.5 & 5.5 & 6 & 8 & 8 & 5 & 5 & 64 \\
\hline$x_{2}$ & 2 & 1.5 & 3 & 5 & 5 & 5 & 1 & 4 & 1.5 & 5.5 & 6.5 & 2 & 1.5 & 43.5 \\
\hline$x_{3}$ & 5 & 4.5 & 7.5 & 6 & 3.5 & 7.5 & 3 & 8 & 3.5 & 5.5 & 6.5 & 8 & 7 & 75.5 \\
\hline$x_{4}$ & 7 & 4.5 & 4 & 7.5 & 7 & 3 & 2 & 3 & 1.5 & 2.5 & 1 & 2 & 1.5 & 46.5 \\
\hline$x_{5}$ & 8 & 7 & 5 & 1.5 & 2 & 5 & 7 & 1.5 & 8 & 5.5 & 2.5 & 5 & 6 & 64 \\
\hline$x_{6}$ & 2 & 1.5 & 1.5 & 1.5 & 1 & 2 & 7 & 1.5 & 6 & 1 & 2.5 & 2 & 3 & 32.5 \\
\hline$x_{7}$ & 6 & 8 & 6 & 3.5 & 7 & 5 & 7 & 7 & 3.5 & 2.5 & 4 & 7 & 8 & 74.5 \\
\hline$x_{8}$ & 4 & 4.5 & 1.5 & 7.5 & 7 & 7.5 & 4.5 & 5.5 & 6 & 5.5 & 5 & 5 & 4 & 67.5 \\
\hline$\sum_{j=1}^{m} \sum_{i=1}^{n} a_{j i}^{(2) \leftarrow}$ & 36 & 36 & 36 & 36 & 36 & 36 & 36 & 36 & 36 & 36 & 36 & 36 & 36 & 468 \\
\hline
\end{tabular}

\section{EXPERT ASSESSMENT METHODOLOGY}

By sequentially checking a series of null hypotheses, a fairly high qualification and consistency of expert opinions on the formation of the initial matrix and matrix of related ranks were statistically confirmed.

Based on the statistical analysis of rank correlation, a priori information on the estimated indicators was formalized. To assess the significance of the influence of individual indicators on electricity consumption, a cluster analysis of expert assessments was used.

Cluster analysis is carried out according to an algorithm corresponding to two qualitative levels: distribution of sums of ranks of expert assessments; matrix of distances between expert assessments.

The distribution of the ranks sums of expert assessments allows one to preliminarily divide the indicators by their impact on electricity consumption into significant and insignificant.

Calculation algorithm (Klyuev, Bosikov, Gavrina \& Revazov. 2018).

Median of the distribution polygon of weighted averaged averaged fuzzy numbers of indicators:

$$
m_{0}=\frac{1}{2}\left(\operatorname{maxa}_{l}+\operatorname{mina}_{l}\right)
$$

where $l=1, n ; n=$ number of indicators; $n=11$.

Weighted average of the fuzzy number for the $i$-th indicator, taking into account the "weight" of experts: 
Table 5. The calculated values of the weighted average fuzzy numbers for the indicators of the enterprise.

\begin{tabular}{|c|c|c|c|c|c|c|c|c|}
\hline \multirow[b]{2}{*}{ Designation } & \multicolumn{8}{|l|}{$\underline{x_{i}}$} \\
\hline & $x_{1}$ & $x_{2}$ & $x_{3}$ & $x_{4}$ & $x_{5}$ & $x_{6}$ & $x_{7}$ & $x_{8}$ \\
\hline$A_{i}$ & 5.0 & 3.62 & 6.31 & 3.92 & 5.00 & 2.46 & 6.38 & 5.31 \\
\hline$A_{\beta i}$ & 4.89 & 3.64 & 6.41 & 3.76 & 4.95 & 2.26 & 6.43 & 5.15 \\
\hline$A_{i^{*}}$ & 1.05 & 0.76 & 1.33 & 0.83 & 1.05 & 0.52 & 1.34 & 1.12 \\
\hline$A_{\beta i^{*}}$ & 1.13 & 0.84 & 1.47 & 0.86 & 1.14 & 0.52 & 1.48 & 1.18 \\
\hline
\end{tabular}

$$
\bar{A}_{\beta i}=\sum_{l=1}^{n} a_{l} w_{i}\left(a_{l}\right)
$$

where $w_{i}\left(a_{l}\right)=$ frequency; $\beta_{i}\left(a_{l}\right)=$ "weight" of the $j$-th expert who gave his expert assessment; $a_{l}\left(\beta_{j}\left(a_{l}\right)=(0,7 \div 1,3) ; m=\right.$ number of experts; $m=12$.

$$
w_{i}\left(a_{l}\right)=\frac{\sum_{j=1}^{m} \beta_{j}\left(a_{l}\right)}{\sum_{j=1}^{m} \beta_{j}}
$$

In relative units:

$$
\bar{A}_{\beta i *}=\frac{\bar{A}_{\beta i}}{m_{0}^{\prime}}
$$

where $m_{0^{\prime}}=$ the median value taking into account the "weight" of experts:

$$
m_{0}^{\prime}=\frac{1}{2}\left(\max \bar{A}_{\beta_{i}}+\min \bar{A}_{\beta i}\right)
$$

The results of calculating the weighted averaged fuzzy numbers are given in Table 5 .

A histogram of the distribution of the ranks sums of indicators is constructed with a preliminary determination of the relative values of the ranked sum of ranks $\Delta_{i} *$ :

$$
\Delta_{i *}=\frac{1}{m_{01}} \sum_{j=1}^{m} a_{j i}
$$

where $m_{01}=$ median of the sum of the ranks of all indicators:

$$
m_{01}=\frac{1}{2}\left(\max \sum_{j=1}^{m} a_{j i}+\min \sum_{j=1}^{m} a_{j i}\right)
$$

\section{CLUSTER ANALYSIS OF INDICATORS AFFECTING ELECTRICITY CONSUMPTION}

Figure 1 Shows a histogram of the distribution of the ranks sums and the dependence of the enterprise approximating it using the least squares method. 


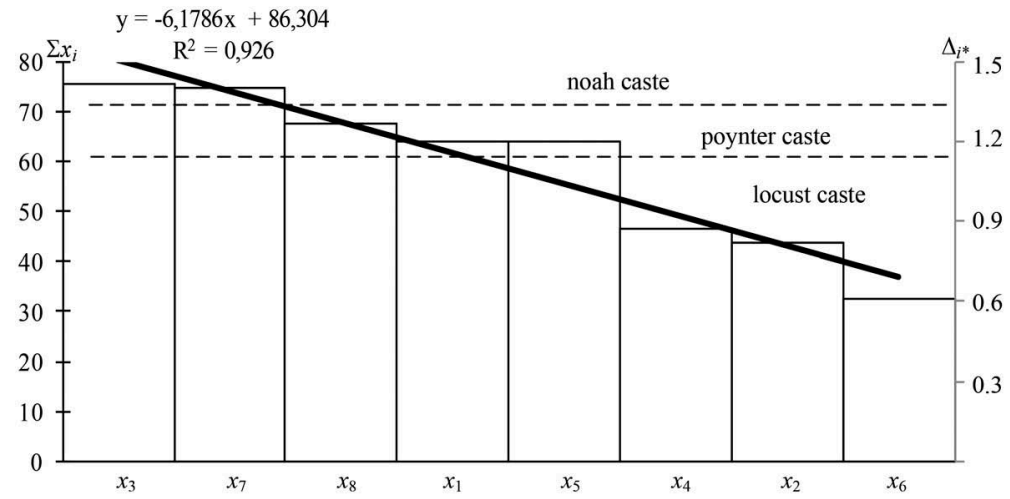

Figure 1. A histogram of the distribution of the ranks sums of expert ratings of indicators for the enterprise.

To determine the degree of proximity (correlation) between the indicators, a cluster analysis is carried out. Cluster formation is based on a matrix of distances between grouped indicators, each of which at the beginning is considered as a separate cluster (Zaalishvili, Kanukov, Melkov, Makiev \& Dzobelova. 2018).

Calculation algorithm.

The degree of proximity of the indicators, calculated as the Euclidean distance between them:

$$
d_{k l}^{2}=\frac{n\left(n^{2}-1\right)}{6}\left(1-r_{k l}^{2}\right)
$$

where $k, l=$ considered indicators; $k \neq l$.

Sample pair correlation coefficient:

$$
r_{k l}=\frac{\frac{\left[\sum_{j=1}^{m}\left(a_{j k} a_{j l}\right)\right]}{m-1}-a_{k} a_{l}\left(\frac{m}{m-1}\right)}{\bar{s}_{k} \bar{s}_{l}}
$$

where $a_{k}, a_{l}=$ sample averages of indicators $k, l$; standards of indicators $k, l$ :

$$
\begin{aligned}
& \bar{s}_{k}^{2}=\frac{1}{m-1} \sum_{j=1}^{m}\left(a_{j k}-\bar{a}_{k}\right)^{2} \\
& \bar{s}_{l}^{2}=\frac{1}{m-1} \sum_{j=1}^{m}\left(a_{j l}-\bar{a}_{l}\right)^{2}
\end{aligned}
$$

The process of cluster formation ends when all indicators are combined, which will happen in the last step of the unification.

Based on the calculation results, a divisible tree of hierarchical classification of indicators and the corresponding dendrogram of indicator clusters, shown in Figure 2 and Figure 3 are drawn. 


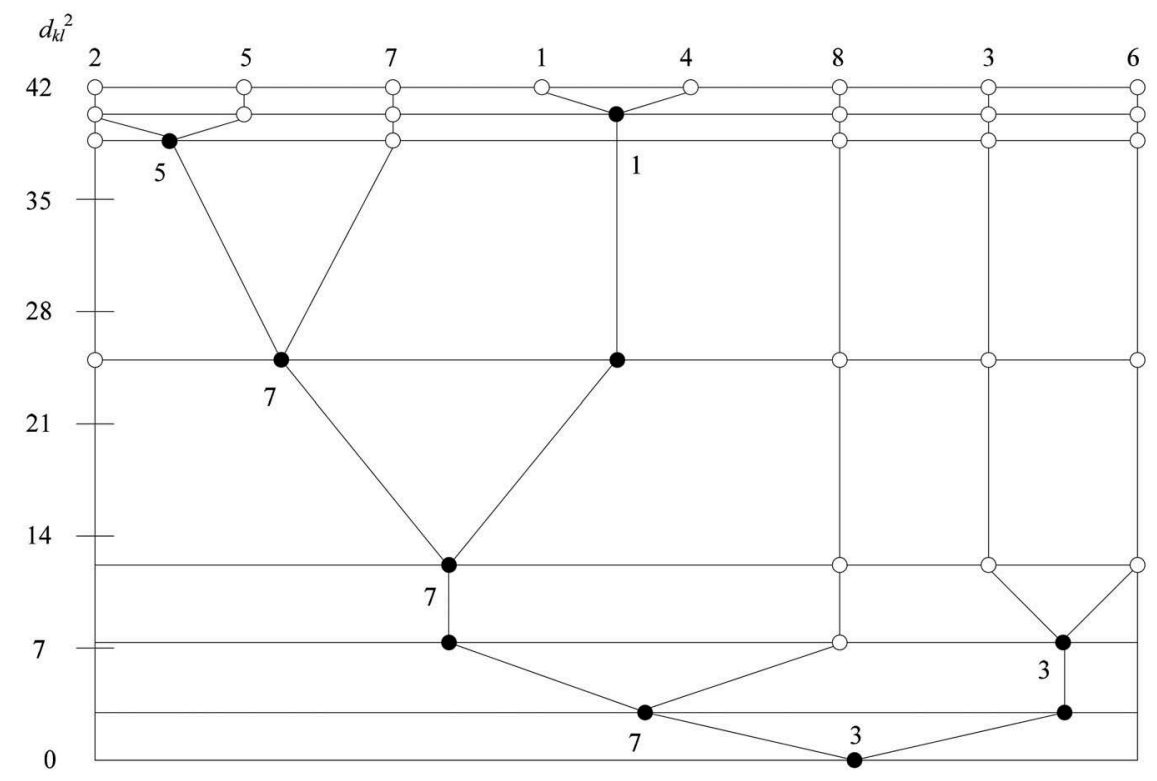

Figure 2. Divisible tree of hierarchical classification of enterprise indicators.

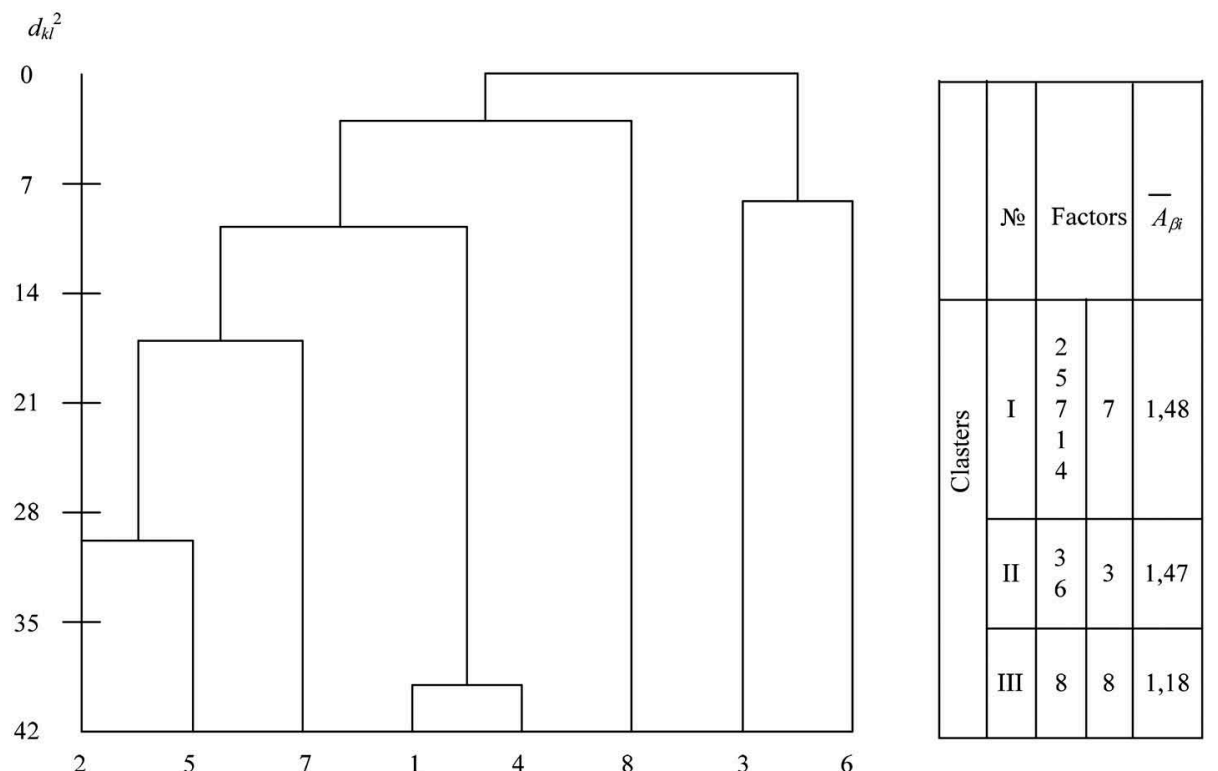

Figure 3. Dendrogram clusters of enterprise indicators.

\section{CLUSTER ANALYSIS RESULTS}

The cluster analysis made it possible to clarify significant weakly correlated indicators among the workshop of the enterprise that have the greatest impact on electricity consumption (Shempelev, Zaalishvili \& Kukhmazov. 2017). The list of indicators included in Noah, Pointer, Locust distribution castes and the values of weighted average fuzzy numbers are shown in Table 6. 
Table 6. List of indicators divided by distribution castes.

\begin{tabular}{llll}
\hline & & \multicolumn{2}{l}{ Designation } \\
\cline { 3 - 4 } № & Name of indicator & $x_{i}$ & $A_{\beta i^{*}}$ \\
\hline Noah distribution caste & $x_{3}$ & 1.47 \\
1 & Hydrogen consumption & $x_{7}$ & 1.48 \\
2 & Loading mass of material into the boat & $x_{8}$ & 1.18 \\
Poynter caste distribution & $x_{5}$ & 1.14 \\
1 & Irregular operation of equipment & $x_{1}$ & 1.13 \\
2 & Thermal insulation of furnaces & & \\
3 & Temperature in reduction, sintering and calcining furnaces & $x_{4}$ & 0.86 \\
Locust distribution caste & $x_{2}$ & 0.84 \\
1 & Voltage drops & $x_{6}$ & 0.52 \\
2 & Hydrogen quality &
\end{tabular}

An analysis of significant indicators that are weakly correlated with each other showed that they are all divided into two main groups based on their possible use to obtain a regression equation of the form $y=f\left(x_{i}\right)$.

The first group includes indicators that make it possible to quantify them directly or indirectly (points 1, 2 (Noah caste), point 3 (Pointer caste), points 1, 3 (Locust caste)).

The second group includes indicators that are difficult (points 1, 2 (Pointer caste), or non formalized point 2 (Locust caste).

Increasing material interest and improving working conditions will increase the level of repair and maintenance of equipment and have a significant impact on reducing losses and specific electricity consumption (Eraky, M.T., Zubov, D.V. \& Krysanov K.S. 2019).

\section{MATHEMATICAL MODEL OF SPECIFIC POWER CONSUMPTION OF METALLURGICAL PRODUCTION FURNACES BASED ON A FULL FACTORIAL EXPERIMENT}

Mathematical models of the dependence of the specific energy consumption on technological factors were obtained during a full factorial experiment (PFE). On resistance furnaces, PFE of the form $N=2^{2}$ was carried out using two technological factors $\left(x_{1}, x_{2}\right)$ at two levels of variation.

The algorithm for obtaining a mathematical model based on PFE is given below.

1. According to the current technological control of the studied factors, the conditions for conducting experiments in natural and code scales are determined.

2. A planning matrix for PFE is compiled, which presents the results of the experiments. To calculate the variances of the output parameter (specific energy consumption) and to verify their homogeneity, parallel experiments are performed with the number $m$.

3. The hypothesis $\mathrm{H} 0$ is tested: at the accepted significance level $\alpha=0,05$, the variances are homogeneous. The homogeneity of the dispersions is checked by the Cochren criterion $G_{\max }$. The tabulated critical value of the Cochren criterion $G\left(f_{1}, f_{2}\right)$ is determined at values $f_{1}=m-1 ; f_{2}=N$ and $\alpha=0,05$.

4. The coefficients of the regression equation are determined from the PFE planning matrix.

5. The significance of the coefficients of the regression equation is estimated based on the method of regression analysis using the calculated values of the Student t-test. Significant are the coefficients for which the condition $t_{i j}>t_{m}\left(f_{1}, \alpha\right)$ is satisfied.

6. The adequacy of the obtained regression equation is checked by the variance values - the average of the PFE and the residual - regression equation. The regression equation adequately describes the process under study if the condition $>$ is satisfied. 
Table 7. Test conditions in natural and code scales.

\begin{tabular}{|c|c|c|c|c|c|c|}
\hline \multirow[b]{2}{*}{ № } & \multirow[b]{2}{*}{ Factors } & & \multicolumn{4}{|c|}{$\underline{\text { Levels and interval of variation of factors }}$} \\
\hline & & & lower & upper & main & interval \\
\hline 1 & $x_{1}$ & $\gamma, \mathrm{kg}$ & 110 & 130 & 120 & 10 \\
\hline \multirow[t]{2}{*}{2} & $x_{2}$ & $V, \mathrm{~m}^{3}$ & 8 & 10 & 9 & 1 \\
\hline & & & -1 & 1 & 0 & $\Delta i$ \\
\hline
\end{tabular}

Table 8. PFE planning matrix $N=2^{2}$ and experimental results.

\begin{tabular}{|c|c|c|c|c|c|c|c|c|c|}
\hline \multirow[b]{2}{*}{ № } & \multicolumn{3}{|c|}{ Code scale } & \multicolumn{2}{|c|}{ Natural scale } & \multicolumn{3}{|c|}{$W_{\text {specific }}, \mathrm{kWh} / \mathrm{kg}(y)$} & \multirow[b]{2}{*}{$W_{\text {specific.average }}, \mathrm{kWh} / \mathrm{kg}$} \\
\hline & $x_{0}$ & $x_{1}$ & $x_{2}$ & $\gamma, \mathrm{kg}$ & $V, \mathrm{~m}^{3}$ & 1 & 2 & 3 & \\
\hline 1 & 1 & -1 & -1 & 110 & 8 & 0.91 & 0.95 & 0.86 & 0.91 \\
\hline 2 & 1 & 1 & -1 & 130 & 8 & 0.78 & 0.81 & 0.74 & 0.78 \\
\hline 3 & 1 & -1 & 1 & 110 & 10 & 1 & 1.05 & 0.98 & 1.01 \\
\hline 4 & 1 & 1 & 1 & 130 & 10 & 0.84 & 0.87 & 0.83 & 0.85 \\
\hline$\Sigma$ & & 0 & 0 & & & & & & 3.55 \\
\hline
\end{tabular}

7. A transition is made from the code values of independent variables to their values in physical units.

To conduct PFE as technological factors that have the most significant effect on the specific energy consumption, the following were determined: $x_{1}$ - mass of ammonium paramolybdate loaded into the furnace, $\gamma, \mathrm{kg} ; x_{2}$ is the amount of hydrogen, $V, \mathrm{~m}^{3}$.

In the Table 7 shows the conditions for conducting PFE experiments in natural and code scales, in Table 8 - PFE planning matrix and experimental results.

According to the condition $t_{i j}>t_{m}\left(f_{1}, \alpha\right)$, the coefficients $\mathrm{b}_{1}$ and $\mathrm{b}_{1}$ are significant. In this case, the regression equation has the form:

$$
\mathrm{y}=88.75 \cdot 10-^{2} \cdot-\cdot 7.25 \cdot 10-^{2} x_{1} \cdot+\cdot 4.25 \cdot 10-^{2} x_{2}
$$

Moving from the code values of independent variables to their values in physical units, we obtain a mathematical model:

$$
W_{\text {specific }}=1.375-7.25 \cdot 10-{ }^{3} \gamma+4.25 \cdot 10-{ }^{2} V, \mathrm{kWh} / \mathrm{kg}
$$

\section{CONCLUSION}

1. An analysis of the histograms of the distribution of the ranks sums of the expert assessments of technological indicators made it possible to select a cluster of significant $(\Delta i *>1)$ indicators and group them according to the degree of influence on energy consumption.

2. The analysis of dendrograms showed that the considered totality of indicators for the workshop of the non-ferrous metallurgy enterprise forms 3 clusters with the values of the weighted average fuzzy number for the $i$-th indicator taking into account the "weight" of experts within $(0.52 \div 1.48)$.

3 . Based on the cluster analysis, statistically significant slightly correlated indicators were specified that have the greatest impact on electricity consumption (Table 6). 
4. The objective of further research is to determine the type of functional of the equation $y=f\left(x_{i}\right)$ and to optimize electricity consumption for a complex of non-ferrous metallurgy enterprises.

5. The results obtained in the work can be used at industrial enterprises of various industries. Of particular relevance are the results when it is impossible to carry out instrumental measurements of the parameters of electricity consumption and the values of technological indicators.

\section{REFERENCES}

Beshelev, S.D. \& Gurvich F.G. 1980. Mathematical and statistical methods of expert estimates. Moscow. Statistics.

Bann, D.V. \& Farmer, E.D. 1987. Comparison models of electric load forecast. Moscow. Energoatomizdat.

Draper, N. \& Smith, H. 1973. Applied regression analysis. Moscow. Mir.

Duran B. \& Odell, P. 1977. Cluster analysis. Moscow. Statistics.

Frenkel, A.A. 1977. Analysis of factors of growth of labor productivity using expert assessments. Moscow. Nauka.

Kendall, M. 1975. Rank correlations. Foreign statistical studies. Moscow. Statistics.

Klyuev, R.V., Bosikov, I.I. \& Gavrina, O.A. 2018. Development of Mathematical Model for Specific Power Consumption of Resistance Furnaces at Non-Ferrous Metallurgy Enterprises. International Russian Automation Conference (RusAutoCon), Sochi, 9-16 September 2018. IEEE.

Klyuev, R.V., Bosikov, I.I., Gavrina, O.A., \& Revazov, V.Ch. 2018. System analysis of power consumption by nonferrous metallurgy enterprises on the basis of rank modeling of individual technocenosis castes. MATEC Web Conf. 226. (2018) 04018. EDP Sciences.

Lee, S. \& Deb, Ch. 2018. Determining key variables influencing energy consumption in office buildings through cluster analysis of pre- and post-retrofit building data. Energy and Buildings 159: 228-245.

Liao, N. \& He, Y. 2018. Exploring the effects of influencing factors on energy efficiency in industrial sector using cluster analysis and panel regression model. Energy 158: 782-795.

Ioppolo, G., Boffardi, R. \& Arbolino, R. 2019. The effectiveness of European energy policy on the Italian system: Regional evidences from a hierarchical cluster analysis approach. Energy Policy 132: 47-61.

Meschede, H., Esparcia, E., Holzapfel, P. \& Bertheau, P. 2019. On the transferability of smart energy systems on off-grid islands using cluster analysis - A case study for the Philippine archipelago. Applied Energy 251. Article 113290.

Shempelev, A.G., Zaalishvili, V.B. \& Kukhmazov, S.U. 2017. Deep structure of the western part of the Central Caucasus from geophysical data. Geotectonics, 51(5): pp. 479-488.

Vartazarov, I.S., Gorlov, I.G., Minaev, E.V., \& Khvastunov, R.M. 1981. Expert assessments and their application in the energy sector. Moscow. Energoizdat.

Zaalishvili, V.B., Kanukov, A.S., Melkov, D.A., Makiev, V.D. \& Dzobelova, L.V. 2018. Development of a unified model of geoinformation system for city planning and integration. International Journal of GEOMATE, 15(51): pp. 160-166.

Eraky, M.T., Zubov, D.V. \& Krysanov K.S. 2019. Manipulator Robot Using a New Developed Geometrical Approach Method for Improvement of Quality Food and Chemical Industries. International Journal of Engineering Research and Technology, 12: 1423-1430. 


\title{
Potential of Modelica for the creation of digital twins
}

\author{
Stefan Vöth \\ Prof. Dr.-Ing, Technische Hochschule Georg Agricola (THGA), Germany \\ Maria Vasilyeva \\ PhD, Associate professor, St. Petersburg Mining University, Russia
}

\begin{abstract}
Digitalization is on path of fast development in all spheres of society. As an outcome the requirements on modeling of systems are increasing. This applies with regard to quantity and quality. In this context the tools for modeling have to be selected. Considering modeling a possible choice is the language Modelica. This language comprises different advantages, finally supporting safe use and effective reuse of already developed components. Especially Modelica is an efficient approach to model acausal interaction between objects, which practically occurs fairly in every system, in technical systems typical for mechanical engineering e.g. The text comes with possible views on the term digital twin, which seems not to be defined exactly. It continues with Modelica, its properties and advantages for the creation of digital twins. Summarized the text should give some support to get acquainted, to evaluate and to decide on the usage of Modelica.
\end{abstract}

\section{DIGITAL TWIN}

The headline mentions two keywords, which have to be understood: Modelica and digital twin. A digital twin is a representation of some object or system of objects in the digital sphere. Certainly the question can be stated, whether this description is sufficient, but it at least depicts a minimum requirement. The object may be material or not material. It may represent products, production systems or services. Such representation will not represent „all“ properties of that object, but some selection of properties. Thus an infinite bunch of representations of a digital twin may exist. The choice of the suitable representation is a main task working on digital twins.

A digital twin may be used for different tasks along the lifecycle of a product, from planning to recycling. The digital twin may be built up independant of the question, whether the object already exists or is planned so far only. History first came up with digital twins for not existing objects to handle early phases of the lifecycle. Today motivation is increasing to support later phases oft he lifecycle by digital twins as well.

Possible areas of application are: The product may be developed just in virtual sphere. Production processes may be tested and optimized there as well. The product may be tested without production of a real prototype. Personnel may be trained on the job without an equipment already existing. Modifications of products and processes may be prepared in digital sphere.

Especially tests in digital sphere comprise severeal advantages: Theoretical and potentially dangerous situations may be analyzed. Tests potentially time, money or space consuming or even not possible to be executed get into focus of availability. In virtual world probably a broader bunch of tests will be executed than in real world. These tests during different project phases with models of different detailing of description can lead to a deepend learning and understanding on theoretical basis.

Preparations in virtual sphere deliver the potential of flawless processes including time and money savings. A focus may be the costly commissioning, e.g. in plant construction. But also the risk of wrong forecasts due to insufficient systems descriptions. 
The digital twin consists of properties and behaviour. Properties are represented by data, behaviour is represented by algorithms and/or equations. Algorithms and equations are associated with causal and acausal modeling.

The digital twin may be coupled with outside world. Via input channels and output channels data may be gained or may be supplied by the digital twin. A special channel are internet connections, which allow distant data exchange. This is one property enabling systems for condition dependant flexible control, called among others „Industry 4.0“.

Along lifetime of the product the idea of a digital twin may be to get a continous digital thread. On basis of operational data the digital twin gathers data. The data may be analyzed, e.g. to execute optimization in order improve usage of the product. In advantage to planning phase this gives the chance of improved optimization on basis of real operational data. Some higher degree of optimization will lead to the modification of the descriptions of properties and beahviour of the system itself. In this case the digital twin is rather dynamically devloping than a static despription. The developed digital twin will give a dramatically enhanced basis for future planning.

Furthermore the data may be analyzed with regard to future behaviour of the system. This gives the chance of enhancement of predictive maintenacne approaches.

This proposes a holistic view of the whole lifecycle. A complete data exchange between all the cycle stages would support variety of new options. This idea introduces several new nontechnical questions on supplier-customer-relation, intercompany data exchange, national and international legislation and data security.

\section{MODELICA}

The headline mentions two keywords, which have to be understood: Modelica and digital twin. Modelica is a programming language especially suitable for the modeling of mathematical models. It can be used for (nearly) any kind of mathematical model. A lot of applications consider technical aspects, but Modelica is not restricted to such. The modeling of social systems or financial systems are options e.g. In fact Modelica has unrestricted multidomain modeling capability.

Different domains may be coupled easily. E.g. using the control domain, the electric domain and the mechanical domain an electro-mechanical drivetrain may be modeled. Objects belonging to a domain are typically collected in toolboxes. Various toolboxes are available, platform built-in, external of platforms, free and commercial.

A core property of Modelica ist he usage of equations. Equations indicate acausal modeling including a flexible data flow direction (Figure 1). This is of importance, as many systems comprise bidirectional flow of information, which can be easily modeled by equations. Assignments, which model unidirectional flow of information (causal modeling), are also supported by Modelica, e.g. in algorithmic sections. Causal and acausal approaches may be used next to each other in one model. This enables a stable object representation.

Modelica is an object-oriented language. This supports the structuring of systems and objects and the reuse of objects. This aspect empowers the toolboxes available.

The focus of Modelica is on modeling. Platforms support the automatic transfer of the model to a mathematical model and finally to an executable program. Basically there is no dealing with differential-algebraic equations, conversion of equations, numerical solvers, code generation and post-processing. The idea is to give the chance to focus on the engineering task rather than programming tasks, in order to increase the productivity of the modeling process.

A further property of Modelica is to associate units with variables. This enables the automatic test on unit integrity of the model.

As Modelica is object-oriented it is recommended, to decompose a system in components and to describe them as software objects. The decomposition should be executed from high complexity on top level to low complexity on the suitable low level. The number of levels depend on the system character. This approach is especially recommended using existing model classses. If no (fitting) model classes are available at all, a bottom up approach may be 


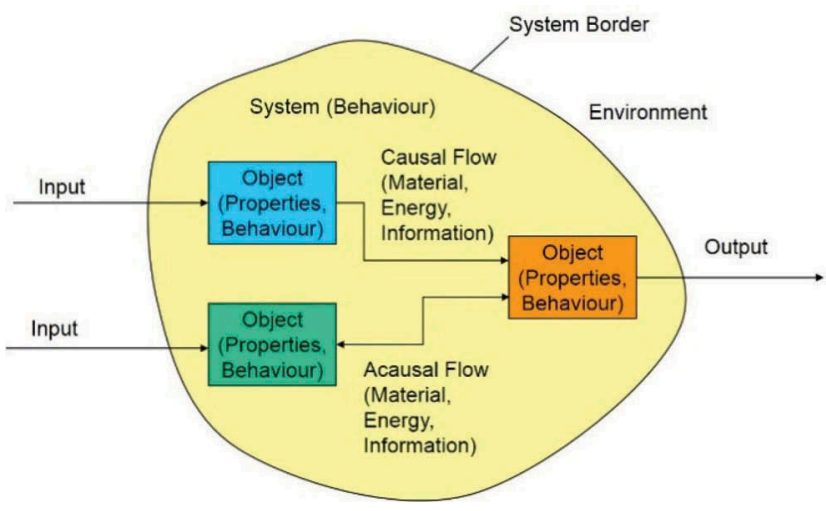

Figure 1. Properties of a system in general.

more suitable. Maybe existing model classes can be applied, maybe new model classes have to be developed. The connection of objects between each other is realized by connector classes. The connector classs defines the data interchanged via the interface between the objects. Connector classes are members of object classes. Connectors with compatible data interface can be connected to each other (Figure 2).

Open-source tools and commercial tool for working with Modelica are available both.

\section{APPLICATIONS}

At THGA Modelica is used to build up digital twins.

First application is the modeling of the behaviour of hoisting systems of fast running cranes. The models are used to plan the parametrization of hoists in order to optimize the loading of drivetrain components.

Second application is the modeling of ventilation systems of mines. Target of this application is the energy efficient control of air mass flows.

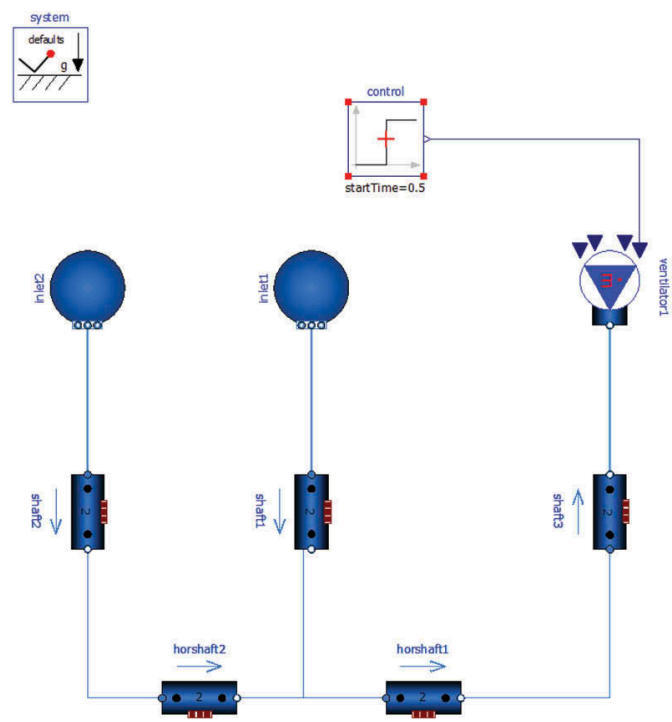

Figure 2. Objects, interfaces and connections as elements of a model for the ventialtion of an underground mine. 


\section{CONCLUSIONS}

There are different languages for modeling objects in digital sphere. One option is Modelica, which comprises several advantages:

- Multidomain modeling. No restrictions to the definition of new domains.

- Model structuring and model reuse supported by object-orientation.

- Supporting of causal modeling and acausal modeling as well.

- Support of units for the description of parameters and variables.

- Focussing on modeling instead of coding.

- Textual and visual tools for programming available on platforms.

- Diverse resources available, free and commercial.

\section{REFERENCES}

Chrisofakis E, Junghanns A: Faster development of automotive control software with Modelica and FMI, 2013.

Elmqvist H: Modelica Evolution - from my Perspective, Proceedings of the 10th International ModelicaConference, Lund, 2014.

Elshekih: Modelica_based Computational Tools for Sensitivity Analysis via Automatic Differentiation, Dissertation, RWTH Aachen, 2012.

Fritzson P: Introduction to Modeling and Simulation of Technical and Physical Systems with Modelica. IEEE Press 2011.

Fritzson P, Rogovchenko O: Introduction to Object-Oriented Modeling, Simulation and Control with Modelica, Tutorial, MODPROD, 2012.

Fritzson P: Principles of Object-Oriented Modeling and Simulation with Modelica 3.3: A Cyber-Physical Approach, John Wiley \& Sons Inc, 2nd edition, 2015.

Junglas P: System-Dynamics-Diagramme als "Physical Modeling" - eine Frage der Kausalität, 2014.

Maurer W: Modelica simuliert komplexe Systeme, Swiss Engineering, 2011.

Maurer W: Modeling of elastic buffers with DyMoRail, 2014.

Norrefeld V, Obelz S, Wirth F: Aufbau einer Modelica Modellbibliothek, BauSIM, 2014.

Ochel L: Petri-Netz-basierte Simulation biologischer Prozesse mit OpenModelica, Bielefeld, 2016.

Peter Beater: Modellbildung und Simulation technischer Systeme mit Modelica 3: Eine kurze Einführung für Ingenieure und Studenten, Books on Demand, 1. Auflage, 2016.

Tatar M, Schaich R: Automated test of the AMG speedshift DCT control software, Berlin, 2010.

Thiele B.A: Framework for Modelica based Function Development, Dissertation, TU München, 2015.

Waurich V, Will F: Simulation der automatisierten Schaufelbefüllung eines Radladers mit Modelica, 2018.

Weck O, Chodas M, Shougarian N: Fundamentals of systems Engineerinmg, MIT, 2015. 


\title{
Analysis and research of the coverage area of the LoRaWAN gateway in various conditions for smart city applications
}

\author{
V.A. Shpenst \\ D.E.Sc., Professor, Saint-Petersburg Mining University, Russia \\ A.V. Terleev \\ Postgraduate student, Saint-Petersburg Mining University, Russia
}

\begin{abstract}
Smart city services nowadays are gaining popularity worldwide. Russia is not an exception. Since early 2000's smart city market is growing steadily and, according to forecasts, will continue to grow. Today, the possible applications of smart city services cover a wide range of sectors - from energy production, distribution and consumption to sustainable mobility and waste management. All the innovative services require millions of monitoring sensors and control devices to be connected between each other and to a management platform. Hence, new types of wireless communication networks that meet the specific requirements of smart city services are needed. LoRaWAN is the most promising M2M (Machine-to-Machine) communication technology among other LPWANs such as NB-IoT and SigFox. Conducted field study of LoRaWAN gateway coverage in different conditions shows the LoRaWAN attenuation coefficient in conditions of city center and outskirt and reveals the factors on which the signal attenuation coefficient depends.
\end{abstract}

Keywords: Smart city, power line, gateway, filter, detection, Energy efficiency, Frequency

\section{INTRODUCTION}

The first mention of the term "Smart city" date back to the early 2000's (Sikora-Fernandez \& Stawasz, 2016). The smart city concept initially described how to use IT infrastructure to create a virtual entity of a city in the information society (Ishida \& Isbister, 2000). Later, the smart city was mainly associated with the strengthening role of intellectual technologies in increasing the efficiency of urban development (Van der Meer \& Van Winden, 2003). Nowadays, the term "Smart city" has transformed to a "smart sustainable city" (SSC), in which information and communication technologies and other tools, on the one hand, are used to improve the effectiveness of the functioning of the city and the provision of urban services and, as a consequence, the overall quality of life, as well as strengthening competitiveness, and on the other hand, satisfy the needs of present and future generations without negatively affecting the economic, social and ecological components of a city (Smart cities and infrastructure, 2019).

There are no unified criteria to assess the level of city's smartness. Therefore, several approaches used in Russian and international practice can be cited. For instance, the National Research Institute for Technology and Communications (NIITS) has developed the "Smart Cities Indicators" rating that is based on data obtained from public sources and considers 26 indicators characterizing the level of development of 7 key areas of the smart city (Indicators of smart cities NIITS, 2017). Another approach is used by specialists of Skolkovo Business School: the smartness index is calculated for 15 biggest Russian cities, such as Moscow, Saint Petersburg, Kazan, Volgograd, Novosibirsk, 
Yekaterinburg, Nizhny Novgorod, Samara, Chelyabinsk, Omsk, Rostov-on-Don, Ufa, Krasnoyarsk, Perm, Voronezh. The calculation method considers 7 spheres of smart city services implementation: transport, healthcare, public administration, media, education, finance, trade (SKOLKOVO Business School Emerging Market Research Institute, 2019).

It is rather difficult to estimate the actual scale of the global market for smart city technologies. Moreover, it is even more complicated to forecast how they will change in the medium and long term. However, some attempts to predict the evolution of the smart city market are still being made. Thus, according to the estimates of the research company Markets \& Markets, the market volume in 2017 amounted to 424.68 billion US dollars, and by 2022 it will already reach 1.2 trillion US dollars (Markets and Markets [Online],2019). Frost \& Sullivan experts give another estimate: according to their forecasts, the smart city technology market will reach $\$ 2.4$ trillion by 2025 . The market growth is also due to the fact that, as it develops, in addition to traditional IT companies and infrastructure giants, new players begin to emerge - small and medium-sized technology firms, engineering and consulting companies. The estimates of the smart city market volume are varying vastly but it is the obvious fact that the number of smart city services will significantly grow in the nearest future.

Smart city services can be divided into groups according to the sphere of its implementation in the city's ecosystem. In Russia, the following 4 groups of services are in the spotlight nowadays:

I. Smart energy. The group covers the whole chain - from efficient and environmentally friendly energy production (both centralized and decentralized), through distribution system with minimum loses up to responsible consumption on the demand side.

II. Smart and sustainable mobility. The main benefits of the smart mobility introduction are reduced congestion of roads, reduction of negative impact on the environment, as well as reduction of energy consumption of vehicles.

III. Smart waste management. This smart city service implies a transparent control of all the waste flows within the city together with best available technics for waste recycling and utilization.

IV. Smart environmental solutions. The package of technological solutions designed to provide better environmental protection for smart cities includes a whole range of components - these are environmental monitoring systems, smart wastewater treatment systems; and renewable energy solutions. Such solutions contribute to improving the quality of the environment (air, soil, water), the transition to a more rational model of energy use and, as a result, improving the health status of citizens and the sanitary situation in the city as a whole.

It is important to understand that all the services require millions of monitoring sensors and actuators which are connected to the single or several management platforms. Today, the number of connected sensors is growing explosively and has already exceeded the number of people with access to the global network (Evans, 2011). The Figure 1 presents the forecast of number of connected devices and sensors until 2025 in comparison with number of people connected to the Internet.

The upcoming smart city revolution requires an infrastructure that can enable the effective interaction of millions of smart devices and sensors. Such interaction has some specific requirements among which:

1. Transfer of small data packages:

2. Energy efficiency;

3. Ability to connect devices in remote areas;

4. High degree of data protection;

5. Interoperability. 


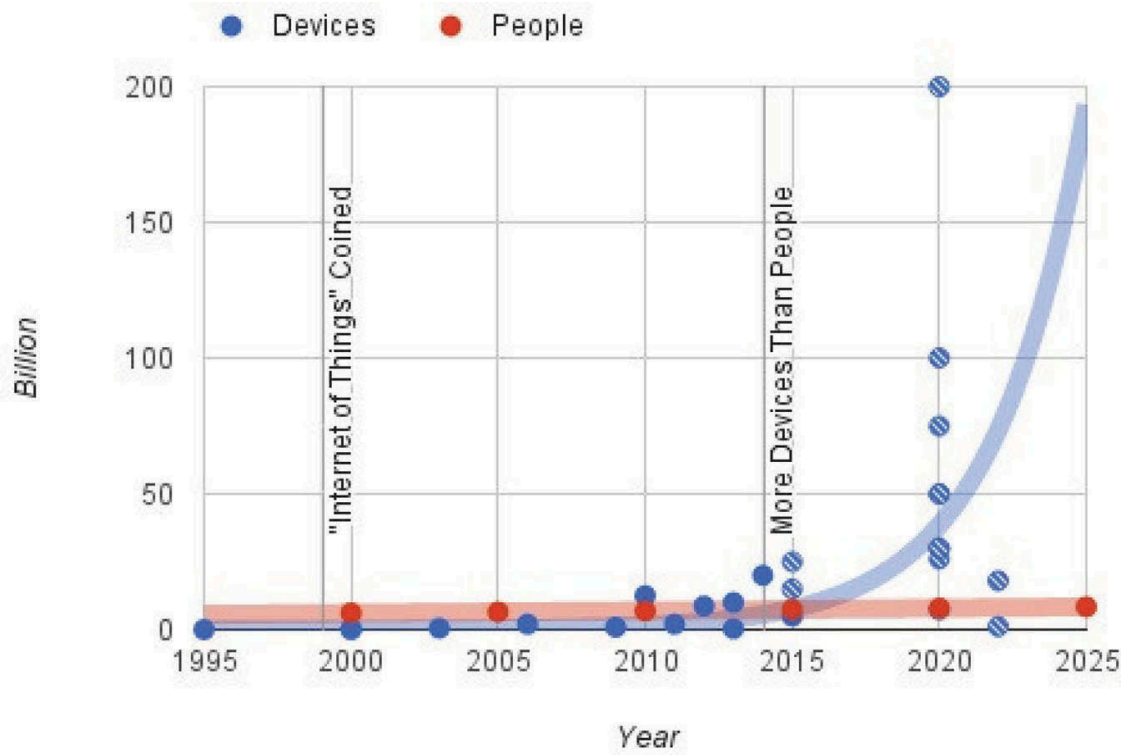

Figure 1. The forecast of number of connected devices and sensors until 2025 (www.brookings.edu).

In practice, energy efficiency is the biggest challenge from the list above. Connected enddevices have to be able to operate for a long period of time (several years) powered by imbedded battery with no connection to the grid. Otherwise the maintenance of the end-devices will be difficult and expensive.

\section{METHODS}

To effectively solve problems related to energy consumption, new types of LPWAN (Low Power Wide Area Networks) have appeared. Technologies that allow connecting autonomous devices to the global network appeared in 2015-2016 and gradually gaining popularity (Koucheryavy \& Vladyko, 2020). The most popular of them are: LoRaWAN, Narrow-band IoT (NB-IoT) and Sigfox. Comparison of the main technical characteristics of the networks is presented in Table 1.

Sigfox is practically not presented in Russia. The first few NB-IoT networks was deployed in Moscow and Saint Petersburg in 2019 by local telecommunication companies. In the same time there are a number of public and private LoRaWAN networks in Russia. It can be explained by affordability of LoRaWAN gateways and end-devices compare to Sigfox and NB-IoT.

Table 1. Comparison of LPWAN.

\begin{tabular}{llll}
\hline Characteristic & LoRa & Sigfox & NB-IoT \\
\hline Modulation method & CSS & - & OFDMA/DSSS \\
Range & ISM & ISM & Licensed \\
Rate & $0.3-50 \mathrm{~Kb} / \mathrm{sec}$ & $100 \mathrm{bit} / \mathrm{sec}$ & $1-200 \mathrm{~Kb} / \mathrm{sec}$ \\
Battery life & up to 10 years & - & up to 10 years \\
Frequency & $868.8 \mathrm{MHz}$ (Europe) & $868.8 \mathrm{MHz}$ (Europe) & $700 / 800 / 900 \mathrm{MHz}$ \\
& $915 \mathrm{MHz}$ (USA) & $915 \mathrm{MHz}$ (USA) & \\
& $433 \mathrm{MHZ}$ (Asia) & & \\
\hline
\end{tabular}




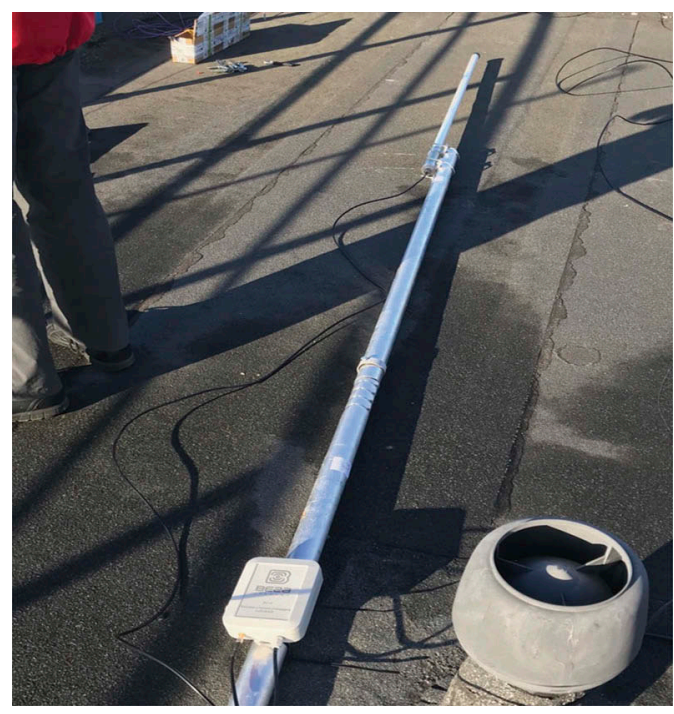

Figure 2. LoRaWAN gateway and antenna.

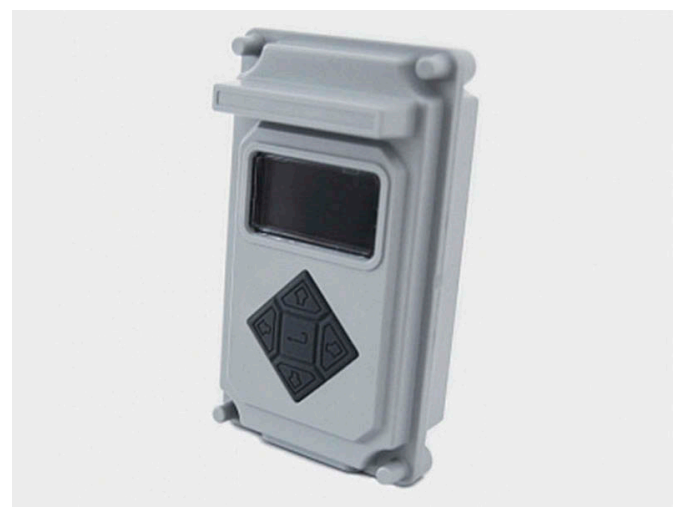

Figure 3. Tester of LoRaWAN network (https://www.euromobile.ru).

In frame of the research the coverage of LoRaWAN gateway in different conditions has been studied. The conditions were (a) city center and (b) outskirt surrounded by coniferous forest. Inboth locations LoRaWAN gateway with vertical omnidirectional antenna (864-876 $\mathrm{MHz} 10 \mathrm{dBi}$ ) were used (Figure 2).

Coverage area was assessed by measuring the special network tester (Figure 3) at preapproved control points. This device sends a special signal to the LoRaWAN network, in response to which the network informs it of the number of gateways that have received this signal and the signal quality. The tester displays this data every time the button is pressed. The device is used to test LoRaWAN networks when they are deployed and configured.

The gateway was stationary at the height of $25 \mathrm{~m}$ above the ground, and the tester moved a predetermined distance from the gateway in the range from 50 to $1500 \mathrm{~m}$ in increments of $50 \mathrm{~m}$. At each point, a series of 10 measurements of the signal level of the gateway by the tester and the tester signal by the gateway was carried out. According to the results, the average Received Signal Strength Indicator (RSSI) value was determined. Then radio signal attenuation coefficients in different conditions were calculated according to the equation 1 (Shpenst, 2015). 


$$
R S S I=T S S I+b \cdot \log 10(x),
$$

where $R S S I$ - Received Signal Strength Indicator, $\mathrm{dBm}$;

$T S S I$ - radio signal level at a distance of $1 \mathrm{~m}$ from the transmitting antenna, $\mathrm{dBm}$;

$b$ - radio signal attenuation coefficient, $\mathrm{dBm}$;

$x$ - distance between the gateway and the tester, $\mathrm{m}$.

\section{RESULTS AND DISCUSSION}

According to the measurements the coverage area of the LoRaWAN gateway in the city center was $1500 \mathrm{~m}$ and in the outskirt surrounded by coniferous forest was $1050 \mathrm{~m}$. After exceeding these distances, the signal was lost. The results of RSSI measurements in the city center and in the outskirt surrounded by coniferous forest are illustrated in Figures 4 and 5 accordingly.

The results of radio signal attenuation coefficients calculation are presented in Table 2.

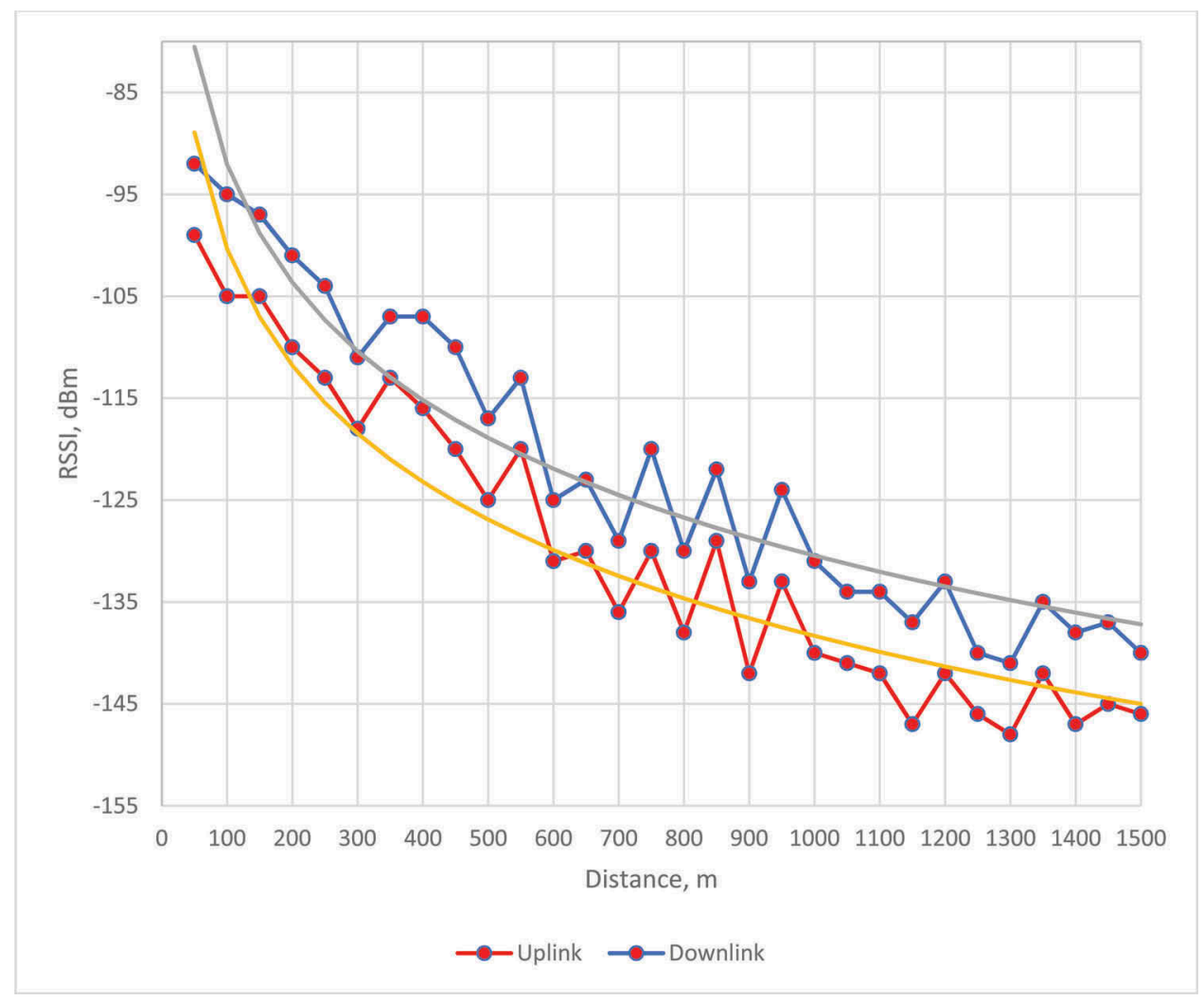

Figure 4. Dependence of LoRaWAN signal level on distance in the city center. 


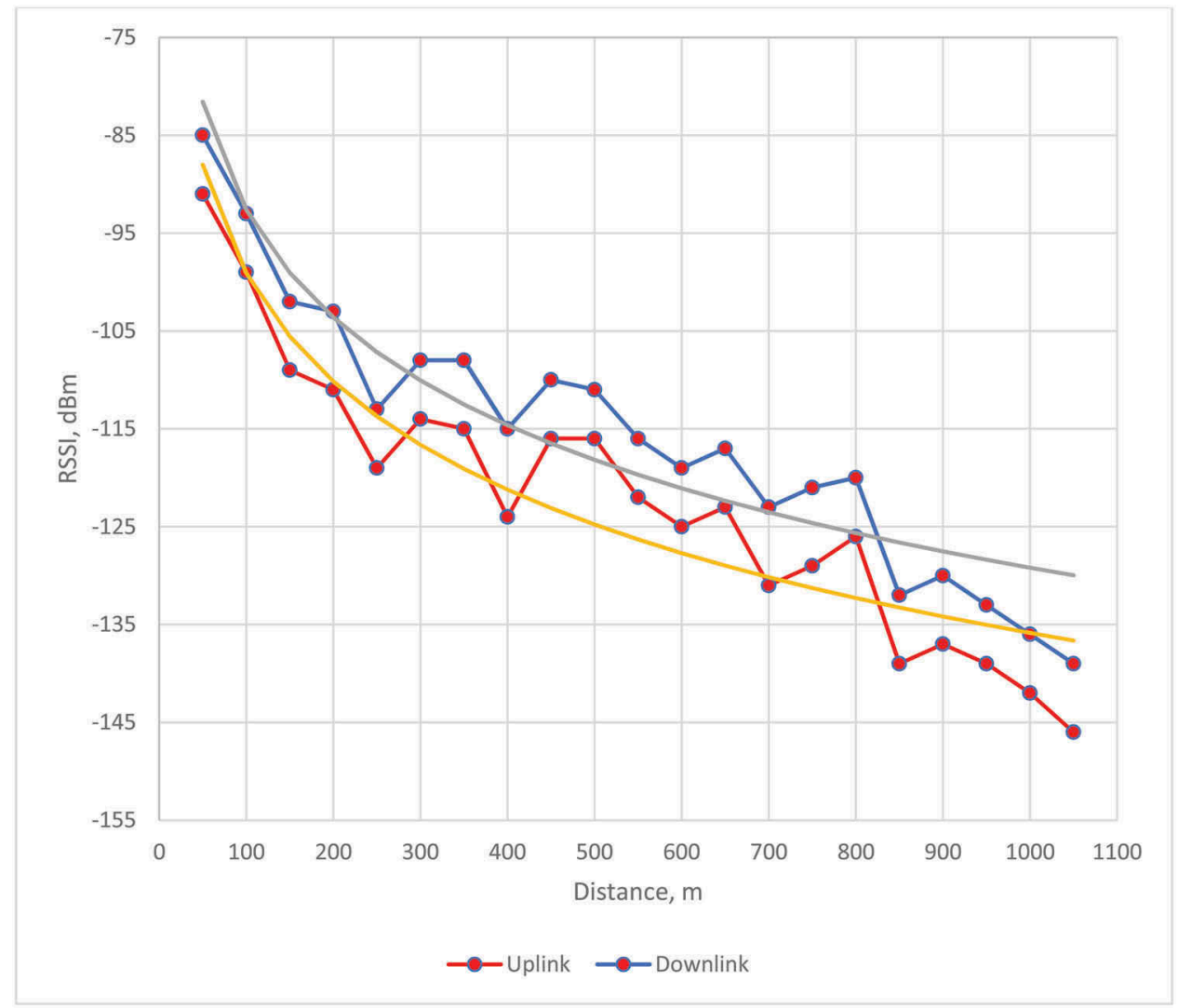

Figure 5. Dependence of LoRaWAN signal level on distance in the outskirt surrounded by coniferous forest.

Table 2. LoRaWAN signal attenuation coefficient in the conditions under the study.

\begin{tabular}{lll}
\hline Conditions & LoRaWAN signal attenuation coefficient, $\mathrm{dBm}$ \\
\hline \multirow{2}{*}{ City center } & Uplink & -24.4 \\
& Downlink & -15.4 \\
Outskirt surrounded by coniferous forest & Uplink & -25.5 \\
\cline { 2 - 3 } & Downlink & -19.4 \\
\hline
\end{tabular}

\section{CONCLUSIONS}

Rapid development of smart city services requires new network solutions to allow millions of sensors and devices to communicate with each other. In the same time, smart city applications have a number of specific requirements. The main condition of effective functioning of distributed network of devices and sensors is energy efficiency. Nowadays, smart city services based on LoRaWAN technology has the best prospects among others LPWANs due to affordability on the Russian market and good characteristics.

According to the field study results, LoRaWAN signal attenuation in conditions of coniferous forest is higher compare to the city center. It can be explained by moisture absorption in the trees.

To provide full LoRaWAN coverage for smart city services it is necessary to locate the gate ways on a distance of $1500 \mathrm{~m}$ at the city center and of $1050 \mathrm{~m}$ at the outskirt at 
maximum. It means that to cover all the area of Saint Petersburg, approximately 400 LoRaWAN gateways are needed and 84000 gateways are required for the Leningrad region.

\section{REFERENCES}

Chukin V., Kachnov Y., Preliminary results of experiments to determine the conditions of radio communication between nodes of wireless sensor networks in the frequency range of EU868 in the urban environment and forest area of the Leningrad Region, The twenty-third scientific conference on radiophysics dedicated to the 100th anniversary of the birth of N.A. Zheleztsova, Nizhny Novgorod, 05. 16.2019

Digital life of Russian megacities. Model. Dynamics. Examples//SKOLKOVO Business School Emerging Market Research Institute (IEMS) [Online]. 2016. Available at: https://iems.skolkovo.ru/downloads/ documents/SKOLKOVO_IEMS/Research_Reports/SKOLKOVO_IEMS_Re-search_2016-11-30_ru. pdf [Accessed: 16.09.2019];

Evans D., (2011), The Internet of Things: How the Next Evolution of the Internet Is Changing Everything, White paper, p.3;

Frost \& Sullivan's Global $360^{\circ}$ Research Team. Smart City Adoption Timeline. Anticipating the Global Advancement of Smart Cities; http://www.sut.ru/doci/nauka/review/20163/1-14.pdf

Indicators of smart cities NIITS 2017//NIITS [Online]. 2017. Available at: http://niitc.ru/publications/ SmartCities.pdf [Accessed: 15.09.2019];

Ishida, T. Isbister K. (2000), Digital Cities: Technologies, experiences, and future perspectives, SpringerVerlag, Berlin;

Koucheryavy A., Vladyko A., The Prospects for Research in the Field of Communications Networks on the 2017-2020 Years//Telecom IT. 2016. Vol. 4. Iss.3. pp. 1-14. Available at:

Shpenst V 2015 Optimum operating zones selection methods for multispectral overhead power lines remote sensing devices, Journal of Mining Institute 214 p.92-101

Sikora-Fernandez D., Stawasz D. The Concept Of Smart City In The Theory And Practice Of Urban Development Management//Romanian Journal of Regional Science [Online]. 2016. Available at: http://www.rrsa.ro/rjrs/V1015.Sikora.pdf .[Accessed: 25.08.2019];

Smart cities and infrastructure//United Nations Economic and Social Council [Online]. 2016. Available at: http://unctad.org/meetings/en/SessionalDocuments/ecn162016d2_en.pdf. [Accessed: 15.09.2019];

Smart Cities Market worth 1,201.69 Billion USD by 2022//Markets and Markets [Online]. Available at: https://www.marketsandmarkets.com/PressReleases/smart-cities.asp

Van der Meer, A. Van Winden, W., (2003), E-governance in Cities: A Comparison of Urban Information and Communication Technology Policies, Regional Studies, Vol. 37, No.4, pp. 407-419 


\title{
Traffic management at the enterprises of the mineral industry
}

\author{
E.B. Mazakov \\ Candidate of Engineering Sciences, Associate Professor Head of the Department of Information systems \\ and computer engineering of Mining University, St. Petersburg, Russian Federation
}

\author{
K.V. Matrokhina \\ Graduate student, Mining University, St. Petersburg, Russian Federation \\ V.Y. Trofimets \\ Doctor of Science, professor at the Department of Information systems and computer engineering of Mining \\ University, St. Petersburg, Russian Federation
}

\begin{abstract}
The issues of traffic management in global computer networks are based on the apparatus of fuzzy logic are considered. As the fuzzy inference algorithm, the Mamdani algorithm was chosen. The rules of fuzzy inference are made, the functions of accessories of three types are constructed, the regularities of the logic of functioning of the proposed fuzzy controller are revealed. Traffic control modeling in the energy company's network was carried out on theory of queues and fuzzy logic. The main characteristics of the network are calculated with and without the use of the proposed fuzzy controller in the control loop, their comparative analysis is carried out.
\end{abstract}

Keywords: traffic control, bandwidth, fuzzy logic, Mamdani algorithm, membership functions, priority, delay, daily network load

\section{INTRODUCTION}

Every hour, over 100 thousand phone calls are made by companies in the mineral industry, more than 80 thousand emails are sent, more than 100 thousand different documents are generated in corporate business systems, and approximately $900 \mathrm{~TB}$ of information is stored in data centers.

At the same time, the situation is different for different units and divisions. So, for corporate functions and oil refining assets operating in megacities, there is always the opportunity to organize communication services almost instantly, since there are dozens of telecom operators. It is only necessary to make the right choice of price/quality/reliability ratio. The mining units, especially in the Far North, have a different situation there may not be any telecom operators at all. And then we have to create the necessary communication networks ourselves.

\section{LITERATURE REVIEW}

The construction of mechanisms, algorithms and protocols to implement the required quality of service for various applications and services of the communication network have long been the subjects of research by domestic and foreign scientists. The problem of improving the quality of network service and traffic management, in particular, was addressed in their writings by (Kucheryavyy 2014; Mazakov 2014; Katuntsov et al. 2017; Lidsky 2006; Stepanov 
2010; Melikov 2007; Brown Martin 2012; Tsvetkov 2011; Simakov 2016; Evseeva 2011; Katuntsov et al. 2018).

Recently, the number of works in which a fuzzy logic apparatus is used to control traffic has increased. So in work by (Potapchuk 2011), a routing method for a BSS network is described, based on a fuzzy logic apparatus. In contributions (Sorokin 2018), a technique is proposed for controlling the process of transmitting information traffic by regulating the load level of network device buffers. The technique includes the use of an adaptive fuzzy controller and neural networks.

For modeling fuzzy systems, as a rule, they use the MatLab computing environment in the Fuzzy Logic Toolbox package. Design issues, application of the decision-making method in fuzzy conditions are considered in the works of (Shtovba 2007; Leonenkova 2005; Bobyr 2018; Fedotova 2012).

The following is a new mechanism for managing traffic in global computer networks based on the Mamdani algorithm.

\section{METHODOLOGY}

Bursts of transmitted information volumes and imperfect traffic management methods lead to network congestion, resulting in buffer filling in queues and deteriorating service quality. Hence, there is a need to study traffic management processes and increase the efficiency of telecommunication systems in general.

To solve the traffic control problem in global computer networks, various algorithms are used, the most famous of which are TailDrop, PI, RED. These algorithms have shown their efficiency and acceptable efficiency, but, nevertheless, they are not free from disadvantages. For example, the TailDrop algorithm causes overload, and the RED algorithm changes the probability of a drop according to a linear law, but does not allow to effectively control the non-linear dynamics of traffic. The PI algorithm requires preliminary calculations in view of the use of machine learning.

To reduce the shortcomings of the mentioned algorithms, a traffic control mechanism in global computer networks based on a fuzzy logic apparatus was proposed.

Fuzzy logic arose as the most convenient way to build control systems and complex technological processes, and also found application in diagnostic and other expert systems. The fuzzy logic apparatus was proposed in 1965 by Lotfi A. Zadeh, a professor at the University of California, Berkeley. The applied aspects of using the fuzzy logic apparatus are reflected in the works of (Paklin 2014; Shtovba 2016; Motorygin Y.D. et al. 2016; Batkovskiy A.M. et al. 2017;Asadulaev 2017; Emelyanova 2013; P. Bauer 1997).

Consider the essence of the proposed approach to traffic management based on the Mamdani algorithm (see Figure 1).

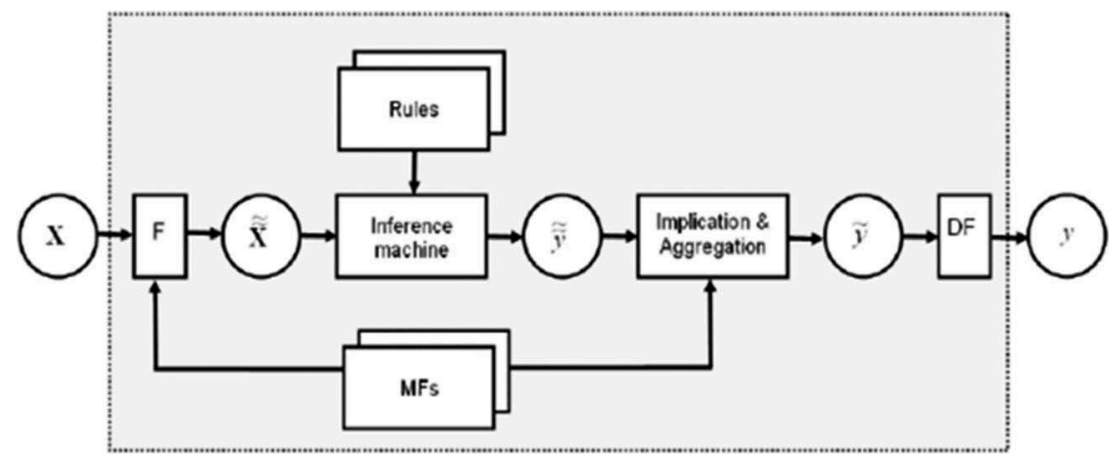

Figure 1. Mamdani algorithm structure. 
At the output of a fuzzy controller, built on the basis of the Mamdani algorithm, a clear value of the throughput is obtained, which can be found using defuzzification.

\section{RESULTS}

At the output of a fuzzy controller, built on the basis of the Mamdani algorithm, a clear value of the throughput is obtained, which can be found using defuzzification.

Next, the mechanism of the fuzzy logic apparatus is considered (see Figure 2).

As the object on which the proposed algorithm was tested, the energy company was selected whose offices are located geographically in different areas of the city. In the central region there are management units (VET, accounting, legal department, reception). In the northern region - operational personnel (electricians, installers), in the south of the city - a suburban branch. All units interact with each other, most often using the Internet to transmit information (see Figure 3).

The organization uses the services of an Internet provider, which, according to the agreement, provides the speed of $100 \mathrm{Mbps}$.

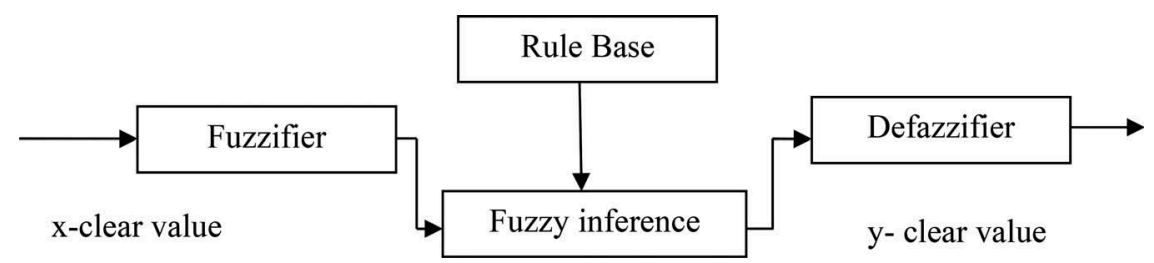

Figure 2. Fuzzy Inference System.

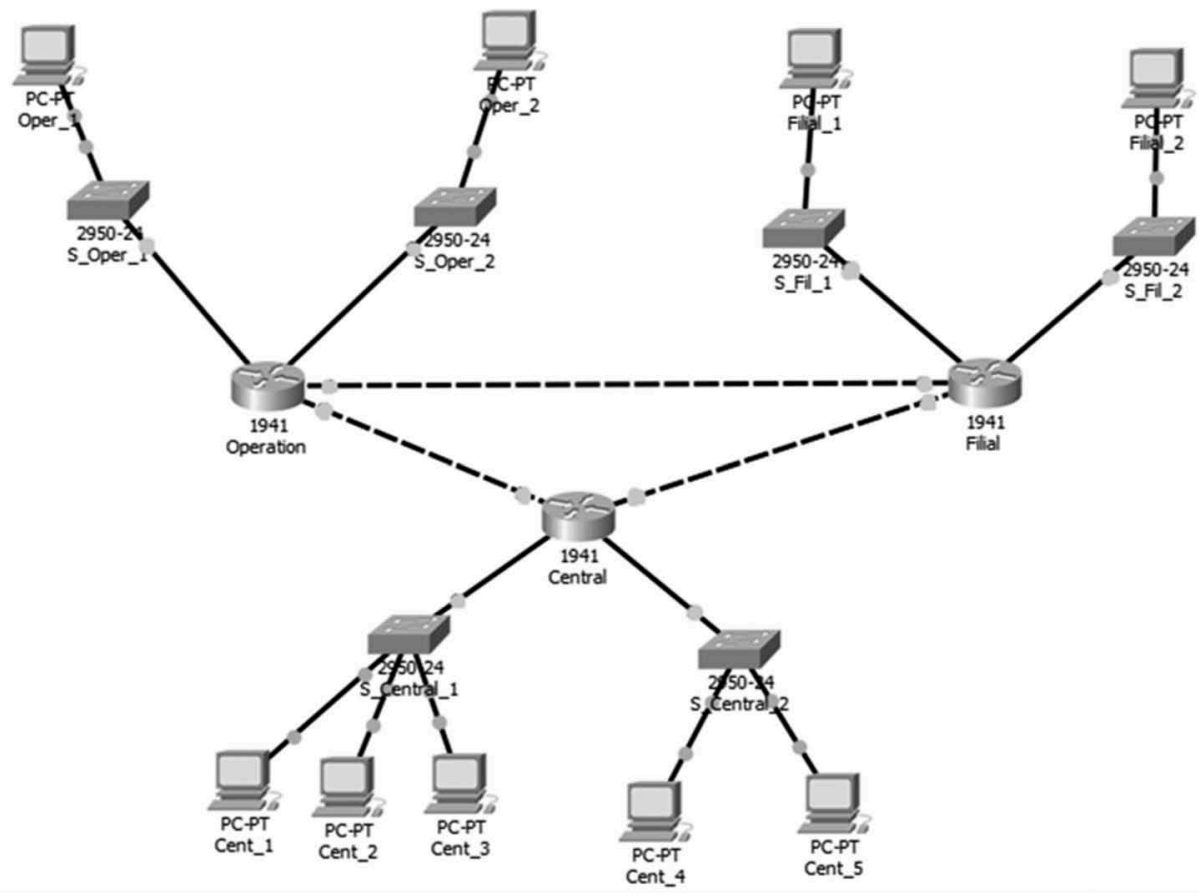

Figure 3. Organization network diagram. 
The most stringent bandwidth requirements are made by video, audio, voice, transactions. In view of the fact that the company in question uses these types of traffic quite often, Quality of Service (QoS) technology is used for this network. Thanks to this technology, you can distribute traffic by service category and priority. Guaranteed quality of service and better transmission conditions are provided for high-priority traffic, so $60 \%$ of the available bandwidth is allocated for transactions and voice, and about $5-10 \%$ for surfing.

1. There are some variables at the input (in operation, this is a delay, traffic priority and daily network load). Each variable has a numerical range of values. For priority, the values are from 0 to $100 \%$, for the delay from 0 to $200 \mathrm{~ms}$, for the daily network load from 0 to 24 hours. At the output, there is one variable, the network bandwidth, that is, the one that we control. It has values from 0 to $100 \mathrm{Mbps}$ (Figure 4).

Next, for each variable, linguistic variables are set to which intervals of values are assigned (see Figure 5-8)

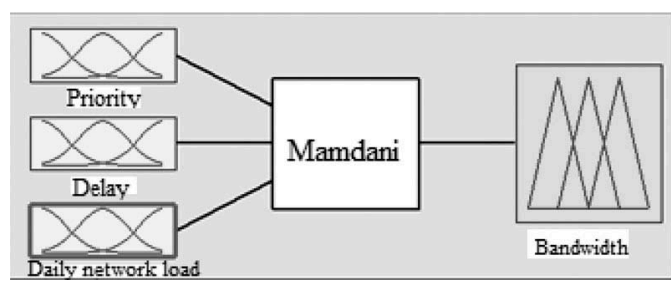

Figure 4. Fuzzy inference system.

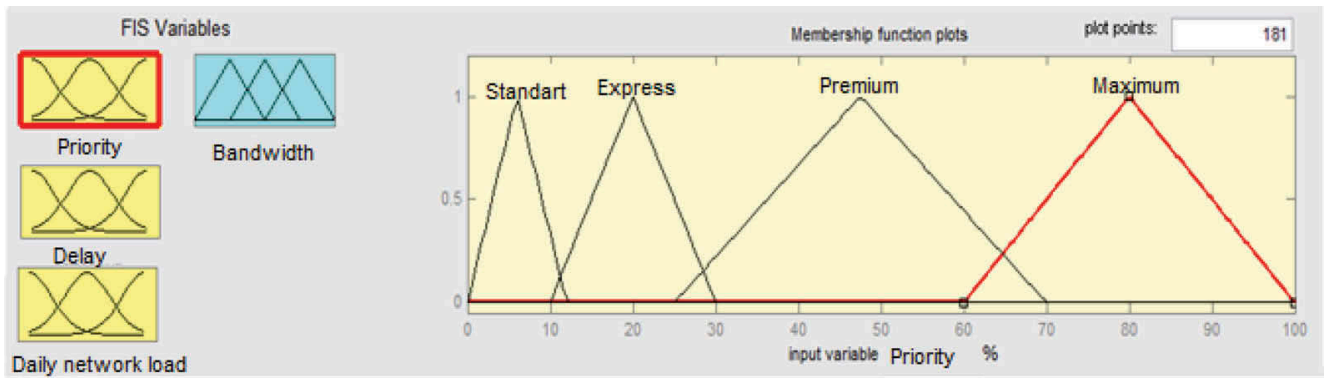

Figure 5. Membership functions for the input parameter "priority".

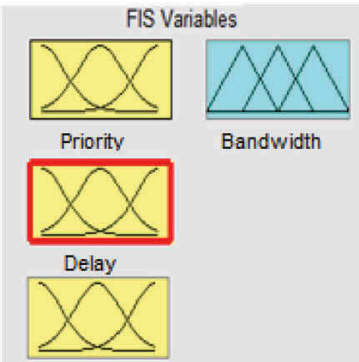

Daily network load

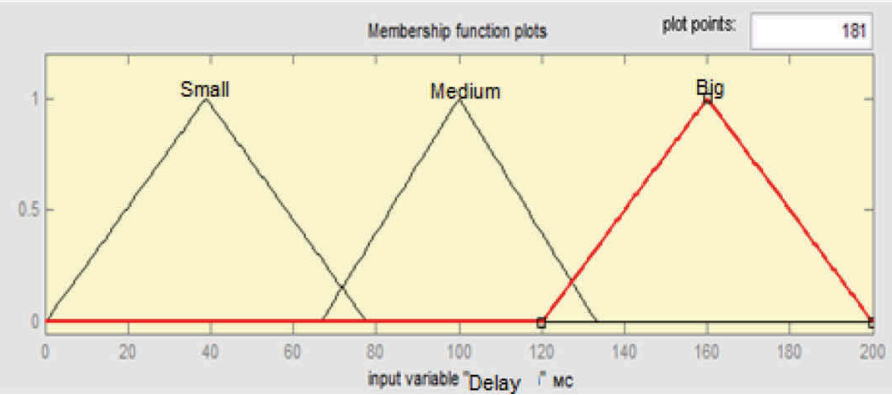

Figure 6. Membership Functions for the Delay Input Parameter. 


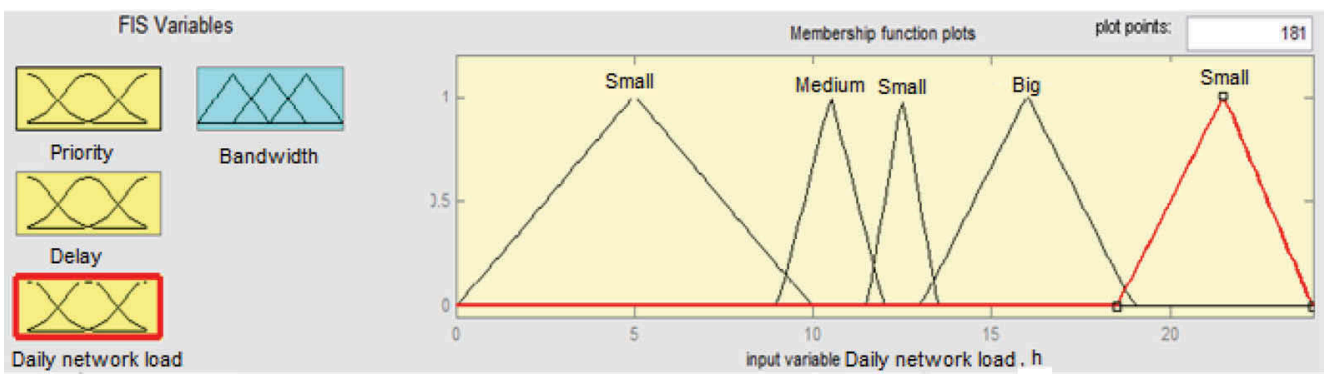

Figure 7. Membership functions for the input parameter "daily network load".

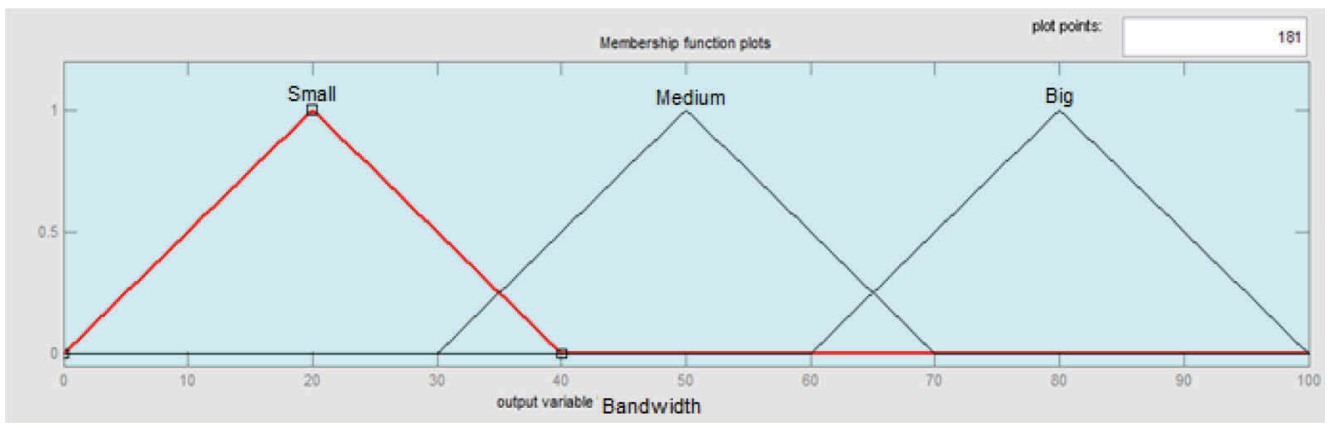

Figure 8. Membership functions for the output variable "user bandwidth".

Next, the base of rules for fuzzy inference is formed.

The logic of the fuzzy controller is as follows: for each variable, the throughput is calculated in accordance with the rule base.

The rule base includes $3 * 3 * 4=36$ rules, due to the fact that each variable takes on three or 4 different values. The full base is not given due to its size. It is important to note that all the rules were drawn up by competent experts in the amount of 20 people. Below are 10/36 rules from the fuzzy logic base:

1) if the priority is "maximum" and the delay is "small" and the daily network load is "small", then the throughput is "large";

2) if the priority is "premium" and the delay is "small" and the daily network load is "medium", then the throughput is "medium";

3 ) if the priority is "express" and the delay is "small" and the daily network load is "medium", then the throughput is "medium";

4) if the priority is "standard" and the delay is "medium" and the daily network load is "medium", then the throughput is "small";

$5)$ if the priority is "premium" and the delay is "medium" and the daily network load is "large", then the throughput is "medium";

6) if the priority is "express" and the delay is "large" and the daily network load is "large", then the throughput is "small";

7) if the priority is "premium" and the delay is "medium" and the daily network load is "small", then the throughput is "large";

8 ) if the priority is "standard" and the delay is "large" and the daily network load is "medium", then the throughput is "small";

9) if the priority is "maximum" and the delay is "large" and the daily network load is "average", then the throughput is "average";

$10)$ if the priority is "maximum" and the delay is "average" and the daily network load is "average", then the throughput is "small". 
4. In the end result, the output variable is reduced to clarity.

Below are the rules for linguistic variables with a triangular t-norm. (see Figure 9).

From fig. Figure 9 shows that with premium priority, average latency and low network load, the throughput is high $(80 \mathrm{Mbit} / \mathrm{s})$.

In addition, to obtain more reliable results, an analysis was performed using the symmetric Gaussian and trapezoidal membership functions.

Further, in Figure 10, you can see the visualization of fuzzy output Gaussian membership functions at given values of the input parameters

The trapezoidal membership functions are shown below visualization of fuzzy inference is presented (Figure 11).

Models for triangular, Gaussian and trapezoidal membership functions were considered. With the same input values of the variables (priority: 50\%; delay: $90 \mathrm{~ms}$; daily network load of 19.5 hours), there are different values of the output variable in all three cases, namely, for the triangular function: $80 \mathrm{Mbit} / \mathrm{s}$; for Gaussian: 77, $4 \mathrm{Mbps}$; for trapezoidal: $79.8 \mathrm{Mbps}$.

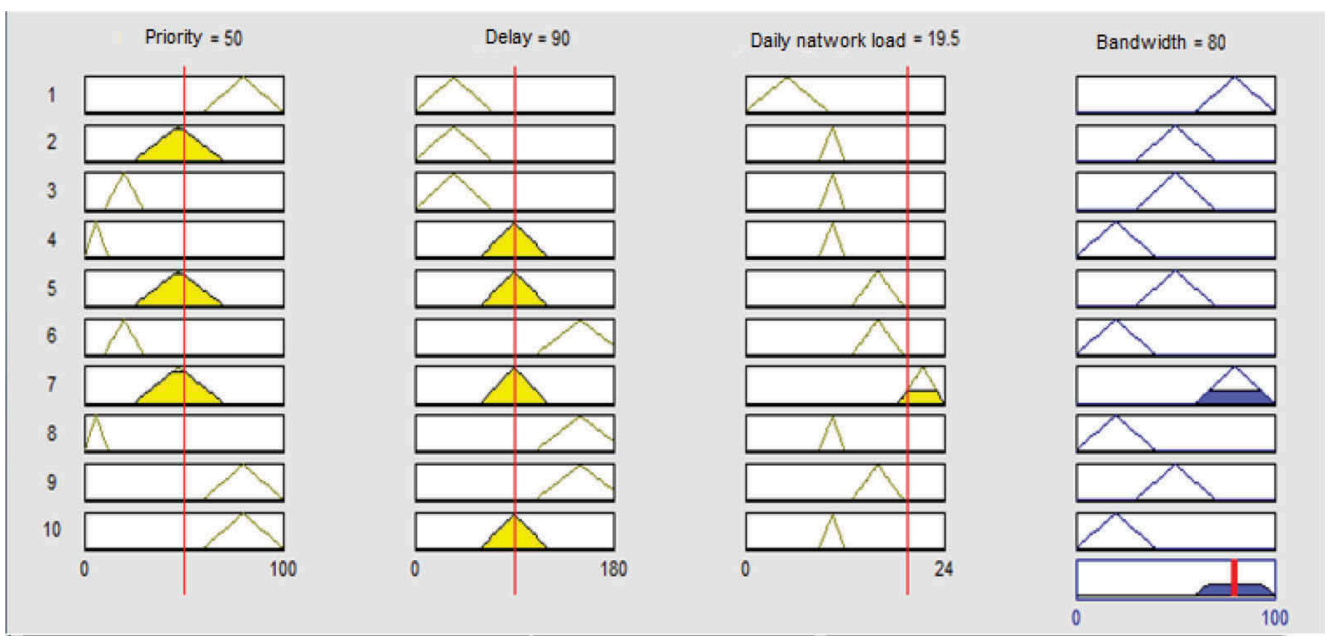

Figure 9. Visualization offuzzy output.
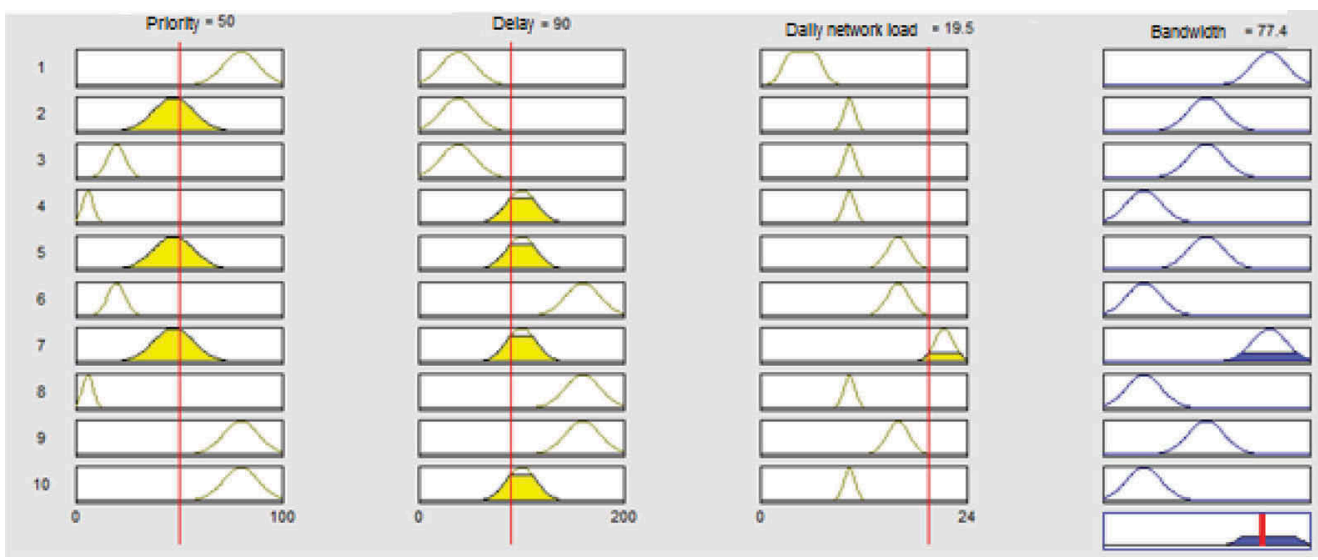

Figure 10. Visualization of fuzzy inference with Gaussian membership functions. 


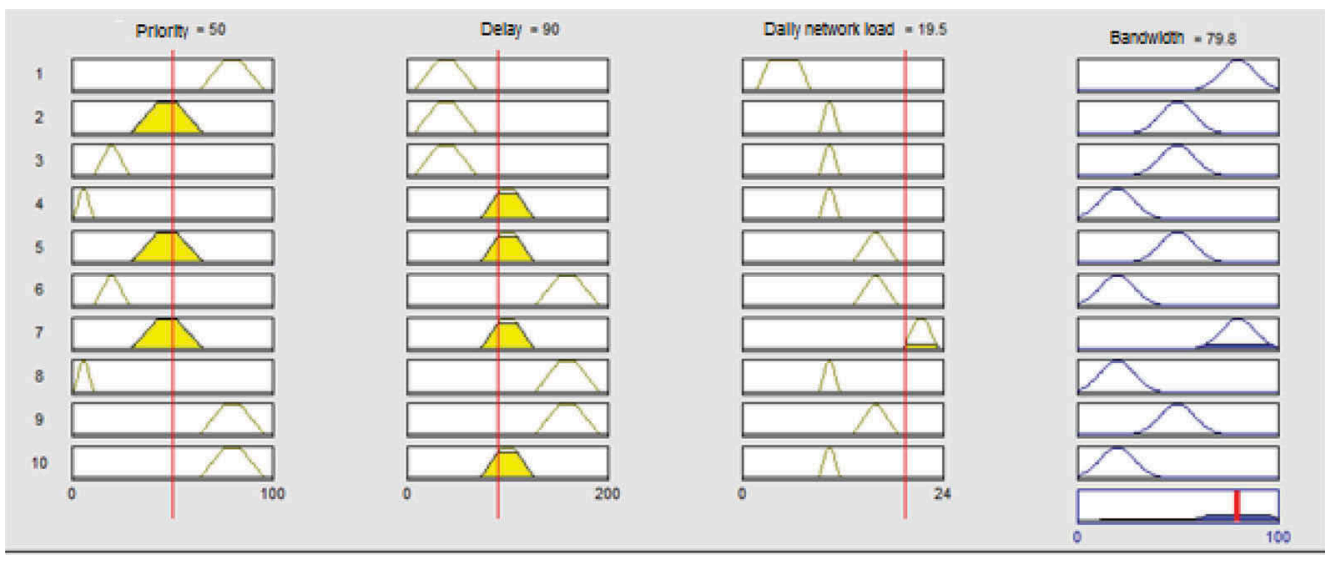

Figure 11. Visualization of fuzzy inference with Gaussian membership functions.

Further, for the problem under consideration, the main characteristics of the queuing system were calculated and graphs of the corresponding dependencies were constructed.

A queuing system having $\mathrm{n}=1$ service channel was considered. In this QS, a packet stream with an intensity of $\lambda=50 \mathrm{Mb} / \mathrm{s}, 80 \mathrm{Mb} / \mathrm{s}, 110 \mathrm{Mb} / \mathrm{s}, 140 \mathrm{Mb} / \mathrm{s}, 170 \mathrm{Mb} / \mathrm{s}$ was received at the input. The service intensity of each packet by the channel is $\mu-100 \mathrm{Mbit} / \mathrm{s}$ (router bandwidth). The maximum number of places in the queue is $\mathrm{m}=256$ (follows from the characteristics of the router). The graph of the system under consideration is presented in Figure 12.

Each state indicated in the circle means: S0 - the channel is free, there is no queue; S1 - there are no free channels, there is no queue; S2 - there are no free channels, in line 1; S3 - there are no free channels, in line 2; S257 - there are no free channels, there are 256 in the queue.

Based on the results of the calculation of the main characteristics, graphs were built of the dependence of each characteristic on the intensity of packet arrival. Below are some graphs of functions with and without fuzzy logic (blue indicates the function without using the fuzzy logic apparatus, red means using the apparatus, see Figures 13-15).

As a result of the simulation, the following results were obtained: on the graphs (Figure 13-15), you can notice that with the use of a fuzzy logic apparatus, the probability of failures and queuing are reduced, and the absolute throughput increases.

\section{CONCLUSION}

Thus, in the framework of the study, traffic management issues in global computer networks based on the fuzzy logic apparatus were considered. As the fuzzy inference algorithm, the Mamdani algorithm was chosen. The rules of fuzzy inference are made, the functions of accessories of three types are constructed, the regularities of the logic of functioning of the proposed fuzzy controller are revealed. It has been established that it is advisable to use triangular membership functions, since their use allows you to provide the user with the highest throughput.

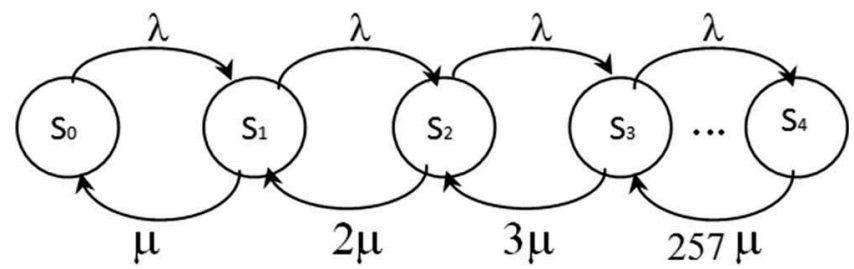

Figure 12. Count of a given queuing system. 


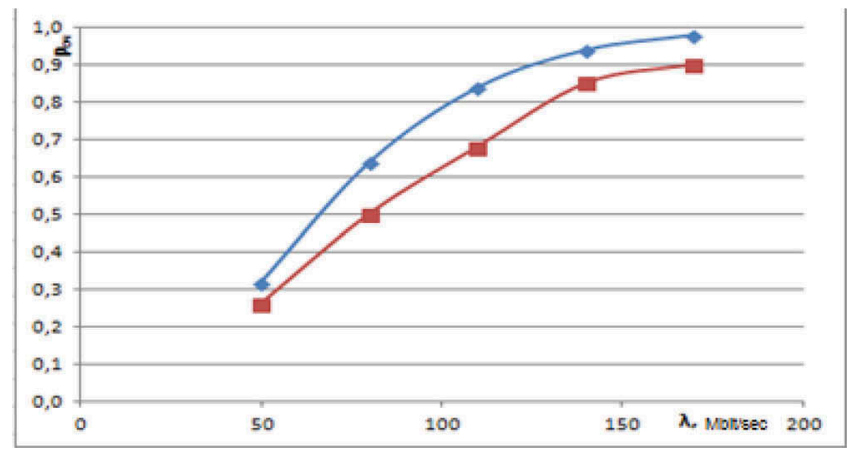

Figure 13. Schedule of queuing versus bandwidth.

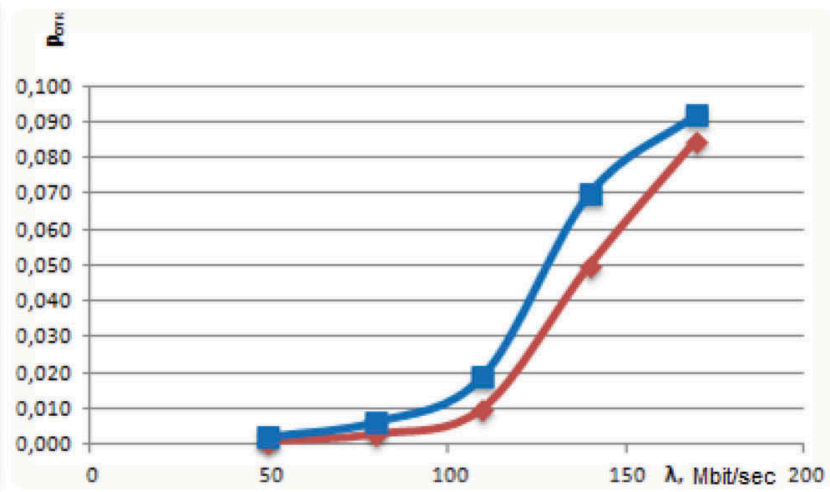

Figure 14. The graph of the probability of failure from bandwidth.

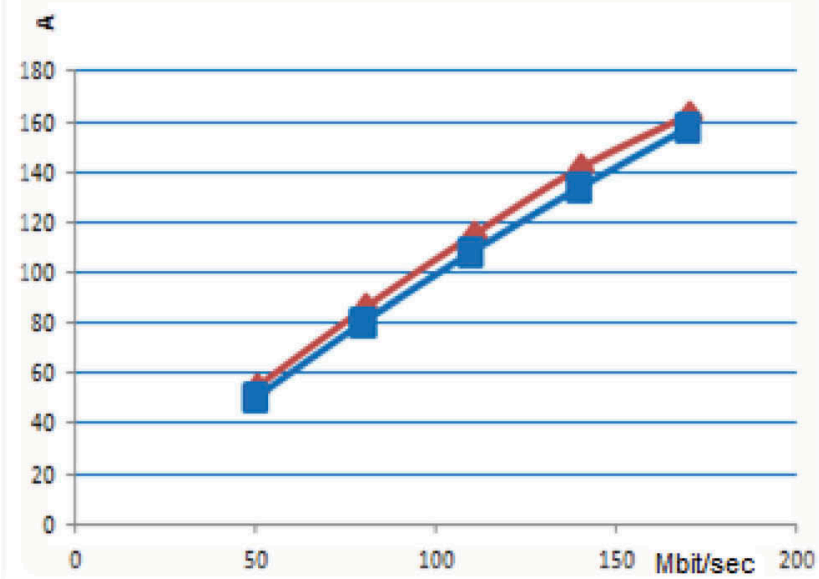

Figure 15. Graph of absolute throughput versus service intensity. 


\section{REFERENCES}

Asadulaev R.G., 2017.Fuzzy logic and neural networks, Belgorod, BelSU: 309

Batkovskiy A.M., Semenova E.G, Trofimets E.N., Trofimets V.Ya., Fomina A.V. 2017. Modified method for sensitivity analysis of investment projects efficiency criteria. Journal of Applied Economic Sciences, Romania: European Research Centre of Managerial Studies in Business Administration. Volume XII, Issue 4(50). Fall 2017: p. 1116-1131

Bauer P., 1997. Introduction to fuzzy logic and fuzzy control system Internet journal: 14.

Brown Martin, 2012. How to on traffic management using NTV, online magazine: 200.

Bobyr M.V., 2018. Designing neural and fuzzy models in the field of computer technology and control systems teaching aid, Moscow "Agramak-Media": 110.

Emelyanov S.G., 2013. Adaptive fuzzy-logical control systems, Moscow:193

Evseeva O.Yu., 2011. Methodology of experimental studies of network traffic control methods, Electronic Scientific Specialized Edition - Journal of Telecommunication Problems: 89-104.

Fedotov V.Kh., 2012. Intelligent Information Systems. Workshop ed. Chuvash State University:78.

Katuntsov E.V., Kosarev O.V., Makhovikov A.B., Tcvetkov P.S. 2018. Digital transformation in oil and gas ex-traction. Innovation-Based Development of the Mineral Resources Sector: Challenges and Prospects - 11th conference of the Russian-German Raw Materials, 2018, Potsdam, Germany. - CRC Press/Balkema, 2019: p.531-538

Katuntsov, E.V., Kultan, Y., \& Makhovikov, A.B. 2017. Application of electronic learning tools for training of specialists in the field of information technologies for enterprises of mineral resources sector. Journal of Mining Institute,226:p.503-508.

Khizhnyakova Yu.N. 2013. Algorithms of fuzzy, neural and fuzzy neuronal control in real time, Publishing house of the Perm National Research Polytechnic University.

Kucheryavy E.A. 2004. Traffic management and quality of service on the Internet, St. Petersburg. Science and Technology:336.

Leonenkov A.V. 2005, Fuzzy modeling in MATLAB and Fuzzy TECH ed. "BHV-Petersburg":736.

Lidsky E.A., 2006.Traffic problems in communication networks, Textbook, Yekaterinburg, UGTTU-UPI GOU VP:202.

Mazakov E.B.,2014 Representation and processing of knowledge in information automated systems of intelligent field, Journal of Mining Institute,208:p.256-262.

Melikov A.Z., 2007 Teletraffic: models, methods, optimization, Internet Journal, p.256.

Motorygin Y.D., Artamonov V.S., Maximov A.V., Trofimets E.N., Trofimets V.Ya.2016. Management of the Formation of Rating Preferences of Economic Entities upon Collective Choice. International Journal of Economics and Financial Issues, 2016, 6(4):p. 1956-1964

Paklin N. Fuzzy logic-mathematical foundation, Internet journal:12.

Potapchuk I.A., 2016. Routing method in a wireless self-organizing network based on fuzzy logic apparatus, Technique and electronics of high voltage: 82-88.

Shtovba S.D. 2007. Designing fuzzy systems using MATLAB, Hotline-Telecom:288.

Shtovba S.D. Introduction to the theory of fuzzy sets and fuzzy logic, Internet journal: 209.

Simakov D.V. 2016. Traffic control in a network with high dynamics of network route metrics Internet journal "Science of Science: 1-13.

Sorokin A.A. 2018. Adaptive fuzzy management of the State Polytechnic University. Computer science. Telecommunications. Management: $36-48$

Stepanov S.N. 2010. Fundamentals of teletraffic of multiservice networks, Moscow, Eco-Trends:392

Tsvetkov V.Yu. 2011. Billing-management of multiservice network traffic, methodological manual, Minsk, BSUIR: 50. 


\title{
Study of structural features of draglines for their possible adaptability to changing mining and geological conditions
}

\author{
A.A. Khoreshok \\ Dr.Sc., Professor, Department of Mining Machines and Complexes, T.F. Gorbachev Kuzbass State \\ Technical University, Mining Institute \\ M.A. Tyulenev \\ MSc, PhD, Professor, Department of Open Pit Mining, T.F. Gorbachev Kuzbass State Technical \\ University, Mining Institute \\ S.O. Markov \\ MSc, PhD, Associate Professor, Department of Surveying and Geology, T.F. Gorbachev Kuzbass State \\ Technical University, Mining Institute
}

\begin{abstract}
Draglines (walking excavators) are widely used in opencast mining. However, the area of their effective use is relatively small and is reduced to the excavating of horizontal and flat coal seams, which makes it possible to use draglines on a transportless (nontransport) scheme of mining with a dumping of the internal spoil (rock dump). In this case, the cost of extracted coal is significantly reduced due to the fact that the costs of rock transportation are completely eliminated.

Currently, more than 100 walking draglines of various sizes are operating in the Russian Federation open pits. Almost all of them are machines of domestic production. The main Russian manufacturer of draglines is the Uralmash plant which produces draglines of a wide range of standard sizes: bucket capacity up to $65 \mathrm{cu} . \mathrm{m}$, boom length up to $130 \mathrm{~m}$.

In addition to domestic draglines, the market presents walking excavators manufacturers «NKMZ», «Komatsu Mining», «Caterpillar», etc. Analysis of their parameters shows that their main characteristics are quite comparable with each other, but excavators are significantly different in terms of boom and A-frame design. The difference in design leads to limitation of possible use of draglines as modular units due to peculiarities of the above mentioned nodes.
\end{abstract}

\section{INTRODUCTION}

Domestic and import walking draglines currently used in opencast mining are characterized (Bereznyak et al, 1970; Demirel, 2011; Huddart and Runge, 1979; Nazarov, 2011; Palamarchuk et al, 2019; Sadri and Lee, 1982; Scott et al, 2010; Seib and Carr, 1990) by the following main parameters (Table 1).

As we can see from table above, the main parameters of draglines are bucket capacity and boom length. The purpose of this work is to define those parameters that can be changed without making significant changes to the design of the dragline as a whole, in other words modular parameters.

Since the area of application of draglines are horizontal and flat beds, it is necessary to say a few words about the geology of developed and prospective coal deposits of Siberia.

The Siberian platform as a whole is characterized by horizontal, flat and slightly inclined bedding (up to 15 degrees) on a highly dislocated crystalline shield represented by deeply metamorphosed gneiss and granitoids (Allison and Palmer, 1980; Markov et al, 2019; 
Table 1. Dragline parameters.

\begin{tabular}{|c|c|c|c|c|}
\hline Manufacturer, model & Working weight, $\mathrm{t}$ & Boom length, $\mathrm{m}$ & Bucket capacity, cu.m & Tub diameter, $\mathrm{m}$ \\
\hline \multicolumn{5}{|c|}{ Caterpillar } \\
\hline CAT 8000 & $1770-1988$ & $75-101$ & $24-34$ & $15.24,15.6$ \\
\hline CAT 8200 & $3836-4123$ & 100 & $46-61$ & 19.5 \\
\hline CAT 8750 & $5800-7500$ & $110-133$ & $76-116$ & 22.9 \\
\hline \multicolumn{5}{|c|}{ NKMZ } \\
\hline ESH 11/70 & No data & 70 & 11 & 9.7 \\
\hline ESH $10 / 100$ & No data & 100 & 10 & 12.3 \\
\hline ESH 15/80 & No data & 80 & 15 & 12.3 \\
\hline ESH 20/65 & No data & 65 & 20 & 12.3 \\
\hline \multicolumn{5}{|c|}{ Uralmash } \\
\hline ESH 11.75 & 840 & 75 & 11 & 10.8 \\
\hline ESH 20.90 & 1690 & 90 & 20 & 14.5 \\
\hline ESH 25.90 & 1900 & 91 & 25 & 15.3 \\
\hline ESH 15.100 & 1710 & 100 & 15 & 14.5 \\
\hline ESH 24.95 & 1960 & 95 & 24 & 15.3 \\
\hline ESH 40.100 & 3310 & 100 & 40 & 18.0 \\
\hline \multicolumn{5}{|c|}{ Komatsu Mining (P\&H draglines) } \\
\hline P\&H 2355 & No data & $42,7-61$ & 15.3 & No data \\
\hline P\&H 736 & No data & $53.3-79.2$ & 22.2 & No data \\
\hline P\&H 752 & No data & $73.2-97.5$ & 35 & No data \\
\hline P\&H 757 & No data & $83.8-106.7$ & 57.3 & No data \\
\hline P\&H 9020 & No data & $88.4-123.4$ & 91.8 & No data \\
\hline P\&H 9160 & No data & $99.1-129.5$ & 122.3 & No data \\
\hline P\&H 9010C & 4056 & $84-107$ & $42-60$ & 18.7 \\
\hline P\&H 9020C & 5940 & $90-125$ & $55-93$ & 22.30 \\
\hline P\&H 9020XPC & 8002 & $100-130$ & $85-122$ & 26.8 \\
\hline $\mathrm{P} \& \mathrm{H} 9030 \mathrm{C}$ & 7539 & 117 & 99.1 & No data \\
\hline \multicolumn{5}{|c|}{ Bucyrus International (was acquired by Caterpillar at 2011) } \\
\hline $680 \mathrm{~W}$ & 1043 & $58-90$ & $12-24$ & No data \\
\hline 7820 & 1996 & $69-99$ & $27-38$ & No data \\
\hline 8050 & 3357 & $76-107$ & $47-67$ & No data \\
\hline $1260 \mathrm{~W}$ & 1678 & $59-92$ & $18-31$ & No data \\
\hline $1300 \mathrm{~W}$ & 2132 & $79-99$ & $22-36$ & No data \\
\hline $1370 \mathrm{~W}$ & 2989 & $87-99$ & $44-48$ & No data \\
\hline $1570 \mathrm{~W}$ & 3630 & $94-105$ & $48-61$ & No data \\
\hline $2570 \mathrm{~W}$ & 6000 & $104-122$ & $69-89$ & No data \\
\hline $2570 \mathrm{WS}$ & 7271 & $110-128$ & $85-120$ & No data \\
\hline 8200 & 4492 & $84-122$ & $53-84$ & No data \\
\hline 8750 & 6580 & $102-131$ & $84-114$ & No data \\
\hline $8750 \mathrm{~B}$ & 7620 & 109.7 & $81-116$ & No data \\
\hline 8750 D3 & 5534 & 109.7 & 90 & No data \\
\hline $8750 \mathrm{R}$ & 5851 & 124.9 & $79-99$ & No data \\
\hline W 2000 & 1780 & $75-101$ & $24-34$ & No data \\
\hline \multicolumn{5}{|c|}{ BEML } \\
\hline W2000 & $1701-1980$ & $74.6-100.85$ & $23-34$ & No data \\
\hline \multicolumn{5}{|c|}{ HEC Draglines } \\
\hline HEC & & $74.6-95.6$ & $24-34$ & No data \\
\hline
\end{tabular}


Katsubin and Fedotov, 2019). Typical cross-sections on some promising deposits from the point of view of draglines application are shown in Figures 1-a, 1-b.

\section{MATERIALS AND METHODS}

In our opinion, the effective use of draglines has no comprehensively substantiated scientific basis. Among the priority problems we can refer to:

- complexity of mining and geological conditions: variability of coal seams' occurrence parameters, their disturbance and variability of physical and mechanical properties of the overburden rocks;

- terrain and orography features, and other topography conditions that hinder the creating of stable dumps;

- remoteness and poor development of deposits with favorable mining and geological conditions (Figure 1-a, b);

- insufficient adaptability of the application of a particular dragline model to the degree of variability of the mining and geological conditions within the developed area (deposit).

Consideration of these problems makes it possible to formulate a number of priority scientific tasks:

1) Determining the degree of variability of the mining and geological conditions as a factor affecting the adaptation of the dragline to the current conditions of its effective work.

2) Upgrading the design of the dragline in order to make it more adaptable to changes in working conditions.
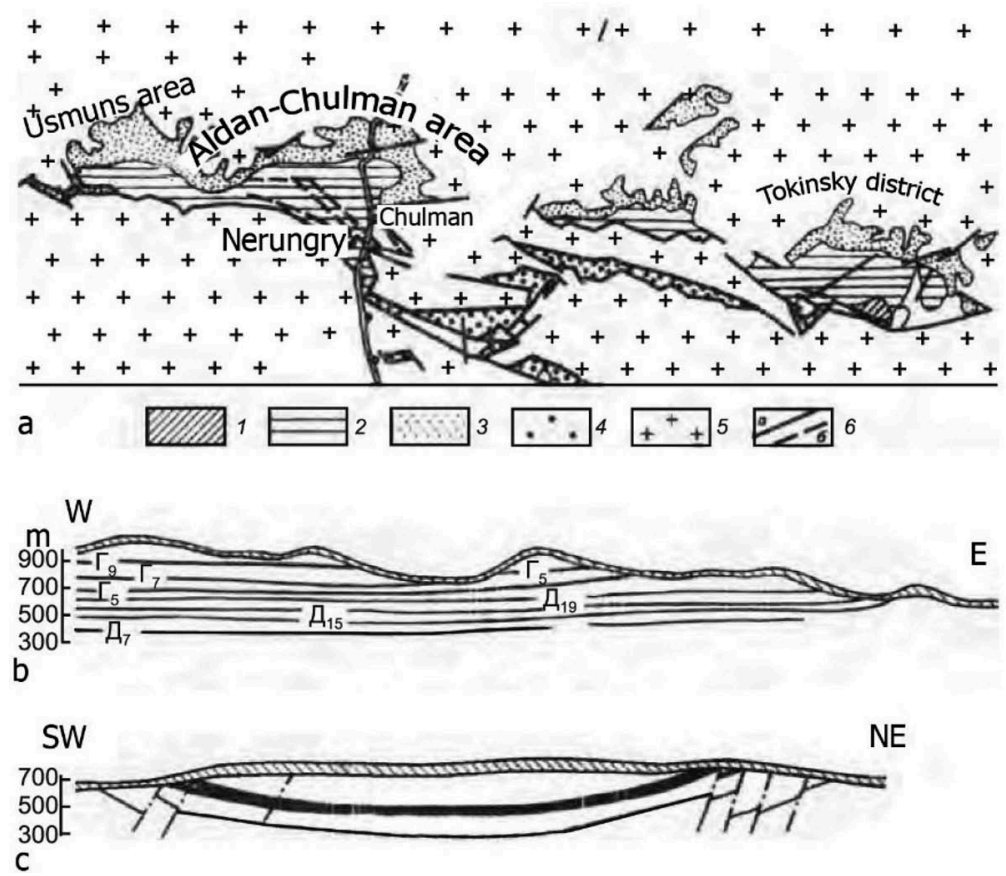

Figure 1. a. Geological scheme of the South Yakut basin: 1 - Lower Cretaceous sediments, 2 - Middle Upper Jurassic sediments, 3 - Lower Jurassic sediments, 4 - Jurassic undifferentiated sediments, 5 Archean foundation, 6 - faults; a - general scheme; b - geological cross-section of the Chulmakan field; $\mathrm{c}-$ geological cross-section of the Nerungri field; $\Gamma_{5}, \Gamma_{7}, \Gamma_{9}, Д_{7}, Д_{15}, Д_{19}-$ coal seams. 


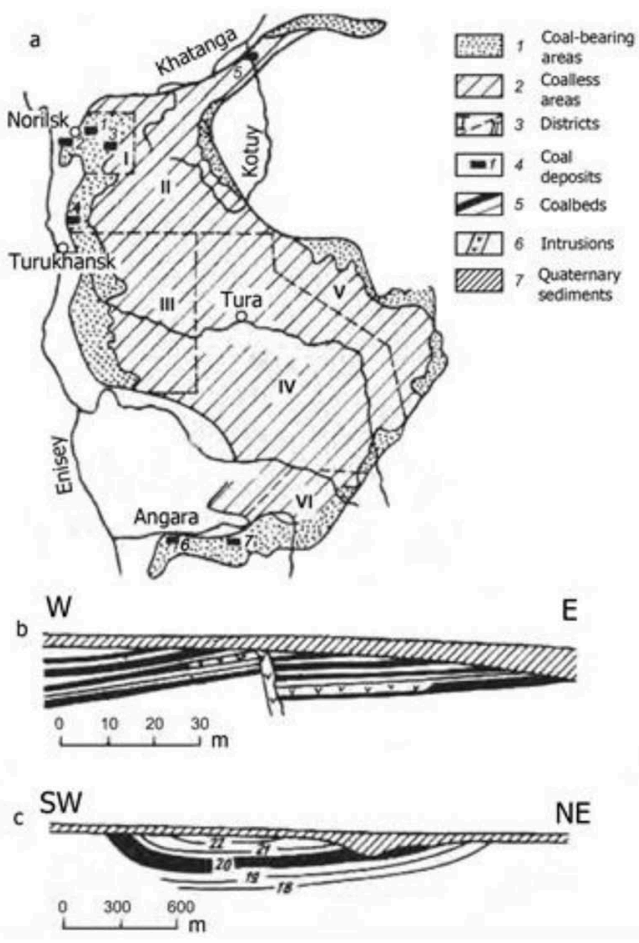

Figure 1. b. Scheme of Tungus coal basin (a), cross-sections of Kayerkan (b) and Kokuisky (c) deposits: I - Norilsk region: 1 - Schmidt and Nadezhda mountains (Norilsk-1), 2 - Kayerkan, 3 - Imangdinskoye; II - Arctic region: 4 - Kureiskoe, 5 - Kayakskoe; III - Western District; IV - Central district; V - Eastern district; VI - Southern district: 6 - Kokuiskoe, 7 - Boguchanskoe.

3) Identification of the most important dragline parameters that can be modified within the same model for specific mining and geological conditions.

4) Determination of the range of changes in the parameters of modular equipment.

\section{RESULTS}

Variability of the mining and geological conditions, in fact, is reduced to changes in the angle of incidence and thickness of the developed coal seams. Besides, it is necessary to take into account the number of coal beds (bed series) and parameters and structure of the series. If parameters of the bed series have been studied to a certain extent by domestic and foreign scientists (Demirel and Frimpong, 2009; Elliott, 1989; Lee, 1988; Michaud and Calder, 1988; Runge, 1983; Ramani and Bandopadhyay, 1985; Soloviev and Kuziev, 2017; Tanaino and Cheskidov, 1999; Vukotic et al, 2013; Sengstock, 1992; Townson et al, 2003), the series structure is still poorly studied, especially for prospective areas. Meanwhile, it significantly affects both the structure of dumps (number of tiers, etc.) and the required characteristics of the equipment used. For example, an increase in the dip angle entails an increase in the number of tiers, a decrease in the general angle of the internal dump slope and the need to increase linear parameters of the dragline. This problem does not occur, for example, with backhoes using (Dubinkin et al, 2019; Strelnikov, 2019a; Strelnikov, 2019b).

This raises the question of applicability to the development of the area (deposit): a) standard dragline models; b) modular draglines; c) a combination of standard models and modular draglines. 
As part of the second task, we would like to focus on the following. Since dragline is a complex multinode machine, there is a problem of identifying those nodes (modular or dynamic nodes), the parameters of which can be changed without affecting the design as a whole. In our opinion, such nodes can include a boom, a bucket, and counterbalances. At the same time, some basic (or static) elements of the structure (tub, revolving frame, winches, rope drums, etc.) should be designed to use modular nodes with maximum parameters. For example, the rope drum as a base element must provide the maximum length of the rope winding used with the maximum length of the boom.

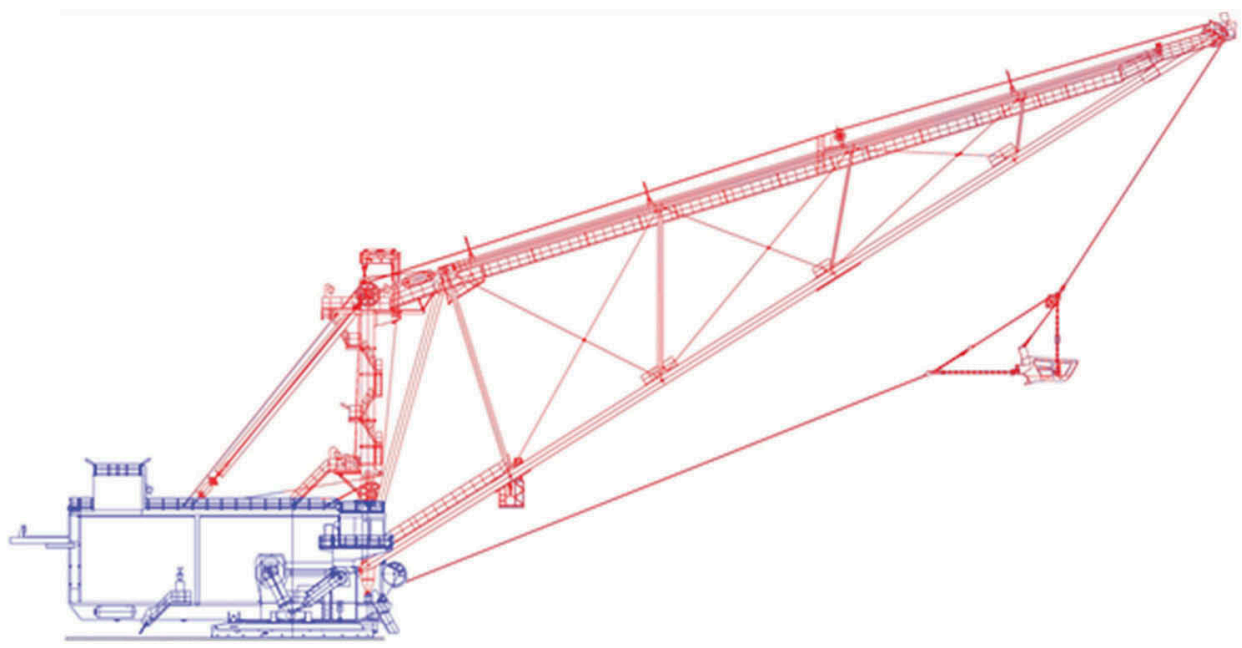

Figure 2. Dragline ESH 20.90 by "Uralmash"; modular (dynamic) elements are highlighted in red; basic (static) elements are highlighted in blue.

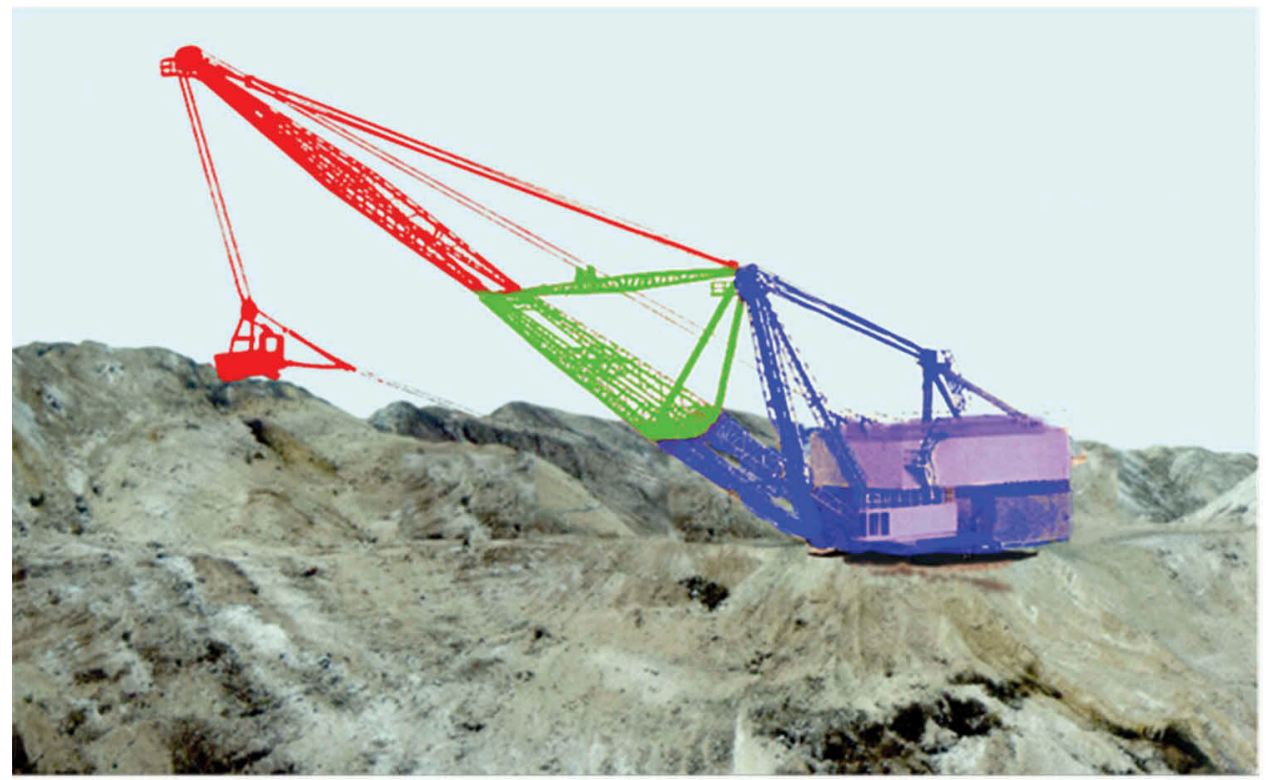

Figure 3. Dragline ESH 15/90 by NKMZ; the modular (dynamic) elements are highlighted in red, the basic (static) elements are highlighted in blue, the elements that can be referred to both modular and basic elements are highlighted in green. 
However, changes in some parameters of modular equipment may be limited by design features. For example, an A-frame of ESH draglines made by Uralmash can be used only with a certain boom (Figure 2), i.e. the parameters of the modular element (boom) cannot be changed without changing the basic element - A-frame.

Thus, the design features of modular elements can limit the consideration of a particular dragline model in the concept of "dragline as a modular system".

At the same time draglines made by "NKMZ" have a boom design that does not depend on the A-frame and allows to change its parameters in a wide range (Figure 3).

Thus, the possibility of changing certain parameters of modular (dynamic) elements within one dragline model is determined by their design features.

\section{CONCLUSIONS}

Hence the necessity to study the significance of changing the parameters of individual modular elements of the dragline's design to its maximum performance in specific mining and geological conditions. On the other hand, it is necessary to define degree of influence of change of mining and geological conditions on necessity of change of parameters of modular elements from the point of view of expediency of such change. For example, along the length of the front of the work there is a change in the angle of formation fall by a certain value. In this case it is necessary to define productivity decrease of base model of a dragline at passage of the complicated site, decrease in productivity of a dragline at change of parameters of its modular equipment and economic expenses connected with such replacement, to compare the received results and to choose the optimum decision.

Whether in this case there is a need to change the parameters of modular equipment or it makes sense to go for a temporary change in the performance of the base model - this question requires a comprehensive solution, taking into account specific geological, mining and technological conditions, as well as technical and economic calculations.

Closer contact with coal mining companies and open pit design institutes could be offered as a recommendation for dragline manufacturers to find a specific dragline model that meets all or almost all the requirements of the mining and geological conditions of a given deposit. In other words, the optimization (adaptability) of dragline parameters should start at the preproject development stage.

\section{REFERENCES}

Allison, I.S. \& Palmer D.F. 1980. Geology: The Science of a Changing Earth. USA: McGraw-Hill Companies.

Bereznyak, M.M., Kalinin A.V. \& Pronoza, V.G. 1970. A method of calculating the width of the caved rubble in the transportless system of working a series of sloping beds. Soviet Mining 6(6):638-643.

Demirel, N. \& Frimpong, S. 2009. Dragline dynamic modelling for efficient excavation. International Journal of Mining, Reclamation and Environment 23(1): 4-20.

Demirel, N. 2011. Effects of the rock mass parameters on the dragline excavation performance. Journal of Mining Science 47(4): 441-449.

Dubinkin, D.M., Sadovets, V.Yu., Kotiev, G.O. \& Kartashov, A.V. 2019. Overburden and coal transportation research at open pit mines. Journal of Mining and Geotechnical Engineering 4(7): 50-66.

Elliott, M.J. 1989. Multiple Seam Stripping at Navajo Mine, Draglines - Operation, Maintenance and Control. ACIRL Proceedings, Monograph OLD.

Huddart, H. \& I. Runge. 1979. Pit design optimised for dragline productivity. Transactions of Institute of Mining and Metallurgy. 88: A6-A12.

Katsubin, A.V. \& Fedotov, A.A. 2019. Systematization of the mining and geological conditions of the coal-bearing and coal-free zones of the Kuzbass open pits. Journal of Mining and Geotechnical Engineering 3(6): 60-75.

Lee, C.D. 1988. A multi-seam dragline mine planning simulator for personal computers. In Singhal (ed.), Mine Planning and Equipment Selection: 397-408. Rotterdam: Balkema. 
Markov, S., Janocko, J., Tyulenev, M. \& Litvin, Y. 2019. Perspectives for the Transportless Mining Technology in Siberia and Far East Coal Deposits. E3S Web of Conferences 105: 01021.

Michaud, L.H. \& P. Calder, 1988. Computerised dragline mine planning. In Fytas, Collins \& Singhal (eds.), Computer Applications in the Mineral Industry: 353-357. Rotterdam: Balkema.

Nazarov, I.V. 2011. Numerical modeling of overburden rehandling with draglines. Journal of Mining Science 48(1): 55-61.

Palamarchuk, A.B., Stukan, A.V. \& Gvozdkova, T.N. 2019. Using of transportless technology during «VI» coal seam mining on Tomusinsky open pit mine. Journal of Mining and Geotechnical Engineering 1(4): 50-68.

Ramani, R.V. \& S. Bandopadhyay. 1985. A computer simulation model for surface mine reclamation planning. Bureau of Mines. United States Department of the Interior.

Runge, I.C. 1983. The design of multi-seam open pit coal mines a step by step case study. Proceeding of the First Conference on Use of Computers in the Coal Industry: 145-155. New York: Society of Mining Engineers, AIME.

Sadri, J.R. \& C. Lee. 1982. Optimization of single and multiple seam dragline mines through simulation. In Johnson and Barnes (eds.), 17th International Symposium on the Application of Computers and Operations Research in the Mineral Industry: 642-654. New York: Society of Mining Engineers, AIME.

Scott, B., Ranjith, P.G., Choi, S.K. \& Manoj. K. 2010. A review on existing opencast coal mining methods within Australia. Journal of Mining Science 46(3): 280-297.

Seib, W \& Carr, G. 1990. Maximum coal recovery using a dragline at Callide mine. Open Cut Mining Coal Marketing \& Mine Planning: 1-13. ACIRL, Coal Research \& Consultants, Seminar Proceedings. Singleton, NSW.

Sengstock, G.W. 1992. Blast profile control for dragline productivity optimization. Proceeding of the Third Large Open Pit Mining Conference: 269-274. Melbourne: The Australasian Institute of Mining and Metallurgy.

Soloviev, S. \& Kuziev, D. 2017. Dragline ESH-10/70 linkage stiffness parameters study. Ugol' 1(1090): 37-38.

Strelnikov, A.V. 2019a. Typical faces passports for the development of coal-bearing zones of Kuzbass quarry fields with backhoes. Part 1. General provisions. Journal of Mining and Geotechnical Engineering 3(6): 4-20.

Strelnikov, A.V. 2019b. Typical faces passports for the development of coal-bearing zones of Kuzbass quarry fields with backhoes. Part 2. Passports of excavators faces. Journal of Mining and Geotechnical Engineering 4(7): 4-29.

Tanaino, A.S. \& Cheskidov, V.I. 1999. Substantiation of the sequence for opencast mining of a series of flat and inclined strata using the mined-out space for internal dumps. Journal of Mining Science 35(3): 304-313.

Townson, P. G., Murthy, D. N.P. \& Gurgenci, H. 2003. Optimization of dragline load, in Case Studies in Reliability and Maintenance. In Blischke, W.R. \& Prabhakar Murthy, D.N. (eds.), Wiley Series in Probability and Statistics: 517-544. New Jersey, USA: Wiley.

Vukotic, I., Kecojevic, V., Zhang, W., Cai, Q., \& Chen, S. 2013. Optimization of transport passage with dragline system in thick overburden open pit mine. International Journal of Mining Science and Technology 23(6): 901-906. 


\title{
Effect evaluation of the boom length and the bucket capacity of a dragline on its weight
}

\author{
A.A. Khoreshok \\ Dr.Sc., Professor, Department of Mining Machines and Complexes, T.F. Gorbachev Kuzbass State Tech- \\ nical University, Mining Institute
}

M.A. Tyulenev

MSc, PhD, Professor, Department of Open Pit Mining, T.F. Gorbachev Kuzbass State Technical University, Mining Institute

S.O. Markov

MSc, PhD, Associate Professor, Department of Surveying and Geology, T.F. Gorbachev Kuzbass State Technical University, Mining Institute

M. Cehlár

Dr.h.c. prof. Ing., Faculty of Mining, Ecology, Process Control and Geotechnologies, Technical University of Kosice

\section{J. Janočko}

Prof. Ing., CSc., Dr. scient., Faculty of Mining, Ecology, Process Control and Geotechnologies, Technical University of Kosice

\begin{abstract}
One of the most important components of a dragline excavator is a boom. The weight of the boom has a significant impact on the weight of the entire machine, despite the fact that its weight is only $4.5-6.5 \%$ of the weight of the entire machine. High weight of the boom increases the weights of the mast, A-frame, revolving frame, etc. All this leads to increased specific ground pressure, which in turn leads to the need to increase the supporting surfaces of the excavator. The moment of inertia of the boom is $30-40 \%$ in the overall balance of the moment of inertia, and therefore significantly affects the power of the rotary mechanism and the duration of the cycle of the excavator, and the tilting moment from the weight of the boom is close to the tilting moment from the weight of the bucket with the rock.

When the weight of the boom is reduced, it is possible to increase the capacity of the bucket or the length of the boom without increasing the weight of the excavator, and these indicators are known to be the main parameters of the dragline. For example, it happened with an ESH 14.75 excavator. The initial parameters of the machine (serial numbers 1 and 2) are 14.65 (bucket capacity is $14 \mathrm{~m}^{3}$, boom length is 65 meters) then 10.75 (serial numbers $3,4,5$ ) and 14.75 (serial numbers from 6 to 28) and ESH 20.65 (serial number 11). Now the factory produces an excavator ESH 15.90. The weight of the excavator has remained unchanged and makes up 1400 tons. Other main components of the excavator (tub, revolving frame, mechanisms) have not undergone significant changes.
\end{abstract}

\section{INTRODUCTION}

There is no consensus on whether the main parameter of a dragline - bucket capacity or boom length - is prevalent. On the one hand, the main idea of the transportless technology implies that the excavator should provide maximum distance for rock removing, and on the other 
hand, minimizing the volume of soil handled in one work cycle of excavator leads to a sharp decrease in the technical performance of the company (Bereznyak et al, 1970; Demirel, 2011; Huddart and Runge, 1979; Nazarov, 2011; Palamarchuk et al, 2019; Sadri and Lee, 1982; Scott et al, 2010; Seib and Carr, 1990). At this paper attempts to assess the impact of the length of the dragline's boom and the bucket capacity on the weight of the machine as a whole, since it is the weight of the excavator that characterizes the metal capacity of machinery.

Optimization of the main parameters of the dragline - bucket capacity and boom length should not lead to a significant increase in the weight of the excavator, as increasing the specific metal capacity of the machine will lead to changes in other technological parameters, changes in the geomechanical conditions of the application of the excavator and changes the parameters of internal dumping technology. In particular, the working cycle time of the excavator will be increased (Poderni, 2001; Markov et al., 2019; Katsubin and Fedotov, 2019; Dubinkin et al., 2019; Strelnikov, 2019), the limit height and angles of slopes of the overburden bench and dump's tiers will be reduced, which will lead to a decrease in the productivity of the excavator and reduce the capacity of internal dumps.

In order to maintain the technological parameters at an optimal level, it is necessary to maintain an optimal ratio between the length of the boom, bucket capacity and the specific metal capacity of draglines working on the internal dumping (Demirel and Frimpong, 2009; Elliott, 1989; Lee, 1988; Michaud and Calder, 1988; Runge, 1983; Ramani and Bandopadhyay, 1985; Soloviev and Kuziev, 2017; Sengstock, 1992; Townson et al, 2003).

\section{MATERIALS AND METHODS}

The weight of a dragline and the weight of its main components, including the boom, all other things being equal, depend on two main factors: the capacity (or weight) of the bucket with soil (rock) and the maximum bucket outreach with soil - the operating parameters of the excavator. Obviously, the latter depends on the length of the excavator boom $L$.

Since the boom angle of powerful excavators is usually equal to $30^{\circ}$, then the bucket outreach $L_{b o}$ is proportional to the length of the boom and usually numerically equal to this length, i.e.

$$
L_{b o}=a+L \cdot \cos \alpha \cong L
$$

where $L_{b o}$ is the bucket outreach, $\mathrm{m} ; a$ is the distance from the excavator's axis of rotation to the boom foot, $\mathrm{m} ; L$ is the boom length, $\mathrm{m} ; \alpha$ is the angle of the boom, degree $\left(\alpha=30^{\circ}\right)$.

However, apart from these two main factors, the excavator weight is also significantly influenced by its design, which is determined by the success and modernity of solutions of its individual components, as well as the correct choice of design and calculation schemes, determining the design loads, calculation methods and reserves of strength, structural materials, etc.

The main indicator used for comparison of draglines is the ratio of excavator weight to the product of bucket capacity into boom length, it is also used when comparing the weight of excavator booms.

$$
W_{e}=k \cdot B \cdot L,
$$

where $k$ - excavator (or excavator boom) weight factor, $\mathrm{t} /\left(\mathrm{m}^{3} \cdot \mathrm{m}\right) ; W_{e}$ - excavator weight, $\mathrm{t} ; B$ excavator bucket capacity, $\mathrm{m}^{3} ; L$ - boom length, $\mathrm{m}$.

The graph of dependence $W_{e}=f(B, L)$ is constructed by Ing. V.V. Rudoiskatel (Figure 1). In this case, it is assumed that the weight of the bucket with soil - the end load allowed at the 


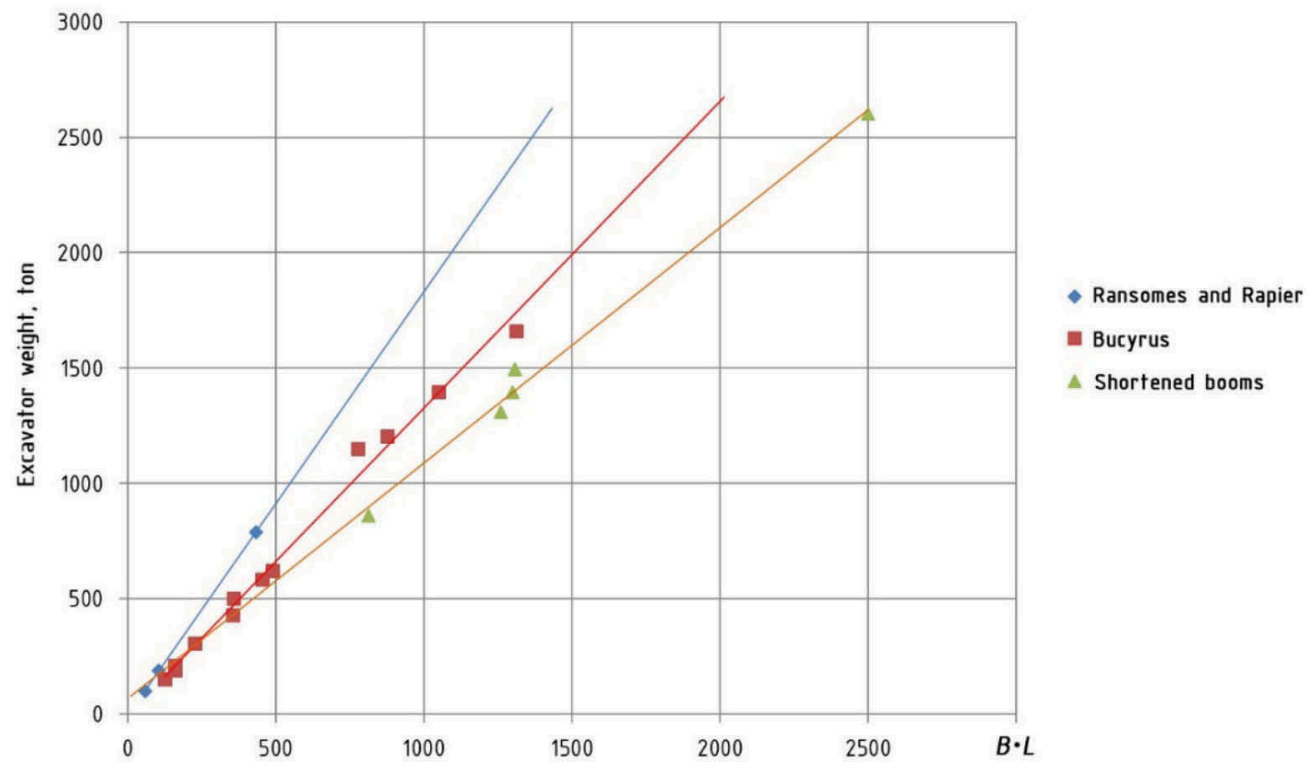

Figure 1. Plots of dependence of excavator weight on the product bucket capacity per boom length.

end of the boom - is proportional to the capacity of the bucket. In fact, the weight of $1 \mathrm{~m}^{3}$ of bucket capacity with soil $-\gamma_{\mathrm{b}+\mathrm{s}}$ of most excavators ranges from 2.9 to $3.2 \mathrm{t} / \mathrm{m}^{3}$. Given this spread, it would be more accurate in the formula (2) instead of the bucket capacity to apply the weight of the bucket with soil (end load $W_{b+s}$ ), or corresponding to this load capacity of the bucket with soil at a standard value of the specific weight of the bucket with soil, for example, $\gamma_{\mathrm{b}+\mathrm{s}}=3.2 \mathrm{t} / \mathrm{m}^{3}$. But even in this form, the formula can accurately reflect the weight of the excavator (and the excavator boom) only at certain ratios of bucket weight and boom length.

A similar relationship is recommended by Bucyrus-Erie engineer Henry Rumfelt.

$$
W_{e}=W \cdot r
$$

where $W_{e}$ is the weight of the excavator, tons; $W$ is the weight of the filled bucket, tons; $r$ is the arm of the highest load, $\mathrm{m}$.

The weight of the filled bucket is taken at the rate of 4750 pounds per cubic yard of bucket nominal size ( 2.8 tons per $1 \mathrm{~m}^{3}$ of bucket nominal capacity). Rumfelt's load radius is as follows: it determines the diameter of the tub based on an average specific pressure of $0.71 \mathrm{~kg} /$ $\mathrm{cm}^{2}$ and a safe distance from the nearest slope, which is assumed to be $1.525 \mathrm{~m}$ ( 5 feet). From the obtained point the distance $r$ to the bucket unloading point is determined. The obtained ratio is characterized by a straight line, having a tangent angle of 1:575 for existing models of excavators and a straight line having tangent angle of 1:467 for the designed models.

K.N. Trubetskoy and K.E. Vinitsky (Trubetskoy et al., 1994) determine the weight of the excavator depending on the value of the tilting moment by expression:

$$
W_{e}=80 \cdot M_{q}^{0.419}-934
$$

where $M_{q}=B \cdot L \cdot \cos \alpha \cdot\left(g_{q}+\gamma\right), t \cdot m, M_{q}=W_{b+s} \cdot L \cdot \cos \alpha$.

This formula does not take into account the design of excavators and is only correct for some sizes of draglines. 
The lack of these dependencies can be easily identified when considering the weighting coefficients of different modifications of the same excavator. For example, a Marion 7800 excavator has a weight factor $k$ that varies from $1.1 \mathrm{t} / \mathrm{m}^{3} \cdot \mathrm{m}$ (for a bucket with a capacity of $15.3 \mathrm{~m}^{3}$ and an $85.3 \mathrm{~m}$ long boom) to $0.81 \mathrm{t} / \mathrm{m}^{3} \cdot \mathrm{m}$ (for a bucket with a capacity of $26.7 \mathrm{~m}^{3}$ and a $67.1 \mathrm{~m}$ long boom), i.e. with a $75 \%$ increase in bucket capacity, the length of the boom is reduced by only $27 \%$. Hence the lower weight factor value for excavators with shortened booms.

Similarly for ESH 14/75 and ESH 20/65 excavators with the same design and all other equal conditions the construction coefficient for ESH 14/75 is $k=1.33$, and for ESH 20/65 - 1.075, i.e. $24 \%$ lower.

From these examples it can be seen that reducing the length of the boom allows increasing the capacity of the bucket by a much higher value, therefore, the length of the boom affects the weight of the excavator and its structure to a greater extent than the capacity of the bucket.

Below are the main dependencies for determining the weight of excavators and excavator booms on the operating parameters of the excavator (bucket capacity and length of the boom), as well as the impact of reducing the weight of the boom and the weight of the bucket on the weight of the entire excavator.

\section{DEPENDENCE OF EXCAVATOR WEIGHT ON OPERATING PARAMETERS}

The weight of an excavator depends on the capacity of its bucket and the length of the boom, because the value of these two parameters depends on the load on the construction of the excavator. If we express the excavator weight $W_{e}$ as a degree dependence on the capacity of the bucket $B$ and the length of the boom $L$, ie

$$
W_{e}=k \cdot B^{\alpha} \cdot L^{\beta}
$$

then the values $k, \alpha, \beta$ can be obtained from the available range of excavators. Then (4) will have the following form:

$$
W_{e}=k_{1} \cdot B^{0.65} \cdot L^{1.65}=k_{1} \cdot A
$$

where $k_{1}$ is the ratio of proportionality depending on the design of the excavator, $A$ is the ratio depending on bucket capacity and boom length.

Table 1 shows the values of $k_{1}$ for draglines of different manufacturers and defines the values of excavator weights calculated by (6) and actual excavator weights; the difference in weights almost everywhere does not exceed $5 \%$.

When using all the dependencies, including the values of $B$ and $L$, it is necessary to bring the bucket capacity to the equivalent weight, i.e. take the weight of the bucket with a soil $3.2 \mathrm{t} / \mathrm{m}^{3}$, and the boom length - to the equivalent length, at an angle of slope of $30^{\circ}$. The table shows that the Ransomes \& Rapier W600 excavator is the heaviest one. The lightest are excavators of Uralmash plant ESH $15 / 90$ and ESH 25/100, for which the value of coefficient $k_{1}=0,147$. For each company the value of coefficient $k_{1}$ is the constant value. Figure 2 shows a nomogram to determine the value of $A$, which is necessary to calculate the weight of an excavator by formula (6). Values of coefficient $k_{1}$ for excavators of different manufacturers are given in Table 2.

The verification of formula (6) according to some models of excavators Ransomes \& Rapier shows that at $k_{1}=0.159$ weights of all modifications of excavator W1880 and W1350 accurately confirm the obtained formula (see Table 1).

Thus, the possibility of changing certain parameters of modular (dynamic) elements within one dragline model is determined by their design features. 
Table 1. Theoretical and calculated by formula (6) excavator weights.

\begin{tabular}{|c|c|c|c|c|c|c|c|}
\hline \multirow[b]{2}{*}{ Manufacturer } & \multirow[b]{2}{*}{ Model } & \multirow[b]{2}{*}{$B, \mathrm{~m}^{3}$} & \multirow[b]{2}{*}{$L, \mathrm{~m}$} & \multirow[b]{2}{*}{$k_{1}$} & \multicolumn{2}{|c|}{ Excavator weight, ton } & \multirow{2}{*}{$\begin{array}{l}\text { Weight deviation } \\
\Delta, \%\end{array}$} \\
\hline & & & & & theoretical & calculated & \\
\hline \multirow{10}{*}{ Marion } & \multirow[t]{4}{*}{ M7800 } & 15.0 & 85.3 & 0.162 & 1460 & 1464 & 0.3 \\
\hline & & 19.0 & 79.0 & 0.162 & 1460 & 1490 & 2.0 \\
\hline & & 23.0 & 73.0 & 0.162 & 1460 & 1476 & 1.1 \\
\hline & & 27.0 & 67.0 & 0.162 & 1425 & 1415 & -0.7 \\
\hline & \multirow[t]{3}{*}{ M7400 } & 5.4 & 71.6 & 0.162 & 550 & 554 & 0.7 \\
\hline & & 6.9 & 67.0 & 0.162 & 585 & 586 & 0.1 \\
\hline & & 8.4 & 61.0 & 0.162 & 585 & 570 & -2.6 \\
\hline & \multirow[t]{2}{*}{ M7200 } & 4.6 & 41.1 & 0.162 & 196 & 201 & 2.5 \\
\hline & & 5.4 & 36.6 & 0.162 & 196 & 184 & -6.4 \\
\hline & $950 \mathrm{~B}$ & 13.0 & 64.0 & 0.205 & 990 & 1038 & 4.6 \\
\hline \multirow{4}{*}{ Bucyrus } & $1250 \mathrm{~B}$ & 17.6 & 67.6 & 0.205 & 1290 & 1383 & 6.7 \\
\hline & $1250 \mathrm{~B}$ & 23.0 & 58.7 & 0.205 & 1330 & 1304 & -2.0 \\
\hline & 500 & 6.1 & 61.8 & 0.205 & 595 & 599 & 0.7 \\
\hline & 500 & 7.65 & 56.4 & 0.205 & 605 & 597 & -1.4 \\
\hline \multirow{10}{*}{ Ransomes \& Rapier } & 200 & 3.1 & 41.1 & 0.205 & 195 & 197 & 0.9 \\
\hline & 1400 & 15.3 & 86.0 & 0.189 & 1740 & 1732 & -0.5 \\
\hline & 150 & 3.1 & 40.2 & 0.189 & 174 & 175 & 0.5 \\
\hline & 600 & 6.1 & 61.5 & 0.277 & 800 & 803 & 0.3 \\
\hline & 600 & 7.65 & 56.0 & 0.277 & 800 & 797 & -0.4 \\
\hline & 600 & 9.2 & 50.0 & 0.277 & 750 & 745 & -0.7 \\
\hline & 1800 & 18.3 & 92.3 & 0.159 & 1880 & 1839 & -2.2 \\
\hline & 1800 & 22.9 & 85.9 & 0.159 & 1880 & 1890 & 0.5 \\
\hline & 1800 & 30.6 & 75.5 & 0.159 & 1880 & 1844 & -2.0 \\
\hline & 1350 & 15.3 & 82.0 & 0.159 & 1350 & 1347 & -0.3 \\
\hline \multirow{4}{*}{ Uralmash } & $14 / 75$ & 14.0 & 75.0 & 0.203 & 1400 & 1401 & 0.0 \\
\hline & $20 / 65$ & 20.0 & 65.0 & 0.203 & 1400 & 1395 & -0.4 \\
\hline & $15 / 90$ & 15.0 & 90.0 & 0.147 & 1430 & 1433 & 0.2 \\
\hline & $25 / 100$ & 25.0 & 100.0 & 0.147 & 2420 & 2377 & -1.8 \\
\hline
\end{tabular}

\section{EFFECT OF BUCKET WEIGHT REDUCTION ON EXCAVATOR WEIGHT}

It is important to lighten the weight of the bucket to reduce the excavator weight. By saving the bucket weight, you can increase its volume or reduce the excavator weight. Let's consider how the excavator weight changes when the bucket weight changes.

The weight $W$ of the bucket with the capacity $B$ with the soil having density $\gamma_{s}$ can be presented in the form:

$$
W=B \cdot\left(\gamma_{b}+\gamma_{s}\right),
$$

where $\gamma_{b}, \gamma_{s}-$ specific weights of bucket and soil, respectively.

At reduction of weight of a bucket design in $n$ times and corresponding increase in bucket capacity, weight of a bucket with soil will be

$$
W_{1}=B_{1} \cdot\left(n \cdot \gamma_{b}+\gamma_{s}\right)
$$

With the constant weight of the bucket with the soil

$$
\begin{gathered}
W=W_{1}, \\
B_{1}=\frac{B \cdot\left(\gamma_{b}+\gamma_{s}\right)}{n \cdot \gamma_{b}+\gamma_{s}} .
\end{gathered}
$$




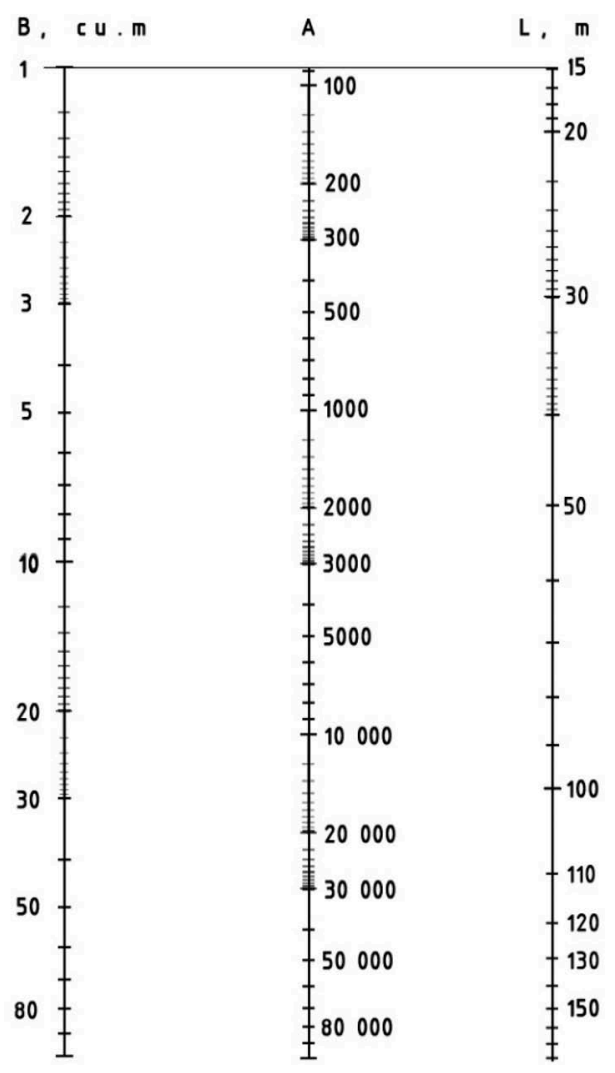

Figure 2. Nomogram for determining $A$ value.

Table 2. Values of coefficient $k_{1}$ and $k_{1}^{\prime}$ for excavators of different manufacturers.

\begin{tabular}{llll}
\hline Manufacturer, model & $k_{1}$ & $k_{1}^{\prime}$ & Boom construction \\
\hline Marion & 0.162 & - & \\
Bucyrus & 0.205 & - & \\
Ransomes \& Rapier & 0.189 & 0.011 & Rigid triple lattice \\
Ransomes \& Rapier 600 & 0.277 & - & Rigid triple lattice \\
Ransomes \& Rapier 1800 & 0.159 & - & Rigid triple lattice \\
ESH 6/60 & 0.208 & 0.0115 & Rigid triple lattice \\
ESH 14/75 & 0.203 & 0.0096 & Cable \\
ESH15/90, ESH 25/100 & 0.147 & 0.008 & Cable advanced \\
\hline
\end{tabular}

Using formula (6) we will find the ratio of excavator weights with buckets of capacity $B$ and $B_{1}$ :

$$
\frac{W_{1}}{W}=\frac{k \cdot B_{1}^{0.65} \cdot L^{1.65}}{k \cdot B^{0.65} \cdot L^{1.65}} \text { or } W_{1}=W \cdot\left(\frac{B_{1}}{B}\right)^{0.65}
$$

Reducing the specific weight of the bucket of an ESH 25/100 excavator by $20 \%$, which is 8 tons with the bucket weight of 40 tons, will reduce the excavator weight by $4 \%$, which is 100 tons. 


\section{EFFECT OF BOOM WEIGHT REDUCTION ON EXCAVATOR WEIGHT}

The weight of the draglines' booms also depends on the above factors (bucket capacity, length of the boom) and can be expressed as the same formula (5) as the weight of the dragline:

$$
W_{\text {boom }}=k_{1}^{\prime} \cdot B^{0.65} \cdot L^{1.65}=k_{1}^{\prime} \cdot A
$$

where $k_{1}^{\prime}$ is a coefficient depending on excavator boom's design.

Table 3 shows the actual weights of the booms and the weights of the same booms determined by the formula (11).

The difference between the theoretical and actual weight does not exceed $1.5 \%$. Thus, the nomogram shown in the Figure 2 can be used to determine the weight of the booms. The load on the excavator boom suspension, and therefore on all other structures, is characterized by the tilting moment relative to the heel of the boom from the weight of the boom and the weight of the bucket with the soil:

$$
M_{\text {tilt }}=W_{\text {boom }} \cdot l_{b f}+W_{\text {bucket }} \cdot l_{b b}
$$

where $l_{b f}, l_{b b}$ - distances from boom foot to mass center of boom and bucket, respectively. Usually, mass center of the boom is located approximately in its middle, i.e.

$$
l_{b f} \approx 0.5 l_{\text {boom }}
$$

Therefore, with respect to the loads on the structures, a decrease in boom weight by $\Delta W_{\text {boom }}$ is equivalent to a decrease in bucket weight by $0.5 \Delta W_{\text {bucket }}$. Thus, the weight reduction of the boom by $\eta$ percent

$$
\Delta W_{\text {boom }}=\frac{\eta \cdot k_{1} \cdot A}{100}
$$

is equal to bucket weight reduction by

$$
\Delta W_{\text {bucket }}=0.5 \cdot \Delta W_{\text {boom }}=\frac{0.5 \cdot \eta \cdot k_{1} \cdot A}{100}
$$

\begin{tabular}{|c|c|c|c|c|c|c|}
\hline \multirow[b]{2}{*}{ Dragline model } & \multirow[b]{2}{*}{$B, \mathrm{~m}^{3}$} & \multirow[b]{2}{*}{$L, \mathrm{~m}$} & \multirow[b]{2}{*}{$k_{1}^{\prime}$} & \multicolumn{2}{|c|}{ Boom weight, ton } & \multirow[b]{2}{*}{ Weight deviation $\Delta, \%$} \\
\hline & & & & actual & theoretical & \\
\hline \multicolumn{7}{|c|}{ Cable boom } \\
\hline ESH 14/75 & 14.0 & 75.0 & 0.00945 & 65.5 & 65.0 & -0.5 \\
\hline ESH 20/65 & 20.0 & 65.0 & 0.00945 & 64.5 & 65.0 & 0.7 \\
\hline \multicolumn{7}{|c|}{ Cable advanced boom } \\
\hline ESH 15/90 & 15.0 & 90.0 & 0.008 & 77.0 & 78.0 & 1.3 \\
\hline ESH 25/100 & 25.0 & 100.0 & 0.008 & 130.0 & 129.0 & -0.5 \\
\hline
\end{tabular}

or reduction of the bucket capacity by

$$
\Delta B=\frac{0.5 \cdot \eta \cdot k_{1} \cdot A}{100 \cdot \gamma_{b+s}} .
$$

Table 3. Comparison of actual excavator boom weights with weights calculated by formula (11). 
Weight of the excavator having bucket of capacity equal to $B_{1}=B-\Delta B$ is

$$
W_{e}^{\prime}=k \cdot A^{\prime}=k \cdot(B-\Delta B)^{0.65} \cdot L^{1.65} .
$$

The weight reduction of the excavator $\beta$ as a percentage will be as follows

$$
\beta=\frac{W_{e}-W_{e}^{\prime}}{W_{e}} \cdot 100=\left(1-\left(\frac{B-\Delta B}{B}\right)^{0.65}\right) \cdot 100=\left(1-\left(1-\frac{0.5 \cdot \eta \cdot k_{1} \cdot L^{1.65}}{B^{0.35} \cdot 100 \cdot \gamma}\right)\right) \cdot 100
$$

If we take the weight of 1 cubic meter of bucket with soil as $\gamma_{\mathrm{b}+\mathrm{s}}=3.2 \mathrm{t} / \mathrm{m}^{3}$, and the coefficient $k_{1}$ for cable booms can be taken as 0.008 , the final expression for $\beta$ will look like:

$$
\beta=\left(1-\left(1-125 \cdot 10^{-7} \cdot \eta \cdot \frac{L^{1.65}}{B^{0.35}}\right)\right) \cdot 100 .
$$

With different $L$ and $B$ we get:

\begin{tabular}{lll}
\hline$L, \mathrm{~m}$ & $B, \mathrm{~m}^{3}$ & $\beta$ \\
75 & $10<B<25$ & $0,35-0,45$ \\
100 & $25<B<50$ & $0,4-0,5$ \\
125 & $25<B<75$ & $0,6-0,7$ \\
\hline
\end{tabular}

Smaller coefficients correspond to larger bucket capacities.

\section{CONCLUSIONS}

The average coefficient value $\beta=0.5 \eta$ shows that a $1 \%$ reduction in the weight of the boom results in a $0.5 \%$ reduction in the weight of the excavator. The weight reduction of ESH $25 /$ 100 boom by $10 \%$ (15 t) will reduce the weight of the excavator by approximately $5 \%(120 \mathrm{t})$.

Reducing the specific weight of the bucket of an ESH 25/100 excavator by $10 \%$, which is 4 tons with the bucket weight of 40 tons, will reduce the excavator weight by $2 \%$, which is 50 tons.

Similarly, the increase in excavator weight will change as the boom and bucket weight increases. Available geomechanical parameters of both natural rock massif and blasted-andmoved rock mass (the tensile and shear strength, internal friction angle, watercut) should ensure placement of the excavator with the maximum possible boom length and bucket capacity. This condition is necessary to achieve optimal performance of the mining enterprise in specific mining and geological conditions.

In other words, a dragline that is planned to be implemented in a particular mining and geological environment must meet its characteristics.

\section{REFERENCES}

Bereznyak, M.M., Kalinin A.V. \& Pronoza, V.G. 1970. A method of calculating the width of the caved rubble in the transportless system of working a series of sloping beds. Soviet Mining 6(6):638-643.

Demirel, N. \& Frimpong, S. 2009. Dragline dynamic modelling for efficient excavation. International Journal of Mining, Reclamation and Environment 23(1): 4-20.

Demirel, N. 2011. Effects of the rock mass parameters on the dragline excavation performance. Journal of Mining Science 47(4): 441-449.

Dubinkin, D.M., Sadovets, V.Yu., Kotiev, G.O. \& Kartashov, A.V. 2019. Overburden and coal transportation research at open pit mines. Journal of Mining and Geotechnical Engineering 4(7): 50-66. 
Elliott, M.J. 1989. <i>Multiple Seam Stripping at Navajo Mine, Draglines - Operation, Maintenance and Control</i>. ACIRL Proceedings, Monograph OLD.

Huddart, H. \& I. Runge. 1979. Pit design optimised for dragline productivity. Transactions of Institute of Mining and Metallurgy. 88: A6-A12.

Katsubin, A.V. \& Fedotov, A.A. 2019. Systematization of the mining and geological conditions of the coal-bearing and coal-free zones of the Kuzbass open pits. Journal of Mining and Geotechnical Engineering 3(6): 60-75.

Lee, C.D. 1988. A multi-seam dragline mine planning simulator for personal computers. In Singhal (ed.), Mine Planning and Equipment Selection: 397-408. Rotterdam: Balkema.

Markov, S., Janocko, J., Tyulenev, M. \& Litvin, Y. 2019. Perspectives for the Transportless Mining Technology in Siberia and Far East Coal Deposits. E3S Web of Conferences 105: 01021.

Michaud, L.H. \& P. Calder, 1988. Computerised dragline mine planning. In Fytas, Collins \& Singhal (eds.), Computer Applications in the Mineral Industry: 353-357. Rotterdam: Balkema.

Nazarov, I.V. 2011. Numerical modeling of overburden rehandling with draglines. Journal of Mining Science 48(1): 55-61.

Palamarchuk, A.B., Stukan, A.V. \& Gvozdkova, T.N. 2019. Using of transportless technology during «VI» coal seam mining on Tomusinsky open pit mine. Journal of Mining and Geotechnical Engineering 1(4): 50-68.

Poderni, R.Yu. Mechanical equipment of open pits. 2001. Moscow: Mining Media Group.

Ramani, R.V. \& S. Bandopadhyay. 1985. A computer simulation model for surface mine reclamation planning. Bureau of Mines. United States Department of the Interior.

Runge, I.C. 1983. The design of multi-seam open pit coal mines a step by step case study. Proceeding of the First Conference on Use of Computers in the Coal Industry: 145-155. New York: Society of Mining Engineers, AIME.

Sadri, J.R. \& C. Lee. 1982. Optimization of single and multiple seam dragline mines through simulation. In Johnson and Barnes (eds.), 17th International Symposium on the Application of Computers and Operations Research in the Mineral Industry: 642-654. New York: Society of Mining Engineers, AIME.

Seib, W \& Carr, G. 1990. Maximum coal recovery using a dragline at Callide mine. Open Cut Mining Coal Marketing \& Mine Planning: 1-13. ACIRL, Coal Research \& Consultants, Seminar Proceedings. Singleton, NSW.

Sengstock, G.W. 1992. Blast profile control for dragline productivity optimization. Proceeding of the Third Large Open Pit Mining Conference: 269-274. Melbourne: The Australasian Institute of Mining and Metallurgy.

Soloviev, S. \& Kuziev, D. 2017. Dragline ESH-10/70 linkage stiffness parameters study. Ugol' 1(1090): $37-38$.

Strelnikov, A.V. 2019. Typical faces passports for the development of coal-bearing zones of Kuzbass quarry fields with backhoes. Part 1. General provisions. Journal of Mining and Geotechnical Engineering 3(6): 4-20.

Townson, P. G., Murthy, D. N.P. \& Gurgenci, H. 2003. Optimization of dragline load, in Case Studies in Reliability and Maintenance. In Blischke, W.R. \& Prabhakar Murthy, D.N. (eds.), Wiley Series in Probability and Statistics: 517-544. New Jersey, USA: Wiley.

Trubetskoy, K.N., Potapov, M.G., Vinitskiy, K.E. \& Melnikov N.N. (eds.). 1994. Open pit mines: guidebook. Moscow: Mine Bureau. 


\title{
Analysis of hazardous processes in the natural-industrial system
}

\author{
I.I. Bosikov \\ PhD in Engineering sciences, Associate Professor, North-Caucasian Institute of mining and metallurgy \\ (State Technological University), Vladikavkaz, Russia
}

\author{
R.V. Klyuev \\ Grand PhD in Engineering sciences, Head of (the) Department, North-Caucasian Institute of mining \\ and metallurgy (State Technological University), Vladikavkaz, professor, Moscow polytechnic university, \\ Moscow, Russia \\ Yu.V. Dmitrak \\ Grand PhD in Engineering sciences, rector, North-Caucasian Institute of mining and metallurgy (State \\ Technological University), Vladikavkaz, Russia
}

\begin{abstract}
The article describes the research and analysis of the occurring hazardous processes in the natural-industrial system and the assessment of the effectiveness of its functioning using mathematical models. Relevance. Studies of the laws governing the functioning of the natural-industrial system are becoming increasingly relevant in connection with the statement of the problem of modernizing the mining and processing industry and the Russian economy as a whole. Due to the significant amount of poorly structured data, it is complicated by the regulations for the effective functioning of production processes, social and natural complexes, which would ensure the sustainable development of the natural-industrial system of the mining and processing complex. Therefore, scientific and applied problems, the solution of which allows us to formalize the hidden structural laws of the functioning of the naturalindustrial system and make managerial decisions of an organizational and technological nature to increase the efficiency of the system's functioning, are very relevant. The purpose of the work: is to study the relationship between the parameters of the teaching staff of the mining and processing complex and the development of methods, criteria, and algorithms for determining effective and safe technologies to ensure the effective functioning of teaching staff. Research methods include mathematical modeling, laboratory and industrial experimental studies, multivariate and regression - correlation analysis. Research results. The obtained criterion in terms of indicators of technological and technogenic factors of the mining and processing complex allows us to evaluate and predict the level of pollution from the territory of the formed dumps. Conclusion The validity and reliability of scientific statements, conclusions and research results are based on the use of leading scientists in the field of system analysis of the technosphere as a theoretical and methodological base, confirming the conformity of the results of theoretical studies and practical information, as well as implementation in production.
\end{abstract}

\section{INTRODUCTION}

The problems of choosing effective and safe technologies using methods, models and criteria that describe complex technical systems are developed in the works of domestic and foreign scientists: B.Ya. Sovetova, S.A. Yakovleva, A.S. Rykova, P.G. Belova, N.N. Moiseeva A.A. Samarsky, D.N. Khomyakova, D. Neumann, K. Pearson, R. Fisher, A. Wald, Yu.I. Zhuravleva, K.V. Rudakova, V.D. Mazurova, V.P. Maslova, M.A. Aizerman, N.S. Kremer. 
When considering the teaching staff of the mining and processing complex, numerous tasks arise that require an assessment of the quantitative and qualitative regularities of the processes of the functioning of the system. The limited capabilities of the experimental study of teaching staff makes it urgent to develop methods and models that would allow us to represent the processes of the functioning of the system in an appropriate form, a description of the course of these processes using mathematical dependencies, and an assessment of the characteristics of the objects under study.

The questions of studying the laws governing the functioning of teaching staff are becoming more relevant in connection with the statement of the problem of modernizing production and the Russian economy as a whole. In connection with a significant amount of poorly structured data, it is complicated by the regulations for the effective functioning of production processes, social and natural complexes, where sustainable development of teaching staff would be ensured. Therefore, scientific and applied problems, the solution of which allows us to formalize the hidden structural laws of the functioning of teaching staff and make managerial decisions of an organizational and technological nature to increase the efficiency of its functioning, are very relevant.

The authors analyzed the teaching staff of the mining and processing complex of the Dzhezkazgan mining and processing plant: the features of the functioning of the natural-industrial system are examined; dangerous processes that occur in the teaching staff of the mining and processing industry and their modeling features; an analysis of the technologies for mining and processing the useful component, as well as methods for choosing safe technologies; experimental data of studies of the parameters of the teaching staff are presented.

The teaching staff, in fact, is a geographically distributed system, the basic components of which are: people, equipment and the working environment, interconnected by an external (for the whole system) environment using technology. NIS states are determined by the NIS structure, which includes the above components with their relationships, which are considered time-varying variables and together determine the corresponding factor space.

The paper considers the teaching staff, the general view of which is presented in Figure 1.

The input parameters are: emissions into the atmosphere $\left(X_{1}\right)$, discharges into the aquatic environment $\left(X_{2}\right)$, discharges into the lithosphere $\left(X_{3}\right)$, tailings of concentration plants $\left(X_{4}\right)$, household waste $\left(X_{5}\right)$, radioactive waste $\left(X_{6}\right)$, pesticides and toxic chemicals $\left(X_{7}\right)$. The output parameters are: the number of inpatients $\left(Y_{1}\right)$, cancer patients $\left(Y_{2}\right)$, deceased $\left(Y_{3}\right)$, cancer patients $\left(Y_{4}\right)$ and children born with abnormalities $\left(Y_{5}\right)$, the general incidence of NIS $\left(Y_{6}\right)$.

The following are considered as hazardous processes arising in the teaching staff:

- man-caused, associated with the possibility of unwanted emissions of energy and substances accumulated in man-made technological objects (industries);

- anthropogenic, caused by the harmful effects on people of pollutant emissions (pollutants) of the teaching staff of the mining and processing complex.

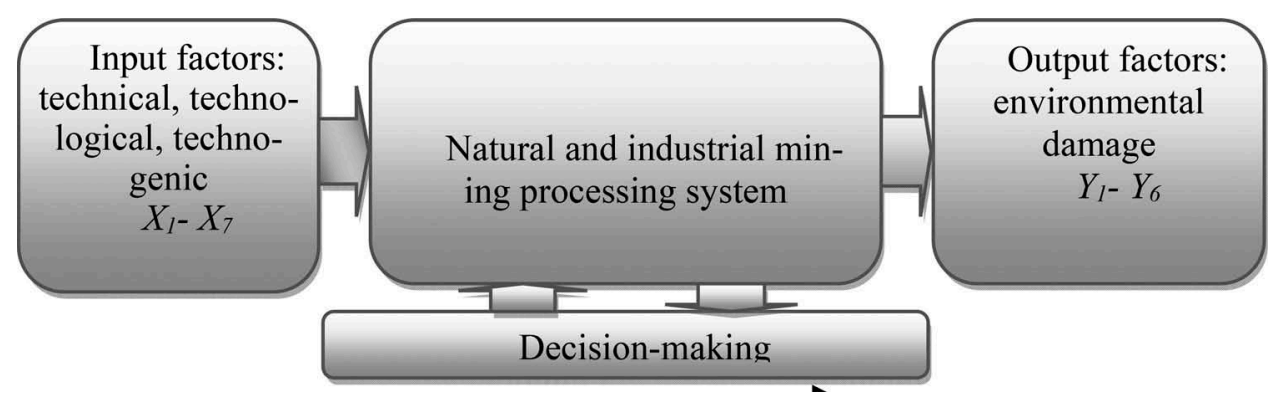

Figure 1. A generalized scheme of the teaching staff of the mining and processing complex. 


\section{INITIAL DATA FOR RESEARCH}

Environmental pollutants in the functioning of natural systems of industrial mining and processing complex are the sources of contaminant's release. The pollution source - the object (production processes, machines, etc.), as well as storage places of bulk or liquid materials, quarries, waste dumps, waste disposal sites, which under the influence of weather and other factors are subtracting contaminants.

The influence of harmful emissions into the atmosphere $\left(X_{1}\right)$, discharges into the aquatic environment $\left(X_{2}\right)$, discharges to surface topography $\left(X_{3}\right)$, the tails of enrichment plants $\left(X_{4}\right)$, municipal waste $\left(X_{5}\right)$, radioactive waste $\left(X_{6}\right)$, pesticides and toxic chemicals $\left(X_{7}\right)$, the number of inpatients $\left(Y_{1}\right)$, cancer patients $\left(Y_{2}\right)$, deceased $\left(Y_{3}\right)$, births $\left(Y_{4}\right)$, children born with abnormalities $\left(Y_{5}\right)$, and the overall incidence of NIS population $\left(Y_{6}\right)$ (Bosikov, Klyuev, Revazov \& Pilieva. 2018), (Yegorova, Klyuev, Bosikov \& Tsidaev. 2018), (Klyuev, Bosikov, Gavrina \& Revazov. 2018).

The ranges used by independent variables varied:

a) in a dimensional scale:

1) $47.142<A<94.285$

2) $11.5<B<23.0$;

3) $131.5<C<394.5$;

4) $3223.7<D<8059.43$;

5) $2750.0<E<6875.0$;

6) $0.011935 .5<F<1935.5$;

7) $0.4<G<0.65$.

b) in a dimensionless scale:

$$
\begin{aligned}
& x_{1}=\frac{A-70.71}{23.575} \mathrm{r} \\
& x_{2}=\frac{\mathrm{B}-17.25}{5.75} \\
& x_{3}=\frac{\mathrm{C}-263.0}{131.5} \\
& x_{4}=\frac{\mathrm{D}-5641.58}{2417.85} \\
& x_{5}=\frac{\mathrm{E}-4812.5}{2062.5} \\
& x_{6}=\frac{\mathrm{F}-967.755}{967.745} \\
& x_{7}=\frac{\mathrm{G}-0.525}{0.125}
\end{aligned}
$$

The influence of harmful substances on the social complex of mining and processing complex (the value $Y_{1}-Y_{5}$ ), with the use of mathematical experiment planning in accordance with the plan shown in Table 1 matrix.

Data processing method of least squares provides a linear regression equation variables $Y_{1}-Y_{5}$ in general form:

$$
Y=b_{0}+b_{1} \cdot x_{1}+b_{2} \cdot x_{2}+b_{3} \cdot x_{3}+b_{4} \cdot x_{4}+b_{4} \cdot x_{4}+b_{5} \cdot x_{5}+b_{6} \cdot x_{6}+b_{7} \cdot x_{7} .
$$


Table 1. Matrix of experimental design and results.

\begin{tabular}{|c|c|c|c|c|c|c|c|c|c|c|c|c|c|}
\hline \multirow{3}{*}{ Years } & \multicolumn{8}{|c|}{$\begin{array}{l}\text { Input } \\
\text { factors }\end{array}$} & \multicolumn{5}{|c|}{ response functions } \\
\hline & & A & B & $\mathrm{C}$ & $\mathrm{D}$ & $\mathrm{E}$ & $\mathrm{F}$ & G & K & $\mathrm{L}$ & M & $\mathrm{N}$ & $\mathrm{W}$ \\
\hline & $x_{0}$ & $x_{1}$ & $x_{2}$ & $x_{3}$ & $x_{4}$ & $x_{5}$ & $x_{6}$ & $x_{7}$ & $Y_{1}$ & $Y_{2}$ & $Y_{3}$ & $Y_{4}$ & $Y_{5}$ \\
\hline 1999 & + & + & - & + & - & - & + & - & 89.7 & 8.32 & 8.63 & 7.32 & 2.02 \\
\hline 2000 & + & - & - & + & + & + & - & - & 109.87 & 4.77 & 8.38 & 7.76 & 1.56 \\
\hline 2001 & + & + & + & + & + & + & + & + & 111.91 & 4.34 & 8.41 & 7.13 & 1.85 \\
\hline 2002 & + & - & + & + & - & - & - & + & 109.57 & 6.82 & 7.33 & 8.55 & 1.3 \\
\hline 2003 & + & + & - & - & + & - & - & + & 108.31 & 3.92 & 8.51 & 8.04 & 1.60 \\
\hline 2004 & + & - & - & - & - & + & + & + & 113.84 & 4.15 & 8.57 & 8.78 & 1.36 \\
\hline 2005 & + & + & + & - & - & + & - & - & 111.75 & 4.55 & 8.18 & 7.76 & 1.72 \\
\hline 2006 & + & - & + & - & + & - & + & - & 113.5 & 3.98 & 8.32 & 8.80 & 1.56 \\
\hline 2007 & + & + & - & + & + & - & + & + & 112,4 & 4.15 & 8.12 & 8.02 & 1.68 \\
\hline 2008 & + & - & - & + & - & + & - & + & 119.87 & 3.77 & 8.28 & 5.76 & 1.57 \\
\hline 2009 & + & + & + & + & + & + & - & + & 101.91 & 5.34 & 8.31 & 9.13 & 1.75 \\
\hline
\end{tabular}

With the independent variables:

in dimensionless scale:

$$
\left\{\begin{array}{l}
\mathrm{Y}_{1}=108.55-25.64 \mathrm{x}_{1}-2.74 \mathrm{x}_{2}+1.90 \mathrm{x}_{3}+ \\
+4.195 \mathrm{x}_{4}+2.27 \mathrm{x}_{5}-3.12 \mathrm{x}_{6}+3.33 \mathrm{x}_{7} \\
\left(\mathrm{~F}=15.423, \mathrm{~F}_{0.05,10,3}=5.719\right) \\
\mathrm{Y}_{2}=5.11+0.34 \mathrm{x}_{1}+0.087 \mathrm{x}_{2}-0.7116 \mathrm{x}_{3}- \\
-0.851 \mathrm{x}_{4}+0.883 \mathrm{x}_{5}+0.341 \mathrm{x}_{6}+0.198 \mathrm{x}_{7} \\
\left(\mathrm{~F}=17.527, \mathrm{~F}_{0.05,10,3}=5.719\right) \\
\mathrm{Y}_{3}=8.293-1.146 \mathrm{x}_{1}+0.12 \mathrm{x}_{2}+0.078 \mathrm{x}_{3}+ \\
+0147 \mathrm{x}_{4}+0.142 \mathrm{x}_{5}+0.147 \mathrm{x}_{6}-0.90 \mathrm{x}_{7} ; \\
\left(\mathrm{F}=13.213, \mathrm{~F}_{0.05,10,3}=5.719\right) \\
\mathrm{Y}_{4}=8.027-0.121 \mathrm{x}_{1}-0.245 \mathrm{x}_{2}-0.0863 \mathrm{x}_{3}+ \\
+0.11 \mathrm{x}_{4}-0.0438 \mathrm{x}_{5}-0.121 \mathrm{x}_{6}+0.179 \mathrm{x}_{7} ; \\
\left(\mathrm{F}=12.417, \mathrm{~F}_{0.05,10,3}=5.719\right) \\
\mathrm{Y}_{5}=1.628-0.351 \mathrm{x}_{1}+0.098 \mathrm{x}_{2}+0.067 \mathrm{x}_{3}+ \\
+0.0098 \mathrm{x}_{4}+0.129 \mathrm{x}_{5}+0.007 \mathrm{x}_{6}-0.0218 \mathrm{x}_{7} \\
\left(\mathrm{~F}=29.658, \mathrm{~F}_{0.05,10,3}=5.719\right)
\end{array}\right.
$$

in the size scale:

$$
\left\{\begin{array}{l}
Y_{1}=162.72-1.71 A-0.48 B+0.014 C+0.2 \cdot 10^{-2} D+0.1 .10^{-2} E-0.3 \cdot 10^{-2} F+26.64 G \\
Y_{2}=-4.603+0.14 A+0.015 B-0.5 \cdot 10^{-2} C-0.04 \cdot 10^{-2} D+0.04 \cdot 10^{-2} E+0.35 \cdot 10^{-3} F+1.58 G \\
Y_{3}=14.358-0.048 A+0.02 B+0.6 \cdot 10^{-3} C+0.6 \cdot 10^{-4} D+0.7 \cdot 10^{-4} E+0.15 \cdot 10^{-3} F-7.2 G \\
Y_{4}=8.513-0.5 \cdot 10^{-2} A-0.043 B-0.7 \cdot 10^{-3} C+0.5 \cdot 10^{-4} D-0.2 \cdot 10^{-4} E-0.13 \cdot 10^{-3} F+1.48 G \\
Y_{5}=2.016-0.0149 A+0.017 B+0.5 \cdot 10^{-3} C+0.4 \cdot 10^{-5}+0.6 \cdot 10^{-4} E+0.007 \cdot 10^{-3} F-0.174 G
\end{array}\right.
$$

\section{RESULTS OF THE EXPERIMENT}

In planning and conducting experiments, the reproducibility, evaluation of the significance of the regression coefficients of the equation and the adequacy of the obtained relationships were tested (Alexeyev \& Levich. 1997), (Balzter, Braun \& Kohler. 1998). 
Verification of the experiment reproducibility was carried out on the dispersion of response functions defined for each planning row of the matrix. To verify the homogeneity of dispersions the Cochran's criterion was used. For these investigations the variance in lines and in total were calculated (Kremer. 2004), (Sovetov \& Yakovlev. 1999). To test the homogeneity of dispersions at significance level $\alpha=0.05$, the statistics $G_{\mathrm{v}}$ was calculated:

$$
G_{\mathrm{v}}=\frac{S_{y_{i \max }}^{2}}{\sum S_{y_{i}}^{2}}=0.376
$$

Compared with the critical values $G_{j-\alpha ; b}, q$, while $p=N-1=7, k=m-1=2$; table-valued $G_{1-0.05 ; 7,2}=0.7218$. Then $G_{v}=0.3765<G_{1-0.05 ; 7,2}=0.7218$, i.e. hypothesis about the accuracy of the measurements is not rejected.

Checking on adequacy is an estimate of the approximation errors and was performed using Fisher's ratio test for a given factor of significance $\alpha=0.05$. The calculated value of $F$ - statistics was found by the formulas:

$$
\begin{gathered}
F=\frac{S^{2}(Y)}{S_{\text {adqt }}^{2}} \\
S^{2}(Y)=\frac{\sum\left(Y_{i}-\hat{Y}_{i}\right)^{2}}{N-1} \\
S_{\text {adqt }}^{2}=\frac{\sum\left(Y_{i}-\hat{Y}_{i}\right)^{2}}{N-k}
\end{gathered}
$$

where $Y=$ wherein the arithmetic mean value of the dependent variable; = the value calculated by the equation variable; $s_{\text {adq }}^{2}=$ adequacy dispersion equation regression of experimental data; $S^{2}(Y)=$ the dispersion of the dependent variable.

For dependencies $Y_{1}-Y_{5}(8)$, the values $F_{i}>F_{0.05 ; 10 ; 3}=5.719$, i.e. the adequacy of the regression equations hypothesis is accepted (Kremer. 2004).

From the equations it follows that the independent variables on the degree of influence on the dependent parameters, taking into account boundary conditions adopted were ranked as follows, as shown in Table 2.

This shows that the greater influence on social and technological subsystem is made by air emissions, discharges into the aquatic environment and radioactive waste, and the least by domestic wastes.

Confidence intervals for the regression coefficients of equation (8) were calculated using the formula:

$$
\Delta S=\sqrt{S_{a d q t}^{2}} \cdot G_{i j}
$$

Table 2. Ranging, the absolute value of the regression coefficients, the degree of influence on the dependent parameters.

\begin{tabular}{ll}
$y_{1}$ & $x_{1}(\mathrm{~A})>x_{3}(\mathrm{C})>x_{7}(\mathrm{G})>x_{6}(\mathrm{~F})>x_{2}(\mathrm{~B})>x_{5}(\mathrm{E})>x_{4}(\mathrm{D})$ \\
$y_{2}$ & $x_{6}(\mathrm{~F})>x_{4}(\mathrm{D})>x_{3}(\mathrm{C})>x_{7}(\mathrm{G})>x_{1}(\mathrm{~A})>x_{2}(\mathrm{~B})>x_{5}(\mathrm{E})$ \\
$y_{3}$ & $x_{1}(\mathrm{~A})>x_{7}(\mathrm{G})>x_{6}(\mathrm{~F})>x_{4}(\mathrm{D})>x_{3}(\mathrm{C})>x_{2}(\mathrm{~B})>x_{5}(\mathrm{E})$ \\
$y_{4}$ & $x_{2}(\mathrm{~B})>x_{7}(\mathrm{G})>x_{1}(\mathrm{~A})>x_{6}(\mathrm{~F})>x_{4}(\mathrm{D})>x_{3}(\mathrm{C})>x_{5}(\mathrm{E})$ \\
$y_{5}$ & $x_{1}(\mathrm{~A})>x_{6}(\mathrm{~F})>x_{2}(\mathrm{~B})>x_{7}(\mathrm{G})>x_{3}(\mathrm{C})>x_{4}(\mathrm{D})>x_{5}(\mathrm{E})$ \\
\hline
\end{tabular}


where $t=$ table-valued Student's t-test for significance levels of 0.05 and the number of degrees of freedom $N-k ; G_{i j}=$ reverse-diagonal elements of the information matrix (XTX)-1.

Investigation on the presence of autocorrelation using Durbin-Watson statistics was performed. Calculation of the Durbin-Watson test showed:

$$
d_{1}=\frac{\sum_{i=1}^{n}\left(e_{i}-e_{i-1}\right)^{2}}{\sum_{i=1}^{n} e_{i}^{2}}=2.215
$$

$d_{2}=2.114 ; d_{3}=2.015 ; d_{4}=2.11 ; d_{5}=2.084$, since $d>2$, then there is no autocorrelation, therefore obtained models can be used as predictive (Kremer. 2004).

The identified linear mathematical models allow to analyze the nature of the emissions, to plan and make decisions in the development of measures to reduce the impact of technological and man-made factors on the social complex NIS.

With the help of the developed models, it is possible to conduct the forecast values of the $Y_{1}-Y_{5}$ and eventually choose efficient production technology and processing of useful minerals.

Calculation of the Durbin-Watson test:

$$
d_{1}=\frac{\sum_{i=1}^{n}\left(e_{i}-e_{i-1}\right)^{2}}{\sum_{i=1}^{n} e_{i}^{2}}=\frac{5998.124}{2736.788}=2.191
$$

Since $d>2$, then there are no alternatives to the existence of autocorrelation negative autocorrelation. From the table defined for $n=27, k=2$ (the number of explanatory variables) and the significance level $a=0.05: d_{1}=1.24$ and $d_{2}=1.56$. Since $4-d=1.809>d_{2}=1.56$ therefore there is no autocorrelation.

Eliminating autocorrelation 1 - order generalized least squares method.

The covariance matrix of the vector of regression residuals was built. Then find its assessment and build a model of GLS. The random variables are investigated $\varepsilon_{i}$ :

$$
M\left[\varepsilon_{i}\right]=k \sum_{k=0}^{\infty} \rho \mathbf{M}\left[\delta_{i-k}\right]=0
$$

Dispersion of regression excesses is a permanent value:

$$
\begin{gathered}
D\left[\varepsilon_{i}\right]=\sigma_{0}^{2} \frac{1}{1-\rho^{2}} \\
\sum \varepsilon=\frac{\sigma_{0}^{2}}{1-\rho^{2}}\left(\begin{array}{cccc}
1 & \rho & \ldots & \rho^{n-1} \\
\rho & 1 & \ldots & \rho^{n-2} \\
\ldots & \ldots & \ldots & \ldots \\
\rho^{n-1} & \rho^{n-2} & \ldots & \rho^{n-k}
\end{array}\right)
\end{gathered}
$$

Thus, the type of the covariance matrix of the vector of regression excesses was specified. To estimate the GLS regression coefficients the matrix was constructed. Using the form $\Sigma$, can be specified $\Omega$. 


$$
\Omega=\frac{1}{1-\rho^{2}}\left(\begin{array}{cccc}
-\rho & 1 & -\rho & 0 \\
0 & -\rho & 1 & -\rho \\
\ldots & \ldots & \ldots & \ldots \\
0 & -\rho & 1 & -\rho
\end{array}\right)
$$

In practice, the value $\rho$ is unknown. The method of assessing using the Cochrane-Orcutt method, which is an iterative approach that includes the following steps:

1. The GLS regression was assessed: $Y=X^{T} b$;

2. The excesses were calculated $e_{i}^{(1)}$;

3. The regression dependence of $e_{i}$ on $e_{i-1}$ was assessed: $e_{i}=\rho^{(1)} e_{i-1} \delta_{i}, e_{i-1}$ is the coefficient of assessment, it represents an estimate $\rho^{(i)}$,

4. $\Omega^{(1)}$ was built. The regression dependence of $Y$ on $X$ GLS was assessed using this matrix.

5. Re-calculated, $e_{i}$ the process is returned to step 3 .

The process ended when $\rho^{(i)}$ the values of the last and the penultimate stages became about the same.

After the analysis were identified anomalous values. The separation of inhomogeneous sample collections was produced. The assessment of influence degree of various factors on the nature of the variability of the properties of objects of natural and industrial systems is given. It was found that in particular NIS health is mostly affected by emissions into the atmosphere, lithosphere, and hydrosphere. These factors must be considered when choosing the safe production and processing technology, in terms of the negative impact on public health.

Taking into account the obtained dependence $Y_{6}$, influence dependencies of anthropogenic factors on the social and technological subsystem NIS will take the form:

$$
\left\{\begin{array}{l}
Y_{1}=108.55-2.27 x_{1}-2.74 x_{2}+1.90 x_{3}+4.195 x_{4}+25.64 x_{5}-3.12 x_{6}+3.33 x_{7} \\
Y_{2}=5.11-0.34 x_{1}-0.087 x_{2}+0.7116 x_{3}-0.851 x_{4}+0.198 x_{5}-0.341 x_{6}+0.883 x_{7} \\
Y_{3}=8.293-0.147 x_{1}+0.12 x_{2}+0.078 x_{3}+1.146 x_{4}+0.142 x_{5}-0.147 x_{6}+0.90 x_{7} \\
Y_{4}=8.027-0.121 x_{1}-0.0438 x_{2}-0.0863 x_{3}+0.11 x_{4}-0.245 x_{5}-0.121 x_{6}+0.179 x_{7} \\
Y_{5}=1.628-0.3511 x_{1}+0.098 x_{2}+0.067 x_{3}+0.0098 x_{4}+0.129 x_{5}+0.0071 x_{6}-0.0218 x_{7} \\
Y_{6}=-14.9+14.4 x_{1}+4.0 x_{2}+0.906 x_{3}+0.174 x_{4}+0.237 x_{5}
\end{array}\right.
$$

For the equation $Y_{6}-F_{0.05 ; 10 ; 3}=5.719$;

$F=15.423>F_{0.05} ; 10 ; 3$, i.e. the adequacy of the regression equations hypothesis is accepted.

Investigation on the autocorrelation using Durbin-Watson statistic was done (21): $d_{1}=$ $2.215 ; d_{2}=2.114 ; d_{3}=2.015 ; d_{4}=2.11 ; d_{5}=2.084 ; d_{6}=2.191$.

Since $d>2$, therefore, there is no autocorrelation, so these models can be used as predictive (Kremer. 2004), (Spitsnadel. 2002), (Jorgensen. 1976), (Belov. 2003).

\section{CONCLUSION}

With the help of the developed models, it is possible to conduct the forecast values of the $Y_{1}-Y_{6}$ and choose effective technology of mining and processing of useful minerals. Identified linear mathematical models enable reasonably plan and make organizational and technical solutions in the development of measures to reduce the impact of technological and man-made factors in the social and technological NIS subsystem.

The influence assessment of anthropogenic factors on the social and technological subsystem faculty of mining and processing complex is conducted. The revealed dependences allow to analyze the nature of the emissions, to plan and make decisions in the development of measures to reduce the impact of technological and man-made factors on the social and technological NIS subsystem. 
The correlation and regression dependences of anthropogenic factors influence of production subsystem on social subsystem of NIS are developed.

The conducted studies made it possible to use the developed methods and models for ensuring sustainable development of mountainous territories.

\section{REFERENCES}

Alexeyev, V.L. \& Levich, A.P. 1997. A search for maximum species abundances in ecological communities under conditional diversity optimization. Bull. of Mathemat. Biology 59: 649-677.

Balzter, H., Braun, P.W. \& Kohler, W. 1998. Cellular automata models for vegetation dynamics. Ecological Modeling 107: 113-125.

Belov, P.G. 2003. System analysis and modeling of hazardous processes in the technosphere. Moscow: Publishing Center Academy.

Bendoricchio, G. \& Jorgensen, S.E. 1997. Exergy as a goal function of ecosystems dynamic. Ecological modeling 102: 5-15.

Birch, L.O. 1979. The effect of species of animals which share common resources on one another's distribution and abundance. Fortschr. Zool. 25: 197-221.

Boer, P.J. 1980. Exclusion or coexistence and the taxonomic or ecological relationship between species. Neth. J. Zool. 30: 278-306.

Bosikov, I.I., Klyuev, R.V., Revazov, V.Ch. \& Pilieva, D.E. 2018. Performance evaluation of functioning of natural-industrial system of mining-processing complex with help of analytical and mathematical models. IOP Conference Series: Materials Science and Engineering 327.

Jorgensen, S.E. 1976. A eutrophication model for a lake. J. Ecol. model 2: 147-165.

Klyuev, R.V., Bosikov, I.I., Gavrina, O.A., \& Revazov, V.Ch. 2018. System analysis of power consumption by nonferrous metallurgy enterprises on the basis of rank modeling of individual technocenosis castes. MATEC Web Conf. 226. (2018) 04018. EDP Sciences.

Kremer, N.S. 2004. Theory of Probability and Mathematical Statistics. Moscow: UNITY DANA.

Saaty, T. L. 1986. Axiomatic foundation of the analytic hierarchy process. Management Science 32: 841-855.

Sovetov, B.Y. \& Yakovlev, S.A. 1999. Modeling systems. Moscow: Higher School.

Spitsnadel, V.N. 2002. Theory and practice of optimal decision making. St. Petersburg: Publishing house Business press.

Yegorova, E.V., Klyuev, R.V., Bosikov, I.I. \& Tsidaev, B.S. 2018. Evaluation of use of effective technologies for increasing sustainable development of natural and technical system of oil and gas complex. Sustainable Development of Mountain Territories 3(37): 392-403. 


\title{
The implementation of Indonesian PSC gross split scheme in Russian offshore
}

\author{
M.I. Kiat \\ Student, National Research University of Oil and Gas named after I.M. Gubkin, Moscow, Russian Federation \\ S.I. Iliukhin \\ Student, National Research University of Oil and Gas named after I.M. Gubkin, Moscow, Russian Federation
}

A.Kh. Ozdoeva

Phd, Associate Professor, National Research University of Oil and Gas named after I. M. Gubkin, Moscow, Russian Federation

\begin{abstract}
Russia should implement Product Sharing Contract (PSC) "Gross Split (GS) Scheme" as an alternative contract to optimally extract hydrocarbon in its offshore. Existing contracts don't have necessary functionality for efficient, certain and transparent interaction with International Oil Companies (IOCs), while the collaboration is significant due to the absence of technologies, facilities and investments. Goals: Analyzing the implementation of Indonesian PSC GS; creating an adaptive model on Russian offshore. Methodology: Theoretical survey (analysis and synthesis, comparison, mental modeling). Results: Based on technical and economic characters of Russia, authors found adjustments in determining base split, incentive components and their splits as well as in taxation. This paper describes GS Scheme and discusses opportunities, problems and challenges of its application. Regarding that, Indonesian PSC GS is believed to have precise ingredients to bring about healthy, fair and sustainable business corporations in Russian offshore.
\end{abstract}

Keywords: Production Sharing Contract (PSC), Cost-recovery (CR), Gross Split (GS), HostGovernment (HG), International Oil Companies (IOCs), Joint Venture (JV)

\section{INTRODUCTION}

In the last ten years, there have been various problems in the oil and gas business faced by HGs around the World. A familiar matter is the long though discussion about Plan of Development (POD) between IOC and HG which leads to the delay of production period. In some cases, HG's income is lower than operation expenditure (OPEX). These issues are closely related to old contracts that are no longer applicable in the current situation. Therefore, HG should be more careful in selecting the future contracts. For instance, in Indonesia. After considering low-level income by applying PSC Cost Recovery since 1970 and the incompatibility of existing contract types, Indonesia recently designed a new concept "PSC Gross split scheme", which is until now considered attractive to Investors and has been signed for 39 working areas since the date it came into force in January 2017. The main differences of this hybrid of PSC and concession from others are as follows: split starts from gross revenue; IOC takes $100 \%$ responsibility of E\&P cost; and HG can increase/decrease IOC's share by assessing variable (every POD) and progressive components (monthly), design of which is based on existing oil and gas fields calibration. Overall, this scheme is believed to offer best approaches in ensuring certainty, efficiency and simplicity in the world oil and gas business. 
In Russia, having traumatic problems with Cost Recovery (CR) Scheme last two decades and continuous changes in Russian tax mechanism lead to the main challenge in accepting new offer of Product Sharing Contract's (PSC) scheme, though GS may able to increase Russian fiscal attractiveness. In case GS becomes acceptable, the next challenge is the adaptation process in both HG and IOCs.

The purpose of this study is to comprehensively show to what extent PSC Gross Split Scheme (GSS) can fairly meet business interests of HG and IOC. This paper seeks to present a mapping of problems, opportunities and challenges in the GSS implementation. This paper, most of all, focuses on adjusting-split components and tax mechanism. This paper is based on both qualitative and quantitative comparative analysis methods of gov. documents (Indonesian Minister's regulation on PSC GS and on taxation; Russian tax code), companies' outlooks (BP Statistical Review; Gazprom in numbers), statistics (Russian Minister of Energy; Indonesian Central Bureau of Statistics; Indonesian Energy Outlook) and academic literatures (Books and papers from Johnston D. (USA), Harimurti D. (Indonesia), Konoplyanik A.A. (Russia)).

\section{LITERATURE REVIEW}

\subsection{Highlight of oil and gas contracts}

Petroleum fiscal system consists of concessionary and contractual. Concessionary allows IOC to have the ownership of mineral resources and $\mathrm{HG}$ to accept payment of taxes and royalties. Under contractual, HG retains ownership of minerals and IOC receives a share of revenues from the sale of oil and gas or production in accordance with a service contract (SC) or a Production Sharing Contract. SC is divided based on whether the fee is based upon a flat fee (pure) or profit (risk). PSC is generally characterized by Cost Recovery, FTP (Royalties), domestic market obligation (DMO) and income tax. It's then called PSC CR. PSC Gross Split means PSC based on the principle of gross production sharing without cost recovery mechanism (Johnston D, 1994).

In Russia, there are such types of contracts as licenses (concessions), service contracts, and PSC $\mathrm{CR}$. The difference lies in multiple tax regulation, which are applied to all types of contract. Mostly, license (tax/royalty) type combined with Joint Venture (JV) is used in this country. Besides there are only three PSC CR contracts left, namely, Kharyagenskoe, Sakhalin 1 and Sakhalin 2 petroleum fields. All of them work with JV with HG participation (Konoplyanik A.A, 1989).

\subsection{The origin of product sharing contract gross split scheme}

As was the case with PSC CR, PSC GR also appeared for the first time in Indonesia in 2017. There are number of phenomena underlying its emergence: 1) Prolonged dispute frequently happened due to slow approval process on budgeting by HG bureaucracy and cost inefficiency (practice of mark-up) by IOCs; 2) HG's revenue from 1997-2014 were higher than cost recovery, but 2015 and 2016 it was vice versa. Revenue and cost relations in two years are respectively 12,0/13,7 and 9,9/11,5 billion US\$; 3) HG's Reserve Replacement Ratio (RRR) wasn't higher than $50 \%$ or lower than India, Malaysia and Vietnam, which are respectively more than $70 \%, 120 \%, 170 \%$; 4) HG's oil production (bopd) was sharply decreasing because of declining upstream oil and gas investment, shrinking of oil and gas reserves and low exploration activities (Harimurti, D., 2017). Besides, those problems are completed by the HG's inability to self-invest and its rigid fiscal system against oil price fluctuations. Thus, in effort to build again the business stability, Indonesia according to Ministry of Energy and Natural Resources regulation no. 8/2017 introduced new scheme of PSC which brings along 3 basic principles: 1) Certainty - providing transparent and measurable incentive parameters in consonance with the level of complexity of field development; 2) Simplicity - boosting simplification and accountability business process by minimizing bureaucratic procurement system and frequent debates; and 3) Efficiency - advocating IOCs and their supporting systems to be more efficient with the intention of being able to better adapt to oil price fluctuations ("Indonesia Energy Roundtable," UK-ASEAN Business Council, last modified April 25, 2019, https://www.ukabc.org.uk/news/ukabc-indonesia-energy-roundtable/). 
During half year after its publication date, GS is not working well almost in all fields compared to CR based on the economic analysis results (IRR and NPV). It seems like, in that critical era, IOCs significantly reduce capital expenditure and act very selectively in investing. IOCs basically require a business climate that has high legal certainty and competitive fiscal provisions. Taking the facts as consideration, HG issued ministry regulation no.52/2017 as a revision on the previous GS regulation, and new government regulation 53/2017 on GS taxation. HG added new progressive component "gas price", edited incremental splits for cumulative production and committed to compensate additional certain split "Ministry share", if IOC share, after split adjustment, is still uneconomic. Regarding fiscal incentive, from exploration to first production, HG exempts IOC for import duty, VAT and LBT tax. IOC is also simplified with accelerated depreciation and 10-years tax loss carryforward. Other elements in oil and gas policy reform are simplification of permit process (deregulation), transfer of firm commitment, asset transfer to other contractor, land acquisition by HG through Special Task Force for Upstream Oil and Gas Business "SKK Migas", land acquisition through lease, and free and open access for oil and gas data. Nevertheless, GS doesn't eliminate state control. The reasons are working places and lifting capacity are determined by State; the title to equipment belongs to state; and share split is happened at the transfer point (White M., et all, "Energy: Oil and Gas 2019-Indonesia," Chambers and partners, last modified August 9, 2019, https://practiceguides.chambers.com/practice-guides/energy-oil-and-gas-2019/indonesia).

Hence, economic indicators of revised GS are considered more competitive than CR. Consequently, from the date of issue on 29th August 2017 till January 2019, GS has been started to implement in 39 blocks consisting of 14 auction results, 21 terminations and 4 contract amendments with approximate investment commitment 2,2 milliard US\$. And there are 5 contracts, one of them is unconventional field - Tanjung Enim Blok, will follow soon (Deha D., "Indonesia Wins Two-Working Areas Auction US\$116.7M," The insider stories, last modified May 7, 2019, https://theinsiderstories.com/indonesias-two-working-areas-auction-reached-us $116-7 \mathrm{~m} /$ ).

Evolution summary of Indonesian Product Sharing Contract is depicted in Figure 1 in the form of scheme and the details in Table 1.

Figure 2 shows the parameters and their split adjustments of every component applied in Indonesia. The whole calculation was created by special group of Minister of Energy based on data calibration of 10 main petroleum fields in Indonesia. The parameters were adopted from terms and conditions of rate of return contracts by Daniel Johnston (Johnston, D., 1994).

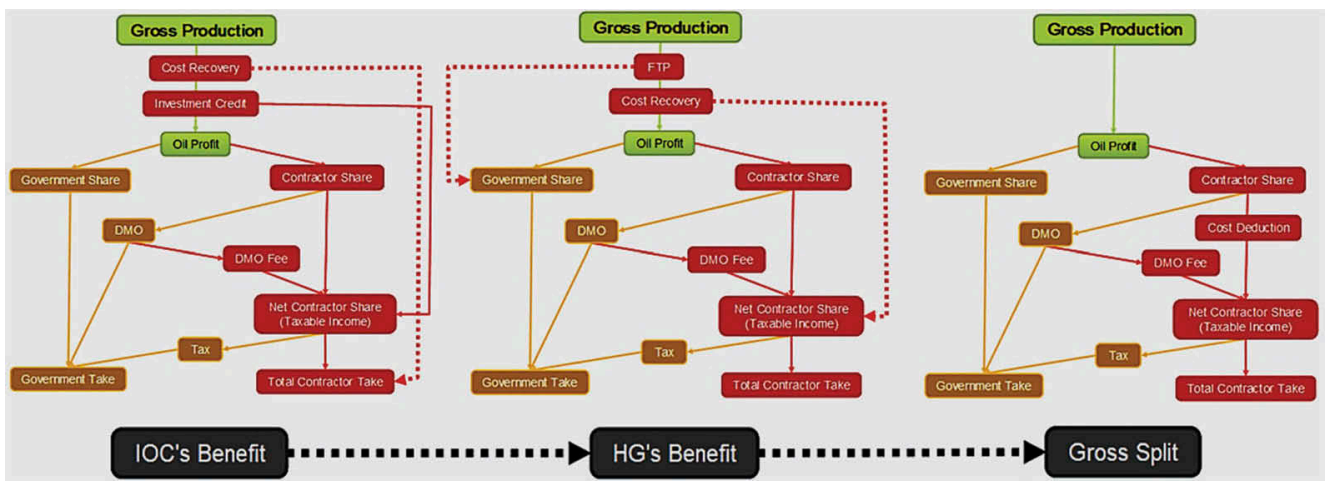

*Designed by authors

Figure 1. Scheme evolution summary of Indonesian PSC (Harimurti, D. "Milestone in Production-Sharing Contract in Perspective of Government Take, Contractor Take, Cost Recovery and Production Target", 10). 
Table 1. Details of evolution summary of Indonesian product sharing contract (Harimurti, D.).

\begin{tabular}{|c|c|c|c|}
\hline Element & $\begin{array}{l}\text { Past Law no } 22 / 2001 \\
(1976-1987)\end{array}$ & $\begin{array}{l}\text { New Contracts } \\
(2008-2016)\end{array}$ & $\begin{array}{l}\text { PSC GS } \\
\text { (2017-Present) }\end{array}$ \\
\hline FTP & None & 20 to $\mathrm{HG}$ & None \\
\hline $\begin{array}{l}\text { Cost Recovery } \\
\text { Limit }\end{array}$ & $100 \%$ & POD basis (ring fencing) & None \\
\hline Income Tax & $56 \%$ & $40 \%$ & $40 \%$ \\
\hline Equity Split & 85/15 (Oil) & 80/20 (Oil) & Base Split: 57/43 \\
\hline (HG/IOC) & 70/30 (Gas) & 70/30 (Gas) & $\begin{array}{l}\text { (Oil) \& 52/48 (Gas) } \\
\text { Progress. \& var. } \\
\text { comp. }\end{array}$ \\
\hline $\begin{array}{l}\text { Investment } \\
\text { Credit }\end{array}$ & $20 \%$ & N/A & N/A \\
\hline $\mathrm{DMO}$ & $\begin{array}{l}25 \% \text { of IOC's share } \\
\text { At } 0,02 \mathrm{USD} / \mathrm{bbl}\end{array}$ & $\begin{array}{l}25 \% \text { of IOC's share } \\
\text { At } 25 \% \text { export price }\end{array}$ & $\begin{array}{l}25 \% \text { of IOC's share } \\
\text { At } 100 \% \text { export } \\
\text { price }\end{array}$ \\
\hline Depreciation & $\begin{array}{l}7 \text { years for capex (DDB) } 10 \text { years } \\
\text { amortization for OPEX (SLD) }\end{array}$ & 5 years & 10 years \\
\hline $\begin{array}{l}\text { Abandonment } \\
\text { Liability }\end{array}$ & None & Yes & Yes \\
\hline Others & No CR limit & $\begin{array}{l}\text { ASR is stated in CR } 79 / 2010 \text {. } \\
\text { Additional indirect tax. }\end{array}$ & $\begin{array}{l}\text { No CR. Additional } \\
\text { indirect tax. }\end{array}$ \\
\hline Alignment & IOC's benefit & HG's benefit & Compromise \\
\hline
\end{tabular}

* Abandonment site recovery (ASR), double declining balance (DDB), and straight line depreciation (SLD)

** Designed by authors

\begin{tabular}{|c|c|c|c|c|c|c|c|}
\hline \multicolumn{2}{|c|}{$\begin{array}{l}\text { PROGRESSIVE CONPONENTS } \\
\text { (MONTHLY ADJUSTED) }\end{array}$} & \multicolumn{6}{|c|}{ VARLABLE COMPONENTS (ADJUSTED BASED ON NEW POD) } \\
\hline Parameter & $\begin{array}{c}\begin{array}{c}\text { Split (40) } \\
\text { adjustment }\end{array} \\
\end{array}$ & Parameter & $\begin{array}{c}\text { Split (96) } \\
\text { adjustment }\end{array}$ & Parameter & \begin{tabular}{c|} 
Split (90) \\
adjustment
\end{tabular} & Parameter & \begin{tabular}{c|} 
Split (90) \\
adjustment
\end{tabular} \\
\hline \multicolumn{2}{|c|}{ Oit Price (USS.bb1) } & \multicolumn{2}{|l|}{ Infrastructure } & \multicolumn{2}{|c|}{ Reseryoir Depth (m) } & \multicolumn{2}{|c|}{ Domestic Content } \\
\hline \multicolumn{2}{|c|}{$(85-I C P)+0.25$} & Well developed & 0.0 & $x \leq 2500$ & 0.0 & $30 \leq x<50$ & 2.0 \\
\hline \multicolumn{2}{|c|}{ Gas Price (USS:MMBTU) } & New Frontier Ofshore & 2.0 & $x>2500$ & 1.0 & $50 \leq x<70$ & 3.0 \\
\hline$x<7$ & $(7-x)+2.5$ & New Frontier Onshore & 4.0 & \multicolumn{2}{|c|}{$\mathrm{CO} 2$ Content } & $70 \leq x<100$ & 4.0 \\
\hline $7 \leq x \leq 10$ & 0 & \multicolumn{2}{|c|}{ Field Location (ses depth, m) } & $x<5$ & 0.0 & \multicolumn{2}{|c|}{ API Gravity (Density) } \\
\hline$x>10$ & $(10-x)+2.5$ & Onshore & 0.0 & $5 \leq x<10$ & 0.5 & $x<25$ & 1.0 \\
\hline \multicolumn{2}{|c|}{ Cumulative Production (MIMBOE) } & Otshore $(0<\mathrm{h} \leq 20)$ & 8.0 & $10 \leq x<20$ & 1.0 & $x \geq 25$ & 0.0 \\
\hline$x<30$ & 10.0 & Oshore $(20<\mathrm{h} \leq 50)$ & 10.0 & $20 \leq x<40$ & 1.5 & \multicolumn{2}{|c|}{ Production Stage } \\
\hline $30 \leq x<60$ & 9.0 & Ofshore $(50<\mathrm{h} \leq 150)$ & 12.0 & $40 \leq x<60$ & 2.0 & Primery & 0.0 \\
\hline $60 \leq x<90$ & 8.0 & Ofshore $(150<\mathrm{h} \leq 1000)$ & 14.0 & $x \geq 60$ & 4.0 & Secondery & 6.0 \\
\hline $90 \leq x<125$ & 6.0 & Ofshore $(\mathrm{h}>1000)$ & 16.0 & \multicolumn{2}{|c|}{ H2S Convent } & Tertiary & 10.0 \\
\hline $125 \leq x<175$ & 4.0 & \multicolumn{2}{|c|}{ Reservoir Type } & $x<100$ & 0.0 & \multicolumn{2}{|c|}{ Field Status } \\
\hline$x \geq 175$ & 0.0 & Conventional & 0.0 & $100 \leq x<1000$ & 1.0 & POD I & 5.0 \\
\hline \multicolumn{2}{|c|}{ BASE SPLIT } & Non-conventional & 16.0 & $1000 \leq x<2000$ & 2.0 & POD II & 3.0 \\
\hline \multicolumn{2}{|c|}{ FG (1OC) Share } & & & $2000 \leq x<3000$ & 3.0 & NO POD & 0.0 \\
\hline Crude Oil & $57 \%(43 \%)$ & & & $3000 \leq x<4000$ & 4.0 & & \\
\hline Natural Gas & $52 \%(48 \%)$ & & & $x \geq 4000$ & 5.0 & & \\
\hline
\end{tabular}

*Designed by authors

Figure 2. Base, progressive and variable components of Indonesian PSC GS (Roach B. \& Dunstan A., 2018). 


\section{RESEARCH}

\subsection{PSC "gross split scheme" (study case: Russian offshore fields)}

To confirm the hypothesis about the possibility of using PSC GS in the Russian Federation, the authors made a set of components by analogy with the Indonesian scheme, based on own analysis of publicly available information of main petroleum fields in Russian offshore (Figure 3).

\subsubsection{Base components}

Based on the petroleum business culture in Russia, e.g. in Sakhalin II, the base percentage of crude oil for $\mathrm{HG}$ must be more than $50 \%$. But gas percentage is $80 \%$, considering that Russia is the largest country of gas proven reserve and doesn't crucially in need of cooperation.

\subsubsection{Variable components}

The components show how much split HG can give to or take from IOC for its CAPEX and OPEX, which is regulated in every POD based on level of difficulty of each circumstance.

1) Supporting Infrastructure (SI) shows how far from the nearest island with port field is situated - Transport cost is essential in offshore production. People, basic needs, fabrication materials and equipment are multiply transported from/to the nearest well-developed city by helicopter, plane, ice breaker, tanker, etc.

2) Field location - Either located in offshore or onshore (remoted islands), due to extremely high cost and risk, only large fields are beneficial to exploit. Moving ice, extreme climate, high waves are the main threats. In offshore, applied technics and technologies depend on vertical sea depth.

3) Reservoir type - Russia has the largest hard-to-recover reserve in the world. It refers to heavy oil and bitumens, gas hydrates, shale oil, and light oil of dense rocks with lowpermeable reservoir. Based on the fact, it's necessary to provide $16 \%$ incentive to the IOC, that's ready to bear the risk and start producing the unconventional reservoir.

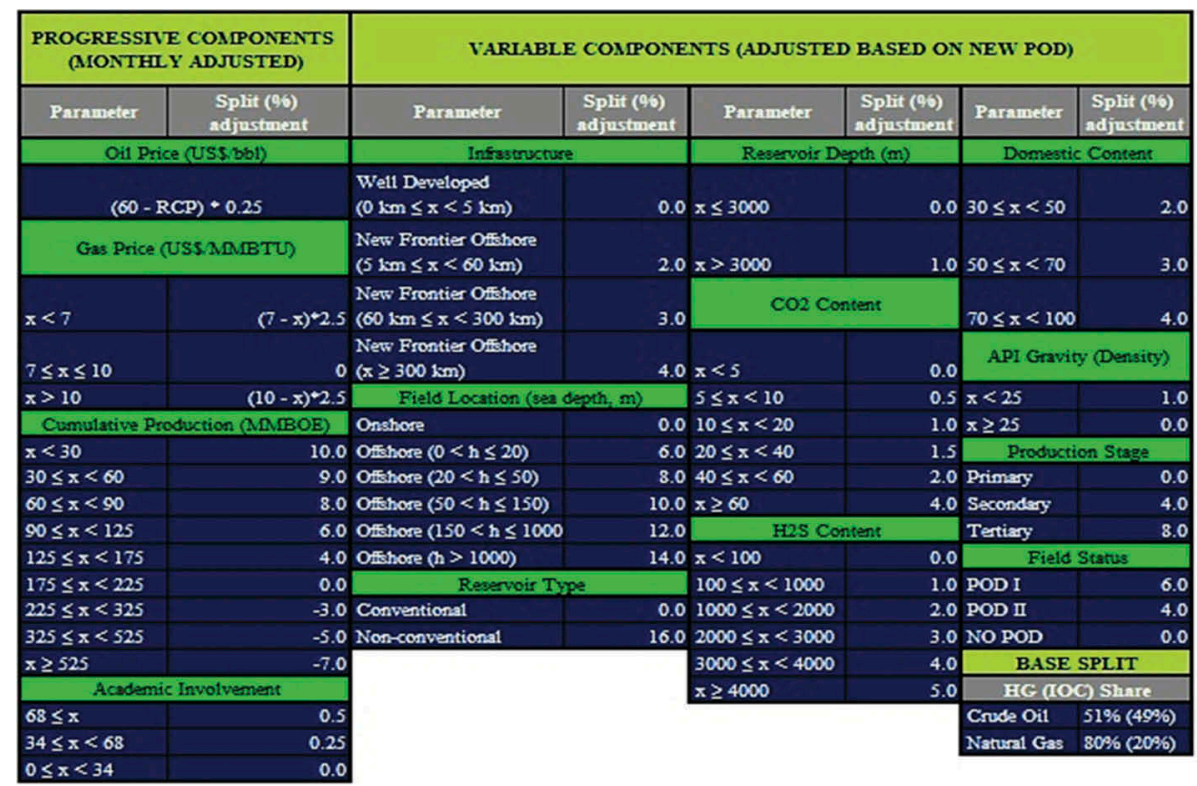

*Designed by authors

** Based on public accessible data

Figure 3. Base, progressive and variable components of Russian PSC GS. 
4) Reservoir depth shows depth of the strata from sea bottom- Low temperature gradient and preserved formation in Russia lead to high average depth of HC deposit. It's about $3 \mathrm{~km}$, although there are deposits at a depth of $7 \mathrm{~km}$ (Osadchi. A., "Oil and gas of Russian shelf: estimates and forecasts," Science and life №7, last modified August, 2006, https://www.nkj.ru/archive/articles/6334/). For depth more than average value, HG contributes $1 \%$ additional split. Because extraction process takes more time and cost.

5) $\mathrm{CO} 2$ content - Produced $\mathrm{CO} 2$ must be separated from oil/natural gas to be disposed, burned or injected into reservoir. This case decreases HC production percentage.

6) $\mathrm{H} 2 \mathrm{~S}$ content shows $\%$ of $\mathrm{H} 2 \mathrm{~S}$ in crude oil - Produced $\mathrm{H} 2 \mathrm{~S}$ must be separated from oil/ natural gas for disposal due to its toxic effect or for utilization to produce Sulphur.

7) Domestic content - it includes people (engineers, skilled/unskilled workers), material and equipment, technologies, daily goods and every available thing in Russia ("Comments towards Article 346.38 features of determining the tax base, the calculation and payment of corporate income tax in the implementation of agreements, "Tax Code, Chapter 26.4 (December 29, 2017), http://nkodeksrf.ru/ch-2/rzd-8-1/gl-26-4/st-346-38-nk-rf). Domestic content must be fulfilled with the $30 \%$ minimum rate. Job provision and demand on national commodities will cause a significant domino effect to Russian economy. As the parameter is critical, HG should provide great incentive.

8) Oil density - quality of oil is measured based on API gravity. The higher API gravity, the lighter the oil, the higher percentage of gasoline and diesel fuel it produces, and accordingly the higher price on market, and that happens otherwise. Heavy oil is hard to extract, threat and sell. Hence, HG should give $1 \%$ percent incentive for it.

9) Production stage - The more recovery stages are executed, the more complex technologies are implemented, the bigger financial burden, and the more production percentage of initial oil in places, respectively, primary $-10 \%$, secondary $-15 \%-40 \%$, tertiary $-50 \%-$ $75 \%$. In this case, HG should add significant incentive to motivate IOC to reach recovery percentage as much as possible.

10) Field status - First POD changes exploration to production process. IOC independently purchases equipment and builds facilities for petroleum operations. Next POD continues developing working area. IOC purchases an additional equipment and builds facilities, in case the new IOC operator, they need either to adapt with available applied technologies, or propose POD category I. For the continued production without POD mechanism, HG doesn't provide incentive. POD can be revised in case of force majeure conditions, e.g. accidents (disasters), which are not caused by IOC's faults.

\subsubsection{Progressive components}

The components show how much split HG can give to or take from IOC for its OPEX, which is monthly regulated based on level of fluctuation of each circumstance (Figure 4).

1) RCP (Russian Crude Price) \& gas price are set by Minister based on the law, regulation \& global market price tendency. In this case, Urals or new marker can serve as RCP.

2) Cumulative production calculation is started since first oil. For the prolonged contract, cumulative production is calculated by continuing previous cumulative production. While for the new POD, the calculation is started from 0 .

3) In terms of dealing with optimization issues, limited qualified human resources, increasingly complex technical challenges, and environmental problems, it's necessary to encourage IOC, HG and Universities to collaborate and coordinate with each other. Besides, this parameter also potentially facilitates transfer of knowledge and technology. Level of academic involvement (LAI) is based on the formula below:

$$
\operatorname{LAI}(\%)=\mathrm{II}^{*} \overleftarrow{\mathrm{x}}_{1}^{\leftarrow *} \mathrm{y}_{1}{ }^{*} \mathrm{z}_{1}+\mathrm{PI}^{*} \overleftarrow{\mathrm{x}}_{2}{ }^{*} \mathrm{y}_{2}{ }^{*} \overleftarrow{\mathrm{z}}_{2}+\mathrm{IPP}^{*} \overleftarrow{\mathrm{x}}_{3}{ }^{*} \mathrm{y}_{3}{ }^{*} \mathrm{z}_{3}
$$

where II - Introductory Internship; PI - Paid Internship; IPP - International Published Papers; $\mathrm{x}$ - IOC coefficient; $\mathrm{y}$ - HG coefficient; $\mathrm{z}$ - university coefficient; $\mathrm{x}_{1}=0.3, \mathrm{x}_{2}=0.5, \mathrm{x}_{3}=0.2$, $\mathrm{y}_{1}=0.3, \mathrm{y}_{2}=0.6, \mathrm{y}_{3}=0.1, \mathrm{z}_{1}=0.2, \mathrm{z}_{2}=0.2, \mathrm{z}_{3}=0.6$ (Authors' expert analysis). 

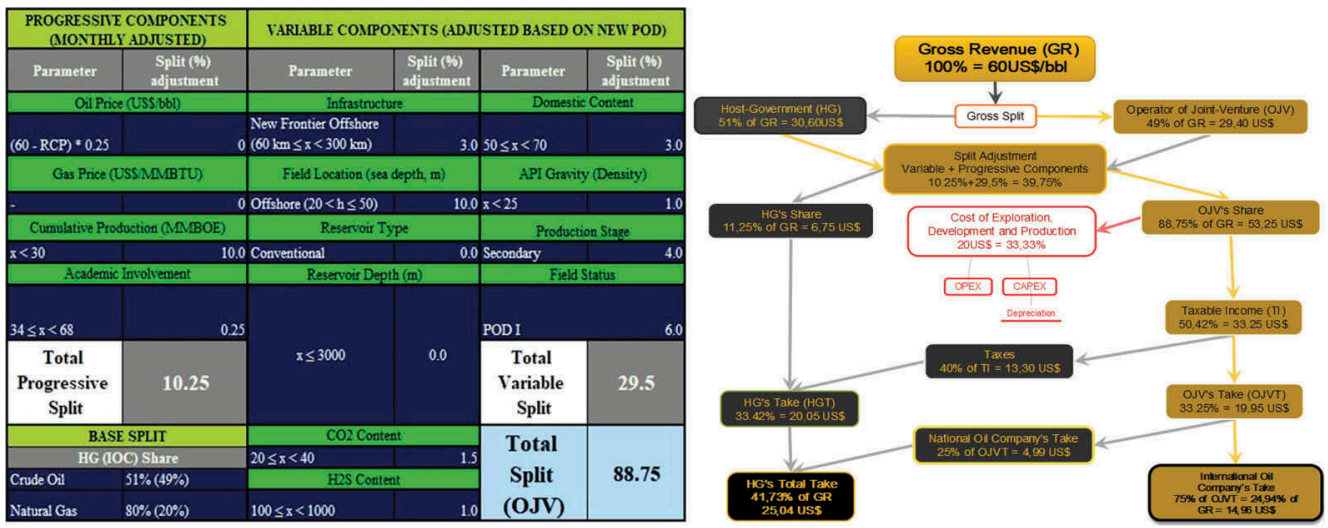

*Created by authors

Figure 4. Russian PSC GS illustration: a) calculation; and b) scheme.

\subsection{Comparisons}

Figure 5 shows a comparison of PSC GS and PSC CR in terms of the distribution of takes between IOC and $\mathrm{HG}$ at different reserves and fixed cost. The distribution of takes displayed in percentage and cumulative number of revenue (Figure 5a). And the distribution/variation of IOC's take in percentage at different oil prices and cost of production in PSC CR.

Based on the graph (a), IOC's, HG's take \& the cost at GS scheme are quietly balancing. This considers to be fair and attractive for investors. Decreasing trend of percentage indicates production limit set by sliding scale of GS progressive component. Nevertheless, the amount of IOC's take is increasing. While CR method shows us big gap between HG's and IOC's take. This rigid scheme doesn't fit with IOC's condition, where IOC bears full risk burden e.g. in crisis era, 2014-2016, increase in cost percentage results in uneconomic production. This situation pushes IOC to find ways to increase their revenue as in the graph (b). Even mark-up strategy is used to be the option. It means that IOC intentionally increases the cost, which is beneficial for them and decreases HG split. This is the source of long debate between IOC and HG. Therefore, GS came up with more transparent sliding scale mechanism to minimalize the dispute potential. Including it confirms weaknesses of PSC CR in comparison with PSC GS.

The graphs (Figure 6) show how IOC's and HG's take are changing related to 12-years production period and fluctuating market crude price. This oil price sensitivity graphic doesn't display change in annual cost. There are some fixed elements: annual production -15 MMBOE/year, cost - 20\$/bbl, STOIIP - 1000 MMBOE (large oil field), first oil - 4th year, $2^{\text {nd }}-$-recovery $-7^{\text {th }}$ year, depletion-at-peak $-3,75 \%$, declining rate $-7,7 \%$ and recovery rate $40 \%$. Oil price sensitivity assumptions: 1 ) Max percentages in the $15^{\text {th }}$ year at oil price $60 \mathrm{USD} /$

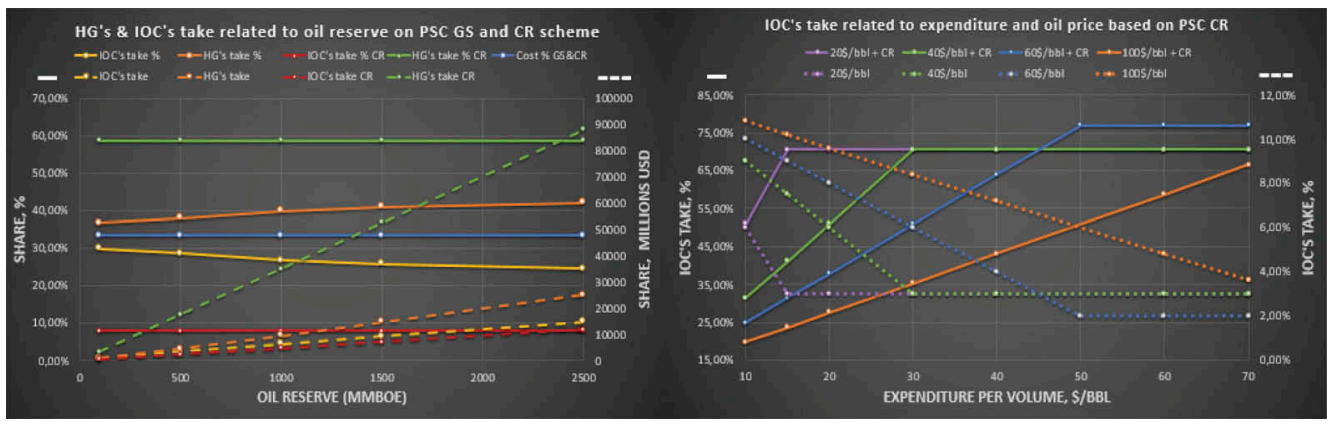

*Created by authors

Figure 5. a) Oil reserves sensitivity graph; b) Oil cost sensitivity PSC CR. 


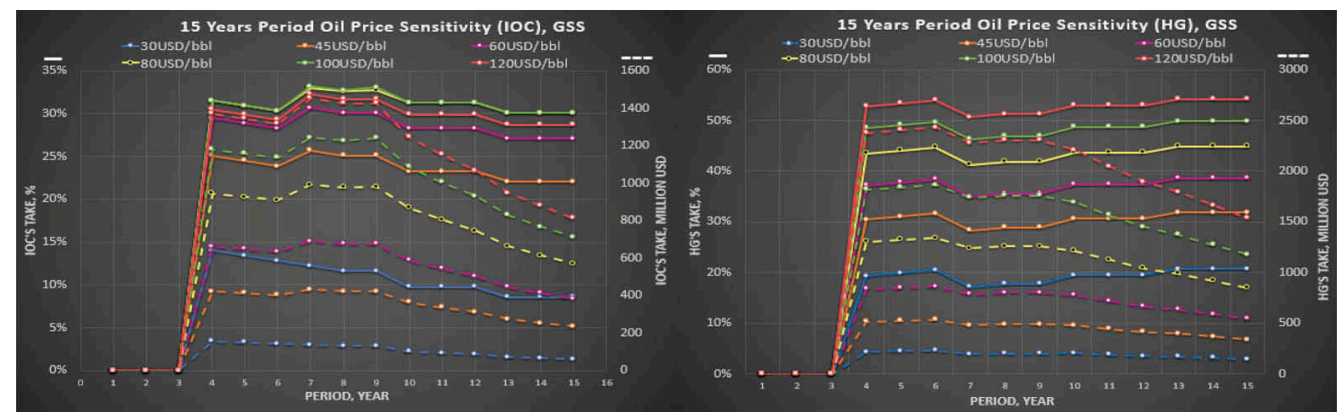

*Created by authors

Figure 6. Oil price sensitivity graph.

bbl are respectively $24,1 \%$ for IOC and $42,6 \%$ for HG. The cost is accordingly $16 \%$. In principle, the more efficient IOC, the more revenue it can earn; 2) IOC share percentage of 100 $\mathrm{USD} / \mathrm{bbl}$ oil price equals to $80 \mathrm{USD} / \mathrm{bbl}$ and is higher than 120USD/bbl. But it doesn't mean that the amount of revenue follows the same trend; 3) The trend of IOC's take is decreasing, that indicates that production is controlled by HG through PSC GS; 4) The minimum IOC's take occurs when oil price is $30 \mathrm{USD} / \mathrm{bbl}$. Sometimes it doesn't fairly benefit IOC considering high risk burden IOC bears. In case, the oil price keeps low for a month that impacts on uneconomic IOC take, HG through Minister of Natural Resources will provide bonus up to $5 \%$ split; 5) Secondary recovery starts in $7^{\text {th }}$ years, since when HG will add $4 \%$ split to IOC. In the low oil price, that all $4 \%$ take will be spent as technological cost. But when the price raises, remaining percentage belongs to IOC.

\section{DISCUSSIONS}

\subsection{Problems}

Besides, investment, sci-tech transfer, collaboration, maximal oil and gas production are important indicators for all HG in boosting their national economy. Based on the 2019 BP statistical review, Russian is the world largest country of potential recoverable oil and gas resource, $6^{\text {th }}$ and $1^{\text {st }}$ largest of proven oil and gas reserve. To maximally explore and extract that resource and reserve, huge financial indicator is needed. And it depends on HG's fiscal attractiveness, level of which is still slowly increasing in Russia, based on "Wood Mackenzie" ("Russian Federation upstream: 5 things to look for in 2019," Wood Mackenzie, last modified 19 December, 2018, https://www.woodmac.com/news/editorial/russia-federation-upstream5-things-to-look-for-in-2019/). Secondly, why it's necessary to maximize the production. Based on BP statistical review, in 2050 oil share in world energy demand will significantly decrease. This phenomenon will lower the crude price and threat countries, whose economy is built on oil sector. Thirdly, collaboration and sci-tech transfer between Gov., IOC and universities can potentially contribute idea to help IOC in dealing with tech problems effectively, prepare high-qualified engineers, provide national job fields and build high IOC image.

For IOC, the basic needs to invest is a certain, simple and efficient fiscal system. Based on the dispute records and dynamic change in tax system, political risk is considered a big attention in Russia. Some "specialists" insistently continue to argue that attracting IOCs and retaining national capital are possible only by providing a special exemption regime. But in the current situation in Russia, the interests of IOCs are precisely not to have exemption regime compared with Russian companies. Because history shows that exemptions are easy to give and take away. While for the investor, the main thing is stability (Subbotin M.A., 1995). Moreover, bureaucratic process in Russia is complex and layered (Konoplyanik A.A., 1998). This takes much time and money, that might productively be used in upstream process. Lastly, as long as capital, technology and E\&P risks are burdened to IOC, its take of JV in royalty/tax or PSC should be 
added and system chain should be leaner. Unless HG is willing to share risks with IOC, which is hard to apply in many contracts due to HG's financial and technical limits. However, the Russian PSC JV points to HG's share as just another layer of taxation, and a large one at that.

\subsection{Opportunities}

The presence of Gross split impulses the compromise to cover both sides' interests, considering its adjustment machine, namely variable $\&$ progressive components. What makes this $7^{\text {th }}$ evolution of Indonesian PSC different from the previous or general schemes is that: 1) It excludes HG cost recovery burden, Investment credits and Royalty. The split directly starts from gross revenue and the cost is recovered by IOC share. As a result, IOC tends to make efficiency. Notwithstanding, balanced base split, permanent variable components (based on POD), and monthly changed progressive component are the tools to create an efficient fiscal system. They guarantee certainty, transparency, high commitment and flexibility towards oil price fluctuation. Regarding that, GS will absolutely pumps up fiscal attractiveness of Russia; 2) In order to avoid wasting-time debate in bureaucratic systems, especially in procurement approval process, HG allows IOC to independently determine their budgeting and only asks annual report for monitoring. The implication is earlier project on stream, approximately less 2-3 years; 3) Russian version GS contains academic involvement as a spark to boost research, technology and HR development. This component is intended to prepare young generation to their more challengeable future. Another effect of universities involvement is that it might help IOC to provide alternative solution on technical problems as well as support technology transfer among all parties.

For IOC, 1) PSC GS and its taxation mechanism must have its own permanent law and regulation, appearance and change of which don't affect previous signed contracts. Regulation making process should account the aspiration not only from HG bodies, but also IOCs through survey or discussion. It's also necessary that adoption of PSC GS would not only give HG a reliable tool for the effective management of its ownership, but also create a clear, stable and transparent budgetary fundraising regime for the investor (Subbotin M.A., 1995). With this effort, it's believed that political (legal) risks will decrease; 2) To simplify interaction in a layered and complex bureaucratic process, PSC GS provides special department, e.g., federal agency for upstream oil and gas business (Federal Agency for Exploration and Production of Oil and Gas) (FAEPOG). FAEPOG is under the direction of the Ministry of Natural Resources. The department performs the functions of collecting information on the management of the GS contract, and also transmits information to such bodies as: Ministry of Finance of the Russian Federation, Federal Tax Service, VneshEconomBank, NPO Agency for Strategic Initiatives, Accounts Chamber of the Russian Federation; supervises compliance and its verification with real data. FAEPOG is a link between IOC and HG bodies; 3) As it's mentioned earlier that if the production is still uneconomic, Minister could give 5\% from his/ her privilege bonus. This is called another mechanism of risk sharing.

\subsection{Challenges}

However, Gross Split is a new scheme of petroleum business contract. Although investment in Indonesia sharply arises due to its attractiveness, the sustainability of corporation doesn't give yet any result. Then again, it's not the same scheme to offer to implement in different countries, but the analogy of it by maintaining the basic ideas. For that reason, every stage of PSC GS penetration, from introduction, legal process, marketing and implementation, has its challenges.

1) Comprehensive, quick and deep research - before introducing this fiscal system, Universities or Government should create focus group discussion to do research about to what extent this scheme can meet national interests by not harming investment level;

2) Massive socialization - published papers, newspaper, conferences or other academic activities can be best media to introduce the research and build animo in academic society. Next, best strategy's needed to assure and make executive (related ministries) and legislative to know detail about how it works. This is not only because of traumatic experiences 
of previous PSC, but also tax culture that has been set in all Russian model oil and gas business;

3) Legal process - as what happened in Indonesia, the law and regulation were reviewed 2 times before, even the fields with this scheme has been offered and introduced to the market. This is necessary to make sure that the scheme is optimal for HG and IOC conditions generally;

4) FAEPOG establishment - this department requires high credible and professional members. Besides, HG's to make sure that the terms \& conditions are not overlapped with other its related bodies and make sure the bodies understand detail functions of this department;

5) National application - before offering this scheme to world market, it's somehow necessary to implement this contract with state-owned and national companies.

\section{CONCLUSION}

This new adaptive model can be used to extend existing and sign new contracts between HG and IOCs on offshore. Fair percentage distribution of revenue and risks allows to increase Russian fiscal attractiveness which further creates efficient, certain and transparent cooperation between HG and IOC. Addition of "level of academic involvement" as new variable component stimulates appearance of new technologies, talented specialists (engineers), new job fields, and mutually beneficial relation with universities. Next, establishment of FAEPOG helps bridge IOC and HG's related bodies in terms of collecting and transmitting information on the management of the GS contract, and supervising compliance and its verification with real data.

To sum up, considering huge potentials, PSC GS can be alternative solution for developing a healthy international oil and gas business in Russian Federation. For GS case, benefits will be optimal for all parties if all legal requirements and business interests are met. This model should be taken as an excellent consideration to be studied further and implemented as soon as possible.

\section{REFERENCES}

Behavior." Natural Resources Research, (2009): 13-14.

Harimurti, D. "Indonesian Milestone in Production-Sharing Contract in Perspective of Government Take, Contractor Take, Cost Recovery and Production Target." Society of Petroleum Engineers, (2017): 6-16.

Höök, M., Söderbergh, B., Jakobsson, K., Aleklett, K. "The evolution of giant oil field production.

Johnston, D. International petroleum fiscal systems and production sharing contracts, 25-93. Tulsa, Oklahoma: PennWell, 1994.

Klubnichkin, M. "Concession agreement or production sharing agreement." Mineral resources of Russia, (1994): № 6. 22-24

Konoplyanik. A.A. "The main types and conditions of agreements in force in the oil industry of the capitalist states between IOCs and host governments." Bulletin of Foreign Commercial Information, 1989, Appendix 10. 3-23

Konoplyanik A.A. "Russian law about PSC." In Overview of the economic situation of Europe, 156-161. New York and Geneva: United Nation, 1998.

Ministry of Energy and Mineral Resources of Indonesia. Amendment of Regulation no 8/2017 on Gross Split Production Sharing Contract. 2017, Regulation no 52, Jakarta: Government Printing Office.

Republic of Indonesia. Taxation Treatment on Upstream Oil and Gas Activities with Product Sharing Contract Gross Split. 2017, Government Regulation no 53, Jakarta: Government Printing Office.

Roach B., Dunstan A. "The Indonesian PSC: the end of an era." Journal of World Energy Law and Business, (2018): 116-135.

Subbotin M.A. "Supporters and opponents of production sharing fight for benefits for foreigners." Sevodnya. July 18, 1995, 172.

The State Duma of Russian Federation. Taxation system in the implementation of production sharing agreements. 2019, Tax Code of the Russian Federation Chapter 26.4., Moscow: Gov. Printing Office. 


\title{
Risk management: Systematization in the context of oil and gas projects
}

\author{
D.C Trinh
}

Postgraduate student, St. Petersburg Mining University, Saint Petersburg, Russia

A.E Cherepovitsyn

Doctor of Economic Sciences, Professor, St. Petersburg Mining University, Saint Petersburg, Russia

\author{
A.A Ilinova \\ Ph.D. of Economic Sciences, Associate professor, St. Petersburg Mining University, Saint Petersburg, \\ Russia
}

\begin{abstract}
A number of risks are known to exist in various stages of the projects i.e. from the initial stage through the planning and finally at the implementation stage. This may be related to either subjective or objective reasons. Risk management and systematization plays an integral role in the assessment of the feasibility of the projects and further to make decisive investments. Identification and systematization of risks require regular updates for operational management throughout the project life-cycle. This paper introduces the importance of systematizing the risks in projects for optimal project outcomes, during the search, exploration and development in oil and gas projects. The essence of the design, national and international spheres of oil and gas projects, as well as the relationship between them is presented. We further systematized the risks on the basis of the decomposition of risk factors by the sphere of their occurrence. The occurrence of most of the risks were found to be mostly associated with geology, oil and gas reserves, production factors, trades, markets, the economy, finances, investment environment, and political mechanism. It was deduced that the systematization of risks is one of the effective management-components and an optimum solution to achieving the desired outcomes with less to zero risks in oil and gas and oil projects.
\end{abstract}

Keywords: risk, systematization of risks, oil and gas projects, risk management

\section{INTRODUCTION}

The exploration and development stage in oil and gas projects is normally associated with a number of risks due to a number of factors. Firstly, this may be due to the complex nature of such projects at the stages of search, exploration, evaluation, development and operation, high capital intensity and long-pay back periods. A successful implementation of oil and gas projects requires complex technical, technological, organizational, economic and political decisions (ISO 31000:2009). In particular, such projects are characterized by uncertainties regarding the potential of reserves, production, components and the quality of oil and gas. In addition, the external factors of the business environment may also affect the projects such as: the national environment (the situation of macroeconomics, politics, law, culture, society); international environment (geopolitics, technological progress, development of renewable energy markets, the oil market and the price of oil) (IHRDC, 2017). These factors are closely related, therefore, the risks of oil and gas projects are intertwined, and when spread may 
affect the entire project or its part depending on the risk event, as well as on the ability to manage these risks.

Risk management plays a critical role in making investment decisions and effectively managing oil and gas projects. In particular, the systematization of risks is very important in ensuring a correct, complete and unified understanding of project risks and their subsequent management in the project. In this regard, it is necessary to compile a profile and a list of project risks, to assess the level of their impact; identify critical risks, find appropriate controls and solutions to minimize losses or increase benefits; develop risk management action plans (programs) for successful project implementation. The purpose of this study is to systematize the risks of oil and gas projects by their sphere of origin and to analyze key risk groups at such stages as establishing the context, identifying the risk and analyzing the risk from the point of view of its impact on the project goal.

\section{LITERATURE REVIEW}

In the scientific literature, the topic of systematization, analysis, assessment and management of project risks as a whole is well developed. Problems of identification and classification of risks in the process of project management were considered in various studies carried out by G.D. Antonov, O. Yu. Klein, A. Yu. Tsvetkova, E.M. Rogova, M.V. Tikhonov, Frederick Funston, Cooper D.F., Paul Hopkin, Robert Mark, Thomas S. Coleman, John Hollmann, etc.

Risk management (including systematization of risks) is one of the fundamental problems of business, especially in the context of integration into the global economy. In the oil and gas industry, risk management is becoming increasingly relevant, especially when taking into account risks such as politics, environmental safety, price fluctuations, society and technology. Ignoring risks can lead to closure of projects and bankruptcy of the company.

Business actions contain many risks, but also many opportunities to be firm and develop for those who understand them (Stephen Wagner, 2016). In other words, risk is an inevitable byproduct of all activities. Organizations and project teams cannot completely eliminate risks. The risk of an enterprise (project) is as a result of damages which arise from factors which are difficult to control. They affect the achievement of its goals (profit, market share, brand, corporate culture, social security, etc.). Risk management is a general decision that a corporate governance system must take to identify, prevent, or reduce losses when risks arise (Michel Crouhy \& Thomas S., 2017). And this becomes particularly relevant in project management, since the activities within the project are unique (not repetitive) (Polkovnikov, 2015).

Risks are associated with benefits. In business, high risk often brings great benefits (risk-return ratio). However, in some cases, high risk may lead not to benefits, but to losses, closure of the project, bankruptcy of the enterprise (Norman Marks \& David Vose, 2018). Systematization of risks in the process of project management not only protects assets, but also increases value and provides opportunities for business growth (John Hollmann, 2018).

Systematization of risks, accurate and comprehensive measurement and quantification of each risk based on continuous adjustment and reflection of these changes in management decisions are the most important tasks at all levels of management (Douglas et al. 2019).

This paper is therefore aimed at reviewing and analyzing both the international and Russian literature on the research topic and attempts to systematize the risks in oil and gas projects according to the scope of their occurrence. The basic methods used in the process of systematizing risks are considered, the basic principles of systematizing risks are identified. The decomposition of possible risks of oil and gas projects is presented; such more common risks as geological and operational are considered in more detail and their impact on the ultimate goal of the project is determined. 


\section{RESEARCH METHODS AND MATERIALS}

The study relied on the previous literature in the field of risk and project management to construct a theoretical basis. The main research method was desktop research, as well as general methods of scientific analysis (abstract-logical and comparative), methods of system analysis.

The decomposition method such as the risk management technique in the form of a process of establishing a context in: risk identification, risk analysis were also used directly to systematize and analyze risks. Information on practical activities in the field of risk management of Russian and foreign oil and gas companies was used as materials for the study. Much attention was paid to the analysis of the activities of the Vietnam Oil and Gas Group (PetroVietnam) in the field of risk management.

\section{RESULTS AND DISCUSSION}

As noted above, oil and gas projects are influenced by a number of factors that relates to the project (internal) environment itself, as well as to the external environment on a national and international scale. Figure 1 shows the role of the project management and systematization in national and international environments of the oil and gas projects, as well as the relationship between them.

Risk systematization is the process of identifying risk events from the internal and external operating environment that can affect the goals (tasks) of a project (Heriot Watt, 2017). Systematization of risks requires understanding and correctly identifying factors that can lead to risk events; that is, to determine the context, origin (source), causes (primary and secondary), as well as possible consequences. In the process of systematizing risks, the following questions arises (John Shortreed, 2016):

1. Which risks may appear in project management? To answer this question, it is necessary to systematically analyze the process or activity in order to identify possible risks at each stage.

2. Which forms and causes of risks could be? To answer this question, it is necessary to indicate the potential cause and situations or a description of the risks, incidents or accidents.

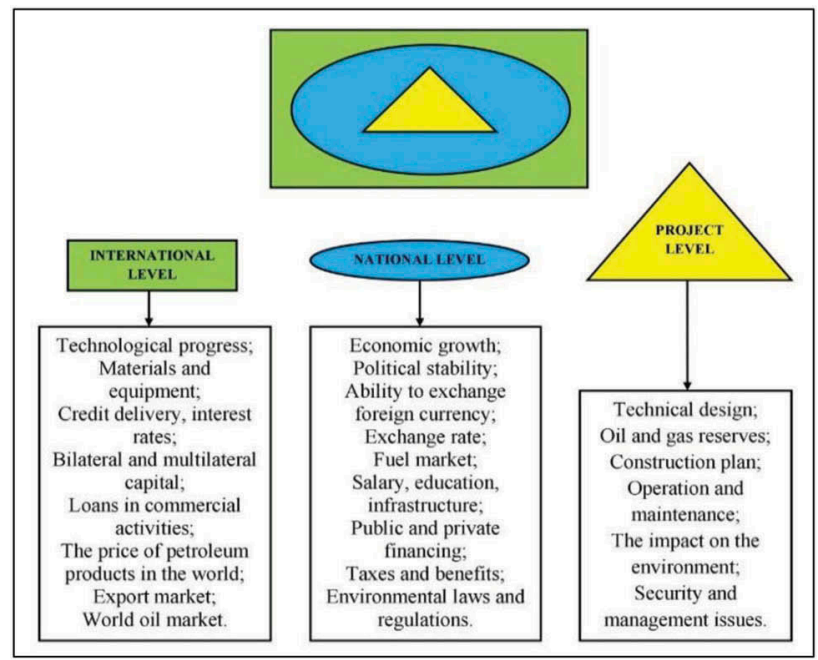

Figure 1. Levels of interconnection between operating environments of the oil and gas projects (Stephen Wagner et al. 2018). 
The risk systematization process will help to collect sufficient information and make a list of existing project risks. Various methods may be used in this process. The choice of specific methods depends on the complexity of the problem in consideration, the level of availability of information and resources. Some methods of risk management are presented in Table 1.

Effective methods of risk management are discussions, group work without limiting the participants, including the project team, business department, technical department, contractors, etc. (John Berhaz, 2015).

Oil and gas projects include a number of complex technical measures that are influenced by many factors from the project and business environment, therefore, the systematization of risks is not simple. Risk systematization should be carried out at the projects initiatial stage. Even if the project at the search and exploration stage has uncertainties, risks should be taken into account in the process of making investment decisions (Deloitte Vietnam Co., Ltd. 2018). This also form the basis for choosing risk response solutions during the project implementation. Systematization of risks should take into account the following factors to ensure the success of the process:

1. The need to establish goals (objectives) of the project. Risk is associated with the purpose of the project and affects its success. The interaction of risks and project objectives in project management are close (Vietnam Petroleum Institute (VPI), 2018).

2. The specificity of the risks in each project. There are differences at the project stage: search, exploration, evaluation, development and operation. Risks are temporary, and current risks may not be risks in the future (Nguyen Duc Huynh \& Le Thi Phuong, 2017).

3. The complexity and instability of risks in the systematization process. Not all risks are identified at the beginning; there are unknown risks that will appear in the future. Thus, risk systematization is a regularly updated process in the project life cycle (FMIT, 2018).

4. Risk systematization should be carried out by stakeholders and agreed in order to have a comprehensive view of risks (Klein, 2017).

5. In describing the risks need to be considered causal relationship. In order to correctly describe the risks, it is necessary to understand their relationship (Figure 2).

Table 1. Methods used in the risk systematization process (PVN-VPI, 2018).

\begin{tabular}{|c|c|c|c|}
\hline № & Methods & The purpose of the method & Description of the method \\
\hline 1 & $\begin{array}{l}\text { Questionnaire } \\
\text { (or interview) }\end{array}$ & $\begin{array}{l}\text { Identification of possible types of } \\
\text { risks. }\end{array}$ & $\begin{array}{l}\text { Preparation of a questionnaire on the types } \\
\text { of risks, the level of losses, the number of } \\
\text { cases of risk occurrence in a given period of } \\
\text { time. }\end{array}$ \\
\hline 2 & $\begin{array}{l}\text { Risk profile } \\
\text { check }\end{array}$ & $\begin{array}{l}\text { Identification of possible types of } \\
\text { risks. }\end{array}$ & $\begin{array}{l}\text { Consideration of the risk profile, which was } \\
\text { developed earlier. }\end{array}$ \\
\hline 3 & $\begin{array}{l}\text { Initiative } \\
\text { (brainstorming). }\end{array}$ & $\begin{array}{l}\text { Gather feedback (ideas) about the } \\
\text { risks. }\end{array}$ & $\begin{array}{l}\text { Instructions on how to share and discuss } \\
\text { ideas for summarizing a risk portfolio. }\end{array}$ \\
\hline 4 & Delphi Method & $\begin{array}{l}\text { Formation of expert consensus on } \\
\text { identified risks. }\end{array}$ & $\begin{array}{l}\text { Using the questionnaire to obtain opinions } \\
\text { and information from scientists and experts; } \\
\text { - Summary of results and transfer to other } \\
\text { experts for consensus. }\end{array}$ \\
\hline 5 & $\begin{array}{l}\text { Value chain } \\
\text { analysis }\end{array}$ & $\begin{array}{l}\text { Understanding the flow of events, } \\
\text { identifying significant risks at each } \\
\text { stage of the project. }\end{array}$ & $\begin{array}{l}\text { Development of a diagram, description of } \\
\text { work over time to determine the scope, } \\
\text { properties and operational characteristics of } \\
\text { the project. }\end{array}$ \\
\hline 6 & Change analysis & $\begin{array}{l}\text { The study about danger warnings, } \\
\text { the planned and inadvertent changes. }\end{array}$ & $\begin{array}{l}\text { Comparison of the current and previous } \\
\text { situation. }\end{array}$ \\
\hline 7 & $\begin{array}{l}\text { Research about } \\
\text { operability and } \\
\text { hazard }\end{array}$ & Identification of potential hazards. & $\begin{array}{l}\text { Separation of operational components; } \\
\text { study of the interaction between compo- } \\
\text { nents; systematic analysis of the relation- } \\
\text { ship between components; identification of } \\
\text { input data, properties, potential deviations; } \\
\text { record of the reason for deviations. }\end{array}$ \\
\hline
\end{tabular}




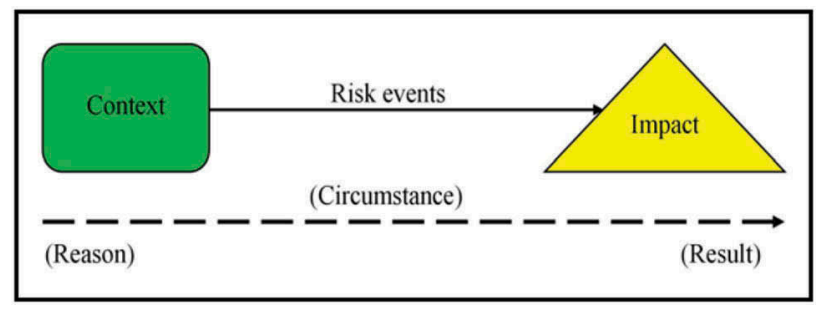

Figure 2. Description of risk (John Shortreed, 2016).

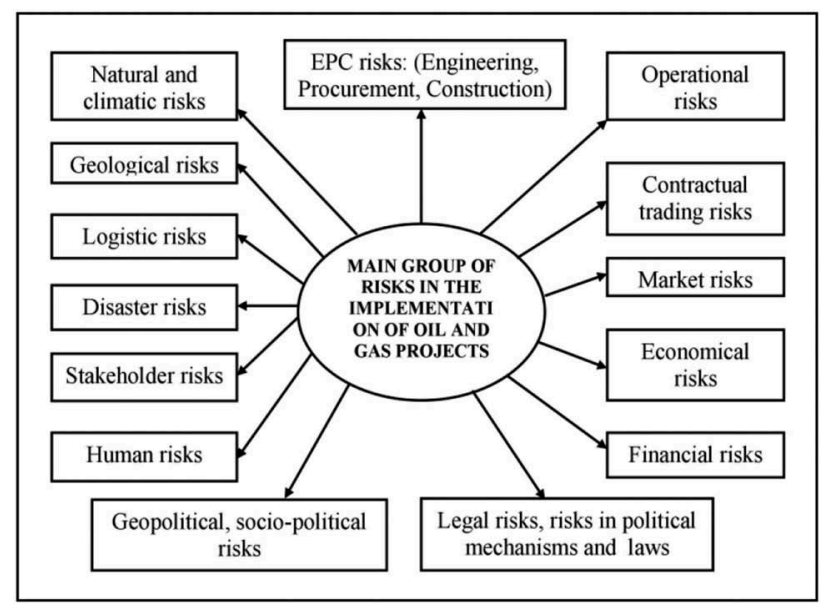

Figure 3. Decomposition of possible risks of oil and gas projects (Heriot Watt, 2017; ISO 31000:2009).

In the process of project implementation, various types of risks are manifested. The decomposition of possible risks of oil and gas projects is presented in Figure 3.

For risk analysis, it is necessary to understand the external and internal factors that can influence the success in achieving the objectives of the project (setting the context). Table 2 clearly shows the context for such risk groups as geological and operational, as well as the impact of these factors on the project goals.

\section{CONCLUSIONS}

Thus, based on our study, it can be concluded that oil and gas projects are subject to the influence of a whole range of risks, which were systematized according to such a sign as the scope of their occurrence.

Among the considered types of risks, geological risks are considered as typical, and are a determining factor for investments in exploration and production of oil and gas. Modern equipment and technologies, favorable financial conditions are really interesting only when the area in which it is planned to invest has oil potential. In general, depending on each phase of the project, type of project, the presented risk groups may appear in aggregate or separately, the level of their influence on the project also varies (Tsvetkova, 2016). For example, the risks of reserves and production volume decrease over the duration of the project. Consequently, for each project risks are dynamic, constantly changing, and their roster needs regular updating. 
Table 2. Analysis of geological and operational risks of the oil and gas projects (Phan Ngoc Trung \& Nguyen Thi Thanh Le, 2019).

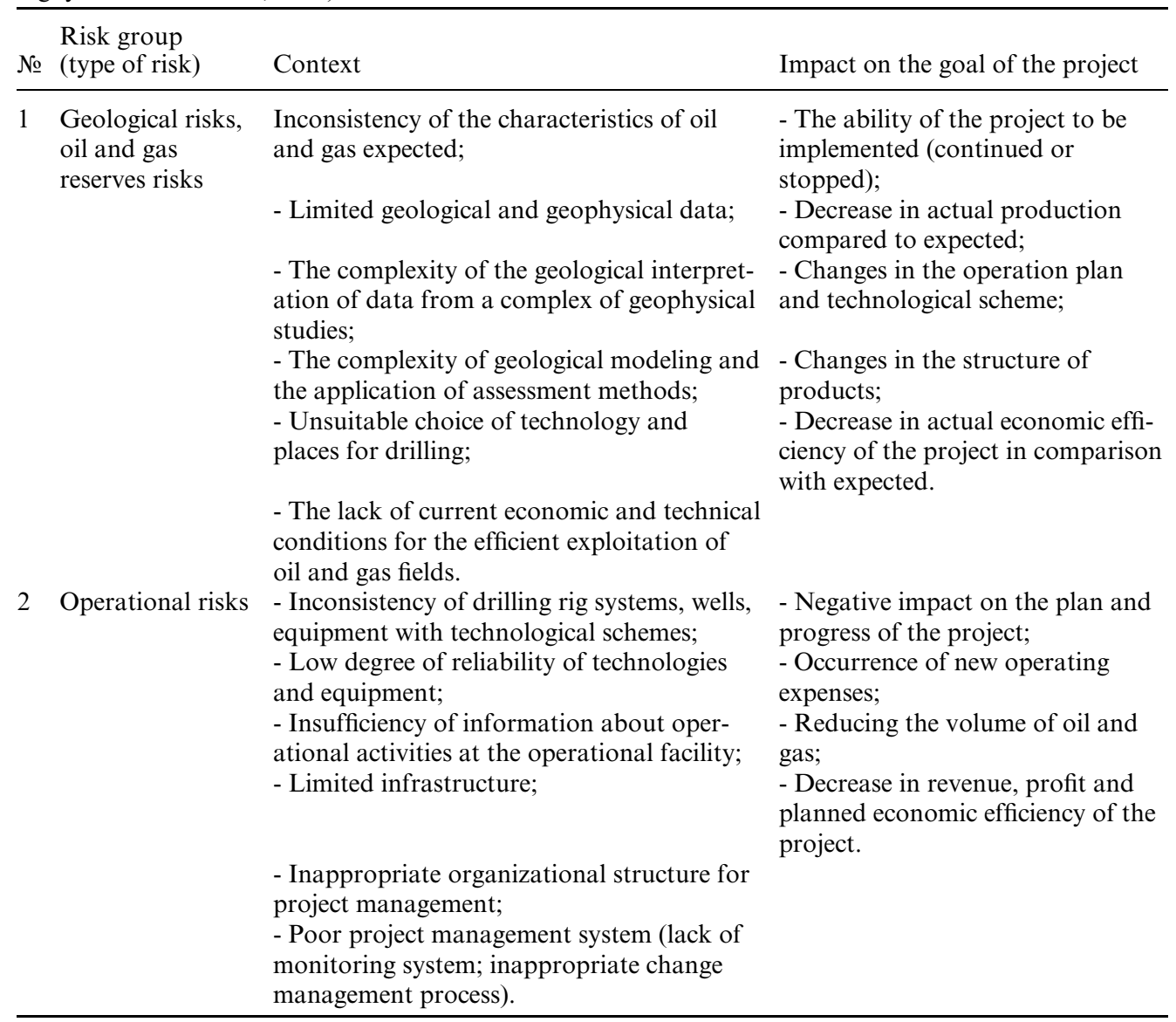

Oil and gas projects are subject to a sufficiently large number of risks in terms of geology, reserves, production, trade, markets, economics, finance, investment environment, politics, natural disasters, etc. Thus, the systematization of risks plays the role of a source of information to determine the characteristics of the project, development trends in the project management process and the selection of optimal solutions to achieve the project goals.

\section{ACKNOWLEDGEMENT}

The research was carried out with the financial support of the grant by the President of the Russian Federation for the state support of leading scientific schools of the Russian Federation, the number of the project NSh-2692.2020.5 "Modelling of ecological-balanced and economically sustainable development of hydrocarbon resources of the Arctic".

\section{REFERENCES}

Annual Report of Exxon Mobil, Total, BP, Repsol, 2018.

Antonov, G.D. 2019. Organization risk management: Textbook. Antonov, G.D. et al. - M .: Infra-M, - 464 p.

Balashov, A.I. 2016. Project Management: Textbook and workshop for academic undergraduate. Balashov, A.I. et al. - Lyubertsy: Yurayt, - 383p. 
Cooper, D.F. 2017. Project Risk Management Guidelines: Managing Risk in Large Projects and Complex Procuremen. Cooper, D.F. et al. John Wiley \& Sons, Ltd., England, 384 p.

Corporate Regulations on Enterprise Risk Management, 2019.

David Vose, 2018. Risk Analysis: A Quantitative Guide. John Wiley \& Sons, 3rd edition - 752

Deloitte Vietnam Co., Ltd. 2018. Survey report on enterprise risk management model for Vietnam Oil and Gas Group.

Douglas, W. Hubbard, 2019. Failure of Risk Management: Why It's Broken and How to Fix It. Wiley, 1 edition - 304 pages.

FMIT. 2018. Risk management and Internal control according to COSO standards.

Heriot Watt, 2017. Institute of Petroleum Engineering. Petroleum economics.

IHRDC, 2017. Petroleum project economics and risk analysis.

International Organization for Standardization. Risk management - Principles and guidelines. ISO 31000:2009.

John Berhaz, 2015. Business environment analysis and risk management in oil and gas industry. Probabilistic Publishing - $256 \mathrm{p}$.

John C. Hull, 2018. Risk Management and Financial Institutions. Wiley, 4th edition - 740 p.

John Hollmann, 2018. Project Risk Quantification. Probabilistic Publishing - 416 p.

John Shortreed, 2016. Basic frameworks for risk management. Network for Environmental Risk Assessment and Management. John Shortreed et al. John Wiley \& Sons - $180 \mathrm{p}$.

Klein O. Yu. 2017. Project risk insurance in the development of oil and gas fields. Notes of the Mining Institute, (S.1.), v. 155, n. 2, p. 201.

Michel Crouhy, 2019. The Essentials of Risk Management. Michel Crouhy et al. McGraw-Hill Education, 2 edition -672 p.

National Assembly of the Socialist Republic of Vietnam (Session XIII), 2014. Enterprise Law. No. 68/ $2014 / Q H 13$.

Nguyen Duc Huynh \& Le Thi Phuong, 2017. Identify risks of climate change affecting the activities of the oil and gas industry. McGraw-Hill Education. - Oil and gas magazine, № 8, p. 53-60.

Norman Marks, 2015. World-Class Risk Management. CreateSpace Independent Publishing Platform $234 \mathrm{p}$.

Paul Hopkin, 2018. Fundamentals of Risk Management: Understanding, evaluating and implementing effective risk. John Wiley \& Sons, Ltd., England. 480 Pages.

Phan Ngoc Trung \& Nguyen Thi Thanh Le, 2019. Overview of upstream oil and gas operations from the value chain approach. Oil and gas magazine, № 3, p. 63-69.

Polkovnikov, A.V. 2015. Project management. Full MBA course. Polkovnikov, A.V. et al. - M .: CJSC "Olympus Business" - 552 p.

Price water house Coopers (Vietnam) Co., Ltd. (PwC). Risk management training materials. 2018.

PVN-VPI. Building a risk assessment process for PVN's exploration and exploitation project. 2018.

Stephen Wagner, 2016. Surviving and thriving in uncertainty: creating the risk intelligent enterprise. Stephen Wagner et al. John Wiley \& Sons - 230 p.

Supervising State investment in enterprises; financial monitoring, performance evaluation and disclosure of financial information of state-owned enterprises and state-owned enterprises. Decree No. 87-2015ND-CP. 2015.

The Committee of Sponsoring Organizations of the Treadway Commission (COSO), 2017. Enterprise risk management framework.

The Institute of Internal Auditors, 2015. The three lines of defense in effective risk management and control.

Thomas S. 2017. Practical Guide to Risk Management. Thomas S. et al. Research Foundation of CFA Institute $-228 \mathrm{p}$.

Tsvetkova, A. Yu. 2016. Overview of the main risks of the enterprises of mining and metallurgical branches in modern conditions. Notes of the Mining Institute, (S.1.), v. 194, p. 339.

Vietnam Petroleum Institute (VPI), 2018. Study and propose a model of risk management organization for Vietnam Oil and Gas Group. 


\title{
Role of renewables in strategies of oil companies from Central and Eastern Europe
}

\author{
A. Ilic \\ Postgraduate student, Saint Petersburg Mining University, St. Petersburg, Russia \\ T.V. Ponomarenko \\ Doctor of economics, Professor, Saint Petersburg Mining University, St. Petersburg, Russia
}

\begin{abstract}
This paper deals with the role of renewables in strategies of oil companies from Central and Eastern Europe (CEE) in the process of energy transition. In particular, we analyze whether and to which extent CEE oil companies focus on renewables; if focus, what are the main area of renewable investments; and if focus, is there linkage between their position in oil upstream and investments in renewables. Our research showed that so far activities of CEE oil companies in renewables have been relatively weak, but, under the assumptions that announced projects will be realized, (1) level of investment in renewables of CEE companies in the future will be relatively significant, (2) there are strong differences among CEE oil companies in terms of the significance of renewable productions, (3) those oil companies with relatively weak upstream (crude oil reserves and production) are more interested in renewables and (4) production of electricity from wind and solar dominates the renewable activities of CEE oil companies.
\end{abstract}

Keywords: oil companies, strategy, CEE, renewables, wind farm, solar power plant, biofuels

\section{INTRODUCTION}

Energy transition, defined by the International Renewable Energy Agency (IRENA) as "a pathway toward transformation of the global energy sector from fossil-based to zero-carbon by the second part of this century", has strong implication on oil companies to the extent that the International Energy Agency (IEA) in their recent report (IEA, 2020) stress that no energy company will be unaffected by this transition. In the process of energy transition or so called "decarbonization" one of the key roles rests on production of renewables since renewable energy and energy efficiency measures can potentially achieve $90 \%$ of the required carbon change.

The process of energy transition is spurred by the regulatory changes such as the Paris Agreement (according to the agreement 170 countries agreed to work on bringing climate change under control by limiting the global temperature rise in this century well below 2 degrees Celsius which will demand new in-vestments in low-carbon energy sources) and different incentive schemes imposed by governments to increase production of renewables and reduction of technology costs of renewable energy production. For example, according to IRENA, 2019 the global weighted-average cost of onshore wind projects fell from \$85/MWh in 2010 to $\$ 56 / \mathrm{MWh}$ in 2018 , while the weighted-average cost of utility-scale solar has fallen from $\$ 371 / \mathrm{MWh}$ in 2010 to $\$ 85 / \mathrm{MWh}$ in 2018 and is expected to fall further.

As a result of this processes, global energy demand for renewables reached in 201778 quadrillion British thermal units (QBTU) increasing by $21 \%$ comparing to 2010 , while in the same period demand for oil, gas, and coal grew by 10\%, 12\%, and 5\%, respectively (ExxonMobil, 2019). Demand for renewables is likely to be the key driver of the growth of global energy 
demand in the future, estimated to reach 115 QBTU by 2040 with growth of $47 \%$ comparing to 2017 , while in the same period oil, gas and coal are likely to grow by $14 \%, 36 \%$, and $-9 \%$, respectively. In the group of renewable energy, solar, wind and biofuels are likely to grow the most.

Although the role of renewables is expected to be strong, oil is likely remain the most important global fuel with the share in global energy demand of 30\% (reduction from $32 \%$ in 2017), while the renewables will account to $17 \%$ (increase from $14 \%$ in 2017). Share of coal will be reduced from $26 \%$ to $20 \%$, while the share of gas is likely to increase from $23 \%$ to $20 \%$. This is in line with conclusion of (West \& Fattough, 2019) who argue that, based on their projections, demand for oil and gas will remain robust well after 2050, due to the fact that, even in the case of substantial increase of investments in solar and wind to USD 1trn per annum (from USD 300bn), it will take 55 years for solar and wind to ramp up to $50 \%$ of the world's energy mix.

In such an environment one of strategic dilemmas for an oil company is how to approach this issue, particularly whether to enter this business segment and, if yes, to which extent. In such circumstances some of the reasons why they would enter this business segment are pressure from local governments and shareholders, keeping up with technology - risk of being left behind new energy revolution, fighting with substitutes since electricity suppling electric vehicles pose a long term treat to the industry, finding the new areas for growth and other.

In this paper we deal with strategies of oil companies toward renewables. Since the literature on role of renewables in strategies of global oil companies is relatively reach, we will focus on the analysis of the importance of this business segment in strategies of oil companies from Central and Eastern Europe (Central and Eastern Europe usually includes countries of former the Eastern Bloc: Poland, Czech Repub-lic, Slovakia, Hungary, Romania, Bulgaria, Serbia, Slovenia, Croatia, Bosnia and Herzegovina, Monte-negro, North Macedonia, Albania, Estonia, Latvia and Lithuania. Due to the close proximity and strong focus of business activities on CEE, we include in analysis two more countries - Austria and Greece and its largest oil companies OMV and Hellenic Petroleum). In the part two we provide the analysis of the recent research in this area with special focus on the importance of renewables in strategies of major oil companies. In the part three we introduce the methodology of the research and the sample of analyzed companies. In the part four we provide results with special focus on the relationship between the strength of companies' upstream oil segment and their interest in renewables and in the final part we conclude the research.

\section{LITERATURE REVIEW}

International Energy Agency (IEA, 2020) identifies four possible strategies options for oil companies in energy transition: (1) continuing with traditional oil and gas operations, (2) the use of CCUS technologies (carbon capture, utilization and storage) to bring down emissions, (3) focusing on to supply low-carbon liquids and gases to consumers, and (4) the transition from "fuel“ to „energy“ company, with supply of electricity and other energy services as a part of a diversified offering. Points (3) and (4) relate to renewable production where by low-carbon liquids and gases many consider biofuels based on biomass (for example, wood or crops) such as bioethanol or bio-methane, but also hydrogen, while transition to energy company mostly assumes putting larger focus on renewables in different segments: power production, power trading, electric mobility (e.g. electric vehicle charging), energy storage (production of lithium-ion batteries to power electric vehicles) and other.

Carbon dioxide sequestration technologies in the oil and gas industry are seen as one of the the very important pillars of energy transition. For, example carbon capture and storage (CCS) is a technology enabling to use fossil fuels in a sustainable way. Cherepovitsyn \& Ilinova (2016) indicate that promotion of the technology of carbon dioxide sequestration by means of capturing and injecting it into the underground reservoirs is a promising mechanism of reducing carbon dioxide (CO2) concentration, while (Illinova et al. 2018) point out that CO2 utilizing technologies are circular business models connected with the usage of emissions for providing added benefits 
throughout the value chain and lead to significant ecological, economic and social benefits. Romasheva et al. (2018) showed that the global portfolio of CCS projects is still expanding and developing in a flexible manner and that in some countries, advanced centers are created with the support of the government to promote sequestration technologies where various companies reveal information on the specifics of projects from a process, economic, social, etc. viewpoints. However, (Tcvetkov et al. 2019) stress that although this technology attracts much attention from the industrial sector, government authorities and scientific community, public awareness of the technology is still extremely low. According to (Romasheva \& Ilinova, 2019) coordinated efforts to succeed in CCS activities, as well as the participation of all stakeholders, in particularly government, are needed. Since the implementation of those technologies is not only question at the company level, authors have come to conclusion that aspects such as the planning and programming of CCS activities at the state level, stable financial support, clear legislation, public outreach, and adequate country-specific taxation and crediting are critical to CCS technologies propagation.

Especially interesting strategic option is the transition of an oil company from "fuel" to "energy" company since it assume a substantial change of business model and corporate philosophy. On the individual level there are different examples including extremes on both sides - from staying only exclusively oil company without renewables in portfolio to fully becoming renewable energy company. For example, Danish company Ørsted, formerly DONG Energy (Dansk Olie og Naturgas), experienced full strategic transformation from leading oil and gas company to becoming a leader in renewables without oil and gas production in portfolio since in 2017 divested its oil and gas assets (IEA, 2020). Norway's oil and gas company Equinor is another example of oil company strongly focusing on renewables. The company has recently started with substantial investment cycle in renewables and also changed the name in order to additionally stress these strategic changes. By 2020 Equinor plans to invest into renewables $15-20 \%$ of total investments (Pickl, 2019).

On the other extreme, there are some oil companies without presence in renewables or their presence is symbolic. For example, (Pickl, 2019) indicates that ExxonMobil, one of seven major oil companies, "has shown no interests in renewables, resulting in criticism from climate activists". In addition, there are oil companies that entered renewable business segment, but decided to exit it such as Chevron, another oil major company, who established presence in renewables in the beginning of 2000s, but decided to divest their renewables portfolio in 2014 and 2016, stating as the reason lower returns compared to core activities. The same approach has been recently taken by the Brazilian company Petrobras.

Between the two extremes, there are companies still focusing on their core activities, but with increased share of renewables. According to (Pickl, 2019) Royal Dutch Shell, Total, BP, Eni, and Equinor are in their transition process from oil to energy companies, with Total being the leader in the process with the highest score. In addition, he demonstrated linkage between the oil major's proved oil reserves and their renewable energy strategies indicating that those with lower proved reserves are more oriented to renewables.

Overall, it seems that the role of renewables in strategy of oil companies is growing, but is still relatively weak in spite of increased investments. For example (Zhong \& Bazilian, 2018) claim that "international oil companies (IOCs) have become substantive players in the renewables market, lending their scale and business expertise to deploying clean energy" and investing hundreds of millions of dollars in renewables. However, in spite of hundreds of millions of dollars of investments, the share of investment in renewables is still relatively low compared to the other investments, with some oil companies being very passive in expanding their renewable portfolio, see (Zhong \& Bazilan, 2018) and (Pick1, 2019). This is confirmed by the recent research of the International Energy Agency (IEA, 2020) indicating that investments in lowcarbon businesses represent less than $1 \%$ of oil and gas companies' capital expenditure. Based on this research (Table 1) total value of investments in low-carbon business of major oil companies in 2019 accounted for USD $2.1 \mathrm{bn}$, mostly in the solar and wind renewable energy.

Research of (Csomos 2014) stresses weak role of major oil companies in renewables indicating that "certain companies firmly deny investments in the renewable sector (because of the lower-than-expected returns), while others superficially address them". According to him there is only one company - the France-based supermajor oil company Total - that has 
Table 1. CAPEX on new projects outside oil and gas by large companies [USD bn].

\begin{tabular}{llllll}
\hline & 2015 & 2016 & 2017 & 2018 & 2019 \\
\hline Solar PV & 0.6 & 0.6 & 0.5 & 0.7 & 1.1 \\
Offshore wind & 0.3 & 0.4 & 0.4 & 0.4 & 0.4 \\
Onshore wind & 0.2 & 0.3 & 0.4 & 0.3 & 0.4 \\
CCUS* & 0.4 & 0.2 & 0.2 & 0.3 & 0.1 \\
Biofuels & 0.0 & 0.1 & 0.2 & 0.2 & 0.1 \\
\hline Total & $\underline{1.5}$ & $\underline{1.6}$ & $\underline{1.7}$ & $\underline{1.9}$ & $\underline{0.7} \%$ \\
\hline$\underline{\text { \%of total CAPEX }}$ & $\underline{0.4 \%}$ & $\underline{0.7 \%}$ & $\underline{0.7} \%$ & $\underline{0.8} \%$ \\
\hline
\end{tabular}

Source: IEA (2019)

* CCUS - carbon capture, utilization and storage

globally important renewable energy business. On the other hand, based on the general descriptive analysis (Zhong \& Bazilan, 2018) concluded that results of renewable strategies of oil companies were mixed, with investment models being still emerging.

In summary, review of recent researches show that: 1) investments in renewables of global oil companies increase, 2) in spite of the increase share of investments in total investments is low, below $1 \%$, on average, 3 ) there is difference in significance of renewables in portfolio with some extreme situations and 4) those companies with lower proved oil reserves are likely to be more interested in renewables.

\section{RESEARCH METHODS AND MATERIALS}

In this paper we analyze role of renewables in strategies of oil companies from Central and Eastern Europe with special focus on these questions: 1) whether and to which extent CEE oil companies have renewables as a business segment, 2) if have, what are the main area of renewable investments and 3) if have, is there linkage between their position in oil upstream and investments in renewables. Given the low level of activities of CEE companies in the segment CCUS, we excluded it from the analysis.

Sample of our research consists of eight Central and Eastern European (CEE) companies: PKN Orlen, OMV, MOL, Hellenic Petroleum, OMV Petrom, INA, Petrol and NIS, diversified in terms of the size, business model, ownership structure and geographical presence and, as such, serves as a good analytical foundation. Selected companies are important market players in 12 countries (by important market player, we mean that company has oil refinery in that country or/and has market share of $>10 \%$ in retail market for oil derivatives): Poland (PKN Orlen), Czech Republic (PKN Orlen through its related company Unipetrol), Slovakia (PKN through its related company Unipetrol and MOL through its related company Slovnaft), Lithuania (PKN Orlen through its related company Orlen Lietua, former Mažeiku Nafta), Austria (OMV), Hungary (MOL), Slovenia (Petrol), Croatia (INA), Romania (OMV Petrom), Greece (Hellenic Petroleum), Serbia (NIS) and Bosnia and Herzegovina (INA, NIS, OMV). These countries cover $89 \%$ of CEE region in terms of population. All relevant information are taken from the companies' annual reports and other documents, including public releases, from the official websites.

Based on the descriptive and empirical statistics we analyze renewables strategies of CEE oil companies and with the correlation analysis we evaluate the strength of relationship between their interests in renewables and their level of oil self-sufficiency.

\section{RESULTS AND ANALYSIS}

Activities of oil companies from Central and Eastern Europe are analyzed in three categories: renewables power production, biofuels production and electric mobility (Table 2). 
Table 2. Activities in renewables of CEE oil companies.

\begin{tabular}{|c|c|c|c|}
\hline Company & Power production & Biofuels & Electric mobility \\
\hline PKN Orlen, Poland & $\begin{array}{l}\text { - Acquired license to } \\
\text { build off-shore wind } \\
\text { farm in Baltic Sea with } \\
\text { capacity of } 1,200 \mathrm{MW}\end{array}$ & $\begin{array}{l}\text { - Acquired license to } \\
\text { construct commercial } \\
\text { plant for the produc- } \\
\text { tion of cellulosic etha- } \\
\text { nol from agricultural } \\
\text { residues } \\
\text { - Analyzing possibilities } \\
\text { to deploy advanced } \\
\text { hydrotreated vegetable } \\
\text { oil (HVO) and used } \\
\text { cooking oil (UCO) } \\
\text { technologies at its } \\
\text { plant in Płock }\end{array}$ & $\begin{array}{l}\text { - Planning to invest in } \\
250 \text { electric vehicles } \\
\text { charging stations } \\
\text { (EVCSs) }\end{array}$ \\
\hline OMV, Austria & $\begin{array}{l}\text { - Entered in strategic } \\
\text { partnership with Ver- } \\
\text { bund to build photo- } \\
\text { voltaic plant capacity } \\
\text { of } 16 \mathrm{MW}\end{array}$ & $\begin{array}{l}\text { - No specific actions } \\
\text { announced }\end{array}$ & $\begin{array}{l}\text { - As a minority owner } \\
\text { of SMATRICS }(40 \%) \text {, } \\
\text { has } 435 \text { EVCSs }\end{array}$ \\
\hline MOL, Hungary & $\begin{array}{l}\text { - In } 2018 \text { began to build } \\
\text { solar power plants in } \\
\text { three Hungarian sites } \\
\text { with a total capacity } \\
\text { of } 18.4 \mathrm{MW} \\
\text { - Planning development } \\
\text { of geothermal power } \\
\text { plant with capacity of } \\
3.8 \mathrm{MW}\end{array}$ & $\begin{array}{l}\text { - No specific actions } \\
\text { announced }\end{array}$ & $\begin{array}{l}\text { - Planning to invest in } \\
150 \text { electric vehicles } \\
\text { charging stations }\end{array}$ \\
\hline $\begin{array}{l}\text { Hellenic Petroleum, } \\
\text { Greece }\end{array}$ & $\begin{array}{l}\text { - Currently poses solar } \\
\text { power plants with cap- } \\
\text { acity of } 19 \mathrm{MW} \text { and } \\
\text { wind farm with cap- } \\
\text { acity of } 7 \mathrm{MW} \\
\text { - Plan to invest in } \\
\text { renewables with cap- } \\
\text { acity of } 300 \mathrm{MW}\end{array}$ & $\begin{array}{l}\text { - No specific actions } \\
\text { announced }\end{array}$ & $\begin{array}{l}\text { - No specific actions } \\
\text { announced }\end{array}$ \\
\hline $\begin{array}{l}\text { OMV Petrom, } \\
\text { Romania }\end{array}$ & $\begin{array}{l}\text { - In } 2017 \text { sold Doro- } \\
\text { bantu wind park with } \\
\text { capacity of } 45 \mathrm{MW} \\
\text { - No further specific } \\
\text { actions announced }\end{array}$ & $\begin{array}{l}\text { - No specific actions } \\
\text { announced }\end{array}$ & $\begin{array}{l}\text { - No specific actions } \\
\text { announced }\end{array}$ \\
\hline INA, Croatia & $\begin{array}{l}\text { - Planning two solar } \\
\text { power plants with cap- } \\
\text { acity of } 11 \mathrm{MW}\end{array}$ & $\begin{array}{l}\text { - No specific actions } \\
\text { announced }\end{array}$ & $\begin{array}{l}\text { - No specific actions } \\
\text { announced }\end{array}$ \\
\hline Petrol, Romania & $\begin{array}{l}\text { - Has renewables cap- } \\
\text { acities of } 32 \mathrm{MW} \\
\text { mostly in wind and } \\
\text { hydro segments } \\
\text { - Planning to increase } \\
\text { capacities by add- } \\
\text { itional } 20 \mathrm{MW}\end{array}$ & $\begin{array}{l}\text { - No specific actions } \\
\text { announced }\end{array}$ & $\begin{array}{l}\text { - By September } 2019 \\
\text { providing charging } \\
\text { services at } 130 \text { EVCSs }\end{array}$ \\
\hline NIS, Serbia & $\begin{array}{l}\text { - Started construction } \\
\text { of wind farm with cap- } \\
\text { acity of } 102 \mathrm{MW}\end{array}$ & $\begin{array}{l}\text { - No specific actions } \\
\text { announced }\end{array}$ & - One EVCS \\
\hline
\end{tabular}

Annual reports and official statements of selected companies 
Until 2020 role of renewables in business of CEE oil companies was relatively weak. Only Petrol (32 MW) and Hellenic Petroleum (26 MW) currently have installed capacities for production of electricity from renewable sources, while NIS has recently started a substantial investment in this segment. OMV, through its subsidiary OMV Petrom, sold its wind farm in 2017 in order to focus on the core business, while MOL and their related company INA plan symbolic investments in renewable power production.

So far, PKN Orlen has not been very active in renewables, but recent announcements indicate change in their strategy - they are now in the process of analyzing possibilities to construct off-shore wind farm in the Baltic See with capacity 1,200 MW, for which have already acquired the license. This can be regarded as a natural step for further development given the fact that the company has strong presence in power generation (total installed capacities of $1,871 \mathrm{MW}$ ) which accounts to $15 \%$ of EBITDA. In addition, the company acquired license to construct bioethanol factory and has plans for development of electric mobility business segment.

In terms of relative significance of renewables for total business one of the good example is Petrol from Slovenia. Currently, production of electricity from renewables accounts for 3\% of the company's EBITDA, while the plan for 2022 is to have $8 \%$ of EBITDA coming from renewables. In general, the company is very active in business activities other than oil, with strong presence in gas distribution and energy efficiency solutions and their activities in renewables are in the direction for becoming fully diversified energy company.

Serbian company NIS has recently started development of wind farm with capacity of 102 MW worth 140 million of euros, which is a relatively substantial investment for the company investing around 300 million of euros yearly on average. However, it is yet to be seen whether this move is step of strategic positioning in renewables or only opportunistic approach taking advantage of opportunities in the Serbian renewable market due to favorable government's incentives through stimulating feed-in tariffs.

In order to further investigate significance of renewable power generation as potential business segment, we compared announced investment in renewable power generation with total CAPEX of selected companies (Table 3) in the period 2013-2018 since there are no data for CAPEX for the next five year period (this is a part of broader research of Ilic and Ponomarenko related to level of vertical integration and di-versification of CEE oil companies - Ilic, A. \& Ponomarenko, T. (2019). Role of vertical integration and diversification in strategies of CEE oil companies in circumstances of increased uncertainty and energy transition. Work in progres).

Some companies, for example PKN Orlen and Hellenic Petroleum, are planning strong investment in this segment both in absolute terms and in relative terms (as \% of CAPEX executed in the period 2013-2018), while Petrol and NIS have a bit moderate approach. For example, PKN Orlen is making preparations for an offshore wind farm project on the Baltic Sea with 1,200 MW of installed capacity which represent around 1/3 of CAPEX executed in the period 2013-2018. According to the 2018 annual report, Hellenic Petroleum plans to invest $€ 300-400$ in different renewables power production, which also represents $1 / 3$ of CAPEX in the period 2013-2018. Serbian oil company NIS is in the process of constructing wind farm with installed capacity of $102 \mathrm{MW}$, while Slovenian Petrol, already present in the renewables power generation, plans to add additional $20 \mathrm{MW}$ of installed capacities. On the other hand, OMV and MOL and their related parties, OMV Petrom and INA, are planning only symbolic investment in power generation based on renewables.

In addition, we compared investments of renewable power generation in relative terms with oil self-sufficiency in which oil sufficiency is defined as share of produced crude oil in total processed crude oil (Figure 1).

Companies that have lower crude oil self-sufficiency, such as PKN Orlen and Hellenic Petroleum, intend to significantly invest in renewables, while companies that have higher oil selfsufficiency, such as OMV and OMV Petrol, do not plan to substantially invest in renewables. Petrol and NIS also plan a substantial amount of investment in renewables, while MOL and INA remained focused on other business segments. Correlation coefficient between oil selfsufficiency and new CAPEX for renewables is relatively high at -0.61 indicating that 
Table 3. Planed new investment in renewable power generation.

\begin{tabular}{|c|c|c|c|c|c|c|}
\hline & $\begin{array}{l}\text { New power } \\
\text { RES cap**. } \\
{[\mathrm{MW}]}\end{array}$ & $\begin{array}{l}\text { New power RES } \\
\text { CAPEX [€ mn]* }\end{array}$ & Type & $\begin{array}{l}\text { CAPEX } \\
13-18 \\
{[€ \mathrm{mn}]}\end{array}$ & $\begin{array}{l}\text { New power } \\
\text { RES CAPEX } \\
{[\% \text { CAPEX }} \\
13-18]\end{array}$ & $\begin{array}{l}\text { Oil self- } \\
\text { sufficiency } \\
2018\end{array}$ \\
\hline $\begin{array}{l}\text { PKN Orlen, } \\
\text { Poland }\end{array}$ & 1,200 & 1,800 & Wind & 5,414 & $33 \%$ & $1 \%$ \\
\hline $\begin{array}{l}\text { OMV, } \\
\text { Austria }\end{array}$ & 16 & 24 & Solar & 20,770 & $0 \%$ & $57 \%$ \\
\hline $\begin{array}{l}\text { MOL, } \\
\text { Hungary }\end{array}$ & 32 & 48 & $\begin{array}{l}\text { Solar/ } \\
\text { geothermal }\end{array}$ & 6,999 & $1 \%$ & $12 \%$ \\
\hline $\begin{array}{l}\text { Hellenic } \\
\text { Petrol., } \\
\text { Greece }\end{array}$ & 200 & 300 & Different & 905 & $33 \%$ & $0 \%$ \\
\hline $\begin{array}{l}\text { OMV } \\
\text { Petrom, } \\
\text { Romania }\end{array}$ & 0 & 0 & - & 5,625 & $0 \%$ & $99 \%$ \\
\hline $\begin{array}{l}\text { INA, } \\
\text { Croatia }\end{array}$ & 10 & 15 & $\begin{array}{l}\text { Solar/ } \\
\text { geothermal }\end{array}$ & 1,224 & $1 \%$ & $18 \%$ \\
\hline $\begin{array}{l}\text { Petrol, } \\
\text { Slovenia }\end{array}$ & 20 & 30 & Different & 434 & $7 \%$ & $0 \%$ \\
\hline NIS, Serbia & 102 & 140 & Wind & 1,855 & $8 \%$ & $24 \%$ \\
\hline Total & 1,580 & 2,357 & & 43,226 & $5 \%$ & $18 \%$ \\
\hline $\begin{array}{l}\text { Total con- } \\
\text { solidated }\end{array}$ & $\overline{1,570}$ & $\overline{2,342}$ & & $\underline{36,377}$ & $6 \%$ & $\overline{15 \%}$ \\
\hline
\end{tabular}

Source: Annual reports and official statements of selected companies

* Estimation of authors based on the type of investment

** RES - Renewables

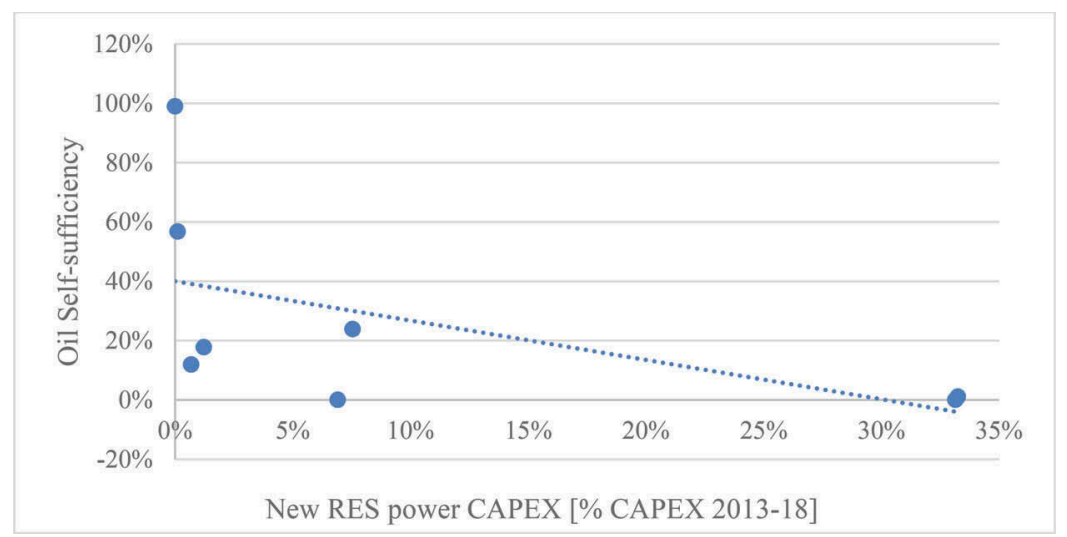

Figure 1. Dependence of investment in RES power and oil self-sufficiency.

Source: Annual reports of selected companies and estimations of authors

companies which have low or limited reserves and production of oil are more interested in power generation based on renewables. 


\section{CONCLUSION}

So far, the role of renewables in strategies of CEE oil companies has been relatively weak, even below the average of global oil companies. However, project started recently (for example, NIS's construction of wind farm of capacity of $102 \mathrm{MW}$ ) and recently announced projects (PKN Orlen's construction of wind farm) and potential realization of renewable projects of Hellenic Petroleum (still uncertain timing and the scope), with Petrol's existing and planned activities indicate an increased role of renewables in strategies of CEE companies. Our research showed, under the assumptions that announced projects will be realized, that: (1) level of investment in renewables of CEE companies in the future will be relatively high (around 5\% of CAPEX from the period 2013-2018), (2) there are strong differences among CEE oil companies in terms of the significance of renewable productions (PKN Orlen, Hellenic Petroleum, NIS and Petrol with relatively strong renewables and OMV and MOL and their related parties OMV Petrom and INA with only symbolic presence), (3) those oil companies with relatively weak upstream (crude oil reserves and production) are more interested in renewables (confirmed findings of (Pickl, 2019) based on the analysis of oil majors) and (4) production of electricity from wind and solar dominates the renewable activities of CEE oil companies. In addition to this, renewable segment in the portfolio of CEE oil companies is at an early stage of development with only a few projects ongoing.

It is obvious that decision on entering and developing renewables business segment is done at case-by-case basis without any generalization. Additionally, it seems that an oil company decides based on the estimation of its competitive advantages and the prospects to success in the specific environment. This specific environment encompasses: (1) regulation and expected regulatory changes (how regulatory bodies are strict to carbon reduction and how lucrative are the government incentives, which is the most likely reason why NIS started production of wind farm), (2) interest of shareholders and other stakeholders (how they are strict to promoting green energy, which was the case with transformation of Ørsted to a renewable-based company), (3) relative internal competences in electricity production (this was probably the case with PKN Orlen's intention to construct a big wind park since the company has strong position in power production from which it gets $15 \%$ of EBITDA), (4) resource availability at reasonable costs, primarily reserves of crude oil (the most likely reason why American companies and OMV are not focused on renewables), (5) expected changes of technology and its costs (keeping up with technology changes in order not to be late new energy revolution) and (6) expected change in customer preferences. However, this part of analyzing specific reasons for existence or non-existence of renewables in the strategies of oil companies deserves further investigations.

\section{REFERENCES}

Annual reports and other official documentations and press releases: PKN Orlen, OMV, MOL Group, Hellenic Petroleum, OMV Petrom, INA, Petrom, NIS [2013, 2014, 2015, 2016, 2017, 2018, 2019].

Cherepovitsyn, A. \& Ilinova, A. 2016. Ecological, Economic and Social Issues of Implementing Carbon Dioxide Sequestration Technologies in the Oil and Gas Industry in Russia. Journal of Ecological Engineering, volume 17. Issue 2. 19-23.

Csomos, G. 2014. Relationship between Large Oil Companies and the Renewable Energy Sector. Environment Engineering and Management Journal.

ExxonMobil. 2019. Outlook for Energy: A Perspective to 2040.

Fattouh, B., Poudineh, R. \& West, R. 2018. The Rise of Renewables and Energy Transition: What Adaptation Strategy for Oil Companies and Oil-Exporting Countries? The Oxford Institute for Energy Studies, Paper: MEP 19.

Fattouh, B., Poudineh, R. \& West, R. 2019. Energy Transition, Uncertainty, and the Implications of Change in the Risk Preferences of Fossil Fuel Investors. The Oxford Institute for Energy Studies, Energy Insight 45 OIES.

Gielen, D., Boshell, F., Saygin, D., Bazilian, M., Wagner. N. \& Gorini, R. 2019. The Role of Renewable Energy in the Global Energy Transformation. Energy Strategy Review 24. 
Ilic, A. \& Ponomarenko, T. 2019. Role of vertical integration and diversification in strategies of CEE oil companies in circumstances of increased uncertainty and energy transition. Work in progress.

Ilinova, A., Cherepovitsyn, A. \& Evseeva, O. 2018. Stakeholder Management: An Approach in CCS Projects. Resources 7(4) 83.

International Energy Agency. 2019. Global EV Outlook 2019: Scaling-up the Transition to Electric Mobility.

International Energy Agency. 2020. The Oil and Gas Industry in Energy Transition. Insights from IEA analysis.

International Renewable Energy Agency. 2019. Renewable Power Generation Costs in 2018, IRENA, Abu Dhabi.

Mojarad, A. A. S., Atashbari, V. \& Tantau, A. D. 2018. Challenges for Sustainable Development Strategies in Oil and Gas Industries. Conference paper, De Gruyter Open.

Pickl, M. 2019. The Renewable Energy Strategies of Oil Majors - From Oil to Energy. Energy Strategy Reviews 26.

Romasheva, N. \& Ilinova, A. 2019. CCS Projects: How Regulatory Framework Influences Their Deployment. Resources, No. 8.

Romasheva, N., Kruk, M. \& Cherepovitsyn, A. 2018. Propagation Perspectives of CO2 Sequestraction in the World. International Journal of Mechanical Engineering and Technology, volume 9, issue 11 $1877-1885$.

Shivakumar, A., Dobbins, A., Fahl, U. \& Singh, A. 2019. Drivers of Renewable Energy Deployment in the EU: An Analysis of Past Trends and Projections. Energy Strategy Reviews 26.

Tcvetkov, P., Cherepovitsyn, A. \& Fedoseev, S. 2019. Public Perception of Carbon Capture and Storage: A State-of-the-Art-Review. Heliyon 5 e02845.

West, R. \& Fattouh, B. 2019. The Energy Transition and Oil Companies' Hard Choices. The Oxford Institute for Energy Studies, Energy Insight 50.

Zhong, M. \& Bazilian, M. D. 2018. Contours of Energy Transition: Investment by International Oil and Gas Companies in Renewable Energy. The Electricity Journal 31. 


\title{
Strategic forecasting of REE mining projects development in Russian Arctic
}

\author{
V.M. Solovyova \\ Postgraduate student, Department of Organization and Management, Saint-Petersburg Mining University, \\ Saint-Petersburg, Russia
}

\begin{abstract}
A.A. Ilinova
Candidate of Economic Sciences, Associate Professor, Department of Organization and Management, Saint-Petersburg Mining University, Saint-Petersburg, Russia
\end{abstract}

\author{
A.E. Cherepovitsyn \\ Doctor of Economic Sciences, Professor, Department of Organization and Management, Saint-Petersburg \\ Mining University, Saint-Petersburg, Russia
}

\begin{abstract}
To date, issues related to the effective development of mineral and raw material base are becoming increasingly important especially for Arctic zone. Particular attention is paid to expanding the possibility of the integrated use of mineral deposits in order to extract rare-earth components. Currently, a significant deficit has formed in these elements, however, the prospects for the domestic REE industry's development remain uncertain. It determines the relevance of the topic. This paper deals with the investigation of possibilities for REE mining projects development strategic forecasting. The overview of national and global rare earth market is presented. Strategic importance of REE projects implementation for Russia is discussed. Existing strengths, weaknesses, threats and opportunities of REE mining industry projects in Russian Arctic with the aid of SWOT-analysis are identified. Decomposition of factors determining uncertainty of rare earth projects forecasts is presented. The study makes a number of recommendations aimed at the creation of strategic forecasting system of REE industry development in Russia.
\end{abstract}

\section{INTRODUCTION}

In recent years, there has been an increasing interest in the development of Russian Arctic mineral resources (Larichkin 2008; Dmitrieva \& Ilinova 2017). However, existing challenges related to the low rate of recourses reproduction, gradual depletion of mineral base, low probability of novel deposits identification with huge amount of high-quality reserves were the causes of formed deficit in rare earth elements (REE) in the national market (Larichkin 2011). According to statistical data, the need for REE at the side of Russian industrial complex seven times more than the volume of national production (Scripachev 2018). Obviously, it leads to the increase in import dependence of national high tech industries.

Despite the great potential of rare earth elements mineral base in Arctic Zone, rare earth elements mining industry projects aren't been implemented in Russia. The prospects of REE industry projects development stay undetermined. To overcome this uncertainty it's necessary to identify what kind of rare earth elements have critical importance, analyze market trends (supply, demand on certain types of elements), investigate prospective projects, and evaluate existing threats and opportunities. It's required the formation of special system within strategic forecasting that allows to take into account the specific features of REE mining industry projects implementation. 
This paper attempts to show that the development of rare earth industry both strategic and one of the most complicated direction. The objectives of this research are to investigate existing trends within national REE industry, to determine factors influenced the rare earth elements projects development and discuss specific features of these projects.

\section{LITERATURE REVIEW}

The existing literature on the aspects of complex use of mineral raw materials in Russian Arctic is extensive (Ponomarenko et al. 2018; Cherepovirsyn et al. 2018; Nevskaya 2019). The efficiency of mineral and raw materials base's development is related to the possibilities of rational subsoil use and opportunities in the sphere of extraction and processing of worth components, including REEs (Nedosekin 2019; Ponomarenko et al. 2019).

There is a large volume of published studies describing the role of rare earth elements in modern global economics (Wall 2014; Charalampides et al. 2015; Eggert et al. 2016; Zhou et al. 2017; Ganguli 2018; Balaram 2019). Much of the current literature on REE market pays particular attention to analyses of available resource potential (Saveleva 2011; Paulick \& Machacek 2017), determination of technological accessibility (Takeda \& Okabe 2014; Anderson 2016), investigation for global market conditions (Nassar et al. 2015; Alvin 2018).

The existing foreign literature focuses particularly on the forecasting of REE industry development (Goodenough et al. 2017; Fernandez 2017). Most researchers investigating this sphere have utilised methods and instruments of strategic analyses (Chen 2011; Kalvig \& Machacek 2016). Using these instruments, researchers have been able to make medium- and long-term quantitative forecasts taking into account reliable trends of global market.

Nevertheless, there is a relatively small body of national literature that is concerned with forecasting trends of Russian REE industry development. A number of studies have begun to examine main prospects of this industrial branch (Postolateva et al. 2013; Novikov \& Salikhov 2015; Glushchenko et al. 2017; Scripachev 2018). However, such studies remain narrow in focus dealing only with certain aspects of industrial potential and focus on common directions of future development.

In Russia special document devoted to REE industry development is established («The development Strategy of the rare and rare earth metals industry of the Russian Federation for the period up to 2035»). However, most of document provisions are theoretical, the directions of future industrial development are not determined, the prospects stay uncertain.

Thus, despite the range of existing papers devoted to different aspects of rare earth market, there are no publications devoted to strategic forecasting of REE mining industry projects in Russian Arctic.

\section{METHODOLOGY}

The study uses qualitative analysis in order to gain insights into main directions within analysis of REE global and national market, investigation of foreign critical materials concepts (Massari \& Ruberti 2013). Key features of the rare earth projects development were studied on the basis of scientific works of Russian and foreign researchers (Novikov \& Salikhov 2015; Glushchenko et al. 2017; Goodenough et al. 2017; Fernandez 2017, et al.).

A strategic method - SWOT analysis - was used to allow a deeper insight into prevailing conditions of REE industry development in Russia. The benefit of this instrument is that it allows to identify strengths, weaknesses, opportunities and threats related to selected object of study. However, there are certain drawbacks associated with the use of offered method, as it does not permit to take into account specific factors connected with REE projects development. Therefore, application of this method was complemented by the decomposition of factors determining uncertainty of forecasts.

The legal basis of the study is formed by analyzing the Federal Law «On Subsoil», the «Strategy of development of mineral resources base of the Russian Federation till 2035», «The 
development Strategy of the rare and rare earth metals industry of the Russian Federation for the period up to 2035 », et al.

The methods collectively used in the study made it possible to ensure the reliability and validity of the conclusions.

\section{RESULTS}

\subsection{Market overview}

Rare-earth metals are among the types of minerals that are of strategic importance to all developed countries in the world. Global market of REE is growing rapidly. Its volume increased by more than 25 times (from 5 thousand tons to 125 thousand tons per year) over the last ten years (Samsonov \& Semyagin 2014). Main global consumers of rare earth elements are Japanese (approximately 60\%) and Malaysia (about 23\%). The leader in the production of REE in the world market remains China (more than $90 \%$ of global market) (Paulick \& Machacek 2017; Rare earth market outlook: supply, demand, and pricing from 2016 through 2025).

Today the opportunities of high-tech sectors are associated with the development of REE industrial potential (Future Supply of Rare Earth Elements). In Russia the largest share in the structure of rare earth elements consumption is occupied by the production of catalysts, metallurgy, glass production (Figure 1).

Although the great opportunities within significant mineral and raw materials base, the national REE industry remains poorly developed. Russian share of REE supply in the global market not exceed the values of $2 \%$.

Nowadays, the production of certain types of rare earth elements is carried out by three companies: JSC Solikamsk Magnesium Works (carbonates), Acron Group (cerium and lanthanum oxides) and The Laboratory of Innovative Technologies - «LIT» (cerium, neodymium, lanthanum and lanthanum oxides) (Scripachev 2018). According to the «Development Strategy of the rare and rare earth metals industry of the Russian Federation for the period up to 2035», there are a range of prospective REE projects including Integrated Chemical and Metallurgical Complex «African Project», Tomtor rare metal deposit (Burany site) in the Republic of Sakha (Yakutia), Development of germanium-containing lignite deposit in Krasnoyarsk, et al. Nevertheless, the prospects of these projects implementation remain unclear today.

The annual volume of REE national market increased sharply between 2017 and 2018 with the rate of growth $31,3 \%$ (Figure 2). The major of required elements (more than $80 \%$ ) are imported from China, Estonia, Austria, et al. On the one hand, it allows to ensure national

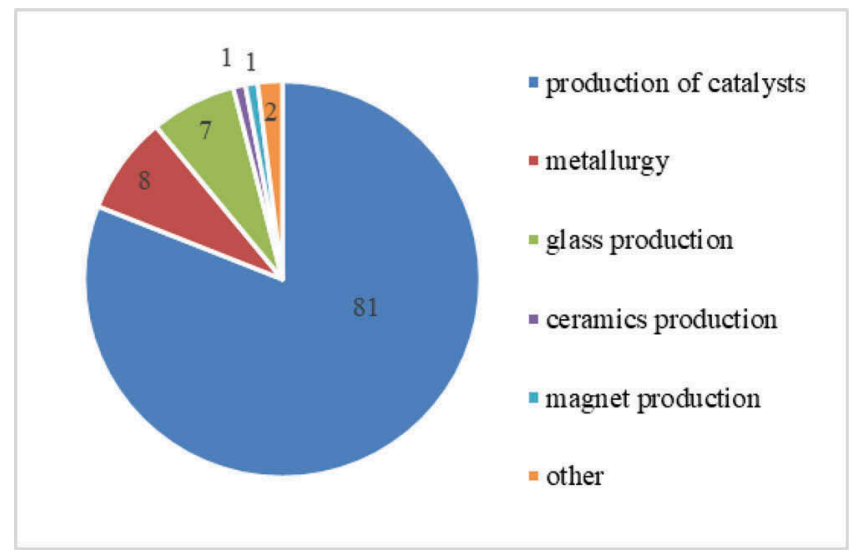

Figure 1. Structure of REE consumption in Russia, \% (2018) (Scripachev 2018). 


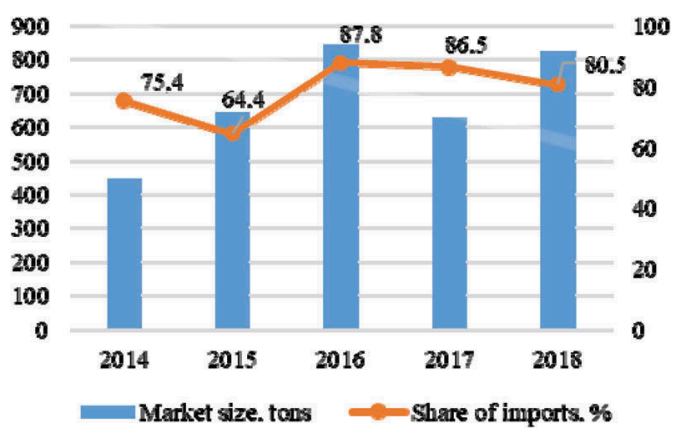

Figure 2. Market size of national REE market 2014-2018 (Scripachev 2018; Alvin 2018).

industry with rare earth elements. On the other hand, import dependence is increasing, that can influence the sustainability of strategic industrial branches including military complex, oil and gas machinery, et al.

In medium term, it's expected the increase in domestic demand for REE. Possible directions of prospective growth in production volumes of rare earth elements are the following:

- Volume of catalysts production is on the increase. New capacities for the manufacture of catalysts are established at Gaspromneft - Catalytic Systems LLC production site.

- Development of aircraft engines industry (PD-14, PD-35).

- Development of the production gas turbine engine, marine gas turbine engine.

- Expanding the use of rare-earth metals as burnable additives in uranium oxide fuel from VVER and RBMK reactors.

- Construction of the neodymium versatate production with a capacity of 120 tons per year at the site of JSC Voronezhsintezkauchuk, et al.

At present, main priorities within development of national REE industry include satisfaction of the needs of defense industry enterprises with domestic rare earth metals, ensuring national consumption of REE with its further growth and reduction in the share of imports to a minimum level (import substitution), increase in export potential.

\subsection{Forecasting of REE mining projects development}

Nowadays the reduction in level of import substitution within REE industry is relevant direction. Thus, it's necessary to remove existing barriers connected with REE industry development in Russia. To achieve this aim it's required the formation of complex planning and forecasting systems. The first step must be to determine specific factors of rare earth elements projects and aspects influenced their development and implementation.

As it was mentioned before, in Russia there are significant reserves of rare earth metals. The technologies for the extraction of individual elements are available. The legal and regulatory conditions are being improved (Solovyova \& Cherepovitsyn 2019). However, along these «strengths» there is a range of negative factors. They include high cost of extracting worth components, lack of special instruments to support REE projects, imperfection of legal regulation of the development of the rare earth metals industry in the country, et al.

Globally, the REE market is monopolized. Thus, the main external risk is the strengthening of the competitive position of foreign manufacturing companies in the national market. This risk comes down to the supply of cheaper REE products, which can lead to unprofitable development of new deposits and a drop in demand for domestic REE. Internal risks are directly related to instability of demand for REE (lack of long-term contracts), lack of consumer interest in the supply of national REE products. Moreover, the process of replacing traditionally used materials (metals and alloys) with new materials based on REE can be long-term.

Main strengths, weaknesses, opportunities and threats of REE mining industry projects in Russian Arctic have been determined. The results in Table 1 are shown. 
Table 1. SWOT analysis of REE mining projects development in Russian Arctic.

\begin{tabular}{|c|c|}
\hline Strengths & Weaknesses \\
\hline $\begin{array}{l}\text { - significant reserves of rare-earth metals in Russian } \\
\text { Arctic (large mineral resource base); } \\
\text { - high quality of mineral resources; } \\
\text { - possibility of involving technogenic deposits in } \\
\text { order to extract individual components; } \\
\text { - availability of technologies for the extraction of } \\
\text { individual components of rare-earth metals; } \\
\text { - development of REE projects on the basis of the } \\
\text { existing mining enterprises }\end{array}$ & $\begin{array}{l}\text { - lack of geological data (necessity of additional } \\
\text { exploration); } \\
\text { - high cost of extracting worth components; } \\
\text { - remote location of REE deposits; } \\
\text { - lack of special instruments to support REE } \\
\text { projects; } \\
\text { - lack of experience of REE projects } \\
\text { implementation; } \\
\text { - absence of the strategic planning system that allows } \\
\text { to determine the forecasts of certain REE projects }\end{array}$ \\
\hline Opportunities & Threats \\
\hline $\begin{array}{l}\text { - expansion of the use of rare-earth elements } \\
\text { (growth in domestic and global demand); } \\
\text { - increasing demand for rare-earth metals in the } \\
\text { production of steel, metals and alloys; } \\
\text { - presence of trends in price levels for most types of } \\
\text { rare-earth elements; } \\
\text { - development of enrichment technologies in order } \\
\text { to extract valuable components of mineral raw } \\
\text { materials (integrated use of mineral raw } \\
\text { materials); } \\
\text { - development of import substitution policy; } \\
\text { - creation of special industrial and raw material } \\
\text { centers for the development of projects; } \\
\text { - establishment of tax benefits on mineral extraction } \\
\text { for rare earth metals (in } 2020 \text {, the tax rate was } \\
\text { reduced from } 8 \% \text { to } 4.8 \% \text { ); } \\
\text { - adoption of the development Strategy of the rare } \\
\text { and rare earth metals industry }\end{array}$ & $\begin{array}{l}\text { - high risks of changes in market; } \\
\text { - slowdown in the growth of national high-tech } \\
\text { industries; } \\
\text { - long-term process of replacing traditionally used } \\
\text { materials (metals and alloys) with new materials } \\
\text { based on REE; } \\
\text { - monopolized market at the world level (more than } \\
\text { 90\% of supplies are made by China); } \\
\text { - high level of competition in the national market at } \\
\text { the side of foreign companies; } \\
\text { - imperfection of legal regulation of the develop- } \\
\text { ment of the rare earth metals industry in the } \\
\text { country; } \\
\text { - lack of incentives for subsoil users (economic, } \\
\text { administrative, financial) to implement projects; } \\
\text { - strengthening import substitution strategies in } \\
\text { Europe (critical materials) }\end{array}$ \\
\hline
\end{tabular}

According to the obtained results, one of the most significant factors restraining the development opportunities of the industry is a high degree of uncertainty and the impossibility of its reduction as there are no special methods and instruments allow to forecast future prospects of REE projects implementation. It's critical to understand that REE projects have their specific features that must be taken into account within formation the directions of future development.

Key features of these projects implementation are the following:

1. Geological uncertainty;

2. Market uncertainty;

3. Uniqueness of each REE deposit and characteristics of ore reserves (unique location, content of commercial components and their distribution, which determines different mining rent);

4. Gradual depletion of resources;

5. Capital-intensive and long-term development of the projects;

6. Geographical attachment of production to mining sites (reduced flexibility compared to the other types of industries; geographical distance and underdeveloped infrastructure, entailing additional investment), etc.

Thus, making forecasts regarding the prospects for implementing REE projects, scientists may encounter the following difficulties: lack of reliable data related to geological information, possible volume of production, et al.; need for taking into account and linking a range of 


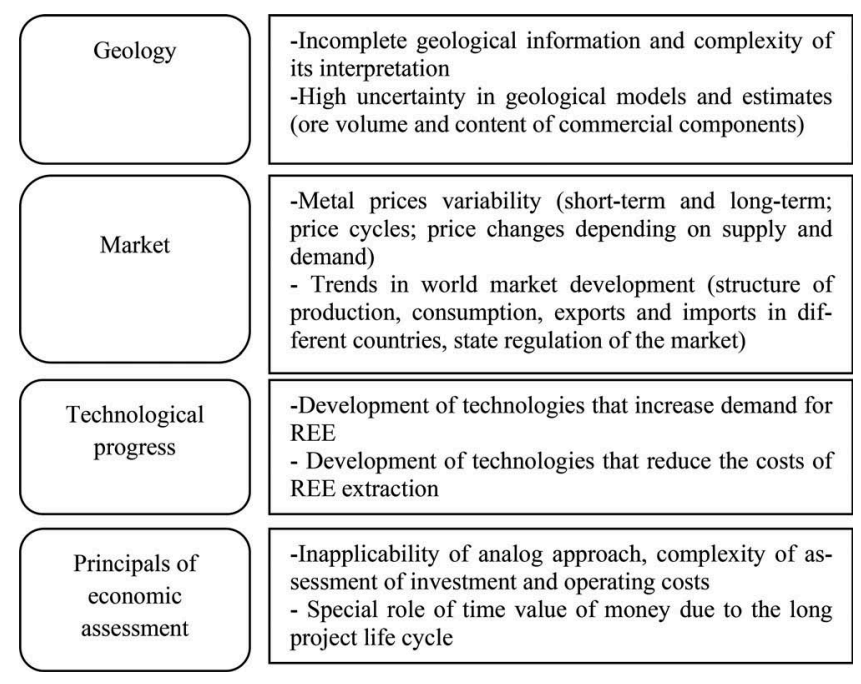

Figure 3. Decomposition of factors determining uncertainty of forecasts.

different specific factors related to REE projects implementation; uniqueness of each project; necessity for combining business interests with strategic priorities of the national REE industry.

All listed above determines the peculiarities of forecasting the development of REE projects. As it was noted, the need for REE in Russia is obvious, but the prospects for such projects remain unclear today. A high degree of uncertainty is associated with the influence of a range of factors, which together create a difficult predictable situation.

Figure 3 shows the decomposition of key factors that create uncertainty in forecasting of REE projects development in the Arctic.

Identified factors include geology, market, technological progress and principals of economic assessment. To reduce the existing uncertainty, it is necessary to explore each of the given parameters and take into consideration the factors and features of REE projects that has been discussed.

To create and establish strategic forecasts regarding the development of the national rareearth industry, the following recommendations are necessary:

1. Updating the list of strategically significant types of mineral raw materials;

2. Study of market parameters for each type of rare earth metals (national and world market) using tools and methods of strategic analysis;

3. The establishment of strategic priorities for the development of the industry, the selection of development objects, the formation of a critical technologies list;

4. Formation of special mineral resource centers for the development of certain areas of the rare earth industry;

5. Creation of a methodological base for planning and forecasting complex industrial systems;

6. Formation of a controlled development parameters system of individual complexes taking into consideration the specifics of REE projects.

\section{DISCUSSION}

The findings of this study suggest that the rare earth elements projects implementation is significant direction within strategic development of Russian industrial complex and economics. Obviously, in the medium term, it is necessary to solve the emerging problem of high import dependence on supplies of products from foreign countries. 


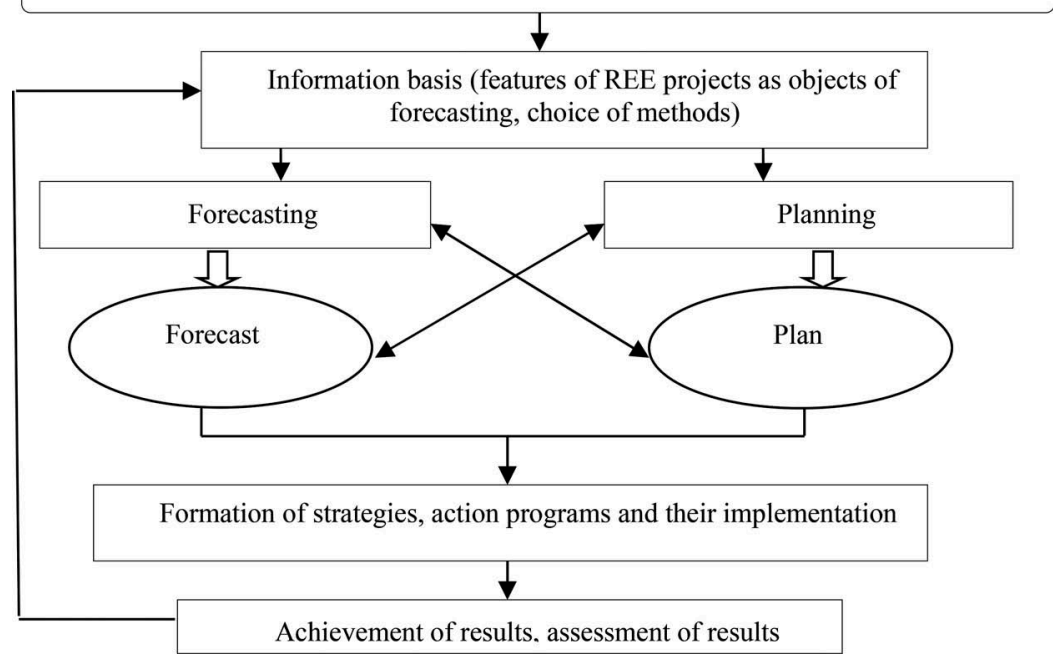

Figure 4. The algorithm of strategic management system.

Rare earth industry is a part of mining industry. However, it has significant specific features that must be taken in consideration. Despite the urgency of the problem of the domestic rare earth industry development, the real prospects remain uncertain. It is unclear what projects will be implemented in the future, whether there will be a demand for domestic rare-earth elements from Russian consumers, what will be the volume of the domestic market in the medium term, etc. That is why it is critically important to forecast the prospects of industry development despite the high level of uncertainty. The forecasting process is closely interconnected with planning. Based on forecasts, specific plans are formed containing a list of activities necessary to achieve the goals and objectives, as well as criteria, indicators and performance indicators for their implementation. The algorithm of strategic management system of REE industry development is presented in Figure 4.

The results of this study related to the features of REE projects and key criteria allow to form an information basis for future research. The study presents factors determining uncertainty of REE projects development forecasts. Based on these factors, it is planned to develop specific indicators, the calculation of which will allow to form conclusions regarding the development of individual projects and the industry as a whole.

The determined features of forecasting the implementation of rare earth elements projects will be taken into account within development of special methodological approaches to forecasting and planning. The findings of this study have a number of important implications for future practice.

\section{CONCLUSION}

The Arctic region of the Russian Federation is essential for the whole country because of its unique mineral raw material base. Obviously, efficient development of the Arctic zone resource potential is one of the strategic priorities for Russia. That goes also for development of rare earth elements resource base.

This paper has argued that development of national REE industry is of strategic importance. The efficiency of rare earth industrial potential realization determines the future of high-tech branches. However, the prospects of REE projects implementation remain unclear today. 
This study has identified key trends of national and global REE markets. The investigation has presented SWOT analysis of REE mining projects development. Key strengths, weaknesses, opportunities and threats have been determined.

The investigation has identified the features of rare earth elements projects implementation in Russian Arctic. They include uniqueness of each REE deposit and characteristics of ore reserves, geographical attachment of production to mining sites, market uncertainty, etc. Key factors creating uncertainty in forecasting of REE projects development in the Arctic have been formed. The study has made also a number of recommendations aimed at creation of strategic forecasts regarding the development of the national rare-earth industry. The results achieved will form the basis for formation of strategic forecasting system of REE projects development.

\section{ACKNOWLEDGEMENTS}

The research was carried out with the financial support of the Russian Science Foundation, the project "Strategic forecasting of development of industrial and mineral resources centers in the Arctic" No. 19-78-00108.

\section{REFERENCES}

Alvin, M.A. 2018. Rare Earth Elements Extraction \& Recovery: Research, Development, Demonstration and Deployment \& Market Outlook National Association of State Energy Officials (NASEO) Houston, TX.

Anderson, C. et al.2016. Rare Earth Recycling Opportunities Institute of Scrap Recycling Industries Annual Meeting April 6, 2016-Las Vegas, Nevada.

Balaram, V. 2019. Rare earth elements: A review of applications, occurrence, exploration, analysis, recycling, and environmental impact Geoscience Frontiers 10(4): 285-1303.

Charalampides, G. et al.2015. Rare Earth Elements: Industrial Applications and Economic Dependency of Europe Procedia Economics and Finance 24: 126-135.

Chen, Z. 2011. Global Rare Earth Resources and Scenarios of Future Rare Earth Industry Journal of Rare Earths 29(1): 1-6.

Cherepovitsyn, A.E., Lipina, S.A. \& Evseeva, O.O. 2018. An innovative approach to the development of the mineral resource potential of the Arctic zone of the Russian Federation Journal of Mining institute 232: $438-444$.

Dmitrieva, D.M. \& Ilinova, A.A. 2017. Development of the Russian Arctic zone: The role of innovation infrastructure and legal regulation International Journal of Applied Engineering Research 12 (19): 8179-8187.

Eggert, R. et al.2016. Rare earths: Market disruption, innovation, and global supply chains Annual Review of Environment and Resources 41: 199-222.

Fernandez, V. 2017. Rare-earth elements market: A historical and financial perspective Resources Policy 53: 26-45.

Future Supply of Rare Earth Elements. Overview. IPC. viewed 17.02.2020 http://www.ipc.org/Content Page.aspx?pageid=future-supply-of-rare-earth-elements.

Ganguli, R. \& Cook, D.R. 2018. Rare earths: A review of the landscape MRS Energy \& Sustainability: A Review Journal 5(e9): 1-16.

Glushchenko, Y.G., Nechaev, A.V. \& Polyakov, E.G. 2017. Development trends of the rare-earth industry in the Russian Federation Theoretical Foundations of Chemical Engineering 51(5): 835-840.

Goodenough, K.M., Wall, F. \& Merriman, D. 2017. The Rare Earth Elements: Demand, Global Resources, and Challenges for Resourcing Future Generations Natural Resources Research doi: 10.1007/s11053-017-9336-5.

Ilinova, A.A. \& Dmitrieva, D.M. 2018. The mechanism of innovative development of the Russian arctic zone International Journal of Mechanical Engineering and Technology 9(9): 1439-1451.

Kalvig, P. \& Machacek, E. 2016. Examining the rare-earth elements (REE) supply-demand balance for future global wind power scenarios Geological Survey of Denmark and Greenland Bulletin 41: 87-90.

Larichkin, F.D. 2008. Mineral Resources in the Russian Economy Journal of Mining Institute 179: 9-13.

Larichkin, F.D. 2011. Problems of study and rational development of mineral resources of the North and the Arctic Kola Scientific Center of the Russian Academy of Sciences 15-23. 
Massari, S. \& Ruberti, M. 2013. Rare earth elements as critical raw materials: Focus on international markets and future strategies Resources Policy 38(1): 36-43.

Nassar, N., Xiaoyue, D \& Graedel, T. 2015. Criticality of the Rare Earth Elements Journal of Industrial Ecology 19(6): 1044-1054.

Nedosekin, A.O., Rejshahrit, E.I. \& Kozlovskij, A.N. 2019. Strategic Approach to Assessing Economic Sustainability Objects of Mineral Resources Sector of Russia Journal of Mining Institute 237: $354-360$.

Nevskaya M.A. et al.(2019) Environmental and Business Challenges Presented by Mining and Mineral Processing Waste in the Russian Federation Minerals 9: 445.

Novikov, N.I. \& Salikhov, V.A. 2015. The main directions and prospects for the development of the mineral raw material base of non-ferrous and rare metals in the world and in Russia Bulletin of Tomsk State University 2(30): 138-150.

Paulick, H. \& Machacek, E. 2017. The global rare earth element exploration boom: an analysis of resources outside China and discussion of development perspectives Resource Policy 52: 134-153.

Ponomarenko, T.V., Khan-Tsai, E.A. \& Bavuu Chantsalma. 2019. Integrated mining projects in underdeveloped territories of Russia: substantiation of implementation parameters Journal of Mining institute 240: 724-730.

Ponomarenko, T.V., Nevskaya, M.A. \& Marinina, O.A. 2018. Complex use of mineral resources as a factor of the competitiveness of mining companies under the conditions of the global economy International Journal of Mechanical Engineering and Technology 9: 1215-1223.

Postolateva, A., Tverdov, A \& Zhura, A. 2013. Rare earth deposits - features, complicity and prospects. Gold and technologies 1(19): 33-36.

Rare earth market outlook: supply, demand, and pricing from 2016 through 2025 Adamas Intelligence: Critical Metals and Minerals Research. viewed 12.02.2020 https://1b9dn310cnw45swh730g66pj-wpen gine.netdna-ssl.com/wp-content/uploads/2018/02/Adamas-Intelligence-Rare-Earth-Market-OutlookDecember-2016-Executive-Summary.pdf.

Samsonov, N.Y. \& Semyagin, I.N. 2014. Overview of the global and Russian rare earth metals market All-Russian ECO journal 44(2): 45-54.

Saveleva, L.I. 2011. The rare-earth metals industry of Russia: Present status, resource conditions of development Geography and Natural Resources 32(1): 65-71.

Scripachev, S.Y. 2018. About the state and prospects of REE industry development Presentation The All-Russian Institute Of Aviation Materials (VIAM).

Solovyova, V.M. \& Cherepovitsyn, A.E. 2019. CUMR projects: Possibilities for implementation on Arctic territories Topical Issues of Rational Use of Natural Resources 2019 doi: 10.1201/ 9781003014638-23.

Takeda, O. \& Okabe, T. 2014. Current Status on Resource and Recycling Technology for Rare Earths The Minerals, Metals \& Materials Society and ASM International 160 doi:10.1007/s40553-014-0016-7.

The development strategy of the rare and rare earth metals industry of the Russian Federation for the period up to 2035. viewed 10.01.2019. http://static.government.ru/media/files/WXRSEBj6jnRWN rumRkDakLcqfAzY14VE.pdf.

Wall, F. 2014. Rare earth elements. In Critical Metals Handbook Hoboken, NJ 312-339.

Zhou, B., Li, Z. \& Chen, C. 2017. Global Potential of Rare Earth Resources and Rare Earth Demand from Clean Technologies Minerals 7(203) doi: 10.3390/min7110203. 


\title{
Organizational and economic mechanism for the development of the oil and gas complex of developing countries
}

\author{
K.Y.B. Cofie \\ Postgraduate student, St. Petersburg Mining University, Saint Petersburg, Russia \\ N.V. Romasheva \\ Ph.D. of Economic Sciences, Assistant professor, Petersburg Mining University, Saint Petersburg, Russia
}

\begin{abstract}
Republic of Côte d'Ivoire is the world's largest producer and exporter of cocoa beans and a major producer and exporter of coffee and palm oil. By the fact that the country's economy is very sensitive to fluctuations in world prices for these products, in recent years there has been a diversification of the economy due to the development of other sectors of the industry, including the oil and gas complex. For a long time, the successful development of the oil and gas complex was observed, however, in 2017, the country's investment and geological attractiveness sharply declined, the contribution of the oil and gas sector in the gross domestic product decreased significantly. The article is devoted to identifying strengths and weaknesses, as well as opportunities and threats for the development of the Côte d'Ivoire oil and gas complex, analyze regulatory aspects of its functioning. As a result of the analysis and systematization, recommendations for improving instruments and methods of its regulation was made. The research was based on publications by Russian and international experts in scientific electronic and printed journals such as Energy Policy, Energy Reports, Petroleum Exploration and Development, The Extractive Industries and Society, Resources Policy, Resources, etc. The methodology of the research includes desk studies, comparative, logicalstructural, situational analysis, decomposition method and SWOT - analysis.
\end{abstract}

\section{INTRODUCTION}

Primary energy consumption grew at a rate of $2,9 \%$ last year, almost double its 10 -year average of $1,5 \%$ per year. By fuel, energy consumption growth was driven by natural gas, which contributed more than $40 \%$ of the increase. Oil consumption grew by an above average 1,4 million barrels per day, or 1,5\%. Oil remains the dominant fuel in Africa, Europe and the Americas, while natural gas dominates in the Commonwealth of Independent States (CIS) and the Middle East, accounting for more than half of the energy mix in both regions (BP: Statistical Review of World Energy - 2019 edition). In modern conditions, hydrocarbons are one of the main energy resources that can satisfy the energy needs of a growing population and a developing global economy (Smirnova\&Rudenko 2017).

In recent times, the promise of oil and gas reserves and resources in Africa (Khatib 2014; Modelevsky\& Modelevsky 2016) continues to generate a great interest in achieving national economy growth by its exploration and to attract new investment, especially from China and India (Ayanoore 2020; Graham\&Ovadia 2019). This fact led to different policy initiatives and regulatory base development in such countries as Nigeria, Angola, Tanzania, Uganda and Ghana, aimed at securing greater oil and gas rents (Ayanoore 2020; Hansen et al. 2016; Ovadia, 2016).

The economy of Republic of Côte d'Ivoire has always been based on agriculture, but the past few decades have seen economic diversification through the development of various industries, including the oil and gas complex (Côte d'Ivoire - Country Strategy Paper; Kuadio \& Dukart). Oil and gas production has been increasing for several years, but in recent years there has been 
a decline in its development: there is a decrease in the share in gross domestic product, in investment inflows, in the number of foreign companies and new projects.

It is known that policy initiatives and regulatory frameworks have a great impact on an effective industry development, including the oil and gas complex (Araujo \& Leoneti 2019; Lipina et al.2018; Mukesh 2016), so it can be suggested that regulatory framework in Republic of Côte d'Ivoire does not include measures that promote foreign investments, does not create conditions for successful functioning of oil and gas companies.

So, this paper attempts to investigate the current situation in the Côte d'Ivoire oil and gas complex, analyze and classify instruments and methods of state regulation in considered sphere, in order to make recommendations for accelerate the pace of oil and gas complex development.

\section{LITERATURE REVIEW}

Features and development trends of the developing countries' economies were investigated in the Lewis William Arthur, Rostow Walt Whitman, Samir Amin and others' works (Lewis 1955; Rostow 1971). The papers of many Russian and foreign scientists are devoted to general aspects of government regulation of a market economy, state regulation, functioning and development of the oil and gas sector (Cherepovitsyn, Moe \& Smirnova 2016; Deberdieva 2015; Gubin 2018; Mihalchenkova 2004; Oreshin 1999; Romasheva\&Ilinona 2019; Trofimov 2018).

A great number of researchers deal with regulatory framework in various context. Some papers examine the role and challenges of local content policies for petroleum and mining in different African countries (Graham\&Ovadia 2019; Ovadia 2016). Several publications are devoted to the study of oil and gas regulatory framework attractiveness to investors (Araujo \& Leonetti 2019; Florêncio 2016). In several papers, the authors tried to analyze institutional arrangements and the importance of the national oil and gas companies (Melyoki 2017; Paz \& Cendero 2013). Some authors investigated the government support tools, policy preferences, fiscal regimes, priorities for improving taxation in oil and gas industry (Cendrero \&Paz 2017; Lipina 2018; Mayer 2017; Smirnova \& Rudenko 2016), others analyze the regulatory changes and factors that resulted in the limited success of a regulatory framework (Khatib 2014; Mukesh 2016).

However, despite the large number of different publications on the research topic, several aspects of state regulation of oil and gas resources development in specific country require further research. A small number of articles are devoted to the Côte d'Ivoire oil and gas complex development and its regulation (Liu et al. 2010; Kuadio \& Dukart). So, the present study analyzes the prospects and problems of the Côte d'Ivoire oil and gas complex development, as well as policy incentives and regulatory framework.

\section{RESEARCH METHODS AND MATERIALS}

In the research, desk studies, comparative, logical-structural, situational analysis, decomposition method was carried out to generalize, analyze, and systematize information in order to understand the current situation in oil and gas complex, its importance for Côte d'Ivoire economy development and to reveal instruments and methods of state regulation in Côte d'Ivoire' oil and gas sector.

This paper uses a SWOT analysis method to identify the internal strengths (S) and weaknesses (W) and external opportunities (O) and threats (T) facing Côte d'Ivoire' oil and gas complex development. Findings from the SWOT analysis helps understand strengths, realize new opportunities as well as work towards the minimization or elimination of any possible threat to the business (Agyekum, Ansah \& Afornu).The SWOT analytical tool is widely accepted by researchers in the energy sector for energy planning.

The research was based on publications by Russian and international experts in scientific electronic and printed journals such as Energy Policy, Energy Reports, Petroleum Exploration and Development, The Extractive Industries and Society, Resources Policy, Resources, etc. 
The legal basis of the study is formed by analyzing the regulations of the Republic of Côte d'Ivoire, economic and financial reviews and statistical materials the Republic of Côte d'Ivoire government.

\section{RESULTS}

The study of oil and gas potential began in 1941, when the African Oil Company (SAP) announced that the subsoil of Republic of Côte d'Ivoire was not promising for the presence of hydrocarbon resources. However, exploration had been conducted since 1970, covering an area of 22,740 sq. km. in the coastal sedimentary basin of Côte d'Ivoire Republic, led to the discovery of the first oil field in 1974. The development of this area was carried out by the operator ESSO from 1980 to 1992 using a fixed platform. The continuation of prospecting has revealed signs of the presence of oil and natural gas in other areas of the coast. The Government of Côte d'Ivoire has entered contracts for prospecting with a few the world's largest oil monopolies. Since then, more than 207 wells have been drilled in the coastal sedimentary basin of Côte d'Ivoire Republic of, leading to the discovery of eight fields, four of which are currently in use. Most of the deposits now discovered are in the Abidjan region.

Analyzing the dynamics of oil and gas production, it can be concluded that their production has been unstable over the past 5 years (Figure 1). Real gross domestic product (GDP) growth was $7.4 \%$ in 2018 (Figure 2) and could remain above 7,0\% during 2020-2021. Figure 2 shows the share of the oil and gas industry in gross domestic product (GDP), which in 2018 amounted to $0.83 \%$ and significantly decreased compared to 2015 . Compared to income from agricultural production, oil and gas revenues look negligible.

This decrease occurred as a result of changes in oil and gas prices, the strengthening of other industrial sectors, and the absence of a well-developed investment policy.

According to the general index of attractiveness for investment, as shown by a Fraser Institute study, in 2017 Republic of Côte d'Ivoire fell from 17th to 78th place in the world; in terms of the policy perception index, it occupies 67 th place $(2016-40$ th place); in terms of geological attractiveness - 73rd place (2016 - 9th place). The significant decline happened due to an insufficiently effective and transparent legal and tax system, low quality infrastructure, trade barriers, relative political instability, security threats, poor quality of available geological information, and a lack of qualified personnel.

Among the advantages can be identified exploration potential, however, the development of deposits requires unique technologies - the depth of the sea reaches $3500 \mathrm{~m}$, clear regulation of environmental protection and protected areas.

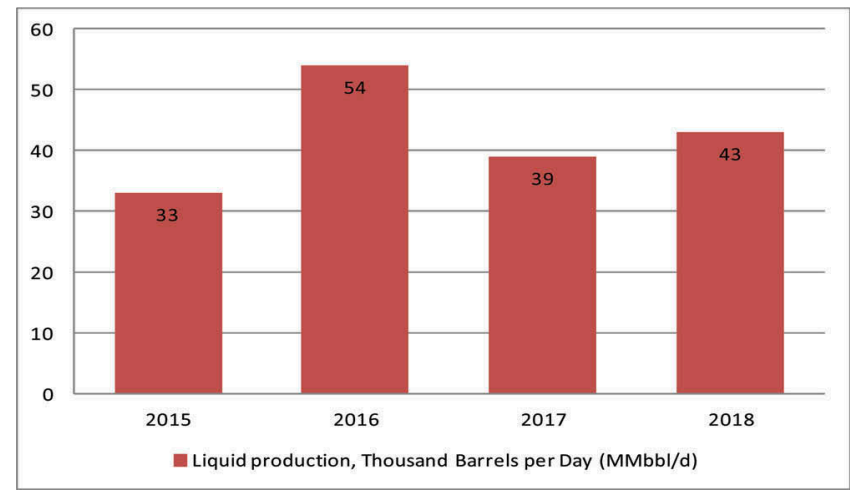

Figure 1. Cote d'Ivoire liquid production from 2015 to 2018. 


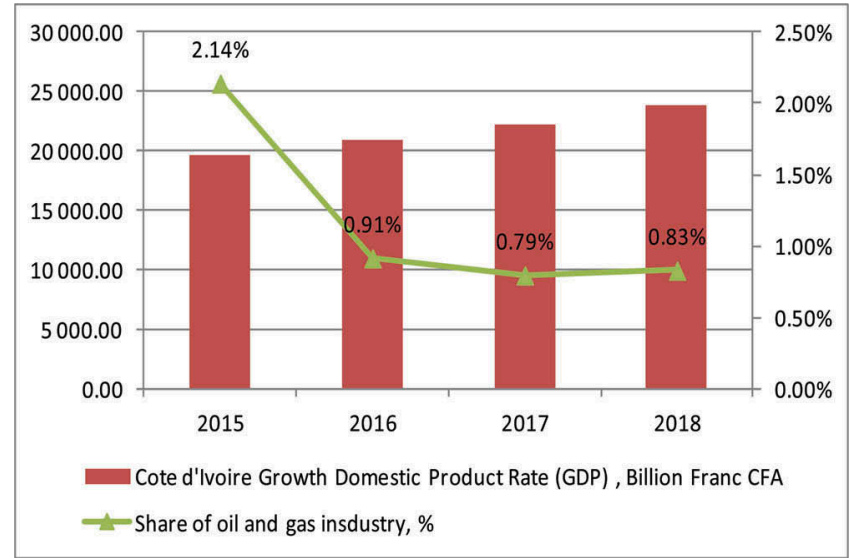

Figure 2. Cote d'Ivoire GDP Rate and contribution of Oil and gas sector to the local economy.

Nevertheless, according to the Ministry of Energy, it is planned to increase oil production over 5 years to 200 thousand barrels per day, which will be possible thanks to recently discovered large oil and gas fields, as well as ongoing exploration drilling.

In the paper, strengths-weaknesses-opportunities and threats analysis (SWOT) as a methodology for analyzing the Côte d'Ivoire Republic oil and gas complex from an internal and external perspective was made (Table 1).

Table 1. SWOT analysis of the Côte d'Ivoire Republic oil and gas complex.

\begin{tabular}{ll}
\hline Strengths & Weaknesses \\
\hline - significant amount of forecast resources; & - capital-intensive structure of the complex; \\
- equipment for hydrocracking (two atmospheric & - lack of geological data and long-term process of \\
distillation units of 75,000 barrels per day and & geological exploration; \\
a hydro-reactor of 18,000 barrels per day); & - difficult development conditions; \\
- major exporter of petroleum products; & - lack of a clear investment attractiveness policy; \\
- state priority; & - lack of a unified state strategy for the development \\
- presence of foreign companies & of the oil and gas complex to increase revenues \\
& from the oil and gas production; \\
& - lack of necessary infrastructure; \\
& - unstable growth in crude oil and natural gas pro- \\
& duction from 2015 to 2018; \\
& - an insufficiently effective and transparent legal \\
& and tax system; \\
& - low technological structure; \\
& - high depreciation of fixed assets \\
\hline Opportunities & Threats \\
\hline - expansion of the oil and gas using (growth in & -high risks of changes in oil and gas prices; \\
internal and external demand); & - development of alternative energy and fuel \\
- introduction of new technologies for the develop- & sources; \\
ment of oil and gas fields. & - negative impact on ecosystems of the coastal zone \\
- liquefied natural gas projects development & of Côte d'Ivoire; \\
& - lack of incentives for subsoil users (economic, \\
& administrative, financial) to implement projects; \\
& - further decline in investment activity \\
\hline &
\end{tabular}


The oil and gas complex of Republic of Côte d'Ivoire has a number of strengths, the potential for development and can become a key factor in the country's economy development for the following reasons:

1. The exploitation of oil and gas fields will increase budget revenues and the level of wellbeing of society.

2. Providing own needs in oil products.

3. Obtaining additional income from the sale of refined products.

4. Stimulating the development of related sectors of the economy.

However, as can be seen from the Table 1, in recent years there has been an increase in negative trends in the development of the oil and gas complex of Côte d'Ivoire Republic, due to various factors, including the lack of policy incentives and the underdevelopment of the regulatory framework.

Policy incentives and the regulatory framework plays a decisive role for the successful development of various industries, including oil and gas. The formation of a favorable investment climate, the expansion of the mineral resource base is impossible without targeted political intervention through the development of a regulatory framework, the formation of a system of incentives and restrictions, the introduction of support mechanisms, international cooperation. All existing instruments of state regulation can be classified as administrative and economic. Administrative is actively used with the aim of directly influencing the object of regulation: legislative acts, standards, prohibitions. With the help of economic instruments, state structures act on objects of regulation in order to ensure their necessary behavior by influencing material interests. Economic methods provide more options for choosing actions, since they are indirect methods that motivate effective investment. Moreover, economic and administrative instruments of state regulation are interconnected. So, any instrument related to economic carries the elements of administration, since it is controlled by one or another state structure.

Figure 3 shows the process of oil and gas complex state regulation in Côte d'Ivoire Republic.

The Government of Côte d'Ivoire Republic as an oil-producing country has adopted a series of laws defining activities in the oil industry, in particular the Petroleum Code, which

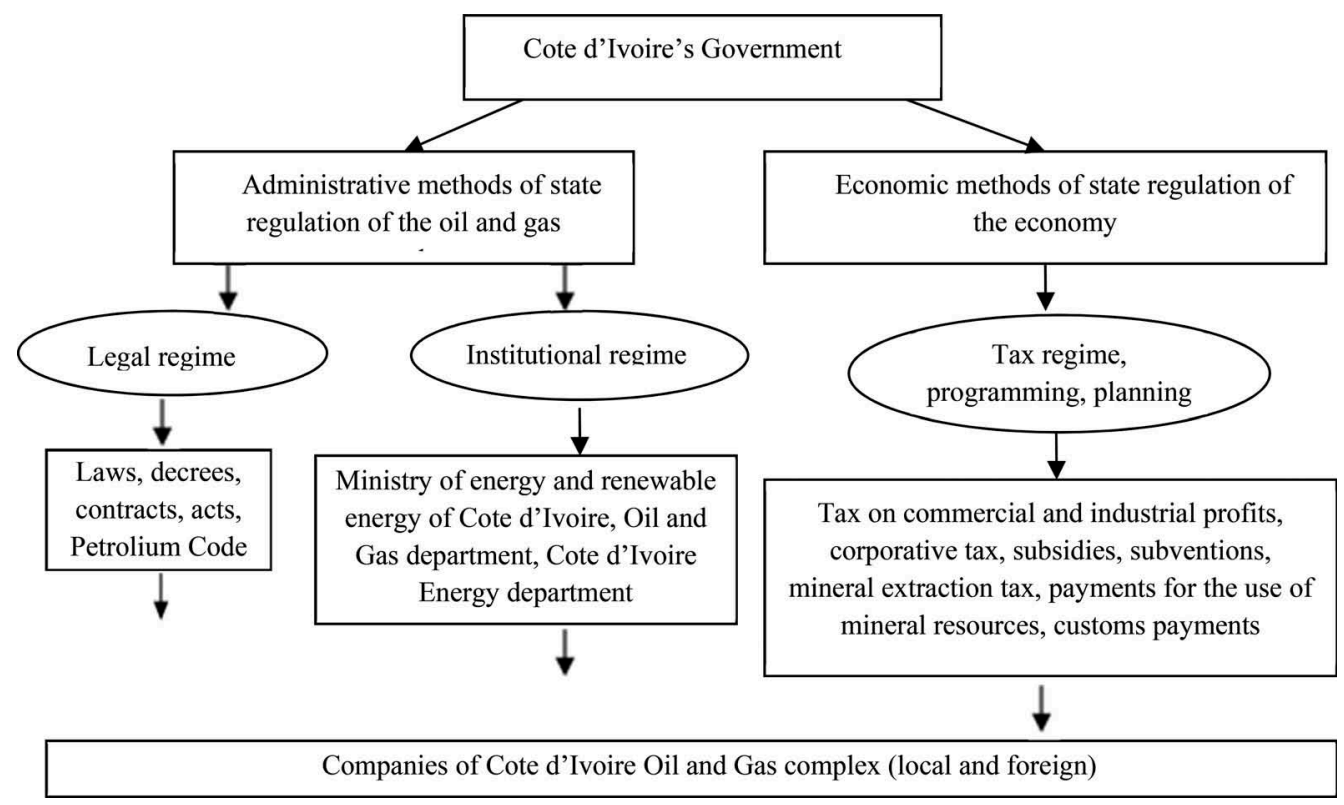

Figure 3. The mechanism of Cote d'Ivoire oil and gas complex state regulation. 
defined Côte d'Ivoire's oil policy. The national oil company Petroci was created, which became an instrument for implementing the national oil policy. The following tasks were set for this company (Amadou \& Makarova):

- research and exploitation of deposits of all types of hydrocarbons;

- Association of industry, transport and trade in hydrocarbons and their products;

- Supervision of all financial transactions related to oil industry facilities.

Côte d'Ivoire Product Sharing Agreement Model

Part I. Norms and procedures governing the right of a contractor to conduct oil transactions, as well as a description of the contract territory.

Part II Description of financial conditions and production features. The contractor provides all the financing and technology that is required to carry out activities under the contract, and assumes the risk associated with costs. Therefore, investor is economically interested in the effective development of the field on the contract area.

Part III. Rules and procedures relating to production sharing (including compensation and remuneration of the contractor) and the rules for the payment of income tax for the contractor

The remaining part of the oil recovered after reimbursement is divided between the contractor and PETROCI on the terms specified in the contract (often $10 \%$ to $15 \%$ of the oil recovered depends on the contract). Contractor income tax is levied after PETROCI withdraws its share of the profits. PETROCI pays the remaining taxes associated with the contract work.

Part IV. Aspects of organization and cooperation. PETROCI represents the Government of Côte d'Ivoire to the contractor, the contractor is responsible to PETROCI for its activities in accordance with the terms of the contract. Ownership of equipment and information. All equipment purchased and delivered in Côte d'Ivoire by the contractor becomes the property of PETROCI. Equipment of service companies and leased equipment are returned. All information obtained during the contract work is the property of PETROCI.

Part V. Legal and non-operational issues. The main obligation is that the contractor should provide $75 \%$ of local participation in the work.

To attract investment in the Cote d'Ivoire oil and gas complex, it is necessary to develop an organizational and economic mechanism providing for regulatory framework development in such areas as tax legislation, investment, provision of mineral resources for use, and lending.

Government policies to support the Cote d'Ivoire oil and gas complex should include the following:

1. Stimulation of monetary relations, involving the creation of an objective environment for the development and successful functioning of local companies

2. Optimization of tax legislation, providing an effective regime for the foreign and local companies

3. Creation of an investment climate conducive to attracting foreign companies to exploration

4. Development of an understandable strategy and programs in the field of oil and gas production, oil refining, transportation of oil and gas resource

5. Improving the mechanism for oil and gas exploitation by reviewing the conditions for concluding production sharing agreements

A more detailed presentation of this mechanism will be considered in future studies.

\section{CONCLUSION}

Republic of Côte d'Ivoire ranks first in the world to produce cocoa beans and one of the leading positions in the export of coffee and palm oil. However, in recent years, the prices of these goods have been unstable, therefore the country's government is forced to diversify the economy, primarily due to the development of the oil and gas sector. 
For a long time, oil and gas production in Côte d'Ivoire grew and the country was considered as one of the promising areas for the search and production of hydrocarbons. However, the civil war in 2011 led to a serious drop in oil and gas production, the restoration of which occurred only in 2015. Today, a number of negative trends are contributing to a decrease in the country's investment attractiveness. The paper identifies the main trends in the development of the oil and gas complex of Côte d'Ivoire, analyze and classify instruments and methods of state regulation.

In the research the authors came to conclusion that such aspects as planning and programming at the state level, clear legislation, adequate country-specific taxation and crediting are critical to investment attractiveness increasing and the Cote d'Ivoire oil and gas complex development.

\section{ACKNOWLEDGEMENT}

The research was carried out with the financial support of the Russian Foundation for Basic Research (RFBR), the project "Evolution of methodology of technological forecasting of development of the interconnected industrial and social and economic systems at hydrocarbon resources development in the Arctic " No. 18-010-00734".

\section{REFERENCES}

Amadou, K. S. \& Makarova, M.G. 2014. Assessment of opportunities for elimination oil contamination of the coastal area of Cote d'Ivoire Vestnik RUDN Ecology and Life Safety series 4: 89-96.

Agyekum, E.B., Ansah M.N.S. \& Afornu K.B. 2020. Nuclear energy for sustainable development: SWOT analysis on Ghana's nuclear agenda Energy Reports 6:107-115 https://doi.org/10.1016/j. egyr.2019.11.163.

Araujo, F.C. \& Leoneti, A.B. 2019. How attractive is Brazil's oil and gas regulatory framework to investors? The Extractive Industries and Society 6(3): 906-914 https://doi.org/10.1016/j.exis.2019.05.009.

Ayanoore I., 2020. The politics of local content implementation in Ghana's oil and gas sector The Extractive Industries and Society Article in press.

BP: Statistical Review of World Energy - 2019 edition. Available at: https://nangs.org/analytics/bp-statis tical-review-of-world-energy.

Côte d'Ivoire - Country Strategy Paper (CSP 2018-2022) combined with 2018 Country Portfolio Performance Review African Development Bank Group https://www.afdb.org/en/countries/west-africa/ cote-divoire.

Cherepovitsyn, A., Moe, A. \& Smirnova, N. 2016. Development of transboundary hydrocarbon fields: Legal and economic aspects Indian Journal of Science and Technology 9(46), doi:10.17485/ijst/2016/ v9i46/107527.

Deberdieva, E.M. 2015. Regulation of the oil and gas sector of the economy: state and corporate aspects Theory and practice of social development 6: 60-62.

Florêncio, P. 2016. The Brazilian 2010 oil regulatory framework and its crowding-out investment effects Energy Policy 98: 378-389 https://doi.org/10.1016/j.enpol.2016.08.038.

Graham, E. \& Ovadia, J.S. 2019. Oil exploration and production in Sub-Saharan Africa, 1990-present Trends and developments The Extractive Industries and Society 6(2): 593-609 https://doi.org/10.1016/j. exis.2019.02.001.

Gorbunova, E.N. 2015. Reforming the tax system of the Russian oil sector Taxes and Financial Law 4: $124-127$.

Gubin, E.P. 2018. State regulation of the market economy and entrepreneurship. Legal problem JURIST-M: 320.

Hansen, M.W. et al. 2016. The economics and politics of local content in African extractives: Lessons from Tanzania, Uganda and Mozambique Forum for Development Studies, Taylor \& Fransis.

Hunter, T. 2014. The role of regulatory frameworks and state regulation in optimising the extraction of petroleum resources A study of Australia and Norway The Extractive Industries and Society 1(1): 48-58 https://doi.org/10.1016/j.exis.2014.02.001.

Kapkanchikov, S.G. 2018. State regulation of the economy KnoRus-M: 528. 
Khatib, H. 2014. Oil and natural gas prospects Middle East and North Africa Energy Policy 64: 71-77 https://doi.org/10.1016/j.enpol.2013.07.091.

Kuadio, A. K. D \& Dukart S. A. 2017. Prospects for the development of the economy of Cote d'Ivoire Materials of the International scientific-practical conference (Novosibirsk) 2 (161)

Lewis,William Arthur, 1955. The theory of economic growth Allen \& Unwin: 455

Lipina, S.A., Bocharova, L.K. \& Belyaevskaya-Plotnik L.A. 2018. Analysis of Government Support Tools for Mining Companies in the Russian Arctic Zone. Zapiski Gornogo Instituta 230: 217-222. https://doi.org/10.25515/PMI.2018.2.217.

Liu, J. et al. 2010. Exploration targets in the Côte d'Ivoire-Ghana transform margin in Equatorial West Africa Petroleum Exploration and Development February 37(1): 43-50 https://doi.org/10.1016/S18763804(10)60013-4.

Mayer, A. 2017. Political identity and paradox in oil and gas policy: A study of regulatory exaggeration in Colorado US Energy Policy 109: 452-459 https://doi.org/10.1016/j.enpol.2017.07.023.

Melyoki, L.L. The governance of the petroleum sector in Tanzania Institutional arrangements and the role of the National Oil Company The Extractive Industries and Society 4(1): 180-190 https://doi.org/ 10.1016/j.exis.2016.12.005.

Mihalchenkova, N.A. \& Smetanina, T.M. 2004. State regulation of the economy Syktyvkar: KRAG$\mathrm{SiU}: 35$.

Modelevsky, M.S. \& Modelevsky, M.M. 2016. Assessment of the discovered and undiscovered oil and gas of Africa Russian Geology and Geophysics 57(9): 1342-1348 https://doi.org/10.1016/j.rgg.2016.08.019.

Mukesh, S.S.S. 2019. Impact of regulatory framework on bidding behavior of firms policy implications for the oil \& gas sector Energy Policy 131: 33-42 https://doi.org/10.1016/j.enpol.2019.01.075.

Ovadia, J.S. 2016. Local content policies and petro-development in Sub-Saharan Africa A comparative analysis Resources Policy 49: 20-30 https://doi.org/10.1016/j.resourpol.2016.04.003.

Orechin, V.P. 1999. State regulation of the national economy V. P. Oreshin. - Moscow: Moscow state University. M. V. Lomonosova 1999: 12.

Paz, M.J. \& Ramírez-Cendrero, J.M. 2013. How important are national companies for oil and gas sector performance? Lessons from the Bolivia and Brazil case studies Energy Policy 61: 707-716 https://doi. org/10.1016/j.enpol.2013.05.126.

Ramírez-Cendrero, J.M. \& Paz, J.P. 2017. Oil fiscal regimes and national oil companies: A comparison between Pemex and Petrobras Energy Policy 101: 473-483 https://doi.org/10.1016/j.enpol.2016.11.009.

Rostow, W. W. 1971. Politics and the Stages of Economic Growth Cambridge.

Romasheva,N. \& Ilinova A. 2019. CCS Projects: How Regulatory Framework Influences Their Deployment Resources 8(4), 181 https://doi.org/10.3390/resources8040181.

Smirnova, N.V. \& Rudenko, G.V. 2016. Priorities for improving taxation in oil industry in Russia. Indian Journal of Science and Technology 9(19). doi:10.17485/ijst/2016/v9i19/93907.

Trofimov, S.E. 2018. On state regulation of the oil and gas complex Voprosy Ekonomiki 1: 151-160 https://doi.org/10.32609/0042-8736-2018-1-151-160. 


\title{
Implementation of renewable energy into the mining industry: A hybrid energy system
}

\author{
K. Pollack, J.C. Bongaerts \& C. Drebenstedt \\ Technical University Bergakademie Freiberg, Institute for Mining and Civil Engineering, Gustav-Zeuner \\ Straße, Freiberg
}

\begin{abstract}
An availability of technological solutions together with priorities to decarbonize the mining sector lead renewable energy (RE) to become an attractive energy source for the mining industry. Pilot projects were run in several countries. However, there is still a lack of knowledge on hybrid energy systems (HES) as an efficient technological solution towards integration of RE into the mining industry.

A HES is proposed to reduce energy cost for off-grid mines, which have much higher energy related costs then on-grid mines. In addition, replacing a part of diesel consumption by $\mathrm{RE}$ will reduce greenhouse gas (GHG) emissions and lead a mine towards sustainable operations. To take a decision in favor the integration of a HES into the mining industry globally, a technological feasibility of these systems is required. This work aims to provide a detailed analysis of a HES and a comparison of different technological solutions for powering a mine. The main results of this paper are a comparative analysis of a HES, microgrids, stand-alone systems as a technological solution to power the mining industry. Moreover, to discuss benefits and challenges of a HES and input parameters which have to be optimized in order to ensure a secure energy consumption of a HES.

This analysis of a HES can be generalized to all settings of mines, with specific practical implications especially for off-grid mines. This paper aims to attract attention of policy makers, decision makers, and experts on fossil fuel and RE technologies in order to give alternatives in powering the mining industry and can be applied worldwide.
\end{abstract}

Keywords: Mining Industry, Renewable Energy, Hybrid Energy System, Levelized Cost of Electricity (LCOE), $\mathrm{CO}_{2}$ Emissions

\section{INTRODUCTION}

The United Nations General Assembly in 2015 has been set up the sustainable development goals and the global goal on energy towards energy transition as follows: ensure universal, reliable, and affordable access to innovative energy services; increase substantially the share of $\mathrm{RE}$ in the worldwide energy mix; and double the worldwide rate of improvement in energy efficiency (Gielen, et al., 2019). To reach these targets, $\mathrm{CO}_{2}$ emission should be regulated under 1,100 gigatons; further, around $85 \%, 50 \%$, and $34 \%$ of global coal, natural gas, and oil reserves must not be combusted before 2050 (Shen, et al., 2018).

The highest proportion causing approximately $25 \%$ of all greenhouse gases (GHG) is emitted by electricity generation and heat, increasing the progress of RE sources is a valuable strategy for decreasing GHG emissions and thus resisting climate change (Jenniches 2018). RE has the capability to offer energy free of air pollutants and GHG by emitting (almost) zero of these gasses (Hussain, Arifen Aslam 2017).

According to the International Energy Outlook (Vidal 2018), with energy consumption by an industry about $40 \%$ of global energy consumption, about a quarter of the energy globally is used to produce mineral raw materials. In South Africa, the situation is similar, as the mining 
sector consumes more than $30 \%$ of total electricity generation and it supplies over $90 \%$ of all primary energy to generate electricity (Holman 2019).

The mining industry significantly depends on energy prices (Zharan and Bongaerts 2018). It appears, the share of energy costs accounts for 30-35\% of all operating costs of mining operations (Slavin, 2017), (Vyhmeister, et al., 2017), (Cormack, et al., 2017).

The recent years, PV modules have been the fastest developing RE technology. So a dieselPV hybrid energy system may produce about $1.8 \mathrm{GWh}$ of electricity per year, or about $60 \%$ of the mine's annual daytime power needs (Zharan, 2017). A hybrid PV-diesel system is more reliable in electricity production than a stand-alone diesel system and a stand-alone PV system Pollack, (Bongaerts and Drebenstedt 2020). Consequently, a HES can be an effective solution to enhance RE integration towards the mining industry.

Sustainable mining comprises many issues, such as engaging with communities towards establishing accountability and responsibility to enhance the industry's performance; establishing clear relationships with communities as a basic metric for investment decisions; decreasing the environmental impact in all phases of the mining operation; and finally striving for high levels of safety and health at work and maintain equally beneficial relationships with government authorities.

The research questions addressed in this paper are as follows:

- Can a HES be applicable in mining settings?

- What can be benefits and challenges of a HES to be implemented in mining operations?

- Which input parameters have to be optimized in order to ensure a secure energy consumption of a HES?

- What is a comparative analysis of a HES and conventional generator as two alternatives to power the mining industry?

\section{LITERATURE REVIEW}

By definition, any energy resource that is naturally regenerated over a short-time scale and derived directly from the sun (such as thermal, photochemical, and photoelectric), indirectly from the sun (such as hydropower, wind, and photosynthetic energy stored in biomass), or from other natural mechanisms and movements of the environment (such as tidal and geothermal energy) (Ellabban, Abu-Rub and Blaabjerg 2014) is considered as RE. The different RE technologies (e.g. hydro power, wind, solar photovoltaic (PV), geothermal energy, and others) are characterized by different performance characteristics and each among them requires specific location factors. Consequently, not each location is similarly appropriate (Jenniches 2018). Therefore, if this location is not attractive for RE, conventional energy sources still might be preferred, especially for on-grid mines.

A HES is a combined use of two or more energy technologies, such as photovoltaic, diesel, wind, and geothermal energy technologies (Mazzeo, et al. 2018), (Khan, Yadav and Mathew 2017). There are many types of a hybrid RE system, such as PV-gas, PV-diesel (Breyer, Goerig and Schmid 2011), diesel-PV-wind-batteries (Forough and Roshandel 2018), wind-diesel, PVwind, wind-fuel cell (Khan, Yadav and Mathew 2017), solar-wind (Yang, Lu and Zhou 2007). All of these HESs can be implemented in mining operations (Zharan and Bongaerts 2017).

Taking intermittent energy supply generated by renewables into account, it is still considered unfeasible to use a RE source without backup as a reliable energy source to power a mine. The potential temporal disparity of demand and supply raises two vital questions: how to serve demand at times when supply is rare, and how to deal with fluctuating RE at times when there is too much supply (Zerrahn, Schill and Kemfert 2018).

In the mining industry, characterized by a huge energy demand, strong safety requirements and a strong interaction and integration of operating sectors the first questionis more relevant. Thus, a combination of two or more energy sources (both renewables and non-renewables) so-called a HES can contribute to the issue of intermittency. This HES is completely sufficient and can be developed without exclusively dependence on a grid. 
Nevertheless, fossil fuel energy sources are still more reliable and suitable for industrial needs with high daily level of energy consumption. However, replacing conventional energy sources by RE is feasible for the mining companies nowadays and was done at several pilot projects (Zharan and Bongaerts 2017). On the one hand, the investigated topic has a strong business and scientific interest for project development from mining and RE companies. On the other hand, there is only a little contribution on scientific studies related to the integration of RE into the mining industry.

To our knowledge, some of them investigate perspectives on this topic. Particularly, (Nasirov and Agostini 2018) published a paper with particular focus on mining experts' perspectives on the determinants of solar technologies adoption in the Chilean mining industry. Additionally, a review of photovoltaic and wind power systems utilized in the mining industry was made by (Choi and Song 2017).

\section{RESEARCH METHODS AND MATERIALS}

This paper contains a comparative analysis of a HES. The description, benefits, barriers, and challenges of a HES are first discussed. Based on this, a deeper technological analysis of a HES is performed accounting for the different types of a HES. The input characteristics, optimization and control of a HES, and total cost parameters of a HES are discussed with a focus on mining settings. Additionally, case studies with particular focus on cost of a HES for various off-grid locations are compared applying the literature review method. Similarly, a detailed description of each technology as a part of a HES is given with the focus on the integration into the mining sector. The technologies observed are solar PV, wind, battery storage, and conventional generator systems (i.e. diesel engines, gas turbi nes). The summary and recommendations on a comparative analysis of a HES are given.

\section{RESULTS AND ANALYSIS}

A set of case studies (Zharan and Bongaerts 2017) for the mining industry shows, that a most applicable HES are stand-alone systems (so-called microgrids) for remote mining settings. By definition, a microgrid is a small-scale power grid consisting of distributed generation units, electrical or heat loads which operates as a single-controllable unit at the distribution voltage level, and energy storage systems (Mirsaeidi, Dong and Said 2018). On the one hand, a comparison of pros of on-grid and off-grid HESs including configurations of these systems is given as follows.

\section{Pros of an off-grid HES:}

- A HES can be either connected to many load centers or can be operated as a source of supply for one or two loads (Nema and Dutta 2012);

- A stand-alone system does not require a distribution system.

Pros of an on-grid HES (Nema and Dutta 2012):

- the stability of the overall system relies on grid in case of any technological problems of a HES;

- Feeding power to a grid in cases of redundant energy generation;

- Boosting the voltage and minimizing power cuts strengthens the grid.

On the other hand, due to intermittency of RE, it is not possible to replace completely fossil-based energy by RE in the mining industry (Pollack and Bongaerts 2019). Indeed, RE sources cannot usually meet required energy demand of a mine at all times.

However, there is a solution such as a HES combining RE and fossil fuel energy generating technologies towards avoiding intermittency of renewables. In this matter, a fossil fuel system considers as base-supply and backup system preventing a fluctuation of RE. In many remote 
applications, a diesel generator (DG) is used as a backup system (Jamshidi and Askarzadeh 2019) and usually used at the time, when energy generated from renewables cannot completely cover the mining needs or RE sources are not available.

Moreover, DG is usually added to a HES for its stabilization. However, a conventional generator system is still the main energy generating technology for electricity supply in off-grid mining operations. Table 1 shows a comparison of the benefits and challenges of a conventional generator.

A comparison of a HES and conventional generator can be seen in Table 2. This table shows the benefits and challenges of two energy generating technologies.

The shortcoming of the volatility of HES output can be avoided by adding battery storage to a HES. Further, a HES can be integrated to a new or as add-on to an already operating mine, thus, minimizing supplementary investments. Consequently, almost all challenges of a HES seen in Table 2 can be prevented, thus, giving to a HES more benefits to be integrated in mining settings comparing to a conventional generator.

A switch between different energy sources of a HES can lead to power outage (interruption in power supply). As defined by the Institute of Electrical and Electronics Engineers, an interruption means the complete loss of supply voltage or load current (Diboma and Tatietse

Table 1. Comparison of benefits and challenge of a conventional generator.

\begin{tabular}{ll}
\hline Benefit & Challenge \\
\hline $\begin{array}{l}\text { Improved power reliability, quality and protecting } \\
\text { against outages }\end{array}$ & $\begin{array}{l}\text { So far, the most common DG technologies operate } \\
\text { by diesel and gasoline-fueled engines depending on } \\
\text { diesel price fluctuation }\end{array}$ \\
$\begin{array}{ll}\text { Applicable for off-grid locations } \\
\text { Reduce project costs over time due to improving } \\
\text { of adjustment of additional demand and supply }\end{array}$ & $\begin{array}{l}\text { Utility competitive rates } \\
\begin{array}{l}\text { Provides standby power and peak power and } \\
\text { energy related costs savings }\end{array}\end{array}$ \\
$\begin{array}{l}\text { Avoiding a fuel disruption risks and high system } \\
\text { efficiency }\end{array}$ & $\begin{array}{l}\text { A fossil-based system produces the } \mathrm{CO}_{2} \text { emissions by } \\
\text { Utility competitive rates }\end{array}$ \\
\hline
\end{tabular}

Source: adapted from (National Renewable Energy Laboratory 2013)

Table 2. Benefits and challenges of a HES and conventional generator.

\begin{tabular}{|c|c|c|}
\hline \multirow[t]{2}{*}{ Benefit } & HES & Conventional generator \\
\hline & $\begin{array}{l}\text { Can be integrated into an existing mining } \\
\text { energy system } \\
\text { Reliable technology } \\
\text { Low GHG emissions impact } \\
\text { The instability of a system output can be } \\
\text { compensated by including a suitable energy } \\
\text { storage system (Behera and Nandkeolyar } \\
\text { 2017) }\end{array}$ & $\begin{array}{l}\text { Well-known established technology } \\
\text { Predicted energy supply }\end{array}$ \\
\hline \multirow[t]{2}{*}{ Challenge } & HES & Conventional generator \\
\hline & $\begin{array}{l}\text { An interruption in power supply require } \\
\text { stabilization } \\
\text { Updating or upgrading the equipment which } \\
\text { is presently applied in the distribution net- } \\
\text { works that require supplementary } \\
\text { investments } \\
\text { Relatively high initial cost }\end{array}$ & $\begin{array}{l}\text { High O\&M cost (Laquaniello, Montanari } \\
\text { and Salladinic 2017) } \\
\text { High fuel consumption due to ineffciency } \\
\text { under low load operation (Laquaniello, Mon- } \\
\text { tanari and Salladinic 2017) } \\
\text { High GHG emissions impact }\end{array}$ \\
\hline
\end{tabular}

Source: self-generated 
2013). For the mining industry, as a large energy consumer, a power outage can lead to unexpected expenses. Consequently, sizing, optimization and control, interaction and monitoring have to be carefully planned in order to avoid blackout of a HES.

Technological analysis of a HES. Usually, a HES is designed explicitly for each individual mine. To supply industrial load with reliable and stable power, the HES design is a very complex process and has to take all input characteristics into account, such as RE sources input parameters, total costs of a HES, and optimization and control of a HES. Overall these input characteristics influence on optimization of a system and storage and output of a HES. Figure 1 shows these input characteristics of a HES powering a mine.

Based on a study (Zharan and Bongaerts 2017) and depending on its location, the most feasible RE systems for a mine are solar PV, solar thermal, concentrated solar power (CSP), and wind. These RE systems can be grid-connected or used as a stand-alone system. For offgrid stand-alone systems, a conventional generator (operated by diesel or natural gas) is the stabilizing component of this system buffering the alternative supply of RE. In addition, in off-grid locations storage plays an important role for reliability of a HES. Nevertheless, a HES including storage is cost intensive, therefore, a question of reliability stays in conflict with total costs of a HES. On the one hand, the grid availability can be an option towards avoiding storage and making a HES project less cost intensive. On the other hand, a HES is economic relevant for off-grid mines where the energy costs are higher than for on-grid mines.

As summarized in Figure 1, the input characteristics of a HES require optimization in terms of costs, generation capacity, and volatility. Generation capacity of a HES depends on RE sources input parameters, such as solar irradiation, ambient temperature, and wind speed. The total costs of a HES consist of CAPEX, operating expenditures (OPEX), fuel cost, transmission cost, financing mechanism, and operation related losses. Finally, a volatility of a HES can be stabilized by optimization and control integrating monitoring of a system i.e.

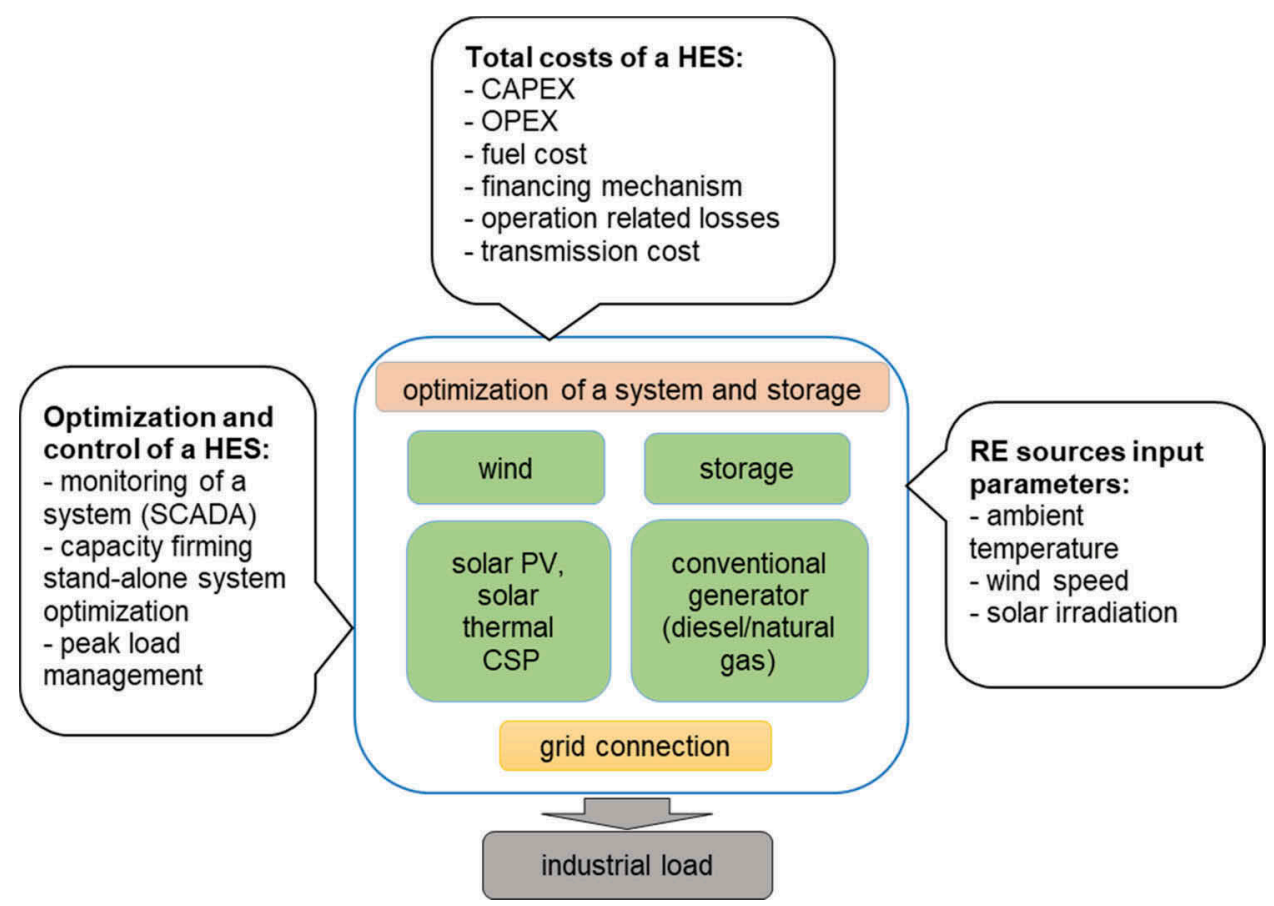

Figure 1. Input characteristics of a HES to be implemented in mining sector.

Source: self-generated 
Table 3. Analysis of each technology used to power a mine.

\begin{tabular}{|c|c|c|}
\hline Technology & Description of technology & Source \\
\hline $\begin{array}{l}\text { Conventional } \\
\text { DG/gas CC }\end{array}$ & $\begin{array}{l}\text { Ability to operate from } 100 \% \text { load down to } \\
\text { zero load } \\
\text { It ensures very fast response on required load } \\
\text { It is possible to declutch from the alternator } \\
\text { to stop } \\
\text { Can be used as a backup going in stable } \\
\text { reserves operations }\end{array}$ & $\begin{array}{l}\text { Zharan and Bongaerts 2017, Zhang, et al. } \\
2019\end{array}$ \\
\hline Wind & $\begin{array}{l}\text { Can be easy connected to a DG } \\
\text { Can be feasible solution at night-time sup- } \\
\text { porting a HES with additional power }\end{array}$ & Buonomano, et al. 2018 \\
\hline Solar PV & $\begin{array}{l}\text { Can be easy connected to a DG } \\
\text { A significant decrease in LCOE } \\
\text { No need of storage by using solar energy in } \\
\text { a direct way }\end{array}$ & Chaib, Achour and Kesraoui 2016 \\
\hline HES & $\begin{array}{l}\text { Secure and dynamic load balance between } \\
\text { variations in energy consumption and solar } \\
\text { intermittency } \\
\text { Diesel fuel savings } \\
\text { Simple in operation and maintenance } \\
\text { Reliable power supply } \\
\text { CAPEX of this HES is more than offset by } \\
\text { the direct fuel savings up to } 30-40 \% \text { per year, } \\
\text { assuming an usual } 24 \text { hour demand cycle. }\end{array}$ & $\begin{array}{l}\text { (Hybrid Power for Mining 2018), (Pollack } \\
\text { and Bongaerts 2019), (Zharan and Bon- } \\
\text { gaerts 2017) }\end{array}$ \\
\hline
\end{tabular}

Source: self-generated

a supervisory control and data acquisition (SCADA) control system, a stand-alone system optimization, peak load management, and capacity firming.

Every HES requires system optimization, system sizing, and economic modelling. These requirements can be reached using software dealing with a techno-economic feasibility of a HES, such as hybrid optimization of multiple energy resources (HOMER) microgrid software, hybrid optimization by genetic algorithms (HOGA) software (Zhang, et al. 2019), RETScreen, Dymola/Modelica, HYBRID 2, and Hybrid (DesignerPadron, et al. 2019). Furthermore, HYBRIDS is a Microsoft Excel spreadsheet-based application tool for a RE assessment and needs environmental data for each month of the year and daily average load (Anoune, et al. 2018). Each of this software can be used to optimize and model of a HES integrated into the mining sector. Further, various methods can be used to optimize a HES, such as nonlinear programming, linear programming, genetic algorithm, and others (Zhang, et al. 2019). Table 3 shows the analysis of each technology used to power a mine.

\section{CONCLUSION}

- A HES is widely applicable in existing and new energy systems in mining settings. Moreover, a HES has its benefits (i.e. improved power reliability, quality and protecting against outages, applicable for off-grid locations, and provides standby power and peak power and energy related costs savings) and challenges (i.e. relatively high initial cost, an interruption in power supply require stabilization), and is feasible to be implemented in mining operations. 
- A technological analysis of a HES has been done, and input characteristics of a HES have been analyzed. These characteristics require optimization in terms of costs, generation capacity, and reliability.

- Each HES requires the optimal sizing, cost optimization, and system stabilization process before applying into mining settings.

- Despite a noticeable increase in projects integrating a HES into the mining industry and environmental issues, conventional generator systems are still a dominant technology in mining operations providing a reliable energy supply. Therefore, a conventional generator is an essential part of a HES and can be used as a backup of each HES.

The further investigation will be focus on a technological analysis of storage facilities as a part of a HES with particular focus on off-grid mining settings.

\section{REFERENCES}

Anoune, K., Bouya M., Astito A., \& Abdellah, A. B. 2018. Sizing methods and optimization techniques for PV-wind based hybrid renewable energy system: A review. Renewable and Sustainable Energy Reviews 93: 652-673.

Behera, S. \& Nandkeolyar S. 2017. Analysis of isolated hybrid system for power supply to a remote island. Energy Procedia 117: 1040-1046.

Buonomano, A., Calise F., MD d'Accadia, \& Vicidomini M. 2018. A hybrid renewable system based on wind and solar energy coupled with an electrical storage: dynamic simulation and economic assessment. Energy. doi: 10.1016/j.energy.2018.05.006.

Chaib, A, Achour D., \& Kesraoui M. 2016. Control of a solar PV/wind hybrid energy system. Energy Procedia 95: 89-97.

Choi, Y., \& Song J. 2017. Review of photovoltaic and wind power systems utilized in the mining industry. Renewable and Sustainable Energy Reviews 75: 1386-1391.

Cormack, D., Wood M., Swart A., \& Davidse A. 2017. Renewables in Mining: Rethink, Reconsider, Replay. Deloitte Touche Tohmatsu, 27. Accessed 10 11, 2018. https://www2.deloitte.com/con tent/dam/Deloitte/global/Documents/Energy-and-Resources/gx-renewables-in-mining-final-reportfor-web.pdf.

Diboma, B.S, \& Tamo Tatietse, T. 2013. Power interruption costs to industries in Cameroon. Energy Policy 62: 582-592.

Ellabban, O., Abu-Rub, H., \& Blaabjerg, F. 2014. Renewable energy resources: Current status, future prospects and their enabling technology. Renewable and Sustainable Energy Reviews 39: 748-764.

Forough, A.B., \& Roshandel, R. 2018. Lifetime optimization framework for a hybrid renewable energy system based on receding horizon optimization. Energy 150: 617-630.

Gielen, D., Boshell, F., Saygin D., Bazilian, Morgan D., \& Wagner, N. 2019. The role of renewable energy in the global energy transformation. Energy Strategy Reviews 24: 38-50.

Holman, J. 2019. Big Eskom rate hike a 'death knell': MCSA. Mining Journal, 02 01. Accessed 02 04, 2019. https://www.mining-journal.com/events-coverage/news/1355580/big-eskom-rate-hike-deathknell-mcsa?utm_medium =email\&utm_campaign $=020419-074515-542 \% 20-\% 20 \mathrm{Doh} \% 20 \mathrm{Mint} \%$ 20launches $\% 20$ Simpsons $\% 20$ coins $\% 20$ Tethyan $\% 20$ on $\% 20 \mathrm{a} \% 20$ tear $\% 20$ Big $\% 20$ Eskom $\% 20 \mathrm{rate} \%$ 20hike $\% 20 \mathrm{a} \% 20$ dea.

Hussain, A., Arif, S. M., \& Aslam, M. 2017. Emerging renewable and sustainable energy technologies: State of the art. Contents lists available atScienceDirectRenewable and Sustainable Energy Reviews 71: $12-28$.

2018. Hybrid Power for Mining. Accessed 12 12, 2018. http://hybridpowerformining.com.

Jamshidi, M, \& Askarzadeh, A. 2019. Techno-economic analysis and size optimization of an off-grid hybrid photovoltaic, fuel cell and diesel generator system. Sustainable Cities and Society 44: 310-320.

Jenniches, S. 2018. Assessing the regional economic impacts of renewable energy sources-A literature review. Renewable and Sustainable Energy Reviews 93: 35-51.

Khan, M. J., Yadav, A. K., \& Mathew, L. 2017. Techno economic feasibility analysis of different combinations of PV-Wind-Diesel-Battery hybrid system for telecommunication applications in different cities of Punjab, India. Renewable and Sustainable Energy Reviews 76: 577-607.

Laquaniello, G., Montanari, W., \& Salladinic, A. 2017. Standalone CSP-DG system for electrification of remote areas and desalinated water supply. Solar Energy 157: 1056-1063. 
Mazzeo, D., Oliveti, G., Baglivo, C., \& Congedo, P.M. 2018. Energy reliability-constrained method for the multi-objective optimization of a photovoltaic-wind hybrid system with battery storage. Energy. doi: 10.1016/j.energy.2018.04.062.

Mirsaeidi, S., Dong, X., \& Said, D. M. 2018. Towards hybrid AC/DC microgrids: Critical analysis and classification of protection strategies. Renewable and Sustainable Energy Reviews 90: 97-103.

Nasirov, S., \& Agostini, C. A. 2018. Mining experts' perspectives on the determinants of solar technologies adoption in the Chilean mining industry. Renewable and Sustainable Energy Reviews 95: 194-202.

National Renewable Energy Laboratory. 2013. OpenEI. 3 7. Accessed 11 7, 2018. https://openei.org/wiki/ Distributed_Generation.

Nema, P., \& Dutta, S. 2012. Feasibility Study of 1 MW Standalone Hybrid Energy System: For Technical Institutes. Low Carbon Economy 3: 63-68.

Padron, I., Avila, D., Marichal, G. N., \& Rodriguez, J. A. 2019. Assessment of Hybrid Renewable Energy Systems to supplied energy to Autonomous Desalination Systems in two islands of the Canary Archipelago. Renewable and Sustainable Energy Reviews 101: 221-230.

Pollack, K., \& Bongaerts, J. C. 2019. Mathematical Model on the Integration of Renewable Energy in the Mining Industry. International Journal of Energy Sector Management.

Slavin, A. 2017. New renewable energy for mine project - LAMGOLD Essakane to benefit from largest hybrid plant in Africa (Case Study). Energy and Mines, 03 06: 547-559.

Shen, W., Qiu, J., \& Dong, Z. 2018. Electricity network planning targeting Low-Carbon energy transition. Global Energy Interconnection 1 (4): 487-499.

Yang, H., Lu, L., \& Zhou, W. 2007. A novel optimization sizing model for hybrid solar-wind power generation system. Solar Energy 81: 76-84.

Vidal, O. 2018. Energy Requirements of the Mining and Metallurgical Industries. Mineral Resources and Energy 27-52.

Vyhmeister, E., Munoz, C. A., Miquel, J. M. B., Moya, J. P., Guerra, C. F., Mayor, L. R., GodoyFaundez, A., et al. 2017. A combined photovoltaic and novel renewable energy system: An optimized techno-economic analysis for mining industry applications. Journal of Clenear Production 149: 999-1010.

Zerrahn, A., Schill, W.-P., \& Kemfert, C. 2018. On the economics of electrical storage for variable renewable energy sources. European Economic Review 108: 259-279.

Zhang, W., Akbar M. I, Rosen, M. A., \& Liu, J. 2019. Sizing a stand-alone solar-wind-hydrogen energy system using weather forecasting and a hybrid search optimization algorithm. 15.

Zharan, K. 2017. Renewable Energy for the Mining Industry: Trends and Developments. In: L. a. Matasci, ed. Boosting Resource Productivity by Adopting. St.Galen: A World Resources Forum Production, p. 429 Energy Conversion and Management 180: 609-621.

Zharan, K., \& Bongaerts, J. C. 2017. Decision-making on the integration of renewable energy in the mining industry: A case studies analysis, a cost analysis and a SWOT analysis. Journal of Sustainable Mining 16 (4): 162-170.

Zharan, K., \& Bongaerts, J. C. 2018. Survey on Integrating of Renewable Energy into the Mining Industry. Journal of Environmental Accounting and Management 6 (2): 149-165. 


\title{
Possible effects of economy digitalization processes on Russian mining industry from economic theory point of view
}

\author{
M. Khaikin \\ Doctor of Economics, Professor, Department of Economic Theory, Saint Petersburg Mining University, \\ Saint-Petersburg, Russian Federation \\ M. Shabalov \\ PhD, Associate Professor, Department of Economics, Accounting and Finance, Saint Petersburg Mining \\ University, Saint-Petersburg, Russian Federation \\ D. Ivanova \\ PhD student, Department of Economics, Accounting and Finance, Saint Petersburg Mining University, \\ Saint-Petersburg, Russian Federation
}

\author{
N.A. Shapiro \\ Doctor of Economics, Professor, ITMO University
}

\begin{abstract}
The subject of discussion in the article are the results of the study presented in the World Bank reports (World Development Report-2016: Digital Dividends and Reaping Digital Dividends: Leveraging the Internet for Development in Europe and Central Asia, 2017) devoted to the development of the digital economy in the modern world; the main conclusions of the reports projected on the sphere of mineral resources management are presented. The scope of the dynamic development of the digital economy and the economic effects of its successful use in developed countries have provided leading countries with high development indicators. Possible prospects and threats for those countries that are behind in the development of the digital economy are presented, attention is focused on the relationship between the digital and the old (analogue) economies as well as on the need to improve its institutions, and economic policy directions. The article raises a number of theoretical and economic aspects related to both the change in the well-known ideas about the asymmetry of information and the problem of the cost of information itself in the digital economy. The sphere of mineral resources management and the inevitable objective changes and threats associated with the underestimation of the digital economy role in this segment are considered through the main characteristics of the digital economy. Attention is focused on the urgency of the development problems of the digital economy in the field of mineral resources management, the role of the state in this process is indicated.
\end{abstract}

Keywords: information and communication technologies (ICT), digital economy, digitalization process, analogue environment, mineral resources management, competitiveness, digital money

\section{INTRODUCTION}

The real content of the concept of the digital economy is rapidly expanding, changing and complementing.

The term "digital economy", first used by Nicholas Negroponte (University of Massachusetts) in 1995 to explain the advantages of a new profitable segment in the economy, emerging 
on the basis of information and communication technologies (ICT), compared with the old (analogue) economy, today can be interpreted much broader.

The initial version of the concept included electronic business (e-business) and electronic commerce (e-commerce), electronic goods (e-goods) and services produced and sold by these means and, as a rule, with the use of electronic money (e-money/digital money). This was followed by the expansion of the e-business opportunities use through the financial sector, as well as traditional production, which has a "physical" embodiment of goods and services (weight, raw materials, transportation processes). Another segment of the digital economy has become the non-market sector of health care services, education, public administration, etc. (Bowers M.R. 2017).

This article is intended to consider effects of the digital economy introduction into one of the most traditional sectors of economic activity - mineral resources management.

\section{LITERATURE REVIEW}

Despite the high level of development of the digitalization topic in certain technical aspects of mineral resources management (Gogolinskiy et al. 2019; Bazhin et al. 2018; Trushko V. L. et al. 2019), there are practically no papers on this subject generally recognized by the scientific community (if we consider high citation in international databases like Scopus, Web of Science, etc. as the modern recognition criteria). Moreover, there are of an order of magnitude more articles and notes in the media, as well as in the advertising and analytical departments of large consulting companies (Durrant-Whyte 2017; Schneider 2018). The gap between the scientific community and business in the field of mineral resources management, unfortunately, is very characteristic for the modern world, but it can in no way be considered normal.

If we leave aside the issue of mineral resources management, we can state that a lot of research has been carried out, both on the digital economy as a whole and on its individual components. A large number of publications is related to the impact of ICT on labor productivity (Kretschmer 2013; Czernich, 2011), as well as on economic growth in general (Latif 2018; Prieger 2013; Gruber 2014).

The importance of understanding the role of the digital economy in the modern world is supported by the fact that the World Bank regularly publishes reports on this area (World Development Report. Digital Dividends, 2016; Reaping Digital Dividends: Leveraging the Internet for Development in Europe and Central Asia, 2017). The competitiveness and the potential of the development of the digital economy are described in a comprehensive study covering 60 countries - Digital Evolution Index - 2017.

Defining the digital economy "here and now", it should be recognized that the digital economy is not only an activity directly related to the further development of provision services of electronic payments, online trading, crowdfunding and other digital technologies, but also a widespread adoption of existing techniques in traditional areas of the economy (Revenko, 2017).

The wide and successful "digitization" in a number of countries brought tangible positive economic results, affected the growth rate of GDP, the increase in the number of jobs, and the quality and speed of service delivery.

In countries with advanced digitalization, there is a real opportunity to influence the effectiveness of international trade by adjusting existing rules (Crozet 2016), improve cross-border trade in an integration union (Gomez-Herrera 2013), improve labor market mechanisms (Vazquez 2017), composition and the structure of jobs (Lewandowski 2016), assess the quality of jobs (Autor 2013), help remove internal obstacles for company development (Paunov 2015), optimize the costs of logistics firms and budget organizations (Loch et al. 2008), etc.

For countries with a low level of ITC development, researchers predict various - depending on the areas of operation - effects in further digitalization progress. For example, dependence was found in exports and imports - a 10\% increase in the number of Internet users in individual countries led to an increase in trade between these countries by $0.6 \%$. Traditional industries that have never been previously associated with digitalization were analyzed in detail, 
and it turned out that $75 \%$ of the total economic impact of Internet technologies was obtained in such industries.

Thus, based on the positive practices of the digital economy, the formation of a influence instruments portfolio has already started in the scientific literature, both at the micro and macro levels of economic development.

\section{METHODOLOGY}

To study the state of mineral resources management in the context of the development of the digital economy, a set of methods is used, such as descriptive analysis, a comparative results analysis of successful and problematic practices of the digital economy and its relationship with mineral resources management. Some well-known economic deductive hypotheses about the asymmetry of information used in microeconomics are interpreted and the macroeconomic hypothesis about the nature of money and its properties is interpreted.

The empirical basis of the study were the materials of two reports of the World Bank (2016, 2017) devoted to the problems of the digital economy, as well as data from the Digital Evolution Index - 2017.

The results of the study represent the authors' judgments about the relatively immediate prospects for the development of the digital economy in the field of mineral resources management, the advantages and issues of the development of mineral resources management, depending on the level and pace of implementation of the digital economy in this area. It is shown that a misunderstanding of the digital economy advantages in the field of mineral resources management can lead to inadequate assessments of the country's ability of geological studies, exploration and mining in world markets.

The basis of the scientific soundness of the article is representativeness, reliability and consistency of data provided by competent world institutions, as well as building the authors' reasoning on the ideas and views of recognized scientists and experts in the field of digitalization and subsoil use.

\section{ANALYTICAL PART}

\subsection{Possible threats of digitalization to developing countries.}

The rapid expansion of the digital economy is just as rapidly making adjustments to assessing accumulated experience and recommendations for those countries that are starting to work, or those that are trying to improve their results in the development of the digital economy today (Table 1).

The Digital Evolution Index - 2017 uses 170 parameters that describe 4 main factors that determine the rate of digitalization:

1) level of supply (Internet access and infrastructure development, as international studies show, more than half of the world's population use the Internet);

2) level of demand for digital technologies;

3) institutional environment (government policy, legislation, resources);

4) innovative climate (investments in $\mathrm{R} \& \mathrm{D}$ and digital startups).

In addition to a slowdown, i.e. investing in the development of methods of the digital economy itself and its distribution in the modern dynamic and unstable world, even the digital economy itself cannot avoid risks. The risks of the digital economy are associated with the criminal use of its own achievements, creating cyber threats, such as cyber fraud, "digital slavery", "digital gap", etc.

Practical measures arising from the experience of today's and yesterday's leaders in overcoming risks and confronting threats are as follows. 
Table 1. State and growth rate of the digital economy in 2017. Compiled by the authors based on http://web-payment.ru/article/250/top-10-cifrovaya-ekonomika/.

\begin{tabular}{|c|c|c|}
\hline Group of countries & Characteristics & Examples \\
\hline Leading countries & $\begin{array}{l}\text { demonstrate high rates of digital devel- } \\
\text { opment, maintain it and continue to } \\
\text { lead in the diffusion of innovation. }\end{array}$ & $\begin{array}{l}\text { Singapore, the United Kingdom, New } \\
\text { Zealand, the United Arab Emirates, } \\
\text { Estonia, Hong Kong, Japan and Israel }\end{array}$ \\
\hline $\begin{array}{l}\text { Countries slowing } \\
\text { down the digital } \\
\text { economy }\end{array}$ & $\begin{array}{l}\text { for a long time they have shown steady } \\
\text { growth, but now without the introduc- } \\
\text { tion of innovations they run the risk of } \\
\text { lagging behind the leaders of } \\
\text { digitalization }\end{array}$ & $\begin{array}{l}\text { South Korea, Australia, countries in } \\
\text { Western Europe and Scandinavia, the } \\
\text { USA }\end{array}$ \\
\hline $\begin{array}{l}\text { Promising countries } \\
\text { for the growth of the } \\
\text { digital economy }\end{array}$ & $\begin{array}{l}\text { despite the relatively low overall level } \\
\text { of digitalization, they are at the peak } \\
\text { of digital development and have the } \\
\text { potential that can enable them to } \\
\text { occupy leading positions, that attract } \\
\text { investors }\end{array}$ & $\begin{array}{l}\text { China, Kenya, Russia, India, Malaysia, } \\
\text { Philippines, Indonesia, Brazil, Colom- } \\
\text { bia, Chile, Mexico }\end{array}$ \\
\hline Countries of concern & $\begin{array}{l}\text { face serious challenges related to low } \\
\text { digital development and slow growth. }\end{array}$ & $\begin{array}{l}\text { South Africa, Peru, Egypt, Greece, } \\
\text { Pakistan }\end{array}$ \\
\hline
\end{tabular}

The most important way to reduce these threats is digital literacy of the population, digital education, and the corresponding professional competencies of enterprises employees. If the gap in the level of well-being of the population can hinder the improvement of digital literacy, then the inadequate understanding of the opportunities and threats of the digital economy by senior management as a result of voluntary or involuntary ignorance can be a barrier to the formation of digital competencies.

Of course, for various reasons, people want to have a universal tool in the development of the digital economy (Ustyuzhanina 2017). However, inclusive development strategies are a set of measures that are more complex than focusing on one, albeit important, relevant and new development factor. In particular, studies show that one of the ways to ensure inclusive development is to identify relevant segmentation of the territory and to identify in each segment the nuclei that produce impulses for the generation and diffusion of innovations (Shapiro 2017)

The digital economy can be compared with an advanced application to the program for scientific society development, for instance modern professions, business or government management of information technology capabilities. ICT tools are designed to free human activity from routine operations, but not to replace it. ICTs make standard operations faster and cheaper, but ICTs are not able to make decisions, especially non-standard ones, not foreseen in any models, programs or other documents. Models and programs systematize, formalize the accumulated experience and extrapolate it for the future. To fulfill the main component in human activity, which goes beyond the use of proven standards and related to decisionmaking, artificial intelligence does not replace human one, it only frees it from performing formal and monotonous operations. In any profession today, there are operations performed from a template by an accountant, a cashier, or a broker who makes payments or transfer money, that is already automated.

But other operations, such as making plans, strategies, developing tax changes, or advising clients (Khaykin 2017), require complex cognitive, economic, social, and communication skills. And the functioning of such professional areas as teaching or performing police functions requires tolerance, patience and prudence, and a certain level of knowledge and wisdom.

The digital economy will not bring benefits if the "analogue" environment is not adapted to a certain progress of events and is not institutionally aimed at inclusive development, when growth in certain segments gives positive effects in all others sectors that are not directly related to it. Otherwise, the digital economy will not only face difficulties while utilizing its advantages, but also may enhance problems and lead to increased inequality and stagnation. 
"Analogue" additions are the legal support of competition, skills of the population, as well as professional competencies that allow the use of new technology and institutions (Lewandowski 2016).

The lack of competition protection against the backdrop of the ICT development leads to an excessive concentration of power in the market and increased monopolization if the company is characterized by the economy of scale, since any monopolization inhibits innovation (Aghion 2015). Competition promotion policies are crucial in this area. It is important to pay attention to such an effective development tools as public-private partnership agreements (Kalgina 2017), regulation of the telecommunications and the Internet functioning. In addition to the complete absence of competition protection, a similar effect can be created with use of protectionism measures, for example, in Panama in 2010, only $25 \%$ of firms used ICTs for electronic commerce, which was caused by a government ban of companies with foreign capital in the retail sector (WDR 2016).

Absence of professional Internet skills will inevitably lead to one of the following facts: the expected increase in labor productivity does not occur or increase in inequality between employees or reduce motivation and so on. It is employees with higher education who receive the greatest amount of positive results from the possession of "digital" skills.

Talking about the ways of providing public services within the framework of digital technologies, there are usually 4 main areas - informing the public and issuing digital identity cards, improving existing bureaucratic procedures, obtaining "feedback", and improving management procedures of state institutions. Informing the population and issuing digital passports instead of traditional ones has the greatest impact on society at the moment (for example, in India this is a very well-developed area). In the world, about 2.4 billion people do not have birth certificates and/or passports, which indicates poorly developed population identification systems in developing countries (World Bank, 2015). However, if the Internet helps to overcome information barriers between officials and citizens in informing about the provision of public services, then there may be problems in receiving feedback - the relevant structures may ignore the information received, which will lead to a drop in trust between the state and the population. Extremely negative results can also be achieved - it is a control of the information sources and its content at the input in a way of more strict censorship. Thus, with the help of public state digital services, problems of weak population awareness and high transaction costs in the public services provision can be solved, as well as information asymmetry in this segment of the digital economy can be reduced.

\subsection{The impact of digitalization on mineral resources management}

But let us turn to the declared topic of mineral resources management and consider what can happen if we do not invest in the digital economy in the field of mineral resources management and the "analogue" correction of institutions.

Subsoil along with soil and water will for a long time be the main raw material for the production of end-use goods, which allow humanity to eat, drink, dress, build housing and lead comfortable life. Subsurface resources are a strategic factor not only for the survival of the countries where they occur, but, ultimately, the foundation of the global economy. Subsoil is an important part of the natural wealth that a person needs as a raw material for production. Rational use of mineral resources is the area of responsibility of those countries where there resources are located (Palyanova et al. 2017).

The Program "Digital Economy of the Russian Federation" [Program "Digital Economy of the Russian Federation" dated July 28, 2017 No. 1632-r Consultant.ru >document/cons_doc_LAW_221756 / . . / ] states that the digital economy is aimed at creating conditions for the development of a knowledge society in Russia, improving the welfare and citizens quality of life by increasing the availability and quality of goods and services produced in the digital economy using modern digital technologies, raising awareness and digital literacy, improving accessibility and quality of public services for citizens, as well as security both domestically and abroad. 
Government programs are expected to be criticized by society, albeit constructive. So the program "Digital Economy of the Russian Federation" caused a lively discussion: in the course of analyzing its goals, content, main areas of work and implementation mechanisms, the importance for solving the problems of socio-economic development, increasing competitiveness in global markets and enhancing national security, many researchers have expressed some concerns (Yakutin 2017). They certainly didn't pay much attention to the mineral resources management.

The literature notes both the positive and negative aspects of the digitalization process in the mineral resources management. In particular, the disadvantages of the digital economy in the field of mineral resources management include: the lack of publicity and the difficulty of obtaining information because the country does not have publicly accessible Internet portals of geological information databases; no open license information; the institutional environment for transactions with subsoil use rights and an objective market assessment of the mining companies assets (state registration of licenses as property) are poorly formed (Zabajkin 2017). This state of affairs leads to a narrowing of the circle of potential investors, complicates the use of geological information by domestic and international companies and investors for market purposes, and complicates the listing of company shares.

It may seem that while total mineral wealth is unknown and reserves are not calculated, the lack of data can serve as informational protection against other potential users.

Digital ignorance in the field of mineral resources management can lead to the fact that the subsoil will be bought up and used outside the control of their owners if they neglect the means of possession of reliable information and relevant knowledge.

Information sources allow us to compare data on the leading countries in the digital economy and the wealth of natural resources (Table 2).

The greater the discrepancy between those countries that have a developed digital economy and countries that own resources, the more information the first countries will have about the second ones and they also can become their actual users, without being formal owners.

Comparison shows that there are few "intersections" in "TOP-10", in this case these are Australia and the USA, but the situation is changing rapidly. The USA was assigned to the second group of countries where the development of the digital economy slowed down, therefore, in "TOP-10" the country is not represented. It is also clear that the level of digitalization in countries that have achieved high results in the development of the digital economy will allow them to have "digital" channels of information about mineral resources and their use in other countries. The development of the digital economy leads to global mineral resources management (Litvinenko 2019). If the countries-owner the subsoil will be "second" in this process, they will have to integrate into those structures and rules that will be established by others.

Table 2. TOP-10 in terms of mineral reserves and the growth rate of the digital economy. Compiled by the authors based on https://newsroom.mastercard.com/digital-press-kits/digital-evolu tion-index-2017/ and http://www.online812.ru/2012/04/28/002/.

\begin{tabular}{lrl}
\hline Resources & & Digital economy \\
\hline Russia & 1 & Singapore \\
The United States of America & 2 & The UK \\
Saudi Arabia & 3 & New Zealand \\
Canada & 4 & The UAE \\
Iran, I.R. & 5 & Estonia \\
China & 6 & Hong Kong \\
Brazil & 7 & Japan \\
Australia & 8 & Israel \\
Iraq & 9 & South Korea \\
Venezuela & 10 & Australia \\
\hline
\end{tabular}


Since Russia is the first country in terms of mineral resources, it should first of all "digitize" its irreplaceable advantages.

"Digitalization of mineral resources management in Russia is a real and concrete process for creating a resource-innovative development model. This process is not opposed to the well-known fact that the main engine of progress and well-being are investments in technology, and not in traditional resources. It logically complements the development strategy of this area, expanding the possibilities of investment policy in technology; it leads to sustainable provision with energy resources; increasing environmental requirements for energy resources and their processing; optimal fuel and energy balance at the regional level and in the whole country; the efficiency of the use of electricity and raw materials", as noted by V.S. Litvinenko, rector of Mining University (Litvinenko 2014).

The digital economy allows us to use such an important competitive advantage as intellectual potential in any field (Vasilenko et al.2020).

The economy is designed so that the leader in new technologies has advantages not only in making profit, but also in setting the rules. If we miss the chance to be the first in the development of the digital economy in the field of mineral resources management, Russia will soon have to integrate into the global mineral resources management according to the rules that are established by others. For example, the economies of countries at the transitional level of development in the digital economy are already facing the difficult task of facilitating and simplifying the international trade. Facilitation is a measure of trade that would have the greatest impact on trade flows and could reduce costs (up to $3 \%$ ).

Of course, mineral resources management is not a virtual process and it is associated with real work and presence on the territory. This means that development of digitization in it may not lead to progress in more "virtual" directions. Risks of being not able to introduce "digital money" in mining segment, from that point of view, are more than real - because it is an unknown concept for traditional mining models. Digitized money is formed as big data sets, where it is stored and, accordingly, can be collected and represented in short time - for example, all property information about economic entities of any level and status (physical, legal, individual, institutional, etc.). New money is becoming extremely informative. The question is not whether or not the information will be used for legal or illegal purposes, but that it will be easy to collect. And then it can be used as an economic resource, which will require correct assessment.

The economy with new, "digitized money" is characterized by a different connection of economic agents. If, as stated in the Report "Obtaining Digital Dividends ..." distances lose importance in the Internet, then the relationship between people, governments and enterprises will become stronger and, moreover, more transparent.

In the context of the digital economy, the profile of information market asymmetries is fundamentally changing, as well as commercial and state secrets take on a different shape. The information asymmetry profile becomes mobile in the sense that not only the seller, but also the buyer of goods and services can possess more information (Lendle 2015), thereby gaining advantages over other buyers or using the ignorance of the seller (Hallward-Driemeier 2015). The asymmetry of information will be determined by the ability or inability of economic agents to handle information flows.

Based on the definition of the economy in the "pre-information era", we can assume that the economy is a monetary system, and the "digitization" of money provides the basis for defining the modern economy as an economy with new, "digitized money".

As noted by J.M. Keynes, money should certainly be included in our conclusions about the real world, and the special properties of money are manifested as a link between the present and the future. Therefore, no one can reliably forecast future changes without understanding of this link - otherwise than in monetary terms (Keynes 1973). The question of what digitized money can do, what their properties are, remains open.

Another important economic problem is the assessment of the information itself. As Andrea Di Mayo, managing vice president of Gartner Research, notes, “... now we measure the value of goods such as oil, but we do not measure the value of the data that will be goods in the digital economy ... In fact, not the real value of the digital economy will be measured, but the way we move towards it. The process of finding ways to measure the digital economy 
requires the participation of not only people involved in ICT, but of those engaged in economic activities" (Di Maio 2017).

One of the important aspects of the issue of digitized money is the issue of security.

\section{DISCUSSION}

Authors would like to highlight the fact that mining industry has been always functioning within information inequality principle and yet nowadays we stand before another problem we have too much information. This leads to a number of peculiarities regarding mining industry financing processes. First, we more often find ourselves in situations with extreme levels of income data unreliability. Secondly, industry is severely disconnected from main price influencers. Lastly, long-term forecasts are dependent on actual observations of market conditions, business psychology etc. Specialists who are trying to work within these peculiarities in industry have to understand that this is an important issue, which has to be solved before we will be able to stabilize processes of natural resources management.

The work carried out to comprehend existing information on the digital economy and its impact on the mining industry was aimed at describing the acute problems of this issue and a rather poor understanding of this process impact on the fundamentals of economic theory the asymmetry of information and the concept of "money". Further research can continue in two directions - changing the theoretical economy under the influence of the digitalization process and the practical sense of it for mineral resources management.

\section{CONCLUSION}

It is possible to apply the general rule of ensuring the efficiency and sustainability of enterprises operating in the mineral resource sector for government participation in solving the problem of digitalization of mineral resources management. This rule states that the lower the efficiency of development and extraction of resources are, the higher the role of the state as a kind of shock absorber of constantly growing economic problems in the field of mineral resources management (Khaykin 2017).

If the state does not actively engage in the digitalization process in the field of mineral resources management, then it may be excluded from real economic processes and sink into informational isolation.

Such a pessimistic forecast for the development of mineral resources management will not come true (although it seems quite realistic) if the sphere of mineral resources management is removed from the peripheral position in digital development, if the policy in this area overcomes the idea that information technology and the digital economy exist parallel to the real world. Attempts to avoid change will only delay, but in no way prevent changes, because new technologies always find a way to overcome barriers, but belated awareness can make changes more difficult for the economy and lead to the loss of the advantages that the country has in the field of mineral resources management today. Reducing investments in the digital economy in mineral resources management today, tomorrow it is possible find yourself in such a virtual innovation environment that getting out of it will be extremely expensive.

\section{ACKNOWLEDGEMENTS}

The reported study was funded by RFBR and MCESSM according to the research project № 19-510-44013\19 


\section{REFERENCES}

Aghion, P., Cai, J., Dewatripont, M., Du, L., Harrison, A. \& Legros, P. 2015. Industrial Policy and Competition. American Economic Journal: Macroeconomics 7 (4): 1-32.

Autor, D., \& Dorn D., 2013. The Growth of Low-Skill Service Jobs and the Polarization of the U.S. Labor Market. The American Economic Review 103 (5): 1553-1597.

Bazhin, V. \& Danilov, I \& Petrov, P.. (2018). Development of automated system based on neural net-work algorithm for detecting defects on molds installed on casting machines. Journal of Physics: Confer-ence Series. 1015. 032025. 10.1088/1742-6596/1015/3/032025.

Bowers, M.R., Hall, J.R. \& Srinivasan, M.M. 2017. Organizational culture and leadership style: The missing combination for selecting the right leader for effective crisis management. Business Horizons 60 (4): July-August, 551-563. URL: http://www.sciencedirect.com/journal/business-horizons/vol/60/ issue/4 (reference date: $25 / 03 / 2018$ ).

Comin, D.A. \& Mestieri, M.F. 2013. If technology has arrived everywhere, why has income diverged? Cambridge: National Bureau of Economic Research. URL: https://www.nber.org/papers/w19010.pdf (reference date: 15/04/2019).

Crozet, M., Milet, E. \& Mirza, D. 2016. The Impact of Domestic Regulations on International Trade in Services: Evidence from Firm-Level Data. Journal of Comparative Economics 44 (3): 585-607.

Czernich, N., Falck, O., Kretschmer, T., \& Woessmann, L. 2011. Broadband infrastructure and eco-nomic growth. Economic Journal, 121(552): 505-532. doi:10.1111/j.1468-0297.2011.02420.x.

Di Maio, A. 2017. Data is fuelling digital economy. Information society 2: 4-8. URL: http://emag.iis.ru/ arc/infosoc/emag.nsf/BPA/3feebdab8714b12f4425818b002f1f6c.

Durrant-Whyte, H., Geraghty, R., Pujol, F. \& Sellschop, R. 2015. How digital innovation can improve mining productivity. URL: https://www.mckinsey.com/industries/metals-and-mining/our-insights/ how-digital-innovation-can-improve-mining-productivity (reference date: 15/04/2019).

Gogolinskiy, K \& Syasko, V. (2019). Prospects and challenges of the Fourth Industrial Revolution for instrument engineering and metrology in the field of non-destructive testing and condition monitoring. In-sight - Non-Destructive Testing and Condition Monitoring. 61. 434 440. 10.1784/insi.2019.61.8.434.

Gomez-Herrera, E., Martens, B. \& Turlea, G. 2013. The Drivers and Impediments for Cross-Border e-Commerce in the EU. Seville: Institute for Prospective Technological Studies. Digital Economy Working Paper 2013/02.

Gruber, H., Hätönen, J., \& Koutroumpis, P. 2014. Broadband access in the EU: An assessment of fu-ture economic benefits. Telecommunications Policy 38(11): 1046-1058. doi:10.1016/j.telpol.2014.06.007.

Hallward-Driemeier, M., \& L. Pritchett. 2015. How Business Is Done in the Developing World: Deals versus Rules. Journal of Economic Perspectives 29 (3): 121-140.

Kalgina, I.S. 2017. Modeli otsenki proyektov gosudarstvenno-chastnogo partnerstva $\mathrm{v}$ sfere nedropol-zovaniya [Models for evaluating projects of public-private partnership in the field of subsoil use]. Zapiski Gornogo instituta 224: 247-254.

Keynes, J.M. 1973. The General Theory of Employment, Interest and Money (1936), Collected Writ-ings 7. URL: https://www.files.ethz.ch/isn/125515/1366_KeynesTheoryofEmployment.pdf (reference date: 15/04/2019).

Khaikin M.M. \& Knysh V.A. 2017b. Yestestvennye monopolii v rossiyskoy ekonomike: vybor modeli regulirovaniya [Natural monopolies in the Russian economy: the choice of regulation model]. Upravlencheskoe konsultirovanie 5 (101): 44-55.

Khaikin, M.M., Knysh, V.A. \& Podolyanets, L.A. 2017a. Industrialno-syrievaya ekonomika: problemy regulirovaniya i upravleniya [Industrial raw materials economy: problems of regulation and manage-ment] St Petersburg: Lema.

Kretschmer, T., Cardona, M., \& Strobel, T. 2013. The Contribution of ICT to Productivity: Key Con-clusions from Surveying the Empirical Literature. Information Economics and Policy 25(3): 109-125. URL: https://doi.org/10.1016/j.infoecopol.2012.12.002 (reference date: 15/04/2019).

Kuznetsov, V.I. \& Khaikin, M.S. 2017. Sotsialno-ekologicheskie aspekty osvoeniya mineralnykh re-sursov mirovogo okeana [Social and environmental aspects of the development of the mineral resources of the oceans]. Zapiski Gornogo instituta 90, June: 55. URL: http://pmi.spmi.ru/index.php/ pmi/article/view/5823. ISSN 2541-9404.

Latif, Z., Mengke, Y., Latif, S., Ximei, L., Pathan, Z.H., Salam Sh. \& Jianqiu, Z. 2018. The dynamics of ICT, foreign direct investment, globalization and economic growth: Panel estimation robust to hetero-geneity and cross-sectional dependence. Telematics and Informatics 35(2): 318-328. doi:10.1016/ j.tele.2017.12.006.

Lederer, M., Knapp, J. \& Schott, P. The digital future has many names: How business process man-agement drives the digital transformation. 6th International Conference on Industrial Technology 
and Management (ICITM). University of Erlangen-Nuremberg. DOI: 10.1109/ICITM.2017.7917889. URL: https://ieeexplore.ieee.org/document/7917889 (reference date: 15/04/2019).

Lendle, A. \& Vézina, P.L. 2015. Internet Technology and the Extensive Margin of Trade: Evidence from eBay in Emerging Economies. Review of Development Economics 19 (2): 375-386.

Lewandowski, P., Hardy, W. \& Keister, R. 2016. Technology or Upskilling? Trends in the Task Composition of Jobs in Central and Eastern Europe. Warsaw: Instytut Badañ Strukturalnych. IBS Working Pa-per 01/2016.

Litvinenko, V. 2014. The future is about investments in technology, and not in resources: Interview with the rector of St Petersburg Mining University on April 12, 2014. Information Agency of St Peters-burg Mining University. URL: http://www.iagorny.ru/novosti/201412/vladimir-litvinenkobudushchee-za-investiciyami-v-tehnologii-ne-v-resursy (reference date: 31/03/2018).

Litvinenko, V.S. 2009. Mineralno-syrievoy kompleks: tekushchaya situatsiya - problemy razvitiya banki [Mineral resources complex: current situation, development problems, and banks]. Dengi i kredit 7: 14-17.

Litvinenko, Vladimir. (2019). Digital Economy as a Factor in the Technological Development of the Mineral Sector. Natural Resources Research. 10.1007/s11053-019-09568-4.

Loch, C.H., Huchzermeier, A., \& Chick, S.E. 2008. Management quality and competitiveness. BerlinHeidelberg: Springer. doi:10.1007/978-3-540-79184-3.

Makhovikov, A.B., Katuntsov, E.V., Kosarev, O.V. \& Tsvetkov, P.S. 2019. Digital transformation in oil and gas extraction. In V. Litvinenko (ed.), Innovation-Based Development of the Mineral Resources Sector: Challenges and Prospects: 11th conference of the Russian-German Raw Materials. St Petersburg: Mining University: 531-538. ISBN: 978-0-367-07726-6.

Manyika, J. et al. 2011. Internet matters: The Net's sweeping impact on Growth, Job and Prosperity. McKinsey Global Institute Report: McKinsey and Company. URL: http://www.mckinsey.com/ insights/high_tech_telecoms_internet/internet_matters (reference date: 15/04/2019).

National Program "Digital Economy of the Russian Federation" dated July 28, 2017 No 1632-p. (In Russian) URL: http://ac.gov.ru/files/content/14091/1632-r-pdf.pdf (reference date: 15/04/2019).

Palyanova, N.V. \& Zadkov, Denis \& Chubukova, S.G.. (2017). Legal framework for the sustainable economic and ecological development in the coal industry in Russia. Eurasian Mining. 2017. 3-5. 10.17580/em.2017.01.01.

Paunov, C., \& Rollo, V. 2015. Overcoming Obstacles: The Internet's Contribution to Firm Development. World Bank Economic Review 29 (Suppl. 1): S192-204.

Prieger, J.E. 2013. The broadband digital divide and the economic benefits of mobile broadband for ru-ral areas. Telecommunications Policy, 37(6-7): 483-502. doi:10.1016/j.telpol.2012.11.003

Revenko, N.S. 2017. Tsifrovaya ekonomika Soedinennykh Shtatov v epokhu informatsionnoy globali-zatsii: aktualnye tendentsii [The US digital economy in the era of information globalization: current trends]. US i Kanada: ekonomika, politika, kultura 8 (572): 78-100.

Schneider Electric Blog. 2018. The modern mine: How digitization is transforming industry from pit to port. URL: https://blog.schneider-electric.com/mining-metals-minerals/2018/11/06/the-modern-minehow-digitization-is-transforming-industry-from-pit-to-port/ (reference date: 15/04/2019).

Shapiro, N.A., Kaplina, Yu.E., Medvedev, E.A. \& Krasnov, E.A. 2017. Theoretical and economic as-pects of the decision of the problem of regional policy in the Russian economy. Economics of sustainable development 4 (32): 222-232.

Tan, Sh.W. 2015. The effects of the Internet on Firm Export Behavior. Background paper for the World Development Report 2016, World Bank, Washington DC.

Tapscott, D. 1995. The Digital Economy: Promise and Peril in the Age of Networked Intelligence. NewYork: McGrawHill.

The Passport of the National Program "Digital Economy of the Russian Federation", approved on December 24, 2018 at a meeting of the Presidium of the Presidential Council for Strategic Development and National Projects under the President of the Russian Federation (In Russian) URL: http://static. government.ru/media/files/urKHm0gTPPnzJlaKw3M5cNLo6gczMkPF.pdf (reference date: 15/04/ 2019).

Trushko V.L., Protosenya A.G. 2019. Perspektivy razvitiya geomekhaniki v usloviyah novogo tekhnologicheskogo uklada. [Prospects of geomechanics development in the context of new technological paradigm]. Zapiski Gornogo instituta 236: 162-166.

Ustyuzhanina, E.V., Sigarev, A.V. \& Shein, R.A. Tsifrovaya ekonomika kak novaya paradigma eko-nomicheskogo razvitiya [Digital economy as a new paradigm of economic development]. Natsionalnye interesy: prioritety i bezopasnost 13, 10 (355): 1788-1804.

Vasilenko, Natalia \& Khaykin, Marck \& Kirsanova, Natalia \& Lapinskas, Arunas \& Makhova, Larisa. (2020). Issues for development of economic system for subsurface resource management in Russia 
through lens of economic process servitization. International Journal of Energy Economics and Policy. 10. $44-48.10 .32479 /$ ijeep.8303.

Vazquez, E.J. \& Winkler, H. 2017. How Is the Internet Changing Labor Market Arrangements? Evi-dence from Telecommunications Reforms in Europe. World Bank, Washington, DC. Policy Research Working Paper No. 7976.

World Bank. 2015. Identification for Development (ID4D) Global Dataset. Washington, DC: World Bank. URL: http://data.worldbank.org/data-catalog/id4d-dataset (reference date: 15/04/2019).

Yakutin, Yu.V. 2017. Rossiyskaya ekonomika: strategiya tsifrovoy transformatsii [Russian Economy: Digital Transformation Strategy]: On Constructive Criticism of the Government Program "Digital Econ-omy of the Russian Federation”. Menedzhment i biznesadministrirovanie 4: 27-52.

Zabaikin, Yu.V., Shenderov, V.I. \& Ibragimov, R.R. 2017. Nedostatki informatsionnogo obe-specheniya nedropolzovaniya Rossijskoj Federatsii [Flaws in subsoil use information system of Russia] Aktualnye problemy i perspektivy razvitiya ekonomiki: rossijskij i zarubezhnyj opyt 7: 92-94. 


\title{
Economic and legal aspects of digital transformation in mining industry
}

\author{
M. Paschke \\ University Hamburg, Hamburg, Germany \\ O. Lebedeva
}

PhD, Associate Professor, Department of Economics, Accounting and Finance, Saint Petersburg Mining University, Saint-Petersburg, Russian Federation

M. Shabalov

PhD, Associate Professor, Department of Economics, Accounting and Finance, Saint Petersburg Mining University, Saint-Petersburg, Russian Federation

D. Ivanova

PhD student, Department of Economics, Accounting and Finance, Saint Petersburg Mining University, Saint-Petersburg, Russian Federation

\begin{abstract}
The article presents the aspects of the industrial digital transformation that currently is taking place in various economic sectors and mining industry is not an exception. Particularly, the authors analyze the development of information technologies in the industry and conduct comparative analysis of digital technologies use in mining with reference to the business sector. The article highlights various features accompanying the digital development of a company, such as the share of employed ICT specialists in a company, the presence of Internet sites, the use of cloud services etc. Apart from economic aspects the article raises a number of social problems that cause the low level of digital development in Russia. In addition, international comparisons are given. Other crucial aspect analyzed in the article is the legal regulation of the process of digital transformation of industry. Its imperfection and need for improvement is justified. Special attention is given to the role of education in the development of the digital technologies and the mining industry as a whole.
\end{abstract}

\section{INTRODUCTION}

In the era of rapid digitalization of economy and society, sustainable development of digital technologies and their successful application in management are the source of comparative competitive advantages at different levels - from countries and sectors of the economy to entities and individuals. For instance, Federation of German Industries estimates the potential of adding extra value due to digital transformation to be around 425 billion Euros by 2025 , while European industry as a whole can get additional 1.25 trillion Euros for the period of 2015-2025 (Bloching et al. 2015). An interest in international comparisons of countries' positions in terms of success in digitalization is expressed in the emergence of a fairly large number of ratings and indexes. Russia's positions in them are neither leading nor lingering. So, for example, in 2017, according to the ICT Development Index 2017, Russia ranked 45th in the world (out of 176), and in 2018 it became one of the 62 leading countries, ranking 32nd in the e-Government Development Index (UN E-Government Survey 2018), and 26th out of 175 in Global Cybersecurity Index (Global Cybersecurity Index, ITU 2018). Judging by maturity indicator, calculated in the Dell Digital Transformation Index, Russia scored 49 
points out of 100 in 2018, along with countries such as Spain, Poland and China (Dell 2019). According to the same rating, $7 \%$ of Russian companies participating in the survey are classified as digital leaders ( $5 \%$ worldwide average), another $19 \%$ are implementing large-scale innovative digital projects, which is slightly lower than the global average of $23 \%$ (Dell 2019).

Both the scientific and business community are actively involved in the study of methodological and applied aspects of the industrial digital transformation (including mining industry). They also exchange their opinions and experience on international scientific platforms about development and implementation of industry-specific digital solutions and creation of the necessary infrastructure. Another discussion those communities have is focused on urgent development issues of the laws governing digitalization at the national and international levels, and the search for acceptable forms of economic cooperation.

\section{LITERATURE REVIEW}

Issues devoted to the relevance of digital technologies in solving production and business tasks of mining companies are widely covered in scientific publications. These issues involve the needs of companies arising from the specific features of mining production, application areas of digital solutions and industry achievements in digital transformation of business (Litvinenko et al. 2019). Recent publications summarize mining's digital demand (Young \& Rogers 2019) and highlight development trends for digital technologies in the sector, as well as scientific interest for them (Barnelwold 2019). In Barnewold (2019), conclusions on current trends in the use of digital technologies in the extractive sector were formulated by the author based on the results of three-steps co-word analysis, including programmed based text-mining algorithms. As a result of 2400 publications of consulting firms and online libraries analysis, the author identified most actual digital trends in industry: automation, big data, internet of things, artificial intelligence and machine learning, and he also detected links between them (Barnelwold 2019). Analyzing the annual reports of the world's largest mining companies by capitalization, other researchers also confirm that "automation" is the most common term, along with "innovations" and "technologies", which reflects the general orientation of mining companies' development priorities in the world (Young \& Rogers 2019).

Numerous scientific publications are devoted to the advantages of the industry technological development based on Internet of things (Gackowiec et al. 2019; Bhuiya 2019, Zhukovskiy et al. 2019a), digital twins (Oracle 2017; Jiewu et al., 2019), predictive capabilities of big data technologies in terms of production safety (Lee et al. 2019). The influence of digital technologies on operational efficiency, sustainable supply chain performance, competitive advantages and value delivery is also investigated (Young \& Rogers 2019; Bag et al., 2019), as well as the role of predictive data mining algorithms, which in conjunction with real options create operational flexibility (Ajak et al. 2018; Fourie 2019). The researchers also pay attention to essential components of big data ecosystem in manufacturing (Cui et al. 2020).

Among widely discussed issues regarding digital technologies is the mutual impact of academia and digitalization process. It is nowadays accepted that contemporary higher education will be relying on digital technologies more and more since students nowadays have deeper understanding of them (Castañeda 2018; Bergdahl et al. 2020, Blaj-Ward 2019). The trend has ingrained in developed countries, where Learning Management Systems (LMS) are essential for any high ranked University administration and education processes. Of course, in other countries LMS are being introduced in Universities with less success, but process is inevitable due to the time costs reduction.

In "What's next for Ed-Tech?" (Selwynn et al. 2020) authors describe and forecast 6 main challenges regarding education development in next decade, naming commercialization of digital learning tools as a main threat to freedom of this process - which is a very vague problem. At the same time, there are a number of end-to-end digital technologies already introduced in education with different levels of efficiency, which are of special interest for researchers, who are trying to understand which digital technologies are in demand in 
educational process and how it is affected by them via various means of direct questioning interviews, polls, queries (Henderson et al. 2017; Bond, 2018; Magana, 2017; Wright, 2014). All these publications are applicable to specific field of mining industry education as well as to any other industry. It is worth noting that visualization of teaching material is far more important in mining - and this problem is being rapidly solved by introduction of augmented, virtual and mixed reality technologies (Abdelrazeq et al. 2019).

Such kind of modern technologies facilitate both a better perception of information and its memorization and integration into the student's existing knowledge system. This contributes to the fact that the student gain knowledge that becomes a "living practice" and get satisfaction from the learning process, which effectiveness increases (Kretschmann et al. 2020).

Despite the impressive number of academic papers, justifying different kinds of advantages of digital technologies application, there is still a gap between the digitalization degree of the extractive sector and other sectors of the economy.

Since some researchers characterize the level of digital transformation of mining industry as low, in comparison with other sectors of the economy (Young \& Rogers 2019; Stepanov 2019), and the reasons underpinning the current status have not been totally investigated yet, the aim of this work is to reveal some economic and legal issues that impede the intensive digital transformation of mining companies in Russia and abroad and to suggest potential mitigation options. The research questions corresponding to the aim of the study are formulated as follows:

1. What is the position of Russian mining companies regarding digital technologies application?

2. Which factors, economic and legal by nature, can be considered as barriers to more successful digital transformation of mining industry?

\section{METHODOLOGY}

The results obtained by the authors are based on application of desk research aimed at collecting and analysis of the relevant industry-oriented academic papers, official statistics and company data, which enabled classification of the key constraints preventing full-scale application of digital technologies in production processes and management of mining companies in Russia. Authors applied elements of benchmarking while carrying out comparative analysis of mining and other industries' achievements in the field of digital transformation. To detect and characterize the challenging legal issues of digitalization, both national and international, the analysis of laws was involved.

The official statistics and materials of analytical overviews, prepared by High School of Economics (HSE) in conjunction with Federal State Statistics Service, as well as reports of companies (KPMG, PwC, Dell Technologies, Accenture) and international organizations (UN, ITU) devoted to mining sector and international comparisons in digitization were used in the research.

\section{RESULTS}

\subsection{Sectoral analysis of digital transformation of Russian business}

To define the relative position of Russian mining companies in application of digital technologies we used domestic sectoral statistics. The analysis allowed us to conclude that in many respects organizations of extractive sector are lagging behind other sectors of the Russian economy. For example, only $39.7 \%$ of mining organizations have websites (as of 2017). For comparison: on average, for all organizations in business sector, the figure is $44 \%$, in telecommunications industry $-67.9 \%$; in manufacturing $-63.8 \%$; in energy supply organizations $47.5 \%$ (HSE 2019). The share of ICT specialists employed in the extractive industry is small only $1.3 \%$ of their total number in the country (for comparison: $14.2 \%$ of ICT specialists are employed in the manufacturing sector) (HSE 2019). In terms of the use of cloud services, the industry is one of the three lagging behind $-17.8 \%$ of mining organizations use cloud services 
(the business sector as a whole - 22.6\%), of which $10.6 \%$ - for the use of e-mail; $9.3 \%$ - for hosting databases, file storage, $7.8 \%$ - for access to software provided by the provider, and only $3.5 \%$ - for hosting their own software (HSE 2019). The industry holds a similar position in terms of the share of organizations using electronic data exchange technologies between internal and external information systems; electronic purchases and sales; using software to provide access to databases through global information networks; as well as the cost of acquiring software, which comes to $3 \%$ of total in business sector (Table 1).

Nevertheless, in several indicators, mineral extraction organizations in Russia are superior to the average indicators for the business sector; for example, in the use of information protection tools and software to control automated equipment, processes, and factories (Table 1). The emphasis put by mining industry on these applications of digital technologies, from our point of view, can be explained by capital intensive and continuous character of production processes, on the one hand. On the other hand, due to uncertainty arising from the nature of mineral assets and enhanced by systematic and market risks, the quality of engineering design and operational efficiency are still the prior goals of mining companies.

\subsection{Economic and social issues}

It is worth noting that the average situation of Russian mining companies which are passing through the initial stage of digital transformation of business is also typical for foreign mining enterprises. Researchers see reasons for this in the management's underestimation of the digital transformation importance to business, in the age structure of the staff and a fairly high share of contracted workers in the industry (the global average is about a third), which together prevent the industry from quickly adapting to technological changes (Young \& Rogers, 2019). Russian companies are also experiencing problems due to the lack of incentives for digital transformation of business among management, staff resistance to ongoing changes and insufficient level of its digital culture, as well as a shortage of specialists with the necessary skills to work with modern digital technologies (KPMG, 2019). Even for such an indicator as the use of commercial Internet by organizations employees, Russia lags significantly behind European countries: $29 \%$ of the total number versus $75 \%$ in Sweden, $73 \%$ in Denmark, $70 \%$ in

Table 1. Comparative indicators of digital technologies use, as a percentage of the total number of organizations in the industry/business sector (2017).

\begin{tabular}{lll}
\hline Indicator & Mining industry, \% & Business average, $\%$ \\
\hline $\begin{array}{l}\text { The use of electronic data exchange technologies between } \\
\text { internal and external information systems }\end{array}$ & 59.4 & 62.2 \\
$\begin{array}{l}\text { Electronic procurement/sales } \\
\text { Software application: }\end{array}$ & $14.7 / 6.9$ & $18.5 / 12.3$ \\
- for access to databases through global information & 24.0 & 27.5 \\
networks & & 53.7 \\
- for financial evaluation in electronic form & 55.6 & 20.1 \\
- for managing automated production and (or) individual & 38.1 & 17.0 \\
technical equipment and technological processes & & 52.7 \\
- for engineering design & 29.9 & 64.8 \\
- for solving organizational, managerial and economic & 58.7 & \\
problems & & \\
$\begin{array}{l}\text { Application of software, hardware in order to prevent the } \\
\text { unauthorized access of malware }\end{array}$ & 77.0 & 61.4 \\
$\begin{array}{l}\text { Strong authentication } \\
\text { Application of software for automation processes of ana- } \\
\text { lysis and security computer systems control }\end{array}$ & 40.5 & 34.9 \\
$\begin{array}{l}\text { Biometric user authentication } \\
\text { The cost of acquiring software, million rubles }\end{array}$ & 7.5 & 5.7 \\
\hline
\end{tabular}

Source: Compiled by authors on the basis of HSE, 2019 Digital Economy Indicators 
Finland (HSE 2019). The social aspect is compounded by financial and economic barriers the lack of ability to finance digitalization projects in their businesses and doubts about the commercial feasibility of such projects.

International comparisons allow us to conclude that there are significant differences in the level of investment in European countries and the United States. For example, USA invest nearly 17.5 billion Euros per year in digital innovations, European countries - 3.5 billon Euros approximately (Bloching et al. 2015). The estimated Russian investments in digital transformation are almost three times lower than European and almost 15 times less compared to American ones. The cost of research and development in the Russian Federation in the direction of Information and Telecommunication Systems in 2017 amounted to 81.390 billion rubles, $61.4 \%$ of which was budget funds of all levels, and the own funds of companies and organizations amounted to only 15.6\% (HSE 2019). Such a cautious attitude of the mining business to digital projects is due to a combination of internal (managerial, technical and economic) and external (market, technical and institutional) barriers. Among them, especially following ones should be noted: the insufficient level of Russian integrated digital solutions supply for mining with high dependence on foreign technologies and equipment supplies; the lack of regulation of the digitalization process as well as a single digital platform for informing and interacting with parties interested in research and digital technology development (Lebedeva 2019).

European countries put a special emphasis on creating a balanced regulating framework which enables industry and governments to keep in pace with the dynamic digital transformation. Such a framework comprises conditions necessary for pan-European digital market functioning; revision of legal framework regulating data protection and issues, which are subjects to antitrust law; guaranteed high-quality network connections (Bloching et al. 2015).

\subsection{Legal aspects of digital data handling, ownership and intellectual property protection}

The large-scale use of digital technologies in the production and financial activities of mining companies will inevitably lead to the need to resolve a number of legal issues that concern the protection of the interests of mining companies when transferring information to third parties and using digital data structured in a certain way and unprocessed. The implementation of complex digital solutions in production and business processes is impossible without the open interaction of at least three parties - the company developing the digital solution, the company user of the solution and the company providing the development and creation of the necessary infrastructure - at the level of sharing machine data, structuring it and the creation of databases, the development of organizational, technical and information solutions that meet the specific needs and requirements of subsoil users, as well as the creation of digital ecobusiness systems. Such a diverse interaction creates the need to harmonize the economic interests of the parties in relation to the results obtained.

According to the standards of Russian law, the results of intellectual activity and equivalent means of individualization are subject to legal protection and are intellectual property (Civil Code of the Russian Federation, Article 1225). Being objects of civil rights, the results of intellectual activity themselves cannot be transferred (alienated) by one person to another, but the rights to such results and the tangible media in which they are expressed can be transferred from one person to another or alienated on the basis of license agreements and an agreement on the alienation of exclusive rights (the provisions of Section II of the Civil Code of the Russian Federation "Property Law and Other Property Rights" do not apply to intellectual rights).

State regulation envelopes issues related to intellectual property, computer programs (protected copyright objects, equivalent to literary works), databases (including those made upon fulfillment of contracts for research, development or technological work) and uniform technologies (created at the cost of or with the involvement of the federal budget of the Russian Federation or subjects of the Russian Federation). However, "ideas, concepts, principles, methods, processes, systems, means, solutions to technical, organizational or other problems, discoveries, facts, programming languages, geological information about subsurface resources" 
do not extend copyrights and, accordingly, legal protection (Civil Code of the Russian Federation, Article 1259). Among not regulated by the Civil Code of the Russian Federation are the collection, processing, transmission and other use of unstructured data that are not personal.

The question arises both of the legal status of the raw data, the systematization and further use of which will allow the company to derive economic benefits in the form of added value, savings on the amount of current costs, prevention of damage, reduction of capital costs and optimization of design decisions, and their economic content - determination of value for the purpose of acquisition (or, conversely, transfer) to third parties.

Legal regulation of the process of digital transformation of industry as a whole does not have time to follow the speed of technical and technological innovations, and this state of affairs is common not only for the Russian economy, but also of European countries where the legal status of digital data is also not defined, and «...the applicable national and international legal systems recognize neither ownership of data nor right of disposal over data ownership" (Paschke 2019). However, foreign companies have gained some practice in solving this problem - they provide legal protection of machine data through contractual agreements and factual control over such data (Paschke 2019).

\section{DISCUSSION}

The comparative analysis performed in the work, albeit indirectly (we admit that by the share of companies using certain digital solutions, it is impossible to draw full conclusions about the scale and depth of the transformation taking place in the industry), but reflects the presence of factors that impede the more intensive use by Russian mining companies digital technology. Industry specifics (the risky and inertial nature of the activity due to the capital intensity of production, the long lead time of projects, exposure to market fluctuations) are reinforced by institutional factors. At the government level, work is just beginning to create conditions for the development of the digital economy - a legal framework is being formed, infrastructure projects are being launched, and the need for training specialists with qualitatively new knowledge and skills is being recognized.

Even the current legal regulations already allow the mining industry the extensive digitalization of corporate communications and technical control processes. The legal regulations do not represent an obstacle but are open to the digitization of the industry in general and the mining industry in particular. The possibility of concluding contracts by digital means and the introduction of block chain technology, which could take place without changes in the law, are only exemplary but impressive proof of this. In the mining industry, too, the existing regulatory leeway can already be used to get the advantages of speed, reliability and ubiquitous availability of digital technology in the mining industry itself, in internal company communication, in communication with companies in the supply and sales chain and with government agencies.

Representatives of mining companies (usually large ones) have an interest in transforming businesses based on digital technologies, but today there is no confidence in the commercial feasibility of implementing such projects, since it is not always possible to evaluate them based on classical approaches and investment analysis methods. In this regard, the role of cooperation between universities (the scientific community), mining companies and companies developing digital business solutions is growing (Kazanin et al. 2017, Zhukovskiy et al. 2019b). Only in the process of coordinated interaction can one identify, explain, systematize and link the benefits of introducing digital technologies into mining business processes; offer a reasonable approach to the evaluation of digital projects and, finally, train specialists with the knowledge and skills that are in demand in the industry.

\section{CONCLUSION}

Answering the research question on the position of Russian mining companies in successful application of digital technologies, it was revealed that they are lagging behind other sectors 
of the economy (information technology, media, finance, insurance and manufacturing) in the scale and pace of the digital transformation of business processes.

Some barriers of economic and legal nature impede these processes. On the one hand, at the level of companies, there is not always a clear understanding of the potential and benefits of using digital technologies. Even oil and gas companies, being the leaders within extractive sector by adoption degree of digital technologies, struggle difficulties in scaling the digital initiatives (Accenture, 2019).

On the other hand, there is no comprehensive information about exactly what kind of solutions the mining business really needs and what domestic and foreign technology developers can offer. The creation of an integrated platform for the exchange of information on those technologies that are in demand by the Russian mining industry and can be offered by IT companies, would reduce the gap. The cooperation of mining, engineering and IT companies is of crucial importance to the process of digital transformation.

Another aspect influencing the process concerns the legal framework. The review of current laws and standards which are lagging behind technological progress and rapid development of information use underpins comprehensive application of digital technologies in mining.

\section{FUTURE RESEARCH AND ACKNOWLEDGEMENTS}

This research has been conducted under agenda of the Digitalization Work Group of Russian-German Raw Material Conference (27-29/11/2019). The Work group deals with the effects, opportunities and possibilities for cooperation in the digitization of the raw materials industry along the entire value chain. Authors would like to thank all participants of work group for a very fruitful meeting. This article is setting up a legal and economic scene for future research and cooperation endeavors in the Group, which will try to diversify its attention between a very wide range of problems encountered in digitalization of mining industry.

Regarding other aspects of digitalization in mining industry authors are inclined to highlight an educational side of this process. As was shown in literature review, there are three main directions for it - influence of technically enhanced learning on traditional education process; evaluation of already implemented digital technologies effectiveness; possible digital solutions of practical issues in mining industry education. In Saint Petersburg Mining University there are a number of possibilities regarding implementation of augmented and virtual reality projects (open pit mining training simulations, subsea oil and gas extraction visualization) in education. It is possible to evaluate these projects based on students and specialists' feedback and to appraise economic effect of advanced training cost cuts for enterprises because of higher level of students' skills.

\section{REFERENCES}

Abdelrazeq A., Daling L., Suppes R., Feldmann Y., Hees F. (2019) A virtual reality educational tool in the context of mining engineering - the virtual reality mine, Inted2019 Proceedings, pp. 8067-8073.

Accenture Oil and Gas Digital Trends Survey (2019). Access mode: https://www.accenture.com/fi-en/ insights/energy/trends-digital-investment. Access date: 06.04.2020.

Ajak, A.D., Lilford E., Topal, E. (2018) Application of predictive data mining to create mine plan flexibility in the face of geological uncertainty. Resources Policy. 55: 62-79. https://doi.org/10.1016/j. resourpol.2017.10.016.

Bag, S., Wood C. Wood, Xu L., Dhamija, P., Kayikci, Y. (2019) Big data analytics as an operational excellence approach to enhance sustainable supply chain performance. Resources, Conservation \& Recycling. 153, 104559. https://doi.org/10.1016/j.resconrec.2019.104559.

Barnelwold, L. (2019) Digital technology trends and their implementation in the mining industry. Mining Goes Digital - Mueller et al. (Eds). Taylor\&Francis Group, London. pp. 9-16.

Bergdahl, N., Nouri, J. \& Fors, U. (2020). Disengagement, engagement and digital skills in technology-enhanced learning. Educ Inf Technol 25: 957-983. https://doi.org/10.1007/s10639-01909998-w. 
Bhuiya, S. (2019) IoT applications in the mining industry. International Journal of Innovations in Engineering and Technology (IJIET). 12(3): 8-13. http://dx.doi.org/10.21172/ijiet.123.02.

Blaj-Ward, L., \& Winter, K. (2019). Engaging students as digital citizens. Higher Education Research and Development, 38(5), 879-892. doi:10.1080/07294360.2019.1607829.

Bloching, Björn \& Leutiger, Philipp \& Oltmanns, Torsten \& Rossbach, Carsten \& Schlick, Thomas \& Remane, Gerrit \& Quick, Paul \& Shafranyuk, Oksana. (2015). The digital transformation of industry - How important is it? Who are the winners? What must be done? Access mode: https://www.research gate.net/publication/304525645_The_digital_transformation_of_industry_-_How_important_is_it_ Who_are_the_winners_What_must_be_done Access date: 06.04.2020.

Bond, M., Marín, V.I., Dolch, C. et al. (2018). Digital transformation in German higher education: student and teacher perceptions and usage of digital media. Int J Educ Technol High Educ 15, 48 https:// doi.org/10.1186/s41239-018-0130-1.

Castañeda, L., Selwyn, N. (2018). More than tools? Making sense of the ongoing digitizations of higher education. Int J Educ Technol High Educ 15, 22. https://doi.org/10.1186/s41239-018-0109-y.

Civil Code of the Russian Federation. (2020). Access mode: Consultant+ database (in Russian).

Cui, Y., Kara, S., Chan, Ka C. (2020) Manufacturing big data ecosystem: a systematic literature review. Robotics and Computer Integrated Manufacturing. 62, 101861. https://doi.org/10.1016/j.rcim.2019.101861.

Digital technologies in Russian companies. Results of KPMG research. January 2019. Access mode: https://home.kpmg/ru/ru/home/insights/2019/01/digital-technologies-in-russian-companies-survey.html Access date: 06.04.2020.

Digital Transformation Index II. Dell Technologies. Access mode: https://www.delltechnologies.com/enus/perspectives/digital-transformation-index.htm Access date: 06.04.2020.

Digital twins for IoT applications (2017). Oracle white paper. Retrieved from http://www.oracle.com/us/ solutions/internetofthings/digital-twins-for-iot-apps-wp-3491953.pdf Access date: 06.04.2020.

Fourie Willem A.S. The digital mine eco-system. In: Mining Goes Digital: Proceedings of the 39th International Symposium "Application of Computers and Operations Research in the Mineral Industry" (APCOM 2019). Mueller et al. (Eds). pp. 491-496.

Gackowiec, P., Podobinska-Staniec M. (2019) IoT platforms for mining industry: an overview. Journal of the Polish Mineral Engineering Society. pp.267-272. http://doi.org/10.29227/IM-2019-01-47.

Global Cybersecurity Index (2018). ITU. Access mode: https://www.itu.int/pub/D-STR-GCI.01 Access date: 06.04.2020.

Henderson, M., Selwyn, N., \& Aston, R. (2017). What works and why? student perceptions of 'useful' digital technology in university teaching and learning. Studies in Higher Education, 42(8): 1567-1579. doi:10.1080/03075079.2015.1007946.

ICT Development Index 2017. Retrieved from: https://www.itu.int/net4/ITU-D/idi/2017/index.html\#i di2017rank-tab.

Indicators of digital economy (2019). Higher school of economics. https://www.hse.ru/primarydata/ ice2019 Access date: 06.04.2020.

Jiewu L., Qiang L., Shide Y., Jianbo J., Yan W., Chaoyang Z., Ding Z. (2019) Digital twin-driven rapid reconfiguration of the automated manufacturing system via an open architecture model. Robotics and Computer Integrated Manufacturing. 63, 101895. https://doi.org/10.1016/j.rcim.2019.101895.

Kazanin O.I., Sergeev I.B. (2017). Training a modern mining engineer: Objectives of universities and professional communities. Gornyi Zhurnal, 10, 75-80.

Kretschmann J., Plien M., Nguyen T.H.N., Rudakov M. (2020). Effective capacity building by empowerment teaching in the field of occupational safety and health management in mining. Journal of Mining Institute, 242, 248-256. DOI: 10.31897/PMI.2020.2.248.

Lee J., Cameron I., Hassal M. (2019). Improving process safety: what roles for digitalization and Industry 4.0? Process Safety and Environmental Protection. 132: 325-339. https//:doi.org/10.1016/j. psep.2019.10.021.

Litvinenko V.S., Sergeev I.B. (2019) Innovations as a factor in the development of the natural resources sector. Stud. Russ. Econ. Dev., 30, 637-645. https://doi.org/10.1134/S107570071906011X.

Magana A.J. (2017). Modeling and Simulation in Engineering Education: A Learning Progression. Journal of Professional Issues in Engineering Education and Practice. 143(4). DOI: 10.1061/(ASCE)EI.19435541.0000338.

Paschke M. (2019). Legal issues of the use of digital technology in mining - data ownership and liability. Scientific and Practical Studies of Raw Material Issues - Litvinenko (Ed.), 2020 Taylor \& Francis Group, London. P. 213-218.

Selwyn N., Hillman T., Eynon R., Ferreira G., Knox J., Macgilchrist F. \& Sancho-Gil J. M. (2020) What's next for Ed-Tech? Critical hopes and concerns for the 2020s, Learning, Media and Technology, 45(1): 1-6, DOI: 10.1080/17439884.2020.1694945. 
Stepanov I. Digitalization of coal and metal/Kommersant, "Mining. Metallurgy. Generation". Appendix \#174 25.09.2019, p. 9. Access mode: https://www.kommersant.ru/doc/4103010. Access date: 06.04.2020.

UN E-Government Survey 2018. Retrieved from: https://publicadministration.un.org/en/Research/UNe-Government-Surveys.

Wright, F., White, D., Hirst, T., \& Cann, A. (2014). Visitors and residents: Mapping student attitudes to academic use of social networks. Learning, Media and Technology, 39(1), 126-141. doi:10.1080/ 17439884.2013.777077.

Young A., Rogers, P. (2019) A review of digital transformation in mining. Mining, Metallurgy \& Exploration. 36: 683-699. https://doi.org/10.1007/s42461-019-00103-w.

Zhukovskiy Y., Batueva D., Buldysko A., \& Shabalov M. (2019a). Motivation towards energy saving by means of IoT personal energy manager platform. Journal of Physics: Conference Series, 1333, 062033. doi:10.1088/1742-6596/1333/6/062033.

Zhukovskiy Y.L., Koteleva N.I., Kovalchuk M.S. (2019b) Development of course feedback questionnaires of continuing professional education in the mining industry. Innovation-Based Development of the Mineral Resources Sector: Challenges and Prospects - 11th conference of the Russian-German Raw Materials, 589-597. 


\title{
Alexander von Humboldt's letters to Sergey Uvarov in the Russian manuscript collections
}

\author{
E.G. Pivovarov \\ Doctor of history, Leading researcher, St. Petersburg Branch of the Institute for the History of Natural \\ Sciences and Technology, Russian Academy of Sciences, St. Petersburg, Russia
}

\author{
A.Yu. Skrydlov \\ PhD in history, St. Petersburg Branch of the Institute for the History of Natural Sciences and Technology, \\ Russian Academy of Sciences, St. Petersburg, Russia
}

\begin{abstract}
The year of 2019 was significant for A. von Humboldt studies in Russia. The prominent Prussian researcher was familiar with a lot of scientists and statesmen in our country. The press hugely covered his famous voyage to the Empire in 1829. Humboldt's public lectures in the Academy of Sciences and other Imperial institutions were held with resounding success. The same year he got acquainted with S.S. Uvarov, the Academy President. Their correspondence, lasting for many years, has not been comprehensively studied yet. The authors revealed previously unpublished documents allowing to investigate their relationships. Humboldt often reminded about his German colleagues, having obtained positions in Russia. Due to his patronage, the future Academy of Sciences members (G.V. Abih, L.M. Kämtz, A. Y. Kupfer, Yu.F. Fritz) were invited to the country. He repeatedly complained about such "brain drain" caused by the fact that those specialists could build their scientific careers more successfully in Russia than in Germany. Humboldt and Uvarov constantly sent their books and articles, discussed international book exchanges, tried to create the journal, devoted to the Asian studies. Their correspondence continued after Uvarov's dismissal from the Ministry of National Education. In their last letters they frequently lamented about the revolutionary extremes of the epoch.
\end{abstract}

\section{INTRODUCTION}

Alexander von Humboldt's ideas hugely influenced the development of natural studies in Russia. In 2006 Natalia Suhova compiled the bibliography describing over 350 articles and books, devoted to his legacy, having been issued in our country (Suhova, 2006). Dozens of new works have been written since then. A new wave of the public interest was inspired by the joint jubilee: Humboldt's personal and the anniversary of his "Russian" voyage. Several Russian archives are holding over 200 letters written from/to the Prussian polymath. For decades he corresponded with a wide range of Russian scientists and authorities. Some of those documents were published in the USSR in 1962 (Shcherbakov, 1962).

Our article is an attempt to continue our Institute predecessors' investigations. We are trying to trace some aspects of long lasting relationships between Humboldt and Sergey Semionovich Uvarov, an influential statesman during Nicholas I reign, the Minister of National Education and the Imperial Academy of Sciences (IAS) President. During the Soviet period the latter was regarded as one of the most high-ranking standpatters of that time. His famous triad "Orthodoxy, Autocracy, and Nationality" was heavily criticized by the Marxist scholars. The compilers of the 1962 edition tried to avoid promulgating a great deal of his "ideologically dangerous" correspondence. It is not easy to imagine some of their doxology towards monarchs to be issued that time by the USSR Academy of Sciences. 
On 27 March, 1833, Uvarov, having been recently appointed a minister exclaimed: "No one is better aware than I myself, how weak is my strength to bear the burden, entrusted to me by His Majesty, but I dare say, that no one would have reacted to this important and difficult matter, with such selfless devotion to the country and the monarch whose high and rare advantages, you, yourself, had the opportunity to evaluate. His intentions regarding public education are as wise, as fatherly, as enlightened as in other areas of government" (Rossijskij Gosudarstvennyj Istoricheskij Arhiv (henceforth RGIA), coll. 735, aids 1, fol. 413, pp. 7, 16).

\section{SOURCES REVIEW}

Obviously, it is impossible to reconstruct all circumstances of their multiple collaborations without revealing letters, having survived in the European archives and any involvement of other types of sources. We have tried to make a general overview of Humboldt's appeals to Uvarov, kept in our country. Nowadays, 17 identified letters are held in Russian archives. 9 were previously published in the original language (Otdel Pis'mennyh Istochnikov Gosudarstvennogo Istoricheskogo Muzeja, Moscow (henceforth OPI GIM), coll. 17, aids 41/174, p. 201 in Knobloch, 2009) or in Russian translation (Sankt-Peterburgskij Filial Arhiva Rossijskoj Akademii Nauk (henceforth SPbF ARAN), coll. 1, aids 3, fol. 81, p. 208; RGIA, coll. 735, aids 1, fol. 413, p. 8; OPI GIM, coll. 17, fol. 41/174, p. 192; Otdel Rukopisej Rossijskoj Nacional'noj Biblioteki, St. Petersburg (henceforth OR RNB). Coll. 991, fol. 603, pp. 1-4; OPI GIM, coll. 17, fol. 41/174, p. 193; p. 194; p. 195-196; p. 197). 8 items are a still waiting to be properly investigated (OPI GIM, coll. 17, fol. 41/174, p. 204; RGIA, coll. 735, aids 1, fol. 413, p. 9; p. 10; p. 11; p. 13-14; OPI GIM, coll. 17, fol. 41/174, p. 198; p. 199-200; p. 227-228 in Shcherbakov, 1962.).

Besides, Russian manuscript repositories hold a number of Humboldt's letters to "unidentified persons". Judging by their content, in several cases, Uvarov might have been a hypothetical recipient. Such documents final attribution is a complicated task. Lack of any substantial evidence prevents us from quoting them. Only two such documents will be mentioned. The files cover of the first (OR RNB. Coll. 965, fol. 1310, p. 1) suggests, that the letter might belong to "Prince Lobanov". Probably, - a famous collector A.Ja. LobanovRostovsky. Such opinion is based on a handwritten pencil inscription, made within the text. However, we suppose that neither he nor any of his relatives were able to resolve Humboldt's questions. While Uvarov was the person, being authorized to do it. We have ventured to cite that bright example of the scientist's care about his younger colleagues. The second one (RGIA, coll. 735, aids 1, fol. 413, p. 6) is held in the National Education Minister Office collection alongside with other letters from the Prussian naturalist to Uvarov. Its plot, content, and design evidence quite clear whom they were sent to.

\section{ACQUAINTANCESHIP}

They knew each other, although probably fist in absentia since the 1810-s. Notifying on 18 April 1835 about the death of his brother Wilhelm, an IAS honorary member, Humboldt wrote: "My brother, during his stay in Vienna [Uvarov was in Vienna at the Russian Embassy in 1806-1809. W. Humboldt was a Prussian Ambassador to Vienna in 1810], had the pleasure of being on friendly terms with Your Excellency [Uvarov], and saw at the early successes of yours in the noble field of classical literature" (SPbF ARAN, coll. 1, aids 3, fol. 81, p. 208).

In 1818, the scientist was also elected as an honorary member (SPbF ARAN, coll. 1, aids 1a, 1818, fol. 29, § 71). On 11 February 1818, several IAS members - "academicians" signed Uvarov's preposition to elect "baron Alexander von Humboldt, well-known for his scholarship and merits" (SPbF ARAN, coll. 1, aids 2, 1818, fol. 71). On 7 October 1818, the General Assembly noted that he had thanked for the "honor" to become its affiliate. He was especially grateful for Uvarov, "speaking with the high esteem about the accomplishments of the present President, exploring with such incomparable wisdom the most mysterious sources of antiquity 
and combining with extensive knowledge that noble independence of the opinion, by which the Enlightenment should inspire everyone in any life vicissitudes" (SPbF ARAN, coll. 1, aids 1a, 1818 , fol. $29, \S 356$ ).

Humboldt and Uvarov finally met in person in 1829 (OPI GIM, coll. 17, aids 41/174, p. 204), when the German explorer was invited by the Russian Minister of Finance Georg von Cancrin to visit the Empire. He recalled on 30 July 1852: "I am a little proud of possessing a "heart memory" and therefore do not forget the deep impression, that your reading made on me 23 years ago: you honored me then with special trust <...>" (OPI GIM, coll. 17, fol. 41/174, pp. 199-200). His voyage aroused enthusiasm among Russian aristocrats. Humboldt wrote to his brother: "My beau monde successes are beyond description. All the nobles, all the scientists - all of them constantly revolve around me. No one might be accepted with a greater respect and hospitality $<\ldots .>$. Almost every day I have lunch with the Imperial family in a narrow circle - the table is set for four people" (Suhova, 2006).

There were numerous notes in the Russian periodicals dedicated to the scientist. Thus, a famous litterateur Pavel P. Svinyin informed his "Otechestvennye Zapiski" readers: "He was honored to be invited to the Sovereign Emperor's dinner table and then daily received invitations to our grandees, trying to show him all their respect and Russian hospitality" (S[vin'in], 1829).On 29 April 1829, Humboldt made a report at IAS and soon after that undertook a seven months expedition to the Asian part of the Empire. There, he got acquainted with the local science lovers. Four years later he wrote to Uvarov, that he regularly and warmly recalled about "the geographical data treasury" in Orenburg, collected by a military engineer Gregory F. Gens (RGIA, coll. 735, aids 1, fol. 413, pp. 8).

Upon his coming back to St. Petersburg, Humboldt again visited IAS. The "Extraordinary Meeting" on 16 November 1829 was attended by "Her Majesty Grand Duchess Elena, <. . > Duke Alexander of Württemberg, noble persons from the Imperial Court, State Council members, corps diplomatique, the Minister of Public Education <...>, ministers, the Academy honorary and correspondent members and a large number of dignitaries of both sexes, scientists and writers of our capital" (SPbF ARAN, coll. 1, aids 1a, 1829, fol. 41). Speeches, made by the guest, Uvarov, and academicians were published (Séance extraordinaire. .., 1829).

\section{PATRON OF YOUNG SCIENTISTS}

Soon their personal acquaintance grew into continuous and steady correspondence. Its key issue was scientists' employment. Humboldt frequently recommended German geographers, mineralogists, philologists to vacant positions in Russian universities. Several future academicians (Otto Wilhelm Hermann von Abich, Ludwig Friedrich Kämtz, Adolph-Theodor Kupffer, Karl-Julius Fritzsche etc.) were his protégés and long-time correspondents, thankfully sharing the results of their researchers with the patron. On 25 February 1833, Humboldt wrote to Uvarov from Berlin: "I together with my learned friend Mr. Mitscherlich]Eilhard[(a famous German chemist) would recommend a young man (Mr. Fritzsche), having been distinguished for a witty use of chemical methods to the plant organization study; for several years he has been our Academic Laboratory Head. I think, it would be an excellent acquisition, and I dare to ask you <...> to give him your protection" (RGIA, coll. 735, aids 1, fol. 413, p. 6).

While "the Emperor deigned to entrust [Uvarov] the Ministry of National Education", he willingly informed his "famous friend", that he had fortunately obtained more official channels to promote the German professors (RGIA, coll. 735, aids 1, fol. 413, p. 7, 16). Congratulating him on the new appointment, Humboldt did not forget to remind "his President" that Kupffer's life and work conditions "might be improved" (RGIA, coll. 735, aids 1, fol. 413, p. 8). For decades he continued to trace his protégés' careers and achievements (OPI GIM, coll. 17, fol. 41/174, pp. 193-197; RGIA, coll. 735, aids 1, fol. 413, p. 11). Many of them got their first "Russian" positions at Universität Dorpat, the Empire's most western one. The language of instruction there was German. So, the newcomers did not experience much language or cultural difficulties. 
Since Humboldt, as he wrote, was "doomed to constantly bother Your Excellency with my "Dorpat" interests" (RGIA, coll. 735, aids 1, fol. 413, pp. 13-14), almost all his letters in the 1840 -s contain suggestions about the proper candidates for the University chairs. On 2 June 1842, he wrote from Sans Souci: "Your Excellency has just made two very successful acquisitions to improve the study of physics and geology at the University of Dorpat. Mr. Kämtz and Mr. Abich are two scientists, whose departure I would regret, if I did not know, that we had no conditions to offer them the position and the wide field of research, that could be provided to them under your patronage" (OPI GIM, coll. 17, fol. 41/174, p. 193).

In 1842 Abich, promoted by his famous teachers - Humboldt and Christian Leopold von Buch, was appointed there as a professor of mineralogy. Henceforth, he spent most of his time constantly travelling around the Empire. Semyon Vengerov asserted, that " $<$ Abich $>$ created the geology of that region, having been almost undeveloped before him <...>" (Vengerov, 1889). For many years Humboldt went on asking Uvarov about his expeditions. On 13 July 1842, he reminded Uvarov: "As well as my friend, the great geologist Leopold von Buch, I am interested in Mr. Abich's achievements <... . He is one of the most outstanding people in Germany, studying nature with all the insight of an excellent observer $<\ldots>$. He will give you $\langle\ldots\rangle$, what is currently least studied - the application of chemistry to geology $\langle\ldots\rangle$. If he succeeded under your aegis $\langle\ldots\rangle$, he will someday visit Ararat and the volcanic region between Erivan, Lake Van and Tabriz!" (RGIA, coll. 735, aids 1, fol. 413, p. 11).

\section{PROFESSIONAL CREDO}

Three years later, he again thanked Uvarov for his "very special patronage <...> to Abich, travelling around Ararat" (OPI GIM, coll. 17, fol. 41/174, p. 195-196). Speaking about his innovative researches, Humboldt described his own ideal of the Scientist: a hardy explorer, a mature naturalist and a gifted artist: "Mr. Abich has a rare advantage: he is a geologist, a talented chemist and a draftsman!" (OPI GIM, coll. 17, fol. 41/174, p. 195-196). On 5 November 1847, he once more praised his friend's virtues and proclaimed their joint professional credo, - the extensive field research had to be followed by immediate processing of its results: "Mr. Abich, whom we consider to be the first German geologist after Mr. Leopold Buch, will bring the most valuable results of his observations, and it is necessary, that he would not allow them to become obsolete. Science goes ahead in quick steps; an expedition should never drag on for too long. It is not good, if the observation results are published, when the scientific horizon has already expanded in many directions" (OPI GIM, coll. 17, fol. 41/174, p. 197).

Being aware of Uvarov's interest to antiquity, Humboldt gave references to several philologists, Philipp August Böckh's students. They did not become as famous in Russia as their colleagues - geographers, physicists or chemists. We know only their family names Dr. Gantl, Dr. Merker. In May 1843, he characterized in a playful tone a new university professor: "Dr. Merker, one of Böckh's most prominent students in the field of Hellenism, was elected to the Department of Philology in Dorpat. I would highly recommend him to the high patronage of Your Excellency. <.. > You said in your etudes: "Metaphysics, which assumes facts, can never satisfy the human mind". This axiom makes me hope, that in Dr. Merker you are happy to find a mix of philology, history and philosophy, a mix that excludes empty and fantastic assumptions. Mr. Merker is a solid scholar and speaks various modern languages even Polish. You will see from the attached work, that the only sin, I know of him, is that he writes Greek verses" (RGIA, coll. 735, aids 1, fol. 413, p. 13-14).

It is remarkable that Humboldt always introduced "scientists" himself, while advising "scholars" mainly referred to experts' opinion. On 29 June 1841, he wrote from Paris: "I dare ask my president for high patronage in favor of a German philologist Dr. Gantl, who travels to St. Petersburg after long studies in libraries and manuscript repositories in Rome, Florence, Oxford, Paris and Germany. <...> He published works on Persia and on Horace, based on the sources, which no one has yet scooped. "Snack" from Greek manuscripts also attracted 
him. Böckh, Gottfried Hermann and Amman from Dresden speak about Mr. Gantal's moral qualities in the most favourable way. I feel, that my recommendations will be for Your Excellency something of an intermittent illness" (RGIA, coll. 735, aids 1, fol. 413, p. 10).

In the same letter he personally evaluated another Dorpat professor - anatomist Karl Bogislaus Reichert, speaking as a specialist about his "ovology" researches. Repeating his appeals, Humboldt even complained to Uvarov about incessant "brain drain" from Germany to Russia: "Maybe you will ask, why I deprive my country of people, about whom I speak with a great praise. I answer again, that we are educating more scientists, than we can feed; that your universities offer better positions than ours; I answer, that I believe in the scientific republic, where different nations of Christian and civilized Europe should begin mutual exchange <.. .>" (RGIA, coll. 735, aids 1, fol. 413, p. 13-14).

Promoting his colleagues, Humboldt always described only their professional skills, profound knowledge, and novelty of their ideas. On 8 September 1839, he reminded Uvarov about an outstanding embryologist Robert Remak: "We have here one young scientist <...> who, having received the second prize at the Medical Faculty of Berlin University, became famous for his analytical studies, very subtle, very curious, related to the structure of the nerves $\langle\ldots\rangle$. It seems to me, that there is a currently free vacancy in physiology at Vilnius Medical Academy. < . .> The young man belongs to the Jewish religion. And his scrupulosity, which you do not blame, would prevent him from converting to Christianity only for profit reasons. He hurried to write to Vilna, that he was a Jew, and that the Academy should be aware of this circumstance. I know, your legislation, very tolerant in the affairs of national beliefs, makes it easy to eliminate the difficulty in some cases viewing one's personal merits $<\ldots>$. I would like to hope, that Your Excellency will also regard this case as an exception" (OR RNB, Vaksel's coll., fol. 1310, p. 1).

\section{6 "KEY TO CENTRAL ASIA"}

Among other significant topics, discussed by the correspondents in the 1830-1840-s: newly published works, organization of international scientific periodicals, book exchanges between Russian, Prussian and French institutions, information about Europeans' voyages to the country. Their expeditions throughout the Empire, especially to its eastern regions, surely faced a lot of difficulties not only climatic or transport ones. Red tape poisoned the society, so Humboldt asked "his President" "to appease and mitigate the griffins guarding these treasures" (RGIA, coll. 735, aids 1, fol. 413, p. 9).

Almost in every letter they informed each other about their recent achievements. On 18 May 1843, being in Potsdam Humboldt notified his interlocutor: "I had the high honor to acquire an excellent compilation of your works, devoted to philology, and poetry, and the beginnings of philosophy (Ouvaroff, 1843). I reread your Mysteries with the infinite pleasure (Uvarov, 1812). <..> I once again admired the elevation of the style which as always stems from the sublime order of the soul" (RGIA, coll. 735, aids 1, fol. 413, pp. 13-14).

He also reported, that he finally received the monograph devoted to his rather short but fertile expedition in 1829: "I decide to ask Your Excellency to accept with the favorable indulgence, that you have been giving me for so many years, a respectful offering $<\ldots$. , only a few days ago I received a copy of my "Central Asia". Some introduction pages $<\ldots>$ should attract my President's attention. Perhaps, a sense of scientific modesty should have forced me to refrain from the thought of presenting you a book, teeming with numerical calculations, the enemies of any thought" (RGIA, coll. 735, aids 1, fol. 413, pp. 13-14).

Humboldt regarded himself as an ambassador of the "scientific republic" and regularly tried to organize long-lasing collaborations between the institutions of different countries. On 22 October 1838, working at the "Institute Palace" in Paris, he advised to arrange continuous relations with Stanislas Aignan Julien, an eminent French sinologist: "Concluding the letter I dare appeal to my President with a humble request for a very respectable person, Mr. Julien, a member of the Institute, with the greatest zeal engaged in historical and geographical research in Central Asia. My friend, Mr. Julien, has already donated 116 Chinese books to St. Petersburg Imperial 
Academy for the exchange $<\ldots$. . Mr. Julien added to them all his published works. He extremely needs the geographical dictionary $\mathrm{Si}$-iu-thonbg-wen-tchi, which is available $<\ldots .>$ in the Imperial Library, as well as Li-tsi or the book of rituals. $<\ldots>$ The special propensity, that I have for Central Asia, makes me convincingly ask you $\langle\ldots\rangle$ not to refuse to facilitate these negotiations. I take it very close to my heart. With his package Mr. Julien has beforehand proved the extent, to which he wanted to be useful to your Academy, and it might honor him very well by electing him as its member. He had deserved it with his deep knowledge, the softness of his character and the services, that he likes providing to all Russian travelers" (OR RNB. Foreign Autographs coll., fol. 603, pp. 1-4).

We do not know, what should be blamed, - the Russian beadledom or the pace of international communications at that time, but four years later Si-iu-thonbg-wen-tchi had not been sent to Paris. On 28 September 1842, Humbuldt had to hurry up Uvarov's subjects: "The publication of this work would be extremely important for the history and geography of highland Asia. <...> My love of geography makes me be intrusive. When you live to 73 years old, you need to hurry to enjoy life" (OPI GIM, coll. 17, fol. 41/174, p. 194).

Wishing to popularize knowledge about Siberia and Central Asia, Humboldt advised to open the so called "Asian Journal". On 20 July 1838, he once again reminded: "The key to Central Asia is in your hands. An Asian journal, that would be published under your supervision, could increase the knowledge about this part of the world" (RGIA, coll. 735, aids 1, fol. 413 , p. 8). He repeated the same idea a decade later: "It would be very desirable for Mr. Kämtz to publish a physics journal in Dorpat, that would put Europe in a closer contact with your vast Empire stretching from the permafrost zone to the Herodotus plains and the sugar cane zone" (OPI GIM, coll. 17, fol. 41/174, p. 193).

\section{CONCLUSION}

Their friendly communication did not stop after Uvarov's resignation in 1849. On 21 February 1851, Humboldt solaced his vis-à-vis recalling his achievements as a minister: "Count, if I were late to bring to Your Excellency the expressions of my admiration and my respectful devotion, < . . > I cannot forget the noble services having been rendered by you as a statesman to the sciences which I am mostly engaged in and to the classical literature from which you yourself draw your happy inspiration. Pulkovo <observatory > is a monument of Astronomy erected by you under the auspices of the great monarch; it surpasses all that has been built so far. $<\ldots>$ How I should regret that in order to recuperate $<\ldots>$ you turned to the peace and quiet of scientific life, the joys of which you know" (OPI GIM, coll. 17, fol. 41/174, p. 198).

Letters, sent in the 1850 -s, no longer contain petitions to promote anyone or to participate in any international project. Ceasing to be a minister, he returned to scholarly studies in his manor house in Porechie. Revolutionary events, stunning the European aristocracy, became the constant subject of two elderly gentlemen's fears. Reminding Humboldt about his 1829 expedition and their meetings, Uvarov also emphasized their ideological kinship. In his last letter sent in August 1852 he wrote about their mutual rejection of the revolutionary extremes: "The time of your stay in St. Petersburg will remain one of the most pleasant memories of both public and private lives of mine. <...> As you know, I maintained the same love to the true progress of the human mind. I think, as either you or all genuine conservatives in Europe would have not understood our most cherished interests, if we had elevated to the principle of those extremes and criminal abuses we had witnessed and have been still witnessing. Let us hope, that a true civilization, a progressive civilization will soon cease to be a victim of terrible abuses $<\ldots$. . But I stop talking, because you can add a lot more on this topic while I have neither time nor place. I, therefore, limit myself in assuring you again, dear and respected colleague, in my deep and long-standing respect" (OPI GIM, coll. 17, fol. 41/126, pp. 227-228).

As we have mentioned in the introductory lines of our preliminary survey, our initial research task was rather restricted. We just tried to give a general overview of the main topics raised in Humboldt's letters to Uvarov. It is clear, investigation of their correspondence should be continued. Here we have just retold some interesting and important pieces of 
Humboldt's letters. Such translation significantly reduces the value of the quoted fragments. They have to be published in the original language, with proper translation, and comments. Uvarov's letters to Humboldt also ought to be located.

\section{REFERENCES}

Knobloch, E. (ed.) 2009. Alexander von Humboldt. Briefe aus Russland 1829. Berlin. Briefe 87.

Ouvaroff, S. 1843. Etudes de Philologie et de critique. St. Petersburg.

Shcherbakov, D. (ed.) 1962. Alexander Humboldt's correspondence with scientists and statesmen of Russia, Moscow.

Suhova, N. 2006. Alexander von Humboldt in Russian literature: the annotated bibliography. St. Petersburg.

Svin'in, P. 1829. About Baron Humboldt, Otechestvennye zapiski, 38, pp. 280-283.

Séance extraordinair, tenue par l'Academie Impériale de Sciences de St.-Pétersburg, en l'honneur de M-r le baron Alexandre de Humboldt du 16 November 1829. St. Petersburg, 1829.

Uvarov, S. 1812. Essai sur les Mystères d́ Eleusis. St. Petersburg.

Vengerov, S. 1889. 'Abykh German Vilgelmovich', Critical-biographical dictionary of Russian writers and scientists, vol. 1, pp. 8-11. 


\title{
J. Hermann's studies on salt production in the Urals in late 18th century
}

\author{
L.D. Bondar \\ St. Petersburg Branch of the Archive of the Russian Academy of Sciences, St. Petersburg, Russia
}

\begin{abstract}
The article highlights the activities of the Austrian mining engineer and statistics Johann von Herrmann (1755-1815), associated with the study of salt production in the Urals in the late 18th century. After the invitation to the Russia, a young engineer at the age of 27 years was sent to the Pyshminsky steel factory for inspection of state-owned industrial factories. Herrmann went to Ural several times, and the materials he collected during his first stay there in 1784-1795 were transferred to the academic archive. Thanks to this, we have invaluable information about the state of the Ural factories. One of the objects of study was salt production, concentrated in the Solikamsk district (Perm governorship). Archival papers of Herrmann contain information about the organization of salterns, the staff of employees and workers, the costs of organizing and maintaining salterns, the volume of products, methods of delivery to other governorates, etc.
\end{abstract}

\section{INTRODUCTION}

Benedict Franz Johann von Herrmann (1755-1815), an Austrian mining engineer and statistician, was invited to Russia in 1782 at the age of 27 and was elected a corresponding member of the Imperial Academy of Sciences in the same year. As a mineralogist and mining engineer, Johann von Hermann took up in the Academy of Sciences the issue of statistical study of the productive forces of the Russian Empire, developed methods of statistical analysis and collected information about industrial enterprises.

1783, Hermann was sent to the Urals, and in 1784 he was appointed director of the stateowned Pyshminsky steel factory, which opened its production in 1785 (Tulisov 2001: 397). Hermann collected in the Urals statistical data on state-owned enterprises and on the largest private factories (Bondar 2018: 1043-1049). Subsequently, the results of these and future studies were presented by Hermann in numerous papers, published in Russian and German (Penzin 1989: 63-67). Therefore, the Academy of Sciences elected him its honorary foreign member already in 1786; 1790 became he an ordinary academician in the Department of Mineralogy. As an academician, Hermann supervised the geological study of the Urals and Siberia, as well as empirical research in this region.

Thus, he sent to the Academy of Sciences the results of meteorological observations, which were reported in the Academy on October $21^{\text {st }}, 1790$, January $12^{\text {th }}, 1792$ (meteorological observations from Pyshminsk for July, August and September 1791), June 11 ${ }^{\text {th }}$, 1792 (extract from meteorological observations in Pyshminsk in 1791) (SPbB ARAS, f. 1, 1. 1, fl. 41: 60 rev., f1. 43: 2, 38). On March $24^{\text {th }}, 1788$, the Academy was informed about the sending of a paleontological find by Hermann for the Cabinet of Natural History ("he sent a curious bone found in the gold mines of Berezov") (SPbB ARAS, f. 1, 1. 1, fl. 39: 19). The protocol record of March $1^{\text {st }}, 1790$ reports that the Academy received from Hermann a collection of more than a hundred stones from the mines of the Ural mountains. On March $26^{\text {th }}, 1792$. it was reported that the Academy received a complete collection of Ural stones with a catalog. Protocol data for January $17^{\text {th }}, 1793$ report a new parcel from Hermann - a box with minerals from Perm (SPbB ARAS, f. 1, 1. 1, fl. 41: 15 rev., 60 rev., fl. 43: 20, fl. 44: 5). 
In 1795, Hermann expressed his intention to return to St. Petersburg and take his place in the Academy (SPbB ARAS, f. 1, 1. 1, fl. 46: 9). He arrived to the capital and made at the academic meeting on March $14^{\text {th }}, 1796$ a report On the current situation of the Siberian gold, silver, copper and iron factories and salt mines... (SPbB ARAS, f. 1, 1. 1, fl. 47: 20 rev.-21). Hermann continued in St. Petersburg to collect and process statistical data and was again sent to the Urals soon, receiving at the end of 1801 the appointment of the head of the Yekaterinburg mining administration (SPbB ARAS, f. V, 1. 1-G, fl. 13: 169).

He continued in the Urals to maintain scientific relations with the Academy and organized, as before, meteorological observations. On December $1^{\text {st }}, 1802$, at a meeting of the Conference, it was reported about the sending by Hermann the first results of the observations (SPbB ARAS, f. 1, 1. 1, fl. 53: 103). Hermann's weather observations in the Urals were repeatedly read out at the future academic meetings (SPbB ARAS, f. 1, 1. 1, fl. 55: 43-44, fl. 58: 19, fl. 59: 101 rev., fl. 63: 79 rev.). In the protocols (July $\left.11^{\text {th }}, 1804\right)$, there is also a mention of sending by Hermann to the Academy Ural minerals; systematization and cataloging of these minerals for the Conference archive was entrusted to academician V. M. Severgin (SPbB ARAS, f. 1, 1. 1, fl. 55: 82).

1801 (before leaving for the Urals), Hermann transferred to the academic archive all his statistical and graphic material, that was collected by him during his previous stay in the Urals and during his work in St. Petersburg. These documents formed the personal fond of academician Johann von Hermann and are stored today in the St. Petersburg Branch of the Archive of the Russian Academy of Sciences (fond 27). It gives us possibility to find in academic papers an information on Russian economic history at the end of the 18th century about mining, iron-production, copper-factories, about the state of roads, the population, the prices of basic products and goods, etc. One of the studied by Hermannn issues was the status of salt production and sales of salt.

\section{REGIONS - SALT SUPPLIERS IN THE RUSSIAN EMPIRE}

Salt trade in Russia (as in many countries of the world) was a source of the state income and an object of the state monopoly. Salt production was allowed to private individuals. The first positions in the $18^{\text {th }}$ century were held by the Stroganov family, but the state owned large saltproducing enterprises, too, as in Staraya Russa, Orenburg and Perm governorates (Makhrova 2015).

One of the documents of Hermann's fond (SPbB ARAS, f. 1, 1. 1, fl. 87: 12-17) gives information for 1783 - which of the governorates of the Russian Empire "what salt is satisfied". The governorates of Azov, Astrakhan, Vologda, Irkutsk, Kolyvan and Tobolsk had their own salt; this part of the document does not specify the Perm and Ufa governorates, these governorates used their own salt, too, and it is described in the document below. We find in the Complete collection of laws of the Russian Empire a list of places where salterns worked in this time; the document of Hermann's fond does not contradict this list (PSZRI 1830: 15174). Imported salt was supplied to three governorates (the list of provinces - consumers of salt was established by the Charter on Salt issued by Catherine II in 1781): Vyborg, Revel, and Riga. For other governorates, the document provides such information. Perm salt was used by two capital cities - St. Petersburg and Moscow, as well as Tver, Novgorod, Smolensk, Vladimir, Kaluga, Pskov, Polotsk, Mogilev and Vyatka. It should be noted that the list of governorates consumers of Perm salt is repeated in various documents: the same governorates are named in another document of Hermann's fond (SPbB ARAS, f. 1, 1. 1, fl. 87: 59); the same list is given in the book of Bogdanov (Bogdanov 2014: 93), who quotes documents of the State Archive of the Perm Region. Iletsk salt (from Ufa governorate) was supplied to the Nizhny Novgorod and partially Kazan governorates. The document also names Olonetsk salt (олонеикая соль), which may be an error, it should be about salt from the lake Elton (near Pallasovka, near the border with Kazakhstan). Elton salt (елтонская соль) - so it is listed in the same document below. This salt was supplied to the governorates of Penza, Kostroma, Tula, Tambov, Saratov, Yaroslavl, Ryazan, Voronezh, Simbirsk, Kazan, Kursk, Oryol, Kharkov, partially Kiev, Chernigov, Novgorod. 


\section{PERM REGION AND SOLIKAMSK STATISTICS IN HERMANN PAPERS}

The largest supplier of salt, which supplied both capitals, was the Perm governorate, or rather, in the years of Catherine II - the Perm namestnichestvo (Пермское наместничество; Perm viceroyalty). It was a newly created administrative-territorial entity. The decree on the creation was signed on January $27^{\text {th }}, 1781$ (SPbB ARAS, f. 27, 1. 1, fl. 128: 12-21), and official celebrations were held in October 1781 (SPbB ARAS, f. 27, 1. 1, fl. 128: 51-57 rev.)

A chronicle of official events can also be found in the papers of Hermann. This document mentions the names of local industrialists who made donations for the celebrations. First of all, these are the salt producers Stroganovs: Earl Alexander Sergeyevich Stroganov, who donated 1000 rubles (and 300 rubles each year for the construction of schools), and Baron Alexander Nikolayevich Stroganov, who contributed 500 rubles (and 100 rubles each year for schools). Representatives of the Demidovs family were also included in this list: Alexander Grigoryevich Demidov (donated 1000 rubles) and his cousin Nikita Nikitich Demidov (donated 2000 rubles) (SPbB ARAS, f. 27, 1. 1, fl. 128: 57-57 rev.).

The namestnichestvo was divided into two regions (oblast; область) - Perm region and Yekaterinburg region. 1781, Yekaterinburg has received the status of a city and its name in honor of the Empress. Perm received the status of a city in November 1780. If the Yekaterinburg region was of paramount importance in the organization of metallurgical industry, then the Perm region had absolute primacy in the issue of salt production. Perm region was divided into 8 district (uyezd; уезд), one of the district town of Perm region was Solikamsk, at that time - Sol' Kamskaya (that means "Kama salt"). The city got its name for a reason: it emerged in place of the salterns on the banks of the river Usolka - a tributary of the river Kama. This is enshrined in the city's coat, that was approved 1783 (this day, the coats of all district towns of the Perm namestnichestvo were approved). We can read about the Solikamsk coat in the document Description of the coats of district towns of the Perm governorate (SPbB ARAS, f. 27, 1. 1, f1. 128: 64-65 rev.; cf. PSZRI 1830: 15.786): "There is a salt well in the golden field, with a lowered into it bucket for removing salt and with salt streams on it".

The data collected by Hermann gives us some information about Solikamsk itself. The Hermann's fond contains a demonstrative document, that was compiled according to the data of 1792 - A brief list of state and private factories in the Perm namestnichestvo, the population, state revenues etc. (SPbB ARAS, f. 27, 1. 1, f1. 128: 40).

How we find out, there were 11 stone and 609 wooden houses in 1792 in Solikamsk (for comparison, there were 6 stone houses and 681 wooden houses in Perm). There were 25 villages with churches (село) and 774 villages in the Solikamsk district (there were 15 villages with churches and 537 villages in Perm district). There were 10 stone churches and 1 monastery in Solikamsk city ( 2 stone churches and 1 wooden churche - in Perm city); there were 14 stone churches and 23 wooden ones in all Solikamsk district (3 stone churches and 12 wooden ones - in Perm district).

\section{SALT PRODUCTION IN SOLIKAMSK. STATISTICS OF HERMANN PAPERS}

The industrial situation in Solikamsk was in 1792 as follows. In terms of the number of metallurgical factories, Solikamsk district looked modest: 1 state-owned copper smelter and 2 private ironworks. The picture is completely different for salt factories: there were 9 private salt factories in Solikamsk itself, while 22 state-owned and 89 private ones in the district. There were no salt factories in other districts of the Perm region at all. This document gives us information about the volume of salt production in the entire Solikamsk region. These 120 salt works of Solikamsk district produced in $17925,039,759$ pounds of salt, i.e. $80,636,144 \mathrm{~kg}$. The salt revenue of the Perm region was 194,663 rubles 23 7/8 kopecks that year (SPbB ARAS, f. 27, 1. 1, fl. 128: 40).

For comparison, we present data from the same document for the second state-owned trade - the sale of wine. In 1792, there were 6 drinking houses in Solikamsk itself and 27 in the district; they sold a total of 18,305 6/8 buckets of wine, i.e. about 225,151 liters. In Perm, with 
exactly the same number of drinking houses in the city, three times as much wine was sold. In general, the drinking income significantly exceeded the salt income and was 611,119 rubles 50 kopecks that year.

We also have in Hermann's papers indicators of the dynamics of revenue growth from the sale of salt and wine in the Perm namestnichestvo from 1783 to 1795. It is important to keep in mind that Hermann arrived in the Urals at a difficult time for the salt industry. Researchers (beginning with historians of the early $20^{\text {th }}$ century) note the crisis periods in the history of the Ural state salt production of the second half of 18th century (Kharitonova 1971 \& other works of the author). In June 1782 Catherine II issued a decree "On the multiplication of salt production in the Perm namestnichestvo", that ordered to increase the production of salt in stateowned saltern (PSZRI 1830: 15.421). However, salt production decreased by $9 \%$ that year, and by $12 \%$ - the following year (Bogdanov 2014: 94). This raised concerns about the supply of salt to the other 11 provinces. We cited above the document of 1783 with the information on the distribution of salt by governorates (SPbB ARAS, f. 1, 1. 1, fl. 87: 12-17). There are specific details in the document: "It is required for these 31 governorates according to the average consumption for two years: of Elton salt $-9,101,657$ poods 36 pounds, Perm salt $-8,917,354$ poods, Iletsk salt $-1,700,927$ poods 8 pounds; in fact, there is of all these salts by January $1^{\text {st }}$, 1783 in the provincial stores: of Elton salt $-4,318,731$ poods 1 pound, Perm salt $-4,388,467$ poods 20 pound, Iletsk salt - 1,126,914 poods 26 pounds. Therefore, as for the Perm salt, contracts were signed with private producers for the supply of 3,518,000 poods in 1783 and of $3,578,000$ poods in 1784; but the Perm state chamber (Пермская казенная палата) writes that up to $1,200,000$ can be boiled annually in state-owned factories, and the state chamber promises to add since 1786 , when the pipes are cleared, up to 700,000 poods. $<\ldots$. . ".

There is a special list among the Hermann'spapers, that shows "how much wine and salt were sold in the Perm namestnichestvo from 1783 to 1794 and what was the amount of salt sale"(table 1). We see positive dynamics to 1794. Herewith, drinking income regularly exceeded salt income by more than 3.5 times. There are the data for the extreme two years below (SPbB ARAS, f. 27, 1. 1, f1. 128: 47).

Hermann's papers also contain substantial information about the organization of salt production. On arrival in the Urals, he apparently sent out a questionnaire; the answers from three respondents (from whom exactly the answers were received - it is not obvious) were preserved in the fond (one of the questionnaires was signed Hermann on May $4^{\text {th }}, 1784$ ).

As a result, we have information on the organization of the technological process ( $\mathrm{SPbB}$ ARAS, f. 27, 1. 1, f1. 87: 33-35, 47 rev.-48, 61-67). Generally, the description does not contradict what we know about the production process of salt boiling, which remained unchanged until the beginning of the 20th century (Logunov \& al. 1995, Chivtaev 2017: 71-93). There is also information on the expenses of salt factories for different items. The document informs, that the construction of one pipe for lifting salt solution required 606 rubles 70 kopecks per year. As this tube must be 35 sazhens [ 1 sazhen $($ сажень $)=7$ foots] deep or even deeper and it is possible to pass in the solid and stony ground just for 5 or 6 years, so the establishment of a new pipe costs 3640 rubles 20 kopecks (SPbB ARAS, f. 27, 1. 1, fl. 87: 31-31 rev.). An alternative calculation is also proposed - how much money is required to clean the old

Table 1. Revenue from the sale of salt and wine in the Perm namestnichestvo in 1783 and 1794.

\begin{tabular}{lll}
\hline Year & Salt income & Wine income \\
\hline 1783 & 131,775 rubles 60 kopecks & $\begin{array}{l}494,494 \text { rubles 49 3/4 kopecks } \\
695,073 \text { rubles 25 kopecks }\end{array}$ \\
$1794 *$ & 223,408 rubles 89 kopecks & Fopecks. \\
\hline For the sale of salt, there are also data for 1795 $-214,995$ rubles 62 kopect \\
There aren't indicators for the sale of wine in 1795, because, as the document \\
explains, the sale of wine was transferred to farmers, who must pay the \\
Senate 612,897 rubles 85 kopecks annually.
\end{tabular}


pipe; the result is 289 rubles $671 / 2$ kopecks (SPbB ARAS, f. 27, 1. 1, fl. 87: 32-33 rev.). We have also a calculation of expenses for the annual maintenance of one saltern (for firewood and supplies, but without workers) - 2112 rubles 12 3/4 kopecks (SPbB ARAS, f. 27, 1. 1, fl. 87: 35 rev.-38), for the maintenance of various industrial buildings and other expenses -59 rubles 15 1/2 kopecks (SPbB ARAS, f. 27, 1. 1, f1. 87: 39-43).

Interesting information is contained in the list of servants and workers of salterns. We learn that 24 salterns were serviced by 43 "higher" officials, including a warden, his assistants and clerks; this team has cost 2485 rubles per year, 100 rubles was allocated for office expenses. So, maintenance of one saltern was had 107 rubles 71 kopecks (SPbB ARAS, f. 27, 1. 1, fl. 87: 43 rev.-44). There was also a staff of servants and clerks who performed the functions of external supply, service, communication, etc.; their maintenance, according to the document, cost for one saltern on average 149 rubles 75 kopecks per year (SPbB ARAS, f. 27, 1. 1, fl. 87: 44 rev.46). Taxes cost 109 rubles $21 / 2$ kopecks per year. Thus, as the document says, the maintenance of one saltern cost 3247 rubles 59 1/4 kopecks (SPbB ARAS, f. 27, 1. 1, fl. 87: 46 vol.-47).

The same document gives information about productivity of the salterns: each saltern was supposed to produce 50,000 poods of salt per year; in fact, 47,000 poods were produced. So, the cost price of each pood, taking into account all costs, was 5-7 kopecks (SPbB ARAS, f. $27,1.1$, fl. $87: 46$ rev. -47$)$. At the same time, it is known that by a decree of November $15^{\text {th }}$, 1783 the purchase price of salt for Solikamsk industrialists was 9 kopecks (PSZRI 1830: 15.880); the price increased in the following years (Bogdanov 2014: 96).

There is data on the volume of salt production at the separate factories for 1782-1783. On the state-owned Dedyukhinsky salterns produced $910,142-1,140,000$ poods. Private salt factories produced the following volume of production: count Alexander Sergeyevich Stroganov's 16 salterns in Usolye and Lenva produced 700,000-850,000 poods, baron Alexander Nikolaevich Stroganov's 12 salterns in Usolye and Lenva - 630,000-640,000 poods, Vsevolod Alekseyevich Vsevolozhsky's 10 salterns in Usolye and Lenva - 450,000 poods, princess Anna Alexandrovna Golitsyna's (Mikhail Mikhailovich Golitsyn's wife) 14 salterns in Usolye, Lenva and Chusovsky Gorodki - 530,000-535,000 poods, princess Varvara Alexandrovna Shakhovskaya's (Boris Grigoryevich Shakhovsky's wife) 16 salterns in Usolye and Lenva 620,000 poods, Ivan [Lazarevich] Lazarev's 9 salterns in Usolye and Lenva - 420,000 poods, Alexey [Fedorovich] Turchaninov's 4 salterns in Solikamsk - 120,000 poods, merchant Maxim [Grigoryevich] Surovtsev's in Solikamsk 3 salterns - 45,000-49,000 poods (SPbB ARAS, f. 27, 1. 1, fl. 87: 58-58 rev.). Generally, the productivity of Solikamsk factories is known from a large number of other documents and is well represented in the book by M. V. Bogdanov (Bogdanov 2014).

Detailed information about the functioning of salt factories can be obtained from other documents: a document entitled "Report of Perm namestnichestvo to the State chamber on an Expedition for salt affairs from the Perm state-owned Dedyukhin salterns report" (SPbB ARAS, f. 27, 1. 1, fl. 87: 49); daily record for the half of December (year is not specified), reflecting the amount of boiled salt and spent firewood in several salt factories (SPbB ARAS, f. 27, 1. 1, fl. 87: 49 rev.-50); papers with the title "Brief about the state of salterns in Usolye and other places near the Kama river..." (SPbB ARAS, f. 27, 1. 1, f1. 87: 52-57); statistical data on the salterns of baron Alexander Stroganov (SPbB ARAS, f. 27, 1. 1, fl. 87: 60).

\section{SALT TRADING}

What were the means of salt delivery to remote provinces? Delivery of salt, as well as other heavy goods, was carried out by water until the 20th century. The main waterway of the Perm namestnichestvo was the Kama, a tributary of which is the Usolka river, where Solikamsk was located. One of Hermann's documents reports, that for 10 governorates (i.e. all where Perm salt was supplied, except for Perm itself, as well as the neighboring Vyatka governorate) " $<\ldots$. > Perm salt from state-owned and private factories is sent every year after the release of rivers from ice in ships in caravans to Nizhny Novgorod, served there in stores and from there is already transported to the provinces" (SPbB ARAS, f. 27, 1. 1, fl. 128: 48). In 1783, the price 
for transportation to Nizhny Novgorod for Solikamsk industrialists was set - 6 kopecks per pood, but the price had increased in 1788, and on March $24^{\text {th }}, 1788$ a decision was made to set up warehouses at the mouth of the Kama river. But this salt delivery arrangement proved ineffective and in 1792 it was returned to the previous practice of salt delivering to Nizhny Novgorod (Bogdanov 2014: 94-96). As for the neighboring Vyatka governorate, salt was sent there directly from Perm by road. The length of the postal route from Perm to the borders of the Vyatka province was 130 versts, i. e. nearly $148 \mathrm{~km}$ (SPbB ARAS, f. 27, 1. 1, fl. 128: $22 \mathrm{rev}$.).

No information was found in Hermann's papers about the purchase price for salt - the price that the state paid to salt producers. This is quite understandable: Hermann collected documents of the Perm namestnichestvo, the central administrative acts could be missing in his collection. At the same time, the purchase price for Perm salt for the 18th century is well known from state administrative documents (Bogdanov 2014: 96).

However, documents from the Hermann's fond contain information on the price of salt that was on sale: $1783-1790-35$ kopecks per pood (this is slightly more than two kopecks per kilogram), 1791-1795 - 40 kopecks per pood (2.5 kopecks per kilogram) (SPbB ARAS, f. 27, 1. 1, fl. 128: 47). For comparison, prices for basic food products in Solikamsk district in 1785: rye -1.25 kopecks per 1 liter; wheat -1.9 kopecks per 1 liter, barley -1.19 kopecks per 1 liter, oats -0.76 kopecks per 1 liter, wine -3 rubles per bucket ( 24 kopecks per 1 liter) (SPbB ARAS, f. 27, 1. 1, fl. 128: 41-43).

\section{CONCLUSION}

The first systematized data on this issue were presented by Hermann in a work that he dedicated to Ekaterina Dashkova and which was reported to the Academy of Sciences on February 11 ${ }^{\text {th }}, 1788$ (SPbB ARAS, f. 1, 1. 1, fl. 39: 10) - Description of Perm salt factories, with suggestions for their correction (Beschreibung der Permischen Salzwerke, mit Vorschlägen zu ihrer Verbesserung). At the same time, documents with later information are stored in the archive fond. It was collected by Herman after the completion of the named work, and therefore offer new historical materials.

Hermann appeared in the Urals at a rather significant time. Catherine II, having come to the throne, thoroughly engaged in the "salt" business and on June $16^{\text {th }}, 1781$ issued a new Charter on Salt, which completed the new organization of the state salt trade. Although Hermann was not yet in the Urals at this time, the documents he collected start from this year. Hermann's papers reflect the subsequent crisis years and further time; the latest data relate to 1795 (when Hermann left the Urals), i.e. the time of the end of the Empress reign and, accordingly, of the subsequent state changes. The data presented in Hermann's papers reflect an important time for the Perm salt industry during the second half of the reign of Catherine II.

It is important that the information in Hermann's papers does not differ from the statistical data of other official documents of the time. Information about the presence of its own salt in the governorates of the Russian Empire is identical, as well as information about which province is supplied with which salt. The figures for the volume of salt production in the Perm namestnichestvo are close: the provided above information from Hermann's papers $(\mathrm{SPbB}$ ARAS, f. 27, 1. 1, fl. 87: 58-58 rev.) is comparable to the information, that is provided in other documents of the time and collected in Bogdanov's book (Bogdanov 2014; 95). There are also many copies of Imperial decrees and official orders for the Perm namestnichestvo in Hermann's documents. All this speaks in favor of the objectivity of the by Hermann collected information and the possibility to use it as a full-fledged source on the history of salt production in the last two decades of the 18th century. It is important that these documents reflect repeatedly the known problems of the industry in 1783.

We will not find in the documents of the Hermann's fond fundamentally new information about the equipment of salterns. It was, in general, the same throughout the Empire and did not change in principle for several centuries. On the technical side, the salt works is well described in the known works (Logunov \& al. 1995, Bogdanov 2014, Chivtaev 2017). At the same time, the documents of the Hermann's fond provide important information about the volume of 
production and allow us to determine the place of the Perm namestnichestvo (Solikamsky district) in the general economic picture of salt production in Russia at the end of the 18th century. Even more valuable are the rare data that allow us to determine the cost of construction and maintenance of salterns, and hence - the prime cost of salt, and to obtain justification for both the purchase price and the sale price for salt. All this makes the documents of Hermann's fond a valuable source for the economic history of the reign of Catherine II, in particular - for the history of the Perm salt industry, that was just partially reflected in the work of Herm himself in 1789.

\section{REFERENCES}

Bogdanov, M.V. 2014. Istoria solevareniya Solikamska [History of Solikamsk salt production]. Solikamsk: w. p.

Bondar L.D. 2018. Issledovaniya I. F. Germana na Urale i v Sibiri v kontse XVIII - naczale XIX v. [Johann von Herman's research in the Urals and Siberia in the late $18^{\text {th }}-$ early $19^{\text {th }}$ centuries]. In I. V. Tunkina (ed.), Aktualnoye proshloye: vzaimodeystviye $i$ balans interesov Akademii nauk i Rosiyskogo gosudarstva v XVIII - nachale XX v. Ocherki istorii 2: 1042-1055. Sankt-Petersburg: Renome.

Chivtaev, Y.I. 2017. "Na ust Kuty u soli": Ocherki istorii solzavoda (1639-1750 g.) [“At the mouth of Kuta near salt": essays on the history of the salt factory]. Bratsk: Izd. Dom "Bratsk".

Kharitonova, E.D. 1971. Solevarennaya promyshlennost Prikamya v XVIII veke (K voprosu o genezise kapitalisticheskich otnosheniy v promyshlennosti) [Salt production in Prikamye in $18^{\text {th }}$ century (On the question of the genesis of capitalist relations in industry)]. Perm: w.p.

Logunov, E.B., Perminova, L.B. \& Shkerin, V.A. 1995. Ust-Borovskoy solevarenny zavod: vchera, segodnya, zavtra [Ust-Boroskoy salt factory: yesterday, today, tomorrow]. Yekaterinburg: Bank kulturnoy informatsii.

Makhrova, T.K. 2015. Gosudarstvennoye regulirovaniye solyanogo promysla na Urale v kontse XVIII pervoy polovine XIX v. [State regulation of salt production in the Urals at the end of $18^{\text {th }}-$ first half of $19^{\text {th }}$ centuries]. Provoporyadok: istoriya, teoriya, praktika 3(6): 87-92.

Penzin, E.I. 1989. I. F. German - ucheny i gorny deyatel [J. von Hermann - scientist and mining figure]. In V.A. Chudinovskikh \& al. (eds.), Promyshlennost Urala $v$ period zarozhdeniya i razvitiya kapitalizma: 56-71. Sverdlovsk: UrGU.

Polnoe sobranie zakonov Rossiyskoy Imperii (PSZRI) [Complete collection of laws of the Russian Empire] 1830. Sobranie pervoe. 1649-1825 gg. T. 21. 1781-1783 [The first collection. 1649-1825. Vol. 21. 1781-1783]. Sankt-Petersburg: Tipografia II Otdeleniya Sobstvennoy Ego Imperatorskogo Velichestva Kantselarii.

Sankt-Petersburg Branch of the Archive of the Russian Academy of Sciences (SPbB ARAS), f. V, 1. 1-G, fl. 13. German, Ivan Filippovich, akad. (1755-1815) [Johann von Hermann, academician (1755-1815).].

SPbB ARAS, f. 1, 1. 1, fl. 39. Protocolle, l'anée 1788.

SPbB ARAS, f. 1, 1. 1, fl. 41. Protocolle pour l'an. 1790.

SPbB ARAS, f. 1, 1. 1, fl. 43. Protocoles pour 1792.

SPbB ARAS, f. 1, 1. 1, fl. 44. Protocolle pour l'année 1793.

SPbB ARAS, f. 1, 1. 1, fl. 46. Protocolle pour l'année 1795.

SPbB ARAS, f. 1, 1. 1, fl. 47. Protocolle pour 1796.

SPbB ARAS, f. 1, 1. 1, fl. 53. Protocolle pour l'année 1802.

SPbB ARAS, f. 1, 1. 1, fl. 55. Protocolle pour l'an. 1804.

SPbB ARAS, f. 1, 1. 1, fl. 58. Protocoles de l'an. 1807.

SPbB ARAS, f. 1, 1. 1, fl. 59. Protocoles de l'an. 1808.

SPbB ARAS, f. 1, 1. 1, fl. 63. Protocolle de l'an. 1812.

SPbB ARAS, f. 27, 1. 1, fl. 87. Materialy po organizatsii razrabotki solyanykh mestorozhdeniy i raspredeleniye eya po rayonam potrebleniya [Materials on the organization of development of salt deposits and its distribution by consumption areas]. S. a.

SPbB ARAS, f. 27, 1. 1, fl. 128. Materialy istoriko-ekonomicheskogo kharaktera [Historical and economic materials]. 1781-1787.

Tulisov, E.S. 2001. Pyshminskaya stalnogo dela fabrica [Pyshminskaya steel factory]. In V.V. Alekseev (ed.), Metallurgicheskiye zavody Urala XVII-XX v. Encyclopedia: 397-398. Ekaterinburg: Akademkniga. 


\section{Author Index}

Abdrakhmanov, I.A. 70

Ageev, A. 78

Alashkhanov, A.Kh. 186

Aleksandrova, T.A. 174

Arabey, A.B. 352

Averianova, N.A. 244

Ayrapetyan, M.G. 25, 46

Adekitan, A.I. 274

Aleksandrov, A.N. 283

Alekseenko, V.A. 262

Androkhanov, V.A. 268

Anisimov, K.A. 111

Badikova, A.D. 322

Bataev, D.K-S. 152

Batukaev, A.A. 39

Bazhin, V.Y. 174

Boduen, A.Ya. 196

Bondarenko, A.V. 343

Bongaerts, J.C. 473

Bormotov, I.S. 118

Bosikov, I.I. 377, 422

Brichkin, V.N. 136

Budovskaya, M.E. 309

Belova, D. 93

Bondar, L.D. 508

Cehlár, M. 413

Chaika, V.V. 230

Cherepovitsyn, A.E. 440

Cherepovitsyn, A.E. 456

Chernyshev, V.V. 230

Chekulaev, A.V. 105

Cherdancev, G.A. 32

Chitalov, L.S. 146

Cofie, K.Y.B. 465

Damzaev, Z.M-E. 20, 39, 330

Deev, A.S. 368

Demidov, A. 124, 161, 203

Dmitrak, Yu.V. 422

Dmitriev, A.N. 337

Dolbnya, I.V. 252

Drebenstedt, C. 473
Drozdov, A.N. 358

Dubovtsev, D.A. 322

Dvoynikov, M.V. 309

Dmitrieva, O.S. 296

Egorov, A.S. 105

Egorov, A. 78

Egorov, V.A. 352

Egorova, M. 161

ElDeeb, A.B. 136

Farukshin, A.A. 25, 46

Fedina, R.A. 322

Gabibov, A.F. 343

Gadaeva, Z.I. 20, 39, 330

Gavrina, O.A. 377

Golokhvast, K.S. 222, 230

Gorbachev, M.A. 118

Gorbyleva, Y.A. 358

Gorelkina, E.I. 358

Gridasov, A.V. 222

Grigoreva, V. 196

Gulbin, Yu.L. 70

Gizatullin, R.R. 309

Glinskii, Vitalii V. 99

Gorshkov, A. 124

Gorshkov, L.K. 337

Heide, G. 12, 84

Ibatullin, A.Kh. 52

Ilinova, A.A 440

Ilinova, A.A. 456

Iliukhin, S.I. 430

Issa, B. 174

Ivanova, D. 481, 492

Ilalova, R.K. 62

Ilic, A. 447

Islamov, S.R. 343

Janočko, J. 413

Karabaev, S.D. 358

Kholodov, A.S. 230
Kiat, M.I. 430

Kishchenko, M.A. 283

Klyuev, R.V. 377, 422

Kochneva, O.E. 52

Konischev, K.B. 352

Krikun, N. 78

Kulyashova, I.N. 322

Kurtenkov, R.V. 118, 136

Kushmar, I.A. 32

Kuznetsov, V.A. 236

Khaikin, M. 481

Khoreshok, A.A. 406, 413

Kirichenko, K.Y. 222, 230

Kobylyanski, A. 196

Labazanov, M.M. 20, 39, 330

Lebedev, V.A. 368

Lebedeva, O. 492

Lvov, V.V. 146

Makarov, A. 124, 161, 203

Malyuhin, D.M. 244

Mardashov, D.V. 343

Markov, S.O. 406, 413

Masarov, I.R. 330

Matrokhina, K.V. 397

Matveeva, Y.G. 303

Mazakov, E.B. 397

Medvedev, S.A. 222

Meshkov, A. 93

Mintsaev, M.Sh. 152

Molchanov, A.A. 105

Morgunov, P.A. 1

Murtazaev, S-A.Yu. 152, 186

Murtazaeva, T.S-A. 186

Musaeva, P.U. 20, 39, 330

Milyutina, N.O. 244

Narozhnyy, I.M. 358

Nastavkin, A.V. 262

Nazarova, M.N. 314

Nefedov, Y.V. 1, 46

Nikolaev, A.K. 303 
Nikolaeva, E. 84

Nikiforova, V.S. 12

Olmaskhanov, N.P. 358

Ozdieva, T.Kh. 330

Ozdieva, T.Kh. 20, 39

Ozdoeva, A.Kh. 430

Parshin, S.G. 222

Paschke, M. 492

Pereborova, N. 161, 203

Pikula, K.S. 222, 230

Pivovarov, E.G. 501

Politaeva, N.A. 244, 252

Pollack, K. 473

Ponomarenko, T.V. 447

Puzanov, A.V. 262

Peretyatko, M.A. 368

Prishchepa, O.M. 1

Rock, M. 274

Romasheva, N.V. 465

Salamanova, M.Sh. 152
Semenov, A.M. 352

Semenov, V.P. 32

Shabalov, M. 481, 492

Shapiro, N.A. 481

Sharipov, I.I. 296

Shpenst, V.A. 390

Shvydkaya, N.V. 262

Sidorenko, A. 93

Sizyakov, V.M. 118, 136

Skrydlov, A.Yu 501

Smyatskaya, Y.A. 252

Sobgaida, D.S. 252

Sokol, D.G. 111

Sokolov, D.A. 268

Saidumov, M.S. 186

Solovyova, V.M. 456

Sultanbekov, R.R. 314

Talovina, I.V. 12, 62, 84

Terekhin, R.D. 314

Terleev, A.V. 390

Tretyakova, M.O. 230

Trinh, D.C 440

Trofimets, V.Y. 397
Trushko, V.L. 99

Tsadkin, M.A. 322

Tyulenev, M.A. 406, 413

Vakhniuk, I.A. 222

Van, T.N. 283

Vasilyeva, M. 386

Velikoselsksya, E.S. 244

Volodina, Ya.A. 236

Vorontsovac, I.V. 62

Vöth, S. 386

Volkodaeva, M.V. 236

Wagner, V. 203

Yakovlev, P.V. 368

Zakharenko, A.M. 222, 230

Zaurbekov, Sh.Sh. 39, 330

Zharkov, A.M. 25, 52

Zhukova, V. 196

Zinurov, V.E. 296

Zubov, V.P. 111

Zaripova, N.A. 303 